PNNL-17965

WTP-RPT-172, Rev 0

(20) ENERERG

Prepared for the U.S. Department of Energy

under Contract DE-AC05-76RL01830

\title{
Filtration and Leach Testing for REDOX Sludge and S-Saltcake Actual Waste Sample Composites
}

RW Shimskey

JM Billing

EC Buck

RC Daniel

KE Draper
MK Edwards

JGH Geeting

RT Hallen

ED Jenson

AE Kozelisky
PJ MacFarlan

RA Peterson

LA Snow

RG Swoboda

February 2009

Pacific Northwest

NATIONAL LABORATORY 


\title{
DISCLAIMER
}

This report was prepared as an account of work sponsored by an agency of the United States Government. Neither the United States Government nor any agency thereof, nor Battelle Memorial Institute, nor any of their employees, makes any warranty, express or implied, or assumes any legal liability or responsibility for the accuracy, completeness, or usefulness of any information, apparatus, product, or process disclosed, or represents that its use would not infringe privately owned rights. Reference herein to any specific commercial product, process, or service by trade name, trademark, manufacturer, or otherwise does not necessarily constitute or imply its endorsement, recommendation, or favoring by the United States Government or any agency thereof, or Battelle Memorial Institute. The views and opinions of authors expressed herein do not necessarily state or reflect those of the United States Government or any agency thereof.

\author{
PACIFIC NORTHWEST NATIONAL LABORATORY \\ operated by \\ BATTELLE \\ for the \\ UNITED STATES DEPARTMENT OF ENERGY \\ under Contract DE-ACO5-76RL01830
}

Printed in the United States of America
Available to DOE and DOE contractors from the Office of Scientific and Technical Information,
P.O. Box 62, Oak Ridge, TN 37831-0062;
ph: (865) 576-8401
fax: (865) 5765728
email: reports@adonis.osti.gov

\author{
Available to the public from the National Technical Information Service, \\ U.S. Department of Commerce, 5285 Port Royal Rd., Springfield, VA 22161 \\ ph: (800) 553-6847$$
\text { fax: (703) 605-6900 }
$$ \\ email: orders@nits.fedworld.gov \\ online ordering: http://www.ntis.gov/ordering.htm
}




\section{Filtration and Leach Testing for REDOX Sludge and S-Saltcake Actual Waste Sample Composites}

\author{
RW Shimskey \\ JM Billing \\ EC Buck \\ RC Daniel \\ K Draper \\ MK Edwards \\ JGH Geeting
}

\author{
RT Hallen \\ ED Jenson \\ AE Kozelisky \\ PJ MacFarlan \\ RA Peterson \\ LA Snow \\ RG Swoboda
}

February 2009

Test specification: 24590-PTF-TSP-RT-06-003, Rev. 1

Work Authorization: 019

Test plan: TP-RPP-WTP-467, Rev. 1

Test exceptions: None

R\&T focus area: Pretreatment

Service Requisition Number: 24590-QL-SRA-W000-00107, Rev. 0

Prepared for the U.S. Department of Energy

Under Contract DE-AC05-76RL01830

Pacific Northwest National Laboratory

Richland, Washington 99352 
WTP-RPT-172, Rev 0

\section{COMPLETENESS OF TESTING}

This report describes the results of work and testing specified by Test Specification 24590-PTF-TSP-RT-06-003, Rev. 1 and Test Plan TP-RPP-WTP-467 Rev. 0, 2/2/07 and Rev. $17 / 31 / 07$. The work and any associated testing followed the quality assurance requirements outlined in the Test Specification/Plan. The descriptions provided in this test report are an accurate account of both the conduct of the work and the data collected. Test plan results are reported. Also reported are any unusual or anomalous occurrences that are different from expected results. The test results and this report have been reviewed and verified.

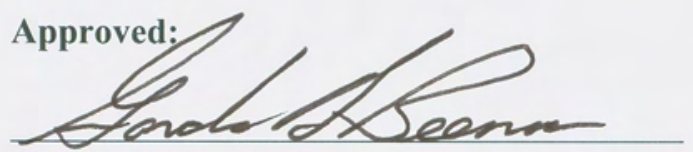

Gordon H. Beeman, Manager WTP R\&T Support Project

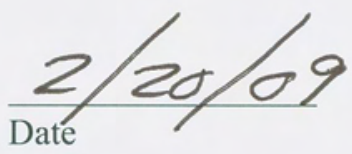




\section{Contents}

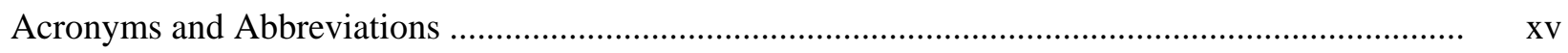

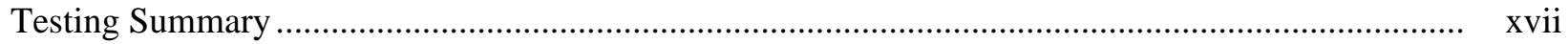

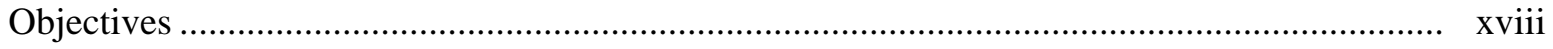

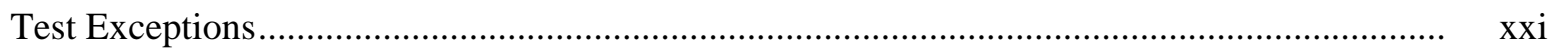

Results and Performance Against Success Criteria ................................................................ xxi

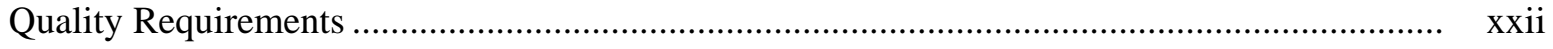

R\&T Test Conditions.................................................................................................... x xiii

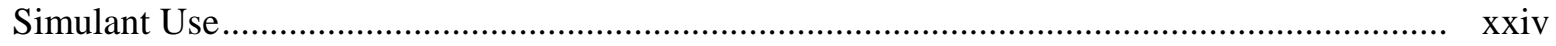

Discrepancies and Follow-on Tests ................................................................................ Xxv

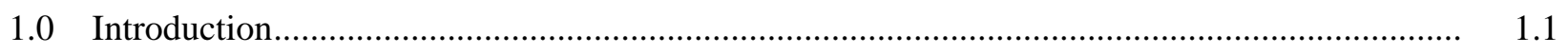

1.1 Tank Waste Pretreatment Operations at the WTP ........................................................ 1.1

1.2 Issues Identified by the External Flowsheet Review Team ............................................ 1.2

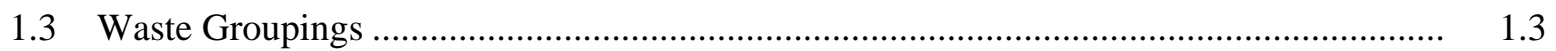

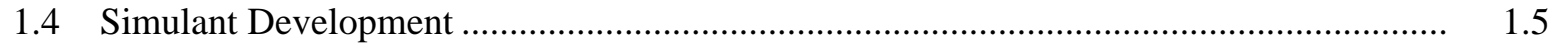

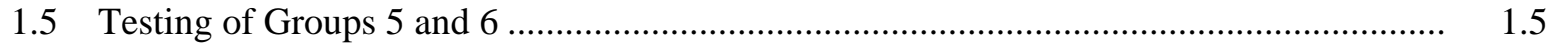

2.0 Experimental Methods and Analyses.............................................................................. 2.1

2.1 Filtration/Leaching Apparatus ............................................................................... 2.1

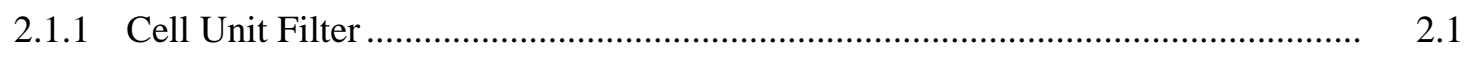

2.1.2 Cross-Flow Ultrafiltration/Leaching Apparatus (CUF) ...................................... 2.2

2.1.3 Instrumentation and Data Acquisition System.................................................. 2.7

2.1.4 Operations of CUF and Sampling ................................................................ 2.10

2.1.5 Baseline Testing of Filter.............................................................................. 2.11

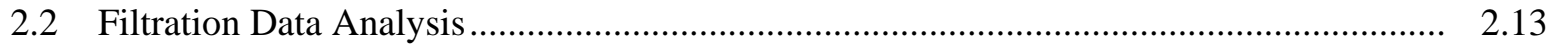

2.2.1 Filtration Terms and Equations .................................................................... 2.13

2.2.2 Filtration Test Matrix ................................................................................ 2.14

2.2.3 Dewatering Operation Analysis .................................................................... 2.16

2.2.4 Effects of Rheology and Particle Size.............................................................. 2.16

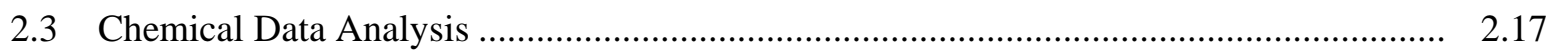

2.3.1 Validation of Filtration Separation of TRU Material........................................... 2.17

2.3.2 Chemical Leach Factors for Caustic and Oxidative Leaching .............................. 2.18

2.3.3 Physical Examination of Final Leach Material ....................................................... 2.19

3.0 Group 5 CUF Testing and Results ...........................................................................

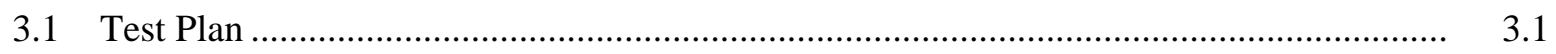

3.2 Low-Solid (5 wt\%) Slurry Characterization ............................................................. 3.4 
3.3 Filter Flux Test Matrix and Initial Dewater............................................................. 3.11

3.3.1 Low-solids (5 wt\%) Test Matrix ...................................................................... 3.11

3.3.2 Dewatering of Group 5 Waste .................................................................... 3.16

3.3.3 High-Solids Matrix .................................................................................. 3.20

3.4 High-Solids (15 wt\%) Slurry Characterization......................................................... 3.27

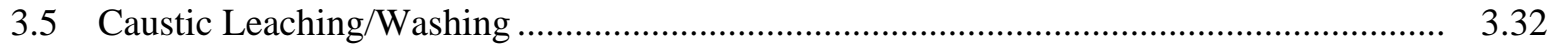

3.5.1 Caustic Batch Leaching Results......................................................................... 3.33

3.5.2 Caustic Leach Dewatering ........................................................................... 3.35

3.5.3 Dewatered Leached Slurry Physical Characterization ........................................ 3.39

3.5.4 Caustic Batch Rinsing Results ..................................................................... 3.45

3.5.5 Dewatering Caustic Wash Solutions ............................................................... 3.56

3.6 Final Filter Flux Test Matrix ......................................................................................

$3.7 \quad$ Leached Material Characterization .................................................................................. 3.61

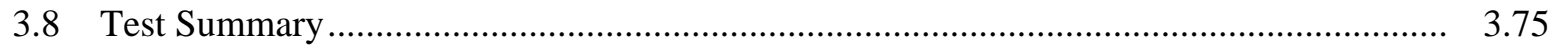

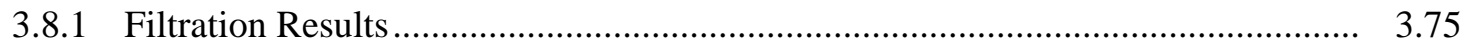

3.8.2 Caustic Leaching Results ............................................................................... 3.75

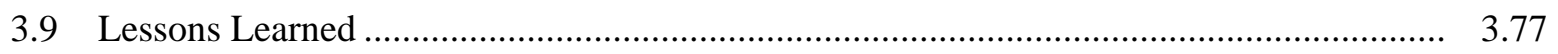

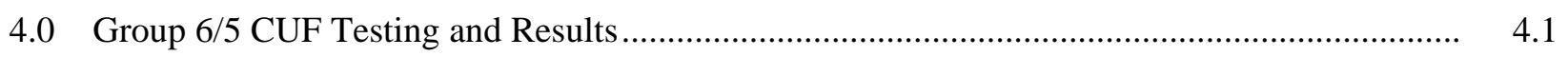

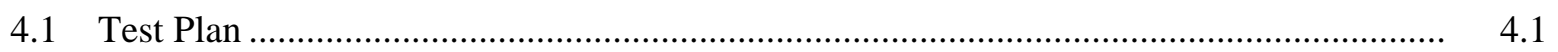

4.2 Initial Feed Characterization..........................................................................................

4.3 Filter Flux Test Matrix and Initial Dewater...................................................................... 4.12

4.3.1 Low-Solids Matrix (4 wt\% UDS) ...................................................................... 4.13

4.3.2 Dewatering of Group 6 Slurry and Group 6/5 Blended Slurry ….......................... 4.18

4.3.3 High-Solids Matrix .................................................................................... 4.20

4.3.4 High-Solids Slurry Characterization .............................................................. 4.26

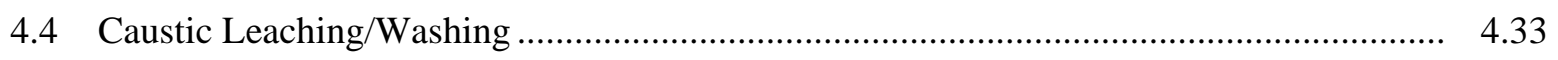

4.4.1 Caustic Batch Leaching Results........................................................................ 4.33

4.4.2 Leach Slurry Dewatering and Physical Characterization..................................... 4.37

4.4.3 Characterization of Dewatered Caustic Leach Slurry ............................................. 4.39

4.4.4 Caustic Batch Washing Results ........................................................................... 4.45

4.4.5 Dewatering of Caustic Wash Solutions ............................................................. 4.58

4.4.6 Characterization of Washed Caustic Leached Slurry.......................................... 4.60

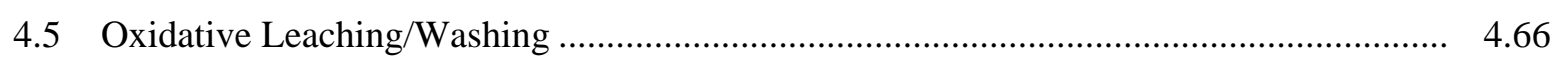

4.5.1 Batching Leach Results..................................................................................... 4.66

4.5.2 Characterization of Oxidative Leached Slurry............................................... 4.71

4.5.3 Batching Rinsing and Dewatering Results After Oxidative Leach........................ 4.76 
4.6 Leached Material Characterization ........................................................................ 4.86

4.7 Final Dewater and Filter Flux Test Matrix ................................................................ 4.97

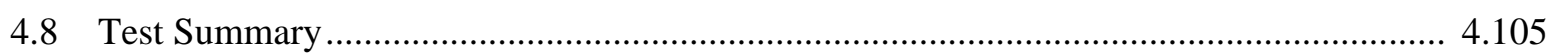

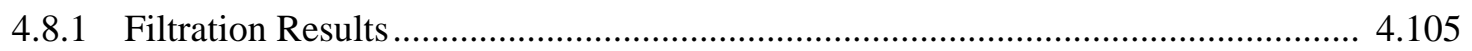

4.8.2 Caustic and Oxidative Leaching Results ........................................................... 4.106

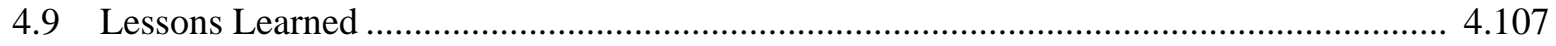

5.0 Group 6/5 Aluminum Leaching Studies ............................................................................... 5.1

5.1 Parametric Testing Varying $\mathrm{NaOH}$ Concentration ...................................................... 5.1

5.1.1 Initial Washing of the Group 6/5 Solids .......................................................... 5.1

5.1.2 Division of the Washed Group 6/5 Solids ........................................................ 5.1

5.1.3 Caustic Leaching of the Washed Group 6/5 Solids ............................................ 5.2

5.1.4 Washing of Caustic-Leached Group 6/5 Solids for Analysis ............................... 5.4

5.1 .5 Caustic Leaching Results ............................................................................. 5.4

5.1.6 Assessment of Final Leach Conditions .................................................................. 5.5

5.1.7 Leached Solids Wash Solution ....................................................................... 5.6

5.1.8 Chemical and Radiochemical Composition...................................................... 5.6

5.2 Benchtop Batch Leaching Varying Solids Concentration .............................................. 5.10

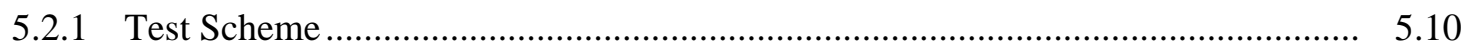

5.2.2 Blending Group 6/5 Samples for Leaching.................................................... 5.13

5.2.3 Leaching Conditions and Sampling ................................................................. 5.13

5.2.4 Results of Leaching..................................................................................... 5.14

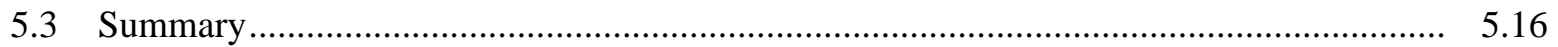

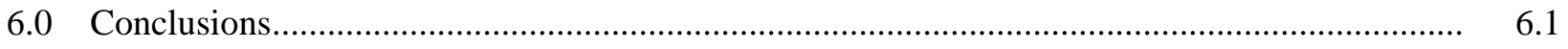

6.1 Summary of Testing and Objectives.......................................................................... 6.1

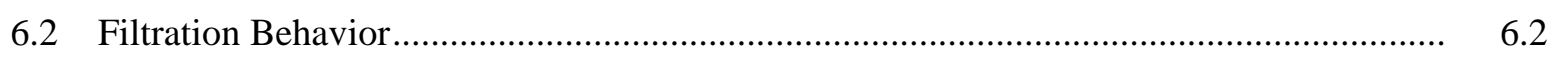

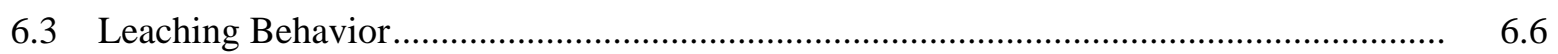

6.4 Characterization of Crystal Habits of Solids .......................................................... 6.7

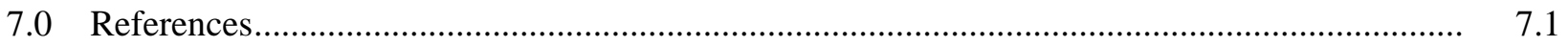

Appendix A: Analytical Methods …………............................................................................... A.1

Appendix B: Physical Property and Rheology Methods..................................................................... B.1

Appendix C: Quality Assurance and Control Methods.............................................................. C.1

Appendix D: Group 6/5 Post-CUF Parametric Analytical Results from Parametric Leaching ........... $\quad$ D.1

Appendix E: Group 5 CUF Test Concurrence Letter..................................................................... E.1

Appendix F: Group 6/5 CUF Test Concurrence Letter................................................................ F.1

Appendix G: Group 5 CUF Particle Size Analysis.................................................................. G.1

Appendix H: Group 5/6 CUF Particle Size Analysis ......................................................................... H.1 
Appendix I: Group 5 CUF Rheology Analysis ....................................................................... I.1

Appendix J: Group 6/5 CUF Rheology Analysis......................................................................... J.1

Appendix K: Group 5 CUF Analytical Results .................................................................... K.1

Appendix L: Group 6/5 CUF Analytical Results.................................................................... L.1

Appendix M: Group 6/5 CUF UFP1/UFP2 Caustic Leaching Analytical Results ............................. M.1 


\section{Figures}

Figure

1.1. Schematic Representation of the Key Processes to be Performed in the PTF.......................... 1.2

2.1. Filter Element …..................................................................................................... 2.1

2.2. Filter Assembly Sketch (Not to Scale) …............................................................................ 2.2

2.3. Picture of Filter Assembly .......................................................................................... 2.2

2.4. Piping Diagram of CUF Testing Apparatus ....................................................................... 2.3

2.5. Picture of CUF Testing Apparatus Before Hot Cell Installation ............................................ 2.4

2.6. Picture of Testing Apparatus Installed in Cell 5 of the Shielded Analytical Laboratory .......... 2.4

2.7. Diagram of DACS System ............................................................................................. 2.8

2.8. Digital Images of DACS Display Windows ........................................................................... 2.9

2.9. Syringe with 0.45-Micron Filter Installed ............................................................................ 2.11

2.10. Initial Clean Water $/ \mathrm{SrCO}_{3}$ Flux Measurements of Filter..................................................... 2.12

2.11. Filtration Test Matrix Chart............................................................................................... 2.15

2.12. Example of a Dewatering Curve at a Constant TMP and AV ........................................... 2.17

3.1. Group 5 Testing Flowchart.......................................................................................

3.2. Group 5 Low-Solids (5 wt\%) Slurry Preparation and Sampling ........................................... 3.4

3.3. Flow Loop Diagram of PSD Instrument.........................................................................

3.4. PSD of CUF Group 5 Low-Solids (5 wt\%) Slurry as a Function of Pump Speed .................... 3.9

3.5. PSD of CUF Group 5 Low-Solids (5 wt\%) Slurry as a Function of Sonication ....................... 3.9

3.6. Flow Curves for Group 5 CUF Low Solids Slurry .............................................................. 3.10

3.7. Group 5 Filter Flux Data for Low-solids (5 wt\%) Matrix ..................................................... 3.13

3.8. Group 5 Filter Test Matrix for Low-solids (5 wt\%) ............................................................ 3.14

3.9. Group 5 Average Flux vs. TMP for Low-solids (5 wt\%)..................................................... 3.14

3.10. Group 5 Average Flux vs. AV for Low-solids (5 wt\%) ..................................................... 3.14

3.11. Group 5 Correlation Calculations of Average Flux as Function of TMP................................. 3.15

3.12. Group 5 Dewatering of Low-solids (5 wt\%) Slurry …............................................................... 3.16

3.13. Filter Flux and Axial Pressure Drop During Dewatering of Group 5 Waste ........................... 3.19

3.14. Group 5 Dilution of Dewatered Slurry for High-Solid (15 wt\%) Matrix................................ 3.21

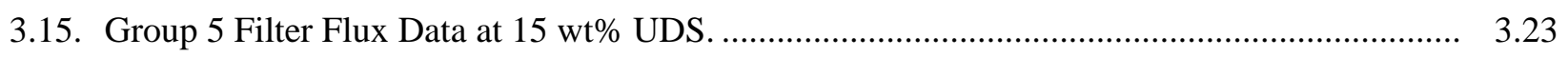

3.16. Group 5 Filter Test Matrix for High-solids (15 wt \%) ........................................................ 3.24

3.17. Group 5Average Flux vs. TMP for High-Solids (15 wt\%) ................................................... 3.24

3.18. Group 5 Average Flux vs. AV for High-Solids (15 wt\%) ................................................... 3.24

3.19. Group 5 Least Square Fit to High-Solid (15 wt\%) Matrix Test Results to Linear Model.......... 3.25 
3.20. Least Square Fit to High-Solid (15 wt\%) Matrix Test Results to Exponential Model.............. 3.26

3.21. Group 5 Sampling of High-Solids (15 wt\%) Matrix ............................................................ 3.27

3.22. PSD of CUF 5 High Solids (15wt\%) Matrix as a Function of Pump Speed ........................... 3.31

3.23. PSD of CUF 5 High Solids (15 wt\%) Matrix as a Function of Sonication .............................. 3.31

3.24. Flow Curves for Group 5 CUF High Solids (15 wt\%) Slurry ................................................ 3.32

3.25. Group 5 Preparation for the Caustic Leach ........................................................................... 3.33

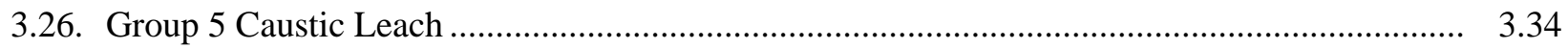

3.27. Group 5 Temperature Profile/Aluminum Leach Factor During Caustic Leaching ................... 3.35

3.28. Group 5 Diluting Caustic Leach Slurry to Planned Volume .................................................... 3.36

3.29. Group 5 Dewatering Caustic Leached Slurry ....................................................................

3.30. Group 5 Dewatering Caustic Leached Slurry from $4 \mathrm{wt} \%$ to $11 \mathrm{wt} \%$ at Standard Conditions

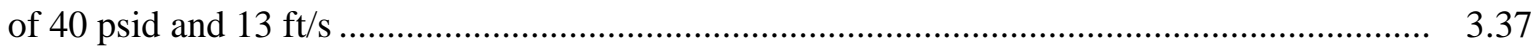

3.31. Group 5 Sampling of Dewatered Caustic Leached Slurry .................................................... 3.39

3.32. PSD of CUF 5 Leached, Dewatered Slurry as a Function of Pump Speed ............................. 3.43

3.33. PSD of CUF 5 Leached, Dewatered Slurry as a Function of Sonication .................................

3.34. Flow Curves for Group 5 CUF Leached Dewatered Slurry ................................................... 3.44

3.35. Group 5 Washing of Caustic Leached Slurry ................................................................... 3.45

3.36. Normalized Aluminum Inventory in Group 5 Slurry through Caustic Leach and Washing ...... 3.51

3.37. Normalized Chromium Inventory in Group 5 Slurry through Caustic Leaching and Washing.....

3.38. Normalized Phosphorus Inventory in Group 5 Slurry through Caustic Leaching and Washing.

3.39. $\mathrm{Al} / \mathrm{Cr} / \mathrm{P}$ removed from the Group 5 CUF Slurry …............................................................... 3.54

3.40. Sodium and Free Hydroxide Molarity in Group 5 CUF Slurry ............................................. 3.55

3.41. Group 5 Dilution of Washed Leached Slurry for Final Matrix Test ...................................... 3.56

3.42. Group 5 Filter Test Matrix for the Washed Solids .............................................................. 3.58

3.43. Group 5 Flux vs. TMP for Washed Solids ....................................................................... 3.58

3.44. Group 5 Flux vs. AV for Washed Solids ....................................................................... 3.58

3.45. Group 5 Least Square Fit of Leached Solid Test Matrix Results with Linear Model ............... 3.59

3.46. Group 5 Least Square Fit of Leached Solid Test Matrix Results with Exponential Model ....... 3.60

3.47. Radionuclides/Total Solids in CUF 5 Slurry, Adjusted for Sampling.................................... 3.65

3.48. Group 5 Anions in Slurry Supernate ............................................................................ 3.65

3.49. XRD Spectra of Leached Group 5 Slurry......................................................................... 3.67

3.50. Group 5 SEM and Energy Dispersive Spectroscopy (EDS) of Leached, Washed Solids .......... 3.68 
3.51. Group 5 SEM Close-up of Leached Washed Particle .......................................................... 3.69

3.52. Group 5 TEM Imaging of Group 5 Leached and Washed Solids......................................... 3.70

3.53. PSD of CUF 5 Leached Washed Slurry as a Function of Pump Speed ................................... 3.71

3.54. PSD of CUF 5 Leached and Washed Slurry as a Function of Sonication ................................. 3.71

3.55. Flow Curves for the Group 5 Leached, Washed Slurry .......................................................... 3.72

3.56. Comparison of Group 5 CUF Slurry Flow Curves at $25^{\circ} \mathrm{C}$, with (a) Showing the Weaker Slurries and (b) Showing the Stronger Slurries ................................................................. 3.74

3.57. Group 5 Slurry Composition Before and After Leaching …................................................... 3.76

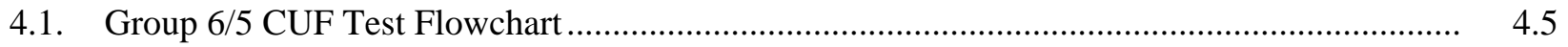

4.2. Group 6/5 Feed Additions and Sampling for the Low-Solids Slurry …................................... 4.6

4.3. PSD for Low Solids Matrix as a Function of Pump Speed .................................................... 4.11

4.4. PSD for Low Solids as a Function of Sonication .............................................................. 4.11

4.5. Flow Curves for Group 6/5 Low-Solids Slurry (Group 6 Only) .......................................... 4.12

4.6. Group 6/5 CUF Low-Solids Slurry ................................................................................. 4.13

4.7. Filter Flux Data for Group 6 Initial Low-Solids Matrix (4 wt\% UDS) ................................... 4.15

4.8. Group 6/5 Filter Test Matrix for Lows-Solids........................................................................... 4.16

4.9. Group 6/5 Flux vs. TMP for Low-Solids ................................................................................16

4.10. Group 6/5 Flux vs. AV for Low-Solids ............................................................................ 4.16

4.11. Group 6/5 Flux vs. Relative Time for Low-Solids ............................................................. 4.16

4.12. Linear Model of Group 6/5 Low-Solid Slurry Filter Flux ................................................... 4.17

4.13. Group 6/5 Slurry Dewatering Operations ............................................................................. 4.18

4.14. Dewatering Filter Flux of Group 6 Slurry and Group 6/5 Slurry .......................................... 4.19

4.15. Group 6/5 High-Solids Slurry ........................................................................................... 4.20

4.16. Group 6/5 Filter Flux Data for High-Solids Slurry ….............................................................

4.17. Group 6/5 Filter Test Matrix for High-Solids ............................................................................ 4.23

4.18. Group 6/5 Flux vs. TMP for High Solids ............................................................................ 4.23

4.19. Group 6/5 Flux vs. AV for High-Solids ............................................................................... 4.23

4.20. Group 6/5 Flux vs. Relative Time for High-Solids ............................................................. 4.23

4.21. Linear Model of Group 6/5 High-Solids Slurry Filter Flux ................................................... 4.24

4.22. Exponential Model for Group 6/5 High-Solids Slurry Filter Flux ........................................... 4.25

4.23. Group 6/5 Sampling of High-Solids Slurry ....................................................................... 4.26

4.24. Measured PSD of Group 6/5 High-Solids Slurry as a Function of Pump Speed....................... 4.30

4.25. Measured PSD of Group 6/5 High-Solids Slurry as a Function of Sonification ...................... 4.30

4.26. Flow Curve for Group 6/5 High-Solids Slurry .................................................................... 4.31 
4.27. Flow Curves of Group 5, 6, and Group 6/5 High-Solid Slurry (at 25) ................................. 4.32

4.28. Group 6/5 Caustic Leaching Preparation............................................................................ 4.34

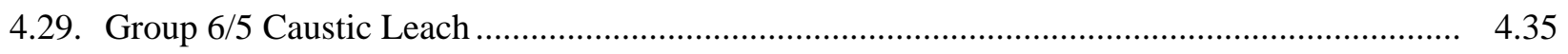

4.30. Temperature Profile and Aluminum Dissolution during Caustic Leach ................................. 4.36

4.31. Group 6/5 Dewatering of Caustic Leach Slurry ...................................................................... 4.37

4.32. Dewatering Filter Flux of Leached Group 6/5 Slurry ............................................................. 4.38

4.33. Group 6/5 Sampling of Dewatered Caustic Leached Slurry …............................................... 4.39

4.34. Measured PSD for Leached, Dewatered Slurry as a Function of Pump Speed ........................ 4.43

4.35. Measured PSD for Leached, Dewatered Slurry as a Function of Sonication ........................... 4.43

4.36. Flow Curves for Group 6/5 Dewatered Caustic Leached Slurry ............................................ 4.44

4.37. Group 6/5 Washing of the Caustic Leach Slurry ................................................................ 4.46

4.38. Group 6/5 Sodium, Free Hydroxide, and Aluminum Concentrations Before and After Caustic Leach and Washing ........................................................................................ 4.55

4.39. Normalized Aluminum Inventory in Group 6/5 Slurry through Caustic Leach and Washing ... 4.56

4.40. Normalized Phosphorus Inventory in Group 6/5 Slurry through Caustic Leach and

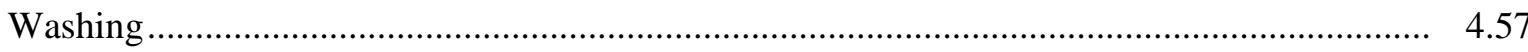

4.41. Filter Flux During Caustic Washes …............................................................................... 4.59

4.42. Slurry Sampling of Group 6/5 Washed Caustic Leached Slurry ............................................. 4.60

4.43. Measured PSD for Caustically Leached, Dewatered, and Washed Slurry as a Function of Pump Speed

4.44. Measured PSD for Caustically Leached, Dewatered, and Washed Slurry as a Function of Sonication

4.45. Flow Curves for Group 6/5 Washed Caustic Leached,Slurry ................................................. 4.65

4.46. Group 6/5 Preparation for the Oxidative Leach ....................................................................... 4.67

4.47. Group 6/5 Oxidative Leach ..................................................................................................68

4.48. Group 6/5 Conversion of $\mathrm{Cr} / \mathrm{Mn}$ from Oxidative Leach ......................................................... 4.69

4.49. Group 6/5 Slurry Supernate Concentrations of Cs, Pu, and U Before and After Oxidative Leach

4.50. Group 6/5 Sampling of Oxidative Leach Slurry .................................................................... 4.71

4.51. Measured PSD for Oxidatively Leached, Dewatered Slurry as a Function of Pump Speed ...... 4.74

4.52. Measured PSD for Oxidatively Leached, Dewatered Slurry as a Function of Sonication ......... 4.74

4.53. A Comparison of Group 6/5 CUF Slurries Showing the Effect of Caustic Leaching on

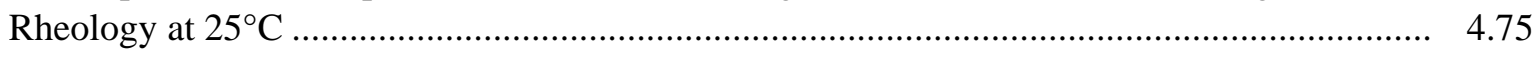

4.54. Group 6/5 Washing of Oxidative Leached Slurry ............................................................. 4.77 
4.55. Normalized Chrominum Inventory in Group 6/5 Slurry through Caustic/Oxidative Leach and Washing

4.56. Alumiunum/Chromium Removed from the Group 6/5 CUF Slurry ...................................... 4.84

4.57. Group 6/5 Oxidative Washing Filter Flux .......................................................................... 4.85

4.58. Group 6/5 Sampling of Washed Oxidative Leach Slurry .................................................... 4.86

4.59. Radionuclides/Total Solids in CUF 6/5 Slurry, Adjusted for Sampling.................................. 4.90

4.60. Selected Anions in CUF 6/5 Slurry Supernate .................................................................... 4.90

4.61. XRD Scan of CUF 6/5 Final Leached and Washed Solids .................................................... 4.91

4.62. SEM Image of Leached Washed CUF 6/5 Solids ................................................................. 4.92

4.63. Al-Fe phase in High Surface Area Particle Agglomerates .................................................... 4.93

4.64. Measured PSD for Final leached, washed slurry as a function of pump speed......................... 4.95

4.65. Measured PSD for Final leached, washed slurry as a function of sonication........................... 4.95

4.66. Flow Curves for Oxidatively Leached and Washed Group 6/5 Slurry .................................... 4.96

4.67. Group 6/5 Dewatering of Combined Leached Slurries ........................................................ 4.97

4.68. Group 6/5 Filter Flux During Washed Leached Solids Matrix ............................................... 4.100

4.69. Group 6/5 Filter Test Matrix for Leached-Solids .................................................................... 4.101

4.70. Group 6/5 Flux vs. TMP for Leached-Solids ......................................................................... 4.101

4.71. Group 6/5 Flux vs. AV for Leached-Solids........................................................................ 4.101

4.72. Group 6/5 Flux vs. Relative Time for Leached-Solids......................................................... 4.101

4.73. Group 6/5 Linear Model of Leached Slurry Filter Flux ........................................................ 4.102

4.74. Group 6/5 Exponential Model of Leached Slurry …............................................................. 4.103

4.75. Comparison of Normalized Flux at the Standard Condition for Group 6/5 Solids at Low and High Solids Before and After Leaching. A time-dependent decay is not observed for

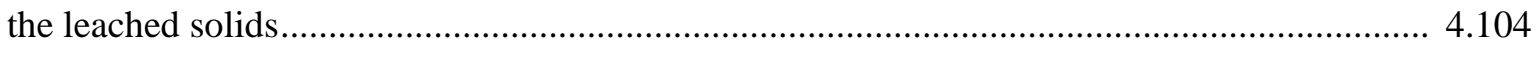

4.76. Group 6/5 Slurry Composition Before and After Leaching ............................................... 4.107

5.1. Aluminum Heating Block and Shaker Table...................................................................

5.2. Group 6/5 Solids Aluminum Dissolution Data at $100^{\circ} \mathrm{C}$ in 3, 5, and $7 \mathrm{M} \mathrm{NaOH}$ Solutions...... 5.5

5.3. Group 6/5 Sludge Reduction in Solid Mass with Caustic Leaching for $24 \mathrm{~h}$ at $100 \mathrm{C}$ in

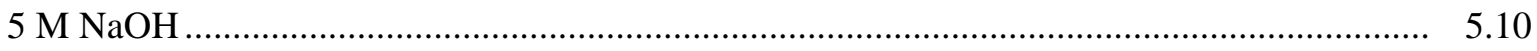

5.4. Group 6/5 Batch Leaching Test Flowchart........................................................................ 5.12

5.5. Group 6/5 Solids Aluminum Dissolution Data at $100^{\circ} \mathrm{C}$ at UFP1/UFP2 Leaching Conditions 


\section{Tables}

Table

Caption

Page

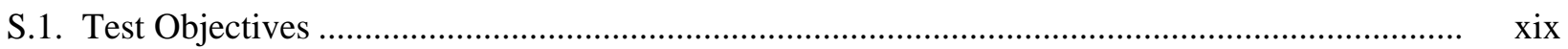

S.2. Results and Performance Against Success Criteria .............................................................. x.. xi

S.3. R\&T Test Conditions.................................................................................................... xxiv

S.4. Test Discrepancies Listed and Described ........................................................................ Xxv

1.1. Water-Insoluable Component Mass (Metric Tons) Inventory as Function of Waste Type........ 1.4

1.2. Projected Distribution of Water-Insoluble Components in the Tank Farm in the Tank Waste

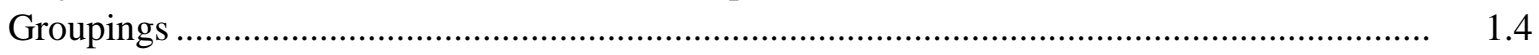

2.1. Filtration Test Matrix Operating Conditions. ................................................................. 2.15

2.2. Abridged Filter Test Matrix................................................................................................ 2.16

3.1. Simulant Addition to Group 5 Waste ….............................................................................. 3.5

3.2. Low-Solids (5 wt\%) Slurry Physical Property Measurements (Slurry Circulation Loop) ......... 3.5

3.3. Low-Solids (5 wt\%) Slurry Composition and Total Inventory (including permeate hold-up)... 3.6

3.4. Group 5 Low-Solids Supernate Opportunistic Composition................................................... 3.7

3.5. Results of Fitting Analysis for Group 5 CUF Low Solids Matrix.......................................... 3.10

3.6. Average Operating Conditions and Permeate Flux for Low-Solids (5 wt\%) Matrix Test ......... 3.12

3.7. Group 5 Mass Balance Overview of Dewatering .............................................................. 3.17

3.8. Group 5 Dewatering Mass Balance Calculation..............................................................

3.9. Filtration Testing of Group 5 Slurry at 19 wt\% UDS......................................................... 3.20

3.10. Average Operating Conditions and Permeate Flux for High-solids (15 wt\%) Matrix Test ....... 3.22

3.11. Group 5 High-Solids (15 wt\%) Slurry Physical Property Measurements (inside slurry loop)... 3.27

3.12. Group 5 High-Solids (15 wt\%) Slurry Composition and total inventory (including permeate hold-up)

3.13. Group 5 High-Solids Slurry Composition Based on ICP-OES/Radionuclide Characterization.

3.14. Results of Fitting Analysis for the Group 5 CUF High Solids (15 wt\%) Matrix ..................... 3.32

3.15. Comparison of Slurry Supernate Attributes to Filter Flux .................................................... 3.38

3.16. Group 5 Dewatered Caustic Leached Slurry Physical-Property Measurements (inside circulation loop).

3.17. Group 5 Caustic leached, dewatered (15 wt\%) Slurry Composition and total inventory (including permeate hold-up)

3.18. Group 5 Dewatered Leached Slurry Composition and Calculated Solids Leach Factors .......... 3.41

3.19. Results of Fitting Analysis for the Group 5 CUF Leached Dewatered Slurry ......................... 3.44

3.20. Group 5 Caustic Leached Slurry Inventory and Composition After the First Wash................. 3.46 
3.21. Group 5 Caustic Leached Slurry Inventory and Composition after the Second Wash............... 3.46

3.22. Group 5 Caustic leached Slurry Inventory and Composition After the Third Wash................. 3.47

3.23. Caustic Wash Solutions Radionuclide and Opportunistic Compositions ................................. 3.48

3.24. Group 5 Comparison of Washed Slurry Supernate Attributes to Filter Flux ........................... 3.56

3.25. Group 5 Average Flux Values for Washed Leached Slurry ................................................... 3.57

3.26. Group 5 Final Leached and Washed Slurry Physical Property Measurements ........................ 3.61

3.27. Group 5 Final Leached and Washed Slurry Composition and Total Inventory ........................ 3.62

3.28. Group 5 Washed Leach Slurry Composition and Caustic Leach Factor Calculations Based on ICP-OES/Radiochemical Characterization...................................................................... 3.63

3.29. Results of Fitting Analysis for the Group 5 Leached, Washed Slurry .................................... 3.73

4.1. Blending of the Group 6 and Group 5 Wastes........................................................................

4.2. Comparison of Planned and Actual Group 5 \& 6 Additions for CUF Testing.......................... 4.2

4.3. Group 6/5 Low-Solids Slurry Physical Property Measurements (Slurry Circulation Loop)...... 4.7

4.4. Group 6/5 Low-Solids Slurry Inventory and Composition (including permeate hold-up)......... 4.8

4.5. Group 6/5 Low-Solids Supernate Opportunistic Composition............................................... 4.9

4.6. Average Operating Conditions and Flux for Low-Solids Matrix Test .................................... 4.14

4.7. Group 6/5Average Operating Conditions and Filter Flux for High-Solids Slurry .................... 4.21

4.8. High-Solids Slurry Physical Properties (Inside Slurry Loop) ................................................ 4.26

4.9. Group 6/5 High-Solids Slurry Composition and Inventory (Including Permeate Hold-up)....... 4.27

4.10. Group 6/5 High-Solids Slurry Composition Based on ICP-OES/Radionuclide

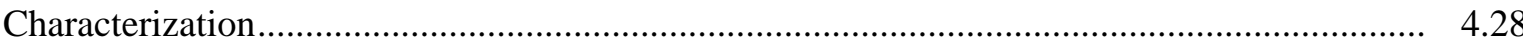

4.11. Results of Fitting Analysis for the High Solids Slurry ….....................................................

4.12. Rheological Behavior of Group 5, 6, and Group 6/5 High-Solid Slurry (at 25).................... 4.32

4.13. Group 6/5 Dewatered Caustic Leached Slurry Physical Property Measurements (inside slurry loop)

4.14. Group 6/5 Dewatered Caustic Leached Slurry Composition and Inventory (including permeate hold-up)

4.15. Dewatered Leached Slurry Composition and Calculated Solids Leach Factors ....................... 4.41

4.16. Results of Fitting Analysis for the Group 6/5 Dewatered Caustic Leached Slurry ................... 4.45

4.17. Group 6/5 Caustic leached Slurry Inventory and Composition after the First Wash ................ 4.47

4.18. Group 6/5 Caustic Leached Slurry Inventory and Composition after the Second Wash........... 4.48

4.19. Group 6/5 Caustic leached Slurry Inventory and Composition after the Third Wash............... 4.49

4.20. Group 6/5 Caustic leached Slurry Inventory and Composition after the Fourth Wash ............. 4.50

4.21. Group 6/5 Caustic Leached Slurry Inventory and Composition after the Fifth Wash............... 4.51

4.22. Group 6/5 Caustic leached Slurry Inventory and Composition after the Sixth Wash ................ 4.52 
4.23. Caustic Wash Solutions Opportunistic Compositions.

4.24. Average Dewatering Flux for Caustic Washes.

4.25. Group 6/5 Washed Caustic Leached Slurry Physical Property Measurements (inside slurry loop).

4.26. Group 6/5 Caustic Leached and Washed Slurry Inventory and Composition.

4.27. Group 6/5 Washed Leach Slurry Composition and Caustic Leach Factor Calculations Based on ICP-OES/Radiochemical Characterization....

4.28. Results of Fitting Analysis for Washed Caustic Leached Slurry

4.29. Group 6/5 Physical property Measurements of the Oxidative Leached Slurry

4.30. Group 6/5 Oxidative Leached Slurry Composition and Caustic/Oxidative Leach Factor Calculations Based on ICP-OES/Radiochemical Characterization

4.31. Effect of caustic / oxidative leaching on Group 6/5 CUF slurry rheology (at $25^{\circ} \mathrm{C}$ ).

4.32. Group 6/5 Oxidative Leached Slurry Inventory and Composition after the First Wash .

4.33. Group 6/5 Oxidative Leached Slurry Inventory and Composition after the Second Wash

4.34. Group 6/5 Oxidative Leached Slurry Inventory and Composition after the Third Wash.

4.35. Oxidative Wash Solutions Radionuclide and Opportunistic Compositions

4.36. Group 6/5 Physical Property Measurement of the Washed Oxidatively Leached Slurry (inside slurry loop)

4.37. Group 6/5 Washed Oxidative Leached Slurry Inventory and Composition

4.38. Group 6/5 Washed Oxidative Leach Slurry Composition and Overall Leach Factor Calculations Based on ICP-OES/Radiochemical Characterization.

4.39. Results of Fitting Analysis for the Oxidatively Leached, Washed Group 6/5 Slurry.

4.40. Average Operating Conditions and Flux for Post Caustic/Post Oxidative Leached HighSolids Matrix Test

5.1. Group 6/5 Caustic Leaching Conditions

5.2. Group 6/5 Leaching Final Aqueous Phase Conditions

5.3. Solids Wash Solution Composition

5.4. Group 6/5 Sludge Leached Solids Composition and Leach Factors After Leaching for $24 \mathrm{~h}$ at $100 \mathrm{C}$ in $5 \mathrm{M} \mathrm{NaOH}$ (dry basis)..

5.5. Composition of Group 6/5 Slurry Solids.

5.6. Group 6/5 Slurry and Caustic Leach Conditions for UFP1/2 Tests

5.7. Results Analysis of Leached Solids

6.1. Summary of Group 5 and Group 6/5 CUF Tests..... 


\section{Acronyms and Abbreviations}

\begin{tabular}{|c|c|}
\hline ASO & Analytical Service Operations \\
\hline ASR & Analytical Services Request \\
\hline AV & axial velocity \\
\hline BET & $\begin{array}{l}\text { Brunauer, Emmett, and Teller (a method for measuring } \\
\text { surface areas) }\end{array}$ \\
\hline BNI & Bechtel National, Inc. \\
\hline CUF & cross-flow ultrafiltration testing system \\
\hline DACS & data-acquisition collection system \\
\hline DI & deionized (water) \\
\hline DOE & U.S. Department of Energy \\
\hline EDS & Energy Dispersive Spectroscopy \\
\hline EFRT & External Flowsheet Review Team \\
\hline fps & feet per second \\
\hline GEA & gamma energy analysis \\
\hline GPM & gallons per minute \\
\hline HDPE & high-density polyethylene \\
\hline HLW & high-level waste \\
\hline IC & ion chromatography \\
\hline ICP & inductively coupled plasma \\
\hline $\mathrm{KOH}$ & potassium hydroxide \\
\hline KPA & kinetic phosphorescence analysis \\
\hline LAW & low-activity waste \\
\hline LRB & laboratory record book \\
\hline MDL & minimum detection limit \\
\hline M\&TE & measuring and test equipment \\
\hline OES & optical emission spectroscopy \\
\hline ORP & Office of River Protection \\
\hline PSD & particle-size distribution \\
\hline psid & pounds per square inch differential \\
\hline psig & pounds per square inch gauge \\
\hline
\end{tabular}


PNNL Pacific Northwest National Laboratory

PTF Pretreatment Facility

QAM Quality Assurance Manual

QARD Quality Assurance Requirements and Descriptions

REDOX reduction-oxidation

RPL Radiochemical Processing Laboratory

RPP-WTP River Protection Project-Waste Treatment Plant Support

Program

RTD resistance temperature detector

R\&T Research and Technology

SAL Shielded Analytical Laboratory

SEM scanning electron microscopy

TEM transmission electron microscopy

TMP transmembrane pressure

TRU transuranic

UDS undissolved solids

WTP Waste Treatment and Immobilization Plant

XRD X-ray diffraction 
WTP-RPT-172, Rev 0

\section{Testing Summary}

A testing program evaluating actual tank waste was developed in response to Task 4 from the M-12 External Flowsheet Review Team (EFRT) issue response plan. ${ }^{(a)}$ The test program was subdivided into logical increments. The bulk water-insoluble solid wastes that are anticipated to be delivered to the Waste Treatment and Immobilization Plant (WTP) were identified according to type such that the actual waste testing could be targeted to the relevant categories. Under test plan TP-RPP-WTP-467, ${ }^{\text {(b) }}$ eight broad waste groupings were defined. Samples available from the 222S archive were identified and obtained for testing. Under this test plan, a waste-testing program was implemented that included:

- Homogenizing the archive samples by group as defined in the test plan

- Characterizing the homogenized sample groups

- Performing parametric leaching testing on each group for compounds of interest

- Performing bench-top filtration/leaching tests in the hot cell for each group to simulate filtration and leaching activities if they occurred in the UFP2 vessel of the WTP Pretreatment Facility.

This report focuses on filtration/leaching tests performed on two of the eight waste composite samples and follow-on parametric tests to support aluminum leaching results from those tests.

The sample groups examined in this report were the reduction-oxidation (REDOX) sludge (Group 5) and S-saltcake (Group 6). The Group 5 waste was anticipated to be high in boehmite, requiring caustic leaching, whereas the Group 6 waste was anticipated to contain a significant fraction of water-insoluble chromium that required oxidative leaching. Project report WTP-RPT- $157^{(\mathrm{c})}$ describes the homogenization, characterization, and parametric leaching activities before bench-top filtration/leaching testing of these two waste groups. Characterization and parametric data in that report were used to plan two filtration/leaching tests_-one test with only Group 5 material and another test that blended Group 5 and Group 6.

The initial Group 5 test focused on filtration testing of the waste and caustic leaching for aluminum in the form of boehmite, and its impact on filtration. The initial sample was diluted with a liquid simulant to simulate the receiving concentration of retrieved tank waste into the UFP2 vessel (from 4 to $6 \mathrm{wt} \%$ undissolved solids). Filtration testing was performed on the dilute waste sample and dewatered to a higher solids concentration. Filtration testing was then performed on the concentrated slurry.

Afterwards, the slurry was leached and was then washed to remove aluminum from the waste. The leach was planned to simulate leaching conditions in the UFP2 vessel. During the leach, permeate samples were collected to measure the dissolution rate of aluminum in the waste. After the solution cooled down from the elevated leach, the leach liquor was dewatered from the solids. The remaining slurry was rinsed

(a) SM Barnes, and R Voke. 2006. "Issue Response Plan for Implementation of External Flowsheet Review Team (EFRT) Recommendations - M12: Undemonstrated Leaching Process.” 24590-WTP-PL-ENG-06-0024 Rev. 0.

(b) SK Fiskum. 2007. Characterization and Small Scale Testing of Hanford Wastes to Support the Development and Demonstration of Leaching and Ultrafiltration Pretreatment Processes. TP-RPP-WTP-467, Rev. 0, 2/2/07 and Rev. 1, 7/31/07.

(c) SK Fiskum, et al. 2008. Characterization and Leach Testing for REDOX Sludge and S-Saltcake Actual Waste Sample Composites. WTP-RPT-157, Rev 0, 7/11/08. 
and dewatered with caustic solutions to remove a majority of the dissolved aluminum from the leached slurry. It was planned that the concentration of the rinse solutions would maintain the solubility of the aluminum in the dewatered rinse solutions. Filtration tests were performed on the final slurry to compare to testing performed before the leach.

The second test used a blend of the Group 5 and Group 6 waste. Because there was an insufficient quantity of solids present in Group 6 waste to achieve $20 \mathrm{wt} \%$ solids for the initial dewater process, the Group 6 waste was blended with Group 5 waste to provide a higher feed concentration for the initial dewater. The focus of this test was to examine how both wastes filtered and examine oxidative leaching of chromium in the Group 6 waste after caustic leaching aluminum in the Group 5 waste. Initially, Group 6 material was added to the testing skid and diluted with excess permeate present from homogenization. Filtration testing was performed and then dewatered to a system minimum volume. Group 5 material was then added to the concentrated slurry and dewatered further. Filtration testing was performed on the concentrated slurry and caustic leached for aluminum present. As before, the leach was to simulate conditions in the UFP2 tank, and permeate samples were taken to measure the dissolution rate of solid aluminum in the slurry. After the caustic leaching, the slurry was rinsed repeatedly until the free hydroxide level of the slurry was below $0.25 \mathrm{M}$. At this point, an oxidative leach was performed on the slurry using $1 \mathrm{M}$ sodium permanganate. Permeate samples were collected during the oxidative leach to measure the dissolution rate of solid chromium in the slurry. The slurry was rinsed and dewatered to remove dissolved chromium from the leached slurry using a dilute caustic solution. A final filtration test was then performed on the slurry after it was combined with the leached slurry solids from the first test.

Follow-on parametric tests were performed to examine boehmite dissolution blended with S-saltcake waste material as performed with the Group 6/5 filtration test. The first series of tests were small benchtop leaching tests performed in the fumehood on material sampled from the Group 6/5 filtration/leaching test. The sample was collected after the slurry was concentrated by filtration, but before the slurry was batch caustic leached. These tests used the same testing protocol as previous parametric tests, but used material that had a similar shear history (that is, they had been sheared by filtration operations for a period of time). These studies also explored the effect of caustic concentrations from 3 to $7 \mathrm{M}$. Another test was performed with material that was blended to the same ratios used in the Group 6/5 filtration/leaching test, but not sheared. This material was leached at a similar caustic concentration used for the Group 6/5 filtration/leaching test, but at different solids concentrations. The concentrations selected were to mimic leaching conditions if they occurred in either the UFP1 or UFP2 tank to understand if the leach factor is impacted by the initial slurry undissolved solids (UDS) concentration.

\section{Objectives}

The test objectives are summarized in Table S.1 along with a discussion of how the objectives were met. Several objectives (in gray shading lighter than header shading) did not specifically apply to the scope provided in this report; they will be reported in companion reports as indicated in the controlling test plan. 
Table S.1. Test Objectives

\begin{tabular}{|c|c|c|c|}
\hline \multicolumn{2}{|r|}{ Test Objective } & $\begin{array}{c}\text { Objective } \\
\text { Met? (Y/N) }\end{array}$ & Discussion \\
\hline & $\begin{array}{l}\text { Determine the physical and chemical } \\
\text { characteristics (summarized in } \\
\text { Section } 6.2 .2 \text { of the test plan) } \\
\text { relevant to leaching and } \\
\text { ultrafiltration behaviors of actual } \\
\text { waste samples required to validate } \\
\text { simulants. }\end{array}$ & $\mathrm{Y}$ & $\begin{array}{l}\text { Initial characterization of the Group } 5 \text { and } 6 \text { samples } \\
\text { was summarized in WTP-RT- } 157 \text { and referenced as } \\
\text { needed in Sections } 3 \text { and } 4 \text { of this report. }\end{array}$ \\
\hline 2) & $\begin{array}{l}\text { Determine the dissolution rate of } \\
\text { aluminum in the actual waste } \\
\text { samples, present predominantly as } \\
\text { gibbsite, as a function of temperature } \\
\text { and free hydroxide concentration, } \\
\text { and over a range of sodium } \\
\text { concentrations of interest to the } \\
\text { caustic leaching process. }\end{array}$ & NA & $\begin{array}{l}\text { This is not applicable for Groups } 5 \text { and } 6 \text { because } \\
\text { gibbsite is not a major component of these wastes. } \\
\text { The gibbsite dissolution parameters will be provided } \\
\text { in the Group } 3 \text { (plutonium-uranium extraction } \\
\text { [PUREX] Cladding Waste) and Group } 4 \text { (REDOX } \\
\text { Cladding Waste) report. }\end{array}$ \\
\hline 3) & $\begin{array}{l}\text { Determine the dissolution rate of } \\
\text { aluminum in the actual waste } \\
\text { samples, present predominantly as } \\
\text { boehmite, as a function of } \\
\text { temperature and free hydroxide } \\
\text { concentration, and over a range of } \\
\text { sodium concentrations of interest to } \\
\text { the caustic leaching process. }\end{array}$ & $\mathrm{Y}$ & $\begin{array}{l}\text { Initial parametric testing of the Group } 5 \text { for Al } \\
\text { dissolution as boehmite was summarized in } \\
\text { WTP-RPT-157. Additional dissolution data of } \\
\text { aluminum as boehmite from caustic leaching are } \\
\text { found in this report from the following activities: } \\
\text { - Caustic leaching during the Group } 5 \\
\text { filtration/leach test (Section 3) } \\
\text { - Caustic leaching during the Group 6/5 filtration } \\
\text { leaching test (Section 4) } \\
\text { - Addition parametric tests on material based on a } \\
\text { Group 6/5 blended waste (Section 5). }\end{array}$ \\
\hline 4) & $\begin{array}{l}\text { Determine the dissolution rate of } \\
\text { chromium and the extent of } \\
\text { dissolution of plutonium and other } \\
\text { safety-related constituents ( } \mathrm{U}, \mathrm{Fe} \text {, } \\
\mathrm{Mn}, \mathrm{Ni} \text {, and } \mathrm{Zn} \text { ) in the actual waste } \\
\text { samples as functions of temperature } \\
\text { and over a range of } \mathrm{NaOH} \\
\text { concentrations of interest for } \\
\text { oxidative leaching. (The } \mathrm{NaMnO}_{4} \\
\text { dosage will be predetermined for the } \\
\text { oxidation of the chromium in the } \\
\text { waste solids.) }\end{array}$ & $\mathrm{Y}$ & $\begin{array}{l}\text { Initial parametric testing of the Group } 6 \text { for } \mathrm{Cr} \\
\text { dissolution was summarized in WTP-RPT- } 157 \text {. } \\
\text { Additional dissolution data of solid Cr from oxidative } \\
\text { leaching is found in this report from the following } \\
\text { activities: } \\
\text { - Oxidative leaching during the Group 6/5 } \\
\text { filtration/leaching test (Section 4). Note as } \\
\text { described below that the } \mathrm{NaMnO}_{4} \text { dosage was } \\
\text { higher than targeted. However, this inadvertent } \\
\text { over addition led only to a very limited } \\
\text { dissolution of Pu. }\end{array}$ \\
\hline
\end{tabular}


Table S.1 (Contd)

\begin{tabular}{|c|c|c|c|}
\hline \multicolumn{2}{|r|}{ Test Objective } & $\begin{array}{c}\text { Objective } \\
\text { Met? (Y/N) }\end{array}$ & Discussion \\
\hline & $\begin{array}{l}\text { Determine the dissolution/reaction } \\
\text { rate of phosphates in the actual waste } \\
\text { samples as a function of temperature } \\
\text { and over a range of } \mathrm{NaOH} \\
\text { concentrations of interest for the } \\
\text { caustic leaching process as well as } \\
\text { the extent of dissolution during post- } \\
\text { leaching wash. }\end{array}$ & NA & $\begin{array}{l}\text { The wastes tested in this report were not high- } \\
\text { phosphate wastes. The phosphate dissolution } \\
\text { parametric testing will be generated from a different } \\
\text { waste type and reported in the appropriate waste- } \\
\text { specific report. }\end{array}$ \\
\hline 6) & $\begin{array}{l}\text { Determine ultrafiltration flux before } \\
\text { and after caustic and oxidative } \\
\text { leaching over the operating range of } \\
\text { solids concentrations during the } \\
\text { leaching processes at } 25^{\circ} \mathrm{C} \text { when } \\
\text { sufficient actual waste sample is } \\
\text { available for testing the filtration } \\
\text { behavior. }\end{array}$ & $\mathrm{Y}$ & $\begin{array}{l}\text { Two tests were performed using both Group } 5 \text { and } \\
\text { Group } 6 \text { wastes where the focus was measuring the } \\
\text { filter flux before and after leaching at } 25^{\circ} \mathrm{C} \text {. } \\
\text { Variables examined were: } \\
\text { - Transmembrane pressure } \\
\text { - Axial velocity } \\
\text { - Undissolved solids concentration } \\
\text { - Differences due to changes in the slurry during } \\
\text { leaching and rinsing of waste solids. } \\
\text { The first test was performed on the Group } 5 \text { waste } \\
\text { sample, as summarized in Section } 3 \text {. } \\
\text { The second test was a combination of the Group } 6 \text { and } \\
\text { Group } 5 \text { samples. Group } 5 \text { material was added to the } \\
\text { second test because not enough material was available } \\
\text { from the Group } 6 \text { sample to run it by itself. The } \\
\text { results from this test are summarized in Section } 4 \text {. }\end{array}$ \\
\hline 7) & $\begin{array}{l}\text { Scanning electron microscopy } \\
\text { (SEM), transmission electron } \\
\text { microscopy (TEM), energy } \\
\text { dispersive spectroscopy (EDS), and } \\
\text { X-ray diffraction (XRD) will be used } \\
\text { to determine the primary mineral } \\
\text { forms present for Al, Cr, and P and } \\
\text { provide information to enable the } \\
\text { correlation of these mineral forms to } \\
\text { dissolution behavior. }\end{array}$ & $\mathrm{Y}$ & $\begin{array}{l}\text { Initial characterization of the material in both the } \\
\text { Group } 5 \text { and } 6 \text { composite waste samples was } \\
\text { summarized in WTP-RPT-157. Additional crystal } \\
\text { imaging was performed on leached material from both } \\
\text { filtration/leaching tests. Results are summarized in } \\
\text { Sections } 3 \text { and } 4 \text { of this report. XRD, SEM, TEM, } \\
\text { and EDS were used during initial characterization and } \\
\text { examination of leach slurry samples resulting from } \\
\text { parametric leaching studies reported in WTP-RPT- } \\
157 \text { Rev. } 0 \text { from the CUF tests discussed in this } \\
\text { report. }\end{array}$ \\
\hline
\end{tabular}




\section{Test Exceptions}

No test exceptions applied to this work.

\section{Results and Performance Against Success Criteria}

The test plan delineated several success criteria, which are listed in Table S.2. Selected criteria were relevant to the test scope included in this report; the other criteria that are outside of the reported scope are shaded.

Table S.2. Results and Performance Against Success Criteria

\begin{tabular}{|c|c|c|}
\hline & List Success Criteria & $\begin{array}{c}\text { Explain How the Tests Did or Did Not } \\
\text { Meet the Success Criteria }\end{array}$ \\
\hline 1) & $\begin{array}{l}\text { A summary (letter report format) of the available } \\
\text { information (including published literature) is } \\
\text { provided on the characteristics (both known } \\
\text { characteristics and those needed to be determined) } \\
\text { relevant to leaching and filtration behaviors of the } \\
\text { tank farm waste groupings identified for testing. }\end{array}$ & $\begin{array}{l}\text { Letter report number RPP-WTP-07-705 (J. G. Lumetta } \\
\text { and R. T. Hallen, WTP-RPT-151, Review of Caustic } \\
\text { Leaching Testing With Hanford Tank Waste Sludges) } \\
\text { which addressed this success criterion, was delivered to } \\
\text { WTP on } 1 / 24 / 2007 \text {. }\end{array}$ \\
\hline 2) & $\begin{array}{l}\text { The physical and chemical characteristics for each } \\
\text { of the actual waste-sample composites selected for } \\
\text { testing are provided (including a format in } \\
\text { conformance with the presentation protocols } \\
\text { [24590-WTP-GPG-RTD-001]). The relevant } \\
\text { physical and chemical characteristics are } \\
\text { elaborated in Test Conditions, Section 6.0, of the } \\
\text { test plan. }\end{array}$ & $\begin{array}{l}\text { All physical and chemical characterization testing as } \\
\text { defined in the test plan was completed and summarized } \\
\text { in project report WTP-RPT- } 157 \text {. }\end{array}$ \\
\hline 3) & $\begin{array}{l}\text { The dissolution rate and the extent of dissolution of } \\
\text { aluminum present predominantly as gibbsite in } \\
\text { actual waste solids are determined as a function of } \\
\text { temperature, free-hydroxide, and sodium } \\
\text { concentrations. The associated uncertainties in test } \\
\text { results are provided. }\end{array}$ & NA \\
\hline 4) & $\begin{array}{l}\text { The dissolution rate and the extent of dissolution of } \\
\text { aluminum present predominantly as boehmite in } \\
\text { actual waste solids are determined as a function of } \\
\text { temperature, free-hydroxide, and sodium } \\
\text { concentrations. The associated uncertainties in test } \\
\text { results are provided. }\end{array}$ & $\begin{array}{l}\text { Initial parametric testing of the Group } 5 \text { waste for Al } \\
\text { dissolution as boehmite was summarized in } \\
\text { WTP-RPT-157. Additional dissolution data of } \\
\text { aluminum as boehmite from caustic leaching are found } \\
\text { in this report from the following activities: } \\
\text { - Caustic leaching during the Group } 5 \text { filtration/leach } \\
\text { test (Section 3) } \\
\text { - Caustic leaching during the Group } 6 / 5 \text { filtration } \\
\text { leaching test (Section } 4 \text { ). } \\
\text { Additional parametric tests were performed on material } \\
\text { based on a Group } 6 / 5 \text { blended waste (Section 5). }\end{array}$ \\
\hline
\end{tabular}


Table S.2 (Contd)

\begin{tabular}{|c|c|c|}
\hline & List Success Criteria & $\begin{array}{c}\text { Explain How the Tests Did or Did Not } \\
\text { Meet the Success Criteria }\end{array}$ \\
\hline 5) & $\begin{array}{l}\text { The dissolution rate and the extent of dissolution of } \\
\text { chromium in the actual waste solids are determined } \\
\text { as a function of temperature and over a range of } \\
\text { NaOH concentrations of interest to oxidative } \\
\text { leaching. The } \mathrm{NaMnO}_{4} \text { dosage will be } \\
\text { predetermined for the oxidation of the chromium in } \\
\text { the waste solids. The associated uncertainties in } \\
\text { the test results are provided. }\end{array}$ & $\begin{array}{l}\text { Initial parametric testing of the Group } 6 \text { waste for Cr } \\
\text { dissolution was summarized in WTP-RPT- } 157 \text {. } \\
\text { Additional dissolution data of solid Cr from oxidative } \\
\text { leaching is found in this report from the following } \\
\text { activities: } \\
\text { - Oxidative leaching during the Group } 6 / 5 \\
\text { filtration/leaching test (Section } 4) \text {. However, the } \\
\text { targeted Mn:Cr ratio of } 1: 1 \text { was exceeded. The } \\
\text { actual ratio tested was } 1.7: 1 \text {. This resulted in some } \\
\text { Pu dissolution, but it was not in a significant } \\
\text { quantity of the starting mass (<1\%). }\end{array}$ \\
\hline 6) & $\begin{array}{l}\text { The dissolution rate and the extent of dissolution of } \\
\text { phosphates in the actual waste solids are } \\
\text { determined as a function of temperature and } \mathrm{NaOH} \\
\text { concentration along with the uncertainty in these } \\
\text { estimates. }\end{array}$ & NA \\
\hline 7) & $\begin{array}{l}\text { The ultrafiltration flux before and after caustic and, } \\
\text { as applicable, oxidative leaching (reconcentration, } \\
\text { if sufficient solids are available) over the operating } \\
\text { range of solids concentrations with the actual waste } \\
\text { samples at } 25^{\circ} \mathrm{C} \text { is defined when the available } \\
\text { sample size is adequate for the testing. }\end{array}$ & $\begin{array}{l}\text { The following variables were examined for both } \\
\text { Group } 5 \text { and Group } 6 \text { wastes where the focus was } \\
\text { measuring the filter flux before and after leaching at } \\
25^{\circ} \mathrm{C} \text { : } \\
\text { - Transmembrane pressure } \\
\text { - Axial velocity } \\
\text { - Undissolved Solid Concentration } \\
\text { - Differences due to changes in the slurry during } \\
\text { leaching and rinses of waste solids. } \\
\text { The first test was performed on the Group } 5 \text { waste } \\
\text { sample, as summarized in Section } 3 \text {. } \\
\text { The second test was a combination of the Group } 6 \text { and } \\
\text { Group } 5 \text { samples. Group } 5 \text { material was added to the } \\
\text { second test because not enough material was available } \\
\text { from the Group } 6 \text { sample to run it by itself. The results } \\
\text { from this test are summarized in Section } 4 \text {. }\end{array}$ \\
\hline 8) & $\begin{array}{l}\text { The primary mineral forms present for } \mathrm{Al}, \mathrm{Cr} \text {, and } \\
\mathrm{P} \text { are determined ,and a qualitative correlation of } \\
\text { the dissolution behavior of these waste elements to } \\
\text { the mineral forms is identified. }\end{array}$ & $\begin{array}{l}\text { Initial characterization of the material in both the Group } \\
5 \text { and } 6 \text { composite waste samples was summarized in } \\
\text { WTP-RPT-157. Additional crystal imaging was } \\
\text { performed on leached material from both tests. Results } \\
\text { are summarized in Sections } 3 \text { and } 4 \text { of this report. }\end{array}$ \\
\hline
\end{tabular}

\section{Quality Requirements}

Pacific Northwest National Laboratory (PNNL) is operated by Battelle for the U.S. Department of Energy. PNNL implements a Quality Assurance Program that is based upon the requirements as defined in the U.S. Department of Energy (DOE) Order 414.1C, "Quality Assurance” and 10 CFR 830, "Energy/Nuclear Safety Management," Subpart A-Quality Assurance Requirements. PNNL has chosen 
to implement the requirements of DOE Order 414.1C and 10 CFR 830, Subpart A by integrating them into the laboratory's management systems and daily operating processes. The procedures necessary to implement the requirements are documented through the laboratory’s Standards-Based Management System (SBMS).

PNNL implemented the RPP-WTP quality requirements by performing work in accordance with the River Protection Project - Waste Treatment Plant Support Program (RPP-WTP) Quality Assurance Plan (RPPWTP-QA-001, QAP). Work was performed to the quality requirements of NQA-1-1989 Part I, Basic and Supplementary Requirements, NQA-2a-1990, Part 2.7, and DOE/RW-0333P, Rev 13, Quality Assurance Requirements and Descriptions (QARD). These quality requirements were implemented through the River Protection Project - Waste Treatment Plant Support Program (RPP-WTP) Quality Assurance Manual (RPP-WTP-QA-003, QAM). The analytical requirements were implemented through RPPWTP's Statement of Work (RPP-WTP-QA-005) with the Radiochemical Processing Laboratory (RPL) Analytical Service Operations (ASO).

A matrix that cross-references the NQA-1, NQA-2a, and QARD requirements with the procedures for RPP-WTP work was provided in the test plan TP-RPP-WTP-467. It included justification for those requirements not implemented.

Experiments that were not method-specific were performed in accordance with RPP-WTP's procedures QA-RPP-WTP-1101 "Scientific Investigations" and QA-RPP-WTP-1201 "Calibration and Control of Measuring and Testing Equipment” so that sufficient data were taken with properly calibrated measuring and test equipment (M\&TE) to obtain quality results.

RPP-WTP addressed internal verification and validation activities by conducting an Independent Technical Review of the final data report in accordance with RPP-WTP's procedure QA-RPP-WTP-604. This review verified that the reported results were traceable, that inferences and conclusions were soundly based, and the reported work satisfied the Test Plan objectives. This review procedure is part of PNNL's RPP-WTP Quality Assurance Manual.

\section{R\&T Test Conditions}

The R\&T test conditions, as defined in the Test Specification, ${ }^{(a)}$ are summarized in Table S.3.

(a) PS Sundar. Nov. 2006. Characterization and Small Scale Testing of Hanford Wastes to Support the Development and Demonstration of Leaching and Ultrafiltration Pretreatment Processes. 24590-PTF-TSPRT-06-003, Rev. 1. 
Table S.3. R\&T Test Conditions

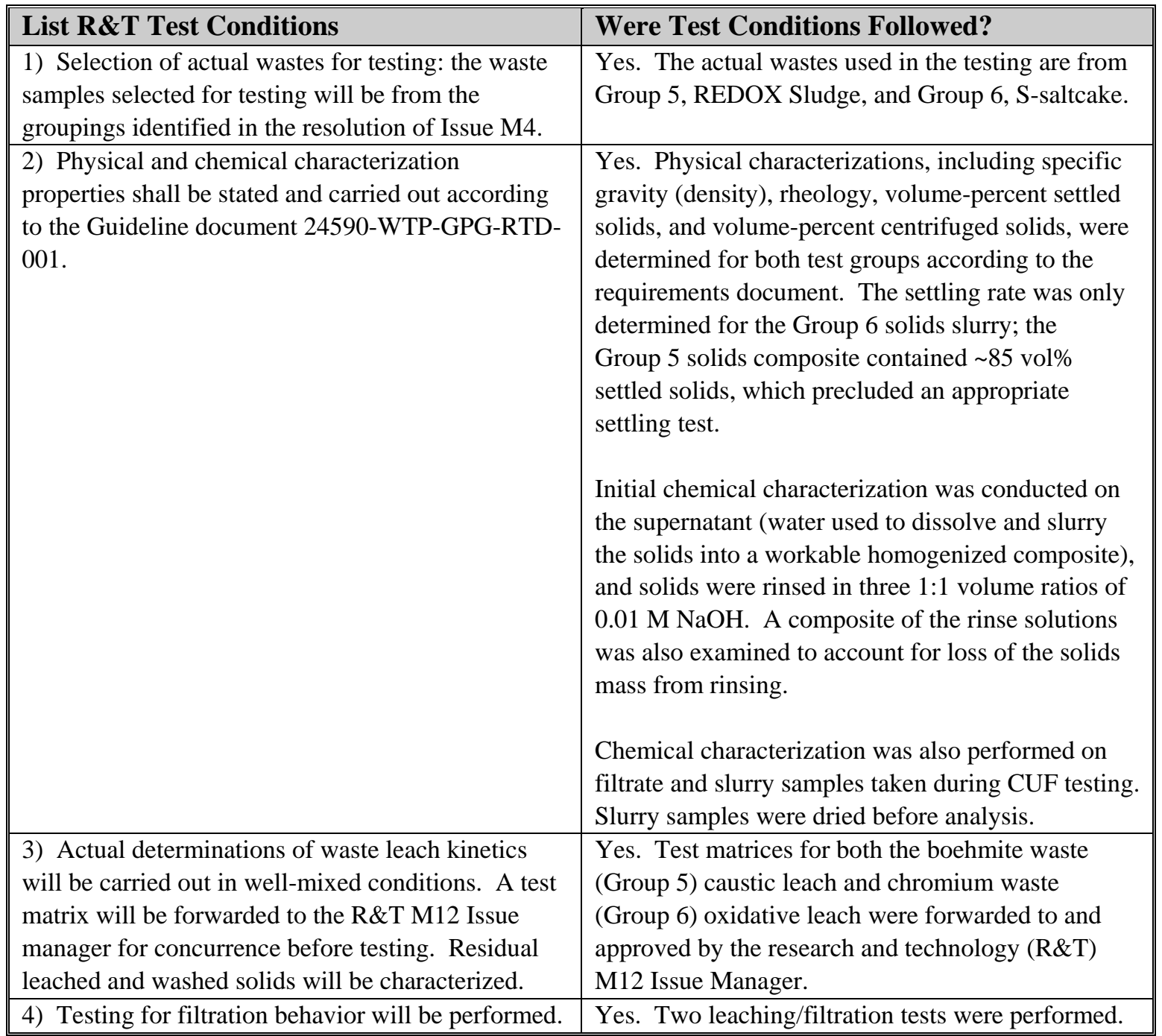

\section{Simulant Use}

The bulk of the testing used actual Hanford tank wastes. However, due to the limitations in the quantity of supernate present, a simulant of the Group 5 supernate fraction was prepared and used to dilute the feed to allow testing at lower solids concentrations. 


\section{Discrepancies and Follow-on Tests}

The testing reported here includes four test discrepancies, which are described in Table S.4.

Table S.4. Test Discrepancies Listed and Described

\begin{tabular}{||l|l|}
\hline \multicolumn{1}{|c|}{ Test Discrepancies } & \multicolumn{1}{c|}{ Description } \\
\hline $\begin{array}{l}\text { Filtration testing of the Group 5 test could not occur at 20 } \\
\text { wt\% UDS as initially planned. }\end{array}$ & $\begin{array}{l}\text { As the Group 5 material was dewatered, the solution's } \\
\text { viscosity rapidly increased. This increased the } \\
\text { pressure drop across the filter from 1 to 2 psid to over } \\
10 \text { psid. The additional friction generated from the } \\
\text { slurry began to generate heat at a rate that } \\
\text { overwhelmed the filtrations skid's cooling system. }\end{array}$ \\
$\begin{array}{l}\text { Permeate was added back to the dewatered slurry until } \\
\text { it was diluted to 15 wt\% UDS, dropped the pressure } \\
\text { across the filter below 10 psid, and allowed the filter } \\
\text { testing to resume. The volume and concentration of } \\
\text { the leach solution added later were adjusted to } \\
\text { maintain the same leaching conditions planned } \\
\text { originally. }\end{array}$ \\
\hline
\end{tabular}


Table S.4 (Contd)

\begin{tabular}{|c|c|c|c|}
\hline & \multicolumn{3}{|c|}{ Description } \\
\hline \multirow[t]{2}{*}{$\begin{array}{l}\text { Group } 5 \text { and Group } 6 \text { slurry mass and the UDS ratio } \\
\text { deviated from the approved concurrence letter WTP/RPP- } \\
\text { MOA-PNNL-00102. }\end{array}$} & \multicolumn{3}{|c|}{$\begin{array}{l}\text { To account for the higher conversion of aluminum } \\
\text { projected for the test, the mass inventory was reduced } \\
\text { to } 70 \% \text { of the original planned slurry. This decreased } \\
\text { the projected leach volume below } 4 \text { liters while } \\
\text { keeping the initial starting UDS inventory at } \\
300 \text { grams. The mass ratio of the Group } 5 \text { and } \\
\text { Group } 6 \text { slurries were to be kept the same as that } \\
\text { provided in WTP/RPP-MOA-PNNL-00102. This } \\
\text { modified plan for the Group 6/5 CUF test was issued } \\
\text { to BNI under concurrence letter WTP/RPP-MOA- } \\
\text { PNNL-00259. } \\
\text { During the test, the actual masses added to the CUF } \\
\text { were less than the projected mass. Some of the } \\
\text { difference was due to holdup in the sample containers. } \\
\text { However, a fraction of the Group } 5 \text { sample inventory } \\
\text { was used for other testing, reducing the available } \\
\text { inventory of the material. This increased the ratio of } \\
\text { Group } 6 \text { to Group } 5 \text { solids present in the test. Below } \\
\text { is a comparison of the approved ratio of the two waste } \\
\text { groups to the ratio tested. }\end{array}$} \\
\hline & $\begin{array}{l}\begin{array}{l}\text { Group 5/Group } 6 \\
\text { Ratio }\end{array} \\
\text { Slurry Mass Ratio } \\
\text { UDS Mass Ratio }\end{array}$ & $\begin{array}{c}\text { Planned } \\
1.89 \\
2.26\end{array}$ & \begin{tabular}{|c|} 
Tested \\
1.68 \\
2.09
\end{tabular} \\
\hline
\end{tabular}


Table S.4 (Contd)

\begin{tabular}{||l|l||}
\hline \multicolumn{1}{|c|}{ Test Discrepancies } & \multicolumn{1}{|c|}{ Description } \\
\hline $\begin{array}{l}\text { Miscommunication between operators caused a 200-mL } \\
\text { solution of } 1 \mathrm{M} \mathrm{NaMnO} \text { to be added to the vessel when } \\
\text { only } 172 \mathrm{~mL} \text { was to be added during the oxidative leach } \\
\text { for the Group } 6 / 5 \text { test. }\end{array}$ & $\begin{array}{l}\text { Typically, solutions are measured to exact volumes } \\
\text { before being placed in the hot cells to minimize } \\
\text { contamination from outside sources. When a solution } \\
\text { of } 1 \mathrm{M} \mathrm{NaMnO}_{4} \text { solution was dropped off, the testing } \\
\text { engineer believed that it was to be only the } 172 \mathrm{~mL} \\
\text { needed for the test. The technician making the } \\
\text { solution did not understand this and provided a } \\
\text { solution of } 200 \mathrm{~mL} \text {, believing the exact solution } \\
\text { volume would be measured in the hot cell. The } \\
\text { mistake was discovered when the gross and tare } \\
\text { weights of the vial were examined. }\end{array}$ \\
& $\begin{array}{l}\text { The goal of the oxidative leach was to add sodium } \\
\text { permanganate to create a slurry solution with a Mn:Cr } \\
\text { mole ratio of } 1: 1 . \text { In the end, the final mole ratio was } \\
1.7 .\end{array}$ \\
\hline
\end{tabular}


WTP-RPT-172, Rev 0

\subsection{Introduction}

This is one in a series of reports that define the characterization, parametric leaching, and filtration testing of actual Hanford tank wastes in support of the Hanford Tank Waste Treatment and Immobilization Plant (WTP) pretreatment process development and demonstration. The tests reported here were conducted according to TP-RPP-WTP-467, ${ }^{\text {a) }}$ which was written in response to Test Specification 24590-PTF-TSPRT-06-003 Rev. $1^{\text {(b) }}$, as well as TP-RPP-WTP-456, ${ }^{(\mathrm{c})}$ written in response to Test Specification 24590PTF-TSP-RT-06-002 Rev. 0 . $^{\text {(d) }}$ This report focuses on filtration and chemical leaching testing performed under TP-RPP-WTP-467 and specifically discusses the results of filtration and leach testing of two composite waste samples representing reduction-oxidation (REDOX) Sludge Waste and S-Saltcake Waste.

\subsection{Tank Waste Pretreatment Operations at the WTP}

Figure 1.1 provides a schematic illustration of the primary functions to be performed in the WTP. Initially, the low-activity waste (LAW) liquid stream will be removed from the high-level waste (HLW) solids phase by ultrafiltration in the Pretreatment Facility (PTF). The concentrated HLW solids will be pretreated using caustic and, in some cases, oxidative leaching processes to dissolve and remove constituents (aluminum, chromium, phosphates, and sulfates) that would otherwise limit HLW loading in the immobilized waste glass. The current plant design calls for the pretreatment leaching processes to be carried out in the ultrafiltration feed vessels. During pretreatment, the concentrated HLW solids will be caustic leached, washed, and in the case of high Cr wastes, oxidatively leached and washed once more. The caustic leaching will be conducted to solubilize the aluminum, phosphorus, and sulfur in the HLW solids; the oxidative leaching will be conducted to oxidize the chromium [from $\mathrm{Cr}$ (III) to $\mathrm{Cr}(\mathrm{VI})$ ] using a sodium permanganate $\left(\mathrm{NaMnO}_{4}\right)$ solution and dissolve chromate in a mild caustic solution. The HLW solids will be re-concentrated after each leach and wash operation in the ultrafilter.

The current design of the PTF was based on aluminum dissolution results from earlier small, bench-scale, caustic leaching tests that were provided to Bechtel National, Incorporated (BNI) by the U.S. Department of Energy's (DOE's) Office of River Protection (ORP). Since a number of previous studies demonstrated the technical feasibility of the oxidative leaching process (Rapko 1998; Lumetta and Rapko 1999; Rapko and Vienna 2002; Rapko et al. 2002), only a limited number of small bench-scale oxidative leaching tests using two selected actual waste tank samples (SX-101 and SY-102) with the preferred oxidant $\mathrm{NaMnO}_{4}$ were carried out to estimate the oxidant dosage and the efficacy of the oxidative leaching process (Rapko et al. 2004; Rapko et al. 2005). The testing with actual radioactive wastes has been generally limited to

(a) SK Fiskum, TP-RPP-WTP-467, Rev. 0, 2/2/07 and Rev. 1 7/31/07, Characterization and Small Scale Testing of Hanford Wastes to Support the Development and Demonstration of Leaching and Ultrafiltration Pretreatment Processes.

(b) PS Sundar. 2006. 24590-PTF-TSP-RT-06-003 Rev. 1, Characterization and Small Scale Testing of Hanford Wastes to Support the Development and Demonstration of Leaching and Ultrafiltration Pretreatment Processes.

(c) SK Fiskum, TP-RPP-WTP-456, Rev. 0, 11/29/06, Pretreatment Demonstration applying Oxidative Leaching to Hanford Tank Wastes.

(d) PS Sundar. 2006. 24590-PTF-TSP-RT-06-002 Rev. 0, Process Development for Design of Oxidative Leaching of Hanford Wastes. 
small-scale testing (typically 1 to $10 \mathrm{~g}$ ) because of limited sample availability and personnel safety associated with sample handling.

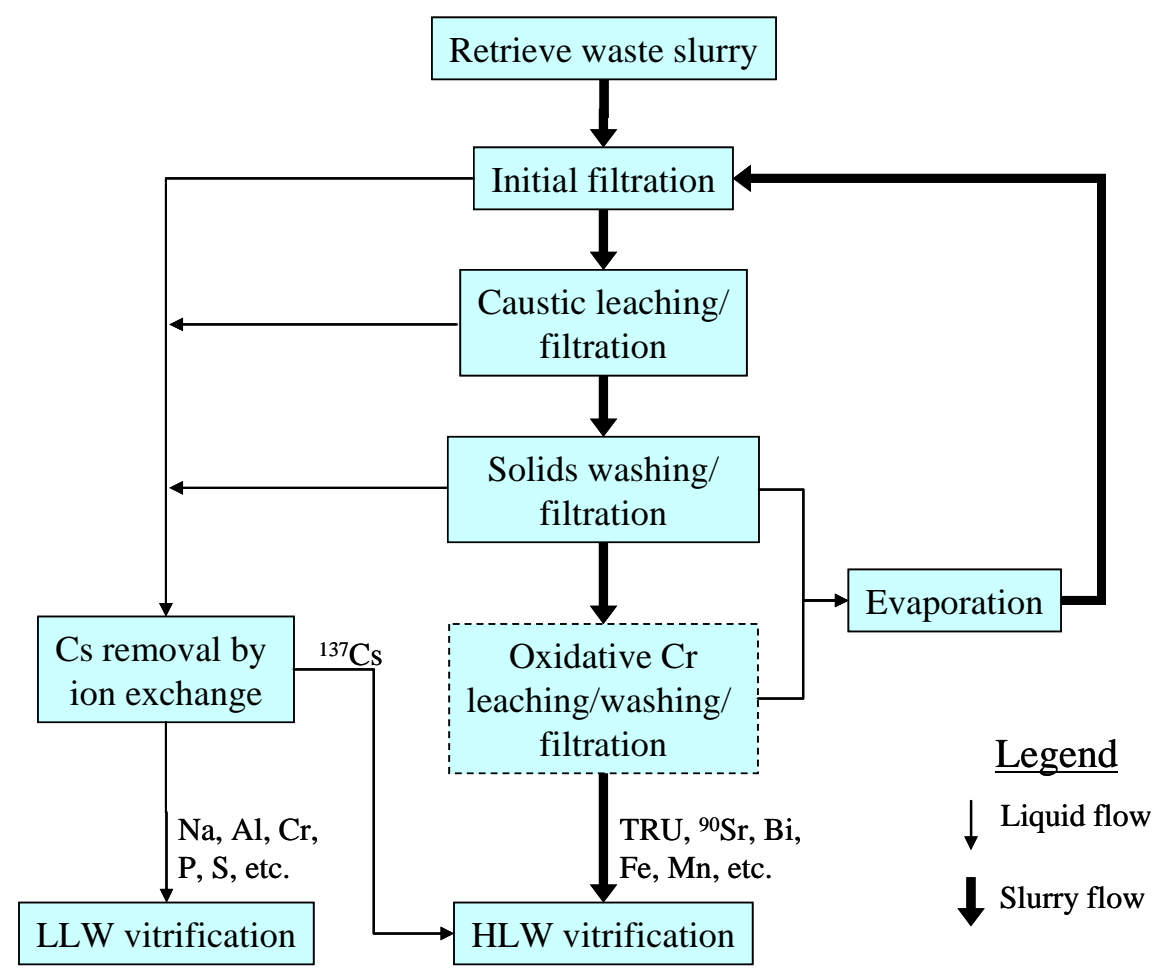

Figure 1.1. Schematic Representation of the Key Processes to be Performed in the PTF (Note: This is for illustrative purposes only; it is not meant to be a comprehensive view of the functions performed within the WTP.)

\subsection{Issues Identified by the External Flowsheet Review Team}

A team of foremost experts from industry, national laboratories, and universities (referred to as the External Flowsheet Review Team or EFRT) was assembled by BNI in October of 2005 to conduct an indepth review of the process flowsheet supporting the design of the WTP. The EFRT identified several issues from the critical review of the process flowsheet, ${ }^{(\mathrm{a}, \mathrm{b})}$ including

- Issue M4: The WTP has not demonstrated that its design is sufficiently flexible to reliably process all of the Hanford tank farm wastes at the design throughputs.

- Issue M12: Neither the caustic leaching nor the oxidative leaching process has been demonstrated at greater than bench scale. The small-scale experiments are capable of defining the leaching chemistry.

(a) WTP Doc. No. 24590-WTP-PL-ENG-06-0008, Rev 0, "Hanford Waste Treatment and Immobilization Plant (WTP) Project Response Plan for Resolution of Issues Identified by the Comprehensive Review of the WTP Flowsheet and Throughput.” L. Lucas, March 2006.

(b) WTP Project Doc. No. CCN 132846 "Comprehensive Review of the Hanford Waste Treatment Plant Flowsheet and Throughput - Assessment Conducted by an Independent Team of External Experts.” March 2006, chartered by the Hanford Waste Treatment and Immobilization Plant Project at the Direction of the U.S. Department of Energy, Office of Environmental Management, Washington DC. 
However, they are limited in their capability to predict the effectiveness of these processes without a scale-up demonstration.

- Issue M13: For wastes requiring leaching, a combination of inadequate filter flux and area will likely limit throughput to the HLW or LAW vitrification facilities.

The work scope defined in the TP-RPP-WTP-467 represented the initial portion of the actual wastetesting portion of Task 4 from the M-12 EFRT issue response plan. ${ }^{(a)}$ The selection of actual tank waste was based on the responses developed to resolve EFRT Issue M4. In this case, a family of waste groupings representing the behavior of $\sim 75 \%$ of the tank-farm inventory was developed to assist in designing subsequent tests that will assess the adequacy of the overall flowsheet design in treating the tank-farm wastes. These waste groupings were the basis for selecting actual wastes for the current scope of testing.

The results from actual waste testing reported herein support the resolution of other related EFRT issues:

- Issue M1: Piping that transports slurries will plug unless it is properly designed to minimize this risk. This design approach has not been followed consistently, which will lead to frequent shutdowns due to line plugging.

- Issue M2: Large, dense particles will accelerate erosive wear in mixing vessels. The effects of such particles on vessel life must be re-evaluated.

- Issue M3: Issues were identified related to mixing-system designs that will result in insufficient mixing and/or extended mixing times. These issues include a design basis that discounts the effects of large particles and of rapidly settling Newtonian slurries. There is also insufficient testing of the selected designs.

- Issue M6: Many of the process operating limits have not been defined. Further testing is required to define process limits for WTP unit operations. Without this more complete understanding of each process, it will be difficult or impossible to define a practical operating range for each unit operation.

\subsection{Waste Groupings}

The available information regarding tank history and tank waste characterization was analyzed. This analysis revealed eight groupings of waste tanks that represent $\sim 75 \%$ of the inventory of those components most significant with respect to leaching in the WTP; i.e., Al, Cr, phosphate, and sulfate (Fiskum et al. 2008). Table 1.1 provides a summary of the calculated water-insoluble quantities of each component for each major waste group studied. Table 1.2 summarizes the selected eight waste groups along with the estimated fractions (with respect to the entire tank farm inventory) of selected components contained in each one. To support the actual waste testing, samples were obtained from the archives at the Hanford 222S Laboratory. Composites of these archived samples were made to obtain the most representative samples of each group as practical.

(a) S. M. Barnes, and R. Voke, September 2006, 24590-WTP-PL-ENG-06-0024 Rev. 0, "Issue Response Plan for Implementation of External Flowsheet Review Team (EFRT) Recommendations - M12: Undemonstrated Leaching Process." 
Table 1.1. Water-Insoluable Component Mass (Metric Tons) Inventory as Function of Waste Type

\begin{tabular}{|lrrrrrrc||}
\hline \multicolumn{1}{|c}{ Waste Type } & Al & Cr & \multicolumn{1}{c}{ F } & Fe & Oxalate & Phosphate & Sulfate \\
\hline Total & 4,871 & 365 & 226 & 1,252 & 884 & 1,304 & 149 \\
\hline Saltcake Category & & & & & & & \\
\hline A & 32 & 35 & 16 & 26 & 166 & 25 & 19 \\
B & 80 & 3 & 45 & 26 & 7 & 37 & 21 \\
BY & 237 & 46 & 52 & 41 & 269 & 145 & 28 \\
R & 170 & 11 & $<0.1$ & 4 & 6 & 1 & 0.3 \\
S & 366 & 166 & 1 & 47 & 242 & 58 & 20 \\
T & 384 & 20 & 2 & 65 & 59 & 151 & 35 \\
Balance of salt cake & 7 & 1 & $<0.1$ & 1 & 5 & 4 & 0.4 \\
\hline Sludge Category & & & & & & & \\
\hline Bismuth phosphate & 218 & 14 & 51 & 280 & 4 & 473 & 11 \\
CWP & 815 & 3 & 3 & 57 & 9 & 25 & 1 \\
CWR & 471 & 4 & $<0.1$ & 17 & 4 & 2 & $<0.1$ \\
REDOX & 1,433 & 23 & 0.1 & 53 & 25 & 9 & 1 \\
TBP & 41 & 1 & 1 & 92 & 1 & 228 & 5 \\
FeCN & 54 & 3 & 1 & 93 & 7 & 84 & 1 \\
Balance of sludge & 562 & 36 & 53 & 450 & 77 & 64 & 8 \\
\hline
\end{tabular}

Table 1.2. Projected Distribution of Water-Insoluble Components in the Tank Farm as the Tank Waste Groupings

\begin{tabular}{|c|c|c|c|c|c|c|c|c|}
\hline $\begin{array}{c}\text { Group } \\
\text { ID }\end{array}$ & Type & $\begin{array}{c}\text { Al } \\
(\%)\end{array}$ & $\begin{array}{l}\mathrm{Cr} \\
(\%)\end{array}$ & $\begin{array}{c}F \\
(\%)\end{array}$ & $\begin{array}{c}\mathrm{Fe} \\
(\%)\end{array}$ & $\begin{array}{c}\begin{array}{c}\text { Oxalate } \\
(\%)\end{array} \\
\end{array}$ & $\begin{array}{c}\text { Phosphate } \\
(\%)\end{array}$ & $\begin{array}{c}\text { Sulfate } \\
(\%)\end{array}$ \\
\hline 1 & Bi Phosphate sludge & 4 & 4 & 22 & 22 & 0.5 & 36 & 7 \\
\hline 2 & $\begin{array}{l}\text { Bi Phosphate saltcake } \\
(\mathrm{BY}, \mathrm{T})\end{array}$ & 13 & 18 & 24 & 8 & 37 & 23 & 42 \\
\hline 3 & $\begin{array}{l}\text { CWP, PUREX } \\
\text { Cladding Waste sludge }\end{array}$ & 17 & 1 & 1.3 & 5 & 1 & 2 & 0.4 \\
\hline 4 & $\begin{array}{l}\text { CWR, REDOX } \\
\text { Cladding Waste sludge }\end{array}$ & 10 & 1 & $<0.1$ & 1 & 0.4 & 0.1 & $<0.1$ \\
\hline 5 & REDOX sludge & 29 & 6 & 0.1 & 4 & 3 & 1 & 0.4 \\
\hline 6 & S - Saltcake (S) & 8 & 46 & 0.6 & 4 & 27 & 4 & 14 \\
\hline 7 & TBP Waste sludge & 1 & 0.4 & 0.5 & 7 & 0.1 & 17 & 3 \\
\hline \multirow[t]{2}{*}{8} & FeCN Waste sludge & 1 & 1 & 0.4 & 7 & 1 & 6 & 1 \\
\hline & Balance & 17 & 24 & 51 & 41 & 30 & 10 & 32 \\
\hline
\end{tabular}




\subsection{Simulant Development}

BNI plans to carry out process development and scale-up testing to demonstrate the design effectiveness of both the caustic and the oxidative-leaching processes over the entire applicable range of Hanford tank farm wastes. ${ }^{(a)}$ Scale-up testing will require substantial volumes of feed. Therefore, the development of simulants that mimic the chemical, leaching, and ultrafiltration behaviors over the range observed for actual waste groups is necessary to the process development and demonstration. The leaching and filtration performance data obtained from the actual waste testing will serve as benchmarks for defining the simulant characteristics and behaviors. The results will also provide inputs for revising the parameters used in evaluating WTP process performance.

\subsection{Testing of Groups 5 and 6}

Leach and filtration testing of two of the eight defined groups, REDOX sludge (Group 5) and S-Saltcake (Group 6), are the subject of this report. These two composite waste groups were homogenized from archive samples and characterized as described in report WTP-RPT-157,Characterization and Leach Testing for REDOX Sludge and S-Saltcake Actual Waste Sample Composites ${ }^{(\mathrm{b})}$. Insoluble aluminum in the tank waste is largely composed of gibbsite and boehmite, with additional minor phases that include, but are not limited to, sodium aluminosilicate and cancrinite. The Group 5 testing was focused on the boehmite $\mathrm{Al}$ phase to better characterize the leaching chemistry of boehmite as found in actual tank waste. Chromium is another component in the solids phase that can limit the HLW loading in the vitrified glass product. The Group 6 testing focused on studying the oxidative leaching of Cr that did not mobilize to the aqueous phase after caustic leaching. However, due to the limited quantity of Group 6 waste available, the Group 6 waste was tested with additional Group 5 material blended into it.

The waste-type definition, sample identification, and sample conditions are discussed throughout the report. The caustic leaching behavior (Group 5) with specific reference to boehmite and oxidative leaching behavior (Group 6/5) with specific reference to Cr dissolution as functions of time, temperature, and hydroxide concentration are provided. Filtration of the composite wastes is examined at different aspects of the pre-treatment process (waste dewatering, caustic leaching, oxidative leaching, washing) and how changes in the waste slurry (e.g., rheology) impacts it. The physical, chemical, radioisotope, and crystal morphology characterization in the waste after leach processing are discussed and compared to previous testing. Filtration behavior is examined throughout the testing.

(a) WTP Doc. No. 24590-WTP-PL-ENG-06-0008, Rev 0, "Hanford Waste Treatment and Immobilization Plant (WTP) Project Response Plan for Resolution of Issues Identified by the Comprehensive Review of the WTP Flowsheet and Throughput.” L. Lucas, March 2006.

(b) S. Fiskum, et al. WTP-RPT-157, Rev 0. Characterization and Leach Testing for REDOX Sludge and SSaltcake Actual Waste Sample Composites. July 2008. 


\subsection{Experimental Methods and Analyses}

This section describes the experimental equipment and analyses used to perform the filtration and leaching tests on the Group 5 and Group 6/5 composite waste samples.

\subsection{Filtration/Leaching Apparatus}

The testing apparatus was a benchtop system mounted on a skid that allowed up to 4 liters of a waste solution to be circulated through a tubular filter that can measure filter feed flow rates, filtrate flow rates, system pressures, and temperatures simultaneously. The testing apparatus used a heat exchanger on the main flow loop to cool the feed solution during filtration operations and had a heater on the main holding tank to perform leaching at elevated temperatures.

\subsubsection{Cell Unit Filter}

The WTP Pre-Treatment facility plans to use cross flow ultrafiltration to separate the LAW liquid streams from the HLW slurry streams through the process. The filter elements, called cell unit filters, are porous sintered metal tubes. The filter feed flows through the inside of the filter element axially while the feed permeate passes through the tube walls radially. Filtration occurs when the pressure differential between the inside and outside walls of the filter element (known as the transmembrane pressure) is high enough to drive the slurry permeate through the tubular walls. The axial flow across the filter walls minimizes solid buildup and allows filtration to occur continuously with minimal downtime for back-pulsing.

The filters purchased for this testing were supplied from the Mott Corporation, ${ }^{(a)}$ using the same specifications $^{(b)}$ for the filters being purchased for the WTP-Pretreatment Facility. The filters were made of 316 stainless steel and have a nominal pore diameter of $0.1 \mu \mathrm{m}$ in diameter. The dimensions of the filter element used in this test are shown in Figure 2.1. These dimensions produce $0.26 \mathrm{ft}^{2}$ of filter surface area.
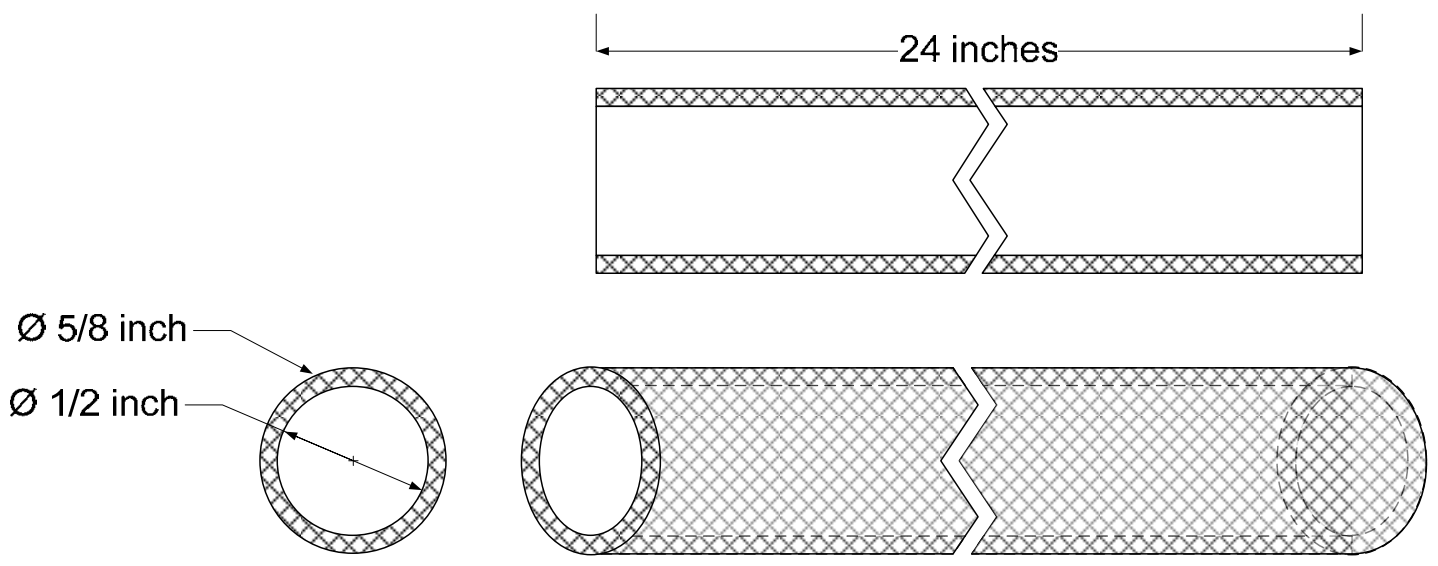

Figure 2.1. Filter Element

(a) Mott Corporation, 84 Spring Lane, Farmington, CT 06032.

(b) WTP-070110 
The filter element was received already installed in a shell-in-tube configuration with an outer tube surrounding the filter element to capture the filtrate while the inlet and the outlet of the filter (which extend past the shell and provide access to the inside diameter of the filter) were welded to steel tubing of a matching outer/inner diameter. The shell side had two $3 / 8$-inch stainless steel tubes exiting from the filter assembly, one in the center to collect filtrate from the filter, and the other near the inlet of the filter to function as a drain. Pressure ports (1/4-inch stainless steel tubing) were installed on the inlet and outlet connections to the assembly to measure the pressure inside the filter. O-ring face seal fittings (Swagelok $^{(\mathrm{a})} \mathrm{VCO}^{\circledR}$ ) were also placed on the inlet and outlet filter feed tube connections for easy installation to the filtration/leaching skid. Figure 2.2 and Figure 2.3 show the filter assembly. Note that the volume of the shell side of this equipment is not scaled proportionally with the full-scale plant. The measured total shell side volume was approximately $0.2 \mathrm{~L}$. Also note that the filter was installed with a slight slope downwards to the drain point to allow draining. However, due to size limitations, this slope was not prototypic of that in the full-scale plant.

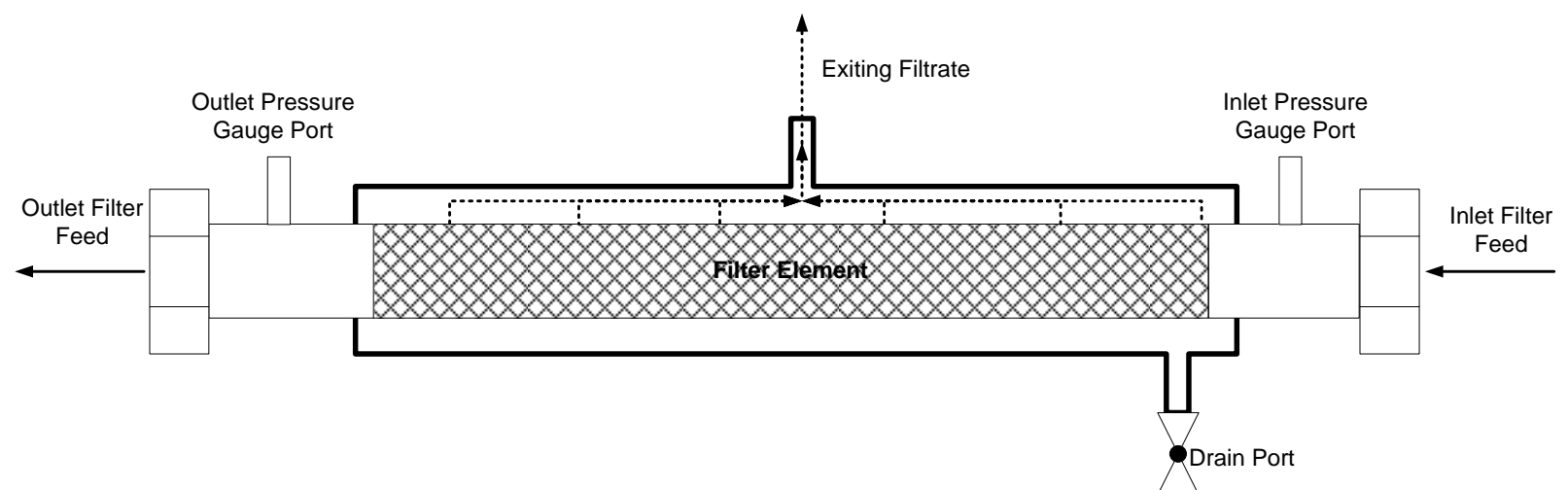

Figure 2.2. Filter Assembly Sketch (Not to Scale)

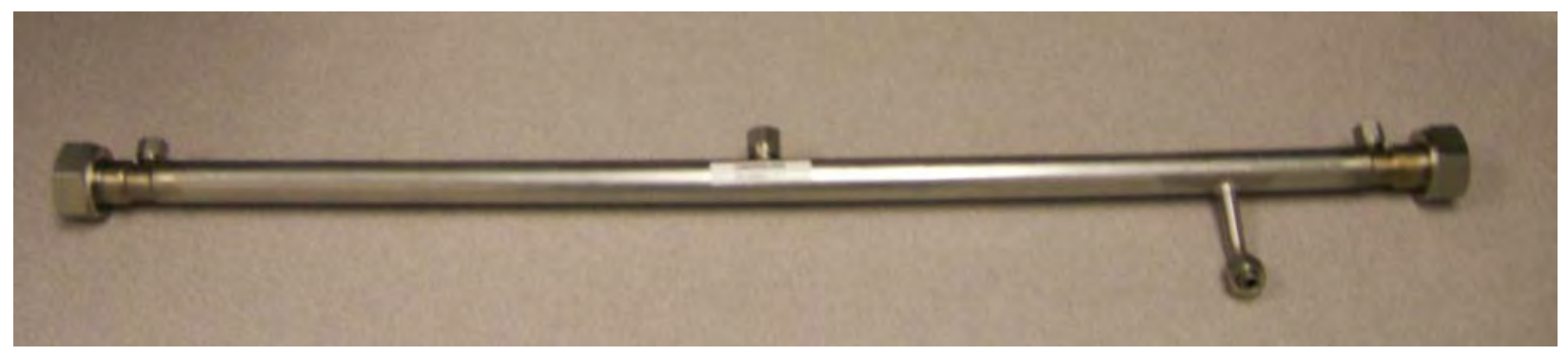

Figure 2.3. Picture of Filter Assembly

\subsubsection{Cross-Flow Ultrafiltration/Leaching Apparatus (CUF)}

The filter described in the section above was installed in a benchtop testing apparatus that circulated the test waste slurries through the inside of the filter and diverted the filter permeate to a collection bottle or recycled it back into the slurry reservoir. Figure 2.4 shows a piping diagram of the testing apparatus. Figure 2.5 and Figure 2.6 are electronic photographs of the assembled system after assembly and installation into a hot cell in the Shield Analytical Laboratory (SAL) where the testing was completed.

(a) Swagelok Company, 31400 Aurora Road, Solon, Ohio, 44139 
The testing apparatus was commonly referred to as the cross-flow ultrafiltration testing apparatus, or CUF for short.

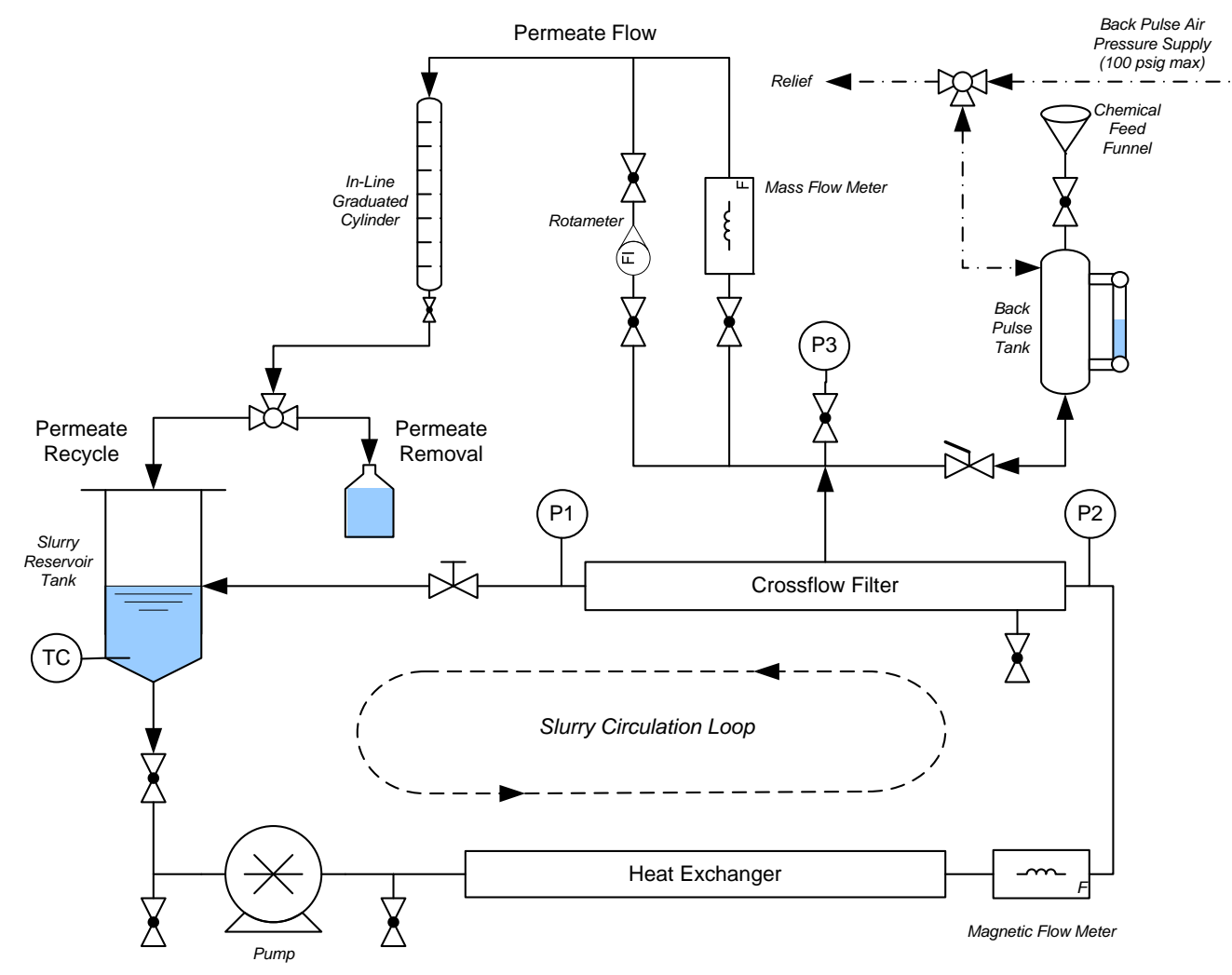

Figure 2.4. Piping Diagram of CUF Testing Apparatus 


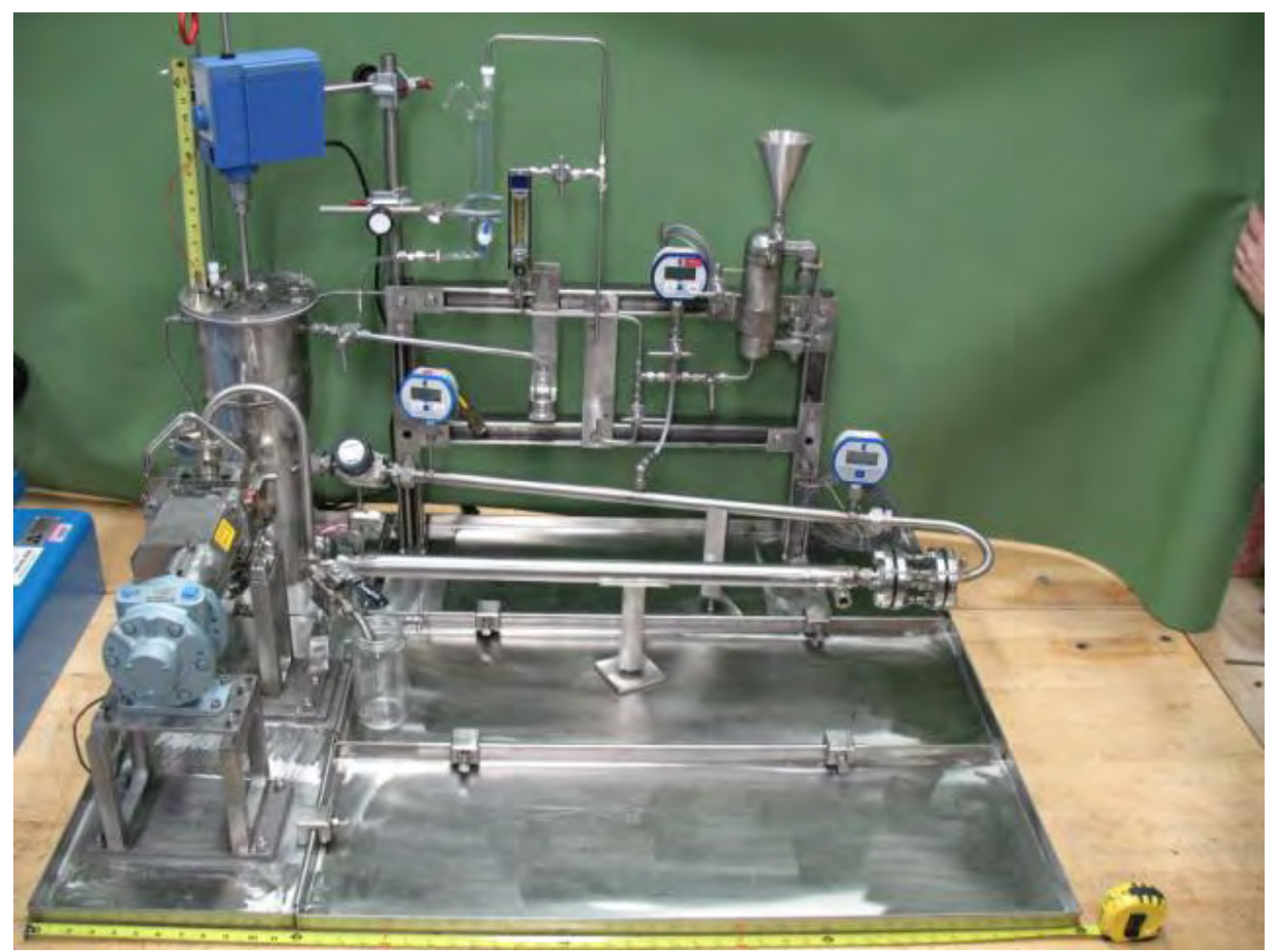

Figure 2.5. Picture of CUF Testing Apparatus Before Hot Cell Installation

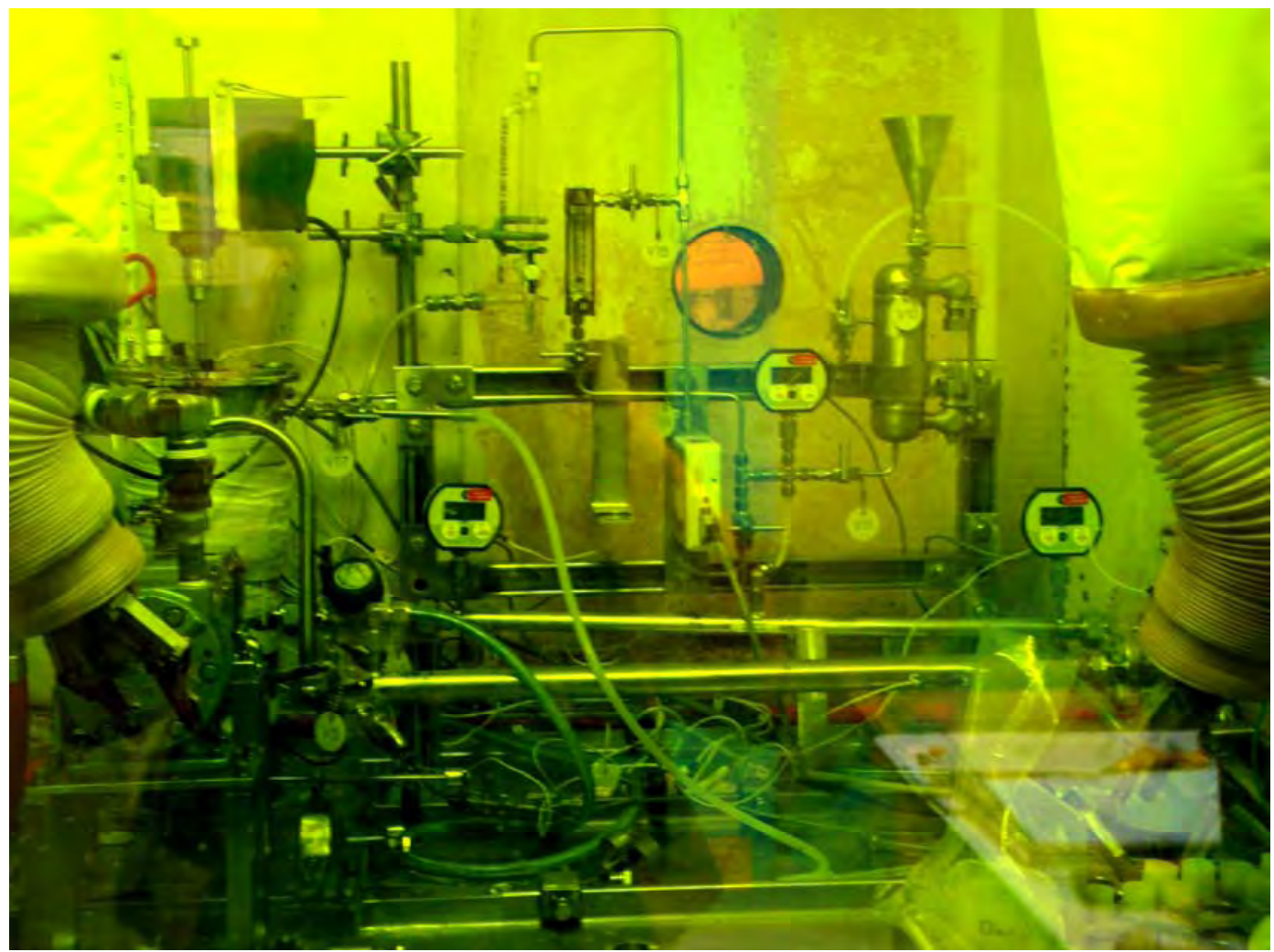

Figure 2.6. Picture of Testing Apparatus Installed in Cell 5 of the Shielded Analytical Laboratory 
The CUF has four main parts:

- Slurry reservoir tank

- Slurry recirculation loop

- Permeate flow loop

- Permeate back pulse chamber.

The slurry reservoir was a cylindrical 304 stainless steel tank with a 4-L capacity. All other major components of the CUF system were also 304 stainless steel. Agitation in the tank was provided from an overhead mixer using a 2-inch diameter 3-blade marine propeller. To allow the system to be easily drained, the bottom of the vessel was sloped at a $15^{\circ}$ angle. Baffles were also installed on the tank wall to verify that the slurry mixing was homogenous. Heat tape was installed around the walls of the tank for leaching at elevated temperatures. The heat tape was connected to a temperature controller that adjusts the electrical load to the heat tape based on a thermocouple input. A dual Type-K thermocouple was installed inside the reservoir tank (extending just below the overhead mixing impeller) to measure the temperature of the slurry inside the reservoir. One of the thermocouple elements was connected to the heat tape's temperature controller and the other to a data collection system. Note that there is a lid on the slurry reservoir; however, there is a slight gap around the agitator opening that allows for some evaporation during the leaching process.

The slurry recirculation loop directed slurry flow from the slurry reservoir, through the filter, and back into the reservoir for filtration operations. The bottom of the slurry reservoir was connected to the suction side of the slurry recirculation pump-a positive displacement rotary lobe pump. The pump was driven with an air motor, supplied with compressed air from an exterior air compressor. The speed of the pump was controlled by an exterior air regulator controlling the pressure of the compressed air supplied to the air motor. An optical tachometer measured the speed of the pump by measuring the rotation speed of the connection coupling between the air motor and the pump, which had a piece of reflective tape placed on it. The discharge of the pump flowed through a single-pass shell and tube heat exchanger used to remove excess heat from the system from mechanical energy input from the mixer and pump, as well as heat generated from frictional flow.

An exterior chiller circulated chiller fluid (water/anti-freeze mixture) through the exterior shell of the heat exchanger to remove heat away from the circulating slurry on the tube side of the heat exchanger. The chiller controlled the chilling fluid temperature by monitoring the temperature of the slurry exiting the heat exchanger via a resistance temperature detector (RTD) installed in the discharge line.

The slurry then flowed through a magnetic flow sensor that monitored the volumetric flow of the slurry inside the slurry recirculation loop. The sensor's output was displayed on an external panel meter that generated an analog output signal monitored by a data collection system. The data from this device was used to calculate the axial velocity (AV) inside the filter element.

The flowing slurry then entered the filter. Digital pressure gauges were installed on the inlet and outlet port of the filter, which displayed the pressure at both locations in pounds per inch squared, gauge (psig). The gauges also transmit analog output signals monitored by a data collection system. The data from these devices were used to calculate the average pressure inside the filter and the axial pressure drop across the element. 
A manual pinch valve was located at the filter's discharge. The valve was used to adjust the pressure inside the filter to drive permeate flow through the filter membrane wall. It was also connected to the slurry reservoir tank and was closed completely when the tank is isolated for leaching.

The permeate flow loop started at the center of the filter assembly where a poly-line connected the filter to a manifold of $1 / 4$-inch stainless steel piping that directed the filter permeate through a series of measurement devices. A digital pressure gauge was installed at this point to measure the pressure on the permeate side of the filter in psig. Like the other two digital gauges, this instrument transmitted an analog output signal to a data collection system. The transmembrane pressure (TMP) across the filter was then calculated by subtracting the pressure on the permeate side of the filter from the average pressure of the slurry inside the filter.

Flow from the filter was either diverted through a mass flow meter calibrated up to $180 \mathrm{~mL} / \mathrm{min}$ or to a user-calibrated rotometer that can measure flow up to $30 \mathrm{~mL} / \mathrm{s}$. The mass flow meter also measured density of the permeate flow and transmitted two analog output signals to the data collection system for the volumetric flow rate and the density. An in-line glass cylinder was installed on the discharge of both meters to take manual measurements of the permeate flow rate. Measurements were taken by closing a valve at the bottom of the cylinder, allowing permeate to fill the vessel. Liquid volume in the glass vessel was measured by markings on the outside. The permeate flow rate was calculated from observed changes in permeate volume in the cylinder over a measured time interval.

Permeate exited through a 3-way valve connected to the slurry reservoir tank. This valve directed permeate either back to the slurry reservoir tank to be mixed back to the slurry or to a sampling hose used to collect permeate into sample containers.

The permeate back pulse chamber was to the right of the permeate flow loop and connected to the filter at the same location of the permeate pressure gauge. The chamber was approximately $500-\mathrm{mL}$ steel vessel with a sight-glass to track the volume inside the chamber. The vessel had three entry ports:

- $1 / 4$ inch line with a two-way toggle valve on the bottom connecting the vessel to the permeate side of the filter

- $1 / 4$-inch line with a two-way valve connecting the top of the vessel to a funnel

- $1 / 4$-inch line with a three-way valve connecting the top of the vessel to a compressed air line and vent line connected to the top of the slurry reservoir tank

The bottom line was used to direct permeate flow from the chamber to the filter. The funnel on the top of the chamber was to introduce cleaning and rinse solutions directly to the vessel. The compressed gas line was used to pressurize the fluid in the chamber with compressed gas and to vent the chamber to atmospheric pressure.

To back pulse the filter, the vessel was first vented to atmospheric pressure. Next, permeate was allowed to fill the chamber by opening the toggle valve. Once the chamber was half full of permeate (as seen from the sight-glass), the toggle valve was closed. The three-way valve was then positioned to allowed compressed gas at 80 psig to fill to the chamber and pressurize the fluid. The three-way valve was then positioned to isolated the now pressurized chamber. The slurry pressure inside the filter was then dropped below the pressure of the compressed gas line ( $<20 \mathrm{psig}$ ). The toggle valve at the bottom of the tank was opened, allowing the pressurized permeate inside the chamber to flow backwards through the 
filter element. The toggle valve was closed when permeate level was below the visible portion of the sight glass. After the back pulse was completed, the 3-way valve was positioned to vent the chamber back to atmospheric pressure.

\subsubsection{Instrumentation and Data Acquisition System}

Because the system was operated in a hot cell, the design goals of the testing apparatus were to minimize the quantity of manual measurements of the process during testing and record the data in an electronic format that could be analyzed readily with other approved software. Most of the sensors on the testing apparatus transmit analog data to an external data-acquisition collection system (DACS), manufactured by National Instruments ${ }^{(a)}$. This system relayed the analog data to a LabView data collection program operating on a computer desktop system using Windows XP, service pack 2. The software program scales the analog data and simultaneously records the data electronically and displays it on the computer's monitor. The program was verified by Software Test Plan RPP-WTP-QA-010 and all reportable data is measured on calibrated instrumentation, including the external DACS board. Figure 2.7 shows a diagram of the electronic sensors attached to the DACS, and Figure 2.8 displays the screen windows from the data collection program. Note that there are no automated level or mass measurements on the slurry reservoir. The volume of slurry present can only be confirmed through periodic level measurements.

(a) National Instruments Corporation, 11500 N Mopac Expwy, Austin, TX 78759-3504 


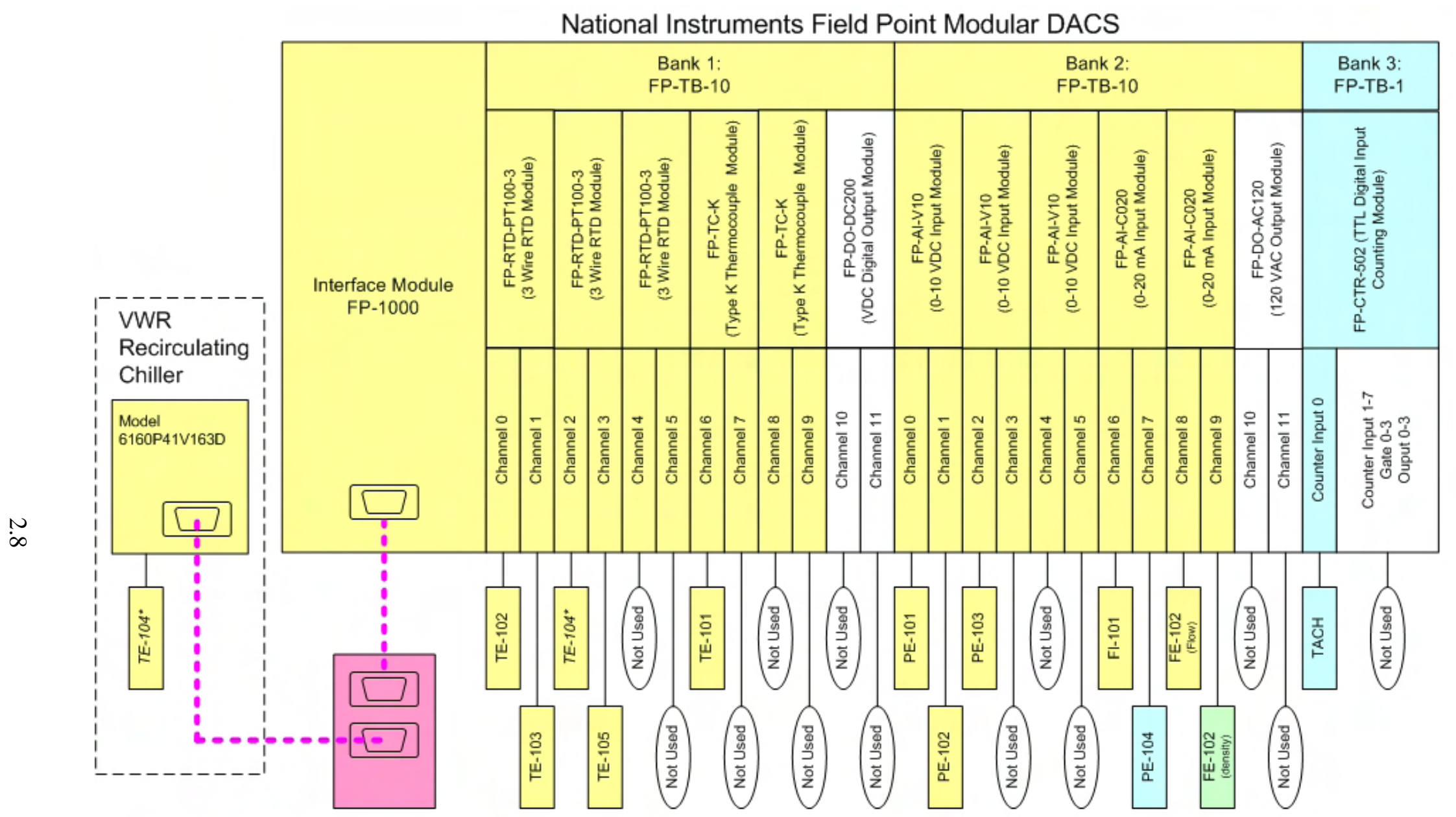

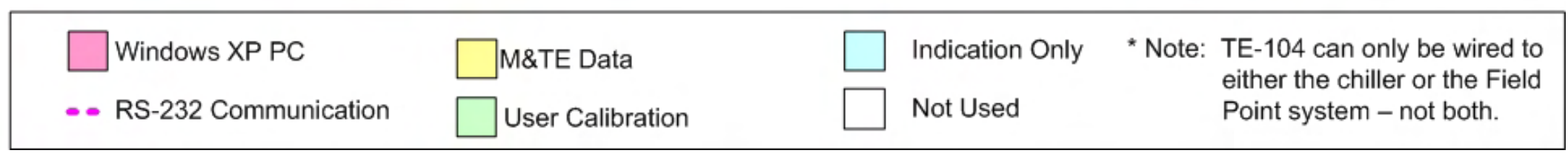

Figure 2.7. Diagram of DACS System 


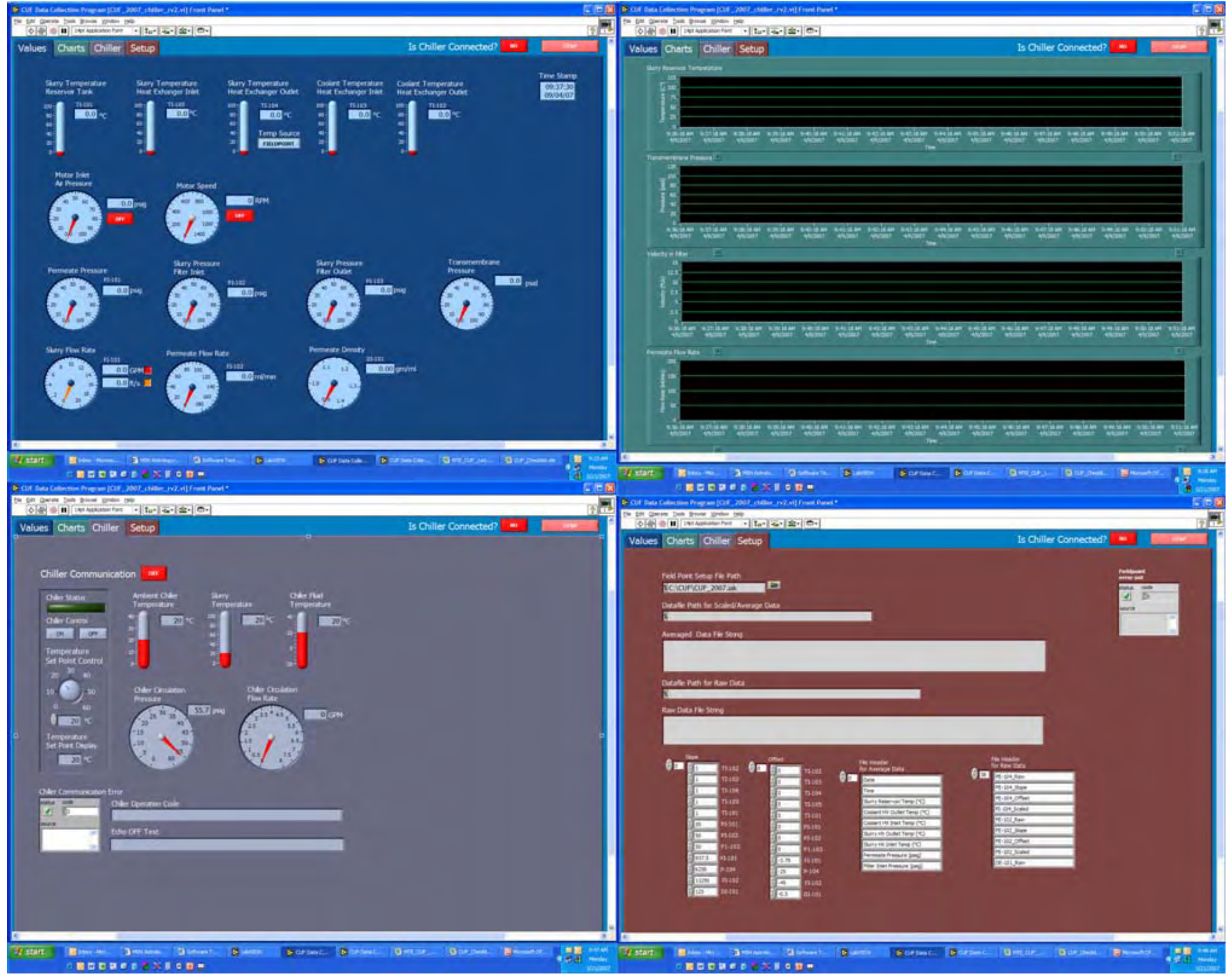

Figure 2.8. Digital Images of DACS Display Windows 


\subsubsection{Operations of CUF and Sampling}

The CUF was developed to operate in several different operational modes to simulate filtration and leaching processes of the WTP Pretreatment system. Filtration operation occurred in a recycling or dewatering mode. During recycling operations, permeate was returned to the slurry reservoir tank. By returning permeate back into the slurry, the undissolved solids (UDS) concentration in the slurry was maintained at a steady state condition. The CUF was operated in this mode to understand how the effects of time, pressure, and axial velocity impact filtration of slurry while maintaining the physical properties of the slurry. During dewatering operations, permeate from the filter was diverted to a collection vessel, operating the system at a constant transmembrane pressure and axial flow rate, allowing the UDS concentration of the slurry to change. The CUF was operated in this mode to understand how the slurry's rheological and filtration properties changed as its UDS concentration changed. Chemical leaching occurred in the slurry reservoir tank when isolated from the slurry circulation loop. To isolate the slurry reservoir tank for leaching operations required draining the slurry and permeate inside the CUF filtration piping first. Once the tank was isolated from the slurry circulation loop, the slurry and permeate was returned to the slurry reservoir tank along with the leaching agent. When the leaching operations occurred at elevated temperatures, heat tape surrounding the slurry reservoir was used to heat the vessel.

Samples were collected throughout testing to measure the physical and chemical properties of the waste slurry or permeate. Slurry samples were collected from two separate locations on the system. Small slurry samples $(20 \mathrm{~mL})$ were collected from the top of the slurry reservoir with the mixer operating using 18-inch long pipettes. The tips of the pipettes were cut at an angle to allow slurry to flow into the pipette to prevent being plugged. Larger samples $(100 \mathrm{~mL})$, such as for rheology measurement, were collected using the drain valve on the pump discharge while the pump is running. Permeate samples were collected during dewatering operations directly from the dewatering sample hose. However, permeate collected during leaching operations required manual filtration. A slurry sample was initially collected from the slurry reservoir using a pipette described earlier. The sample was placed into a 5-mL syringe with a 0.45$\mu \mathrm{m}$ filter installed on the discharge, with the plunger removed. Once slurry sample was in the syringe, the plunger was returned. Pressure was applied to the plunger to force permeate through the filter on the syringe tip into a $20-\mathrm{mL}$ sample vial. Figure 2.9 is a picture of a syringe used for this operation with a filter installed on it. 


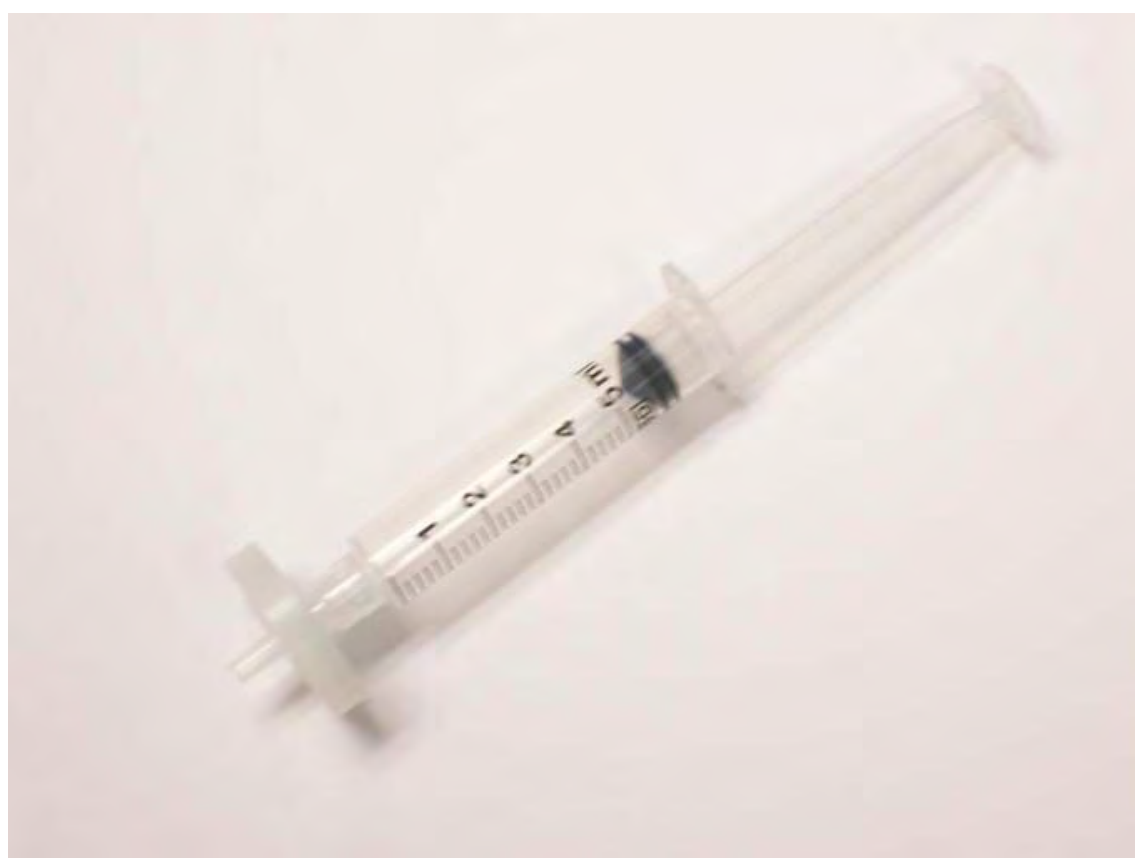

Figure 2.9. Syringe with 0.45 -Micron Filter Installed

\subsubsection{Baseline Testing of Filter}

The CUF slurry and permeate piping was initially cleaned with a laboratory detergent (Alconox ${ }^{(a)}$ at 1:100 dilution) to remove cutting oils and soils from the fabrication process of the testing equipment. Afterwards, the system was rinsed with deionized (DI) water several times until the rinse solution appeared clear. The filter flux was then measured with a solution of $0.01 \mathrm{M} \mathrm{NaOH}$ to verify the cleanliness of the filter - called the clean water flux. Testing was performed at 10, 15, and 20 TMP at an axial velocity of 11 feet per second (fps). Each pressure condition was held for 20 minutes, with a single back-pulse performed before changing the pressure.

Next, a strontium carbonate $\left(\mathrm{SrCO}_{3}\right)$ slurry was prepared to match a $0.35 \mathrm{M}$ SrCO3 slurry used in 2002 for baseline testing of a similar Mott filter, as described in WPT-RPT-043, Filtration, Washing, and Caustic Leaching of Hanford Tank AZ-101 sludge ${ }^{(\mathrm{b})}$. Strontium carbonate has been shown to be a better baseline measurement than a clean water flux measurement. This is due to the tendency of clean water flux measurements to be highly susceptible to the presence of small amounts of foulants that do not ultimately impact filtration performance. For that reason, strontium carbonate has been adapted as a simple measure to make sure that the installed filter is operating correctly. The prepared slurry was placed into the CUF and operated with the permeate recycling back into the slurry reservoir. Filtration tests were performed at 10, 20, and 30 TMP psid using an axial velocity of 11 fps. A single back pulse was performed between each test condition. Afterwards, the slurry was removed and then rinsed out with DI water (approximately 10 liters). After the system was rinsed, the clean water flux was measured again, using a

(a) Alconox, Inc., 30 Glenn Street, Suite 309, White Plains, New York 10603 USA.

(b) Geeting, etal. WTP-RPT-043. Filtration, Washing, and Caustic Leaching of Hanford Tank AZ-101 Sludge. October, 2002. 
solution of $0.01 \mathrm{M} \mathrm{NaOH}$ to verify that the filter was clean before testing with HLW slurries. The same filtration test conditions utilized in the previous clean water flux tests were used again.

The results of the baseline filter flux testing are shown in Figure 2.10, which correlate well with flux data measured in Section 2.3 of report WTP-RPT-043. The measured decrease at the start and end of each test condition indicate that some level of fine particulates were present in the CUF piping that impact the filter flux over time. However, the final clean water flux for the filter was demonstrated to be quite higher than the predicted flux for the waste slurries to be tested (e.g., $0.04 \mathrm{gpm} / \mathrm{ft}^{2}$ for dewatering operations).

Permeate from filtration of the strontium carbonate slurry showed no solids present. The density of filter permeate was measured at $1.12 \mathrm{~g} / \mathrm{mL}$ by the mass flow meter. A sample of filter permeate was taken, and its density was measured as $1.11 \mathrm{~g} / \mathrm{mL}$ using a calibrated balance and a $50-\mathrm{mL}$ volumetric flask. While the density could be measured, the volumetric flow of permeate was beyond the range of the mass flow meter for all three tests. After a density check, permeate flow was diverted through the CUF rotometer. For the $\mathrm{SrCO}_{3}$ flux measurements, the flow was slow enough to verify the flow with the in-line volumetric cylinder to measure the permeate flow.

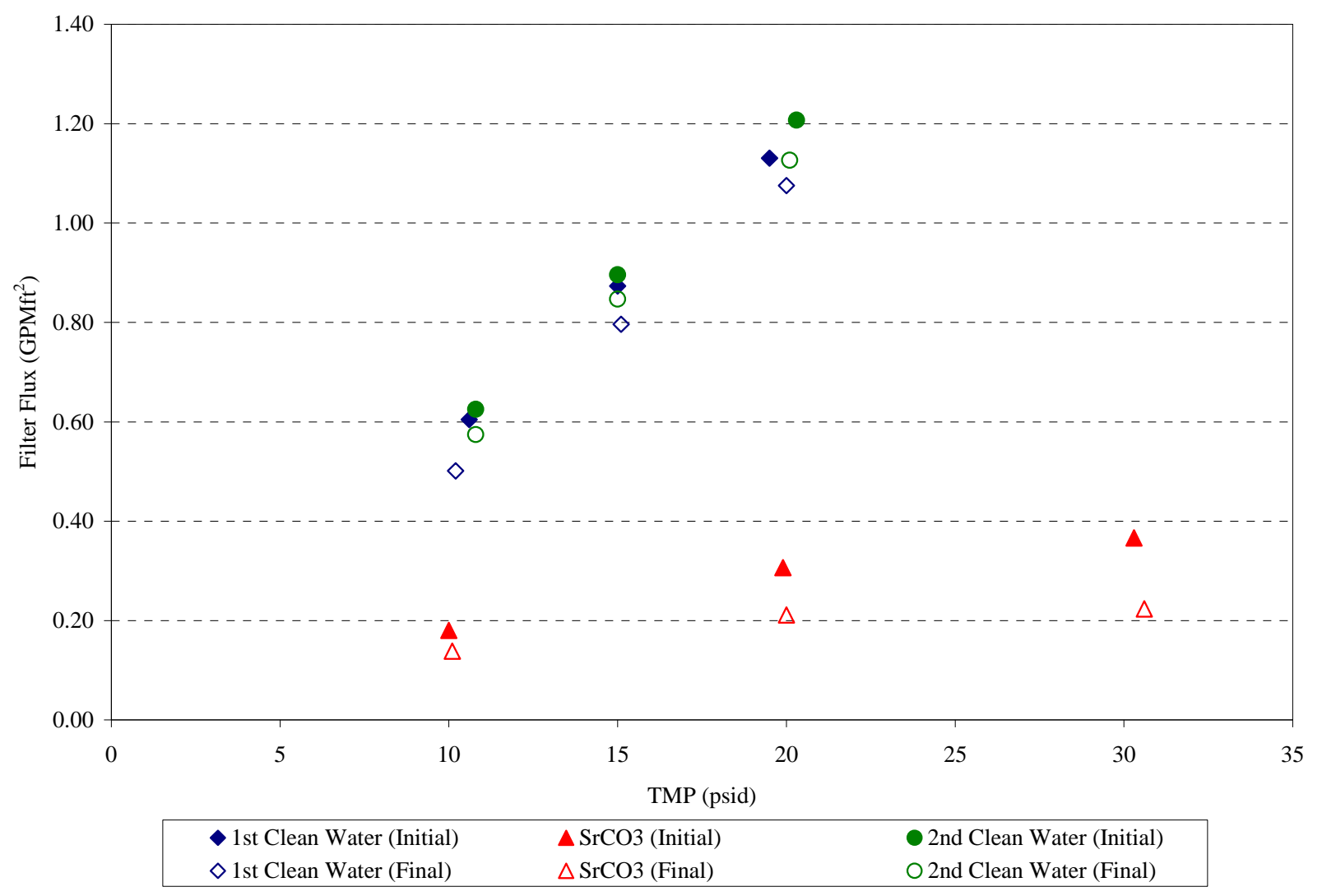

Figure 2.10. Initial Clean Water $/ \mathrm{SrCO}_{3}$ Flux Measurements of Filter (Note: Flux data collected from user calibrated devices) 


\subsection{Filtration Data Analysis}

\subsubsection{Filtration Terms and Equations}

Filtration examined in this report as a filter flux is defined as:

$$
J=\frac{Q_{\text {permeate }}}{A_{\text {fitter }}}
$$

where $J$ is the Filter Flux (gpm/ft ${ }^{2}$ ), $Q_{\text {permeate }}$ is the Volumetric Permeate Flow (gpm), and $A_{\text {filter }}$ is the Filtration Surface Area $\left(\mathrm{ft}^{2}\right)$.

In this study, the filter area is assumed as the inside area of the filter element, which is defined as:

$$
A_{\text {filter }}=\pi D_{i_{\text {flter }}} L_{\text {filter }}
$$

where $D i_{\text {filter }}$ is the Filter Element Inside Diameter, and $L_{\text {filter }}$ is the Filter Element Length.

The permeate volumetric flow rate is also corrected for viscosity and surface tension effects because of the temperature of the permeate deviation from $25^{\circ} \mathrm{C}$. In WTP-RPT-043, the corrected permeate flow rate at a given temperature $\mathrm{T}\left({ }^{\circ} \mathrm{C}\right)$ is defined as:

$$
\begin{aligned}
Q_{25{ }^{\circ} \mathrm{C}} & =Q_{T} e^{2500\left[\frac{1}{T+273}-\frac{1}{298}\right]} \\
J_{25^{\circ} \mathrm{C}} & =J_{T} e^{2500\left[\frac{1}{T+273}-\frac{1}{298}\right]}
\end{aligned}
$$

The pressure drop across the filter is commonly called TMP. It is calculated in this test to be:

$$
T M P=\Delta P_{m}=\frac{\left(P_{\text {inlet }}+P_{\text {outtet }}\right)}{2}-P_{\text {permeate }}
$$

where $P_{\text {inlet }}$ is the pressure at the filter inlet, $P_{\text {outlet }}$ is the pressure at the filter outlet, and $P_{\text {permeate }}$ is the pressure at the permeate side of the filter.

Axial velocity (AV) inside the filter is calculated by dividing the volumetric slurry flow of the filter by the cross section area of the inside diameter of the filter:

$$
A V=\frac{Q_{\text {slury }}}{S_{a}}=\frac{Q_{\text {slury }}}{\frac{\pi}{4} D_{i_{\text {fller }}}{ }^{2}}
$$


where $S_{a}$ is the cross sectional area of the axial flow, and $Q_{\text {slurry }}$ is the volumetric slurry flowrate in the axial direction.

The Darcy equation describes filter flux as:

$$
J=\frac{\Delta P_{m}}{\mu_{\text {permeate }} R_{m}}
$$

where $\Delta P_{m}$ is the Pressure drop across filter membrane, $\mu_{\text {permeate }}$ is the viscosity of the permeate, and $R_{m}$ is the overall resistance of the filter membrane.

The overall filter resistance term is considered a more complicated term that is a sum of the resistance of the actual filter, the resistance of the filter cake that forms on the surface of the filter, and the resistance due to fouling of the filter. For dilute slurries and when turbulent flow conditions exist, the filter resistance is usually constant, the transmembrane pressure and permeate viscosity are the controlling operational parameters. During dewatering, the slurry's flow properties change, and the filter cake resistance becomes more significant. When this occurs, the Darcy equation does not truly apply anymore, as the cake resistance changes with axial velocity and slurry concentration. Eventually, the slurry can only be dewatered to a maximum UDS concentration limit at a given TMP. This limit is known as the gel concentration, As a waste slurry's solid concentration approaches the gel concentration, the filter flux can be described as

$$
J=k \cdot \ln \left[\frac{C_{s}}{C_{g}}\right]
$$

where $C_{s}$ is the slurry UDS concentration, $C_{g}$ is the slurry gel concentration at a given TMP, and $k$ is a constant, for a given TMP and AV (note that $\mathrm{k}$ is a negative value).

When the flux is impacted by the UDS concentration, the impact of axial velocity becomes significant as well. This is due to how the axial velocity affects the thickness of the filter cake inside the filter.

\subsubsection{Filtration Test Matrix}

To understand the impact of the transmembrane pressure and axial velocity on the filter flux of waste slurry, a filtration test matrix was developed to understand their individual effects. Like the clean water and $\mathrm{SrCO}_{3}$ slurry flux testing described in Section 2.1.5, the waste slurry was circulated through the filtration testing apparatus while the slurry permeate leaving the filter was recycled back to the slurry reservoir. By recycling permeate in this way, the UDS concentration of the slurry remained constant. Using a TMP of 40 psid and an AV of 13 fps as the baseline condition, testing conditions were varied to demonstrate how the flux varies as TMP and AV change from the center condition. Table 2.1 and 


\section{Test Matrix}

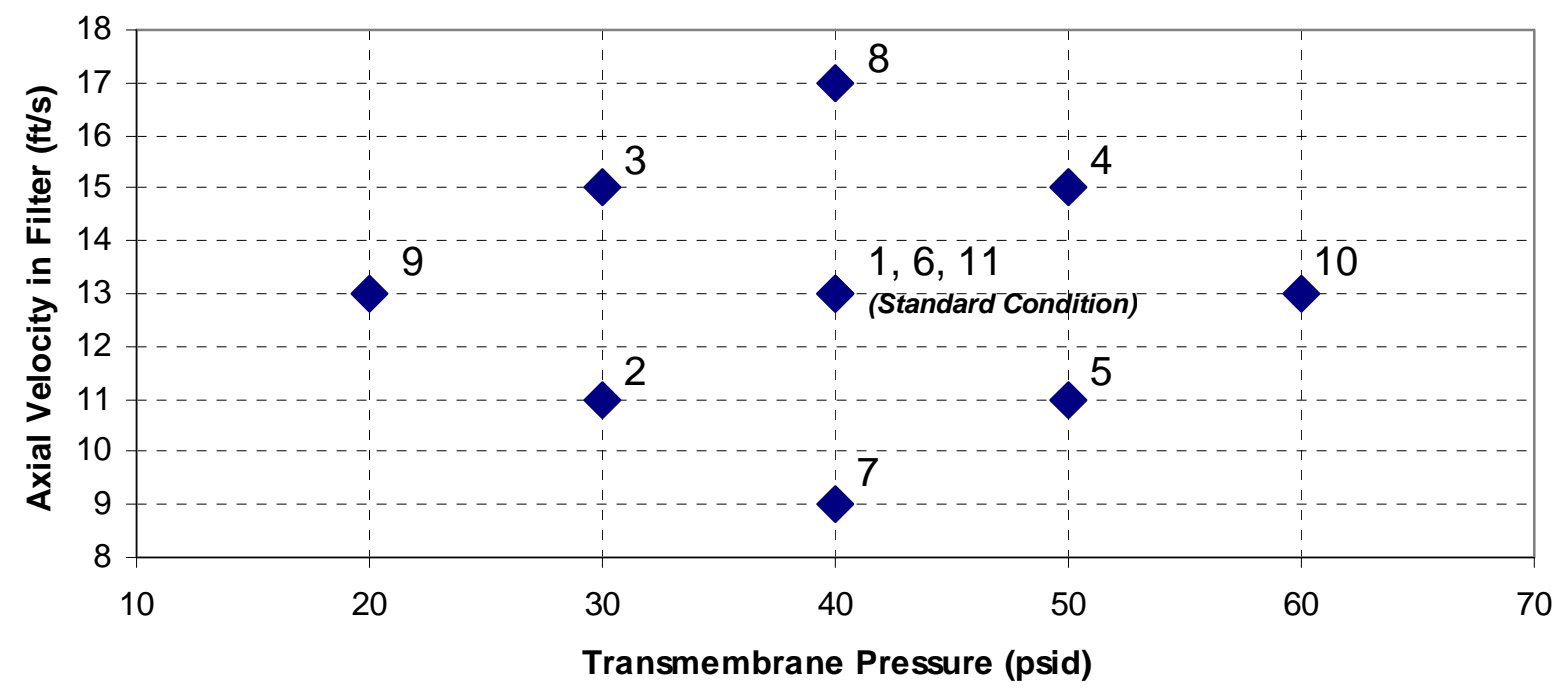

Figure 2.11 outline the target conditions for the testing performed.

Table 2.1. Filtration Test Matrix Operating Conditions.

\begin{tabular}{|c|c|c|c|}
\hline $\begin{array}{c}\text { Test } \\
\text { number }\end{array}$ & $\begin{array}{c}\text { Duration } \\
\text { (hours) }\end{array}$ & $\begin{array}{c}\text { Target TMP } \\
\text { (psid) }\end{array}$ & $\begin{array}{c}\text { Target AV } \\
\text { (fps) }\end{array}$ \\
\hline 1 & 3 (min) & 40 & 13 \\
\hline 2 & 1 & 30 & 11 \\
\hline 3 & 1 & 30 & 15 \\
\hline 4 & 1 & 50 & 15 \\
\hline 5 & 1 & 50 & 11 \\
\hline 6 & 1 & 40 & 13 \\
\hline 7 & 1 & 40 & 9 \\
\hline 8 & 1 & 40 & 17 \\
\hline 9 & 1 & 20 & 13 \\
\hline 10 & 1 & 60 & 13 \\
\hline 11 & 1 & 40 & 13 \\
\hline
\end{tabular}




\section{Test Matrix}

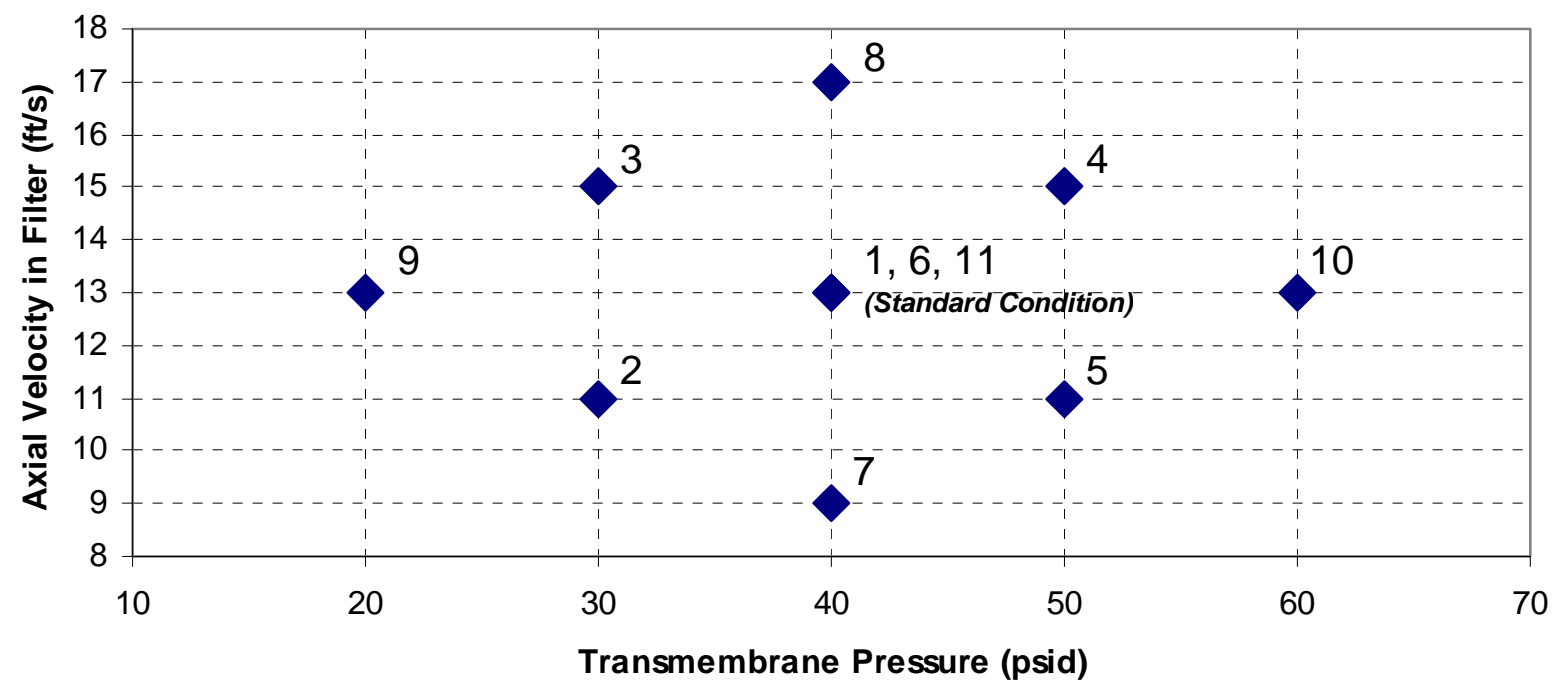

Figure 2.11. Filtration Test Matrix Chart

Each filtration condition was maintained for at least an hour while permeate was recycled back to the slurry reservoir tank. Before test conditions were changed, a back-pulse on the filter was performed to provide the same starting conditions for each test. Typically, the back-pulse occurs after the slurry pressure was below 20 psig and with the back-pulse chamber pressurized to $80 \mathrm{psig}$. The initial test performed at the baseline condition was performed for a minimum of 3 hours to observe how the filter flux varied with time to track possible fouling due to the waste. However, it was recognized that sufficient data could be obtained with an abridged version of the test matrix. This matrix was provided to the client and was approved to be used as shown in Table 2.2. The approvals for these test conditions are provided in Appendices E and F.

When the slurry is at low concentrations, the system is expected to be controlled by the transmembrane pressure (Equation 2.6), with little impact from the axial velocity. However, once the slurry is concentrated and the flow properties change, it is expected that the axial velocity will have some effect on the filtration of the system.

Table 2.2. Abridged Filter Test Matrix

\begin{tabular}{|c|c|c|c||}
\hline $\begin{array}{c}\text { Test } \\
\text { Number }\end{array}$ & $\begin{array}{c}\text { Duration } \\
\text { (hrs) }\end{array}$ & $\begin{array}{c}\text { Target AV } \\
\text { (fps) }\end{array}$ & $\begin{array}{c}\text { Target TMP } \\
\text { (psid) }\end{array}$ \\
\hline 1 & 2 (min) & 13 & 40 \\
\hline 2 & 1 & 17 (or max) & 40 \\
\hline 3 & 1 & 9 & 40 \\
\hline 4 & 1 & 13 & 40 \\
\hline 5 & 1 & 13 & 20 \\
\hline 6 & 1 & 13 & 60 \\
\hline 7 & 1 & 13 & 40 \\
\hline
\end{tabular}




\subsubsection{Dewatering Operation Analysis}

During dewatering operations of the waste slurries, the transmembrane pressure and axial velocity are maintained at the baseline condition of 40 psid and $13 \mathrm{fps}$. By maintaining the operating conditions of the filtration, the only effect on filtration should be the slurry concentration. As the slurry's UDS changes, the filter flux can be monitored and graphically charted, as shown in Figure 2.12. As discussed earlier, the filter flux is initially expected to follow Equation 2.6 for low solids concentrations, which will appear as a horizontal line on the chart when the TMP is held constant. But as the slurry begins to concentrate, the filtration behavior of the slurry is expected to change and begin to follow Equation 2.7. With graphic analysis, the transition in filtration behavior can be understood. The analysis also predicts the slurry's gel UDS concentration. This value can be compared to the measured centrifuge UDS of the slurry, which has been indicated as a good method of estimating the gel concentration ${ }^{(a)}$.

\subsubsection{Effects of Rheology and Particle Size}

During testing operations, rheology and particle-size samples are taken to characterize the solids in the slurry and their impact on flow and filtration behavior. As slurries concentrate, their flow behavior changes becoming more viscous and less Newtonian. This impacts the cross flow behavior of the filter directly and the formation of filter cake. Particle size also can have an impact by affecting the gel concentration of the slurry and possibly impacting the filter fouling. Because the slurries are sheared during filtration, the particle size of the slurry can change — especially if the initial solids are agglomerated. Chemical leaching has a similar impact as well in changing the particle size of the slurry.

(') Peterson, Geeting, Daniel. Estimation of Ultafilter Performance Based on Characterization Data. Chemical Engineering and Technology. August, 2007. Vol. 30. Issue 8. Pages 1050-1054. 


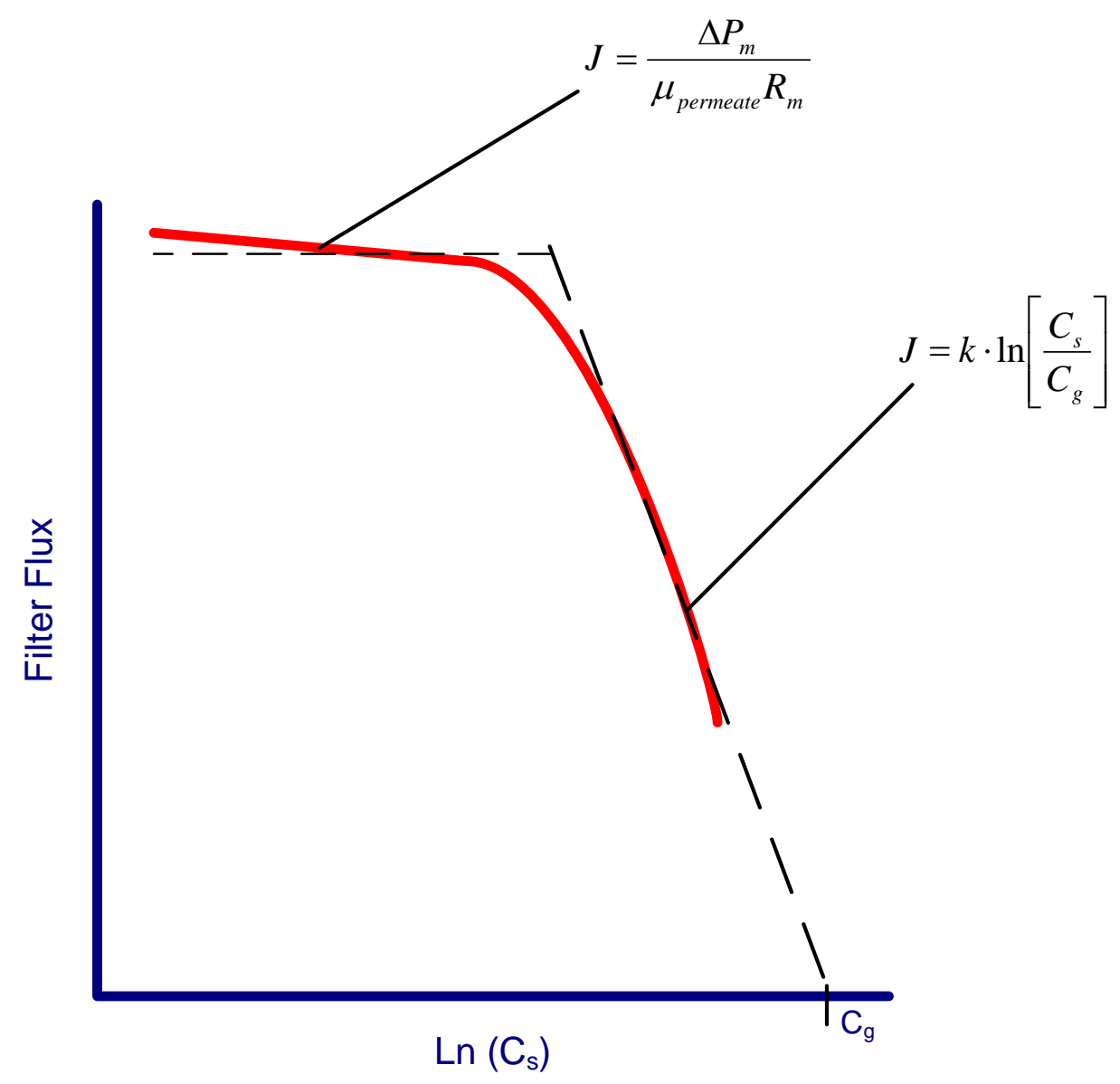

Figure 2.12. Example of a Dewatering Curve at a Constant TMP and AV

\subsection{Chemical Data Analysis}

During the test, the mass of material added to and removed from the testing apparatus is always being measured to perform an overall mass balance of the slurry during the test. Two main goals are to be achieved from this analysis: verification that transuranic (TRU) material stays in the HLW stream and calculation estimates of the chemical leach factors of glass-limiting compounds of interest-in this case, aluminum and chromium.

\subsubsection{Validation of Filtration Separation of TRU Material}

The main goal of the chemical and physical separation processes tested in this report was to demonstrate the effectiveness of removing glass formulation-limiting compounds (e.g., aluminum and chromium) from the HLW stream while not introducing TRU material into the LAW waste stream. During filtration, it was important to verify that TRU materials present in the waste slurry do not pass through the filtration media as a colloid or as a particle $<0.1 \mu \mathrm{m}$. During leaching, it was also important to verify that TRU compounds were not chemically dissolved during operations designed only to remove glass formulationlimiting compounds for the LAW stream. This was achieved by performing radiochemical analysis on permeate and slurry samples throughout the test to verify that the permeate streams contain minimal TRU compounds and that a mass balance on the system shows that almost all the TRU stays in the HLW slurry stream. 


\subsubsection{Chemical Leach Factors for Caustic and Oxidative Leaching}

The chemical leach factor was defined as the percentage difference in mass of a solid component in the waste after chemical leaching.

$$
f_{i}=1-\frac{m_{i}^{\text {final }}}{m_{i}^{\text {initial }}}
$$

where $f_{i}$ was the leach factor for component $i, m_{i}^{\text {initial }}$ was the initial solid mass of component $i$, and $m_{i}^{\text {final }}$ is the final solid mass of component $i$.

The following methods were used to calculate solids leach factors:

1) Perform a continuing analyte mass balance of the system. This approach required the assessment of masses (slurry and aqueous) in and out of the CUF along with the calculated or measured wt\% UDS in conjunction with analytical data. The analyte fractionation from the solids phase to the liquid phase can be calculated.

2) Use an inert or non-leachable component as an internal tracer in the solids fraction. Perform a mass balance of the slurry before and after leaching using insoluble components, such as uranium, to trace the fractional change in mass. Substituting dry mass compositions for leach component $i$ and inert component $j$ in Equation E.9, the leach factor becomes:

$$
f_{i}=1-\left(\frac{x_{i}^{\text {final }}}{x_{i}^{\text {initial }}}\right)\left(\frac{x_{j}^{\text {initial }}}{x_{j}^{\text {final }}}\right)
$$

The ratio between the inert compositions is commonly called a concentration factor (CF), defined as:

$$
C F=\left(\frac{x_{j}^{\text {final }}}{x_{j}^{\text {initial }}}\right)
$$

Equation E.15 then changes to:

$$
f_{i}=1-\left(\frac{x_{i}^{\text {final }}}{x_{i}^{\text {initial }} C F}\right)
$$

3) Perform a mass balance of the liquid phase before and after leaching to measure the analyte mobilization into the aqueous phase. This approach required the determination of total analyte in the aqueous phase before leaching and total analyte quantity in the aqueous phase after leaching. The difference was equivalent to the total mass leached from the solids phase. 


\subsubsection{Physical Examination of Final Leach Material}

The chemical characterization and physical morphology are examined after leaching to understand the crystal structure of the solids in the remaining slurry. While most of the analyses performed are qualitative, they can show:

- if particles are crystalline, agglomerates, or amorphous

- if TRU and glass-limiting compounds (like aluminum) are blends of different phases or single compounds

- what is the crystal phase of remaining glass-limiting compound (e.g., boehmite for aluminum). 
WTP-RPT-172, Rev 0

\subsection{Group 5 CUF Testing and Results}

This section describes the filtration/leaching tests performed for the REDOX waste sludge composite referred to as the Group 5 waste sample performed under TI-RPP-WTP-540 ${ }^{(\mathrm{a})}$ and subsequent results.

\subsection{Test Plan}

Figure 3.1 outlines the testing that was performed and is reported in this section. The goals of this test were to:

- Evaluate the filtration of the REDOX sludge waste composite

- Evaluate the effectiveness of caustic leaching on aluminum present in the blended waste

- Evaluate the filtration of the washed leached solids.

The first half of the testing was to perform filtration studies on the Group 5 waste sample and understand its dewatering behavior, as outlined in the first column of Figure 3.1. The waste was to be initially evaluated at a target UDS concentration of $5 \mathrm{wt} \%$, which is the expected solids concentration entering the WTP-Pretreatment UFP2 vessel. To accomplish this, approximately 1.8L of Group 5 composite material (measured at $18 \mathrm{wt} \%$ UDS) was diluted with 2.1L of a simulant supernate solution (based on the Group 5 permeate composition reported in WTP-RPT-157) to $5 \mathrm{wt} \%$ UDS for a predicted slurry volume of 3.9 liters. Once the slurry was homogenized, a test matrix was performed as described in Section 2.2.2 to determine the filtration behavior of the waste at a low UDS concentration. After completion of the test matrix, the waste sample was dewatered to the minimum operating volume in the slurry recirculation loop at a predicted concentration of $13 \mathrm{wt} \%$ UDS. The final target concentration for this testing was $20 \mathrm{wt} \%$ UDS, so additional Group 5 slurry was added to the CUF and diluted with additional supernate to maintain the slurry UDS concentration at $13 \mathrm{wt} \%$. After the slurry was homogenized again, the slurry was dewatered to minimum volume and target UDS concentration. At this point, another test matrix was performed to evaluate the change in the filtration behavior after concentrating the waste slurry.

The second half of the testing was to evaluate the caustic leaching behavior of the Group 5 waste slurry at predicted leaching conditions of the WTP-Pretreatment UFP2 vessel, as outlined in the right column of Figure 3.1. After completing the high solids concentration filtration test matrix, the sample was drained from the CUF piping and placed back into the slurry reservoir after isolating the tank from the filtration piping. At this point, a known volume and concentration of $\mathrm{NaOH}$ was blended with the concentrated slurry to increase the leach volume to 3.4 liters. The caustic addition was based on:

- 400 grams of Group 5 solids material present and using a predicted Al composition of the solids based on characterization performed in WPT-RPT-157.

- Assuming a 50\% leach factor of aluminum present in the solids, the final free hydroxide concentration is high enough to maintain $\mathrm{Al}$ (relative to gibbsite) solubility ${ }^{(\mathrm{b})}$ after leach solution

(a) Conducted according to TI-RPP-WTP-540, HLW Filtration and Caustic Leaching of Group 5 Waste, R Hallen, A $\mu$ gust, 2007.

(b) Solubility of aluminum and hydroxide taken from data reported by Huixin Li, etal, in The Influence of Al(III) Supersaturation and $\mathrm{NaOH}$ Concentration on the Rate of Crystallization of $\mathrm{Al}(\mathrm{OH}) 3$ Precursor Particles From Sodium Aluminate Solutions, Journal of Colloid and Interface Science (2005, Vol. 286, pg. 511-519). 
cools to room temperature. The final molar ratio of free hydroxide to aluminum was predicted to be 7.5.

- After calculating the free-hydroxide concentration needed to maintain Al solubility (relative to gibbsite) after cooling, the required addition of $\mathrm{NaOH}$ was calculated next. This mass was to be added as a 19-M NaOH solution.

- Once the volume of dewatered slurry and $19 \mathrm{M} \mathrm{NaOH}$ was known, the volume of water to be added to the leach solution representing the leach volume increase due to condensation from heating via steam injection was calculated.

- Note that this process is iterative in that the dilution from condensate would adjust the amount of caustic required to maintain solubility and thus would adjust the calculation.

- Once the caustic addition as $19 \mathrm{M}$ and condensate water addition was known, the two volumes were combined into one solution. Because this was a hot cell operation, the number of entries into the hot cell needed to be minimized. Therefore, combining both the water condensate addition and 19-M caustic addition allowed only one solution to be added instead of two. The final solution became 1.88 liters of $9.13 \mathrm{M} \mathrm{NaOH}$.

This caustic solution was used to rinse additional solids in the CUF piping prior to isolating the slurry reservoir tank for leaching operations. After rinsing the CUF slurry piping with the caustic addition, the drained slurry, supernate, and caustic addition solution was added to the isolated slurry reservoir tank with the overhead mixer operating. The system was heated to $100^{\circ} \mathrm{C}$ over a 5.6 -hour interval. The slurry was then maintained at $100^{\circ} \mathrm{C}$ for 12 hours, during which the slurry supernate was sampled periodically to evaluate the aluminum dissolution rate. Afterwards, the slurry was allowed to cool to room temperature over a 12-hour interval. At this point, the leached slurry was allowed to enter the piping of the CUF, and it was dewatered to minimum operating volume of the circulation pump. Three equal-volume caustic rinse solutions (1.2 liters) were then added to the leached slurry. To prevent aluminum from precipitating during washing, addition caustic was added to each wash solution to prevent the free hydroxide concentration from falling to low to maintain aluminum solubility. The concentration of $\mathrm{NaOH}$ in each wash was:

- 1.9 molal for the first rinse solution

- 0.9 molal for the second rinse solution

- 0.4 molal for the third rinse solution

After 20-30 minutes of mixing the slurry with each rinse solution, the slurry was dewatered afterwards. A final test matrix was performed on the washed leached slurry to compare with the filter behavior of the pre-leached slurry.

During testing, slurry and supernate samples were periodically collected to track the solid content in the waste slurry and to track the chemical composition of the slurry to perform mass balance calculations to evaluate the effectiveness of the process in separating LAW waste components from the HLW components in the waste sample. Details of the analyses performed and planning for this test scheme can be found in Appendices A, B, C, E, and K. 

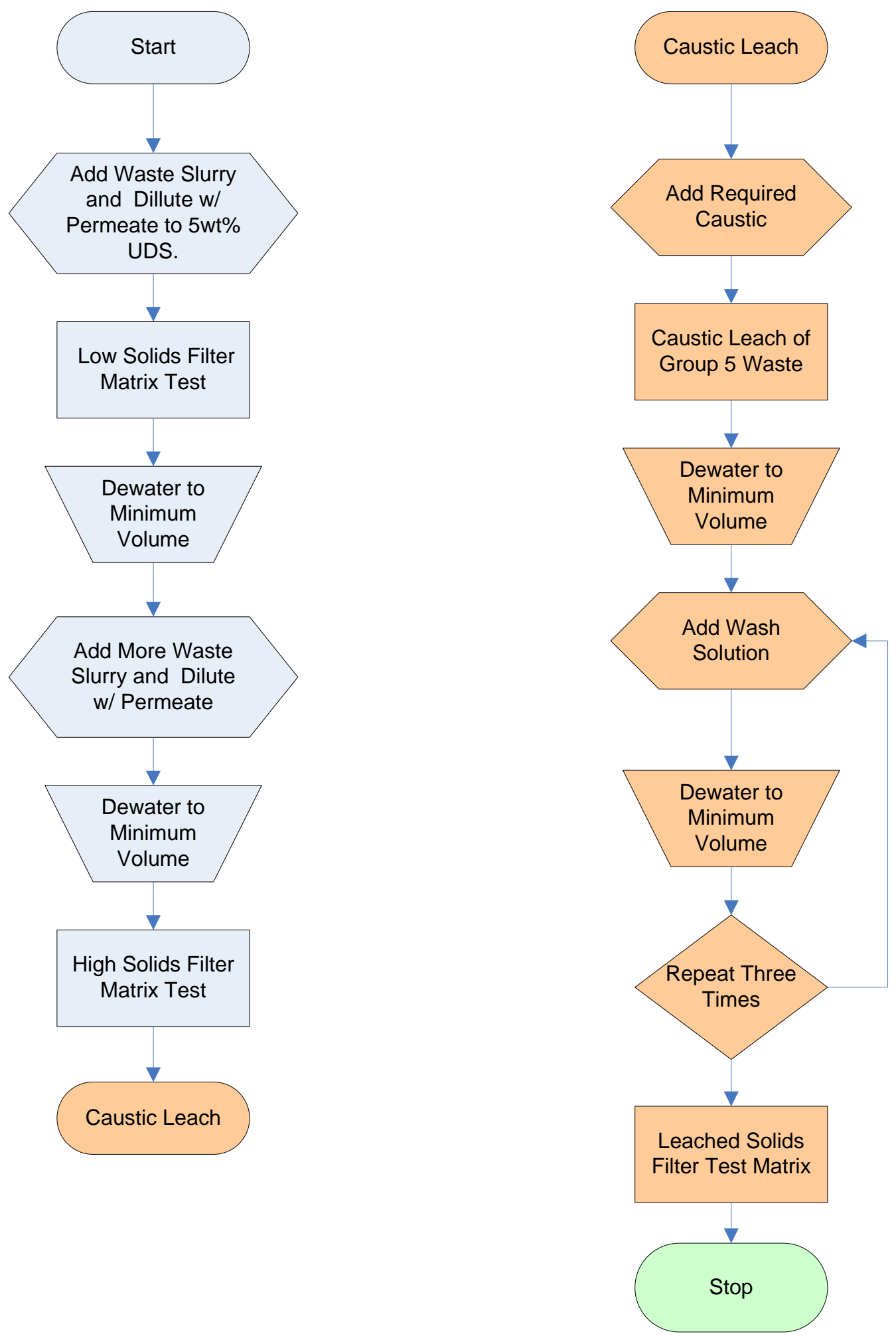

Figure 3.1. Group 5 Testing Flowchart 


\subsection{Low-Solid (5 wt\%) Slurry Characterization}

Figure 3.2 shown below outlines the activities and materials added to the CUF to produce the Low-Solids (5 wt\%) Slurry. Initially, $1.16 \mathrm{~kg}$ of REDOX waste slurry was added to the slurry reservoir. These waste samples were taken from the Group 5 characterization/homogenization study (described in WPT-RPT157). That study compiled archive tank waste samples from the Hanford 222S Laboratory and homogenized them into a single waste slurry described as the Group 5 waste. The waste slurry generated from that study was reported to have a UDS concentration of $18 \mathrm{wt} \%$. To dilute the waste slurry to $5 \mathrm{wt} \%$ UDS for the low-solid matrix test, $3.24 \mathrm{~kg}$ of a simulant supernate was added to the reservoir and blended with the actual waste samples. The composition of the simulant (shown in Table 3.1) was based on results of supernate characterization performed on the homogenized Group 5 waste (see WTP-RPT-157).

Once the actual waste samples and simulant were blended in the slurry reservoir tank, the slurry was circulated thro $\mu$ gh the CUF with permeate from the ultra filter recycling back to the slurry reservoir. The hold-up of slurry supernate in the filter and permeate loop was $\sim 200 \mathrm{~mL}$. Slurry samples were collected for chemical and physical characterization of the slurry inside the slurry circulation loop. Results of physical property measurements are outlined in Table 3.2. Given the sampling uncertainties, the measured UDS (4.3 wt\%) corresponds reasonably well to the predicted value in the slurry loop $(0.21 \mathrm{~kg}$ $14.12 \mathrm{~kg} \cong 5 \mathrm{wt} \%$ ). The chemical and radiological composition of the waste slurry is summarized in Table 3.3 and Table 3.4 below. Results are expressed as the total amount of components in the CUF slurry (mass balance) and include the supernate present in the permeate loop. Based on these data, there is no objective evidence that any significant precipitation occurred after the supernate simulant was added.

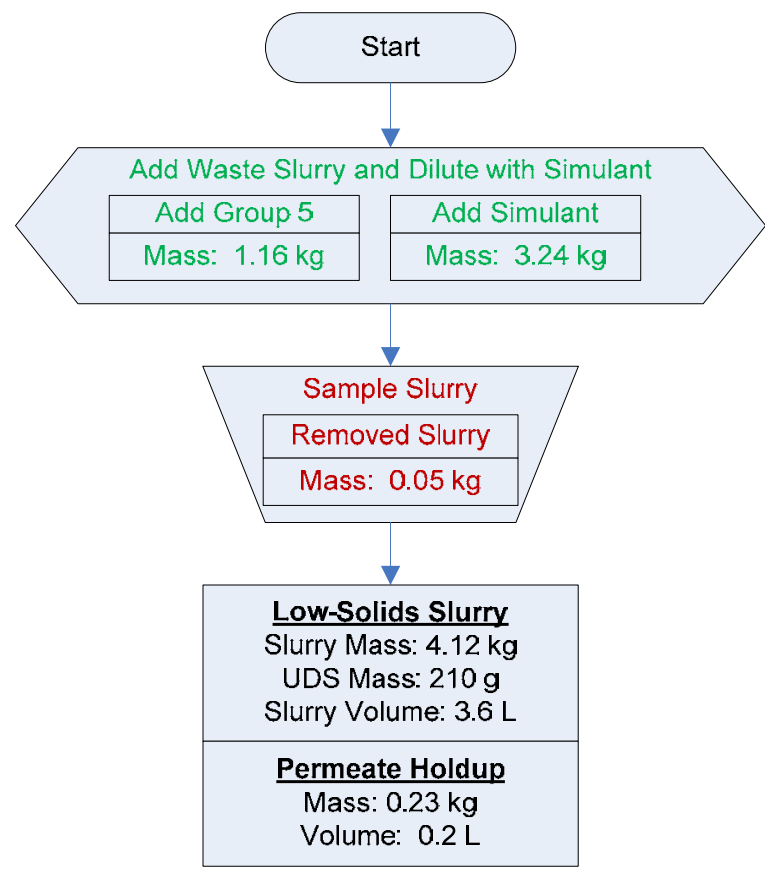

Figure 3.2. Group 5 Low-Solids (5 wt\%) Slurry Preparation and Sampling Note: Mass and volume values in figure are rounded to the nearest significant digit of accuracy. 
Table 3.1. Simulant Addition to Group 5 Waste

\begin{tabular}{|c|c|c|c|c|c|}
\hline \multirow[b]{2}{*}{ Cations } & \multicolumn{2}{|c|}{$\begin{array}{r}\text { Simulant Addition } \\
(2.8 \mathrm{~L}) \\
\end{array}$} & \multicolumn{2}{|c|}{$\begin{array}{r}\text { Actual Slurry Waste } \\
(1.2 \mathrm{~kg})\end{array}$} & \multirow{2}{*}{$\begin{array}{c}\% \text { slurry due } \\
\text { to simulant } \\
\text { wt } \% \\
\end{array}$} \\
\hline & mg/L & mg & $\mathrm{mg} / \mathrm{g}$ & mg & \\
\hline $\mathrm{Na}$ & 75,000 & 210,000 & 68 & 79,000 & $73 \%$ \\
\hline $\mathrm{K}$ & 500 & 1,400 & 4 & 4,300 & $25 \%$ \\
\hline Metals & mg/L & mg & $\mathrm{mg} / \mathrm{g}$ & mg & wt $\%$ \\
\hline $\mathrm{Al}$ & 2,600 & 7,300 & 62 & 72,000 & $9 \%$ \\
\hline $\mathrm{Cr}$ & 1,200 & 3,400 & 1.3 & 1,500 & $69 \%$ \\
\hline $\mathrm{P}$ & 390 & 1,100 & 0.26 & 300 & $79 \%$ \\
\hline Anions & $\mathrm{mg} / \mathrm{L}$ & mg & $\mathrm{mg} / \mathrm{g}$ & mg & wt \% \\
\hline $\mathrm{C}_{2} \mathrm{O}_{4}$ & 1,400 & 3,900 & 0.14 & 160 & $96 \%$ \\
\hline $\mathrm{NO}_{2}$ & 25,000 & 69,000 & 23 & 27,000 & $72 \%$ \\
\hline $\mathrm{NO}_{3}$ & 89,000 & 250,000 & 81 & 94,000 & $73 \%$ \\
\hline $\mathrm{SO}_{4}$ & 710 & 2,000 & 0.45 & 520 & $79 \%$ \\
\hline $\mathrm{PO}_{4}$ & 1,200 & 3,300 & 0.78 & 900 & $79 \%$ \\
\hline $\mathrm{OH}$ & 2,000 & 5,700 & 3.5 & 4,000 & $59 \%$ \\
\hline $\mathrm{CO}_{3}$ & 26,000 & 72,000 & 3.6 & 4,200 & $94 \%$ \\
\hline
\end{tabular}

Table 3.2. Low-Solids (5 wt\%) Slurry Physical Property Measurements (slurry circulation loop)

\begin{tabular}{|r|c||}
\hline Slurry Density (g/mL) & 1.16 \\
\hline Supernate Density (g/mL) & 1.16 \\
\hline Settled Solids (Vol \%) & $47 \%$ \\
\hline Centrif $\mu$ ged UDS (Wt \%) & $22 \%$ \\
\hline Total Solids of the Slurry (Wt \%) & $23 \%$ \\
\hline Dissolved Solids of the Supernate (Wt \%) & $20 \%$ \\
\hline UDS of the Slurry (Wt\%) & $4.3 \%$ \\
\hline
\end{tabular}


Table 3.3. Low-Solids (5 wt\%) Slurry Composition and Total Inventory (including permeate hold-up)

\begin{tabular}{|c|c|c|c|c|c|}
\hline & Slurry $^{(a)}$ & \multicolumn{2}{|c|}{ Liquid Fraction $^{(b)}$} & \multicolumn{2}{|c|}{ Solids Fraction $^{(\mathrm{c})}$} \\
\hline Mass (kg) & 4.35 & \multicolumn{2}{|c|}{4.14} & \multicolumn{2}{|c|}{0.21} \\
\hline Wt\% of Slurry & $100 \%$ & \multicolumn{2}{|c|}{$95.1 \%$} & \multicolumn{2}{|c|}{$4.9 \%$} \\
\hline Metal & g & g & $\mu g / m L$ & g & $\mu g / g$ \\
\hline Al & $7.9 \mathrm{E}+01$ & $7.3 \mathrm{E}+00$ & $2.1 \mathrm{E}+03$ & $7.1 \mathrm{E}+01$ & $3.4 \mathrm{E}+05$ \\
\hline Ca & 2.7E-01 & $1.1 \mathrm{E}-01$ & $3.0 \mathrm{E}+01$ & $1.6 \mathrm{E}-01$ & 7.7E+02 \\
\hline $\mathrm{Cr}$ & $4.9 \mathrm{E}+00$ & $4.3 \mathrm{E}+00$ & $1.2 \mathrm{E}+03$ & $6.2 \mathrm{E}-01$ & $2.9 \mathrm{E}+03$ \\
\hline $\mathbf{F e}$ & $1.5 \mathrm{E}+00$ & $<7$. .E-3 & $<2 . \mathrm{E}+0$ & $1.5 \mathrm{E}+00$ & $7.3 \mathrm{E}+03$ \\
\hline Mn & 9.5E-01 & $<7$. E-4 & $<2$.E-1 & 9.5E-01 & $4.5 \mathrm{E}+03$ \\
\hline $\mathrm{Na}$ & $2.9 \mathrm{E}+02$ & $2.6 \mathrm{E}+02$ & $7.2 \mathrm{E}+04$ & $2.7 \mathrm{E}+01$ & $1.3 \mathrm{E}+05$ \\
\hline $\mathbf{P}$ & $1.4 \mathrm{E}+00$ & $1.3 \mathrm{E}+00$ & $3.5 \mathrm{E}+02$ & 1.3E-01 & $6.2 \mathrm{E}+02$ \\
\hline Si & $1.9 \mathrm{E}+00$ & 9.9E-02 & $2.8 \mathrm{E}+01$ & $1.8 \mathrm{E}+00$ & $8.5 \mathrm{E}+03$ \\
\hline $\mathbf{U}$ & $4.3 \mathrm{E}+03$ & $<3 . \mathrm{E}-2$ & $<8 . \mathrm{E}+0$ & $4.3 \mathrm{E}+03$ & $2.0 \mathrm{E}+07$ \\
\hline \multirow{2}{*}{$\begin{array}{l}\text { Radiochemical } \\
\text { Isotopes }\end{array}$} & Slurry & \multicolumn{2}{|c|}{ Liquid Fraction } & \multicolumn{2}{|c|}{ Solid Fraction } \\
\hline & $\mathrm{mCi}$ & $\mathbf{m C i}$ & $\mathrm{mCi} / \mathrm{mL}$ & $\mathrm{mCi}$ & $\mathrm{mCi} / \mathrm{g}$ \\
\hline Co-60 & $2.5 \mathrm{E}+00$ & $<3 . \mathrm{E}-1$ & $<8 . \mathrm{E}-5$ & $2.5 \mathrm{E}+00$ & $1.2 \mathrm{E}-02$ \\
\hline Cs-137 & $4.6 \mathrm{E}+04$ & $5.9 \mathrm{E}+04$ & $1.7 \mathrm{E}+01$ & $-1.4 \mathrm{E}+04$ & $-6.4 \mathrm{E}+01$ \\
\hline Eu-154 & $2.6 \mathrm{E}+01$ & $<2 . \mathrm{E}+0$ & $<6 . \mathrm{E}-4$ & $2.6 \mathrm{E}+01$ & $1.2 \mathrm{E}-01$ \\
\hline Am-241 & $6.7 \mathrm{E}+01$ & $<3 . \mathrm{E}+1$ & $<7$. E-3 & $6.7 \mathrm{E}+01$ & 3.1E-01 \\
\hline Gross Alpha & $1.9 \mathrm{E}+02$ & $<3 . \mathrm{E}+1$ & $<8$. E-3 & $1.9 \mathrm{E}+02$ & 8.8E-01 \\
\hline Gross Beta & $3.6 \mathrm{E}+05$ & $4.8 \mathrm{E}+04$ & $1.4 \mathrm{E}+01$ & $3.1 \mathrm{E}+05$ & $1.5 \mathrm{E}+03$ \\
\hline Sr-90 & $1.4 \mathrm{E}+05$ & $4.7 \mathrm{E}+01$ & 1.3E-02 & $1.4 \mathrm{E}+05$ & $6.6 \mathrm{E}+02$ \\
\hline $\mathrm{Pu}-239+240$ & $1.9 \mathrm{E}+02$ & 7.4E-02 & $2.1 \mathrm{E}-05$ & $1.9 \mathrm{E}+02$ & 8.8E-01 \\
\hline Pu-238 & $4.8 \mathrm{E}+00$ & $<8 . \mathrm{E}-3$ & $<2$.E-6 & $4.8 \mathrm{E}+00$ & 2.3E-02 \\
\hline \multirow[t]{2}{*}{ Anions } & \multicolumn{3}{|c|}{ Liquid Fraction } & & \\
\hline & $\mu g / m L$ & [M] & g & & \\
\hline $\mathbf{F}$ & $2.3 \mathrm{E}+01$ & $1.2 \mathrm{E}-03$ & $8.2 \mathrm{E}-02$ & & \\
\hline $\mathrm{C}_{2} \mathrm{O}_{4}$ & $1.1 \mathrm{E}+03$ & $1.3 \mathrm{E}-02$ & $4.0 \mathrm{E}+00$ & & \\
\hline $\mathrm{NO}_{2}$ & $2.7 \mathrm{E}+04$ & $5.8 \mathrm{E}-01$ & $9.5 \mathrm{E}+01$ & & \\
\hline $\mathrm{NO}_{3}$ & $9.5 \mathrm{E}+04$ & $1.5 \mathrm{E}+00$ & $3.4 \mathrm{E}+02$ & & \\
\hline $\mathrm{SO}_{4}$ & $7.0 \mathrm{E}+02$ & 7.3E-03 & $2.5 \mathrm{E}+00$ & & \\
\hline $\mathrm{PO}_{4}$ & $1.2 \mathrm{E}+03$ & $1.2 \mathrm{E}-02$ & $4.1 \mathrm{E}+00$ & & \\
\hline OH & $2.6 \mathrm{E}+03$ & 1.6E-01 & $9.5 \mathrm{E}+00$ & & \\
\hline \multicolumn{6}{|c|}{$\begin{array}{l}\text { (a) Slurry Mass components were calculated from characterization data (WPT-RPT-157), and the } \\
\text { masses of materials that were added with simulant. Loss of mass from sampling was incorporated. } \\
\text { (b) Liquid Fraction mass components were calculated using analytical results from supernate sample } \\
\text { TI540-G5-A (ASO ID 07-01779) and the predicted mass of supernate in the system. } \\
\text { (c) Solids Fraction mass components were calculated from the difference between the slurry } \\
\text { component mass and liquid component mass fraction. }\end{array}$} \\
\hline
\end{tabular}


Table 3.4. Group 5 Low-Solids Supernate Opportunistic Composition

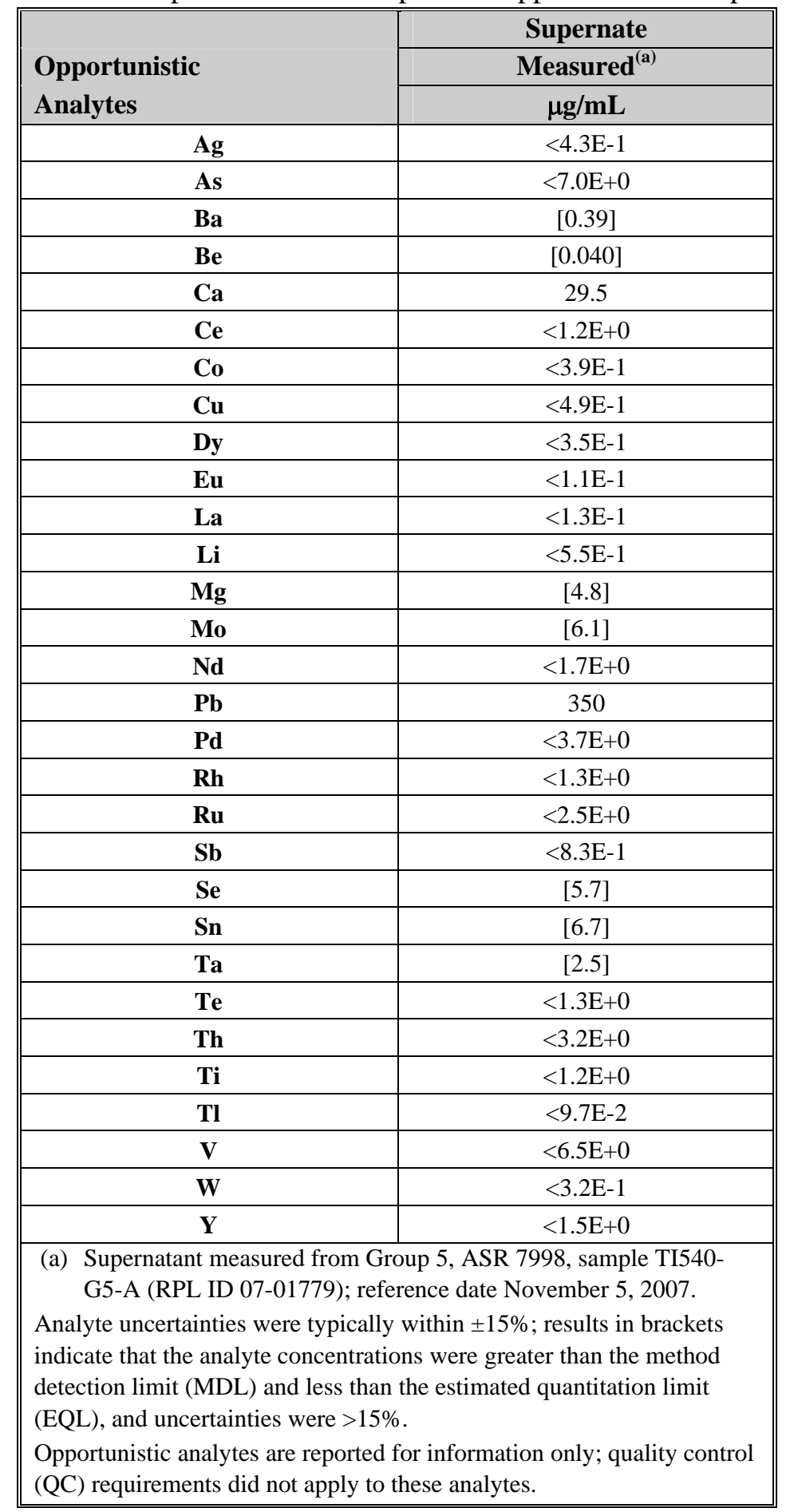

Particle size measurements were performed on the slurry sample taken prior to the filtration testing. A diagram of the flow loop that slurry samples were placed in for PDS analysis is shown in Figure 3.3. The pre-sonic particle-size distribution (PSD) for the as-received low solids sample, shown in Figure 3.4, indicates a broad, continuous, and unimodal distribution that spans $0.2 \mu \mathrm{m}$ to $200 \mu \mathrm{m}$ and peaks at $\sim 3 \mu \mathrm{m}$. The majority of the particle volume exists below $20 \mu \mathrm{m}$. With regard to the effect of the instrument pump 
speed, an increase from 2000 to 3000 RPM shifts the distribution to lower diameters and appears to reduce/eliminate the population of 100 - to $200-\mu \mathrm{m}$ aggregates. This aggregate reduction is accompanied by an increase in the 20- to 100- $\mu$ m particle fraction. A further increase in the pump speed to $4000 \mathrm{RPM}$ appears to 1) shear apart $>100$ - $\mu$ m aggregates, 2) decrease the relative population of 1 - to $10-\mu \mathrm{m}$ particles, and 3) slightly increase the sub-micrometer particle fraction. As such, it can be concluded that the flow rate does impact the PSD at 4000 RPM. The observed PSD behavior is more consistent with agglomerate break-up under shear rather than increased aggregate suspension. Sonication appears to have had a similar influence on the low-solids (5 wt\%) matrix sample as it had on the as-received material (Figure 3.5). Specifically, sonication increases the relative population of 4 - to 20 - $\mu$ m particles while causing a reduction in the relative population of 1- to $4-\mu \mathrm{m}$ particles. Additionally, there is a slight increase in the relative population of submicron particles

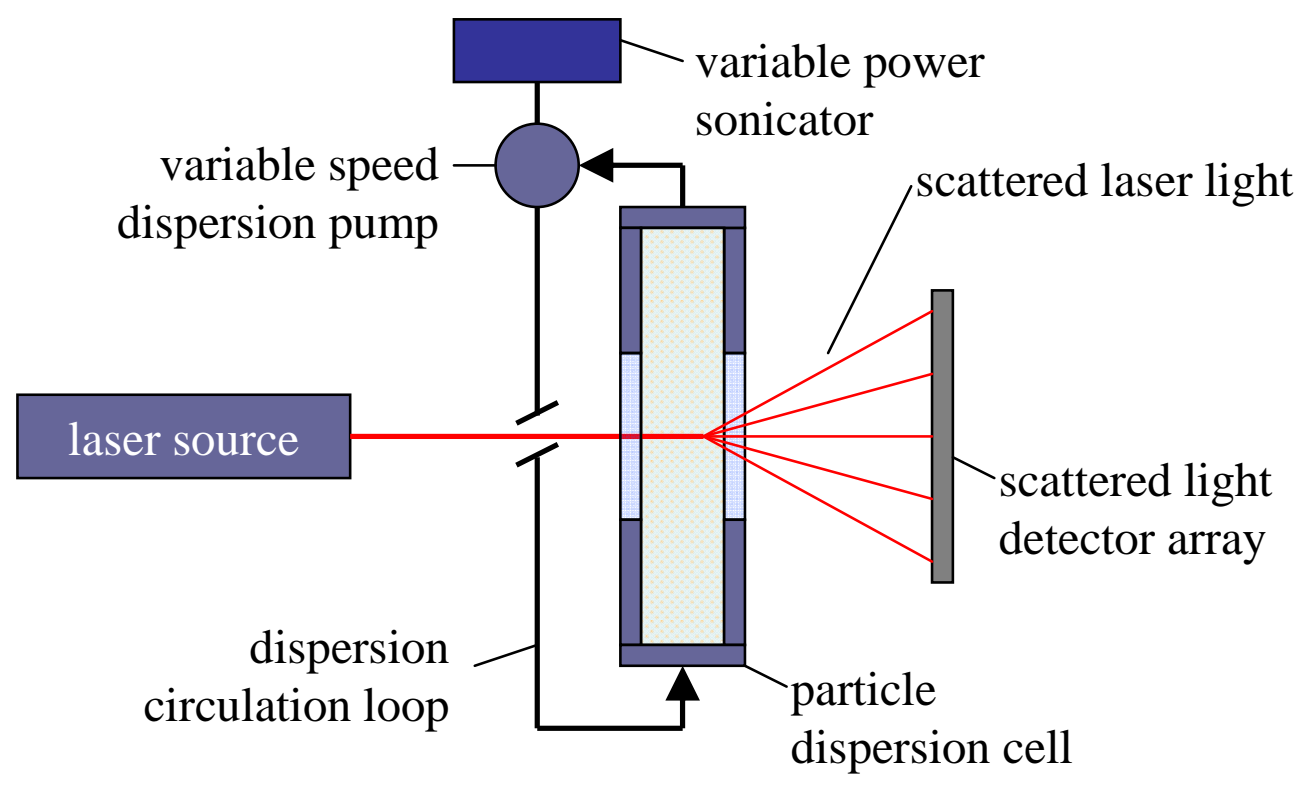

Figure 3.3. Flow Loop Diagram of PSD Instrument 


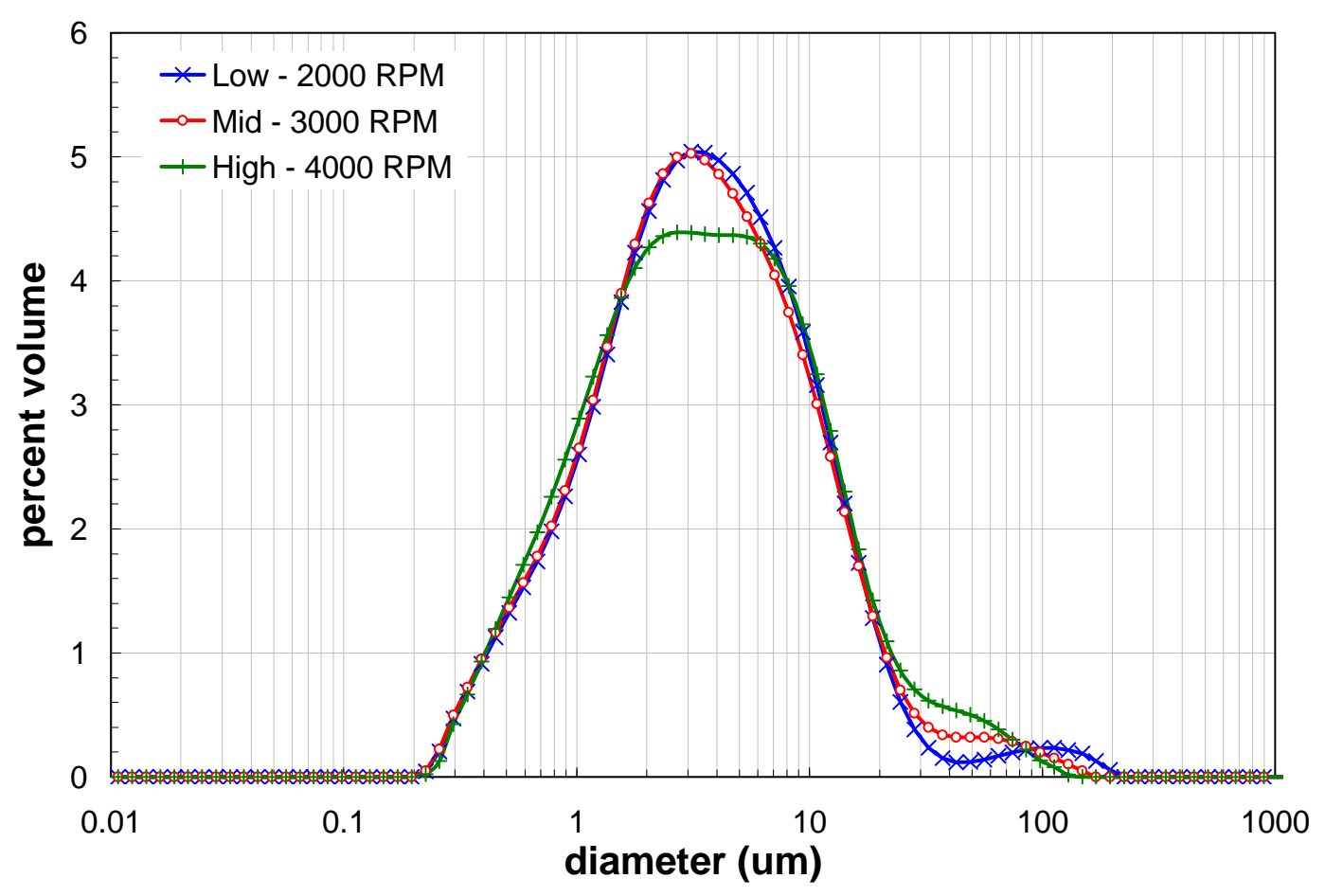

Figure 3.4. PSD of CUF Group 5 Low-Solids ( $5 \mathrm{wt} \%$ ) Slurry as a Function of Pump Speed

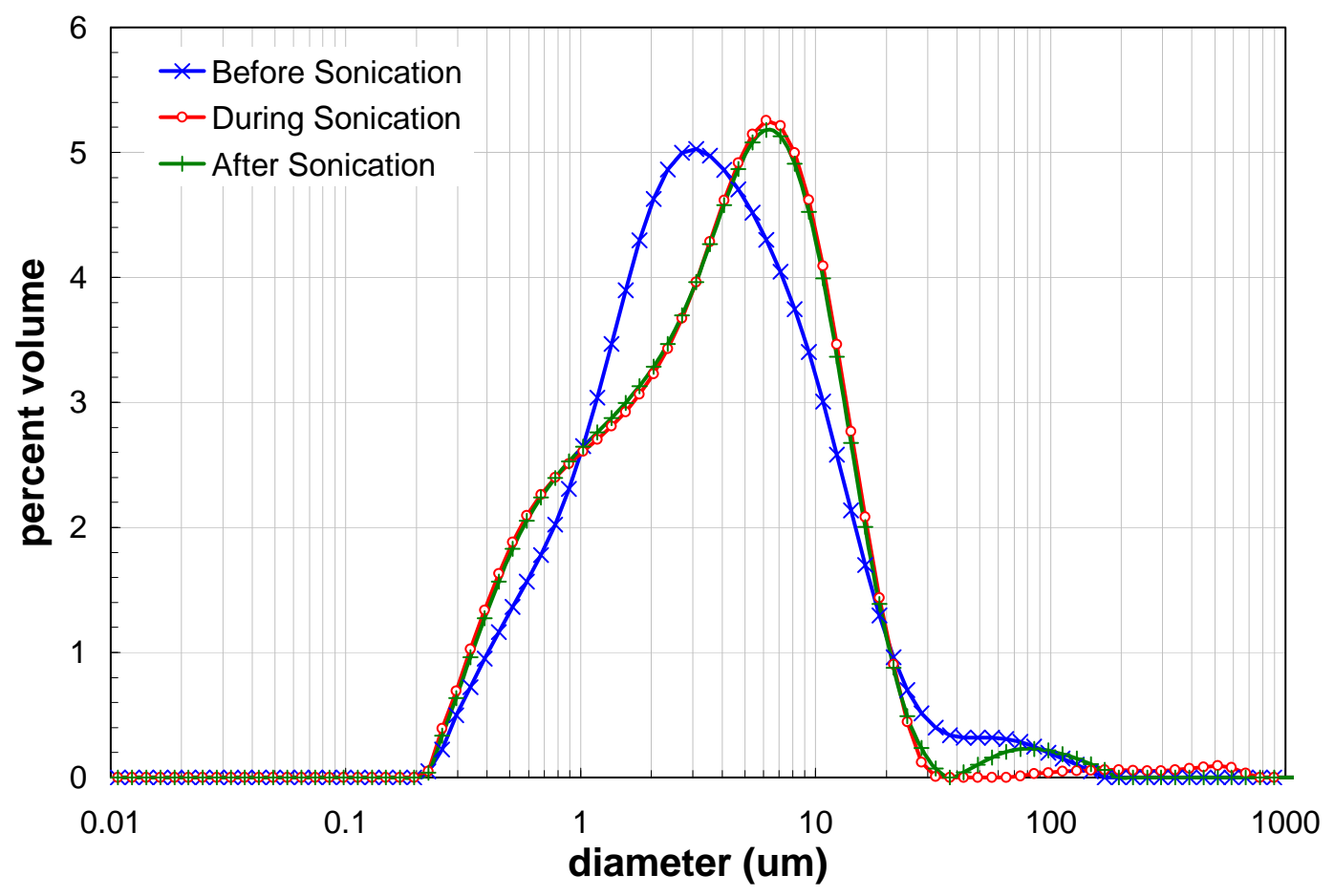

Figure 3.5. PSD of CUF Group 5 Low-Solids ( $5 \mathrm{wt} \%$ ) Slurry as a Function of Sonication 
Rheology measurements of the low-solids ( $5 \mathrm{wt} \%$ ) slurry was taken prior to the filtration test as well. The stress response of the low solids slurry to shear was non-Newtonian (Table 3.5) and behaved similar to that of the initial characterization (source) material (Figure 3.6). Over the 0 - to $100-\mathrm{s}^{-1}$ region, the shear stress increases rapidly and appears to be shear thinning. However, the latter observation may be a result of elastic deformation of the slurry. Beyond $100 \mathrm{~s}^{-1}$, the flow curve data increase linearly for all temperatures tested.

Table 3.5. Results of Fitting Analysis for Group 5 CUF Low Solids Matrix

\begin{tabular}{|c|c|c|c|c|c|}
\hline MODEL & $\begin{array}{c}\text { TEMPERATURE } \\
{\left[{ }^{\circ} \mathrm{C}\right]}\end{array}$ & $\begin{array}{c}\text { YIELD } \\
\text { STRESS } \\
\text { [PA] }\end{array}$ & $\begin{array}{c}\text { CONSISTENCY } \\
{\left[\mathrm{PA} \cdot \mathrm{S}^{\mathrm{N}}\right]}\end{array}$ & $\begin{array}{l}\text { FLOW } \\
\text { INDEX }\end{array}$ & $\overline{\mathbf{R}}$ \\
\hline \multirow[t]{3}{*}{ Power-Law } & 25 & $\mathrm{n} / \mathrm{a}$ & 0.22 & 0.49 & 0.98 \\
\hline & 40 & $\mathrm{n} / \mathrm{a}$ & 0.36 & 0.43 & 0.98 \\
\hline & 60 & $\mathrm{n} / \mathrm{a}$ & 0.42 & 0.40 & 0.95 \\
\hline \multirow[t]{3}{*}{ Herschel-Bulkley } & 25 & 1.4 & 0.028 & 0.76 & 0.94 \\
\hline & 40 & 1.6 & 0.045 & 0.69 & 0.98 \\
\hline & 60 & 1.9 & 0.037 & 0.71 & 0.96 \\
\hline \multirow[t]{3}{*}{ Bingham-Plastic* } & 25 & 2.2 & 0.0046 & $\mathrm{n} / \mathrm{a}$ & 0.97 \\
\hline & 40 & 2.6 & 0.0042 & $\mathrm{n} / \mathrm{a}$ & 0.98 \\
\hline & 60 & 2.7 & 0.0041 & $\mathrm{n} / \mathrm{a}$ & 0.92 \\
\hline \multirow[t]{3}{*}{ Herschel-Bulkley* } & 25 & 2.1 & 0.0060 & 0.97 & 0.97 \\
\hline & 40 & 2.2 & 0.013 & 0.85 & 0.98 \\
\hline & 60 & 2.5 & 0.0077 & 0.92 & 0.92 \\
\hline
\end{tabular}

*Fits restricted to data over 200 to $1000 \mathrm{~s}^{-1}$.

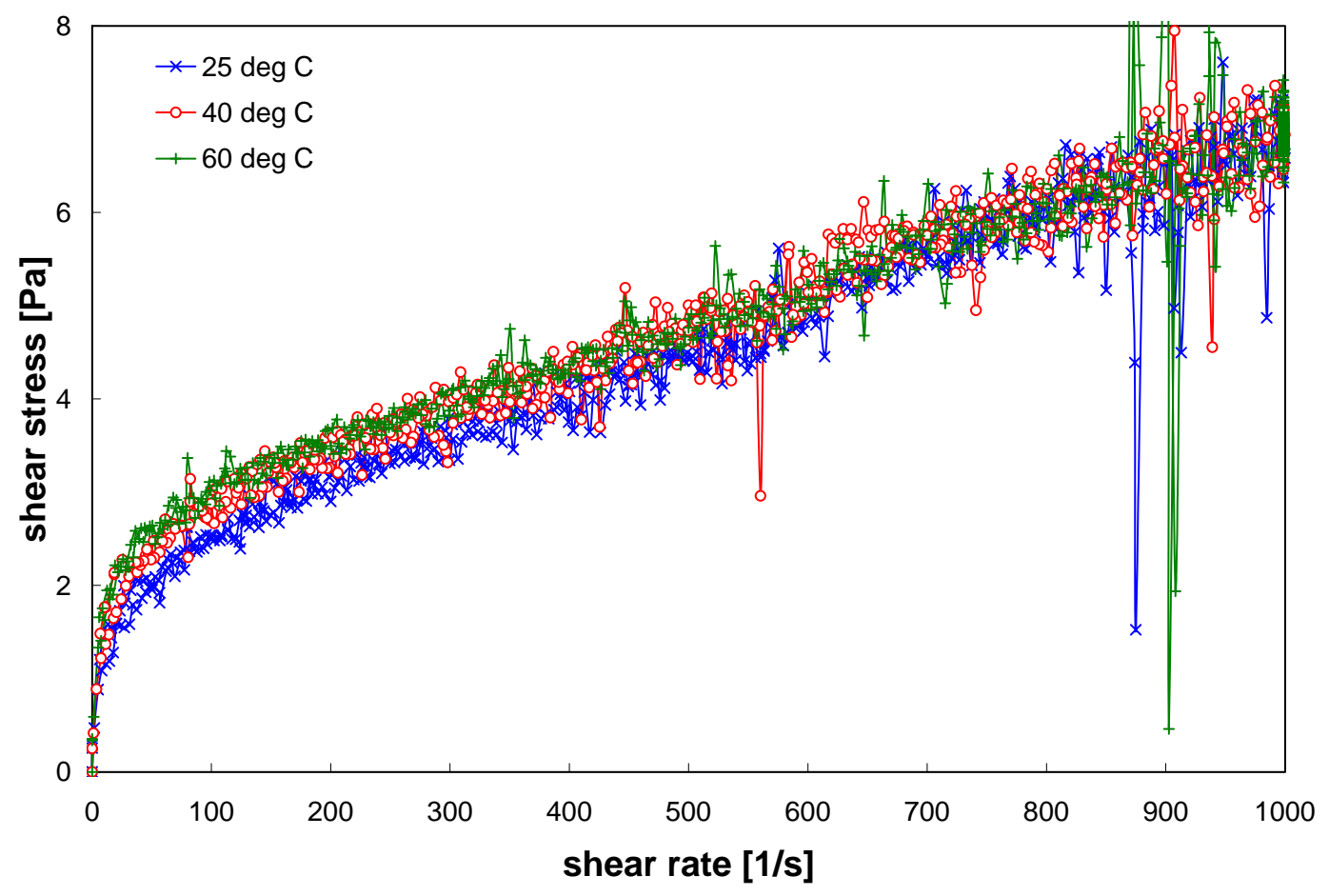

Figure 3.6. Flow Curves for Group 5 CUF Low Solids Slurry 
WTP-RPT-172, Rev 0

\subsection{Filter Flux Test Matrix and Initial Dewater}

This section describes the filtration testing performed using the Group 5 composite before leaching, as shown in the left column of Figure 3.1. The following tests were performed.

- Filtration testing of the composite Group 5 waste slurry at a low-solids (5 wt\%) concentration as described in Section 2.2. Testing compares the effects of transmembrane pressure (TMP), axial velocity (AV), and operation time on filter flux.

- Dewatering of the waste slurry to a higher UDS concentration using a constant TMP and AV to understand the impact of how solid concentration impacts filtration and compare to previous testing of other wastes.

- Filtration testing of the slurry at a high-solids concentration. Like before, testing compares the effects of TMP, AV, and operation time on filter flux.

\subsubsection{Low-solids (5 wt\%) Test Matrix}

After all the slurry samples were collected and the rheology sample was returned to the CUF, the lowsolids (5 wt\%) matrix test was performed. The average filter flux and process parameter for each filtration test in the matrix is reported in Table 3.6. The complete permeate flux data with respect to time are displayed in Figure 3.7. The flux ranged from 0.035 to 0.089 gallons per minute (GPM) $/ \mathrm{ft}^{2}$, with a value near $0.060 \mathrm{GPM} / \mathrm{ft}^{2}$ for the standard filtration condition of TMP $=40$ pounds per square inch differential (psid) and $A V=13 \mathrm{ft} / \mathrm{s}$. Note that in general, the axial velocities were maintained near their target values to $\pm 0.2 \mathrm{ft} / \mathrm{s}$ and \pm 2 psid.

For the low-solids ( $5 \mathrm{wt} \%$ ) test matrix, the slurry was expected to behave according to the Darcy equation (Equation 2.6), with the observed filter flux scaled in proportion to the transmembrane pressure while the permeate viscosity and filter resistance was held constant. This correlation is illustrated in Figure 3.9 where the average value of permeate flux is plotted against the average transmembrane pressure for each test condition. A corresponding chart for the average axial velocity, Figure 3.10, confirms the theoretical categorization of the filtration behavior of this slurry, as this chart mimics the experimental design (Figure 2.1) with no clear correlation of permeate flux with axial velocity.

Modeling of the data using a least square fit method was then used to quantify the effects of TMP and AV on filter flux. The analysis found no significant effect from AV, while a linear correlation for TMP was found with an $\mathrm{R}^{2}$ correlation coefficient of 0.72 . However, further analysis showed that the filter flux increased in the middle of the test matrix after the back pulse of test 4 of the matrix. The results of the test matrix were then split in two different data sets (Tests 1-4, and Test 5-11) and modeled separately. The results of this analysis are shown in Figure 3.11. Linear equations were fit to both data sets with much higher $\mathrm{R}^{2}$ correlation coefficients of 0.94 for Tests $1-4$ and 0.86 for Tests $5-11$. Comparison of the slopes of each line shows that the filter flux increased approximately $30 \%$ at the start of Test 5 of the matrix. While it appears that the overall filter resistance of the system changed during this test, it is not clear what occurred. 
Table 3.6. Average Operating Conditions and Permeate Flux for Low-Solids (5 wt\%) Matrix Test

\begin{tabular}{|c|c|c|c|c|c|c|}
\hline $\begin{array}{c}\text { Design } \\
\text { Test } \\
\text { Condition }\end{array}$ & $\begin{array}{c}\text { Slurry } \\
\text { Temp }^{(a)} \\
\left({ }^{\circ} \mathrm{C}\right)\end{array}$ & $\begin{array}{c}\mathbf{T M P}^{(\mathbf{b})} \\
\text { (psid) }\end{array}$ & $\begin{array}{c}\text { Axial } \\
\text { Velocity } \\
\text { (ft/s) }\end{array}$ & $\begin{array}{l}\text { Permeate } \\
\text { Flowrate } \\
\text { (mL/min) }\end{array}$ & $\begin{array}{c}\text { Corrected } \\
\text { Permeate } \\
\text { Flux } \\
\left(\text { GPM/ft }{ }^{2}\right)\end{array}$ & $\begin{array}{c}\text { Axial } \\
\text { Pressure } \\
\text { Drop }^{(\mathbf{b})} \\
\text { (psid/ft) }^{\text {prid) }}\end{array}$ \\
\hline 1 & 23.5 & 40.5 & 12.9 & 48.2 & 0.051 & 1.2 \\
\hline 2 & 23.3 & 29.5 & 11.0 & 38.6 & 0.041 & 0.9 \\
\hline 3 & 24.1 & 28.4 & 15.5 & 35.4 & 0.037 & 1.6 \\
\hline 4 & 26.7 & 49.9 & 15.0 & 63.2 & 0.061 & 1.6 \\
\hline 5 & 22.9 & 50.1 & 10.9 & 79.0 & 0.085 & 1.1 \\
\hline 6 & 24.6 & 40.7 & 12.9 & 73.2 & 0.075 & 0.5 \\
\hline 7 & 23.7 & 38.4 & 9.1 & 67.5 & 0.071 & 1.9 \\
\hline 8 & 26.3 & 32.9 & 16.8 & 61.8 & 0.060 & 1.7 \\
\hline 9 & 24.2 & 19.6 & 13.0 & 36.4 & 0.038 & 1.1 \\
\hline 10 & 27.3 & 59.8 & 12.8 & 94.3 & 0.089 & 1.2 \\
\hline 11 & 23.4 & 39.7 & 13.1 & 60.6 & 0.064 & 1.2 \\
\hline \multicolumn{7}{|c|}{$\begin{array}{l}\text { (a) Thermocouple accuracy } \pm 2^{\circ} \mathrm{C} \text {. } \\
\text { (b) Pressure transducer accuracy } \pm 1 \text { psig. }\end{array}$} \\
\hline
\end{tabular}




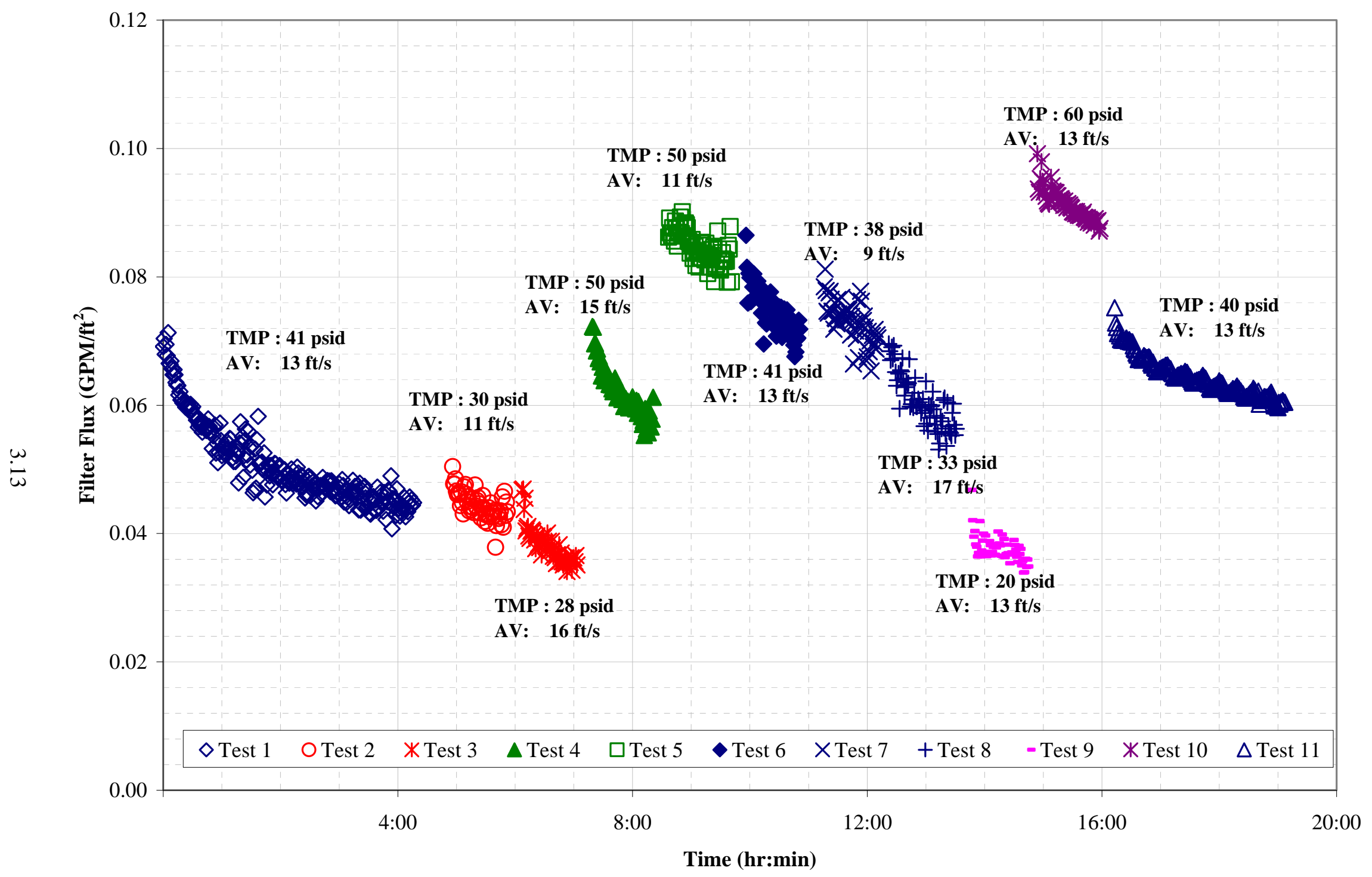

Figure 3.7. Group 5 Filter Flux Data for Low-solids ( 5 wt\%) Matrix 


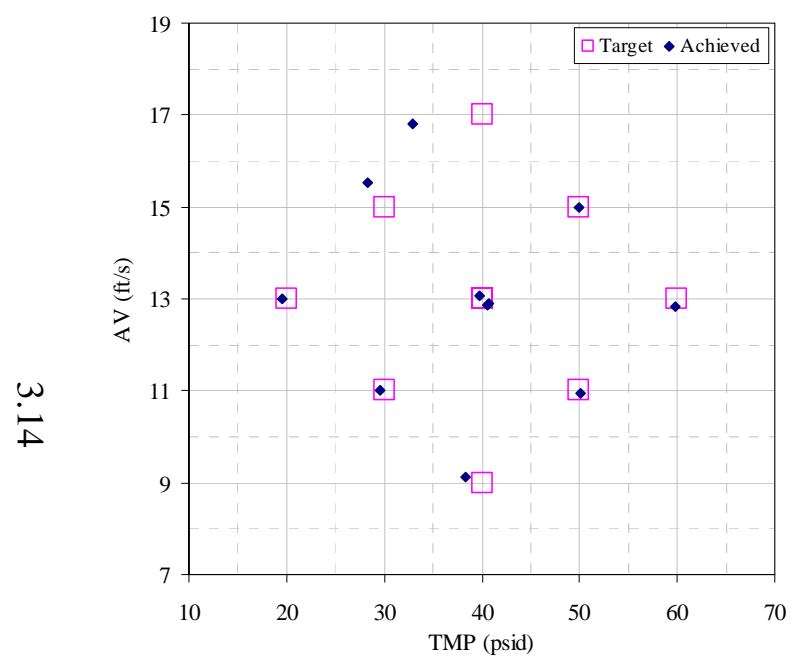

Figure 3.8. Group 5 Filter Test Matrix for Low-solids (5 wt\%)

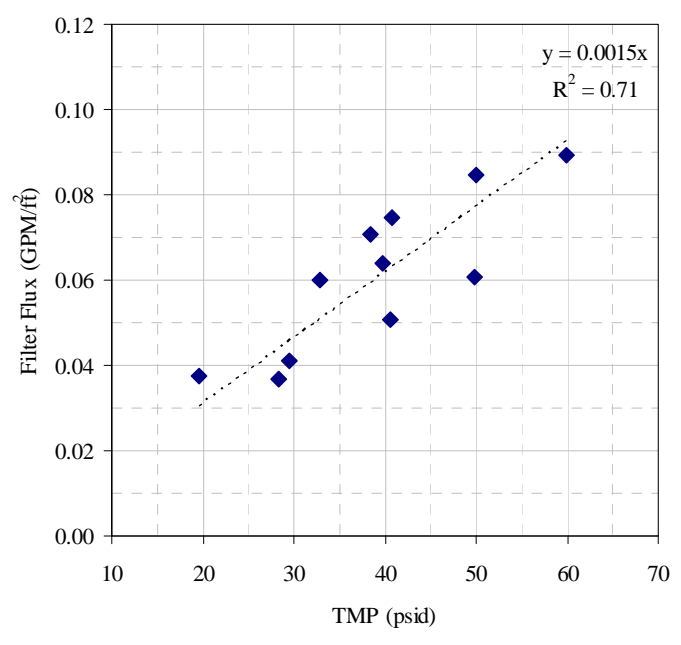

Figure 3.9. Group 5 Average Flux vs. TMP for Low-solids (5 wt\%)

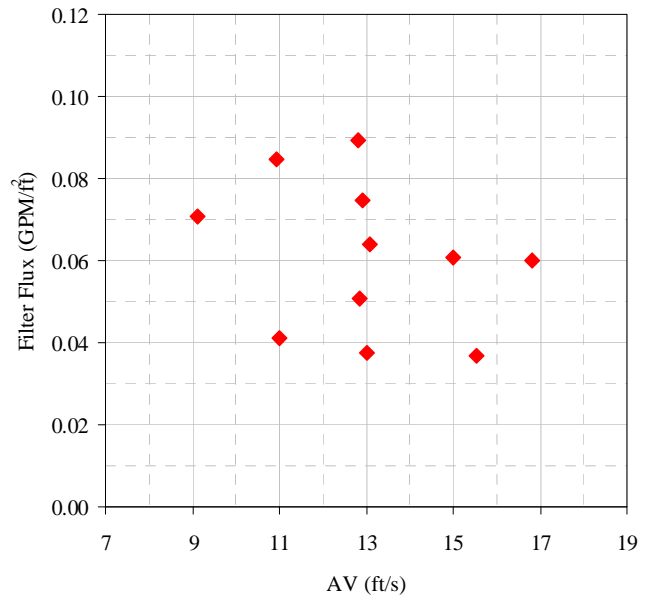

Figure 3.10. Group 5 Average Flux vs. AV for Low-solids (5 wt\%) 
WTP-RPT-172, Rev 0

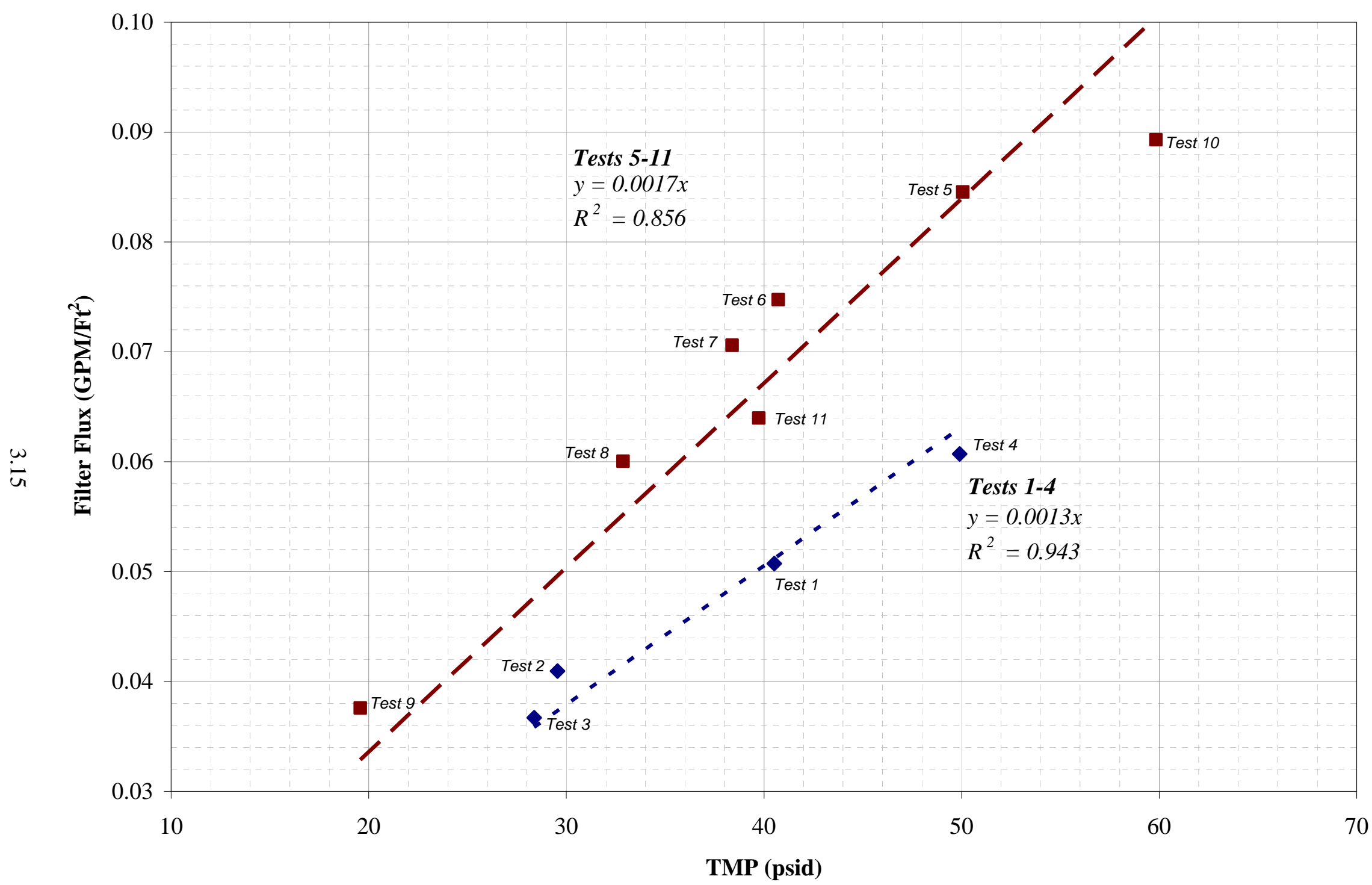

Figure 3.11. Group 5 Correlation Calculations of Average Flux as Function of TMP 


\subsubsection{Dewatering of Group 5 Waste}

After completing the low solids filtration matrix test, the slurry was to be dewatered to a UDS concentration $\sim 20 \mathrm{wt} \%$. An overview of the test activities and mass balance are shown in Figure 3.12 and Table 3.7. The dewatering was accomplished in two segments. This was done because the maximum UDS concentration achievable with the low-solids (5 wt\%) slurry was 11-12 wt\% after dewatering the slurry to the minimum operating volume. This was due to size of the slurry reservoir limiting the quantity of slurry (and solids) needed to concentrate the slurry in one step. To reach $20 \mathrm{wt} \%$ UDS inside the slurry loop, more Group 5 waste samples were added to the slurry to increase the quantity of solids. Filtered supernate was then added back to the CUF to dilute the slurry to the UDS concentration prior to waste addition (to prevent a shift in the filter flux from the addition). The waste slurry was dewatered until the circulating slurry volume was 1.6 liters, when it was estimated that the UDS of the slurry was close to $20 \mathrm{wt} \%$.

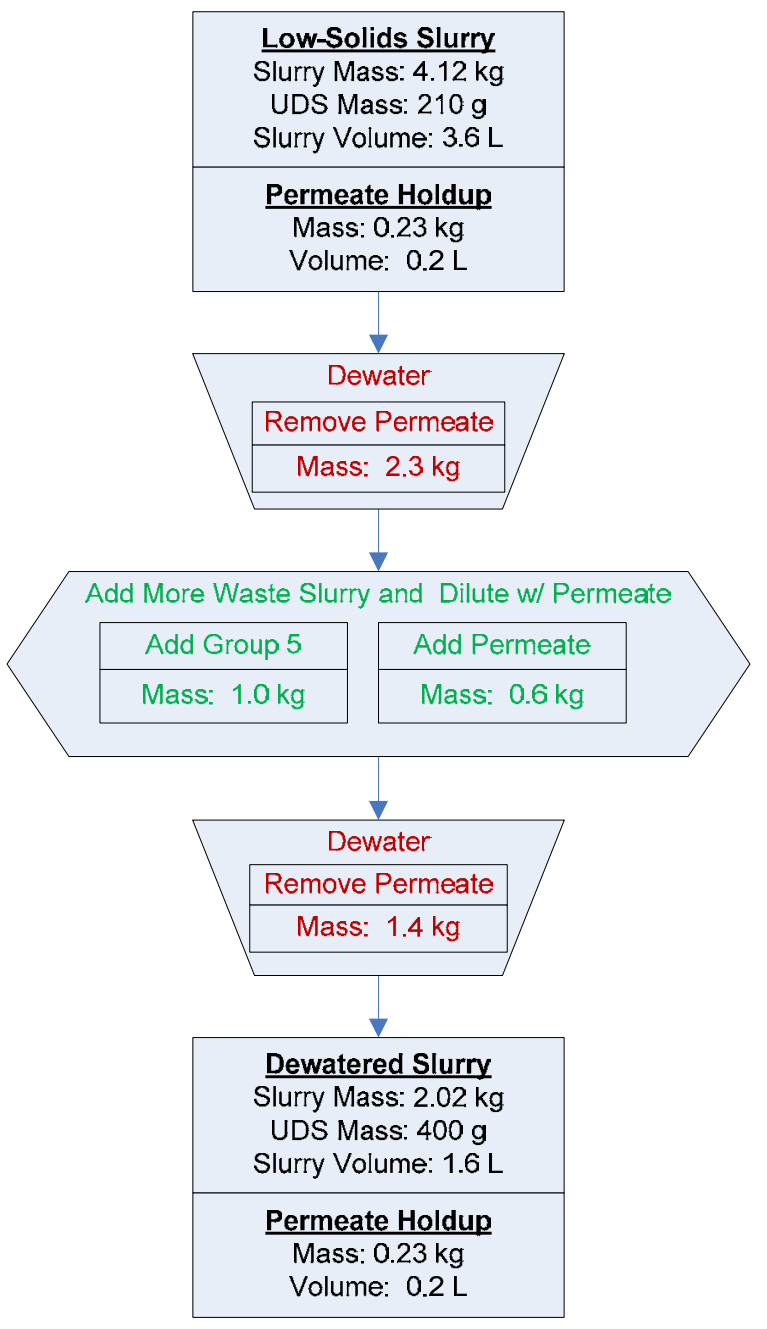

Figure 3.12. Group 5 Dewatering of Low-solids (5 wt\%) Slurry Note: Mass and volume values in figure are rounded to the nearest significant digit of accuracy. 
Table 3.7. Group 5 Mass Balance Overview of Dewatering

\begin{tabular}{|l|c|c|c|c|c|}
\hline \multicolumn{1}{|c|}{ Step } & $\begin{array}{c}\text { Change in } \\
\text { Mass } \\
\text { (g) }\end{array}$ & $\begin{array}{c}\text { Total } \\
\text { Mass } \\
\mathbf{( g )}\end{array}$ & $\begin{array}{c}\text { Estimated } \\
\text { Solid } \\
\text { Mass } \\
\mathbf{( g )}\end{array}$ & $\begin{array}{c}\text { Slurry } \\
\text { Circulating } \\
\text { Mass (g) }\end{array}$ & $\begin{array}{c}\text { Estimated } \\
\text { Slurry } \\
\text { UDS } \\
\text { (wt\%) }\end{array}$ \\
\hline $\begin{array}{l}\text { Low-solids (5 wt\%) } \\
\text { Slurry }\end{array}$ & N/A & 4350 & 210 & 4120 & $5 \%$ \\
\hline Initial dewatering & -2330 & 2020 & 210 & 1790 & $12 \%$ \\
\hline Add solids slurry & +1050 & 3070 & 400 & 2840 & $14 \%$ \\
\hline $\begin{array}{l}\text { Returned filter } \\
\text { permeate }\end{array}$ & +600 & 3680 & 400 & 3450 & $12 \%$ \\
\hline $\begin{array}{l}\text { Dewater to } \\
\text { 20 wt\% UDS }\end{array}$ & -1430 & 2250 & 400 & 2020 & $20 \%$ \\
\hline
\end{tabular}

The first dewatering segment lasted 35 minutes and $2.0 \mathrm{~L}$ of permeate were removed from the system. Two additional jars of solids-rich slurry and one previous rheology sample were added to the CUF (0.8 L). Next, $0.5 \mathrm{~L}$ of permeate from the first dewatering was returned to the CUF to dilute the slurry back to 11-12 wt\% UDS. The second dewatering segment took 23 minutes, and $1.2 \mathrm{~L}$ of permeate were removed from the system, resulting in a final slurry circulating volume of $\sim 1.6 \mathrm{~L}$.

The filter flux of both dewatering segments was analyzed as a function of the UDS concentration of the slurry, as discussed in Section 2.2.3. Because the slurry was not sampled for physical properties during the dewatering operations, the UDS concentration of the slurry was calculated throughout the process by performing a mass balance calculation using the process data from the DACS as shown in Table 3.8. Using the starting mass of the slurry and changes made to the system volume by additions of waste and permeate, changes in the slurry UDS concentration could be made by calculating the mass change of the slurry during dewatering from the permeate mass flow meter. Assuming that the permeate exiting the filter only contained the liquid portion of the slurry, the change in the UDS concentration could be calculated by dividing the solid fraction of the slurry (kept constant) by the new mass of the slurry. The mass balance calculation was validated by comparing the measured mass of permeate removed to the calculated mass. The measured relative difference was only $1 \%$.

Table 3.8. Group 5 Dewatering Mass Balance Calculation

\begin{tabular}{|l|l|}
\hline Calculated value & Description of calculation \\
\hline $\begin{array}{l}\text { Total Circulating } \\
\text { Mass }(\mathrm{g})^{(\mathrm{a})}\end{array}$ & $\begin{array}{l}\text { [Previous mass }(\mathrm{g})]- \\
\text { [Permeate flow rate }(\mathrm{mL} / \mathrm{min}) \times \text { permeate density }(\mathrm{g} / \mathrm{mL})] \times 1 \mathrm{~min}\end{array}$ \\
\hline UDS Mass $(\mathrm{g})^{(\mathrm{b})}$ & $\begin{array}{l}\text { (Mass of waste slurry added) } \times(\mathrm{wt} \% \text { UDS of samples) } \\
\text { (Constant between dewatering segments) }\end{array}$ \\
\hline Slurry wt\% UDS & UDS Mass / Total Circulating Mass \\
\hline \hline $\begin{array}{l}\text { (a) The initial circulation mass is calculated from the mass additions made to the CUF, minus the } \\
\text { hold-up mass in the permeate loop. } \\
\text { (b) The wt\% of the slurry samples are taken from the WTP-RPT-157, as } 18.4 \%\end{array}$ \\
\hline
\end{tabular}


Data from the mass balance calculation is plotted in Figure 3.13. The x-axis is the UDS concentration expressed in wt\%, plotted on a logarithmic scale. The first y-axis is the permeate flux in $\mathrm{GPM} / \mathrm{ft}^{2}$ and the second $\mathrm{y}$-axis is the axial pressure drop in psid/ft. Initially, the dewatering of the slurry appeared to be defined by the Darcy equation (Equation 2.6) with the flux rate staying fairly constant up to 8wt\% UDS. Then between 8-12 wt\% UDS, the flux increases slightly. Once the slurry reaches a UDS concentration of $12 \mathrm{wt} \%$, the flux begins to decrease and follow the relationship described in Equation 2.7. The gel concentration is predicted to be $36 \mathrm{wt} \%$ UDS, which correlates well with physical property measurements taken in the WPT-RPT-157 report that measured the Group 5 centrif $\mu$ ge UDS at $34 \mathrm{wt} \%$.

The axial pressure data across the length of the filter was included here because a sudden increase in the axial pressure drop across the filter correlates to when the Group 5 waste filter flux became dependent on the slurry UDS concentration. This indicates that change in the flow behavior of the slurry occurred at the same time which directly impacted the cake filter resistance. Also, the magnitude of the measured pressure drop ( $>7 \mathrm{pgid} / \mathrm{ft}$ ) was very large for a straight section of tubing. This was not observed during subsequent dewatering steps. 


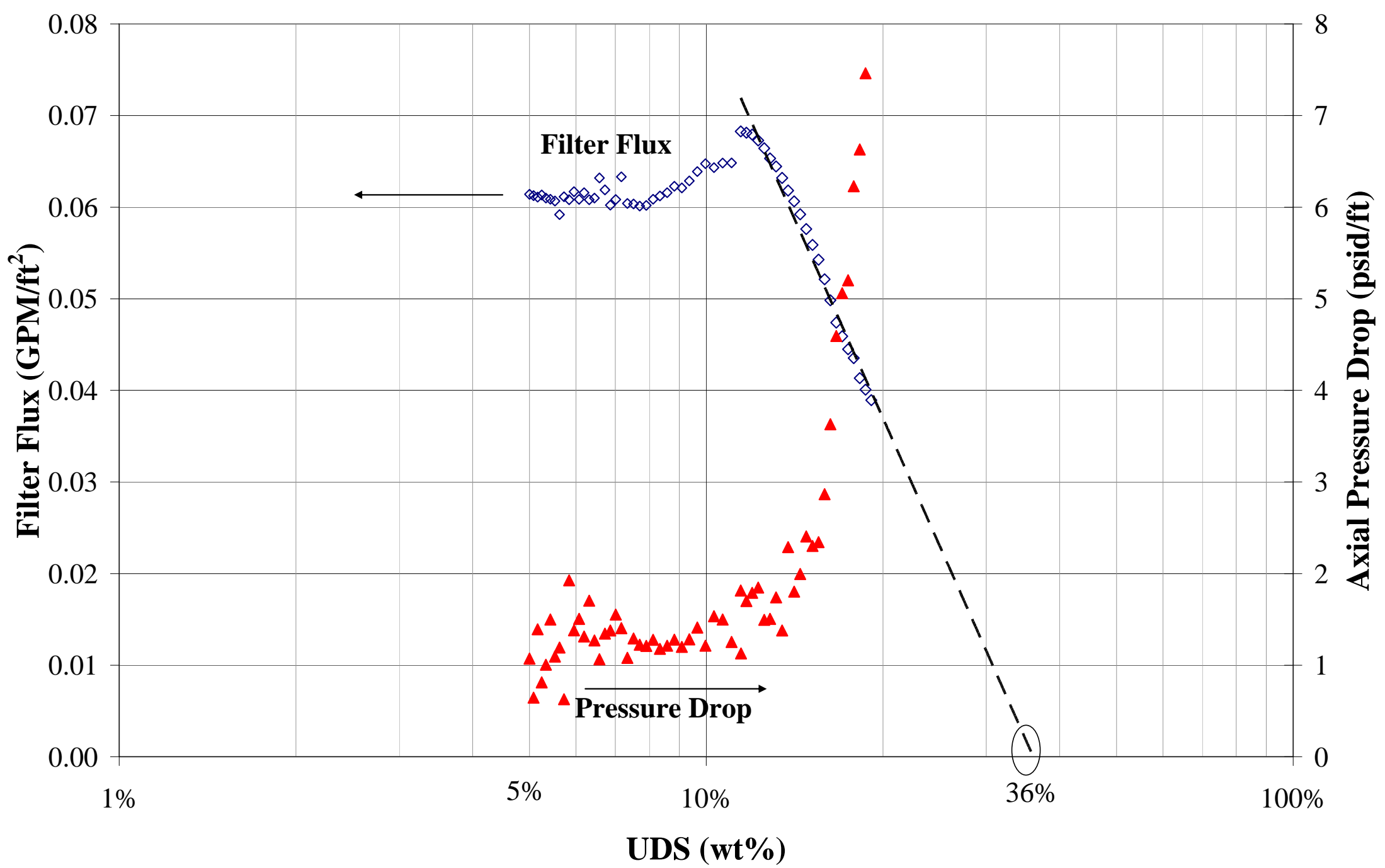

Figure 3.13. Filter Flux and Axial Pressure Drop During Dewatering of Group 5 Waste 


\subsubsection{High-Solids Matrix}

Initially, the high-solids test-matrix was performed with the $20 \mathrm{wt} \%$ UDS slurry produced from the dewatering operation described in the previous section. However, it was difficult to achieve the velocities specified in the test matrix. The test matrix was stopped when the temperature of the slurry increased to $30^{\circ} \mathrm{C}$ because the heat exchanger could not adequately dissipate the energy generated by pumping the high-viscosity slurry. Attempts were made to run the slurry at conditions where the temperature could be maintained, but it was apparent that most of the filter matrix test conditions were not going to be met. The results of the initial filtration testing performed are shown in Table 3.9. A sub-sample of the slurry in the circulation loop was taken for a rheology measurement. The shear stress of the slurry sample was measured at $>70 \mathrm{~Pa}$.

Table 3.9. Filtration Testing of Group 5 Slurry at 19 wt\% UDS

\begin{tabular}{|c|c|c|c|c|c|c|}
\hline $\begin{array}{c}\text { Design } \\
\text { Test } \\
\text { Condition }\end{array}$ & $\begin{array}{c}\text { Slurry } \\
\text { Temp }^{(a)} \\
\left({ }^{\circ} \mathrm{C}\right)\end{array}$ & $\begin{array}{c}\text { TMP }^{(\mathbf{b})} \\
\text { (psid) }\end{array}$ & $\begin{array}{c}\text { Axial } \\
\text { Velocity } \\
\text { (ft/s) }\end{array}$ & $\begin{array}{l}\text { Permeate } \\
\text { Flowrate } \\
\text { (mL/min) }\end{array}$ & $\begin{array}{l}\text { Corrected } \\
\text { Permeate } \\
\text { Flux } \\
\left(\mathrm{GPM} / \mathbf{f t}^{2}\right) \\
\end{array}$ & $\begin{array}{c}\text { Axial } \\
\text { Pressure }^{(\mathbf{b})} \\
\text { Drop }^{(\mathbf{b})} \\
\text { (psid/ft) }^{\text {prid }}\end{array}$ \\
\hline 1 & 31.1 & 38.1 & 12.0 & 47.9 & 0.041 & 10.2 \\
\hline 2 & 24.9 & 19.9 & 13.0 & 25.9 & 0.026 & 6.2 \\
\hline 3 & 24.9 & 40.3 & 6.8 & 30.4 & 0.031 & 10.2 \\
\hline
\end{tabular}

With the concurrence of BNI, $490 \mathrm{~mL}$ of permeate was returned to the tank, decreasing the wt\% UDS to $15 \mathrm{wt} \%$ (Figure 3.14). The shear stress of this concentration slurry was estimated at 30 to $40 \mathrm{~Pa}$ based on previous measurements. However, the rheology measurements conducted after the high-solids matrix (G5-R2) confirm that the shear stress of the slurry was 50 to $70 \mathrm{~Pa}$. Note that this measured shear stress was beyond the upper bound of the WTP design. 


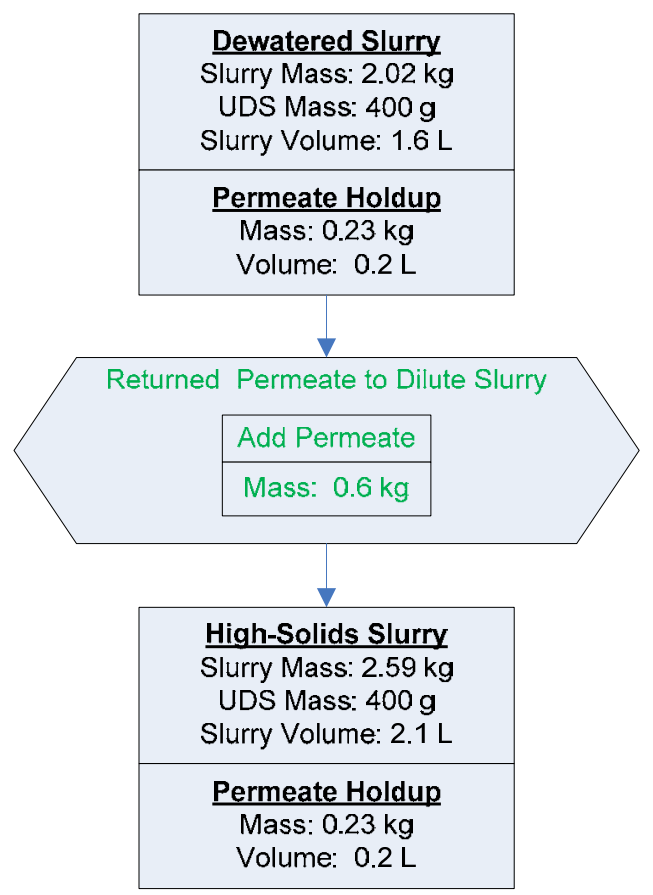

Figure 3.14. Group 5 Dilution of Dewatered Slurry for High-Solid (15 wt\%) Matrix Note: Mass and volume values in figure are rounded to the nearest significant digit of accuracy.

Once the slurry was diluted to an operational working concentration, the high-solids matrix test was started again. Figure 3.15 displays the complete permeate flux data for each step with respect to time. The flux ranged from 0.040 to $0.096 \mathrm{GPM} / \mathrm{ft}^{2}$, with a value near $0.060 \mathrm{GPM} / \mathrm{ft}^{2}$ for the standard filtration condition of $\mathrm{TMP}=40 \mathrm{psid}$ and $\mathrm{AV}=13 \mathrm{ft} / \mathrm{s}$. It was somewhat surprising that the filter flux values were comparable to the low-solids (5 wt\%) matrix.

Table 3.10 contains the average operating conditions and filter flux for each step of the high-solids matrix. For the high solids matrix, it was expected to see the filter flux deviate from the Darcy equation and show the filter flux being more dependent on axial velocity. Evidence that the high-solids matrix was operated in a transition area can be seen in the relative dependence of flux with TMP and AV. The flux is proportional to both TMP and AV, but clearly more dependent on AV, as might be expected of highsolids slurry. There is an imprint of the experimental design on the TMP chart (Figure 3.17), but noticeable correlation at the extremes of pressure. The same imprint is not particularly evident on the AV chart (Figure 3.18).

As before, modeling of the data using a least square fit method was then used to quantify the effects of TMP and AV on filter flux. The data was first fitted against a linear model of TMP and AV as shown in Figure 3.19, resulting in $\mathrm{R}^{2}$ correlation coefficients of 0.88 . The model shows that the impact of AV to be a magnitude higher than TMP when comparing the parameter coefficients. A change in the AV of $1 \mathrm{ft} / \mathrm{s}$ is predicted to be equivalent to a 6 psid change in the TMP. While the $\mathrm{R}^{2}$ correlation coefficient was relatively high, applying this model should be limited to the range of the inputs used to develop it in Table 3.10. The model contains a negative offset value, which predicts a negative flux when TMP and AV are at zero. This implies that the behavior demonstrated here is more complex than is being 
demonstrated in this model. For this reason, this model should not be used to predict filter flux outside the range of TMP and AV in this test matrix.

The data was then fitted against an exponential model of TMP and AV, with the results shown in Figure 3.20. The model showed the flux to be proportionate to the product of AV and the square root of the TMP, resulting in a $\mathrm{R}^{2}$ correlation coefficient of 0.90 . This model confirms the previous analysis that shows filter flux being linearly proportional to the TMP. However, changes in the AV have a much greater impact on the filter flux, with the filter flux being linearly proportional to AV squared. This model predicted that a $10 \%$ increase in the AV was equivalent to a $21 \%$ increase to TMP. While this model does not contain an offset parameter like the linear model, it is not clear if filter flux can be predicted using TMP and AV values outside the range of the test matrix provided in Table 3.10. Without additional experimental data to confirm how the filter flux changes for the waste at this concentration, the use of this model should be limited to the bounding conditions of the test matrix.

Table 3.10. Average Operating Conditions and Permeate Flux for High-solids (15 wt\%) Matrix Test

\begin{tabular}{|c|c|c|c|c|c|c|}
\hline $\begin{array}{c}\text { Design } \\
\text { Test } \\
\text { Condition } \\
\end{array}$ & $\begin{array}{c}\text { Slurry } \\
\text { Temp }\left({ }^{\circ} \mathrm{C}\right)\end{array}$ & TMP (psid) & $\begin{array}{c}\text { Axial } \\
\text { Velocity } \\
\text { (ft/s) }\end{array}$ & $\begin{array}{l}\text { Permeate } \\
\text { Flowrate } \\
\text { (mL/min) }\end{array}$ & $\begin{array}{c}\text { Corrected } \\
\text { Permeate } \\
\text { Flux } \\
\left(\text { GPM/ft }{ }^{2}\right)\end{array}$ & $\begin{array}{c}\text { Axial } \\
\text { Pressure } \\
\text { Drop } \\
\text { (psid/ft) }\end{array}$ \\
\hline 1 & 22.5 & 40.9 & 12.9 & 58.9 & 0.064 & 2.7 \\
\hline 2 & 21.7 & 31.5 & 11.0 & 43.9 & 0.049 & 3.9 \\
\hline 3 & 24.1 & 30.4 & 15.1 & 68.6 & 0.071 & 3.0 \\
\hline 4 & 25.4 & 51.5 & 15.4 & 95.8 & 0.096 & 3.5 \\
\hline 5 & 24.6 & 49.7 & 10.8 & 52.7 & 0.054 & 4.9 \\
\hline 6 & 22.0 & 40.4 & 12.8 & 59.2 & 0.065 & 3.0 \\
\hline 7 & 22.9 & 40.0 & 8.9 & 42.5 & 0.046 & 5.1 \\
\hline 8 & 24.2 & 39.6 & 17.2 & 75.3 & 0.078 & 2.9 \\
\hline 9 & 22.7 & 19.9 & 12.7 & 36.9 & 0.040 & 4.8 \\
\hline 10 & 25.4 & 57.3 & 12.9 & 72.5 & 0.072 & 3.5 \\
\hline 11 & 20.0 & 40.0 & 13.0 & 51.1 & 0.059 & 2.9 \\
\hline \multicolumn{7}{|c|}{$\begin{array}{l}\text { (a) Thermocouple accuracy } \pm 2^{\circ} \mathrm{C} \text {. } \\
\text { (b) Pressure transducer accuracy } \pm 1 \text { psig. }\end{array}$} \\
\hline
\end{tabular}


WPT-RPT-172, Rev 0

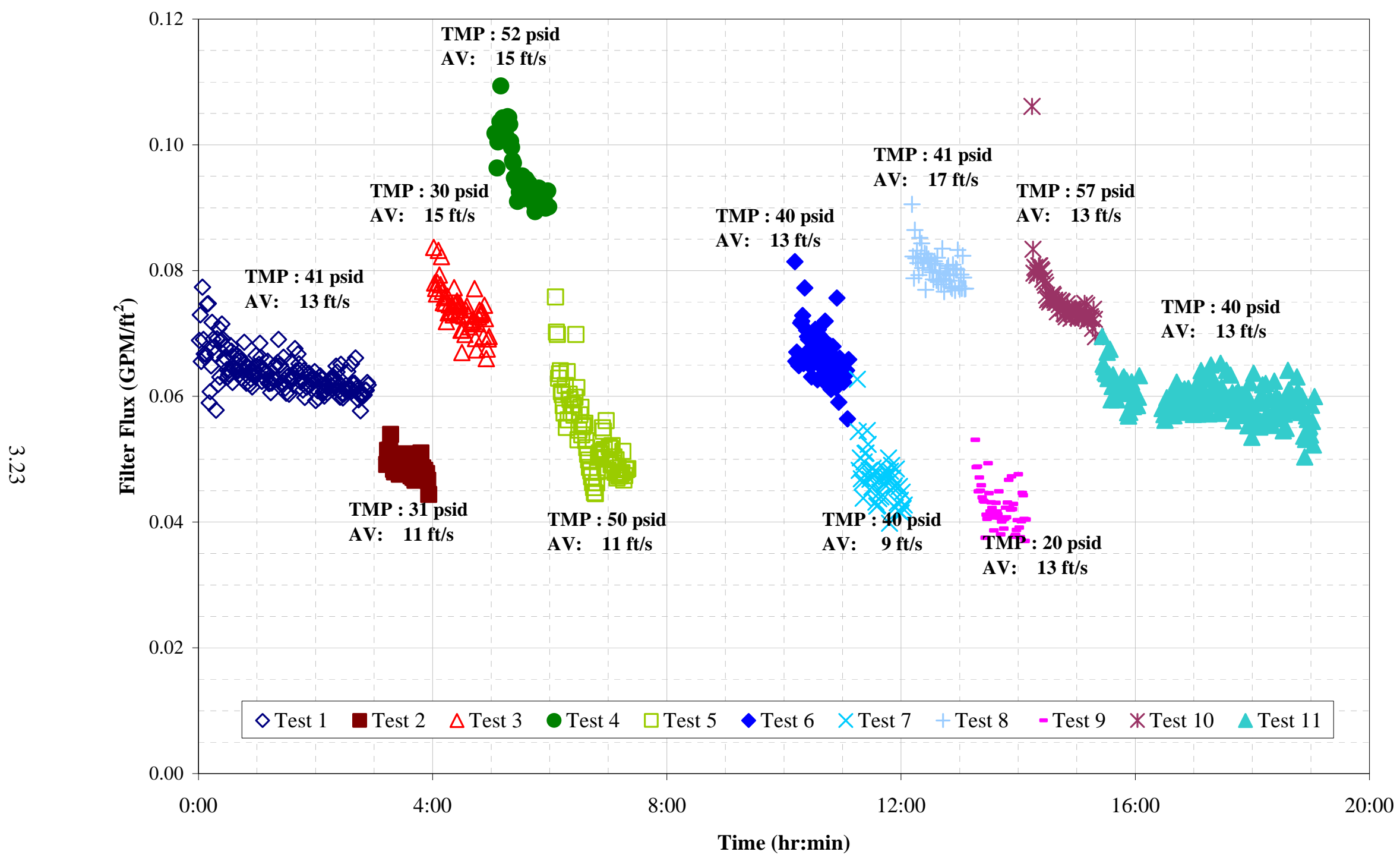

Figure 3.15. Group 5 Filter Flux Data at 15 wt\% UDS. 


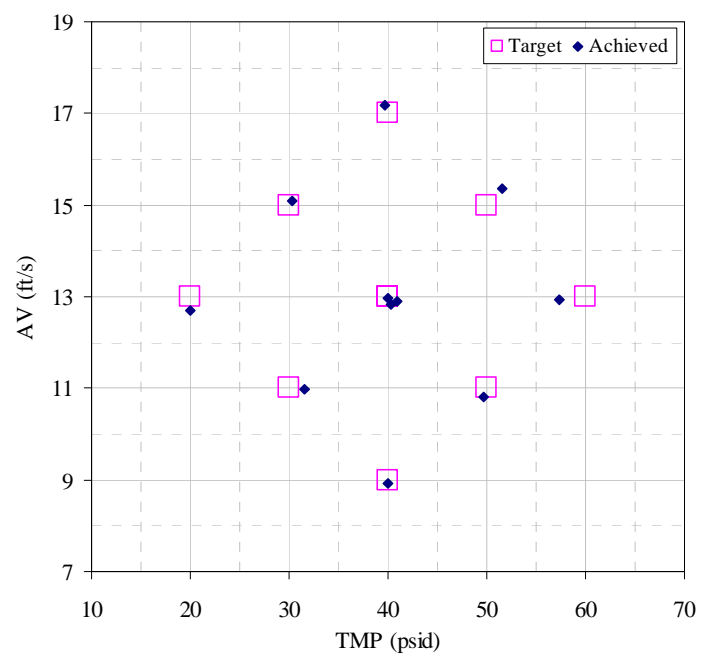

$\underset{\perp}{\perp}$

Figure 3.16. Group 5 Filter Test Matrix for High-solids (15 wt\%)

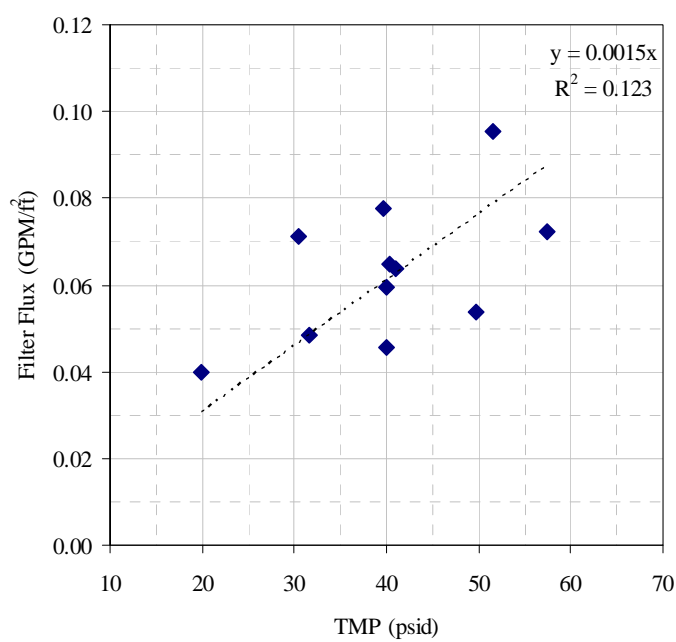

Figure 3.17. Group 5Average Flux vs. TMP for High-Solids (15 wt\%)

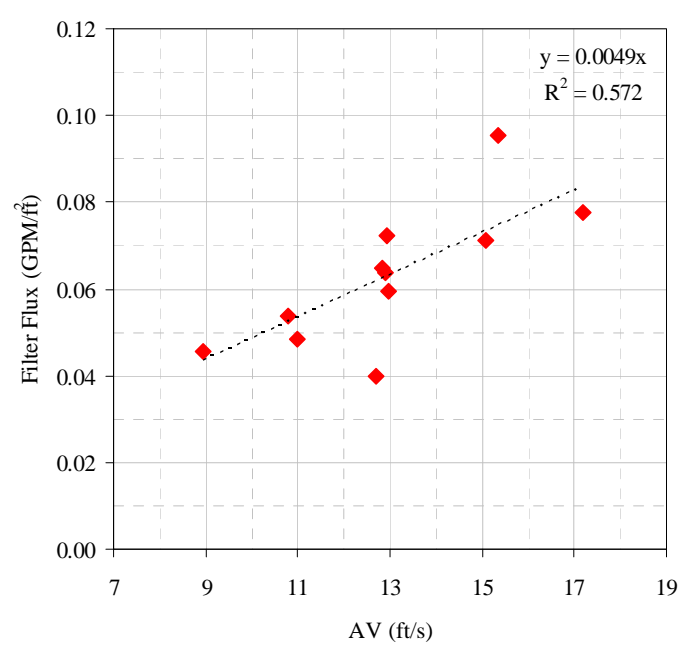

Figure 3.18. Group 5 Average Flux vs. AV for High-Solids (15 wt\%) 
WPT-RPT-172, Rev 0

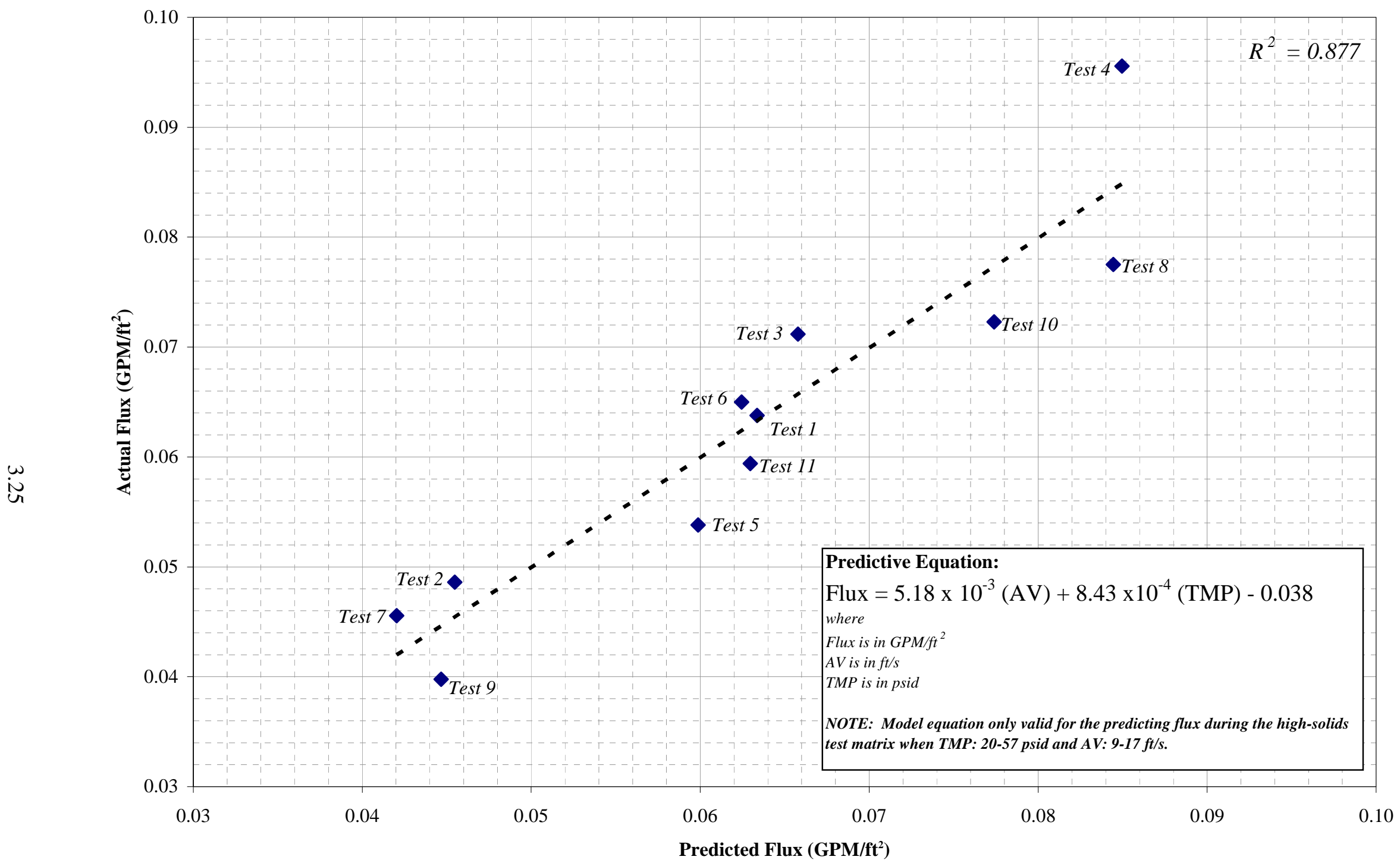

Figure 3.19. Group 5 Least Square Fit to High-Solid (15 wt\%) Matrix Test Results to Linear Model 
WPT-RPT-172, Rev 0

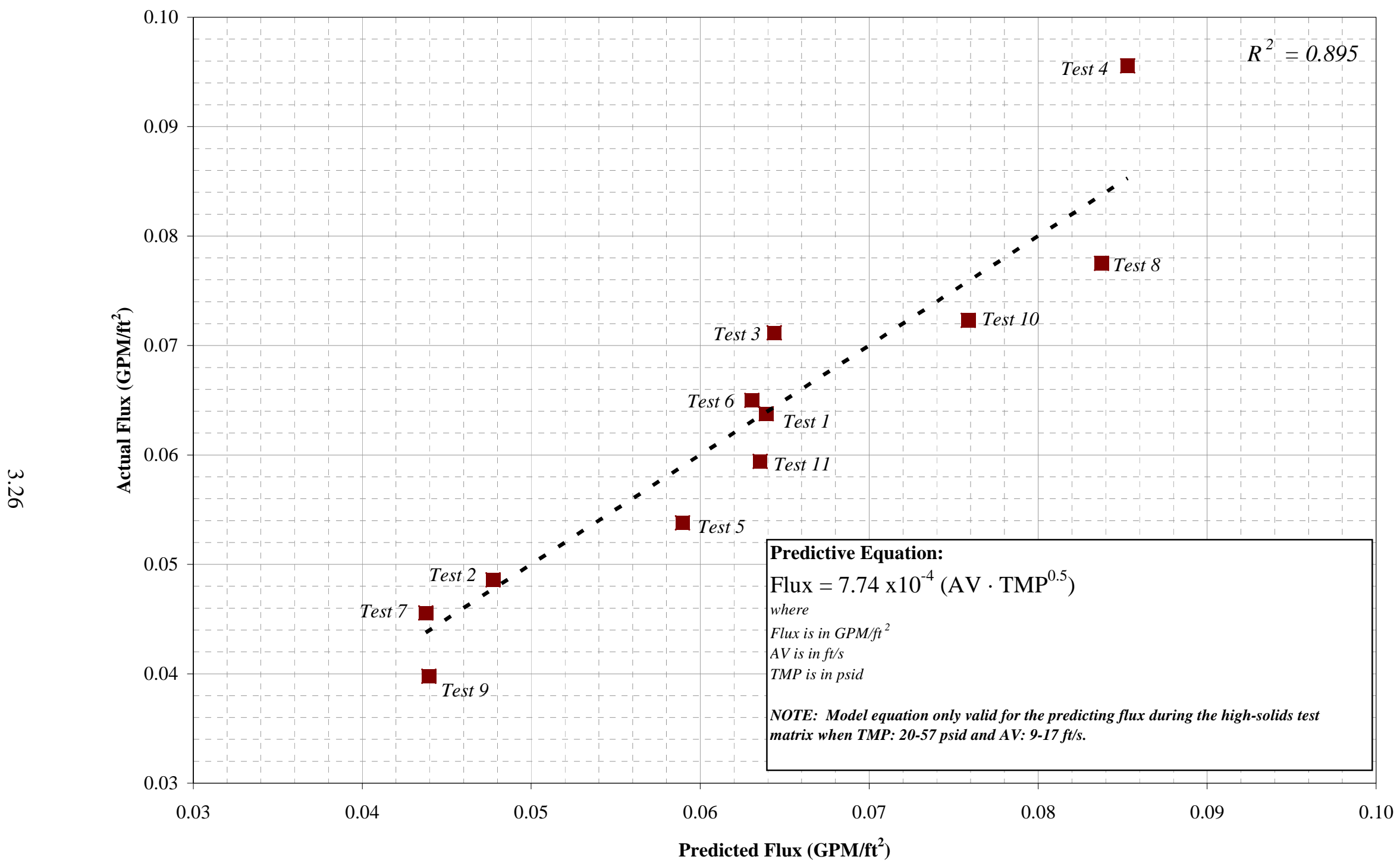

Figure 3.20. Least Square Fit to High-Solid (15 wt\%) Matrix Test Results to Exponential Model 


\subsection{High-Solids (15 wt\%) Slurry Characterization}

At the completion of the high-solids test matrix, the slurry in the recirculation loop was sampled for physical and chemical analysis (Figure 3.21). Physical-property measurements of the slurry samples are shown below in Table 3.11. Note that the measured UDS does not agree well with the predicted UDS values. This is attributed to the significant difficulty in obtaining representative UDS measurements in the Hot Cell environment. The high-solids slurry composition (including permeate hold-up) before caustic leaching based on mass balance calculations is shown in Table 3.12. A slurry sample was also sent for chemical and radiochemical analysis. The dried slurry composition of the sample, along with composition of the supernate and UDS of the slurry, are provided in Table 3.13.

Comparison of the low-solids (5 wt\%) slurry to the high-solids (15 wt\%) slurry shows there is an overall decrease in the $\mathrm{Cr}$ content from the low solids to the high solids. According to the initial characterization of the Group 5 wastes (WTP-RPT-157), 70\% of the chromium was soluble in the slurry supernate. This explains the decrease of total chromium, as it exited the slurry via the dewatering of the supernate. The phosphorus continues to remain as phosphate and largely in the slurry supernate. There was $130 \mathrm{~g}$ of aluminum in the high-solids matrix. According to initial characterization (WTP-RPT-157), the gibbsite/boehmite ratio of Group 5 solids is $0.07: 1$. Therefore, over $90 \%$ of the Group 5 high solids/preleached material is boehmite.

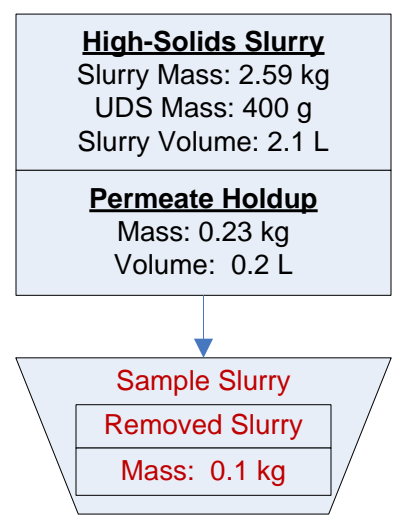

Figure 3.21. Group 5 Sampling of High-Solids (15 wt\%) Matrix

Note: Mass and volume values in figure are rounded to the nearest significant digit of accuracy.

Table 3.11. Group 5 High-Solids (15 wt\%) Slurry Physical Property Measurements (inside slurry loop)

\begin{tabular}{|r|c||}
\hline Slurry Density (g/mL) & 1.24 \\
\hline Supernate Density (g/mL) & 1.13 \\
\hline Settled Solids (Vol \%) & $90 \%$ \\
\hline Centrifuged UDS (Wt $\%)$ & $27 \%$ \\
\hline Total Solids of the Slurry $\mathbf{( W t} \%)$ & $33 \%$ \\
\hline Dissolved Solids of the Supernate $\mathbf{( W t} \%)$ & $21 \%$ \\
\hline UDS of the Slurry $\mathbf{( W t} \%)$ & $16 \%$ \\
\hline
\end{tabular}


Table 3.12. Group 5 High-Solids (15 wt\%) Slurry Composition and total inventory (including permeate hold-up)

\begin{tabular}{|c|c|c|c|c|c|}
\hline & Slurry $^{(a)}$ & \multicolumn{2}{|c|}{ Liquid Fraction $^{(b)}$} & \multicolumn{2}{|c|}{ Solids Fraction $^{(\mathrm{c})}$} \\
\hline Mass (kg) & 2.82 & \multicolumn{2}{|c|}{2.41} & \multicolumn{2}{|c|}{0.41} \\
\hline Wt\% of Slurry & $100 \%$ & \multicolumn{2}{|c|}{$85.5 \%$} & \multicolumn{2}{|c|}{$14.5 \%$} \\
\hline Metal & g & g & $\mu \mathrm{g} / \mathrm{mL}$ & g & $\mu g / g$ \\
\hline Al & $1.3 \mathrm{E}+02$ & $4.2 \mathrm{E}+00$ & $2.1 \mathrm{E}+03$ & $1.3 \mathrm{E}+02$ & $3.3 \mathrm{E}+05$ \\
\hline Ca & 4.2E-01 & $6.1 \mathrm{E}-02$ & $3.0 \mathrm{E}+01$ & 3.6E-01 & $9.2 \mathrm{E}+02$ \\
\hline $\mathrm{Cr}$ & $3.5 \mathrm{E}+00$ & $2.5 \mathrm{E}+00$ & $1.2 \mathrm{E}+03$ & $1.0 \mathrm{E}+00$ & $2.6 \mathrm{E}+03$ \\
\hline $\mathbf{F e}$ & $2.6 \mathrm{E}+00$ & $<4 . \mathrm{E}-3$ & $<2 . \mathrm{E}+0$ & $2.6 \mathrm{E}+00$ & $6.6 \mathrm{E}+03$ \\
\hline Mn & $1.7 \mathrm{E}+00$ & $<4 . \mathrm{E}-4$ & $<2$.E-1 & $1.7 \mathrm{E}+00$ & $4.4 \mathrm{E}+03$ \\
\hline $\mathrm{Na}$ & $1.9 \mathrm{E}+02$ & $1.5 \mathrm{E}+02$ & $7.2 \mathrm{E}+04$ & $3.8 \mathrm{E}+01$ & $9.8 \mathrm{E}+04$ \\
\hline $\mathbf{P}$ & 8.9E-01 & 7.2E-01 & $3.5 \mathrm{E}+02$ & 1.7E-01 & $4.4 \mathrm{E}+02$ \\
\hline Si & $3.4 \mathrm{E}+00$ & 5.7E-02 & $2.8 \mathrm{E}+01$ & $3.4 \mathrm{E}+00$ & $8.6 \mathrm{E}+03$ \\
\hline $\mathbf{U}$ & $7.8 \mathrm{E}+03$ & $<2 . \mathrm{E}-2$ & $<8 . \mathrm{E}+0$ & $7.8 \mathrm{E}+03$ & $2.0 \mathrm{E}+07$ \\
\hline \multirow{2}{*}{$\begin{array}{l}\text { Radiochemical } \\
\text { Isotopes }\end{array}$} & Slurry & \multicolumn{2}{|c|}{ Liquid Fraction } & \multicolumn{2}{|c|}{ Solid Fraction } \\
\hline & $\mathrm{mCi}$ & $\mathrm{mCi}$ & $\mathrm{mCi} / \mathrm{mL}$ & $\mathrm{mCi}$ & $\mathrm{mCi} / \mathrm{g}$ \\
\hline Co-60 & $3.2 \mathrm{E}+00$ & $<2$.E-1 & $<8$. E-5 & $3.2 \mathrm{E}+00$ & $8.1 \mathrm{E}-03$ \\
\hline Cs-137 & $4.8 \mathrm{E}+04$ & $3.4 \mathrm{E}+04$ & $1.7 \mathrm{E}+01$ & $1.4 \mathrm{E}+04$ & $3.7 \mathrm{E}+01$ \\
\hline Eu-154 & $4.8 \mathrm{E}+01$ & $<1 . \mathrm{E}+0$ & $<6 . \mathrm{E}-4$ & $4.8 \mathrm{E}+01$ & $1.2 \mathrm{E}-01$ \\
\hline Am-241 & $1.2 \mathrm{E}+02$ & $<1 . \mathrm{E}+1$ & $<7$. E-3 & $1.2 \mathrm{E}+02$ & $3.1 \mathrm{E}-01$ \\
\hline Gross Alpha & $3.3 \mathrm{E}+02$ & $<2$.E+1 & $<8$. E-3 & $3.3 \mathrm{E}+02$ & 8.5E-01 \\
\hline Gross Beta & $6.3 \mathrm{E}+05$ & $2.8 \mathrm{E}+04$ & $1.4 \mathrm{E}+01$ & $6.0 \mathrm{E}+05$ & $1.5 \mathrm{E}+03$ \\
\hline Sr-90 & $2.6 \mathrm{E}+05$ & $2.7 \mathrm{E}+01$ & 1.3E-02 & $2.6 \mathrm{E}+05$ & $6.6 \mathrm{E}+02$ \\
\hline $\mathrm{Pu}-239+240$ & $3.4 \mathrm{E}+02$ & 4.3E-02 & $2.1 \mathrm{E}-05$ & $3.4 \mathrm{E}+02$ & 8.7E-01 \\
\hline Pu-238 & $8.8 \mathrm{E}+00$ & $<5 . \mathrm{E}-3$ & $<2$.E-6 & $8.8 \mathrm{E}+00$ & 2.3E-02 \\
\hline \multirow[t]{2}{*}{ Anions } & \multicolumn{3}{|c|}{ Liquid Fraction } & & \\
\hline & $\mu \mathrm{g} / \mathrm{mL}$ & [M] & g & & \\
\hline $\mathbf{F}$ & $2.3 \mathrm{E}+01$ & $1.2 \mathrm{E}-03$ & 4.6E-02 & & \\
\hline $\mathrm{C}_{2} \mathrm{O}_{4}$ & $1.1 \mathrm{E}+03$ & 1.3E-02 & $2.3 \mathrm{E}+00$ & & \\
\hline $\mathrm{NO}_{2}$ & $2.7 \mathrm{E}+04$ & $5.8 \mathrm{E}-01$ & $5.3 \mathrm{E}+01$ & & \\
\hline $\mathrm{NO}_{3}$ & $9.5 \mathrm{E}+04$ & $1.5 \mathrm{E}+00$ & $1.9 \mathrm{E}+02$ & & \\
\hline $\mathrm{SO}_{4}$ & $7.0 \mathrm{E}+02$ & 7.3E-03 & $1.4 \mathrm{E}+00$ & & \\
\hline $\mathrm{PO}_{4}$ & $1.2 \mathrm{E}+03$ & $1.2 \mathrm{E}-02$ & $2.3 \mathrm{E}+00$ & & \\
\hline $\mathbf{O H}$ & $2.6 \mathrm{E}+03$ & $1.6 \mathrm{E}-01$ & $5.3 \mathrm{E}+00$ & & \\
\hline \multicolumn{6}{|c|}{$\begin{array}{l}\text { (d) Slurry Mass components were calculated from characterization data (WPT-RPT-157), and the } \\
\text { masses of materials that were added with simulant. Loss of mass from sampling was incorporated } \\
\text { (e) Liquid Fraction mass components were calculated using analytical results from supernate sample } \\
\text { TI540-G5-A (ASO ID 07-01779) and the predicted mass of supernate in the system. } \\
\text { (f) Solids Fraction mass components were calculated from the difference between the slurry } \\
\text { component mass and liquid component mass fraction. }\end{array}$} \\
\hline
\end{tabular}


Table 3.13. Group 5 High-Solids Slurry Composition Based on ICP-OES/Radionuclide Characterization

\begin{tabular}{|c|c|c|c|c|}
\hline $\begin{array}{c}\text { Slurry Prep } \\
\text { Method }\end{array}$ & $\begin{array}{c}\text { ICP-OES } \\
\text { Analytes } \\
\end{array}$ & $\begin{array}{c}\text { Dry Slurry } \\
(\mu \mathrm{g} / \mathrm{g})\end{array}$ & $\begin{array}{c}\text { Supernate }^{(b)} \\
(\mu \mathrm{g} / \mathrm{mL})\end{array}$ & $\begin{array}{c}\text { Dry Solids } \\
(\mu g / g)\end{array}$ \\
\hline \multirow{30}{*}{ 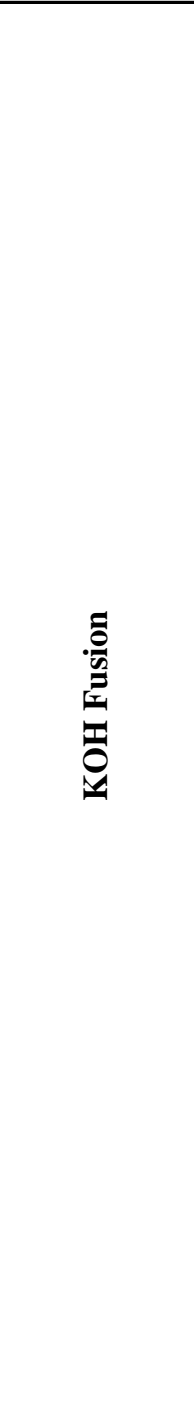 } & Al & 183,667 & 2,050 & 395,011 \\
\hline & B & [107] & 25.0 & [111] \\
\hline & $\mathbf{B i}$ & $<1.4 \mathrm{E}+2$ & $<2.3 \mathrm{E}+0$ & $<3.0 \mathrm{E}+2$ \\
\hline & $\mathrm{Cr}$ & 3,693 & 1,210 & 2,082 \\
\hline & $\mathbf{F e}$ & 6,073 & $<2.1 \mathrm{E}+0$ & 13,391 \\
\hline & Mn & 2,587 & $<2.1 \mathrm{E}-1$ & 5,707 \\
\hline & $\mathrm{Na}$ & 166,000 & 72,400 & 3,239 \\
\hline & $S$ & [692] & [240] & [324] \\
\hline & Si & 5,250 & 27.6 & 11,447 \\
\hline & $\mathrm{Sr}$ & 677 & $<1.7 \mathrm{E}-2$ & 1,493 \\
\hline & $\mathbf{U}$ & {$[8,733]$} & $<8.4 \mathrm{E}+0$ & {$[19,229]$} \\
\hline & Zn & $<4.8 \mathrm{E}+1$ & [4.8] & $<8.1 \mathrm{E}+1$ \\
\hline & $\mathrm{Zr}$ & $<5.5 \mathrm{E}+1$ & $<8.2 \mathrm{E}-1$ & $<1.2 \mathrm{E}+2$ \\
\hline & $B a$ & [72] & [0.39] & [158] \\
\hline & $B e$ & $<9.1 \mathrm{E}-1$ & [0.040] & $<1.8 \mathrm{E}+0$ \\
\hline & $\mathrm{Ca}$ & $<2.9 \mathrm{E}+3$ & 29.5 & $<6.2 \mathrm{E}+3$ \\
\hline & $\mathrm{Ce}$ & $<1.9 \mathrm{E}+2$ & $<1.2 \mathrm{E}+0$ & $<4.1 \mathrm{E}+2$ \\
\hline & Co & $<2.0 \mathrm{E}+1$ & $<3.9 \mathrm{E}-1$ & $<4.1 \mathrm{E}+1$ \\
\hline & $\mathrm{Cu}$ & [28] & $<4.9 \mathrm{E}-1$ & [58] \\
\hline & $E \boldsymbol{E u}$ & $<1.6 \mathrm{E}+1$ & $<1.1 \mathrm{E}-1$ & $<3.4 \mathrm{E}+1$ \\
\hline & $L a$ & $<1.0 \mathrm{E}+1$ & $<1.3 \mathrm{E}-1$ & $<2.2 \mathrm{E}+1$ \\
\hline & $\mathrm{Li}$ & $<3.0 \mathrm{E}+1$ & $<5.5 \mathrm{E}-1$ & $<6.4 \mathrm{E}+1$ \\
\hline & $M g$ & [150] & [4.8] & [307] \\
\hline & Mo & $<2.8 \mathrm{E}+1$ & {$[6.1]$} & $<3.1 \mathrm{E}+1$ \\
\hline & $N d$ & $<2.9 \mathrm{E}+2$ & $<1.7 \mathrm{E}+0$ & $<6.4 \mathrm{E}+2$ \\
\hline & $\boldsymbol{P}$ & [780] & 350 & $-[34]$ \\
\hline & Se & $<2.7 \mathrm{E}+2$ & [6.7] & $<5.7 \mathrm{E}+2$ \\
\hline & Sn & $<2.6 \mathrm{E}+2$ & [2.5] & $<5.5 \mathrm{E}+2$ \\
\hline & $T i$ & $<2.6 \mathrm{E}+1$ & $<9.7 \mathrm{E}-2$ & $<5.6 \mathrm{E}+1$ \\
\hline & $V$ & $<1.3 \mathrm{E}+1$ & $<3.2 \mathrm{E}-1$ & $<2.7 \mathrm{E}+1$ \\
\hline
\end{tabular}


WPT-RPT-172, Rev 0

Table 3.13 (Contd)

\begin{tabular}{|c|c|c|c|c|}
\hline $\begin{array}{c}\begin{array}{c}\text { Slurry Prep } \\
\text { Method }\end{array} \\
\end{array}$ & Radionuclides & $\begin{array}{c}\begin{array}{c}\text { Dry Slurry } \\
(\mu \mathrm{a}) \\
(\mu \mathrm{Ci} / \mathrm{g})\end{array} \\
\end{array}$ & $\begin{array}{c}\text { Supernate }^{(b)} \\
(\mu \mathrm{Ci} / \mathrm{mL})\end{array}$ & $\begin{array}{c}\begin{array}{c}\text { Dry Solids } \\
(\mathrm{c})\end{array} \\
(\mu \mathrm{Ci} / \mathrm{g})\end{array}$ \\
\hline \multirow[t]{11}{*}{ KOH Fusion } & Co-60 & $4.99 \mathrm{E}-2$ & $<8 . \mathrm{E}-5$ & $1.1 \mathrm{E}-1$ \\
\hline & Cs-137 & $5.62 \mathrm{E}+1$ & $1.66 \mathrm{E}+1$ & $4.1 \mathrm{E}+1$ \\
\hline & Eu-154 & $5.29 \mathrm{E}-2$ & $<6 . \mathrm{E}-4$ & $1.1 \mathrm{E}-1$ \\
\hline & Am-241 & $1.61 \mathrm{E}-1$ & $<7 . \mathrm{E}-3$ & $3.2 \mathrm{E}-1$ \\
\hline & Total alpha & $7.07 \mathrm{E}-1$ & $<8 . E-3$ & $1.5 \mathrm{E}+0$ \\
\hline & Total beta & $7.64 \mathrm{E}+2$ & $1.35 \mathrm{E}+1$ & $1.6 \mathrm{E}+3$ \\
\hline & Sr-90 & $3.43 \mathrm{E}+2$ & $1.33 \mathrm{E}-2$ & $7.6 \mathrm{E}+2$ \\
\hline & Pu-239/240 & 4.53E-1 & $2.07 \mathrm{E}-5$ & $1.0 \mathrm{E}+0$ \\
\hline & Pu-238 & $1.17 \mathrm{E}-2$ & $<2 . E-6$ & $2.6 \mathrm{E}-2$ \\
\hline & KPA & $(\mu \mathrm{g} / \mathrm{g})$ & $(\mu \mathrm{g} / \mathrm{mL})$ & $(\mu \mathrm{g} / \mathrm{g})$ \\
\hline & $\mathbf{U}$ & $1.24 \mathrm{E}+4$ & $1.12 \mathrm{E}+0$ & $2.7 \mathrm{E}+4$ \\
\hline $\begin{array}{r}\text { (a) Test s } \\
\text { (b) Test s } \\
\text { (c) Calcu } \\
\text { Note: Analyte } \\
\text { but < EQL, wit }\end{array}$ & $\begin{array}{l}\text { mple TI540-G5- } \\
\text { mple TI540-G5-7 } \\
\text { ted using results } \\
\text { n italics were me } \\
\text { errors likely to e }\end{array}$ & $\begin{array}{l}\text { ASO ID 07-017 } \\
\&-8, \text { ASO ID } 0 \\
\text { rom TI540-G5-A } \\
\text { sured opportuni } \\
\text { ceed } 15 \% \text {. }\end{array}$ & $\begin{array}{l}783 \text { \& } 07-0178 \\
\text { d TI540-G5-7 } \\
\text { ally. Values in }\end{array}$ & $\mathrm{s}$ [ ] are $\geq \mathrm{MDL}$ \\
\hline
\end{tabular}

Figure 3.22 shows the pre-sonic PSD for the high-solids sample as a function of pump speed. As with the previous Group 5 samples, the distribution is broad, spanning 0.2 to $200 \mu \mathrm{m}$, with a peak population at around $2 \mu \mathrm{m}$. The $2-\mu \mathrm{m}$ peak dominates the distribution, but the higher flow rates suggest a bimodal distribution with a second population peak centered around 4 to $10 \mu \mathrm{m}$. The majority of particles fall between 0.2 and $20 \mu \mathrm{m}$. With regard to the influence of flow rate on the pre-sonication PSD, it appears that increased pump speed shears apart large aggregates as evidenced by the decrease in the population of particles greater than $100 \mu \mathrm{m}$ and the increase in the relative population of 20 - to 100 - $\mu \mathrm{m}$ aggregates as the instrument pump speed is increased from 2000 to 4000 RPM.

Application of sonic energy induces the same aggregate restructuring observed in the previous samples (Figure 3.23). In addition, sonication eliminates particles/aggregates larger than $30 \mu \mathrm{m}$. Relative to previous distributions, the low solids is more strongly bimodal such that the submicron and 2- to 30- $\mu \mathrm{m}$ population peaks are more distinct. It appears that, for the current sample, submicron particles are either more prevalent or more stable. This is most likely a result of prolonged shear in the CUF.

The flow curves for the high solids matrix are similar to those for the source material (Figure 3.24). Specifically, they show an apparent elastic deformation over the 0 - to $200-\mathrm{s}^{-1}$ range and significant hysteresis with the down ramp showing larger viscous stress than the up-ramp. The flow curve at $25^{\circ} \mathrm{C}$ is linear (s $\mu$ ggestive of Bingham Plastic behavior), whereas both of the higher temperature flow curves show slight to moderate shear thinning behavior (Table 3.14).

In addition, the $15 \mathrm{wt} \%$ UDS CUF sample shows increasing stress with increasing sample temperature. These similarities are expected, as the $15 \mathrm{wt} \%$ UDS CUF sample has a similar solids concentration to the source material. It is likely that evaporation is the cause of hysteresis and increasing stress with temperature for the current sample (as it was for the source material). 


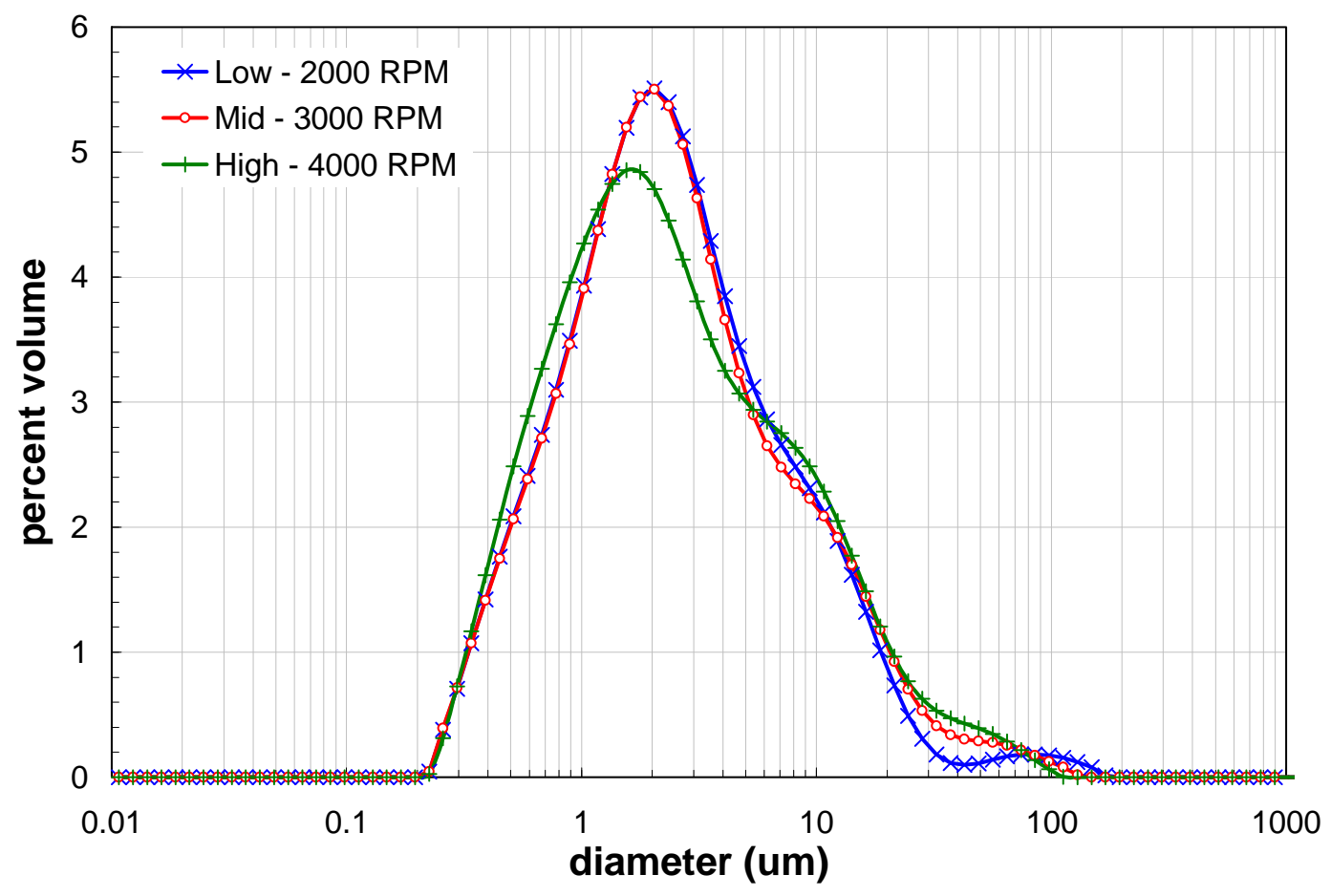

Figure 3.22. PSD of CUF 5 High Solids (15wt\%) Matrix as a Function of Pump Speed

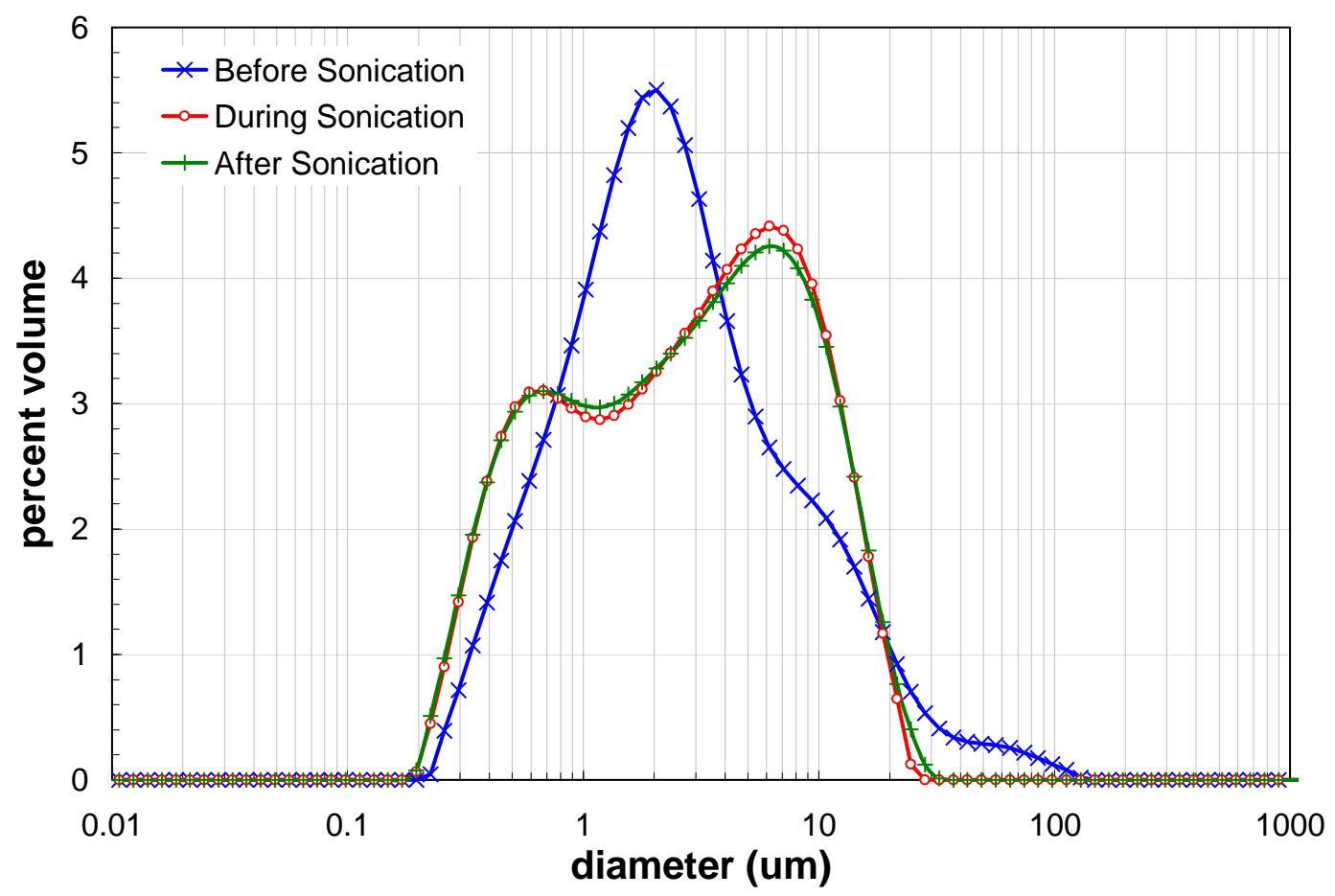

Figure 3.23. PSD of CUF 5 High Solids (15 wt\%) Matrix as a Function of Sonication 


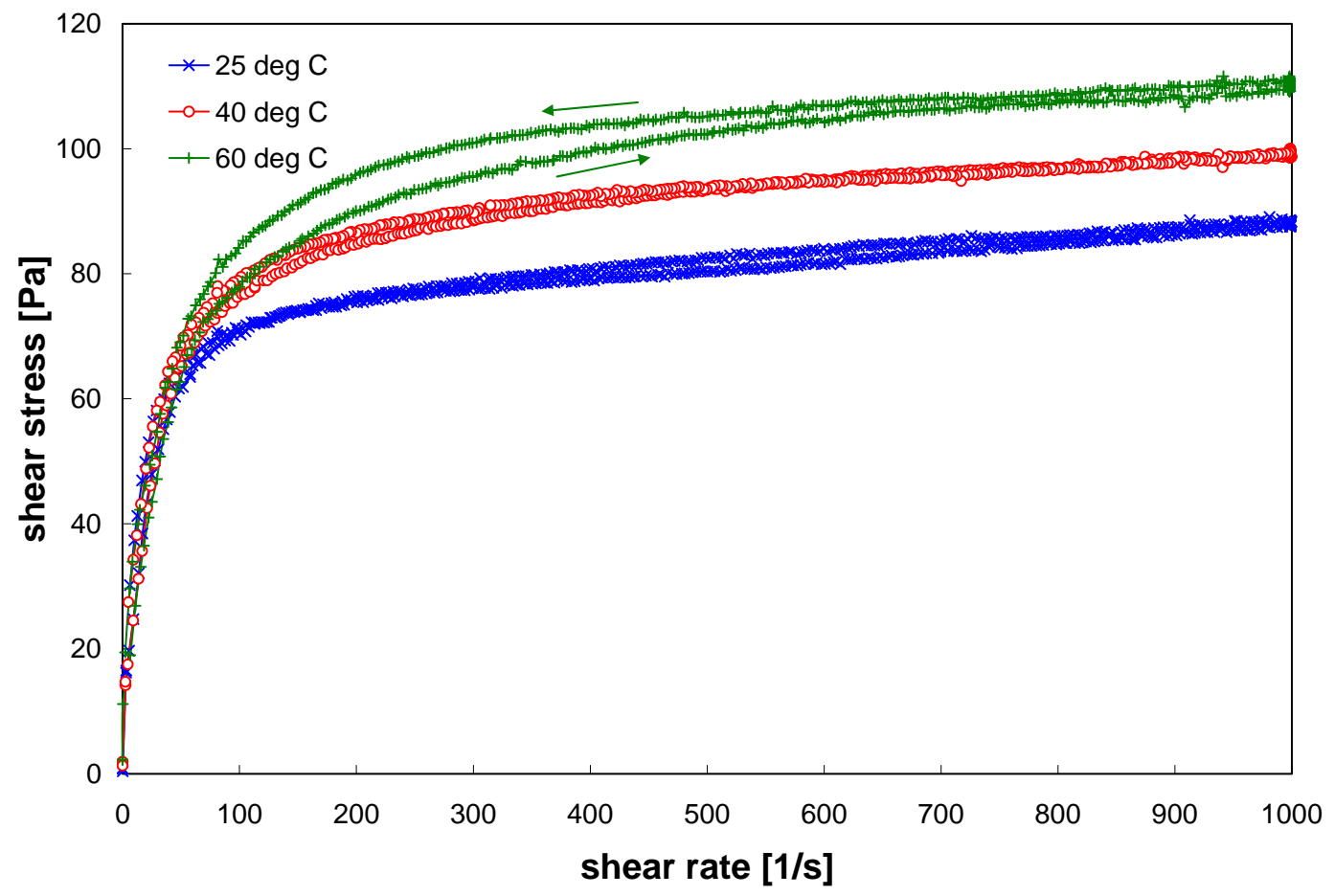

Figure 3.24. Flow Curves for Group 5 CUF High Solids (15 wt\%) Slurry

Table 3.14. Results of Fitting Analysis for the Group 5 CUF High Solids (15 wt\%) Matrix

\begin{tabular}{||c|c|c|c|c|c||}
\hline \hline Model & $\begin{array}{c}\text { Temperature } \\
{\left[{ }^{\circ} \mathbf{C}\right]}\end{array}$ & $\begin{array}{c}\text { Yield } \\
\text { Stress [Pa] }\end{array}$ & $\begin{array}{c}\text { Consistency } \\
{\left[\mathbf{P a} \mathbf{~ s}^{\mathbf{n}}\right]}\end{array}$ & $\begin{array}{c}\text { Flow } \\
\text { Index }\end{array}$ & $\mathbf{R}$ \\
\hline \multirow{3}{*}{ Power-Law* } & 25 & $\mathrm{n} / \mathrm{a}$ & 38 & 0.12 & 0.96 \\
\cline { 2 - 6 } & 40 & $\mathrm{n} / \mathrm{a}$ & 41 & 0.13 & 0.94 \\
\cline { 2 - 6 } & 60 & $\mathrm{n} / \mathrm{a}$ & 40 & 0.15 & 0.95 \\
\hline \multirow{3}{*}{ Bingham-Plastic } & 25 & 74 & 0.014 & $\mathrm{n} / \mathrm{a}$ & 0.98 \\
\cline { 2 - 6 } & 40 & 86 & 0.013 & $\mathrm{n} / \mathrm{a}$ & 0.97 \\
\cline { 2 - 6 } & 60 & 94 & 0.016 & $\mathrm{n} / \mathrm{a}$ & 0.93 \\
\hline \multirow{3}{*}{ Herschel-Bulkley } & 25 & 70 & 0.19 & 0.66 & 0.99 \\
\cline { 2 - 7 } & 40 & 25 & 34 & 0.11 & 0.99 \\
\cline { 2 - 7 } & 60 & -18 & 74 & 0.081 & 0.96 \\
\hline
\end{tabular}

\subsection{Caustic Leaching/Washing}

After completing the filtration and rheological testing of the high-solids slurry, the slurry was drained from the system and prepared for caustic leaching. The slurry loop was rinsed using part of the caustic addition for the leach and additional permeate that was remaining in the back-pulse chamber. After the slurry and caustic additions were recovered from the system, the slurry reservoir was isolated from the slurry loop. At this point, all the recovered slurry, permeate, and caustic solutions were placed into the reservoir for caustic leaching, as outlined in the right column of Figure 3.1. The activities involved in this process were: 
- Batch caustic leaching of the slurry for removing aluminum from UDS in the slurry.

- Dewatering a majority of the leached slurry supernate from the slurry solids.

- Batch washing of the caustic-leached slurry and dewatering of the diluted supernate afterwards. Three total wash solutions were added to the slurry to remove aluminum from the slurry.

\subsubsection{Caustic Batch Leaching Results}

After sampling the slurry, the CUF was prepared for the caustic leach, as outlined in Figure 3.25. In order to isolate the slurry reservoir for leaching operations, the slurry and permeate has to be drained from the CUF. Next, the caustic addition was added to the CUF to wash solids from the slurry loop and drained as well. Once the CUF was drained, the slurry reservoir was then isolated from the slurry circulation loop. The recovered slurry, permeate, and caustic solution was loaded into the slurry reservoir afterwards. It is estimated that $0.2 \mathrm{~kg}$ of material loss occurred due to transfer operations.

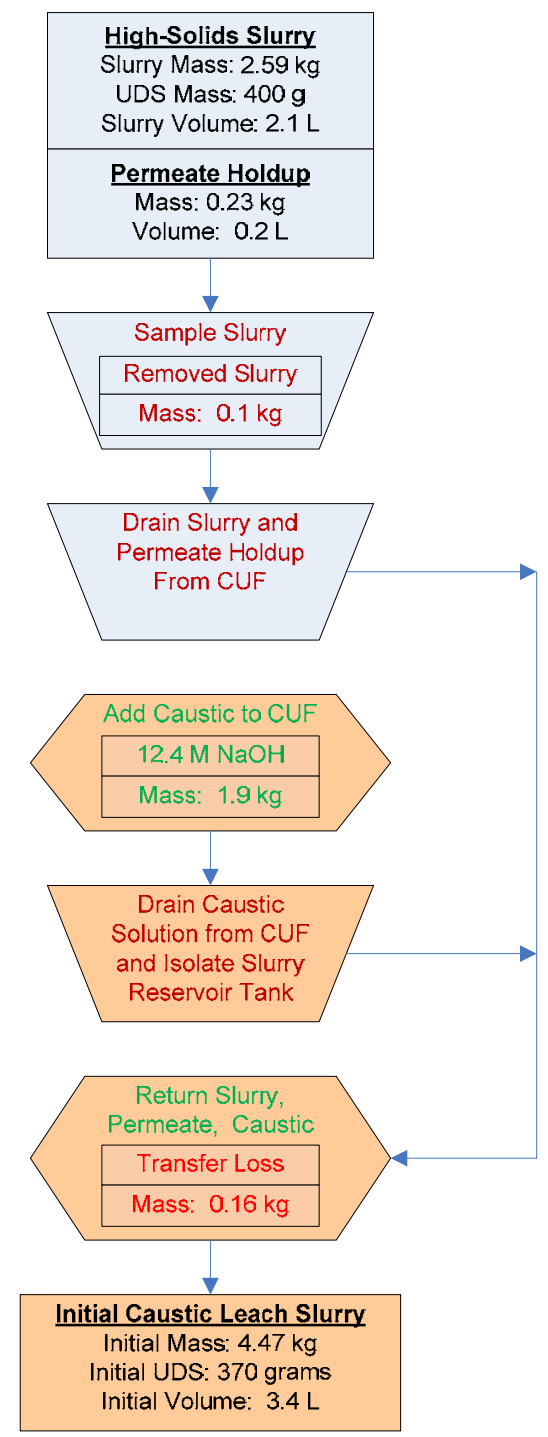

Figure 3.25. Group 5 Preparation for the Caustic Leach

Note: Mass and volume values in figure are rounded to the nearest significant digit of accuracy. 
The addition of $0.5 \mathrm{~L}$ of permeate back to the slurry prior to the high-solids matrix forced changes to be made to the caustic addition. Originally, $1.88 \mathrm{~L}$ of $9.13 \mathrm{M} \mathrm{NaOH}$ was to be added to $1.6 \mathrm{~L}$ of total slurry. When the total slurry volume was increased to $2.1 \mathrm{~L}$ for the test matrix, there was concern that the slurry reservoir would not hold the entire volume ( $>4$ liters). It was decided that the best way to remedy the situation was to reduce the caustic-addition volume by 0.5 liters, but keep the mass of $\mathrm{NaOH}$ added the same (17.2 moles of $\mathrm{NaOH})$. Therefore, the volume of the addition was reduced to $1.38 \mathrm{~L}$ while the concentration was increased to $12.49 \mathrm{M} \mathrm{NaOH}$.

After the slurry, permeate, and caustic was placed in the slurry reservoir, the lid for the slurry reservoir was placed on the tank and the over-head mixer was started. The heat controller was then started to ramp the slurry temperature to $100^{\circ} \mathrm{C}\left(-10 /+5^{\circ} \mathrm{C}\right)$ over a 5.3 hour period. After the heat ramp was completed, this temperature was held for 12 hours, and then allowed to cool to the hot cell ambient temperature over another 12-hour period (Figure 3.26). After the cool down was completed, the leach solution volume was measured so additional water could be added to the slurry to correct for volume losses for evaporation. At this point, the slurry volume was found to be 2.3 liters, which was 1.1 liters lower than at the start of the leach. Prior to dewatering, an additional $1.1 \mathrm{~kg}$ of water was added to return the leached slurry solution to near the desired volume and sodium concentration. Prior to the addition of water, the sodium concentration was measured as 9.9M. After the water addition, the sodium concentration was closer to the planned 6.5M (measured at 6.6M).

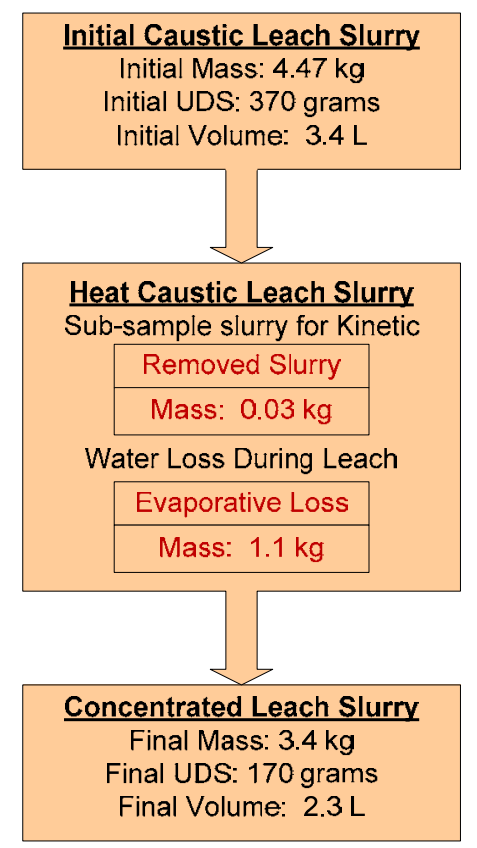

Figure 3.26. Group 5 Caustic Leach

Note: Mass and volume values in figure are rounded to the nearest significant digit of accuracy.

The supernate portion of the slurry was sampled once the heat ramp was completed, and at the 4-, 8-, and 12-hour points during the leach. By the end of the initial heat ramp, 56\% of the aluminum had leached from the solids into solution. By 12 hours, 73\% of the aluminum had leached (Figure 3.27). The leach factor was higher than the $50 \%$ expected. However, evaporation that occurred during heating 
concentrated the leach solution. This increased the free hydroxide concentration up to $6 \mathrm{M}$ (planned at $\sim 3.3 \mathrm{M}$ ). It is suspected that this significant increase in the free-hydroxide concentration caused this increase in the dissolution rate. It should also be noted that the temperature during leaching did very slightly due to the temperature control range for the system. In general, the temperature ranged between 98 and $106^{\circ} \mathrm{C}$ during the caustic leaching process.

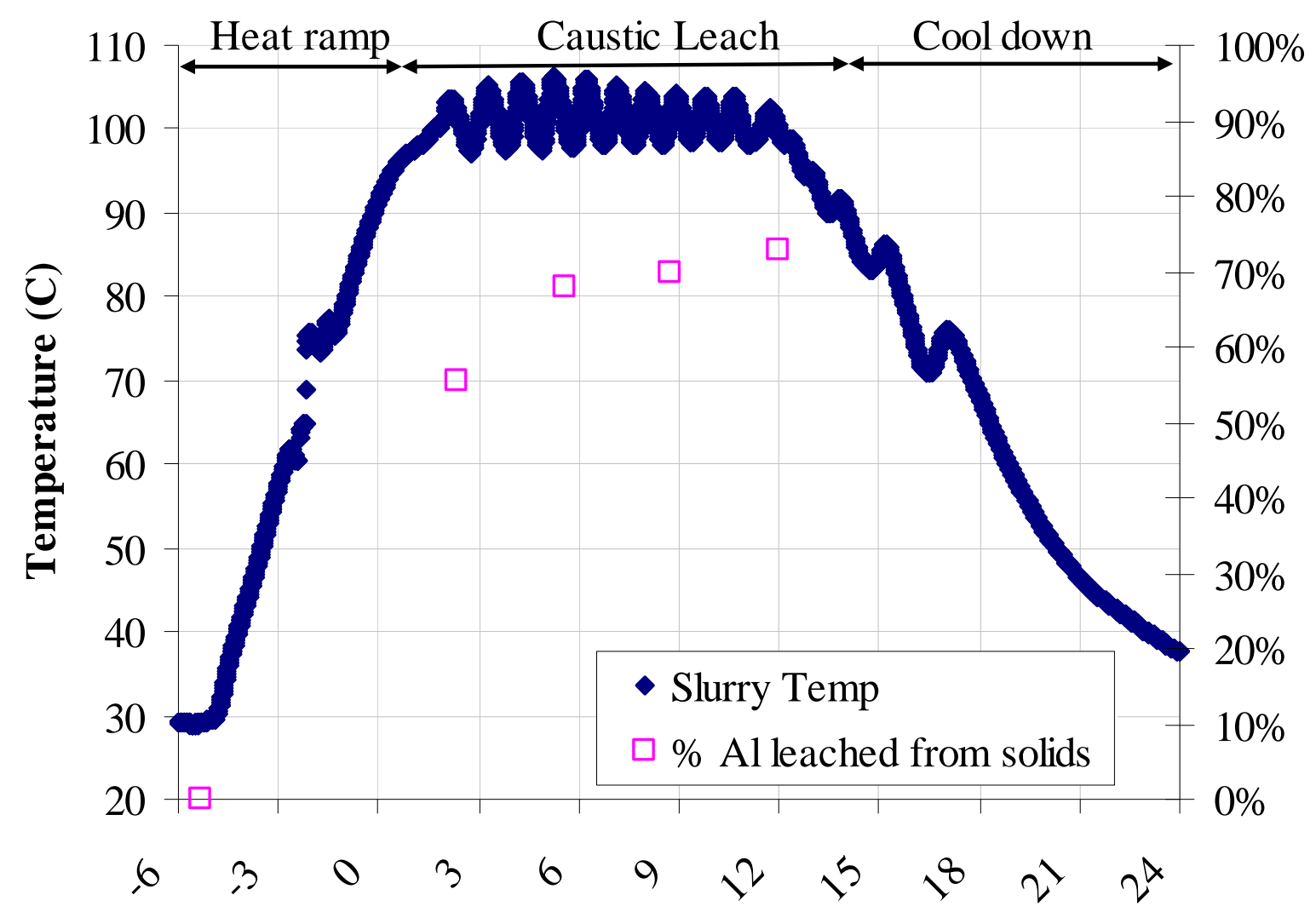

\section{Elapsed Time of Caustic in Hours \\ (Time at 0 is Start of Leach)}

Figure 3.27. Group 5 Temperature Profile/Aluminum Leach Factor During Caustic Leaching

\subsubsection{Caustic Leach Dewatering}

Prior to dewatering the leached slurry, approximately $1.1 \mathrm{~L}$ of $0.01 \mathrm{M} \mathrm{NaOH}(1.14 \mathrm{~kg})$ was added to the leached slurry after it had cooled down to the hot cell ambient temperature (Figure 3.28.). The goal of the addition was to return the leach solution back to its original volume prior to dewatering and washing. Also, it was desired to lower the sodium, aluminum, and free hydroxide concentrations in the slurry supernate to planned concentrations so dewatering operations would not be skewed by the excess evaporation that occurred during leaching. 


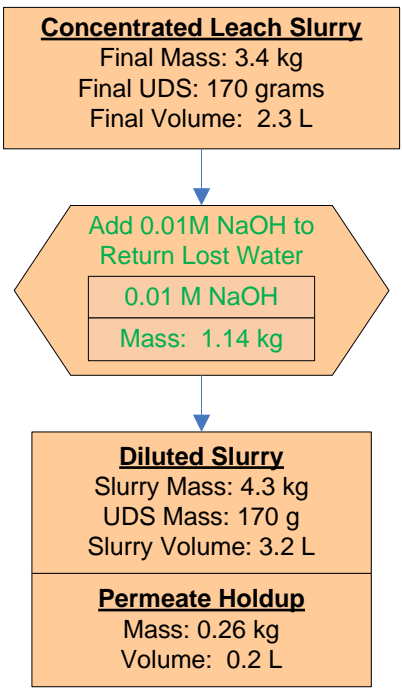

Figure 3.28. Group 5 Diluting Caustic Leach Slurry to Planned Volume

Note: Mass and volume values in figure are rounded to the nearest significant digit of accuracy.

After returning the caustic leach slurry to a total process volume of $\sim 3.4$ liters, the slurry was dewatered at standard condition (Figure 3.29). The caustic-leached slurry was dewatered from a total system volume of $\sim 3.4 \mathrm{~L}$ to $\sim 1.3 \mathrm{~L}$ over 2 hours. A total of $2.75 \mathrm{~kg}$ of permeate was collected during the dewatering step. Figure 3.30 is a plot of the permeate flux for the dewatering step. The permeate flux during post leach dewatering decreased from 0.021 to $0.014 \mathrm{GPM} / \mathrm{ft}^{2}$, compared to rates near $0.060 \mathrm{GPM} / \mathrm{ft}^{2}$ observed during the high solids matrix at the same TMP and AV before caustic leaching. The lower flux value was due to the higher density and viscosity of the caustic leachate (see Table 3.15).

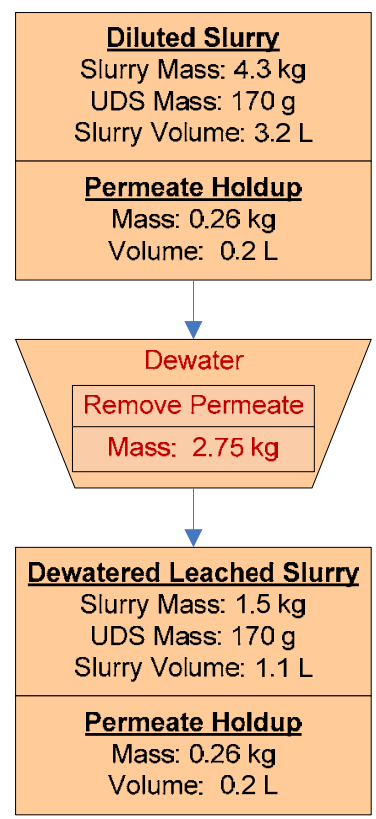

Figure 3.29. Group 5 Dewatering Caustic Leached Slurry

Note: Mass and volume values in figure are rounded to the nearest significant digit of accuracy. 


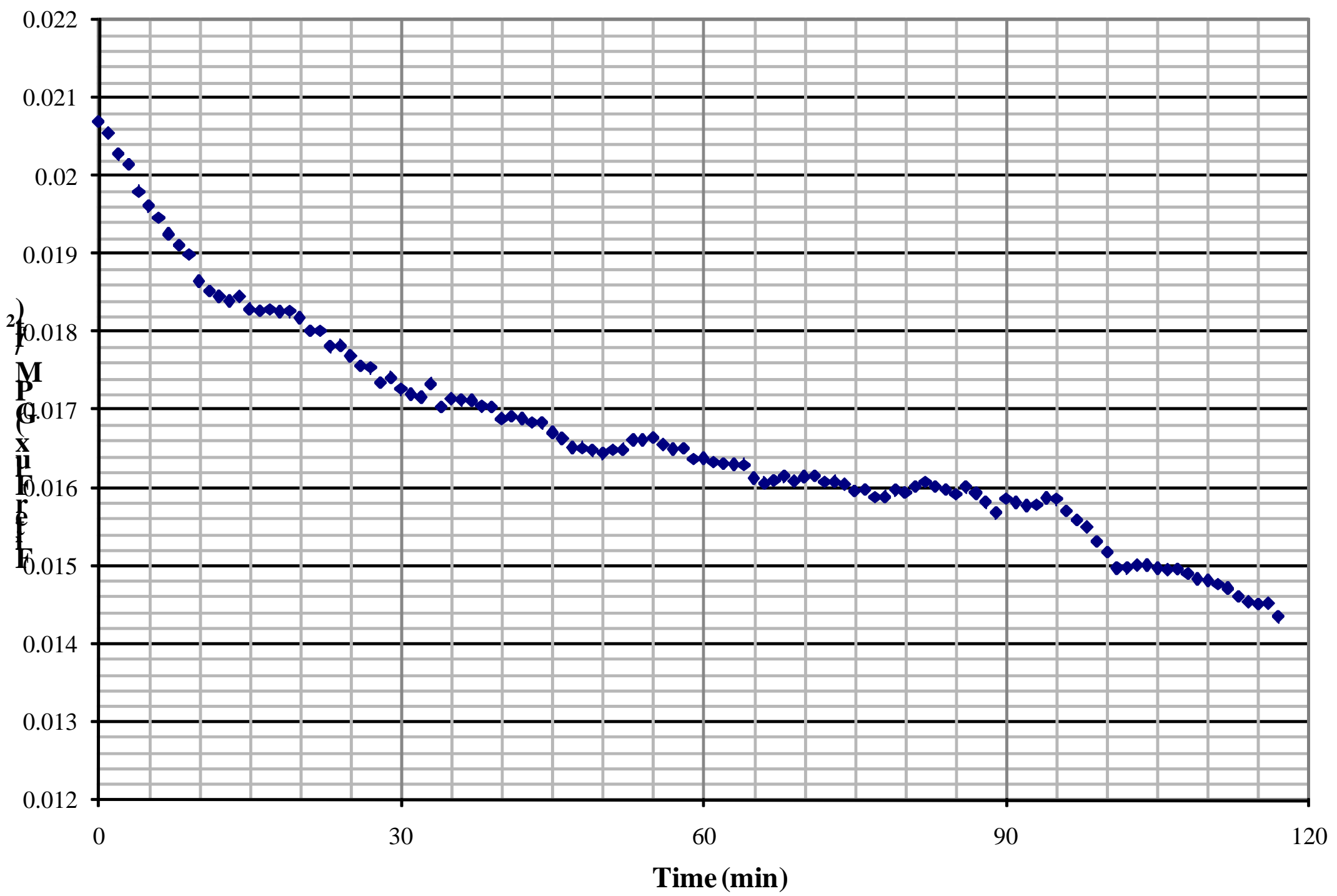

Figure 3.30. Group 5 Dewatering Caustic Leached Slurry from $4 \mathrm{wt} \%$ to $11 \mathrm{wt} \%$ at Standard Conditions of $40 \mathrm{psid}$ and $13 \mathrm{ft} / \mathrm{s}$ 
Table 3.15. Comparison of Slurry Supernate Attributes to Filter Flux

\begin{tabular}{|l|l|l|l|l|l|l|}
\hline $\begin{array}{l}\text { Supernate } \\
\text { sample }\end{array}$ & $\begin{array}{l}\text { Density } \\
(\mathbf{g} / \mathbf{m L})\end{array}$ & $\begin{array}{l}\text { Viscosity } \\
\text { at 25 }{ }^{\circ} \mathbf{C} \\
(\mathbf{m P a} \cdot \mathbf{s})\end{array}$ & $\begin{array}{l}\text { [Na] } \\
\mathbf{( M )}\end{array}$ & $\begin{array}{l}{[\mathbf{O H}]} \\
\mathbf{( M )}\end{array}$ & $\begin{array}{l}\text { [Al] } \\
\mathbf{( M )}\end{array}$ & $\begin{array}{l}\text { Nominal flux at } \\
\text { standard } \\
\text { condition } \\
\left(\mathbf{G P M} / \mathbf{f t}^{2}\right)\end{array}$ \\
\hline $\begin{array}{l}\text { High-solids } \\
\text { slurry before } \\
\text { caustic } \\
\text { leaching }\end{array}$ & 1.13 & 1.5 & 3.1 & 0.2 & 0.1 & 0.060 \\
\hline $\begin{array}{l}\text { Post caustic } \\
\text { leach } \\
\text { permeate }\end{array}$ & 1.28 & 11 & 6.6 & 3.8 & 1.3 & 0.016 \\
\hline
\end{tabular}




\subsubsection{Dewatered Leached Slurry Physical Characterization}

After dewatering the leached slurry, the slurry was sampled for physical and chemical analysis (Figure 3.31). The results of physical-property measurements of the leached, dewatered material are shown in Table 3.16 and the chemical properties in Table 3.17 and Table 3.18. Leach factors for the constituents present in the UDS were calculated by comparing the UDS composition of the slurry to that of the high-solids slurry provided in Table 3.13. Using iron and uranium to calculate a concentration factor for the solid mass, the calculated solid leach factors are provided in Table 3.18.

The leach factor for aluminum was found to be $80 \mathrm{wt} \%$, compared to $73 \mathrm{wt} \%$ calculated from the supernate analysis (Section 3.5.1). The difference between the two values can be attributed to the experimental error of the analysis $( \pm 15 \%)$. Most of the other components in the slurry appeared not to have been affected by the caustic leach. While the leach factor for ${ }^{60} \mathrm{Co}$ was significant, it is not clear if this value is accurate since the supernate analysis did not detect a significant quantity of this isotope.

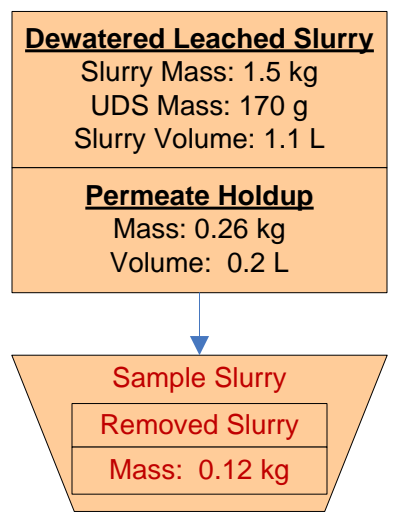

Figure 3.31. Group 5 Sampling of Dewatered Caustic Leached Slurry Note: Mass and volume values in figure are rounded to the nearest significant digit of accuracy.

Table 3.16. Group 5 Dewatered Caustic Leached Slurry Physical-Property Measurements (inside circulation loop)

\begin{tabular}{|r|r||}
\hline Slurry Density (g/mL) & 1.30 \\
\hline Supernate Density (g/mL) & 1.28 \\
\hline Settled Solids (Vol \%) & $78 \%$ \\
\hline Centrifuged UDS (Wt\%) & $24 \%$ \\
\hline Total Solids (Wt\%) & $40 \%$ \\
\hline Dissolved Solids (Wt\%) & $31 \%$ \\
\hline UDS (Wt\%) & $14 \%$ \\
\hline
\end{tabular}


Table 3.17. Group 5 Caustic leached, dewatered (15 wt\%) Slurry Composition and total inventory (including permeate hold-up)

\begin{tabular}{|c|c|c|c|c|c|}
\hline & Slurry $^{(a)}$ & \multicolumn{2}{|c|}{ Liquid Fraction $^{(b)}$} & \multicolumn{2}{|c|}{ Solids Fraction ${ }^{(c)}$} \\
\hline Mass (kg) & 1.76 & \multicolumn{2}{|c|}{1.68} & \multicolumn{2}{|c|}{0.18} \\
\hline Wt\% of Slurry & $100 \%$ & \multicolumn{2}{|c|}{$90.5 \%$} & \multicolumn{2}{|c|}{$9.5 \%$} \\
\hline Metal & g & g & $\mu g / m L$ & g & $\mu g / g$ \\
\hline Al & $5.3 \mathrm{E}+01$ & $4.3 \mathrm{E}+01$ & $3.4 \mathrm{E}+04$ & $9.3 \mathrm{E}+00$ & $5.4 \mathrm{E}+04$ \\
\hline $\mathrm{Ca}$ & 3.4E-01 & 3.5E-02 & $2.8 \mathrm{E}+01$ & 3.0E-01 & $1.8 \mathrm{E}+03$ \\
\hline $\mathrm{Cr}$ & $1.9 \mathrm{E}+00$ & 8.5E-01 & $6.6 \mathrm{E}+02$ & $1.0 \mathrm{E}+00$ & $5.9 \mathrm{E}+03$ \\
\hline $\mathbf{F e}$ & $2.4 \mathrm{E}+00$ & $9.4 \mathrm{E}-03$ & $7.4 \mathrm{E}+00$ & $2.4 \mathrm{E}+00$ & $1.4 \mathrm{E}+04$ \\
\hline Mn & $1.6 \mathrm{E}+00$ & $5.0 \mathrm{E}-04$ & 3.9E-01 & $1.6 \mathrm{E}+00$ & $9.5 \mathrm{E}+03$ \\
\hline $\mathrm{Na}$ & $2.4 \mathrm{E}+02$ & $1.9 \mathrm{E}+02$ & $1.5 \mathrm{E}+05$ & $4.7 \mathrm{E}+01$ & $2.8 \mathrm{E}+05$ \\
\hline $\mathbf{P}$ & $2.5 \mathrm{E}-01$ & $2.5 \mathrm{E}-01$ & $2.7 \mathrm{E}+02$ & $<1$.E-3 & $<1$.E-3 \\
\hline Si & $3.1 \mathrm{E}+00$ & 7.7E-02 & $6.0 \mathrm{E}+01$ & $3.0 \mathrm{E}+00$ & $1.8 \mathrm{E}+04$ \\
\hline $\mathbf{U}$ & $7.3 \mathrm{E}+03$ & $<1 . \mathrm{E}-2$ & $<8 . \mathrm{E}+0$ & $7.3 \mathrm{E}+03$ & $4.3 \mathrm{E}+07$ \\
\hline \multirow{2}{*}{$\begin{array}{l}\text { Radiochemical } \\
\text { Isotopes }\end{array}$} & Slurry & \multicolumn{2}{|c|}{ Liquid Fraction } & \multicolumn{2}{|c|}{ Solid Fraction } \\
\hline & $\mathrm{mCi}$ & $\mathrm{mCi}$ & $\mathrm{mCi} / \mathbf{m L}$ & $\mathrm{mCi}$ & $\mathrm{mCi} / \mathrm{g}$ \\
\hline Co-60 & $3.0 \mathrm{E}+00$ & $<8 . \mathrm{E}-2$ & $<6 . \mathrm{E}-5$ & $3.0 \mathrm{E}+00$ & 1.7E-02 \\
\hline Cs-137 & $2.6 \mathrm{E}+04$ & $1.2 \mathrm{E}+04$ & $9.2 \mathrm{E}+00$ & $1.4 \mathrm{E}+04$ & $8.3 \mathrm{E}+01$ \\
\hline Eu-154 & $4.5 \mathrm{E}+01$ & $<5 . \mathrm{E}-1$ & $<4$.E-4 & $4.5 \mathrm{E}+01$ & 2.6E-01 \\
\hline Am-241 & $1.1 \mathrm{E}+02$ & $<6 . \mathrm{E}+0$ & $<5$. E-3 & $1.1 \mathrm{E}+02$ & 6.7E-01 \\
\hline Gross Alpha & $3.1 \mathrm{E}+02$ & $<8 . \mathrm{E}+0$ & $<6$. E-3 & $3.1 \mathrm{E}+02$ & $1.8 \mathrm{E}+00$ \\
\hline Gross Beta & $5.7 \mathrm{E}+05$ & $1.1 \mathrm{E}+04$ & $8.9 \mathrm{E}+00$ & $5.6 \mathrm{E}+05$ & $3.3 \mathrm{E}+03$ \\
\hline Sr-90 & $2.4 \mathrm{E}+05$ & $1.6 \mathrm{E}+02$ & $1.3 \mathrm{E}-01$ & $2.4 \mathrm{E}+05$ & $1.4 \mathrm{E}+03$ \\
\hline Pu-239+240 & $3.2 \mathrm{E}+02$ & $9.2 \mathrm{E}-03$ & $7.2 \mathrm{E}-06$ & $3.2 \mathrm{E}+02$ & $1.9 \mathrm{E}+00$ \\
\hline Pu-238 & $8.3 \mathrm{E}+00$ & $<2 . \mathrm{E}-3$ & $<2$.E-6 & $8.3 \mathrm{E}+00$ & 4.9E-02 \\
\hline \multirow[t]{2}{*}{ Anions } & \multicolumn{3}{|c|}{ Liquid Fraction } & & \\
\hline & $\mu \mathrm{g} / \mathrm{mL}$ & [M] & g & & \\
\hline $\mathbf{F}$ & $<3 . \mathrm{E}+0$ & $<2$.E-4 & $<4$. E-3 & & \\
\hline $\mathrm{C}_{2} \mathrm{O}_{4}$ & $1.3 \mathrm{E}+02$ & $1.5 \mathrm{E}-03$ & 1.7E-01 & & \\
\hline $\mathrm{NO}_{2}$ & $1.4 \mathrm{E}+04$ & 3.0E-01 & $1.8 \mathrm{E}+01$ & & \\
\hline $\mathrm{NO}_{3}$ & $5.0 \mathrm{E}+04$ & 8.0E-01 & $6.4 \mathrm{E}+01$ & & \\
\hline $\mathrm{SO}_{4}$ & $3.3 \mathrm{E}+02$ & 3.5E-03 & 4.3E-01 & & \\
\hline $\mathrm{PO}_{4}$ & $8.1 \mathrm{E}+02$ & 8.6E-03 & $1.0 \mathrm{E}+00$ & & \\
\hline OH & $6.4 \mathrm{E}+04$ & $3.7 \mathrm{E}+00$ & $8.1 \mathrm{E}+01$ & & \\
\hline \multicolumn{6}{|c|}{$\begin{array}{l}\text { (a) Slurry Mass components were calculated from characterization data (WPT-RPT-157), and the } \\
\text { masses of materials that were added with simulant. Loss of mass from sampling was } \\
\text { incorporated. } \\
\text { (b) Liquid Fraction mass components were calculated using analytical results from supernate } \\
\text { sample TI540-G5-G (ASO ID 07-01780) and the predicted mass of supernate in the system. } \\
\text { (c) Solids Fraction mass components were calculated from the difference between the slurry } \\
\text { component mass and liquid component mass fraction. }\end{array}$} \\
\hline
\end{tabular}


Table 3.18. Group 5 Dewatered Leached Slurry Composition and Calculated Solids Leach Factors

\begin{tabular}{|c|c|c|c|c|c|}
\hline $\begin{array}{l}\text { Slurry Prep } \\
\text { Method }\end{array}$ & $\begin{array}{c}\text { ICP-OES } \\
\text { Analytes }\end{array}$ & $\begin{array}{c}\text { Dry } \\
\text { Slurry }^{(a)} \\
(\mu g / g)\end{array}$ & $\begin{array}{c}\text { Supernate }^{(b)} \\
(\mu \mathrm{g} / \mathrm{mL})\end{array}$ & $\begin{array}{c}\text { Dry Solids }^{(\mathrm{c})} \\
(\mu \mathrm{g} / \mathrm{g})\end{array}$ & $\begin{array}{c}\text { Solids } \\
\text { Leach }^{(d)} \\
\text { Factor }^{(d)}\end{array}$ \\
\hline \multirow{30}{*}{ 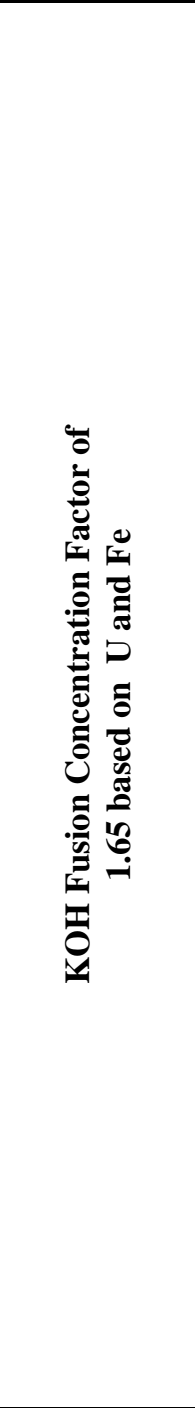 } & Al & 96,400 & 33,900 & 115,933 & 0.82 \\
\hline & B & $<8.8 \mathrm{E}+1$ & 31.3 & $<1.0 \mathrm{E}+2$ & NA \\
\hline & Bi & $<1.5 \mathrm{E}+2$ & [3.5] & $<4.2 \mathrm{E}+2$ & NA \\
\hline & $\mathrm{Cr}$ & 2,740 & 663 & 4,800 & -0.40 \\
\hline & $\mathbf{F e}$ & 7,510 & [7.4] & 22,215 & NA \\
\hline & Mn & 3,120 & {$[0.39]$} & 9,242 & 0.02 \\
\hline & $\mathrm{Na}$ & 286,000 & 152,000 & 86,528 & -15.21 \\
\hline & S & $<7.2 \mathrm{E}+2$ & [130] & $<1.5 \mathrm{E}+3$ & NA \\
\hline & Si & 6,170 & 60.3 & 17,980 & NA \\
\hline & $\mathrm{Sr}$ & 813 & [0.097] & 2,408 & 0.02 \\
\hline & $\mathbf{U}$ & {$[11,000]$} & $<8.5 \mathrm{E}+0$ & {$[32,550]$} & $-[0.03]$ \\
\hline & Zn & $<5.0 \mathrm{E}+1$ & 8.49 & $<1.1 \mathrm{E}+2$ & NA \\
\hline & Zr & $<5.9 \mathrm{E}+1$ & $<8.2 \mathrm{E}-1$ & $<1.7 \mathrm{E}+2$ & NA \\
\hline & $B a$ & [59] & $<3.4 \mathrm{E}-1$ & [173] & [0.33] \\
\hline & $B e$ & $<9.7 \mathrm{E}-1$ & $<1.2 \mathrm{E}-2$ & $<2.8 \mathrm{E}+0$ & NA \\
\hline & $C a$ & $<3.1 \mathrm{E}+3$ & 27.7 & $<8.9 \mathrm{E}+3$ & NA \\
\hline & $\mathrm{Ce}$ & $<2.0 \mathrm{E}+2$ & $<1.2 \mathrm{E}+0$ & $<5.9 \mathrm{E}+2$ & NA \\
\hline & Co & $<2.1 \mathrm{E}+1$ & $<3.9 \mathrm{E}-1$ & $<5.9 \mathrm{E}+1$ & NA \\
\hline & $\mathrm{Cu}$ & [45] & [3.0] & [118] & $-[0.23]$ \\
\hline & $E \boldsymbol{E u}$ & $<1.6 \mathrm{E}+1$ & $<1.1 \mathrm{E}-1$ & $<4.8 \mathrm{E}+1$ & NA \\
\hline & $L a$ & $<1.1 \mathrm{E}+1$ & $<1.3 \mathrm{E}-1$ & $<3.1 \mathrm{E}+1$ & NA \\
\hline & $L i$ & $<3.2 \mathrm{E}+1$ & $<5.5 \mathrm{E}-1$ & $<9.2 \mathrm{E}+1$ & NA \\
\hline & $M g$ & {$[170]$} & [4.5] & [481] & {$[0.05]$} \\
\hline & Mo & $<3.0 \mathrm{E}+1$ & [3.7] & $<6.9 \mathrm{E}+1$ & NA \\
\hline & $N d$ & $<3.1 \mathrm{E}+2$ & $<1.7 \mathrm{E}+0$ & $<9.1 \mathrm{E}+2$ & NA \\
\hline & $\boldsymbol{P}$ & [210] & 273 & $-[744]$ & $-[12.30]$ \\
\hline & Se & $<2.9 \mathrm{E}+2$ & [5.6] & $<8.3 \mathrm{E}+2$ & NA \\
\hline & Sn & $<2.7 \mathrm{E}+2$ & [12] & $<7.5 \mathrm{E}+2$ & NA \\
\hline & $T i$ & $<2.7 \mathrm{E}+1$ & $<9.8 \mathrm{E}-2$ & $<8.0 \mathrm{E}+1$ & NA \\
\hline & $V$ & $<1.4 \mathrm{E}+1$ & $<3.2 \mathrm{E}-1$ & $<3.9 \mathrm{E}+1$ & NA \\
\hline
\end{tabular}


Table 3.18 (Contd)

\begin{tabular}{|c|c|c|c|c|c|}
\hline $\begin{array}{l}\text { Slurry Prep } \\
\text { Method }\end{array}$ & Radionuclides & $\begin{array}{c}\text { Dry } \\
\text { Slurry } \\
(\mu \mathrm{C} i / g)\end{array}$ & $\begin{array}{l}\text { Supernate }^{(b)} \\
(\mu \mathrm{Ci} / \mathrm{mL})\end{array}$ & $\begin{array}{c}\text { Dry Solids }^{(\mathrm{c})} \\
(\mu \mathrm{Ci} / \mathrm{g})\end{array}$ & $\begin{array}{c}\text { Solids } \\
\text { Leach } \\
\text { Factor }^{(\mathrm{d})} \\
\end{array}$ \\
\hline \multirow{11}{*}{$\begin{array}{c}\text { KOH Fusion } \\
\text { Concentration } \\
\text { Factor } \\
\text { of } 1.65 \text { based on } \\
\mathbf{U}\end{array}$} & Co-60 & $4.60 \mathrm{E}-2$ & $<6 . E-5$ & 1.4E-1 & 0.25 \\
\hline & Cs-137 & $4.14 \mathrm{E}+1$ & $9.17 \mathrm{E}+0$ & $7.7 \mathrm{E}+1$ & -0.14 \\
\hline & Eu-154 & 7.42E-2 & $<4 . \mathrm{E}-4$ & 2.2E-1 & -0.16 \\
\hline & Am-241 & $2.08 \mathrm{E}-1$ & $<5 . \mathrm{E}-3$ & 5.9E-1 & -0.12 \\
\hline & Total alpha & $8.22 \mathrm{E}-1$ & $<6 . \mathrm{E}-3$ & $2.4 \mathrm{E}+0$ & 0.04 \\
\hline & Total beta & $9.26 \mathrm{E}+2$ & $8.86 \mathrm{E}+0$ & $2.7 \mathrm{E}+3$ & -0.01 \\
\hline & Sr-90 & $4.16 \mathrm{E}+2$ & $1.28 \mathrm{E}-1$ & $1.2 \mathrm{E}+3$ & 0.01 \\
\hline & Pu-239/240 & $5.26 \mathrm{E}-1$ & $7.24 \mathrm{E}-6$ & $1.6 \mathrm{E}+0$ & 0.05 \\
\hline & Pu-238 & $1.20 \mathrm{E}-2$ & $<2$. E-6 & $3.6 \mathrm{E}-2$ & 0.16 \\
\hline & KPA & $(\mu \mathrm{g} / \mathrm{g})$ & $(\mu \mathrm{g} / \mathrm{mL})$ & $(\mu \mathrm{g} / \mathrm{g})$ & \\
\hline & $\mathbf{U}$ & $1.47 \mathrm{E}+4$ & $9.66 \mathrm{E}-1$ & $4.4 \mathrm{E}+4$ & 0.03 \\
\hline $\begin{array}{ll}\text { (a) Test sample T } \\
\text { (b) Test sample T } \\
\text { (c) Calculated usi } \\
\text { (d) Calculated usi } \\
\text { Note: Analytes in } \\
\text { but }<\text { EQL, with er }\end{array}$ & $\begin{array}{l}\text { 40-G5-G, ASO Il } \\
\text { 40-G5-12, ASO I } \\
\text { results from TI5 } \\
\text { results listed in } \\
\text { lics were measur } \\
\text { rs likely to excee }\end{array}$ & $\begin{array}{l}07-01780 \\
07-01786 \\
0-G 5-G \text { and } \\
\text { able } 3.13 \\
\text { d opportunis } \\
15 \% \text {. }\end{array}$ & tically. Values & in brackets [ ] a & $\mathrm{e} \geq \mathrm{MDL}$ \\
\hline
\end{tabular}

Particle size distribution measurements were performed on the sampled slurry. Figure 3.32 shows the pre-sonicated PSD for the leached and dewatered slurry as a function of pump speed. The distributions at 3,000 and 4,000 RPM show anomalous peaks centered at $\sim 60$ and $\sim 400 \mu \mathrm{m}$. It is unknown if these peaks correspond to particle agglomerates or are a fitting artifact. Based on pre-caustic leach samples, aggregates in the 20- to 200- $\mu \mathrm{m}$ range are plausible. Aggregates larger than this are most likely a fitting artifact, but could result from strong sample instability and aggregation. Even if the $\sim 400-\mu \mathrm{m}$ peak corresponded to real particles, the population contribution would be suspect given the unreliability of the instrument's dispersion unit in suspending particles in this size range (see Appendix $G$ for details). The pre-sonication distribution below $20 \mu \mathrm{m}$ is relatively stable. The distribution here shows a peak population at $2 \mu \mathrm{m}$ and a shoulder at 8 to $10 \mu \mathrm{m}$. Flow rate behavior is similar with the pre-leach highsolids matrix sample. Specifically, high pump speeds cause a reduction in size of the 2- $\mu \mathrm{m}$ primary peak to $\sim 1.5 \mu \mathrm{m}$. Unlike before, the growth of the 4 - to $10-\mu \mathrm{m}$ shoulder population does not appear to be flow induced, but rather a transient effect (Figure 3.33). As a function of sonication, the behavior is consistent with previous Group 5 samples. Sonication causes an increase in the population of the 8- $\mu \mathrm{m}$ peak at the expense of particles in the 2 - $\mu \mathrm{m}$ peak. As in the pre-sonic samples, measurement instability manifests as anomalous peaks centered at $400 \mu \mathrm{m}$. 


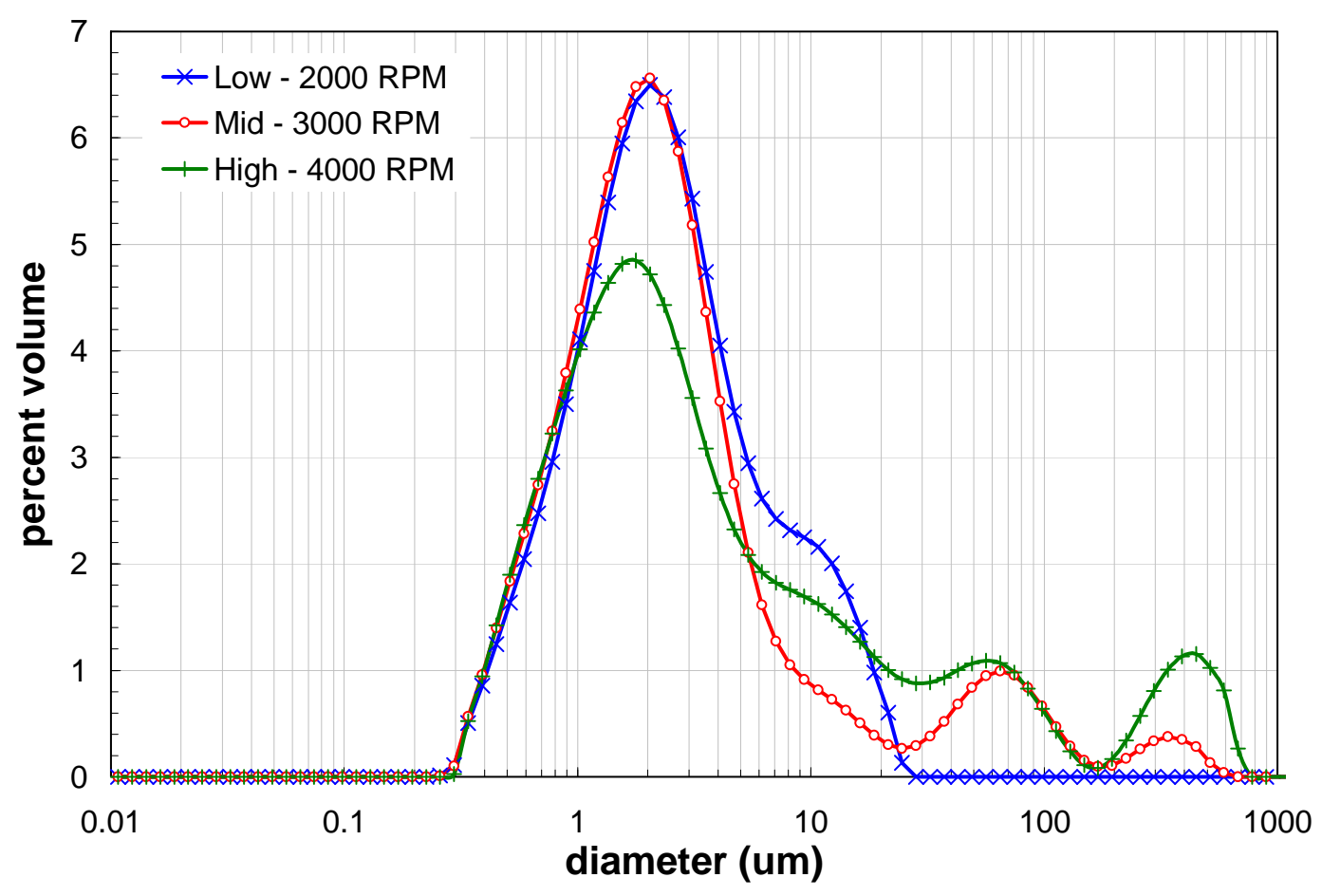

Figure 3.32. PSD of CUF 5 Leached, Dewatered Slurry as a Function of Pump Speed

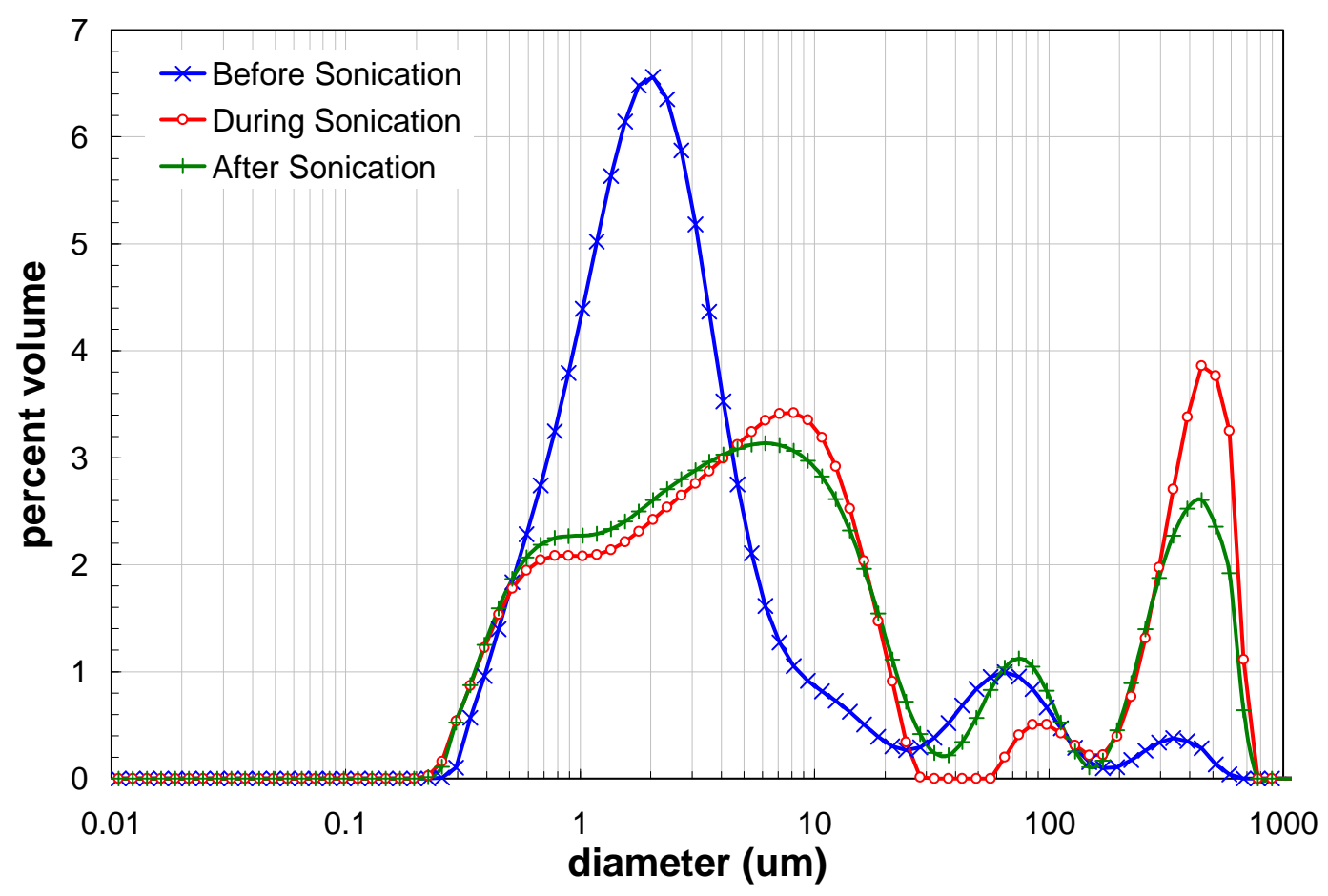

Figure 3.33. PSD of CUF 5 Leached, Dewatered Slurry as a Function of Sonication 
The slurry was also sub-sampled for rheological measurement. The flow curves for the post-leach, dewatered sample (Figure 3.34) show a significant reduction in the range of stresses (5 to $27 \mathrm{~Pa}$ ) relative to the high-solids pre-caustic leach material (15 to $100 \mathrm{~Pa}$ ) experienced over shear rates of 0 to $1000 \mathrm{~s}^{-1}$. It is suspected that the majority of this reduction is attributable to caustic leaching, although some of the change could also be a result of the difference in solids concentrations between the pre-leach and postleach samples. The post-leach sample still shows slip or elasticity over the 0 - to $100-\mathrm{s}^{-1}$ region. All curves appear to show non-Newtonian behavior consistent with the Bingham-plastic or Herschel-Bulkley constitutive equations. Although there is some shear-thinning behavior, it is difficult to discern without the aid of best-fit lines. Increases in slurry temperature appear to raise the apparent Bingham yield stress (likely thro $\mu$ gh slurry evaporation and concentration) and lower the slope of the flow curve over the entire range of shear rates tested (Table 3.19.

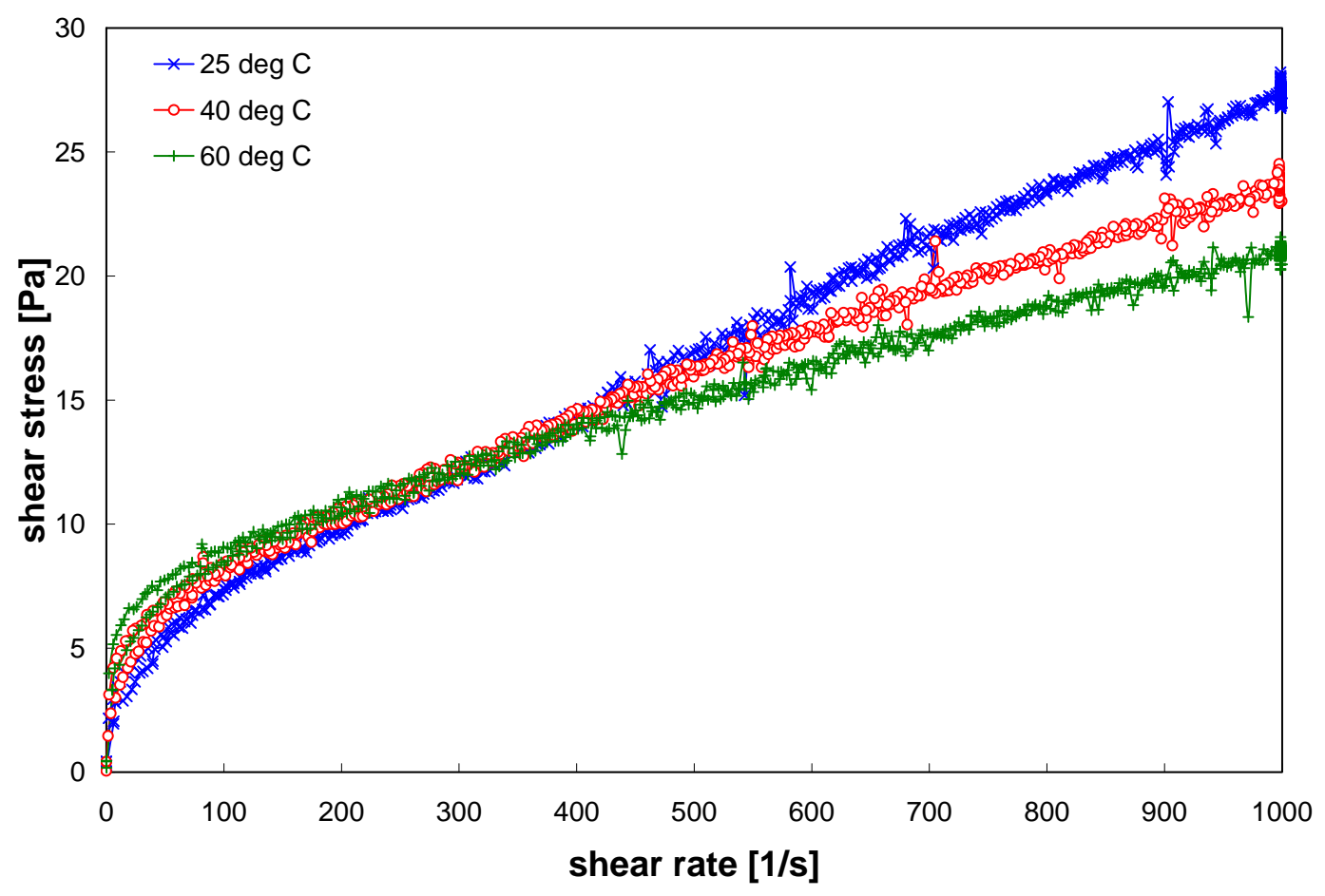

Figure 3.34. Flow Curves for Group 5 CUF Leached Dewatered Slurry

Table 3.19. Results of Fitting Analysis for the Group 5 CUF Leached Dewatered Slurry

\begin{tabular}{||c|c|c|c|c|c||}
\hline \multirow{3}{*}{ Model } & $\begin{array}{c}\text { Temperature } \\
{\left[{ }^{\circ} \mathbf{C}\right]}\end{array}$ & $\begin{array}{c}\text { Yield Stress } \\
{[\mathbf{P a})}\end{array}$ & $\begin{array}{c}\text { Consistency } \\
{\left[\mathbf{P a} \cdot \mathbf{s}^{\mathbf{n}}\right]}\end{array}$ & Flow Index & $\mathbf{R}$ \\
\hline \multirow{3}{*}{ Power-Law } & 25 & $\mathrm{n} / \mathrm{a}$ & 0.30 & 0.65 & 0.997 \\
\cline { 2 - 6 } & 40 & $\mathrm{n} / \mathrm{a}$ & 0.72 & 0.51 & 0.996 \\
\cline { 2 - 6 } & 60 & $\mathrm{n} / \mathrm{a}$ & 1.2 & 0.41 & 0.993 \\
\hline \multirow{3}{*}{ Bingham-Plastic } & 25 & 5.7 & 0.022 & $\mathrm{n} / \mathrm{a}$ & 0.998 \\
\cline { 2 - 6 } & 40 & 7.8 & 0.016 & $\mathrm{n} / \mathrm{a}$ & 0.996 \\
\cline { 2 - 7 } & 60 & 8.7 & 0.012 & $\mathrm{n} / \mathrm{a}$ & 0.996 \\
\hline \multirow{3}{*}{ Herschel-Bolkley } & 25 & 2.4 & 0.11 & 0.79 & 0.998 \\
\cline { 2 - 7 } & 40 & 2.6 & $0 / 26$ & 0.64 & 0.998 \\
\cline { 2 - 6 } & 65 & 5.6 & 0.12 & 0.70 & 0.997 \\
\hline
\end{tabular}




\subsubsection{Caustic Batch Rinsing Results}

After slurry sampling, the slurry was washed three times with decreasing concentrations of sodium hydroxide, as shown in Figure 3.35. The volume of each wash solution was 1.2 liters, approximately the same volume of supernate present in the system after dewatering from caustic leaching. After each solution was added, the slurry was re-circulated in the CUF for $~ 30$ minutes while filter permeate was recycled back to the slurry reservoir. The slurry was then dewatered at standard conditions to return the slurry back to its original volume. To prevent damage on the pump, the final dewatering was stopped at 1 liter due to cavitation that was occurring. Total metal composition of the slurry and supernate after the first, second, and third wash is detailed below in Table 3.20 through Table 3.23.

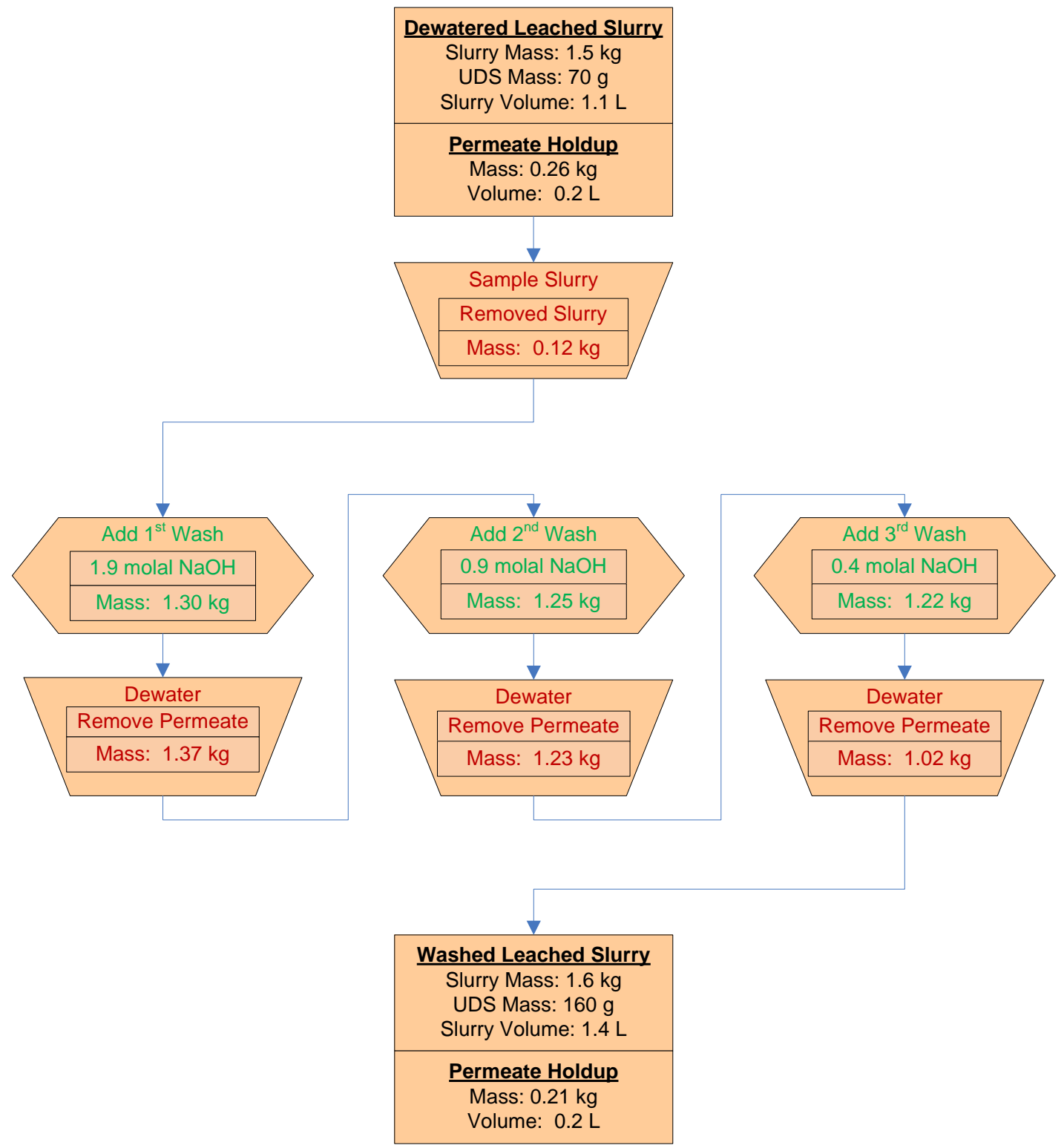

Figure 3.35. Group 5 Washing of Caustic Leached Slurry

Note: Mass and volume values in figure are rounded to the nearest significant digit of accuracy. 
Table 3.20. Group 5 Caustic Leached Slurry Inventory and Composition After the First Wash

\begin{tabular}{|c|c|c|c|c|c|}
\hline & Slurry $^{(a)}$ & \multicolumn{2}{|c|}{ Liquid Fraction $^{(b)}$} & \multicolumn{2}{|c|}{ Solids Fraction $^{(\mathrm{c})}$} \\
\hline Mass (kg) & 1.61 & \multicolumn{2}{|c|}{1.45} & \multicolumn{2}{|c|}{0.16} \\
\hline Wt\% of Slurry & $100 \%$ & \multicolumn{2}{|c|}{$90.1 \%$} & \multicolumn{2}{|c|}{$9.9 \%$} \\
\hline Metal & g & g & $\mu \mathrm{g} / \mathrm{mL}$ & g & $\mu g / g$ \\
\hline Al & $2.8 \mathrm{E}+01$ & $2.1 \mathrm{E}+01$ & $1.7 \mathrm{E}+04$ & $7.7 \mathrm{E}+00$ & $4.9 \mathrm{E}+04$ \\
\hline Ca & 2.9E-01 & 4.9E-02 & $4.0 \mathrm{E}+01$ & $2.4 \mathrm{E}-01$ & $1.5 \mathrm{E}+03$ \\
\hline $\mathrm{Cr}$ & $1.3 \mathrm{E}+00$ & 4.2E-01 & $3.4 \mathrm{E}+02$ & 9.1E-01 & $5.7 \mathrm{E}+03$ \\
\hline $\mathbf{F e}$ & $2.1 \mathrm{E}+00$ & 5.3E-03 & $4.3 \mathrm{E}+00$ & $2.1 \mathrm{E}+00$ & $1.3 \mathrm{E}+04$ \\
\hline Mn & $1.5 \mathrm{E}+00$ & $<3 . \mathrm{E}-4$ & $<2 . \mathrm{E}-1$ & $1.5 \mathrm{E}+00$ & $9.3 \mathrm{E}+03$ \\
\hline $\mathrm{Na}$ & $1.7 \mathrm{E}+02$ & $1.2 \mathrm{E}+02$ & $9.6 \mathrm{E}+04$ & $4.8 \mathrm{E}+01$ & $3.0 \mathrm{E}+05$ \\
\hline $\mathbf{P}$ & 9.5E-02 & 1.7E-01 & $1.4 \mathrm{E}+02$ & -7.3E-02 & $-4.6 \mathrm{E}+02$ \\
\hline Si & $2.7 \mathrm{E}+00$ & $4.1 \mathrm{E}-02$ & $3.3 \mathrm{E}+01$ & $2.7 \mathrm{E}+00$ & $1.7 \mathrm{E}+04$ \\
\hline $\mathbf{U}$ & $6.6 \mathrm{E}+03$ & $<1 . \mathrm{E}-2$ & $<8 . \mathrm{E}+0$ & $6.6 \mathrm{E}+03$ & $4.2 \mathrm{E}+07$ \\
\hline \multicolumn{6}{|c|}{$\begin{array}{l}\text { (a) Slurry Mass components were calculated from characterization data (WPT-RPT-157), and the } \\
\text { masses of materials that were added with simulant. Loss of mass from sampling was incorporated. } \\
\text { (b) Liquid Fraction mass components were calculated using analytical results from supernate sample } \\
\text { TI540-G5-I (ASO ID 07-01777) and the predicted mass of supernate in the system. } \\
\text { (c) Solids Fraction mass components were calculated from the difference between the slurry } \\
\text { component mass and liquid component mass fraction. }\end{array}$} \\
\hline
\end{tabular}

Table 3.21. Group 5 Caustic Leached Slurry Inventory and Composition after the Second Wash

\begin{tabular}{|c|c|c|c|c|c|}
\hline & Slurry $^{(a)}$ & \multicolumn{2}{|c|}{ Liquid Fraction $^{(b)}$} & \multicolumn{2}{|c|}{ Solids Fraction $^{(\mathrm{c})}$} \\
\hline Mass (kg) & 1.63 & \multicolumn{2}{|c|}{1.47} & \multicolumn{2}{|c|}{0.16} \\
\hline Wt\% of Slurry & $100 \%$ & \multicolumn{2}{|c|}{$90.2 \%$} & \multicolumn{2}{|c|}{$9.8 \%$} \\
\hline Metal & g & g & $\mu g / m L$ & g & $\mu g / g$ \\
\hline Al & $1.9 \mathrm{E}+01$ & $1.1 \mathrm{E}+01$ & $8.3 \mathrm{E}+03$ & $8.1 \mathrm{E}+00$ & $5.1 \mathrm{E}+04$ \\
\hline Ca & $2.6 \mathrm{E}-01$ & 3.7E-02 & $2.8 \mathrm{E}+01$ & 2.2E-01 & $1.4 \mathrm{E}+03$ \\
\hline $\mathrm{Cr}$ & $1.1 \mathrm{E}+00$ & 2.3E-01 & $1.7 \mathrm{E}+02$ & $9.1 \mathrm{E}-01$ & $5.7 \mathrm{E}+03$ \\
\hline $\mathbf{F e}$ & $2.1 \mathrm{E}+00$ & $<3 . \mathrm{E}-3$ & $<2 . \mathrm{E}+0$ & $2.1 \mathrm{E}+00$ & $1.3 \mathrm{E}+04$ \\
\hline Mn & $1.5 \mathrm{E}+00$ & $<3 . \mathrm{E}-4$ & $<2$.E-1 & $1.5 \mathrm{E}+00$ & $9.3 \mathrm{E}+03$ \\
\hline $\mathrm{Na}$ & $1.2 \mathrm{E}+02$ & $7.5 \mathrm{E}+01$ & $5.6 \mathrm{E}+04$ & $5.0 \mathrm{E}+01$ & $3.1 \mathrm{E}+05$ \\
\hline $\mathbf{P}$ & $2.1 \mathrm{E}-02$ & 8.8E-02 & $6.6 \mathrm{E}+01$ & -6.7E-02 & $-4.2 \mathrm{E}+02$ \\
\hline Si & $2.7 \mathrm{E}+00$ & 2.7E-02 & $2.0 \mathrm{E}+01$ & $2.7 \mathrm{E}+00$ & $1.7 \mathrm{E}+04$ \\
\hline $\mathbf{U}$ & $6.6 \mathrm{E}+03$ & $<1 . \mathrm{E}-2$ & $<8 . \mathrm{E}+0$ & $6.6 \mathrm{E}+03$ & $4.2 \mathrm{E}+07$ \\
\hline \multicolumn{6}{|c|}{$\begin{array}{l}\text { (a) Slurry Mass components were calculated from characterization data (WPT-RPT-157), and the } \\
\text { masses of materials that were added with simulant. Loss of mass from sampling was incorporated. } \\
\text { (b) Liquid Fraction mass components were calculated using analytical results from supernate sample } \\
\text { TI540-G5-K (ASO ID 07-01778) and the predicted mass of supernate in the system. } \\
\text { (c) Solids Fraction mass components were calculated from the difference between the slurry } \\
\text { component mass and liquid component mass fraction. }\end{array}$} \\
\hline
\end{tabular}


Table 3.22. Group 5 Caustic leached Slurry Inventory and Composition After the Third Wash

\begin{tabular}{|c|c|c|c|c|c|}
\hline & Slurry $^{(a)}$ & \multicolumn{2}{|c|}{ Liquid Fraction $^{(b)}$} & \multicolumn{2}{|c|}{ Solids Fraction $^{(\mathrm{c})}$} \\
\hline Mass (kg) & 2.22 & \multicolumn{2}{|c|}{2.06} & \multicolumn{2}{|c|}{0.16} \\
\hline Wt\% of Slurry & $100 \%$ & \multicolumn{2}{|c|}{$92.8 \%$} & \multicolumn{2}{|c|}{$7.2 \%$} \\
\hline Metal & g & g & $\mu g / m L$ & g & $\mu g / g$ \\
\hline Al & $1.7 \mathrm{E}+01$ & $8.1 \mathrm{E}+00$ & $4.2 \mathrm{E}+03$ & $8.6 \mathrm{E}+00$ & $5.4 \mathrm{E}+04$ \\
\hline Ca & 2.3E-01 & $5.6 \mathrm{E}-02$ & $2.9 \mathrm{E}+01$ & $1.7 \mathrm{E}-01$ & $1.1 \mathrm{E}+03$ \\
\hline $\mathrm{Cr}$ & $1.0 \mathrm{E}+00$ & $1.8 \mathrm{E}-01$ & $9.4 \mathrm{E}+01$ & 8.6E-01 & $5.4 \mathrm{E}+03$ \\
\hline $\mathbf{F e}$ & $2.1 \mathrm{E}+00$ & $<4 . \mathrm{E}-3$ & $<2 . \mathrm{E}+0$ & $2.1 \mathrm{E}+00$ & $1.3 \mathrm{E}+04$ \\
\hline Mn & $1.5 \mathrm{E}+00$ & $<4$.E-4 & $<2$.E- 1 & $1.5 \mathrm{E}+00$ & $9.3 \mathrm{E}+03$ \\
\hline $\mathrm{Na}$ & $9.1 \mathrm{E}+01$ & $6.3 \mathrm{E}+01$ & $3.3 \mathrm{E}+04$ & $2.8 \mathrm{E}+01$ & $1.8 \mathrm{E}+05$ \\
\hline $\mathbf{P}$ & 2.1E-02 & 7.1E-02 & $3.7 \mathrm{E}+01$ & $-5.0 \mathrm{E}-02$ & $-3.1 \mathrm{E}+02$ \\
\hline Si & $2.7 \mathrm{E}+00$ & $2.4 \mathrm{E}-02$ & $1.3 \mathrm{E}+01$ & $2.7 \mathrm{E}+00$ & $1.7 \mathrm{E}+04$ \\
\hline $\mathbf{U}$ & $6.6 \mathrm{E}+03$ & $<2$. E-2 & $<8 . \mathrm{E}+0$ & $6.6 \mathrm{E}+03$ & $4.2 \mathrm{E}+07$ \\
\hline \multirow{2}{*}{$\begin{array}{l}\text { Radiochemical } \\
\text { Isotopes }\end{array}$} & Slurry & \multicolumn{2}{|c|}{ Liquid Fraction } & \multicolumn{2}{|c|}{ Solid Fraction } \\
\hline & $\mathrm{mCi}$ & $\mathrm{mCi}$ & $\mathrm{mCi} / \mathrm{mL}$ & mCi & $\mathrm{mCi} / \mathrm{g}$ \\
\hline Co-60 & 7.7E-01 & $<1$.E-1 & $<6$. E-5 & 7.7E-01 & 4.9E-03 \\
\hline Cs-137 & $1.6 \mathrm{E}+04$ & $2.2 \mathrm{E}+03$ & $1.2 \mathrm{E}+00$ & $1.4 \mathrm{E}+04$ & $9.0 \mathrm{E}+01$ \\
\hline Eu-154 & $4.2 \mathrm{E}+01$ & $<4$.E-1 & $<2$.E-4 & $4.2 \mathrm{E}+01$ & 2.6E-01 \\
\hline Am-241 & $1.0 \mathrm{E}+02$ & $<4 . \mathrm{E}+0$ & $<2$.E-3 & $1.0 \mathrm{E}+02$ & $6.6 \mathrm{E}-01$ \\
\hline Gross Alpha & $2.7 \mathrm{E}+02$ & $<1 . \mathrm{E}+0$ & $<6 . \mathrm{E}-4$ & $2.7 \mathrm{E}+02$ & $1.7 \mathrm{E}+00$ \\
\hline Gross Beta & $5.2 \mathrm{E}+05$ & $2.3 \mathrm{E}+03$ & $1.2 \mathrm{E}+00$ & $5.1 \mathrm{E}+05$ & $3.2 \mathrm{E}+03$ \\
\hline Sr-90 & $2.2 \mathrm{E}+05$ & $9.5 \mathrm{E}+01$ & $5.0 \mathrm{E}-02$ & $2.2 \mathrm{E}+05$ & $1.4 \mathrm{E}+03$ \\
\hline Pu-239+240 & $3.0 \mathrm{E}+02$ & 4.5E-03 & $2.4 \mathrm{E}-06$ & $3.0 \mathrm{E}+02$ & $1.9 \mathrm{E}+00$ \\
\hline Pu-238 & $7.7 \mathrm{E}+00$ & $<2$.E-3 & $<$ 1.E-6 & $7.7 \mathrm{E}+00$ & 4.9E-02 \\
\hline \multirow[t]{2}{*}{ Anions } & \multicolumn{3}{|c|}{ Liquid Fraction } & & \\
\hline & $\mu \mathrm{g} / \mathrm{mL}$ & [M] & g & & \\
\hline $\mathbf{F}$ & $<3 . \mathrm{E}-1$ & $<2$. E-5 & $5.9 \mathrm{E}-04$ & & \\
\hline $\mathrm{C}_{2} \mathrm{O}_{4}$ & $1.2 \mathrm{E}+02$ & 1.3E-03 & 2.2E-01 & & \\
\hline $\mathrm{NO}_{2}$ & $1.7 \mathrm{E}+03$ & 3.7E-02 & $3.3 \mathrm{E}+00$ & & \\
\hline $\mathrm{NO}_{3}$ & $6.3 \mathrm{E}+03$ & $1.0 \mathrm{E}-01$ & $1.2 \mathrm{E}+01$ & & \\
\hline $\mathrm{SO}_{4}$ & $3.9 \mathrm{E}+01$ & 4.1E-04 & 7.5E-02 & & \\
\hline $\mathrm{PO}_{4}$ & $9.5 \mathrm{E}+01$ & $1.0 \mathrm{E}-03$ & $1.8 \mathrm{E}-01$ & & \\
\hline $\mathrm{OH}$ & $1.8 \mathrm{E}+04$ & $1.1 \mathrm{E}+00$ & $3.5 \mathrm{E}+01$ & & \\
\hline \multicolumn{6}{|c|}{$\begin{array}{l}\text { (a) Slurry Mass components were calculated from characterization data (WPT-RPT-157), and the } \\
\text { masses of materials that were added with simulant. Loss of mass from sampling was incorporated } \\
\text { (b) Liquid Fraction mass components were calculated using analytical results from supernate sample } \\
\text { TI540-G5-M (ASO ID 07-01781) and the predicted mass of supernate in the system. } \\
\text { (c) Solids Fraction mass components were calculated from the difference between the slurry } \\
\text { component mass and liquid component mass fraction. }\end{array}$} \\
\hline
\end{tabular}


Table 3.23. Caustic Wash Solutions Radionuclide and Opportunistic Compositions

\begin{tabular}{|c|c|c|c|c|}
\hline & Wash 1 & Wash 2 & Wash 3 & Composite Wash 1 - 3 \\
\hline ASO Sample ID & 07-01777 & 07-01778 & 07-01781 & 07-1782 \\
\hline Density $^{(a)}, \mathrm{g} / \mathrm{mL}>$ & 1.18 & 1.11 & 1.08 & \\
\hline \multicolumn{5}{|l|}{ Analyte } \\
\hline free $\mathrm{OH}, \mathrm{M}$ & $2.69 \mathrm{M}$ & $1.77 \mathrm{M}$ & $1.07 \mathrm{M}$ & \\
\hline $\begin{array}{l}\text { Radionuclides } \\
\text { Analyte }\end{array}$ & $\mu \mathrm{Ci} / \mathrm{mL}$ & $\mu \mathrm{Ci} / \mathrm{mL}$ & $\mu \mathrm{Ci} / \mathbf{m L}$ & $\mu \mathrm{Ci} / \mathrm{mL}$ \\
\hline${ }^{137} \mathrm{Cs}$ & & & $1.15 \mathrm{E}+0$ & $2.63 \mathrm{E}+0$ \\
\hline${ }^{60} \mathrm{Co}$ & & & $<6 . \mathrm{E}-5$ & $<6 . \mathrm{E}-5$ \\
\hline${ }^{241} \mathrm{Am}$ & & & $<2$.E-3 & $<3 . \mathrm{E}-3$ \\
\hline${ }^{90} \mathrm{Sr}$ & & & $4.98 \mathrm{E}-2$ & $7.76 \mathrm{E}-2$ \\
\hline${ }^{238} \mathrm{Pu}$ & & & $<1 . \mathrm{E}-6$ & $<1 . \mathrm{E}-6$ \\
\hline${ }^{239+240} \mathrm{Pu}$ & & & $2.36 \mathrm{E}-6$ & $8.35 \mathrm{E}-6$ \\
\hline Gross alpha & & & $<6$.E-4 & $<7 . \mathrm{E}-4$ \\
\hline Gross beta & & & $1.18 \mathrm{E}+0$ & $2.52 \mathrm{E}+0$ \\
\hline${ }^{154} \mathrm{Eu}$ & & & $<2$.E-4 & $<2 . \mathrm{E}-4$ \\
\hline $\begin{array}{l}\text { Opportunistic } \\
\text { Analyte } \\
\end{array}$ & $\mu \mathrm{g} / \mathrm{mL}$ & $\mu \mathrm{g} / \mathrm{mL}$ & $\mu \mathrm{g} / \mathrm{mL}$ & $\mu \mathrm{g} / \mathrm{mL}$ \\
\hline Ag & $<4.2 \mathrm{E}-1$ & $<4.2 \mathrm{E}-1$ & $<4.2 \mathrm{E}-1$ & $<4.3 \mathrm{E}-1$ \\
\hline As & $<7.0 \mathrm{E}+0$ & $<7.0 \mathrm{E}+0$ & $<7.0 \mathrm{E}+0$ & $<7.0 \mathrm{E}+0$ \\
\hline Ba & {$[0.42]$} & {$[0.34]$} & $<3.4 \mathrm{E}-1$ & {$[0.47]$} \\
\hline Be & $<1.2 \mathrm{E}-2$ & $<1.2 \mathrm{E}-2$ & $<1.2 \mathrm{E}-2$ & $<1.2 \mathrm{E}-2$ \\
\hline Ca & 39.7 & 27.9 & 29.2 & 27.2 \\
\hline Ce & $<1.2 \mathrm{E}+0$ & $<1.2 \mathrm{E}+0$ & $<1.2 \mathrm{E}+0$ & $<1.2 \mathrm{E}+0$ \\
\hline Co & $<3.9 \mathrm{E}-1$ & $<3.9 \mathrm{E}-1$ & $<3.9 \mathrm{E}-1$ & $<3.9 \mathrm{E}-1$ \\
\hline $\mathbf{C u}$ & [1.5] & {$[0.66]$} & $<4.9 \mathrm{E}-1$ & {$[0.86]$} \\
\hline Dy & $<3.5 \mathrm{E}-1$ & $<3.5 \mathrm{E}-1$ & $<3.5 \mathrm{E}-1$ & $<3.5 \mathrm{E}-1$ \\
\hline Eu & $<1.1 \mathrm{E}-1$ & $<1.1 \mathrm{E}-1$ & $<1.1 \mathrm{E}-1$ & $<1.1 \mathrm{E}-1$ \\
\hline La & $<1.3 \mathrm{E}-1$ & $<1.3 \mathrm{E}-1$ & $<1.3 \mathrm{E}-1$ & $<1.3 \mathrm{E}-1$ \\
\hline $\mathbf{L i}$ & $<5.5 \mathrm{E}-1$ & $<5.5 \mathrm{E}-1$ & {$[0.87]$} & $<5.5 \mathrm{E}-1$ \\
\hline Mg & [6.3] & [4.6] & [4.8] & [4.5] \\
\hline Mo & [1.8] & [1.3] & $<6.6 \mathrm{E}-1$ & {$[0.82]$} \\
\hline Nd & $<1.7 \mathrm{E}+0$ & $<1.7 \mathrm{E}+0$ & $<1.7 \mathrm{E}+0$ & $<1.7 \mathrm{E}+0$ \\
\hline $\mathbf{P b}$ & $<3.7 \mathrm{E}+0$ & $<3.7 \mathrm{E}+0$ & $<3.7 \mathrm{E}+0$ & $<3.7 \mathrm{E}+0$ \\
\hline Pd & $<1.3 \mathrm{E}+0$ & $<1.3 \mathrm{E}+0$ & $<1.3 \mathrm{E}+0$ & $<1.3 \mathrm{E}+0$ \\
\hline $\mathbf{R h}$ & $<2.5 \mathrm{E}+0$ & $<2.5 \mathrm{E}+0$ & $<2.5 \mathrm{E}+0$ & $<2.6 \mathrm{E}+0$ \\
\hline Ru & $<8.3 \mathrm{E}-1$ & $<8.2 \mathrm{E}-1$ & $<8.3 \mathrm{E}-1$ & $<8.3 \mathrm{E}-1$ \\
\hline Sb & $<3.2 \mathrm{E}+0$ & $<3.2 \mathrm{E}+0$ & $<3.2 \mathrm{E}+0$ & $<3.2 \mathrm{E}+0$ \\
\hline Se & $<4.9 \mathrm{E}+0$ & $<4.9 \mathrm{E}+0$ & [5.6] & [6.2] \\
\hline Sn & [5.3] & [2.65] & $<2.0 \mathrm{E}+0$ & [2.8] \\
\hline Ta & $<1.3 \mathrm{E}+0$ & $<1.3 \mathrm{E}+0$ & $<1.3 \mathrm{E}+0$ & $<1.3 \mathrm{E}+0$ \\
\hline
\end{tabular}


Table 3.23 (Contd)

\begin{tabular}{||c|c|c|c|c||}
\hline & Wash 1 & Wash 2 & Wash 3 & Composite Wash 1 - 3 \\
\hline ASO Sample ID & $\mathbf{0 7 - 0 1 7 7 7}$ & $\mathbf{0 7 - 0 1 7 7 8}$ & $\mathbf{0 7 - 0 1 7 8 1}$ & $\mathbf{0 7 - 1 7 8 2}$ \\
\hline $\begin{array}{l}\text { Opportunistic } \\
\text { Analyte }\end{array}$ & $\boldsymbol{\mu g} / \mathbf{m L}$ & $\boldsymbol{\mu g} / \mathbf{m L}$ & $\boldsymbol{\mu g} / \mathbf{m L}$ & $\mu \mathbf{g} / \mathbf{m L}$ \\
\hline $\mathbf{T e}$ & $<3.2 \mathrm{E}+0$ & $<3.2 \mathrm{E}+0$ & $<3.2 \mathrm{E}+0$ & $<3.2 \mathrm{E}+0$ \\
\hline $\mathbf{T h}$ & $<1.2 \mathrm{E}+0$ & $<1.2 \mathrm{E}+0$ & $<1.2 \mathrm{E}+0$ & $<1.2 \mathrm{E}+0$ \\
\hline $\mathbf{T i}$ & $<9.7 \mathrm{E}-2$ & $<9.7 \mathrm{E}-2$ & $<9.7 \mathrm{E}-2$ & $<9.8 \mathrm{E}-2$ \\
\hline $\mathbf{T l}$ & $<6.5 \mathrm{E}+0$ & $<6.5 \mathrm{E}+0$ & $<6.5 \mathrm{E}+0$ & $<6.6 \mathrm{E}+0$ \\
\hline $\mathbf{V}$ & $<3.2 \mathrm{E}-1$ & $<3.2 \mathrm{E}-1$ & $<3.2 \mathrm{E}-1$ & $<3.2 \mathrm{E}-1$ \\
\hline $\mathbf{W}$ & $<1.5 \mathrm{E}+0$ & $<1.5 \mathrm{E}+0$ & $<1.5 \mathrm{E}+0$ & $<1.5 \mathrm{E}+0$ \\
\hline $\mathbf{Y}$ & $<8.5 \mathrm{E}-2$ & $<8.5 \mathrm{E}-2$ & $<8.5 \mathrm{E}-2$ & $<8.5 \mathrm{E}-2$ \\
\hline
\end{tabular}

(a) Density values were obtained from the mass flow meter, which had not been calibrated to NQA-1 standards; they are reported for information only.

ASR 7998 Reference date: November 5, 2007.

Analyte uncertainties were typically within $\pm 15 \%$; results in brackets indicate that the analyte concentrations were greater than the method detection limit (MDL) and less than the estimated quantitation limit (EQL), and uncertainties were $>15 \%$.

Opportunistic analytes are reported for information only; QC requirements did not apply to these analytes.

The quantity of aluminum in the slurry during the test is shown in Figure 3.36. The leach factor for the solid aluminum during caustic leaching was $73 \%$ (121 grams of solid aluminum before the leach to 33 grams after the leach). After the three washes, the total aluminum in the slurry had decreased from 125 grams to 22 grams, or $82 \%$ (Figure 3.39). A large portion of the aluminum exited the slurry during the caustic dewatering (as can be seen between the 12-hour leach and the first wash). The aluminum likely continued to leach during the cool-down period, explaining the increased reduction of solid aluminum in the slurry at the beginning of the washes. It should also be noted that the three washes did not sufficiently wash out the aluminum in the supernate-further washing would have removed more of the aluminum.

During initial characterization of the Group 5 waste group (WTP-RPT-157), the chromium solubility in the supernate was determined to be $70 \%$, and, based on dewatering values, the CUF chromium solubility in the supernate was $69 \%$. Therefore, a significant portion of the chromium was soluble before the caustic leach, and it appears that the leach had little to no effect on the water-insoluble chromium in this waste (Figure 3.37). The total initial amount of chromium in the high-solids CUF slurry before caustic leaching was 3,500 mg. Following the caustic leach and the post-caustic leach washing, the slurry chromium content had been reduced to $1,200 \mathrm{mg}$. This is a removal of $66 \%$ of the total initial chromium mass, all of which was soluble prior to the caustic leach (Figure 3.39).

Phosphorous was also found in the Group 5 slurry. A large majority of the phosphorus present was found to be soluble phosphate in the supernate of the slurry. The mass of phosphorous in the slurry was tracked thro $\mu$ gh the test as shown in Figure 3.38. The solid caustic leach factor for the phosphorus in this waste type was $88 \%$, and almost all of the phosphorus (97\%) was removed by subsequent dewatering and washing operations.

The sodium molarity in the total slurry, as well as the sodium, free hydroxide and aluminum molarities in the supernate are outlined in Figure 3.40. During caustic leaching operations, the molarities increased 
WPT-RPT-172, Rev 0

because of evaporation. The sodium, free hydroxide, and aluminum concentrations tracked consistently with each other. 


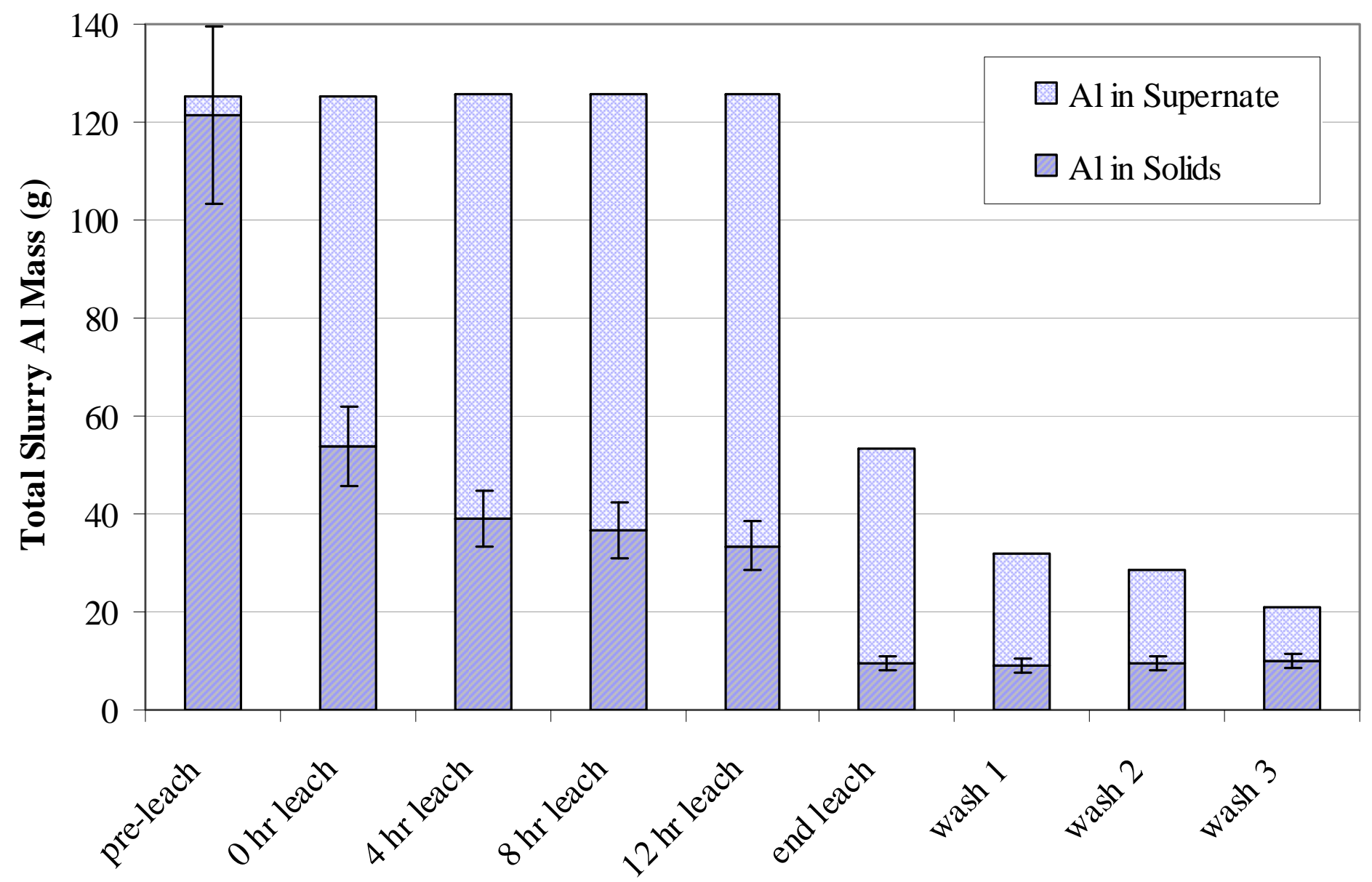

Figure 3.36. Normalized Aluminum Inventory in Group 5 Slurry through Caustic Leach and Washing (Inventory in Figure Normalized to Eliminate Sample Loss Impacts) 


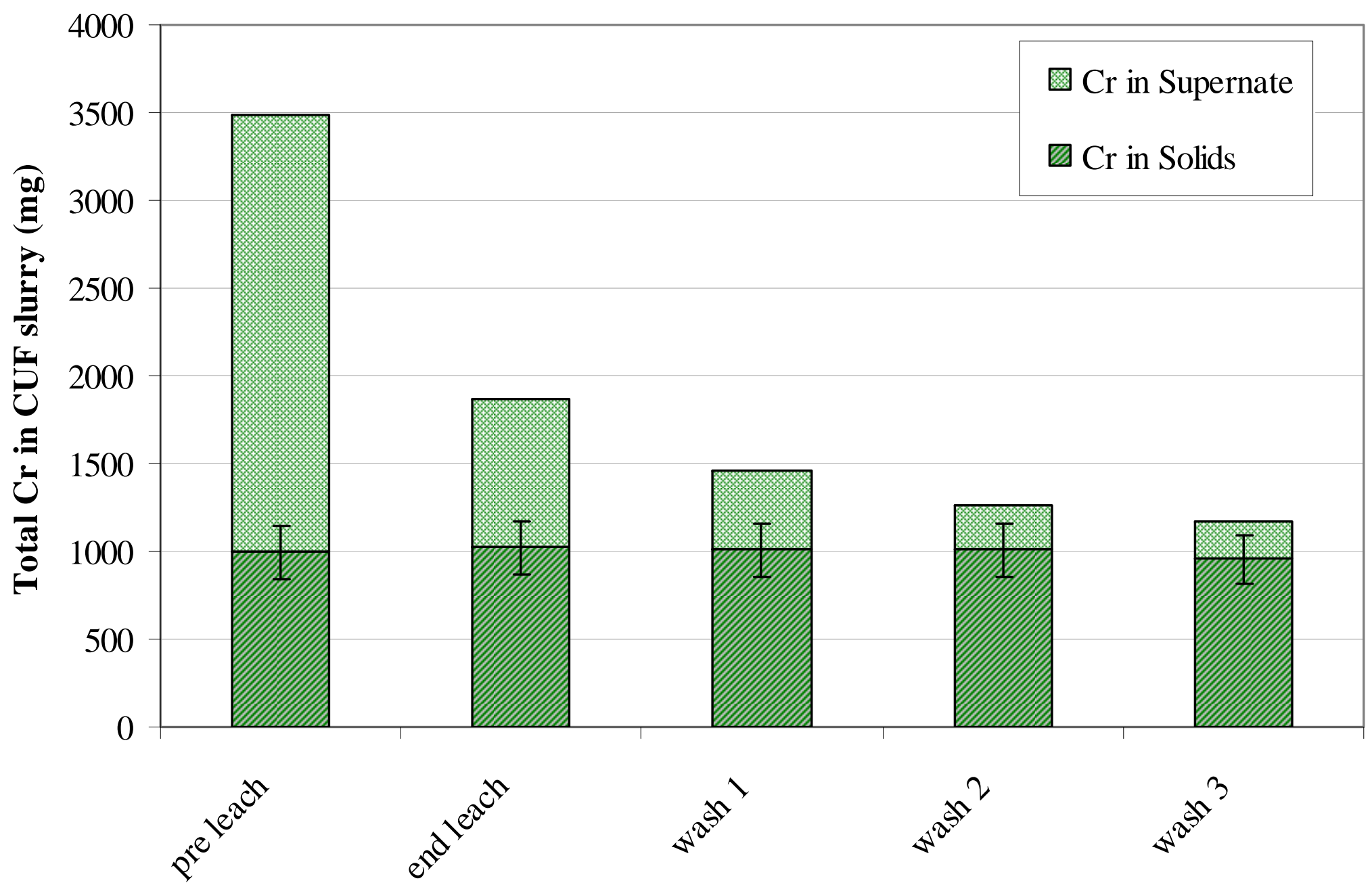

Figure 3.37. Normalized Chromium Inventory in Group 5 Slurry through Caustic Leaching and Washing (Inventory in Figure Normalized to Eliminate Sample Loss Impacts) 
WPT-RPT-172, Rev 0

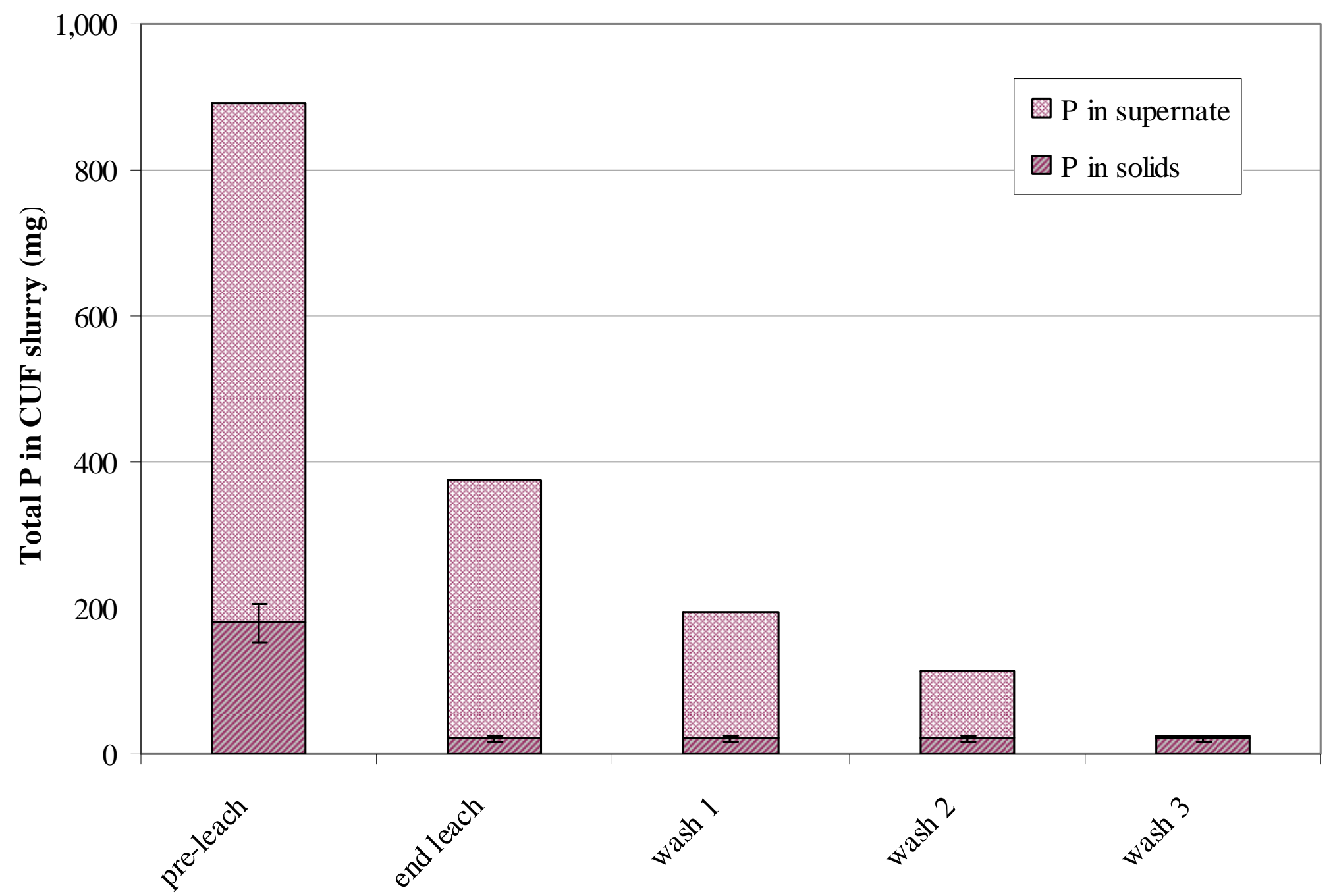

Figure 3.38. Normalized Phosphorus Inventory in Group 5 Slurry through Caustic Leaching and Washing (Inventory in Figure Normalized to Eliminate Sample Loss Impacts) 
WPT-RPT-172, Rev 0

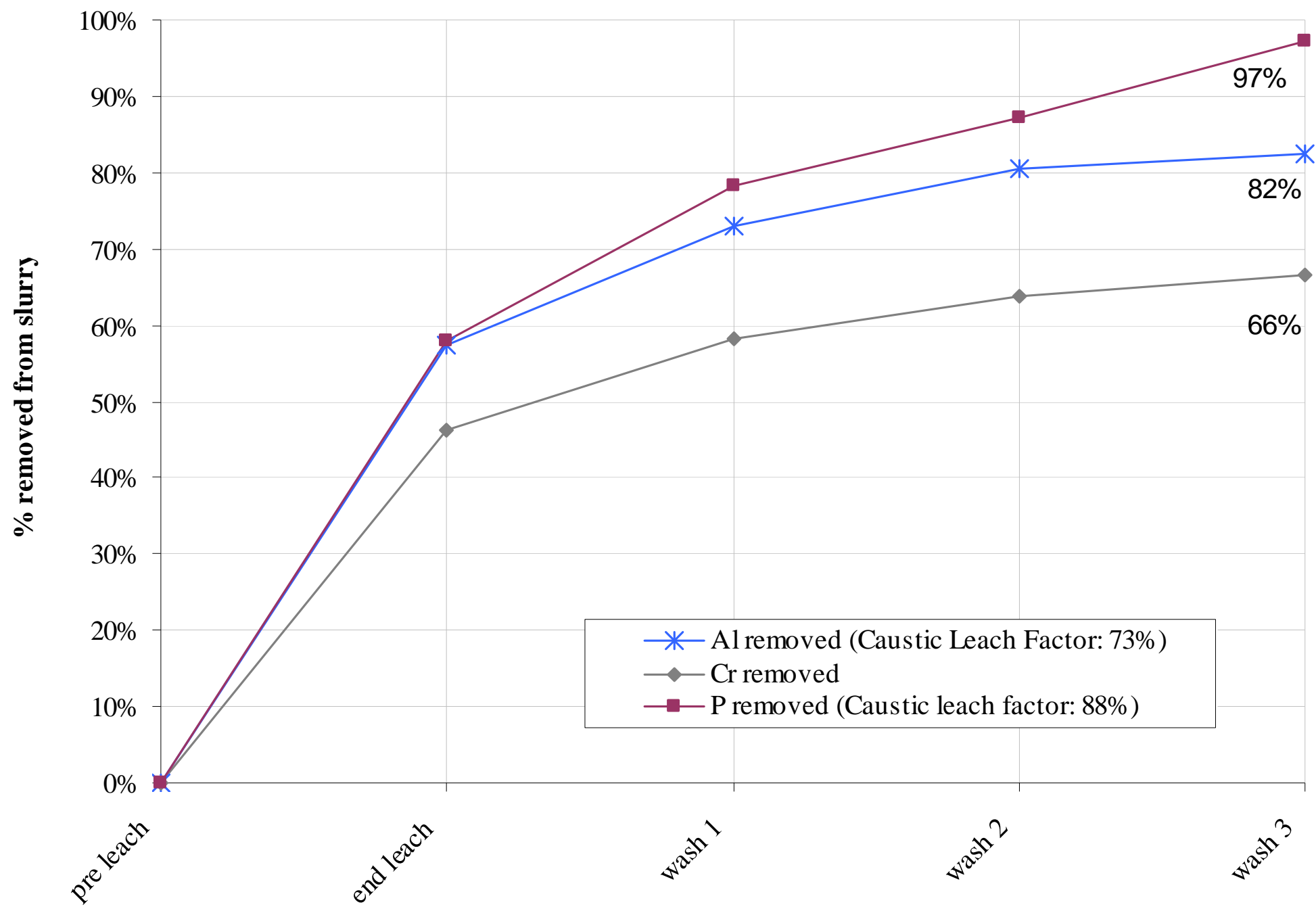

Figure 3.39. $\mathrm{Al} / \mathrm{Cr} / \mathrm{P}$ removed from the Group 5 CUF Slurry (Inventory in Figure Normalized to Eliminate Sample Loss Impacts) 


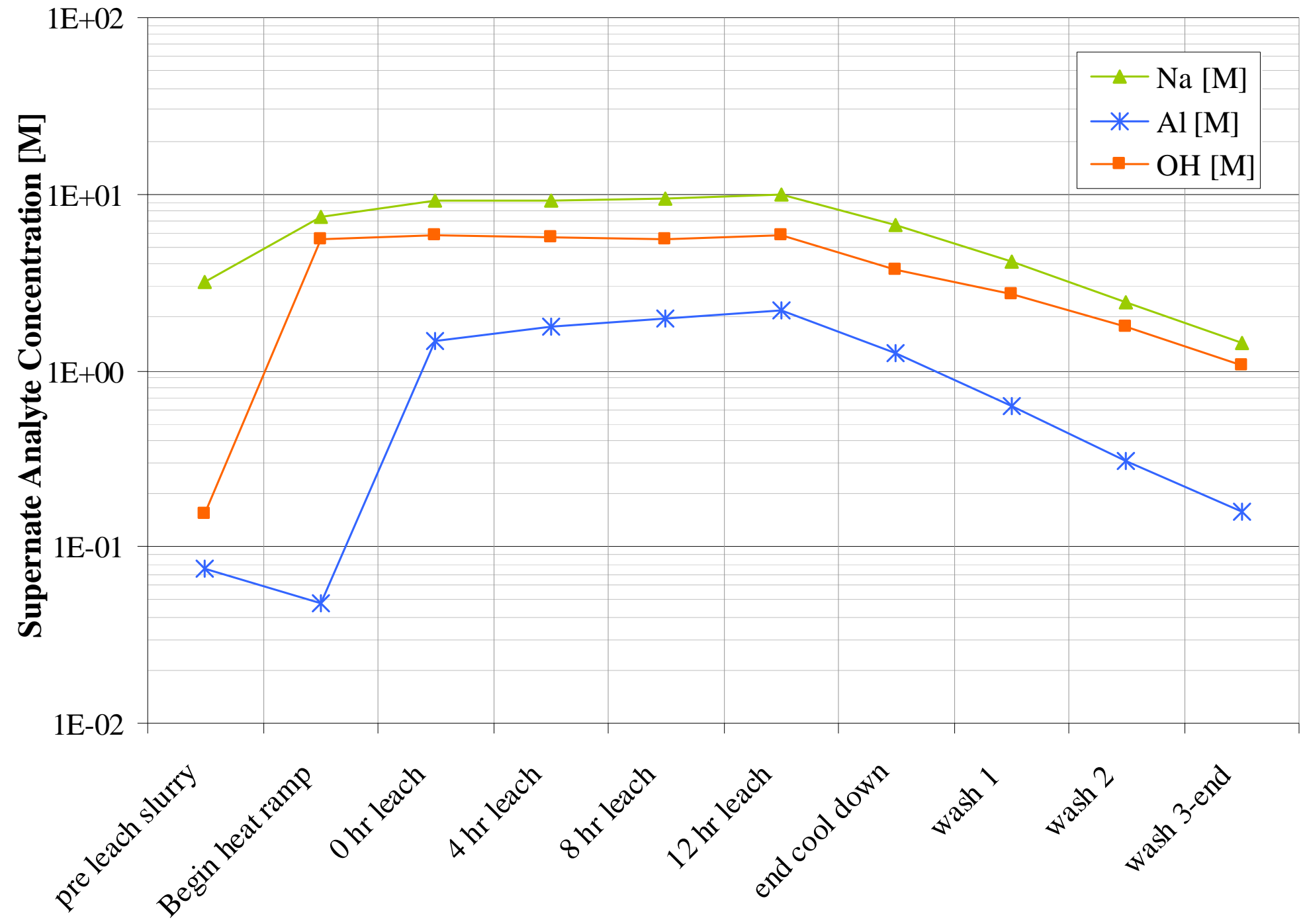

Figure 3.40. Sodium and Free Hydroxide Molarity in Group 5 CUF Slurry 


\subsubsection{Dewatering Caustic Wash Solutions}

The filter flux results from dewatering the slurry after each wash solution is summarized in Table 3.24 below. The filtration of the wash solutions occurred rapidly. For the three washes, the 1.2-L wash volume was filtered from the slurry in 19, 9, and 7 minutes, sequentially.

Table 3.24. Group 5 Comparison of Washed Slurry Supernate Attributes to Filter Flux

\begin{tabular}{|l|c|c|c|c|c|c||}
\hline \hline & $\begin{array}{c}\text { Wash } \\
\text { Volume (L) }\end{array}$ & $\begin{array}{c}\text { NaOH } \\
\text { Concentration } \\
\text { of Wash } \\
(\mathbf{m o l} / \mathbf{k g})\end{array}$ & $\begin{array}{c}\text { [Na] } \\
\mathbf{M}\end{array}$ & $\begin{array}{c}\text { [OH] } \\
\mathbf{M}\end{array}$ & $\begin{array}{c}\text { [Al] } \\
\mathbf{M}\end{array}$ & $\begin{array}{c}\text { Average Filter } \\
\text { Flux } \\
\left.\text { (GPM/ft }^{2}\right)\end{array}$ \\
\hline Wash 1 & 1.20 & 1.9 & 4.2 & 2.7 & 0.62 & 0.063 \\
\hline Wash 2 & 1.20 & 0.9 & 2.5 & 1.8 & 0.31 & 0.127 \\
\hline Wash 3 & 1.20 & 0.4 & 1.4 & 1.1 & 0.16 & 0.183 \\
\hline
\end{tabular}

\subsection{Final Filter Flux Test Matrix}

After dewatering the third wash solution from the slurry, the pump began to cavitate and to entrain air into the slurry. This resulted in a loss of pumping efficiency making it impossible to reach the desired velocities and pressures needed for the test matrix. It was decided that the best course of action was to return permeate from the last dewatering step back to the slurry. Once $0.4 \mathrm{~L}$ of the filtered supernate was returned, the cavitation stopped and the pumping efficiency improved (Figure 3.41).

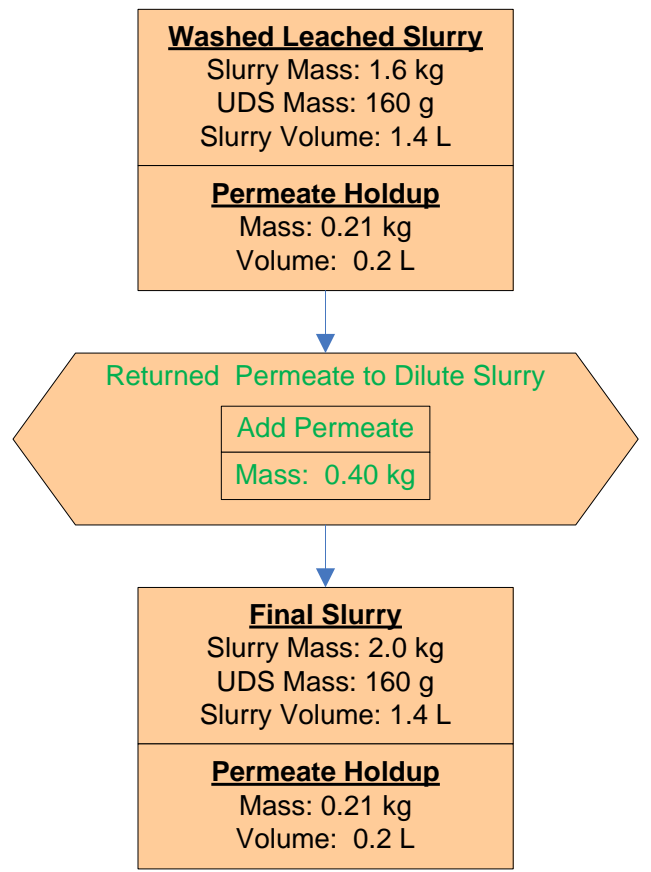

Figure 3.41. Group 5 Dilution of Washed Leached Slurry for Final Matrix Test

A full 11-condition test matrix was performed on the slurry. For all of the test conditions, the permeate flow rate exceeded the range of the digital mass flow meter. The digital flow meter was bypassed, and 
the permeate flow rate was measured using the manual graduated cylinder flow meter and a stopwatch. The sighting of permeate passing the graduations was performed with the assistance of the in-cell video camera, as it is difficult to see the graduations at a distance through the cell window. The resulting average flux data were calculated for the test matrix of the washed solids slurry based on the periodic manual observations. The results of those tests are given in Table 3.25 and plotted with respect to TMP and AV in Figure 3.43 and Figure 3.44.

Modeling of the filter flux test data can be found in Figure 3.45 and Figure 3.46. As before, a statistical least square method was used to fit filter flux as functions of TMP and AV to better compare their impact on filter flux to one another. A linear model was initially used and found a $\mathrm{R}^{2}$ correlation coefficient of 0.90 . The model implies that the effect of each parameter is equally significant and predicts that a $1 \mathrm{ft} / \mathrm{s}$ change in the AV is equivalent to a 2.3 psid change in TMP. An exponential product model was then applied to the data and found that the product of AV and TMP to be proportionate to filter flux with a $\mathrm{R}^{2}$ correlation coefficient of 0.92. As before, the model implies that changes in AV and TMP both significantly impact filter flux. Like with the models presented earlier, it is bounded by the limited range of TMP and AV used to generate the model in Table 3.25. While the correlation coefficients calculated for both models are $>0.8$, they both contain offset values that predict either a negative or positive flux when TMP and AV are zero. This implies that the filtration behavior is more complex than what the models are demonstrating here. For this reason, both models should not be used to predict filter flux outside the range of TMP and AV used in this test matrix.

Table 3.25. Group 5 Average Flux Values for Washed Leached Slurry

\begin{tabular}{|c|c|c|c|c|c|c|}
\hline $\begin{array}{l}\text { Design } \\
\text { Test } \\
\text { Condition }\end{array}$ & $\begin{array}{c}\text { Slurry } \\
\text { Temp }{ }^{(a)} \\
\left({ }^{\circ} \mathrm{C}\right)\end{array}$ & $\begin{array}{c}\operatorname{TMP}^{(\mathbf{b})} \\
\text { (psid) }\end{array}$ & $\begin{array}{c}\text { Axial } \\
\text { Velocity } \\
\text { (ft/s) }\end{array}$ & $\begin{array}{l}\text { Permeate } \\
\text { Flowrate } \\
\text { (mL/min) }\end{array}$ & $\begin{array}{c}\text { Corrected } \\
\text { Permeate } \\
\text { Flux } \\
\left(\text { GPM/ft }{ }^{2}\right)\end{array}$ & $\begin{array}{c}\text { Axial } \\
\text { Pressure } \\
\text { Drop }^{(\mathbf{b})} \\
\text { (psid/ft) }^{\text {pod }}\end{array}$ \\
\hline 1 & 24.2 & 40.3 & 13.2 & 208 & 0.214 & 1.2 \\
\hline 2 & 23.7 & 30.3 & 11.2 & 182 & 0.191 & 0.9 \\
\hline 3 & 24.2 & 30.4 & 15.1 & 204 & 0.210 & 1.2 \\
\hline 4 & 25.3 & 49.9 & 14.6 & 291 & 0.291 & 1.5 \\
\hline 5 & 23.8 & 49.3 & 10.8 & 222 & 0.232 & 1.0 \\
\hline 6 & 24.3 & 39.6 & 13.2 & 192 & 0.198 & 1.1 \\
\hline 7 & 23.6 & 41.3 & 9.0 & 171 & 0.180 & 0.7 \\
\hline 8 & 25.1 & 38.7 & 15.9 & 247 & 0.249 & 1.3 \\
\hline 9 & 24.3 & 21.2 & 13.1 & 143 & 0.147 & 0.9 \\
\hline 10 & 25.4 & 60.8 & 13.2 & 338 & 0.336 & 1.2 \\
\hline 11 & 24.2 & 43.2 & 13.2 & 226 & 0.233 & 1.1 \\
\hline \multicolumn{7}{|c|}{ (a) Thermocouple accuracy $\pm 2^{\circ} \mathrm{C}$. } \\
\hline
\end{tabular}




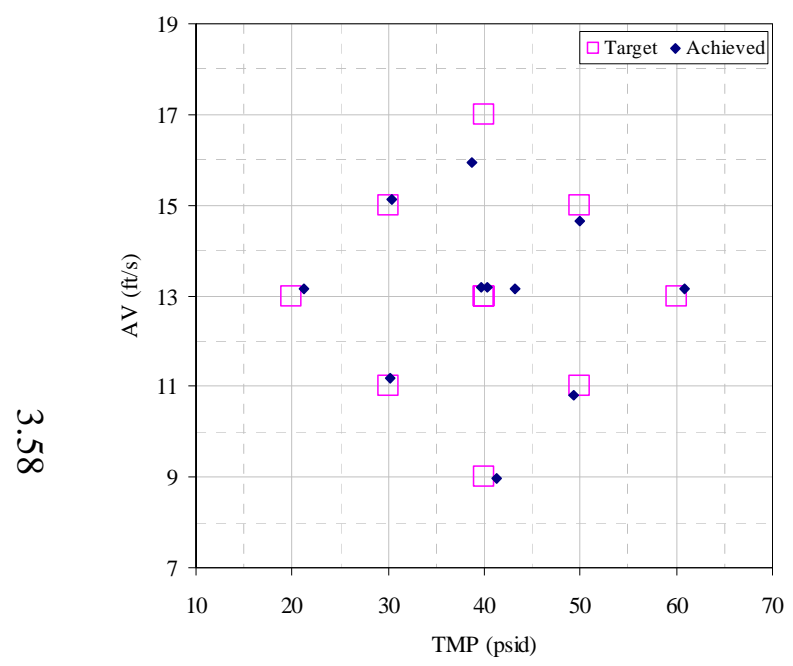

Figure 3.42. Group 5 Filter Test Matrix for the Washed Solids

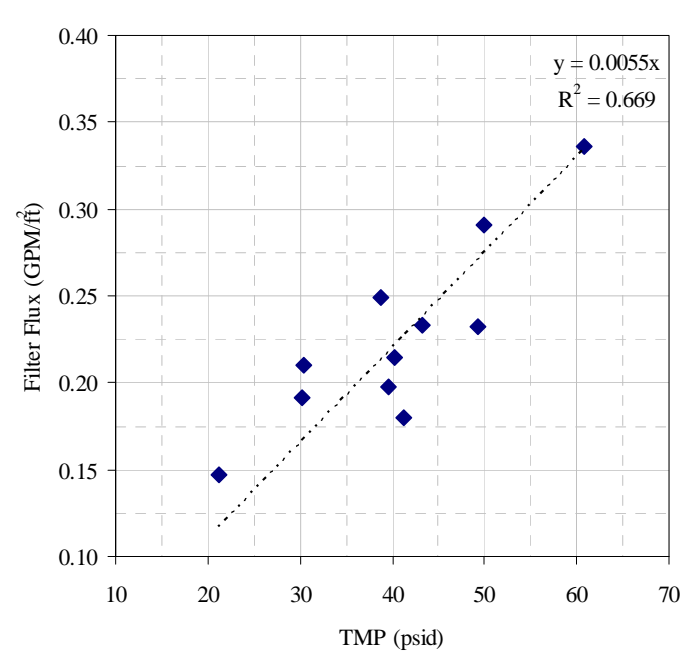

Figure 3.43. Group 5 Flux vs. TMP for Washed Solids

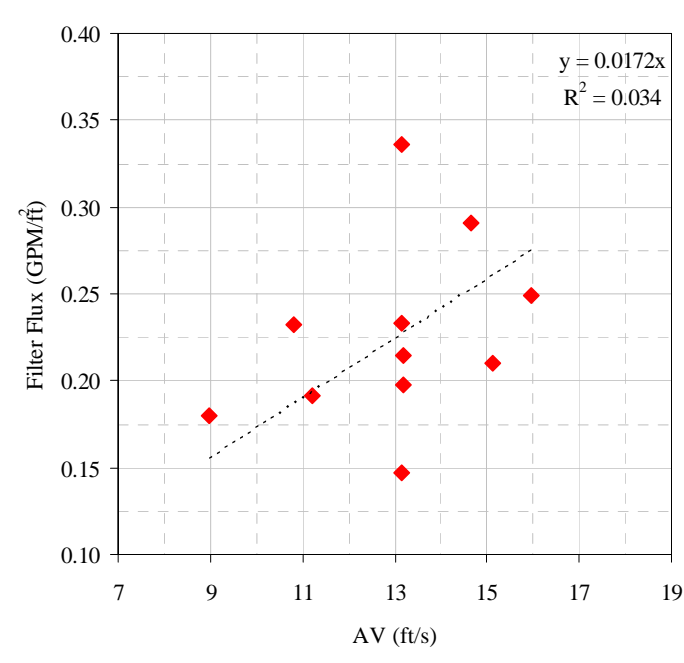

Figure 3.44. Group 5 Flux vs. AV for Washed Solids 


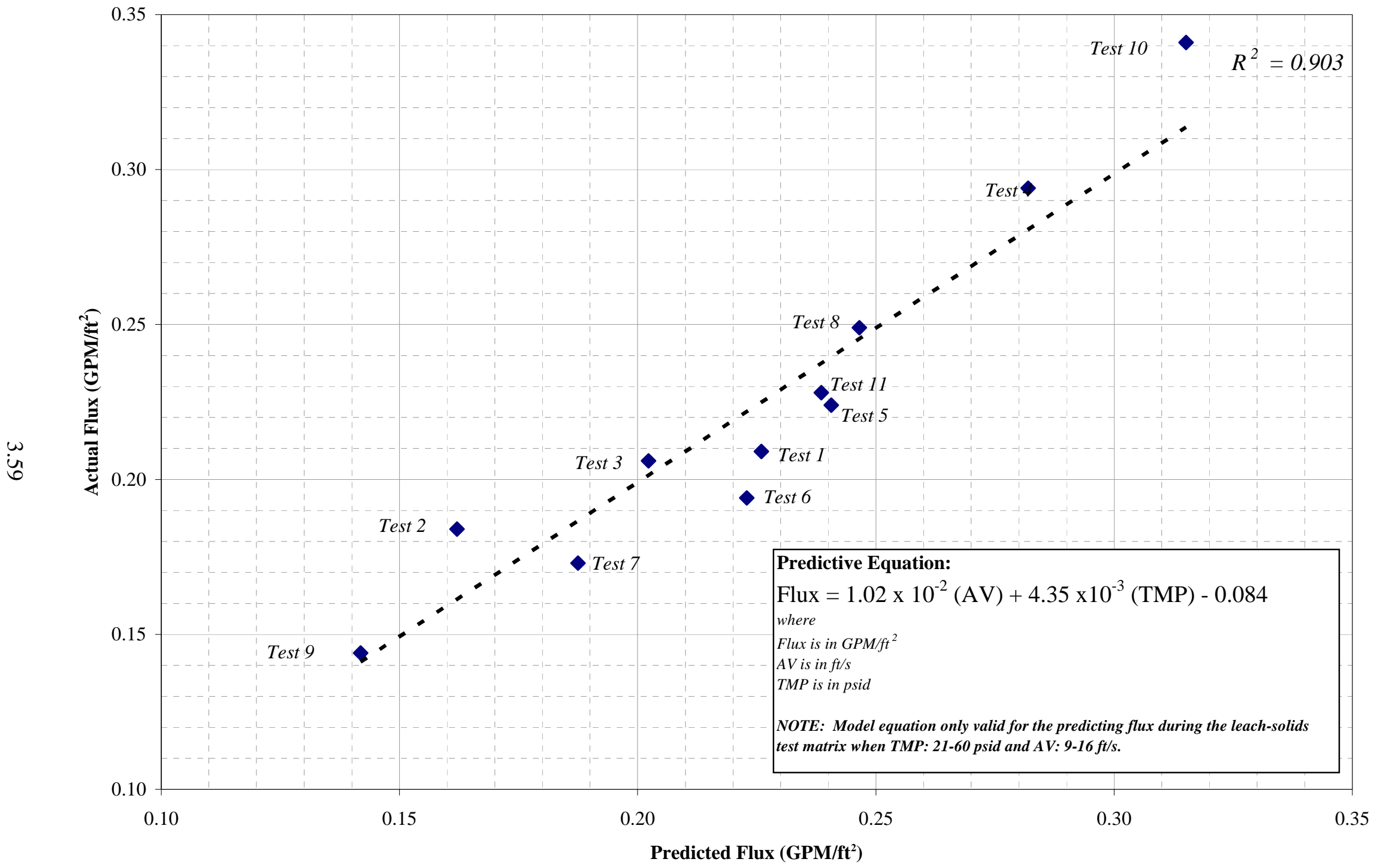

Figure 3.45. Group 5 Least Square Fit of Leached Solid Test Matrix Results with Linear Model 


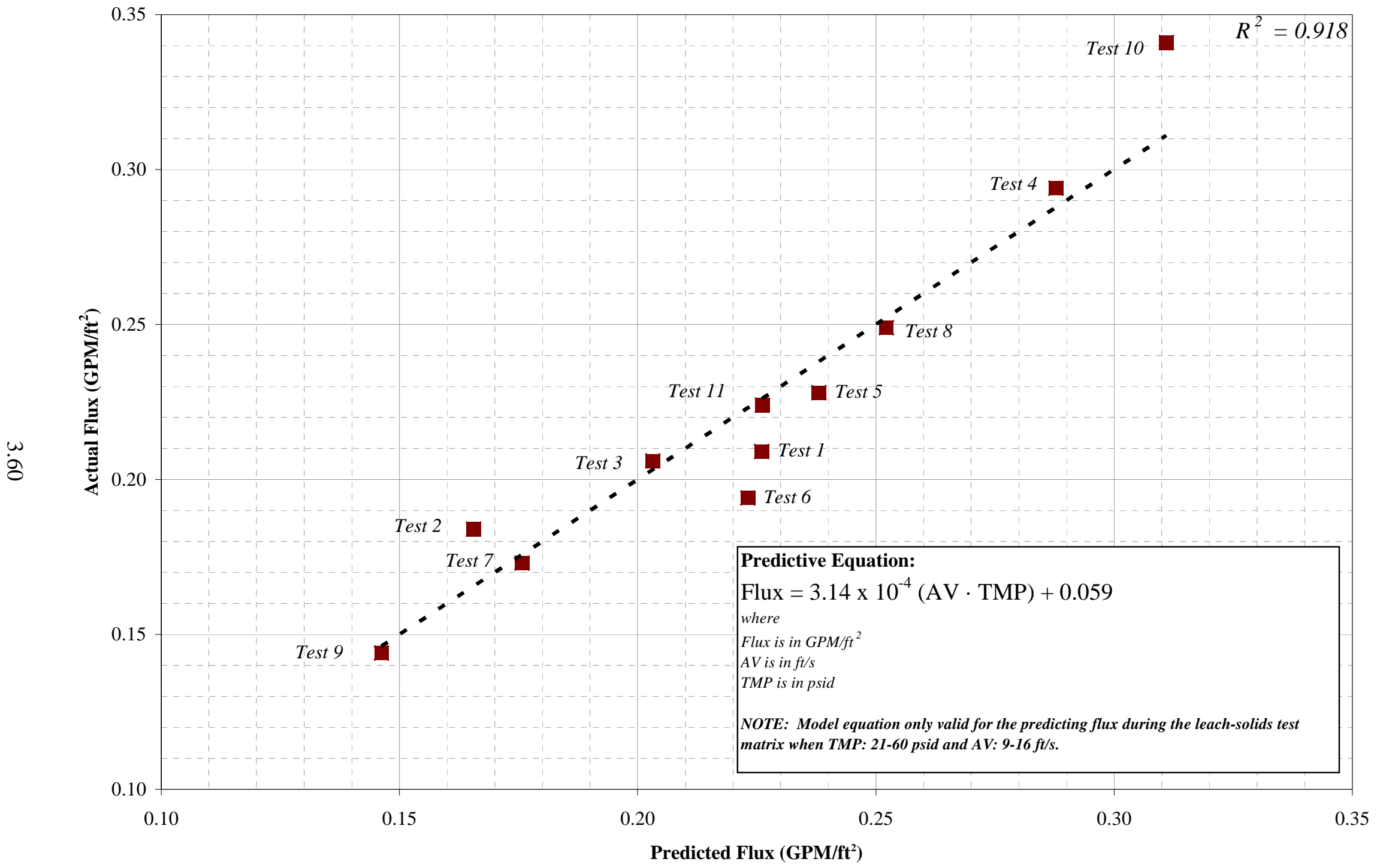

Figure 3.46. Group 5 Least Square Fit of Leached Solid Test Matrix Results with Exponential Model 


\subsection{Leached Material Characterization}

After leaching and washing operations, the slurry was sampled and drained from the CUF. Physical and chemical analyses were performed on the samples collected and the remaining slurry was saved as an archive sample to be utilized later. Physical property data for the leached and washed slurry is shown in Table 3.26. The final UDS measurement of $4.7 \mathrm{wt} \%$ was considerably lower than the expected $7.24 \mathrm{wt} \%$. This is attributed to difficulties sampling the slurry after the viscosity of the supernate being low after washing. However, the high dissolution rate of aluminum during the leach and dilution of the slurry prior to the matrix test also contributed to this. The final composition of the slurry is shown in Table 3.27.

Table 3.26. Group 5 Final Leached and Washed Slurry Physical Property Measurements

\begin{tabular}{|r|c||}
\hline Slurry Density (g/mL) & 1.11 \\
\hline Supernate Density (g/mL) & 1.08 \\
\hline Settled Solids (Vol \%) & $77 \%$ \\
\hline Centrifuged UDS (Wt $\%)$ & $22 \%$ \\
\hline Total Solids (Wt\%) & $14 \%$ \\
\hline Dissolved Solids (Wt\%) & $10 \%$ \\
\hline UDS (Wt $\%)$ & $4.1 \%$ \\
\hline
\end{tabular}


Table 3.27. Group 5 Final Leached and Washed Slurry Composition and Total Inventory

\begin{tabular}{|c|c|c|c|c|c|}
\hline & Slurry $^{(a)}$ & \multicolumn{2}{|c|}{ Liquid Fraction $^{(b)}$} & \multicolumn{2}{|c|}{ Solids Fraction $^{(\mathrm{c})}$} \\
\hline Mass (kg) & 2.21 & \multicolumn{2}{|c|}{2.05} & \multicolumn{2}{|c|}{0.16} \\
\hline Wt\% of Slurry & $100 \%$ & \multicolumn{2}{|c|}{$92.8 \%$} & \multicolumn{2}{|c|}{$7.2 \%$} \\
\hline Metal & g & g & $\mu \mathrm{g} / \mathrm{mL}$ & g & $\mu \mathrm{g} / \mathrm{g}$ \\
\hline Al & $1.5 \mathrm{E}+01$ & $7.6 \mathrm{E}+00$ & $4.2 \mathrm{E}+03$ & $7.0 \mathrm{E}+00$ & 4.7E+04 \\
\hline Ca & 2.3E-01 & $5.2 \mathrm{E}-02$ & $2.9 \mathrm{E}+01$ & $1.8 \mathrm{E}-01$ & $1.2 \mathrm{E}+03$ \\
\hline $\mathrm{Cr}$ & $9.4 \mathrm{E}-01$ & $1.7 \mathrm{E}-01$ & $9.4 \mathrm{E}+01$ & 7.7E-01 & $5.1 \mathrm{E}+03$ \\
\hline $\mathbf{F e}$ & $1.7 \mathrm{E}+00$ & $<4$.E-3 & $<2 . \mathrm{E}+0$ & $1.7 \mathrm{E}+00$ & $1.1 \mathrm{E}+04$ \\
\hline Mn & $1.3 \mathrm{E}+00$ & $<4$.E-4 & $<2$.E-1 & $1.3 \mathrm{E}+00$ & $9.0 \mathrm{E}+03$ \\
\hline $\mathrm{Na}$ & $8.6 \mathrm{E}+01$ & $5.9 \mathrm{E}+01$ & $3.3 \mathrm{E}+04$ & $2.7 \mathrm{E}+01$ & $1.8 \mathrm{E}+05$ \\
\hline $\mathbf{P}$ & $2.1 \mathrm{E}-02$ & 2.1E-02 & $3.7 \mathrm{E}+01$ & $<$ 1.E-3 & $<1$.E-3 \\
\hline $\mathrm{Si}$ & $2.5 \mathrm{E}+00$ & $2.2 \mathrm{E}-02$ & $1.3 \mathrm{E}+01$ & $2.5 \mathrm{E}+00$ & $1.7 \mathrm{E}+04$ \\
\hline $\mathbf{U}$ & $5.9 \mathrm{E}+03$ & $<2$.E-2 & $<8 . \mathrm{E}+0$ & $5.9 \mathrm{E}+03$ & $4.0 \mathrm{E}+07$ \\
\hline \multirow{2}{*}{$\begin{array}{l}\text { Radiochemical } \\
\text { Isotopes }\end{array}$} & Slurry & \multicolumn{2}{|c|}{ Liquid Fraction } & \multicolumn{2}{|c|}{ Solid Fraction } \\
\hline & $\mathrm{mCi}$ & $\mathrm{mCi}$ & $\mathrm{mCi} / \mathrm{mL}$ & $\mathrm{mCi}$ & $\mathrm{mCi} / \mathrm{g}$ \\
\hline Co-60 & 7.7E-01 & $<1 . \mathrm{E}-1$ & $<6 . \mathrm{E}-5$ & 7.7E-01 & $5.2 \mathrm{E}-03$ \\
\hline Cs-137 & $1.5 \mathrm{E}+04$ & $2.1 \mathrm{E}+03$ & $1.2 \mathrm{E}+00$ & $1.3 \mathrm{E}+04$ & $8.8 \mathrm{E}+01$ \\
\hline Eu-154 & $3.8 \mathrm{E}+01$ & $<4 . \mathrm{E}-1$ & $<2 . \mathrm{E}-4$ & $3.8 \mathrm{E}+01$ & 2.6E-01 \\
\hline Am-241 & $9.6 \mathrm{E}+01$ & $<4 . \mathrm{E}+0$ & $<2$.E-3 & $9.6 \mathrm{E}+01$ & $6.4 \mathrm{E}-01$ \\
\hline Gross Alpha & $2.3 \mathrm{E}+02$ & $<1 . \mathrm{E}+0$ & $<6 . \mathrm{E}-4$ & $2.3 \mathrm{E}+02$ & $1.5 \mathrm{E}+00$ \\
\hline Gross Beta & $4.8 \mathrm{E}+05$ & $2.1 \mathrm{E}+03$ & $1.2 \mathrm{E}+00$ & $4.8 \mathrm{E}+05$ & $3.2 \mathrm{E}+03$ \\
\hline Sr-90 & $2.0 \mathrm{E}+05$ & $8.9 \mathrm{E}+01$ & $5.0 \mathrm{E}-02$ & $2.0 \mathrm{E}+05$ & $1.4 \mathrm{E}+03$ \\
\hline Pu-239+240 & $2.7 \mathrm{E}+02$ & $4.2 \mathrm{E}-03$ & $2.4 \mathrm{E}-06$ & $2.7 \mathrm{E}+02$ & $1.8 \mathrm{E}+00$ \\
\hline Pu-238 & $7.3 \mathrm{E}+00$ & $<2$.E-3 & $<1$.E-6 & $7.3 \mathrm{E}+00$ & 4.9E-02 \\
\hline \multirow[t]{2}{*}{ Anions } & \multicolumn{3}{|c|}{ Liquid Fraction } & & \\
\hline & $\mu \mathrm{g} / \mathrm{mL}$ & [M] & g & & \\
\hline $\mathbf{F}$ & $<3$. E-1 & $<2$. E-5 & $<1 . \mathrm{E}-3$ & & \\
\hline $\mathrm{C}_{2} \mathrm{O}_{4}$ & $1.2 \mathrm{E}+02$ & $1.3 \mathrm{E}-03$ & 4.4E-01 & & \\
\hline $\mathrm{NO}_{2}$ & $1.7 \mathrm{E}+03$ & 3.7E-02 & $7.6 \mathrm{E}+00$ & & \\
\hline $\mathrm{NO}_{3}$ & $6.3 E+03$ & $1.0 \mathrm{E}-01$ & $2.8 \mathrm{E}+01$ & & \\
\hline $\mathrm{SO}_{4}$ & $3.9 \mathrm{E}+01$ & 4.1E-04 & $2.0 \mathrm{E}-01$ & & \\
\hline $\mathrm{PO}_{4}$ & $9.5 \mathrm{E}+01$ & $1.0 \mathrm{E}-03$ & 3.9E-01 & & \\
\hline $\mathbf{O H}$ & $1.8 \mathrm{E}+04$ & $1.1 \mathrm{E}+00$ & $3.3 \mathrm{E}+01$ & & \\
\hline \multicolumn{6}{|c|}{$\begin{array}{l}\text { (a) Slurry Mass components were calculated from characterization data (WPT-RPT-157), and the } \\
\text { masses of materials that were added with simulant. Loss of mass from sampling was incorporated. } \\
\text { (b) Liquid Fraction mass components were calculated using analytical results from supernate sample } \\
\text { TI540-G5-M (ASO ID 07-01781) and the predicted mass of supernate in the system. } \\
\text { (c) Solids Fraction mass components were calculated from the difference between the slurry } \\
\text { component mass and liquid component mass fraction. }\end{array}$} \\
\hline
\end{tabular}


Table 3.28. Group 5 Washed Leach Slurry Composition and Caustic Leach Factor Calculations Based on ICP-OES/Radiochemical Characterization

\begin{tabular}{|c|c|c|c|c|c|}
\hline $\begin{array}{c}\text { Slurry Prep } \\
\text { Method }\end{array}$ & $\begin{array}{c}\text { ICP-OES } \\
\text { Analytes }\end{array}$ & $\begin{array}{c}\text { Dry } \\
\text { Slurry }{ }^{(a)} \\
(\mu \mathrm{g} / \mathrm{g})\end{array}$ & $\begin{array}{c}\text { Supernate }^{(\mathrm{b})} \\
(\mu \mathrm{g} / \mathrm{mL})\end{array}$ & $\begin{array}{c}\text { Dry Solids }{ }^{(\mathrm{c})} \\
(\mu \mathrm{g} / \mathrm{g})\end{array}$ & $\begin{array}{c}\text { Solids } \\
\text { Leach } \\
\text { Factor }^{(d)} \\
\end{array}$ \\
\hline \multirow{30}{*}{ 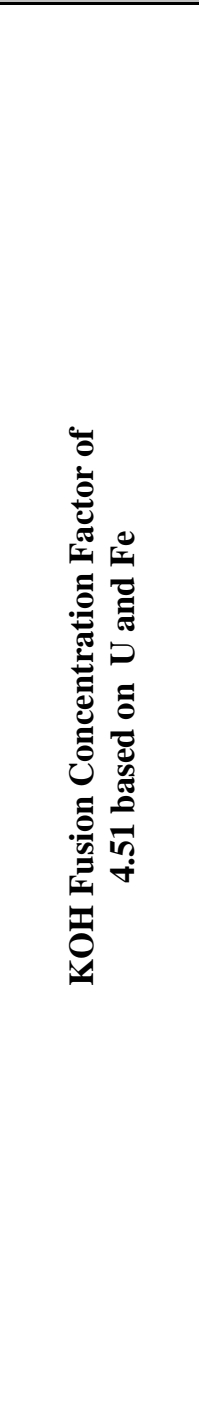 } & Al & 112,000 & 4,230 & 282,632 & 0.84 \\
\hline & $\mathbf{B}$ & $<9.1 \mathrm{E}+1$ & [6.3] & $<1.7 \mathrm{E}+2$ & NA \\
\hline & $\mathbf{B i}$ & $<1.5 \mathrm{E}+2$ & $<2.3 \mathrm{E}+0$ & $<4.6 \mathrm{E}+2$ & NA \\
\hline & $\mathrm{Cr}$ & 4,840 & 93.5 & 14,148 & -0.51 \\
\hline & $\mathbf{F e}$ & 18,000 & $<2.1 \mathrm{E}+0$ & 60,102 & NA \\
\hline & Mn & 6,990 & $<2.1 \mathrm{E}-1$ & 23,352 & 0.09 \\
\hline & $\mathrm{Na}$ & 244,000 & 33,000 & 100,615 & -5.89 \\
\hline & $S$ & $<7.5 \mathrm{E}+2$ & $<3.3 \mathrm{E}+1$ & $<1.8 \mathrm{E}+3$ & NA \\
\hline & Si & 13,600 & 12.5 & 45,173 & NA \\
\hline & $\mathrm{Sr}$ & 2,020 & 0.326 & 6,743 & 0.00 \\
\hline & $\mathbf{U}$ & 28,000 & $<8.4 \mathrm{E}+0$ & 93,379 & -0.08 \\
\hline & Zn & $<5.2 \mathrm{E}+1$ & [1.5] & $<1.4 \mathrm{E}+2$ & NA \\
\hline & $\mathrm{Zr}$ & [170] & $<8.1 \mathrm{E}-1$ & [550] & $-[0.03]$ \\
\hline & $B a$ & [150] & $<3.4 \mathrm{E}-1$ & [494] & [0.31] \\
\hline & $B e$ & $<1.0 \mathrm{E}+0$ & $<1.2 \mathrm{E}-2$ & $<3.1 \mathrm{E}+0$ & NA \\
\hline & Ca & $<3.2 \mathrm{E}+3$ & 29.2 & $<1.0 \mathrm{E}+4$ & NA \\
\hline & $\mathrm{Ce}$ & $<2.1 \mathrm{E}+2$ & $<1.2 \mathrm{E}+0$ & $<6.7 \mathrm{E}+2$ & NA \\
\hline & Co & $<2.1 \mathrm{E}+1$ & $<3.9 \mathrm{E}-1$ & $<6.3 \mathrm{E}+1$ & NA \\
\hline & $\mathrm{Cu}$ & [59] & $<4.9 \mathrm{E}-1$ & [187] & [0.29] \\
\hline & $E u$ & $<1.7 \mathrm{E}+1$ & $<1.1 \mathrm{E}-1$ & $<5.4 \mathrm{E}+1$ & NA \\
\hline & $L a$ & [27] & $<1.3 \mathrm{E}-1$ & [87] & [0.12] \\
\hline & $\mathrm{Li}$ & $<3.3 \mathrm{E}+1$ & {$[0.87]$} & $<9.1 \mathrm{E}+1$ & NA \\
\hline & $M g$ & [380] & [4.8] & {$[1,166]$} & {$[0.16]$} \\
\hline & Mo & [35] & $<6.6 \mathrm{E}-1$ & [103] & {$[0.27]$} \\
\hline & $N d$ & $<3.2 \mathrm{E}+2$ & $<1.7 \mathrm{E}+0$ & $<1.0 \mathrm{E}+3$ & NA \\
\hline & $\boldsymbol{P}$ & [330] & [37] & [301] & [2.97] \\
\hline & Se & $<3.0 \mathrm{E}+2$ & [5.6] & $<8.8 \mathrm{E}+2$ & NA \\
\hline & Sn & $<2.8 \mathrm{E}+2$ & $<2.0 \mathrm{E}+0$ & $<9.0 \mathrm{E}+2$ & NA \\
\hline & $T i$ & [43] & $<9.7 \mathrm{E}-2$ & [142] & {$[0.44]$} \\
\hline & $V$ & $<1.4 \mathrm{E}+1$ & $<3.2 \mathrm{E}-1$ & $<4.0 \mathrm{E}+1$ & NA \\
\hline
\end{tabular}


Table 3.28. (Contd)

\begin{tabular}{|c|c|c|c|c|c|}
\hline $\begin{array}{l}\text { Slurry Prep } \\
\text { Method }\end{array}$ & Radionuclides & $\begin{array}{c}\text { Dry } \\
\text { Slurry } \\
(\mu \mathrm{C} i / g)\end{array}$ & $\begin{array}{c}\text { Supernate }^{(b)} \\
(\mu \mathrm{Ci} / \mathrm{mL})\end{array}$ & $\begin{array}{c}\text { Dry Solids }^{(\mathrm{c})} \\
(\mu \mathrm{Ci} / \mathrm{g})\end{array}$ & $\begin{array}{c}\text { Solids } \\
\text { Leach } \\
\text { Factor }^{(\mathrm{d})} \\
\end{array}$ \\
\hline \multirow{11}{*}{$\begin{array}{c}\text { KOH Fusion } \\
\text { Concentration } \\
\text { Factor } \\
\text { of } 4.51 \text { based on } \\
U \text { and Fe }\end{array}$} & Co-60 & $9.91 \mathrm{E}-2$ & $<6 . E-5$ & 3.3E-1 & 0.33 \\
\hline & Cs-137 & $6.48 \mathrm{E}+1$ & $1.15 \mathrm{E}+0$ & $1.9 \mathrm{E}+2$ & -0.04 \\
\hline & Eu-154 & $1.71 \mathrm{E}-1$ & $<2 . E-4$ & $5.7 \mathrm{E}-1$ & -0.11 \\
\hline & Am-241 & $4.34 \mathrm{E}-1$ & $<2$.E-3 & $1.4 \mathrm{E}+0$ & 0.03 \\
\hline & Total alpha & $2.15 \mathrm{E}+0$ & $<6 . \mathrm{E}-4$ & $7.2 \mathrm{E}+0$ & -0.04 \\
\hline & Total beta & $2.05 \mathrm{E}+3$ & $1.18 \mathrm{E}+0$ & $6.8 \mathrm{E}+3$ & 0.06 \\
\hline & Sr-90 & $9.15 \mathrm{E}+2$ & $4.98 \mathrm{E}-2$ & $3.1 \mathrm{E}+3$ & 0.11 \\
\hline & Pu-239/240 & $1.31 \mathrm{E}+0$ & $2.36 \mathrm{E}-6$ & $4.4 \mathrm{E}+0$ & 0.03 \\
\hline & Pu-238 & $2.33 \mathrm{E}-2$ & $<1$. E-6 & $7.8 \mathrm{E}-2$ & 0.33 \\
\hline & KPA & $(\mu \mathrm{g} / \mathrm{g})$ & $(\mu \mathrm{g} / \mathrm{mL})$ & $(\mu \mathrm{g} / \mathrm{g})$ & \\
\hline & $\mathbf{U}$ & $3.42 \mathrm{E}+4$ & $7.01 \mathrm{E}-1$ & $1.1 \mathrm{E}+5$ & 0.07 \\
\hline $\begin{array}{ll}\text { (a) Test sample T } \\
\text { (b) Test sample T } \\
\text { (c) Calculated usi } \\
\text { (d) Calculated usi } \\
\text { Note: Analytes in } \\
\text { but }<\text { EQL, with er }\end{array}$ & $\begin{array}{l}\text { 40-G5-M, ASO I } \\
\text { 40-G5-17, ASO I } \\
\text { results from TI5 } \\
\text { results listed in } \\
\text { lics were measur } \\
\text { rs likely to excee }\end{array}$ & $\begin{array}{l}07-01781 \\
07-01785 \\
0-G 5-M \text { and } \\
\text { able } 3.13 \\
\text { d opportunis } \\
15 \% \text {. }\end{array}$ & $\begin{array}{l}\text { TI540-G5-17 } \\
\text { tically. Values }\end{array}$ & in brackets [ ] a & $\mathrm{e} \geq \mathrm{MDL}$ \\
\hline
\end{tabular}

Cesium was the only radionuclide that decreased by a significant factor during the CUF test. As detailed in Figure 3.47, the cesium decreased to $48 \%$ of the original. By contrast, the rest of the radionuclides decreased $\pm 4 \%$ and, when compared to the $49 \%$ solids decrease, it is assumed there was very little effect of the leaches on the radionuclides. Calculated values greater than $100 \%$ in Figure 3.47 indicated that the sampling and analytical errors were greater than measured losses of the analytes presented.

Anions were measured in the supernate samples of the slurry material thro $\mu$ ghout the test (Figure 3.48). All of the anion concentrations decreased at similar rates with the exception of oxalate $\left(\mathrm{C}_{2} \mathrm{O}_{4}\right)$. The solubility of the oxalate exiting the slurry was significantly less than the other anions. 


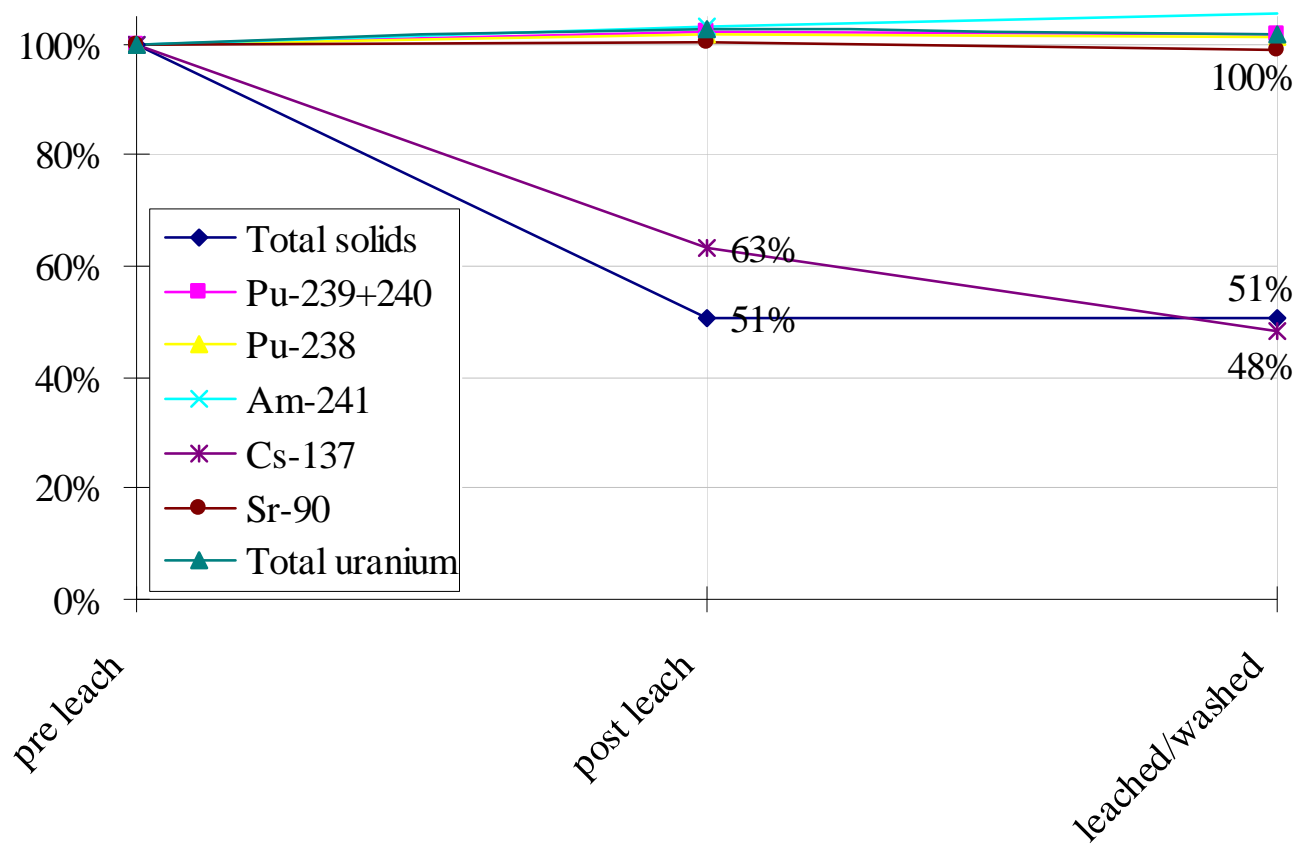

Figure 3.47. Radionuclides/Total Solids in CUF 5 Slurry, Adjusted for Sampling

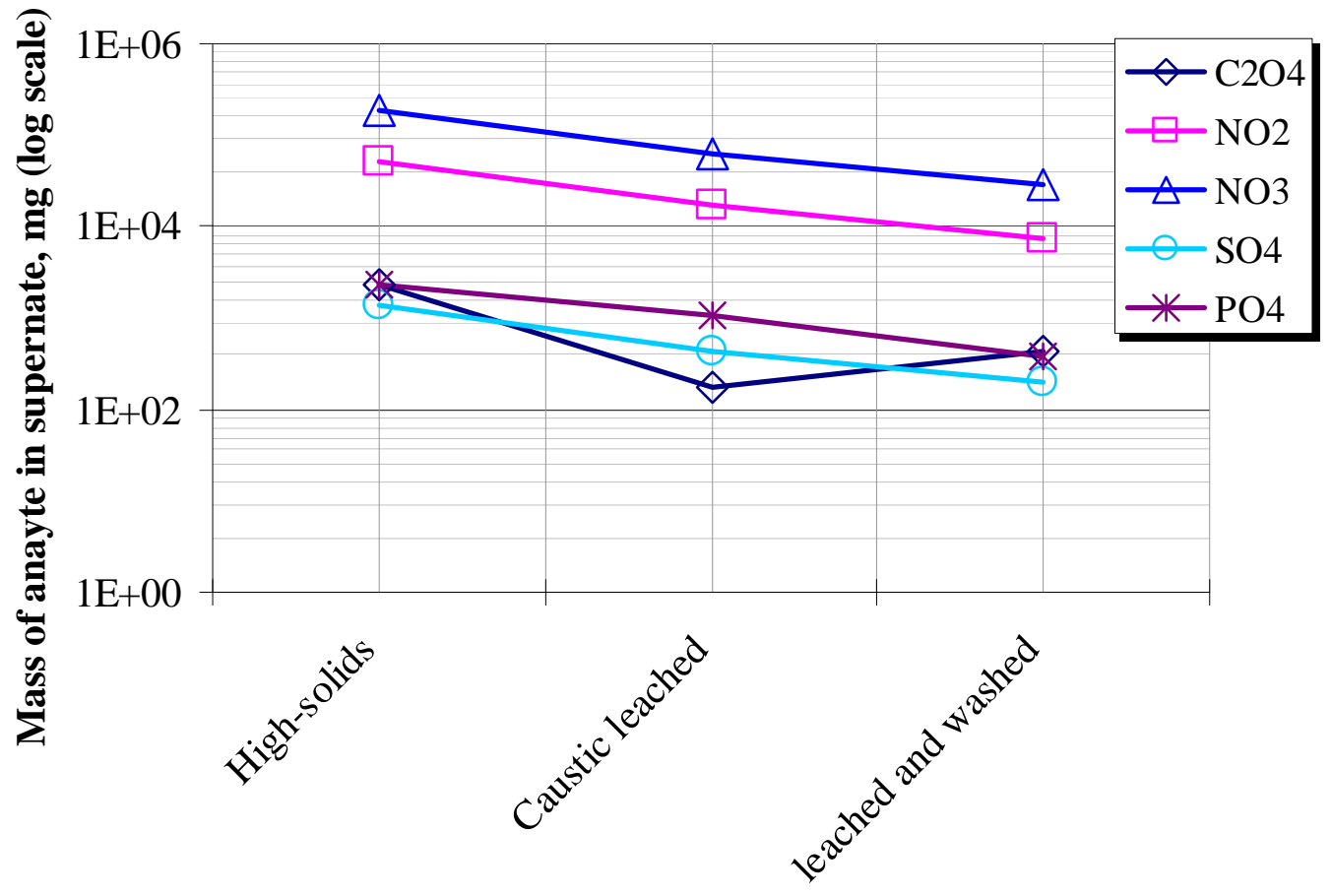

Figure 3.48. Group 5 Anions in Slurry Supernate 
The surface area of the leached solids was determined by Brunauer, Emmett, and Teller (BET), a method for measuring surface areas, analysis and found to be $38 \mathrm{~m}^{2} / \mathrm{g}$. The major crystalline component identified in the final solids material (Figure 3.49) was boehmite $[\mathrm{AlO}(\mathrm{OH})]$, with minor contributions of cancrinite $\left[\mathrm{Na}_{7.6}\left(\mathrm{Al}_{6} \mathrm{Si}_{6} \mathrm{O}_{24}\right)\left(\mathrm{HCO}_{3}\right)_{1.2}\left(\mathrm{CO}_{3}\right)_{0.2}\left(\mathrm{H}_{2} \mathrm{O}\right)_{2.28}\right]$ and clarkeite $\left[\mathrm{Na}\left(\mathrm{UO}_{2}\right) \mathrm{O}(\mathrm{OH})\right]$. Whole pattern fitting done by the JADE software indicates the boehmite/clarkeite ratio as 4.1:1 and the boehmite/cancrinite ratio as 2.2:1. This has a 10 to $20 \%$ error and should only be used as an approximation.

Scanning electron microscopy (SEM) imaging was taken of the leached slurry as shown in Figure 3.50 and Figure 3.51. Figure 3.50 showed an image of two large particles: one that appeared to be a single crystal in the upper left corner and an agglomerate composed of smaller crystals close to the center. EDS found only aluminum present in the larger crystal, indicating that this was a likely a boehmite crystal.

The EDS identified Na, Al, Si, and U, in the agglomerate. This was consistent with the X-ray diffraction (XRD) analysis, which found cancrinite and clarkeite. Figure 3.51 provided a closer view of the surface of the larger particle. TEM imaging (Figure 3.52) indicates that the agglomerate actually consists of very small - 100-micron primary crystals. 
[071031b_G5-16_noStd.dif] Log\# 103107b

نூ

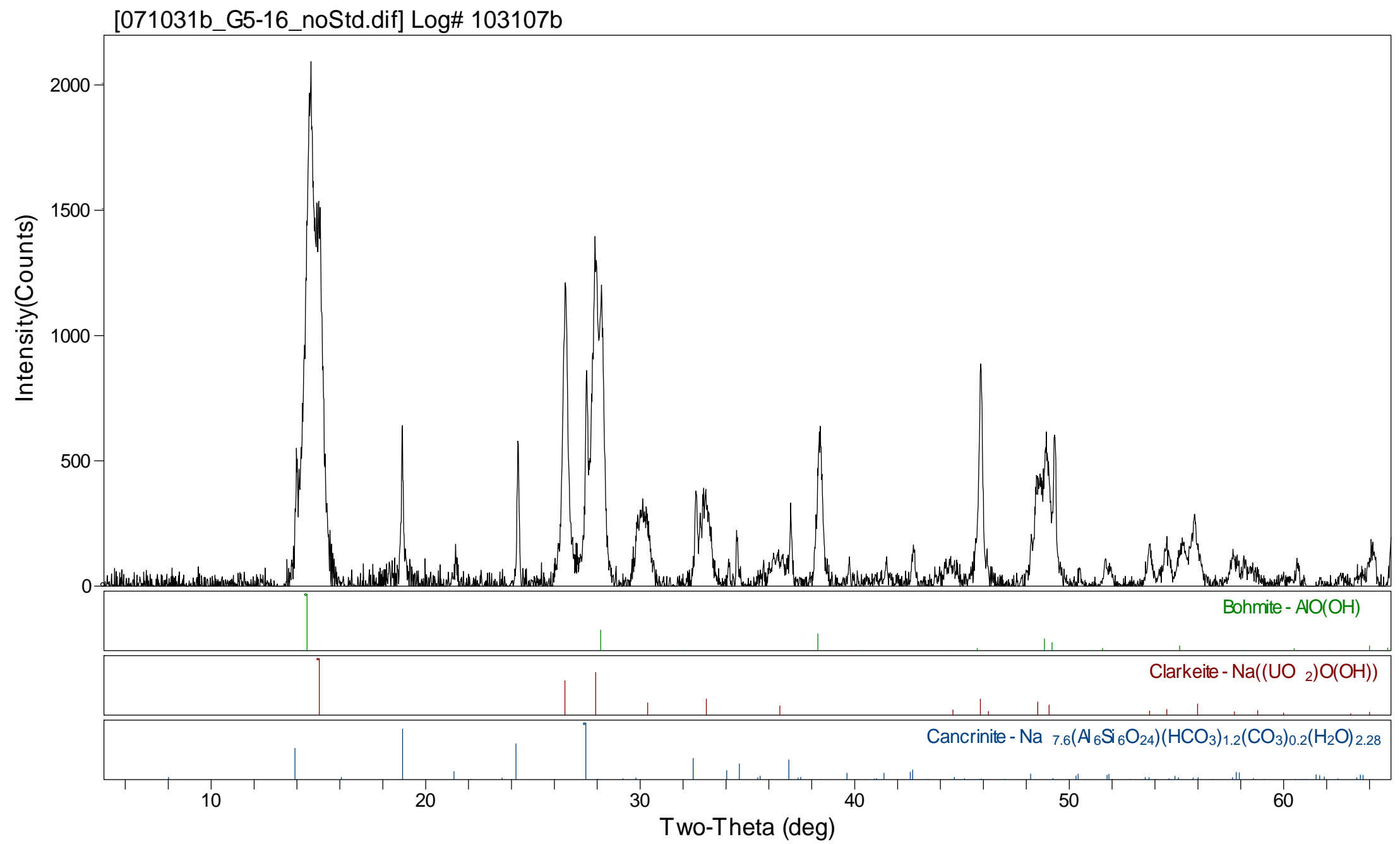

3.49. XRD Spectra of Leached Group 5 Slurry 

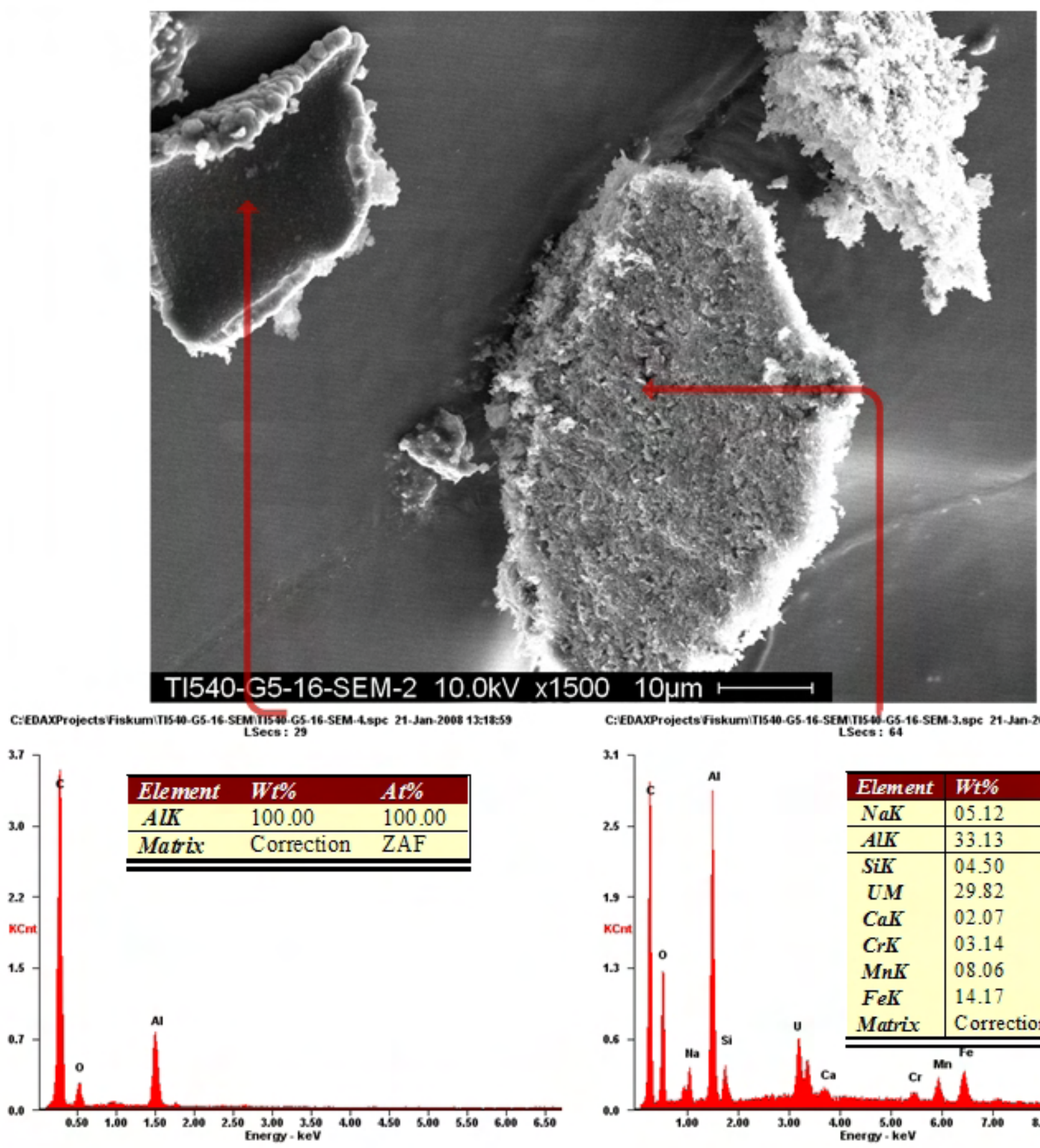

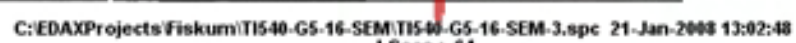

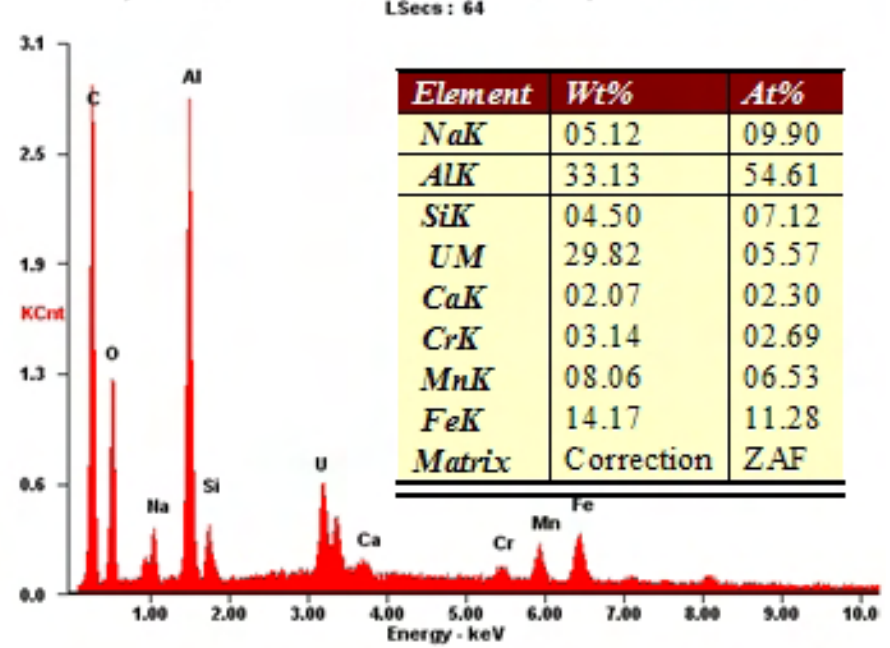

Figure 3.50. Group 5 SEM and Energy Dispersive Spectroscopy (EDS) of Leached, Washed Solids 


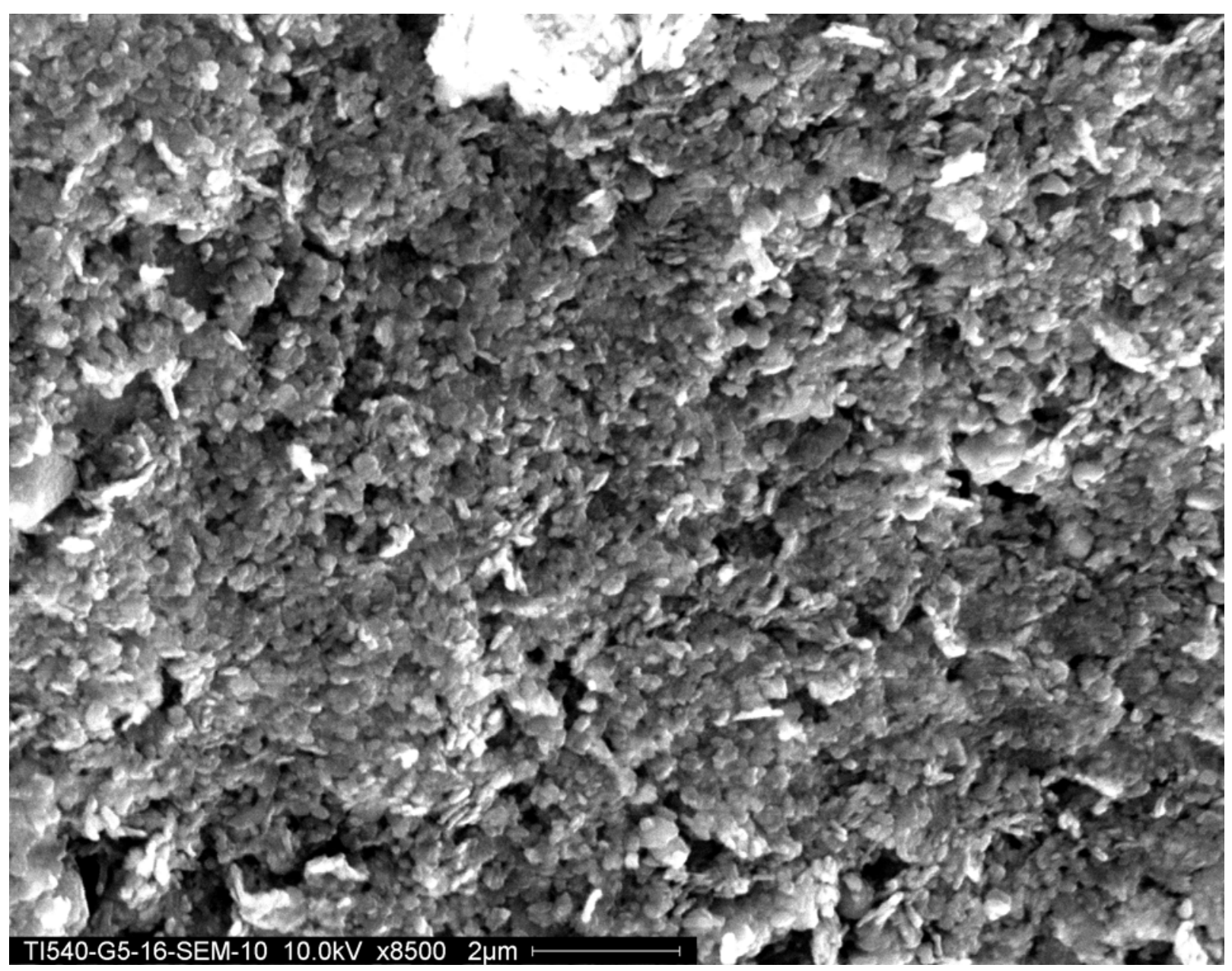

Figure 3.51. Group 5 SEM Close-up of Leached Washed Particle 


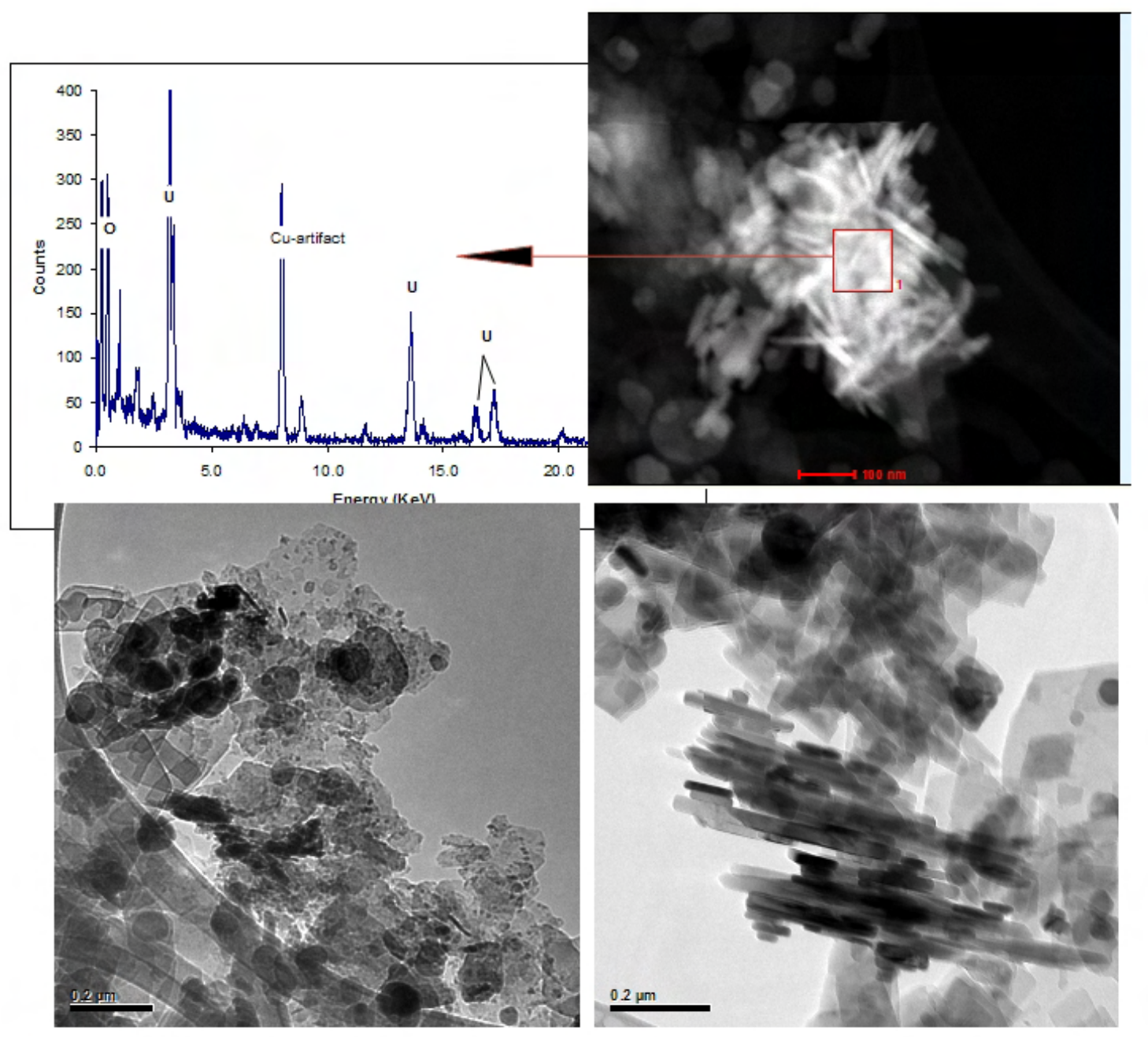

Figure 3.52. Group 5 TEM Imaging of Group 5 Leached and Washed Solids

Particle size measurements were taken of the final slurry. Figure 3.53 shows the pre-sonic PSD for a sample of the leached, washed slurry as a function of pump speed. The size distribution and behavior of the leached, dewatered, and washed slurry solids is similar to the leached and dewatered only slurry. The distribution is broad with the majority of particles falling between 0.2 - and $20-\mu \mathrm{m}$ particles. The population peaks at slightly smaller diameters than the previous sample (i.e., $\sim 1.5 \mu \mathrm{m}$ as opposed to $2 \mu \mathrm{m}$ previously). Aggregates may exist in the 20- to 200- $\mu \mathrm{m}$ size range, but the measurement instability makes this difficult to reliably determine (see Appendix $\mathrm{G}$ for details). As in the previous sonication data set, the peaks beyond $20 \mu \mathrm{m}$ are suspected of being the result of the sample instability effect (Figure 3.54). The distribution below $20 \mu \mathrm{m}$ shows similar behavior to the previous samples, namely aggregate restructuring upon sonication. Here, the $\sim 1.5-\mu \mathrm{m}$ primary population that exists before sonication appears to split into populations centered on $0.7 \mu \mathrm{m}$. 


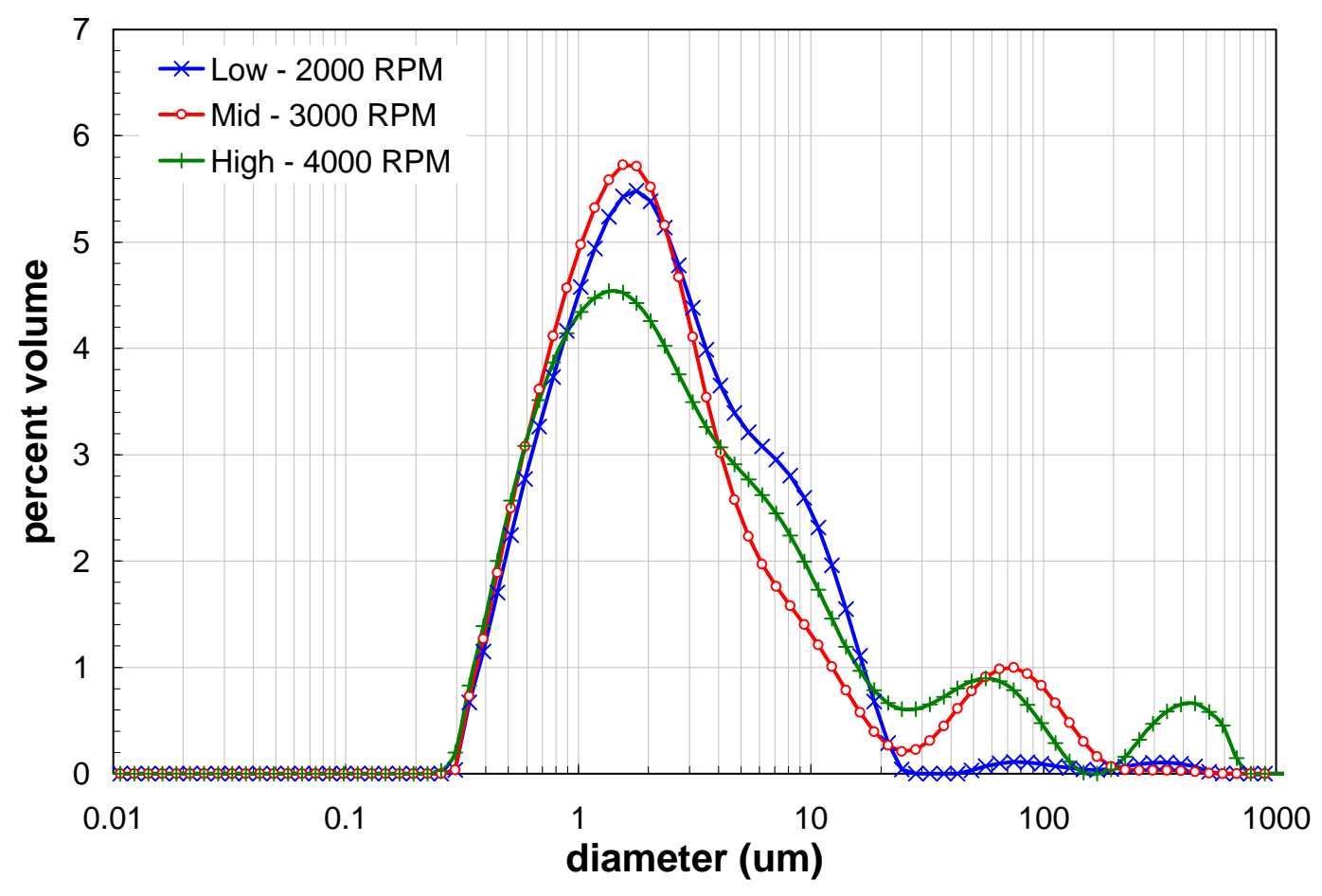

Figure 3.53. PSD of CUF 5 Leached Washed Slurry as a Function of Pump Speed

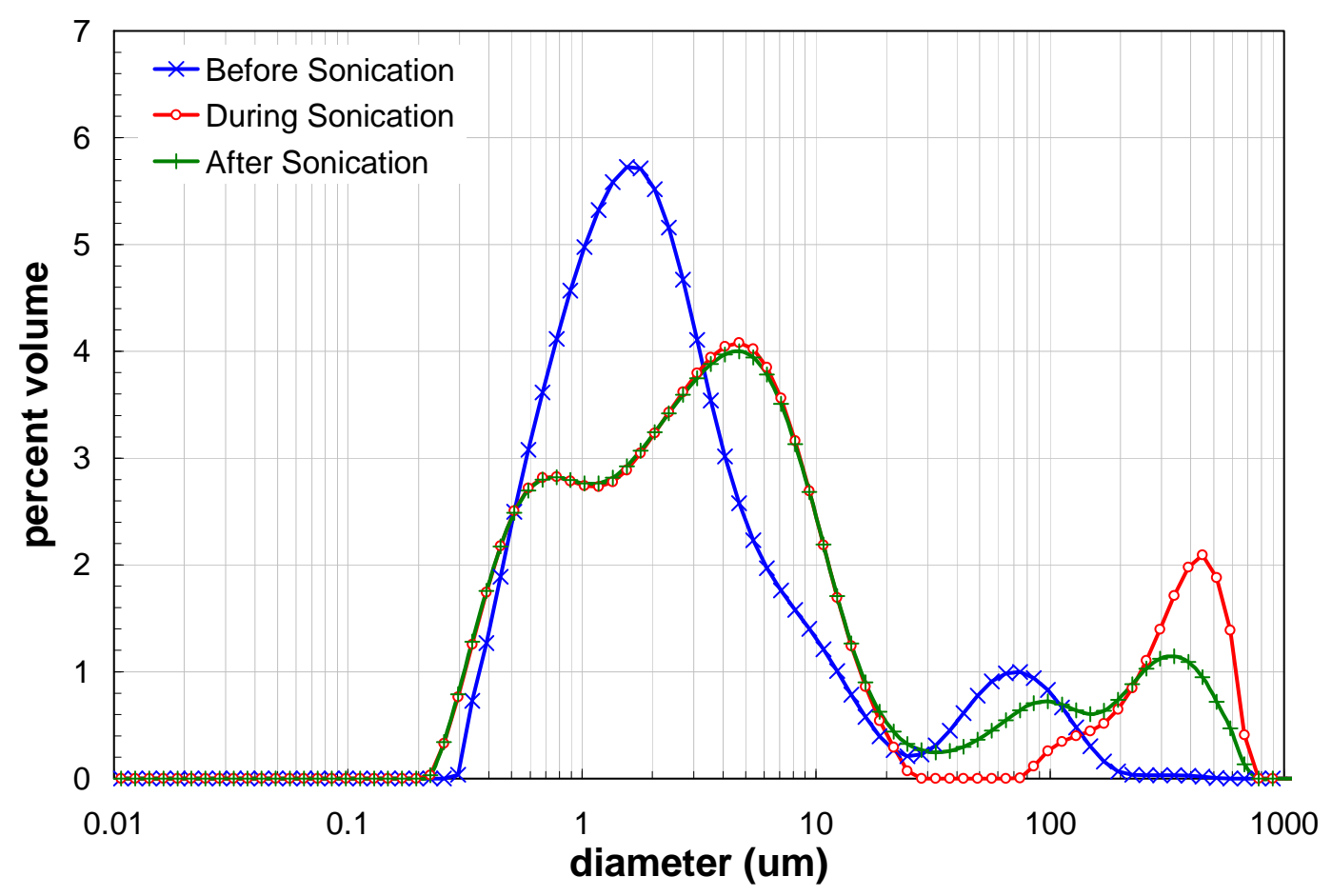

Figure 3.54. PSD of CUF 5 Leached and Washed Slurry as a Function of Sonication 
Rheological measurements of the final slurry were also performed to observe changes in the slurry's shear stress and consistency after washing. The flow curves for the leached, washed slurry suggest that washing of the post-leach dewatered slurry further reduces the shear stress and consistency of waste but does not alter its non-Newtonian rheological behavior (Figure 3.55). All curves show non-Newtonian behavior consistent with the Bingham-plastic or Herschel-Bulkley constitutive equations. The samples still show slip or elasticity over the 0 -to $100-\mathrm{s}^{-1}$ region. The apparent Bingham yield stress has decreased by (approximately) a factor of two relative to the dewatered post-leach slurry (Table 3.29). Increases in slurry temperature do not appear to affect Bingham yield stress but do appear to lower the slope of the flow curve over the entire range of shear rates tested (likely through lowering of suspending phase viscosity).

A comparison of Group 5 CUF sample rheology at $25^{\circ} \mathrm{C}$ is given in Figure 3.56. Higher temperatures showed similar trends. The initial dilute CUF slurry and the final washed leached slurry were more or less equal in terms of rheology. The post-leach, dewatered slurry was viscous relative to these two, but this was expected because of its concentration and because of the fact that the suspending phase contains all of the leaching products from caustic contact. All concentrated pre-leach slurries showed stress magnitudes of $50 \mathrm{~Pa}$ or greater. Of the three concentrated pre-leach slurries, the source material for the CUF run showed the lowest rheology.

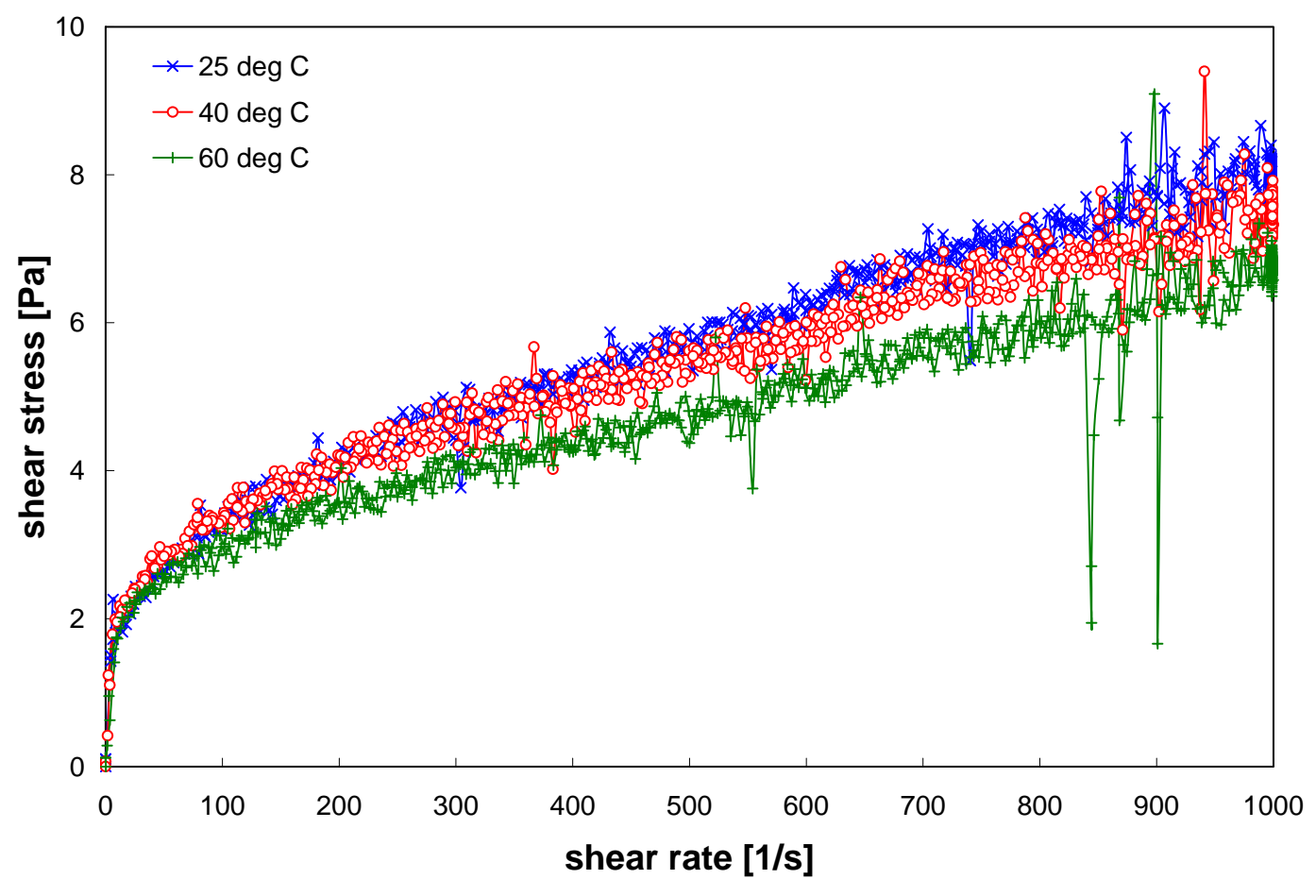

Figure 3.55. Flow Curves for the Group 5 Leached, Washed Slurry 
Table 3.29. Results of Fitting Analysis for the Group 5 Leached, Washed Slurry

\begin{tabular}{||c|c|c|c|c|c||}
\hline Model & $\begin{array}{c}\text { Temperature } \\
{\left[{ }^{\circ} \mathbf{C}\right]}\end{array}$ & $\begin{array}{c}\text { Yield } \\
\text { Stress [Pa] }\end{array}$ & $\begin{array}{c}\text { Consistency } \\
{\left[\mathbf{P a} \mathbf{~ s}^{\mathbf{n}}\right]}\end{array}$ & $\begin{array}{c}\text { Flow } \\
\text { Index }\end{array}$ & $\mathbf{R}$ \\
\hline \multirow{3}{*}{ Power-Law* } & 25 & $\mathrm{n} / \mathrm{a}$ & 0.46 & 0.41 & 0.990 \\
\cline { 2 - 6 } & 40 & $\mathrm{n} / \mathrm{a}$ & 0.57 & 0.37 & 0.985 \\
\cline { 2 - 6 } & 60 & $\mathrm{n} / \mathrm{a}$ & 0.44 & 0.39 & 0.964 \\
\hline \multirow{3}{*}{ Bingham-Plastic } & 25 & 3.3 & 0.0047 & $\mathrm{n} / \mathrm{a}$ & 0.998 \\
\cline { 2 - 6 } & 40 & 3.4 & 0.0041 & $\mathrm{n} / \mathrm{a}$ & 0.978 \\
\cline { 2 - 6 } & 60 & 2.8 & 0.0039 & $\mathrm{n} / \mathrm{a}$ & 0.948 \\
\hline \multirow{3}{*}{ Herschel-Bulkley } & 25 & 2.4 & 0.031 & 0.75 & 0.989 \\
\cline { 2 - 6 } & 40 & 2.7 & 0.022 & 0.78 & 0.979 \\
\cline { 2 - 6 } & 60 & 3.0 & 0.0018 & 1.1 & 0.945 \\
\hline \multirow{3}{*}{ Herschel-Bulkley* } & 25 & 1.6 & 0.10 & 0.60 & 0.994 \\
\cline { 2 - 6 } & 40 & 1.6 & 0.13 & 0.55 & 0.998 \\
\cline { 2 - 6 } & 60 & 1.8 & 0.046 & 0.68 & 0.970 \\
\hline \hline
\end{tabular}


a)

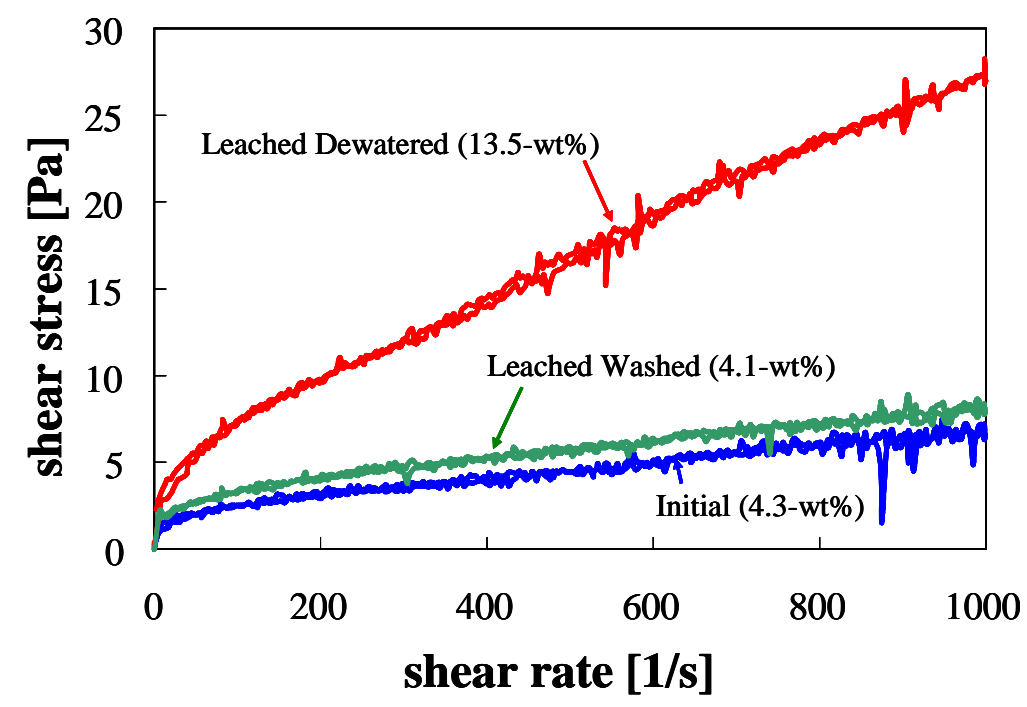

b)

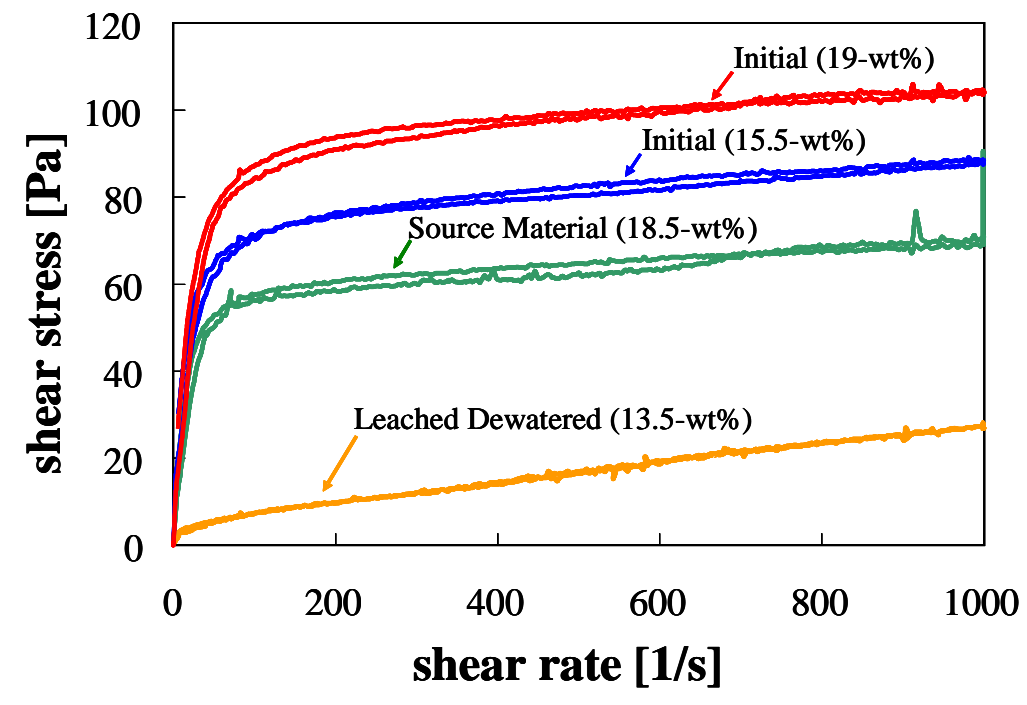

Figure 3.56. Comparison of Group 5 CUF Slurry Flow Curves at $25^{\circ} \mathrm{C}$, with (a) Showing the Weaker Slurries and (b) Showing the Stronger Slurries. The leached dewater [red curve in (a), amber curve in (b)] is included in both graphs as a point of reference. 


\subsection{Test Summary}

Objectives of the test plan that were accomplished in this test were:

- Filtration of actual waste before and after caustic leaching was performed and compared.

- Caustic dissolution of aluminum in the form of boehmite was performed utilizing the Group 5 waste, which $\sim 90 \%$ of the UDS were boehmite.

- Final characterization of the leach waste was performed using XRD, SEM, and TEM to confirm the final phases of undissolved leach solids.

\subsubsection{Filtration Results}

Filtration of the Group 5 waste was quite high at dilute UDS concentration ( $<10 \mathrm{wt} \%$ ), averaging $~ 0.06$ $\mathrm{GPM} / \mathrm{ft}^{2}$ at a TMP $=40$ psid. Axial velocity impact on filter flux was negligent at these concentrations. As the waste was dewatered, its filter flux behavior changed as its UDS concentration increased above 12 wt\%. At this point, the following occurred:

- Filter flux began to be dependent on the slurry UDS concentration, and AV (as well as TMP).

- This correlated to the slurry shear stress increasing, changing the flow behavior of the slurry to a laminar condition.

- The change in rheology also correlated to a dramatic increase in the axial pressure drop of the slurry inside the slurry flow loop which forced the slurry to be diluted to continue testing.

Caustic leaching of the slurry initially decreased the filter flux (from 0.01 to $0.02 \mathrm{GPM} / \mathrm{ft}^{2}$ ) of the slurry by significantly increasing the viscosity of the slurry supernate. However, caustic leaching appeared to reduce the slurry shear stress, returning the slurry to a turbulent flow regime. Once washing of the slurry began, the filter flux increased to levels ten times higher at the same TMP. This was higher than the initial flux rate, which implied that the leach dissolved some fouling agent in the slurry and washed out of the CUF.

Particle size distribution measurements showed that the average particle size in the slurry decreased over time, but did not change significantly enough to impact the filter flux. However, changes in the slurry rheology due to changes in the slurry UDS concentration or dissolved solids concentration in the supernate made big impacts on filtration.

\subsubsection{Caustic Leaching Results}

The caustic leach factor resulting from the test was found to be much higher that expected (76\%). However, the results of this test were believed to be skewed because of evaporation that occurred during the caustic leach that concentrated the slurry permeate by over $40 \%$. This increased the slurry's free hydroxide concentration and may have shifted the kinetics. Of the radiochemical isotopes tracked, only Cs-137 showed any significant change in waste slurry concentration. However, this was mainly due to the fact a majority of the Cs-137 was already in the slurry supernate. The change in the slurry composition is shown in Figure 3.57.

After leaching, XRD, SEM, and TEM identified Na, Al, U, and Si in crystalline phases. XRD identified $\mathrm{Al}$ present in the form of boehmite, and $\mathrm{U}$ in the form of mainly cancrinite and clarkite. SEM and TEM showed larger boehmite crystals (>10 um) mixed with agglomerates of smaller particles probably boehmite and other inert phases (e.g., iron and uranium). 
WPT-RPT-172, Rev 0

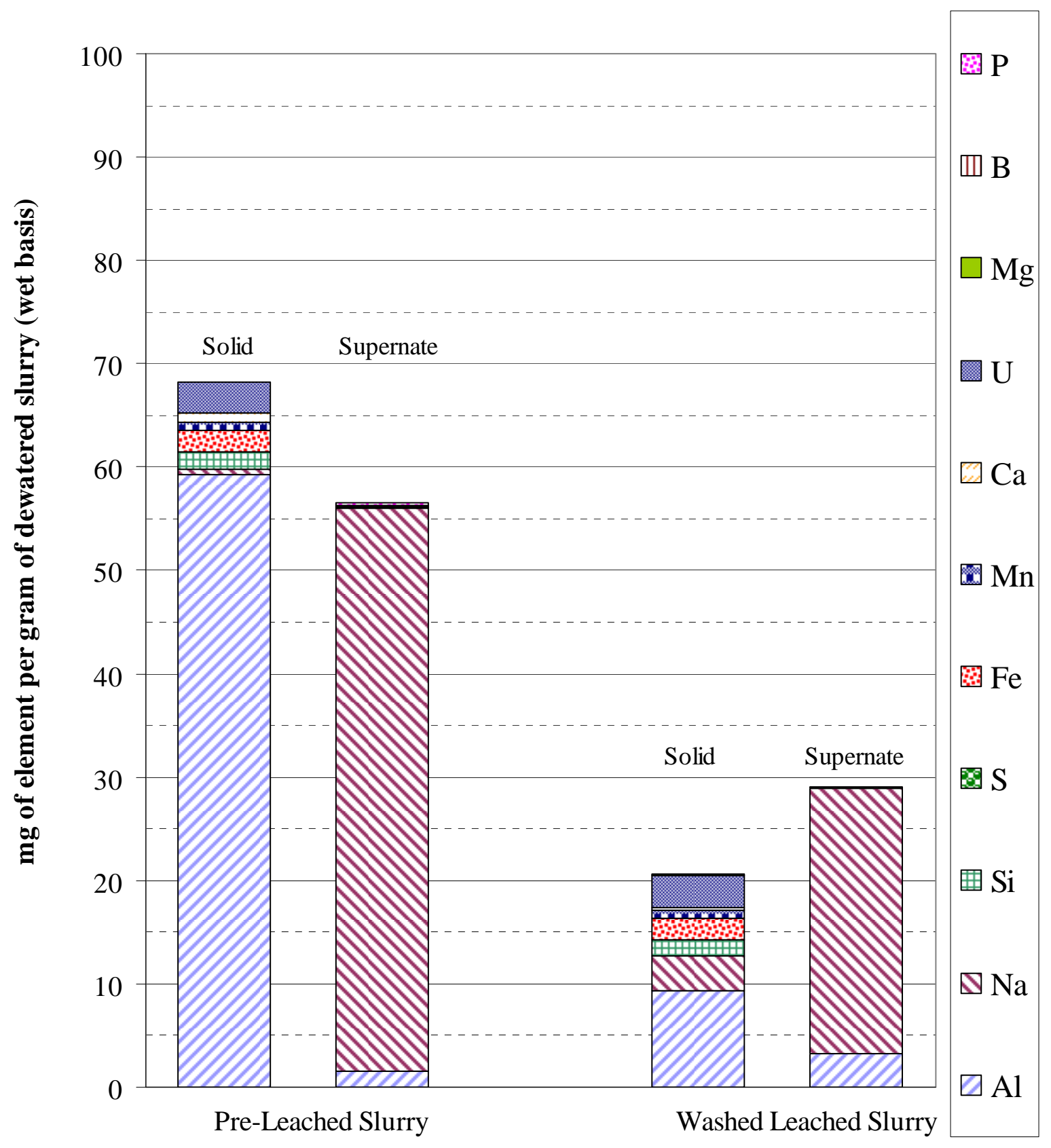

Figure 3.57. Group 5 Slurry Composition Before and After Leaching 


\subsection{Lessons Learned}

During the course of the test, several problems occurred that impacted the performance of the test and have created some uncertainty about the results. However, conducting the test created additional understanding about the process that had added benefits.

\section{Evaporation}

During the leaching operation, significant evaporation of the slurry occurred. While attempts had been made to minimize the quantity of water lost thro $\mu$ gh evaporation, subsequent analysis of the results indicated that a significant quantity of water had been lost. This significant evaporation may have resulted in greater-than-expected boehmite leaching during this test. During future tests, steps were taken to counter this evaporation by adding water to maintain the vessel level constant during the leaching steps.

\section{Slurry Rheology}

During the initial dewater, the slurry became very viscous and experienced very high yield stress and consistency. Because of this, very large axial pressure drops were encountered. Due to these high pressure drops, not all of the process conditions for the high-solids filtration matrix could be achieved at the target solids concentration, and the slurry required dilution to enable performing this matrix. This change required a quick change to the testing protocol for the subsequent step based on a new process condition entering the leaching operation. During future tests, it will be necessary to assess the impact of terminating the dewatering steps early in the downstream activities and make sure that adequate contingencies are in place. 


\subsection{Group 6/5 CUF Testing and Results}

This section describes the filtration/leaching tests ${ }^{(a)}$ performed with the S-Saltcake waste composite, referred to as the Group 6 waste sample, blended with the remaining Group 5 waste sample.

\subsection{Test Plan}

Figure 4.1 outlines the testing sequence of the blended Group 6/5 sample.

The goals of this test were to:

- Evaluate the filtration of the S-Saltcake waste and compare it to the REDOX sludge waste

- Evaluate the effectiveness of caustic leaching on aluminum and possible chromium present in the blended waste

- Evaluate the effectiveness of oxidative leaching (using sodium permanganate) on chromium present in the blended waste

- Evaluate the filtration of the washed leached solids.

The blending of the Group 5 and Group 6 test was proposed in concurrence letter WTP/RPP-MOAPNNL-00102. The goal of the letter was to dictate the ratio of slurry and UDS solids. However, the mass quantities listed in this letter proved to be a problem when planning the test. Based on the results from the Group 5 CUF test, the conversion of aluminum was suspected to be as high as $80 \mathrm{wt} \%$ in the UDS solids. This meant that the quantity of sodium hydroxide needed to be added increased beyond the initial planning for this test. Once the caustic addition was estimated, we learned that the volume of the slurry reservoir was not large enough to contain the projected volume of condensate water to be added to the vessel. To correct for this, only $70 \%$ of the original inventory was to be used, as dictated in the testing concurrence letter WTP/RPP-MOA-PNNL-00259. The slurry and UDS masses of the initial plan and modified plan are provided in Table 4.1 .

Table 4.1. Blending of the Group 6 and Group 5 Wastes

\begin{tabular}{|l|c|c|c|c||}
\hline \multirow{2}{*}{} & \multicolumn{2}{|l|}{$\begin{array}{l}\text { Initial Plan } \\
\text { Based on Concurrence Letter } \\
\text { WTP/RPP-MOA-PNNL-00102 }\end{array}$} & \multicolumn{2}{l||}{$\begin{array}{l}\text { Modified Plan } \\
\text { Based on Concurrence Letter } \\
\text { WTP/RPP-MOA-PNNL-00259 }\end{array}$} \\
\cline { 2 - 5 } & Slurry Mass & UDS Mass & Slurry Mass & UDS Mass \\
\hline Group 5 slurry & 1599 grams & 288 grams & 1157 grams & 208 grams \\
\hline Group 6 slurry & 849 grams & 127 grams & 613 grams & 92 grams \\
\hline $\begin{array}{l}\text { Slurry ratio } \\
\text { Group 5/6 }\end{array}$ & 1.88 & 2.27 & 1.89 & 2.26 \\
\hline
\end{tabular}

(a) Conducted according to TI-RPP-WTP-552, HLW Filtration and Caustic/Oxidative Leaching of Group 6/5 Composite Waste, R Shimskey, November, 2007. 
Initial filtration testing is outlined in the first column of Figure 4.1. During homogenization of the Group 6 material, $1.1 \mathrm{~kg}$ of concentrated slurry was generated (15 wt\% UDS) and $2.6 \mathrm{~kg}$ of excess supernatant. Approximately $0.61 \mathrm{~kg}$ of the concentrated slurry and $1.9 \mathrm{~kg}$ of the excess supernatant were introduced to the CUF to produce a final slurry at $4 \mathrm{wt} \%$ UDS (90 grams of UDS in 1.9L slurry). A filter test matrix was performed on the diluted Group 6 waste as described in Table 2.1, and then the waste was dewatered to the CUF's minimum volume ( 1.2L) at a predicted concentration of $6 \mathrm{wt} \% \mathrm{UDS}$. At this point, available Group 5 material (1.16 kg at $18 \mathrm{wt} \%$ UDS) was added to the CUF to increase mass of UDS in the waste slurry to 300 grams. The combined waste composite slurry was diluted back to $6 \mathrm{wt} \%$ UDS using the remaining Group 6 supernate from the Group 6 homogenization, and the filtered permeate from the dewatering of the Group 6 slurry. Afterwards, the blended waste was dewatered again to a volume of 2L (predicted $16 \mathrm{wt} \%$ UDS). At this point, another test matrix (Table 2.2) was performed to evaluate the change in the filtration behavior after concentrating the waste slurry.

During the test, holdup in the sample jars and diversion of available Group 5 material to other tests caused the actual mass used for each test to differ from the planned UDS ratio. Table 4.2 compares the planned mass additions for this CUF test to the actual mass addition made. The results show that the percentage of Group 6 solids in the blended waste slurry was higher than planned.

Table 4.2. Comparison of Planned and Actual Group 5 \& 6 Additions for CUF Testing

\begin{tabular}{|l|c|c|c|c|}
\hline \multirow{2}{*}{} & \multicolumn{2}{|l|}{$\begin{array}{l}\text { Planned Waste Additions } \\
\text { Based on Concurrence Letter } \\
\text { WTP/RPP-MOA-PNNL-00259 }\end{array}$} & \multicolumn{2}{l|}{$\begin{array}{l}\text { Actual Slurry Additions } \\
\text { Based on Entries Made in } \\
\text { TI-RPP/WTP-552 }\end{array}$} \\
\cline { 2 - 5 } & Slurry Mass & Slurry Mass & Slurry Mass & UDS Mass \\
\hline Group 5 slurry & 1157 grams & 208 grams & 993 grams & 184 grams \\
\hline Group 6 slurry & 613 grams & 92 grams & 602 grams & 88 grams \\
\hline $\begin{array}{l}\text { Slurry ratio } \\
\text { Group 5/6 }\end{array}$ & 1.89 & 2.26 & 1.65 & 2.09 \\
\hline \hline
\end{tabular}

Next, the waste slurry was removed from the CUF to be caustic leached in the slurry reservoir tank (column two of Figure 4.1). As in the Group 5 CUF test, a known volume and concentration of $\mathrm{NaOH}$ was blended with the concentrated slurry. The concentration of the caustic addition was based on a predicted $80 \%$ dissolution of aluminum in the solids due to the high dissolution rate that occurred in the Group 5 CUF test. As before, the volume of the addition was established to include the volume of water representing the leach solution volume increase predicted to occur from heating with steam injection in the UFP2 vessel. Including the volume of water from steam condensate, leach slurry volume was planned to be $3.8 \mathrm{~L}$.

Once the volume of the caustic addition at $19 \mathrm{M}$ and water condensate addition were calculated, a single solution was created by combining the two solutions. This was done to reduce the number of entries into the hot cell from 2 to 1 . The combined solution volume and caustic concentration was $2.3 \mathrm{~L}$ at $10 \mathrm{M}$ $\mathrm{NaOH}$. The planned volume of the slurry after the high solids matrix test was to be $1.4 \mathrm{~L}$. For the highsolids test matrix, additional permeate was returned to the CUF, and the final volume of the slurry before leaching was $1.6 \mathrm{~L}$ instead. To maintain the same final leach volume, the volume of the caustic addition was reduced to $2.1 \mathrm{~L}$. To maintain the same addition of $\mathrm{NaOH}$, the concentration of the solution was raised to $10.9 \mathrm{M} \mathrm{NaOH}$. The target concentrations of key analytes for the caustic leached supernate were: 
- $7.7 \mathrm{M}$ sodium

- $6.0 \mathrm{M}$ free hydroxide

- $0.8 \mathrm{M}$ aluminum.

Like in the previous test, the leach solution was heated to $100^{\circ} \mathrm{C}$ over a 5.3-hour interval. However, the solution was held at $100^{\circ} \mathrm{C}$ for 8 hours, instead of 12 hours, because of the high aluminum dissolution results seen from the Group 5 test. The slurry permeate was sampled during the heat ramp and temperature soak to evaluate the aluminum dissolution rate during these two periods. Afterwards, the solution was allowed to cool to room temperature over a 12-hour interval. At this point, the leached slurry solution in the slurry reservoir tank was allowed to enter the piping of the CUF, and it was dewatered to minimum volume. Six equal volume caustic rinse solutions (1.2 liters) were then added to the leached solution and dewatered each time. The $\mathrm{NaOH}$ concentration of each rinse solution was established so that the free hydroxide concentration of the leached solution was high enough after each rinse to maintain the solubility of the aluminum in solution (based on a predicted $100 \%$ dissolution rate). After the sixth rinse, the free hydroxide level of the washed permeate was predicted to be below $0.25 \mathrm{M}$. The concentration of the wash solutions used were:

- $1.53 \mathrm{M} \mathrm{NaOH}$ for the first wash

- $0.66 \mathrm{M} \mathrm{NaOH}$ for the second wash

- $0.24 \mathrm{M} \mathrm{NaOH}$ for the third wash

- $0.09 \mathrm{M} \mathrm{NaOH}$ for the fourth wash

- $0.02 \mathrm{M} \mathrm{NaOH}$ for the fifth wash

- $0.01 \mathrm{M} \mathrm{NaOH}$ for the sixth wash.

Once the slurry was rinsed after caustic leaching, it was removed from the CUF for oxidative leaching (third column in Figure 4.1). The waste solution was returned to the slurry reservoir tank once the tank was isolated from the filtration piping. At this point, a solution of 1-M sodium permanganate was added to the slurry. The volume of sodium permanganate added was to achieve a 1:1 molar ratio of Mn to the predicted quantity of $\mathrm{Cr}$ in the waste solids. Due to experimental error, the volume of 1-M sodium permanganate added to the reaction vessel exceeded the target addition. Examination of the testing results has shown that the actual Mn:Cr molar ratio from the sodium permanganate addition was 1.7:1 pontentially resulting in greater oxidation of $\mathrm{Pu}$ and other safety-related components. After the solution was added to the waste slurry, it was mixed for 6 hours at room temperature. Slurry supernate samples were periodically collected during this time to evaluate the chromium dissolution rate of solid $\mathrm{Cr}$ in the blended waste sample. After 6 hours, the oxidative leached slurry was immediately rinsed with three equal volume washes of $0.01-\mathrm{M} \mathrm{NaOH}$ solutions and dewatered each time.

After dewatering the last rinse solution, the rinse leached slurry was combined with the remaining washed leached slurry from the previous CUF test (Group 5), to increase the quantity of UDS in the CUF. This combined slurry was further dewatered to a minimum volume to increase the UDS concentration higher than that from the previous test and obtain more dewatering data of leached waste. After dewatering the combined leached slurries from both tests, an abridged filter matrix test was performed (Table 2.2) on the dewatered slurry to see if there was any difference from the previous test. 
As before, slurry and supernate samples were periodically collected to track the solids loading in the waste slurry and to track the chemical components of the slurry to perform mass balance calculations to evaluate the effectiveness of the process in separating LAW components from the HLW components in the waste sample. More details of the analyses performed and test scheme are found in Appendices A, B, C, F, and L. 
WTP-RPT-172, Rev 0
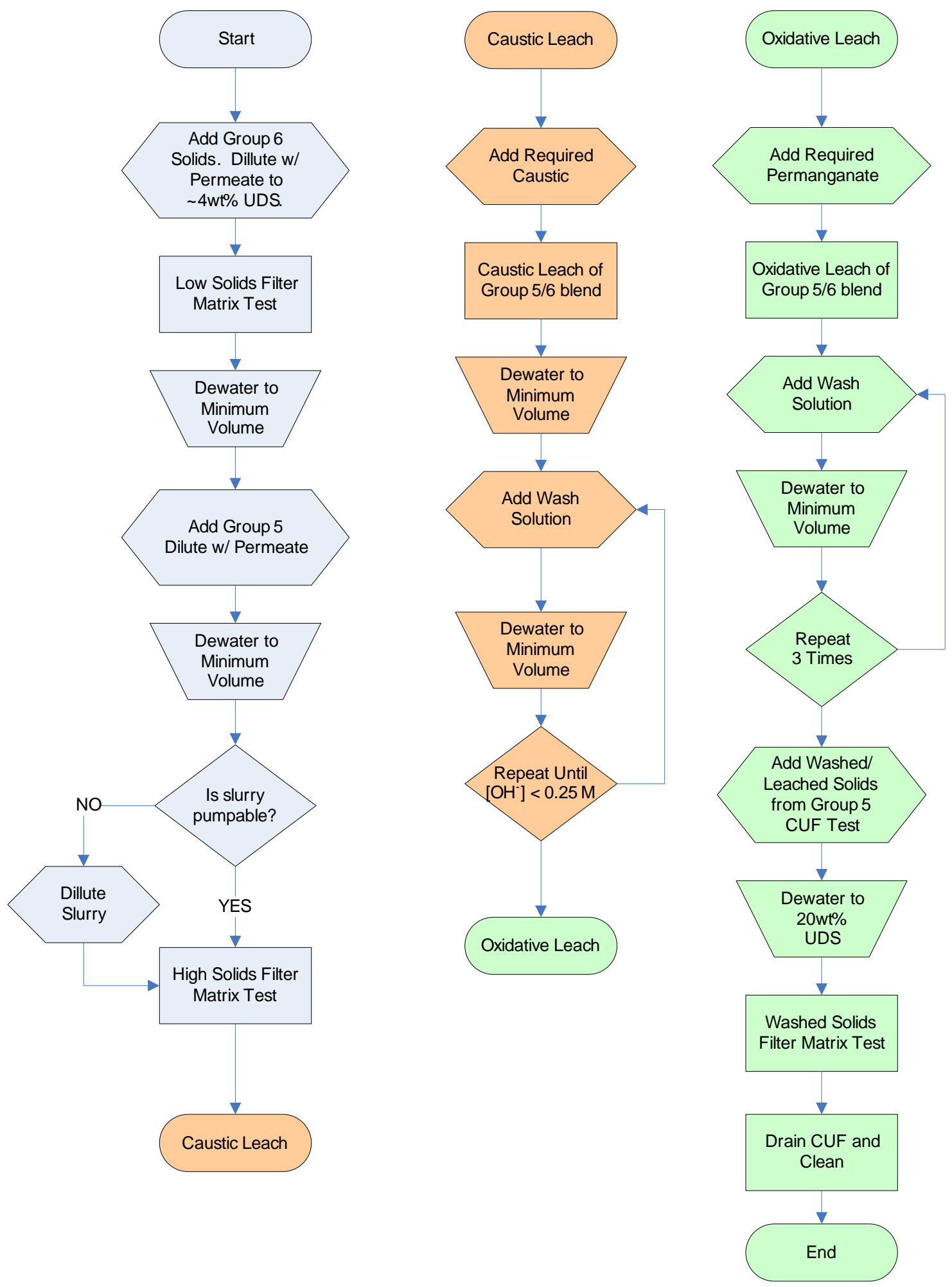

Figure 4.1. Group 6/5 CUF Test Flowchart 


\subsection{Initial Feed Characterization}

Figure 4.2 outlines the activities and materials added to the CUF to produce the low-solids slurry. This slurry was created from waste samples formed during the homogenization of the Group 6 composite (WTP-RPT-157). During this process, a large majority of the solid material was found to be soluble. In the end, $\sim 0.8 \mathrm{~L}$ of settle slurry with a UDS concentration of $14.7 \mathrm{wt} \%$ was created along with $\sim 3 \mathrm{~L}$ of excess supernate with a sodium concentration of $5.1 \mathrm{M}$. After characterization was completed, $0.60 \mathrm{~kg}$ of the slurry sample was available for testing, along with most of the excess supernate. The testing began with the slurry reservoir isolated from the CUF. The available Group 6 slurry was placed into the slurry reservoir and diluted with $1.84 \mathrm{~kg}$ of excess Group 6 supernate. After blending the diluted slurry inside the slurry reservoir tank for 30 minutes with the overhead mixer, the valves isolating the tank were opened and the circulation pump was turned on. Permeate was allowed to flow through the filter and the back pulse chamber was filled with permeate. Once the density on the mass flow meter was stable, the slurry was sampled for physical and chemical characterization. Physical property measurements of the low solids slurry inside the slurry loop are detailed in Table 4.3. The overall composition of the slurry (including permeate hold-up) is shown in Table 4.4 and Table 4.5.

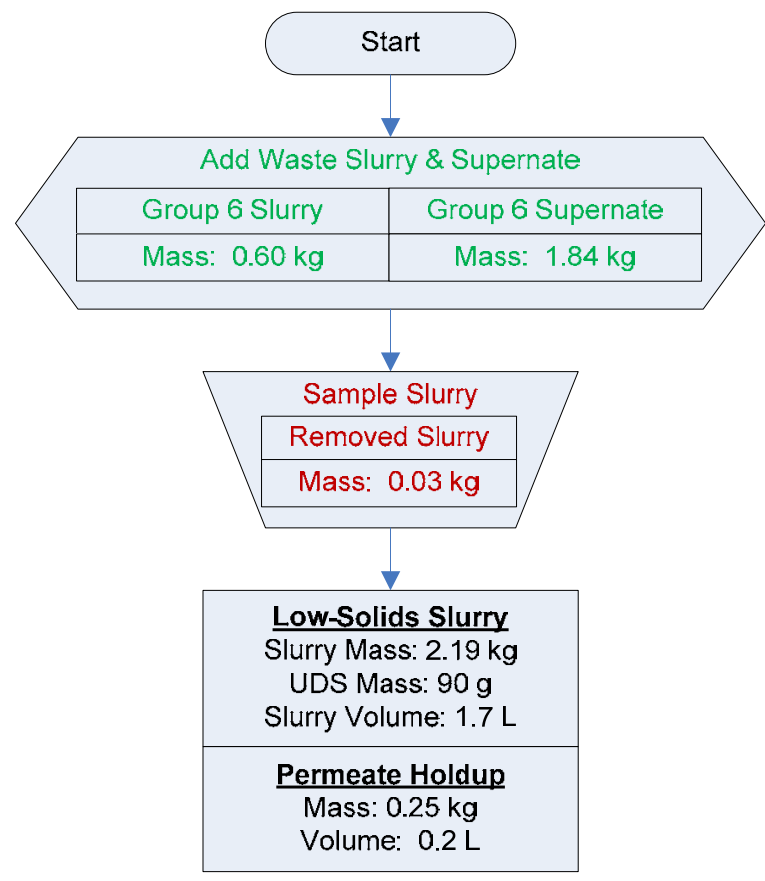

Figure 4.2. Group 6/5 Feed Additions and Sampling for the Low-Solids Slurry Note: Mass and volume values in figure are rounded to the nearest significant digit of accuracy. 
Table 4.3. Group 6/5 Low-Solids Slurry Physical Property Measurements (Slurry Circulation Loop)

\begin{tabular}{|r|c||}
\hline Slurry Density (g/mL) & 1.25 \\
\hline Supernate Density (g/mL) & 1.25 \\
\hline Settled Solids (Vol\%) & $16 \%$ \\
\hline Centrifuged UDS (Wt $\%)$ & $42 \%$ \\
\hline Total Solids of Slurry (Wt\%) & $37 \%$ \\
\hline Dissolved Solids of Supernate (Wt\%) & $35 \%$ \\
\hline UDS of Slurry (Wt $\mathbf{0})$ & $3 \%$ \\
\hline
\end{tabular}


Table 4.4. Group 6/5 Low-Solids Slurry Inventory and Composition (including permeate hold-up)

\begin{tabular}{|c|c|c|c|c|c|}
\hline & Slurry $^{(a)}$ & \multicolumn{2}{|c|}{ Liquid Fraction $^{(b)}$} & \multicolumn{2}{|c|}{ Solids Fraction ${ }^{(\mathrm{c})}$} \\
\hline Mass (kg) & 2.44 & & 2.36 & & 0.09 \\
\hline Wt\% of Slurry & $100 \%$ & & $96.9 \%$ & & $3.6 \%$ \\
\hline Metal & g & g & $\mu \mathrm{g} / \mathrm{mL}$ & g & $\mu g / g$ \\
\hline Al & $4.7 \mathrm{E}+01$ & $1.5 \mathrm{E}+01$ & $8.3 \mathrm{E}+03$ & $3.1 \mathrm{E}+01$ & $3.6 \mathrm{E}+05$ \\
\hline $\mathbf{B}$ & $5.8 \mathrm{E}-02$ & $<2$.E-2 & $<9 . \mathrm{E}+0$ & $5.8 \mathrm{E}-02$ & $6.6 \mathrm{E}+02$ \\
\hline Cd & $1.0 \mathrm{E}-02$ & $<2$.E-3 & $<1 . \mathrm{E}+0$ & $1.0 \mathrm{E}-02$ & $1.2 \mathrm{E}+02$ \\
\hline $\mathrm{Cr}$ & $8.6 \mathrm{E}+00$ & $1.1 \mathrm{E}+00$ & $6.1 \mathrm{E}+02$ & $7.5 \mathrm{E}+00$ & $8.5 E+04$ \\
\hline $\mathbf{F e}$ & $1.7 \mathrm{E}+00$ & $<2$.E-2 & $<1 . \mathrm{E}+1$ & $1.7 \mathrm{E}+00$ & $1.9 \mathrm{E}+04$ \\
\hline Mn & $7.5 \mathrm{E}-01$ & $<2$.E-3 & $<1 . \mathrm{E}+0$ & 7.5E-01 & $8.5 \mathrm{E}+03$ \\
\hline $\mathrm{Na}$ & $2.3 \mathrm{E}+02$ & $2.3 \mathrm{E}+02$ & $1.2 \mathrm{E}+05$ & $-2.8 \mathrm{E}+00$ & $-3.2 \mathrm{E}+04$ \\
\hline $\mathbf{P}$ & $6.3 \mathrm{E}+00$ & $5.0 \mathrm{E}+00$ & $2.7 \mathrm{E}+03$ & $1.3 \mathrm{E}+00$ & $1.5 \mathrm{E}+04$ \\
\hline S & $5.3 \mathrm{E}+00$ & $4.2 \mathrm{E}+00$ & $2.2 \mathrm{E}+03$ & $1.1 \mathrm{E}+00$ & $1.2 \mathrm{E}+04$ \\
\hline Si & $2.8 \mathrm{E}+00$ & $1.5 \mathrm{E}-01$ & $7.8 \mathrm{E}+01$ & $2.6 \mathrm{E}+00$ & $3.0 \mathrm{E}+04$ \\
\hline $\mathbf{U}$ & $1.1 \mathrm{E}+00$ & $<8 . \mathrm{E}-2$ & $<4 . \mathrm{E}+1$ & $1.1 \mathrm{E}+00$ & $1.3 \mathrm{E}+04$ \\
\hline \multirow{2}{*}{$\begin{array}{l}\text { Radiochemical } \\
\text { Isotopes }\end{array}$} & Slurry & \multicolumn{2}{|c|}{ Liquid Fraction } & \multicolumn{2}{|c|}{ Solid Fraction } \\
\hline & $\mu \mathrm{Ci}$ & $\mu \mathrm{Ci}$ & $\mu \mathrm{Ci} / \mathrm{mL}$ & $\mu \mathrm{Ci}$ & $\mu \mathrm{Ci} / \mathrm{g}$ \\
\hline Co-60 & $8.5 \mathrm{E}+00$ & $1.0 \mathrm{E}+00$ & 5.6E-04 & $7.5 \mathrm{E}+00$ & 8.5E-02 \\
\hline Cs-137 & $1.7 \mathrm{E}+05$ & $1.7 \mathrm{E}+05$ & $9.2 \mathrm{E}+01$ & $-5.4 \mathrm{E}+03$ & $-6.1 \mathrm{E}+01$ \\
\hline Eu-154 & $1.3 \mathrm{E}+02$ & $<1 . \mathrm{E}+0$ & $<8$. E-4 & $1.3 \mathrm{E}+02$ & $1.5 \mathrm{E}+00$ \\
\hline Eu-155 & $5.9 \mathrm{E}+01$ & $<7 . \mathrm{E}+0$ & $<4$.E-3 & $5.9 \mathrm{E}+01$ & 6.7E-01 \\
\hline Am-241 & $4.1 \mathrm{E}+02$ & $<2 . \mathrm{E}+1$ & $<$ 9.E-3 & $4.1 \mathrm{E}+02$ & $4.6 \mathrm{E}+00$ \\
\hline Gross Alpha & $6.1 \mathrm{E}+02$ & $<7 . \mathrm{E}+0$ & $<4$. E-3 & $6.1 \mathrm{E}+02$ & $7.0 \mathrm{E}+00$ \\
\hline Gross Beta & $5.5 \mathrm{E}+05$ & $1.8 \mathrm{E}+05$ & $9.4 \mathrm{E}+01$ & $3.8 \mathrm{E}+05$ & $4.3 \mathrm{E}+03$ \\
\hline Sr-90 & $5.2 \mathrm{E}+04$ & $1.4 \mathrm{E}+02$ & 7.7E-02 & $5.2 \mathrm{E}+04$ & $6.0 \mathrm{E}+02$ \\
\hline $\mathrm{Pu}-239+240$ & $1.2 \mathrm{E}+02$ & 2.6E-01 & $1.4 \mathrm{E}-04$ & $1.2 \mathrm{E}+02$ & $1.3 \mathrm{E}+00$ \\
\hline Pu-238 & $1.8 \mathrm{E}+01$ & 3.9E-02 & $2.1 \mathrm{E}-05$ & $1.8 \mathrm{E}+01$ & 2.0E-01 \\
\hline \multirow[t]{2}{*}{ Anions } & \multicolumn{3}{|c|}{ Liquid Fraction } & \multicolumn{2}{|c|}{ Leached Solids Fraction } \\
\hline & $\mu \mathrm{g} / \mathrm{mL}$ & [M] & g & $\mu \mathrm{g} / \mathrm{g}$ & g \\
\hline $\mathbf{F}$ & $9.9 \mathrm{E}+01$ & $5.2 \mathrm{E}-03$ & $1.8 \mathrm{E}-01$ & $1.9 \mathrm{E}+02$ & $1.7 \mathrm{E}+01$ \\
\hline $\mathrm{C}_{2} \mathrm{O}_{4}$ & $8.1 \mathrm{E}+02$ & $9.2 \mathrm{E}-03$ & $1.5 \mathrm{E}+00$ & $7.1 \mathrm{E}+03$ & $6.2 \mathrm{E}+02$ \\
\hline $\mathrm{NO}_{2}$ & $4.4 \mathrm{E}+04$ & 9.6E-01 & $8.2 \mathrm{E}+01$ & $2.3 \mathrm{E}+04$ & $2.0 \mathrm{E}+03$ \\
\hline $\mathrm{NO}_{3}$ & $1.4 \mathrm{E}+05$ & $2.3 \mathrm{E}+00$ & $2.6 \mathrm{E}+02$ & $7.6 \mathrm{E}+04$ & $6.6 \mathrm{E}+03$ \\
\hline $\mathrm{SO}_{4}$ & $9.2 \mathrm{E}+03$ & $9.6 \mathrm{E}-02$ & $1.7 \mathrm{E}+01$ & $4.2 \mathrm{E}+03$ & $3.6 \mathrm{E}+02$ \\
\hline $\mathrm{PO}_{4}$ & $8.9 \mathrm{E}+03$ & $9.4 \mathrm{E}-02$ & $1.6 \mathrm{E}+01$ & $5.2 \mathrm{E}+03$ & $4.6 \mathrm{E}+02$ \\
\hline $\mathbf{O H}$ & $1.1 \mathrm{E}+04$ & $6.4 \mathrm{E}-01$ & $2.0 \mathrm{E}+01$ & & \\
\hline \multicolumn{6}{|c|}{$\begin{array}{l}\text { (a) Slurry Mass components were calculated from characterization data (WPT-RPT-157), and the } \\
\text { masses of materials that were added with simulant. Loss of mass from sampling was incorporated. } \\
\text { (b) Liquid Fraction mass components were calculated using analytical results from supernate sample } \\
\text { TI552-G6-A (ASO ID 08-00218) and the predicted mass of supernate in the system. } \\
\text { (c) Solids Fraction mass components were calculated from the difference between the slurry } \\
\text { component mass and liquid component mass fraction. }\end{array}$} \\
\hline
\end{tabular}


Table 4.5. Group 6/5 Low-Solids Supernate Opportunistic Composition

\begin{tabular}{|c|c|}
\hline \multirow{3}{*}{$\begin{array}{l}\text { Opportunistic } \\
\text { Analytes }\end{array}$} & Supernate \\
\hline & Measured $^{(\mathbf{a})}$ \\
\hline & $\mu \mathrm{g} / \mathrm{mL}$ \\
\hline Ag & $<2.1 \mathrm{E}+0$ \\
\hline As & $<3.5 \mathrm{E}+1$ \\
\hline Ba & $<1.7 \mathrm{E}+0$ \\
\hline Be & {$[0.074]$} \\
\hline Ca & {$[50]$} \\
\hline Ce & $<5.9 \mathrm{E}+0$ \\
\hline Co & $<1.9 \mathrm{E}+0$ \\
\hline $\mathbf{C u}$ & $<2.4 \mathrm{E}+0$ \\
\hline Dy & $<1.7 \mathrm{E}+0$ \\
\hline Eu & $<5.4 \mathrm{E}-1$ \\
\hline La & {$[1]$} \\
\hline $\mathbf{L i}$ & $<2.7 \mathrm{E}+0$ \\
\hline Mg & $<3.5 \mathrm{E}+0$ \\
\hline Mo & 38 \\
\hline Nd & $<8.5 \mathrm{E}+0$ \\
\hline $\mathbf{P b}$ & $<1.8 \mathrm{E}+1$ \\
\hline Pd & $<6.2 \mathrm{E}+0$ \\
\hline $\mathbf{R h}$ & $<1.3 \mathrm{E}+1$ \\
\hline Ru & [7] \\
\hline Sb & $<1.6 \mathrm{E}+1$ \\
\hline Se & [104] \\
\hline Sn & $<9.9 \mathrm{E}+0$ \\
\hline Ta & $<6.6 \mathrm{E}+0$ \\
\hline Te & $<1.6 \mathrm{E}+1$ \\
\hline Th & [10] \\
\hline $\mathbf{T i}$ & $<4.8 \mathrm{E}-1$ \\
\hline Tl & $<3.2 \mathrm{E}+1$ \\
\hline $\mathbf{V}$ & {$[2]$} \\
\hline $\mathbf{W}$ & 76 \\
\hline $\mathbf{Y}$ & $<4.2 \mathrm{E}-1$ \\
\hline
\end{tabular}

(a) Supernatant measured from, ASR 8055, sample TI552-G6-A (RPL ID 08-00218); reference date November 5, 2007.

Analyte uncertainties were typically within $\pm 15 \%$; results in brackets indicate that the analyte concentrations were greater than the method detection limit (MDL) and less than the estimated quantitation limit (EQL), and uncertainties were $>15 \%$.

Opportunistic analytes are reported for information only; quality control (QC) requirements did not apply to these analytes. 
Particle size distribution measurements were performed on the pulled slurry samples. Initial analysis showed that the PSD appears to be influenced by instrument pump speed. The distribution at 3,000 RPM is broad, spanning from just above $0.2 \mu \mathrm{m}$ to just below $30 \mu \mathrm{m}$. It appears to be composed of two overlapping particle populations with peaks centered at 2 and $7 \mu \mathrm{m}$. At high pump speeds (4,000 RPM), the analyzer appears to suspend a third particle population spanning 20 to $200 \mu \mathrm{m}$ with a peak population ranging from 60 to $70 \mu \mathrm{m}$. At low pump speeds (2,000 RPM), the upper bound of PSD is reduced from $30 \mu \mathrm{m}$ to just above $20 \mu \mathrm{m}$, and the 7- $\mu \mathrm{m}$ particle peak disappears. The results indicate a particle population that is relatively difficult to suspend starting near $7 \mu \mathrm{m}$ and spanning up to $200 \mu \mathrm{m}$ (Figure 4.3). Figure 4.4. shows the PSD for the low solids sample before, during, and after sonication. Sonication appears to eliminate the population that peaks at $7 \mu \mathrm{m}$. The changes observed in PSD upon sonication of the dispersion are similar to those observed in the pre-sonic PSD as the pump speed was decreased to 2,000 RPM. This change indicates that the solid species associated with the population peaking at $7 \mu \mathrm{m}$ are fragile primary particles or agglomerates that are disrupted when sonic energy is applied. This disruption appears to be irreversible on the time scale of PSD measurements because the 7$\mu \mathrm{m}$ peak population does not appear to recover in the post-sonic PSD. Overall, the results from the sample slurry analysis were very similar to the results from the Group 6 characterization testing (see Appendix H. for more details). 


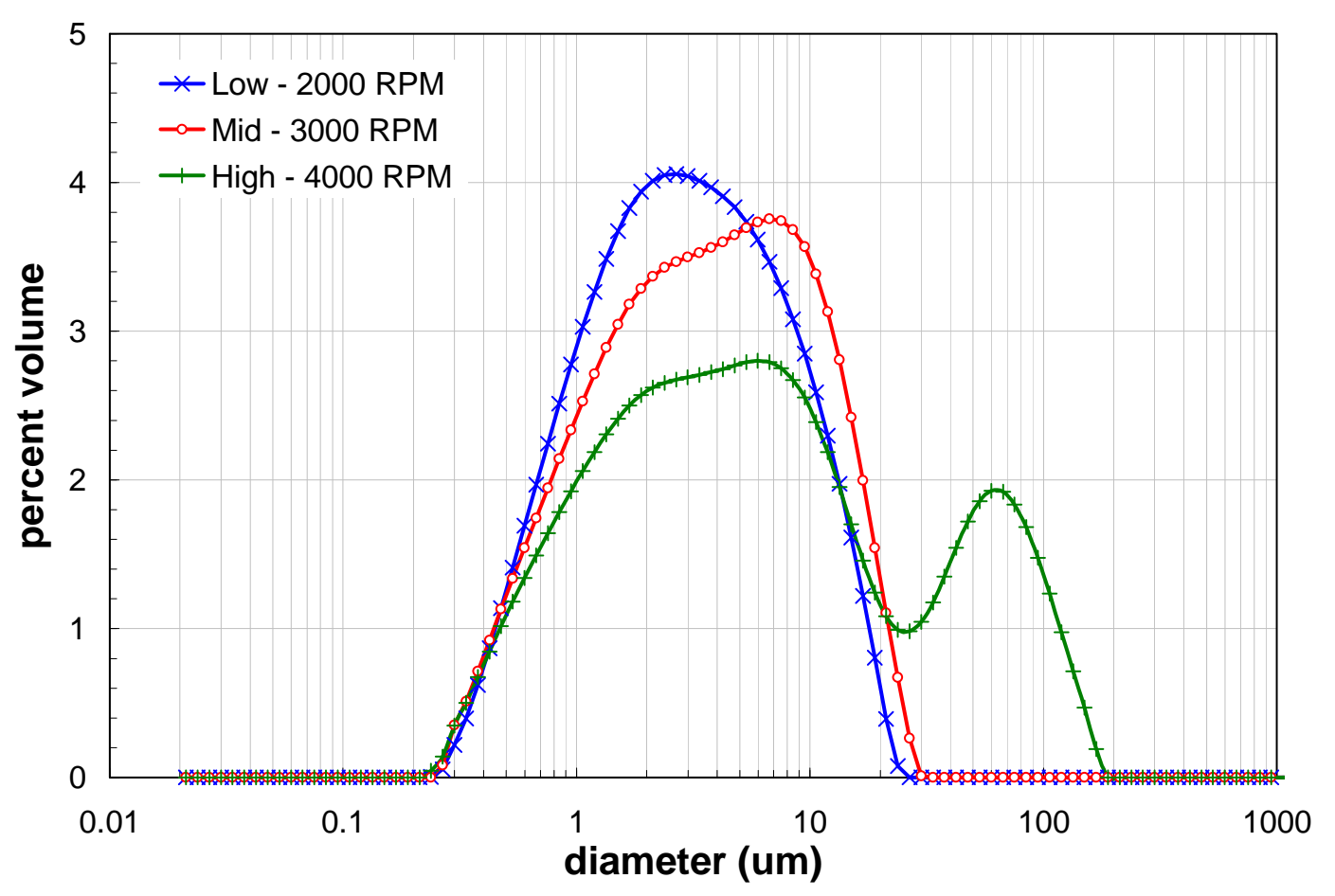

Figure 4.3. PSD for Low Solids Matrix as a Function of Pump Speed

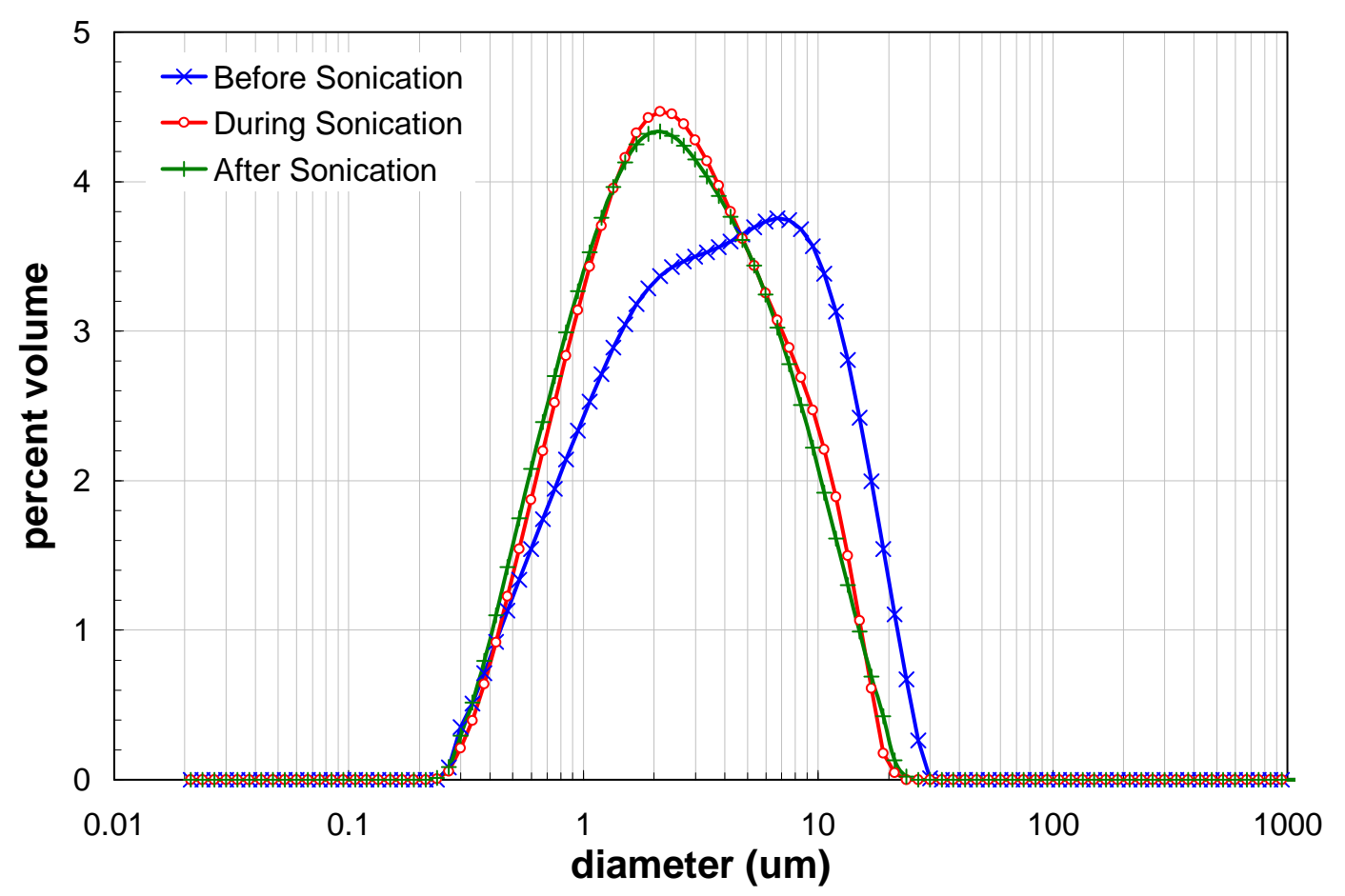

Figure 4.4. PSD for Low Solids as a Function of Sonication 
A slurry sample was also pulled for rheology testing prior to the start of the low-solids matrix testing. The results of the testing showed that the behavior of the low solids slurry (Figure 4.5) was consistent with that observed for the feed material (see Appendix $\mathrm{J}$ for details). Like the more concentrated feed sample, which was composed of the Group 6 material only, the low solids are Newtonian and show sharp transitions in slope near $600 \mathrm{~s}^{-1}$ that are consistent with the formation of Taylor vortices. In addition, increases in the sample temperature from $25^{\circ} \mathrm{C}$ to $40^{\circ} \mathrm{C}$ and from $40^{\circ} \mathrm{C}$ to $60^{\circ} \mathrm{C}$ cause the slope of the flow curves to be reduced, indicating a drop in slurry viscosity. Relative to the feed material, which showed viscosities of 4 to $8 \mathrm{mPa} \cdot \mathrm{s}$ over the $25^{\circ}$ to $60^{\circ} \mathrm{C}$ test range, the viscosity of the low-solids matrix is reduced and shows only 3 to $6 \mathrm{mPa}$-s over the same temperature range. This also confirms that the viscosity of the low-solids matrix slurry decreases with increasing temperature. As was observed in the feed material, the repeat viscosity measurement at $25^{\circ} \mathrm{C}$ for the low solids shows a higher viscosity than the primary measurement. This may be a result of evaporation or changes to the solids structure as a result of shear on the previous tests. Once the testing was completed, the slurry sample was returned to the CUF.

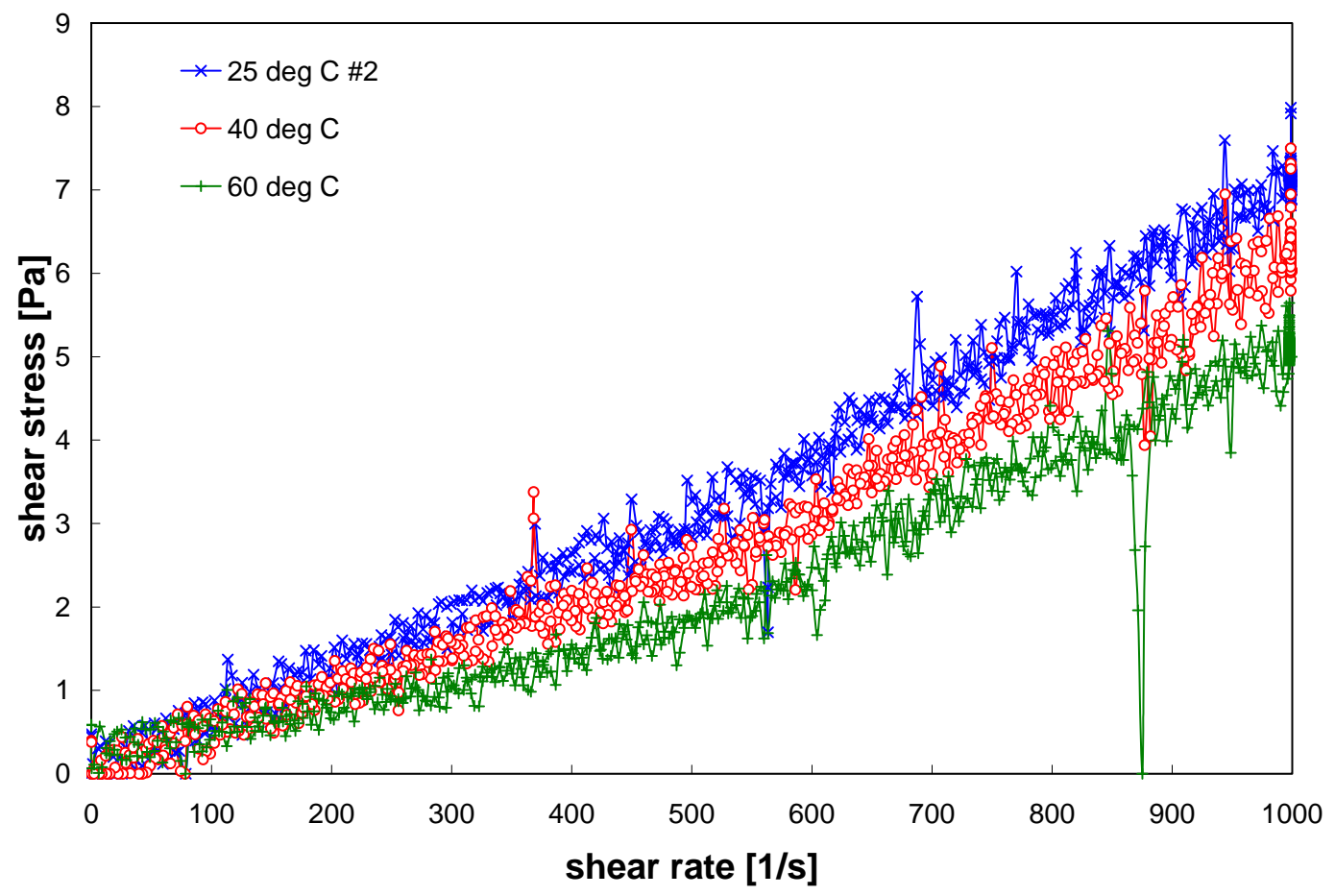

Figure 4.5. Flow Curves for Group 6/5 Low-Solids Slurry (Group 6 Only)

\subsection{Filter Flux Test Matrix and Initial Dewater}

This section describes the filtration testing performed before caustic leaching, as shown in the left column (colored blue) of Figure 4.1, and outlined below:

- Performed filtration testing of the composite Group 6 waste slurry at a low-solids concentration as described in Section 2.2. Testing compared the effects of transmembrane pressure (TMP), axial velocity (AV), and operation time on filter flux. 
- Dewatered of the low-solids waste slurry to a higher UDS concentration using a constant TMP and AV to compare the dewatering behavior of S-Saltcake waste to the REDOX waste.

- Added Group 5 composite waste to the dewatered Group 6 slurry and dewatered the blended slurry. The purpose here was two fold. One was to observe changes in the dewatering behavior from the introduction of a different waste type. The other reason was to increase the UDS in the slurry to 300 grams (solid inventory in the Group 6 material was $\sim 90$ grams).

- Perform filtration testing of the slurry at a high-solids concentration. Like before, testing compared the effects of TMP, AV, and operation time on filter flux.

\subsubsection{Low-Solids Matrix (4 wt\% UDS)}

After slurry sampling and rheology testing was completed, the low-solids matrix test was performed with the remaining slurry (Figure 4.6). The UDS concentration of the slurry inside the slurry loop was estimated as $4 \%$ based on mass balance calculations $(0.09 \mathrm{~kg} / 2.19 \mathrm{~kg} \cong 4 \mathrm{wt} \%)$. Physical property measurements of the slurry found the UDS concentration to be $3 \mathrm{wt} \%$. These physical-property measurements are shown in Table 4.1.

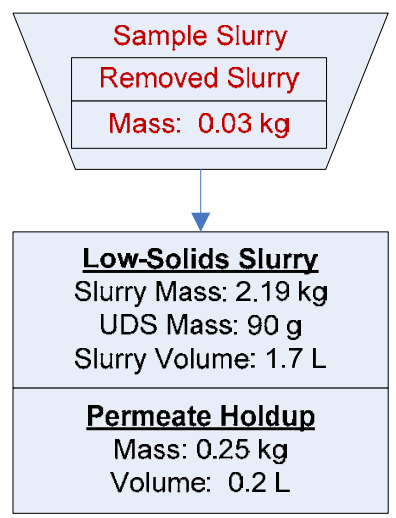

Figure 4.6. Group 6/5 CUF Low-Solids Slurry

Note: Mass and volume values in figure are rounded to the nearest significant digit of accuracy.

The full filter matrix test was performed on the slurry, as outlined in Table 2.1. The filter was back pulsed twice between test conditions. Average values for the operating conditions and corresponding filter flux are given in Table 4.4. Figure 4.7 displays the permeate flux for each of the 11 steps in the matrix with respect to time, and Figure 4.8 compares the actual achieved test conditions to the target test conditions described in Section 2, Table 2.1. The flux ranged from 0.030 down to $0.008 \mathrm{GPM} / \mathrm{ft}^{2}$, with average values of $0.023,0.017$, and $0.013 \mathrm{GPM} / \mathrm{ft}^{2}$ for sequential tests at the standard filtration condition of TMP $=40 \mathrm{psid}$ and $\mathrm{AV}=13 \mathrm{ft} / \mathrm{s}$. The decrease in the filter flux at the standard condition indicated that progressive fouling of the filter element was occurring during the test matrix which was not prevented from back pulsing.

The Group 6 low-solids slurry behaved according to the Darcy equation (Equation 2-6) with the observed permeate flux scaled in proportion to the transmembrane pressure. This correlation is illustrated in Figure 4.9 where the average value of permeate flux is plotted against the transmembrane pressure for each test condition. Data shown in a corresponding chart for axial velocity, Figure 4.10, indicated that there is no proportional relationship of permeate flux with axial velocity. However, the $\mathrm{R}^{2}$ correlation for 
the linear relationship of filter flux to TMP was only 0.04, indicating that other factors were impacting filter flux. In Table 4.6, the median operation time of the test was estimated (where $\mathrm{T}=0$ was the start of the first test condition) for each test condition and plotted against the average filter flux from each test in Figure 4.11. The figure indicates that filter flux decreased significantly over time, with a linear correlation factor of 0.4. This demonstrated that filter resistance was increasing over the course of the test, which explains the observed variability in the linear correlation of filter flux to TMP.

To verify these conclusions, a mathematical model was developed of the filter flux as a function of TMP and AV using the data in Table 4.6 to quantify the individual impact of each process parameter. The relative process time value (the median value during the test as selected in Table 4.6) was also as a variable in the development of the model to compensate for changes in the filter resistance that were occurring over the course of the test. Using a least-square statistical method, a linear model with a $\mathrm{R}^{2}$ correlation coefficient of 0.89 was developed using TMP and time of filtration as parameters, shown in Figure 4.12. As predicted from the initial analysis, the model showed that increases in TMP correlate to increases in the filter flux, and that AV did not significant impact the filter flux. The model also showed that increases in operation time significantly decreased filter flux as well. This implied that the material in the Group 6 waste was fouling the surface of the filter and that the filter resistance was increasing over the course of this test. Because relative process time was significant, the results from this test matrix were skewed because the filter resistance was not at steady state. While the model did confirm that TMP was the dominant process parameter for the Group 6 waste at this concentration, the relationships shown here should not be used to predict filter flux for this waste type other than when this test occurred and for the range of TMP and AV provided in Table 4.6. Future testing of this type of waste or simulant would benefit from extended operational time before this type of matrix test to understand when filter resistance reaches a steady state, or if it does.

Table 4.6. Average Operating Conditions and Flux for Low-Solids Matrix Test

\begin{tabular}{|c|c|c|c|c|c|c|c|}
\hline $\begin{array}{c}\text { Design } \\
\text { Test } \\
\text { Condition }\end{array}$ & $\begin{array}{c}\text { Median } \\
\text { Operation } \\
\text { Time of Test } \\
\text { (hr) }\end{array}$ & $\begin{array}{c}\text { Slurry } \\
\text { Temp }^{(b)} \\
\left({ }^{\circ} \mathbf{C}\right)\end{array}$ & $\begin{array}{c}\text { TMP }^{(\mathrm{c})} \\
\text { (psid) }\end{array}$ & $\begin{array}{c}\text { Axial } \\
\text { Velocity } \\
\text { (ft/s) }\end{array}$ & $\begin{array}{l}\text { Permeate } \\
\text { Flow rate } \\
\text { (mL/min) }\end{array}$ & $\begin{array}{l}\text { Corrected } \\
\text { Permeate } \\
\text { Flux } \\
\left(\text { GPM/ft }{ }^{2}\right)\end{array}$ & $\begin{array}{l}\text { Axial } \\
\text { Pressure } \\
\text { Drop }^{(\mathrm{c})} \\
\text { (psid/ft) }\end{array}$ \\
\hline 1 & 1.5 & 24.2 & 40.5 & 13.1 & 22.0 & 0.023 & 1.7 \\
\hline 2 & 3.5 & 23.9 & 30.8 & 11.0 & 21.5 & 0.022 & 1.3 \\
\hline 3 & 4.5 & 24.0 & 30.8 & 15.1 & 16.6 & 0.017 & 1.8 \\
\hline 4 & 5.5 & 24.4 & 50.2 & 14.9 & 20.6 & 0.021 & 2.0 \\
\hline 5 & 6.5 & 24.3 & 50.0 & 11.1 & 19.8 & 0.020 & 1.4 \\
\hline 6 & 7.5 & 24.2 & 40.4 & 13.0 & 16.1 & 0.017 & 1.6 \\
\hline 7 & 8.5 & 24.1 & 40.3 & 8.9 & 17.0 & 0.018 & 1.2 \\
\hline 8 & 9.5 & 24.5 & 39.7 & 16.6 & 13.6 & 0.014 & 2.2 \\
\hline 9 & 10.5 & 24.2 & 20.3 & 13.1 & 8.0 & 0.008 & 1.5 \\
\hline 10 & 11.5 & 24.4 & 59.5 & 12.6 & 19.3 & 0.020 & 1.7 \\
\hline 11 & 12.5 & 24.4 & 39.9 & 13.2 & 12.8 & 0.013 & 2.0 \\
\hline \multicolumn{8}{|c|}{$\begin{array}{l}\text { (a) Median operation time refers to the mid } \\
\text { relative to the start time of the test }(\mathrm{T}= \\
\text { (b) Thermocouple accuracy } \pm 22^{\circ} \mathrm{C} \\
\text { (c) Pressure transducer accuracy } \pm 1 \mathrm{psig}\end{array}$} \\
\hline
\end{tabular}


WTP-RPT-172, Rev 0

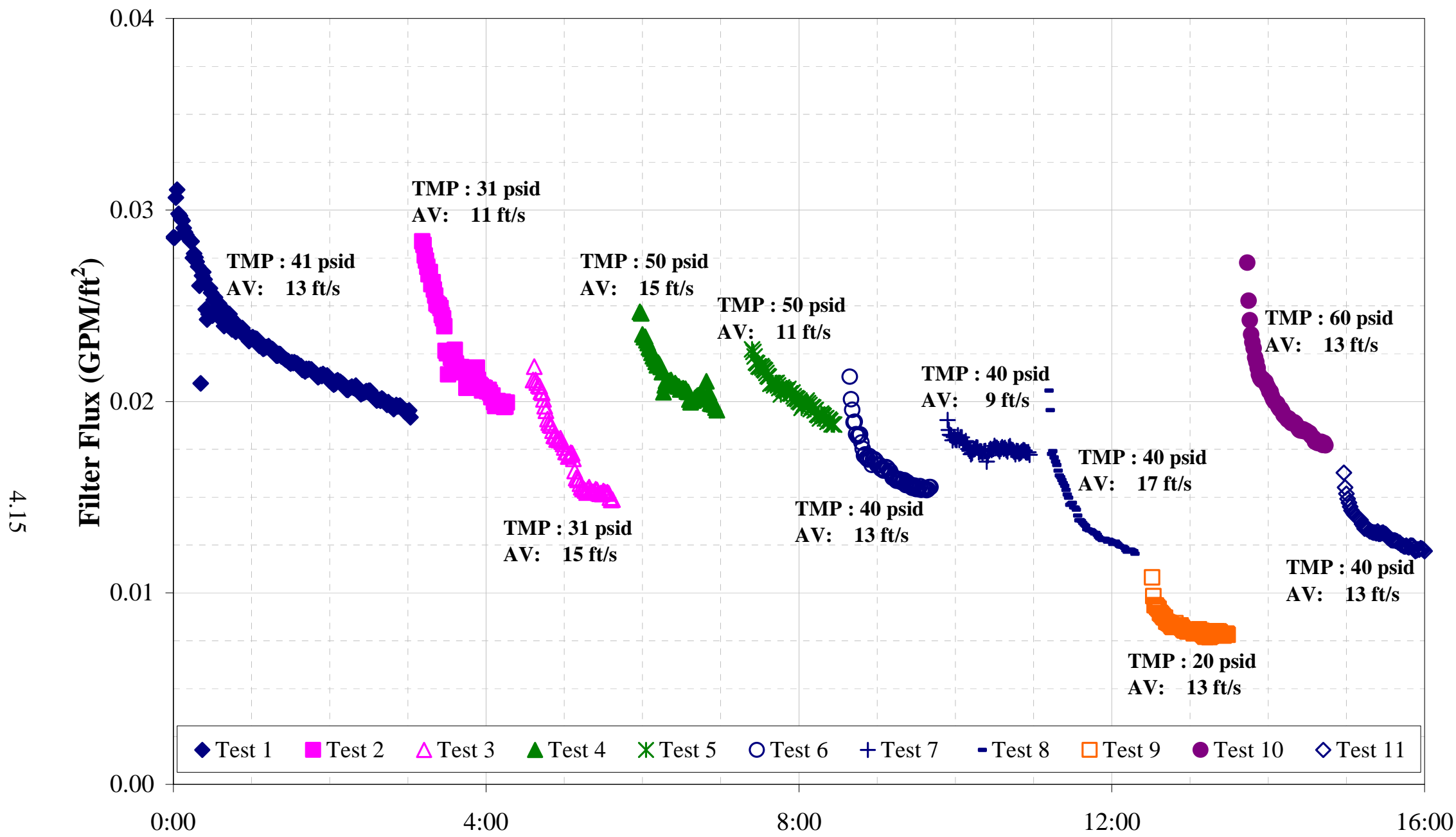

Figure 4.7. Filter Flux Data for Group 6 Initial Low-Solids Matrix (4 wt\% UDS) 


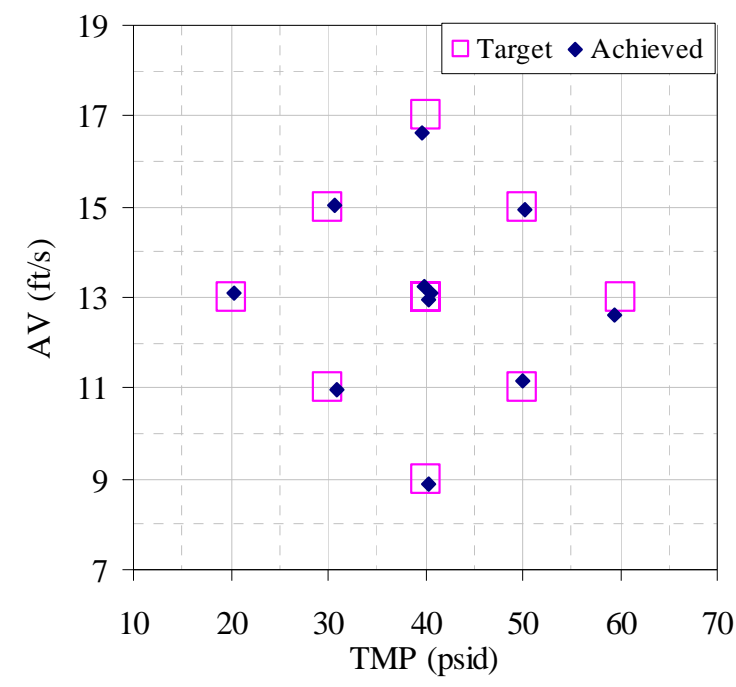

苛

Figure 4.8. Group 6/5 Filter Test Matrix for Lows-Solids

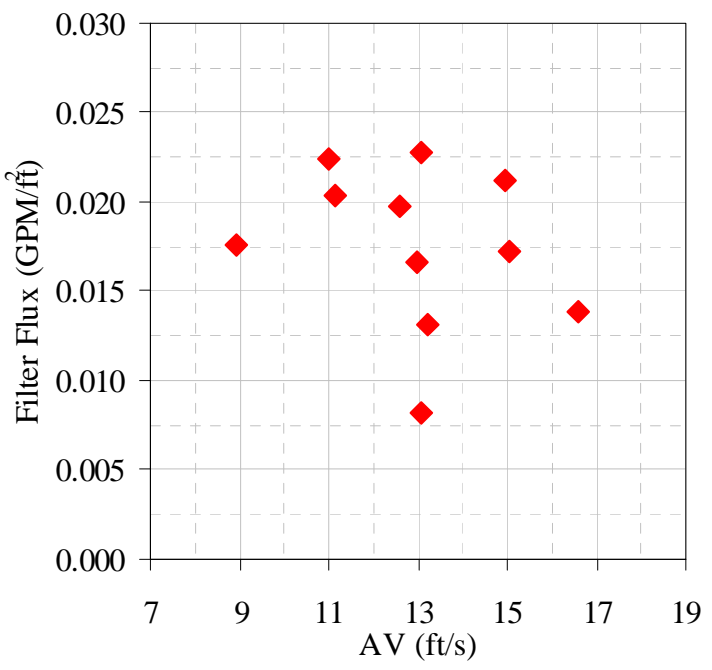

Figure 4.10. Group 6/5 Flux vs. AV for Low-Solids

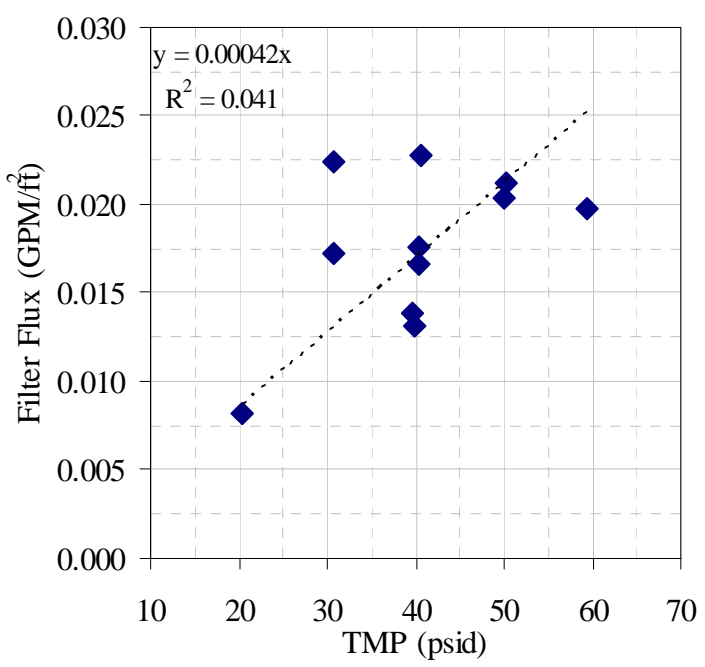

Figure 4.9. Group 6/5 Flux vs. TMP for Low-Solids

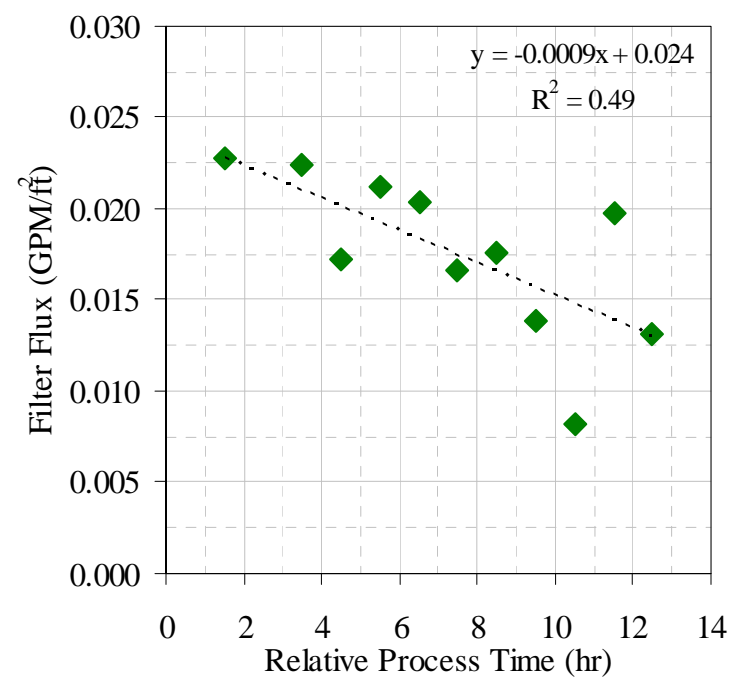

Figure 4.11. Group 6/5 Flux vs. Relative Time for Low-Solids 
WTP-RPT-172, Rev 0

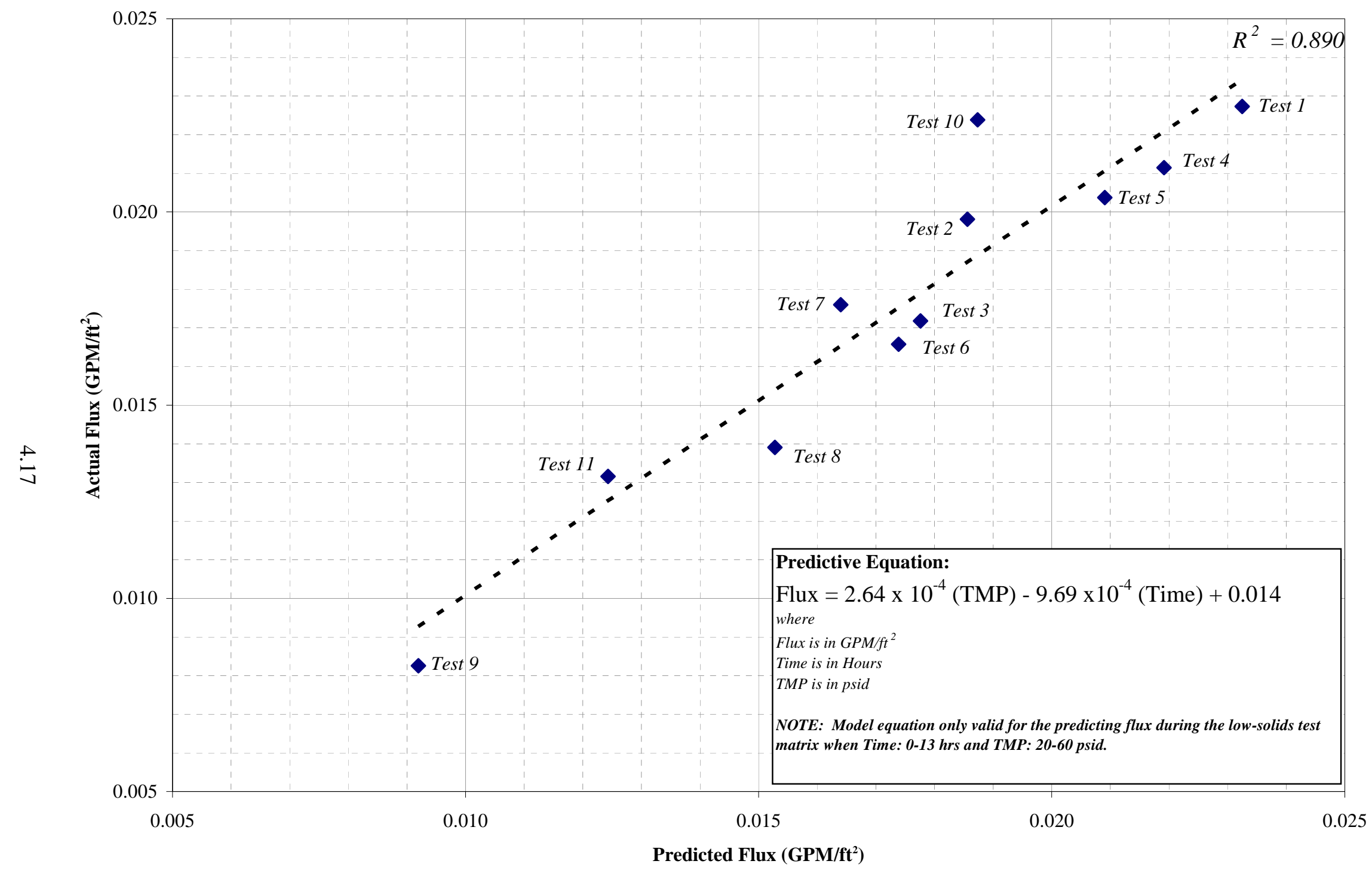

Figure 4.12. Linear Model of Group 6/5 Low-Solid Slurry Filter Flux 


\subsubsection{Dewatering of Group 6 Slurry and Group 6/5 Blended Slurry}

After the low-solids matrix test was completed, dewatering tests occurred as outlined in Figure 4.13. The low-solids slurry composed of only Group 6 waste was initially dewatered for 30 minutes to measure its filter flux. Afterwards, the filter permeate was returned (after being sub-sampled) to the CUF. At this point, Group 5 slurry ( $0.99 \mathrm{~kg})$ and additional Group 6 supernate $(0.55 \mathrm{~kg})$ were added to the CUF as well. The blended slurry was predicted to have 270 grams of UDS. The mass of the Group 6 and Group 5 used in this test was less than that planned due to holdup in the sample containers and because some of the available Group 5 material (1.16 kg) was diverted for other testing.

This slurry was then dewatered to an estimated UDS concentration of $13 \mathrm{wt} \%$, removing $1.50 \mathrm{~kg}$ of permeate. The mixed slurry had an average flux during dewatering of $0.035 \mathrm{GPM} / \mathrm{ft}^{2}$ compared to $0.012 \mathrm{GPM} / \mathrm{ft}^{2}$ for the Group 6 slurry by itself. Dilution of the slow-filtering Group 6 slurry with Group 5 slurry appears to measurably improve the filter flux. The flux for each of the dewatering steps is plotted on a common elapsed time axis in Figure 4.14, although the dewatering steps were sequential. In both cases, no significant decrease in the filter flux was seen as a function of the UDS concentration. This was not completely unexpected, considering that the slurry was only concentrated to $13 \mathrm{wt} \%$ UDS.

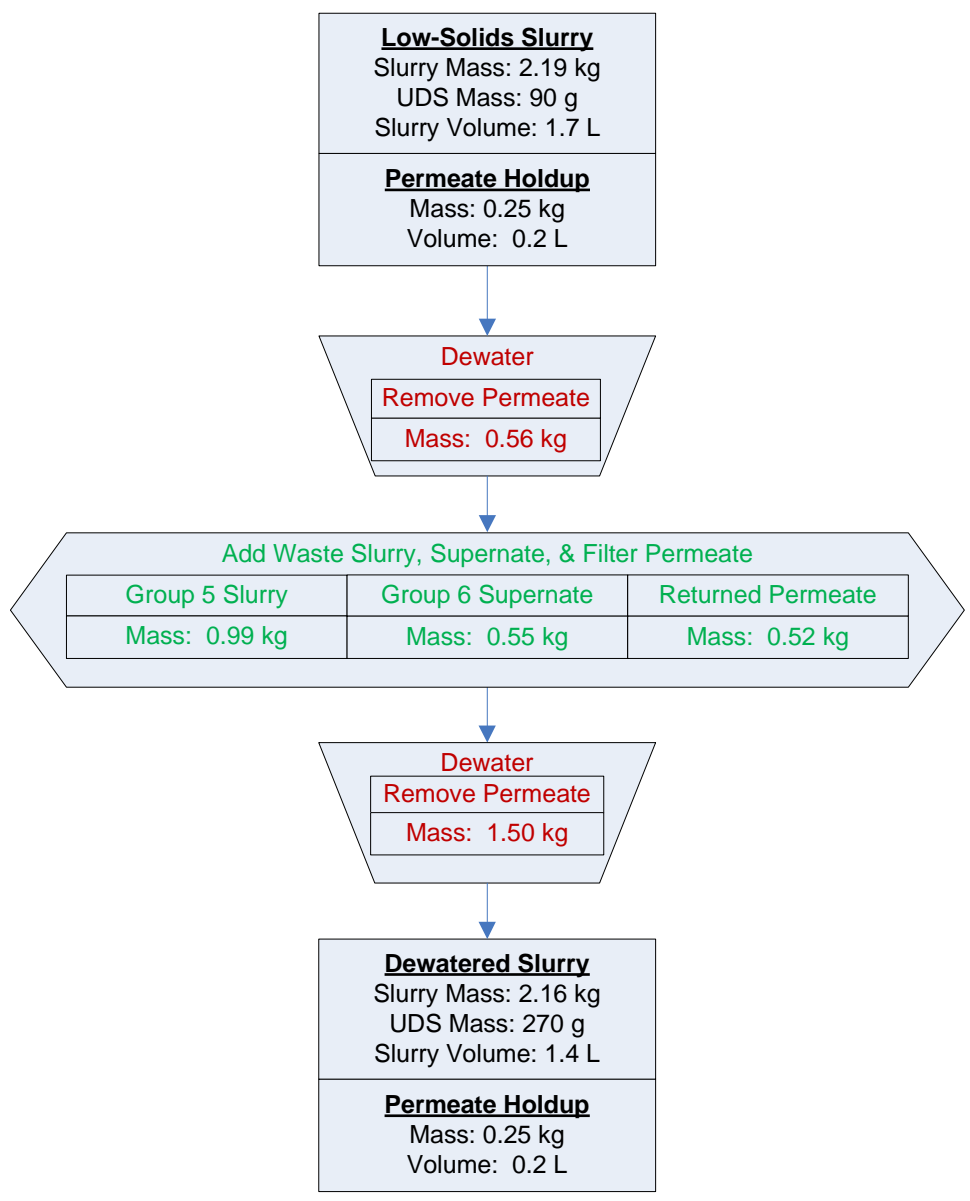

Figure 4.13. Group 6/5 Slurry Dewatering Operations

Note: Mass and volume values in figure are rounded to the nearest significant digit of accuracy. 


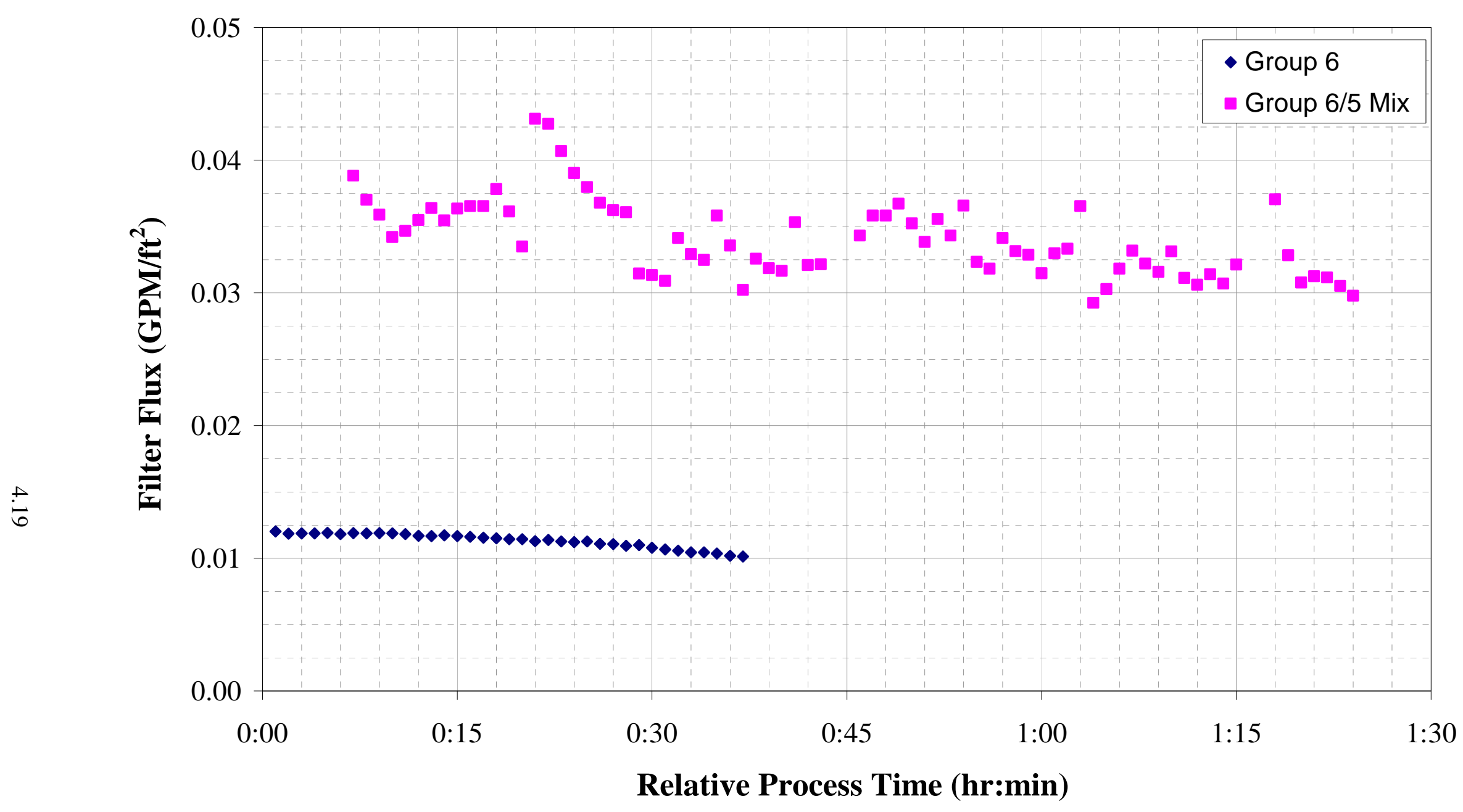

Figure 4.14. Dewatering Filter Flux of Group 6 Slurry and Group 6/5 Slurry 


\subsubsection{High-Solids Matrix}

After the Group 5 material was incorporated in the slurry and dewatered, $0.28 \mathrm{~kg}$ of permeate was added back into the CUF to prevent cavitation of the circulation pump during the high-solids matrix test (Figure 4.15). The circulation mass of the slurry was estimated as $2.50 \mathrm{~kg}$.

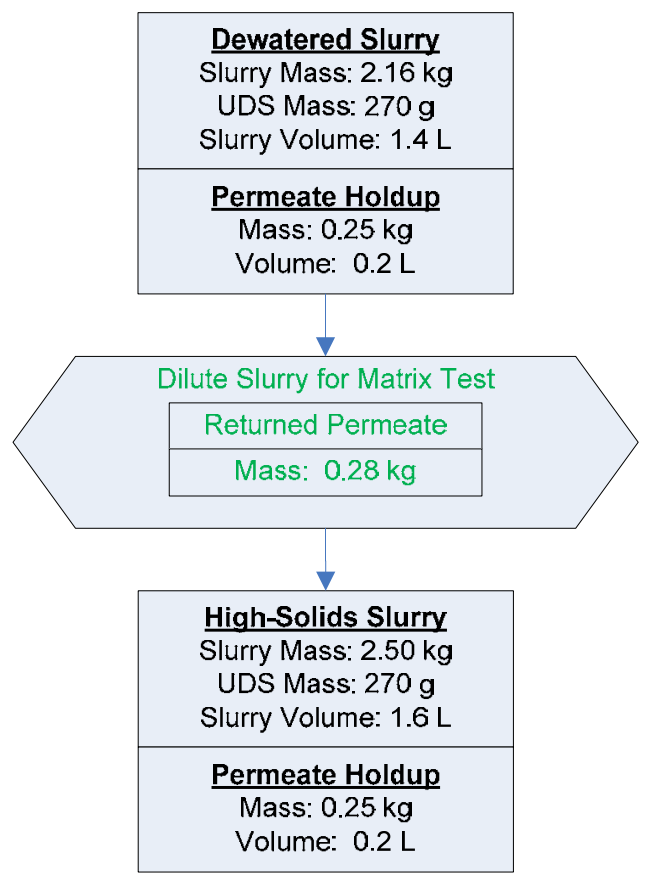

Figure 4.15. Group 6/5 High-Solids Slurry

Note: Mass and volume values in figure are rounded to the nearest significant digit of accuracy.

An abridged version of the test matrix, consisting of seven test conditions listed in Section 2, Table 2.2, was performed using the high-solids slurry. Average values for operating conditions and flux for each condition are given in Table 4.6, and Figure 4.17 compares the actual average TMP and AV from each test condition to the target condition. Figure 4.16 displays the permeate flux with respect to time. The flux ranged from 0.010 to $0.040 \mathrm{GPM} / \mathrm{ft}^{2}$, with an average value near $0.020 \mathrm{GPM} / \mathrm{ft}^{2}$ for the standard filtration condition of $\mathrm{TMP}=40 \mathrm{psid}$ and $\mathrm{AV}=13 \mathrm{ft} / \mathrm{s}$. However, examination of the initial and final test conditions at a $\mathrm{TMP}=40 \mathrm{psid}$ and $\mathrm{AV}=13 \mathrm{ft} / \mathrm{s}$ showed a $20 \%$ difference, indicating that filter resistance was still not at steady state.

The filter flux from each test was plotted against the average TMP, average AV, and the median operation

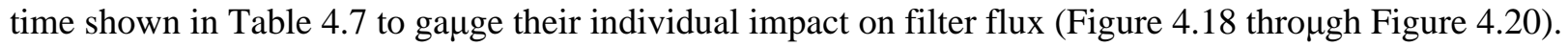
Figure 4.18 demonstrated a linear relationship of filter flux to TMP, with an $\mathrm{R}^{2}$ correlation of 0.92 , while Figure 4.19 showed that AV still was not a significant process parameter for the slurry at this concentration. Examination of Figure 4.20 showed that filter flux over time was still decreasing. While comparison of the correlation factor (0.01) to that of TMP shows that this effect was small, it still demonstrated that filter resistance was not at steady state and that the linear coefficient developed in Figure 4.18 would likely still be decreasing with time. 
Using the data provided in Table 4.7, empirical mathematical models were created defining filter flux as functions of the average TMP, average AV, and median operation time of the test to quantify their impacts on filter flux. Two models (a linear and exponential version) were fitted to the data using a leastsquare statistical method. In both cases, TMP and the median operation time were found to have significant impacts while AV was not. The linear model developed is shown in Figure 4.21. Like the model developed for the low-solids matrix test in Figure 4.12, increases in TMP correlated with increases in flux while the overall flux value decreased with time. The $\mathrm{R}^{2}$ correlation coefficient for the linear model was 0.97. The exponential model developed is shown in Figure 4.22. The power coefficient for each parameter was found to be both one, and the $\mathrm{R}^{2}$ correlation coefficient for this model was 0.96. Because time was included in both models, offset parameters were developed, which limits the range that they could be applied. Both models do not predict a zero filter flux when the TMP is zero, which demonstrates that the input to these models must be bound by the range of TMP used in this filter test, shown in Table 4.7. The use of these models should also be limited to when the test matrix occurred because the filter resistance was not at steady state, and the parameters developed in these models would be expected to change past the 10-hour period that this model predicts.

The correlation coefficients from these models were not much higher than that developed in Figure 4.18 (0.92), but the models confirm that filter resistance was still changing. However, the increase in the correlation coefficient for TMP alone compared to the TMP correlation for the low-solids test (Figure 4.9) implied that changes to the filter resistance were slowing down and approaching a steady state condition. With further operational time, it was likely that TMP would be the only statistically significant parameter.

Table 4.7. Group 6/5Average Operating Conditions and Filter Flux for High-Solids Slurry

\begin{tabular}{|c|c|c|c|c|c|c|c|}
\hline $\begin{array}{c}\text { Design } \\
\text { Test } \\
\text { Condition }\end{array}$ & $\begin{array}{c}\text { Median } \\
\text { Operation } \\
\text { Time }^{(a)} \text { of } \\
\text { Test (hr) }\end{array}$ & $\begin{array}{c}\text { Slurry } \\
\text { Temp }^{(b)} \\
\left({ }^{\circ} \mathbf{C}\right)\end{array}$ & $\begin{array}{l}\operatorname{TMP}^{(\mathrm{c})} \\
\text { (psid) }\end{array}$ & $\begin{array}{c}\text { Axial } \\
\text { Velocity } \\
\text { (ft/s) }\end{array}$ & $\begin{array}{l}\text { Permeate } \\
\text { Flow rate } \\
\text { (mL/min) }\end{array}$ & $\begin{array}{c}\text { Corrected } \\
\text { Permeate } \\
\text { Flux } \\
\left(\mathrm{GPM} / \mathrm{ft}^{2}\right)\end{array}$ & $\begin{array}{c}\text { Axial } \\
\text { Pressure } \\
\text { Drop }^{(\mathrm{c})} \\
\text { (psid/ft) }^{\text {psid }}\end{array}$ \\
\hline 1 & 1.5 & 24.2 & 40.8 & 13.1 & 24.7 & 0.025 & 2.0 \\
\hline 2 & 3.5 & 24.4 & 40.4 & 16.0 & 22.1 & 0.023 & 2.3 \\
\hline 3 & 4.5 & 23.9 & 40.0 & 8.9 & 21.0 & 0.022 & 1.2 \\
\hline 4 & 5.5 & 24.0 & 40.3 & 12.9 & 20.8 & 0.022 & 1.7 \\
\hline 5 & 6.5 & 23.9 & 20.6 & 12.9 & 11.1 & 0.012 & 1.6 \\
\hline 6 & 7.5 & 24.5 & 59.4 & 13.1 & 33.2 & 0.034 & 1.9 \\
\hline 7 & 8.5 & 24.1 & 40.8 & 13.0 & 18.5 & 0.019 & 1.6 \\
\hline \multicolumn{8}{|c|}{$\begin{array}{l}\text { (a) Median operation time refers to the midpoint in processing time of the specific filtration test condition } \\
\text { relative to the start time of the test }(\mathrm{T}=0) \text {. Time period between test conditions was excluded. } \\
\text { (b) Thermocouple accuracy } \pm 2^{\circ} \mathrm{C} \text {. } \\
\text { (c) Pressure transducer accuracy } \pm 1 \text { psig. }\end{array}$} \\
\hline
\end{tabular}




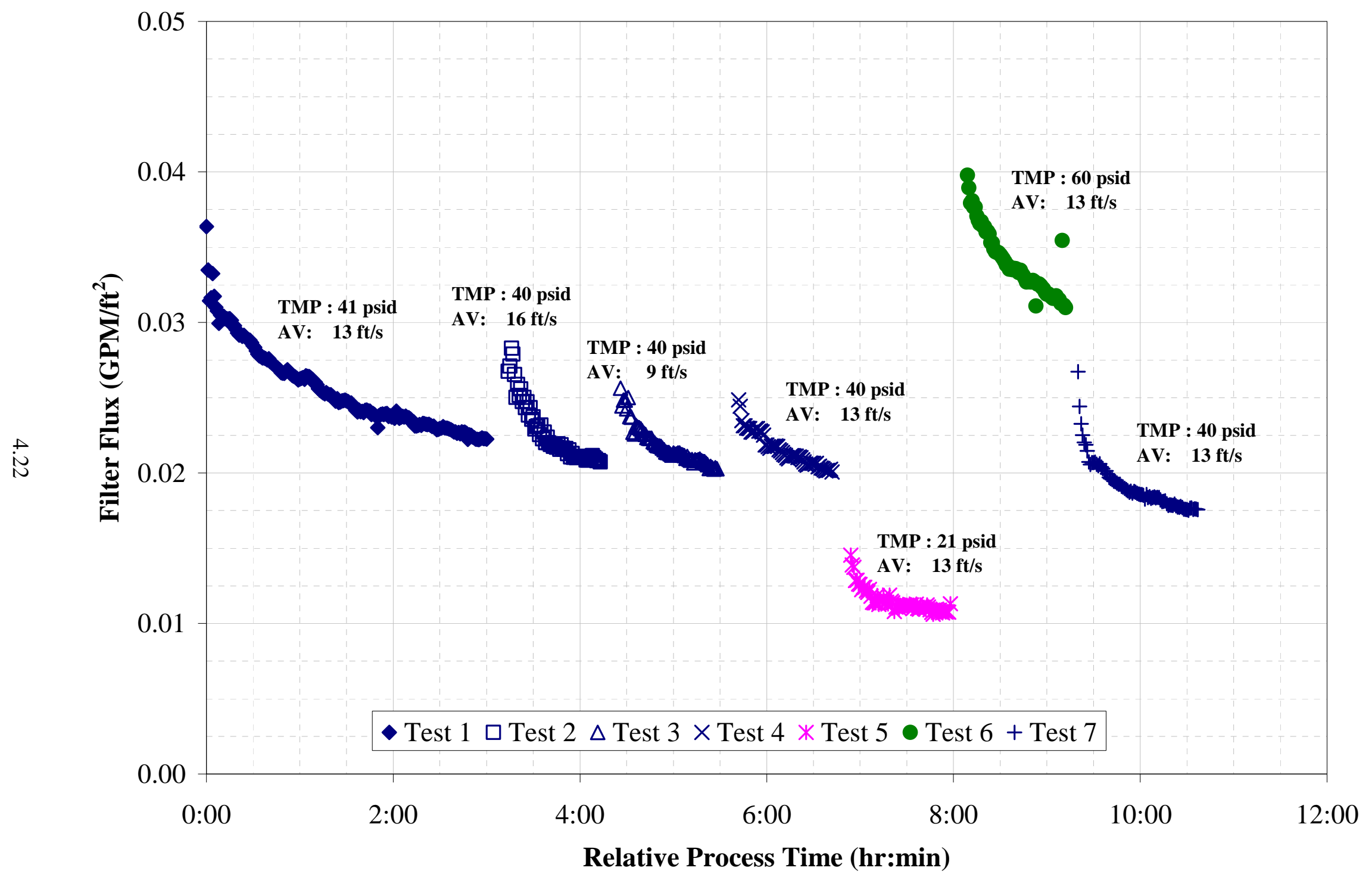

Figure 4.16. Group 6/5 Filter Flux Data for High-Solids Slurry 


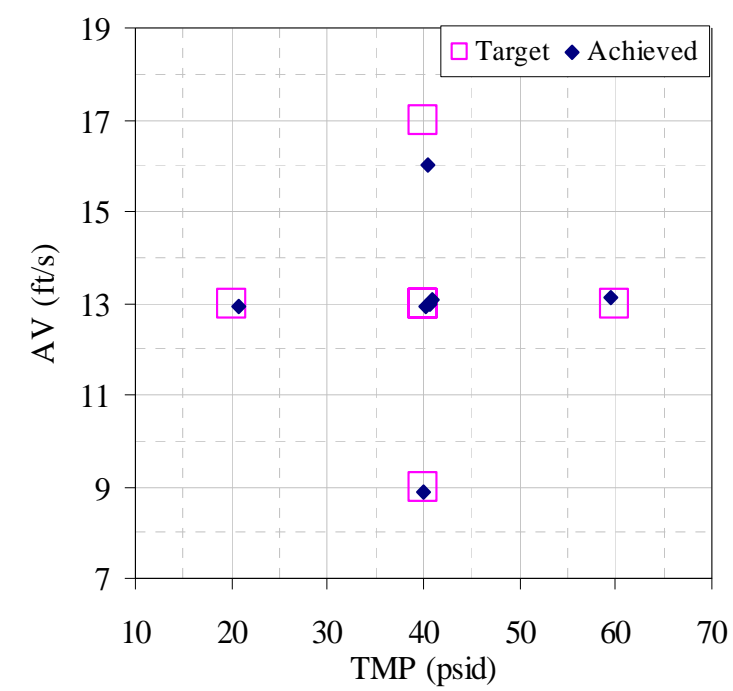

$\stackrel{+}{\stackrel{\sim}{\omega}}$

Figure 4.17. Group 6/5 Filter Test Matrix for High-Solids

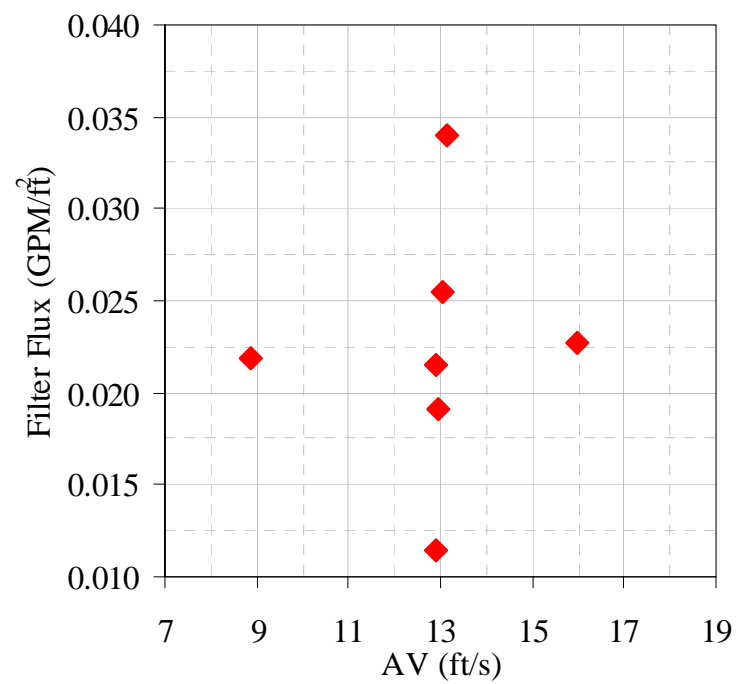

Figure 4.19. Group 6/5 Flux vs. AV for High-Solids

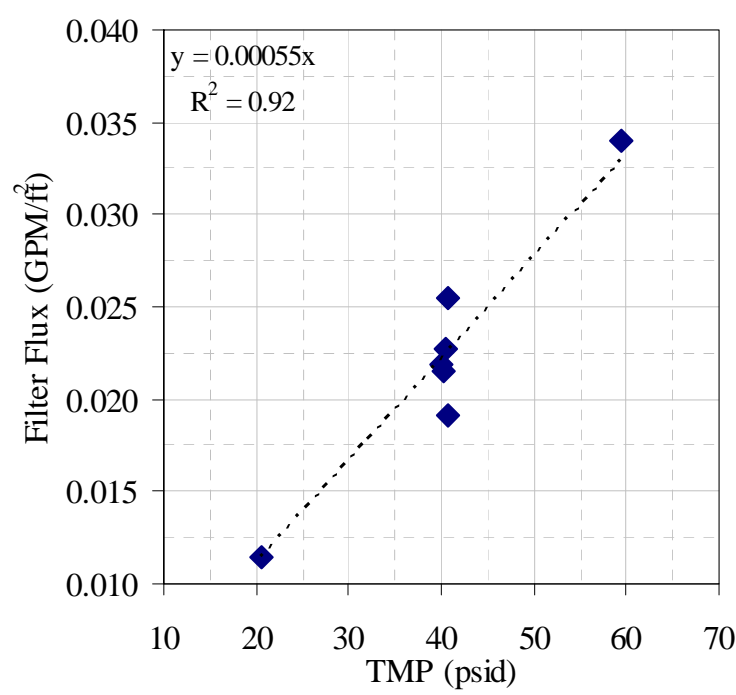

Figure 4.18. Group 6/5 Flux vs. TMP for High Solids

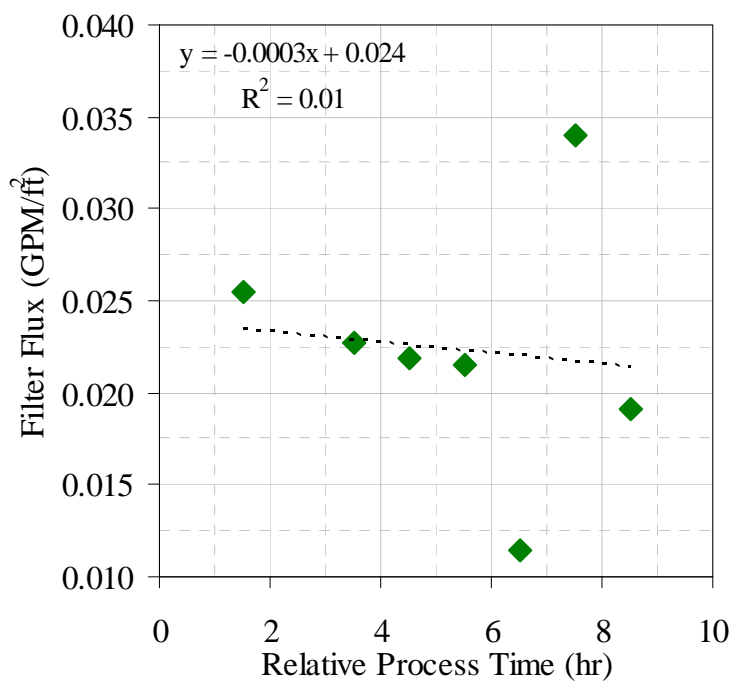

Figure 4.20. Group 6/5 Flux vs. Relative Time for High-Solids 


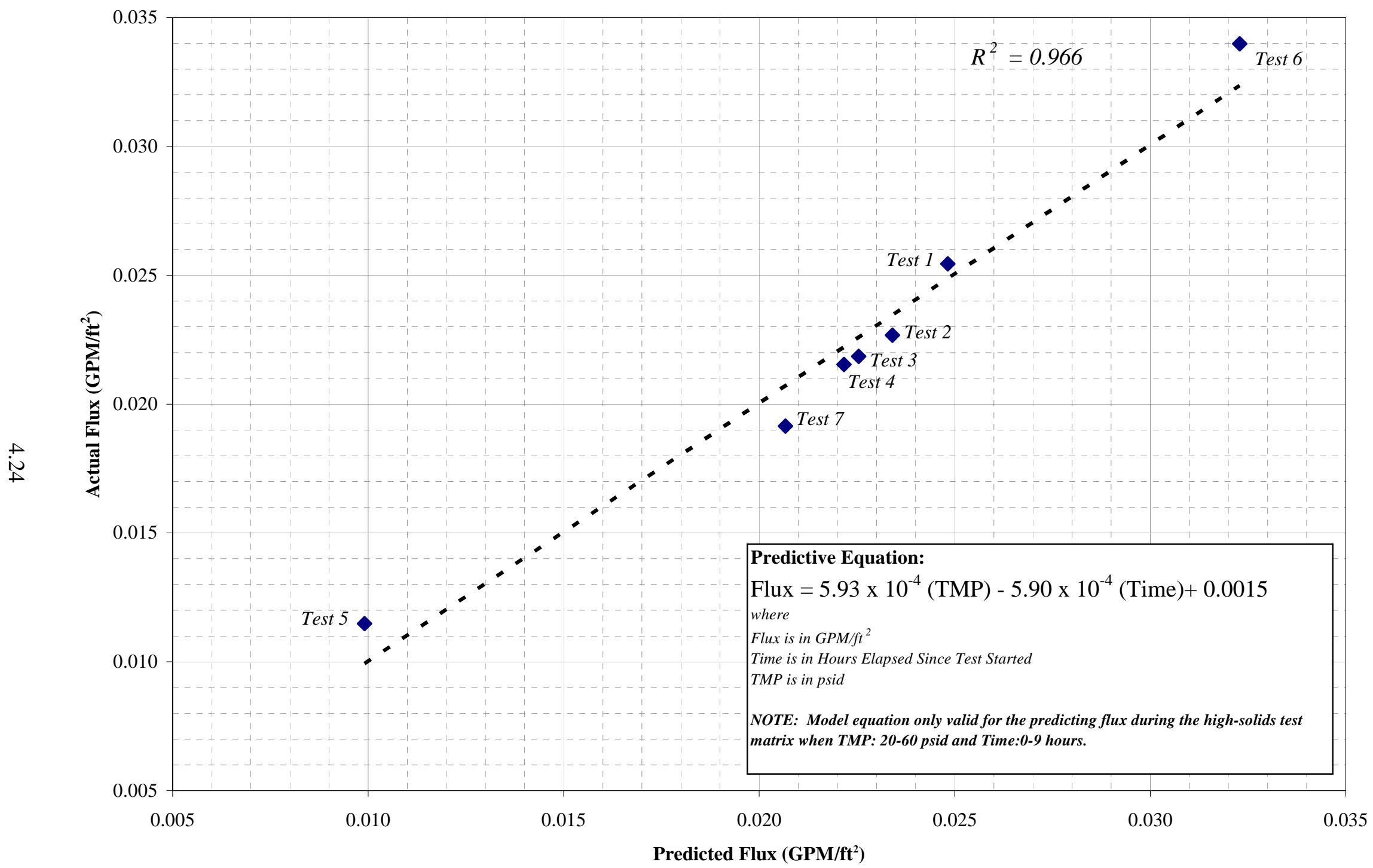

Figure 4.21. Linear Model of Group 6/5 High-Solids Slurry Filter Flux 


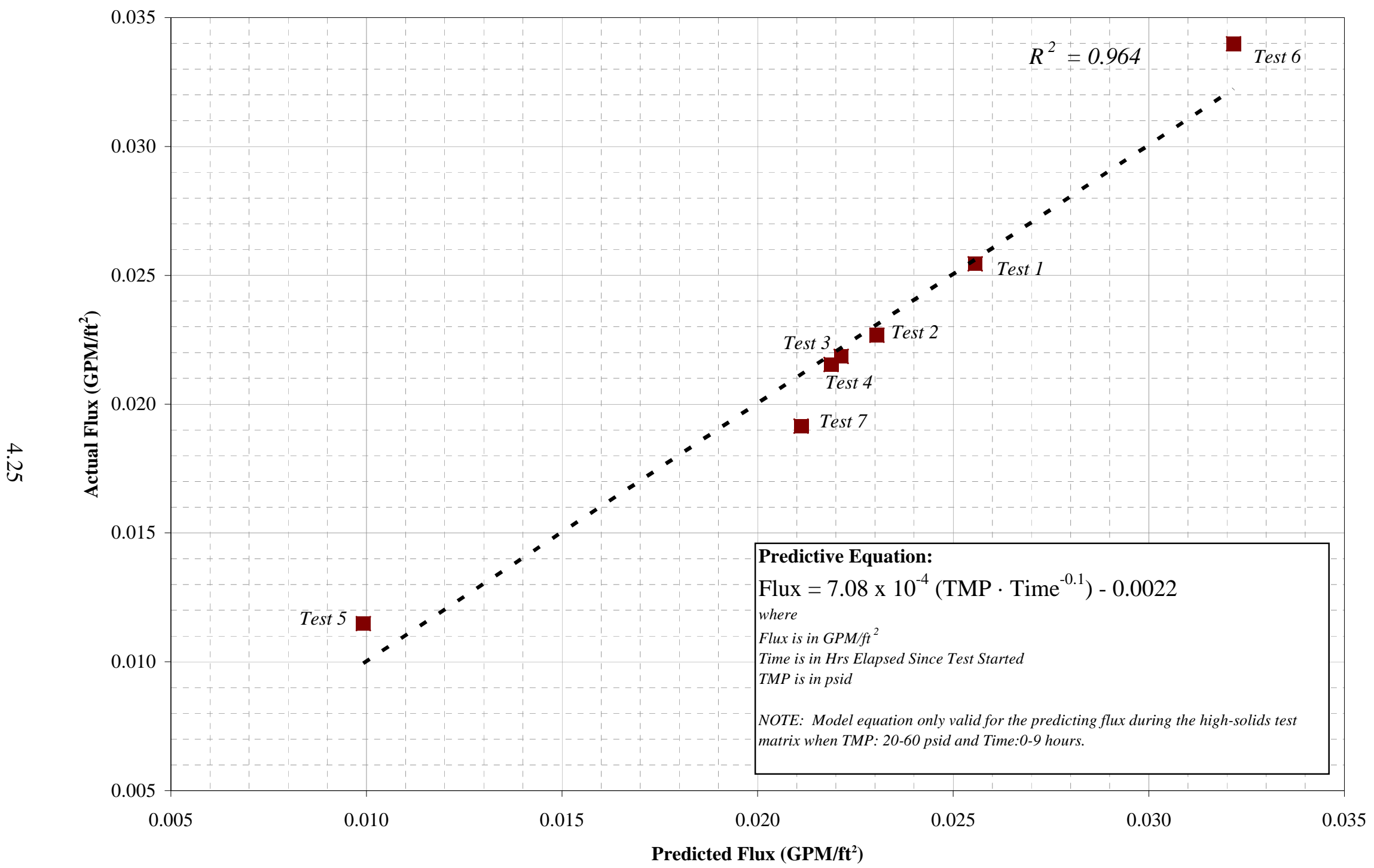

Figure 4.22. Exponential Model for Group 6/5 High-Solids Slurry Filter Flux 


\subsubsection{High-Solids Slurry Characterization}

After completing the high-solids slurry filtration testing, the slurry was sampled for physical and chemical characterization and for parametric leaching studies (Figure 4.23). Results of physical property measurements of the high solids slurry are shown in Table 4.8. The measured UDS value (13 wt\%) is slightly higher than the expected $(0.27 \mathrm{~kg} / 2.5 \mathrm{~kg} \cong 11 \mathrm{wt} \%)$. This indicated that either the solid level in the Group 5 material was higher than expected, or that the slurry sample was not truly representative of the slurry (an issue with sampling in the hot cells). The concentrations and inventory of various species in the high solids slurry are shown in Table 4.9 and Table 4.10. The chromium appears to be mostly insoluble, with a supernate calculated solubility of $12.6 \%$. This compares favorably with the initial characterization of the Group 6 waste in which was found 8.9\% water-soluble chromium. The phosphorus is mostly present in the slurry as phosphate that is dissolved in the supernate fraction of the slurry.

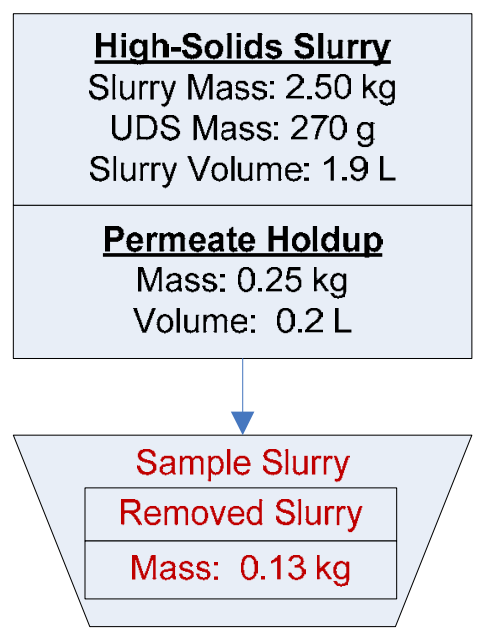

Figure 4.23. Group 6/5 Sampling of High-Solids Slurry Note: Mass and volume values in figure are rounded to the nearest significant digit of accuracy.

Table 4.8. High-Solids Slurry Physical Properties (Inside Slurry Loop)

\begin{tabular}{|r|c||}
\hline Slurry Density (g/mL) & 1.33 \\
\hline Supernate Density (g/mL) & 1.22 \\
Settled Solids (Vol\%) & $82 \%$ \\
\hline Centrifuged UDS (Wt\%) & $34 \%$ \\
\hline Total Solids of the Slurry (Wt $\%)$ & $38 \%$ \\
\hline Dissolved Solids of the Supernate (Wt $\%)$ & $28 \%$ \\
\hline UDS of the Slurry $(\mathbf{W t} \%)$ & $13 \%$ \\
\hline \hline
\end{tabular}


Table 4.9. Group 6/5 High-Solids Slurry Composition and Inventory (Including Permeate Hold-up)

\begin{tabular}{|c|c|c|c|c|c|}
\hline & Slurry $^{(a)}$ & \multicolumn{2}{|c|}{ Liquid Fraction $^{(b)}$} & \multicolumn{2}{|c|}{ Solids Fraction ${ }^{(c)}$} \\
\hline Mass (kg) & 2.75 & \multicolumn{2}{|r|}{2.46} & \multicolumn{2}{|r|}{0.28} \\
\hline Wt\% of Slurry & $100 \%$ & \multicolumn{2}{|r|}{$89.5 \%$} & \multicolumn{2}{|r|}{$10.5 \%$} \\
\hline Metal & g & g & $\mu \mathrm{g} / \mathrm{mL}$ & g & $\mu \mathrm{g} / \mathrm{g}$ \\
\hline Al & $1.0 \mathrm{E}+02$ & $1.2 \mathrm{E}+01$ & $6.3 \mathrm{E}+03$ & $9.2 \mathrm{E}+01$ & $3.4 \mathrm{E}+05$ \\
\hline B & 6.3E-02 & $6.0 \mathrm{E}-02$ & $3.0 \mathrm{E}+01$ & 3.3E-03 & $1.2 \mathrm{E}+01$ \\
\hline Cd & $1.0 \mathrm{E}-02$ & $<2$.E-3 & $<1 . \mathrm{E}+0$ & $1.0 \mathrm{E}-02$ & $3.9 \mathrm{E}+01$ \\
\hline $\mathrm{Cr}$ & $9.5 \mathrm{E}+00$ & $1.4 \mathrm{E}+00$ & $7.3 \mathrm{E}+02$ & $8.0 \mathrm{E}+00$ & $3.0 \mathrm{E}+04$ \\
\hline $\mathbf{F e}$ & $3.0 \mathrm{E}+00$ & $<2$.E-2 & $<1 . \mathrm{E}+1$ & $3.0 \mathrm{E}+00$ & $1.1 \mathrm{E}+04$ \\
\hline Mn & $1.6 \mathrm{E}+00$ & $<2$.E-3 & $<1 . \mathrm{E}+0$ & $1.6 \mathrm{E}+00$ & $5.8 \mathrm{E}+03$ \\
\hline $\mathrm{Na}$ & $2.3 \mathrm{E}+02$ & $2.2 \mathrm{E}+02$ & $1.1 \mathrm{E}+05$ & $1.5 \mathrm{E}+01$ & $5.7 \mathrm{E}+04$ \\
\hline $\mathbf{P}$ & $5.1 \mathrm{E}+00$ & $5.0 \mathrm{E}+00$ & $2.5 \mathrm{E}+03$ & $1.3 \mathrm{E}-01$ & $4.9 \mathrm{E}+02$ \\
\hline $\mathbf{S}$ & $3.9 \mathrm{E}+00$ & $3.2 \mathrm{E}+00$ & $1.6 \mathrm{E}+03$ & 6.6E-01 & $2.4 \mathrm{E}+03$ \\
\hline Si & $4.4 \mathrm{E}+00$ & $1.0 \mathrm{E}-01$ & $5.2 \mathrm{E}+01$ & $4.3 \mathrm{E}+00$ & $1.6 \mathrm{E}+04$ \\
\hline $\mathbf{U}$ & $4.8 \mathrm{E}+00$ & $<8 . \mathrm{E}-2$ & $<4 . \mathrm{E}+1$ & $4.8 \mathrm{E}+00$ & $1.8 \mathrm{E}+04$ \\
\hline \multirow{2}{*}{$\begin{array}{l}\text { Radiochemical } \\
\text { Isotopes }\end{array}$} & Slurry & \multicolumn{2}{|c|}{ Liquid Fraction } & \multicolumn{2}{|c|}{ Solid Fraction } \\
\hline & $\mu \mathbf{C i}$ & $\mu \mathrm{Ci}$ & $\mu \mathrm{Ci} / \mathbf{m L}$ & $\mu \mathbf{C i}$ & $\mu \mathrm{Ci} / \mathrm{g}$ \\
\hline Co-60 & $1.0 \mathrm{E}+01$ & $<3$. E- 1 & $<$ 1.E-4 & $1.0 \mathrm{E}+01$ & 3.9E-02 \\
\hline Cs-137 & $1.6 \mathrm{E}+05$ & $1.4 \mathrm{E}+05$ & $7.2 \mathrm{E}+01$ & $1.8 \mathrm{E}+04$ & $6.7 \mathrm{E}+01$ \\
\hline Eu-154 & $1.6 \mathrm{E}+02$ & $<1 . \mathrm{E}+0$ & $<7$. E-4 & $1.6 \mathrm{E}+02$ & 5.7E-01 \\
\hline Eu-155 & $5.9 \mathrm{E}+01$ & $<2 . \mathrm{E}+1$ & $<9$. E-3 & $5.9 \mathrm{E}+01$ & 2.2E-01 \\
\hline Am-241 & $4.6 \mathrm{E}+02$ & $<2$.E +1 & $<8 . \mathrm{E}-3$ & $4.6 \mathrm{E}+02$ & $1.7 \mathrm{E}+00$ \\
\hline Gross Alpha & $7.8 \mathrm{E}+02$ & $<7 . \mathrm{E}+0$ & $<3 . \mathrm{E}-3$ & $7.8 \mathrm{E}+02$ & $2.9 \mathrm{E}+00$ \\
\hline Gross Beta & $5.4 \mathrm{E}+05$ & $1.5 \mathrm{E}+05$ & $7.4 \mathrm{E}+01$ & $3.9 \mathrm{E}+05$ & $1.4 \mathrm{E}+03$ \\
\hline Sr-90 & $1.7 \mathrm{E}+05$ & $9.7 \mathrm{E}+01$ & 4.9E-02 & $1.7 \mathrm{E}+05$ & $6.4 \mathrm{E}+02$ \\
\hline Pu-239+240 & $2.8 \mathrm{E}+02$ & 3.1E-01 & $1.5 \mathrm{E}-04$ & $2.8 \mathrm{E}+02$ & $1.0 \mathrm{E}+00$ \\
\hline Pu-238 & $2.2 \mathrm{E}+01$ & 4.1E-02 & $2.1 \mathrm{E}-05$ & $2.2 \mathrm{E}+01$ & 8.0E-02 \\
\hline \multirow[t]{2}{*}{ Anions } & \multicolumn{3}{|c|}{ Liquid Fraction } & \multicolumn{2}{|c|}{ Leached Solids Fraction } \\
\hline & $\mu \mathrm{g} / \mathrm{mL}$ & [M] & g & $\mu \mathrm{g} / \mathrm{g}$ & g \\
\hline $\mathbf{F}$ & $2.7 \mathrm{E}+02$ & $1.4 \mathrm{E}-02$ & $5.4 \mathrm{E}-01$ & $1.9 \mathrm{E}+02$ & $5.1 \mathrm{E}+01$ \\
\hline $\mathrm{C}_{2} \mathrm{O}_{4}$ & $8.9 \mathrm{E}+02$ & $1.0 \mathrm{E}-02$ & $1.8 \mathrm{E}+00$ & $7.1 \mathrm{E}+03$ & $1.9 \mathrm{E}+03$ \\
\hline $\mathrm{NO}_{2}$ & $3.7 \mathrm{E}+04$ & 8.1E-01 & $7.4 \mathrm{E}+01$ & $2.3 \mathrm{E}+04$ & $6.2 \mathrm{E}+03$ \\
\hline $\mathrm{NO}_{3}$ & $1.3 \mathrm{E}+05$ & $2.0 \mathrm{E}+00$ & $2.5 \mathrm{E}+02$ & $7.6 \mathrm{E}+04$ & $2.0 \mathrm{E}+04$ \\
\hline $\mathrm{SO}_{4}$ & $6.7 \mathrm{E}+03$ & 7.0E-02 & $1.3 \mathrm{E}+01$ & $4.2 \mathrm{E}+03$ & $1.1 \mathrm{E}+03$ \\
\hline $\mathrm{PO}_{4}$ & $8.3 \mathrm{E}+03$ & 8.8E-02 & $1.6 \mathrm{E}+01$ & $5.2 \mathrm{E}+03$ & $1.4 \mathrm{E}+03$ \\
\hline $\mathbf{O H}$ & $1.1 \mathrm{E}+04$ & $6.2 \mathrm{E}-01$ & $2.1 \mathrm{E}+01$ & & \\
\hline \multicolumn{6}{|c|}{$\begin{array}{l}\text { (a) Slurry component masses were calculated from characterization data (WPT-RPT-157), added } \\
\text { simulant component masses, and removed supernatant component masses. Mass loss from } \\
\text { sampling was included. } \\
\text { (b) Liquid Fraction mass components were calculated using analytical results from supernate sample } \\
\text { TI552-G6-B (ASO ID 08-00219) and the predicted mass of supernate in the system. } \\
\text { (c) Solids Fraction mass components were calculated from the difference between the slurry } \\
\text { component mass and liquid component mass fraction. }\end{array}$} \\
\hline
\end{tabular}


Table 4.10. Group 6/5 High-Solids Slurry Composition Based on ICP-OES/Radionuclide Characterization

\begin{tabular}{|c|c|c|c|c|}
\hline $\begin{array}{c}\text { Slurry Prep } \\
\text { Method }\end{array}$ & $\begin{array}{c}\text { ICP-OES } \\
\text { Analytes } \\
\end{array}$ & $\begin{array}{c}\text { Dry Slurry }{ }^{(a)} \\
(\mu \mathrm{g} / \mathrm{g})\end{array}$ & $\begin{array}{c}\text { Supernate }^{(b)} \\
(\mu \mathrm{g} / \mathrm{mL})\end{array}$ & $\begin{array}{c}\begin{array}{c}\text { Dry Solids }{ }^{(\mathrm{c})} \\
(\mu \mathrm{g} / \mathrm{g})\end{array} \\
\end{array}$ \\
\hline \multirow{25}{*}{ KOH Fusion } & Al & 107,500 & 7,603 & 266,577 \\
\hline & B & [170] & [23] & [363] \\
\hline & $\mathbf{B i}$ & $<1.4 \mathrm{E}+2$ & $<8.3 \mathrm{E}+0$ & $<3.6 \mathrm{E}+2$ \\
\hline & Cd & [8.45] & [1.3] & {$[17.22]$} \\
\hline & $\mathrm{Cr}$ & 9,710 & 648 & 24,285 \\
\hline & Fe & 3,075 & $<7.4 \mathrm{E}+0$ & 8,742 \\
\hline & Mn & 1,615 & $<7.5 \mathrm{E}-1$ & 4,608 \\
\hline & $\mathrm{Na}$ & 237,000 & 119,333 & 42,460 \\
\hline & $\mathbf{P}$ & 5,250 & 2,623 & 1,048 \\
\hline & $S$ & {$[4,000]$} & 2,037 & [596] \\
\hline & Si & 4,500 & 69.6 & 12,481 \\
\hline & $\mathrm{Sr}$ & 283 & 0.06 & 808 \\
\hline & $\mathbf{U}$ & {$[5,450]$} & $<3.0 \mathrm{E}+1$ & {$[15,402]$} \\
\hline & Zn & [94] & $<2.1 \mathrm{E}+0$ & [256] \\
\hline & $\mathbf{Z r}$ & $<5.5 \mathrm{E}+1$ & $<2.9 \mathrm{E}+0$ & $<1.4 \mathrm{E}+2$ \\
\hline & $B a$ & [38] & $<1.2 E+0$ & [102] \\
\hline & Ca & $<2.9 E+3$ & [40] & $<8.0 E+3$ \\
\hline & $\mathrm{Cu}$ & [60] & $<1.8 E+0$ & [162] \\
\hline & $L a$ & [25] & 0 & [69] \\
\hline & $\mathrm{Li}$ & [30] & $<2.0 E+0$ & [75] \\
\hline & $M g$ & [305] & $<2.5 E+0$ & [857] \\
\hline & Mo & [68] & 36 & [4] \\
\hline & $P b$ & [120] & $<1.3 E+1$ & [271] \\
\hline & $T i$ & [28] & $<3.5 E-1$ & [78] \\
\hline & $Y$ & $<1.9 E+1$ & $<3.1 E-1$ & $<5.1 E+1$ \\
\hline $\begin{array}{c}\text { Slurry Prep } \\
\text { Method }\end{array}$ & $\begin{array}{c}\text { ICP-OES } \\
\text { Analytes }\end{array}$ & $\begin{array}{c}\text { Dry Slurry }^{(a)} \\
(\mu \mathrm{g} / \mathrm{g})\end{array}$ & $\begin{array}{l}\text { Supernate }^{(b)} \\
(\mu \mathrm{g} / \mathrm{mL})\end{array}$ & $\begin{array}{c}\text { Dry Solids }{ }^{(c)} \\
(\mu \mathrm{g} / \mathrm{g})\end{array}$ \\
\hline \multirow{2}{*}{$\begin{array}{c}\text { HF assisted } \\
\text { acid digestion }\end{array}$} & $\mathbf{K}$ & 623 & 1,038 & $-3,739$ \\
\hline & $\mathbf{N i}$ & 155 & [3.45] & 423 \\
\hline
\end{tabular}


Table 4.10 (contd)

\begin{tabular}{|c|c|c|c|c|}
\hline $\begin{array}{c}\text { Slurry Prep } \\
\text { Method }\end{array}$ & Radionuclides & $\begin{array}{c}\text { Dry Slurry }{ }^{(a)} \\
(\mu \mathrm{Ci} / \mathrm{g})\end{array}$ & $\begin{array}{c}\text { Supernate }^{(b)} \\
(\mu \mathrm{Ci} / \mathrm{mL})\end{array}$ & $\begin{array}{c}\text { Dry Solids }^{(c)} \\
(\mu \mathrm{Ci} / \mathrm{g})\end{array}$ \\
\hline \multirow[t]{12}{*}{ KOH Fusion } & Co-60 & $5.73 \mathrm{E}-2$ & $5.59 \mathrm{E}-4$ & $1.6 \mathrm{E}-1$ \\
\hline & Cs-137 & $1.65 \mathrm{E}+2$ & $8.57 \mathrm{E}+1$ & $1.7 \mathrm{E}+1$ \\
\hline & Eu-154 & $1.59 \mathrm{E}-1$ & $<8 . E-4$ & 4.5E-1 \\
\hline & Eu-155 & $<6 . \mathrm{E}-2$ & $<9 . \mathrm{E}-3$ & $<1$.E-1 \\
\hline & Am-241 & $4.75 \mathrm{E}-1$ & $<9 . \mathrm{E}-3$ & $1.3 \mathrm{E}+0$ \\
\hline & Total alpha & $7.94 \mathrm{E}-1$ & $<4$.E-3 & $2.2 \mathrm{E}+0$ \\
\hline & Total beta & $5.50 \mathrm{E}+2$ & $8.78 \mathrm{E}+1$ & $1.1 \mathrm{E}+3$ \\
\hline & Sr-90 & $1.78 \mathrm{E}+2$ & $6.73 \mathrm{E}-2$ & $5.1 \mathrm{E}+2$ \\
\hline & Pu-239/240 & $2.88 \mathrm{E}-1$ & $1.46 \mathrm{E}-4$ & $8.2 \mathrm{E}-1$ \\
\hline & Pu-238 & $2.23 \mathrm{E}-2$ & $2.10 \mathrm{E}-5$ & $6.3 \mathrm{E}-2$ \\
\hline & KPA & $(\mu \mathrm{g} / \mathrm{g})$ & $(\mu \mathrm{g} / \mathrm{mL})$ & $(\mu \mathrm{g} / \mathrm{g})$ \\
\hline & $\mathbf{U}$ & $4.94 \mathrm{E}+3$ & $5.81 \mathrm{E}+0$ & $1.4 \mathrm{E}+4$ \\
\hline \multicolumn{5}{|c|}{$\begin{array}{l}\text { (a) Test sample TI552-G6-A, and -B ASO ID 08-00218, 08-00219 } \\
\text { (b) Test sample TI552-G6-7, ASO ID 08-00242 } \\
\text { (c) Calculated using results from TI552-G6-A \& B and TI552-G6-7 } \\
\text { Note: Analytes in italics were measured opportunistically. Values in brackets [ ] are } \geq \text { MDL } \\
\text { but < EQL, with errors likely to exceed 15\%. }\end{array}$} \\
\hline
\end{tabular}

Particle size distribution measurements were performed on the sampled slurry. Figure 4.24 shows the pre-sonic PSD for the high solids slurry as a function of pump speed. The distributions are broad and multimodal. At 3,000 RPM, the PSD spanned from $\sim 0.2 \mu \mathrm{m}$ to $500 \mu \mathrm{m}$ with distinct population peaks at $\sim 1.2,6,70$, and $400 \mu \mathrm{m}$. The majority of particles in the distribution fell between 0.2 and $200 \mu \mathrm{m}$. At low pump speeds (2,000 RPM), the upper bound of this primary population range was reduced to $40 \mu \mathrm{m}$. At 3,000 RPM, a population centered at $70 \mu \mathrm{m}$ appeared and may have been associated with difficult-tosuspend particles. At 4,000 RPM, this particle population appeared to shift to lower particle diameters and merge into the 0.2 - to $40-\mu \mathrm{m}$ particle population, likely as a result of particle attrition. Figure 4.25 shows the PSD for the high-solids slurry before, during, and after sonication. Sonication appeared to eliminate (likely thro $\mu$ gh disruption) particle species greater than $\sim 20 \mu \mathrm{m}$ completely. This disruption corresponded with an increase in the fractional contribution of the 7- $\mu \mathrm{m}$ particles, which is likely the final size of broken agglomerates. 


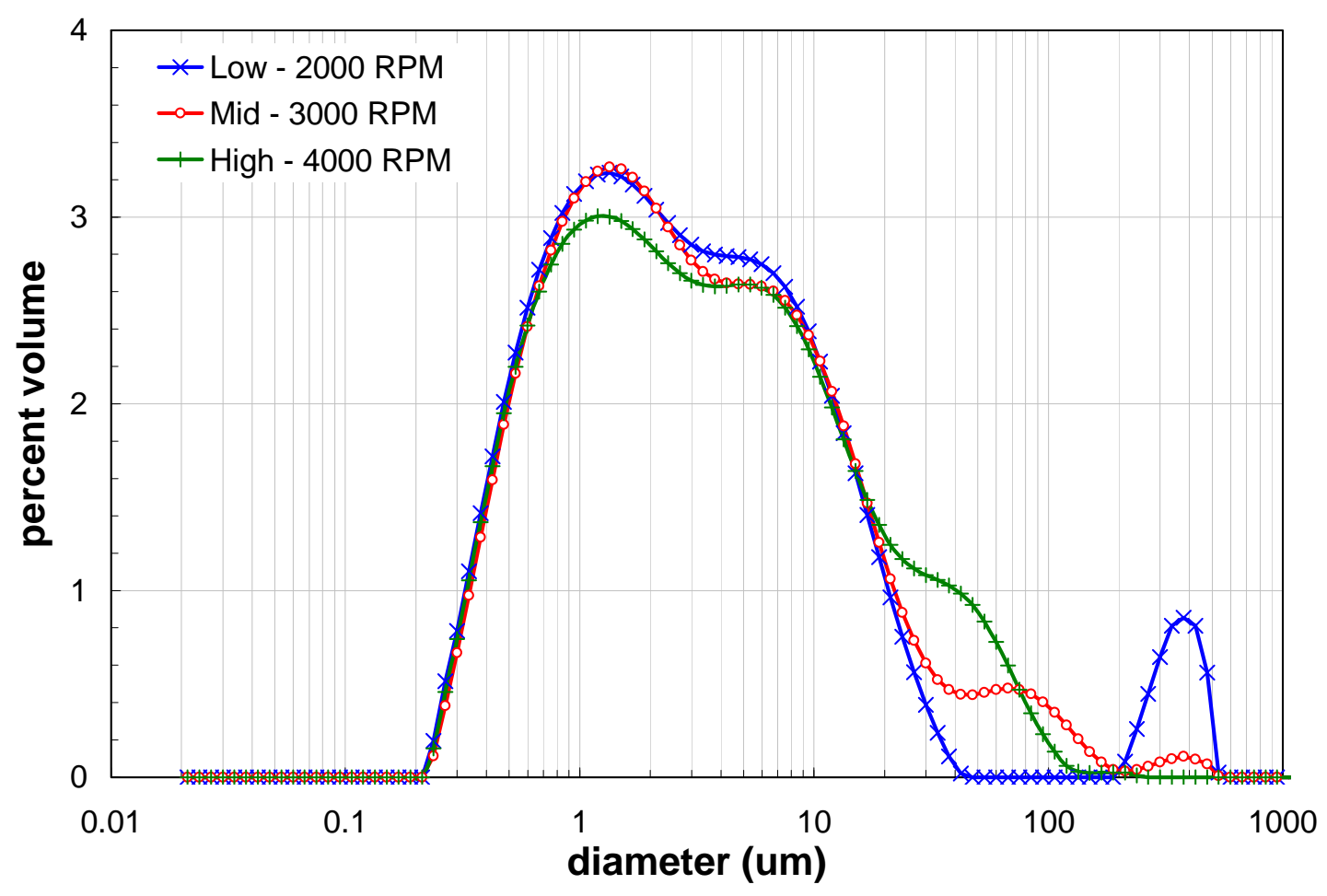

Figure 4.24. Measured PSD of Group 6/5 High-Solids Slurry as a Function of Pump Speed

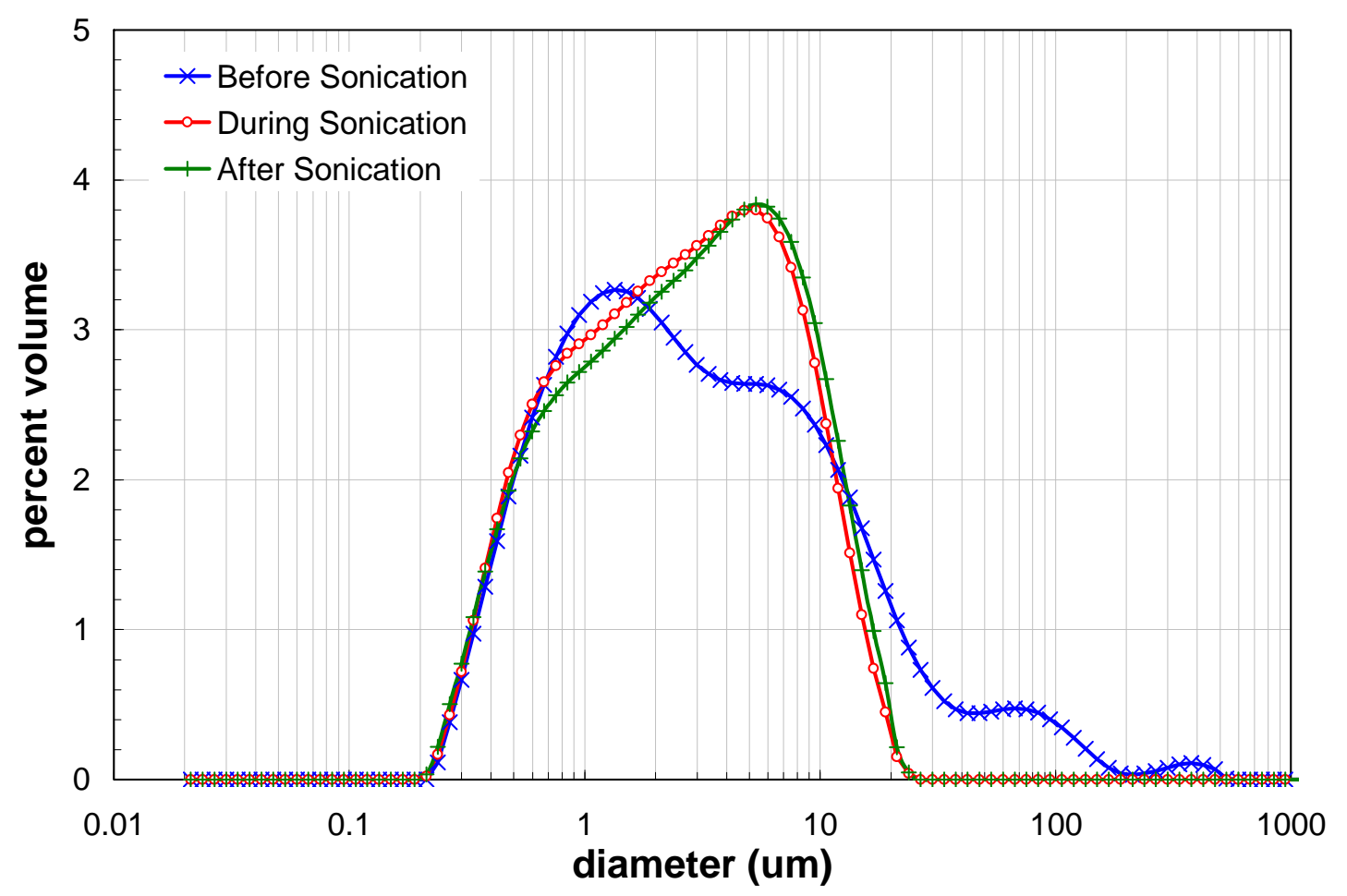

Figure 4.25. Measured PSD of Group 6/5 High-Solids Slurry as a Function of Sonification 
Prior to caustic leaching, a sub-sample of the high-solid slurry was taken for rheology analysis. The highsolids slurry shows non-Newtonian behavior at all temperatures studied (Figure 4.26), with the flow curves showing finite yield points and near-linear to slightly shear-thinning stress behavior over 0 to 1000 $\mathrm{s}^{-1}$, depending on the measurement temperature. Flow-curve hysteresis is absent in the $25^{\circ}$ and $40^{\circ} \mathrm{C}$ measurements. In contrast, measurable hysteresis is present in the $60^{\circ} \mathrm{C}$ flow curve, with the down-ramp showing a 1 to $2 \mathrm{~Pa}$ increase in stress over the range of shear rates. The increase in temperature from $25^{\circ}$ to $40^{\circ} \mathrm{C}$ appears to have no impact on the slurry yield stress but does appear to lower its consistency (i.e., the slope of the near-linear portion of the flow curve). The decrease in consistency is comparable to the decrease in viscosity observed in the Group 6 source material and low-solids matrix slurries. At $60^{\circ} \mathrm{C}$, the stress response of the material increases dramatically, with the range of stresses ranging from 8 to $20 \mathrm{~Pa}$ relative to the 3 to $15 \mathrm{~Pa}$ range observed over the same shear rate range (from 0 to $1000 \mathrm{~s}^{-1}$ ) at $40^{\circ} \mathrm{C}$

(Table 4.11).

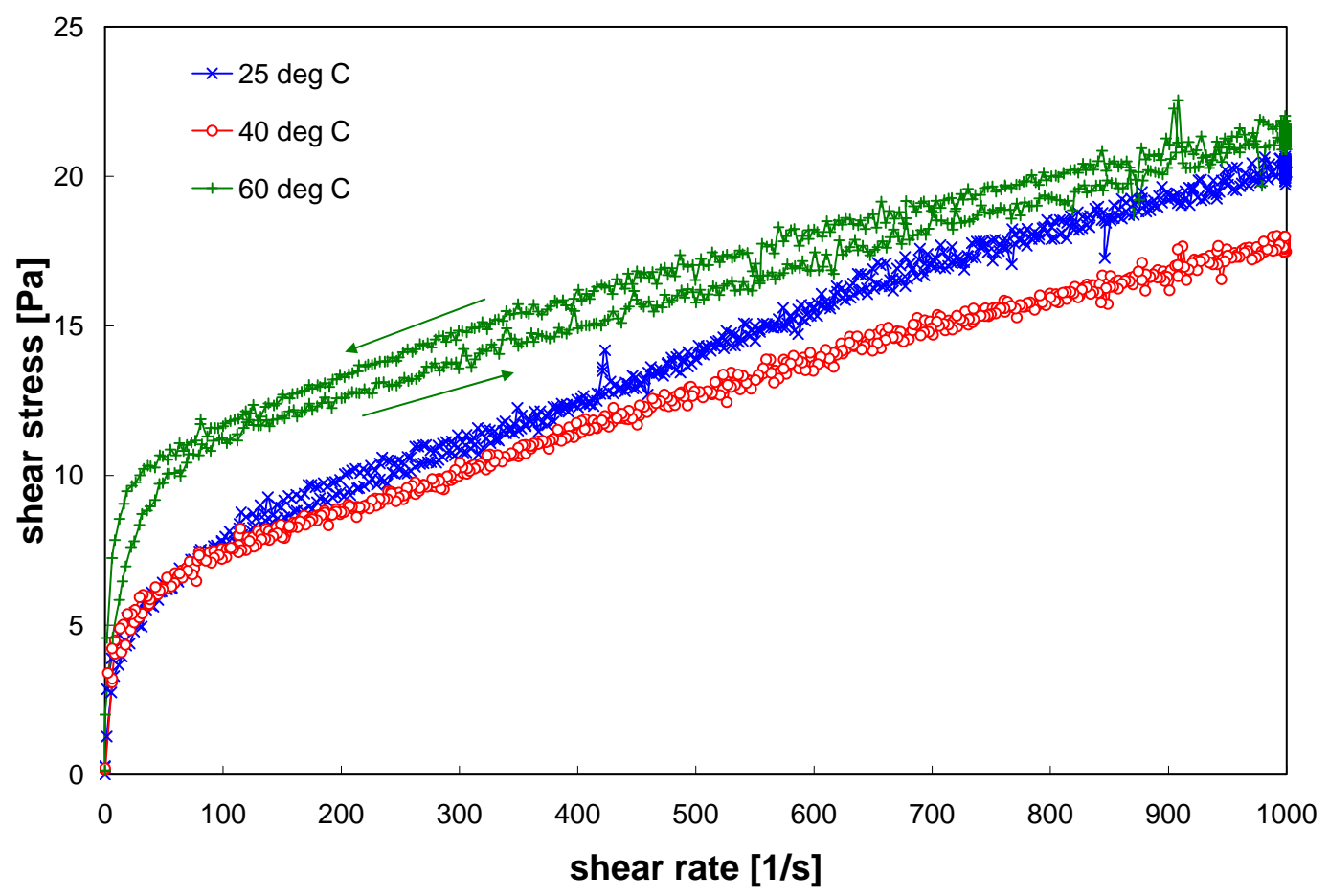

Figure 4.26. Flow Curve for Group 6/5 High-Solids Slurry

Table 4.11. Results of Fitting Analysis for the High Solids Slurry

\begin{tabular}{||c|c|c|c|c|c||}
\hline Model & $\begin{array}{c}\text { Temperature } \\
{\left[{ }^{\circ} \mathbf{C}\right]}\end{array}$ & $\begin{array}{c}\text { Yield } \\
\text { Stress }[\mathbf{P a}]\end{array}$ & $\begin{array}{c}\text { Consistency } \\
{\left[\mathbf{P a} \mathbf{~ s}^{\mathbf{n}}\right]}\end{array}$ & $\begin{array}{c}\text { Flow } \\
\text { Index }\end{array}$ & $\mathbf{R}$ \\
\hline \multirow{3}{*}{$\begin{array}{c}\text { Bingham-Plastic } \\
\left(200-1000 \mathrm{~s}^{-1}\right)\end{array}$} & $25(1$ of 2$)$ & 6.1 & 0.014 & $\mathrm{n} / \mathrm{a}$ & 0.997 \\
\cline { 2 - 6 } & $25(2$ of 2$)$ & 7.4 & 0.013 & $\mathrm{n} / \mathrm{a}$ & 0.997 \\
\cline { 2 - 6 } & 40 & 7.2 & 0.011 & $\mathrm{n} / \mathrm{a}$ & 0.995 \\
\cline { 2 - 6 } & 60 & 11 & 0.010 & $\mathrm{n} / \mathrm{a}$ & 0.997 \\
\hline \multirow{3}{*}{$\begin{array}{c}\text { Herschel-Bulkley } \\
\left(0-1000 \mathrm{~s}^{-1}\right)\end{array}$} & $25(1$ of 2$)$ & 3.7 & 0.083 & 0.768 & 0.996 \\
\cline { 2 - 6 } & $25(2$ of 2$)$ & 3.6 & 0.19 & 0.651 & 0.998 \\
\cline { 2 - 6 } & 40 & 4.0 & 0.16 & 0.646 & 0.987 \\
\cline { 2 - 6 } & 60 & 6.7 & 0.36 & 0.537 & 0.991 \\
\hline
\end{tabular}


Figure 4.27 and Table 4.12 show the influence of mixing the Group 6 slurry with Group 5 slurry on the CUF process material rheology. The source waste groups show highly different rheologies. Group 5 is highly non-Newtonian, having a yield stress of $57 \mathrm{~Pa}$ and a consistency of $13 \mathrm{mPa} \cdot \mathrm{s}$. In contrast, Group 6 is Newtonian and has a viscosity of $8 \mathrm{mPa} \cdot \mathrm{s}$, which is slightly less than the Group 5 source material's consistency. The resulting mixture is non-Newtonian with a yield stress of $7.4 \mathrm{~Pa}$ and a consistency of 13 $\mathrm{mPa} \cdot \mathrm{s}$. From the flow curves it is clear that the Group 5 solids have imparted some of their nonNewtonian behavior to the slurry combination. Although the mixture consistency is similar to that of Group 5, the yield stress of the 13.2-wt\% combined Group 6/5 slurry is much lower than that observed in pre-leach Group 5 CUF slurries of similar concentration. This indicates that the Group 6 solids may be impeding the structuring mechanism Group 5 solids impart to the slurry.

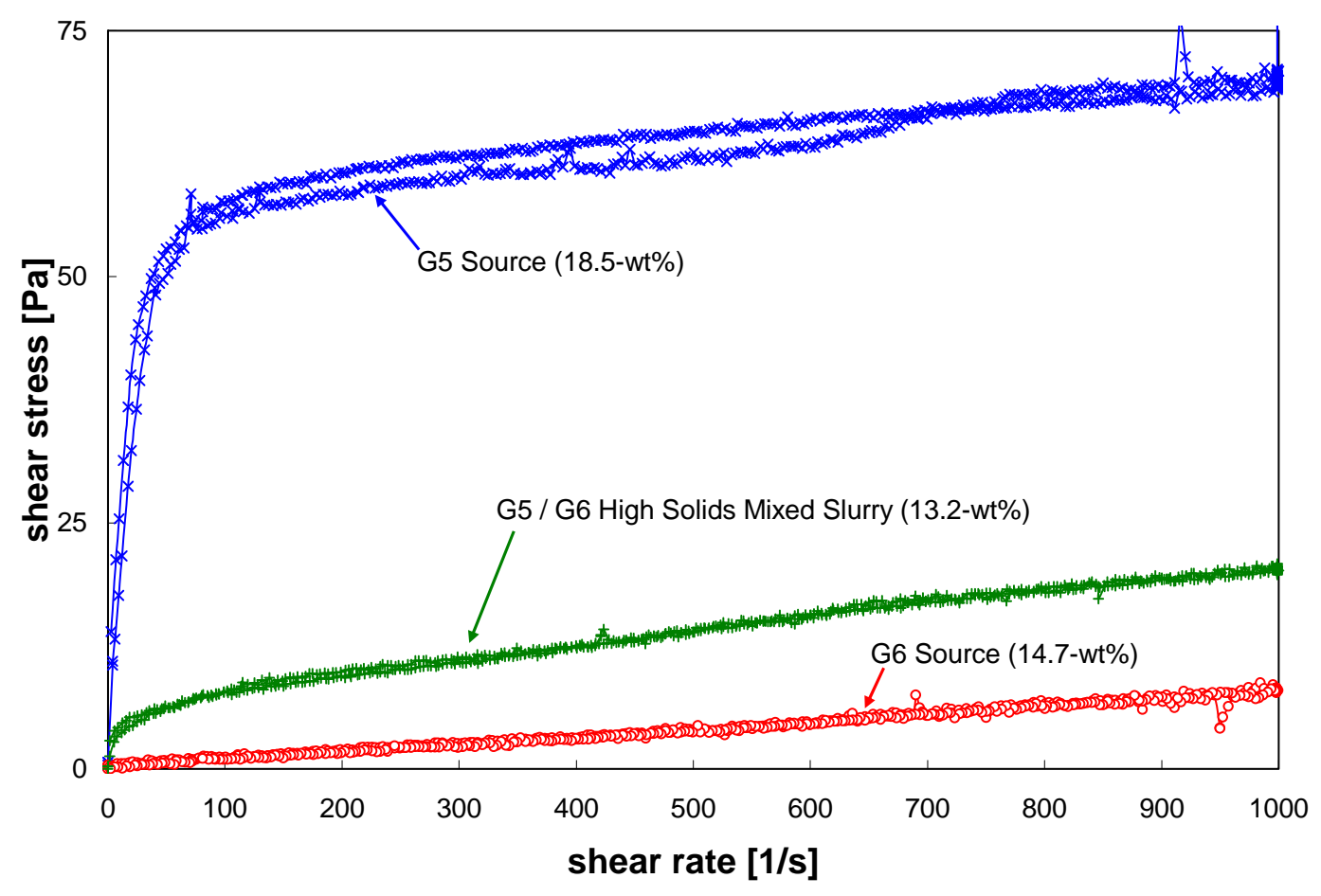

Figure 4.27. Flow Curves of Group 5, 6, and Group 6/5 High-Solid Slurry (at 25)

Table 4.12. Rheological Behavior of Group 5, 6, and Group 6/5 High-Solid Slurry (at 25)

\begin{tabular}{||c|c|c|c|c||}
\hline Description & $\begin{array}{c}\text { Solids } \\
\text { Concentration }\end{array}$ & Rheology & $\begin{array}{c}\text { Yield Stress } \\
{[\text { Pa] }}\end{array}$ & $\begin{array}{c}\text { Consistency } \\
{[\mathbf{c P}]}\end{array}$ \\
\hline $\begin{array}{c}\text { Group 5 Source } \\
\text { (G5-RH-2) }\end{array}$ & $18.5-\mathrm{wt} \%$ & Non-Newtonian & 57 & 13 \\
\hline $\begin{array}{c}\text { Group 6 Source } \\
\text { (TI490-G6-AR-RH) }\end{array}$ & $14.7-\mathrm{wt} \%$ & Newtonian & $\mathrm{n} / \mathrm{a}$ & 8.0 \\
\hline $\begin{array}{c}\text { Group 5/6 Mixture } \\
\text { (TI552-G6-R2) }\end{array}$ & $13.2-\mathrm{wt} \%$ & Non-Newtonian & 7.4 & 13 \\
\hline
\end{tabular}




\subsection{Caustic Leaching/Washing}

After completing the filtration and rheological testing of the high-solids slurry, the slurry was drained from the system and prepared for caustic leaching. The slurry loop was rinsed using part of the caustic addition for the leach and additional permeate that was remaining in the back-pulse chamber. After the slurry and caustic additions were recovered from the system, the slurry reservoir was isolated from the slurry loop. All recovered slurry, permeate, and caustic solutions were placed into the reservoir for caustic leaching, as outlined in the middle column (colored orange) of

Figure 4.1. The activities involved in this process were:

- Batch caustic leaching of the slurry for removing aluminum from UDS in the slurry.

- Dewatering a majority of the leached slurry supernate from the slurry solids.

- Batch washing of the caustic-leached slurry and dewatering of the diluted supernate afterwards. Five total wash solutions were added to the slurry to remove aluminum from the slurry.

\subsubsection{Caustic Batch Leaching Results}

The slurry was completely drained from the system and the slurry tank was isolated. A total of $2.77 \mathrm{~kg}$ (approximately 2.3 L) of $10.9 \mathrm{M} \mathrm{NaOH}$ solution was added to the CUF afterwards and drained as well to capture solids remaining in the slurry circulation loop. The recovered Group 6/5 slurry, supernate, and caustic solution was placed into the reservoir tank after it was isolated from the CUF circulation piping An estimated $0.3 \mathrm{~kg}$ of material was lost during to transfer operations. This loss and the previous slurry sampling reduced the solid inventory of the slurry to 240 grams. 
WTP-RPT-172, Rev 0

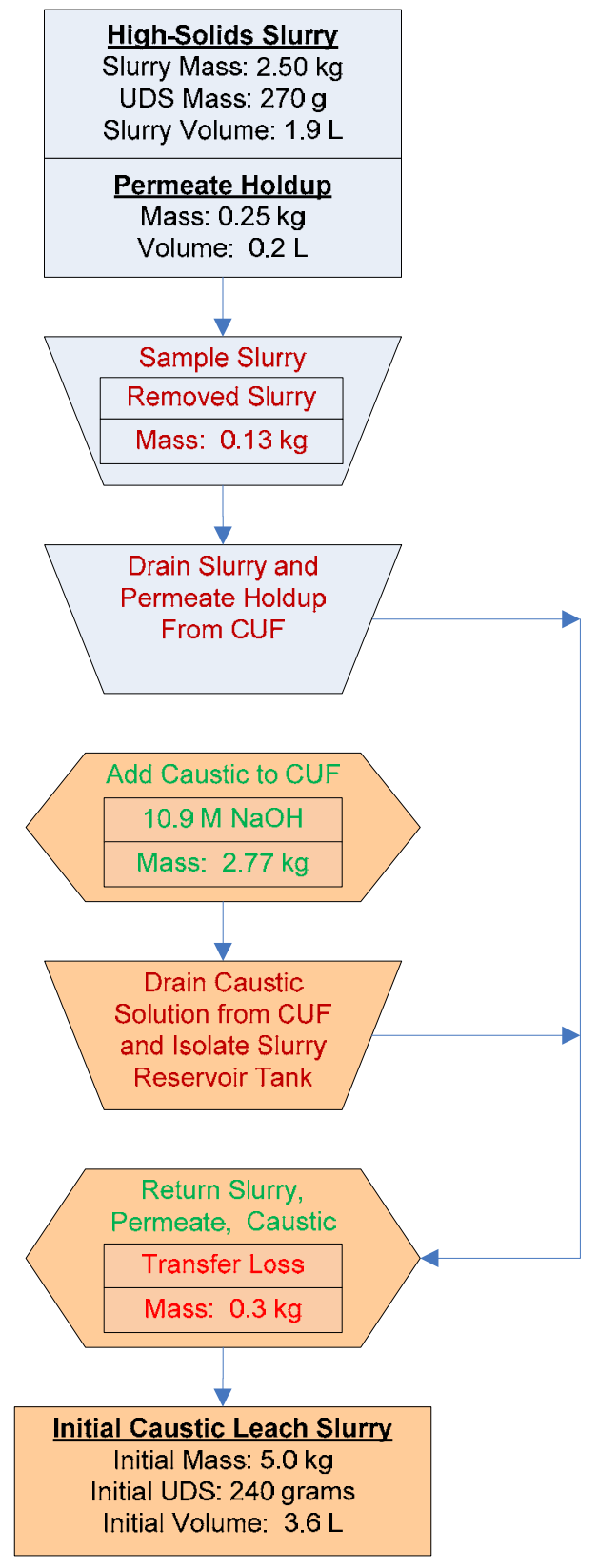

Figure 4.28. Group 6/5 Caustic Leaching Preparation

Note: Mass and volume values in figure are rounded to the nearest significant digit of accuracy.

The resulting slurry was heated to $100^{\circ} \mathrm{C}$ over a 5 .3-hour period and then was maintained at $100^{\circ} \mathrm{C}$ for 8 hours. Slurry supernate samples were collected during the heat-ramp and leach to track the dissolution of aluminum. Level measurements were taken every half hour during the leach, and the slurry was adjusted as necessary with DI water to compensate for slurry evaporation and to maintain hydroxide concentration levels of the leach. Approximately $0.4 \mathrm{~kg}$ of DI water was added during this time period. The slurry was then cooled over 12 hours. By the beginning of the leach soak period $\left(100^{\circ} \mathrm{C}\right.$ slurry temp), $41 \%$ of the aluminum had already leached from the solids. By the end of the leach, $46 \%$ of the aluminum had 
leached (Figure 4.30). Approximately 100 grams of solid material were estimated to have dissolved at the end of the leach (Figure 4.29).

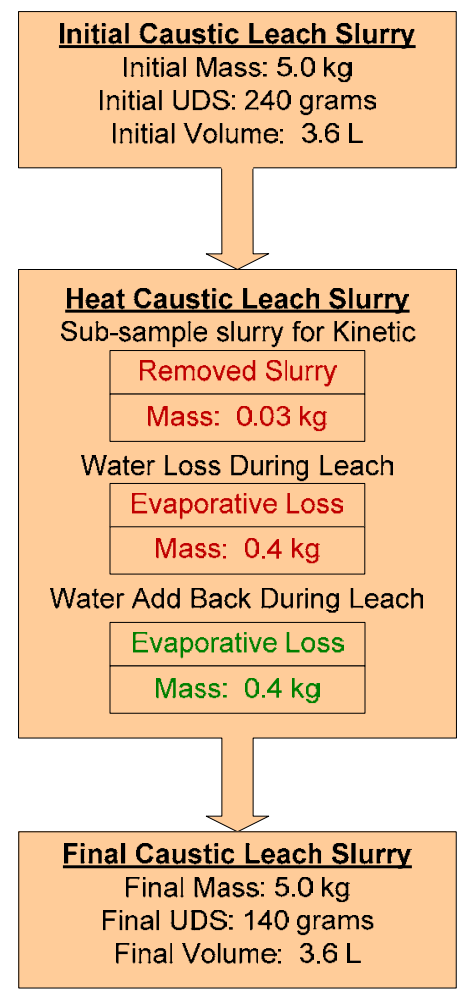

Figure 4.29. Group 6/5 Caustic Leach

Note: Mass and volume values in figure are rounded to the nearest significant digit of accuracy. 


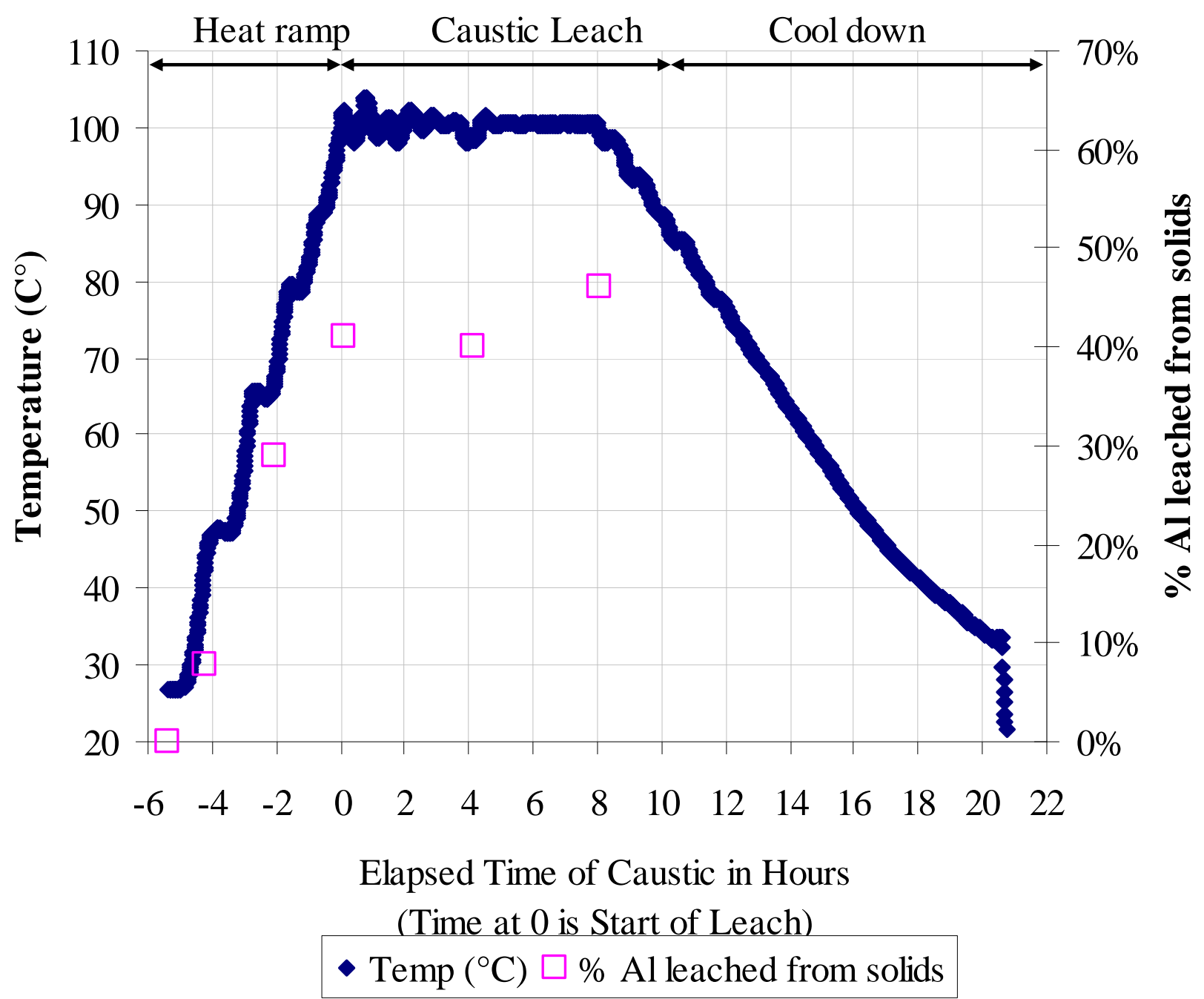

Figure 4.30. Temperature Profile and Aluminum Dissolution during Caustic Leach 


\subsubsection{Leach Slurry Dewatering and Physical Characterization}

After cooling the slurry to ambient cell temperature at the end of 12 hours $\left(27 \pm 3^{\circ} \mathrm{C}\right)$, the slurry was allowed to circulate through the slurry loop. The chiller was turned on, and the slurry was cooled to $25^{\circ} \mathrm{C}$ within 5 minutes and continued to decrease to $19^{\circ} \mathrm{C}$ until the chiller control system adjusted its parameters. The slurry temperature returned to $25^{\circ} \mathrm{C} 20$ minutes later while recirculating the slurry inside the CUF. Once the slurry was at the correct operating temperature for another 30 minutes, the caustic leached slurry was dewatered from a starting volume of $\sim 3.6 \mathrm{~L}$ to a final system volume of $\sim 1.6 \mathrm{~L}$ over 4.5 hours (Figure 4.31). The filtration was performed at the standard condition of TMP $=40$ psid and $\mathrm{AV}=13 \mathrm{ft} / \mathrm{s}$. A total of $2.67 \mathrm{~kg}$ of permeate was collected during the dewatering step, corresponding to $2.0 \mathrm{~L}$ of permeate using the measured slurry supernate density of $1.33 \mathrm{~g} / \mathrm{mL}$

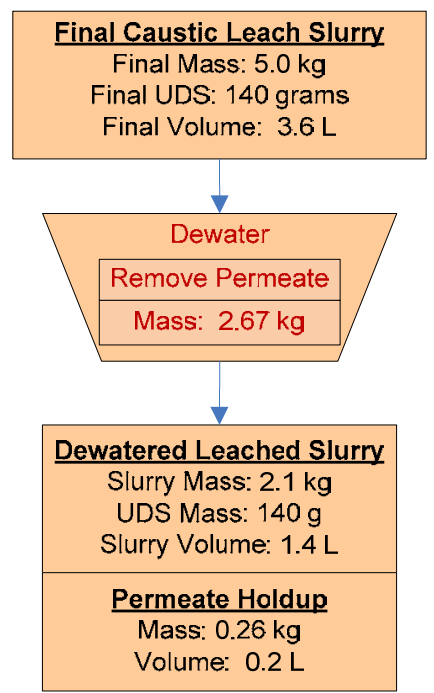

Figure 4.31. Group 6/5 Dewatering of Caustic Leach Slurry Note: Mass and volume values in figure are rounded to the nearest significant digit of accuracy.

Figure 4.32 is a plot of the permeate flux for the dewatering step. The average flux for the Group 5 leach filtration is shown on the chart as a reference. Overall, the Group 5 flux values were consistently higher than Group 6 and Group 6/5 values thro $\mu$ ghout the tests. The Group 6/5 caustic leach filter flux decreased from 0.012 to $0.006 \mathrm{GPM} / \mathrm{ft}^{2}$, about half of the observed filter flux measured during the highsolids matrix at the standard condition. The lower flux value was due to the higher density and viscosity of the caustic leaching solution. In this specific step, the leach dewatering, the Group 5 permeate density was $1.30 \mathrm{~g} / \mathrm{mL}$ compared to $1.33 \mathrm{~g} / \mathrm{mL}$ for Group 6/5. Comparison of the sodium concentration of the caustic leach supernate showed that the Group 6/5 sodium concentration was $8.4 \mathrm{M}$ while the Group 5 was $6.6 \mathrm{M}$. Increased variation was observed in the permeate flow rate half way thro $\mu$ gh the dewatering. This appears to have been caused by pump cavitation as the slurry volume decreased. 


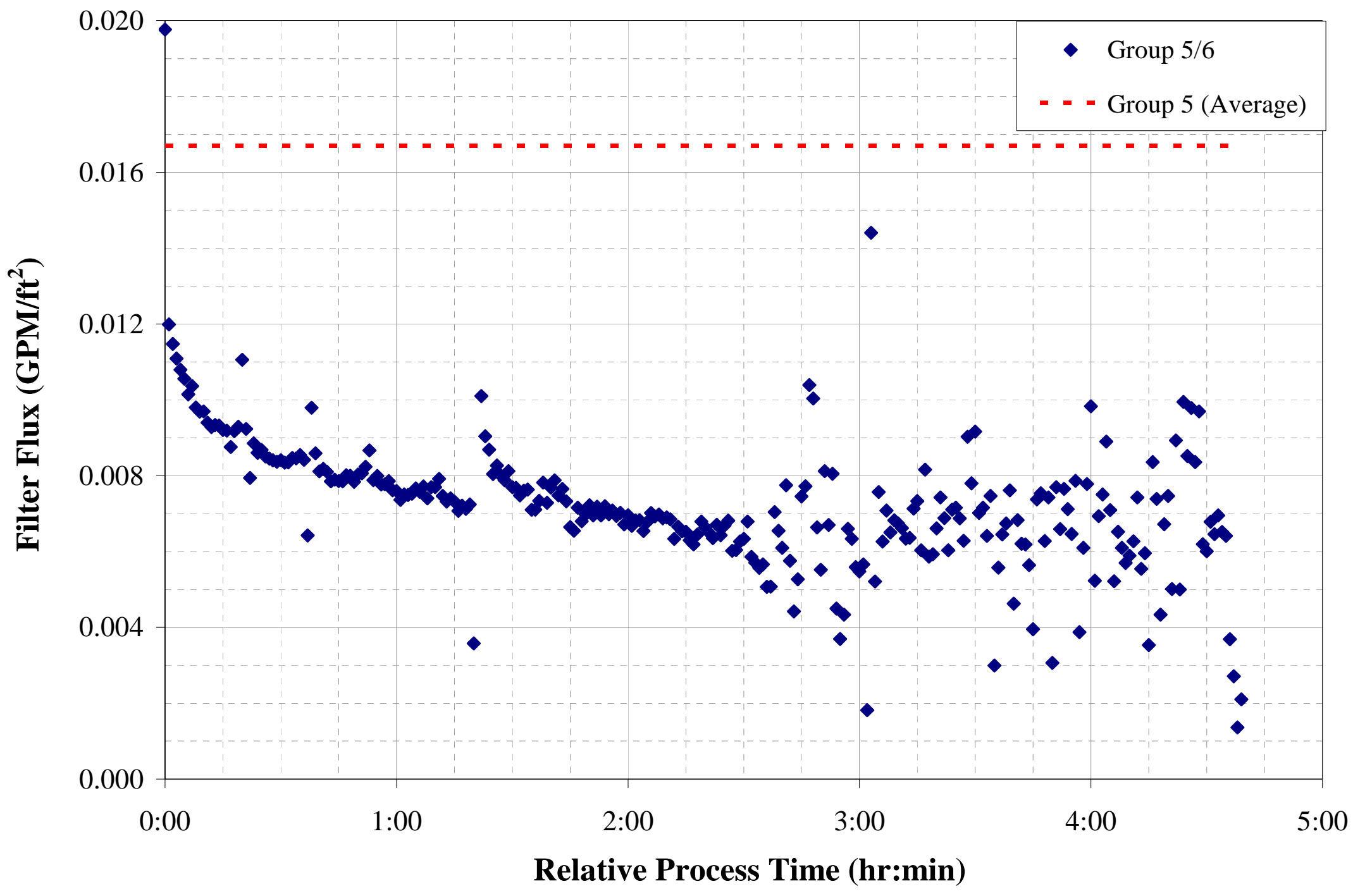

Figure 4.32. Dewatering Filter Flux of Leached Group 6/5 Slurry 


\subsubsection{Characterization of Dewatered Caustic Leach Slurry}

After dewatering the caustic leached slurry, the slurry was sampled again for physical and chemical characterization (Figure 4.33). Table 4.13 details the physical properties and Table 4.14 and Table 4.15 the chemical properties for the caustic leached, dewatered slurry. The measured UDS concentration was higher that the predicted UDS from the mass balance $(0.14 \mathrm{~kg} / 2.1 \mathrm{~kg} \cong 7 \mathrm{wt} \%)$.

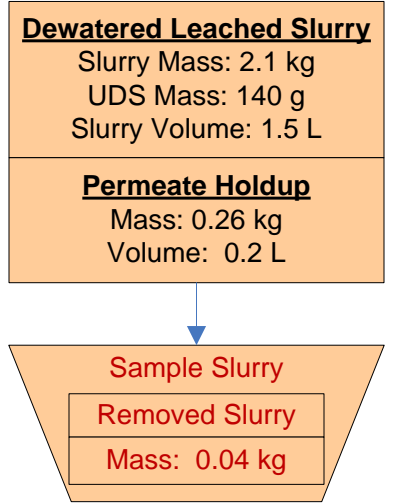

Figure 4.33. Group 6/5 Sampling of Dewatered Caustic Leached Slurry Note: Mass and volume values in figure are rounded to the nearest significant digit of accuracy.

Table 4.13. Group 6/5 Dewatered Caustic Leached Slurry Physical Property Measurements (inside slurry loop)

\begin{tabular}{|r|c||}
\hline Slurry Density (g/mL) & 1.34 \\
\hline Supernate Density (g/mL) & 1.29 \\
Settled Solids (Vol\%) & $86 \%$ \\
\hline Centrifuged UDS (Wt\%) & $14 \%$ \\
\hline Total Solids (Wt\%) & $39 \%$ \\
\hline Dissolved Solids (Wt\%) & $33 \%$ \\
\hline UDS (Wt $\%)$ & $9 \%$ \\
\hline
\end{tabular}


Table 4.14. Group 6/5 Dewatered Caustic Leached Slurry Composition and Inventory (including permeate hold-up)

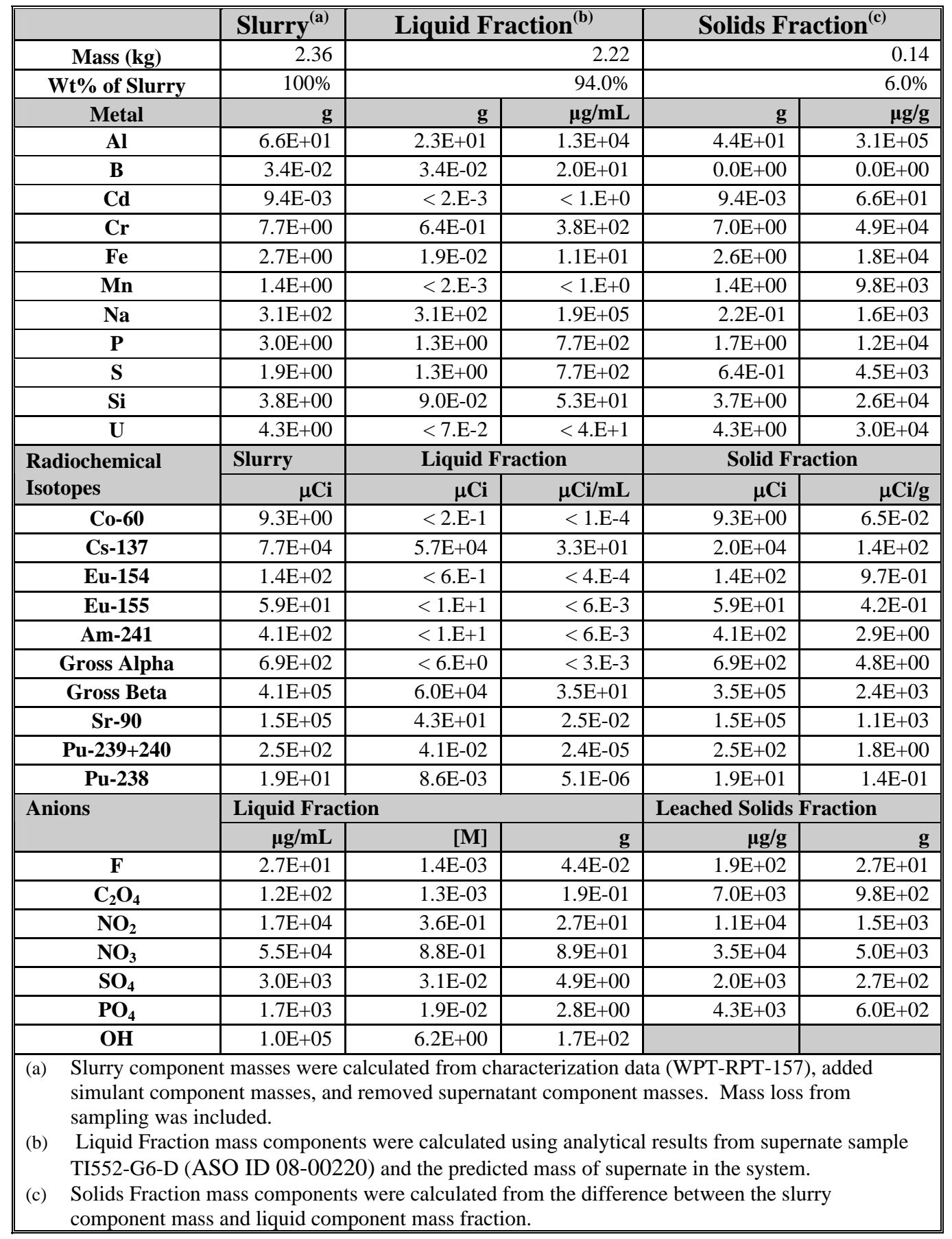


Table 4.15. Dewatered Leached Slurry Composition and Calculated Solids Leach Factors

\begin{tabular}{|c|c|c|c|c|c|}
\hline Slurry Prep Method & $\begin{array}{c}\text { ICP-OES } \\
\text { Analytes }\end{array}$ & $\begin{array}{c}\text { Dry } \\
\text { Slurry }{ }^{(a)} \\
(\mu \mathrm{g} / \mathrm{g})\end{array}$ & $\begin{array}{c}\text { Supernate }^{(\mathrm{b})} \\
(\mu \mathrm{g} / \mathrm{mL})\end{array}$ & $\begin{array}{c}\text { Dry Solids }^{(\mathrm{c})} \\
(\mu \mathrm{g} / \mathrm{g})\end{array}$ & $\begin{array}{c}\text { Solids } \\
\text { Leach }^{(\mathrm{d})} \\
\text { Factor }^{(\mathrm{d})}\end{array}$ \\
\hline \multirow{25}{*}{ 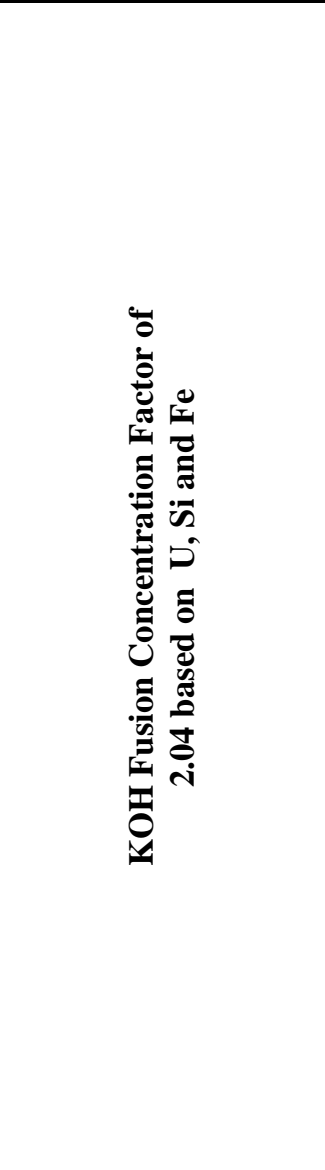 } & Al & 95,500 & 13,400 & 311,889 & 0.43 \\
\hline & $\mathbf{B}$ & [79] & {$[20]$} & [187] & {$[0.75]$} \\
\hline & $\mathbf{B i}$ & $<1.1 \mathrm{E}+2$ & $<4.5 \mathrm{E}+0$ & $<4.6 \mathrm{E}+2$ & $\mathrm{n} / \mathrm{a}$ \\
\hline & Cd & [19] & $<4.8 \mathrm{E}-1$ & [79] & $-[1.26]$ \\
\hline & $\mathrm{Cr}$ & 11,400 & 378 & 46,954 & {$[0.05]$} \\
\hline & $\mathbf{F e}$ & 4,280 & [11] & 18,671 & NA \\
\hline & Mn & 2,040 & $<4.0 \mathrm{E}-1$ & 8,938 & 0.05 \\
\hline & $\mathrm{Na}$ & 328,000 & 185,000 & $-35,054$ & 1.40 \\
\hline & $\mathbf{P}$ & 3,650 & 766 & 9,900 & -3.63 \\
\hline & $\mathrm{S}$ & {$[1,700]$} & 766 & {$[1,353]$} & $-[0.11]$ \\
\hline & Si & 5,490 & 53.2 & 23,638 & $\mathrm{n} / \mathrm{a}$ \\
\hline & $\mathrm{Sr}$ & 372 & {$[0.046]$} & 1,630 & 0.01 \\
\hline & $\mathbf{U}$ & {$[7,400]$} & $<1.7 \mathrm{E}+1$ & {$[32,301]$} & $\mathrm{n} / \mathrm{a}$ \\
\hline & Zn & {$[70]$} & {$[8.7]$} & [238] & {$[0.55]$} \\
\hline & $\mathbf{Z r}$ & $<6.6 \mathrm{E}+1$ & {$[1.8]$} & $<2.8 \mathrm{E}+2$ & $\mathrm{n} / \mathrm{a}$ \\
\hline & $B a$ & [48] & $<6.7 \mathrm{E}-1$ & [205] & {$[0.02]$} \\
\hline & $C a$ & $<5.2 \mathrm{E}+3$ & {$[17]$} & $<2.3 \mathrm{E}+4$ & $\mathrm{n} / \mathrm{a}$ \\
\hline & $\mathrm{Cu}$ & {$[51]$} & $<9.5 \mathrm{E}-1$ & [216] & {$[0.35]$} \\
\hline & $L a$ & [24] & $<2.6 \mathrm{E}-1$ & [103] & {$[0.27]$} \\
\hline & $\mathrm{Li}$ & [26] & {$[1.7]$} & {$[100]$} & {$[0.35]$} \\
\hline & $M g$ & [150] & $<1.4 \mathrm{E}+0$ & [646] & {$[0.63]$} \\
\hline & Mo & [31] & 16.3 & {$[6]$} & {$[0.26]$} \\
\hline & $P b$ & [92] & {$[25]$} & {$[204]$} & {$[0.63]$} \\
\hline & Ti & [37] & $<1.9 \mathrm{E}-1$ & {$[161]$} & $-[0.01]$ \\
\hline & $Y$ & $<1.5 \mathrm{E}-1$ & $<1.7 \mathrm{E}-1$ & $-<6.9 \mathrm{E}-1$ & $\mathrm{n} / \mathrm{a}$ \\
\hline Slurry Prep Method & $\begin{array}{l}\text { ICP-OES } \\
\text { Analytes }\end{array}$ & $\begin{array}{c}\text { Dry } \\
\text { Slurry } \\
(\mu \mathrm{g} / \mathrm{g})\end{array}$ & $\begin{array}{c}\text { Supernate } \mathrm{e}^{(\mathrm{b})} \\
(\mu \mathrm{g} / \mathrm{mL})\end{array}$ & $\begin{array}{c}\text { Dry Solids }^{(\mathrm{c})} \\
(\mu \mathrm{g} / \mathrm{g})\end{array}$ & $\begin{array}{c}\text { Solids } \\
\text { Leach } \\
\text { Factor }^{(d)}\end{array}$ \\
\hline HF Acid Digestion & $\mathbf{K}$ & 306 & 470 & $-2,400$ & 0.42 \\
\hline Con. Factor 1.11 & $\mathrm{Ni}$ & 126 & $<1.1 \mathrm{E}+0$ & 543 & -0.16 \\
\hline
\end{tabular}


Table 4.15 (Contd)

\begin{tabular}{|c|c|c|c|c|c|}
\hline Slurry Prep Method & Radionuclides & $\begin{array}{c}\text { Dry } \\
\text { Slurry }^{(a)} \\
(\mu \mathrm{Ci} / \mathrm{g})\end{array}$ & $\begin{array}{l}\text { Supernate }^{(b)} \\
(\mu \mathrm{Ci} / \mathbf{m L})\end{array}$ & $\begin{array}{l}\text { Dry Solids }^{(c)} \\
\quad(\mu \mathrm{Ci} / \mathrm{g})\end{array}$ & $\begin{array}{c}\text { Solids } \\
\text { Leach } \\
\text { Factor }^{(d)}\end{array}$ \\
\hline \multirow{12}{*}{$\begin{array}{c}\text { KOH Fusion } \\
\text { Concentration Factor } \\
\text { of } 2.16 \text { based on } U\end{array}$} & Co-60 & $5.73 \mathrm{E}-2$ & $5.59 \mathrm{E}-4$ & $1.6 \mathrm{E}-1$ & 0.84 \\
\hline & Cs-137 & $1.65 \mathrm{E}+2$ & $8.57 \mathrm{E}+1$ & $1.7 \mathrm{E}+1$ & -0.88 \\
\hline & Eu-154 & $1.59 \mathrm{E}-1$ & $<8 . E-4$ & $4.5 \mathrm{E}-1$ & 0.19 \\
\hline & Eu-155 & $<6 . \mathrm{E}-2$ & $<9 . \mathrm{E}-3$ & $<1 . \mathrm{E}-1$ & $\mathrm{n} / \mathrm{a}$ \\
\hline & Am-241 & 4.75E-1 & $<9 . \mathrm{E}-3$ & $1.3 \mathrm{E}+0$ & 0.06 \\
\hline & Total alpha & $7.94 \mathrm{E}-1$ & $<4 . \mathrm{E}-3$ & $2.2 \mathrm{E}+0$ & 0.13 \\
\hline & Total beta & $5.50 \mathrm{E}+2$ & $8.78 \mathrm{E}+1$ & $1.1 \mathrm{E}+3$ & 0.10 \\
\hline & Sr-90 & $1.78 \mathrm{E}+2$ & 6.73E-2 & $5.1 \mathrm{E}+2$ & 0.01 \\
\hline & Pu-239/240 & $2.88 \mathrm{E}-1$ & $1.46 \mathrm{E}-4$ & $8.2 \mathrm{E}-1$ & 0.09 \\
\hline & Pu-238 & $2.23 \mathrm{E}-2$ & $2.10 \mathrm{E}-5$ & $6.3 \mathrm{E}-2$ & 0.31 \\
\hline & KPA & $(\mu g / g)$ & $(\mu \mathrm{g} / \mathrm{mL})$ & $(\mu \mathrm{g} / \mathrm{g})$ & \\
\hline & $\mathbf{U}$ & $4.94 \mathrm{E}+3$ & $5.81 \mathrm{E}+0$ & $1.4 \mathrm{E}+4$ & -0.06 \\
\hline \multicolumn{6}{|c|}{ (a) Test sample TI552-G6-D, ASO ID 08-00220 } \\
\hline \multicolumn{6}{|c|}{ (b) Test sample TI552-G6-12, ASO ID 08-00243 } \\
\hline \multicolumn{6}{|c|}{ (c) Calculated using results from TI552-G6-D and TI552-G6-12 } \\
\hline \multicolumn{6}{|c|}{ (d) Calculated using results listed in Table 4.10} \\
\hline \multicolumn{6}{|c|}{$\begin{array}{l}\text { Note: Analytes in italics were measured opportunistically. Values in brackets [ ] are } \geq \text { MDL but }<\text { EQL, } \\
\text { with errors likely to exceed } 15 \% \text {. }\end{array}$} \\
\hline
\end{tabular}

A slurry sample was sent for particle size distribution measurement to quantify changes caused from leaching. Figure 4.34 shows the pre-sonic PSD for the leached, dewatered slurry as a function of pump speed. The distribution was approximately bimodal. At 3,000 RPM, the PSD was composed of a population peak with a maximum at $2 \mu \mathrm{m}$ and spanned ro $\mu$ ghly 0.20 to $20 \mu \mathrm{m}$, and a second population peak had a maximum at $\sim 60 \mu \mathrm{m}$ and spanned 20 to $200 \mu \mathrm{m}$. The 0.20 - to 20 - $\mu \mathrm{m}$ population dominated the PSD. Overall, the size distribution of particles remained relatively unchanged at different flow rates. Changes in the PSD with pump speed primarily resulted from changes in the fractional contribution of small and large particle populations. At high pump speeds, the fractional population contribution of 20to 200- $\mu \mathrm{m}$ particles increased relative to 3,000 RPM. Likewise, the fractional contribution of this species was reduced at 2,000 RPM. Both observations are suggestive of difficult to suspend particles or agglomerates. At 2,000 RPM, a 400- $\mu$ m particle peak appeared. This could correspond to particle agglomerates that form under reduced shear or could be an artifact of the light-scattering analysis.

Figure 4.35 shows the PSD for the leached, dewatered slurry before, during, and after sonication. Sonication appears to eliminate particle population with sizes greater than $20 \mu \mathrm{m}$. These observations are consistent with sonic disruption of fragile particles and agglomerates. After sonication, there was a slight recovery of the 15 - to $25-\mu \mathrm{m}$ population, indicating that breakdown of agglomerate was partially reversible. While sonication did have an influence on particles greater than $10 \mu \mathrm{m}$, overall, the influence of the majority of particles (i.e., those from 0.2 to $10 \mu \mathrm{m}$ ) was minimal. The shape of the PSD over this size range did not change significantly over the course of sonication. This indicates that a significant portion of this sample was robust with respect to breakage. 


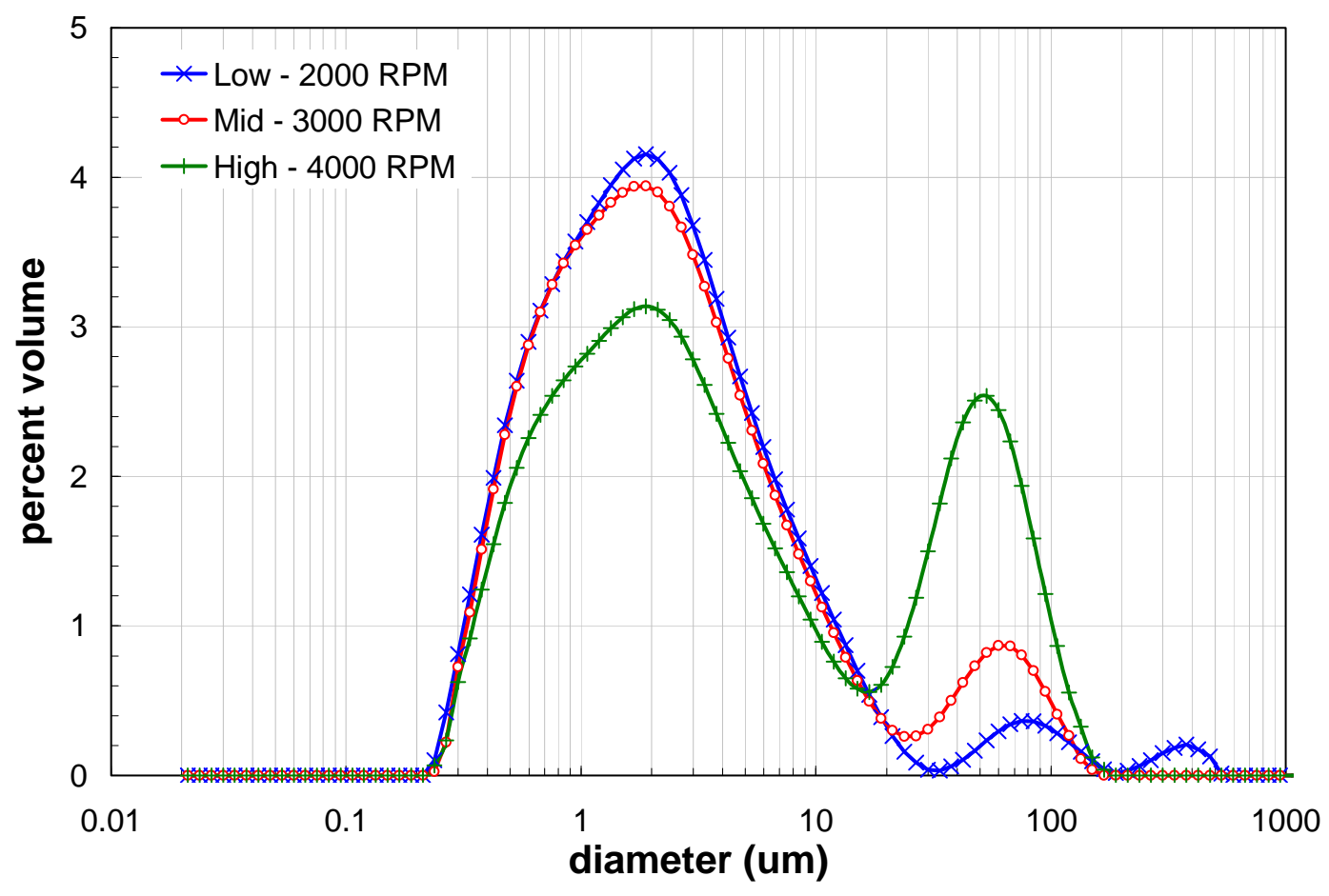

Figure 4.34. Measured PSD for Leached, Dewatered Slurry as a Function of Pump Speed

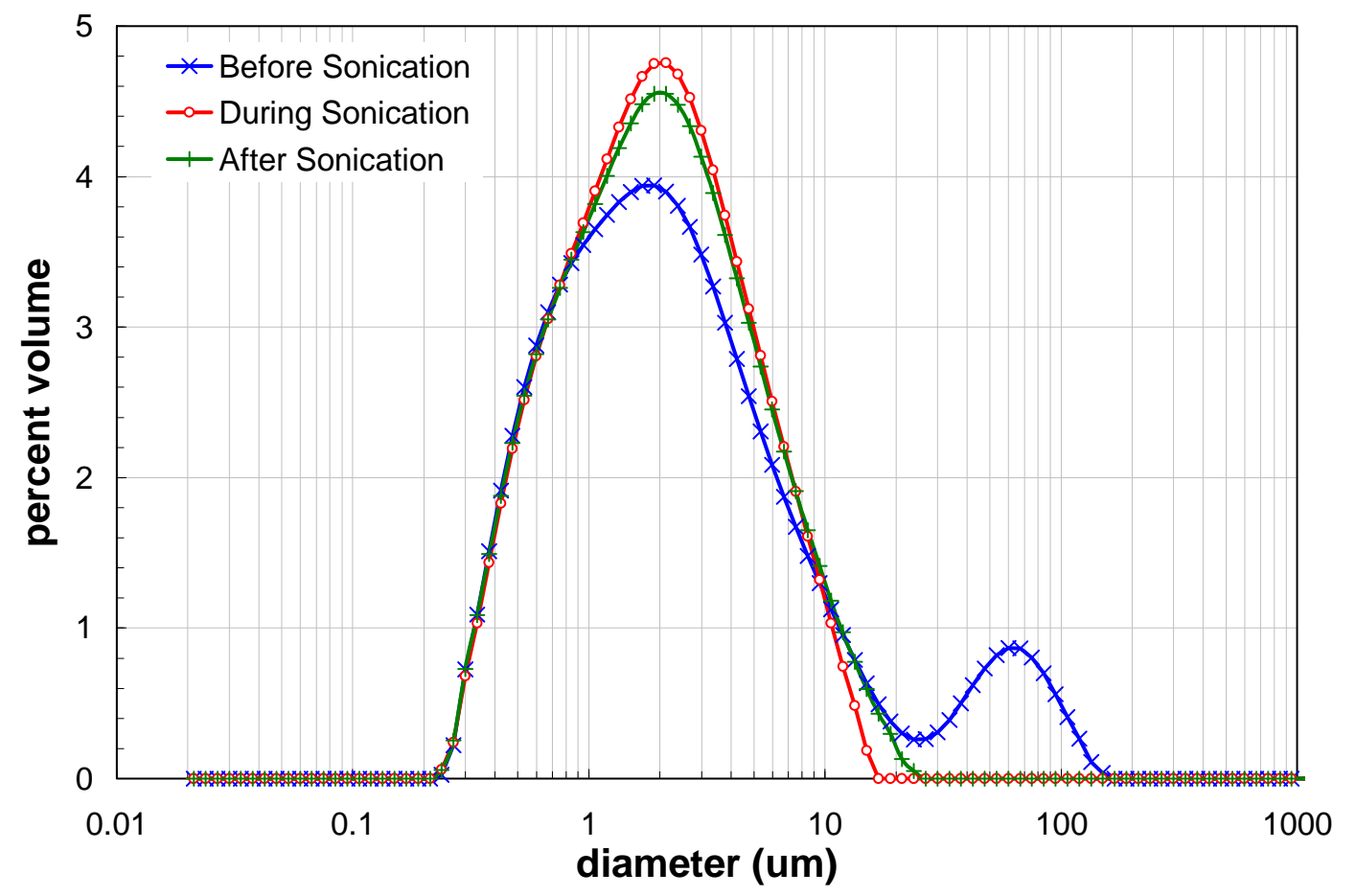

Figure 4.35. Measured PSD for Leached, Dewatered Slurry as a Function of Sonication 
The dewatered leach slurry was sub-sampled for rheology analysis prior to washing operations. Flow curves for the dewatered leached slurry (Figure 4.36) show non-Newtonian behavior at all temperatures and are consistent with the pre-caustic leach high-solids matrix slurry. The current flow curves exhibit finite yield points, are shear-thinning over $0-200 \mathrm{~s}^{-1}$, and are near-linear beyond $200 \mathrm{~s}^{-1}$. Hysteresis appears at specific shear regions for all flow curves. The regions of hysteresis for $25^{\circ} \mathrm{C}$ and $40^{\circ} \mathrm{C}$ flow curves are 200-600 s $\mathrm{s}^{-1}$ and 800-1000 s $\mathrm{s}^{-1}$, respectively. The flow-curve behavior with respect to increasing temperature is unusual. In particular, the higher temperature measurements $\left(40^{\circ}\right.$ and $\left.60^{\circ} \mathrm{C}\right)$ are both significantly higher than the $25^{\circ} \mathrm{C}$ at all shear rates but the highest (800 to $1000 \mathrm{~s}^{-1}$ ). That is, the yield point for the $25^{\circ} \mathrm{C}$ is only 3 to $5 \mathrm{~Pa}$, whereas those for the $40^{\circ}$ and $60^{\circ} \mathrm{C}$ measurements range from 15 to $20 \mathrm{~Pa}$.

The Bingham-Plastic fitting results show that both the primary and repeat flow-curve measurements show ro $\mu$ ghly the same yield stress and consistency, a significant jump occurs in both yield stress ( $\sim 10 \mathrm{~Pa}$ increase) and consistency ( 0.010 Pa`s decrease) between $25^{\circ}$ and $40^{\circ} \mathrm{C}$, and a smaller but continued change occurs between 40 and $60^{\circ} \mathrm{C}$. In addition, the Herschel-Bulkley flow indices tend to decrease with increasing temperature, indicating that the slurry is becoming more non-Newtonian as temperature is increased (Table 4.16). Finally, with regards to measurement repeatability, the two measurements at $25^{\circ} \mathrm{C}$ show similar consistency but different yield stress. Between repeat measurements, the yield stress increases from 9.9 to 11 Pa based on Bingham-Plastic fitting parameters. This increase is consistent with evaporation effects observed in the previous sample.

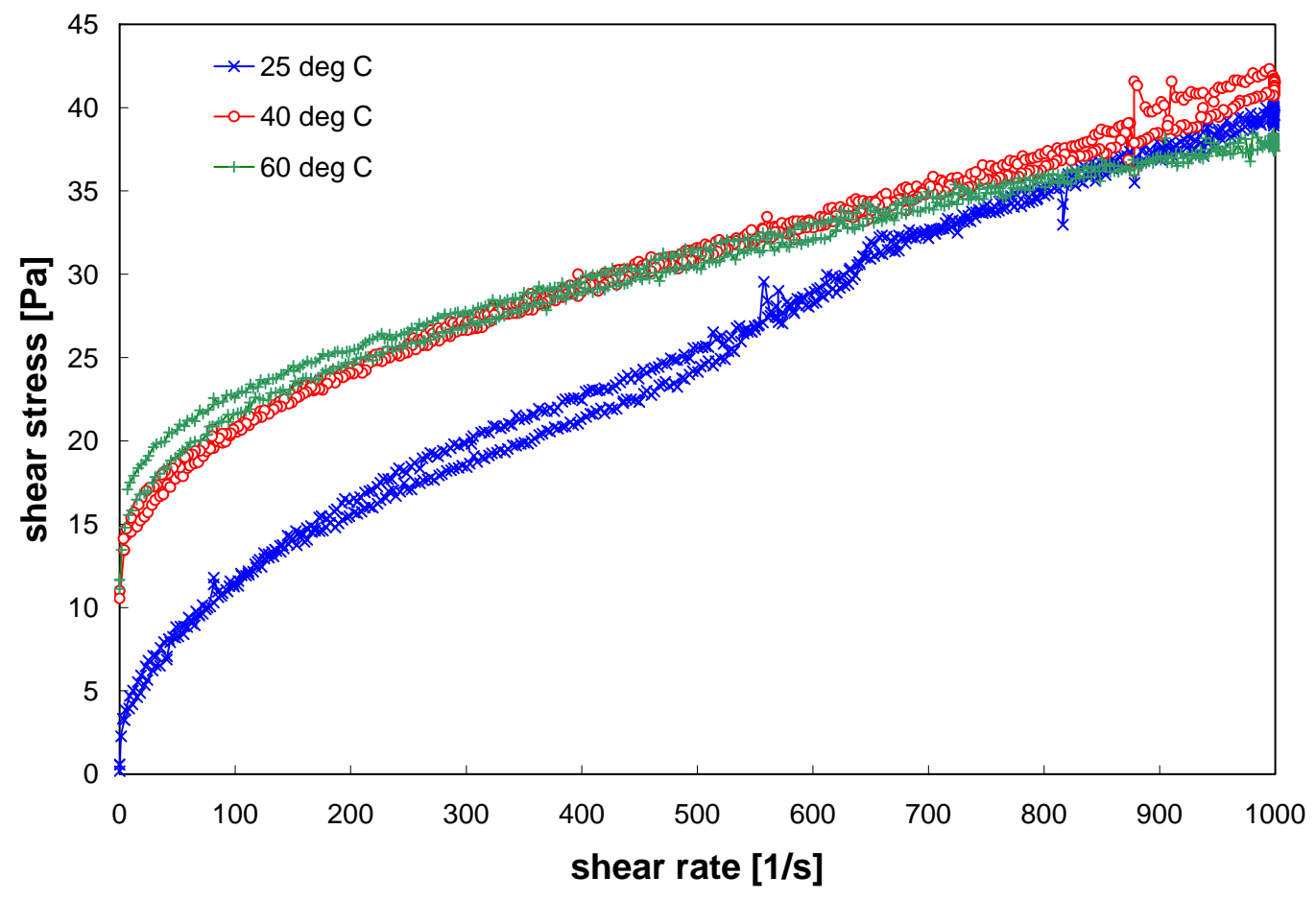

Figure 4.36. Flow Curves for Group 6/5 Dewatered Caustic Leached Slurry 
Table 4.16. Results of Fitting Analysis for the Group 6/5 Dewatered Caustic Leached Slurry

\begin{tabular}{||c|c|c|c|c|c||}
\hline \multirow{3}{*}{ Model } & $\begin{array}{c}\text { Temperature } \\
{\left[{ }^{\circ} \mathbf{C}\right]}\end{array}$ & $\begin{array}{c}\text { Yield } \\
\text { Stress [PA] }\end{array}$ & $\begin{array}{c}\text { Consistency } \\
{\left[\mathbf{P A} \cdot \mathbf{S}^{\mathbf{N}}\right]}\end{array}$ & $\begin{array}{c}\text { Flow } \\
\text { Index }\end{array}$ & $\mathbf{R}$ \\
\hline $\begin{array}{c}\text { Bingham-Plastic } \\
\left(200-1000 \mathrm{~s}^{-1}\right)\end{array}$ & $25(1$ of 2$)$ & 9.9 & 0.029 & $\mathrm{n} / \mathrm{a}$ & 0.984 \\
\cline { 2 - 6 } & $25(2$ of 2$)$ & 11 & 0.029 & $\mathrm{n} / \mathrm{a}$ & 0.996 \\
\cline { 2 - 6 } & 40 & 21 & 0.020 & $\mathrm{n} / \mathrm{a}$ & 0.997 \\
\cline { 2 - 6 } & 60 & 23 & 0.015 & $\mathrm{n} / \mathrm{a}$ & 0.992 \\
\hline \multirow{3}{*}{$\begin{array}{c}\text { Herschel-Bulkley } \\
\left(0-1000 \mathrm{~s}^{-1}\right)\end{array}$} & $25(1$ of 2$)$ & 3.7 & 0.25 & 0.72 & 0.994 \\
\cline { 2 - 7 } & $25(2$ of 2$)$ & 3.8 & 0.29 & 0.70 & 0.998 \\
\cline { 2 - 7 } & 40 & 14 & 0.32 & 0.64 & 0.998 \\
\cline { 2 - 7 } & 60 & 14 & 0.86 & 0.48 & 0.997 \\
\hline
\end{tabular}

\subsubsection{Caustic Batch Washing Results}

Following the caustic leach, the slurry was washed six times with decreasing concentrations of sodium hydroxide (Figure 4.37) to remove dissolved aluminum away from the slurry and lower the free hydroxide concentration of the slurry supernate below $0.25 \mathrm{M}$. Each solution's caustic concentration (1.53M, 0.66M, 0.24M, 0.09M, 0.02M, \& $0.01 \mathrm{M}$ ) was calculated to maintain the aluminum solubility in the slurry supernate after the addition. After each wash solution (1.2 liters) was added, it was allowed to mix with the slurry for 30 minutes with permeate recycling back to the slurry reservoir. Afterwards, an equal volume of permeate was dewatered from the slurry to keep the system volume constant. Each wash solution was sub-sampled for chemical analysis. Overall, $7.2 \mathrm{~kg}$ of wash was added to the CUF and 7.7 $\mathrm{kg}$ of permeate was dewatered from the slurry. The metals content, broken down by supernate and solids, of the slurry for the first five slurry washes are detailed in Table 4.17 through Table 4.21. Opportunistic compositions for the first five washes are shown in Table 4.23. The sixth wash characterization is outlined in the next Section, 4.4.3. 


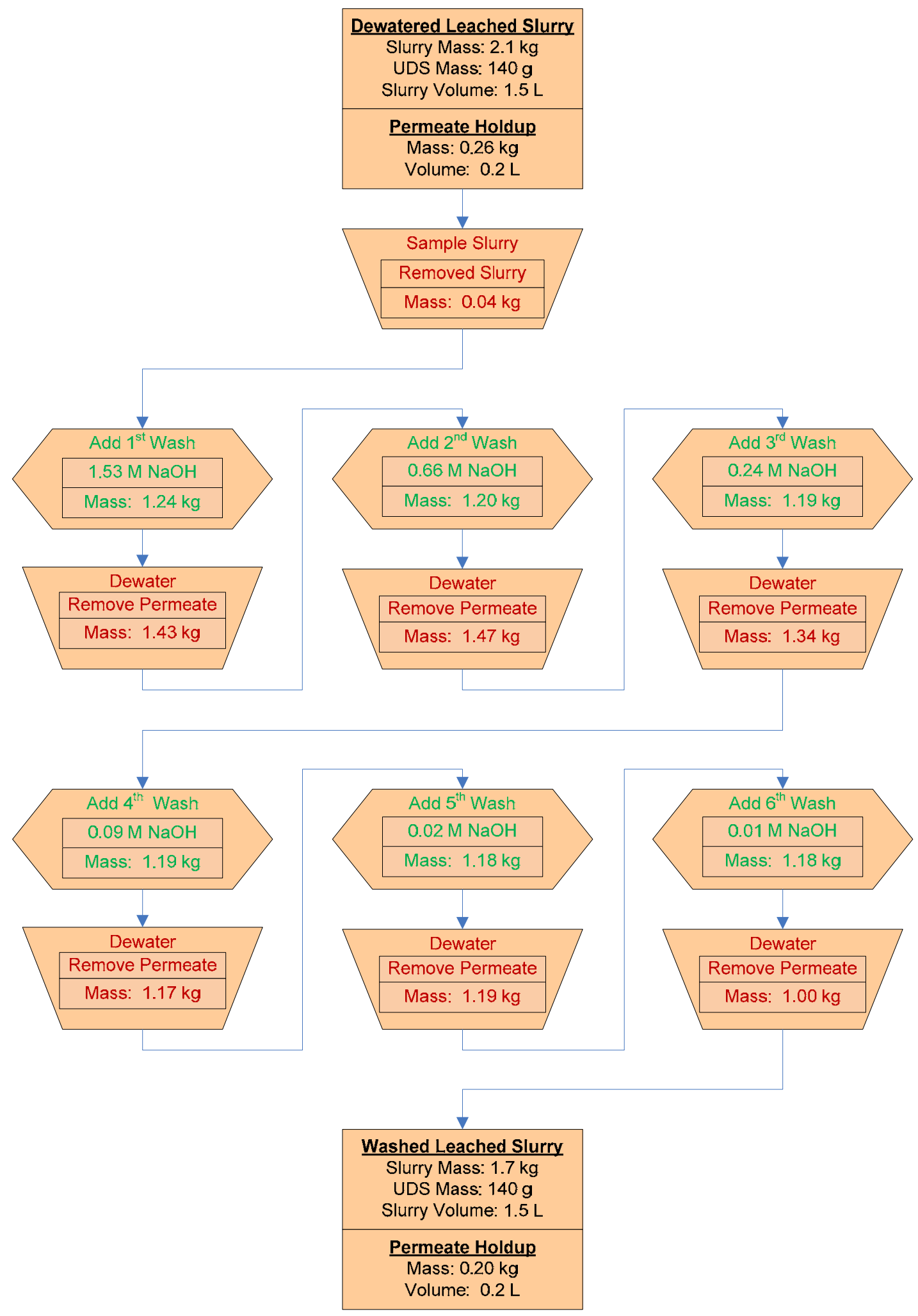

Figure 4.37. Group 6/5 Washing of the Caustic Leach Slurry

Note: Mass and volume values in figure are rounded to the nearest significant digit of accuracy. 
Table 4.17. Group 6/5 Caustic leached Slurry Inventory and Composition after the First Wash

\begin{tabular}{|c|c|c|c|c|c|c|}
\hline & & Slurry $^{(a)}$ & \multicolumn{2}{|c|}{ Liquid Fraction $^{(b)}$} & \multicolumn{2}{|c|}{ Solids Fraction ${ }^{(c)}$} \\
\hline & Mass (kg) & 2.12 & & 1.98 & & 0.14 \\
\hline & Wt $\%$ of Slurry & $100 \%$ & & $93.4 \%$ & & $6.6 \%$ \\
\hline & Metal & g & g & $\mu \mathrm{g} / \mathrm{mL}$ & g & $\mu \mathrm{g} / \mathrm{g}$ \\
\hline & $\mathrm{Al}$ & $5.7 \mathrm{E}+01$ & $1.2 \mathrm{E}+01$ & $7.2 \mathrm{E}+03$ & $4.5 \mathrm{E}+01$ & $3.2 \mathrm{E}+05$ \\
\hline & B & $6.6 \mathrm{E}-03$ & $1.7 \mathrm{E}-02$ & $1.1 \mathrm{E}+01$ & $\mathrm{n} / \mathrm{a}^{(\mathrm{d})}$ & $\mathrm{n} / \mathrm{a}^{(\mathrm{d})}$ \\
\hline & $\mathrm{Cd}$ & 9.3E-03 & $<4 . \mathrm{E}-4$ & $<3$. E-1 & 9.3E-03 & $6.6 \mathrm{E}+01$ \\
\hline & $\mathrm{Cr}$ & $7.2 \mathrm{E}+00$ & 4.5E-01 & $2.8 \mathrm{E}+02$ & $6.8 \mathrm{E}+00$ & $4.8 \mathrm{E}+04$ \\
\hline & $\mathrm{Fe}$ & $2.6 \mathrm{E}+00$ & $5.8 \mathrm{E}-03$ & $3.6 \mathrm{E}+00$ & $2.6 \mathrm{E}+00$ & $1.9 \mathrm{E}+04$ \\
\hline & $\mathrm{Mn}$ & $1.4 \mathrm{E}+00$ & $<4 . \mathrm{E}-4$ & $<2$.E-1 & $1.4 \mathrm{E}+00$ & $9.8 \mathrm{E}+03$ \\
\hline & $\mathrm{Na}$ & $2.2 \mathrm{E}+02$ & $1.9 \mathrm{E}+02$ & $1.2 \mathrm{E}+05$ & $2.7 \mathrm{E}+01$ & $1.9 \mathrm{E}+05$ \\
\hline & $\mathrm{P}$ & $1.9 \mathrm{E}+00$ & $1.6 \mathrm{E}+00$ & $9.6 \mathrm{E}+02$ & $3.0 \mathrm{E}-01$ & $2.1 \mathrm{E}+03$ \\
\hline & S & $1.3 \mathrm{E}+00$ & 8.0E-01 & $4.9 \mathrm{E}+02$ & 5.5E-01 & $3.9 \mathrm{E}+03$ \\
\hline & $\mathrm{Si}$ & $3.7 \mathrm{E}+00$ & $4.0 \mathrm{E}-02$ & $2.4 \mathrm{E}+01$ & $3.7 \mathrm{E}+00$ & $2.6 \mathrm{E}+04$ \\
\hline & $\mathrm{U}$ & $4.2 \mathrm{E}+00$ & $1.6 \mathrm{E}-02$ & $9.7 \mathrm{E}+00$ & $4.2 \mathrm{E}+00$ & $3.0 \mathrm{E}+04$ \\
\hline $\begin{array}{l}\text { (a) } \\
\text { (b) } \\
\text { (c) } \\
\text { (d) }\end{array}$ & $\begin{array}{c}\text { Slurry compon } \\
\text { simulant comp } \\
\text { sampling was } \\
\text { Liquid Fractio } \\
\text { TI552-G6-E ( } \\
\text { Solids Fraction } \\
\text { component ma }\end{array}$ & $\begin{array}{l}\text { masses were } \\
\text { nt masses, an } \\
\text { uded. } \\
\text { lass compone } \\
\text { ID 08-002 } \\
\text { ass componen } \\
\text { ind liquid com }\end{array}$ & $\begin{array}{l}\text { dlated from cl } \\
\text { noved supern } \\
\text { vere calculate } \\
\text { and the predic } \\
\text { ere calculated } \\
\text { ent mass frac }\end{array}$ & $\begin{array}{l}\text { erization de } \\
\text { component } \\
\text { g analytica } \\
\text { ass of supe } \\
\text { the differe }\end{array}$ & $\begin{array}{l}\text { PT-RPT-15 } \\
\text { es. Mass los } \\
\text { lts from supe } \\
\text { in the systen } \\
\text { etween the sl }\end{array}$ & $\begin{array}{l}\text { ded } \\
\text { sample }\end{array}$ \\
\hline
\end{tabular}


Table 4.18. Group 6/5 Caustic Leached Slurry Inventory and Composition after the Second Wash

\begin{tabular}{|c|c|c|c|c|c|c|}
\hline & & Slurry $^{(a)}$ & \multicolumn{2}{|c|}{ Liquid Fraction $^{(b)}$} & \multicolumn{2}{|c|}{ Solids Fraction ${ }^{(\mathrm{c})}$} \\
\hline & Mass (kg) & 1.85 & \multicolumn{2}{|r|}{1.71} & \multicolumn{2}{|r|}{0.14} \\
\hline & Wt\% of Slurry & $100 \%$ & \multicolumn{2}{|r|}{$92.4 \%$} & \multicolumn{2}{|r|}{$7.6 \%$} \\
\hline & Metal & g & g & $\mu \mathrm{g} / \mathrm{mL}$ & g & $\mu \mathrm{g} / \mathrm{g}$ \\
\hline & $\mathrm{Al}$ & $5.2 \mathrm{E}+01$ & $6.2 \mathrm{E}+00$ & $4.1 \mathrm{E}+03$ & $4.6 \mathrm{E}+01$ & $3.2 \mathrm{E}+05$ \\
\hline & B & $0.0 \mathrm{E}+00$ & $<3$. E-3 & $<2 . \mathrm{E}+0$ & $0.0 \mathrm{E}+00$ & $0.0 \mathrm{E}+00$ \\
\hline & $\mathrm{Cd}$ & 9.3E-03 & $<4$.E-4 & $<2$.E-1 & 9.3E-03 & $6.6 \mathrm{E}+01$ \\
\hline & $\mathrm{Cr}$ & $7.0 \mathrm{E}+00$ & 2.5E-01 & $1.7 \mathrm{E}+02$ & $6.8 \mathrm{E}+00$ & $4.8 \mathrm{E}+04$ \\
\hline & $\mathrm{Fe}$ & $2.6 \mathrm{E}+00$ & $<3$. E-3 & $<2 . \mathrm{E}+0$ & $2.6 \mathrm{E}+00$ & $1.9 \mathrm{E}+04$ \\
\hline & Mn & $1.4 \mathrm{E}+00$ & $<3$.E-4 & $<2$.E-1 & $1.4 \mathrm{E}+00$ & $9.8 \mathrm{E}+03$ \\
\hline & $\mathrm{Na}$ & $1.4 \mathrm{E}+02$ & $1.1 \mathrm{E}+02$ & $7.3 \mathrm{E}+04$ & $3.0 \mathrm{E}+01$ & $2.1 \mathrm{E}+05$ \\
\hline & $\mathrm{P}$ & $1.2 \mathrm{E}+00$ & 8.1E-01 & $5.4 \mathrm{E}+02$ & $3.6 \mathrm{E}-01$ & $2.6 \mathrm{E}+03$ \\
\hline & $\mathrm{S}$ & 9.9E-01 & 4.2E-01 & $2.8 \mathrm{E}+02$ & 5.7E-01 & $4.0 \mathrm{E}+03$ \\
\hline & $\mathrm{Si}$ & $3.7 \mathrm{E}+00$ & 2.3E-02 & $1.5 \mathrm{E}+01$ & $3.7 \mathrm{E}+00$ & $2.6 \mathrm{E}+04$ \\
\hline & $\mathrm{U}$ & $4.2 \mathrm{E}+00$ & $<$ 1.E-2 & $<8 . \mathrm{E}+0$ & $4.2 \mathrm{E}+00$ & $3.0 \mathrm{E}+04$ \\
\hline \multicolumn{7}{|c|}{$\begin{array}{l}\text { (a) Slurry component masses were calculated from characterization data (WPT-RPT-157), ac } \\
\text { simulant component masses, and removed supernatant component masses. Mass loss fror } \\
\text { sampling was included. } \\
\text { (b) Liquid Fraction mass components were calculated using analytical results from supernate } \\
\text { TI552-G6-F (ASO ID 08-00236) and the predicted mass of supernate in the system. } \\
\text { (c) Solids Fraction mass components were calculated from the difference between the slurry } \\
\text { component mass and liquid component mass fraction. }\end{array}$} \\
\hline
\end{tabular}


Table 4.19. Group 6/5 Caustic leached Slurry Inventory and Composition after the Third Wash

\begin{tabular}{|c|c|c|c|c|c|c|}
\hline & & Slurry $^{(a)}$ & \multicolumn{2}{|c|}{ Liquid Fraction $^{(b)}$} & \multicolumn{2}{|c|}{ Solids Fraction $^{(\mathrm{c})}$} \\
\hline & Mass (kg) & 1.73 & \multicolumn{2}{|r|}{1.59} & \multicolumn{2}{|r|}{0.14} \\
\hline & Wt\% of Slurry & $100 \%$ & \multicolumn{2}{|r|}{$91.9 \%$} & \multicolumn{2}{|r|}{$8.1 \%$} \\
\hline & Metal & g & g & $\mu g / m L$ & g & $\mu g / g$ \\
\hline & $\mathrm{Al}$ & $4.9 \mathrm{E}+01$ & $3.1 \mathrm{E}+00$ & $2.2 \mathrm{E}+03$ & $4.6 \mathrm{E}+01$ & $3.3 \mathrm{E}+05$ \\
\hline & $\mathrm{B}$ & $0.0 \mathrm{E}+00$ & $<3$. E-3 & $<2 . \mathrm{E}+0$ & $0.0 \mathrm{E}+00$ & $0.0 \mathrm{E}+00$ \\
\hline & $\mathrm{Cd}$ & 9.3E-03 & $<3$. E-4 & $<2 . \mathrm{E}-1$ & $9.0 \mathrm{E}-03$ & $6.4 \mathrm{E}+01$ \\
\hline & $\mathrm{Cr}$ & $6.9 \mathrm{E}+00$ & $1.3 \mathrm{E}-01$ & $8.9 \mathrm{E}+01$ & $0.0 \mathrm{E}+00$ & $0.0 \mathrm{E}+00$ \\
\hline & $\mathrm{Fe}$ & $2.6 \mathrm{E}+00$ & $<3$. E-3 & $<2 . \mathrm{E}+0$ & $2.6 \mathrm{E}+00$ & $1.9 \mathrm{E}+04$ \\
\hline & Mn & $1.4 \mathrm{E}+00$ & $<3$. E-4 & $<2$.E-1 & $1.4 \mathrm{E}+00$ & $9.8 \mathrm{E}+03$ \\
\hline & $\mathrm{Na}$ & $9.4 \mathrm{E}+01$ & $6.1 \mathrm{E}+01$ & $4.2 \mathrm{E}+04$ & $3.4 \mathrm{E}+01$ & $2.4 \mathrm{E}+05$ \\
\hline & $\mathrm{P}$ & 8.2E-01 & 4.0E-01 & $2.8 \mathrm{E}+02$ & 4.2E-01 & $3.0 \mathrm{E}+03$ \\
\hline & $\mathrm{S}$ & $8.1 \mathrm{E}-01$ & 2.0E-01 & $1.4 \mathrm{E}+02$ & 8.1E-01 & $5.8 \mathrm{E}+03$ \\
\hline & $\mathrm{Si}$ & $3.7 \mathrm{E}+00$ & 7.2E-03 & $5.0 \mathrm{E}+00$ & $3.7 \mathrm{E}+00$ & $2.6 \mathrm{E}+04$ \\
\hline & $\mathrm{U}$ & $4.2 \mathrm{E}+00$ & $<$ 1.E-2 & $<8 . \mathrm{E}+0$ & $4.2 \mathrm{E}+00$ & $3.0 \mathrm{E}+04$ \\
\hline \multicolumn{7}{|c|}{$\begin{array}{l}\text { (a) Slurry component masses were calculated from characterization data (WPT-RPT-157), ac } \\
\text { simulant component masses, and removed supernatant component masses. Mass loss fror } \\
\text { sampling was included. } \\
\text { (b) Liquid Fraction mass components were calculated using analytical results from supernate } \\
\text { TI552-G6-G (ASO ID 08-00237) and the predicted mass of supernate in the system. } \\
\text { (c) Solids Fraction mass components were calculated from the difference between the slurry } \\
\text { component mass and liquid component mass fraction. }\end{array}$} \\
\hline
\end{tabular}


Table 4.20. Group 6/5 Caustic leached Slurry Inventory and Composition after the Fourth Wash

\begin{tabular}{|c|c|c|c|c|c|c|}
\hline & & Slurry $^{(a)}$ & \multicolumn{2}{|c|}{ Liquid Fraction $^{(b)}$} & \multicolumn{2}{|c|}{ Solids Fraction $^{(\mathrm{c})}$} \\
\hline & Mass (kg) & 1.73 & \multicolumn{2}{|r|}{1.59} & \multicolumn{2}{|r|}{0.14} \\
\hline & Wt\% of Slurry & $100 \%$ & \multicolumn{2}{|r|}{$91.9 \%$} & \multicolumn{2}{|r|}{$8.1 \%$} \\
\hline & Metal & g & g & $\mu \mathrm{g} / \mathrm{mL}$ & g & $\mu g / g$ \\
\hline & $\mathrm{Al}$ & $4.8 \mathrm{E}+01$ & $1.5 \mathrm{E}+00$ & $1.0 \mathrm{E}+03$ & $4.7 \mathrm{E}+01$ & $3.3 E+05$ \\
\hline & B & $0.0 \mathrm{E}+00$ & $<3$. E-3 & $<2 . \mathrm{E}+0$ & $0.0 \mathrm{E}+00$ & $0.0 \mathrm{E}+00$ \\
\hline & $\mathrm{Cd}$ & 9.3E-03 & $<4 . \mathrm{E}-4$ & $<2$.E-1 & 9.3E-03 & $6.6 \mathrm{E}+01$ \\
\hline & $\mathrm{Cr}$ & $6.9 \mathrm{E}+00$ & $6.9 \mathrm{E}-02$ & $4.5 \mathrm{E}+01$ & $6.8 \mathrm{E}+00$ & $4.8 \mathrm{E}+04$ \\
\hline & $\mathrm{Fe}$ & $2.6 \mathrm{E}+00$ & $<3$. E-3 & $<2 . \mathrm{E}+0$ & $2.6 \mathrm{E}+00$ & $1.9 \mathrm{E}+04$ \\
\hline & Mn & $1.4 \mathrm{E}+00$ & $<3$. E-4 & $<2$.E-1 & $1.4 \mathrm{E}+00$ & $9.8 \mathrm{E}+03$ \\
\hline & $\mathrm{Na}$ & $7.3 \mathrm{E}+01$ & $3.2 \mathrm{E}+01$ & $2.1 \mathrm{E}+04$ & $4.1 \mathrm{E}+01$ & $2.9 \mathrm{E}+05$ \\
\hline & $\mathrm{P}$ & 6.7E-01 & 2.1E-01 & $1.4 \mathrm{E}+02$ & 4.6E-01 & $3.3 \mathrm{E}+03$ \\
\hline & S & 7.5E-01 & $9.1 \mathrm{E}-02$ & $6.0 \mathrm{E}+01$ & 6.6E-01 & 4.7E+03 \\
\hline & $\mathrm{Si}$ & $3.7 \mathrm{E}+00$ & $3.8 \mathrm{E}-03$ & $2.5 \mathrm{E}+00$ & $3.7 E+00$ & $2.6 \mathrm{E}+04$ \\
\hline & $\mathrm{U}$ & $4.2 \mathrm{E}+00$ & $<1 . \mathrm{E}-2$ & $<8 . \mathrm{E}+0$ & $4.2 \mathrm{E}+00$ & $3.0 \mathrm{E}+04$ \\
\hline \multicolumn{7}{|c|}{$\begin{array}{l}\text { (a) Slurry component masses were calculated from characterization data (WPT-RPT-157), ad } \\
\text { simulant component masses, and removed supernatant component masses. Mass loss fror } \\
\text { sampling was included. } \\
\text { (b) Liquid Fraction mass components were calculated using analytical results from supernate } \\
\text { TI552-G6-H (ASO ID 08-00238) and the predicted mass of supernate in the system. } \\
\text { (c) Solids Fraction mass components were calculated from the difference between the slurry } \\
\text { component mass and liquid component mass fraction. }\end{array}$} \\
\hline
\end{tabular}


Table 4.21. Group 6/5 Caustic Leached Slurry Inventory and Composition after the Fifth Wash

\begin{tabular}{|c|c|c|c|c|c|c|}
\hline & & Slurry $^{(a)}$ & \multicolumn{2}{|c|}{ Liquid Fraction $^{(b)}$} & \multicolumn{2}{|c|}{ Solids Fraction $^{(\mathrm{c})}$} \\
\hline & Mass (kg) & 2.31 & \multicolumn{2}{|r|}{2.19} & \multicolumn{2}{|r|}{0.13} \\
\hline & Wt\% of Slurry & $100 \%$ & \multicolumn{2}{|r|}{$94.6 \%$} & \multicolumn{2}{|r|}{$5.4 \%$} \\
\hline & Metal & g & g & $\mu \mathrm{g} / \mathrm{mL}$ & g & $\mu g / g$ \\
\hline & $\mathrm{Al}$ & $4.1 \mathrm{E}+01$ & $1.1 \mathrm{E}+00$ & $5.3 \mathrm{E}+02$ & $4.0 \mathrm{E}+01$ & $3.2 \mathrm{E}+05$ \\
\hline & $\mathrm{B}$ & $0.0 \mathrm{E}+00$ & $<4$.E-3 & $<2 . \mathrm{E}+0$ & $0.0 \mathrm{E}+00$ & $0.0 \mathrm{E}+00$ \\
\hline & $\mathrm{Cd}$ & 8.8E-03 & $<5 . \mathrm{E}-4$ & $<2$.E-1 & $8.8 \mathrm{E}-03$ & $7.0 \mathrm{E}+01$ \\
\hline & $\mathrm{Cr}$ & 8.0E-01 & 5.7E-02 & $2.6 \mathrm{E}+01$ & 7.4E-01 & $6.0 \mathrm{E}+03$ \\
\hline & $\mathrm{Fe}$ & $2.4 \mathrm{E}+00$ & $<4$.E-3 & $<2 . \mathrm{E}+0$ & $2.4 \mathrm{E}+00$ & $1.9 \mathrm{E}+04$ \\
\hline & Mn & $6.0 \mathrm{E}+00$ & $<4$.E-4 & $<2$.E-1 & $6.0 \mathrm{E}+00$ & $4.8 \mathrm{E}+04$ \\
\hline & $\mathrm{Na}$ & $3.1 \mathrm{E}+01$ & $2.5 \mathrm{E}+01$ & $1.2 \mathrm{E}+04$ & $6.2 \mathrm{E}+00$ & $5.0 \mathrm{E}+04$ \\
\hline & $\mathrm{P}$ & $2.8 \mathrm{E}-01$ & $1.9 \mathrm{E}-01$ & $9.0 \mathrm{E}+01$ & 8.3E-02 & $6.6 \mathrm{E}+02$ \\
\hline & $\mathrm{S}$ & $6.4 \mathrm{E}-01$ & $<7$. E-2 & $<3 . \mathrm{E}+1$ & $6.4 \mathrm{E}-01$ & $5.1 \mathrm{E}+03$ \\
\hline & $\mathrm{Si}$ & $3.3 \mathrm{E}+00$ & $<2$.E-3 & $<1 . \mathrm{E}+0$ & $3.3 \mathrm{E}+00$ & $2.6 \mathrm{E}+04$ \\
\hline & $\mathrm{U}$ & $3.7 \mathrm{E}+00$ & $<2$.E-2 & $<8 . \mathrm{E}+0$ & $3.7 \mathrm{E}+00$ & $2.9 \mathrm{E}+04$ \\
\hline \multicolumn{7}{|c|}{$\begin{array}{l}\text { (a) Slurry component masses were calculated from characterization data (WPT-RPT-157), ac } \\
\text { simulant component masses, and removed supernatant component masses. Mass loss fror } \\
\text { sampling was included. } \\
\text { (b) Liquid Fraction mass components were calculated using analytical results from supernate } \\
\text { TI552-G6-I (ASO ID 08-00239) and the predicted mass of supernate in the system. } \\
\text { (c) Solids Fraction mass components were calculated from the difference between the slurry } \\
\text { component mass and liquid component mass fraction. }\end{array}$} \\
\hline
\end{tabular}


Table 4.23. Caustic Wash Solutions Opportunistic Compositions

\begin{tabular}{|c|c|c|c|c|c|c|c|}
\hline & Wash 1 & Wash 2 & Wash 3 & Wash 4 & Wash 5 & Wash 6 & $\begin{array}{c}\text { Composite } \\
\text { Wash }\end{array}$ \\
\hline \begin{tabular}{|l|} 
ASO \\
Sample ID
\end{tabular} & 08-00235 & 08-00236 & 08-00237 & 08-00238 & 08-00239 & 08-00221 & 08-00222 \\
\hline $\begin{array}{l}\text { Density }^{(\mathrm{a})} \text {, } \\
\mathrm{g} / \mathrm{mL}>\end{array}$ & 1.21 & 1.14 & 1.08 & 1.04 & 1.02 & 1.01 & NA \\
\hline \multicolumn{8}{|l|}{ Analyte } \\
\hline free $\mathrm{OH}, \mathrm{M}$ & $3.95 \mathrm{M}$ & $2.41 \mathrm{M}$ & $1.36 \mathrm{M}$ & $0.73 \mathrm{M}$ & $0.38 \mathrm{M}$ & $0.17 \mathrm{M}$ & $1.57 \mathrm{M}$ \\
\hline \multicolumn{8}{|c|}{ Opportunistic Analytes } \\
\hline Analyte & $\mu \mathrm{g} / \mathrm{mL}$ & $\mu \mathrm{g} / \mathrm{mL}$ & $\mu \mathrm{g} / \mathrm{mL}$ & $\mu \mathrm{g} / \mathrm{mL}$ & $\mu \mathrm{g} / \mathrm{mL}$ & $\mu \mathrm{g} / \mathrm{mL}$ & $\mu \mathrm{g} / \mathrm{mL}$ \\
\hline $\mathrm{Ag}$ & $<0.45$ & $<0.42$ & $<0.41$ & $<0.43$ & $<0.42$ & $<0.43$ & $<0.42$ \\
\hline As & {$[10.5]$} & $<6.9$ & $<6.8$ & $<7.1$ & $<7.0$ & $<7.1$ & $<6.9$ \\
\hline $\mathrm{Ba}$ & {$[0.37]$} & $<0.33$ & $<0.33$ & $<0.34$ & $<0.34$ & $<0.34$ & $<0.34$ \\
\hline $\mathrm{Be}$ & {$[0.022]$} & {$[0.022]$} & $<0.01$ & $<0.01$ & $<0.01$ & $<0.01$ & {$[0.018]$} \\
\hline $\mathrm{Ca}$ & {$[4.25]$} & {$[2.5]$} & $\begin{array}{l}{[2.7]} \\
\end{array}$ & $<2.1$ & $<2.1$ & {$[3.3]$} & {$[5.2]$} \\
\hline $\mathrm{Ce}$ & $<1.3$ & $<1.2$ & $<1.2$ & $<1.2$ & $<1.2$ & $<1.2$ & $<1.2$ \\
\hline Co & $<0.41$ & $<0.38$ & {$[0.42]$} & {$[0.42]$} & $<0.39$ & $<0.39$ & $<0.38$ \\
\hline $\mathrm{Cu}$ & $<0.51$ & $<0.48$ & $<0.47$ & $<0.49$ & $<0.48$ & $<0.49$ & $<0.48$ \\
\hline Dy & $<0.37$ & $<0.35$ & $<0.34$ & $<0.36$ & $<0.35$ & $<0.35$ & $<0.35$ \\
\hline Eu & $<0.12$ & $<0.11$ & $<0.11$ & $<0.11$ & $<0.11$ & $<0.11$ & $<0.11$ \\
\hline $\mathrm{La}$ & $<0.14$ & $<0.13$ & $<0.13$ & $<0.13$ & $<0.13$ & $<0.13$ & {$[0.17]$} \\
\hline $\mathrm{Li}$ & {$[2.0]$} & [1.5] & [1.3] & {$[0.61]$} & $<0.54$ & $<0.55$ & $<0.54$ \\
\hline Mg & $<0.75$ & $<0.69$ & $<0.69$ & $<0.71$ & $<0.70$ & $<0.71$ & $<0.70$ \\
\hline Mo & 8.21 & {$[4.5]$} & {$[2.8]$} & {$[1.4]$} & {$[1.3]$} & {$[0.83]$} & [3.1] \\
\hline Nd & $<1.8$ & $<1.7$ & $<1.7$ & $<1.7$ & $<1.7$ & $<1.7$ & $<1.7$ \\
\hline $\mathrm{Pb}$ & {$[4.94]$} & $<3.7$ & $<3.6$ & $<3.7$ & $<3.7$ & $<<3.7$ & $<3.7$ \\
\hline \begin{tabular}{|l}
$\mathrm{Pd}$ \\
\end{tabular} & [1.38] & $<1.2$ & $<1.2$ & $<1.3$ & $<1.3$ & $<1.3$ & $<1.2$ \\
\hline $\mathrm{Rh}$ & $<2.7$ & $<2.5$ & $<2.5$ & $<2.6$ & $<2.5$ & $<2.6$ & $<2.5$ \\
\hline $\mathrm{Ru}$ & $<0.96$ & $<0.81$ & $<0.80$ & $<0.83$ & $<0.82$ & $<0.83$ & $<0.82$ \\
\hline $\mathrm{Sb}$ & $<3.4$ & $<3.1$ & $<3.1$ & $<3.2$ & $<3.1$ & $<3.2$ & $<3.1$ \\
\hline Se & $<5.2$ & [12] & $<4.8$ & $<5.0$ & $<4.9$ & [27] & [29] \\
\hline Sn & {$[3.6]$} & {$[4.9]$} & $<2.0$ & $<2.0$ & {$[4.2]$} & $<2.0$ & $<2.0$ \\
\hline $\mathrm{Ta}$ & $<1.4$ & $<1.3$ & $<1.3$ & $<1.3$ & $<1.3$ & $<1.3$ & $<1.3$ \\
\hline $\mathrm{Te}$ & $<3.3$ & $<3.1$ & $<3.1$ & $<3.2$ & $<3.2$ & $<3.2$ & $<3.1$ \\
\hline Th & $<1.3$ & $<1.2$ & $<1.2$ & $<1.2$ & $<1.2$ & $<1.2$ & $<1.2$ \\
\hline $\mathrm{Ti}$ & $<0.10$ & $<0.10$ & $<0.09$ & $<0.10$ & $<0.10$ & $<0.10$ & $<0.10$ \\
\hline $\mathrm{Tl}$ & {$[9.0]$} & $<6.4$ & $<6.4$ & $<6.6$ & $<6.5$ & $<6.6$ & {$[8.2]$} \\
\hline $\mathrm{V}$ & {$[0.65]$} & {$[0.51]$} & $<0.31$ & $<<0.32$ & $<0.31$ & {$[0.36]$} & {$[0.40]$} \\
\hline \begin{tabular}{|l|}
$\mathrm{W}$ \\
\end{tabular} & [13] & {$[7.6]$} & [5.5] & [2.1] & $<1.5$ & $<1.5$ & [6.5] \\
\hline \begin{tabular}{|l|}
$Y$ \\
\end{tabular} & $<0.09$ & $<0.08$ & $<0.08$ & $<0.09$ & $<0.08$ & $<0.09$ & $<0.08$ \\
\hline \multicolumn{8}{|c|}{$\begin{array}{l}\text { (a) Density values were obtained from the mass flow meter, which had not been calibrated to NC } \\
\text { standards; they are reported for information only. } \\
\text { ASR } 8055 \text { Reference date: November } 5,2007 \text {. } \\
\text { Analyte uncertainties were typically within } \pm 15 \% \text {; results in brackets indicate that the analyte } \\
\text { concentrations were greater than the method detection limit (MDL) and less than the estimated } \\
\text { quantitation limit (EQL), and uncertainties were }>15 \% \text {. }\end{array}$} \\
\hline
\end{tabular}

The concentrations of the sodium, aluminum and hydroxide were measured in the supernate of the slurry before and after caustic leaching (Figure 4.38). As expected, the sodium and hydroxide concentration spikes with the addition of the caustic at the start of the leach, followed with a spike in the aluminum concentration afterwards. Eventually, the concentration of all three species gradually decreased as the wash solution continued to dilute the slurry supernate and remove the compounds from the slurry during dewatering. 
Aluminum concentrations measured in the supernate of the high-solids slurry, caustic leach slurry, and wash permeate solutions were used to measure the removal of aluminum from the slurry (Figure 4.39). After the caustic leach and all associated washes, the total aluminum in the slurry (after accounting for aluminum removed during sampling) was reduced from 94 total slurry grams to 47 total slurry grams (50\%). The slurry feed consisted of 83 grams of solid aluminum (11 grams of which were soluble), which was reduced to 45 grams of solid aluminum following the caustic leach, or a $46 \%$ leach factor.

As in the Group 5 CUF test, a majority of the phosphorous present in the pre-leached slurry was in the form of phosphate in the slurry supernate. As the original slurry supernate was dewatered and washed out of the slurry, the phosphorous content in the slurry decreased as well (Figure 4.40). Note that for both the intial and high solids samples, the amount of $\mathrm{P}$ in the supernate is large relative to the insoluble quantity, and thus the quantity of insoluble $\mathrm{P}$ is highly uncertain due to analytical uncertainties. 


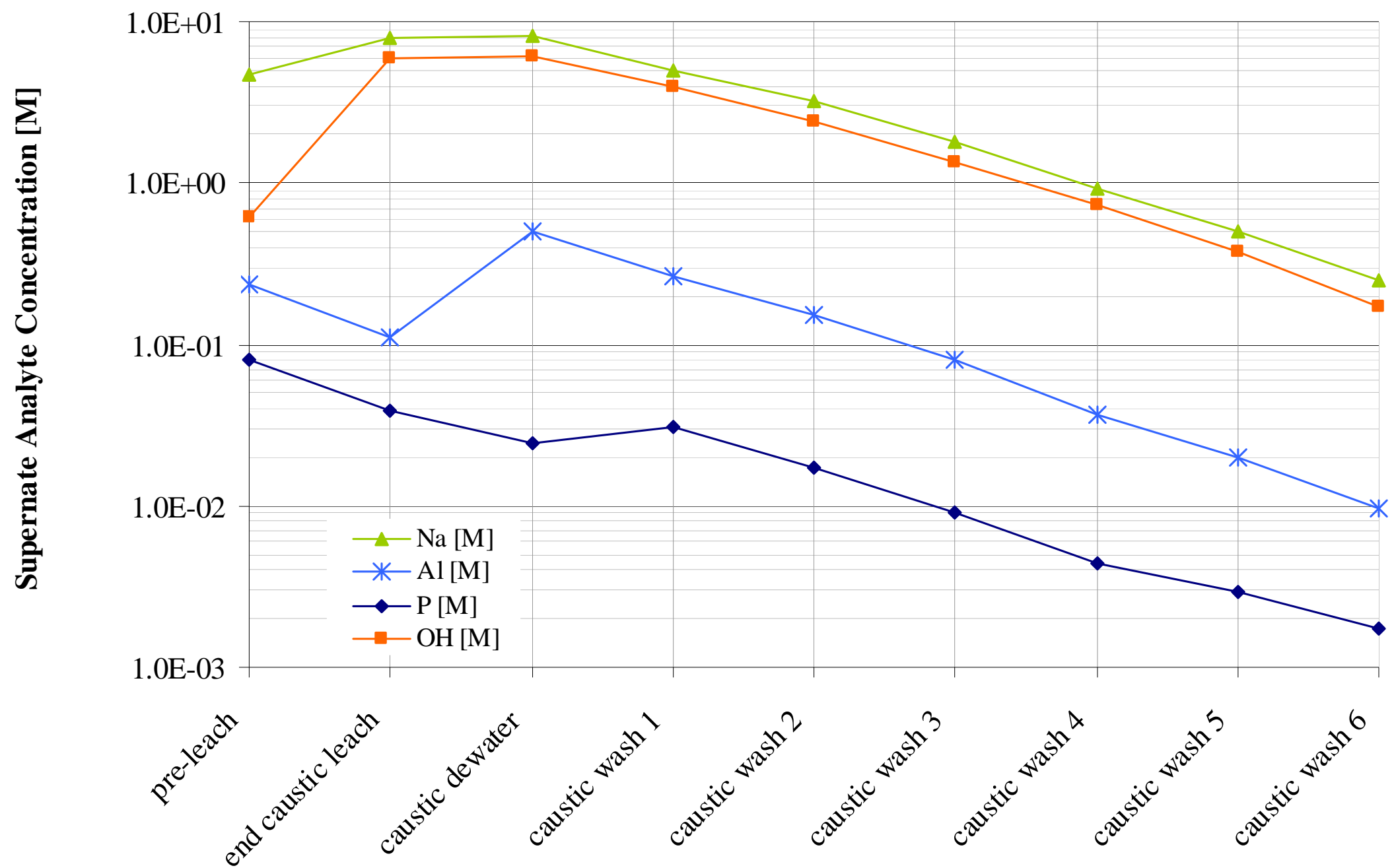

Figure 4.38. Group 6/5 Sodium, Free Hydroxide, and Aluminum Concentrations Before and After Caustic Leach and Washing 


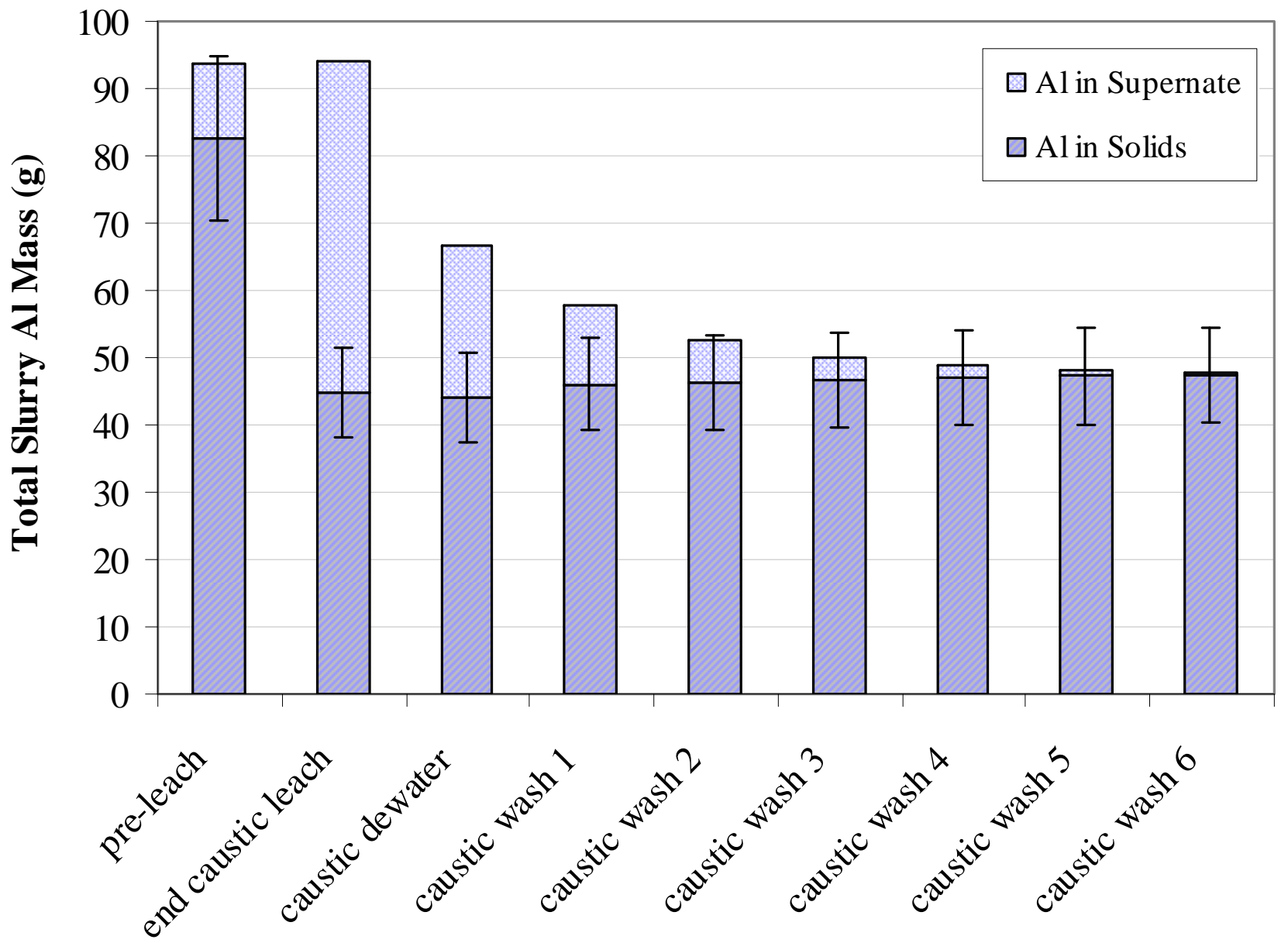

Figure 4.39. Normalized Aluminum Inventory in Group 6/5 Slurry through Caustic Leach and Washing (Inventory in Figure Normalized to Eliminate Sample Loss Impacts) 


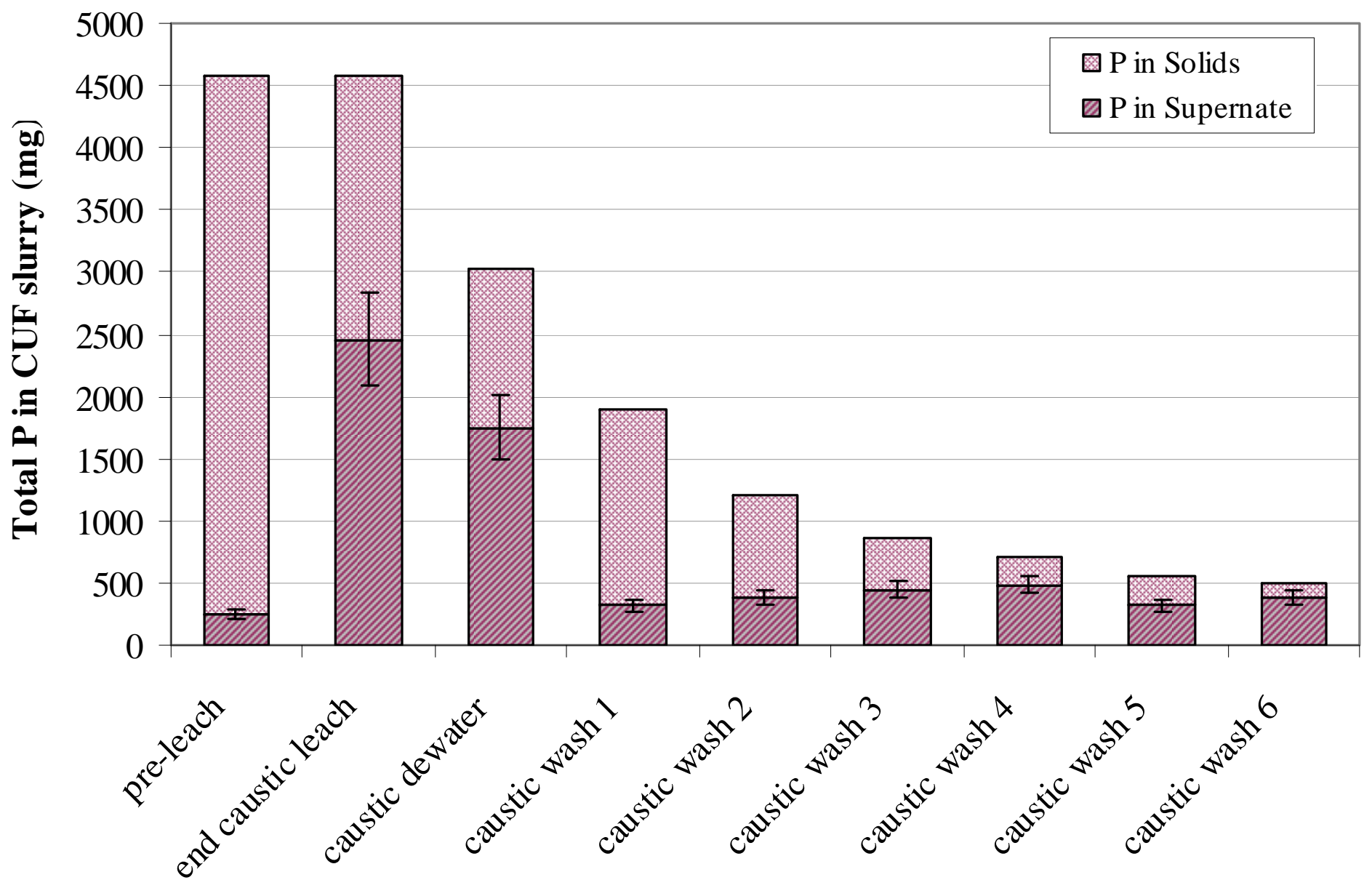

Figure 4.40. Normalized Phosphorus Inventory in Group 6/5 Slurry thro $\mu$ gh Caustic Leach and Washing (Inventory in Figure Normalized to Eliminate Sample Loss Impacts) 


\subsubsection{Dewatering of Caustic Wash Solutions}

As outlined in Figure 4.37 from the previous section, the leached slurry was dewatered six times after the addition of a wash solution used to remove aluminum and hydroxide in the slurry supernate. The filtration of the supernate after the wash solutions were added occurred rapidly as they became more dilute (Table 4.24 and Figure 4.41). A significant improvement in flux was observed on the third and subsequent washes. The improvement is greater than that predicted by differences in viscosity at a constant filter resistance, suggesting a change in effective filter resistance. The current best explanation for this change is that the dissolution of deeply-fouled small particles occurs rapidly in this concentration regime (specifically sodium oxalate). Also note that the filter fluxes appear to go through a maximum during the later washing stages. The drop in filter flux towards the end of these wash cycles is likely due to the increase in solids concentration in the slurries.

Table 4.24. Average Dewatering Flux for Caustic Washes

\begin{tabular}{|c|c|c|c|c|c|c|}
\hline \hline & $\begin{array}{c}\text { Wash } \\
\text { Volume } \\
(\mathbf{L})\end{array}$ & $\begin{array}{c}\text { NaOH } \\
\text { concentration of } \\
\text { wash } \mathbf{( M )}\end{array}$ & $\begin{array}{c}\text { [Na] } \\
\mathbf{( M )}\end{array}$ & $\begin{array}{c}\text { [OH] } \\
(\mathbf{M})\end{array}$ & $\begin{array}{c}{[\text { Al] }} \\
\mathbf{( M )}\end{array}$ & $\begin{array}{c}\text { Average } \\
\text { Filter Flux } \\
\text { (GPM/ft }\end{array}$ \\
\hline Wash 1 & 1.20 & 1.53 & 5.04 & 3.95 & 0.27 & 0.021 \\
\hline Wash 2 & 1.20 & 0.66 & 3.17 & 2.41 & 0.15 & 0.045 \\
\hline Wash 3 & 1.20 & 0.24 & 1.83 & 1.36 & 0.08 & 0.105 \\
\hline Wash 4 & 1.20 & 0.09 & 0.92 & 0.73 & 0.04 & 0.102 \\
\hline Wash 5 & 1.20 & 0.02 & 0.50 & 0.38 & 0.02 & 0.091 \\
\hline Wash 6 & 1.20 & 0.01 & 0.25 & 0.17 & 0.01 & 0.100 \\
\hline
\end{tabular}


WTP-RPT-172, Rev 0

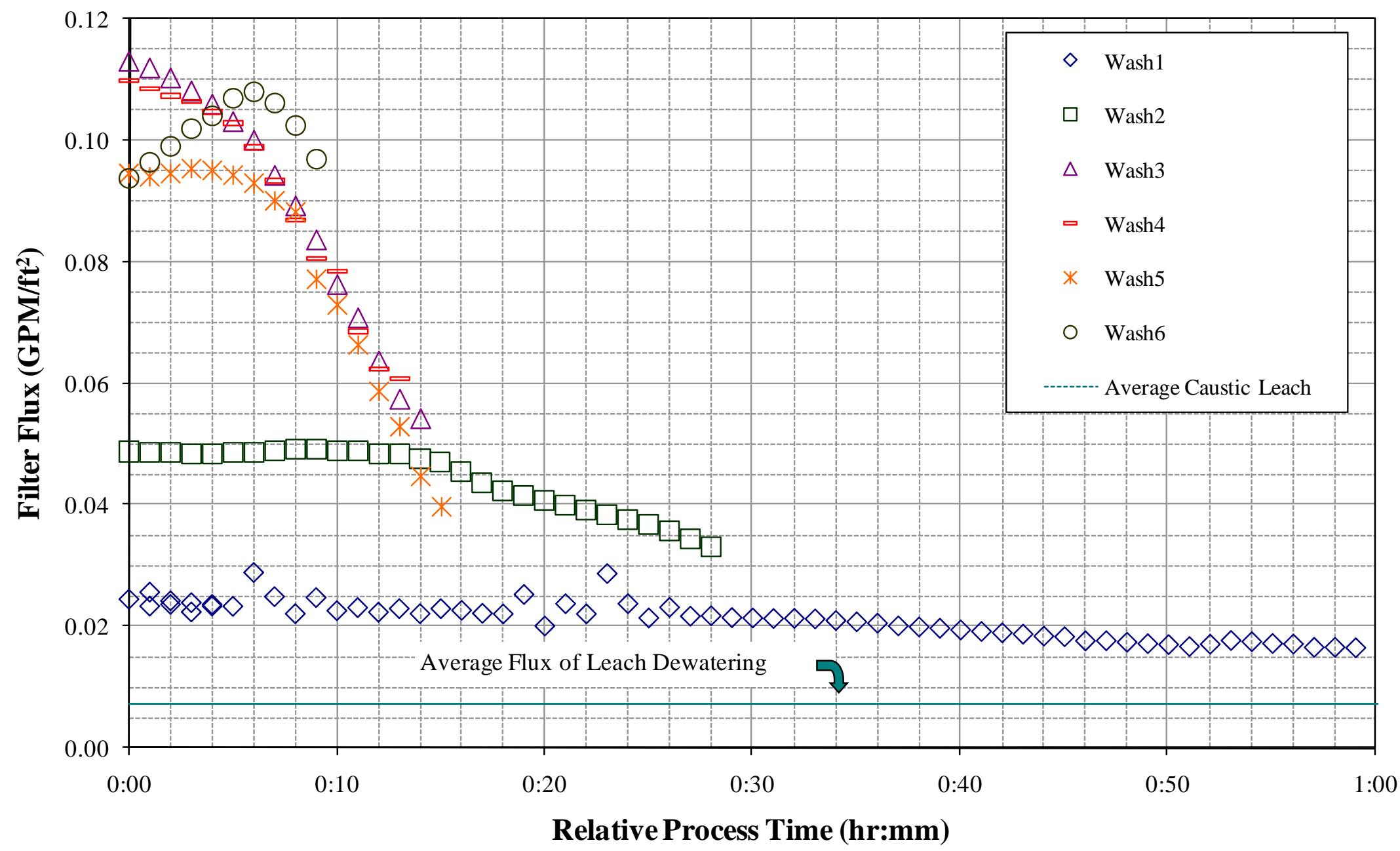

Figure 4.41. Filter Flux During Caustic Washes 


\subsubsection{Characterization of Washed Caustic Leached Slurry}

After dewatering of the sixth wash solution, the washed caustic leached slurry was sampled for physical and chemical characterization. The slurry physical property measurements (Table 4.25) and composition Table 4.26 and Table 4.27) are shown below. As in previous measurements, differences in the measured UDS concentration and that of the predicted slurry solids $(0.14 \mathrm{~kg} / 1.7 \mathrm{~kg} \cong 8 \mathrm{wt} \%)$ indicated variation in the Group 5 UDS concentration in the samples added or variation caused by trying to sample a homogenous slurry in the hot cells. In comparison to Table 4.9, the high solids slurry composition just prior to caustic leaching, there was no appreciable decrease in any radionuclide aside from cesium during the caustic leach. Specifically for ${ }^{238} \mathrm{Pu},{ }^{239} \mathrm{Pu}$, and ${ }^{240} \mathrm{Pu}$, the slight $\sim 50-\mu \mathrm{Ci}$ drop can be attributed to sampling and washing rather than leaching operations.

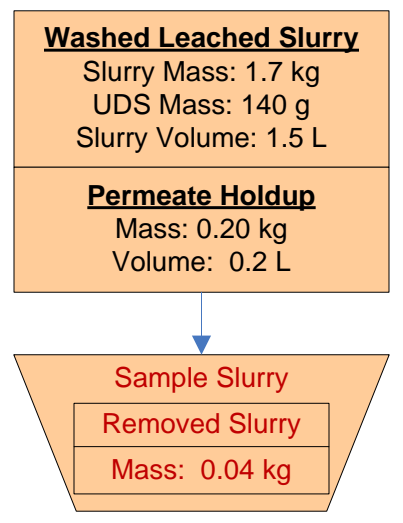

Figure 4.42. Slurry Sampling of Group 6/5 Washed Caustic Leached Slurry Note: Mass and volume values in figure are rounded to the nearest significant digit of accuracy.

Table 4.25. Group 6/5 Washed Caustic Leached Slurry Physical Property Measurements (inside slurry loop)

\begin{tabular}{|r|c||}
\hline Slurry Density $(\mathbf{g} / \mathbf{m L})$ & 1.09 \\
\hline Supernate Density $\mathbf{( g / m L})$ & 1.01 \\
\hline Settled Solids (Vol\%) & $97 \%$ \\
\hline Centrifuged UDS $(\mathbf{W t} \%)$ & $33 \%$ \\
\hline Total Solids of the Slurry $(\mathbf{W t} \%)$ & $15 \%$ \\
\hline Dissolved Solids of the Supernate $\mathbf{( W t} \%)$ & $1.9 \%$ \\
\hline UDS of the Slurry $\mathbf{( W t} \%)$ & $13 \%$ \\
\hline
\end{tabular}


Table 4.26. Group 6/5 Caustic Leached and Washed Slurry Inventory and Composition

\begin{tabular}{|c|c|c|c|c|c|}
\hline & Slurry $^{(a)}$ & \multicolumn{2}{|c|}{ Liquid Fraction $^{(b)}$} & \multicolumn{2}{|c|}{ Solids Fraction $^{(\mathrm{c})}$} \\
\hline Mass (kg) & 1.90 & & 1.76 & & 0.14 \\
\hline Wt\% of Slurry & $100 \%$ & & $92.6 \%$ & & $7.4 \%$ \\
\hline Metal & g & g & $\mu \mathrm{g} / \mathrm{mL}$ & g & $\mu g / g$ \\
\hline Al & $4.5 \mathrm{E}+01$ & 4.3E-01 & $2.6 \mathrm{E}+02$ & $4.4 \mathrm{E}+01$ & $3.3 \mathrm{E}+05$ \\
\hline $\mathbf{B}$ & $0.0 \mathrm{E}+00$ & $<1$.E-2 & $<9 . \mathrm{E}+0$ & $0.0 \mathrm{E}+00$ & $0.0 \mathrm{E}+00$ \\
\hline Cd & 8.8E-03 & $<0 . \mathrm{E}+0$ & $<0 . \mathrm{E}+0$ & $8.8 \mathrm{E}-03$ & $6.6 \mathrm{E}+01$ \\
\hline $\mathrm{Cr}$ & $6.4 \mathrm{E}+00$ & 2.9E-02 & $1.8 \mathrm{E}+01$ & $6.4 \mathrm{E}+00$ & $4.8 \mathrm{E}+04$ \\
\hline $\mathbf{F e}$ & $2.5 \mathrm{E}+00$ & $<2$.E-2 & $<1 . \mathrm{E}+1$ & $2.5 \mathrm{E}+00$ & $1.9 \mathrm{E}+04$ \\
\hline Mn & $1.3 \mathrm{E}+00$ & $<2$.E-3 & $<1 . \mathrm{E}+0$ & $1.3 \mathrm{E}+00$ & $9.8 \mathrm{E}+03$ \\
\hline $\mathrm{Na}$ & $4.1 \mathrm{E}+01$ & $9.4 \mathrm{E}+00$ & $5.7 \mathrm{E}+03$ & $3.2 \mathrm{E}+01$ & $2.4 \mathrm{E}+05$ \\
\hline $\mathbf{P}$ & 4.3E-01 & 8.9E-02 & $5.4 \mathrm{E}+01$ & 3.4E-01 & $2.6 \mathrm{E}+03$ \\
\hline $\mathrm{S}$ & 6.6E-01 & $<3$. E-1 & $<2 . \mathrm{E}+2$ & 6.6E-01 & $5.0 \mathrm{E}+03$ \\
\hline Si & $3.5 \mathrm{E}+00$ & $6.4 \mathrm{E}-03$ & $3.9 \mathrm{E}+00$ & $3.5 \mathrm{E}+00$ & $2.6 \mathrm{E}+04$ \\
\hline $\mathbf{U}$ & $4.0 \mathrm{E}+00$ & $<7$. E-2 & $<4 . \mathrm{E}+1$ & $4.0 \mathrm{E}+00$ & $3.0 \mathrm{E}+04$ \\
\hline \multirow{2}{*}{$\begin{array}{l}\text { Radiochemical } \\
\text { Isotopes }\end{array}$} & Slurry & \multicolumn{2}{|c|}{ Liquid Fraction } & \multicolumn{2}{|c|}{ Solid Fraction } \\
\hline & $\mu \mathrm{Ci}$ & $\mu \mathrm{Ci}$ & $\mu \mathrm{Ci} / \mathrm{mL}$ & $\mu \mathrm{Ci}$ & $\mu \mathrm{Ci} / \mathrm{g}$ \\
\hline Co-60 & $8.7 \mathrm{E}+00$ & $<2$.E-1 & $<1$.E-4 & $8.7 \mathrm{E}+00$ & 6.5E-02 \\
\hline Cs-137 & $3.1 \mathrm{E}+04$ & $5.5 \mathrm{E}+04$ & $3.3 \mathrm{E}+01$ & $-2.4 \mathrm{E}+04$ & $-1.8 \mathrm{E}+02$ \\
\hline Eu-154 & $1.3 \mathrm{E}+02$ & $<6 . \mathrm{E}-1$ & $<4$.E-4 & $1.3 \mathrm{E}+02$ & 9.7E-01 \\
\hline Eu-155 & $5.5 \mathrm{E}+01$ & $<1 . \mathrm{E}+1$ & $<6 . \mathrm{E}-3$ & $5.5 \mathrm{E}+01$ & 4.2E-01 \\
\hline Am-241 & $3.8 \mathrm{E}+02$ & $<9 . \mathrm{E}+0$ & $<6$.E-3 & $3.8 \mathrm{E}+02$ & $2.9 \mathrm{E}+00$ \\
\hline Gross Alpha & $6.4 \mathrm{E}+02$ & $<6 . \mathrm{E}+0$ & $<3$. E-3 & $6.4 \mathrm{E}+02$ & $4.8 \mathrm{E}+00$ \\
\hline Gross Beta & $3.4 \mathrm{E}+05$ & $5.8 \mathrm{E}+04$ & $3.5 \mathrm{E}+01$ & $2.8 \mathrm{E}+05$ & $2.1 \mathrm{E}+03$ \\
\hline Sr-90 & $1.4 \mathrm{E}+05$ & $4.2 \mathrm{E}+01$ & $2.5 \mathrm{E}-02$ & $1.4 \mathrm{E}+05$ & $1.1 \mathrm{E}+03$ \\
\hline $\mathrm{Pu}-239+240$ & $2.3 \mathrm{E}+02$ & $3.9 \mathrm{E}-02$ & $2.4 \mathrm{E}-05$ & $2.3 \mathrm{E}+02$ & $1.7 \mathrm{E}+00$ \\
\hline Pu-238 & $1.8 \mathrm{E}+01$ & 8.3E-03 & $5.1 \mathrm{E}-06$ & $1.8 \mathrm{E}+01$ & 1.4E-01 \\
\hline \multirow[t]{2}{*}{ Anions } & \multicolumn{3}{|c|}{ Liquid Fraction } & \multicolumn{2}{|c|}{ Leached Solids Fraction } \\
\hline & $\mu \mathrm{g} / \mathrm{mL}$ & [M] & g & $\mu g / g$ & g \\
\hline $\mathbf{F}$ & $5.4 \mathrm{E}+00$ & 2.8E-04 & 8.9E-03 & $8.9 \mathrm{E}+00$ & $1.2 \mathrm{E}+00$ \\
\hline $\mathrm{C}_{2} \mathrm{O}_{4}$ & $5.4 \mathrm{E}+02$ & $6.1 \mathrm{E}-03$ & 8.9E-01 & $6.2 \mathrm{E}+02$ & $8.2 \mathrm{E}+01$ \\
\hline $\mathrm{NO}_{2}$ & $2.9 \mathrm{E}+02$ & 6.2E-03 & 4.7E-01 & $4.7 \mathrm{E}+02$ & $6.2 \mathrm{E}+01$ \\
\hline $\mathrm{NO}_{3}$ & $9.8 \mathrm{E}+02$ & $1.6 \mathrm{E}-02$ & $1.6 \mathrm{E}+00$ & $1.9 \mathrm{E}+03$ & $2.6 \mathrm{E}+02$ \\
\hline $\mathrm{SO}_{4}$ & $5.5 \mathrm{E}+01$ & 5.7E-04 & $9.0 \mathrm{E}-02$ & $8.1 \mathrm{E}+01$ & $1.1 \mathrm{E}+01$ \\
\hline $\mathrm{PO}_{4}$ & $1.8 \mathrm{E}+02$ & $1.9 \mathrm{E}-03$ & 3.0E-01 & $1.2 \mathrm{E}+02$ & $1.5 \mathrm{E}+01$ \\
\hline $\mathbf{O H}$ & $2.9 \mathrm{E}+03$ & 1.7E-01 & $4.9 \mathrm{E}+00$ & & \\
\hline $\begin{array}{lr}\text { (a) } & \text { Slurry compon } \\
& \text { simulant comp } \\
& \text { sampling was } \\
\text { (b) } & \text { Liquid Fractic } \\
& \text { TI552-G6-J (A } \\
\text { (c) } & \text { Solids Fraction } \\
& \text { component ma } \\
\end{array}$ & $\begin{array}{l}\text { masses were } \\
\text { nt masses, an } \\
\text { uded. } \\
\text { ass compone } \\
\text { ID 08-0022 } \\
\text { ass componen } \\
\text { ind liquid com }\end{array}$ & $\begin{array}{l}\text { ulated from cl } \\
\text { noved supern } \\
\text { vere calculate } \\
\text { and the predic } \\
\text { ere calculated } \\
\text { ent mass fract }\end{array}$ & $\begin{array}{l}\text { erization di } \\
\text { component } \\
\text { g analytica } \\
\text { ass of supe } \\
\text { the differe }\end{array}$ & $\begin{array}{l}\text { ta (WPT-RPT-15 } \\
\text { masses. Mass los } \\
\text { results from sup } \\
\text { nate in the systen } \\
\text { ce between the s. }\end{array}$ & $\begin{array}{l}\text { Ided } \\
\text { m sample }\end{array}$ \\
\hline
\end{tabular}


Table 4.27. Group 6/5 Washed Leach Slurry Composition and Caustic Leach Factor Calculations Based on ICP-OES/Radiochemical Characterization

\begin{tabular}{|c|c|c|c|c|c|}
\hline "Slurry Prep Method & $\begin{array}{l}\text { ICP-OES } \\
\text { Analytes }\end{array}$ & $\begin{array}{c}\text { Dry Slurry }^{(a)} \\
(\mu \mathrm{g} / \mathrm{g})\end{array}$ & $\begin{array}{c}\text { Supernate } e^{(b)} \\
(\mu \mathrm{g} / \mathrm{mL})\end{array}$ & $\begin{array}{c}\text { Dry Solids }{ }^{(\mathrm{c})} \\
(\mu \mathrm{g} / \mathrm{g})\end{array}$ & $\begin{array}{c}\text { Solids } \\
\text { Leach } \\
\text { Factor }^{(d)}\end{array}$ \\
\hline \multirow{25}{*}{$\begin{array}{c}\text { KOH Fusion } \\
\text { Concentration Factor } \\
\text { of } \\
\begin{array}{c}1.94 \text { based on } \mathrm{U}, \mathrm{Si} \\
\text { and } \mathrm{Fe}\end{array}\end{array}$} & Al & 278,000 & 262 & 312,730 & 0.40 \\
\hline & $\mathbf{B}$ & $<8.8 \mathrm{E}+1$ & $<1.8 \mathrm{E}+0$ & $<8.7 \mathrm{E}+1$ & [0.88] \\
\hline & $\mathbf{B i}$ & [350] & {$[2.6]$} & [378] & NA \\
\hline & Cd & [60] & $<2.4 \mathrm{E}-1$ & {$[66]$} & $-[0.98]$ \\
\hline & $\mathrm{Cr}$ & 38,000 & 17.8 & 42,868 & [0.09] \\
\hline & $\mathbf{F e}$ & 15,800 & $<2.1 \mathrm{E}+0$ & 17,860 & NA \\
\hline & Mn & 7,360 & $<2.1 \mathrm{E}-1$ & 8,325 & 0.07 \\
\hline & $\mathrm{Na}$ & {$[69,000]$} & 5,720 & {$[39,625]$} & 0.52 \\
\hline & $\overline{\mathbf{P}}$ & [980] & {$[54]$} & [746] & 0.63 \\
\hline & $\mathrm{S}$ & [990] & $<3.3 \mathrm{E}+1$ & [898] & {$[0.23]$} \\
\hline & Si & 19,900 & [3.9] & 22,486 & NA \\
\hline & Sr & 1,360 & $<1.7 \mathrm{E}-2$ & 1,538 & 0.02 \\
\hline & $\mathbf{U}$ & 27,100 & $<8.5 \mathrm{E}+0$ & 30,600 & NA \\
\hline & $\mathbf{Z n}$ & [150] & [0.59] & {$[166]$} & {$[0.67]$} \\
\hline & $\mathbf{Z r}$ & [210] & $<8.2 \mathrm{E}-1$ & [232] & $\mathrm{NA}$ \\
\hline & $B a$ & [160] & $<3.4 \mathrm{E}-1$ & [179] & {$[0.10]$} \\
\hline & Ca & {$[3,900]$} & {$[3.3]$} & {$[4,390]$} & NA \\
\hline & $\mathrm{Cu}$ & [150] & $<4.9 \mathrm{E}-1$ & {$[166]$} & {$[0.47]$} \\
\hline & $L a$ & [100] & $<1.3 \mathrm{E}-1$ & [112] & {$[0.16]$} \\
\hline & $L i$ & [47] & $<5.5 \mathrm{E}-1$ & [49] & {$[0.66]$} \\
\hline & $M g$ & [510] & $<7.1 \mathrm{E}-1$ & [572] & {$[0.66]$} \\
\hline & Mo & [53] & {$[0.83]$} & [54] & $-[5.90]$ \\
\hline & $P b$ & [410] & $<3.7 \mathrm{E}+0$ & [439] & {$[0.17]$} \\
\hline & Ti & [97] & $<9.8 \mathrm{E}-2$ & [109] & {$[0.28]$} \\
\hline & $Y$ & [35] & $<8.6 \mathrm{E}-2$ & [39] & NA \\
\hline Slurry Prep Method & $\begin{array}{c}\text { ICP-OES } \\
\text { Analytes }\end{array}$ & $\begin{array}{c}\text { Dry Slurry (a) } \\
(\mu \mathrm{g} / \mathrm{g})\end{array}$ & $\begin{array}{c}\text { Supernate }^{(b)} \\
(\mu \mathrm{g} / \mathrm{mL})\end{array}$ & $\begin{array}{c}\text { Dry Solids }{ }^{(\mathrm{c})} \\
(\mu \mathrm{g} / \mathrm{g})\end{array}$ & $\begin{array}{c}\text { Solids } \\
\text { Leach } \\
\text { Factor }^{(d)}\end{array}$ \\
\hline & $\mathbf{K}$ & $<1.6 \mathrm{E}+1$ & $<1.2 \mathrm{E}+1$ & $-<6.5 \mathrm{E}+1$ & NA \\
\hline Con. Factor 0.45 & $\mathbf{N i}$ & 186 & $<5.9 \mathrm{E}-1$ & 206 & -0.08 \\
\hline
\end{tabular}


Table 4.27 (Contd)

\begin{tabular}{|c|c|c|c|c|c|}
\hline Slurry Prep Method & Radionuclides & $\begin{array}{c}\text { Dry Slurry }^{(a)} \\
(\mu \mathrm{Ci} / g)\end{array}$ & $\begin{array}{c}\text { Supernate }^{(b)} \\
(\mu \mathrm{Ci} / \mathrm{mL})\end{array}$ & $\begin{array}{c}\text { Dry Solids }^{(c)} \\
(\mu \mathrm{Ci} / \mathrm{g})\end{array}$ & $\begin{array}{c}\text { Solids } \\
\text { Leach }^{(d)} \\
\text { Factor }^{(d)}\end{array}$ \\
\hline \multirow{12}{*}{$\begin{array}{c}\text { KOH Fusion } \\
\text { Concentration } \\
\text { Factor } \\
\text { Of } 1.94 \begin{array}{l}\text { based on U, Si } \\
\text { and Fe }\end{array}\end{array}$} & Co-60 & $4.19 \mathrm{E}-2$ & $<7 . \mathrm{E}-5$ & $4.7 \mathrm{E}-2$ & 0.85 \\
\hline & Cs-137 & $8.42 \mathrm{E}+1$ & $6.78 \mathrm{E}-1$ & $9.1 \mathrm{E}+1$ & -1.80 \\
\hline & Eu-154 & $6.42 \mathrm{E}-1$ & $<2$.E-4 & $7.2 \mathrm{E}-1$ & 0.17 \\
\hline & Eu-155 & $<1 . \mathrm{E}-1$ & $<6 . \mathrm{E}-4$ & $<1 . \mathrm{E}-1$ & 0.35 \\
\hline & Am-241 & $2.12 \mathrm{E}+0$ & $<3 . \mathrm{E}-4$ & $2.4 \mathrm{E}+0$ & 0.06 \\
\hline & Total alpha & $3.68 \mathrm{E}+0$ & $<3 . \mathrm{E}-4$ & $4.2 \mathrm{E}+0$ & 0.05 \\
\hline & Total beta & $1.94 \mathrm{E}+3$ & $6.36 \mathrm{E}-1$ & $2.2 \mathrm{E}+3$ & -0.02 \\
\hline & Sr-90 & $8.71 \mathrm{E}+2$ & $8.78 \mathrm{E}-4$ & $9.8 \mathrm{E}+2$ & 0.00 \\
\hline & Pu-239/240 & $1.31 \mathrm{E}+0$ & $1.93 \mathrm{E}-6$ & $1.5 \mathrm{E}+0$ & 0.07 \\
\hline & Pu-238 & 7.70E-2 & $<8 . \mathrm{E}-7$ & 8.7E-2 & 0.29 \\
\hline & KPA & $(\mu \mathrm{g} / \mathrm{g})$ & $(\mu \mathrm{g} / \mathrm{mL})$ & $(\mu \mathrm{g} / \mathrm{g})$ & \\
\hline & $\mathbf{U}$ & $2.63 \mathrm{E}+4$ & $7.52 \mathrm{E}-1$ & $3.0 \mathrm{E}+4$ & -0.09 \\
\hline $\begin{array}{l}\text { (a) Test sample TI552-C } \\
\text { (b) Test sample TI552-C } \\
\text { (c) Calculated using res } \\
\text { (d) Calculated using res } \\
\text { Note: Analytes in italics } \\
\text { with errors likely to exce }\end{array}$ & $\begin{array}{l}\text { 6-J, ASO ID 08-( } \\
6-17, \text { ASO ID } 08 \\
\text { lts from TI552-G } \\
\text { lts listed in Table } \\
\text { were measured of } \\
\text { d } 15 \% \text {. }\end{array}$ & $\begin{array}{l}0221 \\
00244 \\
5-J \text { and TI552-G } \\
4.10 \\
\text { portunistically. }\end{array}$ & 6-17 alues in bracke & [ ] are $\geq \mathrm{MDL}$ & t $<$ EQL \\
\hline
\end{tabular}

Particle size measurements were performed on the washed caustic leach slurry sample to track changes in the distribution due to processing the slurry. The measured cumulative undersize percentiles appear to vary with analyzer pump speed (Figure 4.43). At 3,000 RPM, the distribution is relatively unimodal, with a population maximum at $1 \mu \mathrm{m}$ and with a span of $\sim 0.2$ to $30 \mu \mathrm{m}$. A second small population of particles is centered around $100 \mu \mathrm{m}$ and could correspond to large particle flocculates or may simply be an artifact of the fitting analysis. Subsequent increases and decreases in the pump speed do not appear to strongly influence the distribution of particles over 0.2 to $10 \mu \mathrm{m}$. In contrast, an increase to 4,000 RPM yields a strong peak spanning 10 to $100 \mu \mathrm{m}$ and with a maximum between 40 and $50 \mu \mathrm{m}$. This peak (and the small population centered at $100 \mu \mathrm{m}$ ) disappears as the pump speed is lowered to 2,000 RPM. Both observations indicate, as with previous Group 6/5 samples, a difficult to suspend particle structure in the greater than $10-\mu \mathrm{m}$ size range.

Figure 4.44 shows the PSD for the leached, dewatered, and washed slurry before, during, and after sonication. Although sonication appears to eliminate the secondary peak centered at $100 \mu \mathrm{m}$, it does not appear to change the primary range of particle sizes observed at 3,000 RPM. The majority of particles still fall between 0.2 and $20 \mu \mathrm{m}$ before, during, and after sonication. On the other hand, sonication does appear to introduce a bimodal nature to the PSD. Before sonication, the distribution is relatively unimodal with a maximum at $1 \mu \mathrm{m}$. During and after sonication, the maximum shifts up to $2 \mu \mathrm{m}$, and the original maximum at $1 \mu \mathrm{m}$ is replaced by a shoulder. The changes observed upon sonication are likely a result of breakdown of aggregates not suspended at 3,000 RPM. These aggregates contribute to the 1- to $10-\mu \mathrm{m}$ particle population, shifting the overall maximum to $2 \mu \mathrm{m}$. Because during and after sonication distributions are similar, it can be inferred that changes to the PSD as a result of sonication are irreversible. 
WTP-RPT-172, Rev 0

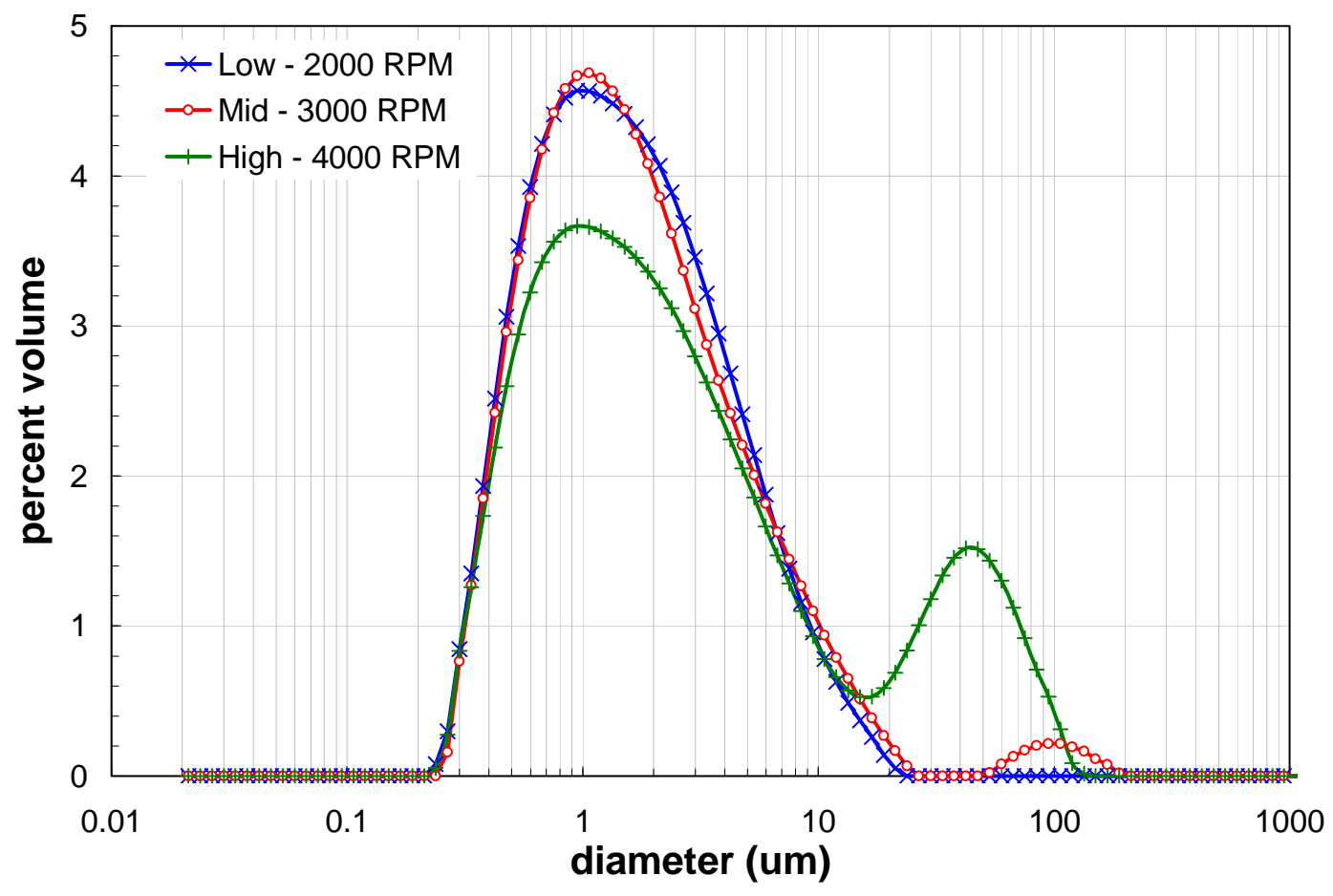

Figure 4.43. Measured PSD for Caustically Leached, Dewatered, and Washed Slurry as a Function of Pump Speed

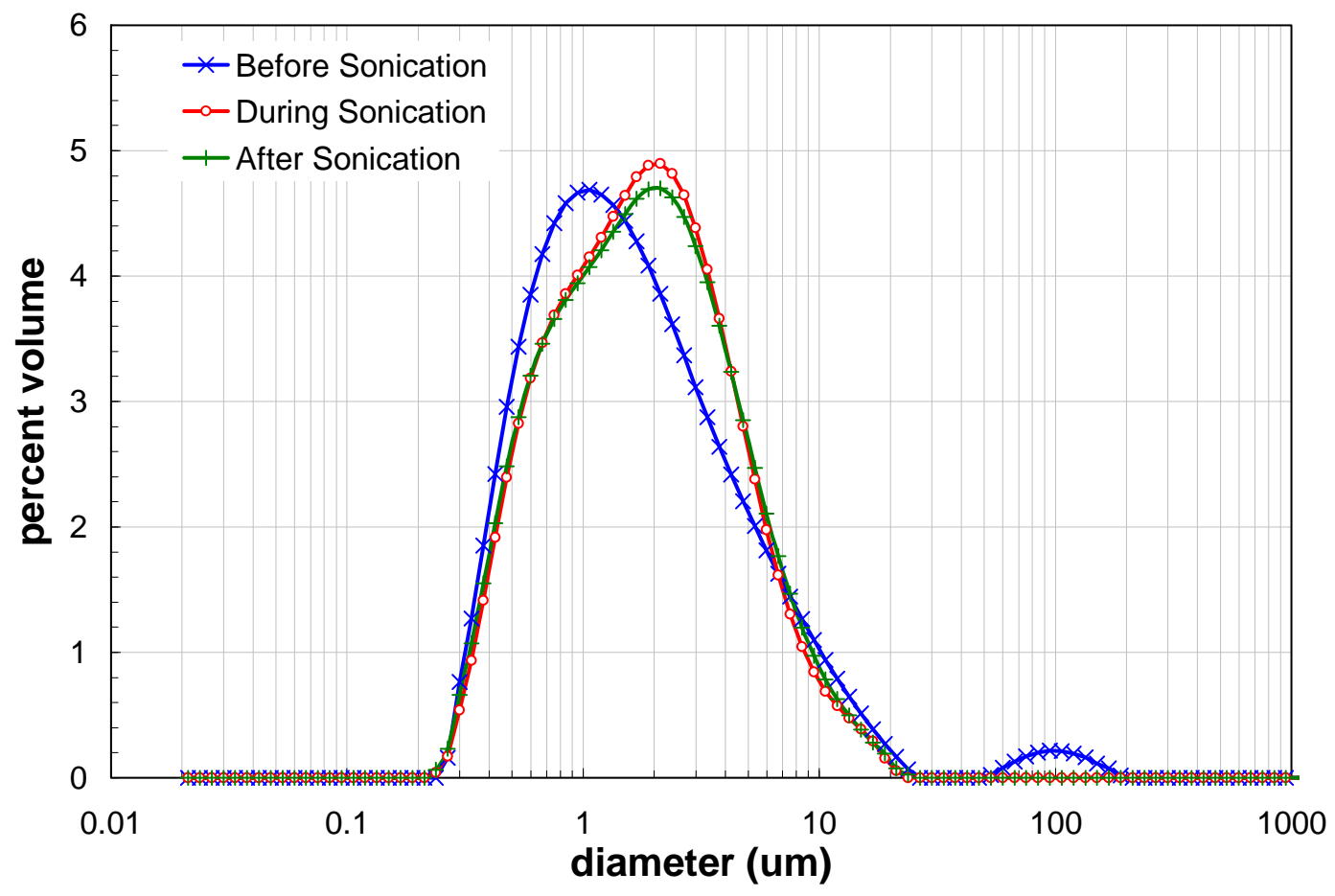

Figure 4.44. Measured PSD for Caustically Leached, Dewatered, and Washed Slurry as a Function of Sonication 
Rheology measurements were performed on a sub-sample of the slurry prior to oxidative leaching. Flow curves for the caustic leached and washed slurry (Figure 4.45) show non-Newtonian behavior at all temperatures and are consistent with the pre-caustic leach high-solids matrix slurry. The current flow curves exhibit finite yield points and are shear-thinning over most of the shear rate range tested. Flowcurve hysteresis is absent in the $25^{\circ} \mathrm{C}$ measurement but is clearly evident in the $40^{\circ} \mathrm{C}$ and $60^{\circ} \mathrm{C}$ measurements. The degree of hysteresis increases with temperature, as the difference between stress observed in the up and down-ramp is much larger in the $60^{\circ} \mathrm{C}$ measurement $(\sim 3$ to $5 \mathrm{~Pa}$ ) relative to the $40^{\circ} \mathrm{C}$ ( $\sim 1$ to $2 \mathrm{~Pa}$ ) measurement. In all cases, the down-ramp shows the higher stress response, indicating an increase in the slurry apparent viscosity with time. Changes in flow-curve behavior as sample temperature is increased from $25^{\circ}$ to $60^{\circ} \mathrm{C}$ are difficult to characterize as they appear to show competing effects that tend to increase and lower apparent viscosity (Table 4.28). Overall, an increase in the viscous stress response is observed with increasing temperature; however, this increase is associated entirely with flow-curve hysteresis.

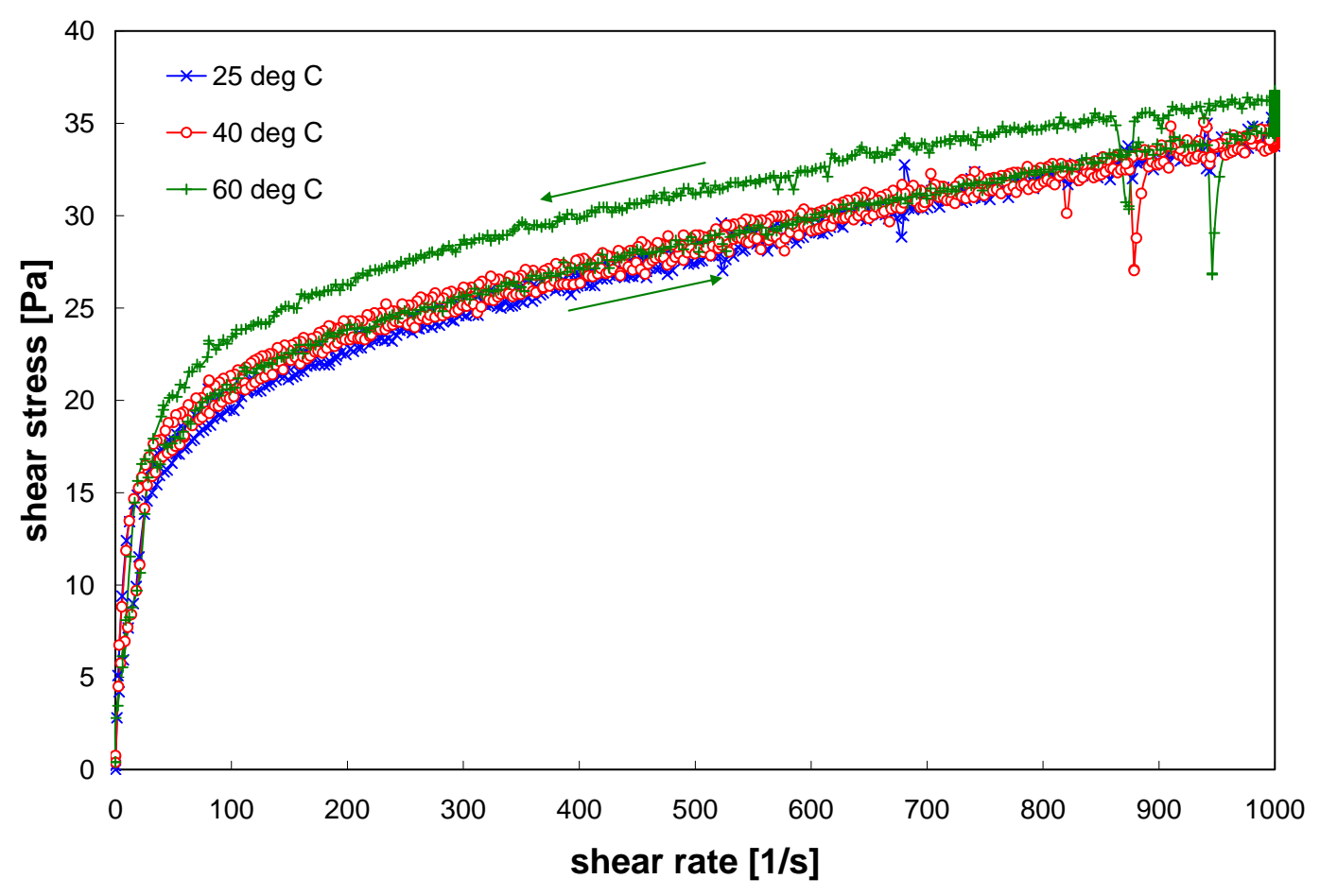

Figure 4.45. Flow Curves for Group 6/5 Washed Caustic Leached,Slurry

Table 4.28. Results of Fitting Analysis for Washed Caustic Leached Slurry

\begin{tabular}{||c|c|c|c|c|c||}
\hline Model & $\begin{array}{c}\text { Temperature } \\
{\left[{ }^{\circ} \mathbf{C}\right]}\end{array}$ & $\begin{array}{c}\text { Yield } \\
\text { Stress [Pa] }\end{array}$ & $\begin{array}{c}\text { Consistency } \\
{\left[\mathbf{P a} \mathbf{~ s}^{\mathbf{n}}\right]}\end{array}$ & $\begin{array}{c}\text { Flow } \\
\text { Index }\end{array}$ & $\mathbf{R}$ \\
\hline \multirow{3}{*}{$\begin{array}{c}\text { Bingham-Plastic } \\
\left(200-1000 \mathrm{~s}^{-1}\right)\end{array}$} & $25(1$ of 2$)$ & 18 & 0.016 & $\mathrm{n} / \mathrm{a}$ & 0.974 \\
\cline { 2 - 6 } & $25(2$ of 2$)$ & 21 & 0.013 & $\mathrm{n} / \mathrm{a}$ & 0.993 \\
\cline { 2 - 6 } & 40 & 22 & 0.012 & $\mathrm{n} / \mathrm{a}$ & 0.985 \\
\cline { 2 - 6 } & 60 & 24 & 0.012 & $\mathrm{n} / \mathrm{a}$ & 0.932 \\
\hline \multirow{3}{*}{$\begin{array}{c}\text { Herschel-Bulkley } \\
\left(0-1000 \mathrm{~s}^{-1}\right)\end{array}$} & $25(1$ of 2$)$ & 5.9 & 1.7 & 0.40 & 0.986 \\
\cline { 2 - 6 } & $25(2$ of 2$)$ & 1.0 & 5.5 & 0.26 & 0.992 \\
\cline { 2 - 6 } & 40 & -2.1 & 8.3 & 0.21 & 0.989 \\
\cline { 2 - 6 } & 60 & -11 & 15 & 0.16 & 0.971 \\
\hline
\end{tabular}




\subsection{Oxidative Leaching/Washing}

After completing the filtration and rheological testing of the washed caustic leached slurry, the slurry was drained from the system and prepared for the oxidative leach. The slurry loop was rinsed using slurry supernate drained from the CUF permeate loop as well some of the filter permeate collected from the sixth wash after caustic leaching. After the slurry and filter supernate additions were recovered from the system, the slurry reservoir was isolated, filter supernate used to wash the CUF were placed into the reservoir for oxidative leaching, as outlined in the right column (colored green) of Figure 4.1. The activities involved in this process were:

- Batch oxidative leaching of the slurry for removing chromium from UDS in the slurry at ambient temperature using sodium permanganate as the reactant.

- Batch washing of the oxidative leached slurry and dewatering of the diluted supernate afterwards. Three total wash solutions $(0.01 \mathrm{M} \mathrm{NaOH})$ were added to the slurry to remove dissolved chromium from the slurry.

\subsubsection{Batching Leach Results}

After sampling of the washed caustic leach slurry was completed, the slurry was drained from the CUF to prepare the CUF for the oxidative leach (Figure 4.46). After draining the slurry, the permeate hold-up and $\sim 300 \mathrm{~mL}$ of filter permeate from the last wash was used to rinse the inside of the CUF slurry loop to remove solids left in the piping. The slurry reservoir tank was then isolated from the slurry loop. The recovered slurry and permeate was placed into the slurry reservoir tank. An estimated $0.06 \mathrm{~kg}$ of material was lost during transfers. After sampling and transfer losses, the estimated UDS remaining in the CUF was now $\sim 130$ grams. 


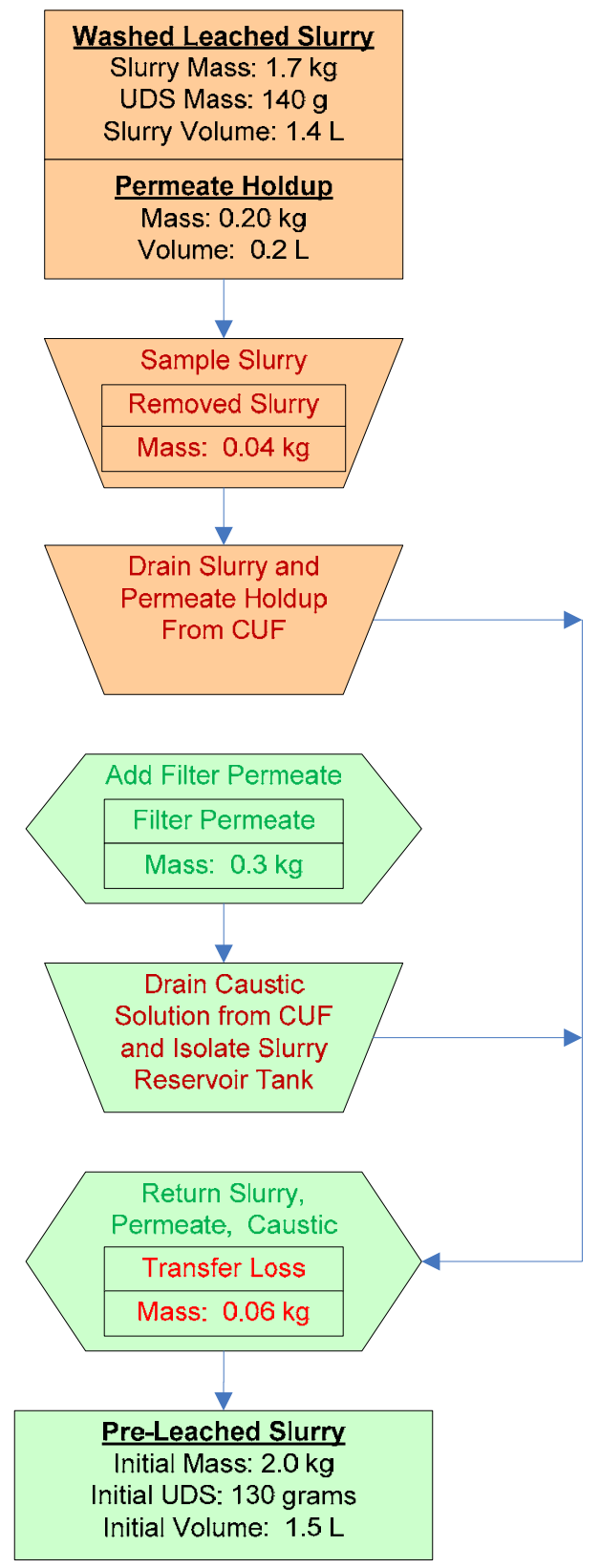

Figure 4.46. Group 6/5 Preparation for the Oxidative Leach

Note: Mass and volume values in figure are rounded to the nearest significant digit of accuracy.

Once the slurry and rinses were placed into the slurry reservoir, a solution of 1-M sodium permanganate $\left(\mathrm{NaMnO}_{4}\right)$ was added and allowed to react with the slurry for 6 hours (Figure 4.47). The slurry was subsampled throughout the leach to perform chemical analysis on the supernate for kinetics. The test scheme called for $173 \mathrm{~mL}$ of 1-M sodium permanganate for the leach to occur at a Mn:Cr ratio of 1:1. However, a $200 \mathrm{~mL}$ solution was sent into the hot cell which was assumed to be $173 \mathrm{~mL}$ solution. This miscommunication led to the entire solution to be added. Also, the quantity of chromium was much less than predicted at this point due to losses in the system from transfers and sampling, shifting the $\mathrm{Mn}: \mathrm{Cr}$ ratio even higher. The final mole ratio of manganese to chromium was estimated to be at 1.7. The 
measured free hydroxide of the slurry prior to the sodium permanganate solution was found to be $0.17 \mathrm{M}$, decreasing to $0.09 \mathrm{M}$ after the sodium permanganate solution was added.

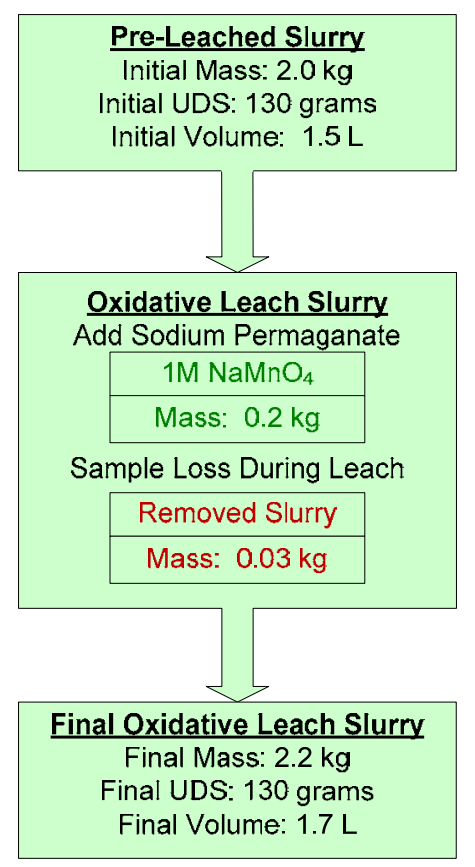

Figure 4.47. Group 6/5 Oxidative Leach

Note: Mass and volume values in figure are rounded to the nearest significant digit of accuracy.

Up to the point of this addition, 19\% of the insoluble chromium had been solubilized. During caustic leaching and washing, the soluble portion had largely been washed out, and of the remaining chromium in the slurry, 99.7\% was present in the insoluble solids. Based on samples taken during the oxidative leach, after sodium permanganate was added, the solid chromium leached rapidly into the solution. By the end of the 6-hour leach, over $90 \%$ of the chromium had leached into solution. Analysis of the supernate showed that 0.09 moles of the 0.2 moles of permanganate was converted to solids compared to the estimated 0.12 moles of chromium released into solution (Figure 4.48). Comparison of the supernate concentrations of Pu before and after oxidative leach showed a measureable increase (Figure 4.49). However, the concentration was still lower that the initial concentration of the pre-leach slurry. 
Chrominum/Maganese Conversion During Group 6/5 Oxidative Leach

(Molar Ratio of $\mathrm{NaMnO}_{4}$ Additon to $\mathrm{Cr}$ in Solids 1.7)

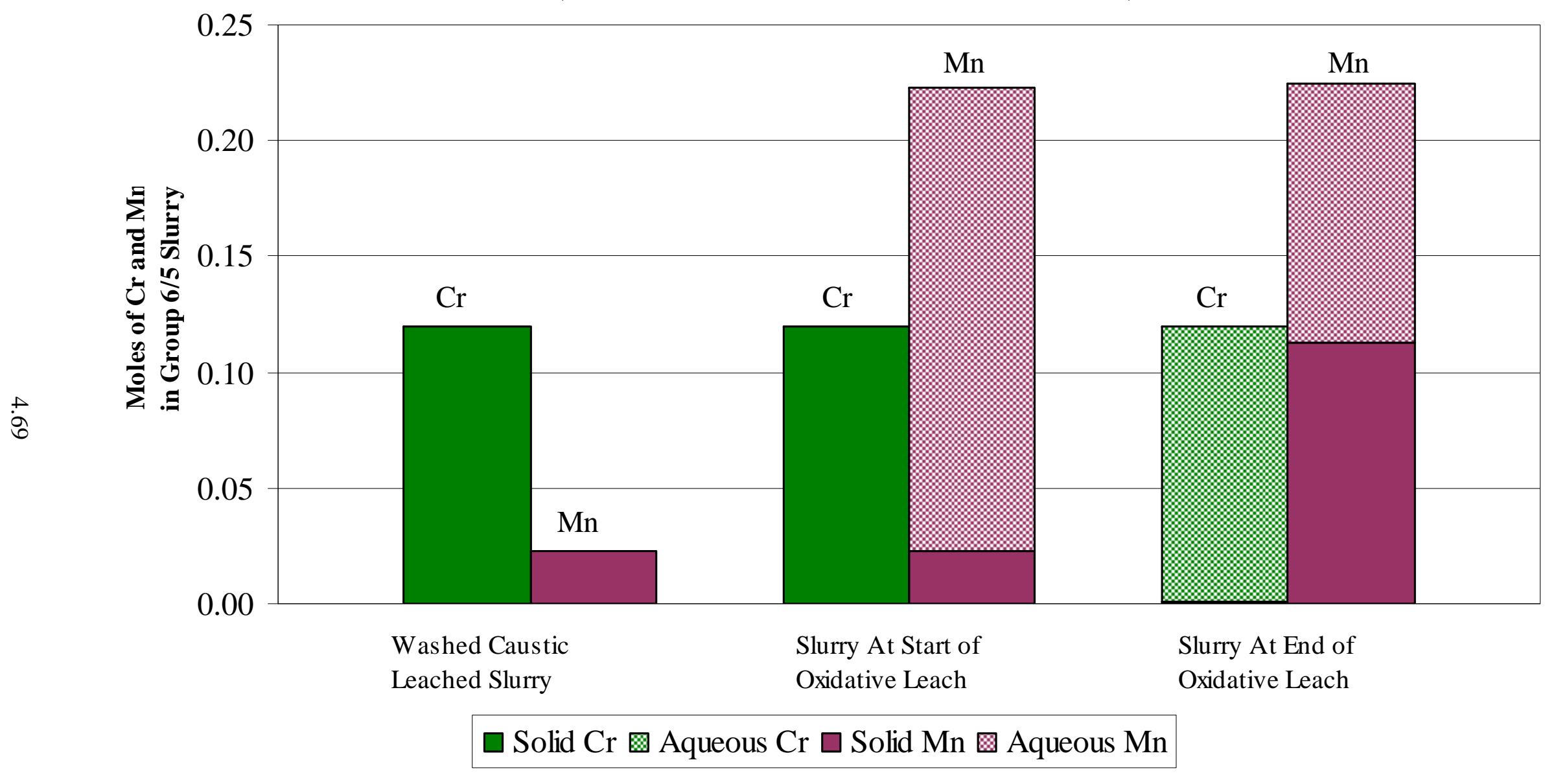

Figure 4.48. Group 6/5 Conversion of $\mathrm{Cr} / \mathrm{Mn}$ from Oxidative Leach 
WTP-RPT-172, Rev 0

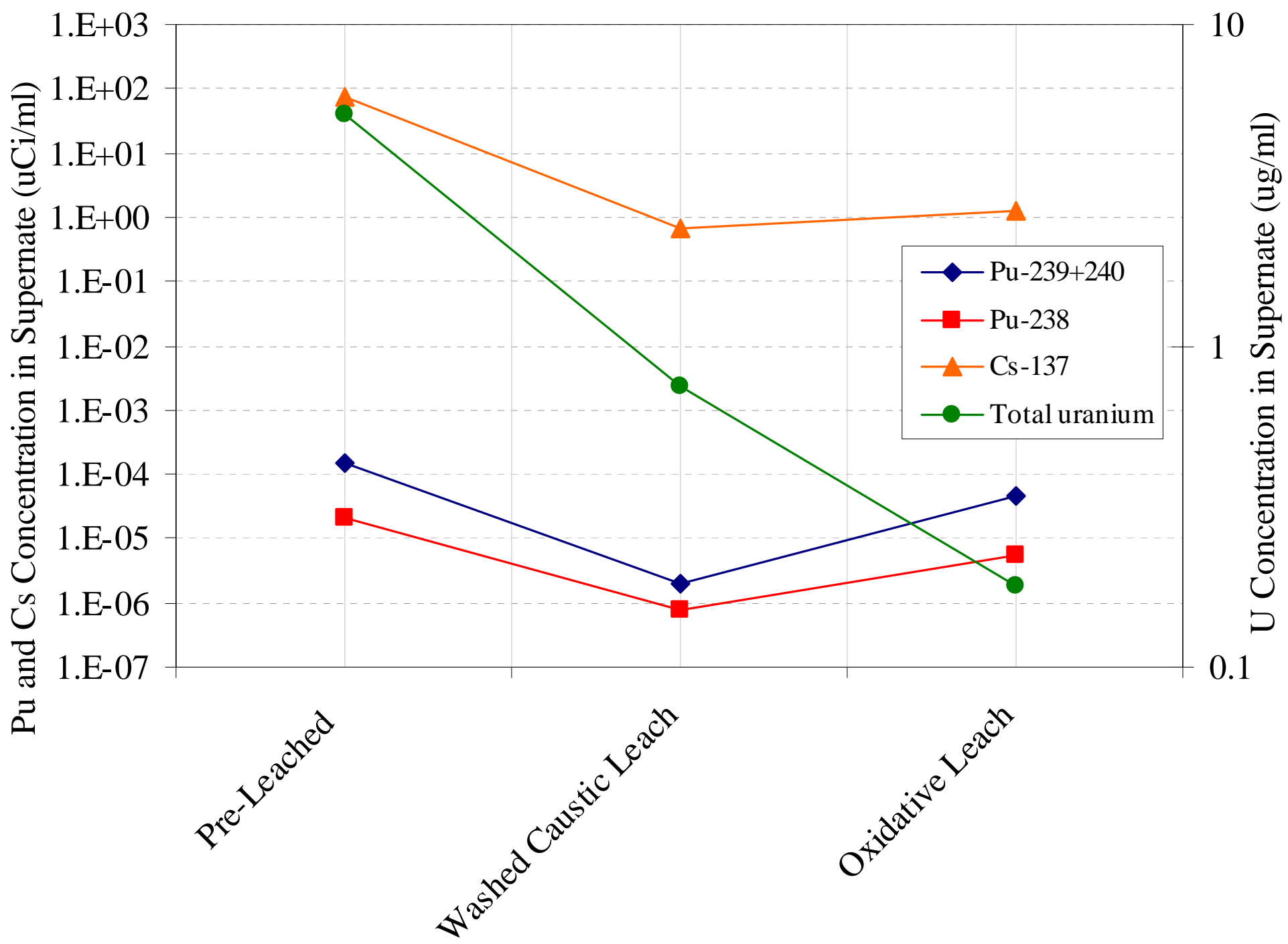

Figure 4.49. Group 6/5 Slurry Supernate Concentrations of Cs, Pu, and U Before and After Oxidative Leach 


\subsubsection{Characterization of Oxidative Leached Slurry}

At the end of the oxidative leach, the leached slurry was sampled for physical characterization of the slurry. Physical property measurements of the slurry sample are provided in Table 4.29 and chemical composition in Table 4.30. Measurement of the UDS concentration was closer to predicted values in the slurry $(0.13 \mathrm{~kg} / 2.2 \mathrm{~kg} \cong 6 \mathrm{wt} \%)$, indicating that perhaps slurry sampling was an issue in previous measurements.

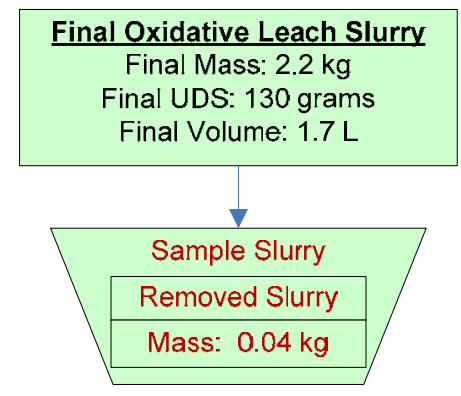

Figure 4.50. Group 6/5 Sampling of Oxidative Leach Slurry Note: Mass and volume values in figure are rounded to the nearest significant digit of accuracy.

Table 4.29. Group 6/5 Physical property Measurements of the Oxidative Leached Slurry

\begin{tabular}{|r|c||}
\hline Slurry Density $(\mathbf{g} / \mathbf{m L})$ & 1.0 \\
\hline Supernate Density $\mathbf{( g / m L})$ & 1.0 \\
\hline Settled Solids (Vol\%) & $92 \%$ \\
\hline Centrifuged UDS (Wt $\%)$ & $25 \%$ \\
\hline Total Solids of the Slurry $(\mathbf{W t} \%)$ & $8.7 \%$ \\
\hline Dissolved Solids of the Supernate $\mathbf{( W t} \%)$ & $2.8 \%$ \\
\hline UDS of the Slurry $\mathbf{( W t} \%)$ & $6.0 \%$ \\
\hline
\end{tabular}


Table 4.30. Group 6/5 Oxidative Leached Slurry Composition and Caustic/Oxidative Leach Factor Calculations Based on ICP-OES/Radiochemical Characterization

\begin{tabular}{|c|c|c|c|c|c|}
\hline Slurry Prep Method & $\begin{array}{c}\text { ICP-OES } \\
\text { Analytes }\end{array}$ & $\begin{array}{c}\text { Dry Slurry }^{(a)} \\
(\mu \mathrm{g} / \mathrm{g})\end{array}$ & $\begin{array}{c}\text { Supernate }^{(b)} \\
(\mu \mathrm{g} / \mathrm{mL})\end{array}$ & $\begin{array}{c}\text { Dry Solids } \\
(\mu \mathrm{g} / \mathrm{g})\end{array}$ & $\begin{array}{c}\text { Solids Leach } \\
\text { Factor }^{(d)}\end{array}$ \\
\hline \multirow{25}{*}{$\begin{array}{c}\text { KOH Fusion } \\
\text { Concentration Factor of } \\
1.88 \text { based on U, Si and } \\
\text { Fe }\end{array}$} & Al & 221,000 & 357 & 313,365 & 0.37 \\
\hline & B & $<7.0 \mathrm{E}+1$ & $<3.6 \mathrm{E}+0$ & $<4.2 \mathrm{E}+1$ & NA \\
\hline & $\mathbf{B i}$ & [290] & $<4.6 \mathrm{E}+0$ & [345] & {$[0.48]$} \\
\hline & Cd & [45] & $<4.8 \mathrm{E}-1$ & [57] & $-[0.77]$ \\
\hline & $\mathrm{Cr}$ & 31,300 & 3,520 & $-12,009$ & 1.26 \\
\hline & Fe & 11,700 & $<4.1 \mathrm{E}+0$ & 16,831 & NA \\
\hline & Mn & 63,800 & 3,250 & 39,316 & -3.54 \\
\hline & $\mathrm{Na}$ & 107,000 & 8,680 & 13,448 & [0.83] \\
\hline & $\mathbf{P}$ & [820] & [64] & [144] & [0.93] \\
\hline & $\mathrm{S}$ & [670] & $<6.5 \mathrm{E}+1$ & $-[93]$ & [1.08] \\
\hline & Si & 15,100 & $<2.3 \mathrm{E}+0$ & 21,771 & NA \\
\hline & $\mathrm{Sr}$ & 1,090 & $<3.4 \mathrm{E}-2$ & 1,574 & -0.04 \\
\hline & $\mathbf{U}$ & 21,200 & $<1.7 \mathrm{E}+1$ & 30,345 & NA \\
\hline & Zn & [96] & $<1.1 \mathrm{E}+0$ & [120] & {$[0.75]$} \\
\hline & $\mathrm{Zr}$ & [120] & $<1.6 \mathrm{E}+0$ & [147] & {$[0.45]$} \\
\hline & $B a$ & [130] & $<6.8 \mathrm{E}-1$ & [177] & {$[0.08]$} \\
\hline & $C a$ & {$[3,200]$} & [5.8] & {$[4,527]$} & {$[0.70]$} \\
\hline & $\mathrm{Cu}$ & [63] & $<9.7 \mathrm{E}-1$ & [75] & {$[0.75]$} \\
\hline & $L a$ & 90.1 & $<2.7 \mathrm{E}-1$ & 125.8 & 0.03 \\
\hline & $\mathrm{Li}$ & [40] & $<1.1 \mathrm{E}+0$ & [40] & {$[0.72]$} \\
\hline & $M g$ & [440] & $<1.4 \mathrm{E}+0$ & [613] & {$[0.62]$} \\
\hline & Mo & $<2.4 \mathrm{E}+1$ & $<1.3 \mathrm{E}+0$ & $<1.3 \mathrm{E}+1$ & NA \\
\hline & $P b$ & [260] & $<7.4 \mathrm{E}+0$ & [255] & {$[0.50]$} \\
\hline & $T i$ & [69] & $<1.9 \mathrm{E}-1$ & [97] & {$[0.34]$} \\
\hline & $Y$ & [30] & $<1.7 \mathrm{E}-1$ & [41] & {$[0.58]$} \\
\hline Slurry Prep Method & $\begin{array}{c}\text { ICP-OES } \\
\text { Analytes } \\
\end{array}$ & $\begin{array}{c}\text { Dry Slurry } \\
(\mu \mathrm{g} / \mathrm{g})\end{array}$ & $\begin{array}{c}\text { Supernate }^{(b)} \\
(\mu \mathrm{g} / \mathrm{mL})\end{array}$ & $\begin{array}{c}\text { Dry Solids }{ }^{(\mathrm{c})} \\
(\mu \mathrm{g} / \mathrm{g})\end{array}$ & $\begin{array}{c}\text { Solids Leach } \\
\text { Factor }^{(d)}\end{array}$ \\
\hline \multirow{2}{*}{$\begin{array}{c}\text { HF Acid Digestion Con. } \\
\text { Factor } 0.29\end{array}$} & $\mathbf{K}$ & [120] & {$[100]$} & $-[1,452]$ & -0.34 \\
\hline & $\mathrm{Ni}$ & 97.1 & $<1.2 \mathrm{E}+0$ & 121 & 0.01 \\
\hline
\end{tabular}


Table 4.30 (Contd)

\begin{tabular}{|c|c|c|c|c|c|}
\hline Slurry Prep Method & Radionuclides & $\begin{array}{c}\text { Dry Slurry } \\
(\mu \mathrm{Ci} / \mathrm{g})\end{array}$ & $\begin{array}{c}\text { Supernate }^{(b)} \\
(\mu \mathrm{Ci} / \mathrm{mL})\end{array}$ & $\begin{array}{c}\text { Dry Solids }^{(c)} \\
(\mu \mathrm{Ci} / \mathrm{g})\end{array}$ & $\begin{array}{c}\text { Solids Leach } \\
\text { Factor }^{(d)}\end{array}$ \\
\hline \multirow{12}{*}{$\begin{array}{c}\text { KOH Fusion } \\
\text { Concentration Factor } \\
\text { of } 1.88 \text { based on } \mathrm{U}, \mathrm{Si} \\
\text { and Fe }\end{array}$} & Co-60 & $3.12 \mathrm{E}-2$ & $<1 . \mathrm{E}-4$ & 4.3E-2 & 0.86 \\
\hline & Cs-137 & $7.17 \mathrm{E}+1$ & $1.07 \mathrm{E}+0$ & $8.6 \mathrm{E}+1$ & -1.75 \\
\hline & Eu-154 & $6.14 \mathrm{E}-1$ & $<3 . E-4$ & $8.8 \mathrm{E}-1$ & -0.04 \\
\hline & Eu-155 & $1.99 \mathrm{E}-1$ & $<2 . E-3$ & $2.6 \mathrm{E}-1$ & -0.21 \\
\hline & Am-241 & $1.99 \mathrm{E}+0$ & $<3 . \mathrm{E}-3$ & $2.8 \mathrm{E}+0$ & -0.15 \\
\hline & Total alpha & $3.10 \mathrm{E}+0$ & $<3 . \mathrm{E}-4$ & $4.5 \mathrm{E}+0$ & -0.06 \\
\hline & Total beta & $1.55 \mathrm{E}+3$ & $9.78 \mathrm{E}-1$ & $2.2 \mathrm{E}+3$ & -0.07 \\
\hline & Sr-90 & $7.10 \mathrm{E}+2$ & 7.63E-5 & $1.0 \mathrm{E}+3$ & -0.07 \\
\hline & Pu-239/240 & $1.09 \mathrm{E}+0$ & $2.11 \mathrm{E}-5$ & $1.6 \mathrm{E}+0$ & -0.03 \\
\hline & Pu-238 & $6.65 \mathrm{E}-2$ & $<2 . E-6$ & $9.6 \mathrm{E}-2$ & 0.20 \\
\hline & KPA & $(\mu \mathrm{g} / \mathrm{g})$ & $(\mu \mathrm{g} / \mathrm{mL})$ & $(\mu \mathrm{g} / \mathrm{g})$ & \\
\hline & $\mathbf{U}$ & $2.63 \mathrm{E}+4$ & $7.52 \mathrm{E}-1$ & $3.0 \mathrm{E}+4$ & -0.02 \\
\hline $\begin{array}{l}\text { (e) Test sample TI552-G } \\
\text { (f) Test sample TI552-G } \\
\text { (g) Calculated using resu } \\
\text { (h) Calculated using resu } \\
\text { Note: Analytes in italics } \\
\text { errors likely to exceed 15\% }\end{array}$ & $\begin{array}{l}5 \text {, ASO ID 08-00 } \\
2, \text { ASO ID 08-00 } \\
\text { from TI552-G6-I } \\
\text { listed in Table } 4 . \\
\text { e measured oppo }\end{array}$ & $\begin{array}{l}229 \\
45 \\
0 \text { and TI552-G } \\
0 \\
\text { unistically. Val }\end{array}$ & es in brackets [ & are $\geq$ MDL but & EQL, with \\
\hline
\end{tabular}

Particle size analysis was performed on the leach slurry samples as well As a function of pump speed, the PSD appears multimodal (Figure 4.51) with the large population peak centered around $2 \mu \mathrm{m}$, a primary distribution spanning 0.3 to $7 \mu \mathrm{m}$, a low population shoulder spanning 7 to $20 \mu \mathrm{m}$, and a separate distribution of large "particles" spanning 50 to $\sim 600 \mu \mathrm{m}$. The 4,000 RPM measurement condition shows a similar distribution to that at 3,000 RPM. The primary peak appears to have shifted to slightly smaller particle diameters, with the population peak at $\sim 1.3 \mu \mathrm{m}$ (down from $2 \mu \mathrm{m}$ ). The large particle peak spanning from 50 to $600 \mu \mathrm{m}$ has disappeared and been replaced with a population centered around 50 to $60 \mu \mathrm{m}$ and an upper bound of $\sim 130 \mu \mathrm{m}$. It is possible that the original 50 to $600 \mu \mathrm{m}$ peak (assuming it was not an artifact of the analysis) was composed of particle aggregates that were sheared apart by high flow, forming smaller aggregates that made up the new large particle peak observed at 4,000 RPM. At 2,000 RPM, the distribution is relatively unimodal and shows the single primary particle peak centered around $1.3 \mu \mathrm{m}$ and present in the 3,000 and 4,000 RPM measurements. No particles greater than $20 \mu \mathrm{m}$ are observed at 2,000 RPM, indicating that those observed at higher pump speeds are difficult-to-suspend primary particles or agglomerates.

Figure 4.52 shows the initial PSD for the oxidatively leached, dewatered slurry before, during, and after sonication. The application of sonic energy appears to shift the primary peak to submicron sizes and collapse the particle population above $10 \mu \mathrm{m}$ to a size of less than $10 \mu \mathrm{m}$. The distributions during and after sonication are broad, spanning $\sim 0.2$ to $10 \mu \mathrm{m}$ with a peak at $0.7 \mu \mathrm{m}$ and shoulders at 2 and $6 \mu \mathrm{m}$. Recovery of greater than $10-\mu \mathrm{m}$ aggregates is not observed after sonication of the dispersion, suggesting that the disruption of these species is irreversible on the time scale of the measurement. 


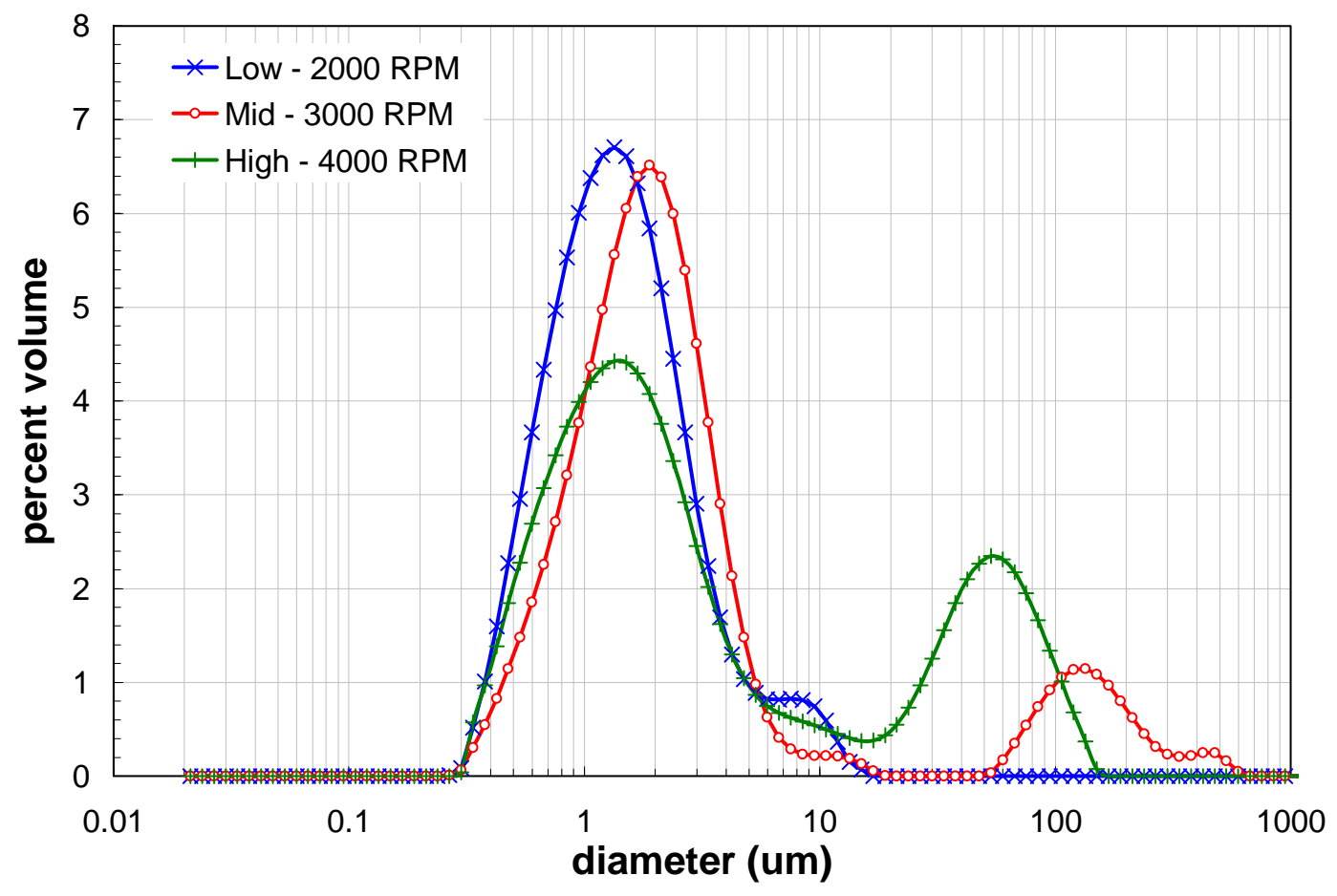

Figure 4.51. Measured PSD for Oxidatively Leached, Dewatered Slurry as a Function of Pump Speed

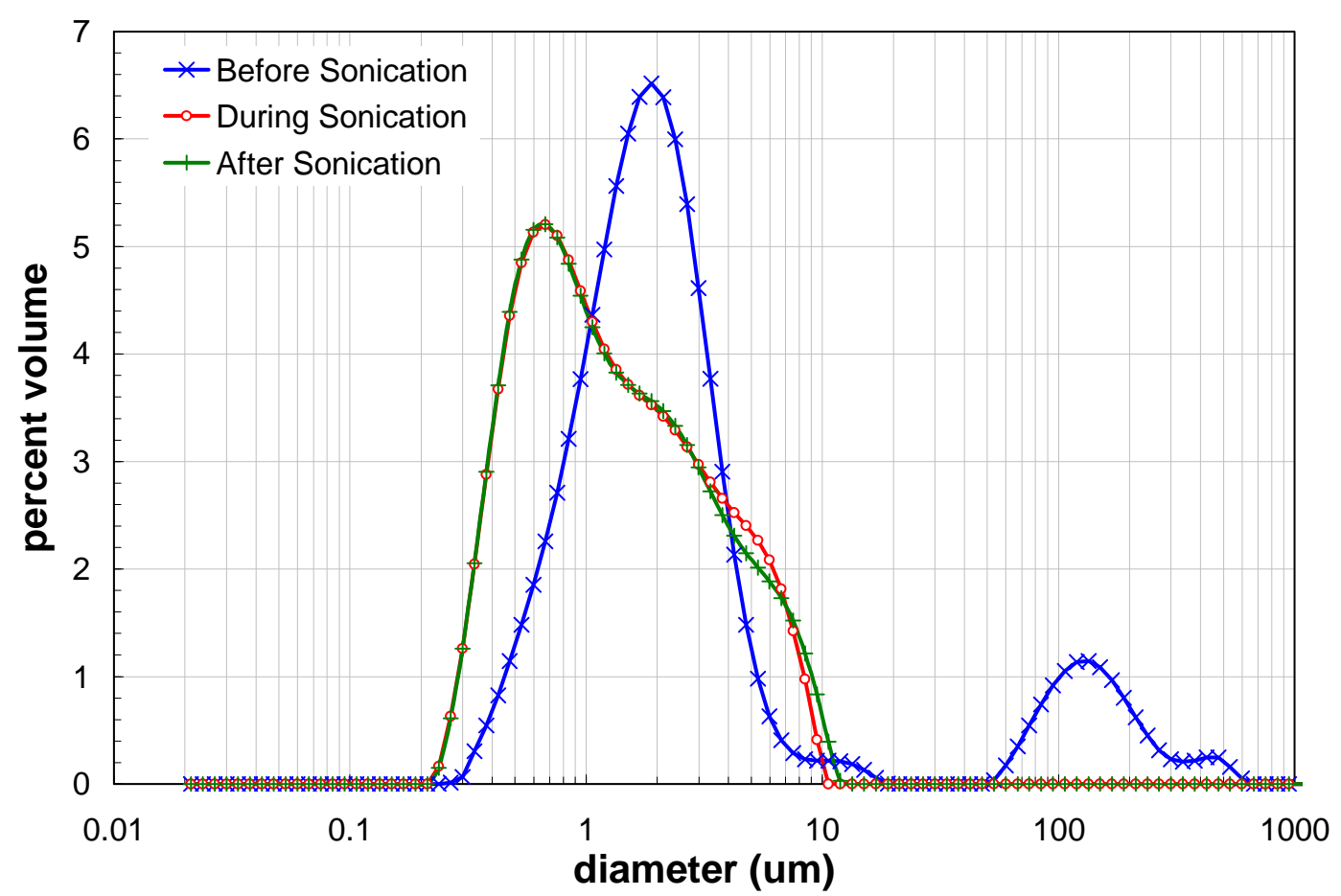

Figure 4.52. Measured PSD for Oxidatively Leached, Dewatered Slurry as a Function of Sonication 
Prior to washing the slurry, it was sub-sampled for rheology measurements. Figure 4.53 shows the influence of caustic and oxidative leaching on the Group 6/5 waste slurry. Both post-leach flow curves correspond to washed slurries. Before leaching, the slurry was non-Newtonian with a yield of 7.4 Pa and a consistency of $13 \mathrm{mPa} \cdot \mathrm{s}$. After caustic leaching and washing, the slurry was still non-Newtonian. The caustic leaching and washing operations were accompanied by an increase in slurry yield stress from 7.4 to $21 \mathrm{~Pa}$; the slurry consistency did not change. The increase in yield stress (Table 4.31) with caustic leaching and washing could indicate that these operations have eliminated the Group 6 solids fraction, causing the slurry properties to more closely resemble those of Group 5. However, the slurry rheology for Group 5 wastes was greatly reduced by caustic leaching with the final leached and washed slurry having a yield of $3.3 \mathrm{~Pa}$ and a consistency of $4.7 \mathrm{mPa} \cdot \mathrm{s}$ at $25^{\circ} \mathrm{C}$. Given these results, the rheology of the Group 6/5 slurry should be similar if the solids were a fraction dominated by Group 5 after leaching. As such, it is possible to infer that the caustic-leached, dewatered, and washed rheology for the Group 6/5 slurry is governed in part by the behavior of caustic leached and washed Group 6 solids.

Subsequent oxidative leaching of Group 6/5 slurry almost completely eliminates the non-Newtonian behavior of the Group 6/5 mixtures. The measured yield for the post-oxidatively leached slurry is $0.7 \mathrm{~Pa}$, which is at the limit of detection for the M5 measuring system $(0.5 \mathrm{~Pa})$. Part of this lowering may be a result of lowered solids concentration; specifically, the 9.7-wt\% post-leach slurry is more dilute (on an UDS basis) than the pre-leach and caustic-leached slurries. However, the consistency for the postoxidatively leached slurry is only $5.0 \mathrm{mPa} \cdot \mathrm{s}$ and is lower than that for the 3.2-wt\% Group 6. As such, it is possible to attribute part of the reduction to oxidative leaching and washing alone.

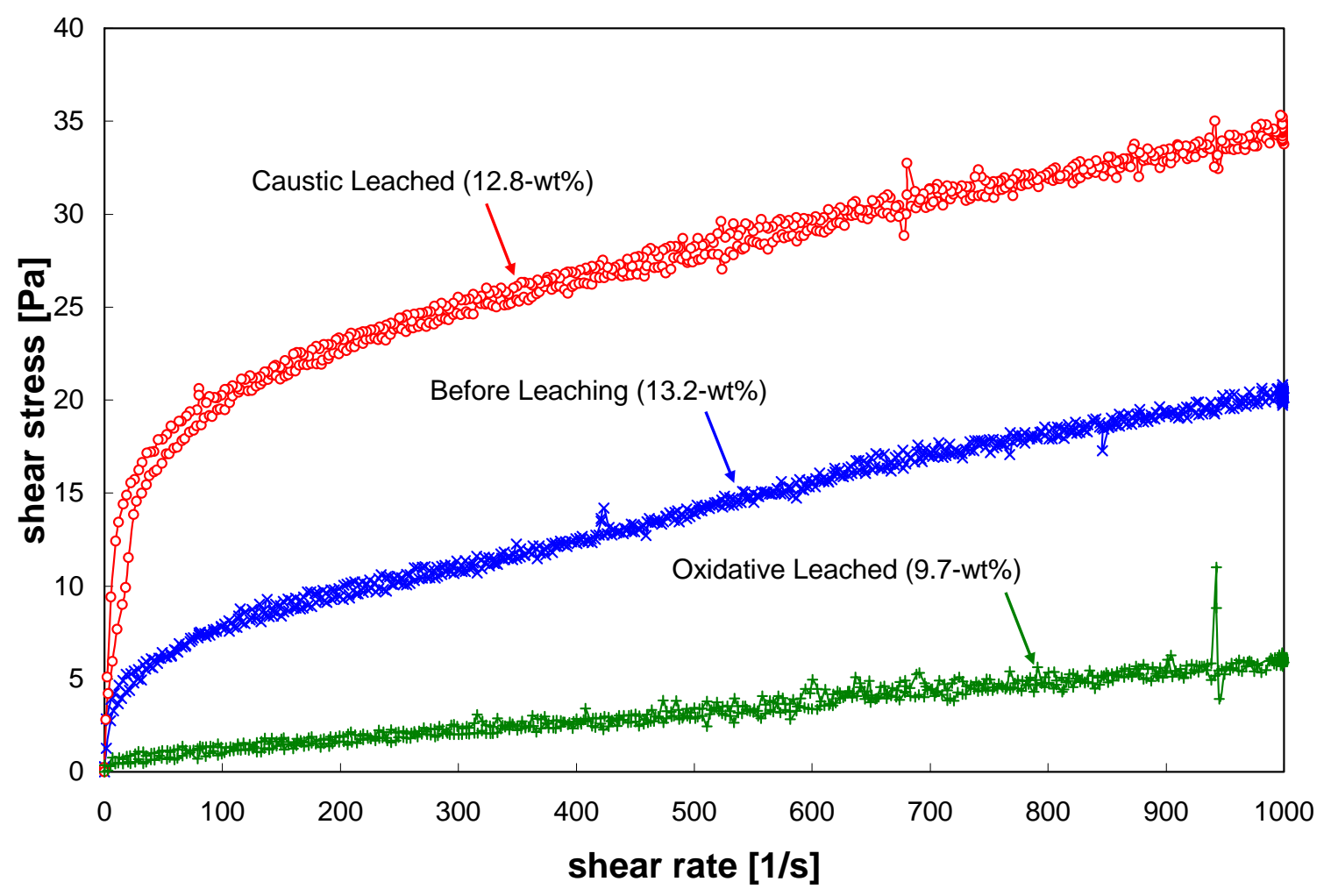

Figure 4.53. A Comparison of Group 6/5 CUF Slurries Showing the Effect of Caustic Leaching on Rheology at $25^{\circ} \mathrm{C}$ 
Table 4.31. Effect of caustic / oxidative leaching on Group 6/5 CUF slurry rheology (at $25^{\circ} \mathrm{C}$ )

\begin{tabular}{||c|c|c|c|c||}
\hline Description & $\begin{array}{c}\text { Solids } \\
\text { Concentration }\end{array}$ & Rheology & $\begin{array}{c}\text { Yield Stress } \\
{[\mathbf{P a}]}\end{array}$ & $\begin{array}{c}\text { Consistency } \\
{[\mathbf{c P}]}\end{array}$ \\
\hline $\begin{array}{c}\text { Pre-leach slurry } \\
\text { (TI552-G6-R2) }\end{array}$ & $13.2-\mathrm{wt} \%$ & Non-Newtonian & 7.4 & 13 \\
\hline $\begin{array}{c}\text { Caustic-leached } \\
\text { (TI552-G6-R4) }\end{array}$ & $12.8-\mathrm{wt} \%$ & Non-Newtonian & 21 & 13 \\
\hline $\begin{array}{c}\text { Oxidative-leached } \\
\text { (TI552-G6-R5) }\end{array}$ & $9.7-\mathrm{wt} \%$ & Non-Newtonian & 0.7 & 5.0 \\
\hline
\end{tabular}

\subsubsection{Batching Rinsing and Dewatering Results After Oxidative Leach}

After sampling the oxidative leach slurry, the slurry was washed to remove the dissolve chrominum out of the slurry (Figure 4.54). The leached material was washed three times with 1.2L solutions of 0.01-M $\mathrm{NaOH}$. After each addition, the slurry was allowed to circulate for $\sim 30$ minutes while permeate from the filter was recycled back to the slurry reservoir. The system was also back pulsed twice to rinse out the back pulse chamber as well. The slurry was then dewatered, removing the same volume that was added for the wash. The chemical content, broken down by supernate and solids, of the slurry for the three slurry washes after the oxidative leach are detailed in Table 4.32 thro $\mu g h$ Table 4.34. Radionuclide and opportunistic compositions for the three washes are shown in Table 4.35. 


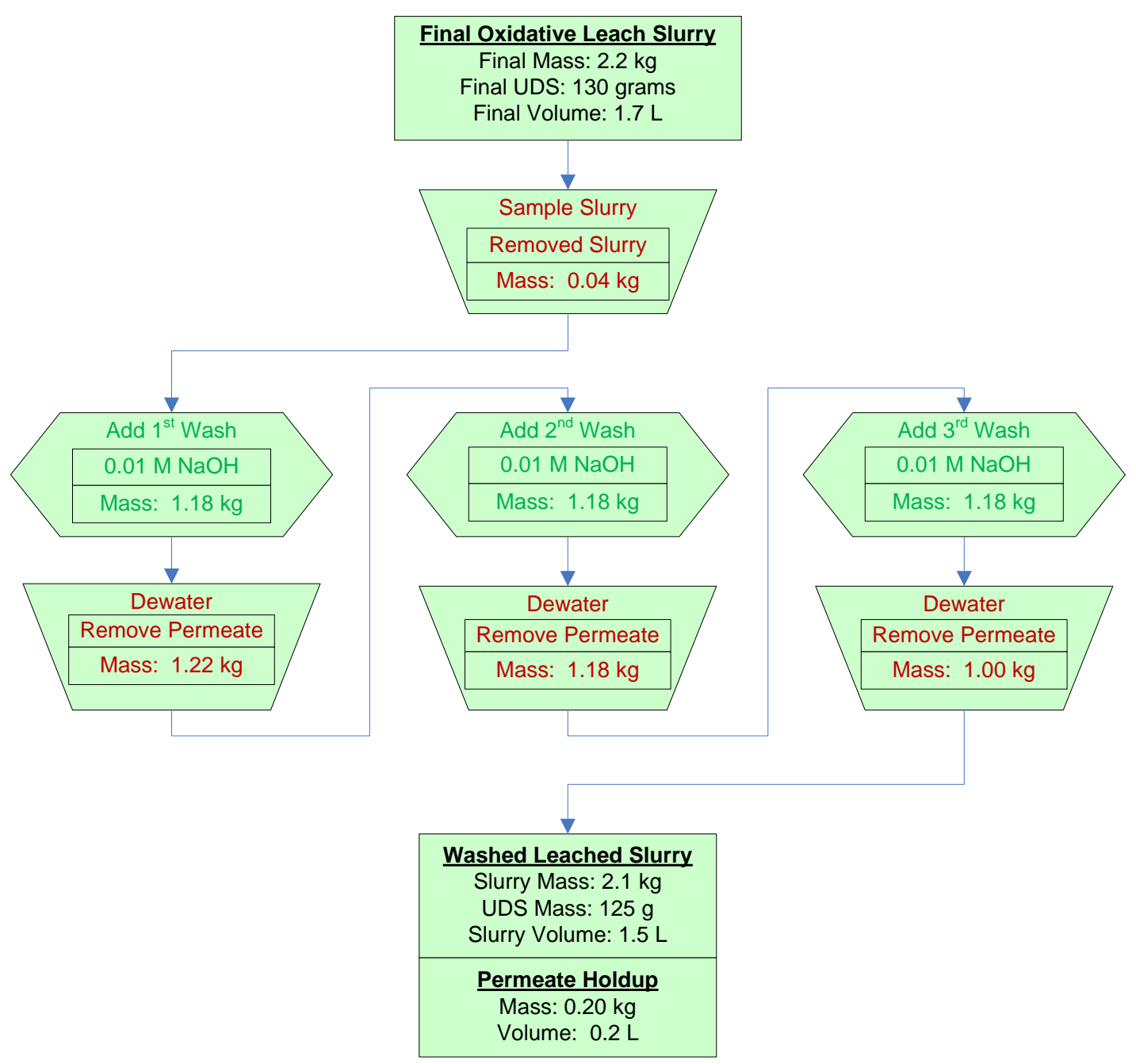

Figure 4.54. Group 6/5 Washing of Oxidative Leached Slurry

Note: Mass and volume values in figure are rounded to the nearest significant digit of accuracy. 
Table 4.32. Group 6/5 Oxidative Leached Slurry Inventory and Composition after the First Wash

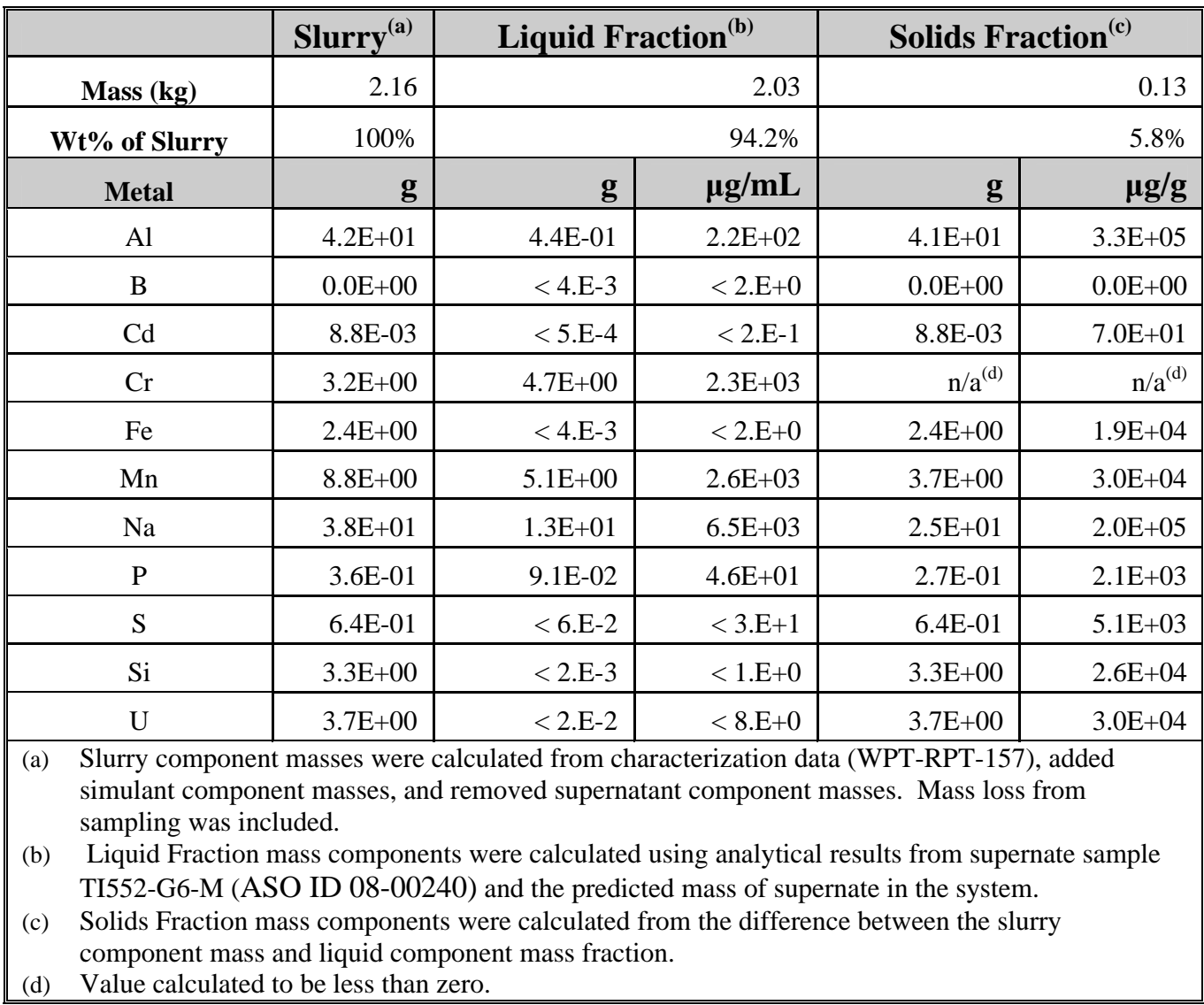


Table 4.33. Group 6/5 Oxidative Leached Slurry Inventory and Composition after the Second Wash

\begin{tabular}{|c|c|c|c|c|c|c|}
\hline & & Slurry $^{(a)}$ & \multicolumn{2}{|c|}{ Liquid Fraction $^{(b)}$} & \multicolumn{2}{|c|}{ Solids Fraction $^{(\mathrm{c})}$} \\
\hline & Mass (kg) & 2.15 & & 2.03 & & 0.13 \\
\hline & Wt\% of Slurry & $100 \%$ & & $94.2 \%$ & & $5.8 \%$ \\
\hline & Metal & g & g & $\mu \mathrm{g} / \mathrm{mL}$ & g & $\mu \mathrm{g} / \mathrm{g}$ \\
\hline & $\mathrm{Al}$ & $4.1 \mathrm{E}+01$ & 3.9E-01 & $2.0 \mathrm{E}+02$ & $4.1 \mathrm{E}+01$ & $3.3 E+05$ \\
\hline & B & $0.0 \mathrm{E}+00$ & $<4$. E-3 & $<2 . \mathrm{E}+0$ & $0.0 \mathrm{E}+00$ & $0.0 \mathrm{E}+00$ \\
\hline & $\mathrm{Cd}$ & 8.8E-03 & $<5$. E-4 & $<2$.E-1 & 8.8E-03 & $7.0 \mathrm{E}+01$ \\
\hline & $\mathrm{Cr}$ & $1.5 \mathrm{E}+00$ & $2.9 \mathrm{E}+00$ & $1.5 \mathrm{E}+03$ & $\mathrm{n} / \mathrm{a}^{(\mathrm{d})}$ & $\mathrm{n} / \mathrm{a}^{(\mathrm{d})}$ \\
\hline & $\mathrm{Fe}$ & $2.4 \mathrm{E}+00$ & $<4 . \mathrm{E}-3$ & $<2 . \mathrm{E}+0$ & $2.4 \mathrm{E}+00$ & $1.9 \mathrm{E}+04$ \\
\hline & Mn & $6.9 \mathrm{E}+00$ & $<4$. E-4 & $<2$.E-1 & $6.9 \mathrm{E}+00$ & $5.5 E+04$ \\
\hline & $\mathrm{Na}$ & $3.3 E+01$ & $8.5 \mathrm{E}+00$ & $4.3 \mathrm{E}+03$ & $2.5 \mathrm{E}+01$ & $2.0 \mathrm{E}+05$ \\
\hline & $\mathrm{P}$ & 3.1E-01 & 7.8E-02 & $3.9 \mathrm{E}+01$ & 2.3E-01 & $1.9 \mathrm{E}+03$ \\
\hline & S & $6.4 \mathrm{E}-01$ & $<7$. E-2 & $<3 . \mathrm{E}+1$ & $6.4 \mathrm{E}-01$ & $5.1 \mathrm{E}+03$ \\
\hline & $\mathrm{Si}$ & $3.3 E+00$ & $<2$. E-3 & $<1 . \mathrm{E}+0$ & $3.3 \mathrm{E}+00$ & $2.6 \mathrm{E}+04$ \\
\hline & $\mathrm{U}$ & $3.7 \mathrm{E}+00$ & $<2$.E-2 & $<8 . \mathrm{E}+0$ & $3.7 \mathrm{E}+00$ & $3.0 \mathrm{E}+04$ \\
\hline \multicolumn{7}{|c|}{$\begin{array}{l}\text { (a) Slurry component masses were calculated from characterization data (WPT-RPT-157), ac } \\
\text { simulant component masses, and removed supernatant component masses. Mass loss froI } \\
\text { sampling was included. } \\
\text { (b) Liquid Fraction mass components were calculated using analytical results from supernate } \\
\text { TI552-G6-N (ASO ID 08-00241) and the predicted mass of supernate in the system. } \\
\text { (c) Solids Fraction mass components were calculated from the difference between the slurry } \\
\text { component mass and liquid component mass fraction. } \\
\text { (d) Values calculated to be less than zero. }\end{array}$} \\
\hline
\end{tabular}


Table 4.34. Group 6/5 Oxidative Leached Slurry Inventory and Composition after the Third Wash

\begin{tabular}{|c|c|c|c|c|c|}
\hline & Slurry $^{(a)}$ & \multicolumn{2}{|c|}{ Liquid Fraction $^{(b)}$} & \multicolumn{2}{|c|}{ Solids Fraction $^{(\mathrm{c})}$} \\
\hline Mass (kg) & 2.32 & & 2.20 & & 0.13 \\
\hline Wt\% of Slurry & $100 \%$ & & $94.6 \%$ & & $5.4 \%$ \\
\hline Metal & g & g & $\mu \mathrm{g} / \mathrm{mL}$ & g & $\mu \mathrm{g} / \mathrm{g}$ \\
\hline Al & $4.1 \mathrm{E}+01$ & 5.5E-01 & $2.5 \mathrm{E}+02$ & $4.0 \mathrm{E}+01$ & $3.2 \mathrm{E}+05$ \\
\hline B & $0.0 \mathrm{E}+00$ & $<4 . \mathrm{E}-2$ & $<2 . \mathrm{E}+1$ & $0.0 \mathrm{E}+00$ & $0.0 \mathrm{E}+00$ \\
\hline Cd & 8.8E-03 & $5.2 \mathrm{E}-04$ & $2.4 \mathrm{E}-01$ & 8.3E-03 & $6.6 \mathrm{E}+01$ \\
\hline $\mathrm{Cr}$ & 8.1E-01 & $1.6 \mathrm{E}+00$ & $7.3 \mathrm{E}+02$ & $\mathrm{n} / \mathrm{a}^{(\mathrm{d})}$ & $\mathrm{n} / \mathrm{a}^{(\mathrm{d})}$ \\
\hline $\mathbf{F e}$ & $2.4 \mathrm{E}+00$ & $<4 . \mathrm{E}-2$ & $<2 . \mathrm{E}+1$ & $2.4 \mathrm{E}+00$ & $1.9 \mathrm{E}+04$ \\
\hline Mn & $6.0 \mathrm{E}+00$ & $2.0 \mathrm{E}+00$ & $9.0 \mathrm{E}+02$ & $4.1 \mathrm{E}+00$ & $3.3 \mathrm{E}+04$ \\
\hline $\mathrm{Na}$ & $3.1 \mathrm{E}+01$ & $5.2 \mathrm{E}+00$ & $2.4 \mathrm{E}+03$ & $2.6 \mathrm{E}+01$ & $2.1 \mathrm{E}+05$ \\
\hline $\mathbf{P}$ & 2.8E-01 & 7.8E-02 & $3.6 \mathrm{E}+01$ & $2.0 \mathrm{E}-01$ & $1.6 \mathrm{E}+03$ \\
\hline $\mathbf{S}$ & $6.4 \mathrm{E}-01$ & $<7 . \mathrm{E}-1$ & $<3 . \mathrm{E}+2$ & $6.4 \mathrm{E}-01$ & $5.1 \mathrm{E}+03$ \\
\hline Si & $3.3 \mathrm{E}+00$ & $1.4 \mathrm{E}-02$ & $6.4 \mathrm{E}+00$ & $3.3 \mathrm{E}+00$ & $2.6 \mathrm{E}+04$ \\
\hline $\mathbf{U}$ & $3.7 \mathrm{E}+00$ & $<2$.E-1 & $<8 . \mathrm{E}+1$ & $3.7 \mathrm{E}+00$ & $3.0 \mathrm{E}+04$ \\
\hline \multirow{2}{*}{$\begin{array}{l}\text { Radiochemical } \\
\text { Isotopes }\end{array}$} & Slurry & \multicolumn{2}{|c|}{ Liquid Fraction } & \multicolumn{2}{|c|}{ Solid Fraction } \\
\hline & $\mu \mathbf{C i}$ & $\mu \mathrm{Ci}$ & $\mu \mathrm{Ci} / \mathrm{mL}$ & $\mu \mathrm{Ci}$ & $\mu \mathrm{Ci} / \mathrm{g}$ \\
\hline Co-60 & $8.2 \mathrm{E}+00$ & $<1$.E-1 & $<6 . \mathrm{E}-5$ & $8.2 \mathrm{E}+00$ & 6.5E-02 \\
\hline Cs-137 & $2.8 \mathrm{E}+04$ & $7.1 \mathrm{E}+02$ & 3.3E-01 & $2.7 \mathrm{E}+04$ & $2.2 \mathrm{E}+02$ \\
\hline Eu-154 & $1.2 \mathrm{E}+02$ & $<3$. E-1 & $<2$.E-4 & $1.2 \mathrm{E}+02$ & 9.6E-01 \\
\hline Eu-155 & $5.2 \mathrm{E}+01$ & $<1 . \mathrm{E}+0$ & $<5$. E-4 & $5.2 \mathrm{E}+01$ & 4.1E-01 \\
\hline Am-241 & $3.6 \mathrm{E}+02$ & $<2 . \mathrm{E}+0$ & $<8$. E-4 & $3.6 \mathrm{E}+02$ & $2.9 \mathrm{E}+00$ \\
\hline Gross Alpha & $6.0 \mathrm{E}+02$ & $<7 . \mathrm{E}-1$ & $<3$. E-4 & $6.0 \mathrm{E}+02$ & $4.8 \mathrm{E}+00$ \\
\hline Gross Beta & $3.2 \mathrm{E}+05$ & $7.6 \mathrm{E}+02$ & 3.5E-01 & $3.2 \mathrm{E}+05$ & $2.5 E+03$ \\
\hline Sr-90 & $1.3 \mathrm{E}+05$ & $5.3 \mathrm{E}+01$ & $2.4 \mathrm{E}-02$ & $1.3 \mathrm{E}+05$ & $1.1 \mathrm{E}+03$ \\
\hline $\mathrm{Pu}-239+240$ & $2.2 \mathrm{E}+02$ & $3.8 \mathrm{E}-02$ & $1.7 \mathrm{E}-05$ & $2.2 \mathrm{E}+02$ & $1.7 \mathrm{E}+00$ \\
\hline Pu-238 & $1.7 \mathrm{E}+01$ & 8.3E-03 & 3.8E-06 & $1.7 \mathrm{E}+01$ & 1.4E-01 \\
\hline \multirow[t]{2}{*}{ Anions } & \multicolumn{3}{|c|}{ Liquid Fraction } & \multicolumn{2}{|c|}{ Leached Solids Fraction } \\
\hline & $\mathrm{Mg} / \mathrm{mL}$ & [M] & g & $\mu \mathrm{g} / \mathrm{g}$ & g \\
\hline $\mathbf{F}$ & $3.0 \mathrm{E}+00$ & $1.6 \mathrm{E}-04$ & 6.6E-03 & $9.2 \mathrm{E}+00$ & $1.2 \mathrm{E}+00$ \\
\hline $\mathrm{C}_{2} \mathrm{O}_{4}$ & $1.5 \mathrm{E}+02$ & 1.7E-03 & 3.3E-01 & $3.2 \mathrm{E}+02$ & $4.1 \mathrm{E}+01$ \\
\hline $\mathrm{NO}_{2}$ & $<5 . \mathrm{E}-2$ & $<1$.E-6 & $1.1 \mathrm{E}-04$ & $2.8 \mathrm{E}+03$ & $3.5 E+02$ \\
\hline $\mathrm{NO}_{3}$ & $4.4 \mathrm{E}+02$ & 7.1E-03 & $9.6 \mathrm{E}-01$ & $1.0 \mathrm{E}+04$ & $1.3 \mathrm{E}+03$ \\
\hline $\mathrm{SO}_{4}$ & $7.0 \mathrm{E}+00$ & 7.3E-05 & $1.5 \mathrm{E}-02$ & $8.3 \mathrm{E}+01$ & $1.0 \mathrm{E}+01$ \\
\hline $\mathrm{PO}_{4}$ & $7.8 \mathrm{E}+01$ & 8.3E-04 & $1.7 \mathrm{E}-01$ & $8.9 \mathrm{E}+01$ & $1.1 \mathrm{E}+01$ \\
\hline $\mathbf{O H}$ & $2.2 \mathrm{E}+02$ & 1.3E-02 & 4.7E-01 & & \\
\hline \multicolumn{6}{|c|}{$\begin{array}{l}\text { (a) Slurry component masses were calculated from characterization data (WPT-RPT-157), added simulant } \\
\text { component masses, and removed supernatant component masses. Mass loss from sampling was included. } \\
\text { (b) Liquid Fraction mass components were calculated using analytical results from supernate sample TI552-G6-O } \\
\text { (ASO ID 08-00223) and the predicted mass of supernate in the system. } \\
\text { (c) Solids Fraction mass components were calculated from the difference between the slurry component mass and } \\
\text { liquid component mass fraction. } \\
\text { (d) Values calculated to be less than zero. }\end{array}$} \\
\hline
\end{tabular}


Table 4.35. Oxidative Wash Solutions Radionuclide and Opportunistic Compositions

\begin{tabular}{|c|c|c|c|c|}
\hline $\begin{array}{r}\text { Sample } \\
\text { Description: }\end{array}$ & Wash 1 & Wash 2 & Wash 3 & $\begin{array}{c}\text { Composite Wash } \\
1-3\end{array}$ \\
\hline Sample ID: & 08-00240 & 08-00241 & 08-00223 & 08-00224 \\
\hline Density $^{(a)}, \mathrm{g} / \mathrm{mL}:$ & 1.02 & 1.01 & 1.01 & 1.01 \\
\hline Analyte & $\mu \mathrm{g} / \mathrm{mL}$ & $\mu \mathrm{g} / \mathrm{mL}$ & $\mu \mathrm{g} / \mathrm{mL}$ & $\mu \mathrm{g} / \mathrm{mL}$ \\
\hline Ag & $<0.41$ & $<0.42$ & $<0.41$ & $<0.41$ \\
\hline As & $<6.7$ & $<7.0$ & $<6.7$ & $<6.7$ \\
\hline $\mathrm{Ba}$ & $<0.33$ & $<0.34$ & $<0.33$ & $<0.33$ \\
\hline $\mathrm{Be}$ & $<0.01$ & $<0.01$ & $<0.01$ & $<0.01$ \\
\hline $\mathrm{Ca}$ & [3.1] & [2.3] & [4.0] & [2.3] \\
\hline $\mathrm{Ce}$ & $<1.2$ & $<1.2$ & $<1.2$ & $<1.2$ \\
\hline Co & $<0.37$ & $<0.39$ & $<0.38$ & $<0.37$ \\
\hline $\mathrm{Cu}$ & $<0.47$ & $<0.48$ & $<0.47$ & $<0.47$ \\
\hline Dy & $<0.34$ & $<0.35$ & $<0.34$ & $<0.34$ \\
\hline $\mathrm{Eu}$ & $<0.11$ & $<0.11$ & $<0.11$ & $<0.10$ \\
\hline $\mathrm{La}$ & {$[0.20]$} & $<0.13$ & $<0.13$ & $<0.13$ \\
\hline $\mathrm{Li}$ & {$[0.80]$} & $<0.55$ & $<0.53$ & $<0.52$ \\
\hline $\mathrm{Mg}$ & $<0.68$ & $<0.70$ & $<0.69$ & $<0.68$ \\
\hline Mo & {$[0.87]$} & $<0.65$ & {$[0.94]$} & [1.5] \\
\hline $\mathrm{Nd}$ & $<1.7$ & $<1.7$ & $<1.7$ & $<1.7$ \\
\hline $\mathrm{Pb}$ & $<3.6$ & $<3.7$ & $<3.6$ & $<3.6$ \\
\hline $\mathrm{Pd}$ & $<1.2$ & $<1.3$ & $<1.2$ & $<1.2$ \\
\hline $\mathrm{Rh}$ & $<2.4$ & $<2.5$ & $<2.5$ & $<2.4$ \\
\hline $\mathrm{Ru}$ & $<0.80$ & $<0.82$ & $<0.81$ & $<0.79$ \\
\hline $\mathrm{Sb}$ & [10] & [7.6] & $<3.1$ & $<3.0$ \\
\hline Se & $<4.74$ & {$[6.1]$} & [21] & [22] \\
\hline Sn & {$[4.1]$} & [3.1] & $<2.0$ & $<1.9$ \\
\hline Ta & $<1.3$ & $<1.3$ & [1.5] & $<1.3$ \\
\hline $\mathrm{Te}$ & $<3.1$ & $<3.2$ & $<3.1$ & $<3.0$ \\
\hline Th & $<1.1$ & $<1.2$ & $<1.2$ & $<1.1$ \\
\hline $\mathrm{Ti}$ & $<0.09$ & $<0.10$ & $<0.09$ & $<0.09$ \\
\hline $\mathrm{Tl}$ & $<6.3$ & $<6.5$ & $<6.4$ & $<6.3$ \\
\hline $\mathrm{V}$ & $<0.30$ & $<0.32$ & {$[0.37]$} & {$[0.33]$} \\
\hline $\mathrm{W}$ & $<1.5$ & $<1.5$ & $<1.5$ & $<1.4$ \\
\hline $\mathrm{Y}$ & $<0.08$ & $<0.08$ & $<0.08$ & $<0.08$ \\
\hline
\end{tabular}


Table 4.35 (Contd)

\begin{tabular}{|c|c|c|c|c|}
\hline $\begin{array}{r}\text { Sample } \\
\text { Description: }\end{array}$ & Wash 1 & Wash 2 & Wash 3 & $\begin{array}{c}\text { Composite Wash } \\
1-3 \\
\end{array}$ \\
\hline Sample ID: & 08-00240 & 08-00241 & 08-00223 & 08-00224 \\
\hline Analyte & $\mu \mathrm{Ci} / \mathrm{mL}$ & $\mu \mathrm{Ci} / \mathrm{mL}$ & $\mu \mathrm{Ci} / \mathrm{mL}$ & $\mu \mathrm{Ci} / \mathrm{mL}$ \\
\hline${ }^{137} \mathrm{Cs}$ & $7.73 \mathrm{E}-1$ & $5.21 \mathrm{E}-1$ & $3.26 \mathrm{E}-1$ & $4.72 \mathrm{E}-1$ \\
\hline${ }^{60} \mathrm{Co}$ & $<7 . \mathrm{E}-5$ & $<7 \mathrm{E}-5$ & $<6$.E-5 & $<5$. E-5 \\
\hline${ }^{241} \mathrm{Am}$ & $<1 \mathrm{E}-3$ & $<1 \mathrm{E}-3$ & $<8 . \mathrm{E}-4$ & $<2 . E-3$ \\
\hline${ }^{90} \mathrm{Sr}$ & $8.98 \mathrm{E}-3$ & $8.94 \mathrm{E}-4$ & $2.44 \mathrm{E}-2$ & $2.81 \mathrm{E}-3$ \\
\hline${ }^{238} \mathrm{Pu}$ & $9.45 \mathrm{E}-6$ & $9.75 \mathrm{E}-6$ & $3.82 \mathrm{E}-6$ & [2.1E-6] \\
\hline${ }^{239+240} \mathrm{Pu}$ & $3.91 \mathrm{E}-5$ & $2.76 \mathrm{E}-5$ & $1.75 E-5$ & [3.2E-6] \\
\hline Gross alpha & $<3 . \mathrm{E}-4$ & $<3 . \mathrm{E}-4$ & $<3 . \mathrm{E}-4$ & $<4$.E-4 \\
\hline Gross beta & 8.03E-1 & $5.31 \mathrm{E}-1$ & $3.48 \mathrm{E}-1$ & $4.20 \mathrm{E}-1$ \\
\hline${ }^{154} \mathrm{Eu}$ & $<2 \mathrm{E}-4$ & $<2 \mathrm{E}-4$ & $<2 \mathrm{E}-4$ & $<1 \mathrm{E}-4$ \\
\hline \multicolumn{5}{|c|}{$\begin{array}{l}\text { (a) Density values were obtained from the mass flow meter, which had not been calibrated to NQA-1 } \\
\text { standards; they are reported for information only. } \\
\text { ASR } 8055,8108 \text { Reference Date November } 5,2007 \text {. } \\
\text { Analyte uncertainties were typically within } \pm 15 \% \text {; results in brackets indicate that the analyte } \\
\text { concentrations were greater than the method detection limit (MDL) and less than the estimated } \\
\text { quantitation limit (EQL), and uncertainties were }>15 \% \text {. }\end{array}$} \\
\hline
\end{tabular}

The total chromium in the system prior to caustic leaching was 8,500 mg. By the end of the test, only 800 mg remained after the oxidative and caustic leach (Figure 4.55). However, sample loss accounted for an additional $900 \mathrm{mg}$ loss of chrominum in the slurry. When this is taken into account, the total removal of chromimum from washing and leaching was $80 \%$ (Figure 4.56). The six washes after the caustic leach appear adequate for washing all the leached aluminum from solution, as can be seen by the $40 \%$ solids leach and 52\% total removal, whereas the three washes following the oxidative leach do not fully remove all of the leached chromium ( $>90 \%$ solids leach and only $80 \%$ total removal). Had the slurry been washed further, the removal of the chromium would have almost been absolute.

Filter flux data for the dewatering solution is provided in Figure 4.57. Filter flux for the leach washing steps averaged $0.120 \mathrm{GPM} / \mathrm{ft}^{2}$, comparable to the flux observed during the last four caustic wash steps and to the standard condition steps of the washed, leached solids test matrix. The supernate was dark purple, indicating the presence of excess permanganate. 


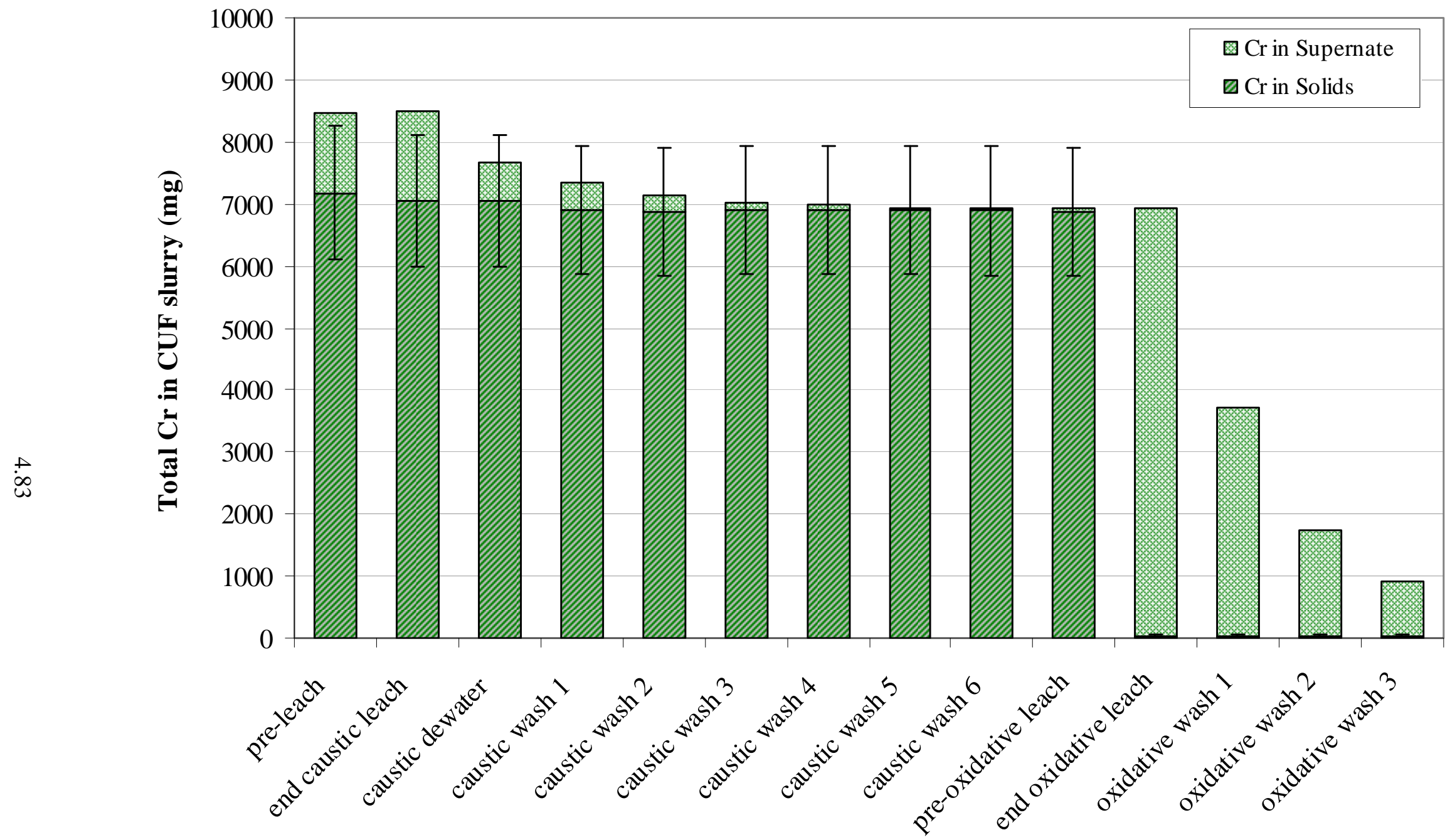

Figure 4.55. Normalized Chrominum Inventory in Group 6/5 Slurry through Caustic/Oxidative Leach and Washing (Inventory in Figure Normalized to Eliminate Sample Loss Impacts) 


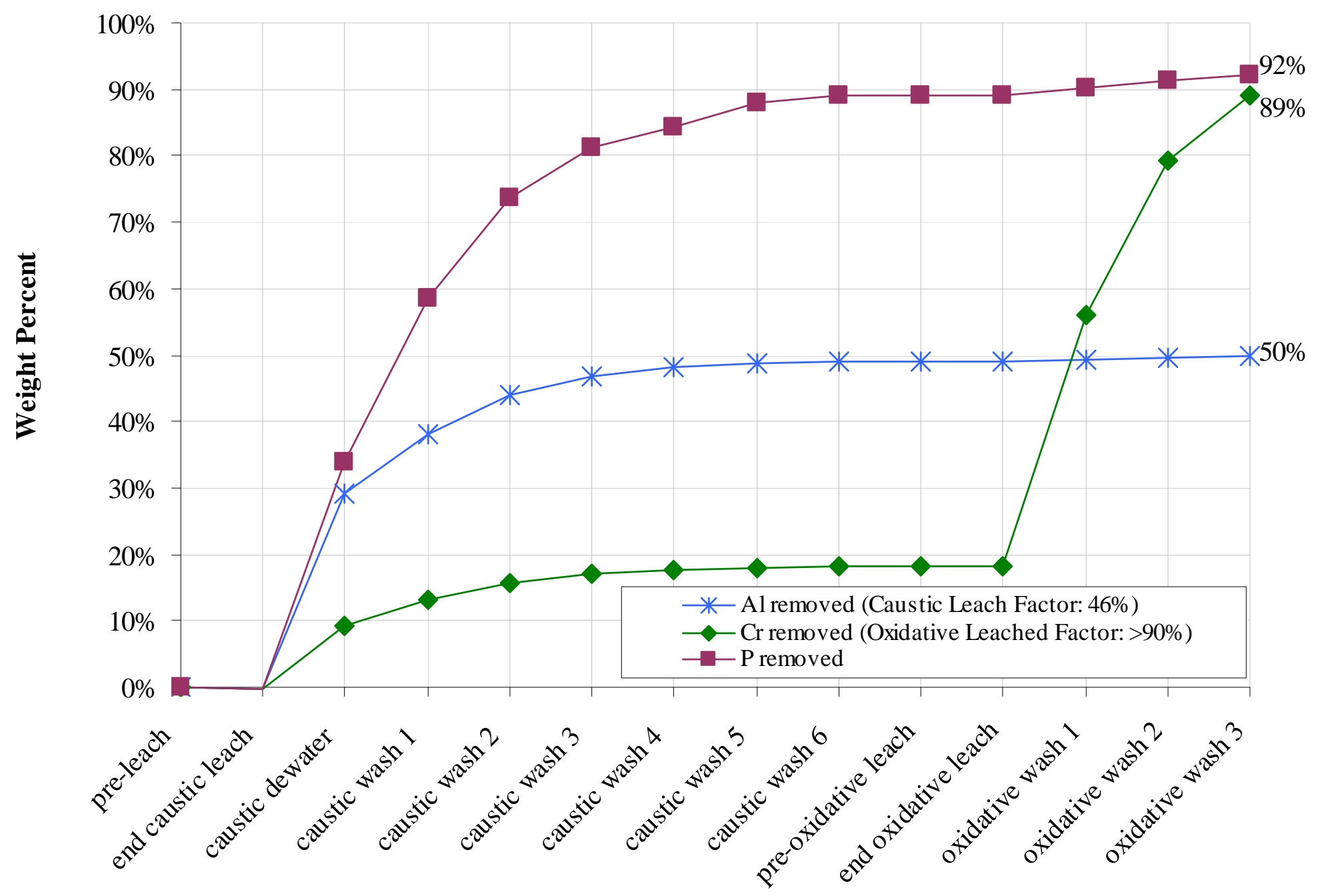

Figure 4.56. Alumiunum/Chromium Removed from the Group 6/5 CUF Slurry (Inventory in Figure Normalized to Eliminate Sample Loss Impacts) 


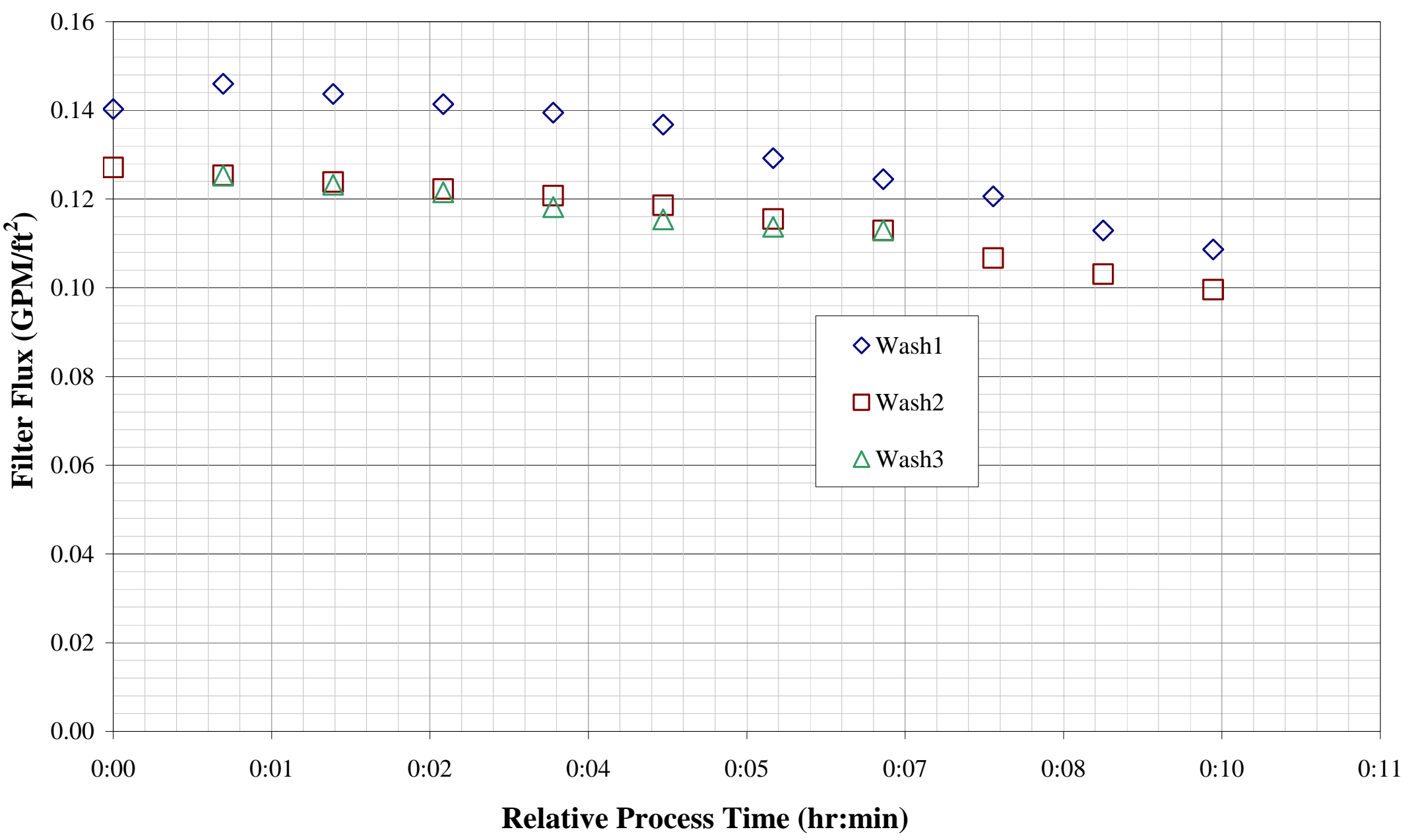

Figure 4.57. Group 6/5 Oxidative Washing Filter Flux 


\subsection{Leached Material Characterization}

After washing the oxidative leached slurry, it was sampled for physical and chemical characterization. The physical properties meaurements of the sampled slurry are shown in Table 4.36, and the overall composition of the washed slurry is found in Table 4.37 and Table 4.38.

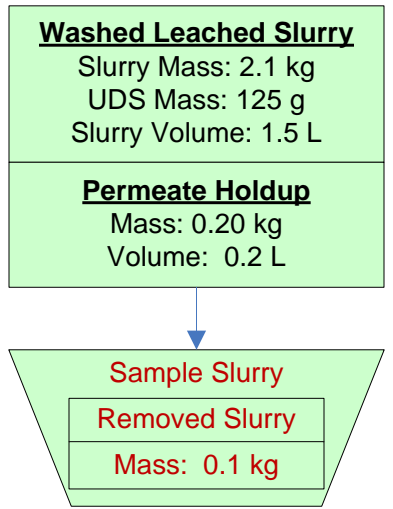

Figure 4.58. Group 6/5 Sampling of Washed Oxidative Leach Slurry Note: Mass and volume values in figure are rounded to the nearest significant digit of accuracy.

Table 4.36. Group 6/5 Physical Property Measurement of the Washed Oxidatively Leached Slurry (inside slurry loop)

\begin{tabular}{|r|c||}
\hline Slurry Density (g/mL) & 1.07 \\
\hline Supernate Density (g/mL) & 1.01 \\
\hline Settled Solids (Vol\%) & $100 \%$ \\
\hline Centrifuged UDS (Wt\%) & $34 \%$ \\
\hline Total Solids (Wt $\%)$ & $12 \%$ \\
\hline Dissolved Solids (Wt\%) & $2 \%$ \\
\hline UDS (Wt $\%)$ & $10 \%$ \\
\hline
\end{tabular}


Table 4.37. Group 6/5 Washed Oxidative Leached Slurry Inventory and Composition

\begin{tabular}{|c|c|c|c|c|c|}
\hline & Slurry $^{(a)}$ & \multicolumn{2}{|c|}{ Liquid Fraction $^{(b)}$} & \multicolumn{2}{|c|}{ Solids Fraction (c) } \\
\hline Mass (kg) & 2.30 & & 2.18 & & 0.13 \\
\hline Wt\% of Slurry & $100 \%$ & & $94.6 \%$ & & $5.4 \%$ \\
\hline Metal & g & g & $\mu \mathrm{g} / \mathrm{mL}$ & g & $\mu \mathrm{g} / \mathrm{g}$ \\
\hline Al & $4.1 \mathrm{E}+01$ & $5.5 \mathrm{E}-01$ & $2.5 \mathrm{E}+02$ & $4.0 \mathrm{E}+01$ & $3.2 \mathrm{E}+05$ \\
\hline B & $0.0 \mathrm{E}+00$ & $<2 . \mathrm{E}-2$ & $<9 . \mathrm{E}+0$ & $0.0 \mathrm{E}+00$ & $0.0 \mathrm{E}+00$ \\
\hline Cd & 8.8E-03 & $5.2 \mathrm{E}-04$ & $2.4 \mathrm{E}-01$ & $8.2 \mathrm{E}-03$ & $6.6 \mathrm{E}+01$ \\
\hline $\mathrm{Cr}$ & 8.0E-01 & $1.6 \mathrm{E}+00$ & $7.3 \mathrm{E}+02$ & $0.0 \mathrm{E}+00$ & $0.0 \mathrm{E}+00$ \\
\hline $\mathbf{F e}$ & $2.4 \mathrm{E}+00$ & $<2$.E-2 & $<1 . \mathrm{E}+1$ & $2.4 \mathrm{E}+00$ & $1.9 \mathrm{E}+04$ \\
\hline Mn & $6.0 \mathrm{E}+00$ & $2.0 \mathrm{E}+00$ & $9.0 \mathrm{E}+02$ & $4.0 \mathrm{E}+00$ & $3.2 \mathrm{E}+04$ \\
\hline $\mathrm{Na}$ & $3.1 \mathrm{E}+01$ & $5.2 \mathrm{E}+00$ & $2.4 \mathrm{E}+03$ & $2.6 \mathrm{E}+01$ & $2.1 \mathrm{E}+05$ \\
\hline $\mathbf{P}$ & 2.8E-01 & 7.8E-02 & $3.6 \mathrm{E}+01$ & $2.0 \mathrm{E}-01$ & $1.6 \mathrm{E}+03$ \\
\hline $\mathbf{S}$ & $6.4 \mathrm{E}-01$ & $<4$.E-1 & $<2 . \mathrm{E}+2$ & $6.4 \mathrm{E}-01$ & $5.1 \mathrm{E}+03$ \\
\hline Si & $3.3 \mathrm{E}+00$ & $1.4 \mathrm{E}-02$ & $6.4 \mathrm{E}+00$ & $3.2 \mathrm{E}+00$ & $2.6 \mathrm{E}+04$ \\
\hline $\mathbf{U}$ & $3.7 \mathrm{E}+00$ & $<9 . \mathrm{E}-2$ & $<4 . \mathrm{E}+1$ & $3.7 \mathrm{E}+00$ & $2.9 \mathrm{E}+04$ \\
\hline \multirow{2}{*}{$\begin{array}{l}\text { Radiochemical } \\
\text { Isotopes } \\
\end{array}$} & Slurry & \multicolumn{2}{|c|}{ Liquid Fraction } & \multicolumn{2}{|c|}{ Solid Fraction } \\
\hline & $\mu \mathrm{Ci}$ & $\mu \mathbf{C i}$ & $\mu \mathrm{Ci} / \mathrm{mL}$ & $\mu \mathrm{Ci}$ & $\mu \mathrm{Ci} / \mathrm{g}$ \\
\hline Co-60 & $8.1 \mathrm{E}+00$ & $<1 . \mathrm{E}-1$ & $<6 . \mathrm{E}-5$ & $8.1 \mathrm{E}+00$ & $6.5 \mathrm{E}-02$ \\
\hline Cs-137 & $2.8 \mathrm{E}+04$ & $7.1 \mathrm{E}+02$ & 3.3E-01 & $2.7 \mathrm{E}+04$ & $2.2 \mathrm{E}+02$ \\
\hline Eu-154 & $1.2 \mathrm{E}+02$ & $<3 . \mathrm{E}-1$ & $<2$.E-4 & $1.2 \mathrm{E}+02$ & $9.6 \mathrm{E}-01$ \\
\hline Eu-155 & $0.0 \mathrm{E}+00$ & $<1 . \mathrm{E}+0$ & $<5$.E-4 & $0.0 \mathrm{E}+00$ & $0.0 \mathrm{E}+00$ \\
\hline Am-241 & $3.6 \mathrm{E}+02$ & $<2 . \mathrm{E}+0$ & $<8 . \mathrm{E}-4$ & $3.6 \mathrm{E}+02$ & $2.8 \mathrm{E}+00$ \\
\hline Gross Alpha & $6.0 \mathrm{E}+02$ & $<7 . \mathrm{E}-1$ & $<3 . \mathrm{E}-4$ & $6.0 \mathrm{E}+02$ & $4.8 \mathrm{E}+00$ \\
\hline Gross Beta & $3.1 \mathrm{E}+05$ & $7.5 \mathrm{E}+02$ & 3.5E-01 & $3.1 \mathrm{E}+05$ & $2.5 \mathrm{E}+03$ \\
\hline Sr-90 & $1.3 \mathrm{E}+05$ & $5.3 \mathrm{E}+01$ & $2.4 \mathrm{E}-02$ & $1.3 \mathrm{E}+05$ & $1.1 \mathrm{E}+03$ \\
\hline $\mathrm{Pu}-239+240$ & $2.2 \mathrm{E}+02$ & $3.8 \mathrm{E}-02$ & $1.7 \mathrm{E}-05$ & $2.2 \mathrm{E}+02$ & $1.7 \mathrm{E}+00$ \\
\hline Pu-238 & $1.7 \mathrm{E}+01$ & $1.7 \mathrm{E}+01$ & $2.0 \mathrm{E}-01$ & $1.7 \mathrm{E}+01$ & $1.4 \mathrm{E}-01$ \\
\hline \multirow[t]{2}{*}{ Anions } & \multicolumn{3}{|c|}{ Liquid Fraction } & \multicolumn{2}{|c|}{ Leached Solids Fraction } \\
\hline & $\mu \mathrm{g} / \mathrm{mL}$ & [M] & g & $\mu \mathrm{g} / \mathrm{g}$ & g \\
\hline $\mathbf{F}$ & $3.0 \mathrm{E}+00$ & $1.6 \mathrm{E}-04$ & $6.6 \mathrm{E}-03$ & $9.2 \mathrm{E}+00$ & $1.2 \mathrm{E}+00$ \\
\hline $\mathrm{C}_{2} \mathrm{O}_{4}$ & $1.5 \mathrm{E}+02$ & $1.7 \mathrm{E}-03$ & 3.3E-01 & $3.2 \mathrm{E}+02$ & $4.1 \mathrm{E}+01$ \\
\hline $\mathrm{NO}_{2}$ & $<5$.E-2 & $<1$.E-6 & $1.1 \mathrm{E}-04$ & $2.8 \mathrm{E}+03$ & $3.5 \mathrm{E}+02$ \\
\hline $\mathrm{NO}_{3}$ & $4.4 \mathrm{E}+02$ & 7.1E-03 & 9.6E-01 & $1.0 \mathrm{E}+04$ & $1.3 \mathrm{E}+03$ \\
\hline $\mathrm{SO}_{4}$ & $7.0 \mathrm{E}+00$ & 7.3E-05 & $1.5 \mathrm{E}-02$ & $8.3 \mathrm{E}+01$ & $1.0 \mathrm{E}+01$ \\
\hline $\mathrm{PO}_{4}$ & $7.8 \mathrm{E}+01$ & 8.3E-04 & 1.7E-01 & $8.9 \mathrm{E}+01$ & $1.1 \mathrm{E}+01$ \\
\hline OH & $2.2 \mathrm{E}+02$ & 1.3E-02 & 4.7E-01 & & \\
\hline $\begin{array}{ll}\text { (a) } & \text { Slurry compon } \\
& \text { simulant comp } \\
& \text { sampling was } \\
\text { (b) Liquid Fractic } & \text { TI552-G6-O ( } \\
& \text { Tolids Fractior } \\
\text { (c) } & \text { component ma }\end{array}$ & $\begin{array}{l}\text { masses were } \\
\text { nt masses, an } \\
\text { uded. } \\
\text { lass compone } \\
\text { O ID 08-002 } \\
\text { ass componen } \\
\text { ind liquid con }\end{array}$ & $\begin{array}{l}\text { llated from ch } \\
\text { noved supern } \\
\text { vere calculate } \\
\text { and the predic } \\
\text { ere calculated } \\
\text { ent mass fract }\end{array}$ & $\begin{array}{l}\text { erization da } \\
\text { component } \\
\text { ig analytica } \\
\text { tass of supe } \\
\text { the differe }\end{array}$ & $\begin{array}{l}\text { ta (WPT-RPT-15 } \\
\text { masses. Mass los } \\
\text { results from sup } \\
\text { rnate in the syste } \\
\text { ce between the s. }\end{array}$ & $\begin{array}{l}\text { ded } \\
\text { sample }\end{array}$ \\
\hline
\end{tabular}


Table 4.38. Group 6/5 Washed Oxidative Leach Slurry Composition and Overall Leach Factor Calculations Based on ICP-OES/Radiochemical Characterization

\begin{tabular}{|c|c|c|c|c|c|}
\hline Slurry Prep Method & $\begin{array}{l}\text { ICP-OES } \\
\text { Analytes }\end{array}$ & $\begin{array}{c}\text { Dry Slurry }{ }^{(a)} \\
(\mu \mathrm{g} / \mathrm{g})\end{array}$ & $\begin{array}{c}\text { Supernate }^{(b)} \\
(\mu \mathrm{g} / \mathrm{mL})\end{array}$ & $\begin{array}{c}\text { Dry Solids }^{(\mathrm{c})} \\
(\mu \mathrm{g} / \mathrm{g})\end{array}$ & $\begin{array}{c}\text { Solids } \\
\text { Leach } \\
\text { Factor }^{(d)} \\
\end{array}$ \\
\hline \multirow{25}{*}{$\begin{array}{l}\text { KOH Fusion } \\
\text { Concentration } \\
\text { Factor of } \\
2.17 \text { based on } \mathrm{Si}\end{array}$} & Al & 230,000 & 253 & 278,001 & 0.52 \\
\hline & $\mathbf{B}$ & $<8.4 \mathrm{E}+1$ & $<1.8 \mathrm{E}+0$ & $<8.6 \mathrm{E}+1$ & $\mathrm{NA}$ \\
\hline & $\mathbf{B i}$ & [300] & $<2.2 \mathrm{E}+0$ & [345] & {$[0.55]$} \\
\hline & Cd & [36] & {$[0.24]$} & [42] & $-[0.11]$ \\
\hline & $\mathbf{C r}$ & 5,890 & 727 & 460 & 0.99 \\
\hline & $\mathbf{F e}$ & 23,900 & $<2.0 \mathrm{E}+0$ & 29,112 & -0.53 \\
\hline & Mn & 34,400 & 902 & 33,593 & -2.35 \\
\hline & $\mathrm{Na}$ & {$[110,000]$} & 2,380 & {$[112,080]$} & $-[0.21]$ \\
\hline & $\mathbf{P}$ & [500] & [36] & [277] & {$[0.88]$} \\
\hline & $S$ & [970] & $<3.2 \mathrm{E}+1$ & [886] & {$[0.32]$} \\
\hline & Si & 22,300 & {$[6.4]$} & 27,122 & NA \\
\hline & Sr & 2,390 & $<1.7 \mathrm{E}-2$ & 2,913 & -0.66 \\
\hline & $\mathbf{U}$ & 40,700 & $<8.2 \mathrm{E}+0$ & 49,532 & -0.48 \\
\hline & Zn & [150] & $<5.6 \mathrm{E}-1$ & [178] & {$[0.68]$} \\
\hline & $\mathbf{Z r}$ & [300] & $<8.0 \mathrm{E}-1$ & [358] & $-[0.16]$ \\
\hline & $B a$ & {$[240]$} & $<3.3 \mathrm{E}-1$ & [289] & $-[0.31]$ \\
\hline & Ca & {$[3,900]$} & {$[4.0]$} & {$[4,717]$} & [0.73] \\
\hline & $\mathrm{Cu}$ & [120] & $<4.7 \mathrm{E}-1$ & [142] & {$[0.60]$} \\
\hline & $L a$ & 111 & $<1.3 \mathrm{E}-1$ & 134 & 0.11 \\
\hline & $L i$ & [59] & $<5.3 \mathrm{E}-1$ & [67] & [0.59] \\
\hline & $M g$ & [610] & $<6.9 \mathrm{E}-1$ & [737] & {$[0.60]$} \\
\hline & Mo & [38] & {$[0.94]$} & [38] & $-[3.27]$ \\
\hline & $P b$ & [270] & $<3.6 \mathrm{E}+0$ & [296] & {$[0.50]$} \\
\hline & $T i$ & [110] & $<9.5 \mathrm{E}-2$ & [133] & {$[0.22]$} \\
\hline & $\boldsymbol{Y}$ & [38] & $<8.3 \mathrm{E}-2$ & [46] & {$[0.59]$} \\
\hline Slurry Prep Method & $\begin{array}{l}\text { ICP-OES } \\
\text { Analytes }\end{array}$ & $\begin{array}{c}\text { Dry Slurry }{ }^{(a)} \\
(\mu \mathrm{g} / \mathrm{g})\end{array}$ & $\begin{array}{l}\text { Supernate }^{(b)} \\
(\mu \mathrm{g} / \mathrm{mL})\end{array}$ & $\begin{array}{c}\text { Dry Solids }{ }^{(\mathrm{c})} \\
(\mu \mathrm{g} / \mathrm{g})\end{array}$ & $\begin{array}{c}\text { Solids } \\
\text { Leach } \\
\text { Factor }^{(d)}\end{array}$ \\
\hline HF Acid Digestion & $\mathbf{K}$ & [51] & [19] & $-[113]$ & 0.96 \\
\hline Con. Factor 0.84 & $\mathrm{Ni}$ & 390 & $<5.7 \mathrm{E}-1$ & 470 & -0.32 \\
\hline
\end{tabular}


Table 4.38 (Contd)

\begin{tabular}{|c|c|c|c|c|c|}
\hline Slurry Prep Method & Radionuclides & $\begin{array}{c}\text { Dry Slurry }^{(a)} \\
(\mu \mathrm{Ci} / \mathrm{g})\end{array}$ & $\begin{array}{c}\text { Supernate }^{(b)} \\
(\mu \mathrm{Ci} / \mathrm{mL})\end{array}$ & $\begin{array}{c}\text { Dry Solids }^{(\mathrm{c})} \\
(\mu \mathrm{Ci} / \mathrm{g})\end{array}$ & $\begin{array}{c}\text { Solids } \\
\text { Leach }^{(d)} \\
\text { Factor }^{(d)}\end{array}$ \\
\hline \multirow{12}{*}{$\begin{array}{c}\text { KOH Fusion } \\
\text { Concentration } \\
\text { Factor } \\
\text { of } 2.17 \text { based on } \mathrm{Si}\end{array}$} & Co-60 & $3.98 \mathrm{E}-2$ & $<6 . \mathrm{E}-5$ & $4.8 \mathrm{E}-2$ & 0.86 \\
\hline & Cs-137 & $8.34 \mathrm{E}+1$ & $3.26 \mathrm{E}-1$ & $9.9 \mathrm{E}+1$ & -1.72 \\
\hline & Eu-154 & $5.76 \mathrm{E}-1$ & $<2$.E-4 & $7.0 \mathrm{E}-1$ & 0.28 \\
\hline & Eu-155 & $<1$.E-1 & $<5 . \mathrm{E}-4$ & $<2$.E-1 & 0.28 \\
\hline & Am-241 & $1.62 \mathrm{E}+0$ & $<8 . E-4$ & $2.0 \mathrm{E}+0$ & 0.31 \\
\hline & Total alpha & $3.69 \mathrm{E}+0$ & $<3 . \mathrm{E}-4$ & $4.5 \mathrm{E}+0$ & 0.08 \\
\hline & Total beta & $2.78 \mathrm{E}+3$ & $3.48 \mathrm{E}-1$ & $3.4 \mathrm{E}+3$ & -0.41 \\
\hline & Sr-90 & $1.27 \mathrm{E}+3$ & $2.44 \mathrm{E}-2$ & $1.6 \mathrm{E}+3$ & -0.40 \\
\hline & Pu-239/240 & $1.65 \mathrm{E}+0$ & $1.75 \mathrm{E}-5$ & $2.0 \mathrm{E}+0$ & -0.13 \\
\hline & Pu-238 & $6.36 \mathrm{E}-2$ & 3.82E-6 & 7.7E-2 & 0.44 \\
\hline & KPA & $(\mu g / g)$ & $(\mu \mathrm{g} / \mathrm{mL})$ & $(\mu \mathrm{g} / \mathrm{g})$ & \\
\hline & $\mathbf{U}$ & $2.63 \mathrm{E}+4$ & 7.52E-1 & $3.0 \mathrm{E}+4$ & -0.50 \\
\hline $\begin{array}{l}\text { (a) Test sample TI55 } \\
\text { (b) Test sample TI55 } \\
\text { (c) Calculated using } \\
\text { (d) Calculated using } \\
\text { Note: Analytes in ital } \\
\text { EQL, with errors likel }\end{array}$ & $\begin{array}{l}\text { G6-O, ASO ID } \\
\text { G6-27, ASO ID } \\
\text { sults from TI552 } \\
\text { sults listed in Ta } \\
\text { s were measured } \\
\text { to exceed 15\%. }\end{array}$ & $\begin{array}{l}-00223 \\
8-00246 \\
\text { G6-O and TI55 } \\
\text { le } 4.10 \\
\text { pportunistically } \\
\end{array}$ & $\begin{array}{l}\text {-G6-27 } \\
\text { Values in brac }\end{array}$ & ets [ ] are $\geq \mathrm{MD}$ & but $<$ \\
\hline
\end{tabular}

The quantity of undissolved solid and radiochemical isotopes remaining in the slurry are shown in Figure 4.59 below. Prior to chemical leaching, there was 240 grams of solid material in the slurry; at the end, there was 125 grams, or $50 \%$ of the original solids. As indicated above, oxidative leaching removed a significant fraction of the $\mathrm{Cr}$ from the system. However, Table 4.18 indicates that the residual solids contain only a small quantity of Mn (approximately $2.6 \mathrm{mg} / \mathrm{g}$ of slurry) compared to $\mathrm{Al}$, the dominant slurry component after oxidative leaching. Adjusting this value for the sampling that was done gives a total solid value of $63 \%$ of the original. Cesium was the only radionuclide that decreased by a significant factor during the leaches and the washes. As detailed in Figure 4.59, the cesium decreased by 70\% to a value $\sim 30 \%$ of the original. By contrast, the rest of the radionuclides decreased $\pm 5 \%$ (assumed sampling and analytical errors) and, when compared to the $\sim 40 \%$ solid decrease, it is apparent there was very little effect by the leaches on the radionuclides. Calculated values greater than $100 \%$ in Figure 4.59 indicated that the sampling and analytical errors were greater than measured losses of the analytes presented.

The anions that were specifically measured in the slurry permeate were dramatically reduced by the final slurry (Figure 4.60). Nitrate and nitrite followed a similar downward trend until directly after the oxidative leach. This is most likely due to permanganate destruction of nitrite to nitrate. The nitrate concentration present in the wash water after oxidative leaching is slightly higher than would be predicted based on simple dilution of the oxidative leachate. Oxalate, though decreasing, leaves the slurry at a much slower rate than nitrite and nitrate because of its limited solubility in the presence of high sodium concentrations from caustic leaching. This limited removal of oxalate until the sodium level decreased after extensive washing. As such, a significant amount of oxalate was still present in solution even after extensive washing. 
WTP-RPT-172, Rev 0

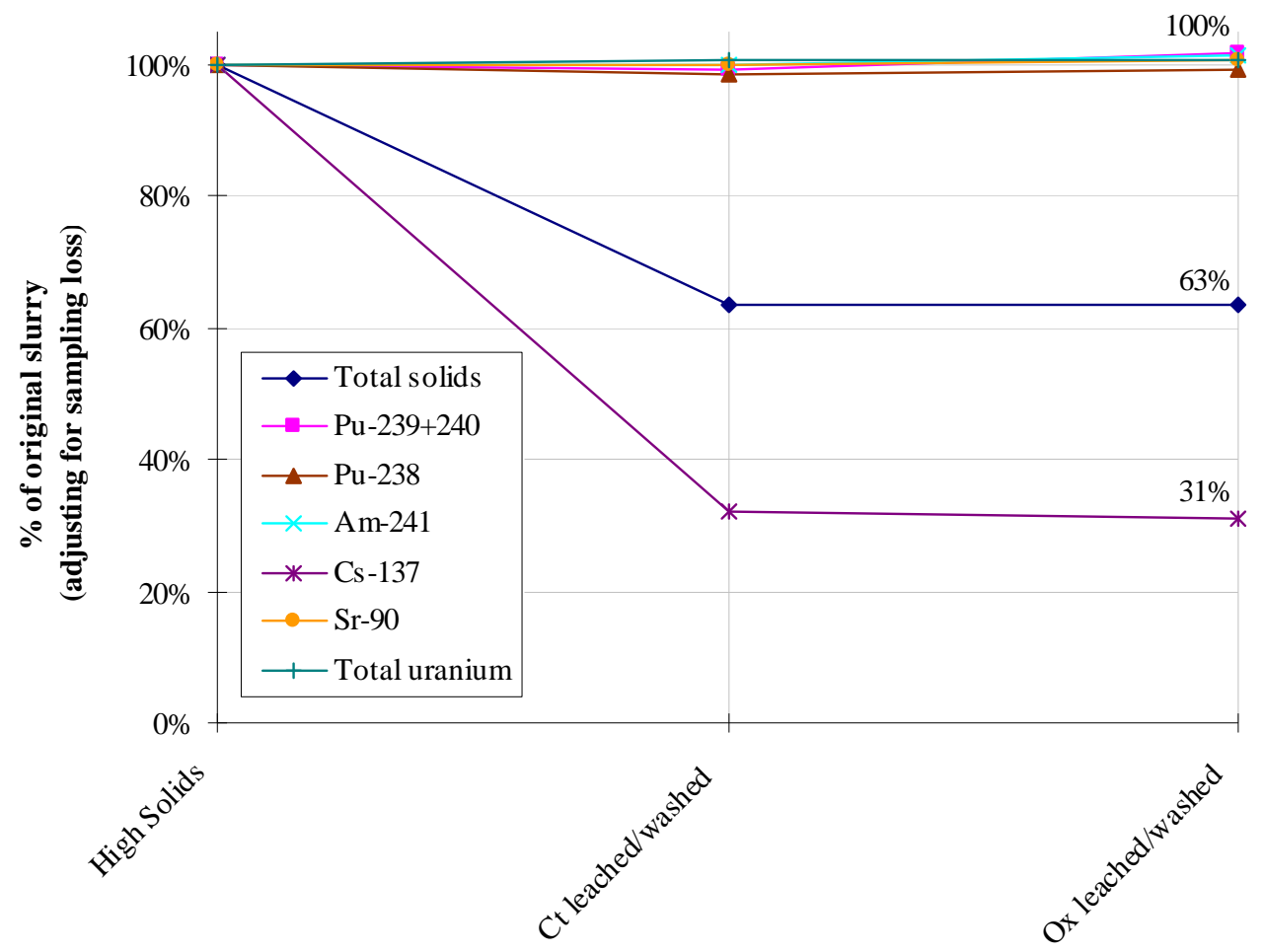

Figure 4.59. Radionuclides/Total Solids in CUF 6/5 Slurry, Adjusted for Sampling

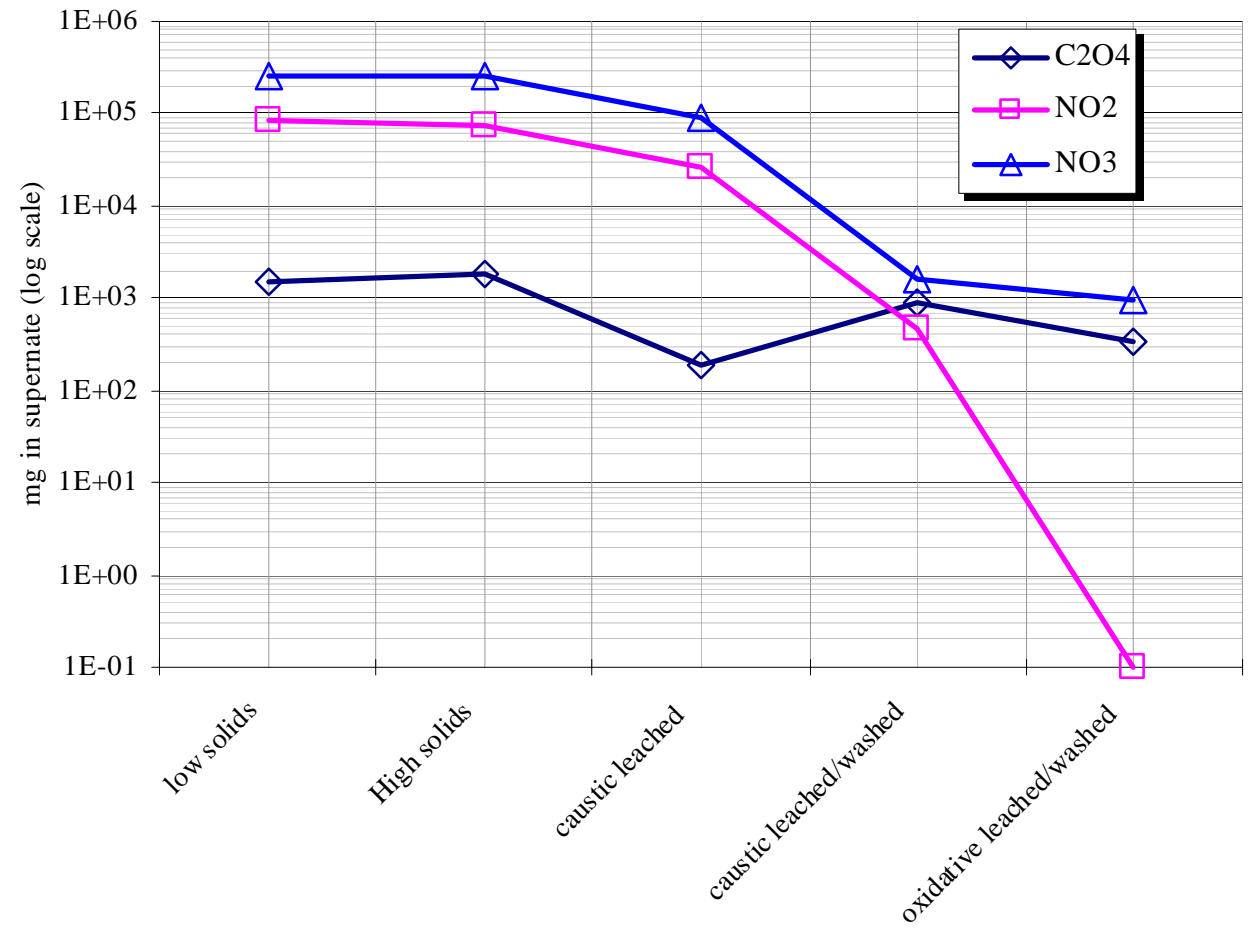

Figure 4.60. Selected Anions in CUF 6/5 Slurry Supernate 
The surface area of the leached solids was determined by BET analysis and found to be $43 \mathrm{~m} / \mathrm{g}$. Boehmite $[\mathrm{AlO}(\mathrm{OH})]$ was the predominant phase found by XRD analysis (Figure 4.61), along with clarkeite $\left\{\mathrm{Na}\left[\left(\mathrm{UO}_{2}\right) \mathrm{O}(\mathrm{OH})\right]\right\}$, cancrinite $\left[\mathrm{Na}_{7.14} \mathrm{Al}_{5} \mathrm{Si}_{7.08} \mathrm{O}_{26.73}\left(\mathrm{H}_{2} \mathrm{O}\right)_{4.87}\right]$ and nitratine $\left[\mathrm{NaNO}_{3}\right]$. Phases that are possibly present, but not confirmed, are anorthite $\left[(\mathrm{Ca}, \mathrm{Na})(\mathrm{Si}, \mathrm{Al})_{4} \mathrm{O}_{8}\right]$, sodium uranium oxide $\left[\mathrm{Na}_{6} \mathrm{U}_{7} \mathrm{O}_{24}\right]$, and calcite $\left[\mathrm{CaCO}_{3}\right]$. Whole pattern fitting, done by the JADE software (this has 10 to $20 \%$ error and should only be used as an approximation), indicates the boehmite/clarkeite ratio as 11.1:1, the boehmite/cancrinite ratio as 5.6:1, and the boehmite/nitratine ratio as 25:1.

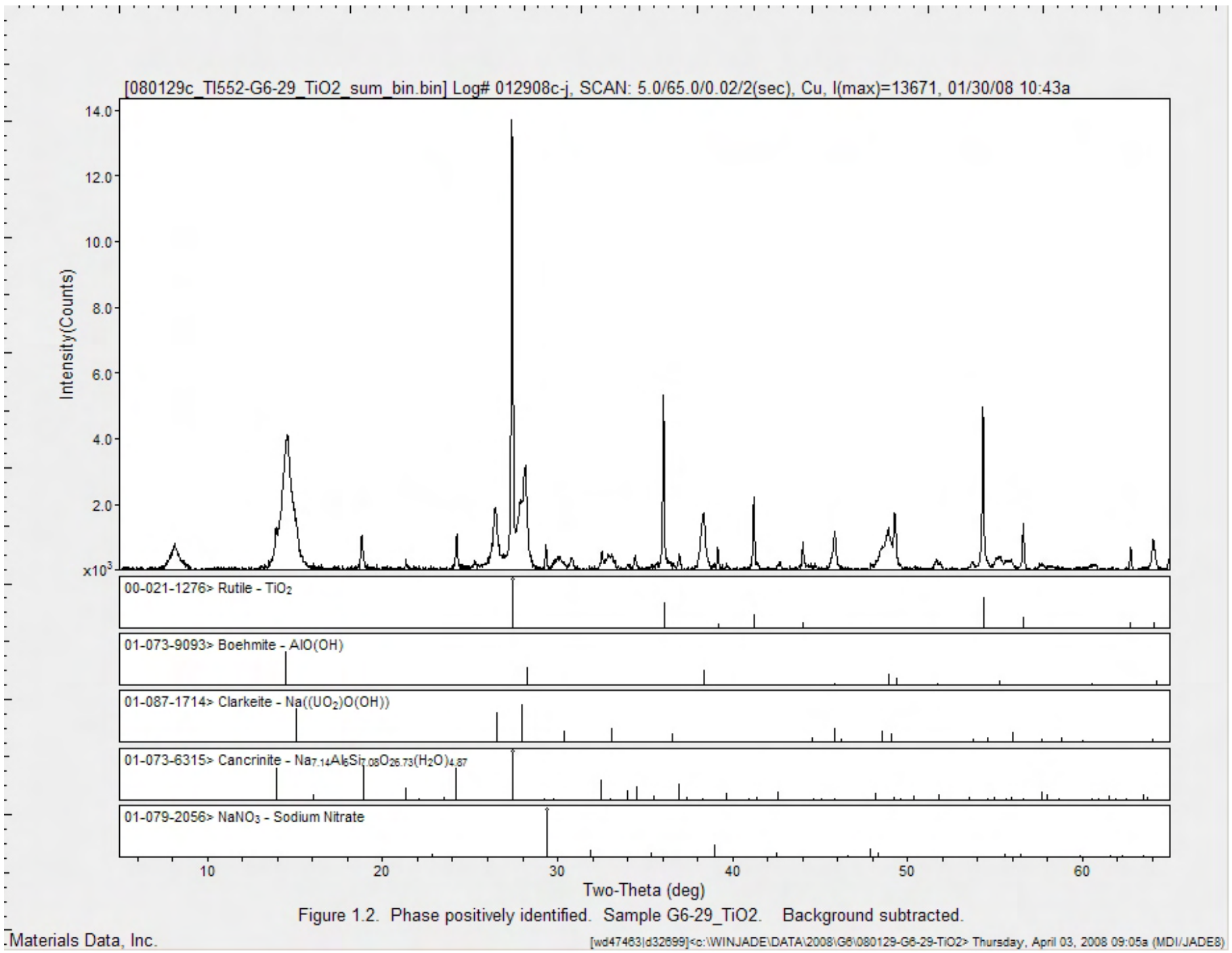

Figure 4.61. XRD Scan of CUF 6/5 Final Leached and Washed Solids

SEM (Figure 4.62) and TEM (Figure 4.63) imaging as well as EDS analysis add validity to the XRD analysis and the suspected crystal forms present. The EDS analysis indicates primarily $\mathrm{Al}$ and $\mathrm{O}$ (from the boehmite) with some U from Clarkeite and Si from Cancrinite. Note that, as expected from the chemical analysis, the EDS samples show Mn and Fe that are not represented in the XRD analyses. Given that these components appear to be present at the same concentrations, and $\mathrm{U}$ and $\mathrm{Si}$ are also present, this suggests that these components (Fe and $\mathrm{Mn}$ ) may be amorphous. The TEM analyses again show primarily $\mathrm{Al}$ and $\mathrm{O}$ from boehmite with some $\mathrm{Mn}$ and $\mathrm{Fe}$ - as expected from the chemical analyses. 


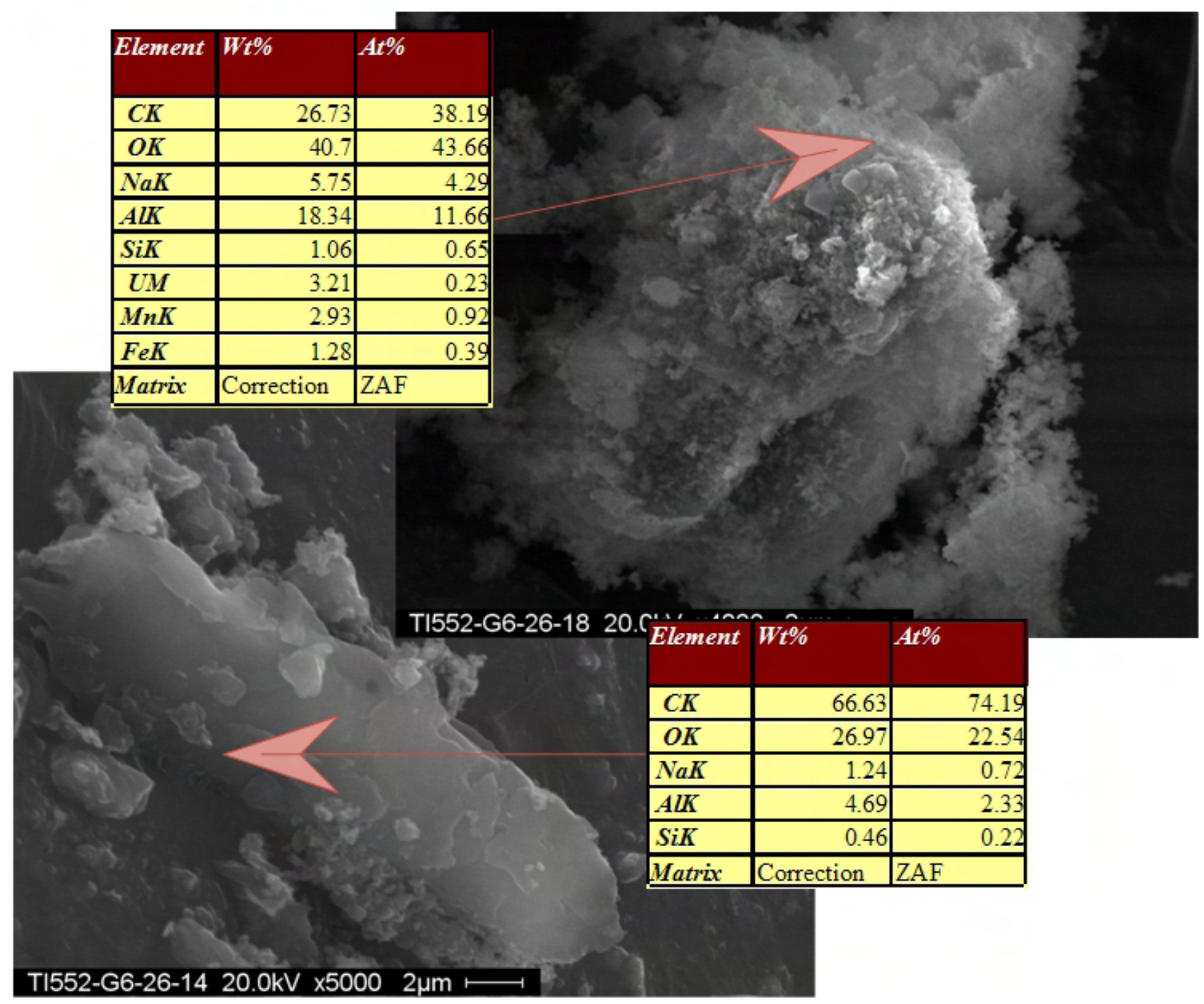

Figure 4.62. SEM Image of Leached Washed CUF 6/5 Solids 


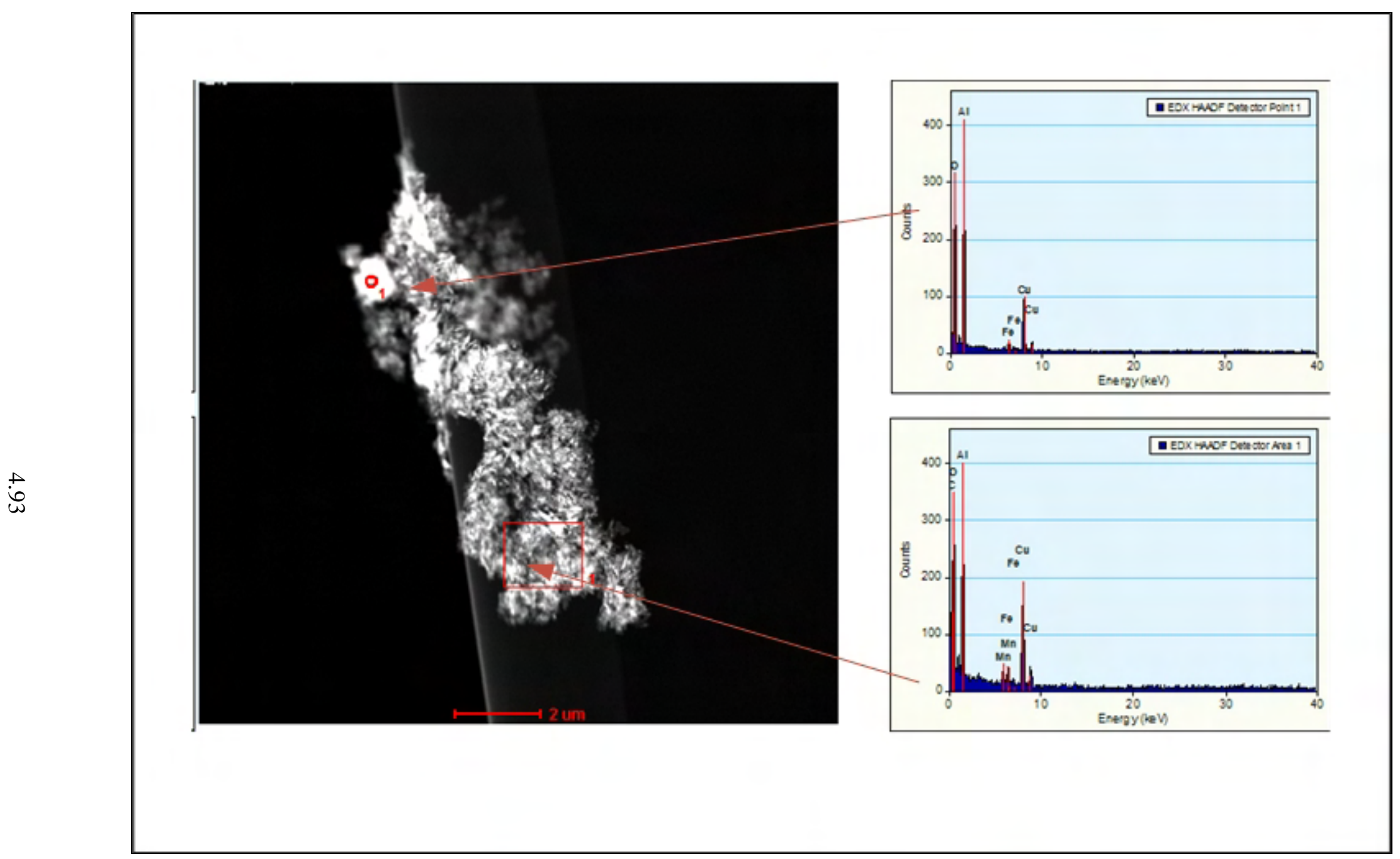

Figure 4.63. Al-Fe phase in High Surface Area Particle Agglomerates 
Particle size measuremnts of the final leached slurry was performed to characterize its distribution. Figure 4.64 shows the pre-sonic particle size distribution for the final leached, washed slurry as a function of pump speed. The initial distribution at 3000 RPM is relatively unimodal and spans 0.3 to $200 \mu \mathrm{m}$. It has a large peak centered at $\sim 1.3 \mu \mathrm{m}$ and a much smaller (in terms of volume contribution) secondary peak centered at $10 \mu \mathrm{m}$. During measurement conditions 2 and 3 (which correspond to pump speeds of 4000 and 2000 RPM, respectively), the large primary peak shifts to smaller particle sizes, such that the peak is centered at $1 \mu \mathrm{m}$. This confirms the pre-sonic decrease in particle percentiles. As stated previously, possible mechanisms for this decrease include shearing apart of agglomerates under shear or particle dissolution. The pre-sonic distributions at 2000 and 4000 RPM appear identical. Relative to 3000 RPM, they show an increased population of 4 to $10 \mu \mathrm{m}$ particles. Relative to each other, the 4000 RPM distribution exhibits a population peak over $\sim 20 \mu \mathrm{m}$ up to $80 \mu \mathrm{m}$ not present in either 2000 or 3000 RPM distributions. This peak is likely a result of improved particle suspension. The 2000 RPM distribution shows a small peak around 100-200 $\mu \mathrm{m}$. This could either be a loose particle flocculate that forms under weak shear conditions or an artifact of the analysis.

Figure 4.65 shows the particle size distribution for the final leached, washed slurry before, during, and after sonication. Sonication appears to increase both populations of submicron particles and particles in the 3 to $\sim 10 \mu \mathrm{m}$ range at the same time reducing the population of greater than $10 \mu \mathrm{m}$ particles. The resulting distribution is bimodal, with population peak maxima at 0.7 and $2 \mu \mathrm{m}$, respectively. Based on previous particle size data for Group 6/5, the changes in size distribution with sonication are most likely caused by disruption of agglomerates. However, this assertion is difficult to confirm because little change is observed in the distribution for particles greater than $10 \mu \mathrm{m}$. In terms of typical particle mechanics, possible explanations accounting for increases in both submicron and 3 to $10 \mu \mathrm{m}$ particles are 1) disruption of difficult-to-suspend particles or 2) dissolution 0.7 to $3 \mu \mathrm{m}$. Dissolution is unlikely, as the changes in distribution were not accompanied by the expected drop in sample obscuration (i.e., how much light is scattered) that should occur when particles are dissolved. Another explanation for the increased 3-10 $\mu \mathrm{m}$ is that sonication of particles induces agglomerate of some of the 1-2 $\mu \mathrm{m}$ particles into larger structures. This behavior served as explanation for the PSD behavior of Group 5 initial characterization samples (WTP-RPT-157). Although such sonic-induced agglomeration is not typically, it can occur for particle dispersions existing in a meta-stable state of aggregation. It should be noted that Group 6 solids are expected to be significantly consumed by the leached processes, such that the solids remaining after caustic- and oxidative-leaching operations are primarily Group 5 solids. For this reason, PSD behavior similar to that of Group 5 is expected. Overall, changes in the PSD for sample TI552-G6-26-PSD with sonication are difficult to describe in terms of expected particle / agglomerate behavior. 


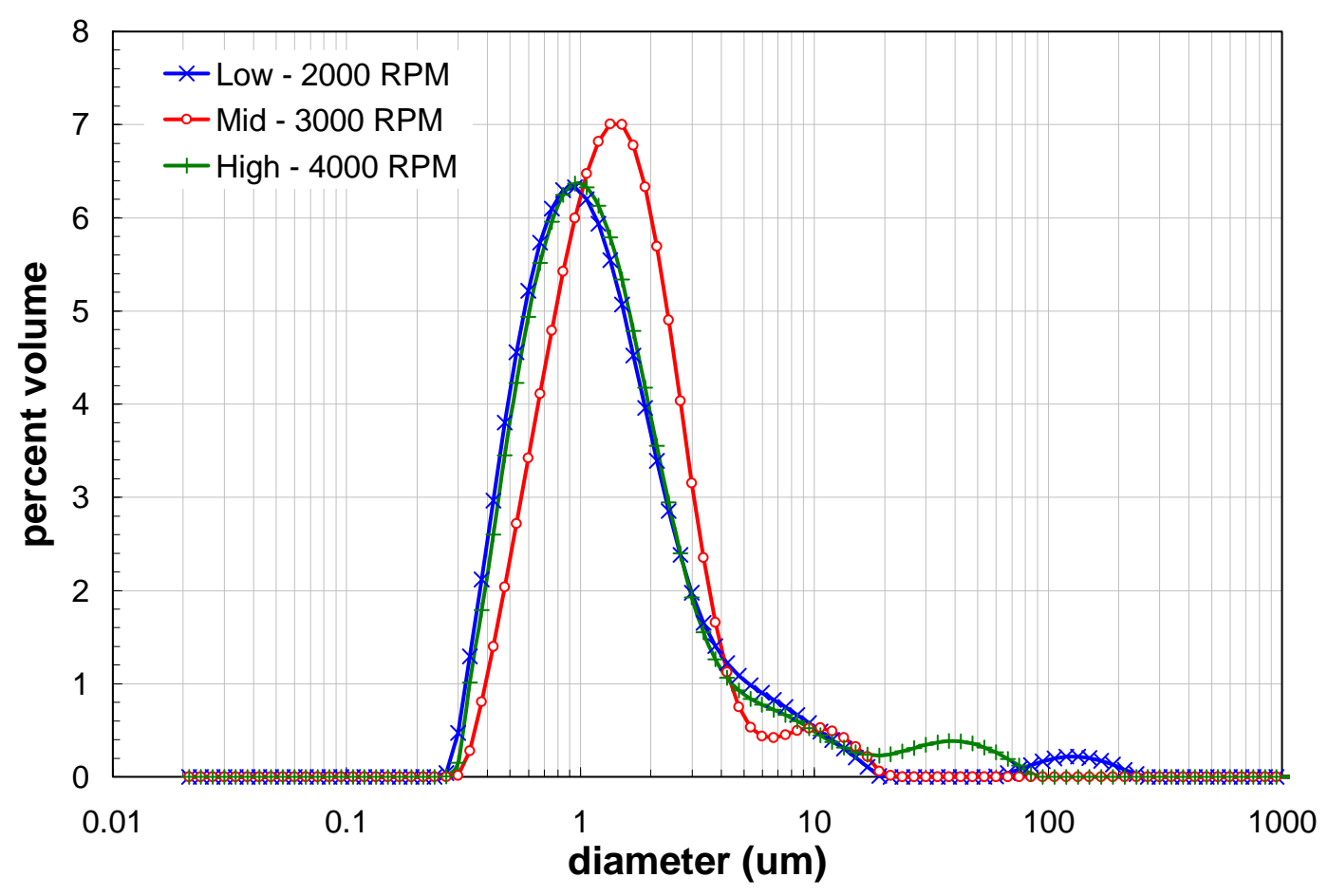

Figure 4.64. Measured PSD for Final leached, washed slurry as a function of pump speed

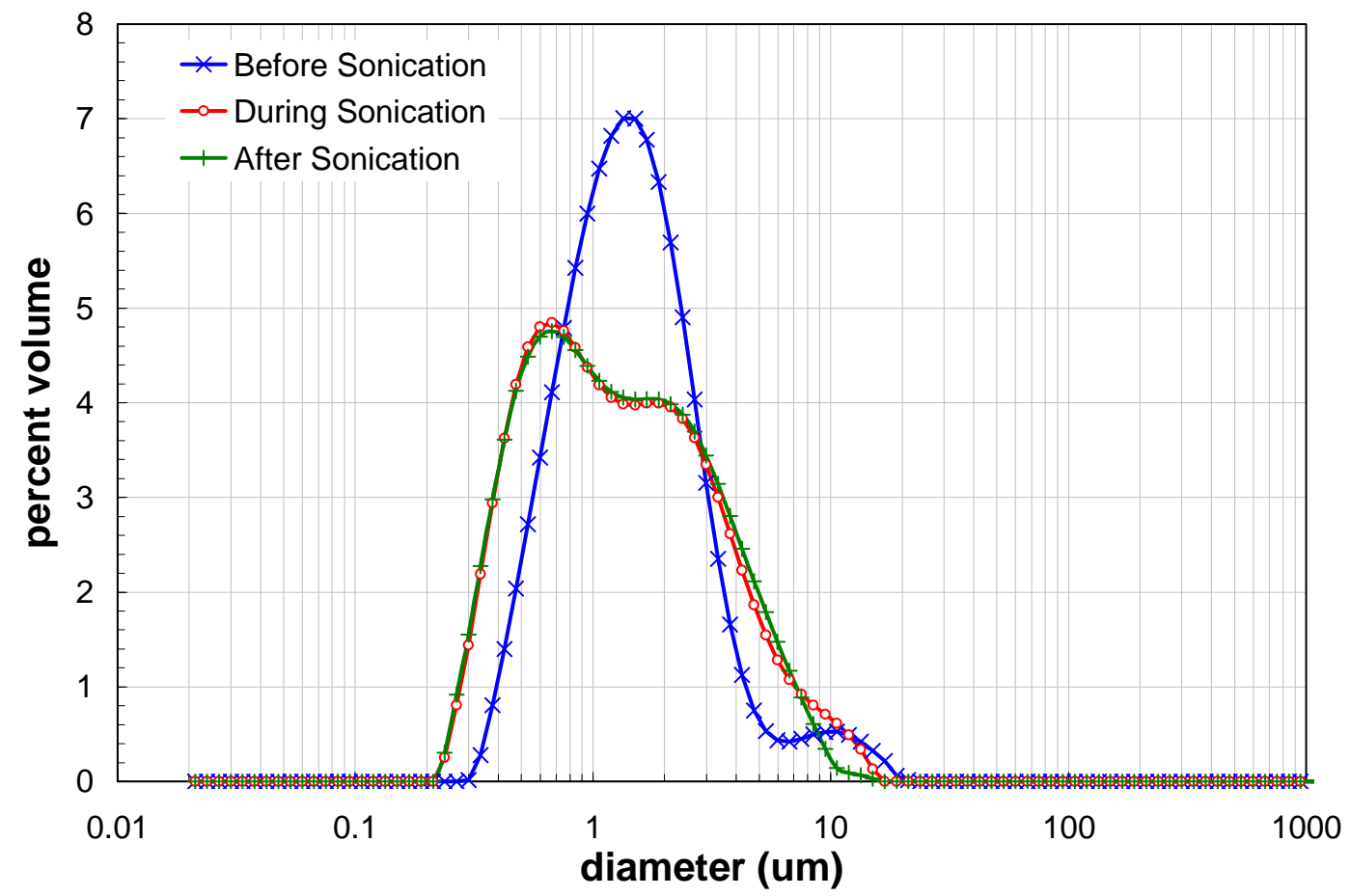

Figure 4.65. Measured PSD for Final leached, washed slurry as a function of sonication

Rheology measurements were also performed on a sub-sample of the washed oxidative leach slurry. Flow curves for the washed oxidative leached (Figure 4.66) show slight non-Newtonian behavior at all 
temperatures; however, relative to the caustic leached and washed slurry, the range of viscous shear stress is reduced ( $~ 0.5$ to $6 \mathrm{~Pa}$ after oxidative leaching as compared to $\sim 5$ to $35 \mathrm{~Pa}$ before). The current flow curves exhibit finite yield stresses ranging from 0.5 to1.3 Pa that are near the limit of detection for the M5-viscometer. The samples are slightly shear thinning and exhibit a sharp increase in flow-curve slope at $500 \mathrm{~s}^{-1}$ that, for a Newtonian sample, would be associated with the formation of Taylor vortices.

Flow-curve data suggest that slurry yield stress increases with increasing temperature, and slurry consistency decreases with increasing temperature. Both observations are consistent with flow-curve measurements for previous Group 5, 6, and 6/5 mixture slurries. There appears to be no temperaturedriven evaporation effects. Flow-curve hysteresis is only observed in the $25^{\circ} \mathrm{C}$ measurement data and is absent from the higher temperature measurements.

Table 4.39 summarizes the best-fit rheology parameters for flow curve data for the oxidatively leached and washed slurry. As with previous Group 6/5 CUF samples, only Bingham-Plastic and HerschelBulkley models were evaluated. Both analyses employ a shear rate range of 0 to $500 \mathrm{~s}^{-1}$ to avoid the vortex region at high shear. The absence of a highly shear-thinning region at low shear means that the Bingham-Plastic fit will not be biased by the inclusion shear stresses over the 0 to $200 \mathrm{~s}^{-1}$ region as with previous results. Based on the Bingham-Plastic and Herschel-Bulkley fitting results, the slurry yield stress falls between 0.4 to $0.8 \mathrm{~Pa}$ at $25^{\circ} \mathrm{C}, 0.4$ to $0.7 \mathrm{~Pa}$ at $40^{\circ} \mathrm{C}$, and 1.2 to $1.4 \mathrm{~Pa}$ at $60^{\circ} \mathrm{C}$. With exception of the $60^{\circ} \mathrm{C}$ measurement, all yield points fall within or on the limit of instrument sensitivity, and as such, are not substantially different from zero. With regards to consistency, Bingham-Plastic fitting parameters indicate a range of slurry consistency from $3 \mathrm{mPa} \cdot \mathrm{s}$ (at higher temperatures) to $5 \mathrm{mPa} \cdot \mathrm{s}$ (at $25^{\circ} \mathrm{C}$ ).

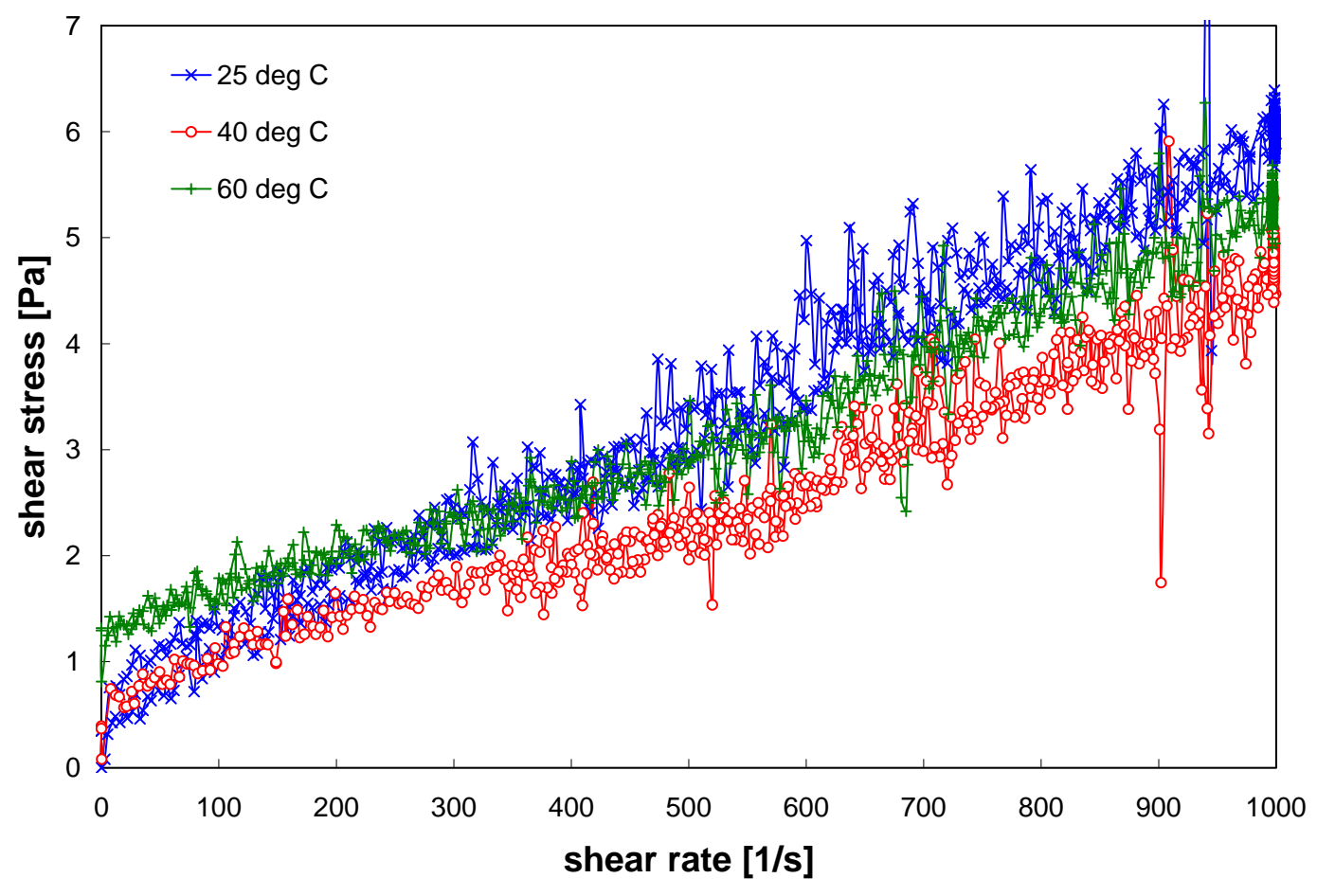

Figure 4.66. Flow Curves for Oxidatively Leached and Washed Group 6/5 Slurry 
Table 4.39. Results of Fitting Analysis for the Oxidatively Leached, Washed Group 6/5 Slurry

\begin{tabular}{||c|c|c|c|c|c||}
\hline Model & $\begin{array}{c}\text { Temperature } \\
{\left[{ }^{\circ} \mathbf{C}\right]}\end{array}$ & $\begin{array}{c}\text { Yield } \\
\text { Stress [Pa] }\end{array}$ & $\begin{array}{c}\text { Consistency } \\
{\left[\mathbf{P a} \text { s }^{\mathbf{n}}\right]}\end{array}$ & $\begin{array}{c}\text { Flow } \\
\text { Index }\end{array}$ & $\mathbf{R}$ \\
\hline \multirow{3}{*}{$\begin{array}{c}\text { Bingham-Plastic } \\
\left(200-1000 \mathrm{~s}^{-1}\right)\end{array}$} & $25(1$ of 2$)$ & 0.8 & 0.0052 & $\mathrm{n} / \mathrm{a}$ & 0.949 \\
\cline { 2 - 6 } & $25(2$ of 2$)$ & 0.7 & 0.0050 & $\mathrm{n} / \mathrm{a}$ & 0.952 \\
\cline { 2 - 6 } & 40 & 0.7 & 0.0031 & $\mathrm{n} / \mathrm{a}$ & 0.936 \\
\cline { 2 - 6 } & 60 & 1.4 & 0.0031 & $\mathrm{n} / \mathrm{a}$ & 0.957 \\
\hline $\begin{array}{c}\text { Herschel-Bulkley } \\
\left(0-1000 \mathrm{~s}^{-1}\right)\end{array}$ & $25(1$ of 2$)$ & 0.4 & 0.041 & 0.68 & 0.955 \\
\cline { 2 - 6 } & $25(2$ of 2$)$ & 0.4 & 0.026 & 0.75 & 0.956 \\
\cline { 2 - 6 } & 40 & 0.5 & 0.023 & 0.71 & 0.966 \\
\cline { 2 - 6 } & 60 & 1.2 & 0.016 & 0.75 & 0.960 \\
\hline
\end{tabular}

\subsection{Final Dewater and Filter Flux Test Matrix}

After sampling of Group 6/5 washed caustic and oxidative leached slurry, the slurry was combined with the washed Group 5 washed caustic leached slurry $(1.1 \mathrm{~kg})$. This combined slurry was then diluted with $0.01 \mathrm{M} \mathrm{NaOH}$ to increase the volume of the slurry to 4.1 liters. This combined leached solids slurry was dewatered to a total system volume of $1.4 \mathrm{~L}$ (Figure 4.67) over the course of 30 minutes. Note that a portion of the solids had been both caustic and oxidatively leached, while a second portion of the solids had only been caustic leached. The first matrix condition was attempted at this point, but more slurry volume was required to prevent pump cavitation, so $470 \mathrm{~mL}$ of permeate was added back into the tank. The resulting slurry UDS concentration was later measured as $8.0 \mathrm{wt} \%$.

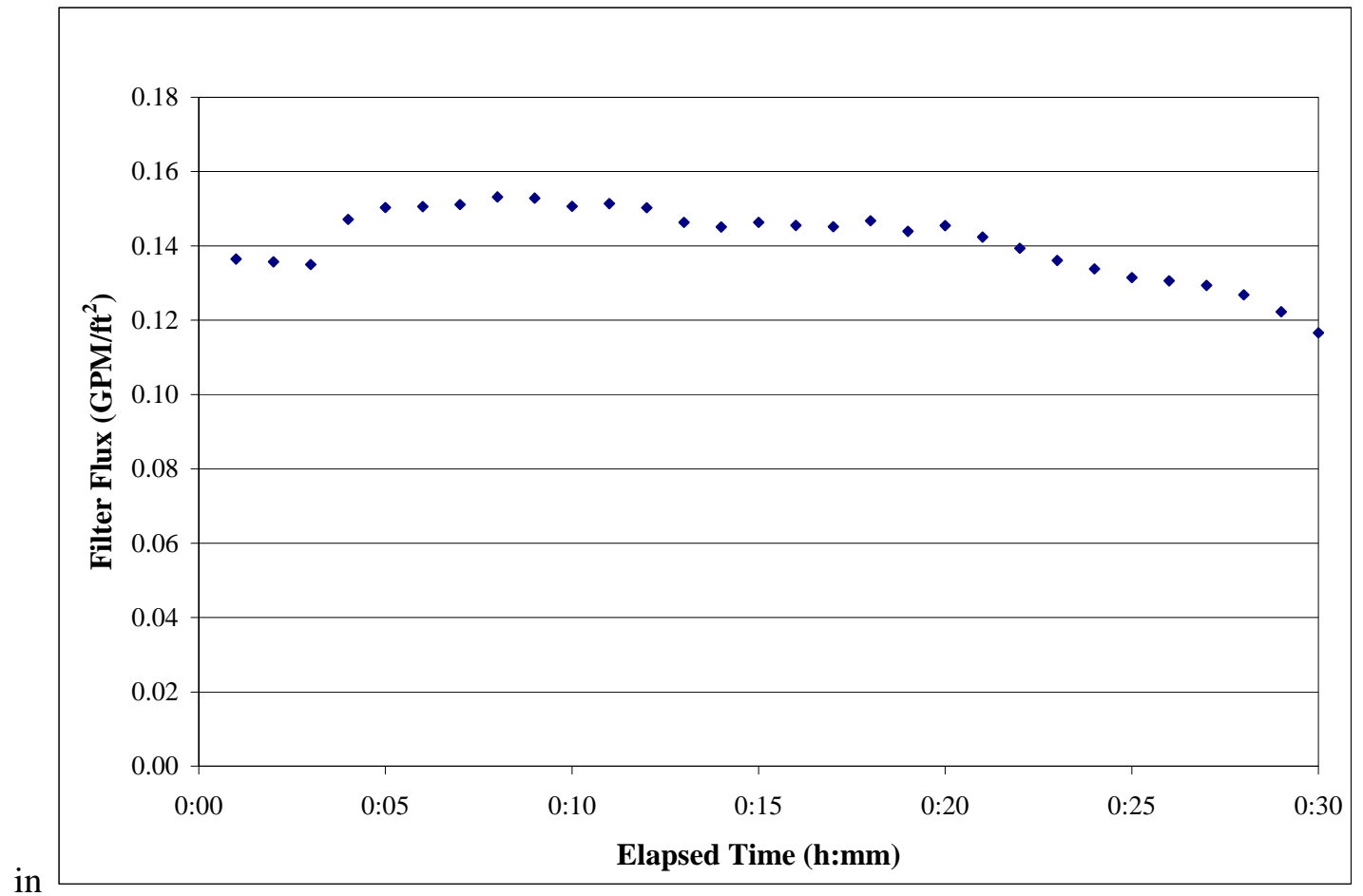

Figure 4.67. Group 6/5 Dewatering of Combined Leached Slurries 
A seven-condition test matrix was performed according to the conditions in Section 2, Table 2.2. The flter flux results for this matrix are summarized in Table 4.40 and displayed in Figure 4.68. The average TMP and AV achieved during each test condition are plotted against the target test condition values in Figure 4.69. The flux ranged from 0.080 to $0.150 \mathrm{GPM} / \mathrm{ft}^{2}$, with an average value of $0.120 \mathrm{GPM} / \mathrm{ft}^{2}$ at the standard filtration condition of $\mathrm{TMP}=40 \mathrm{psid}$ and $\mathrm{AV}=13 \mathrm{ft} / \mathrm{s}$. By inspection, the filtration behavior was characteristic of a low-solids, pressure-controlled slurry with the exception of the TMP $=40$ psid and $A V=9 \mathrm{ft} / \mathrm{s}$ condition. The difference between average flux from the initial and final test conditions (both at the standard filtration conditions) was less than 3\%, which indicated that filter resistance was stable over the course of this test.

The filter flux from each test was plotted against the average TMP, average AV, and the median operation time shown in Table 4.40 to measure their individual impact on filter flux (Figure 4.70 thro $\mu$ gh Figure 4.72). Figure 4.70 demonstrated a linear relationship of filter flux to TMP, with an $\mathrm{R}^{2}$ correlation of 0.53. Figure 4.71 also shows filter flux to be proportional to $\mathrm{AV}$, with an $\mathrm{R}^{2}$ correlation of 0.30 . Examination of Figure 4.72 showed that the filter flux was not significantly impacted by the relative process time of the test, supporting the previous conclusion that filter resistance was now stable.

The filter flux was modeled as a function of TMP, AV, and operation time to quantify the impacts of each parameter, using the data provided in Table 4.40. Two models (a linear and exponential version) were fitted using a least-square statistical method. The modeling showed that the Group 6/5 leached solids behaved much like the Group 5 leached solids. TMP and AV were found to both have significant impacts on filter flux while operational time was no longer significant. When TMP and AV were graphed individually, the regression coefficients of the linear trends indicated a poor fit. However, when TMP and AV were combined into a linear model, shown in Figure 4.73, the $\mathrm{R}^{2}$ correlation coefficient was 0.97. This indicated that filter flux behavior of this slurry was influenced significantly by both filter element resistance and cake resistance. Inspection of the equation indicates that the changes in flux due to changes in TMP ( \pm 20 psid) are greater than the changes in flux due to changes in AV $( \pm 4 \mathrm{ft} / \mathrm{s})$. The exponential model developed is shown in Figure 4.74. The power coefficient for both TMP and AV were found to be both one, and the $\mathrm{R}^{2}$ correlation coefficient for this model was 0.96 . This model confirmed earlier conclusions that TMP influences the flux and that fouling effects appeared not to be significant. While the models developed here were not impacted by changes in filter resistance to skew the data, the analysis technique that produced the models generated offset parameters in both models. This causes the models to falsely predict either a positive or negative filter flux when the TMP and AV are both zero. This indicates that the mechanisms for filter flux were more complex than what the model demonstrated. Without additional experimental data, TMP and AV inputs for these models must be bound by the TMP and AV range used for this test matrix.

To understand this change further, Figure 4.75 compared the normalized flux (J/Jo, where Jo is the flux immediately after a backpulse) for the first test condition in each of the filter matrix tests performed during the Group 6/5 CUF test, all of which occurred at a TMP of $40 \mathrm{psid}$ and AV of $13 \mathrm{ft} / \mathrm{s}$. The chart showed that the filter flux for the Group 6 and Group 6/5 slurries tested before leaching showed similar decays pattern over time. However, the leached Group 6/5 slurry showed almost no decay in the filter flux over the same time period. This confirmed results in the previous filter flux analyses which found elapsed filtration time to have a significant before leaching but not afterwards. As in the Group 5 CUF test, chemical leaching and washing of the slurry appear to have not only improved the overall filter flux, but to have modified the composition of the slurry in a way that it no longer fouled the filter media. 
After the conclusion of the washed solids test matrix, the slurry was sampled and recovered from the system. The CUF was subsequently flushed of remaining solids and well cleaned with inhibited water and nitric acid in preparation for future testing. Clean water flux tests were performed at various stages of the cleaning to compare to starting values and to track both the effectiveness of the cleaning and the relative degree of irreversible fouling present. Overall, the clean water flux tests did not show a significant difference from the filter flux of the leached slurry and no significant impact from nitric cleaning was noted.

Table 4.40. Average Operating Conditions and Flux for Post Caustic/Post Oxidative Leached HighSolids Matrix Test

\begin{tabular}{|c|c|c|c|c|c|c|c|}
\hline $\begin{array}{c}\text { Design } \\
\text { Test } \\
\text { Condition } \\
\end{array}$ & $\begin{array}{c}\text { Median } \\
\text { Operation } \\
\text { Time of } \\
\text { Test }^{(\mathrm{a})} \text { (hr) }\end{array}$ & $\begin{array}{c}\text { Slurry } \\
\text { Temp }^{(b)} \\
\left({ }^{\circ} \mathbf{C}\right) \\
\end{array}$ & $\begin{array}{l}\operatorname{TMP}^{(\mathrm{c})} \\
\text { (psid) }\end{array}$ & $\begin{array}{c}\text { Axial } \\
\text { Velocity } \\
\text { (ft/s) }\end{array}$ & $\begin{array}{l}\text { Permeate } \\
\text { Flow rate } \\
\text { (mL/min) }\end{array}$ & $\begin{array}{c}\text { Corrected } \\
\text { Permeate } \\
\text { Flux } \\
\left(\mathrm{GPM} / \mathrm{ft}^{2}\right) \\
\end{array}$ & $\begin{array}{c}\text { Axial } \\
\text { Pressure } \\
\text { Drop }^{(\mathrm{c})} \\
(\mathrm{psid} / \mathrm{ft}) \\
\end{array}$ \\
\hline 1 & 1 & 24.2 & 40.5 & 12.9 & 116.2 & 0.120 & 1.1 \\
\hline 2 & 3 & 24.3 & 39.2 & 15.3 & 123.3 & 0.127 & 1.3 \\
\hline 3 & 4 & 24.1 & 38.9 & 8.7 & 79.0 & 0.082 & 0.8 \\
\hline 4 & 5 & 24.3 & 40.1 & 12.8 & 116.3 & 0.120 & 1.0 \\
\hline 5 & 6 & 23.8 & 20.1 & 12.9 & 71.0 & 0.074 & 0.7 \\
\hline 6 & 7 & 24.7 & 59.0 & 13.0 & 144.1 & 0.147 & 1.2 \\
\hline 7 & 8 & 24.2 & 40.8 & 13.0 & 119.5 & 0.123 & 1.0 \\
\hline \multicolumn{8}{|c|}{$\begin{array}{l}\text { (a) Median operation time refers to the midpoint in processing time of the specific filtration test condition } \\
\text { relative to the start time of the test }(\mathrm{T}=0) \text {. Time periods between test conditions were excluded. } \\
\text { (b) Thermocouple accuracy } \pm 2^{\circ} \mathrm{C} \text {. } \\
\text { (c) Pressure transducer accuracy } \pm 1 \text { psig. }\end{array}$} \\
\hline
\end{tabular}




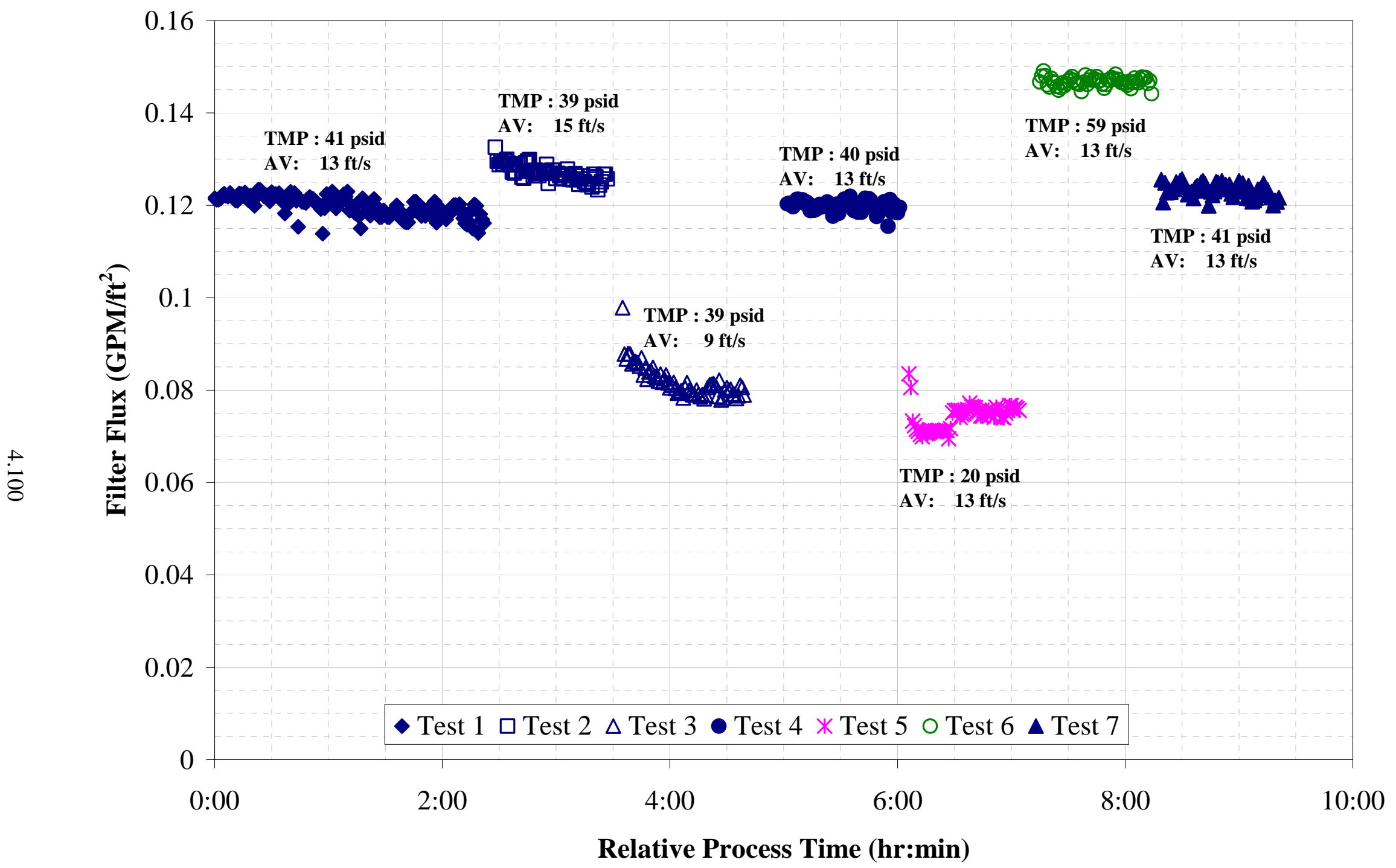

Figure 4.68. Group 6/5 Filter Flux During Washed Leached Solids Matrix 


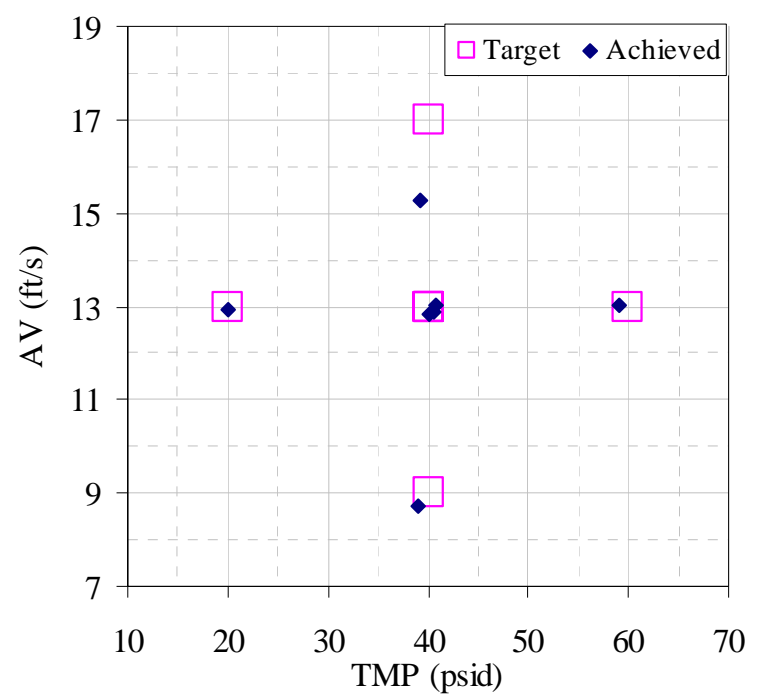

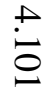

Figure 4.69. Group 6/5 Filter Test Matrix for Leached-Solids

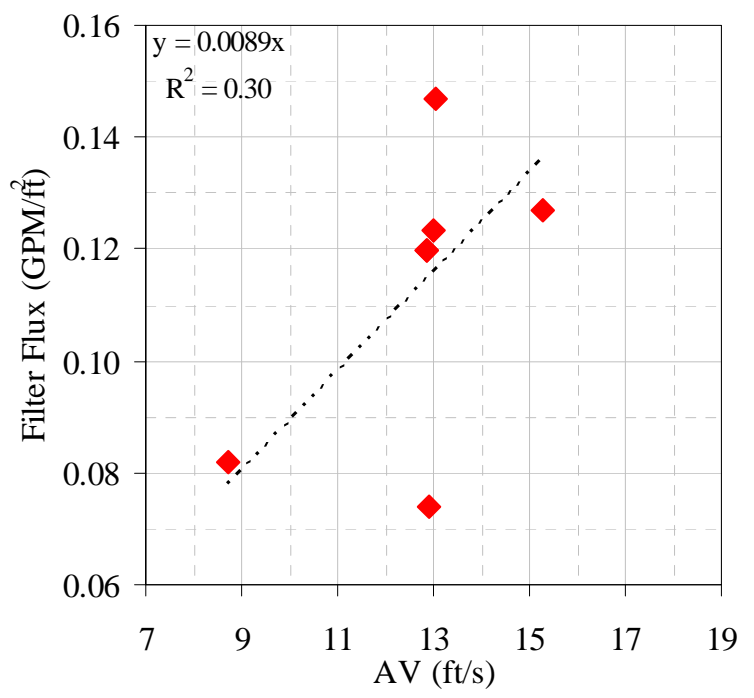

Figure 4.71. Group 6/5 Flux vs. AV for Leached-Solids

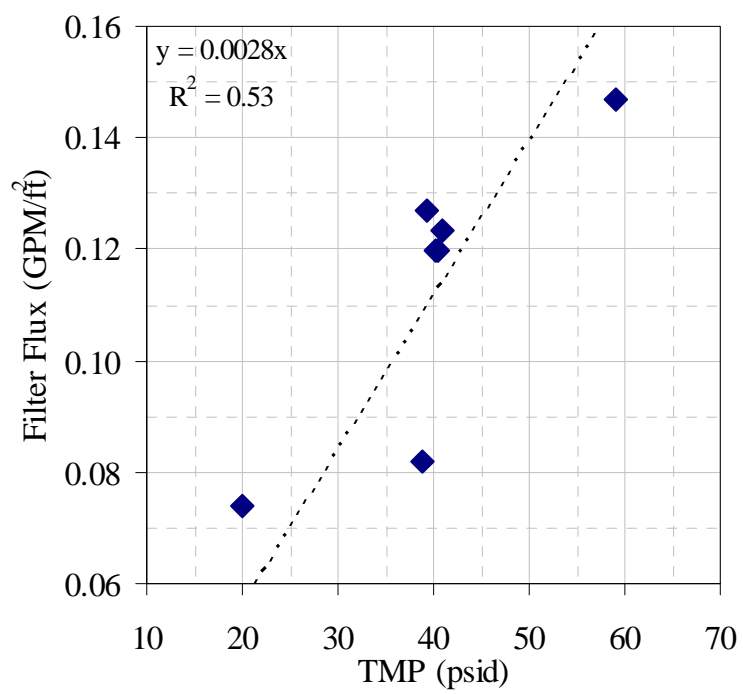

Figure 4.70. Group 6/5 Flux vs. TMP for Leached-Solids

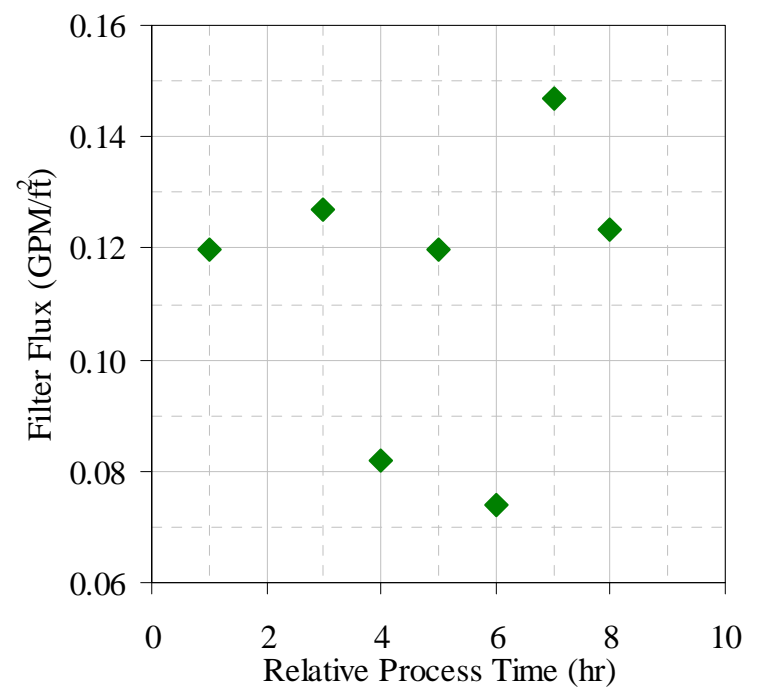

Figure 4.72. Group 6/5 Flux vs. Relative Time for Leached- 


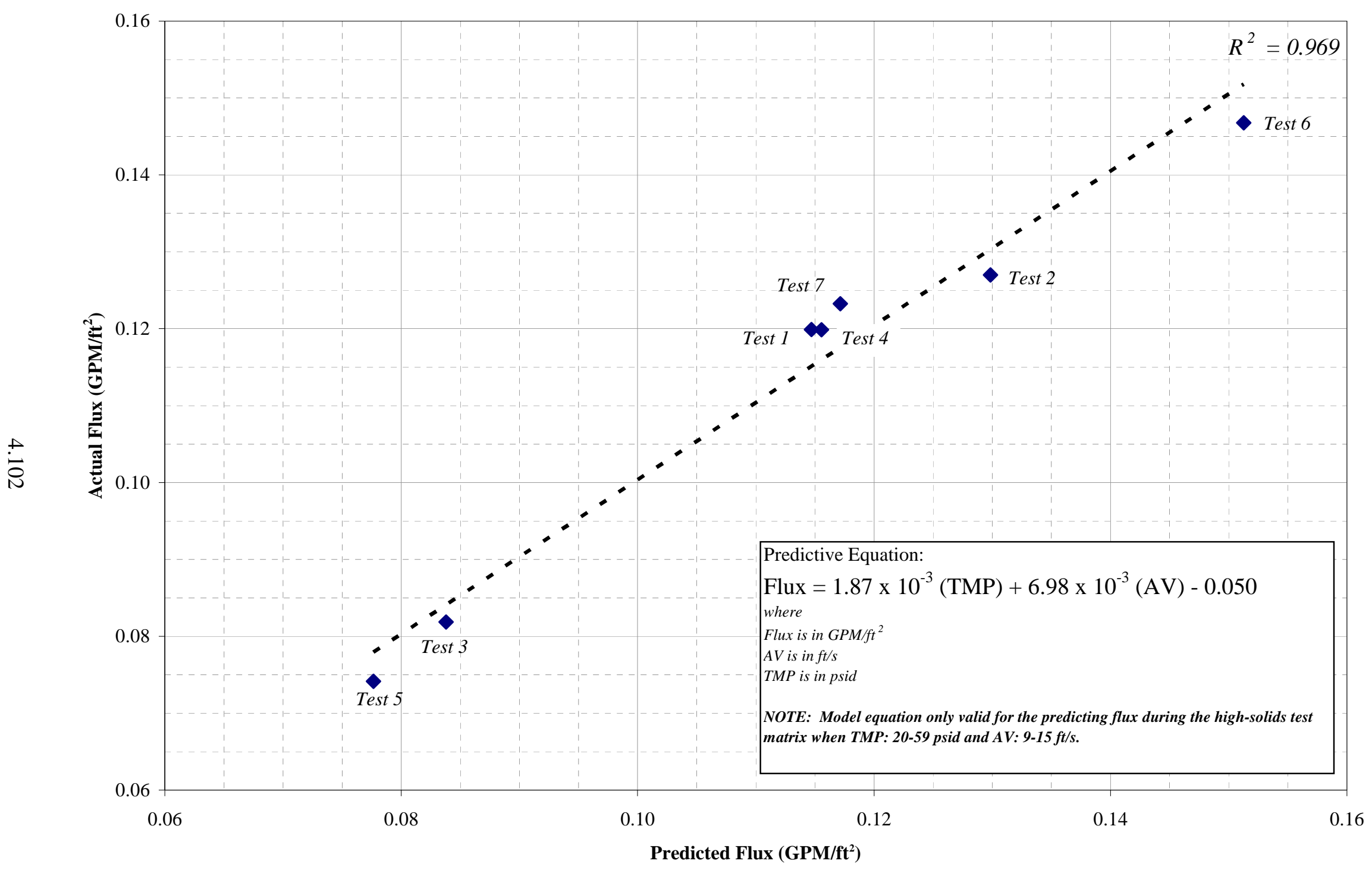

Figure 4.73. Group 6/5 Linear Model of Leached Slurry Filter Flux 
WTP-RPT-172, Rev 0

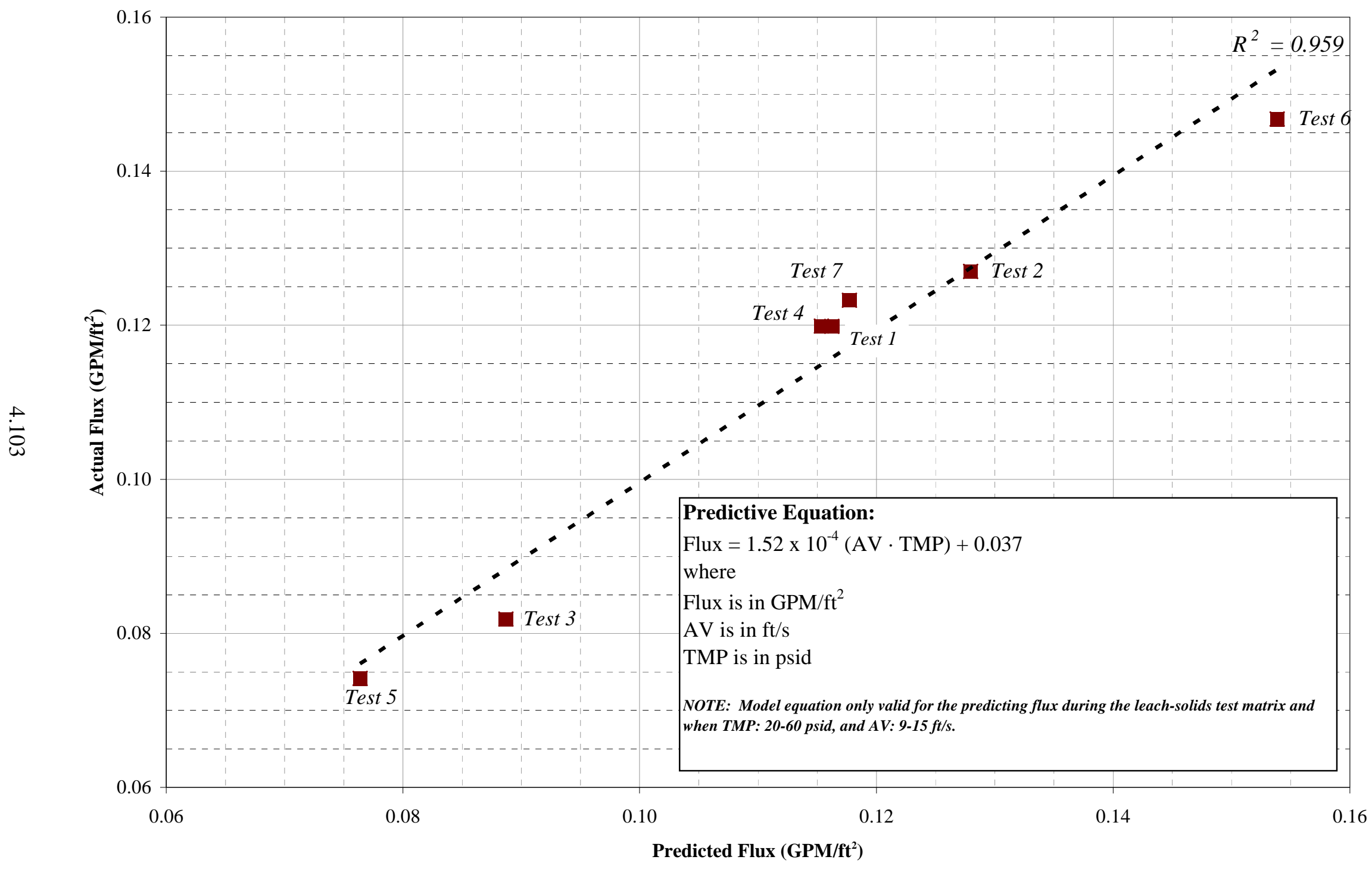

Figure 4.74. Group 6/5 Exponential Model of Leached Slurry 


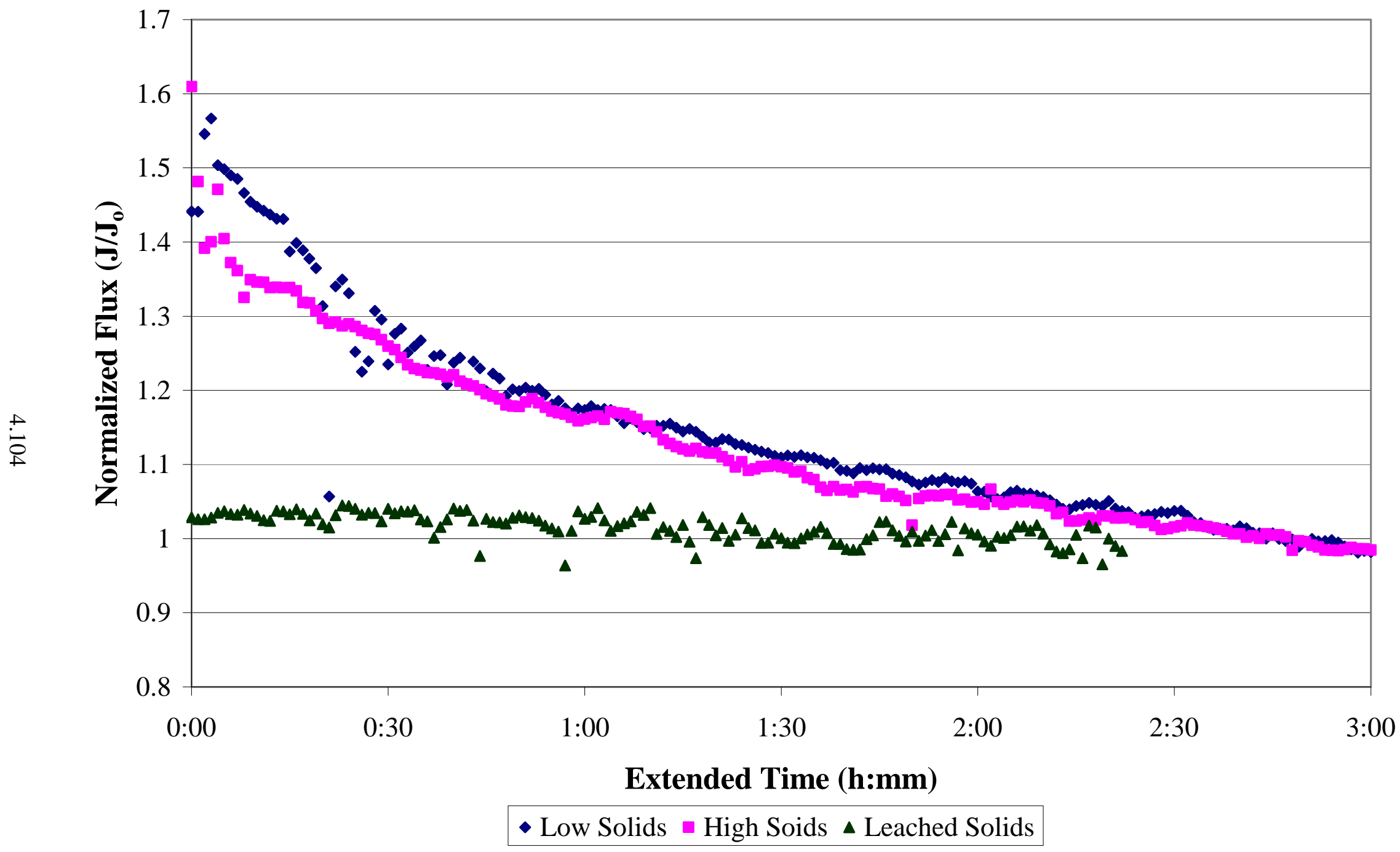

Figure 4.75. Comparison of Normalized Flux at the Standard Condition for Group 6/5 Solids at Low and High Solids Before and After Leaching.

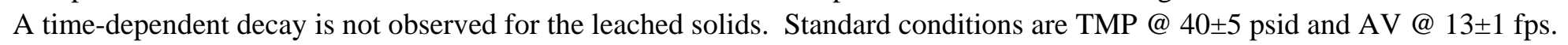




\subsection{Test Summary}

Objectives of the test plan that were accomplished in this test were:

- Filtration of actual waste before and after caustic/oxidative leaching was performed and compared to physical attributes of the slurry.

- Caustic dissolution of aluminum in the form of boehmite was performed with the Group 5 waste, and $\sim 90 \%$ of the UDS were boehmite.

- Oxidative dissolution of chromium was performed with Group 6 waste.

- Final characterization of the leach waste was performed with XRD, SEM, and TEM to confirm the final phases of undissolved leach solids.

\subsubsection{Filtration Results}

Initial filtration of the Group 6 slurry by itself found the filter flux to be lower than that of the Group 5 waste. This was expected, since the sodium concentration of the Group 5 supernate was 3.2M compared to the 5.2M concentration found in the Group 6 supernate. However, the flux significantly decayed over time, indicating that filter resistance was not at steady state during the test. The initial flux started at $0.03 \mathrm{GPM} / \mathrm{ft}^{2}$ and ended at $0.01 \mathrm{GPM} / \mathrm{ft}^{2}$ after 16 hours of operations, which including back pulsing.

To increase the UDS concentration of the slurry, Group 5 waste was blended to the Group 6 material making a composite waste (ratio of Group 5 UDS to Group 6 UDS was 2:1). Surprisingly, the filter flux jumped to $0.035 \mathrm{GPM} / \mathrm{ft}^{2}$. However, decay in the filter flux was still observed. After 16 hours, the filter flux decreased to $0.015 \mathrm{GPM} / \mathrm{ft}^{2}$. An impact from the slurry UDS concentration was not observed when the slurry was dewatered to 13-wt\% UDS. It would have been desirable to concentrate the slurry up to $20 \mathrm{wt} \%$, but this was limited by the quantity of solids used for this test and the limitations of the system.

As in the Group 5 CUF test, caustic leaching of the slurry initially decreased the filter flux (0.006 to 0.01 $\mathrm{GPM} / \mathrm{ft}^{2}$ ) of the slurry by significantly increasing the viscosity of the slurry supernate. But like before, the filter flux increased once the slurry supernate began to be significantly diluted from washing operation. As before, the filter flux increase to level 10 times greater than the flux during caustic dewatering. Oxidative leaching of the slurry appeared to have no impact on the filter flux, despite concerns that precipitation of manganese solids might potential foul the filter. The final filter flux was averaging around $0.12 \mathrm{GPM} / \mathrm{ft}^{2}$. After washing the leach solids, the axial velocity became more significant. This seemed to follow changes measured in the rheology of the slurry that showed increases in consistency and shear stress. Also, it was observed that the decay in the filter flux over time was no longer observed. This supported the idea that the caustic leach and washes of the Group 6 material decreased the slurry's filter resistance by dissolving something in the waste.

Like the Group 5 CUF, PSD measurements again showed particle sizes of UDS in the slurry decreasing over time, but did not change significantly eno $\mu$ gh to impact the filter flux. Overall, filtration rates were impacted the most by changes in the dissolved solids concentration of the supernate, which impacted supernate viscosity. Comparison of the filter flux after caustic leaching $\left(0.006 \mathrm{GPM} / \mathrm{ft}^{2}\right)$ to the final wash $\left(0.12 \mathrm{GPM} / \mathrm{ft}^{2}\right)$ shows a 20 time increase to the filter flux. However, the filter flux increase exceeded the expected increase from viscosity differences. 


\subsubsection{Caustic and Oxidative Leaching Results}

The caustic leach factor resulting from the test was closer to earlier estimates (46\%) and not like the $80 \%$ conversion predicted using the results of the Group 5 CUF test as the basis. The biggest difference between the two tests was that the volume of the leach solution was held constant during the test by making frequent addition of water to make-up for evaporative losses. This indicates that operational problems with the CUF during the first test was the reason for the high leach factor. Additional benchscale leaching tests focused on aluminum dissolution were performed afterwards with a blend of Group 6 and Group 5 material to resolve this discrepancy. These tests are discussed in Section 5.

The oxidative leach occurred using a Mn:Cr ratio of 1.7 and free hydroxide concentration of 0.09M. This resulted in $>95 \%$ of the chromium being leached from the solids, but leaving large amounts of excess permanganate in the wash permeate afterwards. After three volumetric rinses, $90 \%$ of the chromium was removed from the slurry. The remaining $10 \%$ was likely in the supernate and could be removed with additional rinsing. The composition of the slurry after caustic and oxidative leaching is shown in Figure 4.76.

Like before, the only TRU radiochemical isotope in the slurry which saw a significant decrease in the slurry inventory was Cs-137. Measurable quantities of Pu dissolved during the oxidative leach, but the quantity in the supernate was lower than in the as-received waste supernate.

After leaching, XRD, SEM, and TEM identified Na, Al, U, and Si in crystalline phases. XRD identified $\mathrm{Al}$ present in the form of boehmite, and $\mathrm{U}$ in the form of mainly cancrinite and clarkite. SEM and TEM showed larger boehmite crystals (>10 um) mixed with agglomerates of smaller particles, probably boehmite and other inert phases (e.g., iron and uranium). 


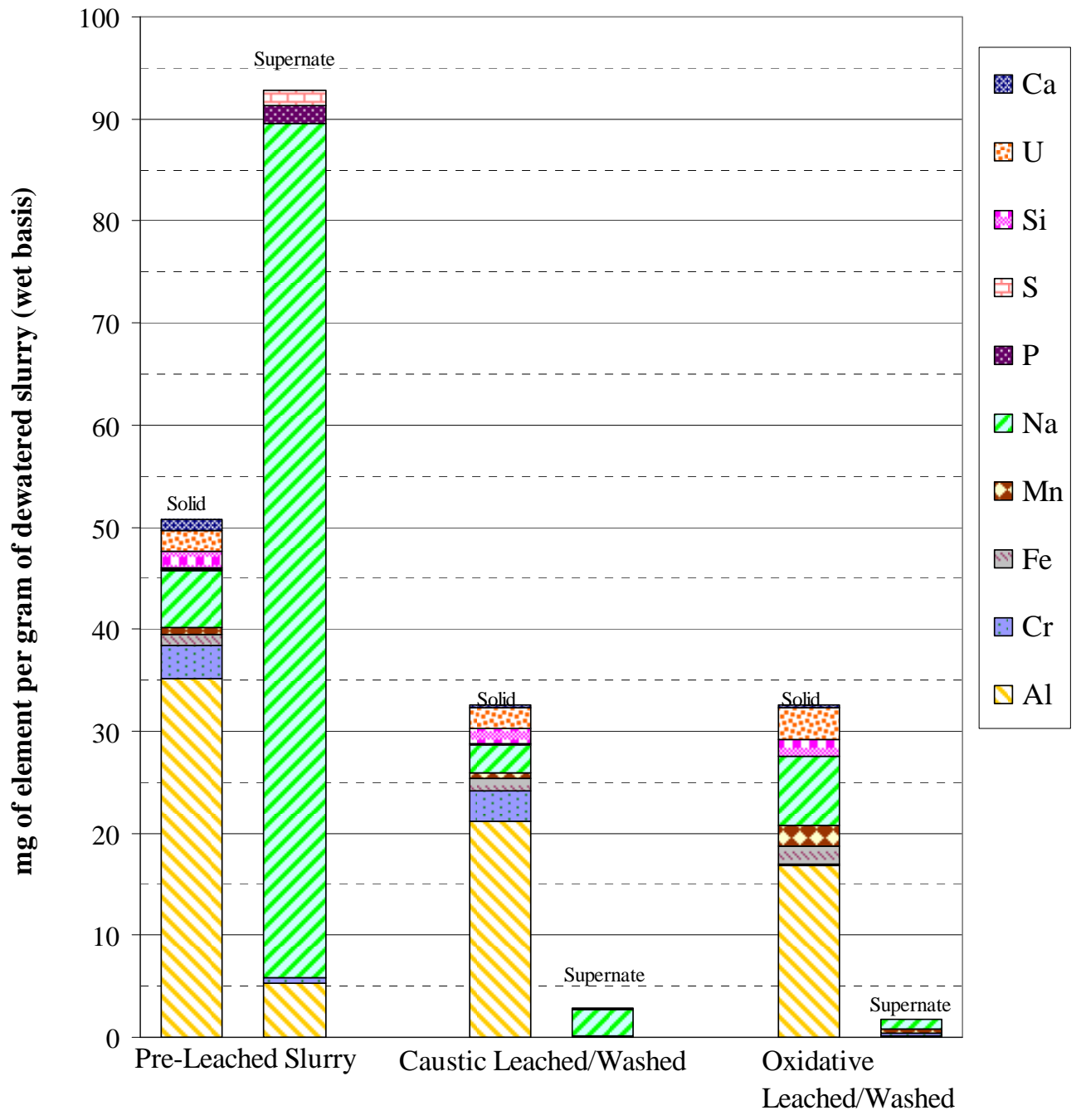

Figure 4.76. Group 6/5 Slurry Composition Before and After Leaching

\subsection{Lessons Learned}

During the course of the test, several problems occurred that impacted the performance of the tests and created some uncertainty about the results. However, conducting the tests created additional understanding about the process that had added benefits.

\section{Sample Evaporation}

During the leaching operation, samples are taken at temperature from the reactor vessel. During this test, the sample vials were not tightly sealed. While these samples were stored in the hot cell before analysis, significant evaporation of the sample occurred. As such, the concentration of the soluble species in the sample increased because of this evaporation. This significant evaporation increases the uncertainty of the measurements. During future tests, steps were taken to account for this evaporation. Samples were weighed immediately after removal from the reactor vessel (before significant evaporation could occur) 
and again immediately before analysis. This allows for correction of the sample results based on the evaporation that occurs during storage.

\section{Slurry Sampling}

During the leaching operation, hot slurry samples must be removed from the reactor vessel with a pipette. However, this process proved to be difficult to accomplish because of the low viscosity of the slurry at elevated temperatures. The pipette would not hold a vacuum, causing the sample to drain out of the pipette quickly before it could be transferred to a sample vial. This limited the quantity of sample that could be reasonably obtained during these process steps. In addition, sub-sampling of slurries appears to have potentially introduced errors into some of the physical-property measurements. To account for these difficulties, future tests should revisit the methods for obtaining slurry samples to avoid attempting to sample hot slurries with pipettes and to evaluate the elimination of sub-sampling of slurries.

\section{$\underline{\text { Sampling Losses }}$}

This type test relied upon the estimated initial chromium content to determine the required permanganate dosage. However, this method did not account for the sampling losses that occurred through the testing before oxidative leaching as it was initially believed that these losses would be relatively small. However, these losses turned out to be significant and as such, the chromium inventory before oxidative leaching was significantly overestimated, resulting in a greater than planned addition of sodium permanganate. Future tests need to evaluate the impact of sample losses on material balance for chromium before oxidative leaching. 
WTP-RPT-172, Rev 0

\subsection{Group 6/5 Aluminum Leaching Studies}

At the conclusion of Group 5 CUF testing, it was observed that very high boehmite conversion had been obtained (relative to the conversion observed during Group 5 parametric testing as reported in WTP-RPT157). There were two series of tests to address differences between the way the CUF leaching tests and the parametric leaching tests were performed. The first series of tests were small benchtop leaching tests performed in the fume hood on material sampled from the Group 6/5 CUF test after filtration, but before the caustic leach. These tests used the same testing protocol as prior parametric tests, but used material that had a similar shear history (that is, they had been sheared through CUF operations for a period of time). These studies also explored the effect of caustic concentrations from 3 to $7 \mathrm{M} \mathrm{NaOH}$. Another test was performed using material that was blended to the same ratios used in the Group 6/5 CUF test, but not sheared in the CUF. This material was leached at a similar caustic concentration used for the CUF test, but at different solids concentrations. The concentrations selected were to mimic leaching conditions if they occurred in either the UFP1 or UFP2 tank to understand if the initial slurry UDS concentration impacts the leach factor. The sections below explain these tests in more detail along with the results.

\subsection{Parametric Testing Varying NaOH Concentration}

Parametric caustic leaching tests were performed on the Group 6/5 sample. The composite Group 6/5 sample material was rinsed with $0.01 \mathrm{M} \mathrm{NaOH}$, subdivided, and subjected to a parametric test matrix for caustic leach testing as discussed in the following sections. ${ }^{(a)}$ The focus on the testing described in this section was specifically for aluminum dissolution, so only a limited analysis of radionuclides in the leached solids was performed. Additional parametric leaching testing of this material was performed that focused more on the impacts on Pu. The results of that testing were reported in WPT-RPT-171, Laboratory Demonstration of the Pretreatment Process with Caustic and Oxidative Leaching Using Actual Hanford Tank Waste (Fiskum 2009).

\subsubsection{Initial Washing of the Group 6/5 Solids}

The Group 6/5 composite sample was mixed using an overhead stirrer fitted with a 3-bladed stainless steel impeller. A 62.4-g aliquot of composite sample was removed with a large transfer pipette and transferred to a 200 -mL centrifuge bottle. The 62.4-g slurry was expected to contain $\sim 6 \mathrm{~g}$ of waterinsoluble solids. The slurry aliquot was centrifuged at 2,500 rpm (1,200 G) for $15 \mathrm{~min}$, and then the supernatant was removed. The volume of centrifuged solids was estimated to be $\sim 10 \mathrm{~mL}$ based on volume graduations on the sample bottle. Approximately $30 \mathrm{~mL}$ ( $3 \times$ the centrifuged solids volume) of $0.01 \mathrm{M} \mathrm{NaOH}$ was added to wash the solids, and the slurry was mixed for 15 minutes using an overhead mixer. The slurry was centrifuged at $\sim 1,200 \mathrm{G}$ for $15 \mathrm{~min}$, and then the supernatant was removed. The washing steps were repeated twice for a total of three washes.

\subsubsection{Division of the Washed Group 6/5 Solids}

To conduct a successful sample subdivision, the washed centrifuged solids needed to be diluted. DI water (75.6 mL) was added to the solids, resulting in a final mass of $\sim 91.4$ g slurry.

(a) Testing was conducted according to TI-RPP-WTP-554, Parametric Caustic and Oxidative Leach Test of Group 5/6 Hanford Tank Waste, Post-CUF Test, L Snow, November 2007. 
An overhead mixer equipped with a 3-bladed stainless steel impeller was used to homogenize the diluted slurry. Four 21 -g slurry samples were transferred into 125-mL HDPE bottles using a large disposable polyethylene pipette. The samples were removed from the hot cell for follow-on processing at the fume hood workstation.

One additional sample (G5/6-WL-Solids) containing approximately $5.1 \mathrm{~g}$ of slurry was transferred to a 60-mL HDPE bottle. A portion of this sample was submitted for a $\mathrm{KOH}$ fusion and the following subsequent analyses: ICP-OES metals, GEA, Pu, total alpha, total beta, ${ }^{90} \mathrm{Sr}$, and U by KPA. Another portion of this sample was dried to determine the wt\% UDS. It was determined that the slurry contained $8.71 \mathrm{wt} \%$ UDS. These analyses were performed to establish the starting composition of the washed solids. Another sample (554-G5/6-WL Liquor) containing $30 \mathrm{~g}$ of the wash solution was transferred to a 60-mL HDPE bottle. This sample was submitted for analysis by ICP, ion chromatography (IC), GEA, and density. Each of the four 21-g slurry samples was intended to contain $\sim 1$ g UDS; however, after determining the wt\% UDS, it was determined that each sample contained $\sim 1.8$ g solids. Based on this, total dissolution of $\mathrm{Al}$ would have resulted in a concentration in solution of $0.223 \mathrm{M} \mathrm{Al}$.

\subsubsection{Caustic Leaching of the Washed Group 6/5 Solids}

The leaching test matrix for each of the four samples is summarized in Table 5.1. The test matrix evaluated the effects of free hydroxide concentration (3 to $7 \mathrm{M} \mathrm{NaOH}$ ) on aluminum leaching kinetics.

Table 5.1. Group 6/5 Caustic Leaching Conditions

\begin{tabular}{|c|c|c|c|c|c|}
\hline \multirow[b]{2}{*}{ Bottle ID } & \multicolumn{2}{|c|}{ Free [OH], M } & \multicolumn{2}{|c|}{ [Na], M } & \multirow{2}{*}{$\begin{array}{c}\text { Temperature, } \\
{ }^{\circ} \mathbf{C}^{(\mathbf{b})}\end{array}$} \\
\hline & Target & Measured $^{(\mathrm{a})}$ & Target & Measured $^{(\mathrm{a})}$ & \\
\hline G5/6-CL-100-3 & 3 & 3.18 & 3 & 3.38 & 100 \\
\hline G5/6-CL-100-5a & 5 & 5.44 & 5 & 5.55 & 100 \\
\hline G5/6-CL-100-5b & 5 & 4.86 & 5 & 4.91 & 100 \\
\hline G5/6-CL-100-7 & 7 & 7.34 & 7 & 7.45 & 100 \\
\hline \multicolumn{6}{|c|}{$\begin{array}{l}\text { (a) The measured analyte concentrations represent the equilibrium concentration obtained } \\
\text { after a 24-h contact time. Samples were allowed to cool to room temperature before } \\
\text { being submitted to ASO for analysis. } \\
\text { (b) The sampling temperature uncertainty was } \pm 2.5^{\circ} \mathrm{C} \text {. } \\
\text { Analytical Service Request (ASR): } 8060\end{array}$} \\
\hline
\end{tabular}

The $\mathrm{NaOH}$ concentration in each leaching mixture was adjusted to support the test matrix. Sodium hydroxide (19 M) was added to each aliquot of the washed solids slurry in the following amounts: $15.8 \mathrm{~mL}$ to yield $3 \mathrm{M} \mathrm{NaOH}$, $26.3 \mathrm{~mL}$ to yield $5 \mathrm{M} \mathrm{NaOH}$, and $36.8 \mathrm{~mL}$ to yield $7 \mathrm{M} \mathrm{NaOH}$. The leaching mixtures were then diluted to a final volume of $100 \mathrm{~mL}$ (with an estimated uncertainty of $2 \mathrm{~mL}$ ) with DI water. The contact time with the concentrated $\mathrm{NaOH}$ was brief $(<5 \mathrm{~min})$. The sample bottles were weighed after each addition of reagents $(\mathrm{NaOH}$ and water). Each leaching vessel was closed with a cap equipped with a tube condenser. The condenser was used to eliminate pressurization and minimize water loss, while at the same time minimizing the spread of contamination.

Sample G5/6-CL-100-5b was inadvertently knocked over after adding the NaOH. Some of the solids and hydroxide were lost. Data for this sample will not be reported. 
The sample slurries were transferred to a temperature-controlled shaker table. The temperature was controlled with an aluminum heating block (J-KEM Scientific, Inc.) equipped with a Type T thermocouple. The heating block was supported on a J-KEM BTS-3500 digital benchtop shaker (Figure 5.1). The shaking speed was digitally controlled to $200 \mathrm{rpm}$; based on visual inspection, the solids were well suspended in solution. Before leach testing was conducted, the heating block was preheated to the appropriate temperature.

The leaching mixtures were shaken at temperature for 24 hours, and solution samples were withdrawn at 0 (taken before insertion into heating block), 1, 2, 4, 8, and 24 hours. At each sampling time, the shaker was stopped, and the solids were allowed to settle for $\sim 5$ to $10 \mathrm{~min}$, resulting in sufficient clarification of the aqueous portion to support sampling without solids removal. Approximately 1.5-mL of the clarified leachate solution was withdrawn with a transfer pipette and filtered through a $0.45-\mu \mathrm{m}$ pore size nylon syringe filter; the syringe filter and the syringe had been pre-heated in an oven to the sample temperature $\left(100^{\circ} \mathrm{C}\right)$ before filtering in an effort to minimize temperature changes impacting the sample. The samples were thus taken as close to $100{ }^{\circ} \mathrm{C}$ as possible and were only cooled after separation from the solid phase. These supernate samples were then prepared for analysis. One 0.5-mL sample of filtered solution was acidified with $15 \mathrm{~mL}$ of $0.3 \mathrm{M} \mathrm{HNO}_{3}$ for analysis by ICP-OES; another $0.5-\mathrm{mL}$ sample of filtered solution was added to $2.5 \mathrm{~mL}$ of $1 \times 10^{-4} \mathrm{M} \mathrm{NaOH}$ for analysis by ion chromatography. The remaining filtered solution was returned to the leaching vessel, and the leaching process was continued. The new liquid level was marked after each sample was taken. Evaporation was minimal during the course of the experiment, but when evaporation was observed, DI water was added to restore the volume to the previously marked liquid level. After 24 hours, additional leachate samples were taken to determine the free hydroxide ion concentration and gamma emitters by GEA.

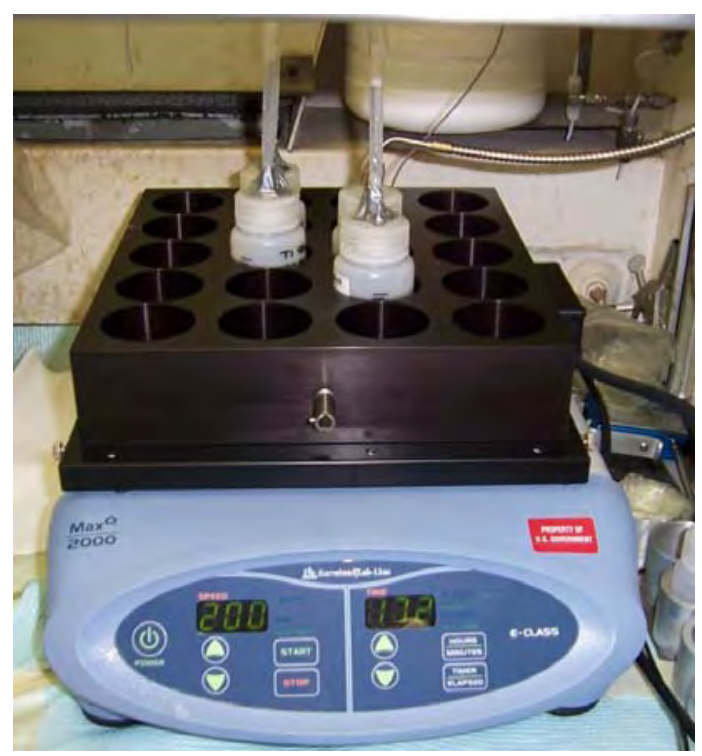

Figure 5.1. Aluminum Heating Block and Shaker Table 
After the final samples were taken at temperature, the slurries were removed from the mixing/heating block and cooled to ambient $\left(\sim 22^{\circ} \mathrm{C}\right)$ temperature. The slurries were centrifuged, and the leachate was decanted. $^{\text {(a) }}$

The equilibrium concentration values for free hydroxide and sodium, which are shown in Table 5.1, were based on results from the samples taken at 24 hours.

\subsubsection{Washing of Caustic-Leached Group 6/5 Solids for Analysis}

The solids from sample G5/6-CL-100-5a, leached at $100^{\circ} \mathrm{C}$ in $5 \mathrm{M} \mathrm{NaOH}$, were prepared for characterization. The solid sample was slurried in $15 \mathrm{~mL}$ of $0.01 \mathrm{M} \mathrm{NaOH}$, the compacted solids were broken up with disposable pipette, and the slurry was mixed on a shaker table for 15 minutes. The slurry was centrifuged for $5 \mathrm{~min}$ and the supernatant removed. The wash steps were repeated twice more for a total of three washes. After the final wash, the solids were slurried in $\sim 2 \mathrm{~mL}$ of DI water. A portion of this sample was submitted for a KOH fusion and the following subsequent analyses: ICP-OES metals, GEA, Pu, total alpha, total beta, ${ }^{90} \mathrm{Sr}$, and U by KPA.

\subsubsection{Caustic Leaching Results}

The $\mathrm{Al}$ dissolution rates of Group 6/5 sludge as a function of time and free hydroxide concentrations were evaluated. The leaching data at constant temperature and varying free-hydroxide concentrations are summarized in Figure 5.2.

(a) The contact dose rates of the leached solids were too high to safely conduct transfer to volume-graduated centrifuge tubes to assess the volume of centrifuged solids. 
WTP-RPT-172, Rev 0

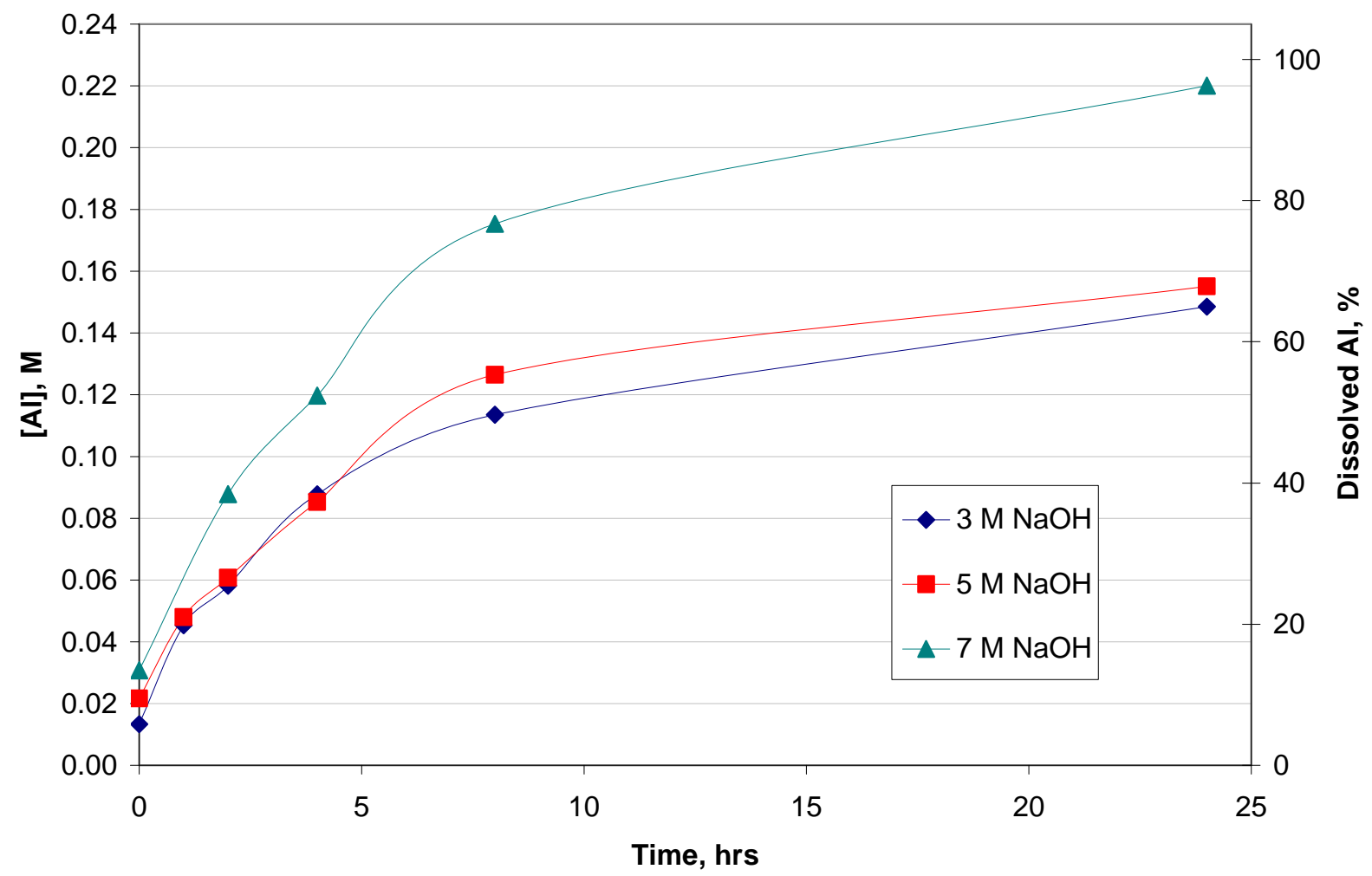

Figure 5.2. Group 6/5 Solids Aluminum Dissolution Data at $100^{\circ} \mathrm{C}$ in 3, 5, and $7 \mathrm{M} \mathrm{NaOH}$ Solutions

The initial rapid rise in $\mathrm{Al}$ concentration over the first four hours was most likely associated with gibbsite dissolution; the subsequent increase in $\mathrm{Al}$ concentration was associated with the dissolution of boehmite. Boehmite is known to dissolve much more slowly than gibbsite (Scotford and Glastonbury 1971).

The material balance indicates that each reaction vessel received 0.61 grams of undissolved Al. Each reaction vessel contained $100 \mathrm{~mL}$ of leachate solution. The final analyses for these samples indicated that the tests at 3, 5, and $7 \mathrm{M} \mathrm{NaOH}$ resulted in the dissolution of $0.4,0.42$, and 0.59 grams of $\mathrm{Al}$ respectively.

\subsubsection{Assessment of Final Leach Conditions}

A summary of the final (24-h) leach solution composition and physical parameters is shown in Table 5.2. The final free hydroxide and sodium concentrations were at the targeted values within the uncertainty of the analytical methods $( \pm 15 \%)$. The calculated percentage of aluminum that was removed at each leaching condition is also shown. Appendix D summarizes the concentrations of Al, Cr, Fe, Na, P, Si, fluoride, nitrite, nitrate, phosphate, and sulfate in the leach solutions at each sampling time. The GEA results for ${ }^{60} \mathrm{Co}$ and ${ }^{241} \mathrm{Am}$ were $<\mathrm{MDL}$ (minimum detection limit); the GEA results are also provided in Appendix D. 
Table 5.2. Group 6/5 Leaching Final Aqueous Phase Conditions

\begin{tabular}{|c|c|c|c|c|c|c|}
\hline $\begin{array}{c}\text { Temp., }{ }^{(a)} \\
{ }^{\circ} \mathrm{C}\end{array}$ & $\begin{array}{c}\text { Density, } \\
\text { g/mL }\end{array}$ & $\begin{array}{c}\text { Free } \\
{[\mathrm{OH}]{ }^{(\mathrm{a})}} \\
\mathrm{M}\end{array}$ & $\mathrm{Na}^{(\mathbf{b})}, \mathrm{M}$ & {$[\mathrm{Al}]^{(\mathrm{a})}, \mathbf{M}$} & $\begin{array}{l}\text { Wt \% Al } \\
\text { Removed }\end{array}$ & $\begin{array}{l}{ }^{137} \mathbf{C s},{ }^{(\mathbf{b})} \\
\mu \mathrm{Ci} / \mathrm{mL}\end{array}$ \\
\hline 100 & 1.14 & 3.18 & 3.38 & 0.148 & 65 & 0.78 \\
\hline 100 & 1.21 & 5.44 & 5.55 & 0.155 & 68 & 0.80 \\
\hline 100 & 1.28 & 7.34 & 7.45 & 0.220 & 97 & 1.18 \\
\hline \multicolumn{7}{|c|}{$\begin{array}{l}\text { (a) The sampling temperature uncertainty was } \pm 2.5^{\circ} \mathrm{C} \text {. } \\
\text { (b) The measured analyte concentrations represent the equilibrium concentration } \\
\text { obtained after a } 24 \text {-h contact time. Samples were allowed to cool to room } \\
\text { temperature before being submitted to ASO for analysis. } \\
\text { Analvtical Service Reauest (ASR) } 8060\end{array}$} \\
\hline
\end{tabular}

\subsubsection{Leached Solids Wash Solution}

The densities of the three sequential wash solutions were $1.027 \mathrm{~g} / \mathrm{mL}, 1.009 \mathrm{~g} / \mathrm{mL}$, and $1.000 \mathrm{~g} / \mathrm{mL}$, respectively. The composite wash solution density, ICP metals, and anion composition are shown in Table 5.3.

Table 5.3. Solids Wash Solution Composition

\begin{tabular}{|c|c|c|c|c|c||}
\hline Analyte & $\boldsymbol{\mu} \mathbf{g} / \mathbf{m L}$ & Analyte & $\boldsymbol{\mu} \mathbf{g} / \mathbf{m L}$ & Physical Properties & Value \\
\hline $\mathrm{Al}$ & 164.1 & $\mathrm{Si}$ & 6.2 & Density & $1.007 \mathrm{~g} / \mathrm{mL}$ \\
\hline $\mathrm{Cr}$ & 13.5 & nitrate & 91.5 & & \\
\hline $\mathrm{Na}$ & 5,290 & phosphate & 1.9 & & \\
\hline $\mathrm{P}$ & {$[2.21]$} & sulfate & {$[0.23]$} & & \\
\cline { 1 - 1 } Analytical Service Request (ASR): 8060 \\
\hline
\end{tabular}

\subsubsection{Chemical and Radiochemical Composition}

The initial composition of washed solids (before caustic leaching) is provided in Table 5.4 as well as the solids composition after leaching in $5 \mathrm{M} \mathrm{NaOH}$ at $100^{\circ} \mathrm{C}$ for $24 \mathrm{hrs}$ and washing. The "average before leaching" value for each analyte was calculated by multiplying the concentration found in the initial solids (in $\mu \mathrm{g} / \mathrm{g}$ ) by the $1.83 \mathrm{~g}$ of solids (on a dry basis) that was in the original sample. The total mass of each analyte that was dissolved was calculated by multiplying the concentration of each analyte in the 24$\mathrm{hr}$ leach samples by the volume of solution $(100 \mathrm{~mL})$. This mass was then subtracted from the initial mass to obtain the total mass of each analyte that was not dissolved, or the "average after leaching" value shown in Table 5.4.

The calculated leach factors for major and minor constituents are provided. Notably, extended (24 hrs) leach times did not significantly mobilize $\mathrm{U}, \mathrm{Sr}$, or $\mathrm{Mn}$ to the aqueous phase. Consistent with previous leaching tests with Hanford sludge solids, a significant fraction (66\%) of the ${ }^{137}$ Cs dissolved, and would be routed to the LAW pretreatment facility in the liquid phase. In the leaching test conducted in $7 \mathrm{M}$ $\mathrm{NaOH}, 98 \%$ of the ${ }^{137} \mathrm{Cs}$ dissolved. Note that $\mathrm{Pu}, \mathrm{U}$, and $\mathrm{Sr}$ were not measured by radchem analysis. 
As shown in Figure 5.3, approximately $60 \%$ of the mass dissolved with a 24-hr leach time. Based on calculations using the glass loading limits of $0.11 \mathrm{~g} \mathrm{Al}_{2} \mathrm{O}_{3}$ and $0.005 \mathrm{~g} \mathrm{Cr}_{2} \mathrm{O}_{3}$ per gram of glass, after leaching in $5 \mathrm{M} \mathrm{NaOH}$, $3.33 \mathrm{~g}$ of glass would be formed per gram of $\mathrm{Al}$ initially present, while $4.5 \mathrm{~g}$ of glass would be formed per gram of $\mathrm{Cr}$ initially present. Therefore chromium is expected to become the limiting component of the glass loading if only caustic leaching is performed. 
Table 5.4. Group 6/5 Sludge Leached Solids Composition and Leach Factors After Leaching for $24 \mathrm{~h}$ at $100 \mathrm{C}$ in $5 \mathrm{M} \mathrm{NaOH}$ (dry basis)

\begin{tabular}{|c|c|c|c|}
\hline Analyte & $\begin{array}{c}\text { Avg. Before } \\
\text { Leaching, } \\
\mu g \\
\text { (ASR 8060) }\end{array}$ & $\begin{array}{c}\text { Avg. After } \\
\text { Leaching, } \\
\mu g \\
\text { (ASR 8060) }\end{array}$ & $\begin{array}{l}\text { Observed } \\
\text { Leach } \\
\text { Factor }\end{array}$ \\
\hline $\mathrm{Al}$ & 612,393 & 193,907 & 0.68 \\
\hline B & [383] & [155] & -- \\
\hline $\mathrm{Bi}$ & {$[1,606]$} & [974] & -- \\
\hline $\mathrm{Cd}$ & [32] & $<1.84$ & -- \\
\hline $\mathrm{Cr}$ & 47,915 & 15,399 & 0.68 \\
\hline $\mathrm{Fe}$ & 20,535 & 16,711 & 0.19 \\
\hline Mn & 9,072 & $<9,046$ & -- \\
\hline $\mathrm{Na}$ & 46,546 & $*$ & -- \\
\hline $\mathrm{P}$ & {$[2,555]$} & {$[1,472]$} & -- \\
\hline$S$ & {$[3,012]$} & 0 & -- \\
\hline $\mathrm{Si}$ & 26,193 & 11,501 & 0.56 \\
\hline $\mathrm{Sr}$ & 1,721 & 1,657 & 0.04 \\
\hline$\overline{\mathrm{U}}$ & 32,126 & $<31,082$ & -- \\
\hline $\mathrm{Zn}$ & 363 & [146] & -- \\
\hline U (KPA) & 27,900 & -- & -- \\
\hline${ }^{60} \mathrm{Co}$ & $4.75 E-02$ & $4.71 \mathrm{E}-02$ & 0.01 \\
\hline${ }^{90} \mathrm{Sr}$ & $1.04 \mathrm{E}+03$ & -- & -- \\
\hline${ }^{137} \mathrm{Cs}$ & $1.21 \mathrm{E}+02$ & $4.05 \mathrm{E}+01$ & 0.66 \\
\hline${ }^{154} \mathrm{Eu}$ & 7.73E-01 & 7.70E-01 & -- \\
\hline${ }^{155} \mathrm{Eu}$ & $2.57 \mathrm{E}-01$ & 2.37E-01 & 0.08 \\
\hline${ }^{239+240} \mathrm{Pu}$ & 1.62 & -- & -- \\
\hline${ }^{241} \mathrm{Am}$ & 2.98 & 2.95 & 0.01 \\
\hline total alpha & 4.95 & -- & -- \\
\hline total beta & $2.25 \mathrm{E}+03$ & -- & -- \\
\hline \multicolumn{4}{|l|}{ Opportunistic } \\
\hline $\mathrm{Ag}$ & [26] & -- & -- \\
\hline As & $<286$ & -- & -- \\
\hline $\mathrm{Ba}$ & 215 & $<173$ & -- \\
\hline $\mathrm{Be}$ & [1.37] & -- & -- \\
\hline $\mathrm{Ca}$ & $<8,080$ & {$[7,749]$} & -- \\
\hline $\mathrm{Ce}$ & $<61$ & -- & -- \\
\hline Co & $<25$ & -- & -- \\
\hline $\mathrm{Cu}$ & 184 & [75.4] & -- \\
\hline Dy & $<21$ & -- & -- \\
\hline $\mathrm{Eu}$ & [7.03] & -- & -- \\
\hline $\mathrm{La}$ & [109] & $<92$ & -- \\
\hline $\mathrm{Li}$ & [120] & {$[3.05]$} & -- \\
\hline $\mathrm{Mg}$ & 628 & $<541$ & -- \\
\hline Mo & [79] & -- & -- \\
\hline $\mathrm{Nd}$ & [237] & $<23.5$ & -- \\
\hline
\end{tabular}


Table 5.4 (Cont'd)

\begin{tabular}{|c|c|c|c|}
\hline Analyte & $\begin{array}{c}\text { Avg. Before } \\
\text { Leaching, } \\
\mu g / g \\
\text { (ASR 8060) }\end{array}$ & $\begin{array}{c}\text { Avg. After } \\
\text { Leaching, } \\
\mu g / g \\
\text { (ASR 8060) }\end{array}$ & $\begin{array}{c}\text { Observed } \\
\text { Leach } \\
\text { Factor }\end{array}$ \\
\hline $\mathrm{Pb}$ & [684] & -- & -- \\
\hline $\mathrm{Pd}$ & $<47$ & -- & -- \\
\hline Rh & $<95$ & -- & -- \\
\hline $\mathrm{Ru}$ & $<49$ & -- & -- \\
\hline $\mathrm{Sb}$ & $<228$ & -- & -- \\
\hline Se & [915] & $<306$ & -- \\
\hline Sn & $<184$ & -- & -- \\
\hline $\mathrm{Ta}$ & $<147$ & -- & -- \\
\hline $\mathrm{Te}$ & $<205$ & -- & -- \\
\hline Th & [99] & -- & -- \\
\hline $\mathrm{Ti}$ & 148 & $<136$ & -- \\
\hline $\mathrm{Tl}$ & $<220$ & -- & -- \\
\hline $\mathrm{V}$ & $<24$ & -- & -- \\
\hline $\mathrm{W}$ & [187] & -- & -- \\
\hline $\mathrm{Y}$ & 43 & $<32.8$ & -- \\
\hline \multicolumn{4}{|c|}{$\begin{array}{l}\text { ASR } 8060 \\
\text { Analyte uncertainties were typically within } \pm 15 \% \text { (2-s); results in } \\
\text { brackets indicate that the analyte concentrations were greater than } \\
\text { the minimum detection limit (MDL) and less than the estimated } \\
\text { quantitation limit (EQL), and uncertainties were }>15 \% \text {. } \\
\text { * - the quantity of insoluble Na remaining could not be determined } \\
\text { because of the presence of a large quantity of unwashed Na from the } \\
\text { leaching process }\end{array}$} \\
\hline
\end{tabular}


WTP-RPT-172, Rev 0

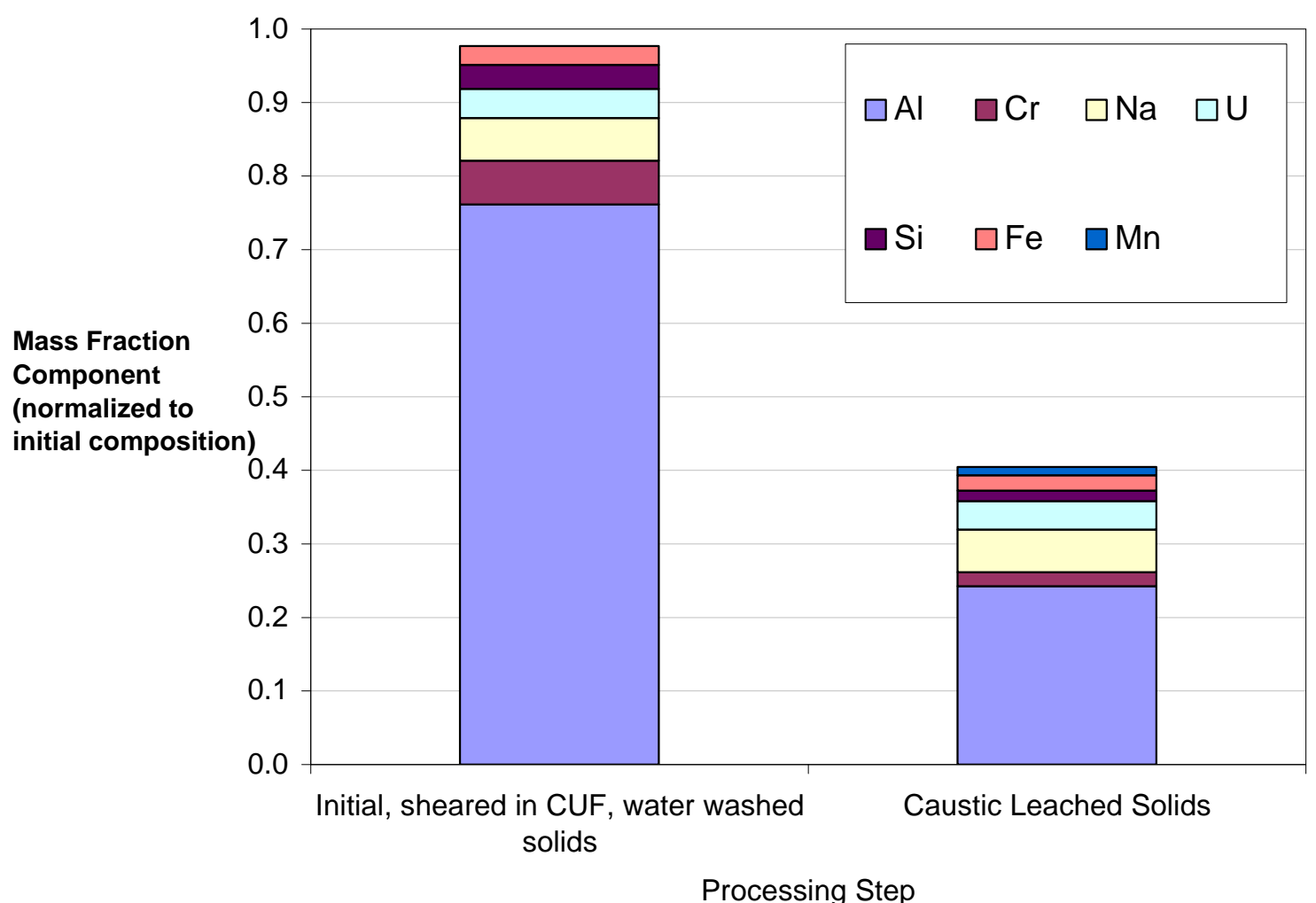

Figure 5.3. Group 6/5 Sludge Reduction in Solid Mass with Caustic Leaching for $24 \mathrm{~h}$ at $100 \mathrm{C}$ in $5 \mathrm{M}$ $\mathrm{NaOH}$

\subsection{Benchtop Batch Leaching Varying Solids Concentration}

As a comparison to the parametric tests performed in the previous section, two 100-mL batch leaches were performed using a blend of the remaining characterization samples of the Group 5 and 6 wastes to simulate the mixture used in the Group 6/5 CUF test. ${ }^{\text {(a) }}$ The tests described in the following sub-section were to focus on two aspects:

1) The composite waste material used was not introduced into the CUF testing apparatus and would show if the shearing action of the cross-flow filtration impacted the aluminum leaching factor.

2) The two waste simulant samples were prepared at different UDS concentrations to simulate leaching conditions in either the pre-treatment UFP1 vessel (UDS 5 wt\%) or UFP2 vessel (UDS up to $\sim 20 \mathrm{wt} \%$ ), to understand if operating at different solid concentrations would impact the leach factor.

\subsubsection{Test Scheme}

Figure 5.4 outlines the batch leaching tests described in the following section.

(a) Testing was conducted according to TI-RPP-WTP-565, Bench Scale Caustic Leaching of Group 5 and 6 Hanford Tank Waste Composite to Simulate Slurry Concentrations in UFP1 and UFP1, R Shimskey, December 2007. 
Initially, the remaining samples of the Group 5 and 6 waste composites were sub-sampled to produce a concentrated slurry (17 wt\% USD) at the same waste-solids ratio implemented on the Group 6/5 CUF test (69\% Group 5 and 31\% Group 6). Once the blended slurry was well mixed, it was sampled for analysis and split into the two reaction vessels used to represent leaching conditions in the UFP1 and UFP2 Pretreatment vessels. After splitting the samples, the slurry in the UFP1 test was diluted with excess slurry supernate from the Group 6/5 CUF test to a concentration of 4-wt\% UDS, while the slurry sample in the UFP2 test was left as is.

Caustic solutions were then added to each testing vessel at concentrations to provide a final freehydroxide concentration to maintain aluminum solubility (relative to gibbsite at room temperature) and simulate volume increase from condensate due to heating with steam. Condensate estimates were based on approximate estimates of the quantity of condensate to be supplied in WTP. After the additions were made, both sample vessels were placed in a boiling water bath and allowed to heat to $100^{\circ} \mathrm{C}$. Magnetic stirring bars were placed inside the vessels to provide agitation. Once the solutions reached temperature, the leach permeate was sub-sampled using filter syringes over an 8-hour heating time to track the aluminum dissolution rate. After 8-hours, the leaching vessels were removed from the water bath and cooled overnight. The next day, the slurries were centrifuged to separate the remaining solids from the leach supernate. The leach supernate was sampled directly for metal and hydroxide analyses. The solids were tripled rinsed with $0.01 \mathrm{M} \mathrm{NaOH}$ and then sub-sampled for metal analyses as well. Details of the sampling plan and analytical results are found in Appendix M. 


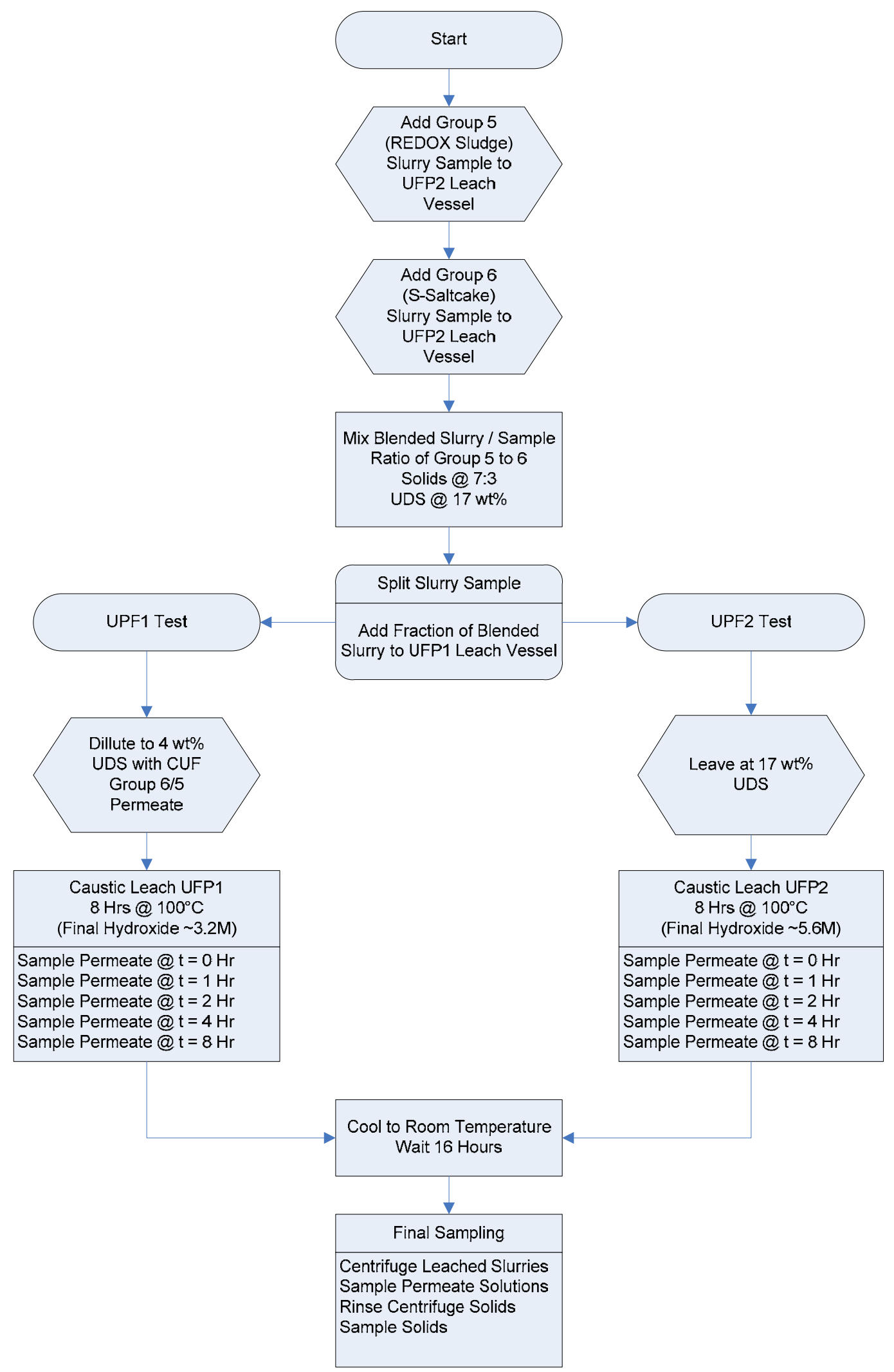

Figure 5.4. Group 6/5 Batch Leaching Test Flowchart 


\subsubsection{Blending Group 6/5 Samples for Leaching}

Archive samples from each of the composite waste samples that remained from the Group 6/5 CUF testing found in the SAL were collected and re-homogenized using an over-headed agitator in the hot cell. While each archive sample was agitated, it was sub-sampled using a pipette and placed in a 200-mL centrifuge bottle that was to be used for performing the UFP2 leaching study. Pipetting is the best available method for transferring samples in cell and has been demonstrated previously to provide very reliable results. The bottle was placed on a balance to track the mass that was being transferred to accurately achieve the desired ratio of each composite waste sample. Afterwards, the sample was mixed using an over-head agitator to homogenize the waste and was sub-sampled for analysis. This sub-sample was analyzed for ICP-metals, and the calculated solid composition using the ICP-metal results from the permeate analysis from the Group 6/5 CUF test. These results are shown in Table 5.5. The results of the analysis show that the calculated aluminum to chromium ratio of the slurry solids was approximately 20 while that of the washed solids taken from the CUF 6/5 parametric sample results shown in Table 5.5 was approximately 12. This higher ratio of aluminum to chromium indicate that the ratio of Group 5 solids to Group 6 solids may be higher than that of the parametric tests, but not significantly enough to affect the testing.

Table 5.5. Composition of Group 6/5 Slurry Solids

\begin{tabular}{|c|c|c|c||}
\hline Component & $\begin{array}{c}\text { Slurry } \\
(\mu \mathbf{g} / \mathbf{g})\end{array}$ & $\begin{array}{c}\text { Supernate }^{(\mathbf{b})} \\
(\mu \mathbf{g} / \mathbf{g})\end{array}$ & $\begin{array}{c}\text { Solids }^{(\mathbf{c})} \\
(\mu \mathbf{g} / \mathbf{g})\end{array}$ \\
\hline $\mathrm{Al}$ & 63318 & 5089 & 347614 \\
\hline $\mathrm{Cr}$ & 3345 & 588 & 16808 \\
\hline $\mathrm{Fe}$ & 1453 & 0 & 8547 \\
\hline $\mathrm{Na}$ & 74298 & 87903 & 7872 \\
\hline $\mathrm{Ni}$ & 95 & 2 & 550 \\
\hline \multicolumn{5}{|c|}{$\mathrm{U}$} & 3733 & 0 & 21960 \\
\hline (a) & $\begin{array}{l}\text { Results taken from ASR 8072, Sample TI565-G6-Slurry, ASO } \\
\text { ID 08-00786. Slurry sample was dried and prepared by HF- } \\
\text { assisted acid digestion. Values shown are reported as a wet basis } \\
\text { (measured TS concentration of sample 36.6 wt\%). }\end{array}$ \\
(b) Results taken from ASR 8055, Sample TI554-G6-B, ASO ID 08- \\
00219. \\
(c) $\begin{array}{l}\text { Results calculated from slurry and supernate data, assuming a } \\
\text { UDS concentration of 17 wt\%. }\end{array}$ \\
\hline
\end{tabular}

After the analytical sample was captured, part of the slurry in the UPF2 testing vessel was transferred to another 200-mL centrifuge bottle where this sample was to be leached at the UFP1 vessel conditions. To reproduce conditions at the UFP1 vessel, the slurry sample was then diluted with excess permeate from the Group 6/5 CUF test. The estimated UDS concentration of the diluted slurry for the UFP1 test is $4 \mathrm{wt} \%$, while the original slurry being used for the UFP2 test is at $17 \mathrm{wt} \%$ UDS.

\subsubsection{Leaching Conditions and Sampling}

Both tests were planned to operate at an estimated final volume of $100 \mathrm{~mL}$ after caustic solutions were added. Each caustic addition was to represent the required $19 \mathrm{M} \mathrm{NaOH}$ addition for leaching and the water condensate volume occurring from heating with steam injection. A breakdown of the slurries, caustic solutions, and leaching concentrations of sodium and hydroxide for the UFP1 and UFP2 test are shown in Table 5.6. 
Each solution was placed in a water bath on top of a heating plate. The solutions were agitated using magnetic stirring bars that could be activated by the heating plate as well. Once the solutions were placed in the water bath and sufficient agitating was applied to the solutions, heat was applied to create a rolling boil in the water bath. The time between adding the caustic solutions and bringing the water bath to a boil was approximately a half-hour.

Table 5.6. Group 6/5 Slurry and Caustic Leach Conditions for UFP1/2 Tests

\begin{tabular}{||l|c|c|c||}
\hline Initial Slurry & UFP2 & UFP1 & Unit \\
\hline Slurry Mass & 44.3 & 63.8 & $\mathrm{~g}$ \\
\hline Estimated Slurry Volume & 33.3 & 52.3 & $\mathrm{~mL}$ \\
\hline Estimated UDS & $17 \mathrm{wt} \%$ & $4 \mathrm{wt} \%$ & $\mathrm{wt} \%$ \\
\hline Caustic Additions & & & \\
\hline Caustic Mass Added & 127.3 & 122.5 & $\mathrm{~g}$ \\
\hline Caustic Volume Added & 64 & 48 & $\mathrm{~mL}$ \\
\hline Caustic Concentration & 9.8 & 6.7 & $\mathrm{M}$ \\
\hline Caustic Volume as 19M NaOH & 33.0 & 16.7 & $\mathrm{~mL}$ \\
\hline Final Slurry (Prior to Leach) & & & \\
\hline Estimated Final volume & 98 & 100 & $\mathrm{~mL}$ \\
\hline Sodium Concentration & 7.5 & 5.4 & $\mathrm{M}$ \\
\hline Hydroxide Concentration & 5.6 & 3.2 & $\mathrm{M}$ \\
\hline \hline
\end{tabular}

Once the water bath was boiling, the first permeate sample from each test solution was collected (using syringe filters to remove solids). This sample was collected at the start of the leach. The solutions were kept in the boiling water bath for 8 hours. During that time period, four more permeate samples were collected ( 1 hour, 2 hours, 4 hours, and 8 hours since the start of the leach) to measure the dissolution of aluminum over time. At the end of 8 hours, the leaching solutions were removed from the water bath and allowed to cool overnight.

In the morning, both leach solutions were centrifuged at 1,000 to 1,200 $\mathrm{G}$ for 1 hour. A final permeate sample was collected to compare to the final permeate sample collected at the end of the leach from the day before. Next, the remaining permeate was decanted and disposed of. The mass of the remaining centrifuged solids were then measured. Afterwards, the solids were triple rinsed using $100 \mathrm{~mL}$ of $0.01 \mathrm{M}$ $\mathrm{NaOH}$. Each rinse solution was separated from the solids by centrifuging the mixture and decanting from the solids, and the mass of the solids was measured. The remaining solids were then sub-sampled to be dried and analyzed by ICP to measure the change in the aluminum present.

\subsubsection{Results of Leaching}

The results of the solids leaching analysis are shown in Table 5.7. On average, the overall solid reduction in mass and aluminum leach factors compares well with the parametric tests performed on the Group 6/5 material taken from the CUF test. This indicates that the shearing of material in the CUF does not significantly impact the dissolution rate or extent of dissolution of solid aluminum in the waste.

The results of the permeate leaching analysis are shown in Figure 5.5. The dissolution rates from the UFP1 and UFP2 agree reasonably well with the leaching results found in the $3 \mathrm{M}$ and $5 \mathrm{M} \mathrm{NaOH}$ found 
in Figure 5.2. Note, however, that due to the higher solids loading in the UFP2 test, the extent of reaction is slightly slower than that for UFP-1. The similarities in the permeate data from both tests confirm that particle shearing from filtration in the CUF does not later impact the aluminum dissolution rate in the solid waste.

Table 5.7. Results Analysis of Leached Solids

\begin{tabular}{||l|c|c|c||}
\hline & UPF2 & UFP1 & Unit \\
\hline Initial Slurry Solids & 7.5 & 2.6 & $\mathrm{~g}$ \\
\hline Percent Al & $34 \%$ & $34 \%$ & $\mathrm{wt} \%$ \\
\hline Initial Al Mass & 2.5 & 0.9 & $\mathrm{~g}$ \\
\hline & & & \\
\hline $\begin{array}{l}\text { Washed Leached Solids Mass } \\
\text { (Wet) }\end{array}$ & 16.665 & 4.65 & $\mathrm{~g}$ \\
\hline Percent Solids after Drying & $20 \%$ & $16 \%$ & $\mathrm{wt} \%$ \\
\hline $\begin{array}{l}\text { Washed Leach Solids Mass } \\
\text { (Dry) }\end{array}$ & 3.40 & 0.75 & $\mathrm{~g}$ \\
\hline Aluminum Fraction & $35 \%$ & $37 \%$ & $\%$ \\
\hline Remaining Solid Al & 1.18 & 0.28 & $\mathrm{~g}$ \\
\hline & & & \\
\hline Solid Loss & $55 \%$ & $70 \%$ & $\mathrm{wt} \%$ \\
\hline Dissolution of Al & $\mathbf{5 4 \%}$ & $\mathbf{6 8 \%}$ & $\mathrm{wt} \%$ \\
\hline
\end{tabular}

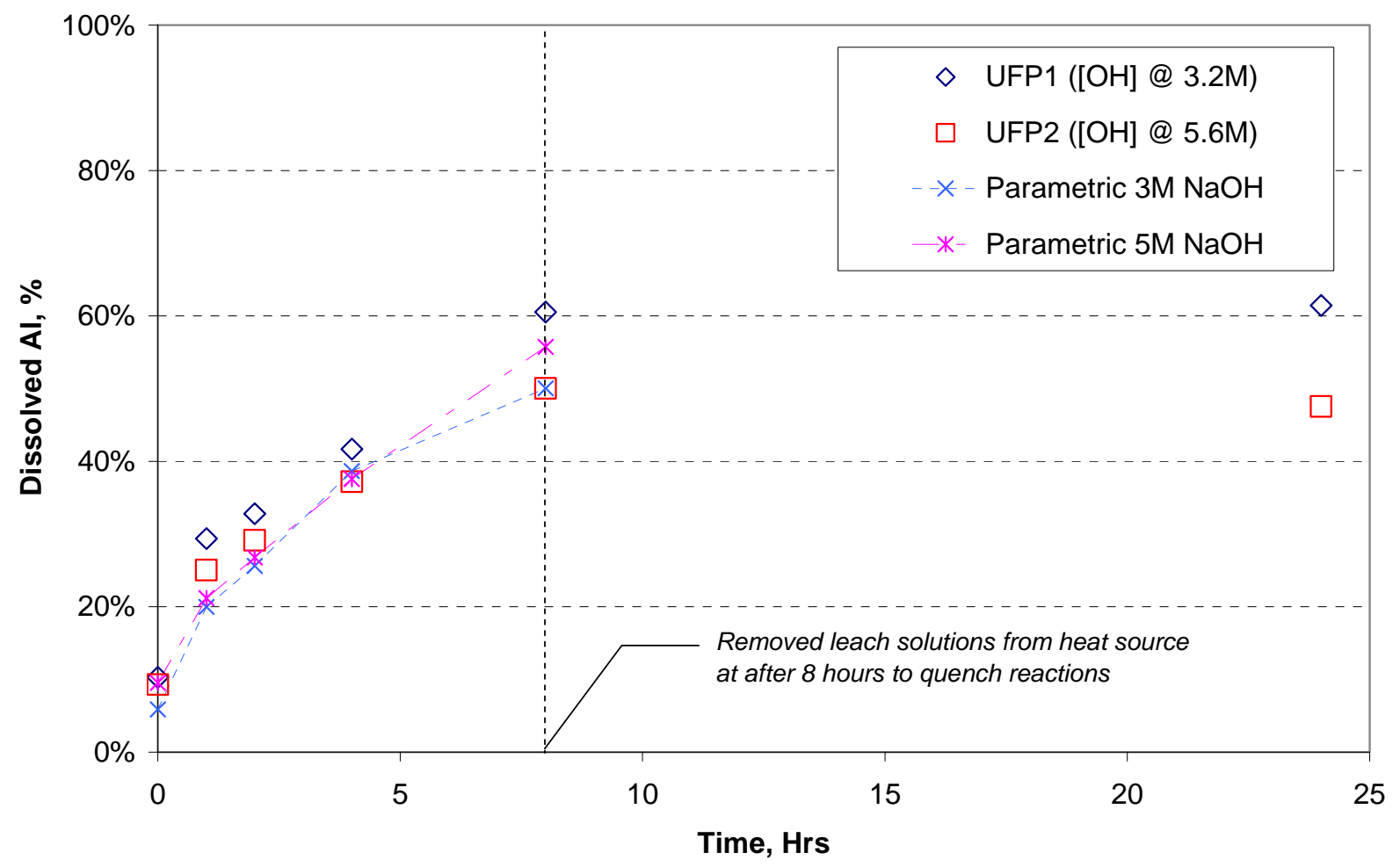

Figure 5.5. Group 6/5 Solids Aluminum Dissolution Data at $100^{\circ} \mathrm{C}$ at UFP1/UFP2 Leaching Conditions 


\subsection{Summary}

Overall, theses studies confirmed that the difference in the aluminum leach factor between the Group 5 and Group 6/5 CUF test was due to the evaporation that occurred in the Group 5 test which concentrated the slurry hydroxide concentration. The dissolution kinetics for aluminum appeared to increase rapidly as the free hydroxide increased to $7 \mathrm{M}$. Unlike the Group 5 CUF test, the volume of the Group 6/5 CUF test was maintained at the same volume, preventing the concentration of the free hydroxide to be artificially increased. The results of the Group 6/5 CUF test correlate well with both series of beaker tests, indicating that the leach factor from Group 6/5 CUF test (46\%) was more plausible in the absence of evaporation than the one calculated for the Group 5 CUF test (76\%).

With the UFP1/UFP2 test matching results from the fume hood tests, particle condition and concentration were shown to have not significant impact on leach factor, while the free hydroxide did. Using higher concentrations of free hydroxide did appear to increase the dissolution of aluminum once the concentration exceeded $5 \mathrm{M}$. This implies there is a real benefit of leaching at higher concentration of solids and hydroxide to improve conversion of boehmite.

The bench top testing confirmed the caustic leaching results in the two CUF tests, showing that the leach factor for TRU waste material to not be measureable or within the $\pm 15 \%$ error band of the analytical methods used. However, only a limited analysis of radionuclides present in the leached solids was performed. Parametric leaching testing of this material that focused more on the impacts of Pu are reported in WPT-RPT-171, Laboratory Demonstration of the Pretreatment Process with Caustic and Oxidative Leaching Using Actual Hanford Tank Waste (Fiskum 2009). Other materials of interest, such as boron, manganese, and zinc, were too low in concentration to come to any true conclusions about their leach factor. 
WTP-RPT-172, Rev 0

\subsection{Conclusions}

\subsection{Summary of Testing and Objectives}

To address Task 4 of the M-12 EFRT response plan, a scope of work was developed to perform caustic and oxidative leaching bench-scale tests of actual tank waste samples, defined under test plan TP-RPPWTP-467. To cover as much as possible of the range of high-level waste (HLW) types at the Hanford site, eight composite samples of waste types were assembled from archive tank samples in the 222S Laboratory and homogenized in the hot cells at the Radiochemical Processing Laboratory (RPL). Each waste type was developed to specifically address a processing challenge. Together, the eight waste composites represented $\sim 75 \%$ of the HLW mass expected to be processed through the Waste Treatment and Immobilization Plant (WTP). After a composite waste group was homogenized, it was characterized for physical properties, chemical composition, and crystal habit of the insoluble solids. Parametric leaching studies were then performed on a small scale to understand the leaching kinetics of aluminum, chromium, and phosphate using planned caustic and oxidative leaching process in the Pre-treatment facility. Finally, the remaining waste sample was placed in a bench top filtration/leaching apparatus in the hot cells where leaching and ultrafiltration operations of the Pre-treatment facility were simulated to understand how leaching operations affect filtration.

The first two waste composites homogenized in this program were the Group 5 (REDOX Sludge Waste) and the Group 6 (S-Saltcake waste). The Group 5 waste was assembled to examine the caustic leaching characteristics of boehmite, a mineral form of aluminum that is difficult to dissolve. The Group 6 waste was assembled because of the presence of insoluble chromium that oxidative leaching was designed to remove. In technical report WTP-RPT-157, it is discussed how each of these two waste groups were homogenized, and the follow-on characterization and parametric leaching studies were described. This report focuses on the follow-on bench-top filtration and leach tests. The focus of this report is on two bench-top filtration/leaching tests using the Group 5 and 6 waste composites.

Leaching and filtration testing performed on the Group 5 and 6 waste groups using a bench-top filtration/leaching testing apparatus, commonly called the crossflow ultrafilter (CUF), that was installed in one of the hot cells at Radiochemical Processing Laboratory (RPL). The system was capable of filtering high-level waste (HLW) slurry using a cross-flow ultrafilter (2 ft long with a 0.5 inch ID) rated for 0.1- $\mu \mathrm{m}$-diameter particles. Batch chemical leach studies could also be performed in the apparatus to compare filtration rates of the slurry at different aspects of the WTP pre-treatment process and evaluate the effectiveness of maintaining transuranic material in the HLW process stream (slurry) and not in the low-activity waste (LAW) stream (filter permeate). The first test used only the Group 5 waste composite. The focus of this test was to caustic leach the Group 5 material, simulating process conditions in the UFP2 vessel of the pre-treatment facility. Filtration studies of the composite waste occurred before and after leaching to understand the impact of caustic leaching on this process. The second test focused on the Group 6 material and the removal of insoluble $\mathrm{Cr}$ as well as the impact of oxidative leaching on filtration. Due to the limited quantity of Group 6 material, it was blended with Group 5 material as well for this test and was caustic leached as well. Like before, filtration studies occurred before and after each leaching step. Additional parametric tests on caustic leaching were performed using a Group 6/5 blended slurry to compare to results from the caustic leach performed in the Group6/5 CUF test. 
Objectives of the test plan that were accomplished were:

- Filtration of actual waste before and after caustic leaching was performed and compared.

- Caustic dissolution of aluminum in the form of boehmite was performed utilizing the Group 5 waste, which $\sim 90 \%$ of the undissolved solids were boehmite.

- Final characterization of the leach waste was performed using XRD, SEM, and TEM to confirm the final phases of undissolved leach solids.

\subsection{Filtration Behavior}

Filtration results of both the Group 5 and Group 6/5 CUF test are summarized in Table 6.1. The following general observations were made:

- The Group 5 filter flux was higher than expected. However, the slurry rheology changed significantly as the undissolved solids concentration increased. Once the solids concentration begins to impact filtration, the slurry viscosity increases to a point where axial pressure drops, and the yield stress of the fluid may impact a pump's ability to transport slurry through piping.

- The Group 6 filter flux showed significant decay over time. Adding Group 5 waste temporarily improved the filter flux, but did not prevent fouling of the filter media.

- Caustic leaching and washing of both waste types appear to reduce issues with rheology and fouling. Once the sodium concentration of the filter permeate falls below $2 \mathrm{M}$, a significant increase in the filter flux occurs, which is due to the change in permeate viscosity.

- Caustic leaching and washing of the Group 6 slurry appeared to remove a compound from the slurry that was significantly fouling the filter over time.

- In the case of the Group 6/5 CUF test, oxidative leaching does not seem to impact filtration performance.

- As predicted, an increase in transmembrane pressure (TMP) correlates to increases in the filter flux. As the solid concentration increases, the axial velocity (AV) of the slurry becomes more significant.

- Particle size measurements (See Appendices G \& H) showed the average particle size decreasing over time in the CUF. However, changes in particle size were not significant enough to impact filtration.

- Rheology measurements (See Appendices I \& J) showed that supernate viscosity and the slurry consistency and shear stress have significant impact on filtration. This usually can be correlated to increases in the dissolved solids concentration of the supernate and the undissolved concentration of the slurry. 
Table 6.1. Summary of Group 5 and Group 6/5 CUF Tests

\begin{tabular}{|c|c|c|c|}
\hline Filtration Step & Property & Group 5 Test & Group 6/5 Test \\
\hline \multirow[t]{4}{*}{$\begin{array}{l}\text { Initial } \\
\text { Characterization }\end{array}$} & Material Description & $\begin{array}{l}\text { Group } 5 \text { Homogenized } \\
\text { Sample }\end{array}$ & $\begin{array}{l}\text { Group } 6 \text { Homogenized } \\
\text { Sludge Sample }\end{array}$ \\
\hline & UDS & $18 \mathrm{wt} \%$ & $15 \mathrm{wt} \%$ \\
\hline & $\begin{array}{l}\text { Rheology Slurry } \\
\text { @ } 25^{\circ} \mathrm{C}-60^{\circ} \mathrm{C}\end{array}$ & $\begin{array}{l}\text { Non-Newtonian } \\
\text { Yield Stress: } 57-74 \mathrm{~Pa} \\
\text { Consistency: } 17-13 \mathrm{mPa} \cdot \mathrm{s}\end{array}$ & $\begin{array}{l}\text { Newtonian } \\
\text { Viscosity: 8-4 mPa·s }\end{array}$ \\
\hline & Particle Size & $\begin{array}{l}\mathrm{d}(10): 1.1 \mu \mathrm{m} \\
\mathrm{d}(50): 4.3 \mu \mathrm{m} \\
\mathrm{d}(90): 16 \mu \mathrm{m}\end{array}$ & $\begin{array}{l}\text { d(10): } 0.69 \mu \mathrm{m} \\
\mathrm{d}(50): 2.8 \mu \mathrm{m} \\
\mathrm{d}(90): 11 \mu \mathrm{m}\end{array}$ \\
\hline \multirow{7}{*}{$\begin{array}{l}\text { Low Solids } \\
\text { Filtration Testing } \\
\text { Filtration Conditions } \\
T M P: 40 \text { psid } \\
\text { AV: } 13 \mathrm{fps}\end{array}$} & Material Description & $\begin{array}{l}\text { Group } 5 \text { diluted w/ simulant } \\
\text { supernatant and circulated } \\
\text { in CUF }\end{array}$ & $\begin{array}{l}\text { Group } 6 \text { diluted with } \\
\text { excess supernatant from } \\
\text { homogenization and } \\
\text { circulated in CUF }\end{array}$ \\
\hline & UDS & $4.3 \mathrm{wt} \%$ & $3.7 \mathrm{wt} \%$ \\
\hline & $\begin{array}{l}\text { Slurry Rheology } \\
\text { @ } 25^{\circ} \mathrm{C}-60^{\circ} \mathrm{C}\end{array}$ & $\begin{array}{l}\text { Non-Newtonian } \\
\text { Yield: } 2.2-2.7 \mathrm{~Pa} \\
\text { Consistency: } 4.6-4.1 \mathrm{mPa} \cdot \mathrm{s}\end{array}$ & $\begin{array}{l}\text { Newtonian } \\
\text { Viscosity: 6-3 mPa·s }\end{array}$ \\
\hline & Particle Size & $\begin{array}{l}\mathrm{d}(10): 0.81 \mu \mathrm{m} \\
\mathrm{d}(50): 3.4 \mu \mathrm{m} \\
\mathrm{d}(90): 13 \mu \mathrm{m}\end{array}$ & $\begin{array}{l}d(10): 0.70 \mu \mathrm{m} \\
\mathrm{d}(50): 2.4 \mu \mathrm{m} \\
\mathrm{d}(90): 8.6 \mu \mathrm{m} \\
\end{array}$ \\
\hline & $\begin{array}{l}\text { Permeate Sodium } \\
\text { Concentration }\end{array}$ & $3.2 \mathrm{M}$ & $5.2 \mathrm{M}$ \\
\hline & Baseline Filter Flux & $0.06-0.07 \mathrm{gpm} / \mathrm{ft}^{2}$ & $0.01-0.03 \mathrm{gpm} / \mathrm{ft}^{2}$ \\
\hline & $\begin{array}{l}\text { Controlling } \\
\text { Parameter }\end{array}$ & Proportional to TMP & $\begin{array}{l}\text { Proportional to TMP } \\
\text { Time Dependent Decay }\end{array}$ \\
\hline \multirow{6}{*}{$\begin{array}{l}\text { Dewatering of } \\
\text { Waste Prior to } \\
\text { Leaching } \\
\text { Filtration Conditions } \\
T M P: 40 \text { psid } \\
A V: 13 \mathrm{fps}\end{array}$} & Initial Flux & $0.06 \mathrm{gpm} / \mathrm{ft}^{2}$ & $0.01-0.02 \mathrm{gpm} / \mathrm{ft}^{2}$ \\
\hline & Final Flux & $0.03 \mathrm{gpm} / \mathrm{ft}^{2}$ & $\begin{array}{l}0.03 \mathrm{gpm} / \mathrm{ft}^{2} \\
\text { (After Group } 5 \text { addition) }\end{array}$ \\
\hline & Final UDS & $19 \mathrm{wt} \%$ & $14 \mathrm{wt} \%$ \\
\hline & Behavior & Gel Concentration Limiting & Time Dependent Decay \\
\hline & Baseline Flux & $0.06 \mathrm{gpm} / \mathrm{ft}^{2}$ & $0.02-0.03 \mathrm{gpm} / \mathrm{ft}^{2}$ \\
\hline & $\begin{array}{l}\text { Controlling } \\
\text { Parameter }\end{array}$ & $\begin{array}{l}\text { AV Dominant } \\
\text { TMP Secondary }\end{array}$ & $\begin{array}{l}\text { TMP and Time both } \\
\text { Dominant }\end{array}$ \\
\hline
\end{tabular}


Table 6.1 (Contd)

\begin{tabular}{|c|c|c|c|}
\hline Filtration Step & Property & Group 5 Test & Group 6/5 Test \\
\hline \multirow{5}{*}{$\begin{array}{l}\text { High Solids } \\
\text { Filtration Testing } \\
\text { Filtration Conditions } \\
T M P: 40 \text { psid } \\
\text { AV: } 13 \text { fps }\end{array}$} & Material Description & $\begin{array}{l}\text { Group } 5 \text { diluted w/ simulant } \\
\text { supernatant and circulated } \\
\text { in CUF }\end{array}$ & $\begin{array}{l}\text { Group } 6 \text { diluted with } \\
\text { excess supernatant from } \\
\text { homogenization and } \\
\text { circulated in CUF }\end{array}$ \\
\hline & UDS & $15 \mathrm{wt} \%$ & $13 \mathrm{wt} \%$ \\
\hline & $\begin{array}{l}\text { Slurry Rheology } \\
\text { @ } 25^{\circ} \mathrm{C}-60^{\circ} \mathrm{C}\end{array}$ & $\begin{array}{l}\text { Non-Newtonian } \\
\text { Yield: 74-86 } \mathrm{Pa} \\
\text { Consistency: } 13-14 \mathrm{mPa} \cdot \mathrm{s}\end{array}$ & $\begin{array}{l}\text { Non-Newtonian } \\
\text { Yield: 6-11 Pa } \\
\text { Consistency: 11-14 mPa·s }\end{array}$ \\
\hline & Particle Size & $\begin{array}{l}\mathrm{d}(10): 0.64 \mu \mathrm{m} \\
\mathrm{d}(50): 2.3 \mu \mathrm{m} \\
\mathrm{d}(90): 12 \mu \mathrm{m}\end{array}$ & $\begin{array}{l}\mathrm{d}(10): 0.57 \mu \mathrm{m} \\
\mathrm{d}(50): 2.8 \mu \mathrm{m} \\
\mathrm{d}(90): 10 \mu \mathrm{m}\end{array}$ \\
\hline & $\begin{array}{l}\text { Permeate Sodium } \\
\text { Concentration }\end{array}$ & $3.2 \mathrm{M}$ & $4.7 \mathrm{M}$ \\
\hline \multirow{6}{*}{$\begin{array}{l}\text { Caustic Leach } \\
\text { Dewater } \\
\text { Filtration Conditions: } \\
T M P: 40 \text { psid } \\
\text { AV: } 13 \mathrm{fps}\end{array}$} & Initial Flux & $0.020 \mathrm{gpm} / \mathrm{ft}^{2}$ & 0.010 \\
\hline & Final Filter Flux & $0.015 \mathrm{gpm} / \mathrm{ft}^{2}$ & $0.006 \mathrm{gpm} / \mathrm{ft}^{2}$ \\
\hline & Final UDS & $14 \mathrm{wt} \%$ & $8.9 \mathrm{wt} \%$ \\
\hline & Behavior & Decay over time & Decay over time \\
\hline & Rheology & $\begin{array}{l}\text { Non-Newtonian } \\
\text { Yield Stress: } 5.7-8.7 \mathrm{~Pa} \\
\text { Consistency: } 22-12 \mathrm{mPa} \cdot \mathrm{s}\end{array}$ & $\begin{array}{l}\text { Non-Newtonian } \\
\text { Yield Stress: 11-23 Pa } \\
\text { Consistency: 29-15 mPa·s }\end{array}$ \\
\hline & Particle Size & $\begin{array}{l}\mathrm{d}(10): 0.73 \mu \mathrm{m} \\
\mathrm{d}(50): 2.1 \mu \mathrm{m} \\
\mathrm{d}(90): 29 \mu \mathrm{m}\end{array}$ & $\begin{array}{l}d(10): 0.56 \mu \mathrm{m} \\
d(50): 1.9 \mu \mathrm{m} \\
d(90): 6.9 \mu \mathrm{m}\end{array}$ \\
\hline \multirow{3}{*}{$\begin{array}{l}\text { Caustic Wash } 1 \\
\text { Filtration Conditions } \\
\text { TMP: } 40 \text { psid } \\
\text { AV: } 13 \text { fps }\end{array}$} & Wash Solution & 1.9 molal $\mathrm{NaOH}$ & $1.53 \mathrm{M} \mathrm{NaOH}$ \\
\hline & Permeate Conc. & $\begin{array}{l}{[\mathrm{Na}]: 4.2 \mathrm{M}} \\
{[\mathrm{OH}]: 2.7 \mathrm{M}}\end{array}$ & $\begin{array}{l}{[\mathrm{Na}]: 5.0 \mathrm{M}} \\
{[\mathrm{OH}]: 4.0 \mathrm{M}}\end{array}$ \\
\hline & Filter Flux & $0.06 \mathrm{gpm} / \mathrm{ft}^{2}$ & $0.02 \mathrm{gpm} / \mathrm{ft}^{2}$ \\
\hline \multirow{3}{*}{$\begin{array}{l}\text { Caustic Wash } 2 \\
\text { Filtration Conditions } \\
T M P: 40 \text { psid } \\
\text { AV: } 13 \text { fps }\end{array}$} & Wash Solution & 0.9 molal $\mathrm{NaOH}$ & $0.66 \mathrm{M} \mathrm{NaOH}$ \\
\hline & Permeate Conc. & $\begin{array}{l}{[\mathrm{Na}]: 2.5 \mathrm{M}} \\
{[\mathrm{OH}]: 1.8 \mathrm{M}}\end{array}$ & $\begin{array}{l}{[\mathrm{Na}]: 3.2 \mathrm{M}} \\
{[\mathrm{OH}]: 2.4 \mathrm{M}}\end{array}$ \\
\hline & Filter Flux & $0.13 \mathrm{gpm} / \mathrm{ft}^{2}$ & $0.04 \mathrm{gpm} / \mathrm{ft}^{2}$ \\
\hline \multirow{3}{*}{$\begin{array}{l}\text { Caustic Wash } 3 \\
\text { Filtration Conditions } \\
\text { TMP: } 40 \text { psid } \\
A V: 13 \mathrm{fps}\end{array}$} & Wash Solution & 0.4 molal & $0.24 \mathrm{M} \mathrm{NaOH}$ \\
\hline & Permeate Conc. & $\begin{array}{l}\mathrm{Na}]: 1.4 \mathrm{M} \\
{[\mathrm{OH}]: 1.1 \mathrm{M}}\end{array}$ & $\begin{array}{l}\mathrm{Na}]: 1.8 \mathrm{M} \\
{[\mathrm{OH}]: 1.4 \mathrm{M}}\end{array}$ \\
\hline & Filter Flux & $0.18 \mathrm{gpm} / \mathrm{ft}^{2}$ & $0.1 \mathrm{gpm} / \mathrm{ft}^{2}$ \\
\hline \multirow{3}{*}{$\begin{array}{l}\text { Caustic Wash } 4 \\
\text { Filtration Conditions } \\
\text { TMP: } 40 \text { psid } \\
\text { AV: } 13 \text { fps }\end{array}$} & Wash Solution & & $0.09 \mathrm{M} \mathrm{NaOH}$ \\
\hline & Permeate Conc. & & $\begin{array}{l}{[\mathrm{Na}]: 0.92 \mathrm{M}} \\
{[\mathrm{OH}]: 0.73 \mathrm{M}}\end{array}$ \\
\hline & Filter Flux & & $0.1 \mathrm{gpm} / \mathrm{ft}^{2}$ \\
\hline
\end{tabular}


Table 6.1 (Contd)

\begin{tabular}{|c|c|c|c|}
\hline Filtration Step & Property & Group 5 Test & Group 6/5 Test \\
\hline \multirow{3}{*}{$\begin{array}{l}\text { Caustic Wash } 5 \\
\text { Filtration Conditions } \\
\text { TMP: } 40 \text { psid } \\
\text { AV: } 13 \mathrm{fps}\end{array}$} & Wash Solution & & $0.02 \mathrm{M} \mathrm{NaOH}$ \\
\hline & Permeate Conc. & & $\begin{array}{l}{[\mathrm{Na}]: 0.50 \mathrm{M}} \\
{[\mathrm{OH}]: 0.38 \mathrm{M}}\end{array}$ \\
\hline & Filter Flux & & $0.09 \mathrm{gpm} / \mathrm{ft}^{2}$ \\
\hline \multirow{3}{*}{$\begin{array}{l}\text { Caustic Wash } 6 \\
\text { Filtration Conditions } \\
T M P: 40 \text { psid } \\
A V: 13 \mathrm{fps}\end{array}$} & Wash Solution & & $0.01 \mathrm{M} \mathrm{NaOH}$ \\
\hline & Permeate Conc. & & $\begin{array}{l}{[\mathrm{Na}]: 0.25 \mathrm{M}} \\
{[\mathrm{OH}]: 0.17 \mathrm{M}}\end{array}$ \\
\hline & Filter Flux & & $0.1 \mathrm{gpm} / \mathrm{ft}^{2}$ \\
\hline \multirow{3}{*}{$\begin{array}{l}\text { Washed Caustic } \\
\text { Leached Slurry }\end{array}$} & UDS & $4.1 \mathrm{wt} \%$ & $13 \mathrm{wt} \%$ \\
\hline & Particle Size & $\begin{array}{l}\mathrm{d}(10): 0.64 \mu \mathrm{m} \\
\mathrm{d}(50): 1.9 \mu \mathrm{m} \\
\mathrm{d}(90): 16 \mu \mathrm{m} \\
\end{array}$ & $\begin{array}{l}\text { d(10): } 0.54 \mu \mathrm{m} \\
\mathrm{d}(50): 1.7 \mu \mathrm{m} \\
\mathrm{d}(90): 5.7 \mu \mathrm{m} \\
\end{array}$ \\
\hline & $\begin{array}{l}\text { Rheology } \\
\text { @ } 25^{\circ} \mathrm{C}-60^{\circ} \mathrm{C}\end{array}$ & $\begin{array}{l}\text { Non-Newtonian } \\
\text { Yield Stress: } 3.3-2.8 \mathrm{~Pa} \\
\text { Consistency: } 4.7-3.9 \mathrm{mPa} \cdot \mathrm{s}\end{array}$ & $\begin{array}{l}\text { Non-Newtonian } \\
\text { Yield Stress: 21-24 Pa } \\
\text { Consistency: 29-15 mPa·s }\end{array}$ \\
\hline \multirow{2}{*}{$\begin{array}{l}\text { Oxidative Leach } \\
\text { Slurry }\end{array}$} & UDS & & $10 \mathrm{wt} \%$ \\
\hline & Particle Size & & $\begin{array}{l}\mathrm{d}(10): 0.44 \mu \mathrm{m} \\
\mathrm{d}(50): 1.2 \mu \mathrm{m} \\
\mathrm{d}(90): 4.9 \mu \mathrm{m}\end{array}$ \\
\hline \multirow{3}{*}{$\begin{array}{l}\text { Oxidative Wash } 1 \\
\text { Filtration Conditions } \\
\text { TMP: } 40 \text { psid } \\
A V: 13 \mathrm{fps}\end{array}$} & Wash Solution & & $0.01 \mathrm{M} \mathrm{NaOH}$ \\
\hline & Permeate Conc. & & $\begin{array}{l}{[\mathrm{Na}]: 0.28 \mathrm{M}} \\
{[\mathrm{OH}]: 0.05 \mathrm{M}}\end{array}$ \\
\hline & Filter Flux & & $0.1 \mathrm{gpm} / \mathrm{ft}^{2}$ \\
\hline \multirow{3}{*}{$\begin{array}{l}\text { Oxidative Wash } 2 \\
\text { Filtration Conditions } \\
T M P: 40 \text { psid } \\
A V: 13 \mathrm{fps}\end{array}$} & Wash Solution & & $0.01 \mathrm{M} \mathrm{NaOH}$ \\
\hline & Permeate Conc. & & $\begin{array}{l}{[\mathrm{Na}]: 0.19 \mathrm{M}} \\
{[\mathrm{OH}]: 0.03 \mathrm{M}}\end{array}$ \\
\hline & Filter Flux & & $0.1 \mathrm{gpm} / \mathrm{ft}^{2}$ \\
\hline \multirow{3}{*}{$\begin{array}{l}\text { Oxidative Wash } 3 \\
\text { Filtration Conditions } \\
T M P: 40 \text { psid } \\
A V: 13 \mathrm{fps}\end{array}$} & Wash Solution & & $0.01 \mathrm{NaOH}$ \\
\hline & Permeate Conc. & & $\begin{array}{l}{[\mathrm{Na}]: 0.10 \mathrm{M}} \\
{[\mathrm{OH}]: 0.01 \mathrm{M}}\end{array}$ \\
\hline & Filter Flux & & $0.1 \mathrm{gpm} / \mathrm{ft}^{2}$ \\
\hline \multirow{3}{*}{$\begin{array}{l}\text { Washed Oxidative } \\
\text { Leached Slurry }\end{array}$} & UDS & & $9.7 \mathrm{wt} \%$ \\
\hline & Particle Size & & $\begin{array}{l}\mathrm{d}(10): 0.43 \mu \mathrm{m} \\
\mathrm{d}(50): 1.2 \mu \mathrm{m} \\
\mathrm{d}(90): 4.2 \mu \mathrm{m}\end{array}$ \\
\hline & $\begin{array}{l}\text { Rheology } \\
\text { @ } 25^{\circ} \mathrm{C}-60^{\circ} \mathrm{C}\end{array}$ & & $\begin{array}{l}\text { Non-Newtonian } \\
\text { Yield Stress: 0.7-1.4 Pa } \\
\text { Consistency: 5-3 mPa·s }\end{array}$ \\
\hline
\end{tabular}


Table 6.1 (Contd)

\begin{tabular}{|c|c|c|c|}
\hline Filtration Step & Property & Group 5 Test & Group 6/5 Test \\
\hline \multirow[t]{6}{*}{$\begin{array}{l}\text { Final Filter Testing } \\
\text { Baseline Condition } \\
\text { TMP: } 40 \mathrm{psid} \\
\text { AV: } 13 \mathrm{fps}\end{array}$} & Material Description & $\begin{array}{l}\text { Washed Caustic Leached } \\
\text { Group } 5 \text { Slurry }\end{array}$ & $\begin{array}{l}\text { Group 6/5 Washed } \\
\text { Leached Slurry } \\
\text { Blended with } \\
\text { Group } 5 \text { Slurry Washed } \\
\text { Leached Slurry }\end{array}$ \\
\hline & UDS & $4.1 \mathrm{wt} \%$ & $8.0 \mathrm{wt} \%$ \\
\hline & Particle Size & $\begin{array}{l}\text { d(10): } 0.64 \mu \mathrm{m} \\
\mathrm{d}(50): 1.9 \mu \mathrm{m} \\
\mathrm{d}(90): 16 \mu \mathrm{m}\end{array}$ & $\begin{array}{l}\mathrm{d}(10): 0.44 \mu \mathrm{m} \\
\mathrm{d}(50): 1.3 \mu \mathrm{m} \\
\mathrm{d}(90): 5.1 \mu \mathrm{m}\end{array}$ \\
\hline & $\begin{array}{l}\text { Rheology } \\
\text { @ } 25^{\circ} \mathrm{C}-60^{\circ} \mathrm{C}\end{array}$ & $\begin{array}{l}\text { Non-Newtonian } \\
\text { Yield Stress: } 3.3-2.8 \mathrm{~Pa} \\
\text { Consistency: } 4.7-3.9 \mathrm{mPa} \cdot \mathrm{s}\end{array}$ & $\begin{array}{l}\text { Non-Newtonian } \\
\text { Yield Stress: 1-3-1.6 Pa } \\
\text { Consistency: 5-4 mPa·s }\end{array}$ \\
\hline & Baseline Flux & $0.2 \mathrm{gpm} / \mathrm{ft}^{2}$ & $0.1 \mathrm{gpm} / \mathrm{ft}^{2}$ \\
\hline & $\begin{array}{l}\text { Controlling } \\
\text { Parameter }\end{array}$ & $\begin{array}{l}\text { Both TMP and AV } \\
\text { Stable over Time }\end{array}$ & $\begin{array}{l}\text { Both TMP and AV } \\
\text { Stable over Time }\end{array}$ \\
\hline
\end{tabular}

\subsection{Leaching Behavior}

Caustic leaching results of both the Group 5 and Group 6/5 CUF test are summarized in Table 6.2. The following general observations were made:

- Caustic leaching of aluminum from HLW solids in the Group 5 and Group 6 material was successfully performed without measureable removal of transuranic isotopes from the HLW solids.

- Leach factors varied from $40 \%$ to $70 \%$ removal over an 8 -hr period at $100^{\circ} \mathrm{C}$.

- Parametric testing of washed solids from the Group 6/5 CUF indicate that aluminum dissolution kinetics are the same for free hydroxide concentrations from 3 to $5 \mathrm{M}$. However, the kinetics increased significantly when the free hydroxide concentration was increased to $7 \mathrm{M}$.

- Parametric testing of Group 6/5 material from homogenization samples showed similar results to the fumehood testing using washed material from the CUF. This implies that particle-size reduction of HLW solids occurring during filtration does not significantly impact the leaching kinetics.

Oxidative leaching was performed during the Group 6/5 CUF test after caustic leaching. The results are summarized below:

- $200 \mathrm{~mL}$ of $1 \mathrm{M}$ sodium permanganate was added to 1.2 L of the caustic leached slurry. The measured hydroxide level of the slurry was $0.17 \mathrm{M}$, and the $\mathrm{Mn}$ :Cr ratio was 1.7.

- A leach factor of $>95 \%$ for insoluble chromium was found after 6 hours. Parametric samples indicate that the reaction was completed within the first hour.

- A measureable increase in the plutonium concentration of the leach permeate was observed. However, the final plutonium concentration of the leach permeate was still less than that of the initial permeate concentration $\left(<10^{-4} \mu \mathrm{Ci} / \mathrm{mL}\right)$. 
Table 6.2. Caustic Leaching Summary of Group 5 and 6 Material

\begin{tabular}{|c|c|c|c|c|c|c|}
\hline \multirow{3}{*}{$\begin{array}{l}\text { Testing Type } \\
\text { CUF }\end{array}$} & \multirow{2}{*}{$\frac{\text { Material }}{\text { Group } 5}$} & \multicolumn{2}{|c|}{$\begin{array}{c}\text { Free } \\
\text { Hydroxide } \\
\text { Concentration } \\
\end{array}$} & \multicolumn{2}{|c|}{$\begin{array}{c}\text { Sodium } \\
\text { Concentration }\end{array}$} & \multirow{2}{*}{$\begin{array}{c}\text { Al } \\
\text { Leach Factor }\end{array}$} \\
\hline & & $\begin{array}{l}\text { Planned: } \\
\text { Final: }\end{array}$ & $\begin{array}{l}3.3 \mathrm{M} \\
5.9 \mathrm{M}\end{array}$ & $\begin{array}{l}\text { Planned } \\
\text { Final: }\end{array}$ & $\begin{array}{l}6.5 \mathrm{M} \\
9.9 \mathrm{M}\end{array}$ & \\
\hline & Group 6/5 & $\begin{array}{l}\text { Planned: } \\
\text { Final: }\end{array}$ & $\begin{array}{l}5.7 \mathrm{M} \\
6.1 \mathrm{M}\end{array}$ & $\begin{array}{l}\text { Planned } \\
\text { Final: }\end{array}$ & $\begin{array}{l}7.7 \mathrm{M} \\
8.0 \mathrm{M}\end{array}$ & 40\% @ 8 hours \\
\hline \multirow[t]{3}{*}{$\begin{array}{l}\text { Parametric } \\
\text { Fume hood Testing }\end{array}$} & \multirow[t]{3}{*}{$\begin{array}{l}\text { Washed CUF } \\
\text { Group 6/5 Solids }\end{array}$} & $\begin{array}{l}\text { Planned: } \\
\text { Final: }\end{array}$ & $\begin{array}{l}3.0 \mathrm{M} \\
3.2 \mathrm{M}\end{array}$ & $\begin{array}{l}\text { Planned } \\
\text { Final: }\end{array}$ & $\begin{array}{l}3.0 \mathrm{M} \\
3.4 \mathrm{M}\end{array}$ & $\begin{array}{l}50 \% @ 8 \text { hours } \\
65 \% @ 24 \text { hours }\end{array}$ \\
\hline & & $\begin{array}{l}\text { Planned: } \\
\text { Final: }\end{array}$ & $\begin{array}{l}5.0 \mathrm{M} \\
5.4 \mathrm{M}\end{array}$ & $\begin{array}{l}\text { Planned } \\
\text { Final: }\end{array}$ & $\begin{array}{l}5.0 \mathrm{M} \\
5.5 \mathrm{M}\end{array}$ & $\begin{array}{l}50 \% @ 8 \text { hours } \\
68 \% @ 24 \text { hours }\end{array}$ \\
\hline & & $\begin{array}{l}\text { Planned: } \\
\text { Final: }\end{array}$ & $\begin{array}{l}7.0 \mathrm{M} \\
7.4 \mathrm{M}\end{array}$ & $\begin{array}{l}\text { Planned } \\
\text { Final: }\end{array}$ & $\begin{array}{l}7.0 \mathrm{M} \\
7.5 \mathrm{M}\end{array}$ & $\begin{array}{l}70 \% \text { @ } 8 \text { hours } \\
97 \% \text { @ } 24 \text { hours }\end{array}$ \\
\hline \multirow[t]{2}{*}{$\begin{array}{l}\text { Parametric UFP1/2 } \\
\text { Hot Cell Testing }\end{array}$} & $\begin{array}{l}\text { Group 6/5 } \\
\text { Low-Solid }\end{array}$ & $\begin{array}{l}\text { Planned: } \\
\text { Final: }\end{array}$ & $\begin{array}{l}3.4 \mathrm{M} \\
3.6 \mathrm{M}\end{array}$ & $\begin{array}{l}\text { Planned } \\
\text { Final: }\end{array}$ & $\begin{array}{l}5.4 \mathrm{M} \\
6.1 \mathrm{M}\end{array}$ & 60\% @ 8 hours \\
\hline & $\begin{array}{l}\text { Group 6/5 } \\
\text { High-Solid }\end{array}$ & $\begin{array}{l}\text { Planned: } \\
\text { Final: }\end{array}$ & $\begin{array}{l}5.6 \mathrm{M} \\
6.6 \mathrm{M}\end{array}$ & $\begin{array}{l}\text { Planned } \\
\text { Final: }\end{array}$ & $\begin{array}{l}7.5 \mathrm{M} \\
8.2 \mathrm{M}\end{array}$ & 50\%@8 hours \\
\hline
\end{tabular}

\subsection{Characterization of Crystal Habits of Solids}

The leached material in both the Group 5 and Group 6/5 CUF were very similar. The results of the finds are provided below.

- After leaching, XRD, SEM, and TEM identified Na, Al, U, Fe and Si in crystalline phases

- XRD identified $\mathrm{Al}$ present in the form of boehmite, and $\mathrm{U}$ in the form of mainly cancrinite and clarkite.

- SEM and TEM showed larger boehmite crystals (>10 um) mixed with agglomerates of smaller particles probably boehmite and other inert phases (eg. Iron and Uranium). 
WTP-RPT-172, Rev 0

\subsection{References}

Agnew SF. 1997. Hanford Tank Chemical and Radionuclide Inventories: HDW Model Rev. 4. LA-UR96-3860, Los Alamos National Laboratory, Los Alamos, NM.

Barnes HA, and NQ Dzuy. 2001. “Rotating Vane Rheometry - A Review.” Journal of Non-Newtonian Fluid Mechanics 98(1):1-14.

Farinato RS, and PL Dubin. 1999. Colloid-Polymer Interactions: From Fundamentals to Practice. John Wiley \& Sons, Inc., New York, NY.

Fiskum SK, EC Buck, RC Daniel, K Draper, MK Edwards, TL Hubler, LK Jagoda, ED Jenson, AE Kozelisky, GJ Lumetta, PJ MacFarlan, BK McNamara, RA Peterson, SI Sinkov, LA Snow, and RG Swoboda. 2008. Characterization and Leaching Testing for REDOX Sludge and S-Saltcake Actual Waste Sample Composites. PNNL-17368 (WTP-RPT-157), Pacific Northwest National Laboratory, Richland, WA.

Garvie LAJ, and AJ Craven. 1994. "Use of Electron-Energy Loss Near Edge Fine Structure in the Study of Minerals.” American Mineralogist 79:411-425.

Geeting JGH, RT Hallen, LK Jagoda, AP Poloski, RD Scheele, and DR Weier. 2002. Filtration, Washing, and Caustic Leaching of Hanford Tank AZ-101 Sludge. PNWD-3206 (WPT-RPT-043), Battelle-Pacific Northwest Division, Richland, WA.

Hallen, RT. 2007. HLW Filtration and Caustic Leaching of Group 5 Waste. TI-RPP-WTP-540.

Li H, J Addai-Mensah, JC Thomas, and AR Gerson. 2005. “The influence of Al(III) supersaturation and $\mathrm{NaOH}$ concentration on the rate of crystallation of $\mathrm{Al}(\mathrm{OH})_{3}$ precursor particles from sodium aluminate solutions.” Journal of Colloid and Interface Science 286:511-519.

Lumetta GJ and BM Rapko. 1999. "Removal of Chromium from Hanford Tank Sludges.” Sep. Sci. Technol. 34:1495-1506.

Lumetta GJ, BM Rapko, J Liu, DJ Temer, and RD Hunt. 1998. Washing and Caustic Leaching of Hanford Tank Sludge: Results of FY 1998 Studies. Pacific Northwest National Laboratory, Richland, WA.

Peterson RA, JGH Geeting, and RC Daniel. 2007. “Estimation of Ultrafiltration Performance Based on Characterization Data.” Chemical Eng. Technology 30(9):1050-1054.

Rapko, BM, GJ Lumetta, JR Deschane and RA Peterson. 2007. Process Development for Permanganate Addition During Oxidative Leaching of Hanford Tank Sludge Simulants. PNNL-16794 (WTP-RPT-164) Battelle-Pacific Northwest Division, Richland, WA.

Rapko BM, GJ Lumetta, JD Vienna, and SK Fiskum. 2005. Oxidative Alkaline Leaching of SX-101 and SY-102 and Its Impact on Immobilized High Level Waste. PNWD-3600 (WTP-RPT-137), Battelle- 
Pacific Northwest Division, Richland, WA. (WTP Doc. No. 24590-101-TSA-W000-0004-168-00002 Rev 00A.)

Rapko, BM, JGH Geeting, SI Sinkov, and JD Vienna. 2004. Oxidative-Alkaline Leaching of Washed 241-SY-102 and 241-SX-101 Tank Sludges. PNWD-3512 (WTP-RPT-117), Battelle-Pacific Northwest Division, Richland, WA. (WTP Doc. No. 24590-101-TSA-W000-0004-99-00012 Rev 00A.)

Rapko BM, and JD Vienna. 2002. Selective Leaching of Chromium from Hanford Tank Sludge 241-U108. PNNL-14019, Pacific Northwest National Laboratory, Richland, WA.

Rapko BM, JD Vienna, SI Sinkov, J Kim, and AJ Cisar. 2002. Alkaline Leaching of Key, NonRadioactive Components from Simulants and Hanford Tank Sludge 241-S-110: Results of FY 01 Studies. PNNL-14018, Pacific Northwest National Laboratory, Richland, WA.

Rapko BM. 1998. Oxidative Alkaline Dissolution of Chromium from Hanford Tank Sludges: Results of FY 98 Studies. PNNL-11908, Pacific Northwest National Laboratory, Richland, WA,

Scotford RF, and JR Glastonbury. 1971. "Effect of Temperature on the Rates of Dissolution of Gibbsite and Boehmite.” Can. J. Chem. Eng. 49:611-616.

Shimskey, RW. 2007. HLW Filtration and Caustic/Oxidative Leaching of Group 6/5 Composite Waste. TI-RPP-WTP-552.

Shimskey, RW. 2007. Bench Scale Caustic Leaching of Group 5 and 6 Hanford Tank Waste Composite to Simulate Slurry Concentrations in UFP1 and UFP1. TI-RPP-WTP-565.

Steffe JF. 1996. Rheological Methods in Food Process Engineering. Freeman Press, East Lansing, MI.

Tingey JM, JD Berg, KD Keefer, AS Lea, DR Rector, JW Virden, and S Stenkamp. 1999. Final Report: Colloidal Agglomerates in Tank Sludge: Impact on Waste Processing. Environmental Management Science Program, Project No. 54628.

Tromans D, and JA Meech. 2002. "Enhanced Dissolution of Minerals: Conjoint Effects of Particle Size and Microtopography.” Minerals Eng. 15:263-269. 
WTP-RPT-172, Rev 0

Appendix A

\section{Analytical Methods}




\section{Appendix A: Analytical Methods}

The following sections describe procedures used to support the chemical and radiochemical characterization of the solids and aqueous samples. Aqueous samples were distributed directly to the free hydroxide, ion chromatrography (IC), and total inorganic carbon/total organic carbon (TIC/TOC) analytical workstations. The solids and liquids required a digestion step before distribution to the inductively coupled plasma-optical emission spectroscopy (ICP-OES) and radiochemistry workstations.

\section{A.1 Free Hydroxide}

The free hydroxide was determined using potentiometric titration with standardized $\mathrm{HCl}$ according to procedure RPG-CMC-228, Determination of Hydroxyl $\left(\mathrm{OH}^{-}\right)$and Alkalinity of Aqueous Solutions, Leachates, and Supernates and Operation of Brinkman 636 Auto-Titrator. The free hydroxide was defined as the first inflection point on the titration curve. Quality control (QC) samples were generated at the analytical workstation and included a sample replicate determination, process blank, blank spike (BS), and matrix spike (MS).

\section{A.2 Anions}

Anions were determined by ion chromatography using a Dionix ICS-2500 IC system equipped with a conductivity detector according to procedure RPG-CMC-212, Determination of Common Anions by Ion Chromatography. Additional sample dilutions from $100 \times$ to $25,000 \times$ were required to accurately measure the analytes. QC samples were generated at the analytical workstation and included a sample replicate determination, process blank, BS, and MS.

\section{A.3 TICITOC}

The TIC was determined by using silver-catalyzed hot persulfate (HP) oxidation according to procedure RPG-CMC-385, Carbon Measured in Solids, Sludge, and Liquid Matrices. The hot persulfate wet oxidation method was used. This method takes advantage of acid decomposition of the carbonate (TIC measure) followed by oxidation of organic carbon (TOC measure) using acidic potassium persulfate at 92 to $95^{\circ} \mathrm{C}$. QC samples were generated at the analytical workstation and included a sample replicate determination, process blank, BS, and MS.

\section{A.4 Acid Digestion}

Aqueous samples were digested with acid according to procedure PNL-ALO-128, $\mathrm{HNO}_{3}-\mathrm{HCl}$ Acid Extraction of Liquids for Metals Analysis Using a Dry-Block Heater. The acid-digested solutions were brought to a nominal $25-\mathrm{mL}$ volume (resulting in a nominal $25 \times$ dilution where the initial sample size was 1-mL); absolute volumes were determined based on final solution weights and densities. The supernatant sample was processed in duplicate. As part of the analytical preparation batch, the ASO processed a digestion preparation blank (PB), a BS, and an MS. The spike solution contained a broad suite of stable elements; radionuclides were not included in the digestion preparation. Aliquots of the BS, MS, and PB, along with the sample aliquots, were delivered to the ICP-OES workstation for analysis; sample and PB aliquots were delivered to the radiochemical workstations for separations supporting specific radioisotope analysis. 


\section{A.5 KOH Fusion}

The potassium hydroxide (KOH) fusion was conducted in the shielded analytical facility (hot cells) according to PNL-ALO-115, Solubilization of Metals from Solids using $\mathrm{KOH}-\mathrm{KNO}_{3}$ Fusion. A nominal sample size of 0.1 to $0.2 \mathrm{~g}$ dry solids was combined with a $\mathrm{KOH} / \mathrm{KNO}_{3}$ flux mixture and fused at $550^{\circ} \mathrm{C}$ for 1 hour in a nickel crucible. The fused material was acidified with $\mathrm{HNO}_{3}$, taken to a 100 -mL volume with deionized (DI) water, and then split for metals and radionuclide analysis. The sample was prepared in duplicate along with a fusion blank and a laboratory control sample (LCS) (SRM-2710, Montana Soil, purchased from the National Institute for Science and Technology [NIST]).

\section{A.6 $\mathrm{NaOH} / \mathrm{Na}_{2} \mathrm{O}_{2}$ Fusion}

The $\mathrm{NaOH} / \mathrm{Na}_{2} \mathrm{O}_{2}$ fusion was conducted in the shielded analytical facility (hot cells) according to PNL-ALO-114, Solubilization of Metals from Solids Using a $\mathrm{Na}_{2} \mathrm{O}_{2}-\mathrm{NaOH}$ Fusion. A nominal sample size of 0.1 to $0.2 \mathrm{~g}$ dry solids was combined with a $\mathrm{NaOH} / \mathrm{Na}_{2} \mathrm{O}_{2}$ flux mixture and fused at $550^{\circ} \mathrm{C}$ for 1 hour in a zirconium crucible. The fused material was acidified with $\mathrm{HNO}_{3}$, taken to a 100 -mL volume with DI water, and then split for metals analysis. The sample was prepared in duplicate along with a fusion blank and an LCS (SRM-2710, Montana Soil).

\section{A.7 HF-Assisted Acid Digestion}

The HF-assisted acid digestion was conducted in the Sample Receiving and Preparation Laboratory according to PNL-ALO-138, $\mathrm{HNO}_{3}-\mathrm{HF}-\mathrm{HCl}$ Acid Digestion of Solids for Metals Analyses Using a Dry Block Heater. A nominal sample size of 0.1 to $0.2 \mathrm{~g}$ dry solids was contacted with a mixture of concentrated $\mathrm{HF}$ and $\mathrm{HNO}_{3}$ and evaporated to dryness in a Teflon ${ }^{\circledR}$ reaction tube. Concentrated $\mathrm{HCl}$ was then added, and the sample was evaporated to dryness a second time. Additional concentrated $\mathrm{HNO}_{3}$ and $\mathrm{HCl}$ were added, the reaction tube was capped tightly, and the mixture was heated in a dry-block heater at $95^{\circ} \mathrm{C}$ for $6.5 \mathrm{~h}$. The digestate was cooled, brought to a 50-mL volume, and then split for metals analysis. The sample was prepared in duplicate along with a fusion blank and an LCS (SRM-2710, Montana Soil).

\section{A.8 Metals Analysis by ICP-OES}

Metals were measured by ICP-OES according to procedure RPG-CMC-211, Determination of Elemental Composition by Inductively Coupled Argon Plasma Optical Emission Spectrometry (ICPOES). The preparative QC samples (duplicate, $\mathrm{PB}, \mathrm{BS}$, MS) were processed along with analytical workstation QC (post digestion spike and serial dilution).

\section{A.9 U (KPA)}

Uranium was determined directly from samples prepared by $\mathrm{KOH}$ fusion using a Chem Chek Instruments KPA according to procedure RPG-CMC-4014, Rev. 1, Uranium by Kinetic Phosphorescence Analysis. The LCS did not contain U, so preparative QC was limited to the duplicate and PB. A post-digestion spike was conducted at the analytical workstation.

\section{A.10 Gamma Energy Analysis}


Gamma energy analysis was performed with direct or diluted samples that were prepared from acid digestion, or fusion. Sample counting was conducted according to procedure RPG-CMC-450, Gamma Energy Analysis (GEA) and Low-Energy Photon Spectroscopy (LEPS), using high-purity germanium detectors. Extended count times (up to $20 \mathrm{~h}$ ) were employed as needed to achieve low detection limits. In many cases, the Compton background from the high ${ }^{137} \mathrm{Cs}$ activity $(661 \mathrm{keV})$ limited the achievable detection limit of lower-energy gamma emitters (e.g., ${ }^{241} \mathrm{Am}$ at $59 \mathrm{keV}$ ). The QC associated with the GEA analysis was composed of the sample duplicate and PB; because this is a direct analysis, no additional QC samples were required.

\section{A.11 Gross Alpha and Gross Beta}

The gross alpha and beta activities were measured from aqueous samples prepared by acid-digestion, and washed-solids samples were prepared by $\mathrm{KOH} / \mathrm{KNO}_{3}$ fusion. Prepared sample aliquots were plated directly onto stainless steel planchets according to procedure RPG-CMC-4001, Source Preparation for Gross Alpha and Gross Beta Analysis. The mounts prepared for gross alpha analysis were counted with Ludlum alpha scintillation counters. The gross alpha analysis tends to be confounded by the dissolved solids in the sample matrix. The solids can absorb the alpha particles, decreasing the intensity relative to the detector, which biases the results low. The sources prepared for gross beta analysis were counted with an LB4100 gas-proportional counter. In both cases, counting operations were conducted according to procedure RPG-CMC-408, Rev.1, Total Alpha and Total Beta Analysis. The preparative QC included the sample duplicates and the preparation blank. The BS and MS were prepared at the analytical workstation on sample dilutions.

\section{A.12 Pu Isotopes: ${ }^{238} \mathrm{Pu}$ and ${ }^{239+240} \mathrm{Pu}$}

The ${ }^{238} \mathrm{Pu}$ and ${ }^{239+240} \mathrm{Pu}$ activities were measured from aqueous samples prepared by acid-digestion, and washed solids samples were prepared by $\mathrm{KOH} / \mathrm{KNO}_{3}$ fusion. Radiochemical separations were conducted according to procedure RPG-CMC-4017, Analysis of Environmental Water Samples for Actinides and Strontium-90 (analyte purification using ion exchange); source preparation was conducted according to RPG-CMC-496, Coprecipitation Mounting of Actinides for Alpha Spectroscopy (co-precipitation of PuF 3 with $\mathrm{LaF}_{3}$ ); and alpha counting was conducted according to RPG-CMC-422, Rev.1, Solutions Analysis: Alpha Spectrometry. The preparative QC included the sample duplicates and the preparation blank. The BS and MS were prepared at the analytical workstation on sample dilutions.

\section{A.13 Strontium-90}

The ${ }^{90} \mathrm{Sr}$ activities were measured from aqueous samples prepared by acid-digestion, and washed-solids samples were prepared by $\mathrm{KOH} / \mathrm{KNO}_{3}$ fusion. Radiochemical separation was conducted according to procedure RPG-CMC-476, Strontium-90 Separation Using Eichrom Strontium Resin; source preparation and beta counting were conducted according RPG-CMC-474, Measurement of Alpha and Beta Activity by Liquid Scintillation Spectrometry. 
WTP-RPT-172, Rev 0

Appendix B

\section{Physical Property and Rheology Methods}




\section{Appendix B: Physical Property and Rheology Measurement Methods}

The following sections describe procedures used to support physical characterization of the slurry samples during bench scale filtration/leach testing to examine their impact on filtration, examine leaching behavior, and support mass balance calculations.

\section{B.1 Physical Properties (Density, Slurry Solid Measurements)}

Slurry samples were collected in tared glass graduated centrifuge cones. Slurry densities were calculated by measuring the slurry mass and the slurry volume in the cone. The vials were centrifuged at $~ 1000 \mathrm{G}$ for 1 hour. Supernatants were decanted into tared graduated cylinders. The supernatant density was calculated from the decanted mass and volume measurements. The supernatant was then placed in a tared glass vial and dried in the oven, along with the slurry solids in the centrifuge cone. Once the samples were dried to a constant mass, the mass of the centrifuge cone and the supernatant vial was measured. The collected data were processed as described by Smith and Prindville ${ }^{(a)}$ to determine the undissolved solids, dissolved solids, and centrifuge solids of the slurry.

\section{B.2 Rheology Measurements}

Rheological testing was conducted on the solids in contact with the supernatant generated as part of the homogenization process. Testing was conducted according to RPL-COLLIOD-02, Measurement of Physical and Rheological Properties of Solutions, Slurries and Sludges. For the current study, two regions of tank waste flow behavior are considered: 1 ) incipient motion in settled tank waste solids (shear strength) and 2) non-elastic flow of tank waste slurries and supernates (flow curve).

\section{B.2.1 Shear-Strength Testing}

For tank waste slurries, a finite stress must be applied before the material will begin to flow. The stress required to transition the material from elastic deformation to viscous flow is referred to as the shear strength, and its origin can be attributed to static and kinetic friction between individual particles and/or aggregates, the strength of the matrix supporting the coarse fraction (i.e., the interstitial fluid), and sludge cohesion arising from interparticle adhesive forces such as van der Waals forces.

The shear strength was measured using the vane method. For the vane technique, the stress required to begin motion is determined by slowly rotating a vane immersed in the test sample's settled solids while continuously monitoring the resisting torque as a function of time. A material's static shear strength is then associated with the maximum torque measured during the transition from initial to steady-state vane rotation.

The maximum torque required for incipient motion is dependent on vane geometry. To account for vane geometry effects, shear strength is expressed in terms of the uniform and isotropic stress acting over the

(a)_24590-WTP-GPG-RTD-001 Rev 0, "Guidelines for Performing Chemical, Physical, and Rheological Properties Measurements,” G. L. Smith and K. Prindiville, May 2002. 
surface area of the cylinder of rotation swept out by the vane. The shear strength is related to the maximal torque during incipient motion according to Equation B.1 (Barnes and Dzuy 2001):

$$
\tau_{S S}=\frac{M_{\max }}{4 \pi R^{3}\left(\frac{H}{2 R}+\frac{1}{3}\right)}
$$

Here, $\tau_{s s}$ is the shear strength $\left(\mathrm{N} / \mathrm{m}^{2}\right), M_{\max }$ is the maximum torque $(\mathrm{N} \cdot \mathrm{m})$, and $R$ and $H$ are the radius and height of the cylinder of rotation swept out by the vane $(\mathrm{m})$. Because the shear band observed upon slow rotation of the vane does not extend appreciably beyond the vane paddles, $R$ and $H$ are taken to be the dimensions of the vane itself.

\section{B.2.2 Flow-Curve Testing}

The non-elastic flow of tank waste slurries and supernates is characterized with rotational viscometry. The typical result of such testing is a set of flow-curve data, which shows the stress response of a material to a range of applied rates-of-deformation. Specifically, flow-curve testing allows characterization of a material's shear stress, $\tau$, and response as a function of applied shear rate, $\dot{\gamma}$. Once measured, the flowcurve data can be interpreted with several constitutive equations for the viscous stress/rate-of-strain relationship. Such analysis allows the flow behavior over a broad range of conditions to be described with just a few rheological descriptors such as viscosity, yield stress, consistency, and flow index.

A concentric cylinder rotational viscometer operated in controlled-rate mode was used for flow-curve testing of tank waste slurries and supernates. Rotational viscometers operate by placing a given volume of test sample into a measurement cup of known geometry. A cylindrical rotor attached to a torque sensor is then lowered into the sample until the slurry is even with, but does not cover, the top of the rotor. A single-point determination of a fluid's flow properties is made by spinning a rotor at a known rotational speed, $\Omega$, and measuring the resisting torque, $M$, acting on the rotor. The torque acting on the rotor can be directly related to the shear stress at the rotor using the equation,

$$
\tau=\frac{M}{2 \pi H R_{I}^{2}}
$$

Shear stress has units of force per area $\left(\mathrm{N} / \mathrm{m}^{2}\right)$. The rotational rate is related to the shear rate. However, calculating the fluid shear rate at the rotor is complicated by the fact that shear rate depends on both the measurement system geometry and the fluid rheological properties. For the simplest fluids (i.e., Newtonian fluids), the shear rate of the fluid at the rotor can be calculated given the geometry of the cup rotor shear by using the equation,

$$
\dot{\gamma}=\left(\frac{2 R_{O}^{2}}{R_{O}^{2}-R_{I}^{2}}\right) \Omega
$$

Here, the shear rate has units of inverse seconds $\left(\mathrm{s}^{-1}\right)$. Calculating the shear rate for materials showing more complex shear-stress versus shear-rate behavior (i.e., non-Newtonian fluids) requires estimates of 
yield stress and degree of shear-thinning or shear-thickening. As the goal of rheological testing is to determine and quantify such behavior, these values are typically not known. This requirement can be circumvented by using a cup and rotor system with a small gap $(\sim 1 \mathrm{~mm})$ for fluid shear. For fluid flow in small gap cup and rotor systems, shear-rate effects introduced by fluid properties are minimized such that Equation B.3 provides an accurate determination of shear rate for non-Newtonian materials. Shear rates examined in this study spanned the range from 1 to $1000 \mathrm{~s}^{-1}$.

The resistance of a fluid to flow is often described in terms of the fluid's apparent viscosity, $\eta_{a p p}$, which is defined as the ratio of the shear stress to shear rate:

$$
\eta_{\text {app }}=\frac{\tau}{\dot{\gamma}}
$$

For Newtonian fluids, the apparent viscosity is independent of shear rate. For non-Newtonian fluids, the apparent viscosity will vary as a function of shear rate. The units of apparent viscosity are Pa·s, although it is typically reported in units of centipoise (cP; where $1 \mathrm{cP}=1 \mathrm{mPa} \cdot \mathrm{s})$.

Flow-curve data are usually combined plots of $\tau$ and $\eta_{\text {app }}$ as a function of $\dot{\gamma}$. As stated above, flow-curve data can be interpreted with several constitutive equations (i.e., flow curves), allowing characterization of that data with just a few rheological descriptors. The behavior of tank waste sludges, slurries, and supernates can be described by four common flow-curve equations:

- Newtonian-Newtonian fluids flow as a result of any applied stress and show constant viscosity over all shear conditions. The flow curve for Newtonian fluids is,

$$
\tau=\eta \dot{\gamma}
$$

where $\eta$ is the Newtonian viscosity.

- Ostwald (Power Law) - Power-law fluids flow as a result of any applied stress and have viscosities that either increase or decrease with increasing shear rate. They are described by,

$$
\tau=m \dot{\gamma}^{n}
$$

where $m$ is the power-law consistency index, and $n$ is the power-law index. Power-law fluids with $n<1$ are referred to as pseudoplastic (shear-thinning), whereas power-law fluids with $n>1$ are referred to as dilatant (shear-thickening).

- Bingham Plastic - Bingham plastics are fluids that show finite yield points. A finite stress (i.e., the yield stress), must be exceeded before these types of materials flow. Once flow is initiated, the stress response of the material is Newtonian over the rest of the shear-rate range. Bingham plastics are described by

$$
\tau=\tau_{O}^{B}+k_{B} \dot{\gamma}
$$


where $\tau_{O}^{B}$ is the Bingham yield index, and $k_{B}$ is the Bingham consistency index.

- Herschel-Bulkley —Fluids that behave in accordance with a Herschel-Bulkley model show a finite yield followed by power-law behavior over the rest of the shear-rate range. They are described by

$$
\tau=\tau_{O}^{H}+k_{H} \dot{\gamma}^{b}
$$

where $\tau_{O}^{H}$ is the Herschel-Bulkley yield index, $k_{H}$ is the Herschel-Bulkley consistency index, and b is the Herschel-Bulkley power-law index.

Power-law fluids, Bingham plastics, and Herschel-Bulkley fluids are examples of non-Newtonian fluids. In general, liquids without internal and/or interconnected structures (such as tank waste supernates) are Newtonian. Sludges and slurries are typically non-Newtonian, but their exact behavior depends on the concentration of solids and suspending phase chemistry. Sufficiently dilute slurries may show Newtonian behavior.

\section{B.2.3 Rheology Instrumentation}

Rheological characterization was accomplished using a Rotovisco ${ }^{\circledR}$ RV20 Measuring System M equipped with an M5 measuring head sold by HAAKE Mess-Technik GmbH u. Co. (now the Thermo Electron Corporation, Madison, WI). The M5 measuring head is a "Searle" type viscometer capable of producing rotational speeds up to 500 revolutions per minute (RPM) and measuring torques up to 0.049 $\mathrm{N} \cdot \mathrm{m}$. The minimum rotational speed and torque resolution achievable by this measuring head are 0.05 $\mathrm{RPM}$ and $0.49 \mathrm{mN} \cdot \mathrm{m}$, respectively.

Specific measurement tools, such as cup and rotor assemblies and shear vanes, are attached to measure selected rheological properties. Shear-strength measurements employed an 8 -mm $\times 16-\mathrm{mm}(\mathrm{R} \times \mathrm{H})$ shear vane tool. Flow-curve measurements employed an MV1 stainless steel measuring cup and rotor. The dimensions of the MV1 and vane measuring systems are listed in Table B.1.

Table B.1. Vane and Cup and Rotor Measuring System Dimensions

\begin{tabular}{||c|c|c|c|c||}
\hline \hline $\begin{array}{c}\text { MEASURING } \\
\text { SYSTEM }\end{array}$ & $\begin{array}{c}\text { VANE/ROTOR } \\
\text { RADIUS, } \\
\text { MM }\end{array}$ & $\begin{array}{c}\text { VANE/ROTOR } \\
\text { HEIGHT, } \\
\text { MM }\end{array}$ & $\begin{array}{c}\text { CUP } \\
\text { RADIUS, } \\
\text { MM }\end{array}$ & $\begin{array}{c}\text { GAP } \\
\text { WIDTH, } \\
\text { MM }\end{array}$ \\
\hline Vane Tool & 8 & 16 & $>16$ & $>8$ \\
\hline MV1 & 20.04 & 60 & 21 & 0.96 \\
\hline
\end{tabular}

The temperature was controlled with a combination of the standard measuring system M temperature jacket and a Cole-Parmer ${ }^{\circledR}$ Polystat ${ }^{\circledR}$ Temperature-Controlled Recirculator, Model Number C-12920-00. The temperature jacket provided a heat-transfer area between the cup and the recirculating fluid. The jacket temperature was monitored using a Type-K thermocouple (Omega Model TJ36-CASS-116-G-6CC). Temperature control was employed only for flow-curve measurements. The shear strengths were measured at ambient temperature $\left(\sim 30^{\circ} \mathrm{C}\right.$ in the hot cells). 
The rheometer was controlled and data were acquired with a remote computer connection using the RheoWin Pro Job Manager Software, Version 2.96. During measurement, the software automatically collects and converts rotor torque readings into shear stresses based on Equation B.1 (for vane testing) or Equation B.2 (for flow-curve testing). Likewise, the software also automatically converts the rotational rate readings into shear rates based on Equation B.3.

\section{B.2.4 Rheology Materials and Methods}

No sample treatment was performed before analysis with the exception of the mechanical agitation required to mix and sub-sample selected waste jars.

\section{B.2.4.1 Shear-Strength Testing}

Before testing, the tank waste slurries that were provided for shear-strength testing were mixed thoroughly and subsequently allowed to settle for at least 48 to $72 \mathrm{~h}$. When possible, the shear strength was measured by immersing the $8-\times 16$-mm vane tool to a depth of $15 \mathrm{~mm}$ into the settled solids. The vane was slowly rotated at 0.3 RPM for $180 \mathrm{~s}$. For the entire duration of rotation, the time, rotational rate, and vane torque were continuously monitored and recorded. At the end of the measurement, shear stress versus time data were parsed, and the maximum measured shear stress (i.e., the material's shear strength) was determined.

\section{B.2.4.2 Flow-Curve Testing}

Each flow curve was measured over a 15-min period and split into three 5-min intervals. Over the first $5 \mathrm{~min}$, the shear rate was smoothly increased from zero to $1000 \mathrm{~s}^{-1}$. For the second $5 \mathrm{~min}$, the shear rate was held constant at $1000 \mathrm{~s}^{-1}$. For the final $5 \mathrm{~min}$, the shear rate was smoothly reduced back to zero. During this time, the resisting torque and rotational rate were continuously monitored and recorded.

Before each test, the sample was left undisturbed in the measuring system for 5 min to allow temperature equilibration. The sample was then mixed for 3 min using the measuring system rotor to re-disperse any settled solids and to pre-shear slurries before measurement.

Flow-curve tests were run at 25,40 , and $60^{\circ} \mathrm{C}$. Because of limited sample volume, all three temperature tests were performed on the same sample. To combat the effects of sample evaporation, a moisture barrier was installed over the opening at the top of the temperature jacket during testing, and after each test, the cup was raised so that fresh sludge/slurry filled the measurement gap.

\section{B.3 Particle-Size Attributes}

Particle attributes, including size distribution and surface area, are discussed in the following sections.

\section{B.3.1 Particle-Size Distribution}

Particle sizes were characterized according to procedure RPL-COLLOID-01, Rev. 1, Particle Size Analysis Using Malvern MS2000. This procedure uses a Mastersizer 2000 (Malvern Instruments, Inc., Southborough, MA 01772 USA) with a Hydro $\mu$ P wet dispersion accessory. Malvern lists the Mastersizer particle-size measurement range as nominally 0.02 to $2000 \mu \mathrm{m}$. The actual PSD measurement range is dependent on the accessory used as well as the properties of the solids being 
analyzed. When coupled with the Hydro $\mu \mathrm{P}$ wet dispersion accessory, the nominal listed measuring range is reduced to 0.02 to $150 \mu \mathrm{m}$. The Malvern 2000 uses laser diffraction technology to define PSD.

A diagram of the flow loop of the instrument and how the sample passes through the flow cell is shown in Figure B.1. The Hydro $\mu$ P wet-dispersion accessory consisted of a 20 -mL sample flow cell with a continuous variable and independent pump and ultrasound. Both flow and sonication can be controlled and altered during measurement. PSD measurements were made before, during, and after sonication, allowing the influence of each on the sample PSD to be determined. The primary measurement functions of the Malvern analyzer were controlled through Mastersizer 2000 software, Version 5.1 (Malvern Instruments, Ltd. Copyright ${ }^{\odot}$ 1998-2002). The optical properties applied to the test samples are summarized in Table B.2.

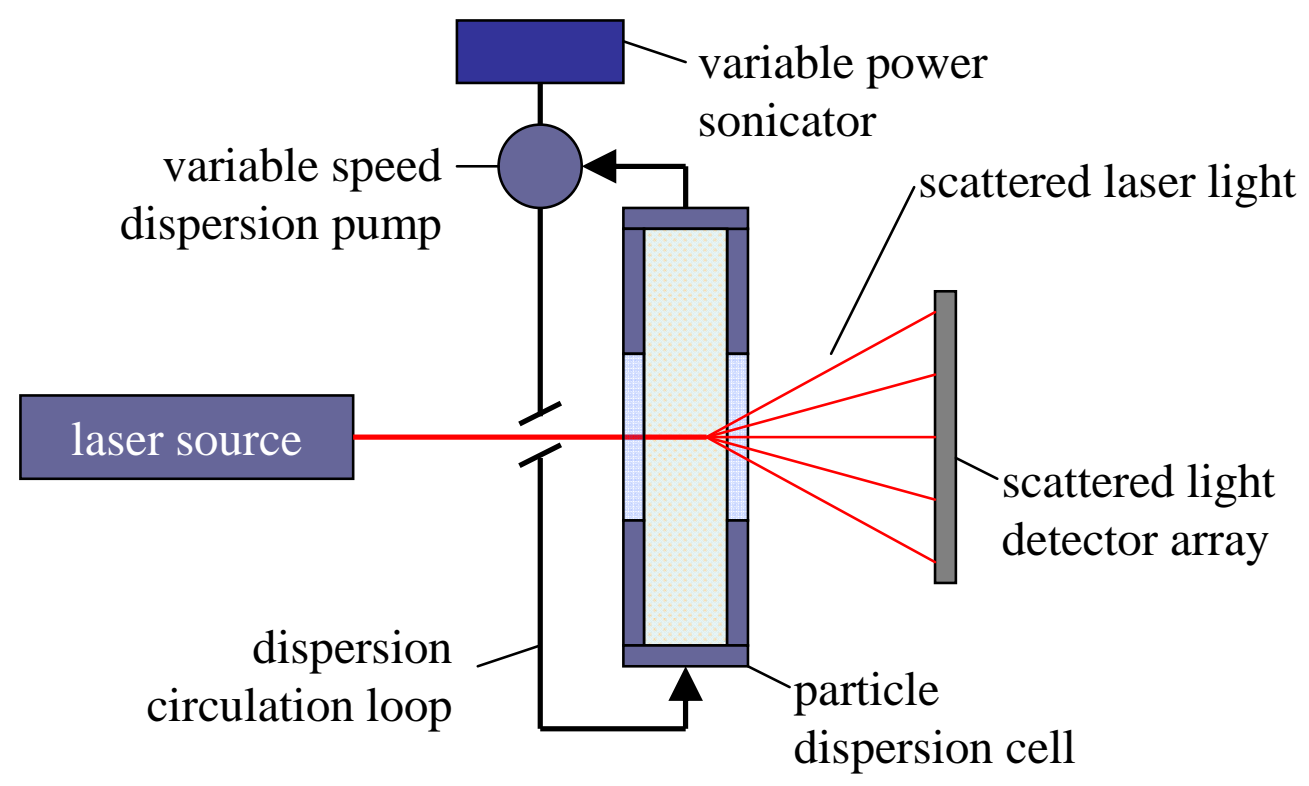

Figure B.1. Flow Loop Diagram of the Malvern PSD Analyzer with Dispersion Cell

Table B.2. Optical Properties Applied To Test Materials

\begin{tabular}{|c|c|c|c||}
\hline Test & $\begin{array}{c}\text { Material Selected for } \\
\text { Optical Properties }\end{array}$ & $\begin{array}{c}\text { Refractive Index } \\
\text { (RI) }\end{array}$ & Absorption \\
\hline Initial Characterization & & & 1.0 \\
\hline Group 5 & Boehmite $^{(\mathrm{a})}$ & 1.655 & 1.0 \\
\hline Group 6 & Boehmite $^{(\mathrm{a})}$ & 1.655 & 1.0 \\
\hline Parametric & & & 1.0 \\
\hline Group 5 & Uranium Oxide $^{(\mathrm{b})}$ & 2.4 & $\mathrm{n} / \mathrm{a}$ \\
\hline Group 6 & Chrome Oxide $^{(\mathrm{a})}$ & 2.5 & \\
\hline All/Suspending Phase & Water $^{(\mathrm{a})}$ & 1.33 & \\
\hline $\begin{array}{l}\text { (a) See reference Malvern Instruments Ltd., April 1997. } \\
\text { (b) See reference Kaminski et al., 2005. }\end{array}$
\end{tabular}


The PSD measurements were conducted on the washed solids in a $0.01-\mathrm{M} \mathrm{NaOH}$ dispersion solution matrix. The sample dispersion was added drop-wise to the instrument (while the pump was active) until an $\sim 10 \%$ obscuration was reached. For all samples, less than $10 \mathrm{mg}$ of solids was required to reach the desired obscuration in the 20-mL flow cell.

The size distributions of particles were measured under varying flow conditions before, during, and after sonication. A typical test matrix is shown in Table B.3. Not all conditions were tested for some samples (e.g., initial characterization samples only employed pump speeds of 3000 RPM). For each condition, three successive 12-second measurements of PSD were taken. An average of these measurements was then generated by the analyzer software. Both individual measurement and average were saved to the analyzer data file. Once measurements were complete, the sonic power for the next condition was set, the sample was given 30 to 60 seconds to equilibrate, and the next set of measurements was taken.

Table B.3. Prototypic Particle-Size Analysis Test Matrix

\begin{tabular}{|c|c|c|c|}
\hline Condition No. & Pump Speed (RPM) & Sonic Power & Comment \\
\hline 1 & 3000 & $0 \%$ & pre-sonic measurement \\
\hline 2 & 2000 & $0 \%$ & pre-sonic measurement \\
\hline 3 & 4000 & $0 \%$ & pre-sonic measurement \\
\hline 4 & 3000 & $25 \%$ & sonicated measurement \\
\hline 5 & 3000 & $50 \%$ & sonicated measurement \\
\hline 6 & 3000 & $75 \%$ & sonicated measurement \\
\hline 7 & 3000 & $0 \%$ & post-sonic measurement \\
\hline 8 & 2000 & $0 \%$ & post-sonic measurement \\
\hline 9 & 4000 & $0 \%$ & post-sonic measurement \\
\hline
\end{tabular}

\section{B.3.2 Surface Area (BET)}

Samples were prepared for surface-area measurements in an effort to minimize solidification into a monolith upon drying. To this end, the solids were rinsed twice with ethanol and twice again with ethyl ether according to procedure TPR-RPP-WTP-486, Procedure for BET Sample Preparation Using Ethanol and Ethyl Ether as Drying Agents. Each rinse was conducted in a centrifuge tube. The solids were well suspended in the rinse solution, and then the phases were separated by centrifuging and decanting. The final ethyl ether rinse was used to transfer the solids slurry to the sample cell. The ethyl ether was then evaporated at room temperature directly from the sample cell.

The sample was further dried and out-gassed using the Quantachrome Instruments Monosorb Model MS-21 (Boynton Beach, FL) outgassing station. This entailed pre-flushing nitrogen through the sample cell for $\sim 10 \mathrm{~min}$ and then heating and flushing for overnight $(>10 \mathrm{~h})$ at $110^{\circ} \mathrm{C}$.

The surface-area measurements were conducted according to OCRWM-BET-01, Surface Area Measurement with a Monosorb Gas Analyzer, which is consistent with ASTM method D5604-96, Test Method B (Single-Point Surface Area by Flowing Gas Apparatus). The flow gas used in the measurement mode was composed of $30 \%$ nitrogen in helium. The system was calibrated per 
manufacturer instructions. The system performance was assessed using a $29.9 \pm 0.75 \mathrm{~m}^{2} / \mathrm{g}$ carbon surface area standard Lot D-6 obtained from Micromeritics Instrument Corporation (Norcross, GA).

\section{B.4 Chemical, Morphological, and Mineralogical Characterization}

The solids crystal characteristics were determined on small aliquots of the washed solids. In all cases, the solids sample fractions were allowed to air dry at room temperature in preparation for analysis. This effort was intended to minimize morphological changes that might occur upon heating. The methods that were applied for XRD, SEM, and TEM evaluations are discussed in the following sections.

\section{B.4.1 X-Ray Diffraction}

The sample mounts for XRD determination were prepared from the dried solids according to procedure RPL-PIP-4, Preparing Sealed Radioactive Samples for XRD and Other Purposes. Specimens were pulverized to a powder with a boron carbide mortar and pestle, mixed with an internal standard (rutile, $\mathrm{TiO}_{2}$, or alumina, $\mathrm{Al}_{2} \mathrm{O}_{3}$ ), and mounted on a glass slide. In some cases, the internal standard was omitted in an effort to provide better clarity of the sample diffraction pattern free from potential interference from the internal standard diffraction pattern. The XRD examination was conducted according to procedure PNNL-RPG-268, Solids Analysis, X-Ray Diffraction Using RGD \#34. Copper Ka X-rays were used Process parameters included examination of the X-ray 2-theta range from 5 to 65 degrees with a step size of 0.02 degrees and a dwell time of 20 seconds.

Phase identification was performed with JADE, Version 8.0 (Materials Data Inc., Livermore, CA) software search and peak match routines with comparison to the International Centre for Diffraction Data (ICDD) database PDF-2, Version 2.0602 (2006). The ICDD database included the Inorganic Crystal Structure Database (ICSD) maintained by Fachinformationszentrum, Karlsruhe, Germany. Phase identification incorporated chemistry restrictions based on the elements determined from chemical analysis.

\section{B.4.2 Scanning Electron Microscopy}

A small sample was transferred with a wooden Q-tip stem onto carbon tape supported by an aluminum pedestal mount. The sample was analyzed using the radiation-shielded Amray Model 1610T SEM according to RPL-611A-SEM, Scanning Electron Microscope Examinations. In selected cases, the mount was carbon-coated. Selected sample areas were evaluated by energy dispersive X-ray spectroscopy (EDS) for qualitative elemental composition.

\section{B.4.3 Transmission Electron Microscopy}

The TEM samples were prepared in a two-step methanol rinsing process. A small amount of the sludge slurry was mixed and transferred into methanol; a drop of the methanol slurry was transferred into a second vial containing methanol; then a drop of this second solution was deposited onto a lacey carbon TEM grid. The particles were air-dried on the lacey grid. Note that the sample drying process may induce changes in the morphology of the particle agglomerates. However, the objective of the TEM investigation was to look at the fundamental characteristics and sizes of individual particle crystallites that are not dependent on drying effects. 
The observations were performed on an FEI Tecnai G2-30 (FEI Inc., Hillsboro, OR) with a field emission filament operating at $300 \mathrm{keV}$ equipped with a Scanning Transmission Unit and High Angle Annular Dark-Field Detector (HAADF), energy dispersive X-ray detector, and a Gatan Imaging Filter (GIF), model GIF2000 (Gatan Inc., Pleasanton, CA). Particles and areas were analyzed by identifying the composition with EDS and electron energy-loss spectroscopy (EELS). Images were obtained with either the scanning transmission electron microscopy (STEM) system or normal bright-field imaging. Energyfiltered images were also obtained with the image filter to produce element-specific area maps.

\section{B.4.4 Electron Energy-Loss Spectroscopy}

For the chromium oxidation study, two Group 6 samples were examined-G6-Cr-TEM (rigorously caustic-leached sample) and G6-IW (initial sample caustic-leached sample)—-together with two mineral standards $\left(\mathrm{Cr}_{2} \mathrm{O}_{3}\right.$ and $\left.\mathrm{PbCrO}_{4}\right)$. The standards were crushed with a mortar and pestle, and a few particles were deposited onto a lacy carbon film. This type of film provided many thin regions where there was no carbon interference.

The EELS spectra were obtained using a 0.6-mm entrance aperture and an energy dispersion of $0.1 \mathrm{eV} /$ channel. Low-loss spectra (including the zero loss peak) were acquired with an integration time of $<0.2 \mathrm{~s}$ and core-loss spectra between 2 and $5 \mathrm{~s}$. To reduce potential beam reduction, the acquisition time was kept as small as possible. The spectra were collected in the imaging mode of the transmission electron microscope and were corrected for dark current and channel-to-channel gain variation of the charge coupled device (CCD) detector.

The energy resolution was about 0.8 to $1.0 \mathrm{eV}$ or better. By lowering the extraction voltage, it was possible to obtain an energy resolution of close to $0.7 \mathrm{eV}$. However, this resolution did not provide sufficient spectral intensity. Garvie and Craven (1994) have reported EELS data on the Cr- $\mathrm{L}_{2,3}$ edge for a series of minerals using a cold-field emission gun instrument. Although they obtained better energy resolution $(0.35 \mathrm{eV})$ than that obtained in this study, the spectra generated by Garvie and Craven were useful for understanding the features present on the chromium edge.

The core-loss regime was energy calibrated, and the energy drift was measured while data were being acquired by collecting zero-loss spectra before or after core-loss spectra were collected. The position of the C-K (1s) peak at $284 \mathrm{eV}$ (arising from transitions to the $\pi^{*}$ molecular orbital) from the TEM lacy carbon support film was used to evaluate the energy calibration and as a means of roughly checking that the energy resolution was sufficient for collecting data.

Two methods were adopted for determining the chemical state of chromium in the sludge samples. In the first method, we obtained the following ratio defined as:

$$
I-\text { ratio }=\frac{I\left(L_{3}\right)}{I\left(L_{2}\right)}
$$

$\mathrm{L}_{2}$ and $\mathrm{L}_{3}$ are the intensities of background-corrected Cr-absorption edges. The second method was to look at the O:Cr ratio as an indication of oxygen content. 
WTP-RPT-172, Rev 0

Appendix C

\section{Quality Assurance and Control Methods}


WTP-RPT-172, Rev 0

\section{Appendix C: Quality Assurance and Control Methods}

The following sections describe the quality assurance (QA) program and quality control (QC) measures applied to the conduct of work.

\section{C.1 Application of Waste Treatment Plant Support Program (WTPSP) QA Requirements}

Pacific Northwest National Laboratory's (PNNL's) QA program is based on requirements defined in DOE Order 414.1C, “Quality Assurance,” and 10 CFR 830, "Energy/Nuclear Safety Management,” Subpart A-“Quality Assurance Requirements” (a.k.a., the Quality Rule). PNNL has chosen to implement the requirements of DOE Order 414.1C and 10 CFR 830, Subpart A by integrating them into the laboratory's management systems and daily operating processes. The procedures necessary to implement the requirements are documented through PNNL’s Standards-Based Management System.

PNNL implemented the RPP-WTP quality requirements by performing work in accordance with the River Protection Project - Waste Treatment Plant Support Program (RPP-WTP) Quality Assurance Plan (RPPWTP-QA-001, QAP). Work was performed to the quality requirements of NQA-1-1989 Part I, "Basic and Supplementary Requirements,” NQA-2a-1990, Part 2.7, and DOE/RW-0333P, Rev 13, Quality Assurance Requirements and Descriptions (QARD). These quality requirements are implemented through the River Protection Project - Waste Treatment Plant Support Program (RPP-WTP) Quality Assurance Manual (RPP-WTP-QA-003, QAM).

A matrix that cross-references the NQA-1, NQA-2a, and QARD requirements with PNNL's procedures for this work was given in the test plan, TP-RPP-WTP-467. ${ }^{(1)}$ It included justification for those requirements not implemented. The QA requirements of DOE/RW-0333P, Rev 13, Quality Assurance Requirements and Descriptions (QARD) and DOE Order 414.1C were not identified as a requirement for this work in the test specification.

\section{C.2 Conduct of Experimental and Analytical Work}

Experiments that were not method-specific were performed in accordance with PNNL's procedures QA-RPP-WTP-1101 "Scientific Investigations" and QA-RPP-WTP-1201 "Calibration and Control of M\&TE,” verifying that sufficient data were taken with properly calibrated measuring and testing equipment (M\&TE) to obtain quality results.

As specified in the supporting Test Specification, 24590-PTF-TSP-RT-06-0001, Rev. 0, BNI's Quality Assurance Project Plan (QAPjP), PL-24590-QA00001, was not applicable because the work was not performed in support of environmental/regulatory testing, and the data will not be used as such.

(1) SK Fiskum, TP-RPP-WTP-467, Rev. 0, 2/2/07, and Rev. 1, 7/31/07, Characterization and Small Scale Testing of Hanford Wastes to Support the Development and Demonstration of Leaching and Ultrafiltration Pretreatment Processes, Pacific Northwest National Laboratory, Richland, Washington. 
Balances are calibrated annually by a certified contractor, QC Services, Portland, Oregon. A balance performance check was conducted each day the balance was used.

The Analytical Services Operation (ASO) conducted analytical testing according to the Statement of Work RPP-WTP-QA-005, Rev. 2, Analytical Support by the PNNL RPL Analytical Support Operation. The analytical results and raw data are traceable through the project files according to the Analytical Services Request (ASR) number and RPL number.

\section{C.3 Internal Data Verification and Validation}

PNNL addressed internal verification and validation activities by conducting an independent technical review of the final data report in accordance with PNNL's procedure QA-RPP-WTP-604. This review verified that the reported results were traceable, that inferences and conclusions were soundly based, and the reported work satisfied the Test Plan objectives. This review procedure is part of PNNL's RPP-WTP Quality Assurance Manual. 
WTP-RPT-172, Rev 0

Appendix D

Group 6/5 Post-CUF Parametric Analytical Results from Parametric Leaching 


\section{Appendix D: Group 6/5 Post-CUF Parametric Analytical Results from Parametric Leaching}

Table D.1. Analyte Concentrations as a Function of Time for Leaching at $100^{\circ} \mathrm{C}$

\begin{tabular}{|c|c|c|c|c|c|c|}
\hline \multirow[b]{2}{*}{ Analyte } & \multicolumn{6}{|c|}{$\begin{array}{l}\text { Analyte Concentration and Density at Given Time and Ambient }\left(\sim 21^{\circ} \mathrm{C}\right) \text { Temperature; } \\
\mathrm{g} / \mathrm{mL} \text { for Density; } \mu \mathrm{g} / \mathrm{mL} \text { for Metals and Anions; } \mu \mathrm{Ci} / \mathrm{mL} \text { for Radionuclides }\end{array}$} \\
\hline & 0 hr & $1 \mathrm{hr}$ & 2 hr & $4 \mathrm{hr}$ & $8 \mathrm{hr}$ & $24 \mathrm{hr}$ \\
\hline \multicolumn{7}{|c|}{$3 \mathrm{M}$ NaOH } \\
\hline Density & 1.13 & 1.14 & 1.19 & 1.16 & 1.14 & 1.14 \\
\hline $\mathrm{Al}$ & 360.6 & 1,224 & 1,570 & 2,269 & 3,063 & 4,006 \\
\hline $\mathrm{Cr}$ & [4.66] & 38.4 & 59.7 & 97.0 & 170.9 & 315.6 \\
\hline $\mathrm{Fe}$ & [2.87] & {$[6.82]$} & {$[8.26]$} & [12.01] & [16.85] & [20.34] \\
\hline $\mathrm{Na}$ & 75,852 & 78,113 & 79,112 & 79,124 & 79,343 & 77,698 \\
\hline $\mathrm{P}$ & {$[10.20]$} & {$[8.68]$} & $<7.18$ & [11.39] & [11.33] & $<6.86$ \\
\hline $\mathrm{Si}$ & 47.10 & 123.4 & 132.2 & 130.9 & 131.7 & 121.7 \\
\hline Fluoride & $<1.20$ & $<0.76$ & $<1.24$ & $<1.22$ & $<1.21$ & $<1.19$ \\
\hline Nitrite & 15.54 & 16.01 & 17.43 & 16.41 & 16.94 & 16.02 \\
\hline Nitrate & 182.3 & 205.1 & 240.9 & 229.1 & 239.0 & 223.2 \\
\hline Phosphate & 46.0 & 53.0 & 56.6 & 51.7 & 52.0 & 48.7 \\
\hline Sulfate & [4.18] & {$[4.57]$} & {$[5.60]$} & [4.25] & 32.06 & {$[4.75]$} \\
\hline${ }^{60} \mathrm{Co}$ & & & & & & $<3 \mathrm{E}-06$ \\
\hline${ }^{137} \mathrm{Cs}$ & & & & & & 0.78 \\
\hline${ }^{241} \mathrm{Am}$ & & & & & & $<7 \mathrm{E}-05$ \\
\hline \multicolumn{7}{|c|}{$5 \mathrm{M}$ NaOH, Trial a } \\
\hline Density & 1.21 & 1.19 & 1.21 & 1.21 & 1.22 & 1.21 \\
\hline $\mathrm{Al}$ & 583.7 & 1,296 & 1,639 & 2,301 & 3,413 & 4,185 \\
\hline $\mathrm{Cr}$ & 7.86 & 36.9 & 52.9 & 81.8 & 151.5 & 325.2 \\
\hline $\mathrm{Fe}$ & [3.10] & [13.93] & [15.12] & [20.83] & 28.52 & 38.24 \\
\hline $\mathrm{Na}$ & 124,508 & 118,070 & 124,618 & 124,692 & 134,291 & 127,653 \\
\hline $\mathrm{P}$ & [13.97] & [10.90] & [8.77] & [10.11] & [12.76] & [10.84] \\
\hline $\mathrm{Si}$ & 69.6 & 129.3 & 139.4 & 140.3 & 154.4 & 146.9 \\
\hline Fluoride & $<1.21$ & $<1.17$ & $<1.21$ & $<1.28$ & $<1.19$ & $<1.21$ \\
\hline Nitrite & [13.26] & [14.06] & [13.32] & [14.70] & [13.70] & [13.88] \\
\hline Nitrate & 195.9 & 215.7 & 233.0 & 231.3 & 227.6 & 228.7 \\
\hline Phosphate & 62.7 & 55.7 & 58.1 & 55.0 & 54.2 & 53.7 \\
\hline Sulfate & $<2.41$ & $<2.34$ & $<2.42$ & $<2.56$ & $<2.38$ & $<2.41$ \\
\hline${ }^{60} \mathrm{Co}$ & & & & & & $<4 \mathrm{E}-06$ \\
\hline${ }^{137} \mathrm{Cs}$ & & & & & & 0.80 \\
\hline${ }^{241} \mathrm{Am}$ & & & & & & $<3 \mathrm{E}-04$ \\
\hline \multicolumn{7}{|l|}{$7 \mathrm{M} \mathrm{NaOH}$} \\
\hline Density & 1.27 & 1.27 & 1.26 & 1.27 & 1.28 & 1.28 \\
\hline $\mathrm{Al}$ & 830.7 & NM & 2,369 & 3,229 & 4,731 & 5,937 \\
\hline $\mathrm{Cr}$ & 13.79 & NM & 61.6 & 98.7 & 167.1 & 368.0 \\
\hline $\mathrm{Fe}$ & [6.13] & NM & 28.36 & [36.56] & 50.01 & 60.30 \\
\hline $\mathrm{Na}$ & 165,836 & NM & 162,644 & 164,217 & 170,688 & 171,317 \\
\hline $\mathrm{P}$ & $<12.47$ & NM & [12.37] & {$[17.06]$} & [16.17] & $<12.58$ \\
\hline
\end{tabular}

D.1 
WTP-RPT-172, Rev 0

\begin{tabular}{|c|c|c|c|c|c|c|}
\hline \multirow[b]{2}{*}{ Analyte } & \multicolumn{6}{|c|}{$\begin{array}{l}\text { Analyte Concentration and Density at Given Time and Ambient }\left(\sim 21^{\circ} \mathrm{C}\right) \text { Temperature; } \\
\mathrm{g} / \mathrm{mL} \text { for Density; } \mu \mathrm{g} / \mathrm{mL} \text { for Metals and Anions; } \mu \mathrm{Ci} / \mathrm{mL} \text { for Radionuclides }\end{array}$} \\
\hline & $\mathbf{0 ~ h r}$ & $1 \mathrm{hr}$ & $2 \mathrm{hr}$ & $4 \mathrm{hr}$ & $8 \mathrm{hr}$ & $24 \mathrm{hr}$ \\
\hline $\mathrm{Si}$ & 90.4 & NM & 196.7 & 203.2 & 214.1 & 213.7 \\
\hline Fluoride & $<1.21$ & $<1.22$ & $<1.21$ & $<1.20$ & $<1.20$ & $<1.20$ \\
\hline Nitrite & $<1.81$ & $<1.84$ & $<1.81$ & $<1.80$ & $<1.80$ & $<1.79$ \\
\hline Nitrate & 213.9 & 292.1 & 277.8 & 305.0 & 299.2 & 277.6 \\
\hline Phosphate & 39.8 & 45.3 & 42.9 & 38.5 & 43.7 & 38.9 \\
\hline Sulfate & $<2.41$ & $<2.45$ & $<2.42$ & $<2.41$ & $<2.39$ & $<2.39$ \\
\hline${ }^{60} \mathrm{Co}$ & & & & & & $<5 \mathrm{E}-06$ \\
\hline${ }^{137} \mathrm{Cs}$ & & & & & & 1.18 \\
\hline${ }^{241} \mathrm{Am}$ & & & & & & $<2 \mathrm{E}-04$ \\
\hline
\end{tabular}


WTP-RPT-172, Rev 0

\section{Appendix E}

\section{Group 5 CUF Test Concurrence Letter}




\title{
Appendix E: Group 5 CUF Test Concurrence Letter
}

\author{
Pacific Northwest \\ National Laboratory \\ Operated by Battelle for the \\ U.S. Department of Energy \\ August 9, 2007 \\ Mr. William L. Graves \\ WTP/RPP-MOA-PNNL-00086 \\ Bechtel National Inc. \\ 2435 Stevens Center Place, MSIN: H4-02 \\ Richland WA 99352 \\ Dear Mr. Graves: \\ Subcontract NO. 24590-QL-HC9-WA49-00001 - Project 53019 (WA\#2007-019) \\ Request for Approval of the Group 5 Filtration and Caustic Leaching Test Matrix \\ Purpose: \\ The purpose of this document is to provide BNI with the necessary information to approve the test \\ matrix for crossflow filtration and caustic leaching of actual sludge samples from the Group 5 \\ Redox Sludge waste tanks. This approval is required per Section 6.4 Item 2.0 in Test Plan TP-RPP- \\ WTP-467 Rev 0, Characterization and Small Scale Testing of Hanford Wastes to Support the Development and \\ Demonstration of Leaching and Ultrafiltration Pretreatment Processes.
}

\section{Overview:}

This test will cover the crossflow filtration and caustic leaching test for Group 5 tank waste solids. Group 5 is a homogenized mixture of tank wastes from Hanford tanks S-101, S-107, S-110, and SX103 and is anticipated to contain aluminum primarily in the form of boehmite. Accordingly, this work addresses determination of the filtration and leaching behavior at the bench-scale using the CUF system as described in Section 6.4, Items 3.0 - 9.5 of TP-RPP-WTP-467. A sample consisting of 5 bottles, approximately $1.8 \mathrm{~L}$, of composite waste slurry containing approximately $18 \mathrm{wt} \%$ UDS from the Group 5 waste will be used for this testing effort. All filtration testing will be conducted at $25+/-5^{\circ} \mathrm{C}$. The filtration test matrix was developed based upon median target transmembrane pressure (TMP) of $40 \mathrm{psi}$ and median target axial velocity (AV) of $13 \mathrm{ft} / \mathrm{s}$.

Dewatering:

Dewatering will be done on the as received solids. Note that because the as received solids contain approximately $18 \mathrm{wt} \%$ UDS, additional supernate will be added to bring the initial solids to approximately $5 \mathrm{wt} \%$ UDS. To minimize the impact of potential precipitation issues, a simulated supernate will be prepared based on the existing characterization of the supernate with this sample. That supernate contains approximately $3.2 \mathrm{M} \mathrm{Na}$.

902 Battelle Boulevard • P.O. Box 999 • Richland, WA 99352

Telephone (509) 375-4373 Email gordon.beeman@pnl.gov Fax (509) 375-2323 
Mr. William L. Graves

August 9, 2007

Page 2

Figure 1 provides a summary of sodium molarity during dewatering during the first five years of operating the Waste Treatment Plant. Inspection of this figure indicates that $3.2 \mathrm{M} \mathrm{Na}$ is within the range of conditions expected to be seen during the initial dewatering of slurry.

Fraction of batches bounded by the sodium molarity during initial dewatering

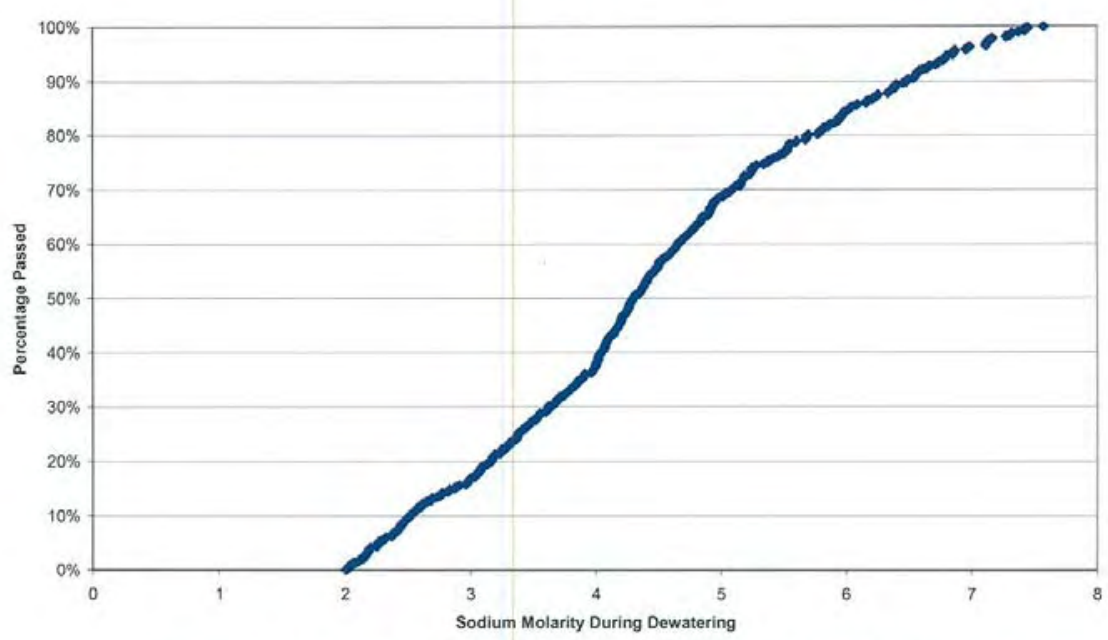

Figure 1. Projected WTP sodium molarity during initial dewatering.

\section{Dewater Process Steps:}

- First prepare a low solids slurry by combining 3 bottles of the composite waste slurry and an appropriate volume of simulated supernatant matching the composition of the actual supernatant to provide $\sim 3.9 \mathrm{~L}$ of slurry at a target of $5 \mathrm{wt} \%$ UDS and $3.2 \mathrm{M}$ sodium. Note that $4 \mathrm{~L}$ is the maximum operating level of the CUF. Thus, with the minimum operating level, it is not possible to put all the feed in the CUF at one time, and thus there will be an initial dewatering followed by the addition of the last two bottles.

- Conduct low solids filtration test matrix, Table 1.

- Dewater to a target of $13 \mathrm{wt} \%$ UDS, or $\sim 1.5 \mathrm{~L}$. Note that $1.5 \mathrm{~L}$ is the minimum operating level of the CUF at which a filtration test matrix can be performed.

- Add remaining 2 bottles of composite waste and an appropriate volume of filtrate to provide $\sim 2.5 \mathrm{~L}$ of slurry at a target of $13 \mathrm{wt} \%$ UDS and $3.2 \mathrm{M}$ sodium.

- Dewater to target of $20 \mathrm{wt} \%$ UDS or $\sim 1.5 \mathrm{~L}$.

- Conduct high solids filtration test matrix, Table 1. 
Mr. William L. Graves

August 9, 2007

Page 3

Table 1. Filtration Test Matrix

\begin{tabular}{|c|c|c|c|}
\hline Test number & Duration (hours) & $\begin{array}{c}\text { Target TMP* } \\
(\mathrm{psi})\end{array}$ & $\begin{array}{c}\text { Target Axial } \\
\text { Velocity* } \\
(\mathrm{ft} / \mathrm{s})\end{array}$ \\
\hline 1 & 3 & 40 & 13 \\
\hline 2 & 1 & 30 & 11 \\
\hline 3 & 1 & 30 & 15 \\
\hline 4 & 1 & 50 & 15 \\
\hline 5 & 1 & 50 & 11 \\
\hline 6 & 1 & 40 & 13 \\
\hline 7 & 1 & 40 & 17 (or max) \\
\hline 8 & 1 & 40 & 13 \\
\hline 9 & 1 & 20 & 13 \\
\hline 10 & 1 & 60 & 13 \\
\hline 11 & 3 & 40 & $\mathrm{c}$ \\
\hline
\end{tabular}

* Actual conditions may vary based upon slurry volume and rheology. All conditions may not be obtainable.

\section{Leaching:}

Testing with this actual waste sample has given a nominal leach factor of 0.51 (in $3 \mathrm{MNaOH}$ at $100 \mathrm{C}$ ). This translates into a leach factor for the boehmite fraction of this waste of 0.47 . The objective of this test is to achieve an equivalent fraction of $\mathrm{Al}$ dissolution under more prototypic process conditions. Table 2 provides a summary of potential leaching conditions. Case 1 presents the conditions used in small scale parametric leaching studies. Cases 2 and 3 represent the quantity of caustic required to reach selected solubility limits for aluminum after cooling. Figure 2 provides a summary of where each of these points fits relative to the gibbsite and boehmite solubility limits.

Table 2. Summary of potential leaching conditions.

\begin{tabular}{|c|c|c|c|c|}
\hline & Case 1 & Case 2 & Case 3 & Case 4 \\
\hline Concentrated Slurry (gal) & 1,515 & 12,000 & 12,000 & 12,000 \\
\hline 19 M Caustic (gal) & 4,784 & 7,238 & 5,434 & 10,393 \\
\hline Condensate (gal) & 24,000 & 7,815 & 7,740 & 8,588 \\
\hline Total Volume (gal) & 30,299 & 27,053 & 25,174 & 30,981 \\
\hline $\begin{array}{l}\text { Supernate Volume (gal) } \\
\mathrm{NaOH}(\mathrm{M}) \\
\text { Total Na Molarity (M) } \\
\mathrm{Al}(\mathrm{M}) \text { - (target for leach } \\
\text { factor) }\end{array}$ & $\begin{array}{r}30,294 \\
3.00 \\
3.00 \\
\\
0.07\end{array}$ & $\begin{array}{r}27,013 \\
5.20 \\
6.53 \\
\\
0.70\end{array}$ & $\begin{array}{r}25,134 \\
4.22 \\
5.65 \\
\\
0.75\end{array}$ & $\begin{array}{r}30,941 \\
6.47 \\
7.64 \\
\\
0.61\end{array}$ \\
\hline
\end{tabular}


Mr. William L. Graves

August 9, 2007

Page 4

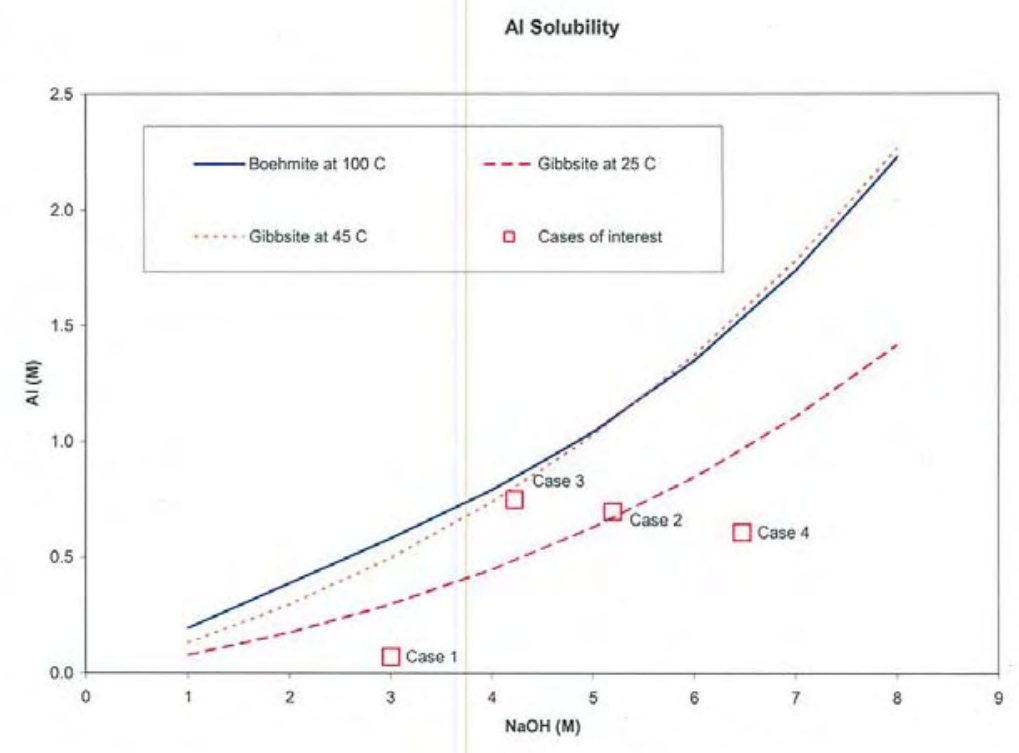

Figure 2. Comparison of various cases to gibbsite and boehmite solubilities at various process conditions.

Based on this data, it is possible to project the leaching performance for boehmite as a function of time. Figure 3 provides this projection. 
Mr. William L. Graves

August 9, 2007

Page 5

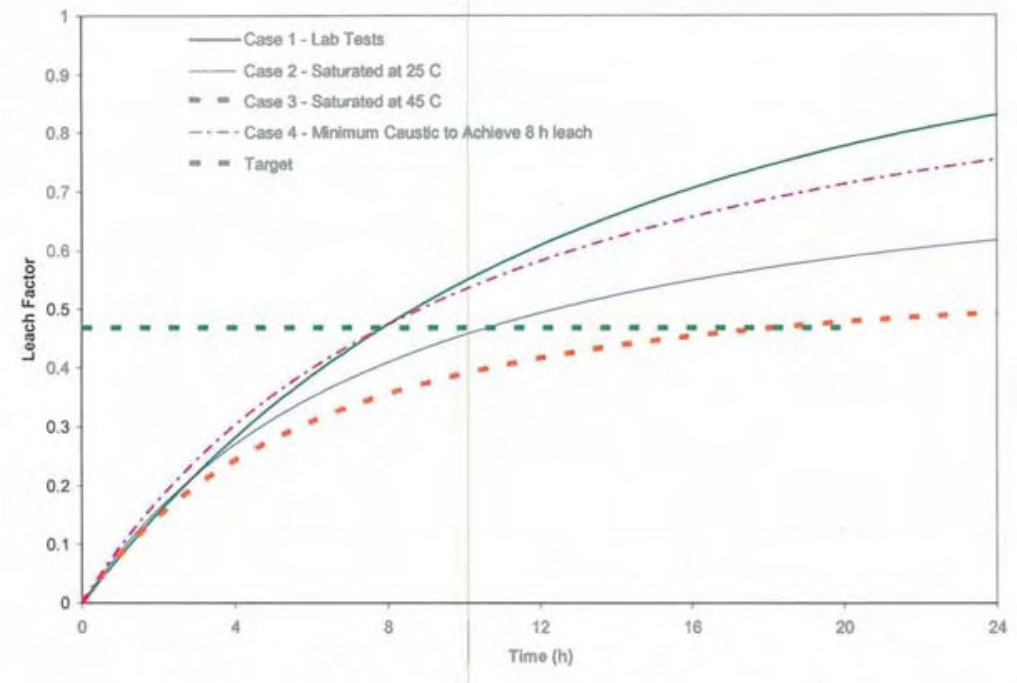

Figure 3. Estimated boehmite leaching performance for various process cases.

Based on the trade-off described in Figure 3, the project elected to use the Case 2 conditions with a 12 hour leach time. This is expected to give nearly equivalent results to the small scale leaching study.

Figure 4 provides a summary of the sodium molarity during caustic leaching for the first 5 years of WTP operation. As seen from this figure, leaching at $6.5 \mathrm{M}$ is within the range of expected leaching conditions. 
Mr. William L. Graves

August 9, 2007

Page 6

Fraction of batches bounded by the sodium molarity during caustic leaching

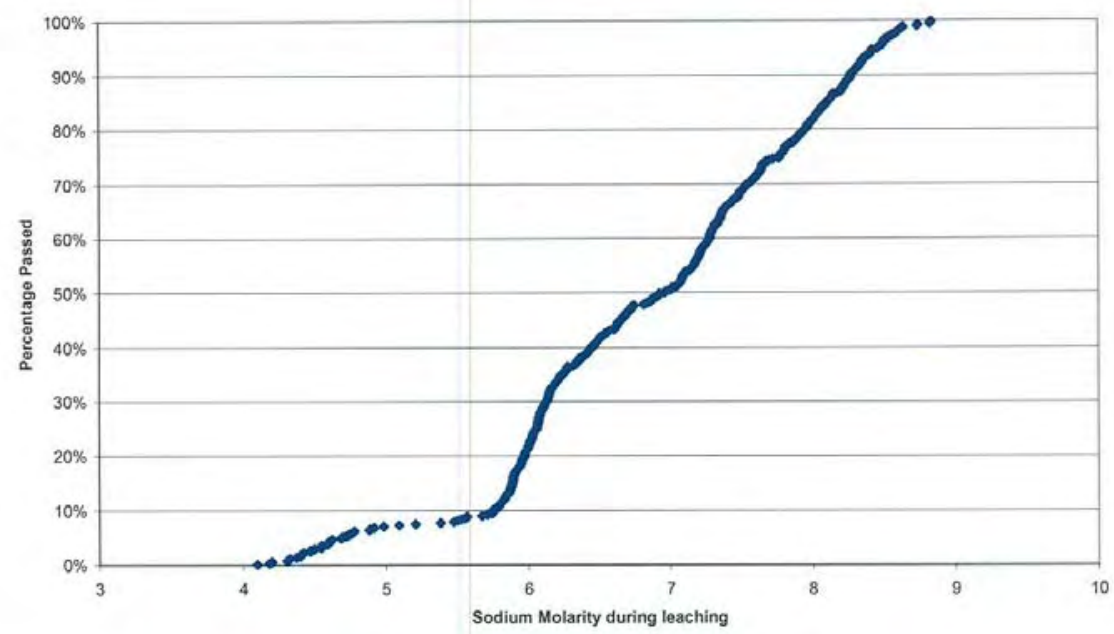

Figure 4. Projected WTP sodium molarity during initial dewatering.

\section{Leaching Process Steps:}

- Retrieve all solids from CUF and isolate in slurry feed reservoir for leaching.

- Heat from $25 \mathrm{C}$ to $100 \mathrm{C}$ in 5.3 hours

- Assuming 1.5 L of 20 wt\% UDS and 3.2M sodium, add $1.88 \mathrm{~L}$ of $9.13 \mathrm{M} \mathrm{NaOH}$, and leach for $12 \mathrm{~h}$ at $100(+5 /-10)^{\circ} \mathrm{C}$. These leaching conditions have been specified by the project to produce a solution saturated at $25^{\circ} \mathrm{C}$ at the conclusion of the leaching process.

- Sample supernate fraction every 4 hours during caustic leaching and analyze supernate fraction by ICP for metals analysis and free- $[\mathrm{OH}]$ concentrations.

- Cool from $100 \mathrm{C}$ to $25 \mathrm{C}$ in 12 hours

\section{Post Leach Dewater Process Steps:}

- Dewater leached solids at $25^{\circ} \mathrm{C}, \mathrm{TMP}=40 \mathrm{psi}$, and $\mathrm{AV}=13 \mathrm{ft} / \mathrm{s}$. Dewater to a target of $18 \mathrm{wt} \%$ undissolved solids (UDS) or to minimum operating volume of CUF $(-1.2 \mathrm{~L})$.

\section{Post Leach Washing:}

The current process outlined by WTP provides for the addition of caustic during water washing to avoid precipitation of aluminum in the wash water. As such, this portion of the process is represented by three equal volume washes, with decreasing caustic in each subsequent wash. 
Mr. William L. Graves

August 9, 2007

Page 7

Post Leach Washing Process Steps:

- Add equal volume of caustic (1.9 molal $\mathrm{NaOH})$ for wash 1, dewater to a target of $19 \mathrm{wt} \%$ UDS or to minimum operating volume of CUF ( $1.2 \mathrm{~L})$.

- Add equal volume of inhibited water $(0.9 \mathrm{molal} \mathrm{NaOH})$ for wash 2, dewater to a target of 20 wt\% UDS or to minimum operating volume of CUF ( $\sim 1.2 \mathrm{~L})$.

- Add equal volume of inhibited water $(0.4$ molal $\mathrm{NaOH})$ for wash 3 , dewater to a target of $20 \mathrm{wt} \%$ UDS or to minimum operating volume of CUF $(\sim 1.25 \mathrm{~L})$.

- Conduct high solids filtration test matrix with leached and washed solids, Table 1.

- Drain slurry from CUF and retain for potential use, only dispose at the guidance of the client.

- Clean CUF and determine clean water $(0.01 \mathrm{M} \mathrm{NaOH})$ flux.

\section{Sample Plan:}

The sample collection and analysis plan is outlined below in Table 3 .

Table 3. Filtration and Leach Testing Characterization Plan

\begin{tabular}{|c|c|c|c|c|}
\hline Process Step & Analyte & Solids & Slurry & $\begin{array}{l}\text { Liquid } \\
\text { or } \\
\text { Filtrate }\end{array}$ \\
\hline \multirow[t]{4}{*}{ Initial slurry } & Rheology (flow curve) & & $\mathrm{x}$ & \\
\hline & Density & & $\mathrm{x}$ & \\
\hline & Wt $\%$ UDS & & $\mathrm{x}$ & \\
\hline & PSD & & $\mathrm{x}$ & \\
\hline \multirow[t]{10}{*}{ Dewatered slurry } & Rheology (flow curve) & & $\mathrm{x}$ & \\
\hline & Density & & $\mathrm{x}$ & \\
\hline & $\mathrm{Wt} \%$ UDS & & $\mathrm{x}$ & \\
\hline & PSD & & $\mathrm{x}$ & \\
\hline & ICP metals (KOH fusion) & & $\mathrm{x}$ & \\
\hline & $\mathrm{Pu}$ (KOH fusion) & & $\mathrm{x}$ & \\
\hline & GEA (KOH fusion) & & $\mathrm{x}$ & \\
\hline & $\begin{array}{l}\text { ICP metal }\left(\mathrm{Na}_{2} \mathrm{O}_{2} \text { fusion or acid }\right. \\
\text { digestion) (Ni) }\end{array}$ & & $\mathrm{x}$ & \\
\hline & $\mathrm{U}(\mathrm{KPA})$ & & $\mathrm{x}$ & \\
\hline & ${ }^{90} \mathrm{Sr}$ & & $\mathrm{x}$ & \\
\hline \multirow[t]{7}{*}{ Filtrate } & ICP metals & & & $\mathrm{x}$ \\
\hline & $\begin{array}{l}\text { Anions (sulfate, phosphate, nitrate, } \\
\text { oxalate) }\end{array}$ & & & $\mathrm{x}$ \\
\hline & Density & & & $\mathrm{x}$ \\
\hline & $\mathrm{Pu}$ & & & $\mathrm{x}$ \\
\hline & GEA ${ }^{137} \mathrm{Cs},{ }^{60} \mathrm{Co},{ }^{241} \mathrm{Am}$ & & & $\mathrm{x}$ \\
\hline & ${ }^{90} \mathrm{Sr}$ & & & $\mathrm{x}$ \\
\hline & Free hydroxide & & & $\mathrm{x}$ \\
\hline
\end{tabular}


Mr. William L. Graves

August 9, 2007

Page 8

\begin{tabular}{|c|c|c|c|c|}
\hline Process Step & Analyte & Solids & Slurry & $\begin{array}{l}\text { Liquid } \\
\text { or } \\
\text { Filtrate }\end{array}$ \\
\hline & Total dissolved solids & & & $\mathrm{x}$ \\
\hline \multirow{12}{*}{$\begin{array}{l}\text { Caustic-leached } \\
\text { slurry }\end{array}$} & wt $\%$ UDS & & $\mathrm{x}$ & \\
\hline & Density & & $\mathrm{x}$ & $\mathrm{x}$ \\
\hline & Rheology (flow curve) & & $\mathrm{x}$ & \\
\hline & PSD & $\mathrm{x}$ & & \\
\hline & ICP metals (acid digestion) & & & $\mathrm{x}$ \\
\hline & ICP metals ( $\mathrm{KOH}$ fusion) & $\mathrm{x}$ & & \\
\hline & $\begin{array}{l}\text { Anions (sulfate, phosphate, nitrate, } \\
\text { oxalate) }\end{array}$ & & & $\mathrm{x}$ \\
\hline & $\mathrm{Pu}$ & $\mathrm{x}$ & & $\mathrm{x}$ \\
\hline & GEA ${ }^{137} \mathrm{Cs},{ }^{60} \mathrm{Co},{ }^{241} \mathrm{Am}$ & $\mathrm{x}$ & & $\mathrm{x}$ \\
\hline & Free hydroxide & & & $\mathrm{x}$ \\
\hline & ${ }^{90} \mathrm{Sr}$ & $\mathrm{x}$ & & $\mathrm{x}$ \\
\hline & $\mathrm{U}(\mathrm{KPA})$ & $\mathrm{x}$ & & $\mathrm{x}$ \\
\hline \multirow{3}{*}{$\begin{array}{l}\text { First and second } \\
\text { washes following } \\
\text { caustic leach }\end{array}$} & Density & & & $\mathrm{x}$ \\
\hline & Free hydroxide & & & $\mathrm{x}$ \\
\hline & ICP metals & & & $\mathrm{x}$ \\
\hline \multirow{6}{*}{$\begin{array}{l}\text { Third wash } \\
\text { following } \\
\text { caustic leach }\end{array}$} & Density & & & $\mathrm{x}$ \\
\hline & Free hydroxide & & & $\mathrm{x}$ \\
\hline & $\begin{array}{l}\text { Anions (sulfate, phosphate, nitrate, } \\
\text { oxalate) }\end{array}$ & & & $\mathrm{x}$ \\
\hline & ICP metals (acid digest) & & & $\mathrm{x}$ \\
\hline & $\mathrm{Pu}$ & & & $\mathrm{x}$ \\
\hline & $\mathrm{GEA}^{137} \mathrm{Cs},{ }^{60} \mathrm{Co},{ }^{241} \mathrm{Am}$ & & & $\mathrm{x}$ \\
\hline \multirow[t]{7}{*}{ Combined washes } & Density & & & $\mathrm{x}$ \\
\hline & ICP metals & & & $\mathrm{x}$ \\
\hline & $\begin{array}{l}\text { Anions (nitrate, sulfate, phosphate, } \\
\text { oxalate) }\end{array}$ & & & $\mathrm{x}$ \\
\hline & Free hydroxide & & & $\mathrm{x}$ \\
\hline & $\mathrm{Pu}$ & & & $\mathrm{x}$ \\
\hline & GEA ${ }^{137} \mathrm{Cs},{ }^{60} \mathrm{Co},{ }^{241} \mathrm{Am}$ & & & $\mathrm{x}$ \\
\hline & ${ }^{90} \mathrm{Sr}$ & & & $\mathrm{x}$ \\
\hline \multirow{8}{*}{$\begin{array}{l}\text { Caustic-leached and } \\
\text { washed slurry }\end{array}$} & wt $\%$ UDS & & $\mathrm{x}$ & \\
\hline & Density & & $\mathrm{x}$ & \\
\hline & Settling rate & & $\mathrm{x}$ & \\
\hline & Volume \% settled solids & & $\mathrm{x}$ & \\
\hline & Rheology (flow curve) & & $\mathrm{x}$ & \\
\hline & PSD & $\mathrm{x}$ & & \\
\hline & ICP metals (KOH fusion) & $\mathrm{x}$ & & \\
\hline & ICP metals $\left(\mathrm{Na}_{2} \mathrm{O}_{2}\right.$ fusion) (Ni) & $\mathrm{x}$ & & \\
\hline
\end{tabular}

E. 8 
Mr. William L. Graves

August 9, 2007

Page 9

\begin{tabular}{|l|l|c|c|c|}
\hline \multirow{2}{*}{ Process Step } & Analyte & Solids & Slurry & $\begin{array}{c}\text { Liquid } \\
\text { or } \\
\text { Filtrate }\end{array}$ \\
\hline \multirow{5}{*}{$\begin{array}{l}\text { Anions (water-leachable) (nitrate, } \\
\text { sulfate, phosphate, oxalate) }\end{array}$} & $\mathrm{x}$ & & \\
\cline { 2 - 5 } & $\mathrm{Pu}$ & $\mathrm{x}$ & & \\
\cline { 2 - 5 } & $\mathrm{GEA}{ }^{137} \mathrm{Cs},{ }^{60} \mathrm{Co},{ }^{241} \mathrm{Am}$ & $\mathrm{x}$ & & \\
\cline { 2 - 5 } & ${ }^{90} \mathrm{Sr}$ & $\mathrm{x}$ & & \\
\cline { 2 - 5 } & $\mathrm{BET}$ & $\mathrm{x}$ & & \\
\hline & $\mathrm{XRD}, \mathrm{SEM} / \mathrm{EDS}, \mathrm{TEM} / \mathrm{ED}$ & & \\
\hline
\end{tabular}

If you have any questions, please contact Reid Peterson on 376-5340.

Sincerely,

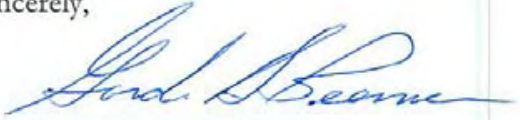

Gordon H. Beeman, Manager

RPP-WTP Support Program

GHB: $\mathrm{c}^{2}$

cc: $\quad$ RA Peterson (PNNL) RW Shimskey (PNNL)

Project File/LB 
WTP-RPT-172, Rev 0

\section{Appendix F}

\section{Group 6/5 CUF Test Concurrence Letter}




\section{Appendix F: Group 6/5 CUF Test Concurrence Letter}

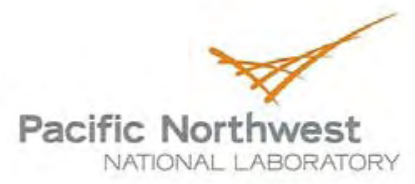

July 31,2008

Mr. Haukur R. Hazen

WTP/RPP-MOA-PNNL-00259

Bechtel National Inc.

2435 Stevens Center Place, MSIN: H4-02

Richland WA 99352

Dear Mr. Hazen:

Subcontract NO. 24590-QL-HC9-WA49-00001 - Project 53019 (WA\#2007-019)

Recommendations for Feed Composition, Bench-Scale Testing, and CUF Testing Using Group 5 and 6 Together for Caustic and Oxidative Leach Testing

The purpose of this letter is to document the concurrence given for the recommendations for feed composition, bench-scale testing, and CUF testing using Group 5 and 6 together for caustic and oxidative leach testing. Testing was performed as defined in TP-RPP-WTP-456 Pretratment Demonstration Applying Oxidative Leaching to Hanford Tank Waste, and TP-RPP-WTP-467 Characterization and Small Scale Testing of Hanford W astes to Support the Development and Demonstration of Leaching and Ultrafiltration Pretreatment Process. Verbal and email concurrence was issued prior to the start of testing on $11 / 4 / 07$ based on the document below.

Recommendations for Filtration, Caustic Leaching, and Oxidative Leaching Test Matrix in the Group 6/5 CUF Test

This test will cover the crossflow filtration, caustic leaching, and oxidative leaching test for Group 6/Group 5 composite tank waste slurry. Accordingly, this work addresses determination of the filtration and leaching behavior at the bench-scale using the CUF system as described in Task 6 of TP-RPP-WTP-456 (as well as Section 6.4 of TP-RPP-WTP-467). The proposed test sequence is summarized in scheme shown in Figure 1.

The initial filtration testing, low solids test matrix, will be conducted with $\sim 2$ L of Group 6 composite waste slurry diluted to $\sim 4 \mathrm{wt} \%$ UDS. Actual Group 6 supernatant at $\sim 5 \mathrm{M}$ sodium will be added back to $\sim 70 \%$ of concentrated slurry to provide the $\sim 4 \mathrm{wt} \%$ UDS slurry. This slurry will be dewatered to the minimum CUF operating volume, then Group 5 samples, consisting of $\sim 70 \%$ of the remaining 3 bottles $(\sim 0.9 \mathrm{~L})$, and additional Group 6 supernatant $(\sim 1 \mathrm{~L})$, added for dewatering to a target of $20 \mathrm{wt} \%$ UDS to generate a dewatering curve. Permeate will then be added back to give $\sim 1.5 \mathrm{~L}$ of slurry at approximately $16 \mathrm{wt} \%$ UDS for filtration matrix testing. All filtration testing will be conducted at $25+/-5^{\circ} \mathrm{C}$. The filtration test matrix was developed based upon median target transmembrane pressure (TMP) of $40 \mathrm{psi}$ and median target axial velocity (AV) of $13 \mathrm{ft} / \mathrm{s}$. 
WTP-RPT-172, Rev 0

Mr. Haukur R. Hazen

July 31,2008

Page 2

Approximately 120 grams of solids from the un-treated Group 5 and 6 waste composites are available for additional caustic leach tests. Two additional caustic leaching tests using this material will be performed. By comparing the reaction rates of the un-processed material in these two tests and to material processed in the CUF, the impact of CUF solids shearing on the extent of $\mathrm{Al}$ leaching can be examined. The first test will be conducted at the same $w \mathrm{t} \%$ UDS and caustic as the CUF test corresponding to the caustic leaching conditions in UFP2 vessel. The second test will be conducted at $4 \mathrm{wt} \%$ UDS and total sodium concentration of the leach would be $\sim 6.7 \mathrm{M}$ corresponding to caustic leach conditions in UFP1 vessel. Approximately $4-8$ grams of solids would be used for each test.

\section{Dewatering:}

Dewatering will be done on the initial $\sim 4 \mathrm{wt} \%$ Group 6 slurry to the CUF minimum operating volume $(\sim 1.2 \mathrm{~L})$. Then Group 5 slurry and additional Group 6 supernatant will be added for continued dewatering to a target of $\sim 20 \mathrm{wt} \%$ UDS. The supernatant will contain approximately 4.5 $\mathrm{M} \mathrm{Na}$. After dewatering, a filtration test matrix will be conducted. Following completion of the test matrix, a slurry sample will be removed for caustic leach parametric tests.

Figure 2 provides a summary of sodium molarity during dewatering for the first five years of operating the Waste Treatment Plant. Inspection of this figure indicates that $4.5 \mathrm{M} \mathrm{Na}$ is within the range of conditions expected to be seen during the initial dewatering of slurry and bounds approximately $50 \%$ of the batches. 
Mr. Haukur R. Hazen

July 31,2008

Page 3

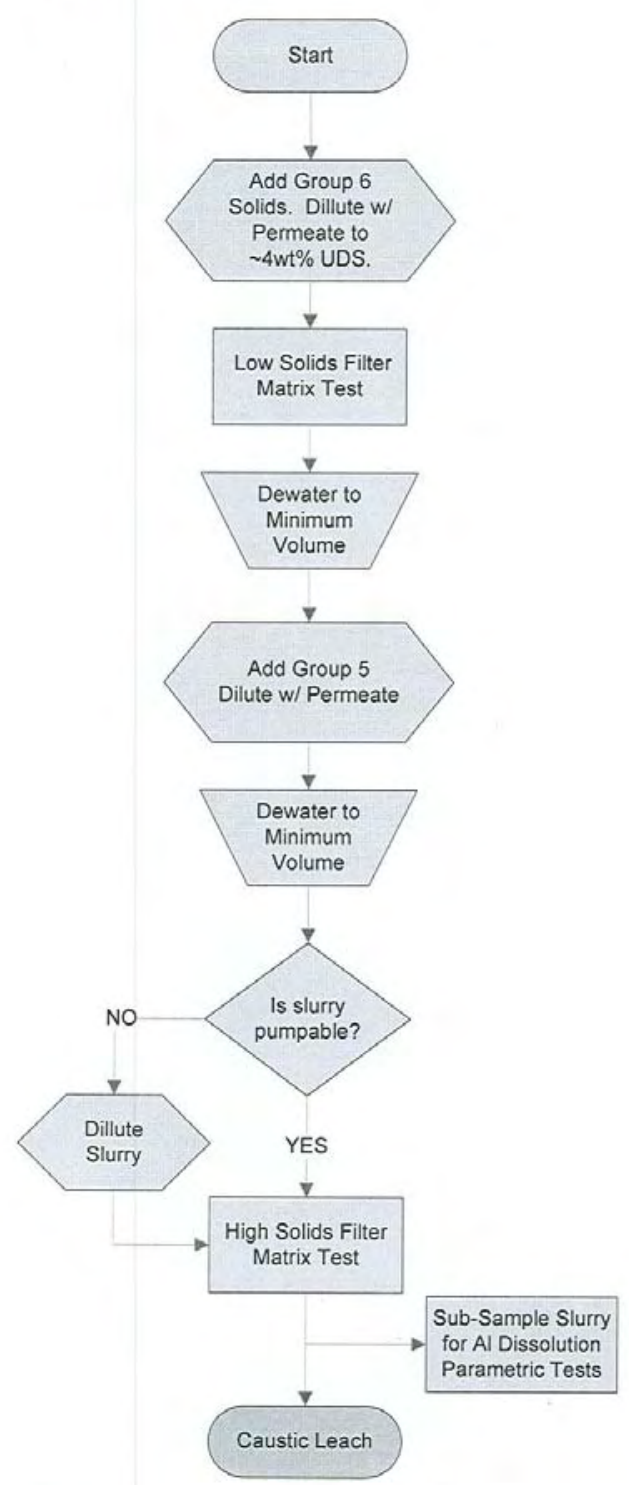

Figure 1. Proposed test scheme for Group 6/5 composite waste sample. 
Mr. Haukur R. Hazen July 31, 2008

Page 4

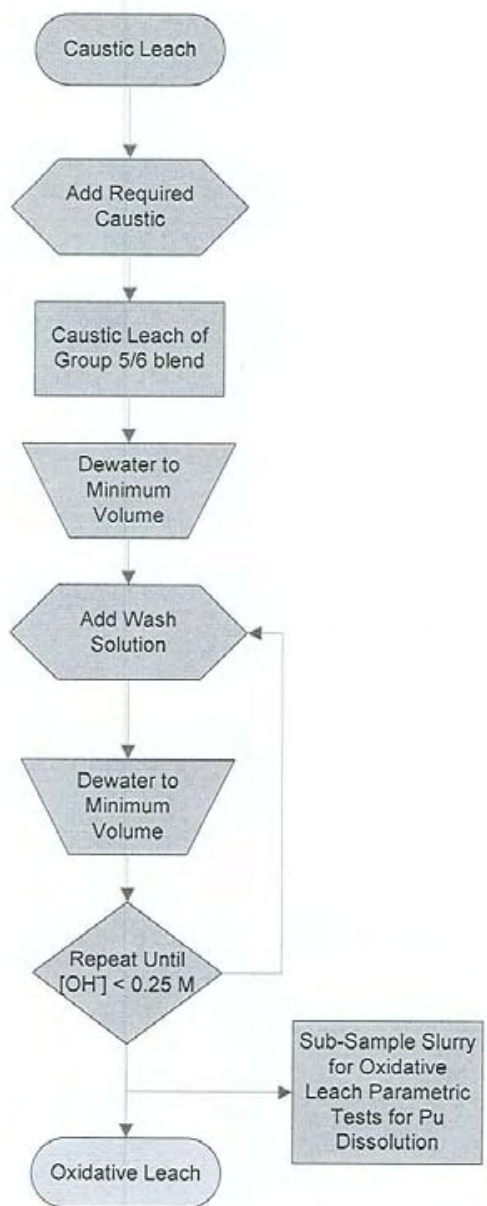

Figure 1 (continued). Proposed test scheme for Group 6/5 composite waste sample. 
Mr. Haukur R. Hazen

July 31, 2008

Page 5

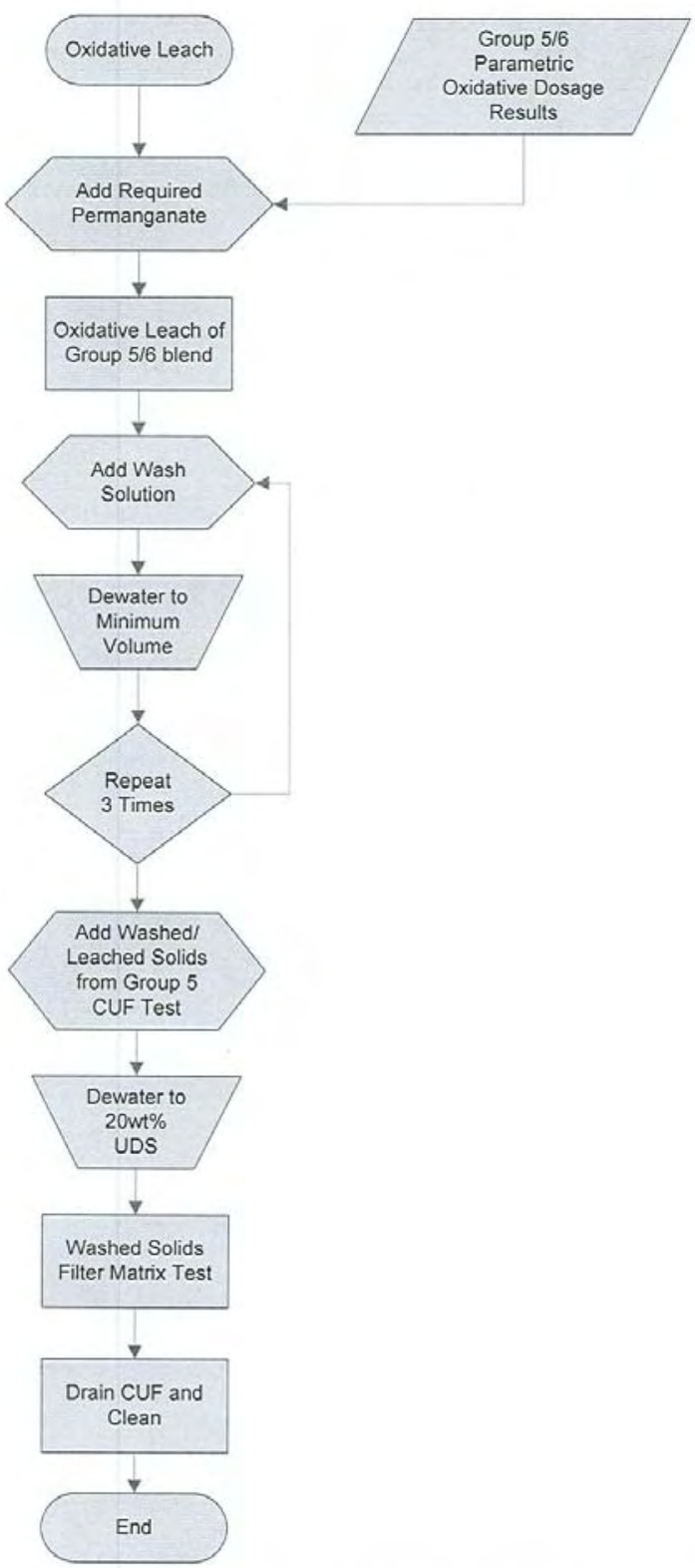

Figure 1 (continued). Proposed test scheme for Group 6/5 composite waste sample. 
Mr. Haukur R. Hazen

July 31,2008

Page 6

Fraction of batches bounded by the sodium molarity during initial dewatering

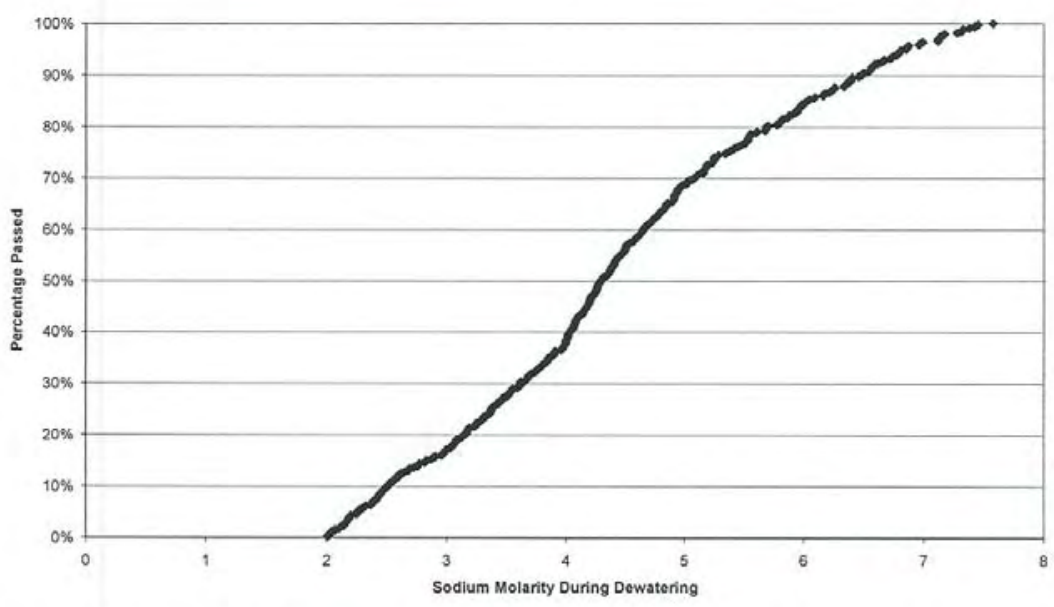

Figure 2. Projected WTP sodium molarity during initial dewatering.

Dewater Process Steps (more details provided in this section):

- First prepare a low-solids slurry by combining the $\sim 70 \%$ of the Group 6 composite waste slurry and an appropriate volume of actual Group 6 supernatant to provide $\sim 2 \mathrm{~L}$ of slurry at a target of $4 \mathrm{wt} \%$ UDS and $5 \mathrm{M}$ sodium.

- Conduct low solids filtration test matrix, Table 1. (This will provide filtration data for Group 6 only waste slurry.)

- Dewater to minimum CUF operating volume ( $\sim 1.2 \mathrm{~L}$ and $\sim 6 \mathrm{wt} \%$ UDS).

- Add Group 5 composite waste and an appropriate volume of Group 6 supernatant to provide $\sim 4 \mathrm{~L}$ of slurry ( $\sim 6 \mathrm{wt} \%$ UDS). Using the expected volume ratios and sodium concentration data, the expected sodium concentration is $4.5 \mathrm{M}$. (Note that $4 \mathrm{~L}$ is the maximum operating level of the CUF.)

- Dewater to target of $20 \mathrm{wt} \%$ UDS or as low volume as possible to generate a detailed dewater curve.

- Add back permeate to give a total volume of $\sim 1.5$ Liter ( $\sim 16 \mathrm{wt} \%$ UDS). Conduct a high solids matrix test as shown in Table 2. (If rheology, air entrainment or temperature control does not allow operation at $16 \mathrm{wt} \%$, permeate will be added back such that the test matrix could be carried out.)

- Remove a slurry sample for parametric leach tests with high sheared solids. The tests ate to be performed like the early parametric leach tests without sheared solids. The solids will be well washed and slurried at $\sim 1 \mathrm{wt} \%$ UDS and leached at 3, 5 and $7 \mathrm{M} \mathrm{NaOH}$. 
Mr. Haukur R. Hazen

July 31,2008

Page 7

Table 1. Low Solids Filtration Test Matrix at targeted $4 \mathrm{wt} \%$ USD*

\begin{tabular}{|l|l|l|l|}
\hline Test number & $\begin{array}{l}\text { Duration } \\
\text { (hours) }\end{array}$ & $\begin{array}{l}\text { Target TMP** } \\
(\mathrm{psi})\end{array}$ & $\begin{array}{l}\text { Target Axial } \\
\text { Velocity** } \\
(\mathrm{ft} / \mathrm{s})\end{array}$ \\
\hline 1 & 3 & 40 & 13 \\
\hline 2 & 1 & 30 & 11 \\
\hline 3 & 1 & 30 & 15 \\
\hline 4 & 1 & 50 & 15 \\
\hline 5 & 1 & 50 & 11 \\
\hline 6 & 1 & 40 & 13 \\
\hline 7 & 1 & 40 & 9 \\
\hline 8 & 1 & 40 & 17 (or max) \\
\hline 9 & 1 & 20 & 13 \\
\hline 10 & 1 & 60 & 13 \\
\hline 11 & 1 & 40 & 13 \\
\hline
\end{tabular}

* Resulting from Group 6 solids being diluted to $4 \mathrm{wt} \%$ UDS with excess permeate.

** Actual conditions may vary based upon slurry volume and rheology. All conditions may not be obtainable. 
Mr. Haukur R. Hazen

July 31,2008

Page 8

Table 2. High Solids Filtration Test Matrix at targeted $16 \mathrm{wt} \%$ UDS*

\begin{tabular}{|l|l|l|l|}
\hline Test number & $\begin{array}{l}\text { Duration } \\
\text { (hours) }\end{array}$ & $\begin{array}{l}\text { Target TMP** } \\
(\mathrm{psi})\end{array}$ & $\begin{array}{l}\text { Target Axial } \\
\text { Velocity** } \\
(\mathrm{ft} / \mathrm{s})\end{array}$ \\
\hline 1 & 2 & 40 & 13 \\
\hline 2 & 1 & 40 & 17 (or max) \\
\hline 3 & 1 & 40 & 9 \\
\hline 4 & 1 & 40 & 13 \\
\hline 5 & 1 & 20 & 13 \\
\hline 6 & 1 & 60 & 13 \\
\hline 7 & 1 & 40 & 13 \\
\hline
\end{tabular}

* Resulting from the addition of Group 5 slurry (UDS $\sim 18 \mathrm{wt} \%$ ) to the Group 6 solids/permeate mixture in CUF, dewatering to $20 \mathrm{wt} \%$ UDS, then diluting with additional Group 6 permeate to target UDS.

** Actual conditions may vary based upon slurry volume and theology. All conditions may not be obtainable.

\section{Leaching:}

Caustic leach conditions for the blended waste slurry are proposed below based on a slutry volume of $\sim 1.5 \mathrm{~L}$ at $\sim 16 \mathrm{wt} \%$ UDS, expected aluminum solid concentration, and leach factors of $80 \%$ dissolution of Group 5 aluminum (assumed beomite) and $80 \%$ dissolution of Group 6 aluminum (assumed gibbsite):

Add $2.3 \mathrm{~L}$ of $10 \mathrm{M} \mathrm{NaOH}$ (adjust as needed for $\mathrm{Al}$ solubility at $25^{\circ} \mathrm{C}$ ), leach for 8 hours at $100^{\circ} \mathrm{C}$, and add water as needed during the caustic leach lost by evaporation to maintain a constant volume. The final sodium concentration is expected to be $\sim 7.7 \mathrm{M}$. Examining Figure 3, a summary of the sodium molarity during caustic leaching for the first 5 years of WTP operation, leaching at $7.7 \mathrm{M}$ bounds over $70 \%$ of the expected batches. 
Mr. Haukur R. Hazen

July 31,2008

Page 9

Fraction of batches bounded by the sodium molarity during caustic leaching

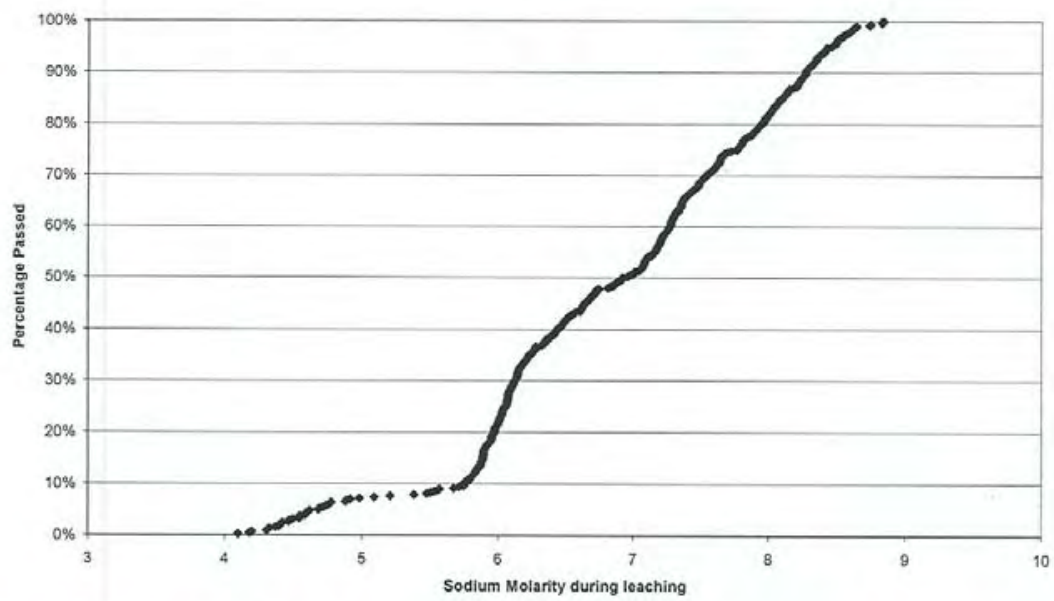

Figure 3. Projected WTP sodium molarity during caustic leaching.

Caustic Leaching Process Steps (more details provided in this section):

- Retrieve all solids from CUF and isolate in slurry feed reservoir for leaching.

- Assuming $\sim 1.5 \mathrm{~L}$ of $\sim 16 \mathrm{wt} \%$ UDS at $4.5 \mathrm{M}$ sodium, add $2.3 \mathrm{~L}$ of $10 \mathrm{M} \mathrm{NaOH}$. (These leaching conditions have been estimated to produce a solution saturated with $\mathrm{Al}$ at $25^{\circ} \mathrm{C}$ at the conclusion of the leaching process.)

- Heat from $25^{\circ} \mathrm{C}$ to $100^{\circ} \mathrm{C}$ in 5.3 hours.

- Leach for $8 \mathrm{~h}$ at $100(+5 /-10)^{\circ} \mathrm{C}$.

- Cool from $100^{\circ} \mathrm{C}$ to $25^{\circ} \mathrm{C}$ in 12 hours.

Post Caustic Leach Dewater Process Steps:

- Dewater leached solids at $25^{\circ} \mathrm{C}, \mathrm{TMP}=40 \mathrm{psi}$, and $\mathrm{AV}=13 \mathrm{ft} / \mathrm{s}$. Dewater to a target of $\sim 1.2 \mathrm{~L}$ or to minimum operating volume of CUF ( $8.3 \mathrm{wt} \%$ undissolved solids (UDS)).

\section{Post Caustic Leach Washing:}

The number of wash steps will be determined based on the results from Group 6 parametric testing and evaluation of the Pu mobilization to the aqueous phase. Current plans are based on washing until the free hydroxide is equal to or below $0.25 \mathrm{M}$. It is estimated that six equal volume wash steps will be conducted to reduce the free hydroxide below the target level of $0.25 \mathrm{M}$.

\section{Post Caustic Leach Washing Process Steps:}

- Add equal volume of caustic wash solution (1.53 M NaOH) for wash 1, dewater to a target of $\sim 1.2 \mathrm{~L}$ or to minimum operating volume of CUF ( $10 \mathrm{wt} \%$ UDS). 
Mr. Haukur R. Hazen

July 31,2008

Page 10

- Add equal volume of caustic wash solution $(0.66 \mathrm{M} \mathrm{NaOH})$ for wash 2, dewater to a target of $\sim 1.2 \mathrm{~L}$ or to minimum operating volume of CUF ( 10 wt $\%$ UDS).

- Add equal volume of caustic wash solution $(0.24 \mathrm{M} \mathrm{NaOH})$ for wash 3 , dewater to a target of $\sim 1.2 \mathrm{~L}$ or to minimum operating volume of CUF ( $10 \mathrm{wt} \%$ UDS).

- Add equal volume of caustic wash solution $(0.09 \mathrm{M} \mathrm{NaOH})$ for wash 4 , dewater to a target of $\sim 1.2 \mathrm{~L}$ or to minimum operating volume of CUF ( 10 wt $\%$ UDS).

- Add equal volume of caustic wash solution $(0.02 \mathrm{M} \mathrm{NaOH})$ for wash 5 , dewater to a target of $\sim 1.2 \mathrm{~L}$ or to minimum operating volume of CUF ( $10 \mathrm{wt} \%$ UDS).

- Add equal volume of caustic wash solution $(0.01 \mathrm{M} \mathrm{NaOH})$ for wash 6 to reduce free hydroxide concentration below $0.25 \mathrm{M}$, dewater to a target of $\sim 1.2 \mathrm{~L}$ or to minimum operating volume of CUF ( $\sim 10 \mathrm{wt} \%$ UDS).

- Remove slurry sample for $\mathrm{Cr}$ parametric studies. Oxidative leaching tests will be conducted on the caustic leached/washed solids at 1.25:1 Mn: $\mathrm{Cr}$ ratio at $0.25,0.5,0.75,1.0$ and $1.25 \mathrm{M}$ $\mathrm{NaOH}$. Theses parametric tests are intended to bound the quantity of Pu that will dissolve. These tests are not intended to be prototypic, but rather to provide an additional input into the washing requirements to ensure limited $\mathrm{Pu}$ oxidation

\section{Oxidative Leaching Process Steps:}

- Retrieve all solids from CUF and isolate in slurry feed reservoir for leaching.

- Assuming $\sim 1.2 \mathrm{~L}$ of $\sim 10 \mathrm{wt} \%$ UDS and all $\mathrm{Cr}$ in the initial waste remaining insoluble, add a 1:1 mole ratio of $1 \mathrm{M} \mathrm{NaMnO}_{4}(173 \mathrm{~mL})$ or other ratio as determined by the Group 6/5 screening tests, and leach for $6 \mathrm{~h}$ at ambient hot cell temperature, $\sim 27^{\circ} \mathrm{C}$.

- Sample supernatant fraction at $0.5,1,2,4$, and 6 hours during oxidative leaching and analyze supernatant fraction for metals (total $\mathrm{Cr}$ ) and $\mathrm{Pu}$.

\section{Post Oxidative Leach Dewater Process Steps:}

- Dewater will be removed, since volume addition is so little, proceed to first wash.

\section{Post Oxidative Leach Washing Process Steps:}

- Add equal volume of inhibited water $(0.01 \mathrm{M} \mathrm{NaOH})$ for wash 1 , dewater to a target of $\sim 1.2$ $\mathrm{L}$ or to minimum operating volume of CUF ( $11 \mathrm{wt} \%$ UDS).

- Add equal volume of inhibited water $(0.01 \mathrm{M} \mathrm{NaOH})$ for wash 2 , dewater to a target of $\sim 1.2$ $\mathrm{L}$ or to minimum operating volume of CUF ( $\sim 11 \mathrm{wt} \%$ UDS).

- Add equal volume of inhibited water $(0.01 \mathrm{M} \mathrm{NaOH})$ for wash 3 , dewater to a target of $\sim 1.2$ $\mathrm{L}$ or to minimum operating volume of CUF ( 11 wt $\%$ UDS).

- Sample at this point, before addition of solids from Group 5 leach test.

- Add back final leached and washed solids from Group 5 test to give a volume of $\sim 4 \mathrm{~L}(\sim 7$ wt $\%$ UDS).

- Dewater to $\sim 1.4 \mathrm{~L}(\sim 20 \mathrm{wt} \%$ UDS) and conduct a high solids matrix test as shown in Table 3.

- Drain slurry from CUF and retain for potential use, only dispose at the guidance of the client.

- Clean CUF and determine clean water $(0.01 \mathrm{M} \mathrm{NaOH})$ flux. 
Mr. Haukur R. Hazen

July 31,2008

Page 11

Table 3. High Solids Filtration Test Matrix at targeted $20 \mathrm{wt} \%$ UDS

\begin{tabular}{|l|l|l|l|}
\hline Test number & $\begin{array}{l}\text { Duration } \\
\text { (hours) }\end{array}$ & $\begin{array}{l}\text { Target TMP** } \\
(\mathrm{psi})\end{array}$ & $\begin{array}{l}\text { Target Axial } \\
\text { Velocity** } \\
(\mathrm{ft} / \mathrm{s})\end{array}$ \\
\hline 1 & 1 & 40 & 13 \\
\hline 2 & 1 & 40 & 9 \\
\hline 3 & 1 & 40 & 17 (or max) \\
\hline 4 & 1 & 40 & 13 \\
\hline 5 & 1 & 20 & 13 \\
\hline 6 & 1 & 60 & 13 \\
\hline 7 & 1 & 40 & 13 \\
\hline
\end{tabular}

* Based on combining washed leached slurry from Group 5 CUF test with the washed oxidative leach slurry from this test, and dewatering the mixture to the target UDS.

** Actual conditions may vary based upon slurry volume and rheology. All conditions may not be obtainable.

\section{Sample Plan:}

The sample collection and analysis plan will be implemented as defined in the test plan.

If you have any questions, please contact Reid Peterson on 376-5340.

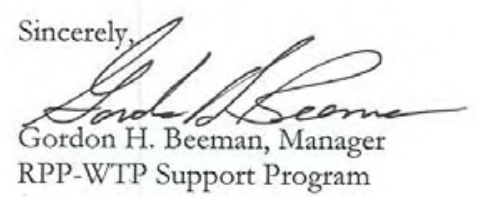

GHB: $\mathrm{c}^{2}$

cc:

SK Fiskum (PNNL

RA Peterson (PNNL)

RW Shimskey (PNNL)

PS Sundar (BNI)

Project File/LB 
WTP-RPT-172, Rev 0

\section{Appendix G}

\section{Group 5 CUF Particle Size Analysis}




\section{Appendix G: Group 5 CUF Particle Size Analysis}

\section{Battelle}

The Business of Innovation

$\begin{array}{lll}\text { Date July 1, } 2008 & \text { Richard Daniel } \\ & \text { File/LB }\end{array}$

From Richard Daniel

Subject $\quad$ Particle Size Distribution Measurements for Group 5

$\underline{\text { CUF Testing Samples }}$

\section{Acronyms and Abbreviations}

$\begin{array}{ll}\text { AV } & \text { Axial velocity } \\ \text { CA } & \text { Contamination area } \\ \text { CUF } & \text { Cells Unit Filter } \\ \text { DI } & \text { Deionized (water) } \\ \text { CCP } & \text { Computational computer program (application) } \\ \text { LRB } & \text { Laboratory Record Book } \\ \text { NIST } & \text { National Institute of Technology } \\ \text { PSD } & \text { Particle size distribution } \\ \text { RI } & \text { Refractive index } \\ \text { RMA } & \text { Radioactive material area } \\ \text { RPL } & \text { Radiochemical Processing Laboratory } \\ \text { RPP } & \text { River Protection Project } \\ \text { SAL } & \text { Shielded Analytical Laboratory } \\ \text { TMP } & \text { Transmembrane pressure } \\ \text { WTP } & \text { Waste Treatment Plant (Support Program) }\end{array}$

\section{Introduction}

In fulfillment of the requirements of Test Plan TP-RPP-WTP-467 [1], the particle size distribution (PSD) of select Hanford tank waste water insoluble solids was characterized at the Radiochemical Processing Laboratory (RPL). This interim characterization report presents PSD results for four samples of waste group 5 solids processed through the Cells Unit Filter (CUF) system installed in Cell 5 of the Shielded Analytical Laboratory (SAL). Group 5 solids are comprised primarily of REDOX (R) wastes.

\section{Samples}


Group 5 CUF particle size measurement samples were derived from bench-scale crossflow ultrafiltration and leaching studies using actual tank waste. During these studies, a low-concentration tank waste slurry (4.3-wt\% solids) was loaded into a CUF unit installed in SAL Cell 5 and subjected to the following operational steps (in order):

1. full-recycle ultrafiltration of the low-concentration (4.3-wt\% solids) waste slurry at various axial velocities (AV) and transmembrane pressures (TMP)

2. dewatering from a low-concentration (4.3-wt\% solids) to a high-concentration (15.5-wt\% solids)

3. full-recycle ultrafiltration of the high-concentration (15.5-wt\% solids) waste slurry at various AV and TMP

4. caustic leaching of the waste slurry with $5 \mathrm{M}$ sodium hydroxide for 24 hours at $100^{\circ} \mathrm{C}$

5. dewatering of the leached slurry

6. washing of the leached slurry

To determine the influence of CUF processing on the size distribution of insoluble waste solids, the waste slurry was sampled at select points in the filtration and leaching steps outlined above. Specifically, waste solids were sampled after steps $1,3,5$, and 6 . These solids were subsequently washed three times with, and suspended in a solution of $0.01 \mathrm{M} \mathrm{NaOH}$ in water at a concentration of $20 \mathrm{mg}$ solids / $\mathrm{mL}$ solution. Approximately $0.2 \mathrm{~g}$ of each waste's insoluble solids were provided as a dispersions in $10 \mathrm{~mL} 0.01 \mathrm{M}$ $\mathrm{NaOH}$ solution. Table 1 provides a summary of the samples and their given sample identification number.

Table 1. Samples associated with Group 5 CUF particle size characterization.

\begin{tabular}{||l|l||}
\hline Sample ID & Description \\
\hline TI540-G5-3-PSD & $\begin{array}{l}\text { Insoluble group 5 waste solids after full recycle filtration at a slurry } \\
\text { concentration of 4.3-wt\% }\end{array}$ \\
\hline TI540-G5-6-PSD & $\begin{array}{l}\text { Insoluble group 5 waste solids after full recycle filtration at a slurry } \\
\text { concentration of 15.5-wt\% }\end{array}$ \\
\hline TI540-G5-11-PSD & $\begin{array}{l}\text { Insoluble group 5 waste solids after caustic leaching and } \\
\text { dewatering operations }\end{array}$ \\
\hline TI540-G5-16-PSD & $\begin{array}{l}\text { Insoluble group 5 waste solids after caustic leaching, dewatering, } \\
\text { and washing operations }\end{array}$ \\
\hline
\end{tabular}

\section{Analysis}

Particle size distributions for Group 5 CUF testing samples were measured from September 26 to September 28, 2007. The analyses produced the following reportable data for samples listed in Table 1:

- particle diameters corresponding to the $10 \%, 50 \%$, and $90 \%$ cumulative mass undersize percentiles

- $\quad$ volume differential distributions (mass population percentage versus diameter)

Alternate analyses of the data, such as number/surface area distributions or cumulative PSD, are available on request.

\section{Instrument}


Particle size characterization was accomplished using a Mastersizer 2000 (Malvern Instruments, Inc., Southborough, MA 01772 USA) with a Hydro $\mu$ P wet dispersion accessory. The Mastersizer has a nominal size measurement range of $0.02-2000 \mu \mathrm{m}$. The actual range is dependent on the accessory used as well as the properties of the solids being analyzed. When coupled with the Hydro $\mu \mathrm{P}$ wet dispersion accessory, the nominal measuring range is reduced to $0.02-150 \mu \mathrm{m}$. Although particle sizes above 150 $\mu \mathrm{m}$ can be measured with the Hydro $\mu \mathrm{P}$, they cannot be adequately suspended by this flow cell. The result is that the fractional volume contribution of particles greater than $150 \mu \mathrm{m}$ cannot be determined reliably.

The Hydro $\mu \mathrm{P}$ wet dispersion accessory consists of a $20 \mathrm{~mL}$ sample flow cell with a continuously variable and independent pump and ultrasound. Both flow and sonication can be controlled and altered during measurement. As such, PSD measurements can be made before, during, and after sonication, allowing determination of the influence of each on the sample's PSD. The primary measurement functions of the Malvern analyzer are controlled through computer software. For the current measurements, Mastersizer 2000 software, Version 5.1 [Malvern Instruments, Ltd. Copyright (C) 19982002] was employed.

Table 2 provides a summary of basic information regarding the analyzer and accessory. The Malvern Mastersizer 2000 is located in the northwest contamination area (CA) fume hood in RPL Room 302.

Table 2. Summary of Malvern Mastersizer 2000 instrument information.

\begin{tabular}{||l|l||}
\hline \hline Analyzer: & Mastersizer 2000 \\
\hline Measurement principle: & Laser Diffraction (Mie Scattering) \\
\hline Analyzer Accessory: & Hydro $\mu \mathrm{P}$ \\
\hline Serial Number: & MAL100406 \\
\hline Measurement Range: & $0.02-2000 \mu \mathrm{m}$ nominal $(0.02-150 \mu \mathrm{m}$ with accessory) \\
\hline Type: & $\begin{array}{l}\text { Flow cell system with continuously variable and } \\
\text { independent pump and ultrasound. }\end{array}$ \\
\hline Capacity: & $20 \mathrm{~mL}$ \\
\hline Pump Speed Range: & $0-5000$ RPM (variable) \\
\hline Ultrasound Power & $0-20 \mathrm{~W}$ (variable) \\
\hline Software Version & 5.1 \\
\hline
\end{tabular}

\section{Governing Test Plan, Procedure, and Test Instructions}

The test plan governing the physical characterizations for these samples is River Protection Project - Waste Treatment Plant Support Program (RPP-WTP) document number TP-RPP-WTP-467, Revision 0 [1]. Operation of the Malvern Mastersizer 2000 is governed by RPL-COLLOID-01, Revision $1[2]$.

\section{Instrument Performance Check}

As required by RPL-COLLOID-01, the performance of the Malvern analyzer must be verified at the beginning of each series of analyses (with the period between performance checks not to exceed 90 days during use). Checks are performed using particle size standards traceable to the National Institute of Technology (NIST). Checks verify that the particle size analyzer can measure the standard's d(50), the 
diameter corresponding to the 50th volume/weight percentile, to within $10 \%$ of the value specified on the manufacturer's standard certificate of analysis.

For the measurements described in this report, the performance check employed NIST traceable polydisperse particle size standards purchased from Whitehouse Scientific (Waverton, Chester, CH3 7PB, UK). Table 3 provides a summary of the standard properties. Standards are traceable back to their certificate of analysis through a unique bottle number identifier.

Table 3. Properties of the NIST standard used to verify performance of the Malvern Mastersizer 2000 and performance check results.

\begin{tabular}{||l|l|c|c||}
\hline \hline Size Range: & $1-10 \mu \mathrm{m}$ \\
\hline Catalogue \#: & PS-192 \\
\hline Bottle \# & 02001 & \multicolumn{3}{l||}{} \\
\hline Weight: & \multicolumn{1}{|l||}{ List } & Measured* & Absolute Error \\
\hline PSD Percentiles & $2.10 \mathrm{~g} \pm 0.24 \mu \mathrm{m}$ & $2.5 \mu \mathrm{m}$ & n/a \\
\hline $\mathrm{d}(10):$ & $4.18 \pm 0.34 \mu \mathrm{m}$ & $4.4 \mu \mathrm{m}$ & $5.0 \%$ \\
\hline $\mathrm{d}(50):$ & $6.23 \pm 0.56 \mu \mathrm{m}$ & $7.7 \mu \mathrm{m}$ & n/a \\
\hline $\mathrm{d}(90):$ &
\end{tabular}

* As measured for the period of performance applicable for this report.

The instrument performance check covering Group 5 CUF sample particle size analyses was run on September $25^{\text {th }}$, 2007. Performance check results were recorded to the Malvern file "2007-09Sept19 PSD Group 2.mea”. Particle size standards from Whitehouse are supplied as $0.10 \mathrm{~g}$ single shots of dry powder that must be dispersed in deionized water in order to achieve the appropriate distribution of particles. Dispersion was accomplished by first adding the entire contents of the particle size standard bottle (\#02001, 0.10g dry powder) to the flow cell and then by subsequent mechanical agitation (via the flow cell pump) and application of sonic energy. A continuous pump speed of 3000 RPM was set to mix the flow cell contents. This pump speed was maintained through both powder dispersion and size measurement. As recommended by Whitehouse Scientific, the particle size standard dispersion was sonicated to eliminate particle aggregates. Sonication was carried out at $75 \%$ power for 5 minutes.

Performance check size analysis employed a particle refractive index and absorption of 1.544 and 0 , respectively, and a suspending phase particle refractive index of 1.33 (for water). An average of three post-sonication measurements of the particle size distribution indicated a d(50) of $4.4 \mu \mathrm{m}$, which deviates $5.0 \%$ from the $\mathrm{d}(50)$ listed on the standard's certificate of analysis from Whitehouse Scientific. As such, acceptable instrument performance was verified for the period of measurement applicable to this report. Figure 1 shows the particle size distribution corresponding to the post-sonication measurement. 


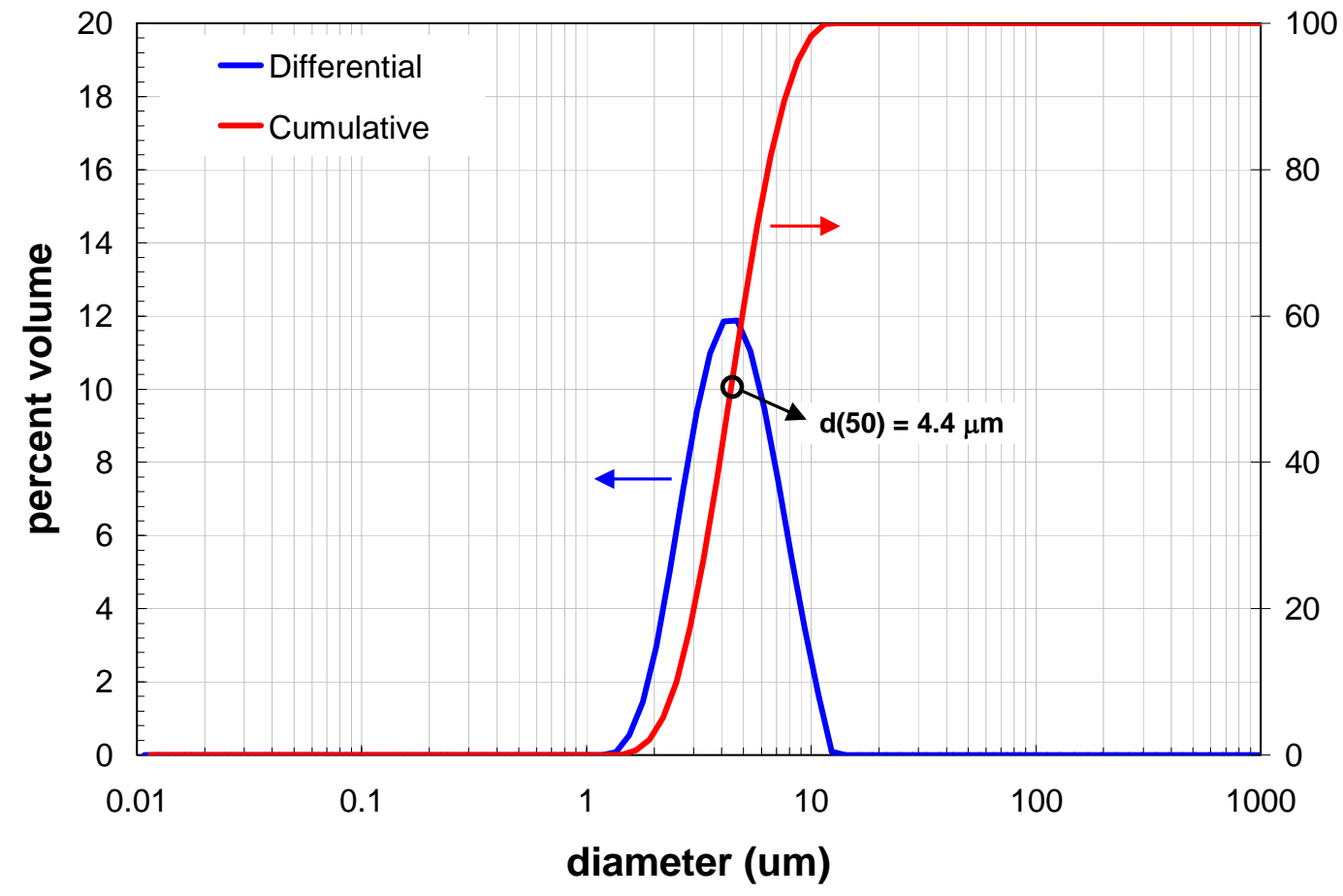

Figure 1. Particle size distribution for Whitehouse Scientific PS192 1-10 $\mu \mathrm{m}$ NIST traceable particle size standard, bottle \#02001. This distribution represents the average of three particle size measurements of $\sim 0.10 \mathrm{~g}$ of standard dispersed in $20 \mathrm{~mL}$ of DI water. The analyzer flow cell pump was operated at 3000 RPM. Prior to analysis, the suspension was sonicated in cell for 5 minutes at $75 \%$ sonic power.

\section{Sample Handling}

The waste samples associated with Group 5 CUF testing were analyzed "as-is”. No additional treatments were performed after sample receipt of the prepared sampled for particle size analysis with exception of the mechanical agitation and re-suspension of any settled solids at the time of analysis. Samples were received on September $21^{\text {st }}, 2007$ and stored in the radioactive material area (RMA) in RPL Room 302 until they were analyzed on September $25^{\text {th }}$, 2007. Immediately before analysis, samples were unpackaged and transferred into the CA fume hood where the particle size analyzer is located.

\section{Experimental}

Particle size measurements over a range of flow rates and sonication conditions were performed for each sample. All measurements were performed in $0.01 \mathrm{M}$ sodium hydroxide solution. Each particle size measurement was accomplished as follows:

1. The analyzer was drained, flushed with $20 \mathrm{~mL}$ of deionized (DI) water at least three times, filled with $20 \mathrm{~mL}$ a solution of $0.01 \mathrm{M} \mathrm{NaOH}$, and brought into a measurement ready state.

2. The analyzer flow cell pump was set to 3000 RPM with no sonication.

3. The material (sample) and suspending phase optical properties were set in the analyzer software (see Table 3).

4. The sample was prepared for analysis by re-suspending the settled solids. This was accomplished by repeatedly pulsing the samples with a $10 \mathrm{~mL}$ disposable plastic pipette until the contents were 
uniformly dispersed. Each pulse involved drawing off a fraction of the sample into the pipette and immediately jetting the drawn liquid back into the sample vial.

5. Immediately after re-suspension, the sample dispersion was added drop-wise to the instrument (while the pump was active) until the appropriate laser obscuration was achieved. Obscurations ranging from 3.5 to $35 \%$ were considered acceptable. For the current analyses, an obscuration of $18-20 \%$ was targeted. The analyzer typically required 10 to $20 \mathrm{mg}$ of solids to reach the desired obscuration in the $20 \mathrm{~mL}$ flow cell.

6. The sample PSD was measured under the conditions outlined in the sample test matrix (see Table 4).

As indicated in the analysis outline above, the optical properties, such as the refractive index (RI) of the sample and suspending phase must be entered into analyzer. Because the exact optical properties of the tank waste solids are unknown, the optical properties of the most prevalent species will be used. For precaustic leach waste samples (TI540-G5-3-PSD and TI540-G5-6-PSD), the most prevalent mineral phase is boehmite. For post-caustic leach waste solids (TI540-G5-11-PSD and TI540-G5-11-PSD), uranium bearing species are the most prevalent. The exact mineral phase that uranium exists in is unknown. Postleach uranium bearing phases will be assumed to be uranium dioxide $\left(\mathrm{UO}_{2}\right)$ for simplicity and because of the availability of its RI. Both boehmite and $\mathrm{UO}_{2}$ are assumed opaque (i.e., their absorption indexes are 1.0). A summary of material optical properties is provided in Table 4.

Use of a single species refractive index to represent the optical properties of the mixture of solid species and mineral phase in the tank waste is not exact. However, given the species diversity in the sample and tendency for tank waste particles to aggregate, the measurement analysis should provide an adequate representation of the apparent particle size of the wastes. As discussed in Appendix B of WTP/RPP-MOA-PNNL-00079 [3], use of the correct optical properties (in particular the RI) only serves to refine the distribution. And correction of assumed refractive indexes to a more accurate value may not significantly alter the particle size distribution determined by the original analysis. As such, use of boehmite and uranium oxide optical properties for the Group 5 CUF sample data analysis should provide a reasonable representation of the actual PSD.

Table 4. Material and suspending optical properties used for measurement of Group 5 CUF Testing particle size distributions.

\begin{tabular}{||c|c|c|c|c||}
\hline \hline Sample Name & $\begin{array}{c}\text { Characterization } \\
\text { Step }\end{array}$ & $\begin{array}{c}\text { Material Selected for } \\
\text { Optical Properties }\end{array}$ & $\begin{array}{c}\text { Refractive } \\
\text { Index (RI) }\end{array}$ & Absorption \\
\hline TI540-G5-3-PSD & Measurement & Boehmite $^{\mathrm{a}}$ & 1.655 & 1.0 \\
\hline TI540-G5-6-PSD & Measurement & Boehmite $^{\mathrm{a}}$ & 1.655 & 1.0 \\
\hline TI540-G5-11-PSD & Measurement & ${\text { Uranium Oxide }\left(\mathrm{UO}_{2}\right)^{\mathrm{b}}}^{\mathrm{b}}$ & 2.4 & 1.0 \\
\hline TI540-G5-16-PSD & Measurement & ${\text { Uranium Oxide }\left(\mathrm{UO}_{2}\right)^{\mathrm{b}}}^{\mathrm{a}}$ & 2.4 & 1.0 \\
\hline Suspending Phase & All & Water $^{\mathrm{a}}$ & 1.33 & $\mathrm{n} / \mathrm{a}$ \\
\hline
\end{tabular}

${ }^{a}$ See Ref Malvern Instruments Ltd., April 1997

${ }^{\mathrm{b}}$ See Ref Kaminski et al., 2005

The size distribution of particles was measured under various flow conditions prior-to and after sonication. Table 5 outlines the test matrix performed for all sample measurements. For each condition, three successive 20-second measurements of PSD were taken. An average of these measurements was then generated by the analyzer software. Both individual and averaged PSDs were saved to the analyzer 
data file. Once measurements were complete, the flow rate and/or sonic power for the next condition were set, the sample was given approximately 30 seconds to equilibrate, and the next set of measurements were taken. Measurements for samples TI540-G5-3-PSD and TI540-G5-6-PSD were logged to the Mastersizer 2000 file "2007-09Sep26-Group 5 CUF PSD.mea”. Measurements for samples TI540-G511-PSD and TI540-G5-16-PSD were logged to the Mastersizer 2000 file "2007-09Sep27-Group 5 CUF PSD.mea”.

Table 5. Particle size analysis test matrix used for Group 5 CUF samples.

\begin{tabular}{||c|c|c|c||}
\hline \hline Condition No. & $\begin{array}{c}\text { Pump Speed } \\
\text { (RPM) }\end{array}$ & Sonic Power & Comment \\
\hline 1 & 3000 & $0 \%$ & pre-sonic measurement \\
\hline 2 & 2000 & $0 \%$ & pre-sonic measurement \\
\hline 3 & 4000 & $0 \%$ & pre-sonic measurement \\
\hline 4 & 3000 & $25 \%$ & sonicated measurement \\
\hline 5 & 3000 & $50 \%$ & sonicated measurement \\
\hline 6 & 3000 & $75 \%$ & sonicated measurement \\
\hline 7 & 3000 & $0 \%$ & post-sonic measurement \\
\hline 8 & 2000 & $0 \%$ & post-sonic measurement \\
\hline 9 & 4000 & $0 \%$ & post-sonic measurement \\
\hline
\end{tabular}

Particle size measurements for both pre- and post-caustic leach samples were free of any noticeable defects such as suspect population peaks in the 500-2000 $\mu \mathrm{m}$ that are typically indicative of bubble entrapment in the flow cell. As such, post-measurement reanalysis of the data was limited to calculation of the number distributions for each measurement. The particle size distributions generated by default by the Malvern software are volume distributions. Number based size distributions for all measurements were calculated using the result transformation routine of the Malvern Mastersizer software.

\section{Results and Discussion}

Particle size analysis results for Group 5 CUF testing samples are presented in the following sections. Results are presented in the order listed in Table 1. As a preface, particle size results for the primary Group 5 Initial Characterization sample shall be presented as a reference for the CUF testing samples.

Particle Size Analysis Results for TI473-G5-S-WL-PSD-1 (As-Received / Source Material)

Group 5 Initial Characterization particle size results have been previously reported in WTP/RPPMOA-PNNL-00079, "Particle Size Distribution Measurements for Groups 5 and 6” (see Ref. 3). Sample TI473-G5-S-WL-PSD-1 is comprised of the as-received homogenized group 5 washed solids. Table 6 shows the $10^{\text {th }}, 50^{\text {th }}$, and $90^{\text {th }}$ diameter percentiles (based on a volume distribution) as a function of measurement condition. Hereafter, these percentiles shall be referred to as $d(10), d(50)$, and $d(90)$, respectively. Particle size measurements for this sample were limited to a pump speed of 3000 RPM.

For sample TI473-G5-S-WL-PSD-1, the $\mathrm{d}(50)$ ranges from 4.3 to $6.6 \mu \mathrm{m}$, the $\mathrm{d}(10)$ ranges from 0.98-1.1 $\mu \mathrm{m}$, and the $\mathrm{d}(90)$ ranges from 16-17 $\mu \mathrm{m}$. The listed fractiles do not appear to be strongly affected by sonication. However, there is a slight increase in the measured d(50) upon the application of sonic power to the sample. 
Table 6. Particle size analysis percentile results for TI473-G5-S-WL-PSD-1. The diameters corresponding to the $10 \%, 50 \%$, and $90 \%$ volume/weight fractiles are given [d(10), d(50), and d(90), respectively].

\begin{tabular}{||c|c|c|c|c|c||}
\hline $\begin{array}{c}\text { Measurement } \\
\text { Condition }\end{array}$ & Pump Speed & Sonication & $\begin{array}{c}\mathbf{d}(\mathbf{1 0}) \\
{[\boldsymbol{\mu \mathbf { m } ]}]}\end{array}$ & $\begin{array}{c}\mathbf{d}(\mathbf{5 0}) \\
{[\boldsymbol{\mu} \mathbf{m}]}\end{array}$ & $\begin{array}{c}\mathbf{d}(\mathbf{9 0}) \\
{[\boldsymbol{\mu m}]}\end{array}$ \\
\hline 1 & 3000 & pre-sonic & 1.1 & 4.3 & 16 \\
\hline 4 & 3000 & $25 \%$ & 0.98 & 5.9 & 17 \\
\hline 5 & 3000 & $50 \%$ & 1.0 & 6.5 & 17 \\
\hline 6 & 3000 & $75 \%$ & 1.1 & 6.6 & 16 \\
\hline 7 & 3000 & post-sonic & 1.0 & 6.4 & 16 \\
\hline
\end{tabular}

Figure 2 shows the particle size distributions prior-to, during, and after sonication for TI473-G5S-WL-PSD-1. The "during sonication” PSDs correspond to test matrix condition 6 (see Table 5). Prior to sonication, the PSD shows a broad and relatively continuous distribution of sizes ranging from $0.3 \mu \mathrm{m}$ up to $\sim 50 \mu \mathrm{m}$ and two distinct size peaks at 2.5 and $8 \mu \mathrm{m}$. The application of sonic power alters the particle size distribution. Although the total range of particle sizes observed in the distribution remains relatively unchanged, the sample shows a significant increase in the population of 8-10 $\mu \mathrm{m}$ particles and a corresponding decrease in the 1-3 $\mu \mathrm{m}$ particles. This is contrary to what would normally be expected, as sonication typically breaks down particle aggregates, increasing the relative fraction of fines. Although the increase in 8-10 $\mu \mathrm{m}$ particle population is contrary to what was expected, there is a reasonable physical basis for this observation. The pre-measurement treatment of these samples involved a significant alteration of the suspending phase chemistry during the compositing of the tank waste samples and subsequent washing and re-suspension activities. The consequence of this alteration is that a stable state of particle aggregation from earlier sample conditions may have been preserved as a semi-stable state in the subsequent conditions. This can occur because of energy barriers to aggregate restructuring that derive from strong interparticle forces. Although dispersion and mixing events may have not been sufficient to overcome this energy barrier, the application of sonic energy is highly disruptive and could have been sufficient to allow aggregate restructuring.

For the current analysis, it appears that the state of particle aggregation in the group 5 source material may have been preserved through solids separations, washing activities, dilution in DI water, and additional dilution in the $0.01 \mathrm{M} \mathrm{NaOH}$. Because the current suspending phase is a solution of $0.01 \mathrm{M}$ $\mathrm{NaOH}$ (rather than the high ionic strength matrix typical of tank wastes), the state of sample aggregation at the start of PSD analysis may not be the most stable configuration. The application of sonic power during measurement appears to have provided a sufficient amount of energy to allow the particle aggregates to overcome the energy barriers for aggregate growth. 


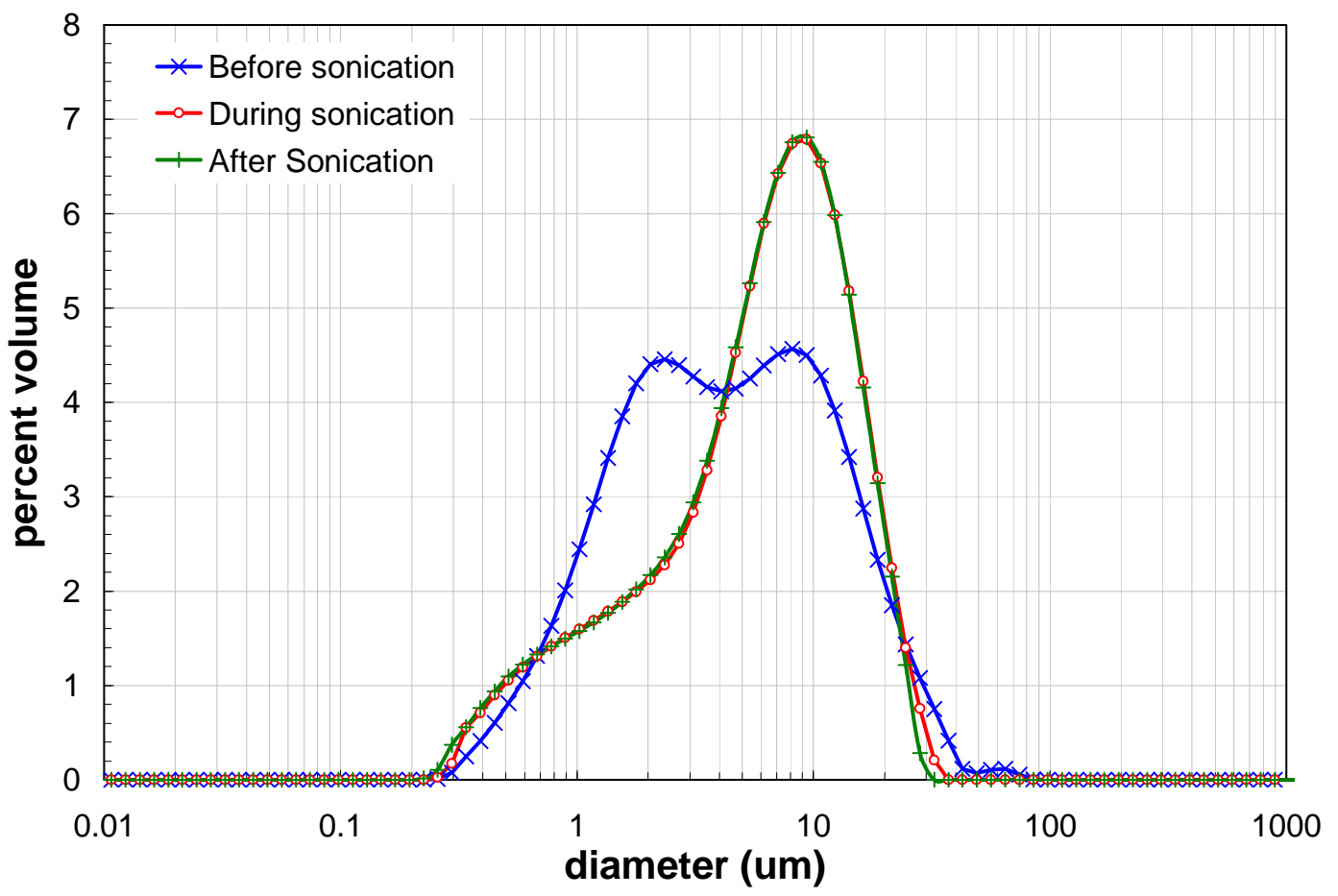

Figure 2. Initial washed Group 5 source material (sample TI473-G5-S-WL-PSD-1) particle size distributions (volume/weight basis) before, during, and after sonication.

\section{Particle Size Analysis Results for TI540-G5-3-PSD (Low-Solids Matrix)}

Sample TI540-G5-3-PSD (also termed low-solids matrix) is comprised of insoluble group 5 solids that have undergone full recycle filtration at a slurry concentration of $4.3-w t \%$. Table 7 shows the $10^{\text {th }}, 50^{\text {th }}$, and $90^{\text {th }}$ diameter percentiles (based on a volume distribution) as a function of measurement condition. For the low-solids matrix sample, $\mathrm{d}(10)$ ranges from $0.67-0.83 \mu \mathrm{m}, \mathrm{d}(50)$ ranges from 3.4-3.9 $\mu \mathrm{m}$, and $\mathrm{d}(90)$ ranges from $12-13 \mu \mathrm{m}$. All particle fractiles measured for the low-solids matrix are lower than those measured for the source material. The PSD diameter range appear to be influenced primarily by the application of sonic energy. Flow rate is observed to have minimal influence of the d(10), d(50), and $\mathrm{d}(90)$.

Table 7. Particle size analysis percentile results for TI540-G5-3-PSD. The diameters corresponding to the $10 \%, 50 \%$, and $90 \%$ volume/weight fractiles are given [d(10), d(50), and d(90), respectively].

\begin{tabular}{||c|c|c|c|c|c||}
\hline $\begin{array}{c}\text { Measurement } \\
\text { Condition }\end{array}$ & Pump Speed & Sonication & $\begin{array}{c}\mathbf{d}(\mathbf{1 0}) \\
{[\boldsymbol{\mu m}]}\end{array}$ & $\begin{array}{c}\mathbf{d}(\mathbf{5 0}) \\
{[\boldsymbol{\mu m}]}\end{array}$ & $\begin{array}{c}\mathbf{d}(\mathbf{9 0}) \\
{[\boldsymbol{\mu m}]}\end{array}$ \\
\hline 1 & 3000 & pre-sonic & 0.81 & 3.4 & 13 \\
\hline 2 & 2000 & pre-sonic & 0.83 & 3.4 & 13 \\
\hline 3 & 4000 & pre-sonic & 0.80 & 3.5 & 15 \\
\hline 4 & 3000 & $25 \%$ & 0.72 & 3.6 & 13 \\
\hline 5 & 3000 & $50 \%$ & 0.67 & 3.8 & 12 \\
\hline 6 & 3000 & $75 \%$ & 0.67 & 3.9 & 12 \\
\hline 7 & 3000 & post-sonic & 0.69 & 3.9 & 13 \\
\hline 8 & 2000 & post-sonic & 0.70 & 3.7 & 12 \\
\hline 9 & 4000 & post-sonic & 0.71 & 3.8 & 13 \\
\hline
\end{tabular}


The pre-sonic particle size distribution for the as-received sample TI540-G5-3-PSD, shown in Figure 3, indicates a broad, continuous, and unimodal distribution that spans $0.2 \mu \mathrm{m}$ up to $200 \mu \mathrm{m}$ and a peak at $\sim 3 \mu \mathrm{m}$. The majority of particle volume exists below $20 \mu \mathrm{m}$. With regard to the effect of pump speed, an increase from 2000 to 3000 RPM shifts the distribution to lower diameters and appears to reduce / eliminate the population of 100-200 $\mu \mathrm{m}$ aggregates. This aggregate reduction is accompanied an increase in the 20-100 $\mu \mathrm{m}$ particle fraction. Further increase in the pump speed to $4000 \mathrm{RPM}$ appears to 1) shear apart $>100 \mu \mathrm{m}$ aggregates, 2) decrease the relative population of 1-10 $\mu \mathrm{m}$ particles, and 3) slightly increase the sub-micrometer particle fraction. As such, it can be concluded that flow rate does impact the distribution at 4000 RPM, but the changes are such that they do not translate into the reported fractiles in Table 7. The observed PSD behavior is more consistent with agglomerate break-up under shear rather than increased aggregate suspension.

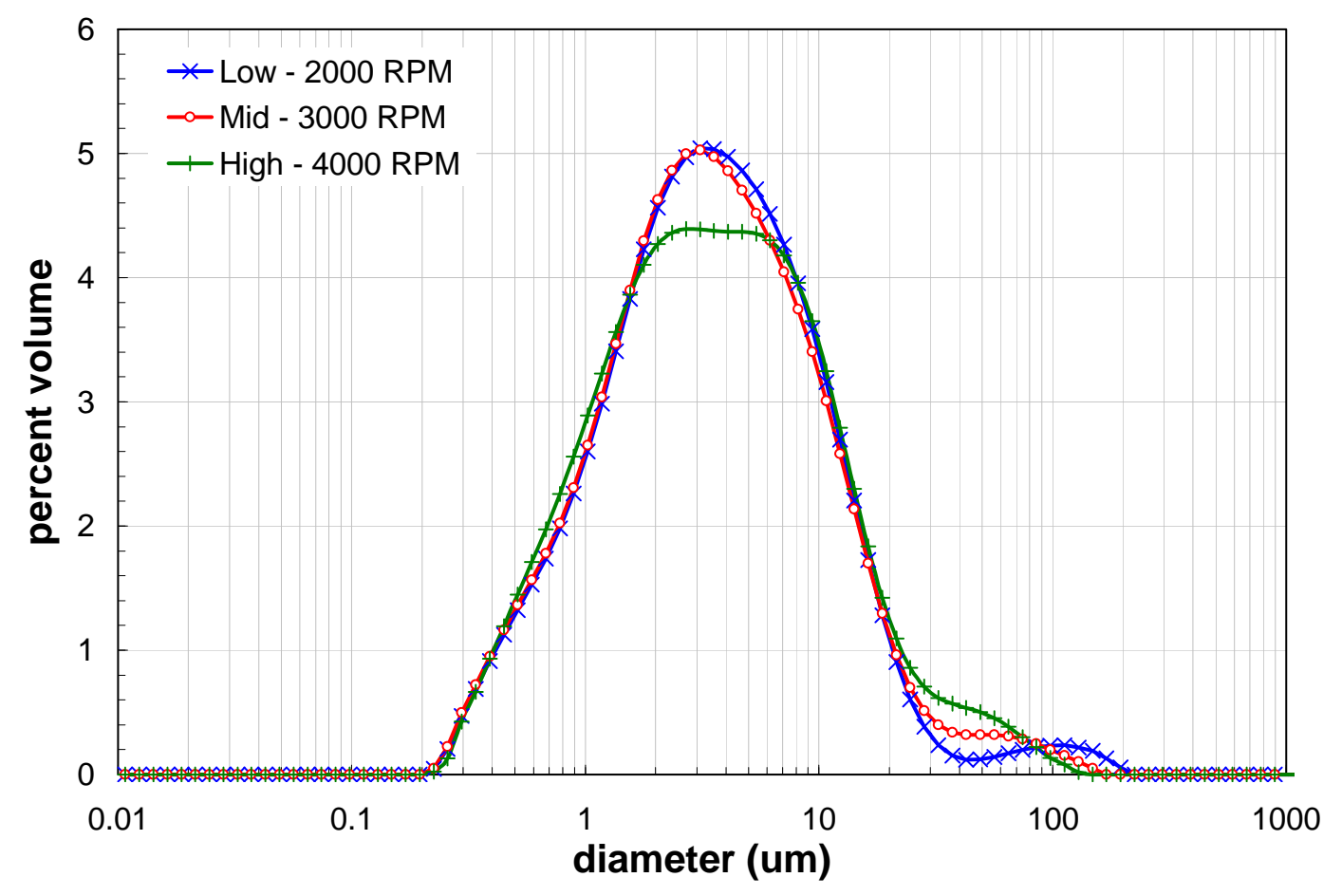

Figure 3. Measured particle size distribution for sample TI540-G5-3-PSD as a function of pump speed before sonication.

The low-solids matrix PSD as a function of sonication is shown in Figure 4. Sonication appears to have had a similar influence on the low-solids matrix sample as it had on the as-received material. Specifically, sonication increases the relative population of 4 to $20 \mu \mathrm{m}$ particles while causing a reduction in the relative population of 1 to $4 \mu \mathrm{m}$ particles. Additionally, there is a slight increase in the relative population of submicron particles.

Analysis of the as-received material suggested that the size alteration described in the preceding paragraph was the result of aggregate restructuring. For the current sample, sonication also appears to eliminate the 30 to $200 \mu \mathrm{m}$ particle/aggregate fraction. Based on this observation, the increases in submicrometer and 4-20 $\mu \mathrm{m}$ fractions may originate from small (1-4 $\mu \mathrm{m})$ and large (20-200 $\mu \mathrm{m})$ aggregate 
pools, respectively (although a number of possible mechanisms exist). It should be noted that during sonication the analyzer shows a small but finite population from 100 to $800 \mu \mathrm{m}$. This fraction is most likely a result of instrument noise. The PSD below $20 \mu \mathrm{m}$ is not strongly affected by the removal of sonic energy and appears to maintain its sonicated population distribution. Above $20 \mu \mathrm{m}$, there appears to be a recovery of the $20-200 \mu \mathrm{m}$ aggregates.

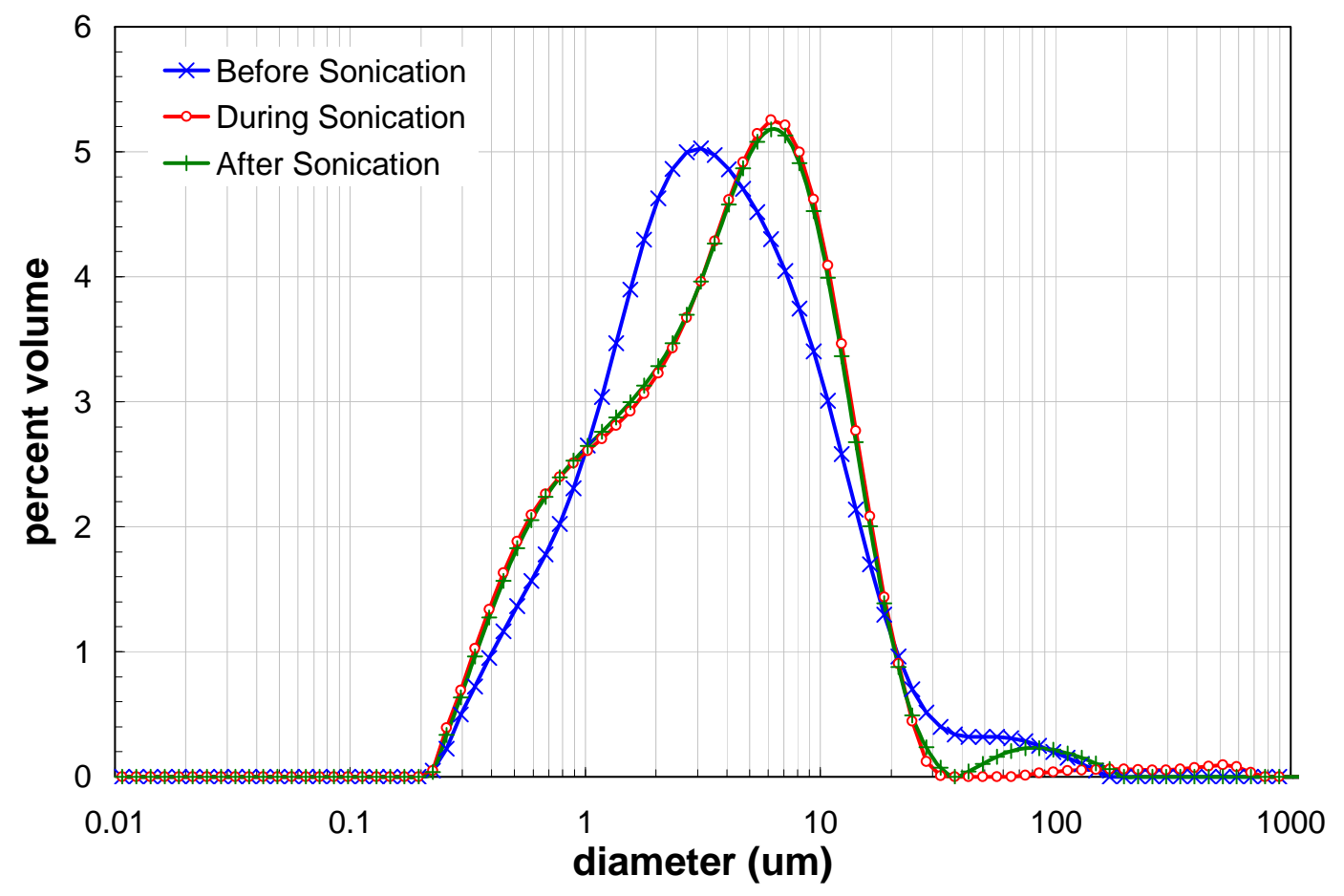

Figure 4. Measured particle size distribution for sample TI540-G5-3-PSD before, during, and after sonication.

The post-sonic behavior of the low-solids matrix slurry is shown in Figure 5. The distribution does not appear to alter appreciably as flow rate is changed. Particle size distributions at both low (2000 RPM) and high (4000 RPM) flow rates show an increased 1-4 $\mu \mathrm{m}$ fraction, but this could indicate a transient recovery of particle aggregates in this size range rather than a flow rate effect. For particles / aggregates greater than $20 \mu \mathrm{m}$, the flow rate behavior observed in the post-sonic PSD is similar to that shown in Figure 2. The main difference is the complete disappearance of greater than $30 \mu \mathrm{m}$ particles at 2000 RPM. This could suggest that sonication has disrupted most of the large particle aggregates and that any $>20 \mu \mathrm{m}$ material that remains exists as large primary particles that are difficult to suspend (i.e., require pump speeds of $3000 \mathrm{RPM}$ or greater). 


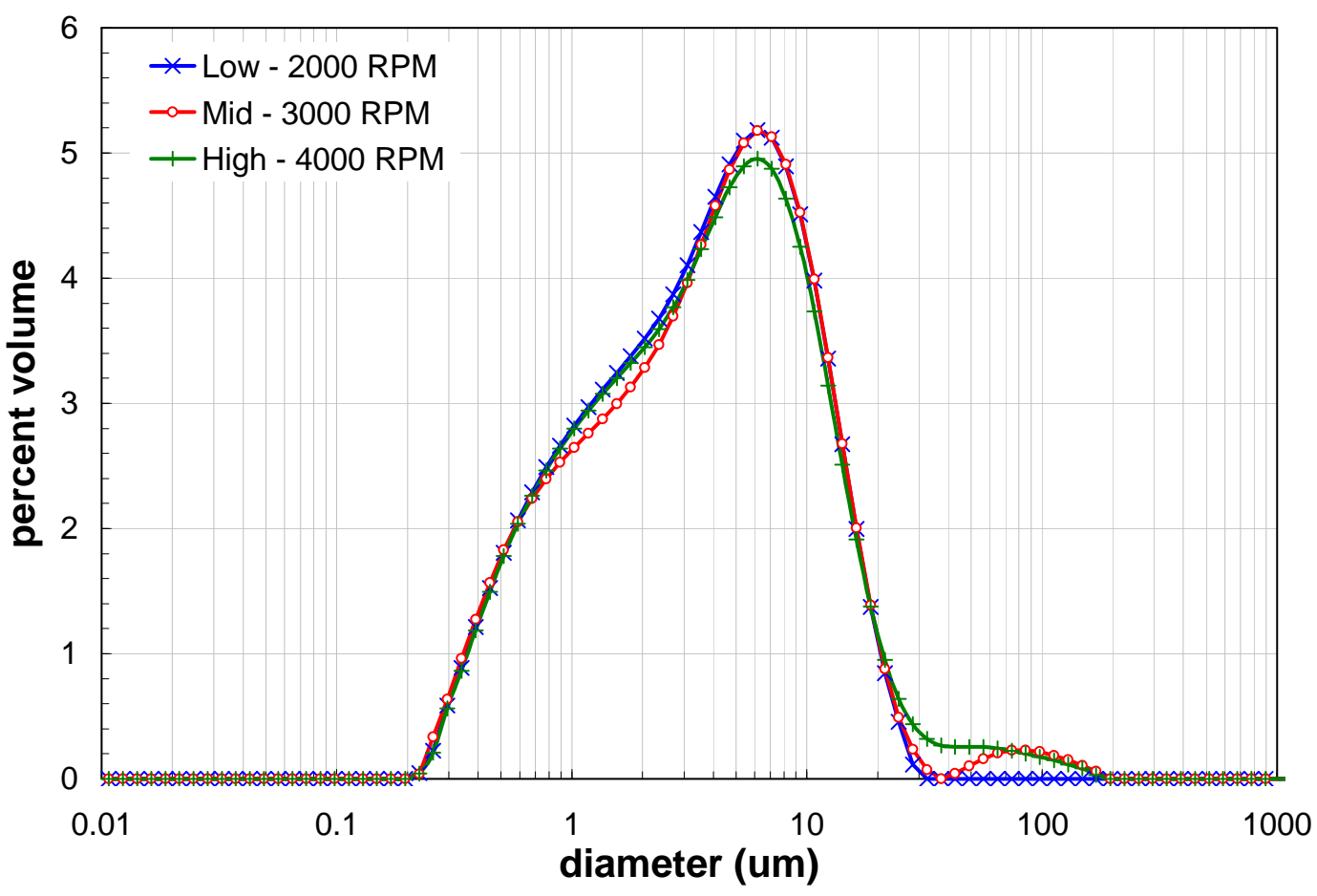

Figure 5. Measured particle size distribution for sample TI540-G5-3-PSD as a function of pump speed after sonication.

\section{Particle Size Analysis Results for TI540-G5-6-PSD (High-Solids Matrix)}

Sample TI540-G5-6-PSD (also termed high-solids matrix) is comprised of insoluble group 5 waste solids that have been filtered continuously at 4.3-wt\% under full permeate recycle, dewatered to $15.5-w t \%$, and subsequently filtered at $15.5-w t \%$ under full permeate recycle. Table 8 shows the diameter percentiles as a function of measurement condition. For this sample, the $\mathrm{d}(10)$ ranges from 0.48-0.64 $\mu \mathrm{m}$, the $\mathrm{d}(50)$ ranges from 2.2-2.9 $\mu \mathrm{m}$, and the $\mathrm{d}(90)$ ranges from $11-13 \mu \mathrm{m}$. The size fractiles observed for the high-solids matrix are, on average, lower than observed for low-solids matrix. As will be discussed in later sections of the report, the pre-caustic leach particle sizes for group 5 insoluble solids appear to decrease as a result of pumping through the CUF.

Table 8. Particle size analysis percentile results for TI540-G5-6-PSD. The diameters corresponding to the $10 \%, 50 \%$, and $90 \%$ volume/weight fractiles are given [d(10), d(50), and d(90), respectively].

\begin{tabular}{||c|c|c|c|c|c||}
\hline $\begin{array}{c}\text { Measurement } \\
\text { Condition }\end{array}$ & Pump Speed & Sonication & $\begin{array}{c}\mathbf{d}(\mathbf{1 0}) \\
{[\boldsymbol{\mu m}]}\end{array}$ & $\begin{array}{c}\mathbf{d}(\mathbf{5 0}) \\
{[\boldsymbol{\mu m}]}\end{array}$ & $\begin{array}{c}\mathbf{d}(\mathbf{9 0}) \\
{[\boldsymbol{\mu m}]}\end{array}$ \\
\hline 1 & 3000 & pre-sonic & 0.64 & 2.3 & 12 \\
\hline 2 & 2000 & pre-sonic & 0.64 & 2.3 & 11 \\
\hline 3 & 4000 & pre-sonic & 0.60 & 2.2 & 13 \\
\hline 4 & 3000 & $25 \%$ & 0.50 & 2.2 & 12 \\
\hline 5 & 3000 & $50 \%$ & 0.48 & 2.6 & 11 \\
\hline 6 & 3000 & $75 \%$ & 0.48 & 2.9 & 11 \\
\hline 7 & 3000 & post-sonic & 0.48 & 2.8 & 11 \\
\hline 8 & 2000 & post-sonic & 0.50 & 2.7 & 11 \\
\hline 9 & 4000 & post-sonic & 0.49 & 2.7 & 12 \\
\hline
\end{tabular}


Figure 6 shows the pre-sonic particle size distribution for sample TI540-G5-6-PSD as a function of pump speed. As with the previous group 5 samples, the distribution is broad, spanning 0.2 to $200 \mu \mathrm{m}$, with a peak population at around $2 \mu \mathrm{m}$. The $2 \mu \mathrm{m}$ peak dominates the distribution, but the higher flow rates suggest a bimodal distribution with a second population peak centered around 4-10 $\mu \mathrm{m}$. The majority of particles fall between 0.2 and $20 \mu \mathrm{m}$.

With regard to the influence of flow rate on the pre-sonication PSD, it appears that increased pump speed shears apart large aggregates as evidenced by the decrease in the population of particles greater than $100 \mu \mathrm{m}$ and the increase in the relative population of $20-100 \mu \mathrm{m}$ aggregates as pump speed is increased from 2000 to 4000 RPM. At 4000 RPM, the distribution begins to show a slight decrease in the peak diameter of the primary population (peak shifts from $\sim 2 \mu \mathrm{m}$ down to $\sim 1.5 \mu \mathrm{m}$ ). An increase in the relative populations of both submicron and 5-10 $\mu$ m particles and a decrease in relative population of 1-4 $\mu \mathrm{m}$ accompanies this population peak down shift. Both changes can be attributed to shear breakage of aggregates at the higher pump speed setting.

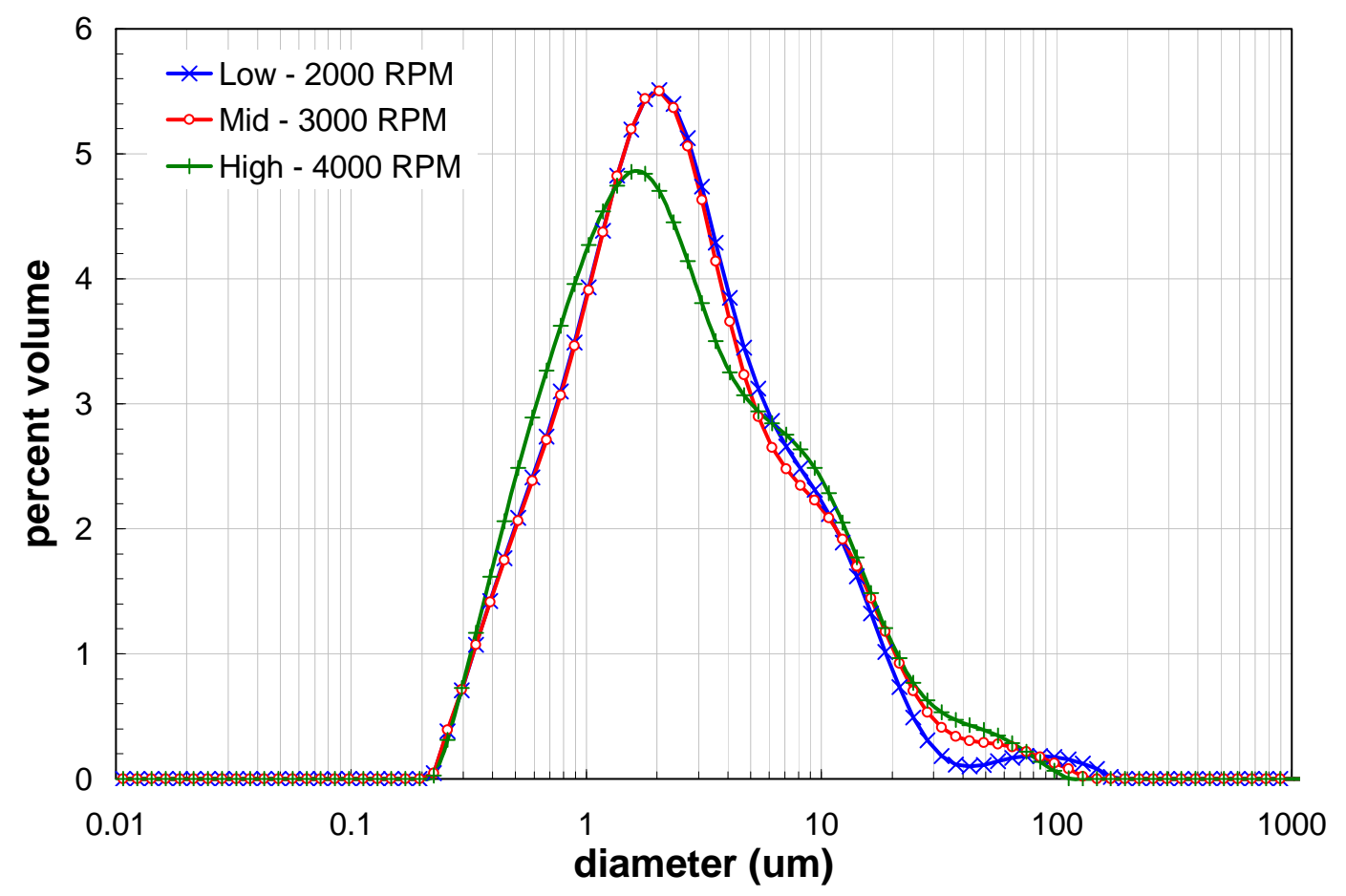

Figure 6. Measured particle size distribution for sample TI540-G5-6-PSD as a function of pump speed before sonication.

Figure 7 shows the particle size distribution for sample TI540-G5-6-PSD as a function of sonication. Application of sonic energy induces the same aggregate restructuring observed in the previous samples. In addition, sonication eliminates particles / aggregates larger than $30 \mu \mathrm{m}$. Relative to previous distributions, that for TI540-G5-6-PSD is more strongly bimodal such that the submicron and 2$30 \mu \mathrm{m}$ population peaks are more distinct. It appears that, for the current sample, submicron particles are either more prevalent or more stable. This is most likely a result of prolonged shear in the CUF. 


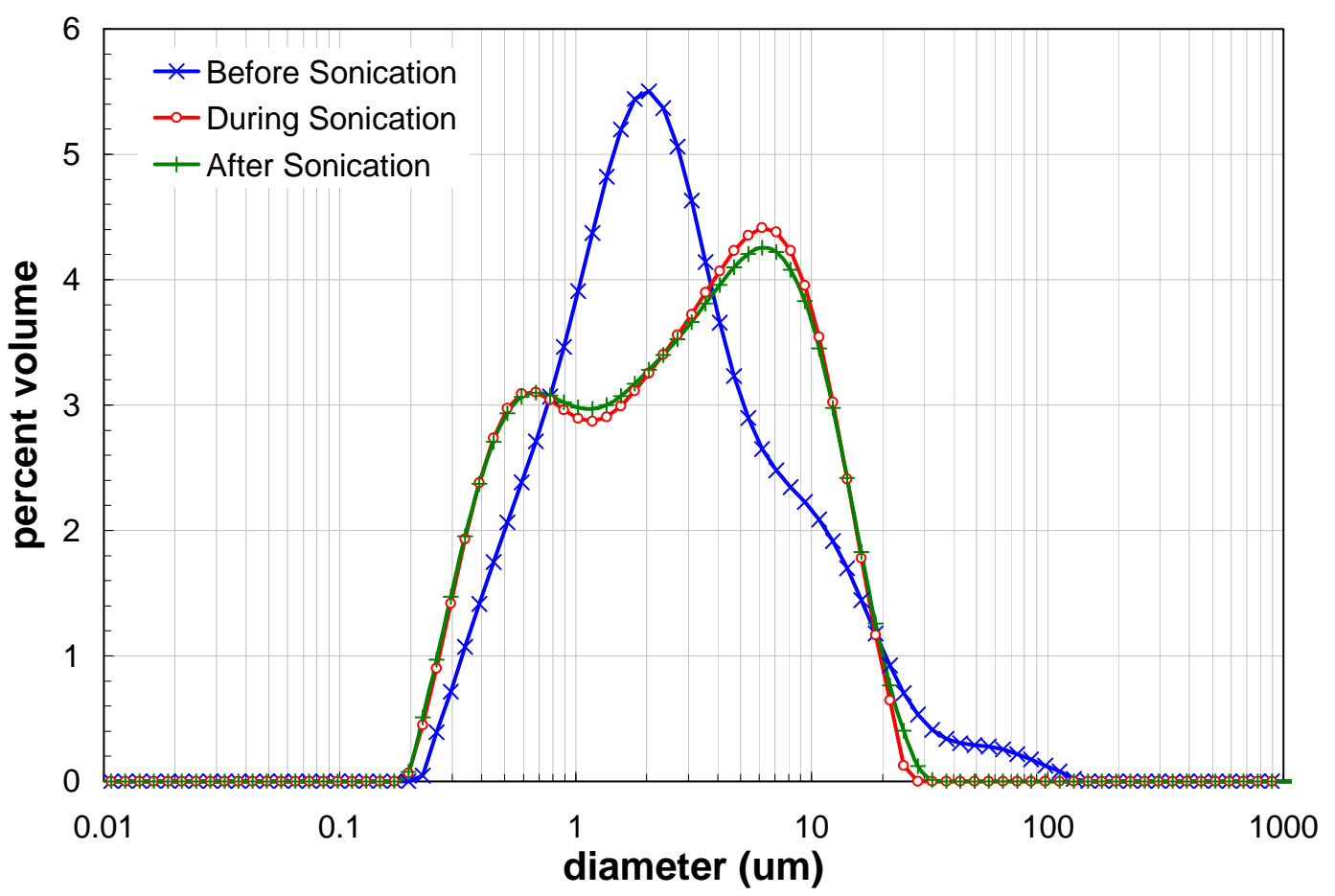

Figure 7. Measured particle size distribution for sample TI540-G5-6-PSD before, during, and after sonication.

Figure 8 shows the post-sonic particle size distribution for sample TI540-G5-6-PSD as a function of pump speed. The particle size distribution after sonication appears insensitive to changes in pump speed. The only major change observed is the appearance of a 30-200 $\mu \mathrm{m}$ fraction at 4000 RPM. This may be dense, difficult to suspend aggregates that remain after sonication.

\section{Particle Size Analysis Results for TI540-G5-11-PSD (Post-Leach Dewatered)}

Sample TI540-G5-11-PSD is comprised of insoluble group 5 waste solids that have been leached in a concentrated sodium hydroxide solution for 24 hours at $100{ }^{\circ} \mathrm{C}$ and subsequently dewatered to 13.5wt\% solids. Table 9 shows the diameter percentiles as a function of measurement condition. For the post-caustic leach dewatered sample, the $\mathrm{d}(10)$ ranges from 0.70-0.74 $\mu \mathrm{m}$, the $\mathrm{d}(50)$ ranges from 2.1-6.5 $\mu \mathrm{m}$, and the $\mathrm{d}(90)$ ranges from 9.4-450 $\mu \mathrm{m}$. Before sonication, the $\mathrm{d}(10)$ and $\mathrm{d}(50)$ are similar to the precaustic leach sample. However, the caustic leaching process appears to have induced sample instability, as the alteration of pump speed and application of sonic energy cause a dramatic increases in the $\mathrm{d}(90)$ fraction. 


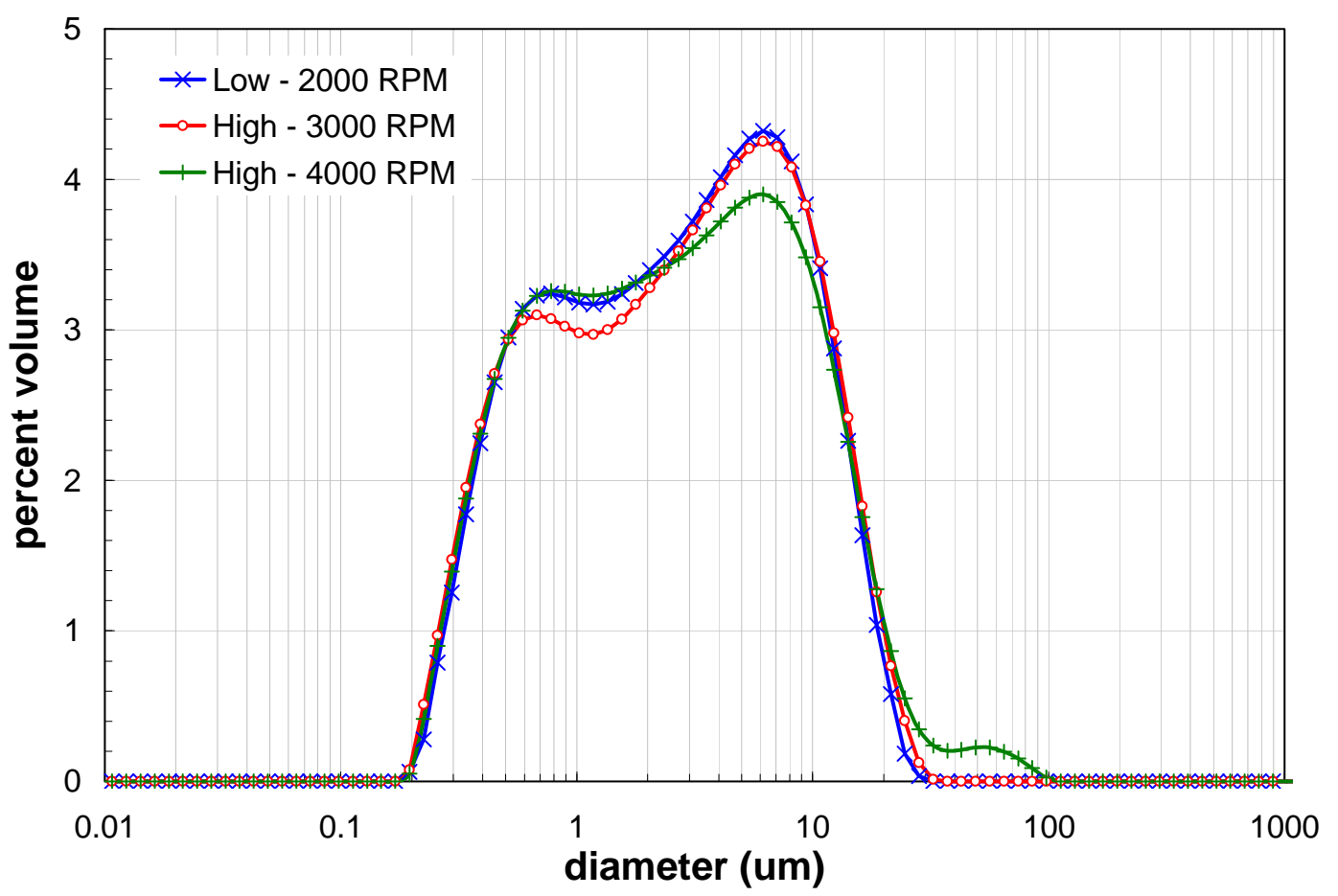

Figure 8. Measured particle size distribution for sample TI540-G5-6-PSD as a function of pump speed after sonication.

Table 9. Particle size analysis percentile results for TI540-G5-11-PSD. The diameters corresponding to the $10 \%, 50 \%$, and $90 \%$ volume/weight fractiles are given [d(10), $d(50)$, and d(90), respectively].

\begin{tabular}{||c|c|c|c|c|c||}
\hline $\begin{array}{c}\text { Measurement } \\
\text { Condition }\end{array}$ & Pump Speed & Sonication & $\begin{array}{c}\mathbf{d}(\mathbf{1 0}) \\
{[\boldsymbol{\mu m}]}\end{array}$ & $\begin{array}{c}\mathbf{d}(\mathbf{5 0}) \\
{[\boldsymbol{\mu} \mathbf{m}]}\end{array}$ & $\begin{array}{c}\mathbf{d}(\mathbf{9 0}) \\
{[\boldsymbol{\mu} \mathbf{m}]}\end{array}$ \\
\hline 1 & 3000 & pre-sonic & 0.73 & 2.1 & 29 \\
\hline 2 & 2000 & pre-sonic & 0.77 & 2.3 & 9.4 \\
\hline 3 & 4000 & pre-sonic & 0.73 & 2.6 & 75 \\
\hline 4 & 3000 & $25 \%$ & 0.71 & 4.0 & 260 \\
\hline 5 & 3000 & $50 \%$ & 0.74 & 6.5 & 400 \\
\hline 6 & 3000 & $75 \%$ & 0.72 & 6.3 & 450 \\
\hline 7 & 3000 & post-sonic & 0.70 & 5.8 & 360 \\
\hline 8 & 2000 & post-sonic & 0.73 & 5.6 & 420 \\
\hline 9 & 4000 & post-sonic & 0.71 & 5.5 & 360 \\
\hline
\end{tabular}

Growth of the d(90) beyond $100 \mu \mathrm{m}$ is accompanied by degradation of scattering pattern and fit thereof observed during sample measurement. Indeed, the scattering pattern recorded by the Malvern showed an "odd-even" effect which grew more pronounced as the measurement proceeded. The "oddeven" effect is characterized by even detectors showing a higher scattering intensity than adjacent odd detectors. Figure 9 shows a comparison of a stable Malvern scattering signal to one strongly affected by the "odd-even" effect. The initial scattering measurement shows a smooth continuous spread over detectors 1-43 and a typical "blip" over detectors 50-52. The Malvern software is able to fit the initial scattering signal with minimal error. In contrast, the second (post-sonic) measurement signal shows 
significant data scatter from detectors 13-33. Data scatter is not random, but always shows high even detector readings and low odd detector readings.

The "odd-even" effect is usually associated with poorly aligned laser-optics systems. For the current measurement, this is not the case because a) the laser was aligned to vendor specifications in July of 2007, b) the system passed its auto-align test, c) the PSD characterizations for samples TI540-G5-3PSD and TI540-G5-6-PSD, performed immediately before TI540-G5-11-PSD, were successful, and d) measurements immediately after sample addition (specifically, conditions 1 and 2) did not show the "oddeven" effect. As such, degradation of the scattering signal appears to be associated with this sample (and with the subsequent samples - see discussion for TI540-G5-16-PSD) and is suggestive of instability with respect to particle aggregation and sticking.

While the Malvern software can accommodate the "odd-even" effect when fitting the data, the fit's weighted residual will be high. Additionally, the uncertainty associated with the PSD derived with that fit will be high as well. As such, PSD results for sample TI540-G5-11-PSD should be approached with caution (i.e., treated qualitatively rather than quantitatively). Later test conditions for this sample, especially those during and after sonication, are affected more strongly by the "odd-even” effect. However, because the degradation of the scattering signal continues throughout the measurement, it is difficult to quantify how representative of the actual sample PSD any of the results are.

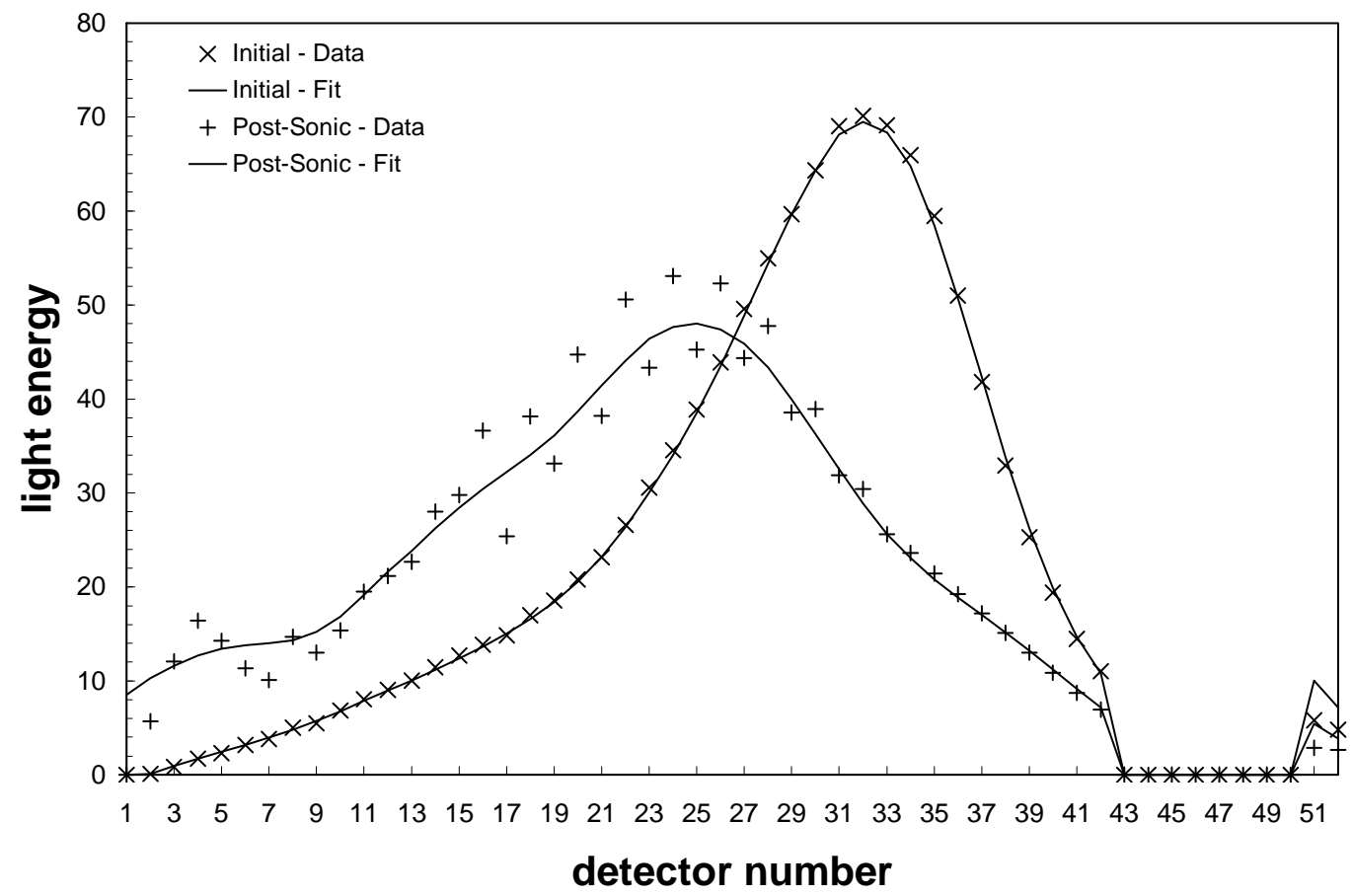

Figure 9. Two Malvern Mastersizer scattering signals recording during particle size measurement. The initial signal is free of defect and can be adequately fit by the Mastersizer software. The "postsonic" data show the "odd-even”, and are poorly fit by the Malvern software. 
Figure 10 shows the pre-sonic particle size distribution for sample TI540-G5-11-PSD as a function of pump speed. The distributions at 3000 and 4000 RPM show anomalous peaks centered at 60 and $\sim 400 \mu \mathrm{m}$. It is unknown if these peaks correspond to particle agglomerates or are a fitting artifact caused by the "odd-even" effect. Based on pre-caustic leach samples, aggregates in the $20-200 \mu \mathrm{m}$ are plausible. Aggregates larger than this are most likely a fitting artifact, but could result from strong sample instability and aggregation. Even if the $\sim 400 \mu \mathrm{m}$ peak corresponded to real particles, the population contribution would be suspect given the unreliability of the Hydro $\mu \mathrm{P}$ in suspending particles in this size range.

The pre-sonication distribution below $20 \mu \mathrm{m}$ is relatively stable. The distribution here shows a peak population at $2 \mu \mathrm{m}$ and a shoulder at 8-10 $\mu \mathrm{m}$. Flow rate behavior is similar with the pre-leach high-solids matrix sample (TI540-G5-6-PSD). Specifically, high pump speeds cause a reduction in size of the $2 \mu \mathrm{m}$ primary peak to $\sim 1.5 \mu \mathrm{m}$. Unlike before, the growth of the 4-10 $\mu \mathrm{m}$ shoulder population does not appear to be flow induced, but rather a transient effect (as it first appears in the 2000 RPM measurement and persists through the 4000 RPM measurement).

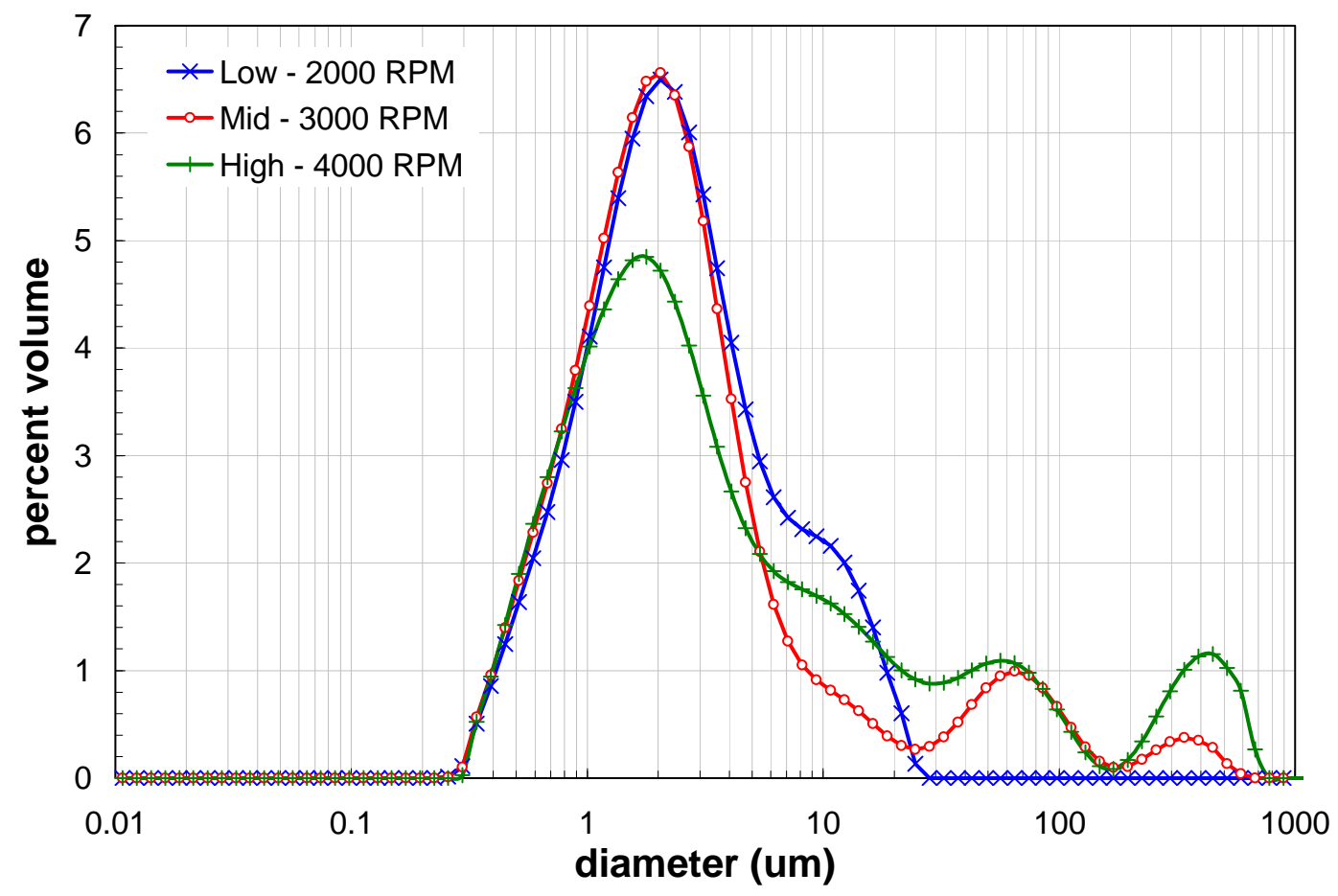

Figure 10. Measured particle size distribution for sample TI540-G5-11-PSD as a function of pump speed before sonication. (For indication only, see discussion.)

Figure 11 shows the particle size distribution for sample TI540-G5-11-PSD as a function of sonication. Behavior is consistent with previous group 5 samples, with sonication causing an increase in the population of the $8 \mu \mathrm{m}$ peak at the expense of particles in the $2 \mu \mathrm{m}$ peak. As in the pre-sonic samples, measurement instability manifests as anomalous peaks centered at $400 \mu \mathrm{m}$. 
Figure 12 shows the post-sonic particle size distribution for sample TI540-G5-11-PSD as a function of pump speed. The distributions appear to maintain the particle populations achieved during sonication over the duration of measurement and range of pump speeds tested. Increased pump speed appears to shift the average (peak) population of 4-10 $\mu \mathrm{m}$ to smaller diameters. Specifically, the peak population of this size fraction decreases from $8 \mu \mathrm{m}$ to $6 \mu \mathrm{m}$ as the pump speed is increased from 2000 to 4000 RPM.

Post-sonication measurements correspond to the final test conditions and were the most affected by the "odd-even" effect. The consequence of sample instability for these measurements are 1) the 20$200 \mu \mathrm{m}$ behavior is unpredictable and cannot be interpreted and 2) the anomalous peaks centered at 400 $\mu \mathrm{m}$ (present in all three measurements) are again likely an analysis artifact.

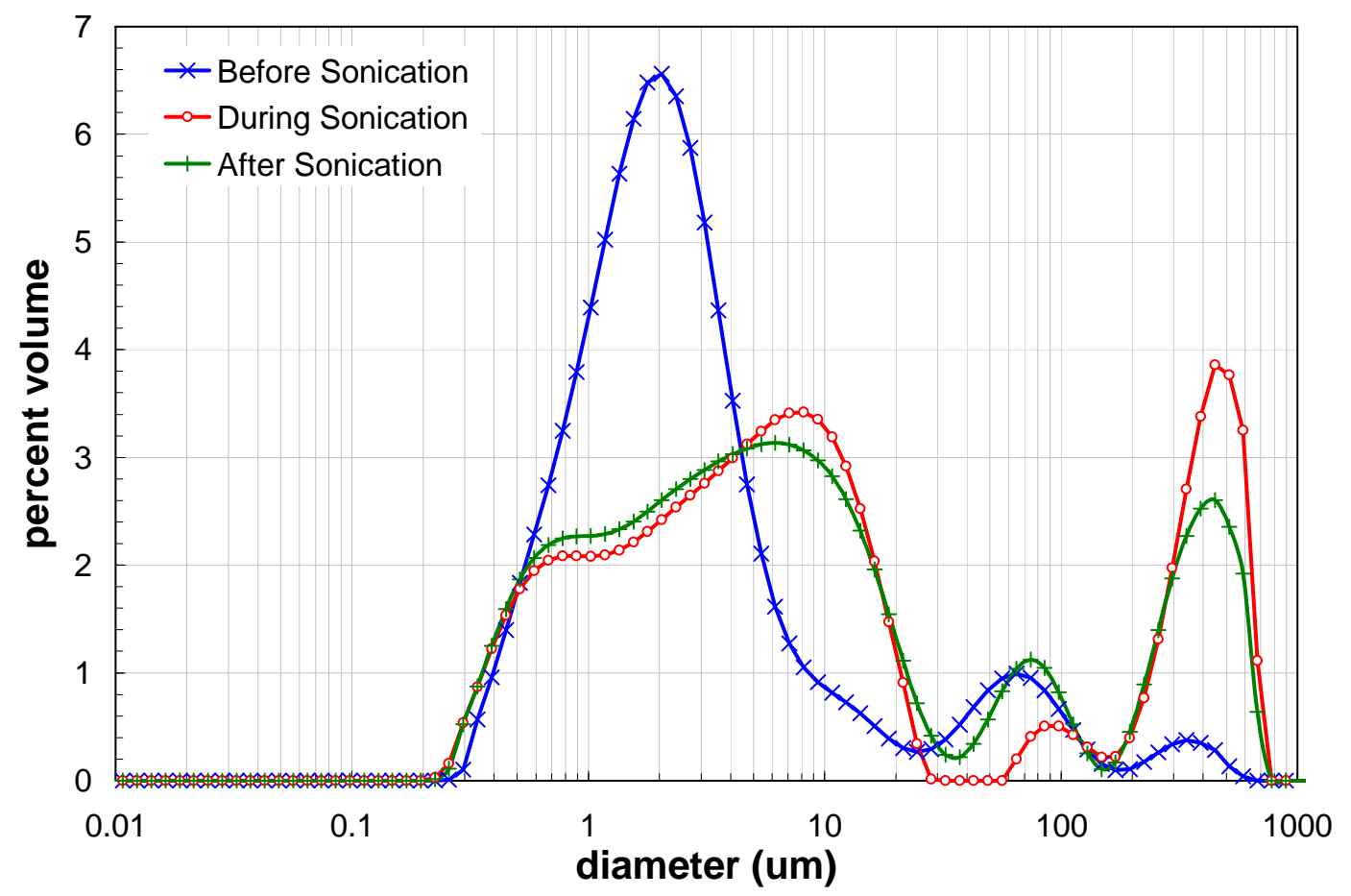

Figure 11. Measured particle size distribution for sample TI540-G5-11-PSD as a function of sonication. (For indication only, see discussion.) 


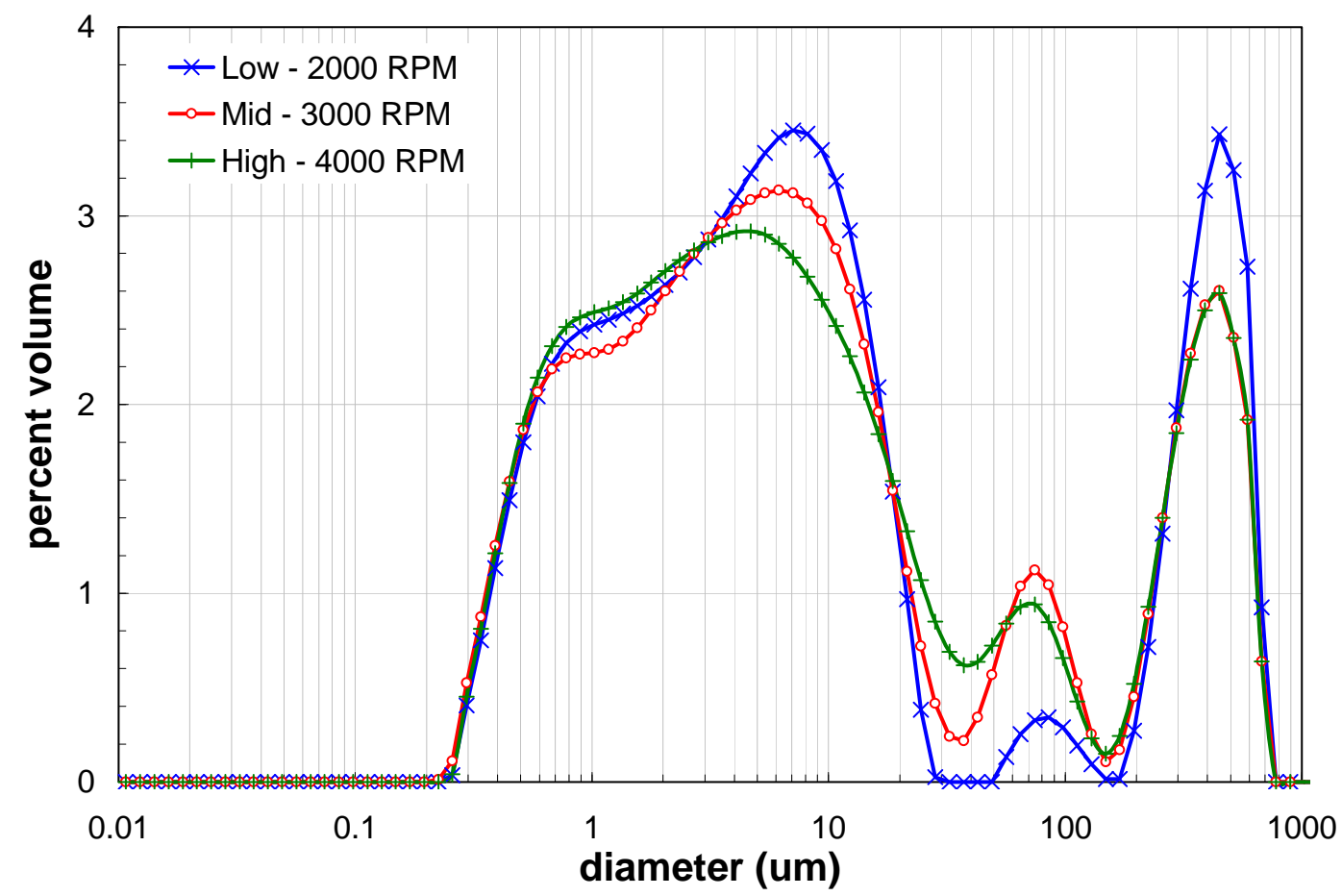

Figure 12. Measured particle size distribution for sample TI540-G5-11-PSD as a function of analyzer pump speed after sonication. (For indication only, see discussion.)

Particle Size Analysis Results for TI540-G5-16-PSD (Post-Leached, Dewatered and Washed)

Sample TI540-G5-16-PSD is comprised of insoluble group 5 waste solids that have been leached in a concentrated sodium hydroxide solution for 24 hours at $100{ }^{\circ} \mathrm{C}$, dewatered to 13.5 -wt $\%$ solids, and washed with dilute hydroxide solutions to a final solids concentration of 4.1-wt\%. Table 10 shows the diameter percentiles as a function of measurement condition. For this sample, the $\mathrm{d}(10)$ ranges from 0.58-0.67 $\mu \mathrm{m}$, the $\mathrm{d}(50)$ ranges from 1.9-3.5 $\mu \mathrm{m}$, and the $\mathrm{d}(90)$ ranges from 9.6-300 $\mu \mathrm{m}$. Relative to the leached and dewatered sample, the fractiles are lower on average. This suggests that washing has removed or reduced the larger particle structures in the slurry. Like sample TI540-G5-11-PSD, the washed slurry shows instability with respect to flow and sonication, as indicated by the dramatic increase in the $d(90)$ over the course of the measurement. Examination of the scattering signals associated with measurement of TI540-G5-11-PSD (not shown in this report) indicate that the current measurements, including the before, during, and after sonication states, are influenced to some extent by the "odd-even" effect.

Figure 13 shows the pre-sonic particle size distribution for sample TI540-G5-16-PSD as a function of pump speed. The size distribution and behavior of the leached, dewatered, and washed slurry solids is similar to the leached and dewatered only slurry. The distribution is broad, with the majority of particles falling between 0.2 and $20 \mu \mathrm{m}$ particles. The population peaks at slightly smaller diameters than the previous sample (i.e., $\sim 1.5 \mu \mathrm{m}$ as opposed to $2 \mu \mathrm{m}$ previously). Aggregates may exist in the 20-200 $\mu \mathrm{m}$ size range, but the measurement instability resulting from the "odd-even” effect makes this difficult to 
reliably determine. Peaks beyond $200 \mu \mathrm{m}$ are likely a data artifact introduced by the "odd-even" effect rather than real particles / particle aggregates in this size range. .

Table 10. Particle size analysis percentile results for TI540-G5-16-PSD. The diameters corresponding to the $10 \%, 50 \%$, and $90 \%$ volume/weight fractiles are given [d(10), $\mathrm{d}(50)$, and d(90), respectively]. (For indication only - see discussion).

\begin{tabular}{||c|c|c|c|c|c||}
\hline $\begin{array}{c}\text { Measurement } \\
\text { Condition }\end{array}$ & Pump Speed & Sonication & $\begin{array}{c}\mathbf{d}(\mathbf{1 0}) \\
{[\boldsymbol{\mu m}]}\end{array}$ & $\begin{array}{c}\mathbf{d}(\mathbf{5 0}) \\
{[\boldsymbol{\mu m} \mathbf{m}}\end{array}$ & $\begin{array}{c}\mathbf{d}(\mathbf{9 0}) \\
{[\boldsymbol{\mu} \mathbf{m}]}\end{array}$ \\
\hline 1 & 3000 & pre-sonic & 0.64 & 1.9 & 16 \\
\hline 2 & 2000 & pre-sonic & 0.67 & 2.1 & 9.6 \\
\hline 3 & 4000 & pre-sonic & 0.63 & 2.3 & 39 \\
\hline 4 & 3000 & $25 \%$ & 0.60 & 2.5 & 11 \\
\hline 5 & 3000 & $50 \%$ & 0.60 & 3.5 & 170 \\
\hline 6 & 3000 & $75 \%$ & 0.59 & 3.5 & 300 \\
\hline 7 & 3000 & post-sonic & 0.58 & 3.5 & 120 \\
\hline 8 & 2000 & post-sonic & 0.58 & 3.3 & 140 \\
\hline 9 & 4000 & post-sonic & 0.60 & 3.5 & 170 \\
\hline
\end{tabular}

Figure 14 shows the particle size distribution for sample TI540-G5-16-PSD as a function of sonication. As in the before sonication data set, the peaks beyond $20 \mu \mathrm{m}$ are suspected of being the result of the sample instability and odd-even effect. The distribution below $20 \mu \mathrm{m}$ shows similar behavior to the previous samples, namely aggregate restructuring upon sonication. Here, the $\sim 1.5 \mu \mathrm{m}$ primary population that exists before sonication appears to split into populations centered on $0.7 \mu \mathrm{m}$ and $5 \mu \mathrm{m}$.

Figure 15 shows the post-sonic particle size distribution for sample TI540-G5-16-PSD as a function of pump speed. Neglecting the anomalous behavior in the $>20 \mu \mathrm{m}$ size range, the distributions appear insensitive to pump speed. However, the odd-even observed during these measurements is significant. It is possible that changes in PSD with pump speed have been lost in the noise. 


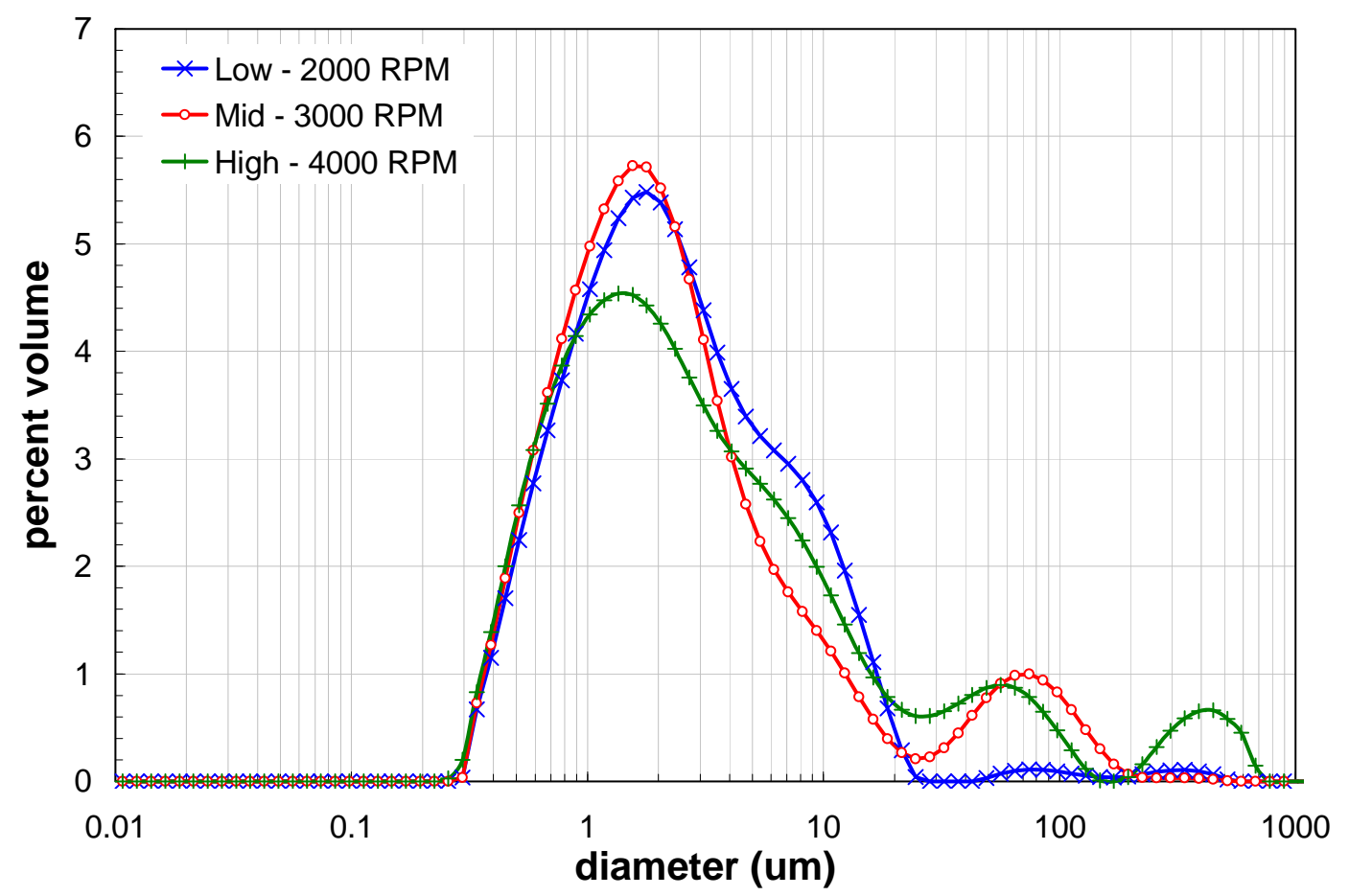

Figure 13. Measured particle size distribution for sample TI540-G5-16-PSD as a function of pump speed before sonication. (For indication only, see discussion.)

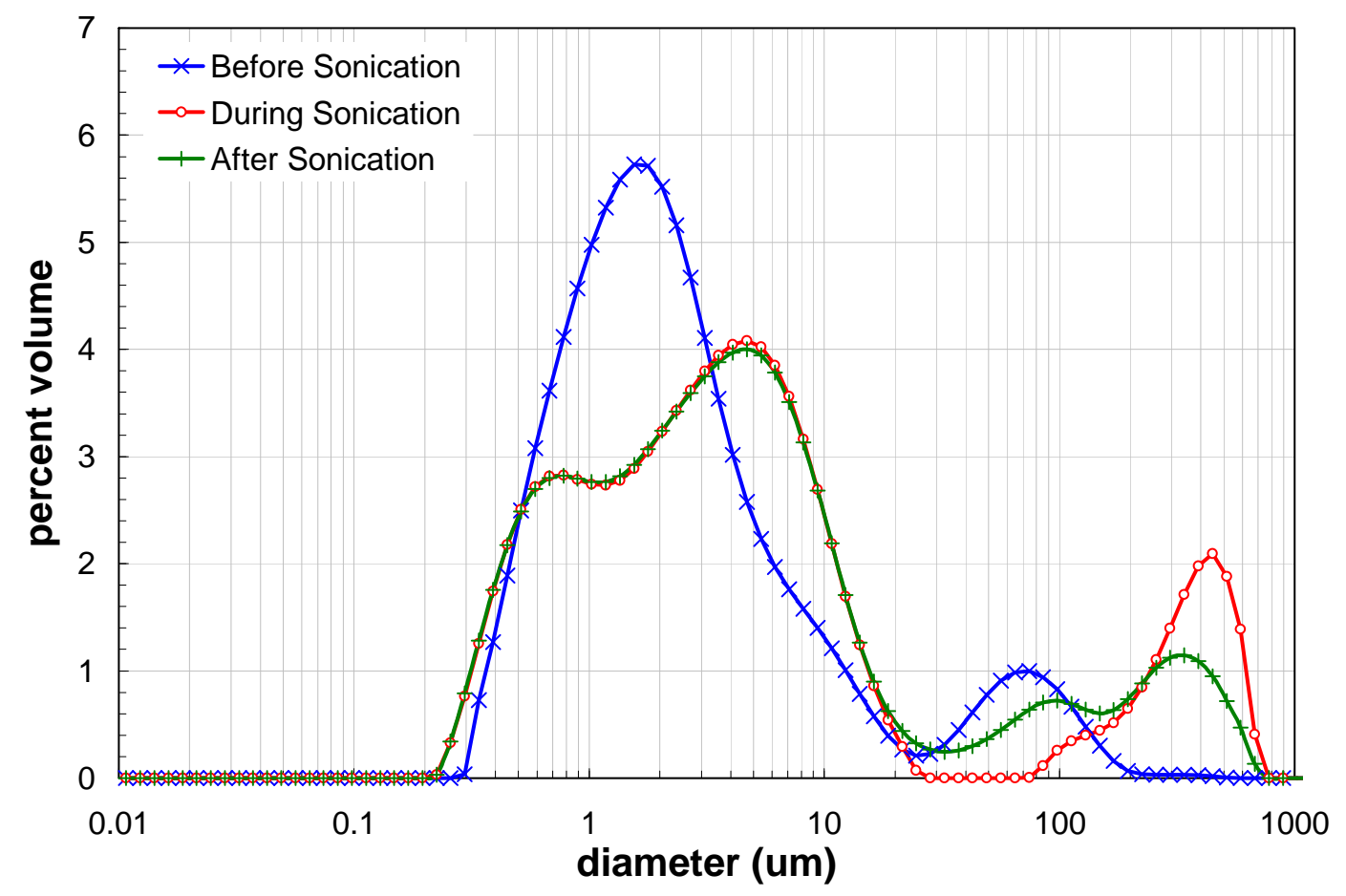

Figure 14. Measured particle size distribution for sample TI540-G5-16-PSD as a function of sonication. (For indication only, see discussion.) 


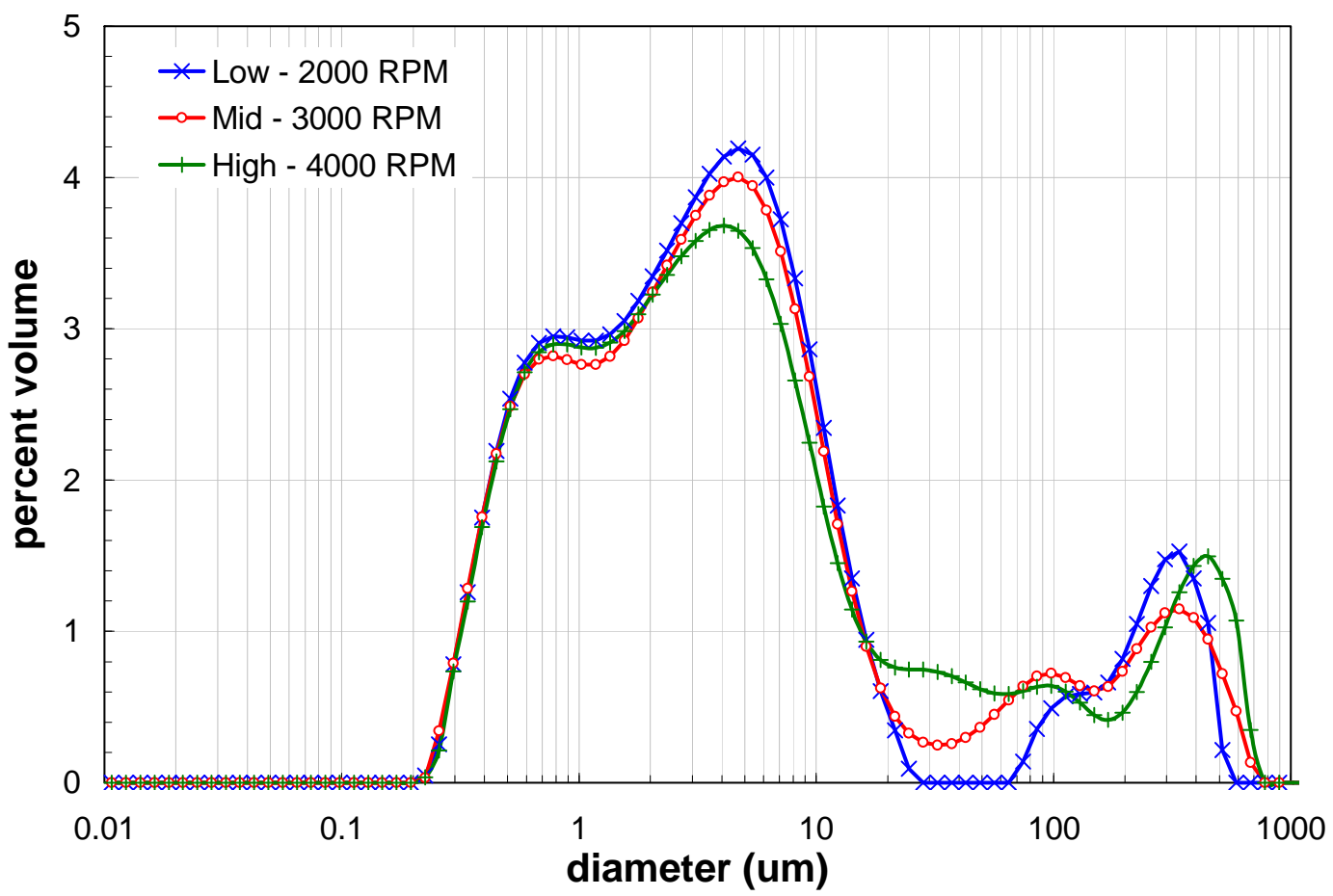

Figure 15. Measured particle size distribution for sample TI540-G5-16-PSD as a function of analyzer pump speed after sonication. (For indication only, see discussion.)

\section{Influence of CUF Processing on Group 5 Particle Size Distribution}

Comparison of the fractiles and distributions presented in the previous sections of this report can highlight the effects of CUF processing on group 5 waste particle size distribution. Caution must be used when directly comparing PSDs from the various points in CUF processing, as these PSDs include both primary particles and particle aggregates. The structure of the aggregate fractions depends on both physical conditions such as the analyzer pump speed and sonication state and chemical conditions such as particle interaction potentials and sample history.

The expected outcome of prolonged CUF processing is a reduction in the size of particles from shear breakage and dissolution effects, respectively. Caustic leaching may also effect a similar reduction, especially in the case of incomplete leaching; however, removal of leachable solid species may reveal the size distribution of particles only minimally represented in the initial sample. Because the pump speed used during size analysis can also shear apart particle aggregates (as well as influence the volume of aggregates suspended), it is important to compare only distributions measured at the same pump speed. Even under comparable shear, differences in particle chemistry, which are highly likely when comparing pre- and post-leach PSDs, may result in different degrees of aggregate formation. This, combined with sample stability issues that manifest in the analysis (such as the "odd-even" effect) further complicate comparison.

To mitigate these issues, comparison of the process PSDs reported above will be made by comparing only PSDs at measurement condition 1 (see Table 5). This allows all PSDs to be compared at the same pump speed (3000 RPM) before the introduction of sonication-induced effects (such as 
aggregate restructuring) while minimizing the influence of the "odd-even" affects in the post-leach samples.

Figure 16 shows the influence of pre-caustic leach CUF processing on the particle size distribution for group 5 wastes. The basic effect shown here is one of shear. The source material has not been processed in the CUF (minimal shear), the low-solids matrix has seen minimal CUF processing (moderate shear), and the high-solids matrix has seen extended CUF processing (extended shear). The comparison indicates that CUF processing effects a reduction in overall particle size. Particles / aggregates in the $30-200 \mu \mathrm{m}$ range appear to persist through processing. Initial CUF processing (i.e., that corresponding to the low-solids matrix) appears to reduce the 4-10 $\mu \mathrm{m}$ population fraction appearing in the source material while slightly increasing the fraction of submicron particles. Extended CUF processing appears to cause a dramatic reduction in the population of 4-10 $\mu \mathrm{m}$ while greatly increasing the fraction of submicron particles. These observations are supported by the decreases observed in the $d(10), d(50)$, and $d(90)$ values corresponding to these measurement states (see Table 11). The mechanism associated with particle size reduction is most likely aggregate break-up induced by high velocity ( 13 $\mathrm{ft} / \mathrm{s}$ ) shearing in the CUF lines or by mechanical action of the rotary pump lobes.

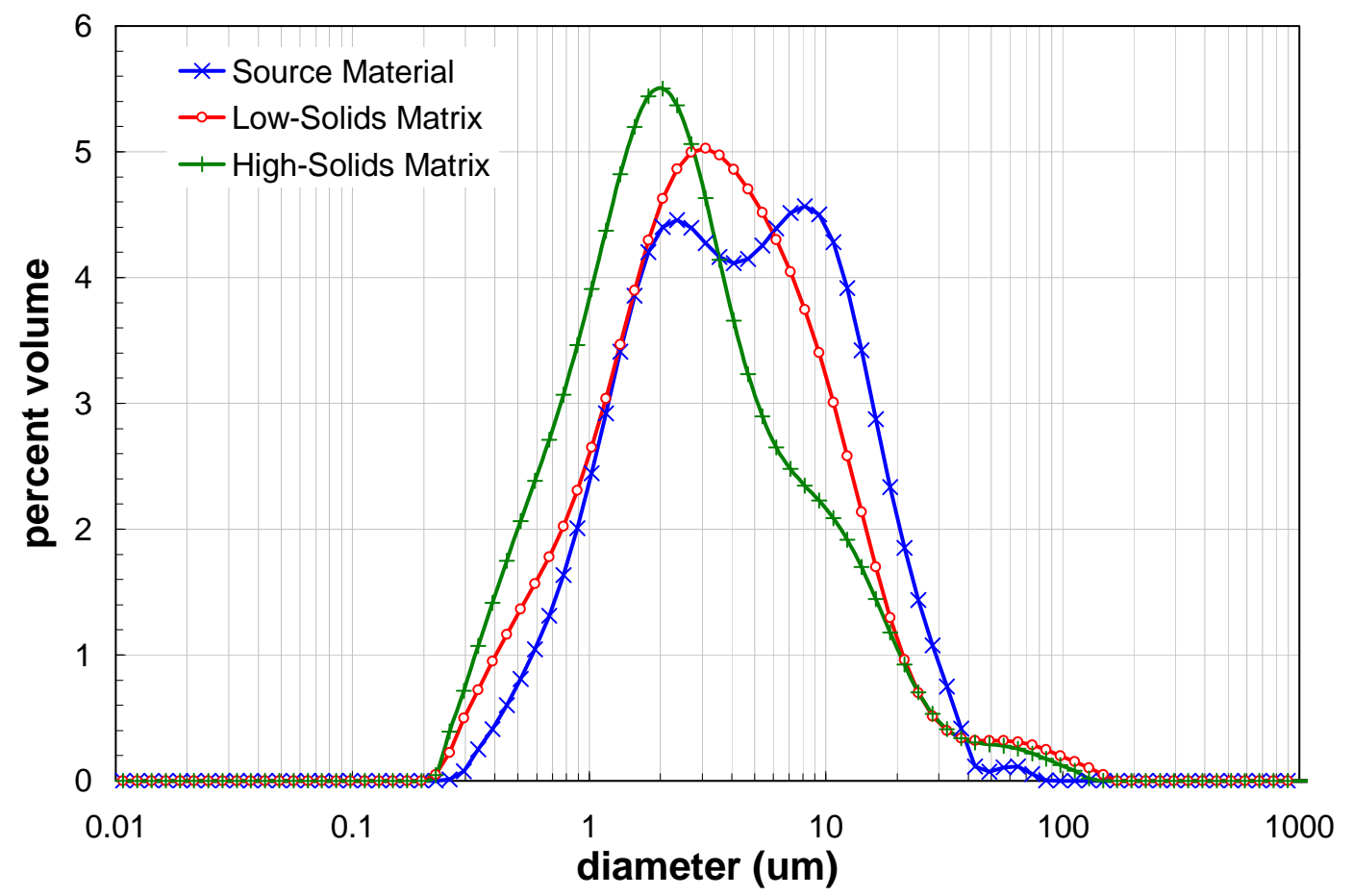

Figure 16. Measured particle size distributions for group 5 samples as a function of pre-caustic CUF processing. The source material has not been processed in the CUF (minimal shear), the low-solids matrix has seen minimal CUF processing (moderate shear), and the high-solids matrix has seen extended CUF process (extended shear). 
Table 11. Pre-caustic leach particle size analysis percentile results as a function of CUF processing. All measurements correspond to measurement condition 1 (see Table 5).

\begin{tabular}{||l|c|c|c||}
\hline \hline Sample & $\begin{array}{c}\mathbf{d}(\mathbf{1 0}) \\
{[\boldsymbol{\mu m}]}\end{array}$ & $\begin{array}{c}\mathbf{d}(\mathbf{5 0}) \\
{[\boldsymbol{\mu m}]}\end{array}$ & $\begin{array}{c}\mathbf{d}(\mathbf{9 0}) \\
{[\boldsymbol{\mu m}]}\end{array}$ \\
\hline Source Material (TI473-G5-S-WL-PSD-1) & 1.1 & 4.3 & 16 \\
\hline Low-Solids Matrix (TI540-G5-3-PSD) & 0.81 & 3.4 & 13 \\
\hline High-Solids Matrix (TI540-G5-6-PSD) & 0.64 & 2.3 & 12 \\
\hline
\end{tabular}

Figure 17 shows the effect of caustic leaching on the CUF processed material's particle size distribution. The high-solids matrix represent insoluble group 5 solids immediately before the leaching process. The dewatered solids show the distribution immediately after caustic leaching. Based on the appearance of the "odd-even" effect in measurements caustically leached samples such as TI540-G5-11PSD, it can be postulated that leaching produces a highly unstable insoluble solid particle / agglomerate (with respect to particle size measurement by laser diffraction). Because the odd-even effect is manifested as anomalous peaks in the $20-1000 \mu \mathrm{m}$ range, this region is not considered in the discussion of leaching effects. Considering the submicron to 20 micron range, caustic leaching appears to sharpen the peak particle population centered at $2 \mu \mathrm{m}$ by reducing the submicron and $4-10 \mu \mathrm{m}$ fractions. This is confirmed by the fractile results reported in Table 12, which show minimal changes in the $\mathrm{d}(50)$ and a slight increase in the $\mathrm{d}(10)$. Possible causes for these changes in the leached PSD include 1) that the $2 \mu \mathrm{m}$ fraction is made up of particles resistant to or unaffected by caustic leaching and/or 2) that submicron particles and particles that hold the 4-10 $\mu$ m aggregates together are removed or changed in chemical/physical character through the caustic leaching process.

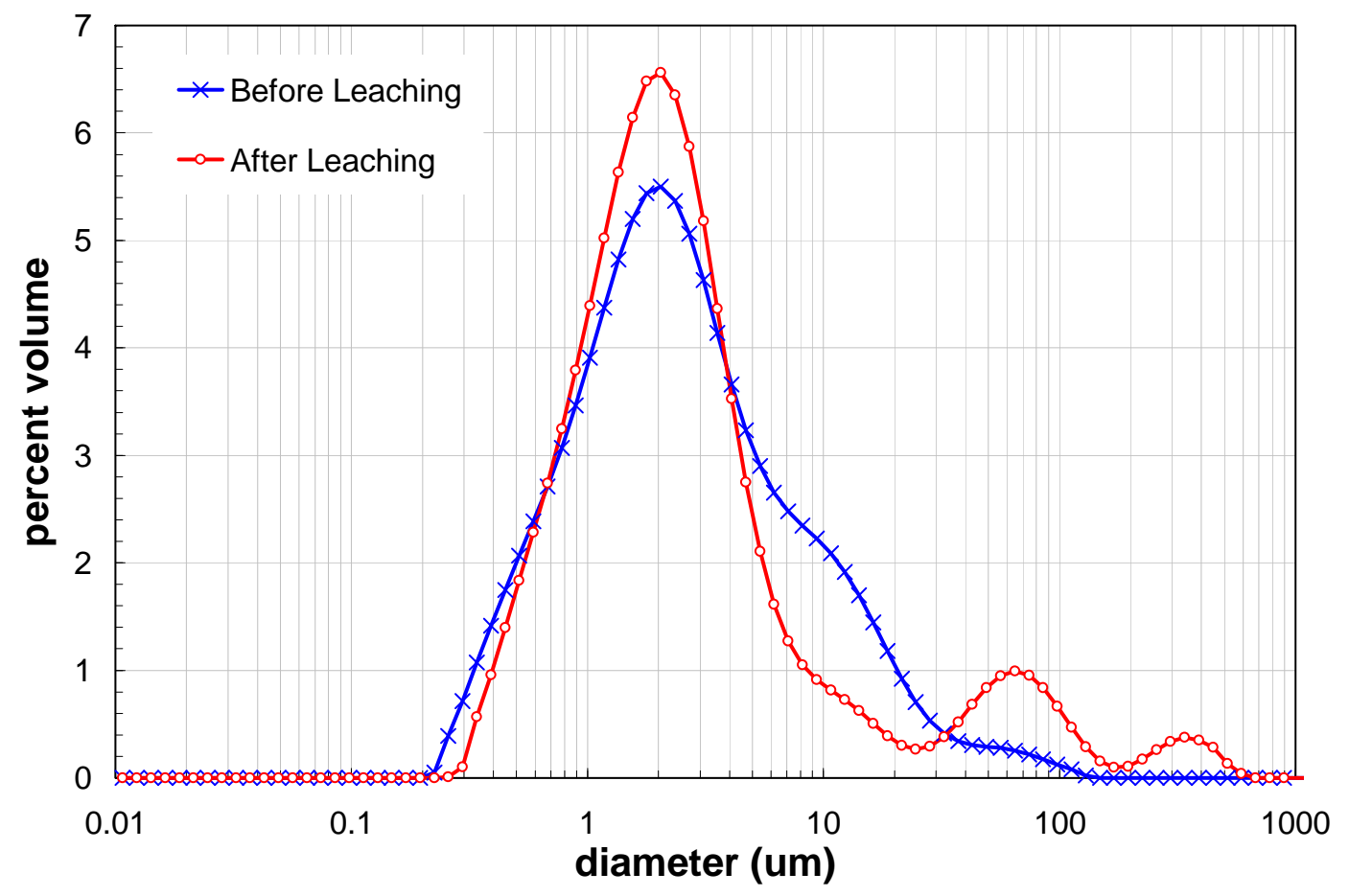

Figure 17. Measured particle size distributions for group 5 samples before and after caustic leaching. 
Table 12. Particle size analysis percentile results as a function of CUF caustic leaching. All measurements correspond to measurement condition 1 (see Table 5)

\begin{tabular}{||l|c|c|c||}
\hline Sample & $\begin{array}{c}\mathbf{d}(\mathbf{1 0}) \\
{[\boldsymbol{\mu} \mathbf{m}]}\end{array}$ & $\begin{array}{c}\mathbf{d}(\mathbf{5 0}) \\
{[\boldsymbol{\mu} \mathbf{m}]}\end{array}$ & $\begin{array}{c}\mathbf{d}(\mathbf{9 0}) \\
{[\boldsymbol{\mu} \mathbf{m}]}\end{array}$ \\
\hline Before Caustic Leaching (TI540-G5-6-PSD) & 0.64 & 2.3 & 12 \\
\hline After Caustic Leaching (TI540-G5-11-PSD) & 0.73 & 2.1 & 29 \\
\hline
\end{tabular}

Figure 18 shows the effect of washing the caustically leached solids. As before, the PSD behavior above $20 \mu \mathrm{m}$ will not be discussed because of the presence of anomalous peaks caused by sample instability. With regard to the fraction below $20 \mu \mathrm{m}$, washing appears to shift the observed particle size distribution to lower particle diameters. This is observed in a left-shift of the peak centered at $2 \mu \mathrm{m}$ down to $\sim 1.5 \mu \mathrm{m}$. The observed decrease in the distribution plot is confirmed by the $\mathrm{d}(10)$, $\mathrm{d}(50)$, and $\mathrm{d}(90)$ (see Table 13). Because both waste samples were washed thoroughly with a $0.01 \mathrm{M}$ sodium hydroxide solution while being prepared for particle size analysis, the decrease in overall particle size is most likely a result of continued CUF processing rather than any loss of material during the CUF washing.

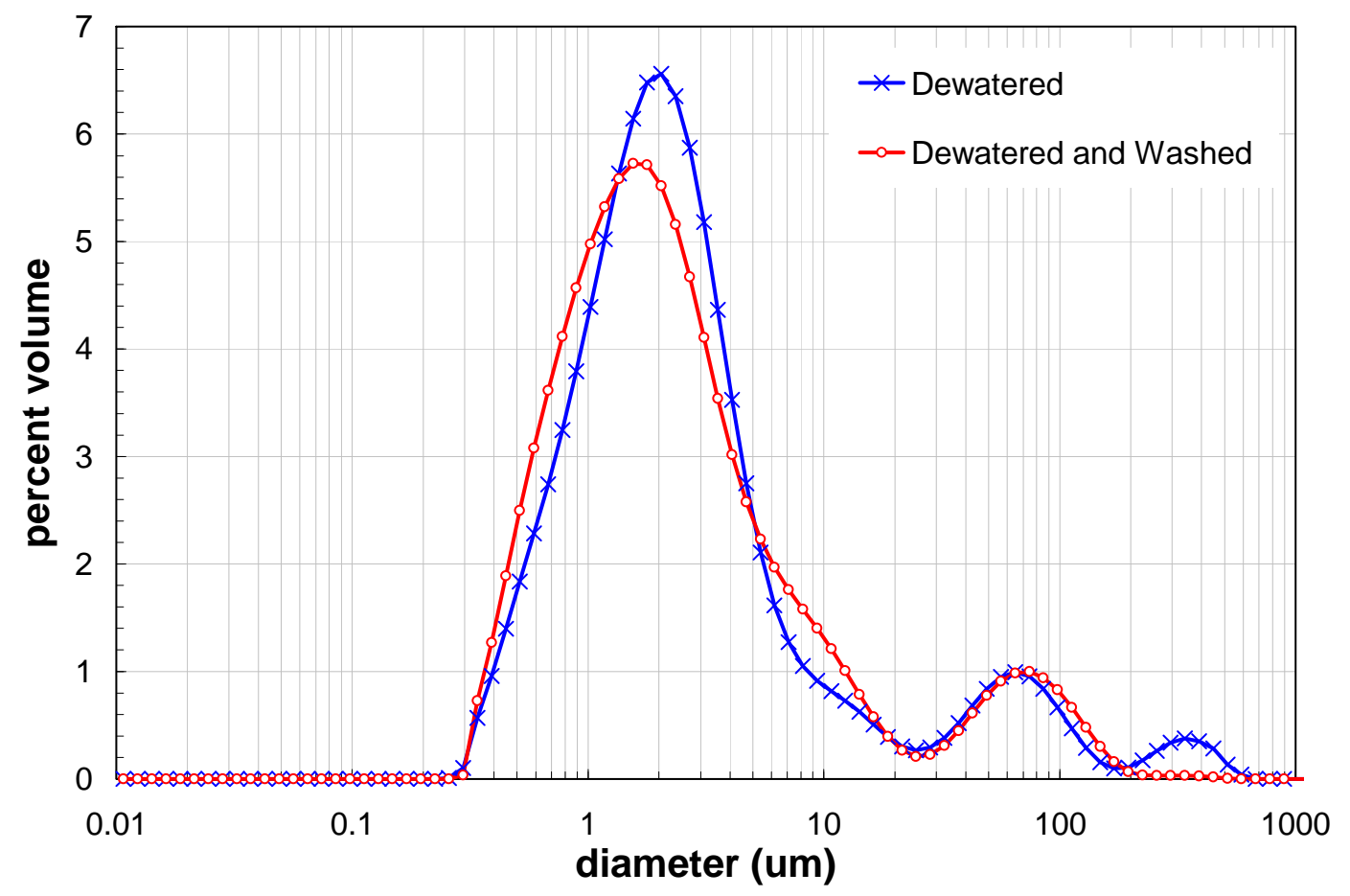

Figure 18. Measured particle size distributions for post-caustic leach group 5 samples before and after washing operations. 
Table 13. Particle size analysis percentile results as a function of CUF caustic leaching. All measurements correspond to measurement condition 1 (see Table 5)

\begin{tabular}{||l|c|c|c||}
\hline Sample & $\begin{array}{c}\mathbf{d}(\mathbf{1 0}) \\
{[\boldsymbol{\mu m}]}\end{array}$ & $\begin{array}{c}\mathbf{d}(\mathbf{5 0}) \\
{[\boldsymbol{\mu} \mathbf{m}]}\end{array}$ & $\begin{array}{c}\mathbf{d}(\mathbf{9 0}) \\
{[\boldsymbol{\mu} \mathbf{m}]}\end{array}$ \\
\hline Before Washing (TI540-G5-11-PSD) & 0.73 & 2.1 & 29 \\
\hline After Washing (TI540-G5-16-PSD) & 0.64 & 1.9 & 16 \\
\hline
\end{tabular}

\section{Conclusions}

The particle size distributions of four group 5 insoluble solids samples derived from CUF testing were measured and the effects of CUF processing on the particle size determined. Samples generally showed complex particle size behavior with respect to both flow rate and sonication. In brief, the following behaviors were observed:

- pre-caustic leach CUF samples appeared to exhibit aggregate formation upon application of sonic energy, a behavior that is consistent with the source material

- CUF processing appears to reduce the size of particles / aggregates - size reduction appeared to continue throughout CUF processing and appeared in both pre- and post-leach samples

- Caustic leaching appears to sharpen the peak population of particles centered around $2 \mu \mathrm{m}$

CUF samples collected after caustic leaching operations showed significant difficulty in measurement. Size measurements taken shortly (i.e., 30-60 seconds) after these samples were loaded into the analyzer showed minor stability issues. At longer measurement times, both caustically leached samples showed significant stability issues which manifest as anomalous (i.e., of uncertain origin) peaks in the 20 to 1000 $\mu \mathrm{m}$ range. The anomalous peaks in the 20-200 $\mu \mathrm{m}$ range may correspond to a real population of particles / agglomerates, as they were are observed in the pre-caustic leach samples analysis that was not influenced by the "odd-even” effect. Anomalous peaks greater than $200 \mu \mathrm{m}$, do not appear in samples before caustic leaching and are most likely an artifact of attempts by the particle size analyzer's data analysis routine to accommodate the "odd-even" effect.

\section{Records}

Data records relating to TI540-G5-3-PSD particle size distribution measurements and postmeasurement analysis exist in original Malvern Mastersizer 2000 data files and Laboratory Record Books (LRBs):

- Malvern Mastersizer File, “2007-09sep26-Group 5 CUF PSD.mea”

- $\quad$ LRB BNW 56933, Pages 51 and 57-58

- $\quad$ Test Data Package TDP-WTP-024

Data records relating to TI540-G5-6-PSD particle size distribution measurements and post-measurement analysis exist in original Malvern Mastersizer 2000 data files and Laboratory Record Books (LRBs):

- Malvern Mastersizer File, “2007-09sep26-Group 5 CUF PSD.mea”

- $\quad$ LRB BNW 56933, Pages 52 and 58-59 
- $\quad$ Test Data Package TDP-WTP-025

Data records relating to TI540-G5-11-PSD particle size distribution measurements and post-measurement analysis exist in original Malvern Mastersizer 2000 data files and Laboratory Record Books (LRBs):

- Malvern Mastersizer File, “2007-09sep27-Group 5 CUF PSD.mea”

- $\quad$ LRB BNW 56933, Pages 52-53 and 59-60

- $\quad$ Test Data Package TDP-WTP-026

Data records relating to TI540-G5-16-PSD particle size distribution measurements and post-measurement analysis exist in original Malvern Mastersizer 2000 data files and Laboratory Record Books (LRBs):

- Malvern Mastersizer File, “2007-09sep27-Group 5 CUF PSD.mea”

- $\quad$ LRB BNW 56933, Pages 53-54 and 60-61

- $\quad$ Test Data Package TDP-WTP-027

\section{References}

1. Doc. No. TP-RPP-WTP-567, Revision 0, “Characterization and Small Scale Testing of Hanford Wastes to Support the Development and Demonstration of Leaching and Ultrafiltration Pretreatment Processes,” SK Fiskum, Battelle - Pacific Northwest Division, February 2007.

2. Doc. No. RPL-COLLOID-01, Revision 1, “Particle Size Analysis Using Malvern MS2000,” AP Poloski, Pacific Northwest National Laboratory, May 2007.

3. Doc. No. WTP/RPP-MOA-PNNL-00079, "Particle Size Distribution Measurements for Groups 5 and 6,” RC Daniel, Battelle - Pacific Northwest Division, July 2007. 
WTP-RPT-172, Rev 0

\section{Appendix $\mathrm{H}$}

Group 5/6 CUF Particle Size Analysis 


\section{Appendix H: Group 5/6 CUF Particle Size Analysis}

\section{Battelle}

The Business of Innovation

$\begin{array}{ll}\text { Date } \quad \text { August 8, } 2008 & \text { Richard Daniel } \\ & \text { File/LB }\end{array}$

To Rick Shimskey

From Richard Daniel

Subject $\quad$ Particle Size Distribution Measurements for Group 5/6

(REDOX Sludge and S-Saltcake Mixtures) CUF

$\underline{\text { Testing Samples }}$

\section{Acronyms and Abbreviations}

$\begin{array}{ll}\text { AV } & \text { Axial velocity } \\ \text { CA } & \text { Contamination area } \\ \text { CUF } & \text { Cells Unit Filter } \\ \text { DI } & \text { Deionized (water) } \\ \text { CCP } & \text { Computational computer program (application) } \\ \text { LRB } & \text { Laboratory Record Book } \\ \text { NIST } & \text { National Institute of Technology } \\ \text { PSD } & \text { Particle size distribution } \\ \text { RI } & \text { Refractive index } \\ \text { RMA } & \text { Radioactive material area } \\ \text { RPL } & \text { Radiochemical Processing Laboratory } \\ \text { RPP } & \text { River Protection Project } \\ \text { SAL } & \text { Shielded Analytical Laboratory } \\ \text { TMP } & \text { Transmembrane Pressure } \\ \text { WTP } & \text { Waste Treatment Plant (Support Program) }\end{array}$

\section{Introduction}

In fulfillment of the requirements of Test Plans TP-RPP-WTP-467 [1] and TP-RPP-WTP-456 [2], the particle size distribution (PSD) of select Hanford tank waste samples was characterized at the Radiochemical Processing Laboratory (RPL). This interim characterization report presents PSD results for Group 5/6 wastes processed in the Cells Unit Filter (CUF) located at the Radiochemical Processing Laboratory's (RPL's) Shielded Analytical Laboratory (SAL). Waste Group 5/6 corresponds to mixtures of S-Saltcake slurry and REDOX (R) sludge. 


\section{Background}

Particle size distribution (PSD) describes the size fractionation of solids species in a given powder, dispersion, or slurry sample. PSD is typically described by either cumulative or differential population fraction versus a given particle size indicator. For example, the size distribution of particles in a slurry are often described using a histogram expressing the differential volume of particles falling between two equivalent sphere diameters over a large array of equivalent sphere diameters (see Figure 1). PSD measurements can be accomplished using a number of approaches, such as settling experiments, microscopic imaging, and light obscuration and scattering.

The particle size measurements discussed herein are carried out on a Malvern Mastersizer 2000 particle size analyzer (Malvern Instruments, Inc., Southborough, MA). This instrument operates using the principle of laser diffraction (see Figure 1). Here, a monochromatic laser (red and/or blue) is directed through a transparent cell containing a dilute dispersion of the solid particles being analyzed. On the opposite side of the flow cell is a series of ring detectors capable of detecting the intensity of laser light at various scattering angles. If the laser does not strike a particle in the flow cell, it simply passes through the cell undisturbed and strikes the central detector. When the laser interacts with a particle, it is scattered at various angles. The scattered light is picked up across a number of rings of the detector, creating a unique "scattering pattern" that can be mapped as a function of scattered light intensity versus ring detector position. Prolonged observation of the light scattered from the dispersion allows complete sampling of the particle species contained therein. Comparison of the time-averaged scattering signal against a reference "clean” cell signal generates a scattering pattern unique to that dispersion. Given the optical properties of the particulate and dispersing phases, mathematical analysis of the averaged "scattering pattern" allows determination of size fractionation species contained in the dispersion.

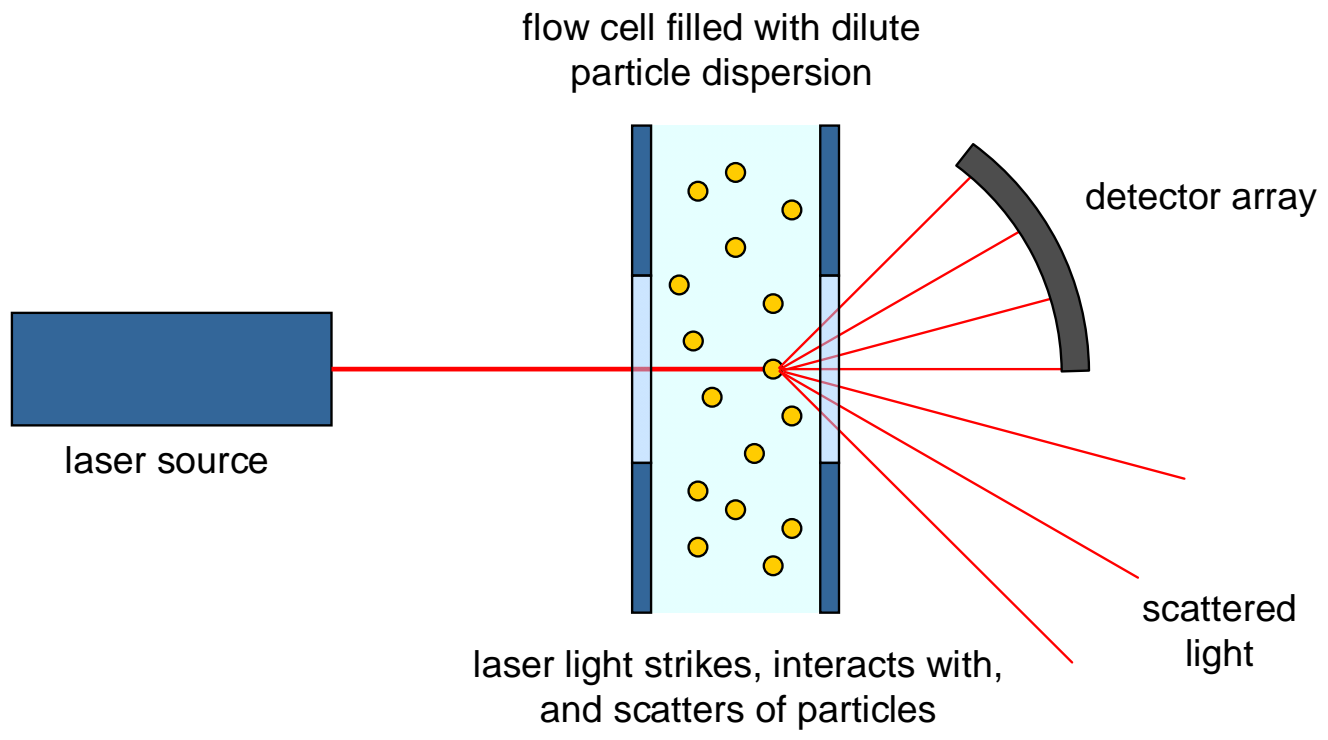

Figure 1. Schematic of a typical laser diffraction particle size analyzer.

It is important to recognize that particle size measurements by laser diffraction are intended to capture size of a single, well-dispersed particle species. This "true” PSD captures all particles in the solid dispersion in an un-aggregated primary particle state. Full dispersion at the primary particle level requires 
the correct selection of suspending phase chemistry, which is often further modified through the use of dispersing agents or surfactants, and sufficient flow to suspend all particles during analysis.

When dealing with complex dispersions such as Hanford tank waste, which contain multiple particle species and a broad distribution of sizes, finding the correct dispersing medium and measurement conditions is difficult (if not impossible), as individual particle species in the solids mixture may have contradictory suspending phase chemistry requirements. As such, particle size analysis of complex solids dispersions is generally performed to determine the "apparent” PSD as a function of processing conditions such as flow rate and sonication and suspending phase chemistry such as $\mathrm{pH}$. The apparent PSD differs from the true PSD in two ways: 1) particle aggregates exist and are treated as single particle species and 2) not all particles may be suspended at the flow conditions selected. Despite these short comings, apparent PSDs provide useful information about how the PSD of the test dispersion exists in the process from which it is derived and can highlight potential difficulties in suspending large / dense particles.

\section{Samples}

Group 5/6 CUF particle size measurement samples were derived as part of bench-scale crossflow ultrafiltration and leaching studies using actual tank waste. Source material for the studies included both Group 5 [REDOX] and Group 6 [S-Saltcake] solids. Initially, a low-concentration Group 6 tank waste slurry (3.2-wt\% solids) was loaded into a CUF unit installed in SAL Cell 5 and subjected to the following operational steps (in order):

1. full-recycle ultrafiltration of the low-concentration (3.2-wt\% solids) waste slurry at various axial velocities (AV) and transmembrane pressures (TMP)

2. dewatering of Group 6 slurry and mixing with Group 5 waste solids to transform the lowconcentration (3.2-wt\% undissolved solids) Group 6 slurry to a high-concentration (13.2-wt\% undissolved solids) Group 5/6 mixture

3. full-recycle ultrafiltration of the high-concentration (13.2-wt $\%$ undissolved solids) waste slurry at various AV and TMP

4. caustic leaching of the waste slurry occurred at a $6 \mathrm{M}$ free hydroxide concentration for 8 hours at $100^{\circ} \mathrm{C}$ (Note: The leached slurry was heated from room temperature to $100^{\circ} \mathrm{C}$ over a 5.3 hour period and cooled back down to room temperature over a 12 hours period.

5. dewatering of the caustically leached slurry

6. washing of the caustically-leached slurry

7. oxidative leaching of the waste slurry with $1 \mathrm{M}$ sodium permanganate for 6 hours at ambient cell temperature

8. washing of the oxidative-leached slurry

9. combination of the oxidative-leached Group 5/6 mixture with caustically-leached Group 5 solids from a previous CUF test

For CUF particle size testing, samples were derived from various points in the ultrafiltration process outlined above. With regard to slurry samples, waste aliquots for particle size were sampled after:

- $\quad$ loading the sample into the CUF (i.e., during step 1)

- dewatering the initial slurry and mixing with Group 5 solids (i.e. after step 2)

- caustic-leaching and dewatering (i.e., after step 5)

- washing the caustic leached slurry (i.e., after step 6)

- oxidative-leaching of the slurry (i.e., after step 7) 
- oxidative-leaching and dewatering (i.e., after step 8)

- combining the oxidative-leached 5/6 slurry with the caustically-leached Group 5 solids (i.e., after step 9)

These slurry samples were subsequently washed three times with, and suspended in, a solution of $0.01 \mathrm{M}$ $\mathrm{NaOH}$ in water at a concentration of $20 \mathrm{mg}$ solids / $\mathrm{mL}$ solution. It should be noted that this washing step may alter both the apparent and primary particle size distributions of solids in the sample submitted for size analysis (by either particle dissolution or change in the state of particle aggregation). As such, the PSDs measured during analysis may not correspond directly to the size distribution that exists in the CUF at a given processing step.

Approximately $0.2 \mathrm{~g}$ of each waste's insoluble solids were provided as a dispersions in $10 \mathrm{~mL}$ $0.01 \mathrm{M} \mathrm{NaOH}$ solution. Table 1 provides a summary of the samples taken and their given sample identification number. Samples were delivered to RPL/302 for particle size analysis in February 2008.

Table 1. Samples associated with Group 6 and 5/6 CUF rheology testing.

\begin{tabular}{||l|l||}
\hline Sample Jar ID & Description \\
\hline TI552-G6-3-PSD & Slurry - Low-solids matrix (3.2-wt\%) Group 6 slurry before caustic leaching \\
\hline TI552-G6-6-PSD & $\begin{array}{l}\text { Slurry - High-solids matrix (13.2-wt\%) Group 5/6 slurry before caustic } \\
\text { leaching }\end{array}$ \\
\hline TI552-G6-11-PSD & Slurry - Dewatered Group 5/6 slurry after caustic leaching (8.9-wt\%) \\
\hline TI552-G6-16-PSD & Slurry - Washed Group 5/6 slurry after caustic leaching (12.8-wt\%) \\
\hline TI552-G6-21-PSD & Slurry - Dewatered Group 5/6 slurry after oxidative leaching (6.1-wt\%) \\
\hline TI552-G6-26-PSD & Slurry - Washed Group 5/6 slurry after oxidative leaching (9.7-wt\%) \\
\hline TI552-G6-32-PSD & $\begin{array}{l}\text { Slurry - Combined leached solids from Group 5/6 and Group 5 tests (8.0- } \\
\text { wt\%) }\end{array}$ \\
\hline
\end{tabular}

\section{Analysis}

Initial particle size distribution measurements for Group 5/6 CUF testing samples were conducted between February $29^{\text {th }}$ and March $11^{\text {th }}$, 2008. During this period, samples TI552-G6-3-PSD, TI552-G6-6-PSD, TI552-G6-21-PSD, and TI552-G6-26-PSD were measured successfully. Instrument errors prevented the remaining samples from being measured properly at that time. Samples TI552-G611-PSD, TI552-G6-16-PSD, and TI552-G6-32-PSD were stored undisturbed in the Radioactive Material Area (RMA) in RPL/302 until July $17^{\text {th }}$, when they were retested and successfully measured. The analyses produced the following reportable data for the samples listed in Table 1: 1) particle diameters corresponding to select cumulative mass undersize percentiles and 2) volume differential distributions (volume population percentage versus diameter. Alternate analyses of the data, such as number distributions, surface area distributions, or cumulative PSD, are available on request.

\section{Instrument}

Particle size characterization was accomplished using a Mastersizer 2000 (Malvern Instruments, Inc., Southborough, MA 01772 USA) with a Hydro $\mu \mathrm{P}$ wet dispersion accessory. The Mastersizer has a nominal size measurement range of $0.02-2000 \mu \mathrm{m}$. The actual range is dependent on the accessory used as well as the properties of the solids being analyzed. When coupled with the Hydro $\mu \mathrm{P}$ wet dispersion accessory, the nominal measuring range is reduced to $0.02-150 \mu \mathrm{m}$. Although particle sizes above 150 
$\mu \mathrm{m}$ can be observed and sized with the Hydro $\mu \mathrm{P}$, they cannot be reliably suspended. Thus, the volume contribution of particles greater than $150 \mu \mathrm{m}$ cannot be determined reliably with this accessory.

The Hydro $\mu \mathrm{P}$ wet dispersion accessory consists of a $20 \mathrm{~mL}$ sample flow cell with a continuously variable and independent pump and ultrasound. Both flow and sonication can be controlled and altered during measurement. As such, PSD measurements can be made before, during, and after sonication, allowing determination of the influence of each on the sample's PSD. The primary measurement functions of the Malvern analyzer are controlled through computer software. For the current measurements, Mastersizer 2000 software, Version 5.4 [Malvern Instruments, Ltd. Copyright (c 19982002] was employed.

Table 2 provides a summary of basic information regarding the analyzer and accessory. The Malvern Mastersizer 2000 is located in the northwest contamination area (CA) fume hood in RPL Room 302.

Table 2. Summary of Malvern Mastersizer 2000 instrument information.

\begin{tabular}{||l|l||}
\hline \hline Analyzer: & Mastersizer 2000 \\
\hline Measurement principle: & Laser Diffraction (Mie Scattering) \\
\hline Analyzer Accessory: & Hydro $\mu \mathrm{P}$ \\
\hline Serial Number: & MAL100406 \\
\hline Measurement Range: & $0.02-2000 \mu \mathrm{m}$ nominal $(0.02-150 \mu \mathrm{m}$ with accessory) \\
\hline Type: & $\begin{array}{l}\text { Flow cell system with continuously variable and } \\
\text { independent pump and ultrasound. }\end{array}$ \\
\hline Capacity: & $20 \mathrm{~mL}$ \\
\hline Pump Speed Range: & $0-5000$ RPM (variable) \\
\hline Ultrasound Power & $0-20 \mathrm{~W}$ (variable) \\
\hline Software Version & 5.4 \\
\hline
\end{tabular}

\section{Governing Test Plan, Procedure, and Test Instructions}

The test plan governing the physical characterizations for these samples is River Protection Project - Waste Treatment Plant Support Program (RPP-WTP) document number TP-RPP-WTP-467, Revision 0 [1] and TP-RPP-WTP-456, Rev. 0 [2]. Operation of the Malvern Mastersizer 2000 is governed by RPL-COLLOID-01, Revision 1 [3].

\section{Instrument Performance Check}

As required by RPL-COLLOID-01, the performance of the Malvern analyzer must be verified at the beginning of each series of analyses (with the period between performance checks not to exceed 90 days during use). Checks are performed using particle size standards traceable to the National Institute of Technology (NIST). Checks verify that the particle size analyzer can measure the standard's d(50), the diameter corresponding to the 50th volume/weight percentile, to within $10 \%$ of the value specified on the manufacturer's standard certificate of analysis.

For the measurements described in this report, two performance checks were conducted: one check covering measurements in late February and early March and another check covering follow-up measurements in July. Both performance checks employed NIST traceable polydisperse particle size 
standards purchased from Whitehouse Scientific (Waverton, Chester, CH3 7PB, UK). Tables 3 and 4 provide a summary of the standards used for performance verifications. Standards are traceable back to their certificate of analysis through a unique bottle number identifier.

Table 3. Properties of the NIST standard used to verify performance of the Malvern Mastersizer 2000 and performance check results. Performance check covers the period of performance for the Group 5/6 measurements made in late February and early March.

\begin{tabular}{|c|c|c|c|}
\hline Size Range: & \multicolumn{3}{|l|}{$1-10 \mu \mathrm{m}$} \\
\hline Catalogue \#: & \multicolumn{3}{|l|}{ PS-192 } \\
\hline Bottle \# & \multicolumn{3}{|l|}{02057} \\
\hline Weight: & \multicolumn{3}{|l|}{$0.10 \mathrm{~g}$} \\
\hline PSD Percentiles & List & Measured* & Absolute Error \\
\hline $\mathrm{d}(10):$ & $2.88 \pm 0.24 \mu \mathrm{m}$ & $2.56 \mu \mathrm{m}$ & $\mathrm{n} / \mathrm{a}$ \\
\hline d(50): & $4.18 \pm 0.34 \mu \mathrm{m}$ & $4.29 \mu \mathrm{m}$ & $2.6 \%$ \\
\hline $\mathrm{d}(90):$ & $6.23 \pm 0.56 \mu \mathrm{m}$ & $7.29 \mu \mathrm{m}$ & $\mathrm{n} / \mathrm{a}$ \\
\hline
\end{tabular}

Table 4. Properties of the NIST standard used to verify performance of the Malvern Mastersizer 2000 and performance check results. Performance check covers the period of performance for the Group 5/6 follow-up measurements made in July.

\begin{tabular}{|c|c|c|c|}
\hline Size Range: & \multicolumn{3}{|l|}{$1-10 \mu \mathrm{m}$} \\
\hline Catalogue \#: & \multicolumn{3}{|l|}{ PS-192 } \\
\hline Bottle \# & \multicolumn{3}{|l|}{02060} \\
\hline Weight: & \multicolumn{3}{|l|}{$0.10 \mathrm{~g}$} \\
\hline PSD Percentiles & List & Measured* & Absolute Error \\
\hline $\mathrm{d}(10):$ & $2.88 \pm 0.24 \mu \mathrm{m}$ & $2.52 \mu \mathrm{m}$ & $\mathrm{n} / \mathrm{a}$ \\
\hline $\mathrm{d}(50):$ & $4.18 \pm 0.34 \mu \mathrm{m}$ & $4.34 \mu \mathrm{m}$ & $3.7 \%$ \\
\hline d(90): & $6.23 \pm 0.56 \mu \mathrm{m}$ & $7.63 \mu \mathrm{m}$ & $\mathrm{n} / \mathrm{a}$ \\
\hline
\end{tabular}

The instrument performance check covering initial measurements of the Group 5/6 CUF sample particle size was run on February $29^{\text {th }}$, 2008. The performance check for the follow-up measurements was run on July $16^{\text {th }}$, 2008. Performance check results were recorded to the Malvern file "2008-02feb29Group 5_6 CUF PSD.mea” and “2008-06June16-Group 5_6 CUF PSD.mea”. Particle size standards from Whitehouse are supplied as $0.10 \mathrm{~g}$ single shots of dry powder that must be dispersed in deionized water in order to achieve the appropriate distribution of particles. Dispersion is accomplished by first adding the entire contents of the particle size standard bottle ( $\sim .10 \mathrm{~g}$ dry powder) to the flow cell and then by subsequently applying mechanical agitation (via the flow cell pump) and sonication. A continuous pump speed of 2500 RPM was set to mix the flow cell contents. This pump speed was maintained through both powder dispersion and size measurement. As recommended by Whitehouse Scientific, the particle size standard dispersion was sonicated to eliminate particle aggregates. Sonication was carried out at $75 \%$ power for 5 minutes.

Both performance check size analyses employed a particle refractive index and absorption of 1.544 and 0 , respectively, and a suspending phase particle refractive index of 1.33 (for water). An average of three post-sonication measurements of the particle size distribution indicated a d(50) of $\sim 4.3$ $\mu \mathrm{m}$ for both checks, which deviates less than $4.0 \%$ from the $\mathrm{d}(50)$ listed on the standard's certificate of 
analysis from Whitehouse Scientific and is also within the range provided on the certificate. As such, acceptable instrument performance was verified for both periods of measurement applicable to this report.

\section{Sample Handling}

The samples associated with Group 5/6 CUF testing were analyzed "as-is”. No additional sample treatments were performed after sample receipt with exception of the mechanical agitation and resuspension of any settled solids at the time of analysis. Samples were received in February and stored in the radioactive material area (RMA) in RPL Room 302. Immediately before analysis, samples were unpackaged and transferred into the CA fume hood, where they remained until the completion of analysis in July.

\section{Experimental}

A series of particle size measurements covering a range of flow rates and sonication conditions was performed for each sample. All measurements were performed in $0.01 \mathrm{M}$ sodium hydroxide solution. PSD characterization for each sample was accomplished as follows:

1. The analyzer was drained, flushed with $20 \mathrm{~mL}$ of deionized (DI) water at least three times, filled with $20 \mathrm{~mL}$ inhibited water, and brought into a measurement ready state.

2. The analyzer flow cell pump was set to 3000 RPM with no sonication.

3. The material (sample) and suspending phase optical properties were set in the analyzer software (see Table 5).

4. The sample was prepared for analysis by re-suspending the settled solids. This was accomplished by repeatedly pulsing the samples with a $10 \mathrm{~mL}$ disposable plastic pipette until the contents were uniformly dispersed. Each pulse involved drawing off a fraction of the sample into the pipette and immediately jetting the drawn liquid back into the sample vial.

5. Immediately after re-suspension, the sample dispersion was added drop-wise to the instrument (while the pump was active) until the appropriate laser obscuration was achieved. Obscurations ranging from 3.5 to 35\% were considered acceptable. For the current analyses, an obscuration of $18-20 \%$ was targeted. The analyzer typically required 10 to $20 \mathrm{mg}$ of solids to reach the desired obscuration in the $20 \mathrm{~mL}$ flow cell.

6. The sample PSD was measured under the conditions outlined in the sample test matrix (see Table $6)$.

As indicated in the analysis outline above, the optical properties, such as the refractive index (RI) of the sample and suspending phase must be entered into analyzer. Because the exact optical properties of the tank waste solids are unknown, the optical properties of the most prevalent species will be used. For precaustic leach waste samples (TI552-G6-3-PSD and TI552-G6-6-PSD), the most prevalent mineral phase is boehmite. For post-caustic leach waste solids (TI552-G6-11-PSD and later), uranium-bearing species were assumed to be the most prevalent at the time of analysis based on analytical from Group 5 CUF testing samples . Post-leach uranium-bearing phases were assumed to be uranium dioxide $\left(\mathrm{UO}_{2}\right)$ for simplicity and because of the availability of its RI. Both boehmite and $\mathrm{UO}_{2}$ are assumed opaque (i.e., their absorption indexes are 1.0). A summary of material optical properties is provided in Table 5.

It should be noted that upon receipt of analytical results for Group 5/6, it was determined that boehmite was still the most prevalent mineral species in the post-leach PSD samples (TI552-G6-11-PSD and later). Use of a uranium oxide properties (as well as a single species refractive index) to represent the optical properties of the mixture of solid species and mineral phase in the tank waste is not exact. 
However, given the species diversity in the sample and tendency for tank waste particles to aggregate, the measurement analysis still provides an adequate representation of the apparent particle size of the wastes. As discussed in Appendix B of WTP/RPP-MOA-PNNL-00079 [4], use of the correct optical properties (in particular the RI) only serves to refine the distribution. And correction of assumed refractive indexes to a more accurate value may not significantly alter the particle size distribution determined by the original analysis. As such, use of boehmite and uranium oxide optical properties for the Group 5/6 CUF sample data analysis should provide a reasonable representation of the "actual” PSD.

Table 5. Material and suspending optical properties used for measurement of Group 5/6 CUF testing PSD.

\begin{tabular}{|c|c|c|c|c|}
\hline Sample Name & $\begin{array}{l}\text { Characterization } \\
\text { Step }\end{array}$ & $\begin{array}{l}\text { Material Selected } \\
\text { for Optical } \\
\text { Properties }\end{array}$ & $\begin{array}{l}\text { Refractive } \\
\text { Index (RI) }\end{array}$ & Absorption \\
\hline TI552-G6-3-PSD & Measurement & Boehmite & 1.655 & 1.0 \\
\hline TI552-G6-6-PSD & Measurement & Boehmite & 1.655 & 1.0 \\
\hline TI552-G6-11-PSD & Measurement & $\begin{array}{c}\text { Uranium Oxide } \\
\left(\mathrm{UO}_{2}\right)\end{array}$ & 2.4 & 1.0 \\
\hline TI552-G6-16-PSD & Measurement & $\begin{array}{l}\text { Uranium Oxide } \\
\left(\mathrm{UO}_{2}\right)\end{array}$ & 2.4 & 1.0 \\
\hline TI552-G6-21-PSD & Measurement & $\begin{array}{c}\text { Uranium Oxide } \\
\left(\mathrm{UO}_{2}\right)\end{array}$ & 2.4 & 1.0 \\
\hline TI552-G6-26-PSD & Measurement & $\begin{array}{c}\text { Uranium Oxide } \\
\left(\mathrm{UO}_{2}\right)\end{array}$ & 2.4 & 1.0 \\
\hline TI552-G6-32-PSD & Measurement & $\begin{array}{c}\text { Uranium Oxide } \\
\left(\mathrm{UO}_{2}\right)\end{array}$ & 2.4 & 1.0 \\
\hline Suspending Phase & All & Water & 1.33 & $\mathrm{n} / \mathrm{a}$ \\
\hline \multicolumn{5}{|c|}{$\begin{array}{l}\text { a See Ref Malvern Instruments Ltd., April } 1997 \\
\text { b See Ref Kaminski et al., } 2005\end{array}$} \\
\hline
\end{tabular}

The size distribution of particles was measured under various flow conditions prior-to and after sonication. Size distribution was measured at a single pump speed during sonication. Table 6 outlines the test matrix performed for all sample measurements. For each condition, three successive 1-minute measurements of PSD were taken consisting of a 20-second red-light scattering signal collection, a 20 second blue-light scattering signal collection, and a 20 -second hold period before the next measurement. Overall, the measurement period at each condition lasted approximately 3 minutes. After completion of the measurements, an average of the PSD results was then generated by the analyzer software. Both individual and averaged PSDs were saved to the analyzer data file. Finally, the flow rate and/or sonic power for the next condition were set, the sample was given approximately 30 seconds to equilibrate, and the next set of measurements were taken. The time to run the entire series of test condition for each sample was typically 30-40 minutes. 
Table 6. Particle size analysis test matrix used for Group 5/6 CUF samples.

\begin{tabular}{||c|c|c|c||}
\hline Condition No. & $\begin{array}{c}\text { Pump Speed } \\
\text { (RPM) }\end{array}$ & Sonic Power & Comment \\
\hline 1 & 3000 & $0 \%$ & pre-sonic measurement \\
\hline 2 & 2000 & $0 \%$ & pre-sonic measurement \\
\hline 3 & 4000 & $0 \%$ & pre-sonic measurement \\
\hline 4 & 3000 & $25 \%$ & sonicated measurement \\
\hline 5 & 3000 & $50 \%$ & sonicated measurement \\
\hline 6 & 3000 & $75 \%$ & sonicated measurement \\
\hline 7 & 3000 & $0 \%$ & post-sonic measurement \\
\hline 8 & 2000 & $0 \%$ & post-sonic measurement \\
\hline 9 & 4000 & $0 \%$ & post-sonic measurement \\
\hline
\end{tabular}

\section{Results and Discussion}

This section presents and discusses particle size analysis results for Group 5/6 CUF testing samples in the order listed in Table 1. Group 5/6 CUF samples are a mixture of both Group 5 (REDOX) and Group 6 (S-Saltcake) waste types, and as such, it is useful to review previous PSD results for these source materials before discussing Group 5/6 CUF testing samples. This will allow evaluation of the effects of mixing on the Group 5/6 mixture PSDs.

\subsection{Source Input Materials}

Before discussing PSD results for Group 5/6 CUF testing samples, the PSDs for Group 5 and 6 reference materials shall be introduced. Selection of a PSD for Group 5 material can draw from both initial characterization and previous CUF testing efforts. Because Group 5 is only introduced to the 5/6 mixture after a low-solids matrix test with pure Group 6 saltcake, the PSD measured for the pre-leach dewatered slurry (sample TI540-G5-6-PSD) from the Group 5 only CUF test shall be used as the reference PSD for comparison. Selection of a Group 6 slurry reference is more limited, as the only preleach Group 6 PSD measurements were performed on initial characterization samples. As such, the Group 6 PSD reference is that measured for the Group 6 initial characterization samples, TI490-G6-SWL-PSD-1 and -2. Finally, PSDs have been measured for the Group 5 caustic-leached, dewatered, and washed slurry (sample TI540-G5-16-PSD) introduced into the Group 5/6 mixture to form the combined leach slurry in the final stage of Group 5/6 CUF testing. The PSD for this Group 5 sample will be a point of comparison for the Group 5/6 combined leach slurry PSD. Beyond these initial comparisons, it is difficult to evaluate changes in Group 5/6 PSD as a result of CUF processing relative to previously measured PSD samples such as Group 5 CUF testing and Group 6 parametric testing samples because previous testing did not consider a waste mixture.

\section{Results for TI540-G5-6-PSD (Group 5 Pre-Leach Source)}

Sample TI540-G5-6-PSD (also termed high-solids matrix) is comprised of insoluble Group 5 waste solids that have been filtered in the CUF continuously at $4.3-\mathrm{wt} \%$ under full permeate recycle, dewatered to $15.5-\mathrm{wt} \%$, and subsequently filtered at 15.5 -wt $\%$ under full permeate recycle. The PSD of this sample is representative of the Group 5 material added to the CUF during mixing of Group 5 and 6 wastes in the initial dewater operations for the Group 5/6 CUF test slurry.

Table 7 shows the diameter percentiles as a function of measurement condition. For this sample, the $d(10)$ ranges from $0.48-0.64 \mu \mathrm{m}$, the $d(50)$ ranges from $2.2-2.9 \mu \mathrm{m}$, and the $d(90)$ ranges from $11-13$ 
$\mu \mathrm{m}$. Figure 2 shows the pre-sonic particle size distribution for sample TI540-G5-6-PSD as a function of pump speed. The distribution is broad, spanning 0.2 to $200 \mu \mathrm{m}$, with a peak population at around $2 \mu \mathrm{m}$. The $2 \mu \mathrm{m}$ peak dominates the distribution, but the higher flow rates suggest a bimodal distribution with a second population peak centered around 4-10 $\mu \mathrm{m}$. The majority of particles fall between 0.2 and $20 \mu \mathrm{m}$.

Table 7. Particle size analysis percentile results for TI540-G5-6-PSD.

\begin{tabular}{||c|c|c|c|c|c||}
\hline $\begin{array}{c}\text { Measurement } \\
\text { Condition }\end{array}$ & $\begin{array}{c}\text { Pump Speed } \\
{[\mathbf{R P M}]}\end{array}$ & Sonication & $\begin{array}{c}\mathbf{d}(\mathbf{1 0}) \\
{[\boldsymbol{\mu m}]}\end{array}$ & $\begin{array}{c}\mathbf{d}(\mathbf{5 0 )} \\
{[\boldsymbol{\mu \mathbf { m } ]}}\end{array}$ & $\begin{array}{c}\mathbf{d}(\mathbf{9 0}) \\
{[\boldsymbol{\mu m}]}\end{array}$ \\
\hline 1 & 3000 & pre-sonic & 0.64 & 2.3 & 12 \\
\hline 2 & 2000 & pre-sonic & 0.64 & 2.3 & 11 \\
\hline 3 & 4000 & pre-sonic & 0.60 & 2.2 & 13 \\
\hline 4 & 3000 & $25 \%$ & 0.50 & 2.2 & 12 \\
\hline 5 & 3000 & $50 \%$ & 0.48 & 2.6 & 11 \\
\hline 6 & 3000 & $75 \%$ & 0.48 & 2.9 & 11 \\
\hline 7 & 3000 & post-sonic & 0.48 & 2.8 & 11 \\
\hline 8 & 2000 & post-sonic & 0.50 & 2.7 & 11 \\
\hline 9 & 4000 & post-sonic & 0.49 & 2.7 & 12 \\
\hline
\end{tabular}

With regard to the influence of flow rate on the pre-sonication PSD, it appears that increased pump speed shears apart large aggregates as evidenced by the decrease in the population of particles greater than $100 \mu \mathrm{m}$ and the increase in the relative population of 20-100 $\mu \mathrm{m}$ aggregates as pump speed is increased from 2000 to 4000 RPM. At 4000 RPM, the distribution begins to show a slight decrease in the peak diameter of the primary population (peak shifts from $\sim 2 \mu \mathrm{m}$ down to $\sim 1.5 \mu \mathrm{m}$ ). An increase in the relative populations of both submicron and 5-10 $\mu \mathrm{m}$ particles and a decrease in relative population of 1-4 $\mu \mathrm{m}$ accompany this population peak downshift. Both changes can be attributed to shear breakage of aggregates at the higher pump speed setting. 


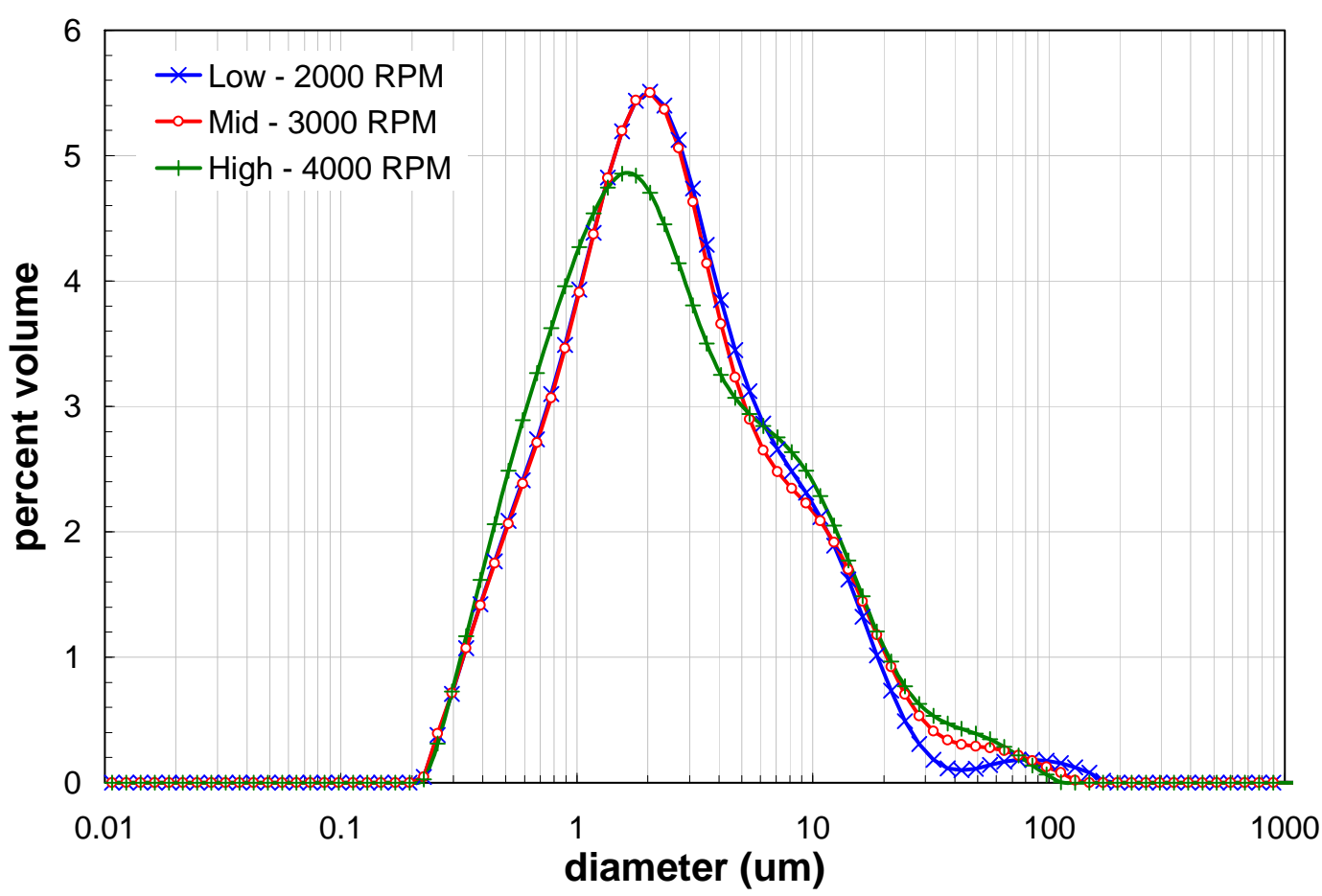

Figure 2. Measured particle size distribution for sample TI540-G5-6-PSD as a function of pump speed before sonication.

Figure 3 shows the particle size distribution for sample TI540-G5-6-PSD as a function of sonication. Application of sonic energy induces the same aggregate restructuring observed in the previous samples. In addition, sonication eliminates particles / aggregates larger than $30 \mu \mathrm{m}$. Relative to previous PSD results, the distribution for sample TI540-G5-6-PSD is more strongly bimodal (i.e., the submicron and 2-30 $\mu \mathrm{m}$ population peaks are more distinct). For the current sample, it appears that submicron particles are either more prevalent or more stable. This is most likely a result of prolonged shear in the CUF.

Figure 4 shows the post-sonic particle size distribution for sample TI540-G5-6-PSD as a function of pump speed. This particle size distribution appears insensitive to changes in the pump speed. The only significant change observed is the appearance of a 30-200 $\mu \mathrm{m}$ fraction at $4000 \mathrm{RPM}$. This fraction may be comprised of dense, difficult to suspend aggregates that remain after sonication. 


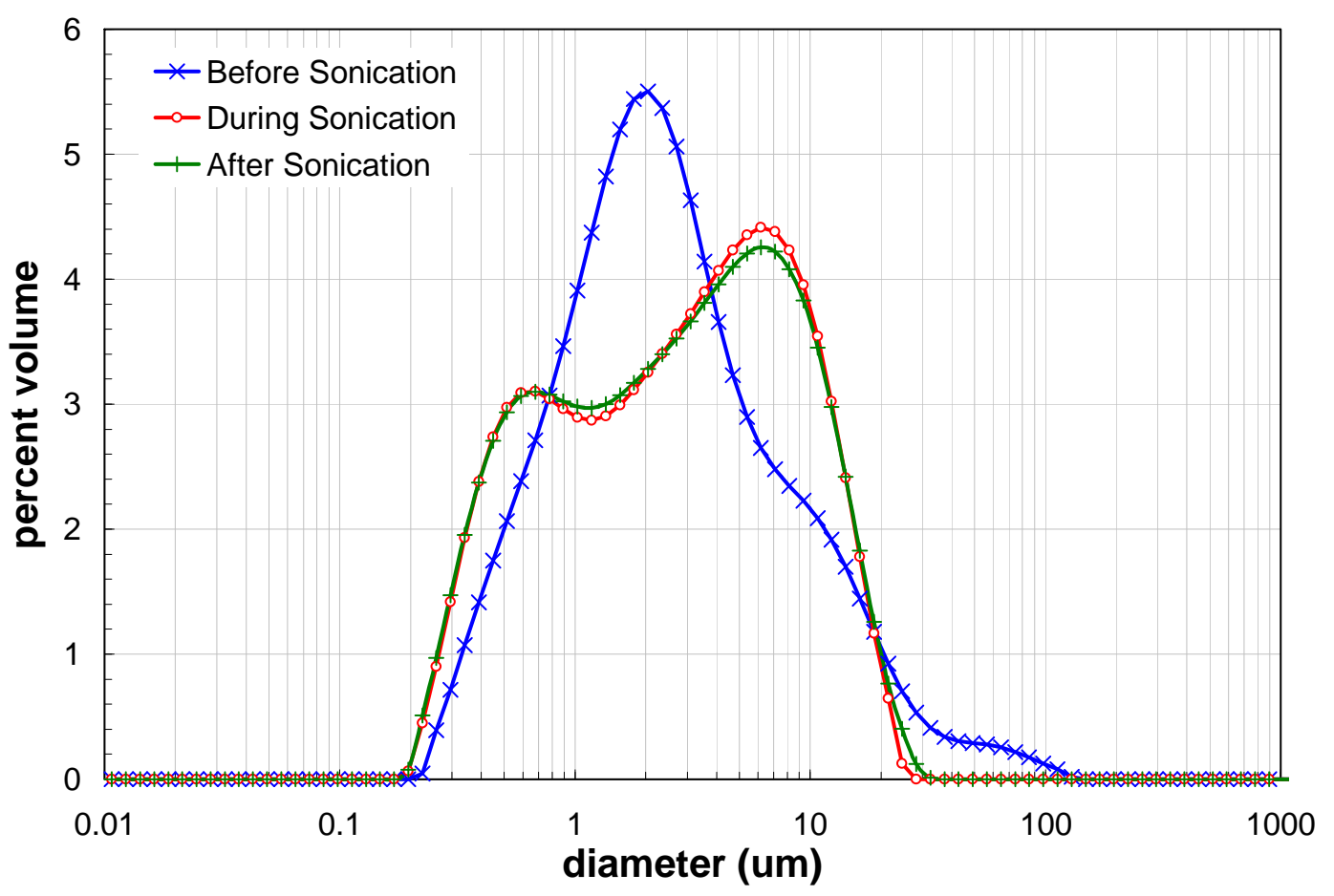

Figure 3. Measured particle size distribution for sample TI540-G5-6-PSD before, during, and after sonication.

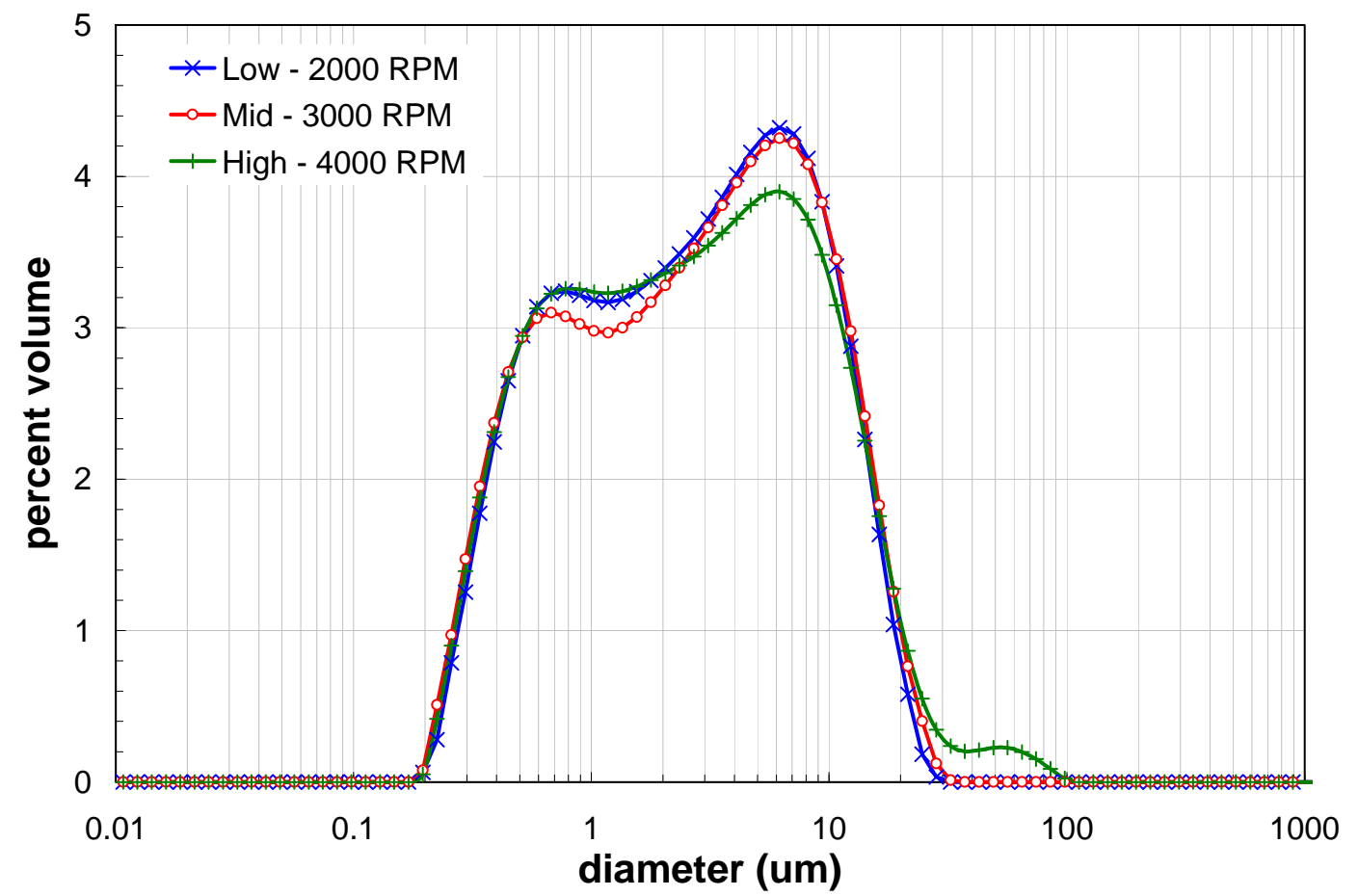

Figure 4. Measured particle size distribution for sample TI540-G5-6-PSD as a function of pump speed after sonication. 
Results for TI490-G6-S-WL-PSD-1 and -2 (Group 6 Pre-Leach Source)

Table 8 is a summary of the particle size measurements for the Group 6 (S-Saltcake) initial characterization primary and duplicate PSD samples. Here, the $\mathrm{d}(10), \mathrm{d}(50)$, and $\mathrm{d}(90)$ diameters are listed as a function of test condition. These measurements did not examine the effects of pump speed. A single pump speed of 3000 RPM was employed for all PSD characterizations.

The S-Saltcake initial characterization samples exhibit d(50) that range from 2.4 to $4.7 \mu \mathrm{m}, \mathrm{d}(10)$ that range from 0.66 to $0.82 \mu \mathrm{m}$, and $\mathrm{d}(90)$ that range from 8.7 to $59 \mu \mathrm{m}$. For both duplicate and primary samples, pre-sonication d(90)'s appear to be reduced by a factor two by the application of sonic power. The reduction in size continues through the duration of sonication. Immediately after sonic power is shut off, the primary sample shows a dramatic increase in both $d(50)$ and $d(90)$. The duplicate sample shows similar behavior, but to a much lesser degree. Specifically, whereas the primary $d(90)$ jumped from 11 to $59 \mu \mathrm{m}$ once sonication is stopped, the duplicate $\mathrm{d}(90)$ only increased from 8.7 to $10 \mu \mathrm{m}$. With regard to the $\mathrm{d}(50)$, the primary sample increases from $3.1 \mu \mathrm{m}$ up to $4.7 \mu \mathrm{m}$ while the duplicate only jumps from $2.4 \mu \mathrm{m}$ to $2.7 \mu \mathrm{m}$.

Table 8. Summary of results for Group 6 particle size analysis.

\begin{tabular}{||l|c|c|c|c|c||}
\hline Sample & $\begin{array}{c}\text { Pump Speed } \\
{[\text { RPM] }}\end{array}$ & Sonication & $\begin{array}{c}\mathbf{d}(\mathbf{1 0}) \\
{[\boldsymbol{\mu m}]}\end{array}$ & $\begin{array}{c}\mathbf{d}(\mathbf{5 0}) \\
{[\boldsymbol{\mu m}]}\end{array}$ & $\begin{array}{c}\mathbf{d}(\mathbf{9 0}) \\
{[\boldsymbol{\mu \mathbf { m } ]}}\end{array}$ \\
\hline Group 6 - Primary & 3000 & pre-sonic & 0.77 & 3.1 & 40 \\
\cline { 2 - 6 } & 3000 & $25 \%$ & 0.74 & 3.0 & 14 \\
\cline { 2 - 6 } & 3000 & $50 \%$ & 0.77 & 3.3 & 12 \\
\cline { 2 - 6 } & 3000 & $75 \%$ & 0.71 & 3.1 & 11 \\
\cline { 2 - 6 } & 3000 & post-sonic & 0.82 & 4.7 & 59 \\
\hline \multirow{3}{*}{ Group 6 - Duplicate } & 3000 & pre-sonic & 0.74 & 3.1 & 19 \\
\cline { 2 - 7 } & 3000 & $25 \%$ & 0.70 & 2.4 & 9.3 \\
\cline { 2 - 6 } & 3000 & $50 \%$ & 0.69 & 2.4 & 9.3 \\
\cline { 2 - 6 } & 3000 & $75 \%$ & 0.66 & 2.4 & 8.7 \\
\cline { 2 - 6 } & 3000 & post-sonic & 0.76 & 2.7 & 10 \\
\hline
\end{tabular}

Comparatively, the percentiles listed for the primary and duplicate samples for Group 6 typically show relative percent differences greater than $20 \%$. The duplicate sample results show $d(50)$ and $d(90)$ values $55 \%$ to $88 \%$ lower than the corresponding primary sample percentiles. While these are large differences, they should be expected for tank wastes as the sampling protocol used in PSD analysis can influence the results dramatically. Differences in primary and duplicate sample could have occurred during the initial sample split (although significant effort was undertaken to minimize sampling error) or during sampling for analysis. As shown in the population graphs in the following pages, the Group 6 initial characterization samples contain particles ranging from 0.2 to $100 \mu \mathrm{m}$. The larger end of this range, $10-100 \mu \mathrm{m}$, tend to settle very quickly after uniform dispersion: the Stoke's settling velocities for $2.5 \mathrm{~g} / \mathrm{cc}$ particles 10 and $100 \mu \mathrm{m}$ in diameter are $0.1 \mathrm{~mm} / \mathrm{s}$ and $10 \mathrm{~mm} / \mathrm{s}$, respectively. This introduces the possibility of significant size segregation during sample preparations, during retrieval for analysis, and during the size analysis. As discussed in later sections of this report, even the conditions selected for particle size analysis have a profound impact on reproducibility (see discussion for sample TI552-G6-21PSD). 
Figures 5 and 6 show the particle size distributions before, during, and after sonication for Group 6 primary and duplicate samples, respectively. Both samples show relatively similar size distributions between $0.3 \mu \mathrm{m}$ and $20 \mu \mathrm{m}$. With regard to this range, the distribution prior to sonication shows a maximum population around $1.5 \mu \mathrm{m}$ for both primary and duplicate sample. After this peak, the population gradually decreases until $10 \mu \mathrm{m}$, after which a sharp reduction is observed. As observed in the Group 5 particle size measurements, the application of sonic power increases the fraction of 8-10 $\mu \mathrm{m}$ particles for both primary and duplicate samples. Although the primary sample distribution between 0.3$20 \mu \mathrm{m}$ is more strongly affected than the duplicate distribution in this range, both samples appear to become slightly bimodal. While the increase could suggest aggregate restructuring, it is more likely a result of break-down of the large aggregate peak that is present in the pre-sonication measurement ( 60 $\mu \mathrm{m})$ but disappears during sonication. This is discussed in more detail in the following paragraph.

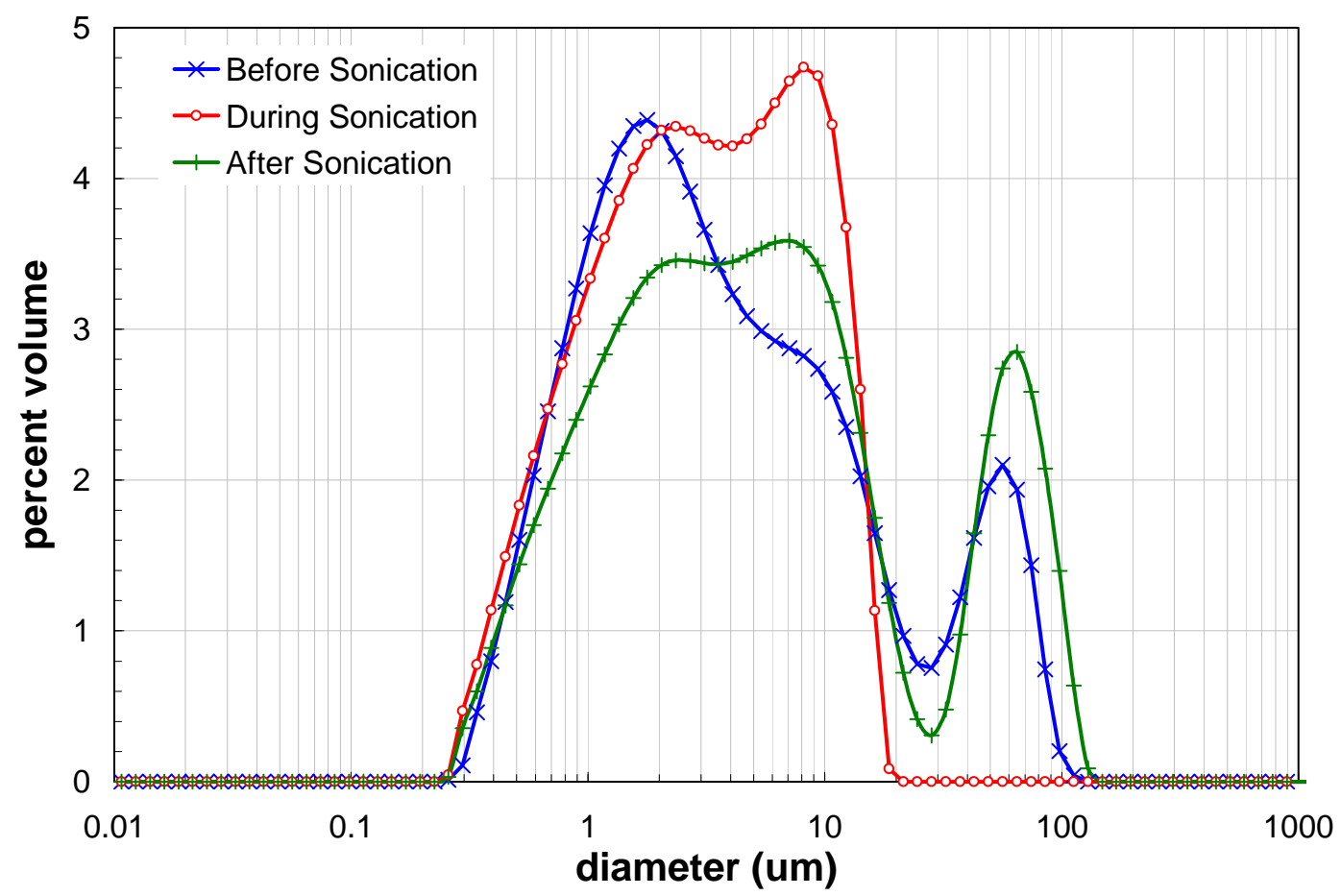

Figure 5. Group 6 primary sample particle size distributions (volume/weight basis) before, during, and after sonication. 


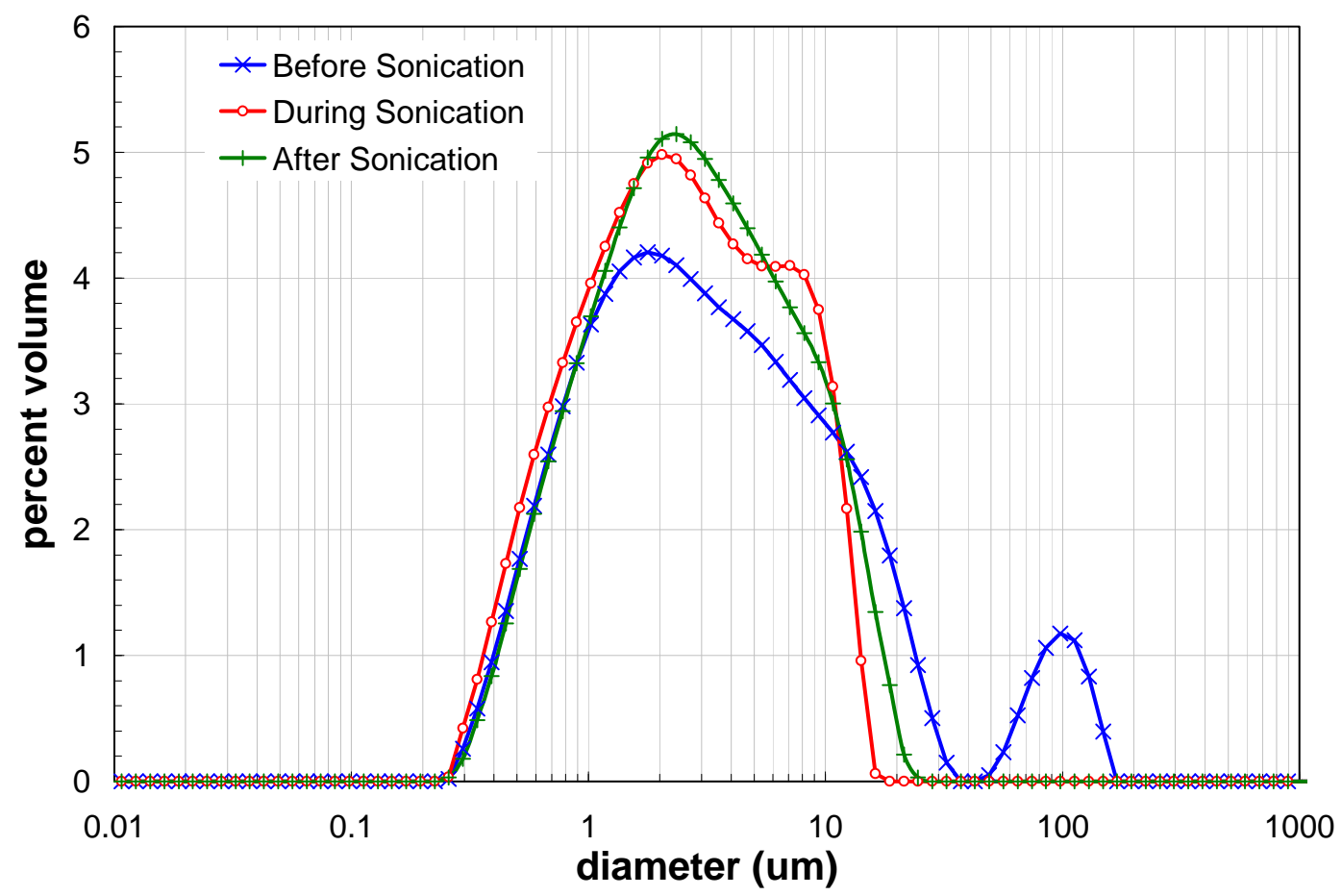

Figure 6. Group 6 duplicate sample particle size distributions (volume/weight basis) before, during, and after sonication.

With regard to the upper range of particle sizes, pre-sonication measurements show a welldefined peak at $\sim 60 \mu \mathrm{m}$ for the primary sample and $\sim 100 \mu \mathrm{m}$ for the duplicate sample. The disappearance of these peaks upon sonication in both cases suggests that these peaks correspond to particle aggregates. After sonication, the aggregate peak reforms for the primary sample distribution, but does not reform in the duplicate sample distribution.

Results for TI540-G5-16-PSD (Post-Leached, Dewatered and Washed - Source Material for the Combined Leach Slurry)

Sample TI540-G5-16-PSD is comprised of insoluble Group 5 waste solids that have been leached in a concentrated sodium hydroxide solution for 24 hours at $100{ }^{\circ} \mathrm{C}$, dewatered to 13.5 -wt $\%$ solids, and washed with dilute hydroxide solutions to a final solids concentration of 4.1-wt\%. This Group 5 slurry is representative of Group 5 material mixed with the oxidative-leached and washed Group 5/6 slurry to form the combined leach slurry. Although the PSD for Group 5 sample TI540-G5-16-PSD would be a useful reference for the combined leach slurry PSD, the distributions measured for this sample were severely impacted by a scattering signal artifact referred to as the "odd-even" effect. The "odd-even" effect is usually associated with poorly aligned laser-optics systems. However, this was not the case for the measurement of sample TI540-G5-16-PSD, because a) the laser was aligned to vendor specifications in July of 2007, b) the system passed its auto-align test, c) the PSD characterizations for samples TI540-G53-PSD and TI540-G5-6-PSD, performed immediately before TI540-G5-16-PSD, were successful, and d) measurements immediately after introduction of sample to the flow cell did not show the "odd-even" effect. As such, degradation of the scattering signal appears to be associated with this sample and is suggestive of instability with respect to particle aggregation and sticking. Because the PSD for sample 
TI540-G5-16-PSD is suspect, comparison of the combined leached slurry PSD measured in the current report to this Group 5 CUF PSD will be avoided.

\subsection{Group 5/6 CUF Testing PSD Results}

The following sub-sections discuss the PSD results for Group 5/6 CUF testing samples in detail. A brief outline of how select cumulative oversize diameter percentiles behave as a function of test condition is given, and graphs of particle size distributions are given as a function of flow rate before and after sonication and at 3000 RPM before, during, and after sonication. In general, the reproducibility of PSD is not assessed with exception of the analysis for sample TI552-G6-21-PSD (which is an oxidativeleached and dewatered Group 5/6 slurry). A single sample of TI552-G6-21-PSD was received and tested twice, yielding an "initial" and "replicate" PSD measurement. The appendix to this report provides an expanded list of cumulative oversize diameter percentiles as a function of test condition.

\section{Results for TI552-G6-3-PSD (Initial Low-Solids Slurry)}

Sample TI552-G6-3-PSD is comprised of insoluble Group 6 (S-Saltcake) source material that has been diluted to 3.2-wt\% for the low-solids matrix CUF filtration tests. Table 9 shows the diameter percentiles as a function of measurement condition. For this sample, the $d(10)$ ranges from $0.68-0.84 \mu \mathrm{m}$, the $\mathrm{d}(50)$ ranges from 2.3-5.3 $\mu \mathrm{m}$, and the $\mathrm{d}(90)$ ranges from 8.6-65 $\mu \mathrm{m}$. The PSD before sonication appears to be influenced by analysis pump speed. As the pump is increased from 3000 to $4000 \mathrm{RPM}$, an increase in the $\mathrm{d}(50)$ from 3.6 to $5.3 \mu \mathrm{m}$ is observed. This increase is greater than $10 \%$, and as such, is probably statistically significant. Likewise, when the pump speed is decreased to $2000 \mathrm{RPM}$, the presonic d(50) decreases from 3.6 to $3.1 \mu \mathrm{m}$ (relative to $3000 \mathrm{RPM}$ ). This decrease is also greater than $10 \%$, and statistically significant. Both the increase in d(50) at 4000 RPM and the decrease at 2000 RPM relative to the 3000 RPM d(50) are indicative of "difficult-to-suspend" particle population. At higher pump speeds, these difficult-to-suspend particles are increasingly suspended and sampled in the laser scattering signal (thus appearing on the PSD in greater volume contributions).

Table 9. Particle size analysis percentile results for TI552-G6-3-PSD.

\begin{tabular}{||c|c|c|c|c|c||}
\hline $\begin{array}{c}\text { Measurement } \\
\text { Condition }\end{array}$ & Pump Speed & Sonication & $\begin{array}{c}\mathbf{d}(\mathbf{1 0}) \\
{[\boldsymbol{\mu m}]}\end{array}$ & $\begin{array}{c}\mathbf{d}(\mathbf{5 0}) \\
{[\boldsymbol{\mu m}]}\end{array}$ & $\begin{array}{c}\mathbf{d}(\mathbf{9 0}) \\
{[\boldsymbol{\mu m}]}\end{array}$ \\
\hline 1 & 3000 & pre-sonic & 0.78 & 3.6 & 13 \\
\hline 2 & 4000 & pre-sonic & 0.84 & 5.3 & 65 \\
\hline 3 & 2000 & pre-sonic & 0.78 & 3.1 & 12 \\
\hline 4 & 3000 & $25 \%$ & 0.75 & 2.8 & 10 \\
\hline 5 & 3000 & $50 \%$ & 0.72 & 2.6 & 9.8 \\
\hline 6 & 3000 & $75 \%$ & 0.74 & 2.5 & 8.9 \\
\hline 7 & 3000 & post-sonic & 0.70 & 2.4 & 8.6 \\
\hline 8 & 4000 & post-sonic & 0.68 & 2.9 & 14 \\
\hline 9 & 2000 & post-sonic & 0.71 & 2.3 & 8.6 \\
\hline
\end{tabular}

Sonication of the particle dispersion appears to reduce particle size. The $d(50)$ decreases from 3.6 $\mu \mathrm{m}$ before sonication, to $2.5 \mu \mathrm{m}$ during sonication and to $2.4 \mu \mathrm{m}$ after sonication. This decrease is likely a result of disruption of particle agglomerates during sonication. After sonication, the PSD responds to changes in pump speed as it did before sonication but to a much lesser degree. The increase in post-sonic $\mathrm{d}(50)$ is still significant as pump speed changes from 3000 to 4000 RPM. In contrast, d(50) shows a minor (insignificant) drop from 2.4 to $2.3 \mu \mathrm{m}$ as the pump speed is lowered from 3000 to $2000 \mathrm{RPM}$. 
This suggests a reduction in the population of "difficult-to-suspend" particles and that the "particles" were likely large agglomerates disrupted by sonication.

Figure 7 shows the pre-sonic PSD for sample TI552-G6-3-PSD as a function of pump speed. The distribution at 3000 RPM is broad, spanning from just above $0.2 \mu \mathrm{m}$ to just below $30 \mu \mathrm{m}$. It appears to be comprised of two overlapping particle populations with peaks centered at 2 and $7 \mu \mathrm{m}$. At high pump speeds (4000 RPM), the analyzer appears to suspend a third particle population spanning 20 to $200 \mu \mathrm{m}$ with a peak population ranging from 60 to $70 \mu \mathrm{m}$. At low pump speeds (2000 RPM), the upper bound of PSD is reduced from $30 \mu \mathrm{m}$ to just above $20 \mu \mathrm{m}$, and the $7 \mu \mathrm{m}$ particle peak disappears. The results indicate a relatively difficult-to-suspend particle population starting near $7 \mu \mathrm{m}$ and spanning up to 200 $\mu \mathrm{m}$.

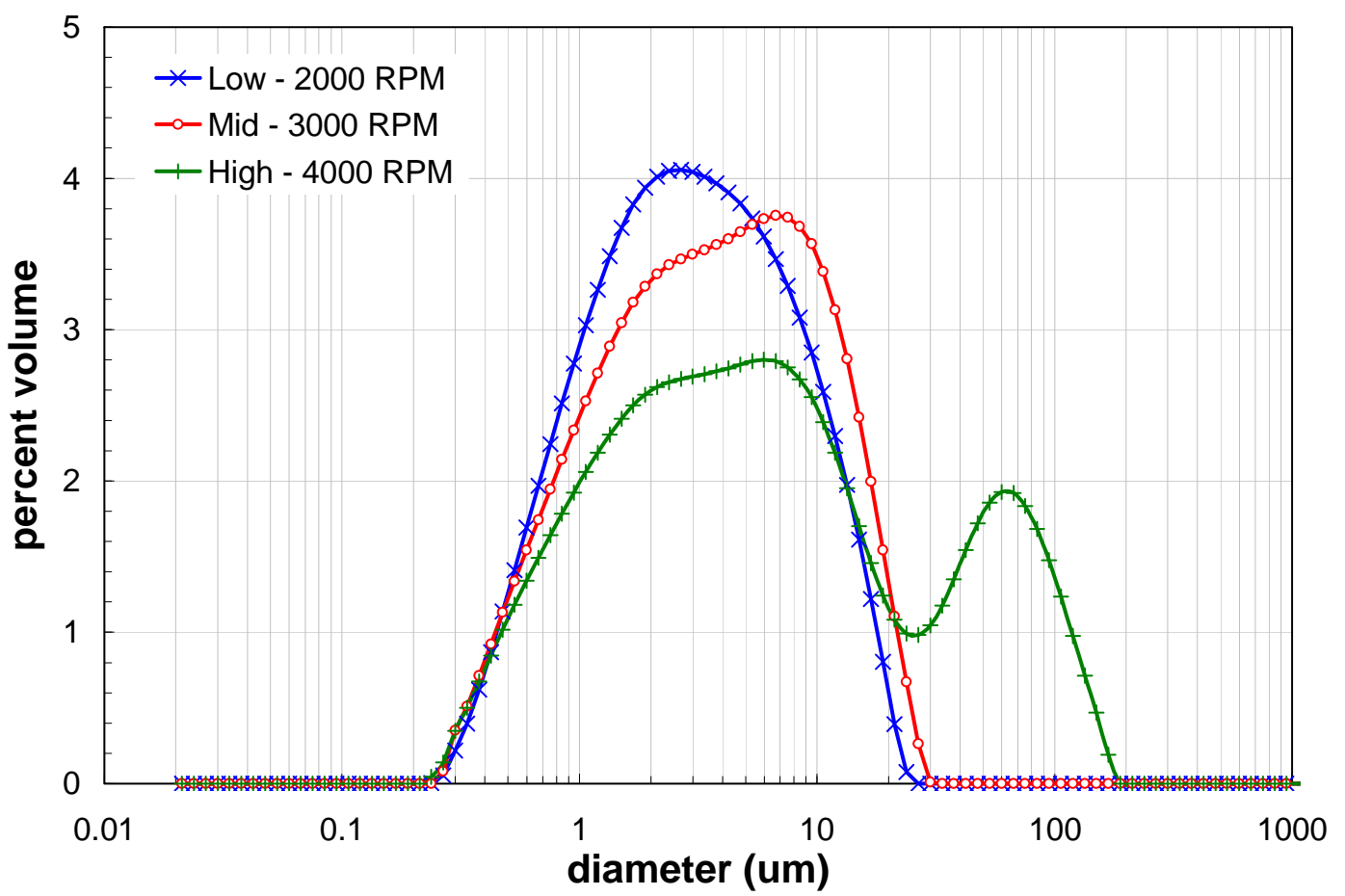

Figure 7. Measured particle size distribution for sample TI552-G6-3-PSD as a function of pump speed before sonication.

Figure 8 shows the particle size distribution for sample TI552-G6-3-PSD before, during, and after sonication. Sonication appears to eliminate the population that peaks at $7 \mu \mathrm{m}$. The changes observed in PSD upon sonication of the dispersion are similar to those observed in the pre-sonic PSD as pump speed was decreased to 2000 RPM. This change indicates that the solid species associated with the population peaking at $7 \mu \mathrm{m}$ are primary particles or agglomerates that are disrupted when sonic energy is applied. This disruption appears to be irreversible on the time scale of PSD measurements, as the $7 \mu \mathrm{m}$ peak population does not appear to recover in the post-sonic PSD.

Figure 9 shows the post-sonic PSD for sample TI552-G6-3-PSD as a function of pump speed. The distributions at low (2000 RPM) and mid (3000 RPM) pump speeds are statistically similar, 
indicating that the state of suspension is similar in both measurements. This could indicate that the majority of difficult-to-suspend particles / agglomerates were eliminated; however, there is some recovery of the $7 \mu \mathrm{m}$ and greater than $30 \mu \mathrm{m}$ particle peaks at high pump speeds $4000 \mathrm{RPM}$. With regard to the $>30 \mu \mathrm{m}$ particles, sonication appears to have significantly reduced or eliminated particles in this range, as the upper bound is now $\sim 80 \mu \mathrm{m}$ (relative to $200 \mu \mathrm{m}$ before sonication) and the peak is $40 \mu \mathrm{m}$ (relative to $\sim 65 \mu \mathrm{m}$ before sonication). Both particles in this larger size range and those at $7 \mu \mathrm{m}$ may be agglomerates that have survived sonication or stable particles.

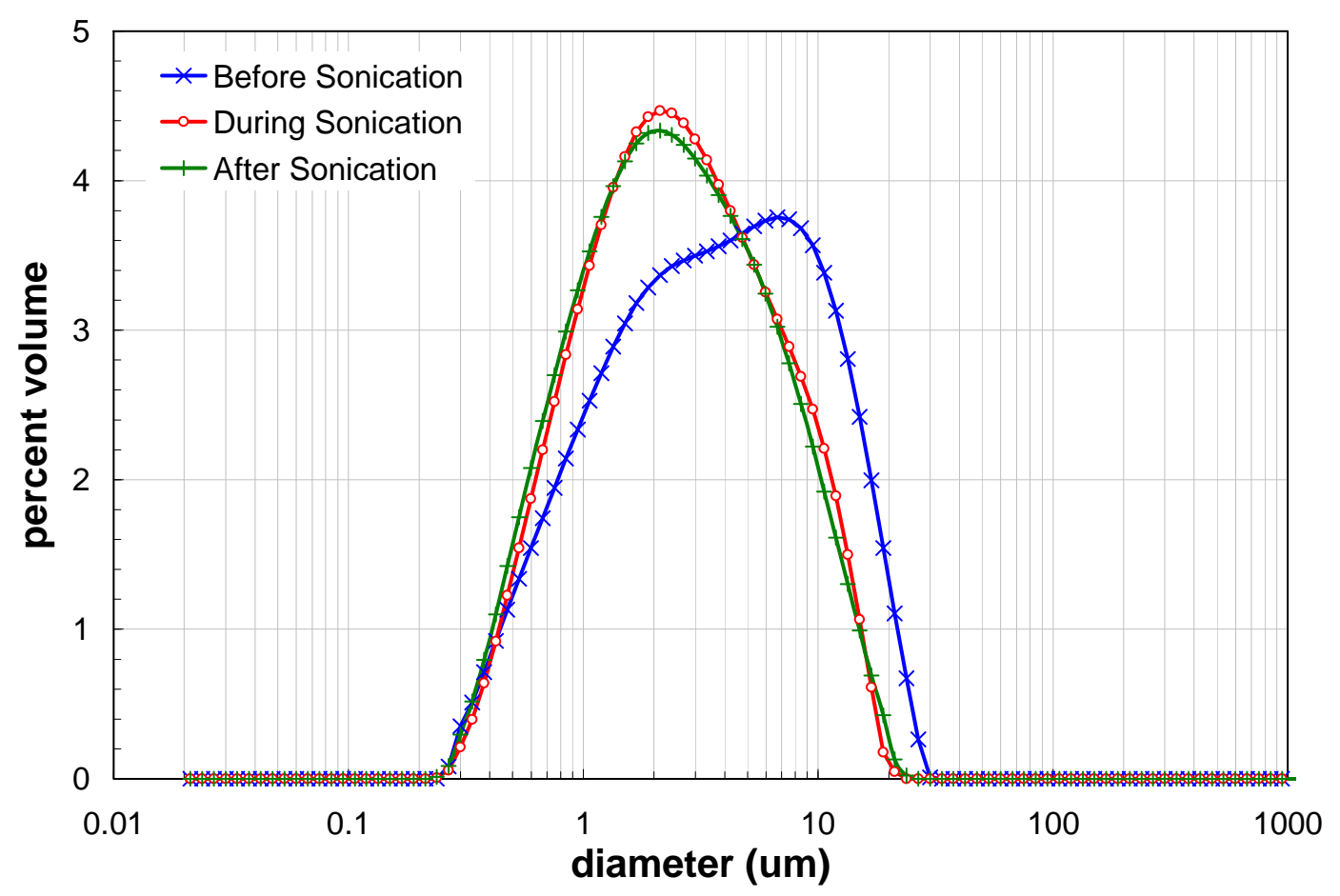

Figure 8. Measured particle size distribution for sample TI552-G6-3-PSD at a single pump speed before, during, and after sonication. 


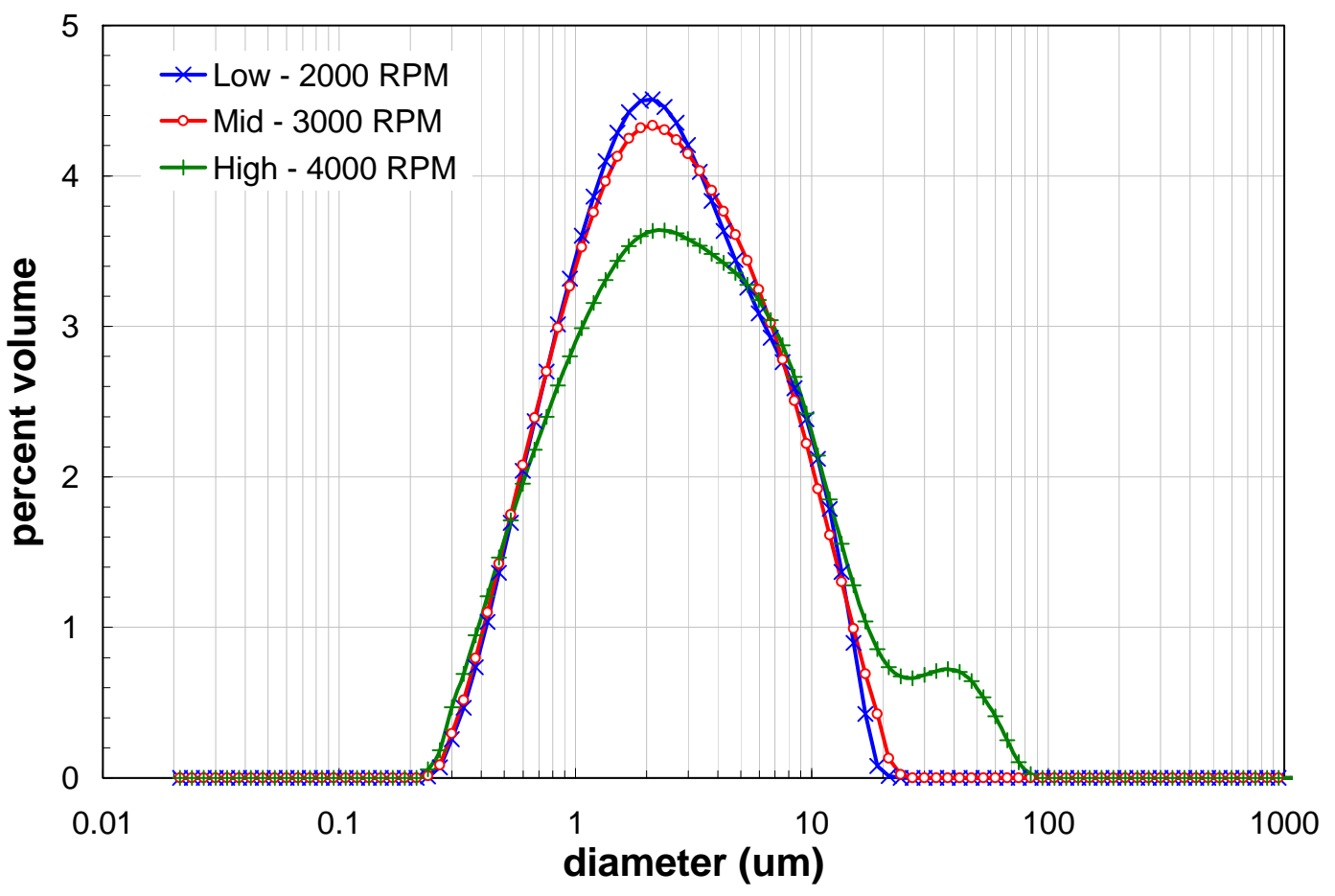

Figure 9. Measured particle size distribution for sample TI552-G6-3-PSD as a function of analyzer pump speed after sonication.

In summary, sample TI552-G6-3-PSD has a particle population spanning from $\sim 0.2 \mu \mathrm{m}$ up to 200 $\mu \mathrm{m}$, with population peaks at 2, 7, and $\sim 65 \mu \mathrm{m}$. Some of the particles in the dispersion can only be suspended at high flows in the particle size analyzer, indicating the presence of difficult-to-suspend single particle species or agglomerates (in terms of the analyzers capabilities). Disruption of these large particle species is observed upon the application of sonic energy. This disruption is irreversible in the time frame tested. After sonication, the distribution of particles ranges from 0.2 to $\sim 80 \mu \mathrm{m}$, with population peaks at 2 and $40 \mu \mathrm{m}$.

\section{Results for TI552-G6-6-PSD (Initial High-Solids Slurry)}

Sample TI552-G6-6-PSD results from dewatering the initial dilute Group 6 only slurry and adding Group 5 insoluble solids. Mixing and dewatering form a concentrated (13.2-wt\%) Group 5/6 mixed slurry that is used in the high-solids matrix filtration tests. Table 10 shows the diameter percentiles as a function of measurement condition. For this sample, the $\mathrm{d}(10)$ ranges from $0.55-0.60 \mu \mathrm{m}$, the $\mathrm{d}(50)$ ranges from 2.6-2.9 $\mu \mathrm{m}$, and the $\mathrm{d}(90)$ ranges from 9.3-24 $\mu \mathrm{m}$. The pre-sonic $\mathrm{d}(50)$ appears relatively insensitive to changes in analyzer pump speed, indicating reasonable suspension of all particle species and sizes over all test conditions. Specifically, an increase in pump speed 3000 to 4000 RPM only increases the $\mathrm{d}(50)$ from 2.7 to $2.9 \mu \mathrm{m}$, a change of $\sim 10 \%$ (which is the limit of accuracy of these PSD analyses). Likewise, a decrease in pump speed from 3000 to 2000 RPM results in an insignificant decrease of $0.1 \mu \mathrm{m}$ in the $\mathrm{d}(50)$. In contrast, the $\mathrm{d}(90)$ does appear to increase significantly when pump speed is increased from 3000 to 4000 RPM, indicating the presence of large, difficult to suspend agglomerates. Sonication does not appear to impact either $\mathrm{d}(10)$ or $\mathrm{d}(50)$ values significantly. A reduction in the $d(90)$ is observed, and can be associated with disruption of the agglomerates. Although this disruption appears permanent, as the $d(90)$ does not recover to its pre-sonic levels after sonication, it 
does not appear to eliminate all of the large species, as a significant increase occurs in the post-sonic d(90) as pump speed is increased from 3000 to 4000 RPM.

Table 10. Particle size analysis percentile results for TI552-G6-6-PSD.

\begin{tabular}{||c|c|c|c|c|c||}
\hline $\begin{array}{c}\text { Measurement } \\
\text { Condition }\end{array}$ & Pump Speed & Sonication & $\begin{array}{c}\mathbf{d}(\mathbf{1 0}) \\
{[\boldsymbol{\mu \mathbf { m } ]}}\end{array}$ & $\begin{array}{c}\mathbf{d}(\mathbf{5 0}) \\
{[\boldsymbol{\mu \mathbf { m } ]}}\end{array}$ & $\begin{array}{c}\mathbf{d}(\mathbf{9 0}) \\
{[\boldsymbol{\mu} \mathbf{m}]}\end{array}$ \\
\hline 1 & 3000 & pre-sonic & 0.59 & 2.7 & 19 \\
\hline 2 & 4000 & pre-sonic & 0.58 & 2.9 & 24 \\
\hline 3 & 2000 & pre-sonic & 0.56 & 2.6 & 16 \\
\hline 4 & 3000 & $25 \%$ & 0.57 & 2.6 & 10 \\
\hline 5 & 3000 & $50 \%$ & 0.60 & 2.8 & 10 \\
\hline 6 & 3000 & $75 \%$ & 0.57 & 2.6 & 9.3 \\
\hline 7 & 3000 & post-sonic & 0.57 & 2.8 & 10 \\
\hline 8 & 4000 & post-sonic & 0.55 & 2.9 & 13 \\
\hline 9 & 2000 & post-sonic & 0.59 & 2.8 & 9.8 \\
\hline
\end{tabular}

Figure 10 shows the pre-sonic particle size distribution for sample TI552-G6-6-PSD as a function of pump speed. The distributions are broad and multimodal. At 3000 RPM, the PSD spans from $\sim 0.2 \mu \mathrm{m}$ to $500 \mu \mathrm{m}$ with distinct population peaks at $\sim 1.2,6,70$, and $400 \mu \mathrm{m}$. The majority of particles in the distribution fall between 0.2 and $200 \mu \mathrm{m}$. At low pump speeds (2000 RPM), the upper bound of this primary population range is reduced to $40 \mu \mathrm{m}$. At $3000 \mathrm{RPM}$, a population centered at $70 \mu \mathrm{m}$ appears and may be associated with difficult-to-suspend particles. At 4000 RPM, this particle population appears to shift to lower particle diameters and merge into the 0.2 to $40 \mu \mathrm{m}$ particle population, likely as a result of particle attrition. It should be noted that since the 2000 RPM measurement follows 4000 RPM, the absence of 40 to $200 \mu \mathrm{m}$ could result from particle attrition rather than the poor particle suspension.

The population centered at $400 \mu \mathrm{m}$ is outside the measuring range of the Hydro $\mu \mathrm{P}$ flow used for the current measurements, and could be an anomalous peak. Its behavior with flow rate is unusual for a large peak, increasing in fractional contribution at 2000 RPM and decreasing in fractional contribution as pump speed is increased to $4000 \mathrm{RPM}$. It is possible that this peak is a loose particle flocculate that is sheared apart with a high pump speeds. Indeed, the changes observed in the fractional contribution of both the $400 \mu \mathrm{m}$ peak and the $70 \mu \mathrm{m}$ are consistent with attrition / disruption of particle flocculates at increased pump speed. It can be speculated that sample TI552-G6-6-PSD contains a fraction of agglomerates that are 1) difficult to suspend and/or 2) sheared apart at high analyzer pump speeds. Based on how the PSD span varies with flow rate, the likely size of these agglomerates is 20 to $500 \mu \mathrm{m}$. In contrast, the PSD below $20 \mu \mathrm{m}$ is relatively insensitive to changes in pump speed, indicate that these "smaller" particles / agglomerates are stable with respect to shear. 


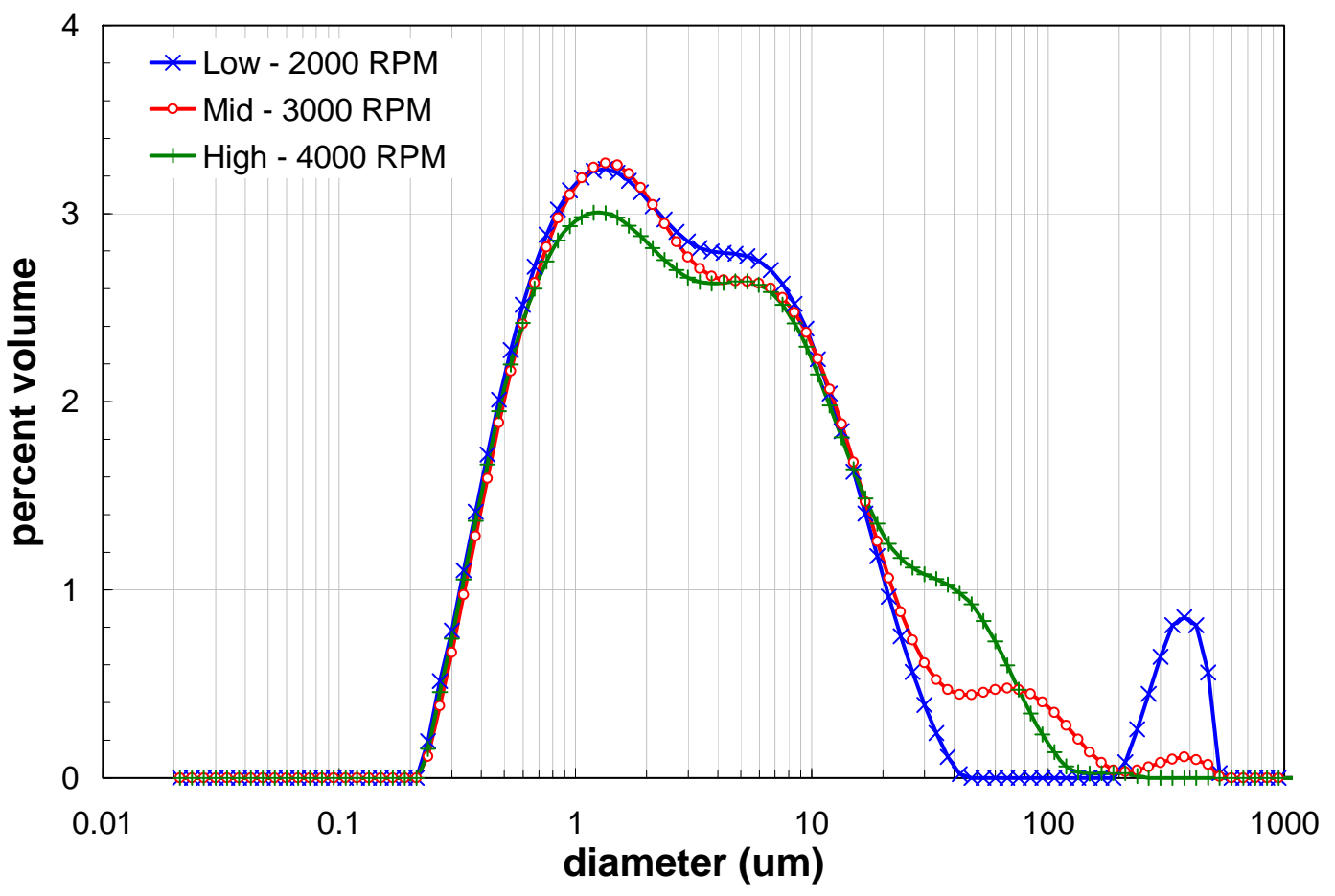

Figure 10. Measured particle size distribution for sample TI552-G6-6-PSD as a function of pump speed before sonication.

Figure 11 shows the particle size distribution for sample TI552-G6-6-PSD before, during, and after sonication. Sonication appears to eliminate (likely through disruption) particle species greater than $\sim 20 \mu \mathrm{m}$ completely. This disruption corresponds with an increase in the fractional contribution of the 7 $\mu \mathrm{m}$ particles, which is likely the final size of broken agglomerates. This behavior is consistent with conclusions about the nature of the $>20 \mu \mathrm{m}$ particle populations made in the preceding paragraphs.

Figure 12 shows the post-sonic particle size distribution for sample TI552-G6-6-PSD as a function of pump speed. Post-sonic PSD are relatively insensitive to changes in pump speed. The distributions at 2000 and 3000 RPM are statistically similar. At high pump speeds (4000 RPM), a 20 to $80 \mu \mathrm{m}$ particle population appears on the distribution chart. These particles correspond to a difficult-tosuspend species. This "large" particle population may correspond to single particles or agglomerates that have survived sonication. Measurement of the post-sonic PSDs did not observe recovery of particle agglomerates in the 20 to $500 \mu \mathrm{m}$, suggesting that agglomerate disruption is irreversible on the time-scale of PSD testing. 


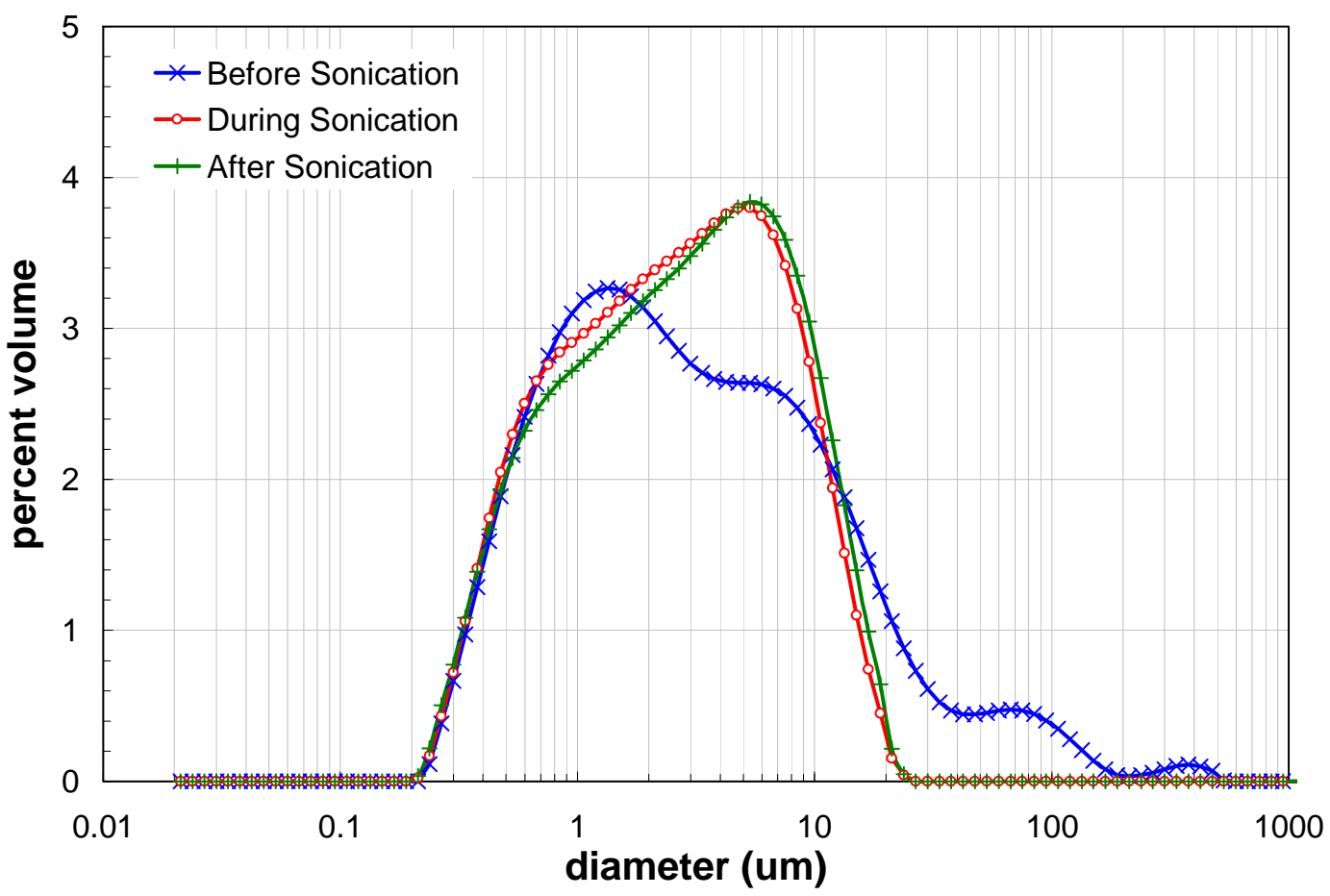

Figure 11. Measured particle size distribution for sample TI552-G6-6-PSD at a single pump speed before, during, and after sonication.

In summary, sample TI552-G6-6-PSD has an initial particle population spanning from $\sim 0.2 \mu \mathrm{m}$ up to $500 \mu \mathrm{m}$, with population peaks at $1.2,6,70$, and $400 \mu \mathrm{m}$. PSD results for this sample suggest that particles in the 20 to $500 \mu \mathrm{m}$ size range are difficult to suspend particles and/or fragile with respect to shear. Disruption of these large particle species is observed upon the application of sonic energy. This disruption is irreversible. After sonication, the distribution of particles ranges from 0.2 to $\sim 80 \mu \mathrm{m}$, with the major of particles below $20 \mu \mathrm{m}$ and population peaks at 1 and $5 \mu \mathrm{m}$. 


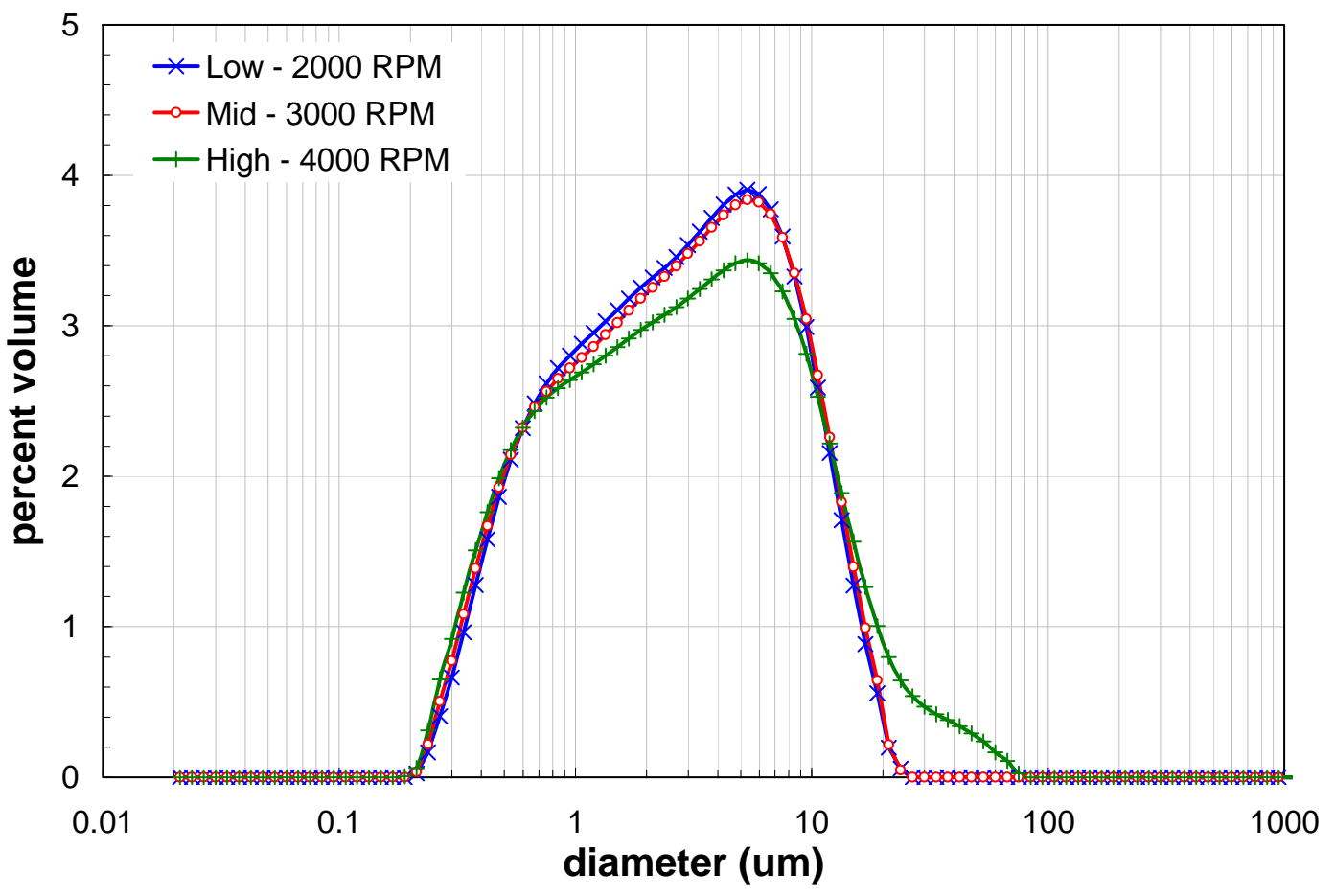

Figure 12. Measured particle size distribution for sample TI552-G6-6-PSD as a function of analyzer pump speed after sonication.

\section{Results for TI552-G6-11-PSD (Caustic-Leached and Dewatered Slurry)}

Sample TI552-G6-11-PSD is comprised of insoluble Group 5/6 mixed waste slurry that have been caustically-leached after and addition of concentrated sodium hydroxide solution occurred. The slurry was heat to $100^{\circ} \mathrm{C}$ over a 5.3 hour period. The temperature was maintained at $100^{\circ} \mathrm{C}$ for 8 hours and then cooled back to room temperature over 12 hours. The leached slurry was subsequently dewatered to a solids concentration of $8.9-\mathrm{wt} \%$. Table 11 shows the diameter percentiles as a function of measurement condition. For this sample, the $d(10)$ ranges from $0.54-0.61 \mu \mathrm{m}$, the $\mathrm{d}(50)$ ranges from 1.9$3.0 \mu \mathrm{m}$, and the $\mathrm{d}(90)$ ranges from $6.2-60 \mu \mathrm{m}$.

Pre-sonic PSDs vary predictably with pump speed. As the speed is increased from 3000 to 4000 RPM, the $\mathrm{d}(50)$ and $\mathrm{d}(90)$ increase significantly (greater than $10 \%$ ) from 2.0 to $3.0 \mu \mathrm{m}$ and from 15 to 60 $\mu \mathrm{m}$, respectively. Only a slight increase is observed in the $\mathrm{d}(10)$. On the other hand, when the pump speed is decreased to 2000 RPM, a significant decrease only occurs in the d(90) relative to the percentile results at 3000 RPM. The $\mathrm{d}(10)$ and $\mathrm{d}(50)$ at $2000 \mathrm{RPM}$ are not statistically different than those at 3000 RPM. The behavior of the pre-sonic PSDs is consistent with the presence of a difficult to suspend species that is sampled at higher (but not at lower) pump speeds. 
Table 11. Particle size analysis percentile results for TI552-G6-11-PSD.

\begin{tabular}{||c|c|c|c|c|c||}
\hline $\begin{array}{c}\text { Measurement } \\
\text { Condition }\end{array}$ & Pump Speed & Sonication & $\begin{array}{c}\mathbf{d}(\mathbf{1 0}) \\
{[\boldsymbol{\mu m}]}\end{array}$ & $\begin{array}{c}\mathbf{d}(\mathbf{5 0}) \\
{[\boldsymbol{\mu m}]}\end{array}$ & $\begin{array}{c}\mathbf{d}(\mathbf{9 0}) \\
{[\boldsymbol{\mu m}]}\end{array}$ \\
\hline 1 & 3000 & pre-sonic & 0.56 & 2.0 & 15 \\
\hline 2 & 4000 & pre-sonic & 0.61 & 3.0 & 60 \\
\hline 3 & 2000 & pre-sonic & 0.54 & 1.9 & 9.6 \\
\hline 4 & 3000 & $25 \%$ & 0.54 & 1.9 & 7.1 \\
\hline 5 & 3000 & $50 \%$ & 0.55 & 1.9 & 6.7 \\
\hline 6 & 3000 & $75 \%$ & 0.56 & 1.9 & 6.2 \\
\hline 7 & 3000 & post-sonic & 0.56 & 1.9 & 6.9 \\
\hline 8 & 4000 & post-sonic & 0.60 & 2.4 & 35 \\
\hline 9 & 2000 & post-sonic & 0.55 & 1.9 & 6.3 \\
\hline
\end{tabular}

Sonication does not appear to significantly impact either $\mathrm{d}(10)$ or $\mathrm{d}(50)$. Indeed, the final postsonic values remain unchanged with regard to normal expectations for experimental error: $\mathrm{d}(10)$ remains the same at $0.56 \mu \mathrm{m}$, whereas $\mathrm{d}(50)$ decreases insignificantly from 2.0 to 1.9 . In contrast, the $\mathrm{d}(90)$ decreases through the course of sonic treatment from a starting (pre-sonic) diameter of $15 \mu \mathrm{m}$, to a sonicated diameter of $6.2 \mu \mathrm{m}$, to a final diameter (post-sonic) of $6.9 \mu \mathrm{m}$. The latter is consistent with sonic disruption of aggregates. The slight recovery of the $\mathrm{d}(90)$ after sonication may indicate some agglomerate reformation.

After sonication, the PSD for sample TI552-G6-11-PSD appears less sensitive to changes in pump speed. An increase from 3000 to 4000 RPM still yields statistically significant increases in d(50) and $\mathrm{d}(90)$, but the magnitude of the increase is less than observed for pre-sonic measurements. For example, the $\mathrm{d}(50)$ increases from 2.0 to $3.0 \mu \mathrm{m}$ before sonication, whereas the increase is only from 1.9 to $2.4 \mu \mathrm{m}$ after sonication. Lowering of the pump speed to 2000 RPM does not see a statistically significant change in either the $d(10)$ or $d(50)$ relative to 3000 RPM. The change observed in the $d(90)$ is at the limit of significance. Taken together, these observations indicate that sonication has disrupted a portion, but not all, of the difficult-to-suspend agglomerates.

Figure 13 shows the pre-sonic particle size distribution for sample TI552-G6-11-PSD as a function of pump speed. The distribution is approximately bimodal. At 3000 RPM, the PSD is comprised of a two populations: 1) one that has a maximum at $2 \mu \mathrm{m}$ and that spans $\sim 0.20$ to $20 \mu \mathrm{m}$ and 2) another that has a maximum at $\sim 60 \mu \mathrm{m}$ and that spans 20 to $200 \mu \mathrm{m}$. The 0.20 to $20 \mu \mathrm{m}$ population dominates the PSD. Overall, the size distribution of particles remains relatively unchanged at different flow rates. Changes in the PSD with pump speed primarily result from changes in the fractional contribution of small and large particle populations. At high pump speeds, the fractional population contribution of 20 to $200 \mu \mathrm{m}$ particles is increased relative to $3000 \mathrm{RPM}$. Likewise, the fractional contribution of this species is reduced at 2000 RPM. Both observations are suggestive of difficult to suspend particles or agglomerates. At 2000 RPM, a $400 \mu \mathrm{m}$ particle peak appears. This could correspond to particle agglomerates that form under reduced shear or could be an artifact of the light scattering analysis. In either case, the size of particles in this peak falls beyond the nominal suspending capabilities of the Hydro $\mu$ P flow cell used for these characterizations. 


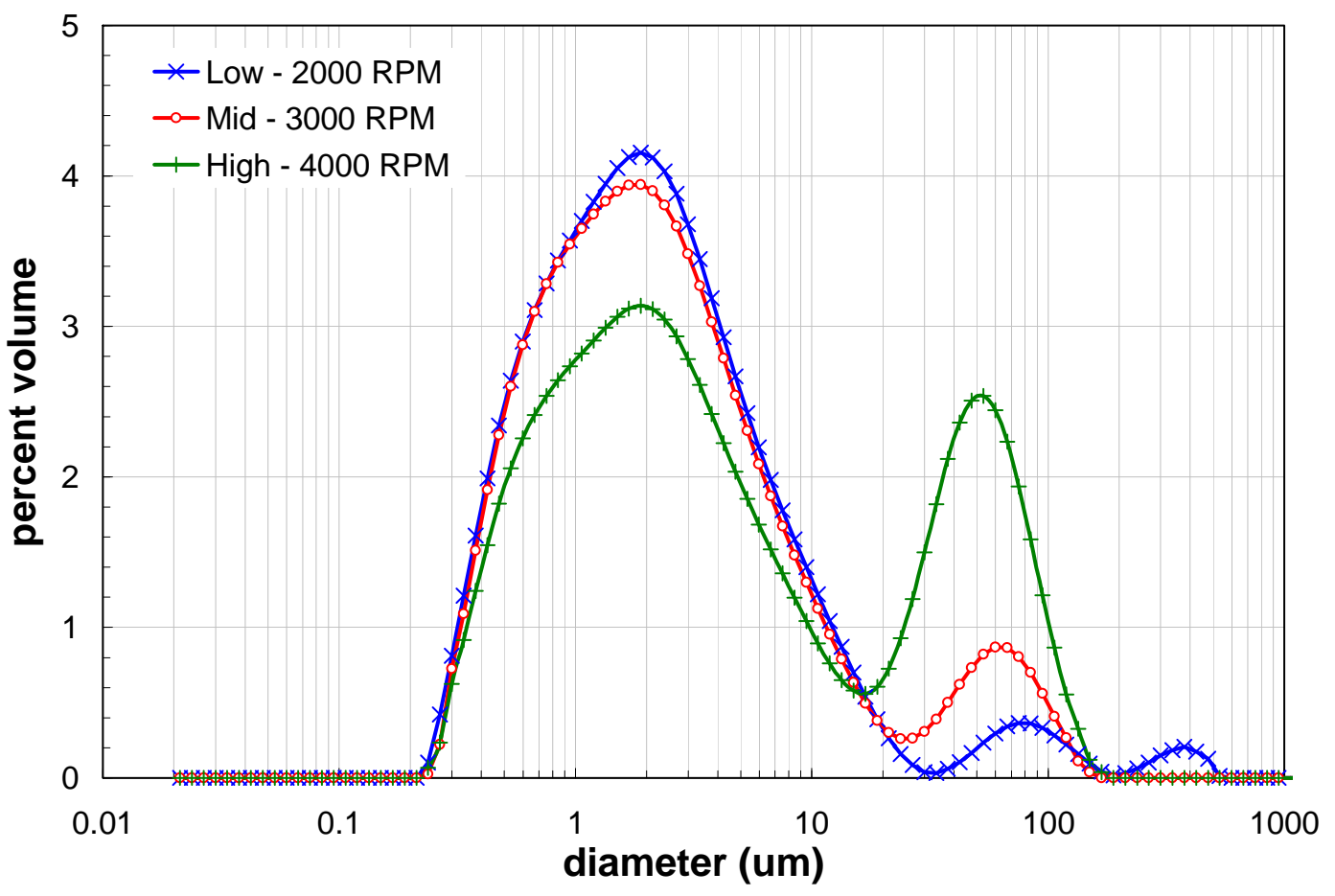

Figure 13. Measured particle size distribution for sample TI552-G6-11-PSD as a function of pump speed before sonication.

Figure 14 shows the particle size distribution for sample TI552-G6-11-PSD before, during, and after sonication. Sonication appears to eliminate particle population with sizes greater than $20 \mu \mathrm{m}$. These observations are consistent with sonic disruption of fragile particles and agglomerates. After sonication, there is a slight recovery of the $15-25 \mu$ m population, indicating that breakdown of agglomerate is partially reversible. While sonication does have an influence on particles greater than $10 \mu \mathrm{m}$, overall, the influence of the majority of particles (i.e., those from 0.2 to $10 \mu \mathrm{m}$ ) is minimal. The shape of the PSD over this size range does not change significantly over the course of sonication. This indicates that a significant portion of this sample is robust with respect to breakage.

Figure 15 shows the post-sonic particle size distribution for sample TI552-G6-11-PSD as a function of pump speed. As the pump speed is increased to $4000 \mathrm{RPM}$, a population of 10 to $100 \mu \mathrm{m}$ particles appears. This is likely a difficult-to-suspend particulate fraction that survived sonication. Relative to the population of 10 to $100 \mu \mathrm{m}$ particles observed at 4000 RPM before sonication, the postsonic fractional contribution of these species to the overall PSD is reduced (confirming that some 10 to $100 \mu \mathrm{m}$ particles were disrupted by sonication). At 2000 RPM, the PSD is not statistically different than the 3000 RPM PSD. 


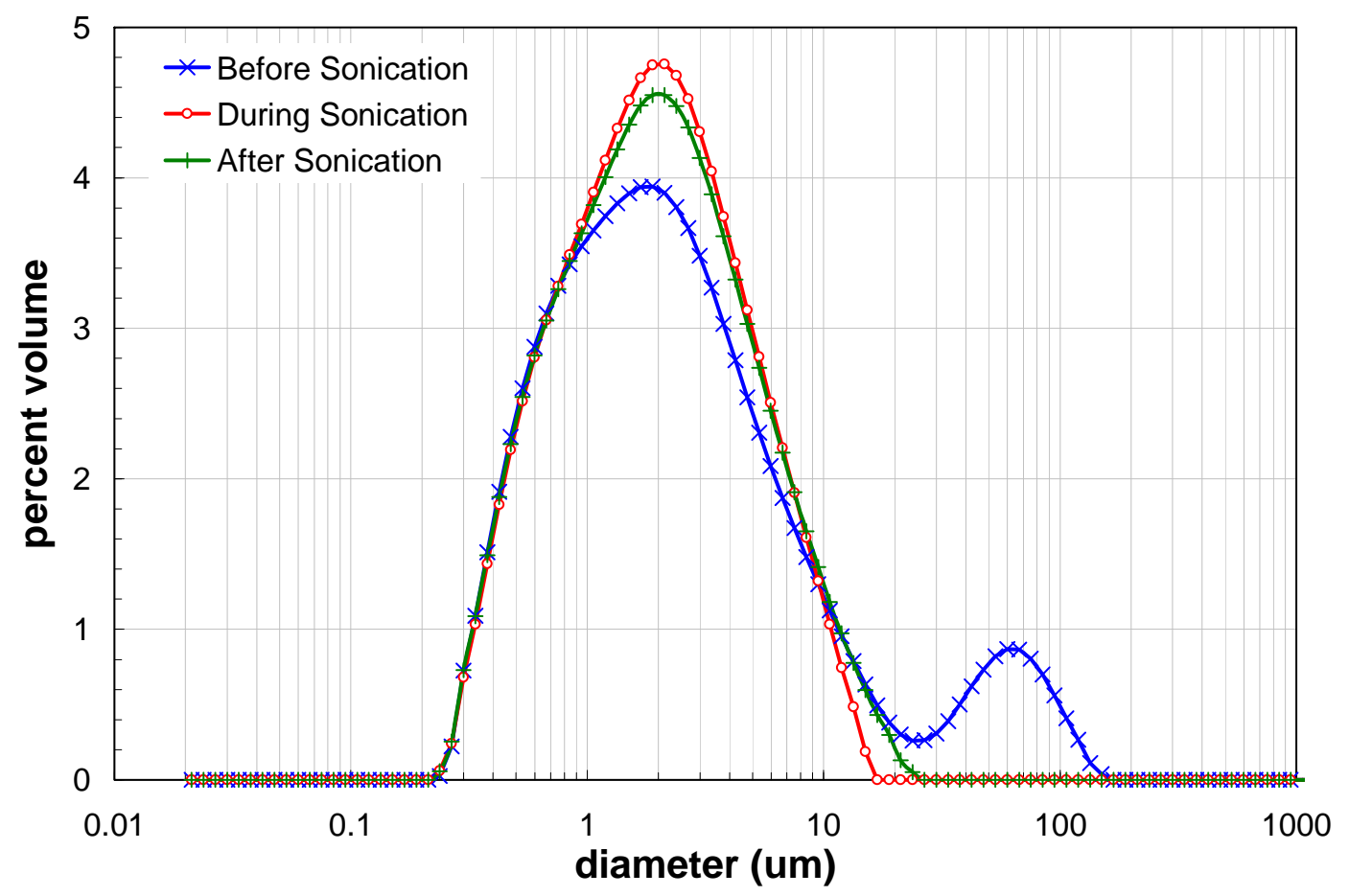

Figure 14. Measured particle size distribution for sample TI552-G6-11-PSD at a single pump speed before, during, and after sonication.

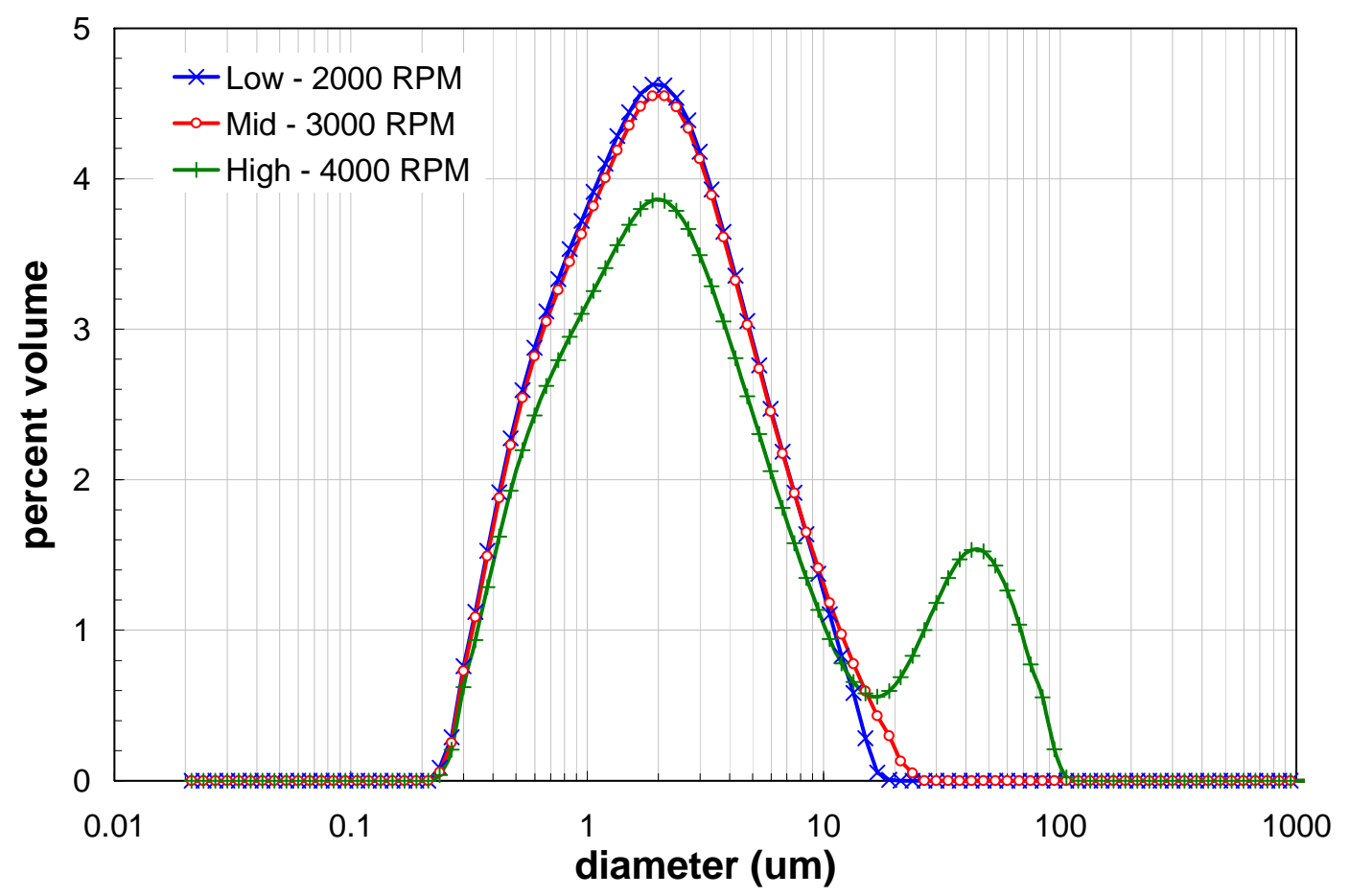

Figure 15. Measured particle size distribution for sample TI552-G6-11-PSD as a function of analyzer pump speed after sonication. 
In summary, sample TI552-G6-11-PSD has an initial particle population spanning from $\sim 0.2 \mu \mathrm{m}$ to $\sim 200 \mu \mathrm{m}$. The pre-sonication PSD is roughly bimodal with population peak maxima at 2 and $50 \mu \mathrm{m}$. At low flow, a third population centered at $\sim 400 \mu \mathrm{m}$ appears (but may be an artifact of the analysis of the light scattering pattern). High flows appear to suspend a fraction of $\sim 20$ to $100 \mu \mathrm{m}$ particles, indicating the presence of difficult-to-suspend single particles or agglomerates. Sonication appears to disrupt particles / agglomerates greater than $10 \mu \mathrm{m}$, but has little effect on particles below $10 \mu \mathrm{m}$. There is a slight recovery of greater than $10 \mu \mathrm{m}$ particles after sonication, indicating that disruption in partially reversible. After sonication, high flows still evidence a difficult-to-suspend fraction of 10 to $100 \mu \mathrm{m}$ particles. However, the fractional contribution of these particles is reduced after sonication, confirming disruption of particles in this size range by sonication.

\section{Results for TI552-G6-16-PSD (Caustic-Leached, Dewatered, and Washed Slurry)}

Sample TI552-G6-16-PSD is comprised of insoluble Group 5/6 mixed waste solids that have been caustically-leached in a concentrated sodium hydroxide solution for 8 hours at $100{ }^{\circ} \mathrm{C}$ and subsequently subjected to a number of dewatering and washing operations to reduce sodium ion concentration. The final solids concentration of the dewatered and washed slurry is $12.8-\mathrm{wt} \%$.

Table 12 shows the diameter percentiles as a function of measurement condition. For this sample, the $d(10)$ ranges from $0.50-0.56 \mu \mathrm{m}$, the $\mathrm{d}(50)$ ranges from 1.5-2.0 $\mu \mathrm{m}$, and the $\mathrm{d}(90)$ ranges from 5.2-38 $\mu \mathrm{m}$. Before sonication, the measured cumulative undersize percentiles appear to vary with analyzer pump speed. Specifically, as the pump speed is increased from 3000 to 4000 RPM, a significant jump in $\mathrm{d}(50)$ and $\mathrm{d}(90)$ is observed. The $\mathrm{d}(10)$ remains relatively unchanged. On the other hand, the pre-sonic d(10) and d(50) do not show significant change when the pump speed is lowered to 2000 RPM (relative to 3000 RPM). However, a significant decrease is observed in the $\mathrm{d}(90)$ as a result of lowered pump speed. Like with previous Group 5/6 CUF samples, this behavior is consistent with the presence of a difficult-to-suspend particle species in the sample. The Hydro $\mu \mathrm{P}$ accessory used in this analysis is unable to sample these particles adequately either as a result of their size and/or density.

Table 12. Particle size analysis percentile results for TI552-G6-16-PSD.

\begin{tabular}{||c|c|c|c|c|c||}
\hline $\begin{array}{c}\text { Measurement } \\
\text { Condition }\end{array}$ & Pump Speed & Sonication & $\begin{array}{c}\mathbf{d}(\mathbf{1 0}) \\
{[\boldsymbol{\mu m}]}\end{array}$ & $\begin{array}{c}\mathbf{d}(\mathbf{5 0 )} \\
{[\boldsymbol{\mu \mathbf { m } ]}]}\end{array}$ & $\begin{array}{c}\mathbf{d}(\mathbf{9 0}) \\
{[\boldsymbol{\mu \mathbf { m } ]}]}\end{array}$ \\
\hline 1 & 3000 & pre-sonic & 0.51 & 1.5 & 6.7 \\
\hline 2 & 4000 & pre-sonic & 0.52 & 2.0 & 38 \\
\hline 3 & 2000 & pre-sonic & 0.50 & 1.5 & 5.5 \\
\hline 4 & 3000 & $25 \%$ & 0.52 & 1.6 & 5.2 \\
\hline 5 & 3000 & $50 \%$ & 0.54 & 1.7 & 5.4 \\
\hline 6 & 3000 & $75 \%$ & 0.56 & 1.7 & 5.5 \\
\hline 7 & 3000 & post-sonic & 0.54 & 1.7 & 5.7 \\
\hline 8 & 4000 & post-sonic & 0.52 & 1.9 & 9.0 \\
\hline 9 & 2000 & post-sonic & 0.56 & 1.7 & 5.4 \\
\hline
\end{tabular}

Sonication has only a minor impact on the particle size distribution. Both $d(10)$ and $d(50)$ increase; however, the magnitude of changes in both parameters as a result of sonication is just at the limit of significance ( $10 \%)$, and as such, are difficult to differentiate from system noise. The d(90) does appear to show a significant decrease before and after sonication (6.7 $\mu \mathrm{m}$ before versus $5.7 \mu \mathrm{m}$ after). 
However, the magnitude of decrease in the $d(90)$ is much smaller relative to that seen for samples TI552G6-3-PSD and TI552-G6-6-PSD.

Figure 16 shows the pre-sonic particle size distribution for sample TI552-G6-16-PSD as a function of pump speed. At 3000 RPM, the distribution is relatively unimodal, with a population maximum at $1 \mu \mathrm{m}$ and with a span of $\sim 0.2$ to $30 \mu \mathrm{m}$. A second small population of particles is centered around $100 \mu \mathrm{m}$, and could correspond to large particle flocculates or may simply be an artifact of the fitting analysis. Subsequent increases and decreases in the pump speed do not appear to strongly influence the distribution of particles over 0.2 to $10 \mu \mathrm{m}$. In contrast, an increase to $4000 \mathrm{RPM}$ yields a strong peak spanning 10 to $100 \mu \mathrm{m}$ and with a maximum between 40 and $50 \mu \mathrm{m}$. This peak (and the small population centered at $100 \mu \mathrm{m}$ ) disappear as pump speed is lowered to $2000 \mathrm{RPM}$. Both observations indicate, as with previous Group 5/6 samples, a difficult to suspend particle structure in the greater than $10 \mu \mathrm{m}$ size range.

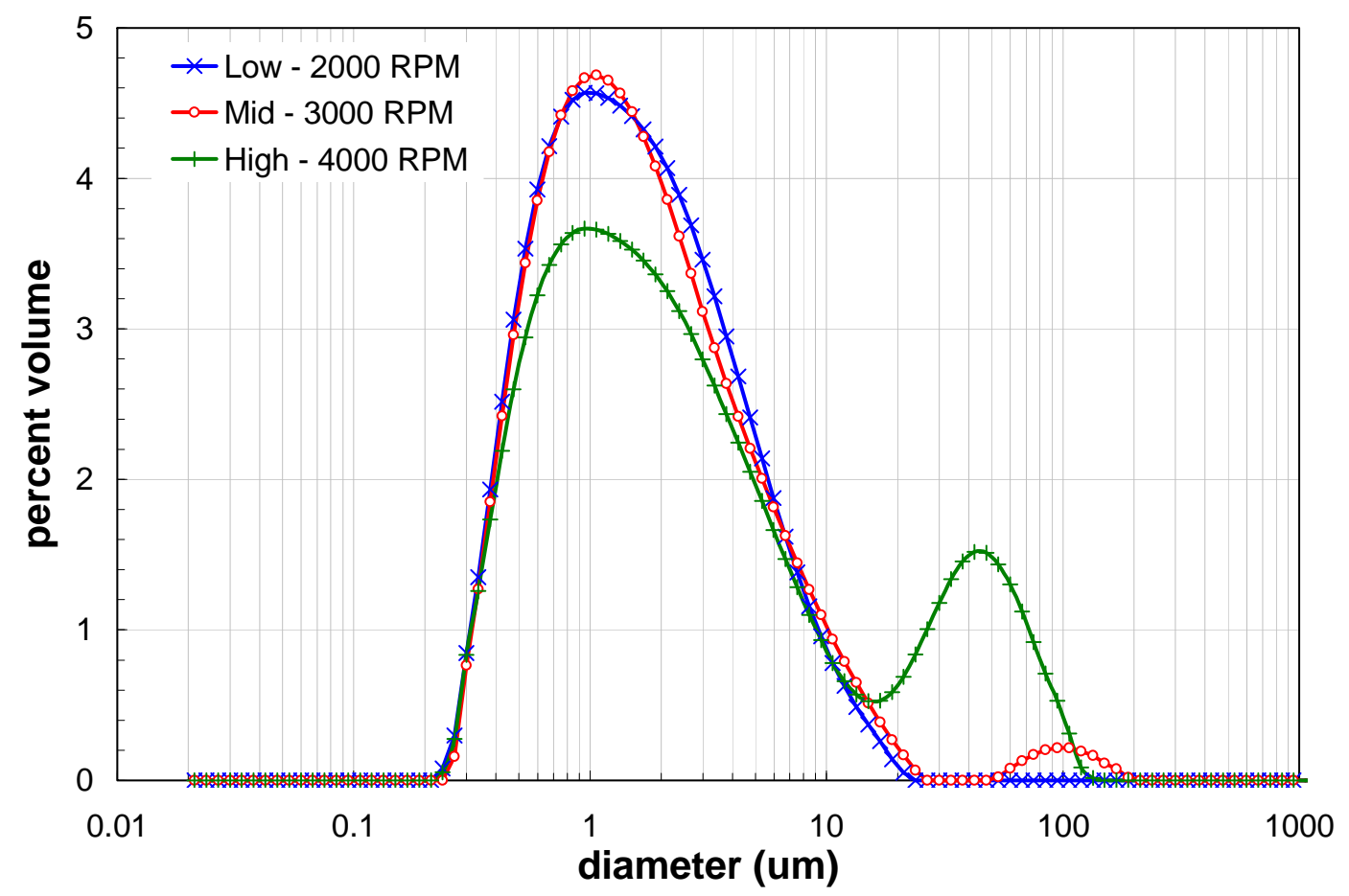

Figure 16. Measured particle size distribution for sample TI552-G6-16-PSD as a function of pump speed before sonication.

Figure 17 shows the particle size distribution for sample TI552-G6-16-PSD before, during, and after sonication. Although sonication appears to eliminate the secondary peak centered at $100 \mu \mathrm{m}$ it does not appear to change the primary range of particle sizes observed at 3000 RPM. The majority of particles still fall between 0.2 and $20 \mu \mathrm{m}$ before, during, and after sonication. On the other hand, sonication does appear to introduce a bimodal nature to the PSD. Before sonication, the distribution is relatively unimodal with a maximum at $1 \mu \mathrm{m}$. During and after sonication, the maximum shifts up to $2 \mu \mathrm{m}$ and the original maximum at $1 \mu \mathrm{m}$ is replaced by a shoulder. The changes observed upon sonication are likely a result of breakdown of aggregates not suspended at $3000 \mathrm{RPM}$. These aggregates contribute to the 1 to 
$10 \mu \mathrm{m}$ particle population, shifting the overall maximum to $2 \mu \mathrm{m}$. Because during and after sonication distributions are similar, it can be inferred that changes to the PSD as a result of sonication are irreversible within the testing time span.

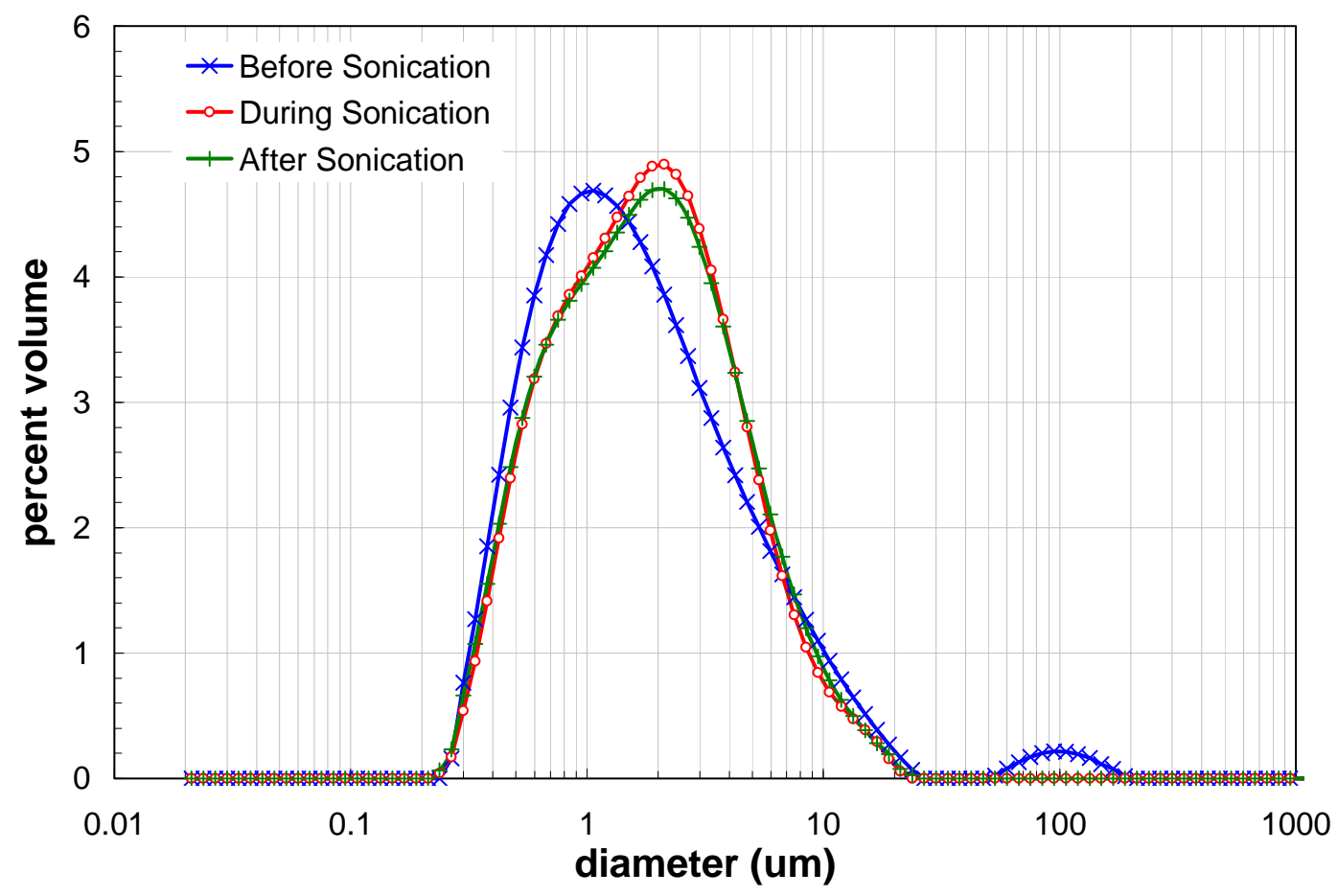

Figure 17. Measured particle size distribution for sample TI552-G6-16-PSD at a single pump speed before, during, and after sonication.

Figure 18 shows the post-sonic particle size distribution for sample TI552-G6-16-PSD as a function of pump speed. The post-sonic distribution still appears to be influenced by changes in pump speed. At 4000 RPM, the distribution exhibits a shoulder spanning 10 to $60 \mu \mathrm{m}$ likely comprised of particle agglomerates that survived sonication. Relative to the pre-sonication 4000 RPM distribution, the population contribution of particles in the 10 to $60 \mu \mathrm{m}$ is reduced. This supports the proposition that disruption of particles in this size range yield the upward shift in population maximum observed during sonication. Despite the formation of this shoulder, the distribution of particles below $10 \mu \mathrm{m}$ appears independent of pump speed. Indeed, the PSDs at 2000 RPM and 3000 RPM are statistically similar. 


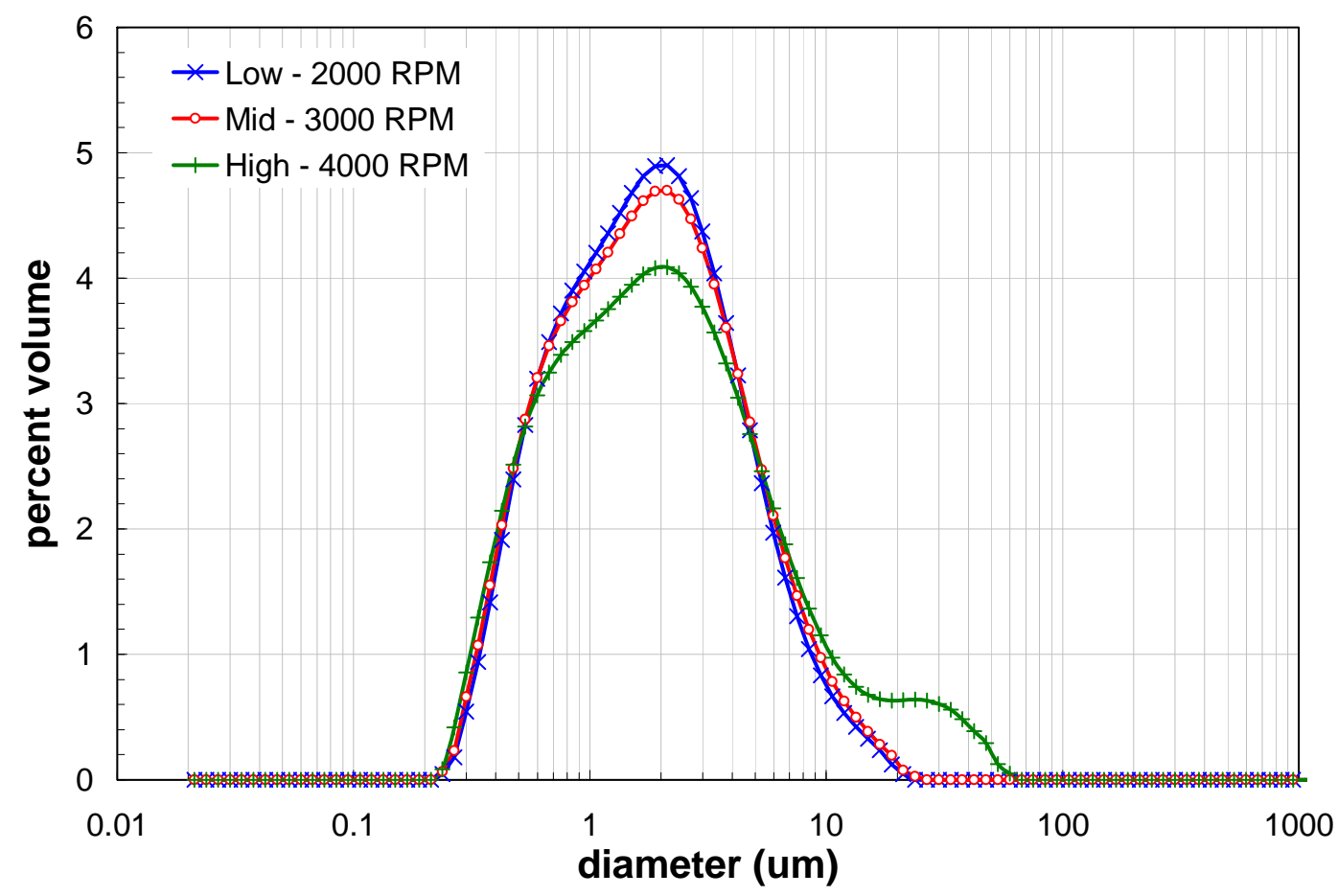

Figure 18. Measured particle size distribution for sample TI552-G6-16-PSD as a function of analyzer pump speed after sonication.

In summary, sample TI552-G6-16-PSD has an initial particle population spanning from $\sim 0.2 \mu \mathrm{m}$ to $\sim 100 \mu \mathrm{m}$. Particles in the 20 to $100 \mu \mathrm{m}$ size range are difficult to suspend, and only appear at the highest pump speeds analyzed during the measurement. Sonication appears to reduce the fractional contribution of the particle population greater than $20 \mu \mathrm{m}$ in diameter, indicating that the solids comprising this size range are likely agglomerates. Disruption of particles greater than $20 \mu \mathrm{m}$ yields an increase in the population of 1-10 $\mu \mathrm{m}$ particles. The distribution shows no recovery after sonication, suggesting the changes to the state of particle agglomeration are permanent. High flows still evidence a difficult-to-suspend fraction of 10 to $60 \mu \mathrm{m}$ particles, but their fractional contribution to the overall distribution is reduce relative to the pre-sonic PSD. As with previous samples, this confirms sonic disruption of 20 to $100 \mu \mathrm{m}$ particles.

\section{Results for TI552-G6-21-PSD (Oxidative-Leached and Dewatered Slurry)}

Sample TI552-G6-21-PSD is derived from waste solids remaining after oxidative-leaching of the caustic-leached, dewatered, and washed Group 5/6 mixed waste solids. The oxidative leach involves contacting the waste solids with $1 \mathrm{M}$ sodium permanganate $\left(\mathrm{NaMnO}_{4}\right)$ at ambient hot cell temperature $\left(\sim 30^{\circ} \mathrm{C}\right)$ for 6 hours. The final solids concentration of the oxidative-leached slurry is $6.1-\mathrm{wt} \% \mathrm{UDS}$. Sample TI552-G6-21-PSD was run in duplicate (termed initial and replicate) to quantify the reproducibility in Group 5/6 PSD measurements. Table 13 and 14 show the diameter percentiles as a function of measurement condition for the initial and replicate samples, respectively. Table 15 shows the absolute relative percent difference between the $d(10), d(50)$, and $d(90)$ values determined for the initial and replicate PSD measurements. Here, absolute relative percent difference of the $n^{\text {th }}$ percentile is determined using the following equation: 


$$
R P D(n)=\left|\frac{d_{r}(n)-d_{i}(n)}{d_{i}(n)}\right| \times 100 \%
$$

where $d_{i}(n)$ and $d_{r}(n)$ are the initial and replicate cumulative oversize diameters, respectively.

For the initial measurement results, the $\mathrm{d}(10)$ ranges from $0.44-0.76 \mu \mathrm{m}$, the $\mathrm{d}(50)$ ranges from 1.1-2.0 $\mu \mathrm{m}$, and the $\mathrm{d}(90)$ ranges from 3.6-88 $\mu \mathrm{m}$. The duplicate sample shows similar range for the $d(10)$ and $d(50)$ but only shows 3.5-7.9 $\mu \mathrm{m}$ for the $d(90)$. The latter could be a result of differences in the state of aggregation of solids sampled for the initial and replicate measurements. Overall, the initial and replicate pre-sonic PSDs do not compare well at measurement conditions 1 and 2 (see Table 15). On the other hand, at low pump speed (2000 RPM - measurement condition 3), the pre-sonic d(10), d(50), and $\mathrm{d}(90)$ for initial and replicate samples agree within $10 \%$.

The pre-sonic PSDs listed in Tables 13 and 14 do not exhibit predictable trends with pump speed. For the initial sample, the $\mathrm{d}(50)$ does not change significantly (less than 10\%) as pump speed is increased from 3000 to 4000 RPM. The subsequent decrease of the pump speed to 2000 RPM is accompanied by a significant decrease (greater than $10 \%$ ) in the $d(50)$. The initial measurement $d(10)$ and $d(90)$ generally decrease throughout the pre-sonic measurements. In contrast, the $\mathrm{d}(10)$ and $\mathrm{d}(50)$ for the duplicate PSD measurement decrease over measurement conditions 1 to 3, with the $d(90)$ showing a greater than $10 \%$ increase at 4000 RPM followed by a significant decrease at 2000 RPM. Because initial and replicate samples exhibit different pre-sonic PSD response to pump speed, it is difficult to draw conclusions about the nature of the particle dispersion.

Sonication reduces particle size in both initial and replicate measurements. This behavior is consistent with other Group 5/6 CUF testing PSD samples and is likely a result of disruption of particle agglomerates. After sonication, the initial and replicate PSD agree within $10 \%$ of each other at 3000 RPM (measurement condition 7). This observation supports the earlier conclusion that differences in the pre-sonic PSD are attributable to differences in the initial state of aggregation of solids sampled for the initial and replicate measurements.

Table 13. Initial particle size analysis percentile results for TI552-G6-21-PSD.

\begin{tabular}{||c|c|c|c|c|c||}
\hline $\begin{array}{c}\text { Measurement } \\
\text { Condition }\end{array}$ & Pump Speed & Sonication & $\begin{array}{c}\mathbf{d}(\mathbf{1 0}) \\
{[\boldsymbol{\mu m}]}\end{array}$ & $\begin{array}{c}\mathbf{d}(\mathbf{5 0}) \\
{[\boldsymbol{\mu m}]}\end{array}$ & $\begin{array}{c}\mathbf{d}(\mathbf{9 0}) \\
{[\boldsymbol{\mu m}]}\end{array}$ \\
\hline 1 & 3000 & pre-sonic & 0.76 & 1.9 & 88 \\
\hline 2 & 4000 & pre-sonic & 0.64 & 2.0 & 61 \\
\hline 3 & 2000 & pre-sonic & 0.59 & 1.4 & 3.6 \\
\hline 4 & 3000 & $25 \%$ & 0.49 & 1.2 & 4.6 \\
\hline 5 & 3000 & $50 \%$ & 0.44 & 1.1 & 4.8 \\
\hline 6 & 3000 & $75 \%$ & 0.44 & 1.2 & 4.8 \\
\hline 7 & 3000 & post-sonic & 0.44 & 1.2 & 4.9 \\
\hline 8 & 4000 & post-sonic & 0.44 & 1.4 & 10 \\
\hline 9 & 2000 & post-sonic & 0.44 & 1.2 & 4.9 \\
\hline
\end{tabular}


Table 14. Replicate particle size analysis percentile results for TI552-G6-21-PSD.

\begin{tabular}{||c|c|c|c|c|c||}
\hline $\begin{array}{c}\text { Measurement } \\
\text { Condition }\end{array}$ & Pump Speed & Sonication & $\begin{array}{c}\mathbf{d}(\mathbf{1 0}) \\
{[\boldsymbol{\mu m}]}\end{array}$ & $\begin{array}{c}\mathbf{d}(\mathbf{5 0}) \\
{[\boldsymbol{\mu m}]}\end{array}$ & $\begin{array}{c}\mathbf{d}(\mathbf{9 0}) \\
{[\boldsymbol{\mu m}]}\end{array}$ \\
\hline 1 & 3000 & pre-sonic & 0.82 & 2.0 & 4.0 \\
\hline 2 & 4000 & pre-sonic & 0.59 & 1.5 & 7.9 \\
\hline 3 & 2000 & pre-sonic & 0.56 & 1.3 & 3.5 \\
\hline 4 & 3000 & $25 \%$ & 0.49 & 1.1 & 4.2 \\
\hline 5 & 3000 & $50 \%$ & 0.44 & 1.1 & 5.1 \\
\hline 6 & 3000 & $75 \%$ & 0.43 & 1.2 & 5.2 \\
\hline 7 & 3000 & post-sonic & 0.43 & 1.2 & 5.3 \\
\hline 8 & 4000 & post-sonic & 0.43 & 1.2 & 5.9 \\
\hline 9 & 2000 & post-sonic & 0.43 & 1.1 & 5.0 \\
\hline
\end{tabular}

Table 15. Relative percent difference for initial and replicate measurements of PSD sample TI552-G6-21-PSD.

\begin{tabular}{|c|c|c|c|c|c||}
\hline $\begin{array}{c}\text { Measurement } \\
\text { Condition }\end{array}$ & Pump Speed & Sonication & RPD(10) & RPD(50) & $\begin{array}{c}\text { RPD(90) } \\
\text { [\%] }\end{array}$ \\
\hline 1 & 3000 & pre-sonic & $8.6 \%$ & $2.0 \%$ & $95 \%$ \\
\hline 2 & 4000 & pre-sonic & $7.5 \%$ & $25 \%$ & $87 \%$ \\
\hline 3 & 2000 & pre-sonic & $5.2 \%$ & $6.4 \%$ & $3.4 \%$ \\
\hline 4 & 3000 & $25 \%$ & $0.41 \%$ & $3.1 \%$ & $9.2 \%$ \\
\hline 5 & 3000 & $50 \%$ & $1.6 \%$ & $0.45 \%$ & $6.4 \%$ \\
\hline 6 & 3000 & $75 \%$ & $1.1 \%$ & $0.26 \%$ & $8.2 \%$ \\
\hline 7 & 3000 & post-sonic & $1.8 \%$ & $2.8 \%$ & $7.4 \%$ \\
\hline 8 & 4000 & post-sonic & $3.2 \%$ & $11 \%$ & $43 \%$ \\
\hline 9 & 2000 & post-sonic & $1.6 \%$ & $3.1 \%$ & $1.4 \%$ \\
\hline \hline
\end{tabular}

Post-sonic PSDs are not substantially influenced by pump speed. Although the initial sample shows significant increases in the $d(50)$ and $d(90)$ when the pump speed is changed from 3000 to 4000 RPM, this is observation is not confirmed in the replicate sample. A comparison of the initial and replicate PSDs at 4000 RPM shows that the post-sonic d(50)s and d(90)s show RPDs greater than $10 \%$. This indicates a significant difference in the "difficult-to-suspend" solids sampled and measured for initial and replicate sample measurement. This is not surprising, as the small volume sampling cell on the Hydro $\mu \mathrm{P}$ typically does not allow representative sampling and measurement of large and/or dense materials. A lowering of the pump speed to 2000 RPM yields a distribution that is statistically similar to the post-sonic 3000 RPM PSD.

The results given in Table 15 indicate that, for sample TI552-G6-21-PSD, PSD repeatability is poor prior to sonication. Differences in the state of particle agglomerate appear to be one cause, as sonication of the dispersion eliminated differences in between initial and replicate PSDs measured at 3000 RPM. Pump speed also plays a role in how well the initial and replicate samples compared. Good agreement was generally obtained at 2000 RPM, which suggests 1) that differences in initial and replicate measurements are caused by particles that cannot be suspended at $2000 \mathrm{RPM}, 2$ ) that the $4000 \mathrm{RPM}$ measurement preceding 2000 RPM shears apart the agglomerates, or 3) some combination thereof. Postsonic repeatability is generally good, but significant deviation between initial and replicate measurements was still observed at 4000 RPM. These observations suggest that when comparing other Group 5/6 CUF 
testing PSD, distributions corresponding to measurement conditions 4-7 and 9 are the most appropriate to use as the PSDs measured at these conditions are less likely to be influenced by "error" introduced by poor sampling of large particle agglomerates. For the current report, measurement condition 7 shall be used for all comparisons.

Figure 19 shows the initial pre-sonic particle size distribution for sample TI552-G6-21-PSD as a function of pump speed. The distribution appears multimodal with the large population peak centered around $2 \mu \mathrm{m}$, a primary distribution spanning 0.3 to $7 \mu \mathrm{m}$, a low population shoulder spanning 7 to 20 $\mu \mathrm{m}$, and a separate distribution of large "particles" spanning 50 to $600 \mu \mathrm{m}$. The latter falls, for the most part, outside the nominal measuring range of the Malvern Hydro $\mu \mathrm{P}$, and is either large particle agglomerates or an artifact of the laser light scattering analysis. Measurement condition 2 (4000 RPM) shows a similar distribution to that at 3000 RPM. The primary peak appears to have shifted to slightly smaller particle diameters, with the population peak at $\sim 1.3 \mu \mathrm{m}$ (down from $2 \mu \mathrm{m}$ ). The large particle peak spanning from 50 to $600 \mu \mathrm{m}$ has disappeared and has been replaced with a population centered around $50-60 \mu \mathrm{m}$ and an upper bound of $\sim 130 \mu \mathrm{m}$. It is possible that the original 50 to $600 \mu \mathrm{m}$ peak (assuming it was not an artifact of the analysis) was comprised of particle aggregates that have been sheared apart by high flow, forming smaller aggregates that make up the new large particle peak observed at 4000 RPM. At 2000 RPM, the distribution is relatively unimodal and shows the single primary particle peak centered around $1.3 \mu \mathrm{m}$. No particles greater than $20 \mu \mathrm{m}$ are observed at $2000 \mathrm{RPM}$, indicate that those observed at higher pump speeds are difficult-to-suspend primary particles or agglomerates.

Figure 20 shows the initial particle size distribution for sample TI552-G6-21-PSD before, during, and after sonication. The application of sonic energy appears to shift the primary peak to submicron sizes and collapse the particle population above $10 \mu \mathrm{m}$ to a size of less than $10 \mu \mathrm{m}$. The distributions duringand after-sonication are broad, spanning $\sim 0.2$ to $10 \mu \mathrm{m}$ with a peak at $0.7 \mu \mathrm{m}$ and shoulders at 2 and 6 $\mu \mathrm{m}$. Recovery of greater than $10 \mu \mathrm{m}$ aggregates is not observed after sonication of the dispersion, suggesting that the disruption of these species is irreversible on the time scale of the measurement. 


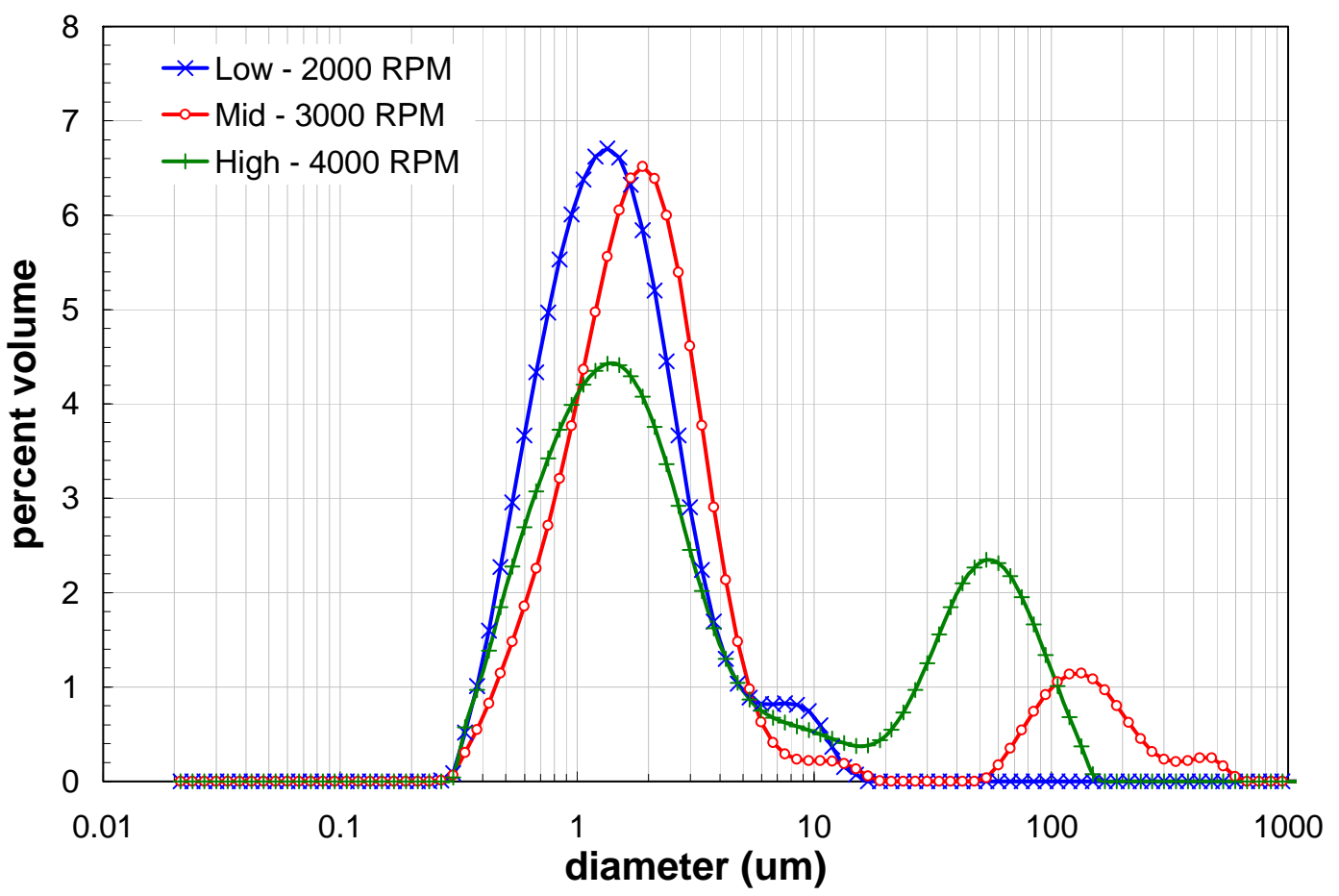

Figure 19. Measured particle size distribution for sample TI552-G6-21-PSD as a function of pump speed before sonication.

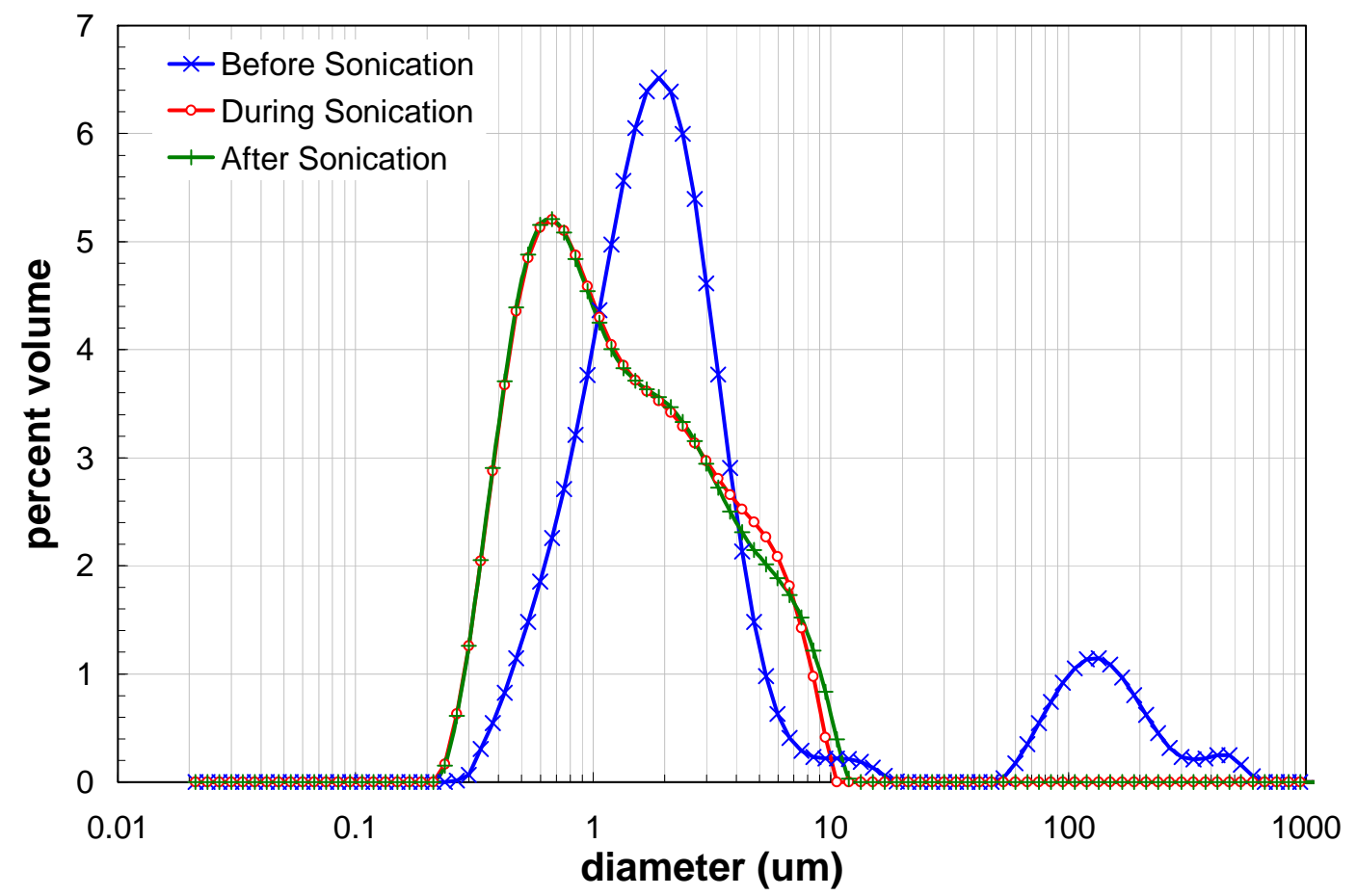

Figure 20. Measured particle size distribution for sample TI552-G6-21-PSD at a single pump speed before, during, and after sonication. 
Figure 21 shows the initial post-sonic particle size distribution for sample TI552-G6-21-PSD as a function of pump speed. Both low- (2000 RPM) and mid- (3000 RPM) pump speeds show statistically similar distributions. The high speed setting for the pump (4000 RPM) shows a peak spanning 10 to 50 $\mu \mathrm{m}$ and centered at $30 \mu \mathrm{m}$ that was not observed at lower pump settings. This peak is likely associated with difficult-to-suspend agglomerates that survived the period of dispersion sonication. Relative to the pre-sonic distributions, this large agglomerate peak is reduced in both the magnitude of population contribution and the size of particles contained therein.

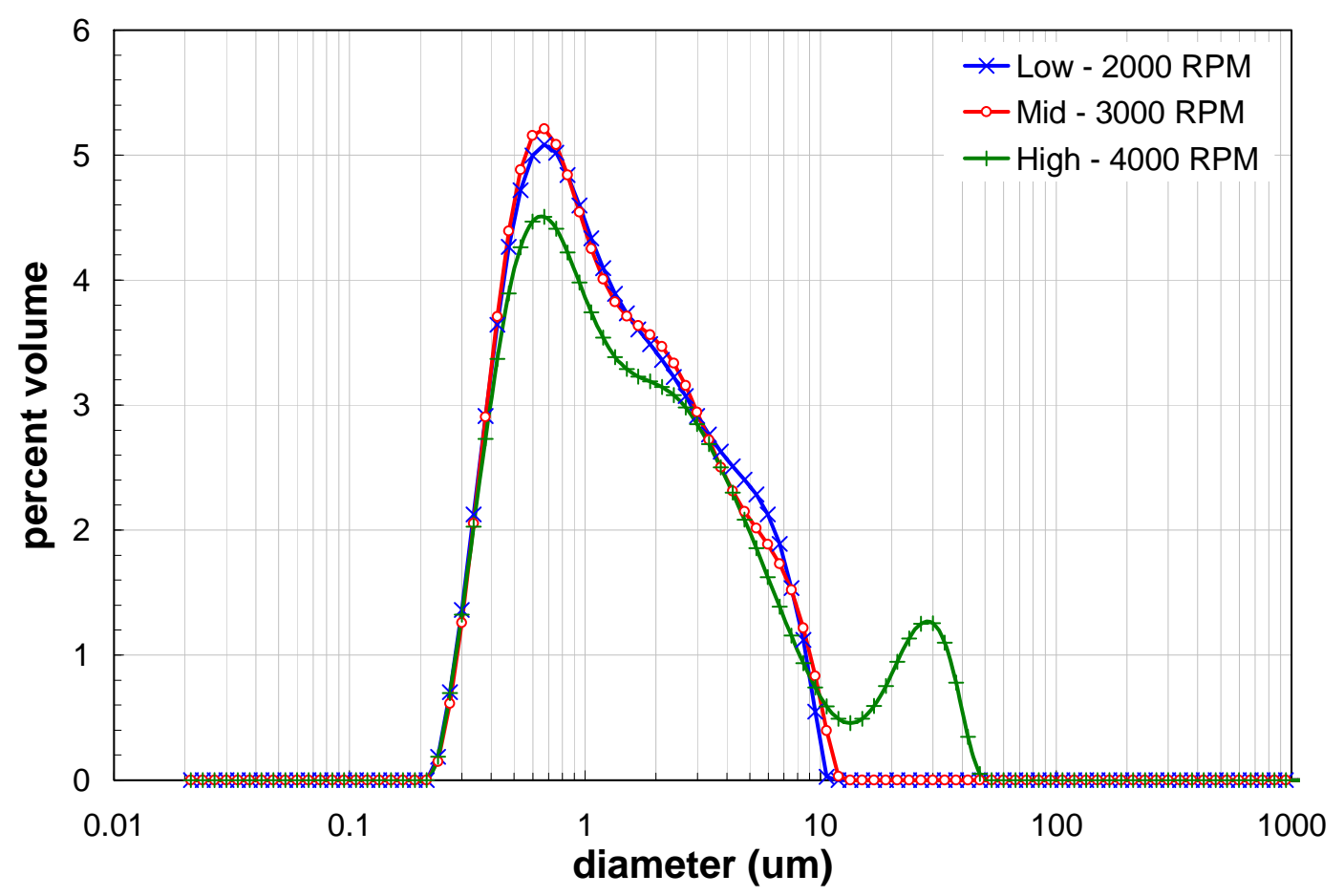

Figure 21. Measured particle size distribution for sample TI552-G6-21-PSD as a function of analyzer pump speed after sonication.

Finally, Figures 22 and 23 show the PSD graphs comparing initial and replicate measurement at 3000 RPM before and after sonication, respectively. Before sonication, the initial and replicate samples show a statistically similar distribution of particles over 0.3 to $10 \mu \mathrm{m}$ (in terms of size). There is some difference in the fractional contribution of particles in this size range; however, this results from the primary difference between initial and replicate measurements, which is an absence of greater than $10 \mu \mathrm{m}$ agglomerates in the replicate distribution. After sonication, the distributions are statistically similar. Differences in the post-sonication distribution are limited to the distinctness and location of distribution shoulder points at $\sim 2 \mu \mathrm{m}$ and $\sim 6 \mu \mathrm{m}$. The range of the replicate distribution is also somewhat larger, with an upper PSD bound of $13 \mu \mathrm{m}$ as opposed to $10 \mu \mathrm{m}$ in the primary distribution. 


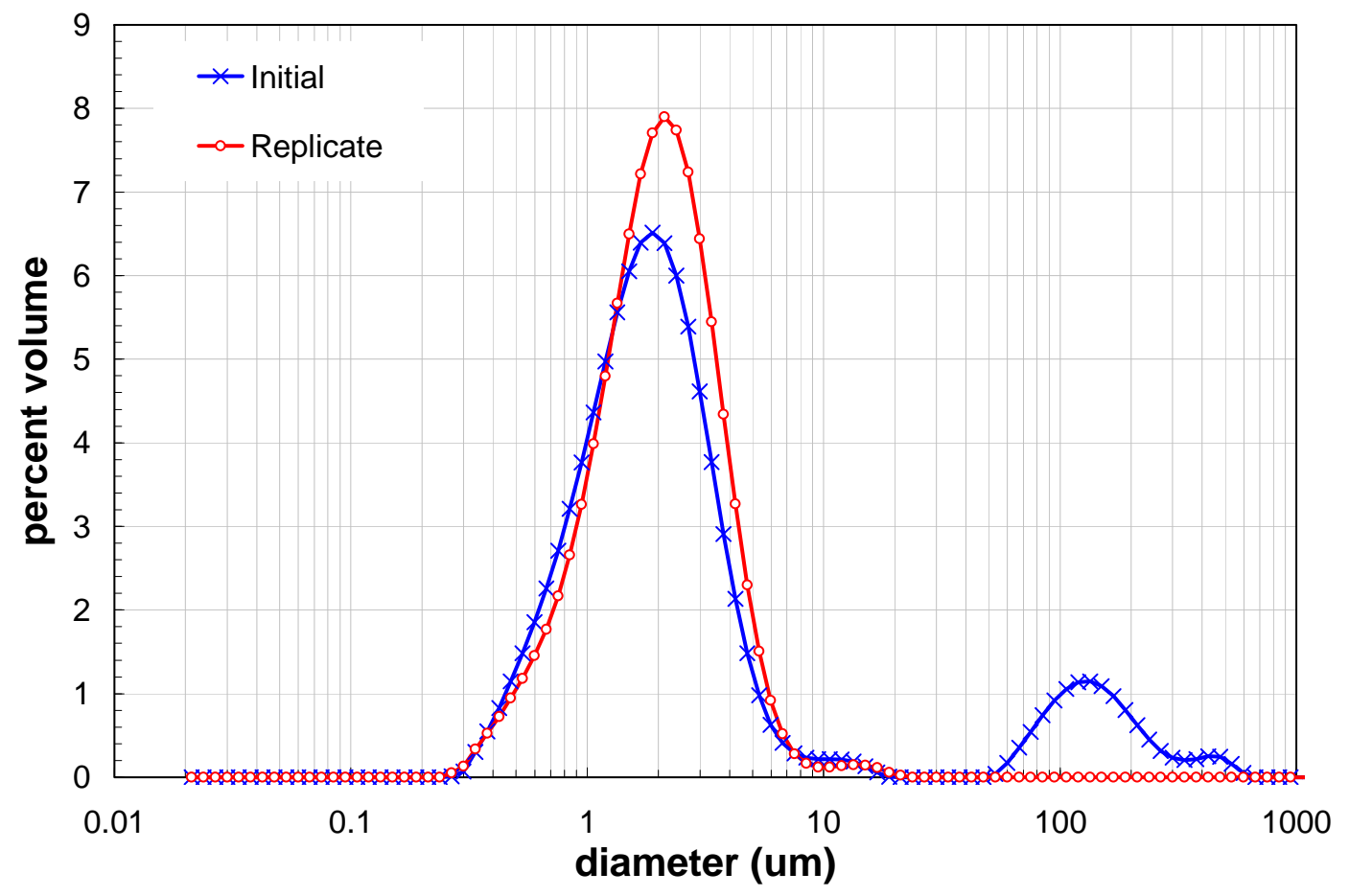

Figure 22. Comparison of initial and replicate particle size measurements at 3000 RPM for sample TI552-G6-21-PSD before sonication.

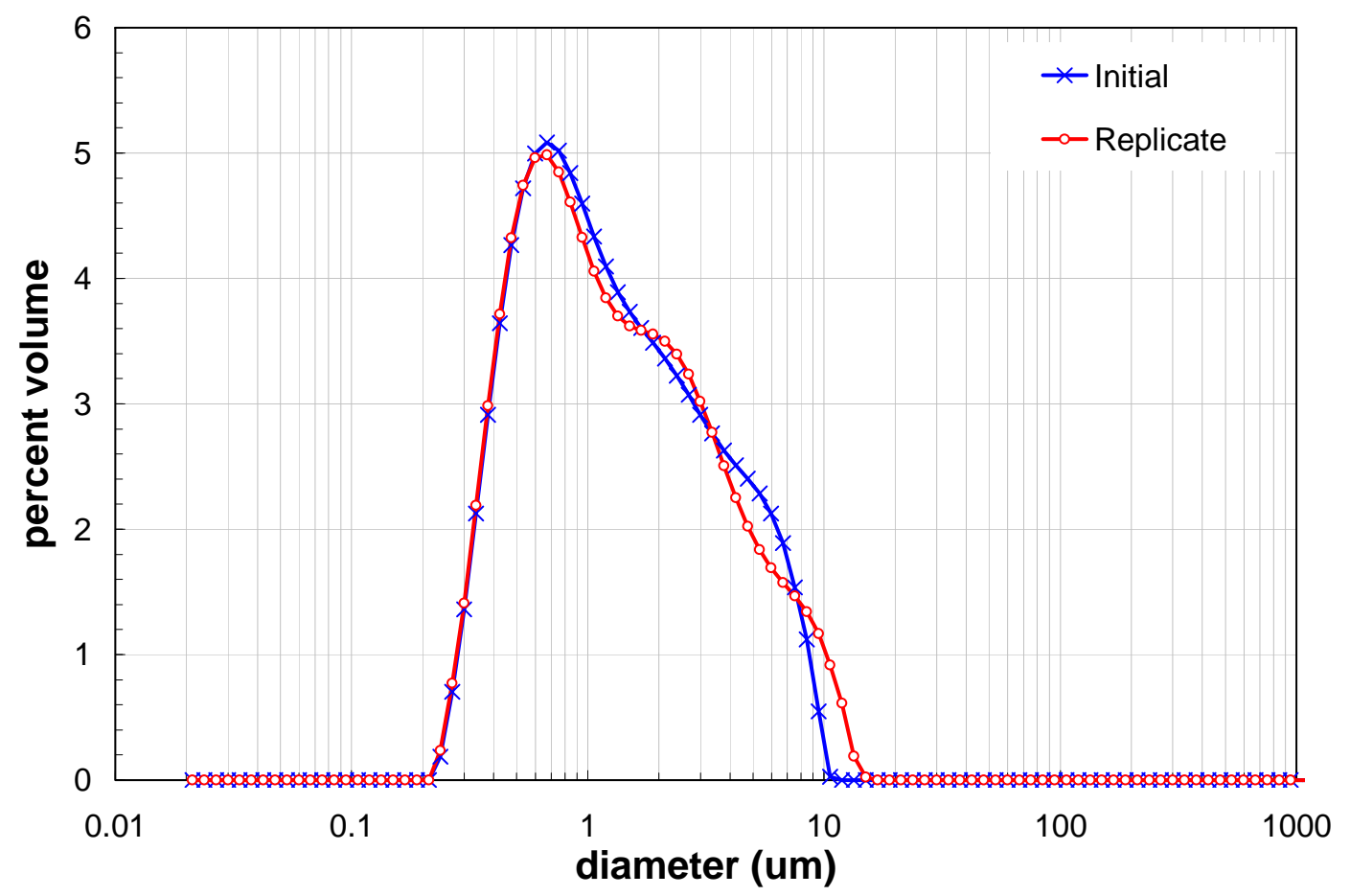

Figure 23. Comparison of initial and replicate particle size measurements at 3000 RPM for sample TI552-G6-21-PSD after sonication. 
In summary, sample TI552-G6-21-PSD has a multimodal PSD with a large population peak centered around $2 \mu \mathrm{m}$, a primary distribution spanning 0.3 to $7 \mu \mathrm{m}$, a low population shoulder spanning 7 to $20 \mu \mathrm{m}$, and a separate distribution of large "particles" spanning 50 to $600 \mu \mathrm{m}$.. Increased pump speeds evidence a difficult-to-suspend fraction of 10 to $100 \mu \mathrm{m}$. Replicate analysis of the pre-sonic PSD indicates poor reproducibility. Indeed, the large particle population spanning 50 to $600 \mu \mathrm{m}$ is entirely absent in the repeat measurement. The application of sonic energy appears to shift the primary peak to submicron sizes and collapse the particle population above $10 \mu \mathrm{m}$ to a size of less than $10 \mu \mathrm{m}$. After sonication, the distribution of particles between 0.2 and $10 \mu \mathrm{m}$ does not change with pump speed. High flows still indicate the presence of large, difficult-to-suspend particles. Measurement repeatability is improved after sonication, with the distributions agreeing within $10 \%$ for the $d(10), d(50)$, and $d(90)$ at low pump speeds (2000 and 3000 RPM). At 4000 RPM, comparability of the post-sonic initial and replicate PSDs is reduced, indicating differences remain in the difficult-to-suspend fraction of particles.

Results for TI552-G6-26-PSD (Oxidative-Leached, Dewatered, and Washed Slurry)

Sample TI552-G6-26-PSD is derived from solids that have been oxidative-leached and subsequently washed to reduce the concentration of sodium in the waste slurry. The final solids concentration of the oxidative-leached, dewatered, and washed slurry is 9.7-wt\%.

Table 16 shows the diameter percentiles as a function of measurement condition. For this sample, the $d(10)$ ranges from $0.42-0.62 \mu \mathrm{m}$, the $d(50)$ ranges from 1.1-1.4 $\mu \mathrm{m}$, and the $\mathrm{d}(90)$ ranges from 3.3-5.6 $\mu \mathrm{m}$. Pre-sonication percentiles indicate mixed PSD functionality with pump speed. Both d(10) and d(50) decrease regardless of pump speed. This decrease could suggest attrition of particles under shear. The pre-sonication $\mathrm{d}(90)$ increases as pump speed is increased from 3000 to $4000 \mathrm{RPM}$; such behavior is consistent with suspension of a dense and/or large species at high flows. On the other hand, the $\mathrm{d}(90)$ at $2000 \mathrm{RPM}$ is larger than that at 3000 RPM. Typically, d(90) is expected to decrease at 2000 RPM (relative to 3000 RPM) because of particle settling. The current $d(90)$ trend suggests better suspension of "large" particle species at 2000 RPM relative to the initial measurement condition. It is possible that this occurs as a result of measurement error; however, the change is significant [ 24\% RPD to the 3000 RPM d(90)] in terms of the typically experimental error for PSD ( 10\%). Another explanation is that shear attrition of poorly suspended large particle agglomerates at measurement condition 2 (4000 RPM) yields a more easily suspended dispersion for measurement condition 3 (2000 RPM).

Table 16. Particle size analysis percentile results for TI552-G6-26-PSD.

\begin{tabular}{|c|c|c|c|c|c||}
\hline $\begin{array}{c}\text { Measurement } \\
\text { Condition }\end{array}$ & Pump Speed & Sonication & $\begin{array}{c}\mathbf{d}(\mathbf{1 0}) \\
{[\boldsymbol{\mu m}]}\end{array}$ & $\begin{array}{c}\mathbf{d}(\mathbf{5 0}) \\
{[\boldsymbol{\mu m}]}\end{array}$ & $\begin{array}{c}\mathbf{d}(\mathbf{9 0}) \\
{[\boldsymbol{\mu m}]}\end{array}$ \\
\hline 1 & 3000 & pre-sonic & 0.62 & 1.4 & 3.3 \\
\hline 2 & 4000 & pre-sonic & 0.52 & 1.2 & 4.8 \\
\hline 3 & 2000 & pre-sonic & 0.49 & 1.1 & 4.1 \\
\hline 4 & 3000 & $25 \%$ & 0.45 & 1.1 & 4.1 \\
\hline 5 & 3000 & $50 \%$ & 0.42 & 1.1 & 4.2 \\
\hline 6 & 3000 & $75 \%$ & 0.43 & 1.2 & 4.4 \\
\hline 7 & 3000 & post-sonic & 0.43 & 1.2 & 4.2 \\
\hline 8 & 4000 & post-sonic & 0.43 & 1.3 & 5.6 \\
\hline 9 & 2000 & post-sonic & 0.44 & 1.2 & 4.3 \\
\hline
\end{tabular}


In terms of the percentiles listed in Table 16, sonication does not appear to significantly affect the PSD. Although the cumulative undersize percentiles after sonication are similar to those at $2000 \mathrm{RPM}$ before sonication (and as such, generally lower than the initial measurement condition 1 PSD), it is difficult to determine if this similarity is a result of sonication or the attrition / dissolution process observed prior-to sonication. The PSD is relatively constant during sonication (conditions 4 through 6) such that any changes that do result from sonication either 1) occur at low sonic power and within the time frame of a single measurement condition and/or 2) do not manifest well in terms of the d(10), d(50), and $d(90)$. As shown in Figure 25, the population distribution of particles does actually change in response to sonication. This highlights the difficulty in accessing PSD behavior from a limited set of percentiles alone: subtle changes in PSD do not always manifest by changes in the percentiles.

After sonication is removed, the PSD percentiles do not change significantly, suggesting a stable particle configuration has been reached. High pump speeds still result in an increase in d(90), which indicate that difficult-to-suspend particles are still present after sonication. At low pump speeds, the percentiles are statistically similar to those at 3000 RPM (post-sonic). From the latter observation, it can be inferred that the state of particle suspension at 2000 RPM is similar to that at 3000 RPM.

Figure 24 shows the pre-sonic particle size distribution for sample TI552-G6-26-PSD as a function of pump speed. The initial distribution at 3000 RPM is relatively unimodal and spans 0.3 to 200 $\mu \mathrm{m}$. It has a large peak centered at $\sim 1.3 \mu \mathrm{m}$ and a much smaller (in terms of volume contribution) secondary peak centered at $10 \mu \mathrm{m}$. During measurement conditions 2 and 3 (which correspond to pump speeds of 4000 and 2000 RPM, respectively), the large primary peak shifts to smaller particle sizes, such that the peak is centered at $1 \mu \mathrm{m}$. This confirms the pre-sonic decrease in particle percentiles listed in Table 16. As stated previously, possible mechanisms for this decrease include shearing apart of agglomerates under shear or particle dissolution. The pre-sonic distributions at 2000 and 4000 RPM appear identical. Relative to 3000 RPM, they show an increased population of 4 to $10 \mu \mathrm{m}$ particles. Relative to each other, the 4000 RPM distribution exhibits a population peak over $\sim 20 \mu \mathrm{m}$ up to $80 \mu \mathrm{m}$ not present in either 2000 or 3000 RPM distributions. This peak is likely a result of improved particle suspension. The 2000 RPM distribution shows a small peak around 100-200 $\mu \mathrm{m}$. This could either be a loose particle flocculate that forms under weak shear conditions or an artifact of the analysis. 


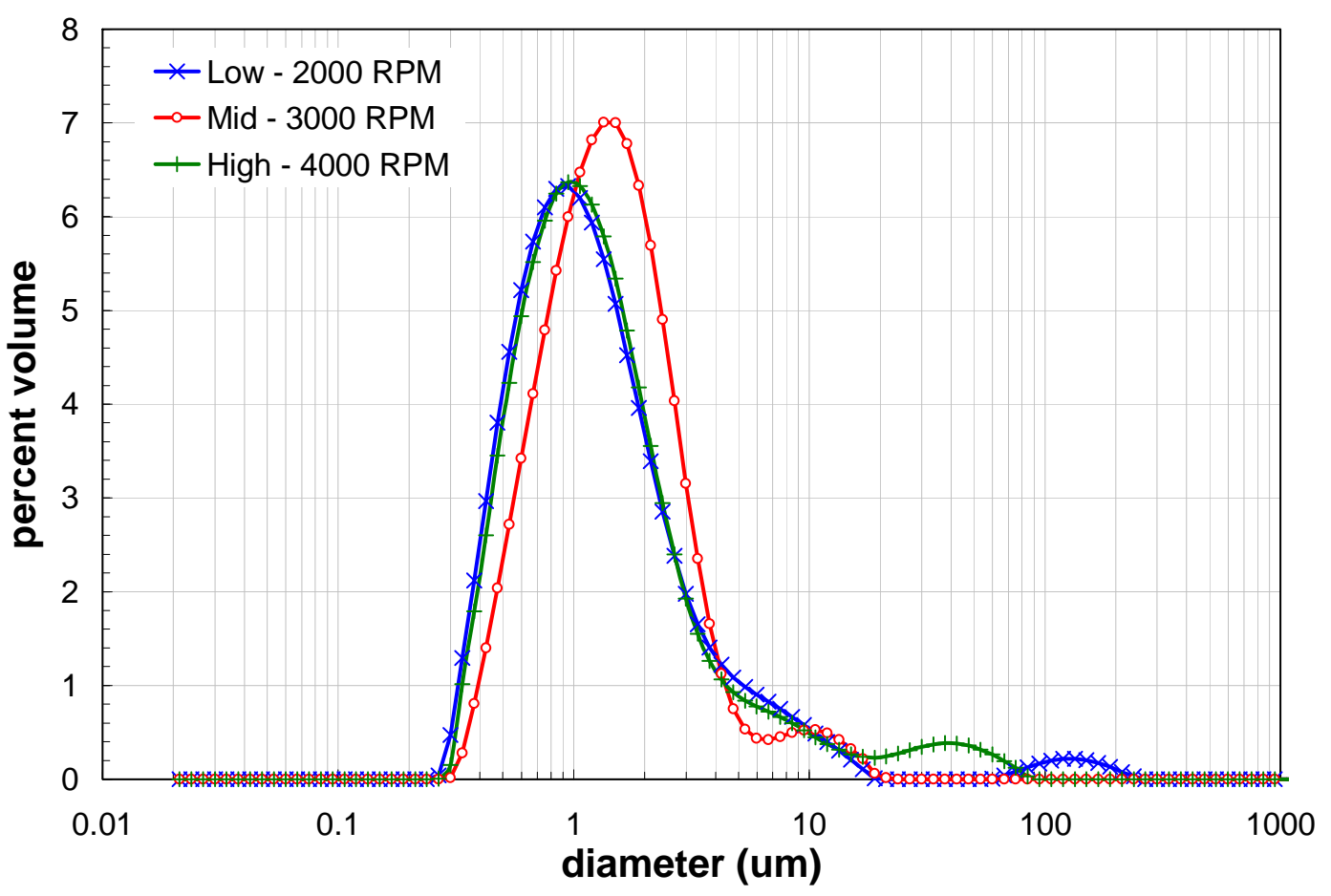

Figure 24. Measured particle size distribution for sample TI552-G6-26-PSD as a function of pump speed before sonication.

Figure 25 shows the particle size distribution for sample TI552-G6-26-PSD before, during, and after sonication. Although the percentiles listed in Table 16 indicate sonication effects are minimal, the distribution profiles suggests otherwise. Relative to measurement condition 1, sonication appears to increase the population of submicron particles and particles in the 3 to $\sim 10 \mu \mathrm{m}$ range. Sonication appears to reduce the population of greater than $10 \mu \mathrm{m}$ particles. The resulting distribution is bimodal, with population peak maxima at 0.7 and $2 \mu \mathrm{m}$, respectively. Based on previous particle size data for Group $5 / 6$, the changes in size distribution with sonication are most likely caused by disruption of agglomerates. In terms of typical particle mechanics, possible explanations accounting for increases in both submicron and 3 to $10 \mu \mathrm{m}$ particles are 1) disruption of difficult-to-suspend particles / agglomerates into two distinct size fractions corresponding to boehmite and manganese particle species or 2) dissolution of 0.7 to $3 \mu \mathrm{m}$ particles. Dissolution is unlikely, as the changes in distribution were not accompanied by the expected drop in sample obscuration (i.e., how much light is scattered) that should occur when particles are dissolved. In addition, all PSD samples were washed before delivery for analysis, so dissolution effects during analysis should be minimal. Indeed, behavior of sample TI552-G6-26-PSD should be similar to the oxidative-leached only sample (TI552-G6-21-PSD).

Another explanation for the increased 3-10 $\mu \mathrm{m}$ is that sonication of particles induces agglomerate of some of the 1-2 $\mu \mathrm{m}$ particles into larger structures. This behavior served as explanation for the PSD behavior of Group 5 initial characterization samples. Although such sonic-induced agglomeration is not typically, it can occur for particle dispersions existing in a meta-stable state of aggregation. It should be noted that Group 6 solids are expected to be significantly consumed by the leached processes, such that the solids remaining after caustic- and oxidative-leaching operations are primarily Group 5 solids and 
manganese solids precipitated during the oxidative-leach. For this reason, PSD behavior similar to that of Group 5 could be expected. That being stated, if sonication-induced agglomeration is occurring for the Group 5/6 waste, its nature is different from that observed in Group 5, which was characterized by the formation of a large dominant peak at $10 \mu \mathrm{m}$ rather than the formation of a bimodal distribution with maxima at 0.7 and $2 \mu \mathrm{m}$ observed herein. Overall, changes in the PSD for sample TI552-G6-26-PSD with sonication are difficult to describe in terms of expected particle / agglomerate behavior.

Figure 26 shows the post-sonic particle size distribution for sample TI552-G6-26-PSD as a function of pump speed. Post-sonic PSD indicate a stable distribution of particles, as the distribution of particles from 0.2 to $10 \mu \mathrm{m}$ does not change with pump speed or time. The only significant change in the PSD that occurs is an increased fraction of 10 to $60 \mu \mathrm{m}$ particles at $4000 \mathrm{RPM}$. These difficult-tosuspend particles were observed at 4000 RPM before sonication. The upper-bound of $60 \mu \mathrm{m}$ observed after sonication appears reduced relative to its $80 \mu \mathrm{m}$ pre-sonic boundary. Without the benefit of statistical analysis, it is difficult to ascertain if this difference is significant. On the other hand, such a decrease in upper bound would be consistent with disruption of agglomerate particles and would help explain the increase in the volume contribution of 3-10 $\mu$ m particles observed during sonication.

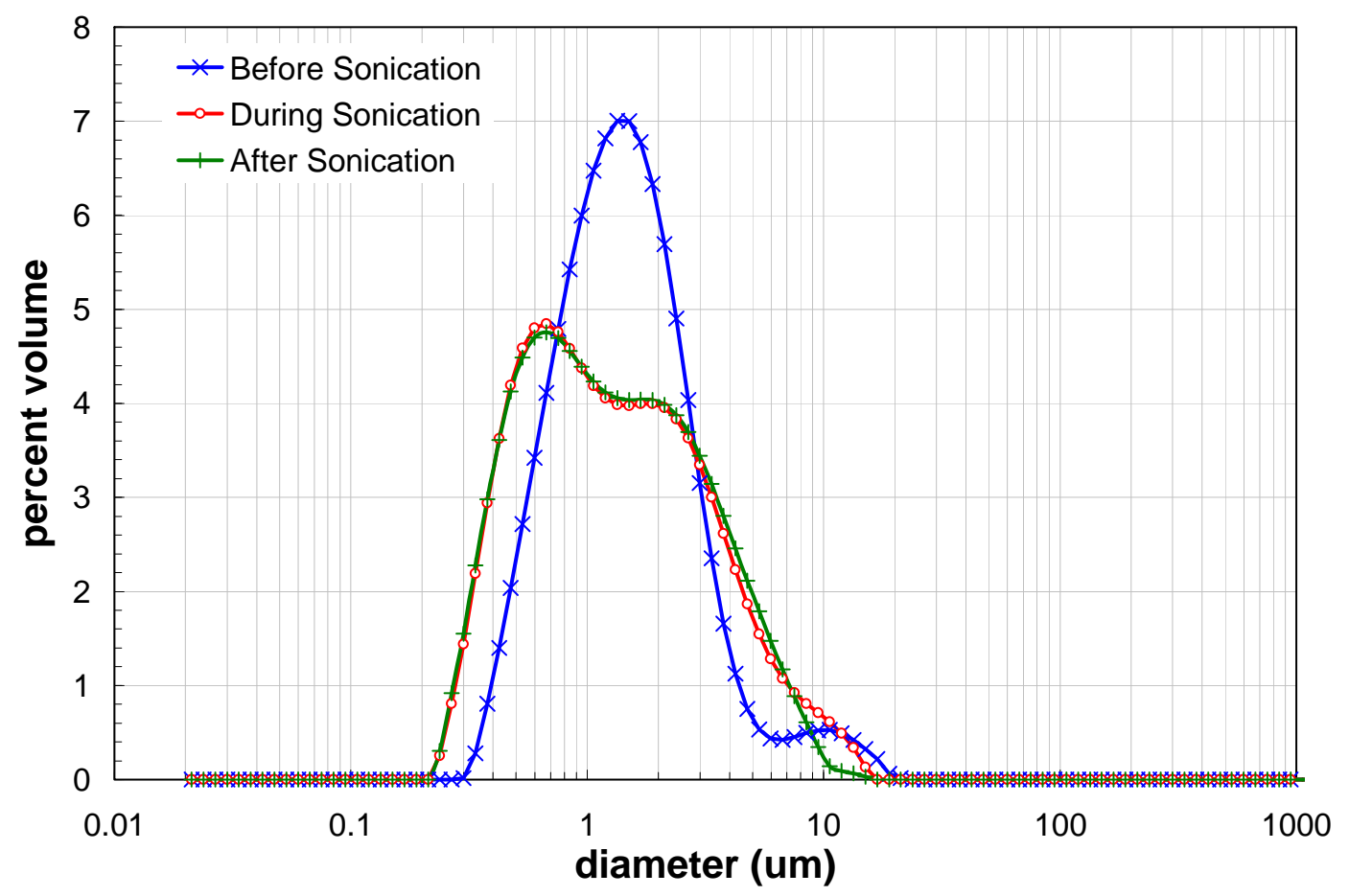

Figure 25. Measured particle size distribution for sample TI552-G6-26-PSD at a single pump speed before, during, and after sonication. 


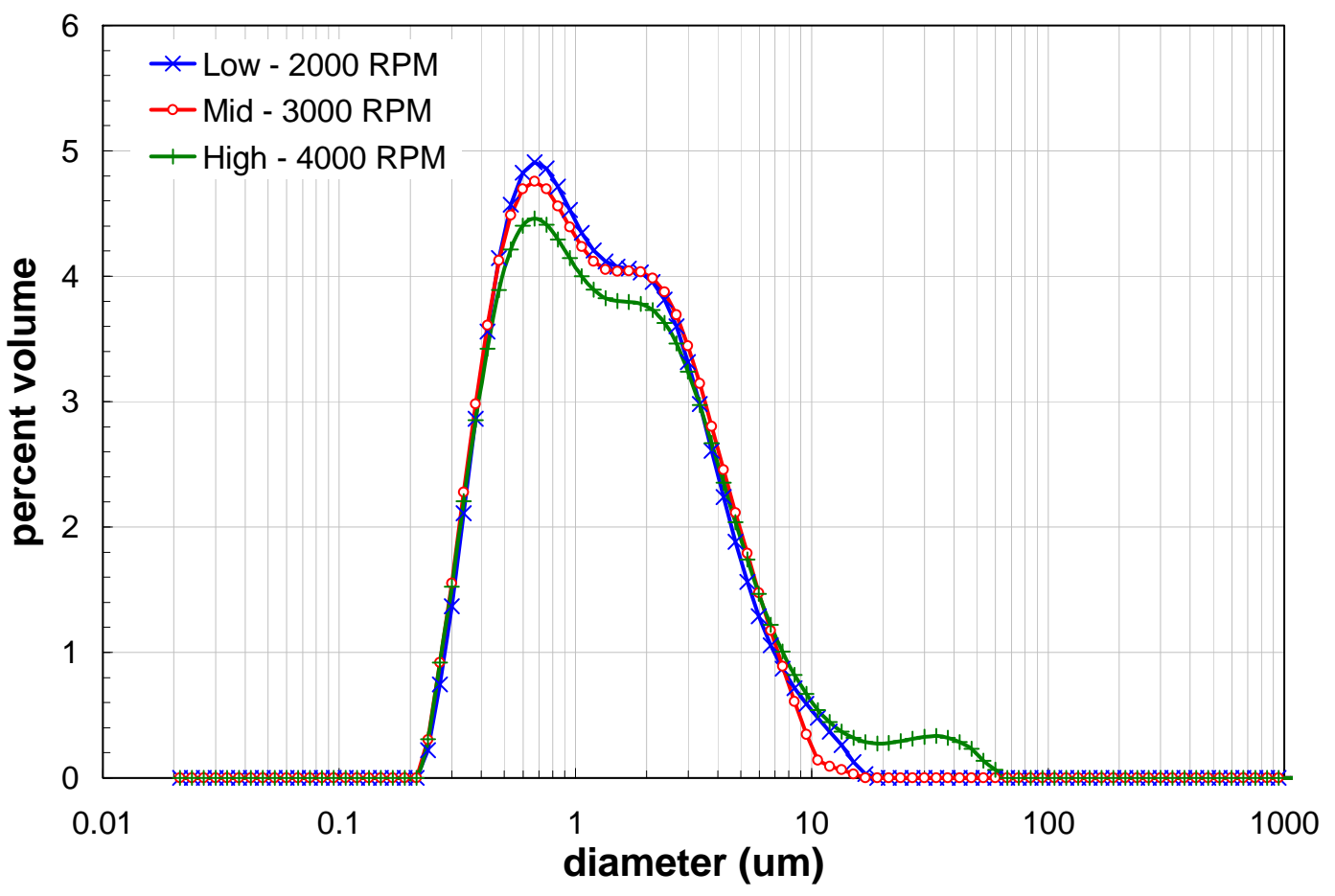

Figure 26. Measured particle size distribution for sample TI552-G6-26-PSD as a function of analyzer pump speed after sonication.

In summary, sample TI552-G6-26-PSD has an initial particle population spanning from $\sim 0.2 \mu \mathrm{m}$ to $\sim 20 \mu \mathrm{m}$ at $3000 \mathrm{RPM}$. The pre-sonic distribution is dominated by a single sharp peak centered at $\sim 1$ $\mu \mathrm{m}$ although the peak also exhibits a small shoulder of particles at $\sim 10 \mu \mathrm{m}$. Increased pump speed suggests difficult-to-suspend particles ranging from 20 to $80 \mu \mathrm{m}$. A decrease in the particle diameter characterizing the main $\sim 1 \mu \mathrm{m}$ population suggests shear disruption of agglomerates or dissolution of particles even before sonication. Sonication increases the particle contribution of both submicron and 3 to $10 \mu \mathrm{m}$ particles. Previous PSD results for Group 5/6 samples indicate that these changes during sonication likely result from disruption of agglomerates. For the current sample, this is difficult to confirm as the post-sonic volume contribution of large and "difficult-to-suspend" particles appears relatively unchanged. After sonication, the main distribution (i.e., that over 0.2 to $10 \mu \mathrm{m}$ ) is not sensitive to changes in pump speed. PSD at high pump speeds still exhibit a 10 to $60 \mu \mathrm{m}$ fraction of "difficult-tosuspend” particles not observed at lower pump speeds.

\section{Results for TI552-G6-32-PSD (Combined Leach Slurry)}

Sample TI552-G6-32-PSD is derived from a mixture of Group 5/6 waste solids that have been oxidative-leached, dewatered, and washed and Group 5 waste solids that have been caustically-leached, dewatered, and washed. This combined leach slurry has a solids concentration of 8.0-wt\%.

Table 17 shows the diameter percentiles as a function of measurement condition. For this sample, the $d(10)$ ranges from $0.42-0.57 \mu \mathrm{m}$, the $d(50)$ ranges from 1.1-2.3 $\mu \mathrm{m}$, and the $d(90)$ ranges from 3.2-64 $\mu \mathrm{m}$. In terms of pre-sonic behavior, the $\mathrm{d}(10)$ shows a decrease over measurement conditions 1 to 3, which indicates possible shear disruption or dissolution effects like those observed for sample TI552G6-26-PSD. On the other hand, an increase in pump speed from 3000 to 4000 RPM causes significant increases in the $\mathrm{d}(50)$ and $\mathrm{d}(90)$. This increase is consistent with the presence of difficult-to-suspend 
particles noted in previous Group 5/6 CUF testing samples. Relative to 3000 RPM, a lowering of the pump speed to 2000 RPM does not yield a significant change in d(50), but does appear to cause an increase in the $d(90)$. Typically, a lowered $d(90)$ would be expected at 2000 RPM. The current observation may result from improved dispersion of particles following the $4000 \mathrm{RPM}$ condition. It may also indicate shear disruption of large, difficult-to-suspend aggregates into structures which contribute to the $\mathrm{d}(90)$.

Table 17. Particle size analysis percentile results for TI552-G6-32-PSD.

\begin{tabular}{||c|c|c|c|c|c||}
\hline $\begin{array}{c}\text { Measurement } \\
\text { Condition }\end{array}$ & Pump Speed & Sonication & $\begin{array}{c}\mathbf{d}(\mathbf{1 0}) \\
{[\boldsymbol{\mu m}]}\end{array}$ & $\begin{array}{c}\mathbf{d}(\mathbf{5 0}) \\
{[\boldsymbol{\mu m}]}\end{array}$ & $\begin{array}{c}\mathbf{d}(\mathbf{9 0}) \\
{[\boldsymbol{\mu} \mathbf{m}]}\end{array}$ \\
\hline 1 & 3000 & pre-sonic & 0.57 & 1.2 & 3.2 \\
\hline 2 & 4000 & pre-sonic & 0.55 & 1.9 & 64 \\
\hline 3 & 2000 & pre-sonic & 0.48 & 1.1 & 4.3 \\
\hline 4 & 3000 & $25 \%$ & 0.42 & 1.1 & 5.0 \\
\hline 5 & 3000 & $50 \%$ & 0.44 & 1.2 & 4.9 \\
\hline 6 & 3000 & $75 \%$ & 0.45 & 1.3 & 5.0 \\
\hline 7 & 3000 & post-sonic & 0.44 & 1.3 & 5.1 \\
\hline 8 & 4000 & post-sonic & 0.48 & 2.3 & 46 \\
\hline 9 & 2000 & post-sonic & 0.45 & 1.3 & 5.1 \\
\hline
\end{tabular}

Changes in the percentiles with sonication are difficult to quantify. Relative to condition 1 , measurement condition 4, which corresponds to the initial sonication of sample TI552-G6-32-PSD, shows significant difference in $10^{\text {th }}$ and $90^{\text {th }}$ diameter percentiles. Based on the pre-sonic behavior, it is likely that part (if not all of this change) occurs as a result of transient particle processes prior-to sonication. Any changes do occur as a result of sonication occur immediately, as continued sonication (measurement conditions 5 and 6) does not effect significant changes in the $\mathrm{d}(10), \mathrm{d}(50)$, and $\mathrm{d}(90)$. In addition, the sonicated PSD is stable after application of sonic energy is stopped. Measurement condition 7 is statistically similar to measurement condition 6 .

Post-sonic PSD percentiles show some pump speed dependency. Percentiles at 2000 and 3000 RPM are statistically similar. At 4000 RPM, a statistically significant increase in d(50) and d(90) indicate the suspension of large and/or dense particles or particle agglomerates. This behavior corresponds to a similar increase observed in the pre-sonic percentiles at 4000 RPM, suggesting that the particles yielding this increase are at least in-part robust with respect to sonication.

Figure 27 shows the pre-sonic particle size distribution for sample TI552-G6-32-PSD as a function of pump speed. The initial distribution at 3000 RPM spans 0.3 to $\sim 20 \mu \mathrm{m}$ and consists of a single dominant peak with maximum just above $1 \mu \mathrm{m}$ and a shoulder population ranging from 4 to 20 $\mu \mathrm{m}$. Pre-sonic measurements at 2000 and 4000 RPM observe a decrease in the peak maximum to particle diameters just below $1 \mu \mathrm{m}$. This decrease is consistent with that observed in the $\mathrm{d}(10)$ over measurement conditions 1 to 3 and may result from shear disruption of agglomerates or particle dissolution. Overall, the distribution of particles from 0.3 to $20 \mu \mathrm{m}$ is similar at 2000, 3000, and $4000 \mathrm{RPM}$. On the other hand, the increase in the pump speed to 4000 RPM yields a second peak spanning 20 to $130 \mu \mathrm{m}$ and 
having a maximum population at $50 \mu \mathrm{m}$. This secondary peak likely corresponds to difficult-to-suspend particles / agglomerates only sampled by the analyzer at high flow rates.

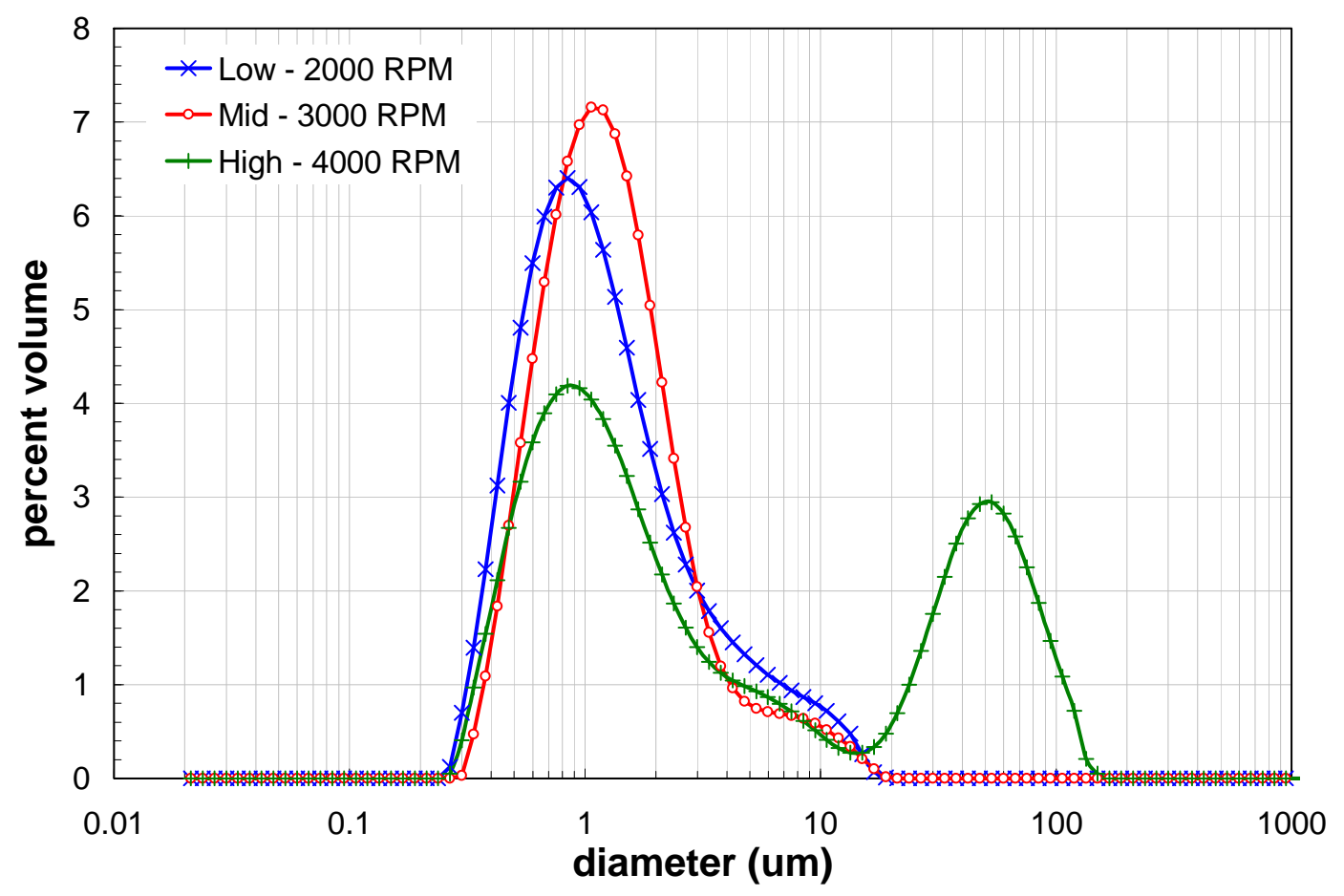

Figure 27. Measured particle size distribution for sample TI552-G6-32-PSD as a function of pump speed before sonication.

Figure 28 shows the particle size distribution for sample TI552-G6-32-PSD before, during, and after sonication. Sonication of sample TI552-G6-32-PSD yields changes in the particle speciation similar to those observed for TI552-G6-26-PSD. Specifically, the distribution resulting from sonication appears bimodal, with population peaks at 0.6 and $2 \mu \mathrm{m}$. The population of both submicron and 2 to $10 \mu \mathrm{m}$ particles is increased by sonication. Increases in the submicron population are probably a result of sonic disruption of particles in the primary range $(0.3$ to $10 \mu \mathrm{m})$. The source of $2-10 \mu \mathrm{m}$ particles is difficult to identify because the post-sonic size distribution (Figure 29) still exhibit a large population of difficult-tosuspend particles. The changes in upper bound of the large / dense peak observed at 4000 RPM before and after sonication (120 and $100 \mu \mathrm{m}$, respectively), may be large enough to suggest some particle disruption. With this in mind, it should be noted that the increase in 2-10 $\mu \mathrm{m}$ "particles" could also be a result of shear-induced agglomeration. 


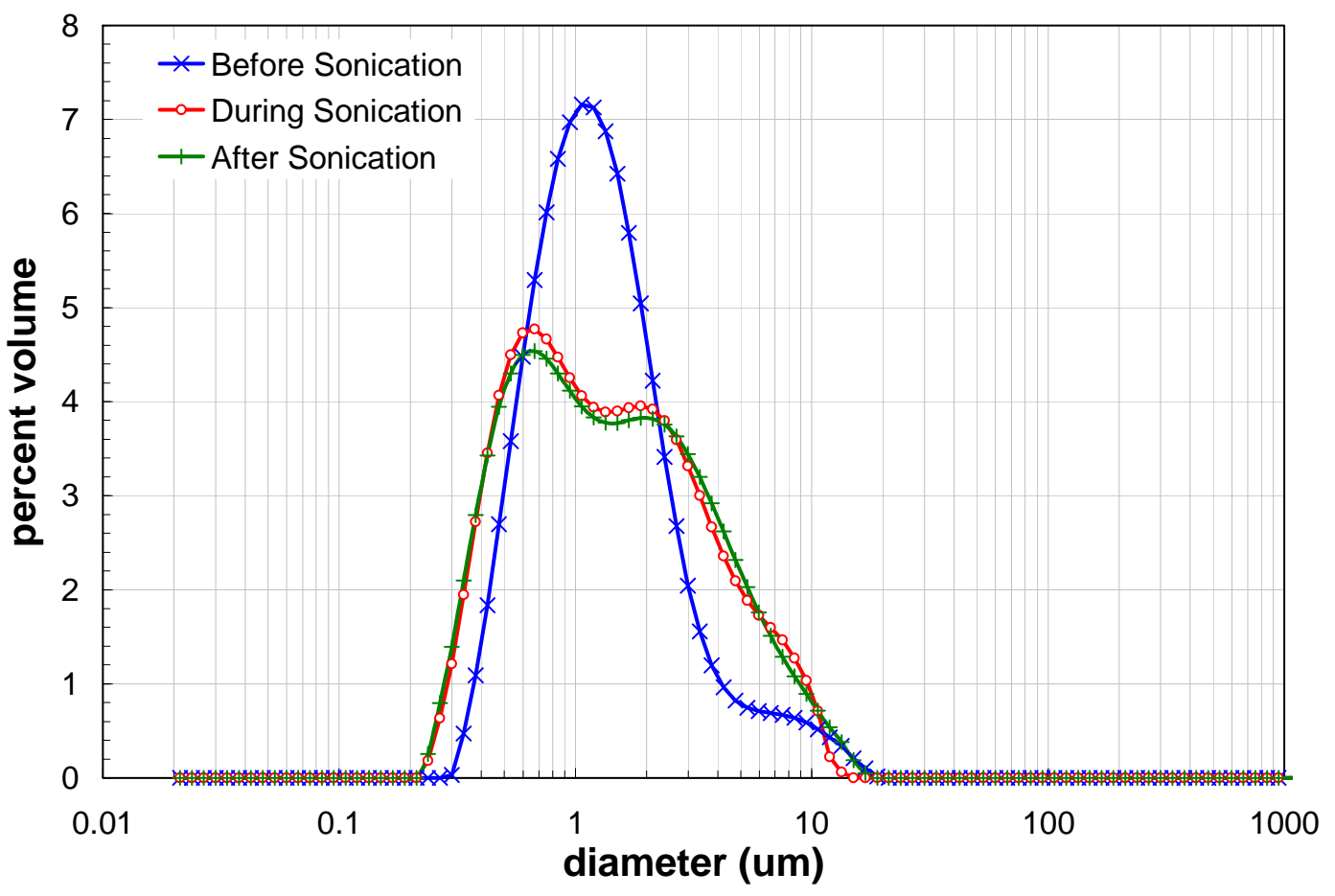

Figure 28. Measured particle size distribution for sample TI552-G6-32-PSD at a single pump speed before, during, and after sonication.

Figure 29 shows the post-sonic particle size distribution for sample TI552-G6-32-PSD as a function of pump speed. Post-sonic PSD indicate a stable distribution of particles: the distribution of particles from 0.2 to $10 \mu \mathrm{m}$ does not change with pump speed or time. At $4000 \mathrm{RPM}$, the fraction of difficult-to-suspend particles from 20 to $\sim 100 \mu \mathrm{m}$ observed before sonication re-appears, indicating that the particles are stable enough to survive prolonged sonication. The upper-bound of $100 \mu \mathrm{m}$ observed after sonication appears reduced relative to its $\sim 130 \mu \mathrm{m}$ pre-sonic boundary. This decrease is consistent with disruption of agglomerate particles and explains the increase in the volume contribution of 3-10 $\mu \mathrm{m}$ particles observed during sonication.

In summary, sample TI552-G6-32-PSD has a pre-sonic distribution that spans 0.3 to $\sim 20 \mu \mathrm{m}$ and consists of a single dominant peak with maximum just above $1 \mu \mathrm{m}$ and a shoulder population ranging from 4 to $20 \mu \mathrm{m}$. High flows appear to suspend particles in the 20 to $\sim 130 \mu \mathrm{m}$ size range. In addition, the peak maximum at $\sim 1 \mu \mathrm{m}$ appears to shift slightly to smaller diameters as a result of pre-sonic operations. Sonication of the dispersion results in a relatively bimodal size distribution, with population peaks at 0.6 and $2 \mu \mathrm{m}$. The fractions of both submicron and 2 to $10 \mu \mathrm{m}$ particles are increased as a result of sonication. After sonication, the PSD is relatively stable with respect to flow and time. The primary distribution over 0.2 to $10 \mu \mathrm{m}$ does not change significantly; however, high flows still appear to suspend a large particle population ranging from 20 to $\sim 100 \mu \mathrm{m}$. 


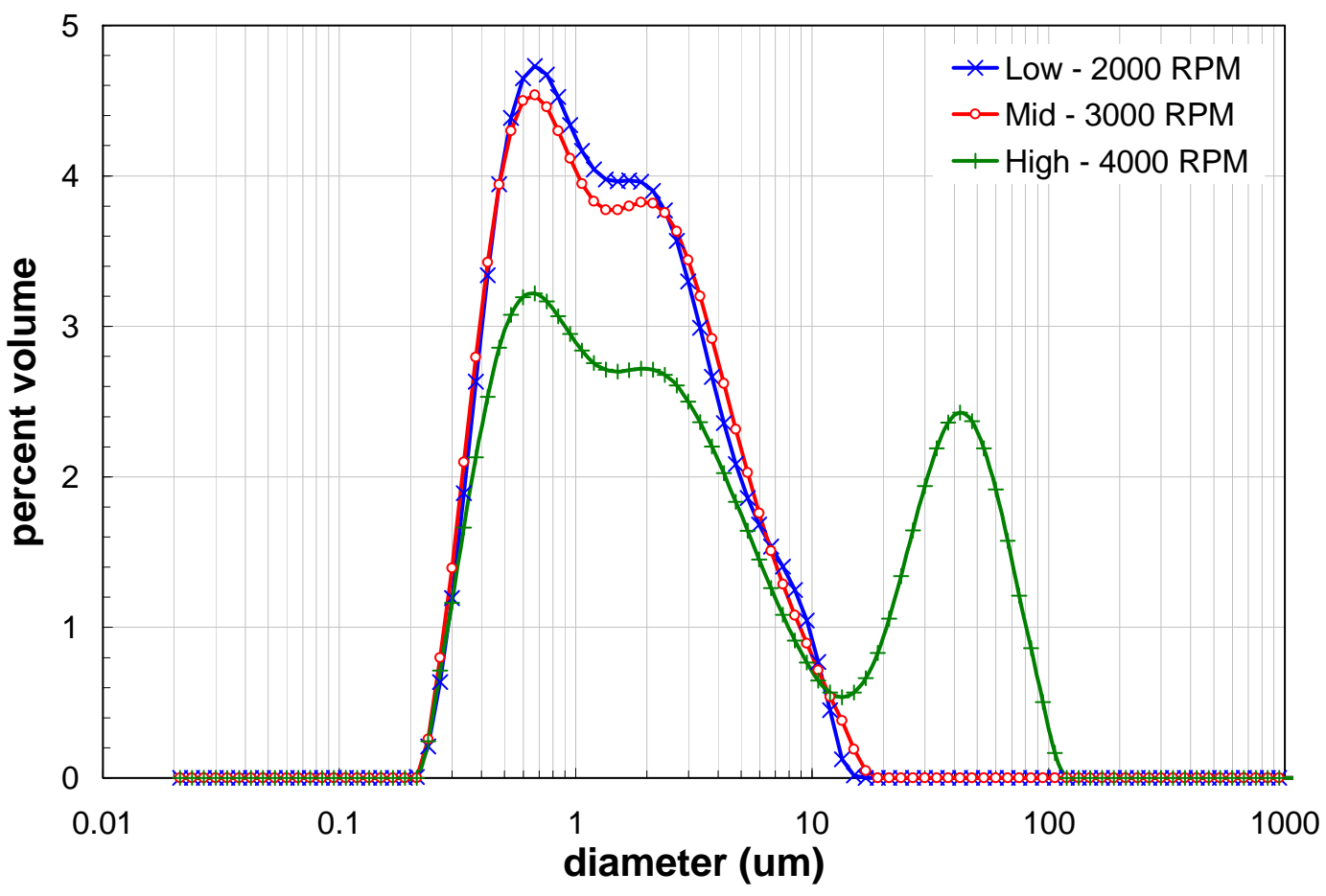

Figure 29. Measured particle size distribution for sample TI552-G6-32-PSD as a function of analyzer pump speed after sonication.

\subsection{Influence of CUF Processing on Group 5/6 Mixture PSD}

Comparison of the percentiles and distributions presented in Section 9.2 of this report can highlight the effects of CUF processing on Group 5/6 waste mixture PSD. Caution must be used when directly comparing PSDs from the various points in CUF processing, as these PSDs include both primary particles and particle aggregates. The structure of the aggregate fractions depends on 1) physical conditions such as the analyzer pump speed and sonication state and 2) chemical conditions such as particle interaction potentials and sample history.

The expected outcome of prolonged CUF processing is a reduction in the size of particles from shear breakage and dissolution effects, respectively. Caustic leaching may also effect a similar reduction, especially in the case of incomplete leaching; however, removal of leachable solid species may reveal the size distribution of particles only minimally represented in the initial sample. Because the pump speed used during size analysis can also shear apart particle aggregates (as well as influence the volume of aggregates suspended), it is important to compare only distributions measured at the same pump speed. Even under comparable shear, differences in particle chemistry, which are highly likely when comparing pre- and post-leach PSDs, may result in different degrees of aggregate formation.

In an attempt to mitigate these issues, comparison of the process PSDs reported above will be made by comparing PSDs at a single measurement condition. Replicate analysis of sample TI552-G6-21PSD suggest that the most reproducible PSDs (i.e., those within the standard $10 \%$ allowed for comparison) for Group 5/6 waste mixtures are post-sonication PSDs at medium to low pump speeds. As such, all comparisons will be made at measurement condition 7, which corresponds to the post-sonication 
3000 RPM PSD test (see Table 6) This allows all PSDs to be compared at the same pump speed (3000 RPM) after agglomerate disruption.

The following sub-sections discuss changes in the Group 5/6 waste mixture PSD as a function of the CUF processing steps applied to the test slurry. Specifically, the influence of the following CUF operations on PSD will be examined:

- $\quad$ initial shearing and filtration of the pure Group 6 (S-Saltcake) slurry

- mixing and filtration of Group 5 and 6 wastes to form the Group 5/6 mixed slurry

- caustic-leaching and dewatering of the Group 5/6 mixed slurry

- post-caustic-leach washing of the Group 5/6 mixed slurry

- oxidative-leaching of the Group 5/6 mixed slurry

- $\quad$ post-oxidative-leach washing of the Group 5/6 mixed slurry

- mixing of Group 5/6 leached slurry with Group 5 leached slurry

Initial Shearing and Filtration of Group 6 (S-Saltcake) Slurry

Figure 30 shows the influence of shear and filtration on the PSD of the Group 6 (sample TI552G6-3-PSD) slurry initially loaded into the CUF. The particle size sample was collected six hours after the homogenized Group 6 sample was added to the CUF. During this time, the waste sample was circulated through the CUF in a recycle mode through the filter while rheology measurements were occurring. As a reference, the PSD measured for the Group 6 S-Saltcake initial characterization sample (TI490-G6-SWL-PSD-2) is included. Table 18 shows the corresponding $d(10), d(50)$, and $d(90)$ for the distributions shown in Figure 30. The Group 6 solids PSD derived from CUF testing is similar to that derived from initial characterization. Both span $\sim 0.2 \mu \mathrm{m}$ up to $\sim 20 \mu \mathrm{m}$ and have maxima at $2 \mu \mathrm{m}$. Relative to the CUF testing sample, the initial characterization PSD shows an increased fractional contribution of 5-20 $\mu \mathrm{m}$ particles and a decreased fractional contribution of 0.6 to $5 \mu \mathrm{m}$ particles. This difference can be attributable to disruption apart of 5-20 $\mu$ m particles in the CUF testing sample as a result of the mechanical shear needed to pump the slurry during filtration. In terms of cumulative undersize percentiles, the CUF testing sample shows significantly (greater than 10\%) lower d(50) and d(90). Overall, both graphical and tabular PSD data indicate that CUF processing reduces the size of Group 6 solids, likely as a result of mechanical shear. These observations are comparable to behavior in Group 5 solids PSD as a function of shear in the CUF, which also showed a decrease in the size of particles as a result of prolonged CUF processing [5].

Table 18. PSD percentiles showing the influence of shear and filtration on the PSD of Group 6 (S-saltcake) solids at measurement condition 7 - 3000 RPM, post-sonication (see Table 6).

\begin{tabular}{||l|c|c|c||}
\hline Sample & $\begin{array}{c}\mathbf{d}(\mathbf{1 0}) \\
{[\boldsymbol{\mu m}]}\end{array}$ & $\begin{array}{c}\mathbf{d}(\mathbf{5 0}) \\
{[\boldsymbol{\mu} \mathbf{m}]}\end{array}$ & $\begin{array}{c}\mathbf{d}(\mathbf{9 0}) \\
{[\boldsymbol{\mu} \mathbf{m}]}\end{array}$ \\
\hline Initial Characterization (TI490-G6-S-WL-PSD-2) & 0.76 & 2.7 & 10 \\
\hline CUF Testing (TI552-G6-3-PSD) & 0.70 & 2.4 & 8.6 \\
\hline
\end{tabular}




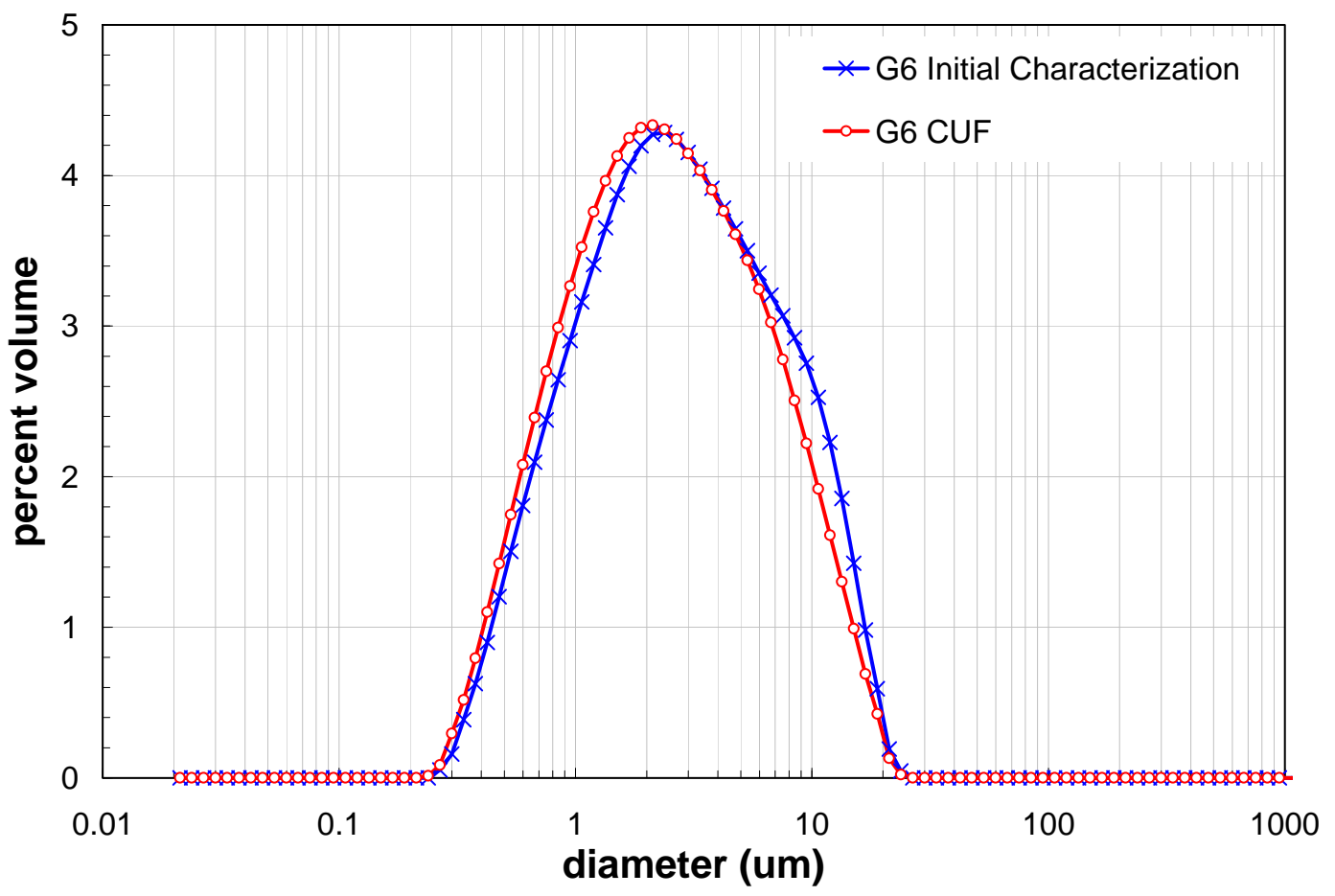

Figure 30. Influence of shear and filtration on the PSD of Group 6 (S-saltcake) solids at measurement condition 7 - 3000 RPM, post-sonication (see Table 6). Note: Differences in the percent volume scaling between the current figure and Figure 6 result from different histogram binning. Original binning for Group 6 Initial Characterization PSD (as presented in Figure 6) was 100 bins spanning 0.01 to $10,000 \mu \mathrm{m}$ For the current figure, 100 bins spanning 0.02 to $2000 \mu \mathrm{m}$. This results in a decrease in the magnitude of volume contribution per bin in Figure 30.

\section{Mixing of Group 5 and 6 Wastes}

Figure 31 shows the PSD of CUF testing for Group 5 and 6 solids and the solids PSD that results when these two waste groups are combined. The PSD for Group 5 corresponds to CUF testing sample TI540-G5-6-PSD. Table 19 shows the corresponding sample IDs, $d(10), d(50)$, and $d(90)$ for the distributions shown in Figure 31. The Group 6 solids initially loaded into the CUF show a unimodal distribution spanning $\sim 0.2$ to $\sim 20 \mu \mathrm{m}$ with a maxima at $2 \mu \mathrm{m}$. The results from previous testing indicate that Group 5 solids show a bimodal distribution spanning 0.2 to $30 \mu \mathrm{m}$, with maxima at $\sim 0.6 \mu \mathrm{m}$ and $\sim 6$ $\mu \mathrm{m}$, after having undergone mechanical shear in the CUF. Particle size analysis of the Group 5/6 waste slurry used for high-solids CUF testing indicates that the mixed solids have a similar size distribution to that of Group 5 solids. Specifically, the mixed waste PSD is relatively bimodal and spans 0.2 to $20 \mu \mathrm{m}$. Instead of two distinct maxima, the mixed solids show only a single maximum at $\sim 5 \mu \mathrm{m}$ but do show a strong shoulder at $0.7 \mu \mathrm{m}$. It should be noted that the resemblance between the Group 5 waste solids and Group 5/6 mixed waste solids PSD is expected, as the mixture is comprised of approximately 68-wt\% Group 5 solids. The Group 5/6 waste mixture does show an increased fraction of 0.7 to $8 \mu \mathrm{m}$ particles relative to Group 5, suggesting a possible increase in insoluble solids in this size range as a result of Group 6 particle addition. 


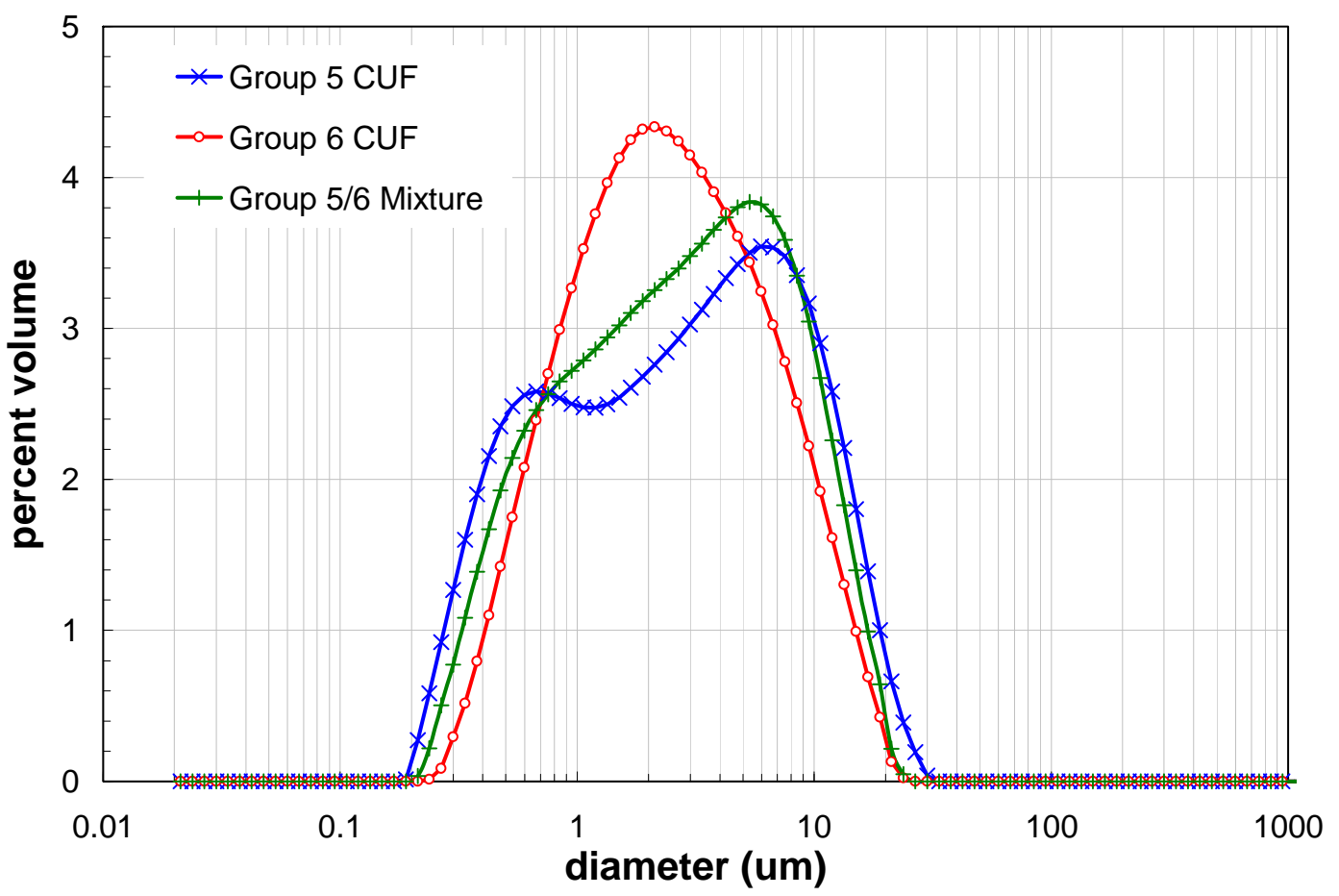

Figure 31. Comparison of Group 5 and 6 waste PSDs and the PSD of the resulting from mixing at measurement condition 7 - 3000 RPM, post-sonication (see Table 6). Note: Differences in the percent volume scaling for Group 5 CUF data between the current figure and Figure 4 result from different histogram binning. Original binning for Group 5 CUF sample TI540-G5-6-PSD was 100 bins spanning 0.01 to $10,000 \mu \mathrm{m}$ For the current figure, 100 bins spanning 0.02 to $2000 \mu \mathrm{m}$. This results in a decrease in the magnitude of volume contribution per bin in Figure 31.

Table 19. PSD percentiles for Group 5, 6, and 5/6 mixtures at measurement condition 7 -3000 RPM, post-sonication (see Table 6).

\begin{tabular}{||l|c|c|c||}
\hline \hline Sample & $\begin{array}{c}\mathbf{d}(\mathbf{1 0}) \\
{[\boldsymbol{\mu} \mathbf{m}]}\end{array}$ & $\begin{array}{c}\mathbf{d}(\mathbf{5 0}) \\
{[\boldsymbol{\mu} \mathbf{m}]}\end{array}$ & $\begin{array}{c}\mathbf{d}(\mathbf{9 0}) \\
{[\boldsymbol{\mu} \mathbf{m}]}\end{array}$ \\
\hline Group 5 CUF Testing (TI540-G5-6-PSD) & 0.48 & 2.8 & 11 \\
\hline Group 6 CUF Testing (TI552-G6-3-PSD) & 0.70 & 2.4 & 8.6 \\
\hline Group 5/6 CUF Mixture (TI552-G6-6-PSD) & 0.57 & 2.8 & 10 \\
\hline
\end{tabular}

\section{Caustic-Leaching and Dewatering of the Group 5/6 Mixed Slurry}

Figure 32 shows the influence of caustic leaching and dewatering on the PSD of solids in the Group 5/6 mixed slurry. Table 20 shows the corresponding sample IDs, $d(10), d(50)$, and $d(90)$ for the distributions shown in Figure 32. Before caustic-leaching, the Group 5/6 mixed waste solids size distribution spans $\sim 0.2$ to $\sim 20 \mu \mathrm{m}$ and appears bimodal with a maximum at $\sim 5 \mu \mathrm{m}$ and a shoulder at 0.7 $\mu \mathrm{m}$. The post-caustic-leach distribution spans the particle size range but is weakly bimodal with a maximum at $2 \mu \mathrm{m}$ and a weak shoulder at $0.5 \mu \mathrm{m}$. Caustic-leaching appears to have reduced the relative contribution of 4 to $20 \mu \mathrm{m}$ particles while increasing that of 0.4 to $4 \mu \mathrm{m}$ particles. This shift to lower diameter populations could indicate that 1) caustic-leaching has (partially) dissolved large particles or broken down agglomerates into 0.4 to $4 \mu \mathrm{m}$ or that 2) the particles comprising the 0.4 to $4 \mu \mathrm{m}$ population 
are not "leachable" or were not completely leached. PSD percentile results in Table 20 confirm an overall decrease in PSD, as significant (greater than 10\%) decreases are observed in the $d(50)$ and $d(90)$.

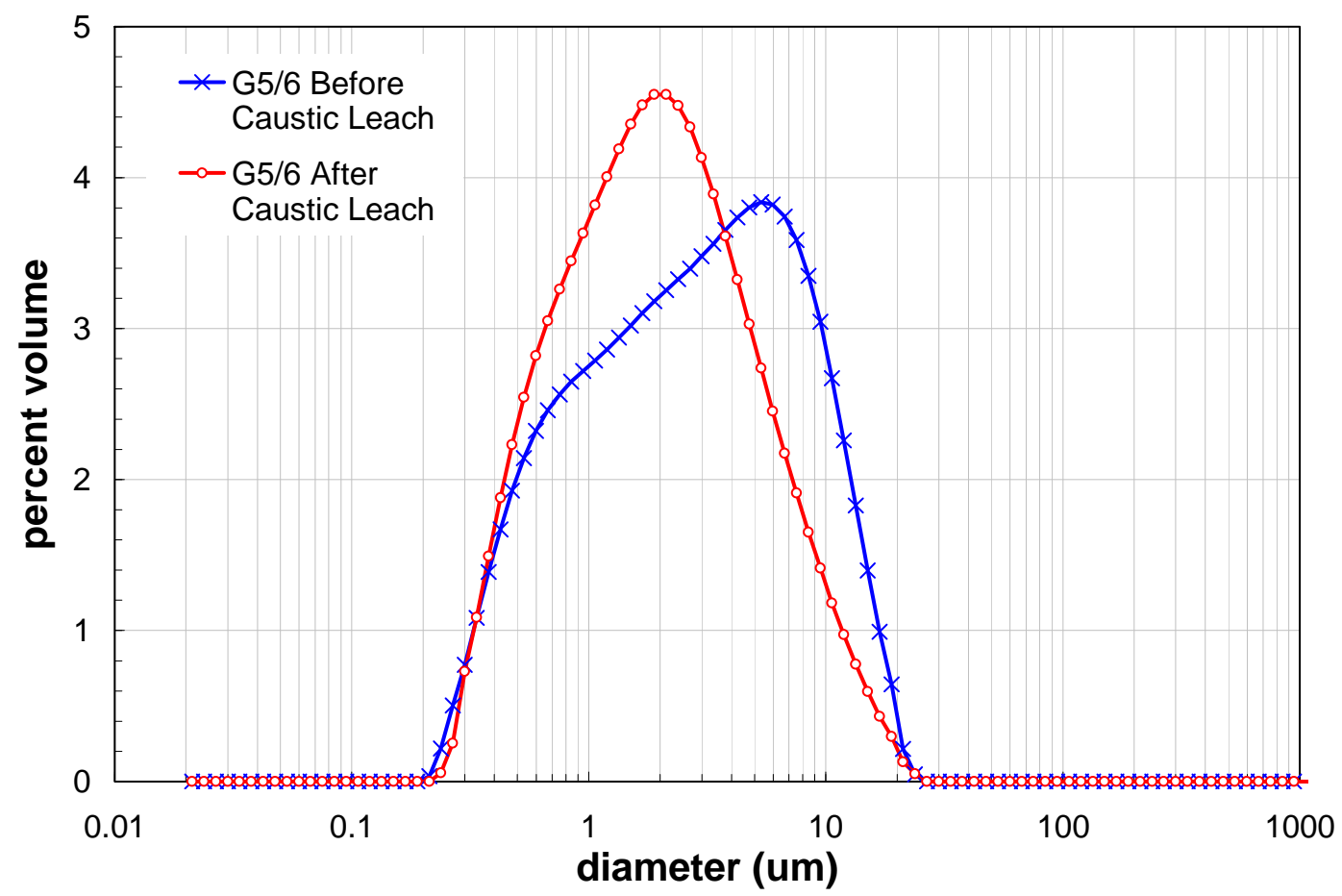

Figure 32. Comparison of Group 5/6 mixed slurry PSDs before and after caustic-leaching at measurement condition 7 - 3000 RPM, post-sonication (see Table 6).

Table 20. PSD percentiles for Group 5/6 slurry mixture before and after caustic leaching at measurement condition 7 - 3000 RPM, post-sonication (see Table 6).

\begin{tabular}{||l|c|c|c||}
\hline \hline Sample & $\begin{array}{c}\mathbf{d}(\mathbf{1 0}) \\
{[\boldsymbol{\mu m}]}\end{array}$ & $\begin{array}{c}\mathbf{d}(\mathbf{5 0}) \\
{[\boldsymbol{\mu m}]}\end{array}$ & $\begin{array}{c}\mathbf{d}(\mathbf{9 0}) \\
{[\boldsymbol{\mu m}]}\end{array}$ \\
\hline Before Caustic-Leaching (TI552-G6-6-PSD) & 0.57 & 2.8 & 10 \\
\hline After Caustic-Leaching (TI552-G6-11-PSD) & 0.56 & 1.9 & 6.9 \\
\hline
\end{tabular}

\section{Post-Caustic-Leach Washing of the Group 5/6 Mixed Slurry}

Figure 33 shows the influence of post-caustic-leach washing on the PSD of solids in the Group 5/6 mixed slurry. Table 21 shows the corresponding $d(10), d(50)$, and $d(90)$ for the distributions shown in Figure 33. The post-caustic-leach size distributions measured before and after solids washing are similar. Both are weakly bimodal with a maximum at $2 \mu \mathrm{m}$ and a weak shoulder near $0.5 \mu \mathrm{m}$. The washed solids have a slightly reduced population of 4 to $20 \mu \mathrm{m}$ particles and a slightly increased relative population 0.4 to $4 \mu \mathrm{m}$ particles. Although the change is slight, the percentiles do indicate significant decrease in the distribution $\mathrm{d}(90)$. It is difficult to conclude with certainty of the changes in the diameters below $\sim 5 \mu \mathrm{m}$ are significant; however, the changes in the PSD would be consistent with either 1) mechanical shearing of greater than $4 \mu \mathrm{m}$ particles as a result of continued CUF processing or 2) dissolution of greater than $4 \mu \mathrm{m}$ particles or agglomerates as a result of washing. 


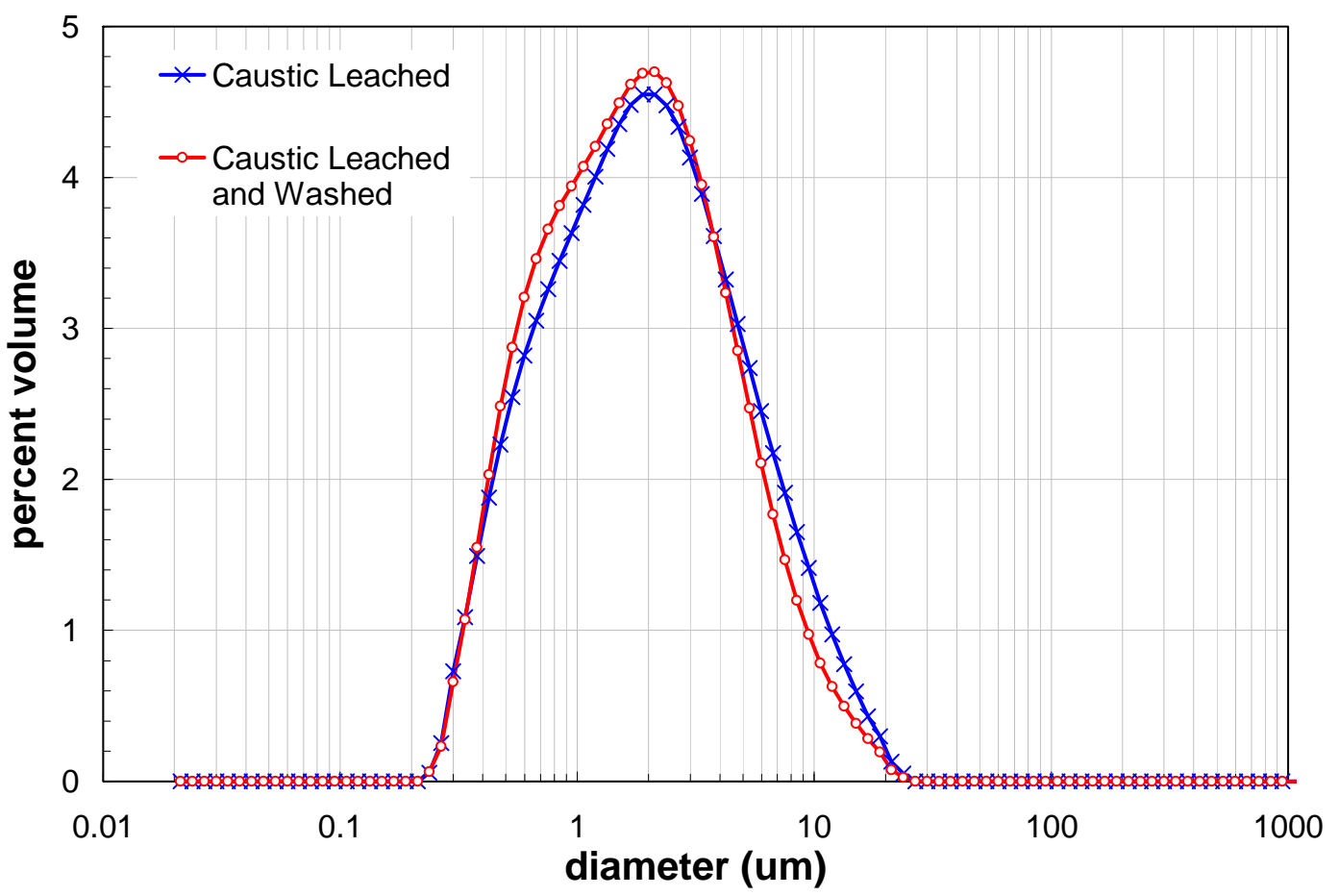

Figure 33. Comparison of Group 5/6 mixed slurry PSDs before and after post-caustic-leach washing at measurement condition 7 - 3000 RPM, post-sonication (see Table 6).

Table 21. PSD percentiles for Group 5/6 slurry mixture before and after post-caustic leach washing at measurement condition 7-3000 RPM, post-sonication (see Table 6).

\begin{tabular}{||l|c|c|c||}
\hline \hline Sample & $\begin{array}{c}\mathbf{d}(\mathbf{1 0}) \\
{[\mu \mathbf{m}]}\end{array}$ & $\begin{array}{c}\mathbf{d}(\mathbf{5 0}) \\
{[\mu \mathbf{m}]}\end{array}$ & $\begin{array}{c}\mathbf{d}(\mathbf{9 0}) \\
{[\mu \mathbf{m}]}\end{array}$ \\
\hline $\begin{array}{l}\text { Before Post-Caustic-Leach Wash (TI552-G6-11- } \\
\text { PSD) }\end{array}$ & 0.56 & 1.9 & 6.9 \\
\hline $\begin{array}{l}\text { After Post-Caustic-Leach Wash (TI552-G6-16- } \\
\text { PSD) }\end{array}$ & 0.54 & 1.7 & 5.7 \\
\hline
\end{tabular}

\section{Oxidative-Leaching and Dewatering of the Group 5/6 Mixed Slurry}

Figure 34 shows the influence of oxidative-leaching and dewatering on the PSD of solids in the Group 5/6 mixed slurry. Both initial and replicate PSD measurements exist for the oxidative-leached and dewatered sample (TI552-G6-21-PSD). The comparison below uses PSD data taken from the initial measurement of this sample. Table 22 shows the corresponding $d(10), d(50)$, and $d(90)$ for the distributions shown in Figure 34. Before oxidative leaching, the distribution spans 0.2 to $20 \mu \mathrm{m}$ with a maximum at $2 \mu \mathrm{m}$ and a weak shoulder at $0.5 \mu \mathrm{m}$. After oxidative leaching the peak spans only 0.2 to $\sim 10 \mu \mathrm{m}$, has a maximum at $0.6 \mu \mathrm{m}$, and has two shoulders at 2 and $8 \mu \mathrm{m}$. Oxidative leaching appears to reduce the relative contribution of 1 to $7 \mu \mathrm{m}$ particles while eliminating $\sim 10$ to $20 \mu \mathrm{m}$ particles. A corresponding increase in the contribution of submicron particles is observed as a result of oxidative leaching. The decrease in greater than $1 \mu \mathrm{m}$ particle population is likely a result of particle dissolution during oxidative leaching or formation of submicron manganese particles precipitated during the oxidative leach process. However, this assertion is contradicted by the resemblance of the oxidativeleached PSD (TI552-G6-21-PSD) to the combined leach PSD (TI552-G6-32-PSD), which contains both 
caustic-leached only Group 5 material (no manganese precipitates) and oxidatively-leached Group 5/6 material. The section titled "Mixing of Group 5 and Group 5/6 Leached Slurries” provides additional discussion. It is also possible that the increased population of submicron particles after leaching could correspond to particles originally masked by the particles dissolved during oxidative leaching.

At least some of the distribution shown in Figure 34 corresponds to solids unaffected by the oxidative leaching process. The particle population maximum at $2 \mu \mathrm{m}$ appears to be preserved in the post-oxidative leach PSD as a shoulder at $2 \mu \mathrm{m}$. These are likely particles robust to oxidative-leaching. Overall, the oxidative-leached and dewatered slurry is characterized by increased fractional contribution of small particles. This is manifest in the PSD percentiles for this waste slurry through significant (greater than 10\%) decreases in the $\mathrm{d}(10), \mathrm{d}(50)$, and $\mathrm{d}(90)$, as shown in Table 22.

Table 22. PSD percentiles for Group 5/6 slurry mixture before and after oxidative leaching at measurement condition 7 - 3000 RPM, post-sonication (see Table 6).

\begin{tabular}{||l|c|c|c||}
\hline \hline Sample & $\begin{array}{c}\mathbf{d}(\mathbf{1 0}) \\
{[\mu \mathbf{m}]}\end{array}$ & $\begin{array}{c}\mathbf{d}(\mathbf{5 0}) \\
{[\mu \mathbf{m}]}\end{array}$ & $\begin{array}{c}\mathbf{d}(\mathbf{9 0}) \\
{[\mu \mathbf{m}]}\end{array}$ \\
\hline Before Oxidative-Leaching (TI552-G6-16-PSD) & 0.54 & 1.7 & 5.7 \\
\hline After Oxidative-Leaching (TI552-G6-21-PSD) & 0.44 & 1.2 & 4.9 \\
\hline
\end{tabular}

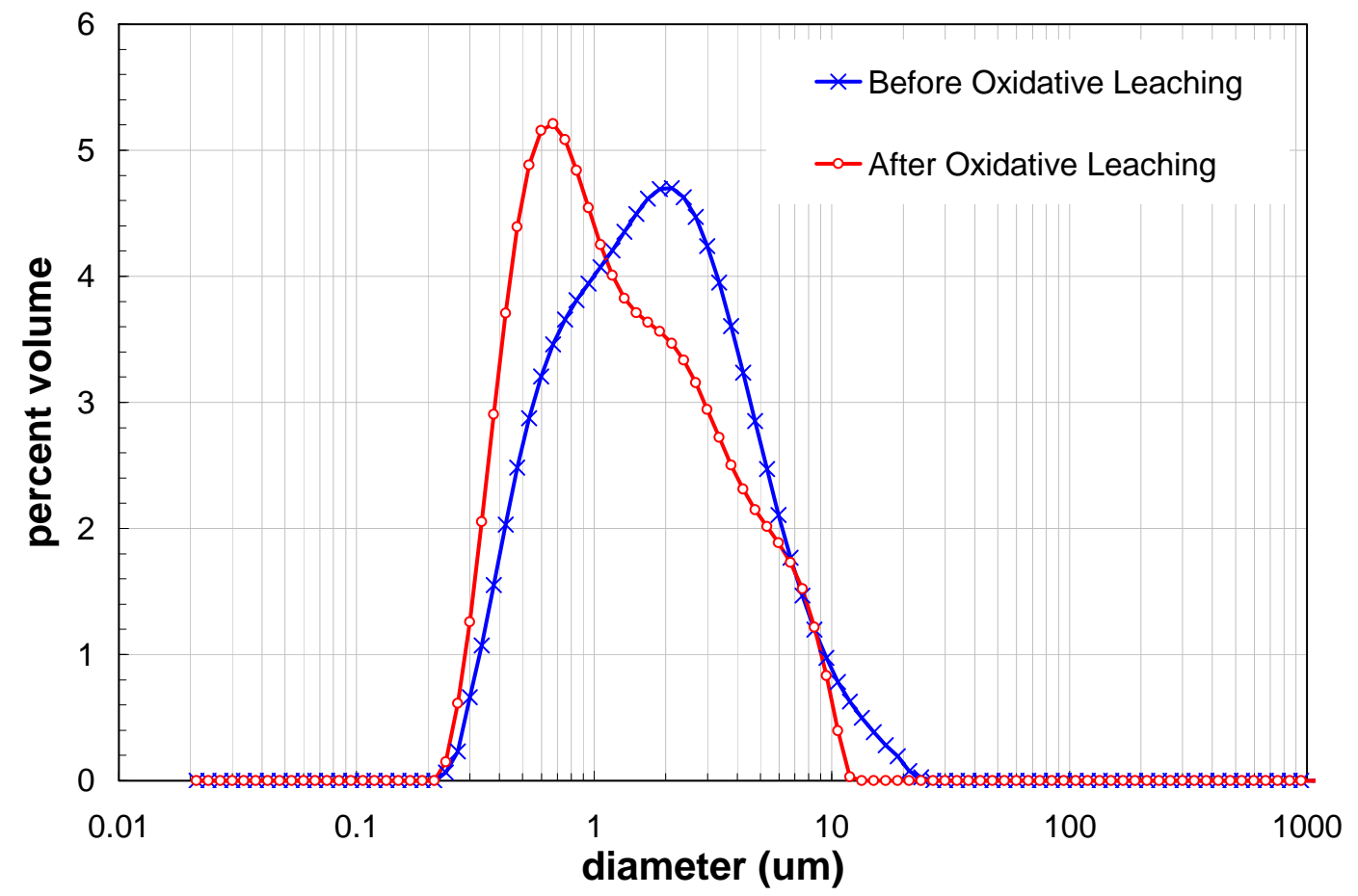

Figure 34. Comparison of Group 5/6 mixed slurry PSDs before and after oxidative-leaching at measurement condition 7 - 3000 RPM, post-sonication (see Table 6).

\section{Post-Oxidative-Leach Washing of the Group 5/6 Mixed Slurry}

Figure 35 shows the influence of post-oxidative-leach washing on the PSD of solids in the Group 5/6 mixed slurry. Table 23 shows the corresponding $d(10), d(50)$, and $d(90)$ for the distributions shown 
in Figure 35. Before washing, the PSD for the oxidative-leached Group 5/6 waste solids spans 0.2 to $\sim 10 \mu \mathrm{m}$, has a maximum at $0.6 \mu \mathrm{m}$ and has two distinct shoulders at 2 and $8 \mu \mathrm{m}$. After washing, the distribution spans the same range, still has a maximum at $0.6 \mu \mathrm{m}$, but now only has a single pronounced shoulder at $2 \mu \mathrm{m}$. Washing of the slurry has appeared to reduce the fractional contribution of both submicron and 5 to $10 \mu \mathrm{m}$. The decrease in 5 to $10 \mu \mathrm{m}$ particles may be a result of dissolution or breakage of agglomerates as a result of washing or may be a result of shear-disruption of aggregates under continued CUF processing. Smaller particles formed by either dissolution or disruption appear to add to the population shoulder at $2 \mu \mathrm{m}$. The decrease in the fractional contribution of submicron particles could simply result from the increased population of $\sim 2 \mu \mathrm{m}$ particles resulting from dissolution / disruption. On the other hand, it could indicate size growth (e.g., through Ostwald ripening or aggregation) of solids precipitated during oxidative-leaching. In terms of the particle percentiles presented in Table 23, change in the oxidative-leached solids PSDs as a result of washing is minor, as a significant change (decrease) is only observed in the $\mathrm{d}(90)$.

Table 23. PSD percentiles for Group 5/6 slurry mixture before and after post-oxidativeleach washing at measurement condition $7-3000$ RPM, post-sonication (see Table 6).

\begin{tabular}{||l|c|c|c||}
\hline \hline Sample & $\begin{array}{c}\mathbf{d}(\mathbf{1 0}) \\
{[\boldsymbol{\mu m}]}\end{array}$ & $\begin{array}{c}\mathbf{d}(\mathbf{5 0 )} \\
{[\boldsymbol{\mu} \mathbf{m}]}\end{array}$ & $\begin{array}{c}\mathbf{d}(\mathbf{9 0}) \\
{[\boldsymbol{\mu m}]}\end{array}$ \\
\hline Before Post-Oxidative-Leach Washing (TI552-G6-21-PSD) & 0.44 & 1.2 & 4.9 \\
\hline After Post-Oxidative-Leach Washing (TI552-G6-26-PSD) & 0.43 & 1.2 & 4.2 \\
\hline
\end{tabular}

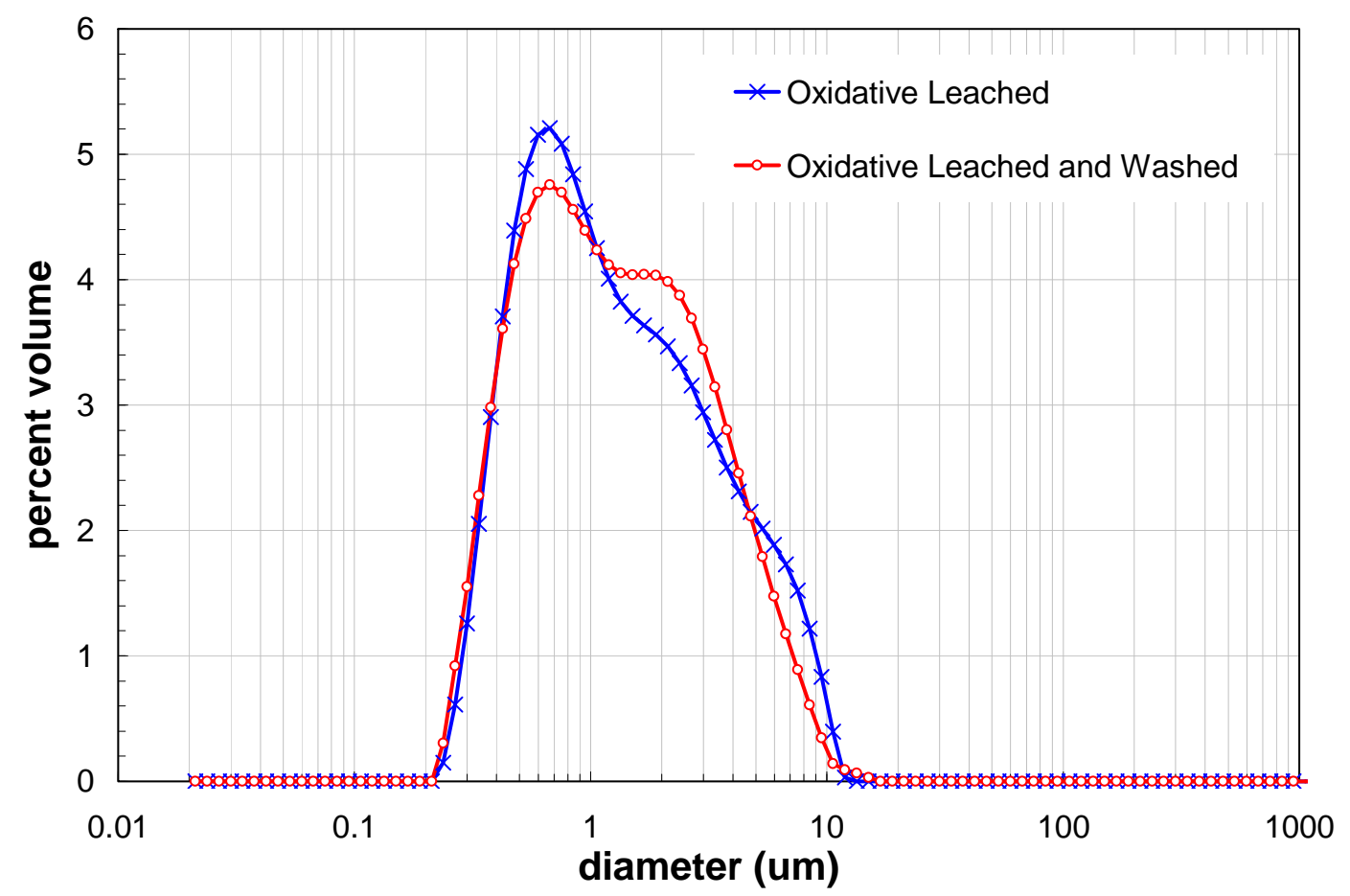

Figure 35. Comparison of Group 5/6 mixed slurry PSDs before and after post-oxidative-leach washing at measurement condition 7 - 3000 RPM, post-sonication (see Table 6). 


\section{Mixing of Group 5 and Group 5/6 Leached Slurries}

Figure 36 shows the effect of addition of caustically-leached, dewatered, and washed Group 5 waste solids to the leached (both caustically and oxidatively) and washed Group 5/6 slurry. It should be noted that comparison against the Group 5 caustically-leached, dewatered, and washed PSD (sample TI540-G6-16-PSD) is avoided as the Group 5 leached PSD data were strongly influenced by poor sample stability (manifest as the "odd-even” PSD effect). Table 24 shows the corresponding $\mathrm{d}(10)$, d(50), and $d(90)$ for the distributions shown in Figure 36. The Group 5/6 solids PSD before and after addition of Group 5 are similar. Both distributions span 0.2 to $20 \mu \mathrm{m}$, have a maximum at $0.6 \mu \mathrm{m}$, and have population shoulder at $\sim 2 \mu \mathrm{m}$. The combined leach PSD slurry (TI552-G6-32-PSD) has an increased fraction of $4-20 \mu \mathrm{m}$, which yields the significant (greater than $10 \%$ ) increase in the $90^{\text {th }}$ cumulative undersize percentile listed in Table 24 for this sample. However, the distribution at smaller particle diameters is statistically similar, as indicated by the agreement of $\mathrm{d}(10)$ and $\mathrm{d}(50)$ diameters before and after Group 5 addition to within 10\%. This agreement contradicts the prior assertion that the particle population yielding the maximum at $0.6 \mu \mathrm{m}$ result from precipitation of manganese bearing species. Instead, the solids remaining after oxidative leaching may be Group 5 solids robust to caustic- and oxidative-leaching. The similarity between the solids distributions also suggests that the fractional contribution of Group 6 solids is not significant (i.e., most or all Group 6 solids have been dissolved).

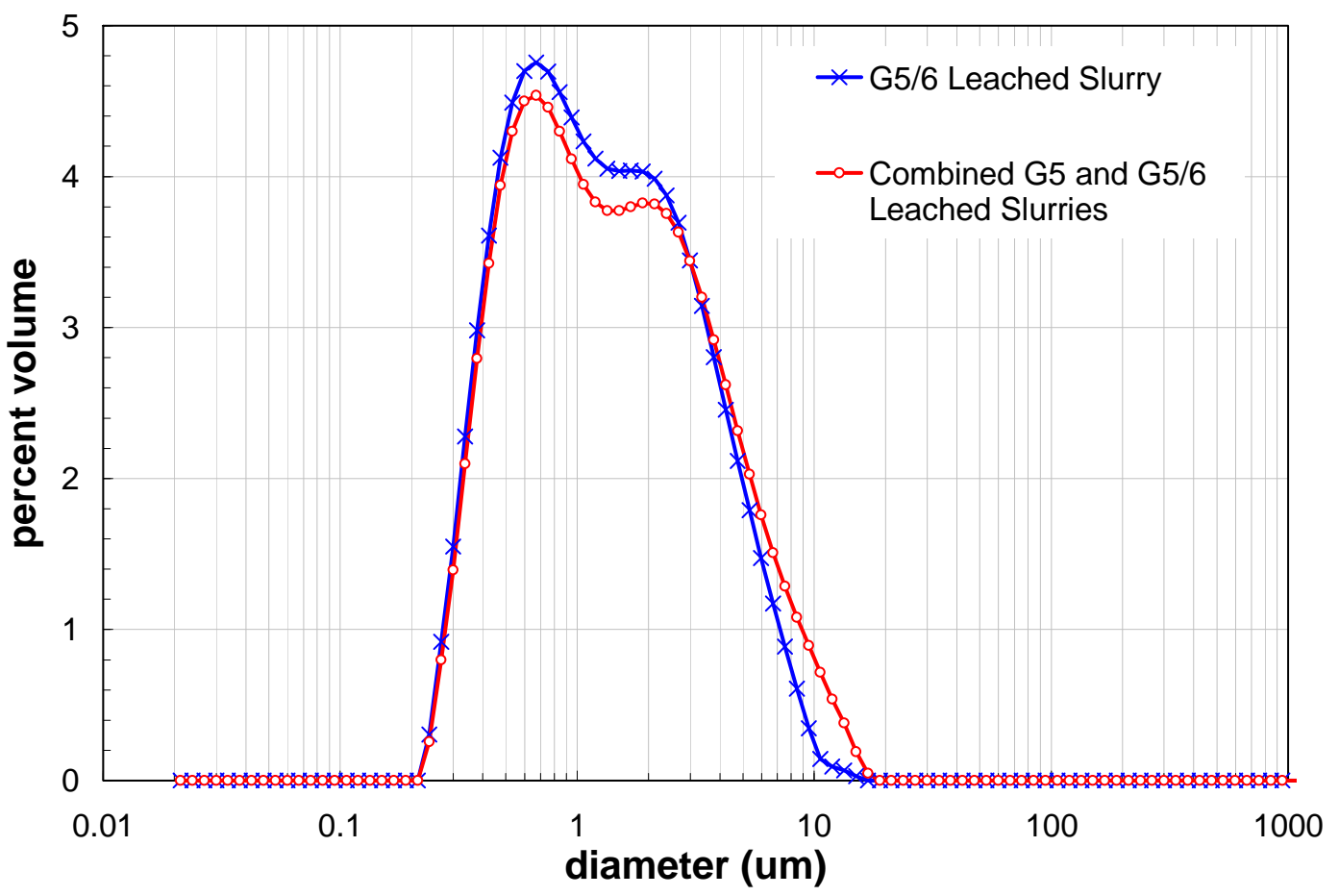

Figure 36. Comparison of leached (both caustic- and oxidative-leached) and washed Group 5/6 solids PSDs before and after addition of Group 5 caustic-leached, dewatered, and washed solids at measurement condition 7 - 3000 RPM, post-sonication (see Table 6). 
Table 24. PSD percentiles for the Group 5/6 leached slurry mixture before and after addition of Group 5 leached solids at measurement condition 7 - 3000 RPM, postsonication (see Table 6).

\begin{tabular}{||l|c|c|c||}
\hline Sample & $\begin{array}{c}\mathbf{d}(\mathbf{1 0}) \\
{[\mu \mathrm{m}]}\end{array}$ & $\begin{array}{c}\mathbf{d}(\mathbf{5 0}) \\
{[\mu \mathrm{m}]}\end{array}$ & $\begin{array}{c}\mathbf{d}(\mathbf{9 0}) \\
{[\boldsymbol{\mu m}]}\end{array}$ \\
\hline $\begin{array}{l}\text { Before Group 5 Leached Solids Addition (TI552-G6-26- } \\
\text { PSD) }\end{array}$ & 0.43 & 1.2 & 4.2 \\
\hline $\begin{array}{l}\text { After Group 5 Leached Solids Addition (TI552-G6-32- } \\
\text { PSD) }\end{array}$ & 0.44 & 1.3 & 5.1 \\
\hline
\end{tabular}

\subsection{Conclusions}

The particle size distributions of seven Group 5/6 insoluble solids samples derived from CUF testing were measured and the effects of CUF processing on the particle size determined. Samples generally showed complex particle size behavior with respect to both flow rate and sonication. In brief, the following behaviors were observed for the seven samples:

- $\quad$ Sample TI552-G6-3-PSD - As-Homogenized Low-Solids Concentration Group 6 Slurry - has a particle population spanning from $\sim 0.2 \mu \mathrm{m}$ up to $200 \mu \mathrm{m}$, with population peaks at 2, 7, and $\sim 65$ $\mu \mathrm{m}$. Some of the particles in the dispersion can only be suspended at high flows in the particle size analyzer, indicating the presence of difficult-to-suspend single particle species or agglomerates (in terms of the analyzers capabilities). Disruption of these large particle species is observed upon the application of sonic energy. This disruption is irreversible. After sonication, the distribution of particles ranges from 0.2 to $\sim 80 \mu \mathrm{m}$, with population peaks at 2 and $40 \mu \mathrm{m}$.

- $\quad$ Sample TI552-G6-6-PSD - As-Homogenized High-Solids Concentration Group 5/6 Slurry - has an initial particle population spanning from $\sim 0.2 \mu \mathrm{m}$ up to $500 \mu \mathrm{m}$, with population peaks at 1.2 , 6,70 , and $400 \mu \mathrm{m}$. PSD results for this sample suggest that particles in the 20 to $500 \mu \mathrm{m}$ size range are difficult to suspend particles and/or fragile with respect to shear. Disruption of these large particle species is observed upon the application of sonic energy. This disruption is irreversible. After sonication, the distribution of particles ranges from 0.2 to $\sim 80 \mu \mathrm{m}$, with the major of particles below $20 \mu \mathrm{m}$ and population peaks at 1 and $5 \mu \mathrm{m}$.

- $\quad$ Sample TI552-G6-11-PSD - Caustic-Leached and Dewatered Group 5/6 Slurry - has an initial particle population spanning from $\sim 0.2 \mu \mathrm{m}$ to $\sim 200 \mu \mathrm{m}$. The pre-sonication PSD is roughly bimodal with population peak maximums at 2 and $50 \mu \mathrm{m}$. At low flow, a third population centered at $\sim 400 \mu \mathrm{m}$ appears (but may be an artifact of the analysis of the light scattering pattern). High flows appear to suspend a fraction of $\sim 20$ to $\sim 100 \mu \mathrm{m}$ particles, indicating the presence of difficult-to-suspend single particles or agglomerates. Sonication appears to disrupt particles / agglomerates greater than $10 \mu \mathrm{m}$, but has little effect on particles below $10 \mu \mathrm{m}$. There is a slight recovery of greater than $10 \mu \mathrm{m}$ particles after sonication, indicating that disruption in partially reversible. After sonication, high flows still evidence a difficult-to-suspend fraction of 10 to 100 $\mu \mathrm{m}$ particles. However, the fractional contribution of these particles is reduced after sonication, confirming disruption of particles in this size range by sonication.

- $\quad$ Sample TI552-G6-16-PSD - Caustic-Leached, Dewatered, and Washed Group 5/6 Slurry - has an initial particle population spanning from $\sim 0.2 \mu \mathrm{m}$ to $\sim 100 \mu \mathrm{m}$. Particles in the 20 to $100 \mu \mathrm{m}$ size range are difficult to suspend, and only appear at the highest pump speeds analyzed during the measurement. Sonication appears to reduce the fractional contribution of the particle population 
greater than $20 \mu \mathrm{m}$ in diameter, indicating that the solids comprising this size range are likely agglomerates. Disruption of particles greater than $20 \mu \mathrm{m}$ yields an increase in the population of 1-10 $\mu \mathrm{m}$ particles. The distribution shows no recovery after sonication, suggesting the changes to the state of particle agglomeration are permanent. High flows still evidence a difficult-to-suspend fraction of 10 to $60 \mu \mathrm{m}$ particles, but their fractional contribution to the overall distribution is reduce relative to the pre-sonic PSD. As with previous samples, this confirms sonic disruption of 20 to $100 \mu \mathrm{m}$ particles.

- $\quad$ Sample TI552-G6-21-PSD - Oxidative-Leached and Dewatered Group 5/6 Slurry - has a multimodal PSD with a large population peak centered around $2 \mu \mathrm{m}$, a primary distribution spanning 0.3 to $7 \mu \mathrm{m}$, a low population shoulder spanning 7 to $20 \mu \mathrm{m}$, and a separate distribution of large "particles" spanning 50 to $600 \mu \mathrm{m}$. Increased pump speeds evidence a difficult-tosuspend fraction of 10 to $100 \mu \mathrm{m}$. Replicate analysis of the pre-sonic PSD indicates poor reproducibility. Indeed, the large particle population spanning 50 to $600 \mu \mathrm{m}$ is entirely absent in the repeat measurement. The application of sonic energy appears to shift the primary peak to submicron sizes and collapse the particle population above $10 \mu \mathrm{m}$ to a size of less than $10 \mu \mathrm{m}$. After sonication, the distribution of particles between 0.2 and $10 \mu \mathrm{m}$ does not change with pump speed. High flows still indicate the presence of large, difficult-to-suspend particles. Measurement repeatability is improved after sonication, with the distributions agreeing within $10 \%$ for the $\mathrm{d}(10)$, d(50), and d(90). At 4000 RPM, comparability of the post-sonic initial and replicate PSDs is reduced, indicating differences remain in the difficult-to-suspend fraction of particles.

- $\quad$ Sample TI552-G6-26-PSD - Oxidative-Leached, Dewatered, and Washed Group 5/6 Slurry - has an initial particle population spanning from $\sim 0.2 \mu \mathrm{m}$ to $\sim 20 \mu \mathrm{m}$ at 3000 RPM. The pre-sonic distribution is dominated by a single sharp peak centered at $\sim 1 \mu \mathrm{m}$ although the peak also exhibits a small shoulder of particles at $\sim 10 \mu \mathrm{m}$. Increased pump speed suggests difficult to suspend particles ranging from 20 to80 $\mu \mathrm{m}$. A decrease in the particle diameter characterizing the main $\sim 1 \mu \mathrm{m}$ population suggests shear disruption of agglomerates or dissolution of particles even before sonication. Sonication increases the particle contribution of both submicron and 3 to $10 \mu \mathrm{m}$ particles. Previous PSD results for Group 5/6 samples indicate that these changes during sonication likely result from disruption of agglomerates. For the current sample, this is difficult to confirm as the post-sonic volume contribution of large and "difficult-to-suspend" particles appears relatively unchanged. After sonication, the main distribution (i.e., that over 0.2 to $10 \mu \mathrm{m}$ ) is not sensitive to changes in pump speed. PSD at high pump speeds still exhibit a 10 to $60 \mu \mathrm{m}$ fraction of "difficult-to-suspend" particles not observed at lower pump speeds.

- $\quad$ Sample TI552-G6-32-PSD - Combined-Leach Group 5 and Group 5/6 Slurry - has a pre-sonic distribution that spans 0.3 to $\sim 20 \mu \mathrm{m}$ and consists of a single dominant peak with maximum just above $1 \mu \mathrm{m}$ and a shoulder population ranging from 4 to $20 \mu \mathrm{m}$. High flows appear to suspend particles in the 20 to $\sim 130 \mu \mathrm{m}$ size range. In addition, the peak maximum at $\sim 1 \mu \mathrm{m}$ appears to shift slightly to smaller diameters as a result of pre-sonic operations. Sonication of the dispersion results in a relatively bimodal size distribution, with population peaks at 0.6 and $2 \mu \mathrm{m}$. The fractions of both submicron and 2 to $10 \mu \mathrm{m}$ particles are increased as a result of sonication. After sonication, the PSD is relatively stable with respect to flow and time. The primary distribution over 0.2 to $10 \mu \mathrm{m}$ does not change significantly; however, high flows still appear to suspend a large particle population ranging from 20 to $\sim 100 \mu \mathrm{m}$. 
In terms of the effects of CUF processing on Group 6 and Group 5/6 waste mixtures, the PSD results indicate the following:

- Initial Shearing and Filtration of Pure Group 6 (S-Saltcake) Solids - indicate that mechanical shear during pumping operations in the CUF disrupts primarily 5-20 $\mu \mathrm{m}$ particles / agglomerates, driving the Group 6 particle size distribution to smaller diameter populations

- Mixing of Group 5 and 6 Wastes - after waste mixing, the Group 5 particle size distribution dominate the mixed waste size distribution. This is expected, as Group 5 solids comprise $68 \%$ of the mixture by weight.

- $\quad$ Caustic-Leaching of Group 5/6 Mixed Solids - shifts the distribution to lower diameter populations, reduce the relative contribution of 4 to $20 \mu \mathrm{m}$ particles while increasing that of 0.4 to $4 \mu \mathrm{m}$ particles. This suggests that caustic-leaching dissolves large particles or breaks down agglomerates. It could also indicate that the particles comprising the 0.4 to $4 \mu \mathrm{m}$ population are not "leachable" or were not completely leached.

- $\quad$ Post-Caustic-Leach Washing of Group 5/6 Mixed Solids - does not change the particle size distribution dramatically. The washed solids have a slightly reduced population of 4 to $20 \mu \mathrm{m}$ particles and a slightly increased relative population 0.4 to $4 \mu \mathrm{m}$ particles. Changes in the particle diameters below the $\mathrm{d}(90)$ are at or below the limit of statistical significance (10\% for PSD analysis).

- Oxidative-Leaching of Group 5/6 Mixed Solids - reduces the relative contribution of 1 to $7 \mu \mathrm{m}$ particles, eliminates the relative contribution of $\sim 10$ to $20 \mu \mathrm{m}$ particles, and increases the relative contribution of submicron particles. The decrease in greater than $1 \mu \mathrm{m}$ particle population is likely a result of particle dissolution during oxidative leaching or particle attrition by mechanical shear during filtration. The increased fraction of submicron particles may be manganese bearing species precipitated during the leach process. However, it is more possible that this population corresponds to particles originally masked by particle removed or sheared apart during CUF processing.

- $\quad$ Post-Oxidative-Leach Washing of Group 5/6 Mixed Solids - slightly reduces the fractional contribution of both submicron and 5 to $10 \mu \mathrm{m}$. This decrease may be a result of dissolution or breakage of agglomerates as a result of washing or may be a result of shear-disruption of aggregates under continued CUF processing. Smaller particles formed by either dissolution or disruption appear to add to the population shoulder at $2 \mu \mathrm{m}$. Overall, the change is slight, with diameters below the $\mathrm{d}(90)$ differing less than 10\% (the limit of instrument reproducibility) before and after washing.

- Mixing of Group 5 and Group 5/6 Leached Solids - does not appreciable change the PSD relative to that of the Group 5/6 Leached Solids alone. This indicates that the Group 5 causticleached solids and Group 5/6 caustic- and oxidative-leached solids have similar PSD. The implications of this observation are 1) that the solids remaining after oxidative leaching are likely Group 5 solids robust to caustic- and oxidative-leaching and 2) that the similarity between the solids distributions suggests that the fractional contribution of Group 6 solids is not significant (i.e., most or all Group 6 solids have been dissolved). 


\section{Records}

Data records relating to particle size characterization of Group 5/6 CUF Testing samples include original Malvern Mastersizer data files, Test Data Packages (TDPs), and LRBs:

\begin{tabular}{|l|l|}
\hline Sample: & TI552-G6-3-PSD \\
\hline LRB Location: & 56933, pages 85 \\
\hline Mastersizer File: & "2008-02feb29-Group 5_6 CUF PSD.mea" \\
\hline TDP Number: & TDP-WTP-214 \\
\hline
\end{tabular}

\begin{tabular}{|l|l|}
\hline Sample: & TI552-G6-6-PSD \\
\hline LRB Location: & 56933, pages 87 \\
\hline Mastersizer File: & "2008-02feb29-Group 5_6 CUF PSD.mea" \\
\hline TDP Number: & TDP-WTP-215 \\
\hline
\end{tabular}

\begin{tabular}{|l|l|}
\hline Sample: & TI552-G6-11-PSD \\
\hline LRB Location: & 56933, pages 96 \\
\hline Mastersizer File: & "2008-06June17-Group 5_6 CUF PSD.mea" \\
\hline TDP Number: & TDP-WTP-217 \\
\hline
\end{tabular}

\begin{tabular}{|l|l|}
\hline Sample: & TI552-G6-16-PSD \\
\hline LRB Location: & 56933, pages 96 \\
\hline Mastersizer File: & "2008-06June17-Group 5_6 CUF PSD.mea" \\
\hline TDP Number: & TDP-WTP-218 \\
\hline
\end{tabular}

\begin{tabular}{|l|l|}
\hline Sample: & TI552-G6-21-PSD \\
\hline LRB Location: & 56933, pages 85-87 \\
\hline Mastersizer File: & "2008-02feb29-Group 5_6 CUF PSD.mea" \\
\hline TDP Number: & TDP-WTP-219 \\
\hline
\end{tabular}

\begin{tabular}{|l|l|}
\hline Sample: & TI552-G6-26-PSD \\
\hline LRB Location: & "2008-02feb29-Group 5_6 CUF PSD.mea" \\
\hline Mastersizer File: & 56933, pages 86 \\
\hline TDP Number: & TDP-WTP-220 \\
\hline
\end{tabular}

\begin{tabular}{|l|l|}
\hline Sample: & TI552-G6-32-PSD \\
\hline LRB Location: & 56933, pages 97 \\
\hline Mastersizer File: & "2008-06June17-Group 5_6 CUF PSD(2).mea" \\
\hline TDP Number: & TDP-WTP-221 \\
\hline
\end{tabular}




\section{References}

1. Doc. No. TP-RPP-WTP-467, Revision 0, "Characterization and Small Scale Testing of Hanford Wastes to Support the Development and Demonstration of Leaching and Ultrafiltration Pretreatment Processes,” SK Fiskum, Battelle - Pacific Northwest Division, February 2007.

2. Doc. No. TP-RPP-WTP-456, Revision 0, "Pretreatment Demonstration Applying Oxidative Leaching to Hanford Tank Waste,” SK Fiskum, Battelle - Pacific Northwest Division, November 2006.

3. Doc. No. RPL-COLLOID-01, Revision 1, “Particle Size Analysis Using Malvern MS2000,” AP Poloski, Pacific Northwest National Laboratory, May 2007.

4. Doc. No. WTP/RPP-MOA-PNNL-00079, "Particle Size Distribution Measurements for Groups 5 and 6,” RC Daniel, Battelle - Pacific Northwest Division, July 2007.

5. Doc. No. TDP-WTP-090, "Particle Size Distribution Measurements for Group 5 CUF Testing Samples,” RC Daniel, Battelle - Pacific Northwest Division, July 2008. 


\section{Appendix A - Detailed Cumulative PSD}

Tables A-1 to A-8 present detailed cumulative oversize distributions (by volume/weight) for Group 5/6 CUF testing samples. A full relative percent difference (RPD) calculation for initial and replicate measurements of sample TI552-G6-21-PSD is given in Table A-9. RPD is calculated as per Eq. 1. For all cases, results are reported as a function of test condition (see Table 6). This appendix does not provide discussion of the detailed distributions; however, a portion of these results (specifically, the $10^{\text {th }}$, $50^{\text {th }}$, and $90^{\text {th }}$ diameter percentiles) are presented and discussed in the main body of this interim report.

Table A-1. Cumulative oversize diameter distributions for TI552-G6-3-PSD.

\begin{tabular}{|c|c|c|c|c|c|c|c|c|c|c|c|c|c|c|c|}
\hline \multirow{2}{*}{\begin{tabular}{|l|} 
Test \\
Condition
\end{tabular}} & \multicolumn{15}{|c|}{ Volume / Weight Cumulative Oversize Diameter $(\mu \mathrm{m})$} \\
\hline & $1 \%$ & $5 \%$ & $10 \%$ & $20 \%$ & $25 \%$ & $30 \%$ & $40 \%$ & $50 \%$ & $60 \%$ & $70 \%$ & $75 \%$ & $80 \%$ & $90 \%$ & $95 \%$ & 99\% \\
\hline $\begin{array}{l}\text { - } 3000 / \\
\text { pre-sonic }\end{array}$ & 0.36 & 0.56 & 0.78 & 1.3 & 1.5 & 1.8 & 2.6 & 3.6 & 4.9 & 6.7 & 7.9 & 9.2 & 13 & 16 & 22 \\
\hline $\begin{array}{l}2 \text { - } 4000 / \\
\text { pre-sonic }\end{array}$ & 0.35 & 0.58 & 0.84 & 1.5 & 1.8 & 2.3 & 3.5 & 5.3 & 8.1 & 13 & 18 & 32 & 65 & 90 & 130 \\
\hline $\begin{array}{l}3 \text { - } 2000 / \\
\text { pre-sonic }\end{array}$ & 0.38 & 0.58 & 0.77 & 1.2 & 1.4 & 1.6 & 2.2 & 2.9 & 3.8 & 5.2 & 6.1 & 7.1 & 10 & 13 & 18 \\
\hline \begin{tabular}{|l}
$4-3000 /$ \\
$25 \%$
\end{tabular} & 0.37 & 0.56 & 0.75 & 1.1 & 1.3 & 1.6 & 2.1 & 2.8 & 3.7 & 5.0 & 5.9 & 7.0 & 10 & 13 & 18 \\
\hline $\begin{array}{l}5-3000 / \\
50 \%\end{array}$ & 0.37 & 0.55 & 0.72 & 1.1 & 1.3 & 1.5 & 2.0 & 2.6 & 3.5 & 4.7 & 5.5 & 6.6 & 9.8 & 13 & 17 \\
\hline $\begin{array}{l}6-3000 / \\
75 \%\end{array}$ & 0.38 & 0.56 & 0.74 & 1.1 & 1.3 & 1.5 & 1.9 & 2.5 & 3.2 & 4.3 & 5.1 & 6.0 & 8.9 & 11 & 16 \\
\hline $\begin{array}{l}7 \text { - } 4000 / \\
\text { post-sonic }\end{array}$ & 0.36 & 0.53 & 0.70 & 1.0 & 1.2 & 1.4 & 1.8 & 2.4 & 3.1 & 4.2 & 4.9 & 5.8 & 8.6 & 11 & 17 \\
\hline \begin{tabular}{|l|}
8 - 2000 / \\
post-sonic
\end{tabular} & 0.33 & 0.50 & 0.68 & 1.1 & 1.3 & 1.5 & 2.1 & 2.9 & 4.0 & 5.6 & 6.7 & 8.2 & 14 & 27 & 54 \\
\hline $\begin{array}{l}9 \text { - } 4000 / \\
\text { post-sonic }\end{array}$ & 0.37 & 0.54 & 0.71 & 1.0 & 1.2 & 1.4 & 1.8 & 2.3 & 3.1 & 4.1 & 4.8 & 5.7 & 8.6 & 11 & 15 \\
\hline
\end{tabular}


Table A-2. Cumulative oversize diameter distributions for TI552-G6-6-PSD.

\begin{tabular}{|c|c|c|c|c|c|c|c|c|c|c|c|c|c|c|c|}
\hline \multirow{2}{*}{\begin{tabular}{|l|} 
Test \\
Condition
\end{tabular}} & \multicolumn{15}{|c|}{ Volume / Weight Cumulative Oversize Diameter $(\mu \mathrm{m})$} \\
\hline & $1 \%$ & $5 \%$ & $10 \%$ & $20 \%$ & $25 \%$ & $30 \%$ & $40 \%$ & $50 \%$ & $60 \%$ & $70 \%$ & $75 \%$ & $80 \%$ & $90 \%$ & $95 \%$ & $99 \%$ \\
\hline \begin{tabular}{|l|}
1 - $3000 /$ \\
pre-sonic
\end{tabular} & 0.31 & 0.45 & 0.59 & 0.90 & 1.1 & 1.3 & 1.8 & 2.7 & 4.1 & 6.4 & 8.0 & 10 & 19 & 43 & 130 \\
\hline \begin{tabular}{|l|}
$2-4000 /$ \\
pre-sonic
\end{tabular} & 0.30 & 0.44 & 0.58 & 0.89 & 1.1 & 1.3 & 1.9 & 2.9 & 4.5 & 7.0 & 8.9 & 12 & 24 & 42 & 78 \\
\hline \begin{tabular}{|l|}
3 - $2000 /$ \\
pre-sonic
\end{tabular} & 0.30 & 0.43 & 0.56 & 0.86 & 1.0 & 1.2 & 1.8 & 2.6 & 3.9 & 5.8 & 7.2 & 9.0 & 16 & 30 & 420 \\
\hline \begin{tabular}{|l|}
$4-3000 / /$ \\
$25 \%$
\end{tabular} & 0.31 & 0.44 & 0.57 & 0.87 & 1.1 & 1.3 & 1.8 & 2.6 & 3.6 & 5.0 & 5.9 & 7.0 & 10 & 14 & 20 \\
\hline \begin{tabular}{|l|}
$5-3000 /$ \\
$50 \%$
\end{tabular} & 0.31 & 0.45 & 0.60 & 0.93 & 1.1 & 1.4 & 2.0 & 2.8 & 3.9 & 5.3 & 6.2 & 7.2 & 10 & 13 & 18 \\
\hline \begin{tabular}{|l|}
$6-3000 /$ \\
$75 \%$
\end{tabular} & 0.30 & 0.43 & 0.57 & 0.87 & 1.1 & 1.3 & 1.8 & 2.6 & 3.6 & 4.8 & 5.6 & 6.6 & 9.3 & 12 & 17 \\
\hline \begin{tabular}{|l|}
$7-3000 /$ \\
post-sonic
\end{tabular} & 0.29 & 0.43 & 0.57 & 0.90 & 1.1 & 1.4 & 2.0 & 2.8 & 3.9 & 5.2 & 6.1 & 7.1 & 10 & 13 & 18 \\
\hline \begin{tabular}{|l|} 
- $4000 /$ \\
post-sonic
\end{tabular} & 0.28 & 0.41 & 0.55 & 0.88 & 1.1 & 1.3 & 2.0 & 2.9 & 4.1 & 5.8 & 6.8 & 8.2 & 13 & 19 & 42 \\
\hline \begin{tabular}{|l|}
$9-2000 /$ \\
post-sonic
\end{tabular} & 0.31 & 0.45 & 0.59 & 0.92 & 1.1 & 1.4 & 2.0 & 2.8 & 3.8 & 5.2 & 6.0 & 7.0 & 9.8 & 12 & 17 \\
\hline
\end{tabular}

Table A-3. Cumulative oversize diameter distributions for TI552-G6-11-PSD.

\begin{tabular}{|c|c|c|c|c|c|c|c|c|c|c|c|c|c|c|c|}
\hline \multirow{2}{*}{\begin{tabular}{|l|} 
Test \\
Condition
\end{tabular}} & \multicolumn{15}{|c|}{ " Volume / Weight Cumulative Oversize Diameter $(\mu \mathrm{m})$} \\
\hline & $1 \%$ & $5 \%$ & $10 \%$ & $20 \%$ & $25 \%$ & $30 \%$ & $40 \%$ & $50 \%$ & $60 \%$ & $70 \%$ & $75 \%$ & $80 \%$ & $90 \%$ & $95 \%$ & $99 \%$ \\
\hline \begin{tabular}{|l|}
1 - $3000 /$ \\
pre-sonic
\end{tabular} & 0.32 & 0.44 & 0.56 & 0.81 & 0.95 & 1.1 & 1.5 & 2.0 & 2.7 & 3.9 & 4.8 & 6.2 & 15 & 54 & 96 \\
\hline $\begin{array}{l}2 \text { - } 4000 / \\
\text { pre-sonic }\end{array}$ & 0.32 & 0.46 & 0.61 & 0.96 & 1.2 & 1.4 & 2.1 & 3.0 & 4.9 & 12 & 26 & 37 & 60 & 78 & 110 \\
\hline $\begin{array}{l}\text { - 2000 / } \\
\text { e-sonic }\end{array}$ & 0.30 & 0.42 & 0.54 & 0.79 & 0.93 & 1.1 & 1.5 & 1.9 & 2.6 & 3.5 & 4.2 & 5.2 & 9.6 & 18 & 230 \\
\hline \begin{tabular}{|l|}
$4-3000 /$ \\
$25 \%$
\end{tabular} & 0.31 & 0.42 & 0.54 & 0.79 & 0.93 & 1.1 & 1.5 & 1.9 & 2.5 & 3.3 & 3.8 & 4.5 & 7.1 & 9.9 & 15 \\
\hline \begin{tabular}{|l|}
$5-3000 /$ \\
$50 \%$
\end{tabular} & 0.31 & 0.43 & 0.55 & 0.81 & 0.96 & 1.1 & 1.5 & 1.9 & 2.5 & 3.2 & 3.8 & 4.4 & 6.7 & 9.1 & 13 \\
\hline \begin{tabular}{|l|}
$6-3000 /$ \\
$75 \%$
\end{tabular} & 0.32 & 0.44 & 0.56 & 0.82 & 0.96 & 1.1 & 1.5 & 1.9 & 2.4 & 3.1 & 3.6 & 4.2 & 6.2 & 8.2 & 12 \\
\hline $\begin{array}{l}7 \text { - 3000 / } \\
\text { post-sonic }\end{array}$ & 0.32 & 0.44 & 0.56 & 0.81 & 0.96 & 1.1 & 1.5 & 1.9 & 2.5 & 3.2 & 3.8 & 4.4 & 6.9 & 9.5 & 16 \\
\hline $\begin{array}{l}8 \text { - } 4000 / \\
\text { post-sonic }\end{array}$ & 0.32 & 0.46 & 0.60 & 0.91 & 1.1 & 1.3 & 1.8 & 2.4 & 3.3 & 4.8 & 6.3 & 9.0 & 35 & 51 & 77 \\
\hline $\begin{array}{l}\mathbf{9}-2000 / \\
\text { post-sonic }\end{array}$ & 0.31 & 0.43 & 0.55 & 0.8 & 0.94 & 1.1 & 1.4 & 1.9 & 2.4 & 3.1 & 3.6 & 4.2 & 6.3 & 8.4 & 12 \\
\hline
\end{tabular}


Richard Daniel

WTP-RPT-172, Rev 0

Page 61 of 63

TDP-WTP-226

August 8, 2008

Table A-4. Cumulative oversize diameter distributions for TI552-G6-16-PSD.

\begin{tabular}{|c|c|c|c|c|c|c|c|c|c|c|c|c|c|c|c|}
\hline \multirow{2}{*}{$\begin{array}{l}\text { Test } \\
\text { Condition }\end{array}$} & \multicolumn{15}{|c|}{ Volume / Weight Cumulative Oversize Diameter $(\mu \mathrm{m})$} \\
\hline & $1 \%$ & $5 \%$ & $10 \%$ & $20 \%$ & $25 \%$ & $30 \%$ & $40 \%$ & $50 \%$ & $60 \%$ & $70 \%$ & $75 \%$ & $80 \%$ & $90 \%$ & $95 \%$ & $99 \%$ \\
\hline $\begin{array}{l}\mathbf{1} \text { - } 3000 / \\
\text { pre-sonic }\end{array}$ & 0.32 & 0.42 & 0.51 & 0.69 & 0.79 & 0.9 & 1.1 & 1.5 & 1.9 & 2.6 & 3.1 & 3.9 & 6.7 & 10 & 89 \\
\hline $\begin{array}{l}2 \text { - } 4000 \text { / } \\
\text { pre-sonic }\end{array}$ & 0.31 & 0.42 & 0.52 & 0.74 & 0.87 & 1.0 & 1.4 & 2.0 & 2.8 & 4.5 & 6.1 & 9.5 & 38 & 56 & 88 \\
\hline $\begin{array}{l}3 \text { - 2000 / } \\
\text { pre-sonic }\end{array}$ & 0.31 & 0.41 & 0.50 & 0.68 & 0.77 & 0.88 & 1.1 & 1.5 & 1.9 & 2.5 & 3.0 & 3.5 & 5.5 & 7.8 & 14 \\
\hline $\begin{array}{l}4-3000 / \\
25 \%\end{array}$ & 0.32 & 0.43 & 0.52 & 0.71 & 0.82 & 0.93 & 1.2 & 1.6 & 2.0 & 2.6 & 3.0 & 3.5 & 5.2 & 7.3 & 13 \\
\hline $\begin{array}{l}5-3000 / \\
50 \%\end{array}$ & 0.32 & 0.44 & 0.54 & 0.76 & 0.88 & 1.0 & 1.3 & 1.7 & 2.2 & 2.8 & 3.1 & 3.6 & 5.4 & 7.5 & 13 \\
\hline $\begin{array}{l}6-3000 / \\
75 \%\end{array}$ & 0.33 & 0.45 & 0.56 & 0.78 & 0.91 & 1.0 & 1.4 & 1.7 & 2.2 & 2.8 & 3.2 & 3.7 & 5.5 & 7.6 & 14 \\
\hline $\begin{array}{l}7 \text { - 3000 / } \\
\text { post-sonic }\end{array}$ & 0.32 & 0.43 & 0.54 & 0.77 & 0.89 & 1.0 & 1.4 & 1.7 & 2.2 & 2.9 & 3.3 & 3.9 & 5.7 & 8.0 & 14 \\
\hline $\begin{array}{l}8-4000 / \\
\text { post-sonic }\end{array}$ & 0.30 & 0.41 & 0.52 & 0.76 & 0.89 & 1.0 & 1.4 & 1.9 & 2.5 & 3.4 & 4.0 & 4.9 & 9.0 & 18 & 38 \\
\hline $\begin{array}{l}\text { - } 2000 / \\
\text { post-sonic }\end{array}$ & 0.33 & 0.45 & 0.56 & 0.78 & 0.9 & 1.0 & 1.4 & 1.7 & 2.2 & 2.8 & 3.2 & 3.7 & 5.4 & 7.4 & 13 \\
\hline
\end{tabular}

Table A-5. Cumulative oversize diameter distributions for TI552-G6-21-PSD (initial measurement).

\begin{tabular}{|c|c|c|c|c|c|c|c|c|c|c|c|c|c|c|c|}
\hline \multirow{2}{*}{\begin{tabular}{|l|} 
Test \\
Condition
\end{tabular}} & \multicolumn{15}{|c|}{ " Volume / Weight Cumulative Oversize Diameter $(\mu \mathrm{m})$} \\
\hline & $1 \%$ & $5 \%$ & $10 \%$ & $20 \%$ & $25 \%$ & $30 \%$ & $40 \%$ & $50 \%$ & $60 \%$ & $70 \%$ & $75 \%$ & $80 \%$ & $90 \%$ & $95 \%$ & $99 \%$ \\
\hline $\begin{array}{l}\text { - } 3000 / \\
\text { pre-sonic }\end{array}$ & 0.40 & 0.59 & 0.76 & 1.1 & 1.2 & 1.3 & 1.6 & 1.9 & 2.3 & 2.8 & 3.2 & 3.8 & 88 & 150 & 340 \\
\hline \begin{tabular}{|l|}
2 - $4000 /$ \\
pre-sonic
\end{tabular} & 0.37 & 0.51 & 0.64 & 0.89 & 1.0 & 1.2 & 1.5 & 2.0 & 2.9 & 6.5 & 21 & 36 & 61 & 80 & 110 \\
\hline $\begin{array}{l}\text { - 2000 / } \\
\text { e-sonic }\end{array}$ & 0.37 & 0.49 & 0.59 & 0.77 & 0.86 & 0.95 & 1.1 & 1.4 & 1.6 & 1.9 & 2.2 & 2.4 & 3.6 & 5.8 & 10 \\
\hline \begin{tabular}{|l|}
$4-3000 /$ \\
$25 \%$
\end{tabular} & 0.32 & 0.41 & 0.49 & 0.63 & 0.71 & 0.78 & 0.95 & 1.2 & 1.5 & 1.9 & 2.2 & 2.6 & 4.6 & 6.6 & 9.4 \\
\hline \begin{tabular}{|l|}
$5-3000 /$ \\
$50 \%$
\end{tabular} & 0.29 & 0.37 & 0.44 & 0.57 & 0.64 & 0.71 & 0.88 & 1.1 & 1.5 & 2.0 & 2.4 & 2.9 & 4.8 & 6.4 & 8.7 \\
\hline \begin{tabular}{|l|}
$6-3000 /$ \\
$75 \%$
\end{tabular} & 0.29 & 0.37 & 0.44 & 0.57 & 0.63 & 0.71 & 0.89 & 1.2 & 1.6 & 2.2 & 2.6 & 3.1 & 4.8 & 6.2 & 8.3 \\
\hline $\begin{array}{l}7 \text { - 3000 / } \\
\text { post-sonic }\end{array}$ & 0.29 & 0.37 & 0.44 & 0.56 & 0.63 & 0.71 & 0.89 & 1.2 & 1.6 & 2.2 & 2.6 & 3.1 & 4.9 & 6.6 & 9.2 \\
\hline $\begin{array}{l}\text { - } 4000 / \\
\text { post-sonic }\end{array}$ & 0.29 & 0.37 & 0.44 & 0.59 & 0.67 & 0.76 & 1.0 & 1.4 & 2.0 & 2.9 & 3.5 & 4.5 & 10 & 25 & 36 \\
\hline $\begin{array}{l}9 \text { - } 2000 / \\
\text { post-sonic }\end{array}$ & 0.29 & 0.37 & 0.44 & 0.57 & 0.63 & 0.71 & 0.9 & 1.2 & 1.6 & 2.2 & 2.6 & 3.1 & 4.9 & 6.4 & 8.5 \\
\hline
\end{tabular}


Table A-6. Cumulative oversize diameter distributions for TI552-G6-21-PSD (replicate measurement).

\begin{tabular}{|c|c|c|c|c|c|c|c|c|c|c|c|c|c|c|c|}
\hline \multirow{2}{*}{\begin{tabular}{|l|} 
Test \\
Condition
\end{tabular}} & \multicolumn{15}{|c|}{ Volume / Weight Cumulative Oversize Diameter $(\mu \mathrm{m})$} \\
\hline & $1 \%$ & $5 \%$ & $10 \%$ & $20 \%$ & $25 \%$ & $30 \%$ & $40 \%$ & $50 \%$ & $60 \%$ & $70 \%$ & $75 \%$ & $80 \%$ & $90 \%$ & $95 \%$ & $99 \%$ \\
\hline \begin{tabular}{|l|}
1 - $3000 /$ \\
pre-sonic
\end{tabular} & 0.40 & 0.62 & 0.82 & 1.1 & 1.3 & 1.4 & 1.7 & 2.0 & 2.3 & 2.6 & 2.9 & 3.1 & 4.0 & 4.8 & 8.1 \\
\hline \begin{tabular}{l|}
$-4000 /$ \\
e-sonic
\end{tabular} & 0.37 & 0.48 & 0.59 & 0.79 & 0.89 & 1.0 & 1.2 & 1.5 & 1.9 & 2.3 & 2.7 & 3.2 & 7.9 & 26 & 57 \\
\hline $\begin{array}{l}\text {-2000/ } \\
\text { e-sonic }\end{array}$ & 0.37 & 0.47 & 0.56 & 0.72 & 0.80 & 0.89 & 1.1 & 1.3 & 1.5 & 1.8 & 2.1 & 2.3 & 3.5 & 5.8 & 11 \\
\hline $\begin{array}{l}-3000 / \\
5 \%\end{array}$ & 0.32 & 0.41 & 0.49 & 0.63 & 0.70 & 0.77 & 0.93 & 1.1 & 1.4 & 1.8 & 2.1 & 2.4 & 4.2 & 6.7 & 11 \\
\hline \begin{tabular}{|l|}
$\mathbf{5}-3000 /$ \\
$50 \%$
\end{tabular} & 0.29 & 0.37 & 0.44 & 0.56 & 0.63 & 0.70 & 0.87 & 1.1 & 1.5 & 2.0 & 2.4 & 3.0 & 5.1 & 7.3 & 11 \\
\hline \begin{tabular}{|l|}
$6-3000 /$ \\
$75 \%$
\end{tabular} & 0.29 & 0.37 & 0.43 & 0.56 & 0.63 & 0.70 & 0.88 & 1.2 & 1.0 & 2.2 & 2.6 & 3.1 & 5.2 & 7.3 & 10 \\
\hline \begin{tabular}{|l|}
7 - $3000 /$ \\
post-sonic
\end{tabular} & 0.28 & 0.36 & 0.43 & 0.56 & 0.63 & 0.70 & 0.90 & 1.2 & 1.6 & 2.2 & 2.7 & 3.2 & 5.3 & 7.5 & 11 \\
\hline \begin{tabular}{|l|}
$8-4000 /$ \\
post-sonic
\end{tabular} & 0.28 & 0.36 & 0.43 & 0.56 & 0.63 & 0.71 & 0.92 & 1.2 & 1.7 & 2.4 & 2.9 & 3.5 & 5.9 & 10 & 19 \\
\hline $\begin{array}{l}\mathbf{9}-2000 / \\
\text { post-sonic }\end{array}$ & 0.28 & 0.36 & 0.43 & 0.55 & 0.62 & 0.69 & 0.87 & 1.1 & 1.5 & 2.1 & 2.5 & 3.1 & 5.0 & 6.9 & 9.7 \\
\hline
\end{tabular}

Table A-7. Cumulative oversize diameter distributions for TI552-G6-26-PSD.

\begin{tabular}{|c|c|c|c|c|c|c|c|c|c|c|c|c|c|c|c|}
\hline \multirow{2}{*}{\begin{tabular}{|l|} 
Test \\
Condition
\end{tabular}} & \multicolumn{15}{|c|}{ Volume / Weight Cumulative Oversize Diameter $(\mu \mathrm{m})$} \\
\hline & $1 \%$ & $5 \%$ & $10 \%$ & $20 \%$ & $25 \%$ & $30 \%$ & $40 \%$ & $50 \%$ & $60 \%$ & $70 \%$ & $75 \%$ & $80 \%$ & $90 \%$ & $95 \%$ & $99 \%$ \\
\hline $\begin{array}{l}\text { - } 3000 / \\
\text { pre-sonic }\end{array}$ & 0.40 & 0.51 & 0.62 & 0.80 & 0.89 & 0.98 & 1.2 & 1.4 & 1.6 & 1.9 & 2.1 & 2.4 & 3.3 & 4.9 & 13 \\
\hline $\begin{array}{l}2 \text { - } 4000 / \\
\text { pre-sonic }\end{array}$ & 0.35 & 0.44 & 0.52 & 0.66 & 0.73 & 0.80 & 0.96 & 1.2 & 1.4 & 1.8 & 2.0 & 2.4 & 4.8 & 11 & 49 \\
\hline \begin{tabular}{|l|}
3 - 2000 / \\
pre-sonic \\
\end{tabular} & 0.33 & 0.42 & 0.49 & 0.63 & 0.69 & 0.76 & 0.92 & 1.1 & 1.3 & 1.7 & 1.9 & 2.3 & 4.1 & 7.3 & 120 \\
\hline \begin{tabular}{|l}
$4-3000 /$ \\
$25 \%$ \\
\end{tabular} & 0.30 & 0.38 & 0.45 & 0.58 & 0.64 & 0.71 & 0.86 & 1.1 & 1.3 & 1.8 & 2.1 & 2.5 & 4.1 & 6.2 & 12 \\
\hline \begin{tabular}{|l|}
$5-3000 /$ \\
$50 \%$ \\
\end{tabular} & 0.28 & 0.35 & 0.42 & 0.54 & 0.60 & 0.67 & 0.83 & 1.1 & 1.4 & 1.9 & 2.3 & 2.7 & 4.2 & 6.1 & 11 \\
\hline \begin{tabular}{|l|}
$6-3000 /$ \\
$75 \%$ \\
\end{tabular} & 0.28 & 0.36 & 0.43 & 0.56 & 0.64 & 0.72 & 0.92 & 1.2 & 1.6 & 2.1 & 2.5 & 2.9 & 4.4 & 6.4 & 11 \\
\hline \begin{tabular}{|l|}
7 - $3000 /$ \\
post-sonic
\end{tabular} & 0.28 & 0.36 & 0.43 & 0.56 & 0.63 & 0.72 & 0.92 & 1.2 & 1.6 & 2.1 & 2.5 & 2.9 & 4.2 & 5.6 & 8.3 \\
\hline $\begin{array}{l}\text { - } 4000 / \\
\text { post-sonic }\end{array}$ & 0.28 & 0.36 & 0.43 & 0.57 & 0.65 & 0.74 & 0.97 & 1.3 & 1.8 & 2.4 & 2.8 & 3.4 & 5.6 & 9.7 & 36 \\
\hline $\begin{array}{l}9 \text { - } 2000 / \\
\text { post-sonic }\end{array}$ & 0.28 & 0.37 & 0.44 & 0.57 & 0.64 & 0.72 & 0.92 & 1.2 & 1.6 & 2.1 & 2.4 & 2.9 & 4.3 & 6.0 & 11 \\
\hline
\end{tabular}


Table A-8. Cumulative oversize diameter distributions for TI552-G6-32-PSD.

\begin{tabular}{|c|c|c|c|c|c|c|c|c|c|c|c|c|c|c|c|}
\hline \multirow{2}{*}{\begin{tabular}{|l|} 
Test \\
Condition \\
\end{tabular}} & \multicolumn{15}{|c|}{ "Volume / Weight Cumulative Oversize Diameter $(\mu \mathrm{m})$} \\
\hline & $1 \%$ & $5 \%$ & $10 \%$ & $20 \%$ & $25 \%$ & $30 \%$ & $40 \%$ & $50 \%$ & $60 \%$ & $70 \%$ & $75 \%$ & $80 \%$ & $90 \%$ & $95 \%$ & $99 \%$ \\
\hline $\begin{array}{l}\mathbf{1}-3000 / \\
\text { pre-sonic }\end{array}$ & 0.38 & 0.48 & 0.57 & 0.72 & 0.79 & 0.86 & 1.0 & 1.2 & 1.4 & 1.7 & 1.9 & 2.1 & 3.2 & 5.6 & 12 \\
\hline $\begin{array}{l}2 \text { - } 4000 \text { / } \\
\text { pre-sonic }\end{array}$ & 0.34 & 0.45 & 0.55 & 0.74 & 0.85 & 0.98 & 1.3 & 1.9 & 3.9 & 24 & 34 & 43 & 64 & 81 & 110 \\
\hline $\begin{array}{l}3 \text { - } 2000 / \\
\text { pre-sonic }\end{array}$ & 0.32 & 0.41 & 0.48 & 0.61 & 0.67 & 0.74 & 0.88 & 1.1 & 1.3 & 1.7 & 1.9 & 2.4 & 4.3 & 6.9 & 12 \\
\hline \begin{tabular}{|l|}
$4-3000 /$ \\
$25 \%$
\end{tabular} & 0.28 & 0.36 & 0.42 & 0.55 & 0.61 & 0.68 & 0.86 & 1.1 & 1.5 & 2.1 & 2.5 & 3.0 & 5.0 & 7.1 & 10 \\
\hline $\begin{array}{l}5-3000 / \\
50 \%\end{array}$ & 0.29 & 0.37 & 0.44 & 0.56 & 0.63 & 0.71 & 0.91 & 1.2 & 1.6 & 2.2 & 2.6 & 3.1 & 4.9 & 6.8 & 10 \\
\hline $\begin{array}{l}6-3000 / \\
75 \%\end{array}$ & 0.29 & 0.37 & 0.45 & 0.58 & 0.66 & 0.74 & 0.96 & 1.3 & 1.7 & 2.3 & 2.7 & 3.2 & 5.0 & 7.0 & 10 \\
\hline $\begin{array}{l}7 \text { - 3000 / } \\
\text { post-sonic }\end{array}$ & 0.28 & 0.36 & 0.44 & 0.58 & 0.66 & 0.75 & 0.98 & 1.3 & 1.8 & 2.4 & 2.8 & 3.3 & 5.1 & 7.2 & 12 \\
\hline $\begin{array}{l}\text { - } 4000 / \\
\text { post-sonic }\end{array}$ & 0.28 & 0.38 & 0.48 & 0.69 & 0.83 & 1.0 & 1.5 & 2.3 & 3.7 & 7.3 & 17 & 28 & 46 & 61 & 85 \\
\hline $\begin{array}{l}9 \text { - } 2000 / \\
\text { post-sonic }\end{array}$ & 0.29 & 0.37 & 0.45 & 0.59 & 0.67 & 0.75 & 0.97 & 1.3 & 1.7 & 2.3 & 2.7 & 3.2 & 5.1 & 7.1 & 11 \\
\hline
\end{tabular}

Table A-9. Relative percent difference between initial and replicate PSD measurements for TI552-G6-21-PSD.

\begin{tabular}{||l|c|c|c|c|c|c|c|c|c|c|c|c|c|c|c||}
\hline $\begin{array}{l}\text { Test } \\
\text { Condition }\end{array}$ & $\mathbf{1 \%}$ & $\mathbf{5 \%}$ & $\mathbf{1 0} \%$ & $\mathbf{2 0 \%}$ & $\mathbf{2 5 \%}$ & $\mathbf{3 0} \%$ & $\mathbf{4 0 \%}$ & $\mathbf{5 0} \%$ & $\mathbf{6 0} \%$ & $\mathbf{7 0 \%}$ & $\mathbf{7 5 \%}$ & $\mathbf{8 0} \%$ & $\mathbf{9 0 \%}$ & $\mathbf{9 5 \%}$ & $\mathbf{9 9 \%}$ \\
\hline $\begin{array}{l}\mathbf{1}-3000 / \\
\text { pre-sonic }\end{array}$ & 2.0 & 5.1 & 8.6 & 8.9 & 8.1 & 7.1 & 4.8 & 2.0 & 1.4 & 6.6 & 11 & 17 & 95 & 97 & 98 \\
\hline $\begin{array}{l}\mathbf{2}-4000 / \\
\text { pre-sonic }\end{array}$ & 1.9 & 5.1 & 7.5 & 11 & 13 & 15 & 19 & 25 & 35 & 64 & 87 & 91 & 87 & 67 & 50 \\
\hline $\begin{array}{l}\mathbf{3}-2000 / \\
\text { pre-sonic }\end{array}$ & 1.6 & 3.9 & 5.2 & 6.2 & 6.5 & 6.6 & 6.7 & 6.4 & 6.0 & 5.4 & 5.0 & 4.5 & 3.4 & 0.85 & 9.0 \\
\hline $\begin{array}{l}\mathbf{4}-3000 / \\
25 \%\end{array}$ & 0.62 & 0.00 & 0.41 & 1.1 & 1.4 & 1.7 & 2.3 & 3.1 & 3.9 & 5.1 & 6.0 & 7.3 & 9.2 & 0.66 & 12 \\
\hline $\begin{array}{l}\mathbf{5}-3000 / \\
50 \%\end{array}$ & 1.4 & 1.6 & 1.6 & 1.2 & 1.1 & 0.99 & 0.80 & 0.45 & 0.07 & 0.25 & 0.38 & 0.68 & 6.4 & 14 & 21 \\
\hline $\begin{array}{l}\mathbf{6}-3000 / \\
75 \%\end{array}$ & 1.0 & 1.4 & 1.1 & 1.2 & 1.1 & 1.1 & 0.79 & 0.26 & 0.26 & 0.28 & 0.23 & 0.55 & 8.2 & 18 & 26 \\
\hline $\begin{array}{l}\mathbf{7}-3000 / \\
\text { post-sonic }\end{array}$ & 2.8 & 2.2 & 1.8 & 0.89 & 0.48 & 0.14 & 1.1 & 2.8 & 4.0 & 4.5 & 4.4 & 4.4 & 7.4 & 13 & 19 \\
\hline $\begin{array}{l}\mathbf{8}-4000 / \\
\text { post-sonic }\end{array}$ & 2.1 & 2.7 & 3.2 & 4.4 & 5.3 & 6.2 & 8.5 & 11 & 14 & 17 & 19 & 23 & 43 & 58 & 47 \\
\hline $\begin{array}{l}\mathbf{9}-2000 / \\
\text { post-sonic }\end{array}$ & 0.7 & 1.4 & 1.6 & 2.5 & 2.8 & 3.1 & 3.2 & 3.1 & 2.2 & 2.2 & 2.5 & 2.7 & 1.4 & 7.6 & 14 \\
\hline
\end{tabular}


WTP-RPT-172, Rev 0

\section{Appendix I}

\section{Group 5 CUF Rheology Analysis}




\section{Appendix I: Group 5 CUF Rheology Analysis}

\section{Battelle}

The Business of Innovation

Date $\quad$ March 28, 2008

To Rick Shimskey

From $\quad$ Richard Daniel

Subject Rheology of Hanford Waste REDOX Sludge (Waste Processing Group 5): CUF Testing (FINAL)
Internal Distribution

Rick Shimskey

Richard Daniel

\section{Acronyms and Abbreviations}

$\begin{array}{ll}\text { AV } & \text { Axial Velocity } \\ \text { CUF } & \text { Cells Unit Filter } \\ \text { DI } & \text { Deionized (water) } \\ \text { LRB } & \text { Laboratory Record Book } \\ \text { NIST } & \text { National Institute of Technology } \\ \text { RPL } & \text { Radiochemical Processing Laboratory } \\ \text { RPP } & \text { River Protection Project } \\ \text { SAL } & \text { Shielded Analytical Laboratory } \\ \text { TMP } & \text { Transmembrane Pressure } \\ \text { WTP } & \text { Waste Treatment Plant (Support Program) }\end{array}$

\section{Introduction}

In fulfillment of the requirements of Test Plan TP-RPP-WTP-467 [1], the rheology of select Hanford tank waste samples was characterized at the Radiochemical Processing Laboratory (RPL). This interim characterization report presents rheology test results for waste processing group 5 Cells Unit Filter (CUF) testing samples. This waste group corresponds to REDOX (R) sludge and supernates. The studies described herein will be limited to flow-curve testing of waste materials.

\section{Background}

Rheology is the science of material flow and deformation. For fluid systems, including pure liquids, mixtures of liquids, and suspensions of solids in liquids, the rheological properties of that system describe how it responds to an applied force or stress. When applied to solids, stress induces a strain or finite deformation in the material as long as the material yield is not exceeded. When applied to pure liquids, any stress causes a continuous deformation of the substance or, in simpler terms, fluid flow. Suspensions of solids in liquids or liquid mixtures with internal structure can show a combination of both solid- and liquid-like behavior. In addition, the response of materials to force and deformation may not be constant. Changes in internal structure of materials that occur as a result of mechanical and chemical processes, such as breakage, precipitation of solids, and gelation, may alter the macroscopic flow and 
deformation properties. For the current study, only non-elastic flow of tank waste slurries and supernates is considered.

Non-elastic flow of tank waste slurries and supernates is characterized with rotational viscometry. The goal of rotational viscometry is measurement of a material's flow curve, which describes the shear stress response, $\tau$, as a function of applied shear rate, $\dot{\gamma}$ (also called the rate-of-strain). The result of a flow curve measurement is a set of $\tau$ versus $\dot{\gamma}$ measurements, which are called flow curve data. Flow curve data can be interpreted with several constitutive equations that relate viscous stress to shear-rate. Such analysis allows the flow behavior over a broad range of conditions to be described with just a few rheological descriptors such as viscosity, yield stress, consistency, and flow index.

A concentric cylinder rotational viscometer operated in controlled-rate mode will be used for flow curve testing of tank waste slurries and supernatants. These viscometers operate by placing a given volume of test sample into a measurement cup of known geometry. A cylindrical rotor attached to a torque sensor is then lowered into the sample until the slurry is even with, but does not cover, the top of the rotor. Both the radius and height of the rotor are well-known such that the gap between cup and rotor and surface area of fluid contact can be determined. The top and bottom of the rotor have recessed surfaces such that the fluid only contacts the radial surfaces of the rotor. A filled rotor-in-cup test geometry is shown in Figure 1. Determination of the fluid flow properties of the sample is made by spinning the rotor at a known rotational speed, $\Omega$, and measuring the resisting torque, $M$, acting on the rotor. Because fluid only contacts the rotor on the radial surfaces of rotation, all of the force resisting steady-state rotation can be ascribed to shearing of the fluid in the cup-rotor gap. Assuming an isotropic fluid and cup and rotor dimensions as shown in Figure 3, the torque acting on the rotor can be directly related to the shear stress at the rotor using the equation,

$$
\tau=\frac{M}{2 \pi H R_{I}^{2}}
$$

Eq. 1

Shear stress has units of force per area $\left[\mathrm{N} / \mathrm{m}^{2}\right]$. Calculation of the fluid shear rate at the rotor is complicated by the fact that shear rate depends on both on the measurement system geometry and the fluid rheological properties. For the simplest fluids (i.e., Newtonian fluids) the shear rate of the fluid at the rotor can be calculated given the geometry of the cup rotor shear (see Figure 3) by using the equation,

$$
\dot{\gamma}=\left(\frac{2 R_{O}^{2}}{R_{O}^{2}-R_{I}^{2}}\right) \Omega
$$

Here, shear rate has units of inverse seconds [1/s]. Calculation of shear rate for materials showing more complex shear stress versus shear rate behavior (i.e., non-Newtonian fluids) requires input of flow curve parameters such as yield stress and degree of shear-thinning or shear-thickening. Because the required input parameters are typically not known prior to measurement, this requirement is typically circumvented by using a cup and rotor system with a small gap $(\sim 1 \mathrm{~mm})$ such that shear rate effects introduced by fluid properties are minimized. For these systems, Eq. 2 provides an accurate determination of shear rate for non-Newtonian materials. 


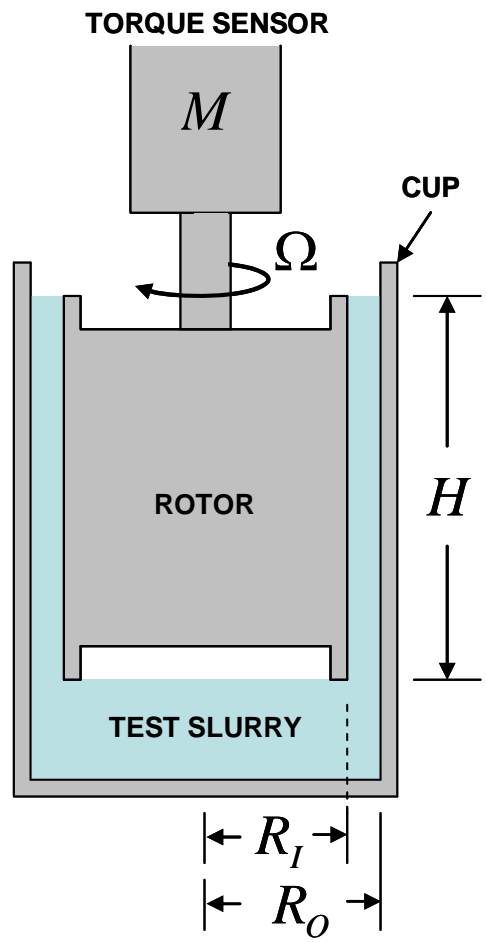

Figure 1. Rotor and cup geometry used in rotational viscometry testing.

Shear rates examined in this study will span approximately 1 to $1000 \mathrm{~s}^{-1}$ and are typical of those shear rates experienced in pipeline flow [2].

The resistance of a fluid to flow is often described in terms of the fluid's apparent viscosity, $\eta_{\text {app }}$, which is defined as the ratio of the shear stress to shear rate:

$$
\eta_{\text {app }}=\frac{\tau}{\dot{\gamma}}
$$

Often the shear stress and viscosity vary as a function of shear rate. Since the viscosity is defined as the ratio of shear stress to shear rate, the units of the variable are Pa·s. Typically, viscosity is reported in units of centipoise (cP; where $1 \mathrm{cP}=1 \mathrm{mPa} \cdot \mathrm{s})$.

Flow curve data are usually combined plots of $\tau$ and $\eta_{\text {app }}$ as a function of $\dot{\gamma}$. As stated above, flow curve data can be interpreted with several constitutive equations (i.e., flow curves), allowing characterization of that data with just a few rheological descriptors. The behavior of tank waste sludges, slurries, and supernates can be described by four common flow curve equations. These are:

- $\quad$ Newtonian - Newtonian fluids flow as a result of any applied stress and show constant viscosity over all shear conditions. The flow curve for Newtonian fluids is,

$$
\tau=\eta \dot{\gamma}
$$


where $\eta$ is the Newtonian viscosity.

- Ostwald (Power Law) - Power law fluids flow as a result of any applied stress and have viscosities that either increase or decrease with increasing shear rate. The are described by,

$$
\tau=m \dot{\gamma}^{n}
$$

Eq. 5

where $m$ is the power law consistency index and $n$ is the power law index. Power law fluids with $n<1$ are referred to as psuedoplastic (shear-thinning), whereas power law fluids with $n$ $>1$ are referred to as dilatant (shear-thickening).

- Bingham Plastic - Bingham plastics are fluids that show finite yield points. A finite stress (i.e., the yield stress), must be exceeded before these types of materials flow. Once flow is initiated, the stress response of the material is Newtonian over the rest of the shear rate range. Bingham plastics are described by,

$$
\tau=\tau_{O}^{B}+k_{B} \dot{\gamma}
$$

where $\tau_{O}^{B}$ is the Bingham yield index and $k_{B}$ is the Bingham consistency index.

- Herschel-Bulkley - Fluids that behave in accordance with a Herschel-Bulkley model show a finite yield followed by power-law behavior over the rest of the shear rate range. They are described by,

$$
\tau=\tau_{O}^{H}+k_{H} \dot{\gamma}^{b}
$$

where $\tau_{O}^{H}$ is the Herschel-Bulkley yield index, $k_{H}$ is the Herschel-Bulkley consistency index, and $\mathrm{b}$ is the Herschel-Bulkley power law index.

Power-law fluids, Bingham plastics, and Herschel-Bulkley fluids are referred to as non-Newtonian fluids. In generally, liquids without internal and/or interconnected structures (such as tank waste supernates) are Newtonian. Sludges and slurries are typically non-Newtonian, but their exact behavior depends on the concentration of solids and suspending phase chemistry. Sufficiently dilute slurries may show Newtonian behavior.

For the purposes of data reporting herein, the model used to fit flow curve data will be reported. Values for $\tau_{O}^{B}$ and $\tau_{O}^{H}$ will then be collectively referred to as the yield stress. Values for $\eta, m, k_{B}$, and $k_{H}$, shall be collectively referred to as the consistency. Values for $n$ and $b$ shall be referred to as the flow index. . 


\section{Samples}

Group 5 CUF rheology samples were derived as part of bench-scale crossflow ultrafiltration and leaching studies using actual tank waste. During these studies, a low-concentration tank waste slurry (4.3-wt\% solids) was loaded into a CUF unit installed in SAL Cell 5 and subjected to the following operations (in order):

1. full-recycle ultrafiltration of the low-concentration (4.3-wt\% solids) waste slurry at various axial velocities (AV) and transmembrane pressures (TMP)

2. dewatering from a low-concentration (4.3-wt\% solids) to a high-concentration (15.5-wt\% solids)

3. full-recycle ultrafiltration of the high-concentration (15.5-wt\% solids) waste slurry at various AV and TMP

4. caustic leaching of the waste slurry with $5 \mathrm{M}$ sodium hydroxide for 24 hours at $100^{\circ} \mathrm{C}$

5. dewatering of the leached slurry

6. washing of the leached slurry

The initial target concentration for dewatering of the pre-leach slurry (i.e., step 2) was 19-wt\% solids. During execution of group 5 CUF testing, the 19-wt\% slurry was achieved during dewatering. At this concentration, the slurry was so thick and generation of heat through viscous dissipation so great that the chiller could not maintain the required operating temperature range of $20-30^{\circ} \mathrm{C}$ at all test TMP and $\mathrm{AV}$. As such, the target concentration for dewatering was lowered to $15.5-\mathrm{wt} \%$.

For CUF rheology testing, samples were derived from various points in the ultrafiltration process outlined above. With regard to slurry samples, rheology was tested

- $\quad$ after loading the sample into the CUF (i.e., before step 1),

- after dewatering step 2,

- following the dewatering step 5, and

- after leached slurry washing.

For dewatering step 2, samples were taken for both concentrations attempted (i.e., 15.5-wt\% and 19$\mathrm{wt} \%$ ). Waste permeate (i.e., supernate) samples were collected during the dewatering steps before and after caustic leaching. Table 1 provides a summary of the samples taken and their given sample identification number.

Table 1. Samples associated with Group 5 CUF rheology testing.

\begin{tabular}{||l|l||}
\hline Sample Jar ID & Description \\
\hline TI540-G5-R1 & Slurry - Low-solids matrix (4.3-wt\%) before caustic leaching \\
\hline TI540-G5-R2A & Slurry - Very-high-solids matrix (19-wt\%) before caustic leaching \\
\hline TI540-G5-R2BN* & Slurry - High-solids matrix (15.5-wt\%) before caustic leaching \\
\hline TI540-G5-R3 & Slurry - Dewatered slurry after caustic leaching (13.5-wt\%) \\
\hline TI540-G5-R4 & Slurry - Washed slurry after caustic leaching (4.1-wt\%) \\
\hline TI540-G5-Dewater4 & Permeate - pre-leach permeate collected during dewatering \\
\hline TI540-G5-Leach2 & Permeate - post-leach permeate before washing \\
\hline
\end{tabular}




\section{Analysis}

Flow curve testing of group 5 waste samples was performed in parallel with the ultrafiltration studies. Testing began on August 20 and finished on August 28, 2007. Flow curve testing produced the following reportable data for the group 5 CUF samples:

- flow curve data for group 5 slurries at $25^{\circ} \mathrm{C}, 40^{\circ} \mathrm{C}$, and $60^{\circ} \mathrm{C}$ at various points in the ultrafiltration and leaching processes

- flow curve data for group 5 supernates at $25^{\circ} \mathrm{C}, 40^{\circ} \mathrm{C}$, and $60^{\circ} \mathrm{C}$ at various points in the ultrafiltration process

- best-fit Power-law, Bingham Plastic, and Herschel-Bulkley parameters for group 5 waste slurries at $25^{\circ} \mathrm{C}, 40^{\circ} \mathrm{C}$, and $60^{\circ} \mathrm{C}$

- Newtonian viscosities for group 5 permeates at $25^{\circ} \mathrm{C}, 40^{\circ} \mathrm{C}$, and $60^{\circ} \mathrm{C}$

\section{Instrumentation}

Rheological characterization was accomplished using a Rotovisco ${ }^{\circledR}$ RV20 Measuring System M equipped with an M5 measuring head and RC20 controller. These components were purchased from HAAKE Mess-Technik GmbH u. Co. (now the Thermo Electron Corporation, Madison, WI 53711). This system is installed in Cell 4 of the Shielded Analytical Laboratory (SAL) at the Radiochemical Processing Laboratory (RPL). The M5 measuring head (SN\# 902398) is a "Searle" type viscometer capable of producing rotational speeds up to $500 \mathrm{RPM}$ and measuring torques up to $0.049 \mathrm{~N} \cdot \mathrm{m}$. The minimum rotational speed and torque resolution achievable by this measuring head are 0.05 RPM and $0.49 \mathrm{mN} \cdot \mathrm{m}$, respectively. Table 2 summarizes the M5 measuring system information.

Table 2. Summary of Haake RV20 system with M5 measuring head.

\begin{tabular}{||l|l||}
\hline \hline Analyzer: & $\begin{array}{l}\text { Rotorvisco }{ }^{\circledR} \text { RV20 Measuring System M with M5 } \\
\text { Measuring Head. }\end{array}$ \\
\hline Measurement principle: & Controlled Rate \\
\hline Serial Number: & 902398 \\
\hline Torque Sensor Range & 0.49 to $49 \mathrm{mN} \cdot \mathrm{s}$ \\
\hline Rotational Rate Range & 0.05 to 500 RPM \\
\hline Calibrated & May 23, 2007 \\
\hline Date Due & May 2008 \\
\hline
\end{tabular}

Flow curve measurements employed an MV1 stainless steel measuring cup and rotor. The dimensions of the MV1 and vane measuring systems are listed in Table 3.

Table 3. Vane and Cup and Rotor Measuring System Dimensions.

\begin{tabular}{||l|c|c|c|c||}
\hline Measuring System & $\begin{array}{c}\text { Vane/Rotor } \\
\text { Radius }\end{array}$ & $\begin{array}{c}\text { Vane/Rotor } \\
\text { Height }\end{array}$ & Cup Radius & Gap Width \\
\hline MV1 & $20.04 \mathrm{~mm}$ & $60 \mathrm{~mm}$ & $21 \mathrm{~mm}$ & $0.96 \mathrm{~mm}$ \\
\hline
\end{tabular}


Temperature control is achieved using a combination of the standard measuring system $\mathrm{M}$ temperature jacket and a Cole-Parmer ${ }^{\circledR}$ Polystat ${ }^{\circledR}$ Temperature-Controlled Recirculator, Model Number C-12920-00. This recirculator allows heating and cooling of recirculation fluid to the rheometer over $-5^{\circ}$ to $80^{\circ} \mathrm{C}$ with a stability of $\pm 0.5^{\circ} \mathrm{C}$. It connects the measuring head to the measuring system, centers the cup, and provides heat transfer area between cup and recirculating fluid. The recirculating unit is located next to, but outside, the SAL Cell 4. The recirculator is connected to the water jacket through a combination of stainless steel piping (outside of cell) and flexible fiber reinforced plastic hose (inside cell). The desired temperature is set using the digital control interface on the recirculating unit. Fluid is circulated between the recirculator and jacket until the desired temperature is achieved at the jacket. Jacket temperature is monitored using a Type-K thermocouple (Omega Model TJ36-CASS-116-G-6-CC) calibrated over $0^{\circ}$ to $100^{\circ} \mathrm{C}$ connected to a multichannel display unit located in the SAL Gallery. Temperature control is employed only for flow curve measurements. Details of the temperature measurement and display calibration are given in Table 4. It should be noted that only the first two channels of the temperature display were calibrated. All measurements taken herein employ channel 1.

Table 4. Calibration information for temperature measurement and display systems.

\begin{tabular}{||l|c|c|c|c|c||}
\hline System & Serial \# & $\begin{array}{c}\text { Calibratio } \\
\text { n Barcode }\end{array}$ & Range Calibrated & $\begin{array}{c}\text { Date } \\
\text { Calibrated }\end{array}$ & $\begin{array}{c}\text { Date } \\
\text { Due }\end{array}$ \\
\hline $\begin{array}{l}\text { Type-K } \\
\text { Thermocouple }\end{array}$ & $\mathrm{n} / \mathrm{a}$ & 22888 & $0^{\circ}$ to $100^{\circ} \mathrm{C}\left( \pm 2^{\circ} \mathrm{C}\right)$ & $5 / 4 / 2007$ & $5 / 4 / 2008$ \\
\hline $\begin{array}{l}\text { Temperature } \\
\text { Display }\end{array}$ & 6070759 & 22889 & $0^{\circ}$ to $100^{\circ} \mathrm{C}\left( \pm 2^{\circ} \mathrm{C}\right)$ & $5 / 7 / 2007$ & $5 / 7 / 2008$ \\
\hline
\end{tabular}

Rheometer control and data acquisition are accomplished through remote computer connection using the RheoWin Pro Job Manager Software, Version 2.96. The RheoWin software serves as a central program for obtaining, processing, and recording to disk data from the RV20-M5 Measuring System. During measurement, the software automatically converted rotor torque readings into shear stresses based on the appropriate A-factor conversion, such that

$$
\tau=A M
$$

For the cup and rotor system, the A-factor is defined by

$$
A=\frac{1}{2 \pi H R_{I}^{2}}
$$

The A-factor for the MV1 measuring system is $6570 \mathrm{~m}^{-3}$. For flow curve testing, the RheoWin software also automatically converted the rotational rate readings into shear rates based on a factory-set "Mfactor”, such that:

$$
\dot{\gamma}=M_{R} \Omega
$$

where $\Omega$ is the rotational rate in radians per second, and $M_{R}$ is the "M-factor". The M-factor is defined as 


$$
M=\left(\frac{2 R_{O}^{2}}{R_{O}^{2}-R_{I}^{2}}\right)
$$

For the MV1 sensor system, the M-factor is 22.350. The RheoWin software also allows postmeasurement processing and interpretation of data. Specifically, it can be used to determine maxima points in shear strength testing and fit flow curve data to any flow curve model (i.e., Eqs. 5-8).

\section{Governing Test Plan, Procedure, and Test Instructions}

The test plan governing the physical characterizations for these samples is River Protection Project - Waste Treatment Plant Support Program (RPP-WTP) document number TP-RPP-WTP-467, Revision 0 [1]. Operation of the HAAKE RV20-M5 Measurement System is governed by RPLCOLLOID-02, Revision 1 [3].

\section{Experimental}

Waste slurries were generally tested "as-is”. Specifically, no sample treatment was performed during the interval between sample extraction from the CUF until rheology testing, with exception of the mechanical agitation required to disperse any settled waste solids in each sample jar. Samples TI-540-G5R1 and TI-540-G5-R2A were pulled from the CUF slurry reservoir. The initial sample of concentrated ( $15 \mathrm{wt} \%$ ) slurry was also pulled from the slurry reservoir; however, this sample showed lower yield stress and consistency than the 5wt\% slurry. Poor mixing and sampling of the slurry in the CUF reservoir was suspected as the cause. To provide a more consistent sampling approach, all subsequent samples (TI540-G5-R2BN*, TI-540-G5-R3, and TI-540-G5-R4) were collected from CUF valve port V5.

\section{Instrument Performance Check}

As required by RPL-COLLOID-02, the performance of the Haake M5 rheometer must be verified at the beginning of each series of analyses (with the period between performance checks not to exceed 30 days during use). Checks are performed using Newtonian viscosity standards certified by methods traceable to the United States National Institute of Standards and Technology (NIST). Checks verify that the Haake M5 rheometer can measure the standard's viscosity to within $10 \%$ for fluids of $10 \mathrm{cP}$ or greater and to within $15 \%$ for fluids less than $10 \mathrm{cP}$ at the temperature listed on the certificate of analysis.

For the measurements described in this report, the performance check employed General Purpose Silicone Fluids purchased from Brookfield Engineering Laboratories, Inc. (Middleboro, Massachusetts, USA, 02346). Silicone oils are single phase liquids and have no suspended solids. For testing, three standards were used: Brookfield Fluid 10, Brookfield Fluid 50, and Brookfield Fluid 100. Tables 5 to 7 provide a summary of each viscosity standard's properties. Standards are traceable back to their certificate of analysis through a unique lot number.

Table 5. Properties of Brookfield Fluid 10.

\begin{tabular}{||l|l||}
\hline Fluid & 10 \\
\hline Viscosity & $9.6 \mathrm{cP}$ \\
\hline Temperature & 25 \\
\hline Lot Number & 121306 \\
\hline PNNL Barcode & 275359 \\
\hline Certificate Date & $12 / 14 / 2007$ \\
\hline
\end{tabular}

Table 6. Properties of Brookfield Fluid 50.

\begin{tabular}{||l|l||}
\hline Fluid & 50 \\
\hline Viscosity & $48.0 \mathrm{cP}$ \\
\hline Temperature & 25 \\
\hline Lot Number & 030607 \\
\hline PNNL Barcode & 275360 \\
\hline Calibration Date & $3 / 7 / 2007$ \\
\hline
\end{tabular}


Table 7. Properties of Brookfield Fluid 100.

\begin{tabular}{||l|l||}
\hline \hline Fluid & 100 \\
\hline Viscosity & $96.0 \mathrm{cP}$ \\
\hline Temperature & 25 \\
\hline Lot Number & 021507 \\
\hline PNNL Barcode & 275361 \\
\hline Calibration Date & $2 / 16 / 2007$ \\
\hline
\end{tabular}

Performance checks consisted of temperature controlled flow curve measurements that employed the MV1 measuring cup and rotor. The instrument performance checks covering the period of testing were run on August $7^{\text {th }}$ and $8^{\text {th }}$, 2007. In both cases, execution of performance verifications was as follows:

1. The appropriate measurement rotor was installed on the measuring head

2. The temperature jacket was installed on the measuring head and the recirculator turned on and set to $25^{\circ} \mathrm{C}$. The jacket is allowed to achieve temperature equilibrium.

3. Approximately 40 to $50 \mathrm{~mL}$ of viscosity fluid was added to the MV1 cup.

4. The measuring cup was installed into the water jacket by slowly raising it on a laboratory jack stand. During installation, the cup slides into the base of the water jacket where it contacts and slides over the rotor. The rotor volume displaces the test material, forcing it to fill the gap between cup and rotor. While the cup was being raised, the liquid level relative to the top of the rotor was monitored through an opening in the top of the water jacket using a small digital video camera installed in-cell. The cup was raised until the test material was observed to spill over the top of the rotor. Before continuing, excess viscosity standard was removed from the top of the rotor using a plastic transfer pipette.

5. The viscosity standard was left undisturbed in the measuring system for 5 minutes to allow temperature equilibration.

6. The material flow curve data were measured. Rheological analysis was performed over a 15minute period, split into three 5-minute intervals. Over the first 5 minutes, the shear rate was gradually increased from zero to $1000 \mathrm{~s}^{-1}$. For the second 5 minutes, the shear rate is held constant at $1000 \mathrm{~s}^{-1}$. For the final 5-minutes, the shear rate was gradually reduced back to zero. During this time, the resisting torque and rotational rate is continuously monitored and recorded.

After the measurement, flow curve data are automatically fit to a Newtonian model (Eq. 4) by the RheoWin software. The regressed value is saved to the measurement file and is also transcribed into the LRB. The percent error, $E$, between the measured viscosity, $\eta_{\text {meas }}$, and that listed on the certificate of analysis, $\eta_{\text {list }}$, is calculated as:

$$
E=\left(\frac{\eta_{\text {meas }}-\eta_{\text {list }}}{\eta_{\text {list }}}\right) \times 100 \%
$$

The performance check is considered acceptable if the absolute value of $E$, defined as $|E|$, is less than $10 \%$ for fluids with list viscosities greater than or equal to $10 \mathrm{cP}$ or is less than $15 \%$ for fluids with list 
viscosities less than $10 \mathrm{cP}$. Prior to start of any quality affecting work, the RV20-M5 was verified to be in acceptable performance.

Table 8 lists the results of each performance verification/check carried out in association with Group 5 CUF testing efforts. As indicated in the table, the RV20-M5 measuring system showed acceptable performance for all three test fluids. All flow curves showed the expected Newtonian behavior for these standards.

Table 8. Results of rheometer performance checks.

\begin{tabular}{||l|c|c|c|c|c||}
\hline Test Fluid & $\begin{array}{c}\text { Performance } \\
\text { Date* }\end{array}$ & $\begin{array}{c}\text { List } \\
\text { Viscosity } \\
\text { (cP) }\end{array}$ & $\begin{array}{c}\text { Measured } \\
\text { Viscosity (cP) }\end{array}$ & $/ E /$ & Acceptable \\
\hline Brookfield Fluid 10 & August 7, 2007 & 9.6 & 9.1 & $5.2 \%$ & Yes \\
\hline Brookfield Fluid 50 & August 7, 2007 & 48.0 & 45.9 & $4.5 \%$ & Yes \\
\hline Brookfield Fluid 100 & August 7, 2007 & 96.0 & 88.5 & $7.8 \%$ & Yes \\
\hline
\end{tabular}

*Period of performance extends for 30 days after the listed performance date.

\section{Flow Curve Testing}

Flow curve testing for both slurry and supernate samples employed an MV1 cup and rotor. Each flow curve measurement was accomplished as follows:

1. The MV1 rotor was installed on the measuring head

2. The temperature jacket was installed and the recirculator turned on and set to $25^{\circ} \mathrm{C}$. The jacket is allowed to achieve temperature equilibrium.

3. The test sample was transferred from its source jar into the MV1 measurement cup. Sample was added to the cup until the fluid level was above the first (i.e., lowest) cup level marker but still below the second level marker. This typically required 40 to $50 \mathrm{~mL}$ of sample. Gross material transfer was accomplished by pouring the sample into the test container until a rough estimate of the required sample volume was obtained. Fine level adjustments were made by adding and removing material to and from the measuring cup using a plastic transfer pipette.

4. The measuring cup was installed into the water jacket by slowly raising it on a laboratory jack stand. The cup was raised until the test material was observed to spill over the top of the rotor. Before continuing, excess material was removed from the top of the rotor (to the extent possible) using a plastic transfer pipette. In most cases, there was approximately 1-3 $\mathrm{mL}$ of excess material that could not be removed from the recessed upper rotor surface.

5. The moisture barrier was wetted and installed over the opening at the top of the temperature jacket. The moisture barrier is a stainless steel clamshell fitting lined with a sponge. It serves to minimize sample evaporation by blocking openings at the top of the water jacket (where the sample is exposed to air) and by humidifying the air space above the sample.

6. The sample was left undisturbed in the measuring system for 5 minutes to allow temperature equilibration.

7. The sample was sheared for 1 to 3 minutes to break sample structure and to attempt re-suspension any settled slurry particles and to verify that the rotor was properly centered.

8. The material flow curve data were measured. Rheological analysis was performed over a 15minute period, split into three 5-minute intervals. Over the first 5 minutes, the shear rate was smoothly increased from zero to $1000 \mathrm{~s}^{-1}$. For the second 5 minutes, the shear rate is held 
constant at $1000 \mathrm{~s}^{-1}$. For the final 5-minutes, the shear rate was smoothly reduced back to zero. During this time, the resisting torque and rotational rate is continuously monitored and recorded.

9. The flow curve data for $25^{\circ} \mathrm{C}$ were saved using the RheoWin file format and a unique filename identifier. Sample information and the associated RheoWin filename were entered into the LRB.

10. The temperature set point was set to $40^{\circ} \mathrm{C}$. Once, the jacket had reached the temperature set point, the sample was allowed an additional 5 minutes to reach temperature equilibrium. The cup was raised so that fresh sludge/slurry filled the gap. Excess sludge was pipetted from the top. The moisture guard was, removed, re-wetted, and then re-installed

11. The flow curve at $40^{\circ} \mathrm{C}$ was re-measured as per steps 7 through 9 .

12. The temperature set point was set to $60^{\circ} \mathrm{C}$. Once, the jacket had reached the temperature set point, the sample was allowed an additional 5 minutes to reach temperature equilibrium. The cup was raised so that fresh sludge/slurry filled the gap. Excess sludge was pipetted from the top. The moisture guard was, removed, re-wetted, and then re-installed

13. The flow curve at $60^{\circ} \mathrm{C}$ was re-measured as per steps 7 through 9 .

14. At the end of testing, the measuring cup was removed from the system. The test material was returned to its original container. The measuring system was disassembled. Any slurry or precipitated salt solids remaining in the cup or rotor were cleaned-off using by rinsing with copious amounts of water and by wiping down with a damp cloth.

Visual inspection of the group 5 slurries prior to testing found no observable solids settling during transfer from sample jar to rheometer measurement cup. In addition, when performing step 7, the rotor torques measured while mixing were constant. This indicates that for short periods of time, such as the 1 to 3 minute mixing step or the time required to transfer the sample to the measuring cup ( $\sim$ minutes), settling and shear history effects were minimal for the Group 5 CUF slurry samples.

For the pre-caustic leach permeate sample (TI540-G5-Dewater4), the viscosity was too low to accurately determine by flow curve because of formation of Taylor Vortices (hereafter referred as flow vortices) in the gap between cup and rotor. Additional details on vortex formation will be given in the discussion of this sample. To obtain viscosity as a function of temperature for TI540-G5-Dewater4, constant rotation experiments were performed at a shear rate of $200 \mathrm{~s}^{-1}$, which is below that at which vortex formation was noted. It should be noted that Newtonian behavior is assumed such that the viscosity of the supernate sample is equal to the apparent viscosity as determined by Eq. 3 . As a check of this method, the viscosity of the post-caustic leach permeate sample was determined both by flow curve and by constant rotation at $500 \mathrm{~s}^{-1}$. Good agreement between flow curve and constant rotation results was found (see Section 8).

At the end of each flow curve or constant rotation measurement, all information relevant to the measurement, including raw and calculated measurement results and sample information, were saved to disk using the RheoWin file format and a unique filename identifier. The filename, temperature, start and end of temperature equilibration, and a basic sample identifier were recorded in a Laboratory Record Book (LRB). A separate data file was used for each flow curve measurement. Note: a summary of flow curve measurement results (including viscous stress and apparent viscosity as a function of shear rate) is provided in Appendix A of this report.

Post-measurement analysis and review of flow curve data were accomplished using the RheoWin Pro Data Manager software, Version 2.96. For each set of measurement data, the flow curve data was 
characterized by determining the best-fit parameters for the constitutive equation outlined in Section 2.0 of this report (i.e., the Newtonian, Power-Law, Bingham-Plastic, and Herschel-Bulkley flow models). This analysis utilized the least-squares data regression routine native to the RheoWin 2.96 software. Each regression analysis included both up- and down-ramp portions of the flow curve, resulting in an "average" set of model parameters for the total flow curve. In certain cases, model fits were limited to specific shear rate ranges to avoid flow curve anomalies such as Taylor Vortices (at high shear rates) and slip (at low shear rates). Alternate flow curve analyses, such as fits to constitutive models not listed herein or fits of specific portions of the flow (e.g., up-ramp only) are available on request.

\section{Results and Discussion}

The following sections discuss the results of flow curve testing for Group 5 CUF samples. Prior to discussing the results of CUF testing, flow curve measurements for the Group 5 source material, namely that derived from homogenization efforts, will be introduced and reviewed as a point-of-reference for discussion of CUF flow curves.

\section{Sample G5-RH-2: Source Group 5 Material for CUF Testing}

Sample G5-RH-2 represents Group 5 tank waste derived from homogenization efforts. This waste slurry has a concentration of 18.5-wt\% undissolved solids. It was tested as part of the initial characterization efforts that took place prior to CUF testing. The results have been previously reported in Test Data Package TDP-WTP-056 [4].

Flow curve testing results for the Group 5 source material are shown in Figure 2. Over shear rates of zero to $100 \mathrm{~s}^{-1}$, shear stress is observed to increase rapidly as a function of shear rate for all temperatures. The rate of increase appears to decrease with increasing temperature, with the $60{ }^{\circ} \mathrm{C}$ measurement showing the slowest response. Beyond $100 \mathrm{~s}^{-1}$, all flow curves level out and show a much slower increase in shear stress with shear rate. Over 100-1000 s-1 , shear stress increases at $25^{\circ} \mathrm{C}$ are linear, whereas both 40 and $60^{\circ} \mathrm{C}$ measurements show slight to moderate downward curvature indicative of a shear thinning fluid.

For all temperatures, the flow curves show hysteresis. Specifically, the shear stress measured during the ramp up to $1000 \mathrm{~s}^{-1}$ is always lower than that measured on the ramp back down to zero. Flow curve data hysteresis occurs as a result of sample alteration brought about by shear, chemical processes (such as precipitation), settling, or evaporation. Even though the sludge is sheared prior to measurement to mix the sample and eliminate structure, continued shearing of the sludge throughout each of the 15minute flow curve tests could continue to alter sample. However, shearing tends to break-up and eliminate particle aggregates, which in turn, lowers the force required to maintain fluid motion. As such, the observation of increased shear stress on all flow-curve down-ramps is not consistent with the expected shear induced hysteresis effects typically seen with tank waste. Settling effects are also unlikely, because the sludge is mixed immediately prior to testing to re-suspend settled solids and because phase separation was not observed when transferring the sample to the measurement cup. 


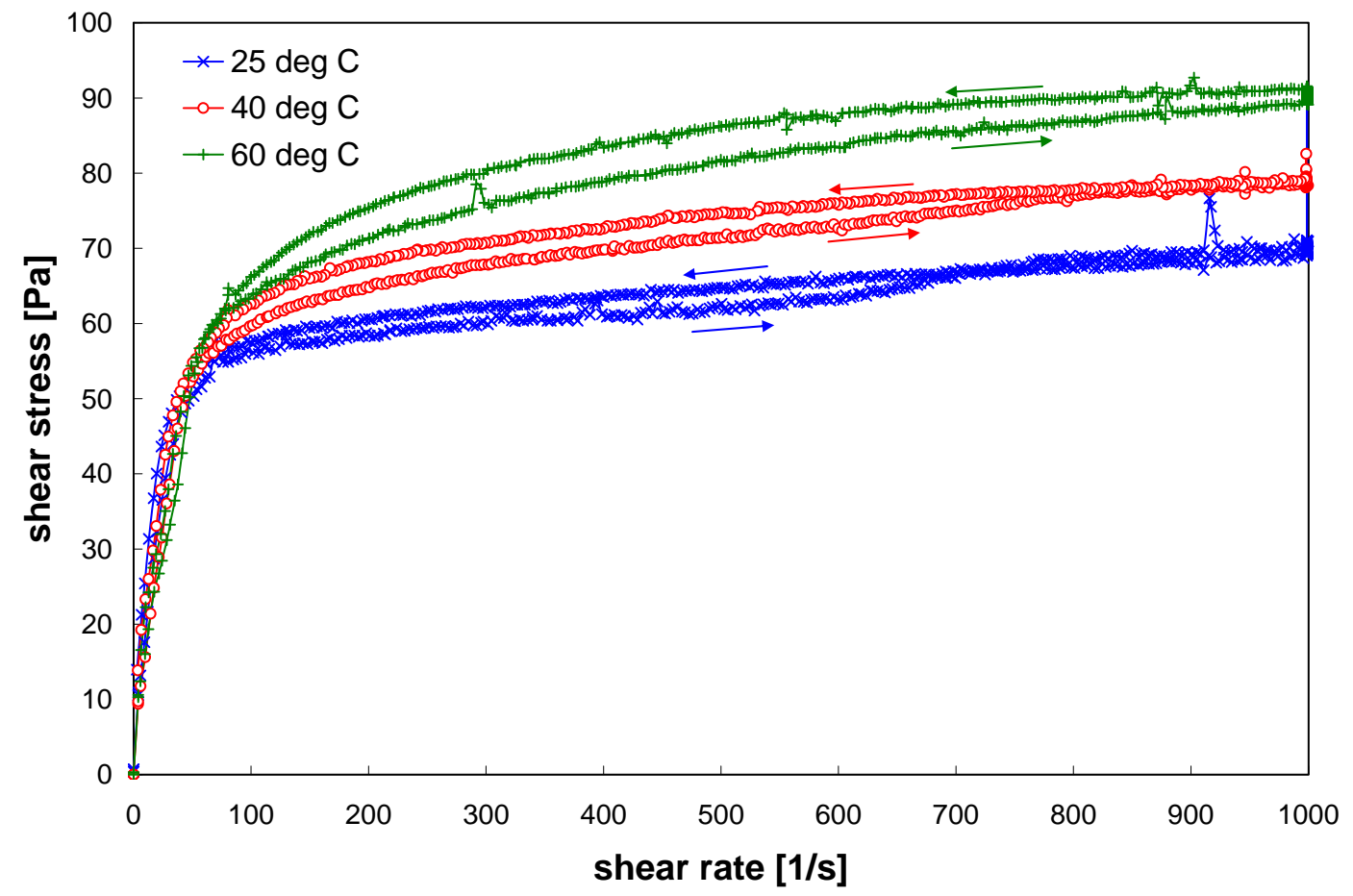

Figure 2. Flow curves for Group 5 initial characterization sample G5-RH-2 at $25^{\circ} \mathrm{C}, 40^{\circ} \mathrm{C}$, and $60^{\circ}$ C. Sample corresponds to the source material for CUF testing. The arrows indicate the direction of the shear/rotational rate ramp.

Although chemical changes are also unlikely (as the jars from which the sample had been taken have at least one month to reach chemical equilibrium), it is possible that heating of the sample could alter particle-particle interactions. Particle size measurements of Group 5 Initial Characterization samples do show sample instability. Specifically, application of sonic energy appear to cause particle coagulation, as it is accompanied by an increase in the fraction of coarse particles and particle aggregates observed in Group 5 waste samples tested. This could be consistent with the observations in Figure 2, as formation of particle aggregates tends to increase the force required for fluid motion. Although particle coagulation can explain the shear stress hysteresis, evaporation of liquid (and the resulting increase in solids concentration it causes) is the most likely cause of the observed hysteresis. This is supported by the fact that separation between up-ramp and down-ramp stress curves increases with increasing temperature.

With regard to the temperature dependence of the flow curves, the measured range of shear stresses beyond $100 \mathrm{~s}^{-1}$ uniformly increases with increasing temperature. For example, an increase of $\sim 30$ $\mathrm{Pa}$ is observed between the $25^{\circ} \mathrm{C}$ for and $60^{\circ} \mathrm{C}$ measurements at $1000 \mathrm{~s}^{-1}$. Like flow curve hysteresis, the increase in measured shear stress with temperature may be either coagulation of particles or evaporation. Because of volume limitations, the same Group 5 waste material was repeatedly tested. As such, evaporation is the most likely cause for the observed shear stress increase.

The flow curve behavior observed in Figure 2 is difficult to characterize. Altogether, the curves look highly pseudo-plastic. However, the sharp transition in slope that occurs around $\sim 100 \mathrm{~s}^{-1}$ is not wellcaptured by the Ostwald equation as shown in Figure 3. Although Figure 3 is restricted to flow curve data at $40^{\circ} \mathrm{C}$, Ostwald fits of $25^{\circ}$ and $60^{\circ} \mathrm{C}$ data show similar problems. The unusual stress versus 
strain-rate behavior over 0-100 $\mathrm{s}^{-1}$ might be an artifact caused by slip between the test sample and sensor surfaces.

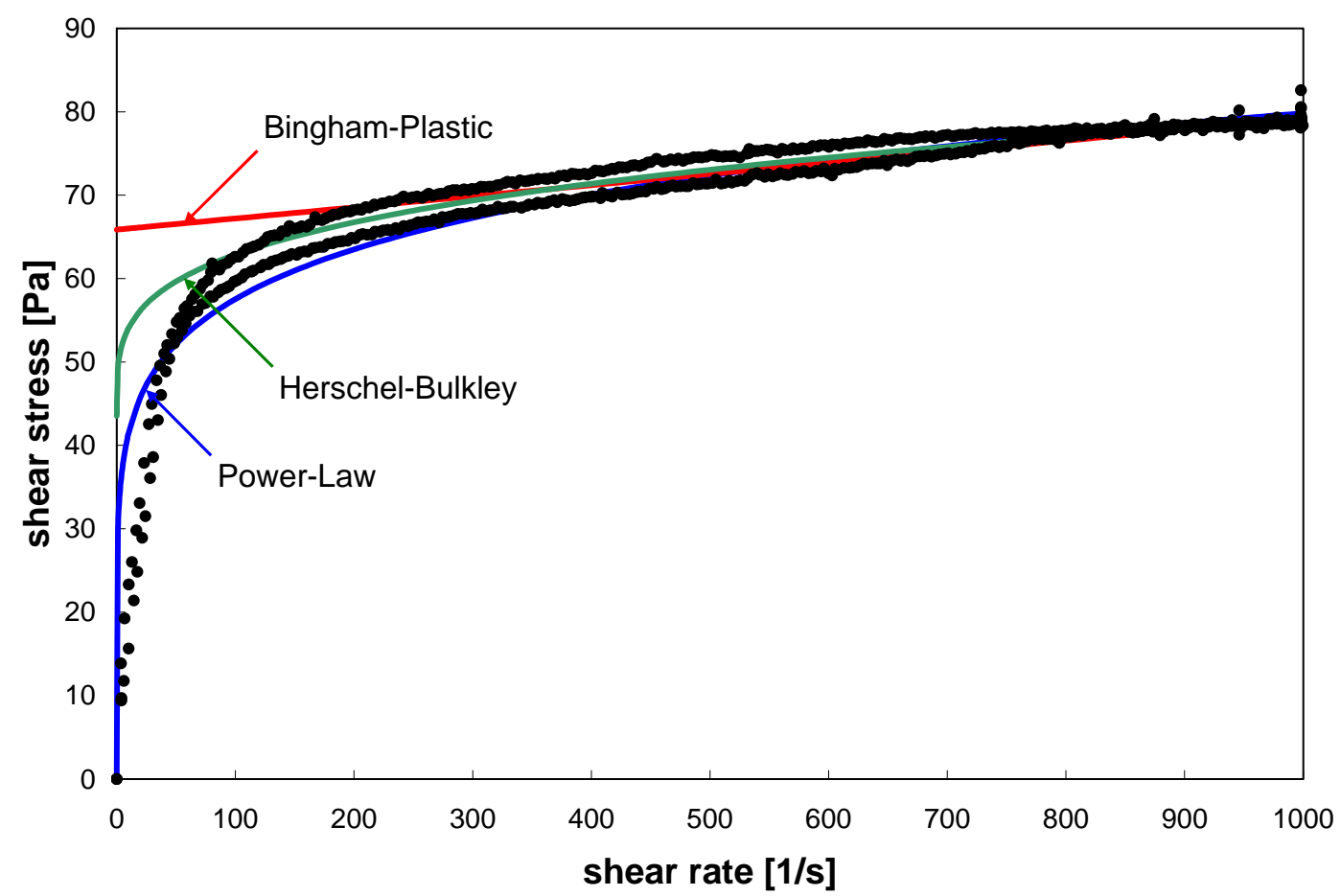

Figure 3. Flow curve fits for sample G5-RH-2 at $40^{\circ} \mathrm{C}$. The Ostwald fit is applied over 0-1000 s $\mathrm{s}^{-1}$, whereas the Bingham-Plastic and Herschel-Bulkley fits are applied over 200-1000 s .

When attempting to analyze the data using Bingham-Plastic and Herschel-Bulkley models, flow curve data in the $0-100 \mathrm{~s}^{-1}$ skewed the curve fits at higher shear rates. To overcome this problem, regression analysis for Bingham-Plastic and Herschel-Bulkley models was limited to the 200-1000 s ${ }^{-1}$ shear rate region. The results of regression analysis for sample G5-RH-2 are shown in Table 9. Figure 3 shows the Bingham-Plastic and Herschel-Bulkley model fits for $40^{\circ} \mathrm{C}$; similar fits were obtained at $25^{\circ}$ and $60^{\circ} \mathrm{C}$. Based on the reported correlation coefficient, $R$, all analyses provide roughly the same fit of the data. It should be noted that although the power-law fit strictly does not have a yield stress, the flow index for the current fits is sufficiently low that the power law fit appears to fall back to a finite yield point for each fit.

Because none of the fitting parameters and corresponding equations provides an accurate representation of the low-shear region, care must be taken when interpreting them. A general representation of the flow curve behavior changes with temperature may be derived from the BinghamPlastic model parameters. Here, the apparent yield stress increases from 57 to $74 \mathrm{~Pa}$ as the temperature is increased from $25^{\circ}$ to $60^{\circ} \mathrm{C}$. Likewise, the consistency of the fluid increases slightly from $13 \mathrm{cP}$ to 17 cP. Whether these numbers are actually representative of the actual yield stress and consistency can not be ascertained from the flow curve measurements alone. Neglecting the unusual behavior between 0 and $100 \mathrm{~s}^{-1}$, examination of the fits in Figure 3 suggests that the Bingham-Plastic model overestimates the actual yield while the Herschel-Bulkley model underestimates the actual yield. Thus, the Bingham- 
Plastic yield stress appears to place conservative upper bound on yield stress. A conservative lower bound is given by the Herschel-Bulkley yield stress.

Table 9. Best fit of select rheological models to Group 5 initial characterization flow curve data.

\begin{tabular}{|c|c|c|c|c|c||}
\hline MODEL & $\begin{array}{c}\text { TEMPERATURE } \\
{\left[{ }^{\circ} \mathbf{C}\right]}\end{array}$ & $\begin{array}{c}\text { YIELD } \\
\text { STRESS } \\
{[\mathbf{P A}]}\end{array}$ & $\begin{array}{c}\text { CONSISTENCY } \\
{\left[\text { PA· }{ }^{\mathbf{N}}\right]}\end{array}$ & $\begin{array}{c}\text { FLOW } \\
\text { INDEX }\end{array}$ & $\mathbf{R}^{*}$ \\
\hline \multirow{3}{*}{ Power-Law } & 25 & $\mathrm{n} / \mathrm{a}$ & 30 & 0.12 & 0.94 \\
\cline { 2 - 6 } & 40 & $\mathrm{n} / \mathrm{a}$ & 30 & 0.14 & 0.95 \\
\cline { 2 - 6 } & 60 & $\mathrm{n} / \mathrm{a}$ & 28 & 0.17 & 0.95 \\
\hline \multirow{3}{*}{ Bingham-Plastic } & 25 & 57 & 0.013 & $\mathrm{n} / \mathrm{a}$ & 0.94 \\
\cline { 2 - 6 } & 40 & 66 & 0.013 & $\mathrm{n} / \mathrm{a}$ & 0.95 \\
\cline { 2 - 6 } & 60 & 74 & 0.017 & $\mathrm{n} / \mathrm{a}$ & 0.92 \\
\hline \multirow{3}{*}{ Herschel-Bulkley } & 25 & 56 & 0.044 & 0.83 & 0.94 \\
\cline { 2 - 7 } & 40 & 44 & 5.8 & 0.26 & 0.96 \\
\cline { 2 - 7 } & 60 & 26 & 19 & 0.18 & 0.94 \\
\hline
\end{tabular}

$* \mathrm{R}$ is the correlation coefficient of the fit

As point of reference, the apparent viscosity at $33 \mathrm{~s}^{-1}$ is derived from each measurement. The results are provided in Table 10. For each temperature, this reference point is determined from the average of up-ramp and down-ramp flow curve measurement data and from the fitting parameters provided in Table 9. Because measurement data at all three temperatures show high shear stress ( 30-75 $\mathrm{Pa}$ ), the apparent viscosities at $33 \mathrm{~s}^{-1}$ are all on the order of $1000 \mathrm{cP}$. Because the consistency of the material is low, apparent viscosities drop off rapidly.

Table 10. Apparent viscosity of sample G5-RH2 at $33 \mathrm{~s}^{-1}$.

\begin{tabular}{||c|c|c|c|c||}
\hline \hline TEMPERATURE & \multirow{2}{*}{$\begin{array}{c}\eta_{\text {APP }}(\mathbf{C P}) \\
\text { FROM }\end{array}$} & \multicolumn{3}{|c||}{$\left.{ }^{\circ} \mathbf{C}\right]$} \\
\cline { 3 - 5 } & $\begin{array}{c}\text { MEASUREMENT } \\
\text { DATA }\end{array}$ & Power-Law & $\begin{array}{c}\text { Bingham } \\
\text { Plastic }\end{array}$ & $\begin{array}{c}\text { Herschel- } \\
\text { Bulkley }\end{array}$ \\
\hline 25 & 1320 & 1400 & 1750 & 1720 \\
\hline 40 & 1250 & 1490 & 2010 & 1760 \\
\hline 60 & 1060 & 1550 & 2260 & 1870 \\
\hline
\end{tabular}

\section{Sample TI540-G5-R1: Pre-Caustic-Leach Low Solids Matrix (4.3-wt\%)}

Figure 4 shows the results of flow curve testing for sample TI540-G5-R1. This sample corresponds to the low concentration (4.3-wt\% solids) slurry that is initially loaded into the CUF. In terms of material processing, the waste slurry was circulated through the CUF prior to sampling. Other than dilution of the source waste for Group 5, the waste had not been subjected to any chemical treatments such as caustic leaching.

The stress response of sample TI540-G5-R1 to shear is non-Newtonian and shows behavior similar to that of the source material. Over the $0-100 \mathrm{~s}^{-1}$ region, the shear stress increases rapidly and appears to be shear thinning. However, the latter observation may be a result of elastic deformation of the slurry. Beyond $100 \mathrm{~s}^{-1}$, the flow curve data increase linearly for all temperatures tested. 


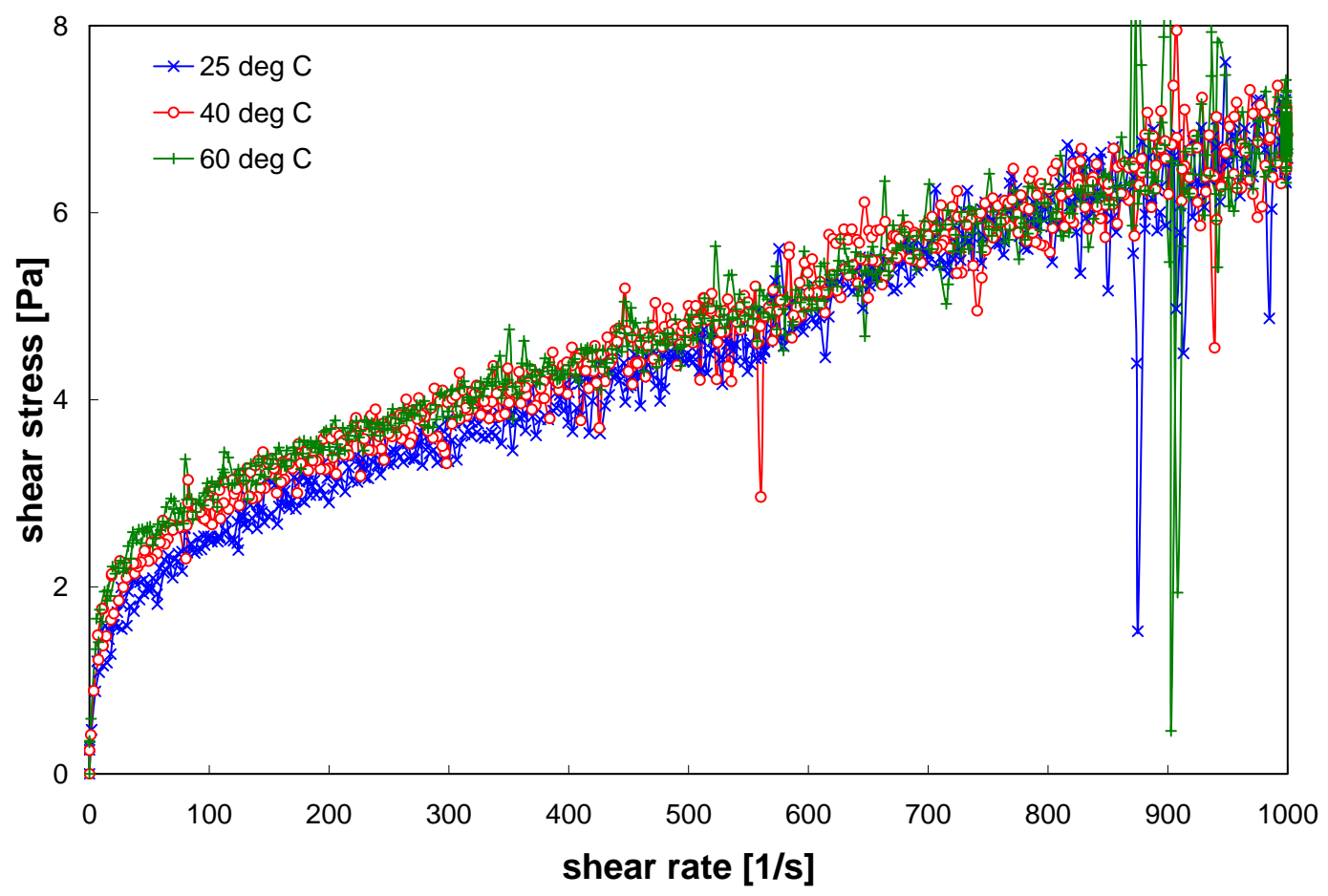

Figure 4. Flow curves for Group 5 CUF slurry sample TI540-G5-R1 at $25^{\circ} \mathrm{C}, 40^{\circ} \mathrm{C}$, and $60^{\circ} \mathrm{C}$. Sample corresponds to a low concentration (4.3-wt\% solids) pre-caustic-leach slurry.

With regard to magnitude of stress response, the 4.3-wt\% slurry flow curves show stresses that are about 1-order of magnitude than those measured for the source material (cf. Figure 2). This is expected, as dilution of the solids concentration can exponentially lower physical properties such as yield stress in slurry systems. Indeed, rheology properties such as consistency and yield stress typically vary directly with $\left(\phi_{o}-\phi\right)^{-1}$, where $\phi$ is the solids concentration and $\phi_{o}$ is the limiting (maximum) solids concentration. This behavior predicts asymptotic behavior as the solids concentration approaches its limit. In terms of group 5 flow curve data data, the source material has a solids concentration $\phi$ that is approaching the limiting concentration $\phi_{o}$, and as a result, has a significant rheology relative to the dilute 4.3-wt\% slurry.

Flow curve hysteresis is not observed in the results for the 4.3-wt\% slurry. Although sample evaporation is likely to have occurred during flow measurement, its influence cannot be observed because evaporation effects only a small change in the "rheology multiplier", $\left(\phi_{o}-\phi\right)^{-1}$, for dilute slurries. Changes in slurry temperature appear to have little impact on the measured flow curves. The most noticeable difference between temperatures is over the 0 to $300 \mathrm{~s}^{-1}$ region, where the viscous stress increases with temperature. Stresses in the 300-1000 s $\mathrm{s}^{-1}$ region do not appear to vary significantly with temperature. All stress variations with temperature in this region are indistinguishable from stress measurement noise.

Based on Figure 4, it appears that increases in temperature increase the "apparent” yield stress of the slurry. The increase in yield stress with temperature appears to be accompanied by a decrease in the fluid consistency (i.e., a lowering of the slope of the flow curve). In both cases, however, the change is 
not dramatic and is close in magnitude to the measurement noise ( $\sim 0.5 \mathrm{~Pa}$ and $\sim 0.5 \mathrm{cP}$ for shear stress and apparent viscosity, respectively). For yield stress, the increase can be associated with either concentration of the slurry through evaporation of the suspending phase or coagulation of particles favored by increases in slurry temperature. Evaporation would be consistent with increases observed in the source material (G5-RH-2); temperature driven coagulation would be consistent with observations of group 5 particle size measured as a function of temperature. For consistency, the lowering could be associated with a lowering of the suspending phase viscosity.

As with the source material, the rheology of sample TI540-G5-R1 is somewhat difficult to characterize. Depending on inclusion of data in the $0-100 \mathrm{~s}^{-1}$ region, the flow curves can be described using Power-Law, Bingham Plastic, or Herschel-Bulkley. If the $0-100 \mathrm{~s}^{-1}$ corresponds to elastic deformation of the slurry, then the material behavior is best described by the Bingham Plastic constitutive equation.

To be comprehensive, parameters providing a best-fit of the data were derived based on Powerlaw, Bingham Plastic, or Herschel-Bulkley models. Power-law and Herschel-Bulkley analyses were applied over shear rates spanning 0 to $1000 \mathrm{~s}^{-1}$. The Bingham Plastic analysis was restricted to data between 200 and $1000 \mathrm{~s}^{-1}$ to avoid inclusion suspected elastic flow. In addition, a second HerschelBulkley analysis considered data over 200 and $1000 \mathrm{~s}^{-1}$. Table 11 provides a summary of the fitting analysis results. Figure 5 presents the fitting results at $40^{\circ} \mathrm{C}$; similar results were obtained at other temperatures.

In terms of their ability to capture trends observed in the data, all models perform reasonably well in the 200-1000 s-1 region. The largest deviations over 200-1000 $\mathrm{s}^{-1}$ are observed for the power-law fit, which tends to over-predict the downward curvature of the flow curve data. Despite this, the power-law model is still able to capture the magnitude of increase within the limits of stress variation.

None of the models are able to full capture the sharp curvature of the flow curve in the $0-200 \mathrm{~s}^{-1}$ region. Difficulties in this region are expected, as the stress response in this range most likely includes time-dependent elastic deformation of the material and is influenced by poor rotational sampling (i.e., torque measurement over small strain angles). For future measurements, the unusual stress response in this region may minimized by slowing the ramp rate of the rheometer and by sampling over additional geometry rotations. However, this can only be done at the expensive of increased measurement time and, as a result, increased evaporation. With regard to the current data fits, the Bingham-Plastic fit over 200$1000 \mathrm{~s}^{-1}$ tends to overpredict stress when extrapolated to $0-200 \mathrm{~s}^{-1}$, whereas the power-law fit tends to under-predict the stress response at low shear. The best overall representation of the data appears to be the Herschel-Bulkley fit to the entire range of shear (i.e., 0-1000 s $\mathrm{s}^{-1}$ ).

The influence of temperature on the flow curve data can be re-evaluated more directly using the Bingham-Plastic fitting results. First, the analysis predicts that yield stress increases from 2.2 to $2.7 \mathrm{~Pa}$ as temperature is increased from 25 to $60^{\circ} \mathrm{C}$. The analysis also shows that consistency decreases from 4.6 cP to $4.1 \mathrm{cP}$ over the same temperature range. Both observations are consistent with those derived from visual inspection of the flow curve data in the preceding paragraphs. 
Table 11. Results of fitting analysis for rheology sample TI540-G5-R1. This sample corresponds to a low concentration (4.3-wt\%) pre-caustic-leach slurry for group 5. Unless otherwise specified, analysis considered shear rates spanning 0 to $1000 \mathrm{~s}^{-1}$.

\begin{tabular}{|c|c|c|c|c|c|}
\hline MODEL & $\begin{array}{c}\text { TEMPERATURE } \\
{\left[{ }^{\circ} \mathrm{C}\right]}\end{array}$ & $\begin{array}{c}\text { YIELD } \\
\text { STRESS } \\
\text { [PA] }\end{array}$ & $\begin{array}{c}\text { CONSISTENCY } \\
{\left[\mathrm{PA} \cdot \mathrm{S}^{\mathrm{N}}\right]}\end{array}$ & $\begin{array}{l}\text { FLOW } \\
\text { INDEX }\end{array}$ & $\overline{\mathbf{R}}$ \\
\hline \multirow[t]{3}{*}{ Power-Law } & 25 & $\mathrm{n} / \mathrm{a}$ & 0.22 & 0.49 & 0.98 \\
\hline & 40 & $\mathrm{n} / \mathrm{a}$ & 0.36 & 0.43 & 0.98 \\
\hline & 60 & $\mathrm{n} / \mathrm{a}$ & 0.42 & 0.40 & 0.95 \\
\hline \multirow[t]{3}{*}{ Herschel-Bulkley } & 25 & 1.4 & 0.028 & 0.76 & 0.94 \\
\hline & 40 & 1.6 & 0.045 & 0.69 & 0.98 \\
\hline & 60 & 1.9 & 0.037 & 0.71 & 0.96 \\
\hline \multirow[t]{3}{*}{ Bingham-Plastic* } & 25 & 2.2 & 0.0046 & $\mathrm{n} / \mathrm{a}$ & 0.97 \\
\hline & 40 & 2.6 & 0.0042 & $\mathrm{n} / \mathrm{a}$ & 0.98 \\
\hline & 60 & 2.7 & 0.0041 & $\mathrm{n} / \mathrm{a}$ & 0.92 \\
\hline \multirow[t]{3}{*}{ Herschel-Bulkley* } & 25 & 2.1 & 0.0060 & 0.97 & 0.97 \\
\hline & 40 & 2.2 & 0.013 & 0.85 & 0.98 \\
\hline & 60 & 2.5 & 0.0077 & 0.92 & 0.92 \\
\hline
\end{tabular}

*Fits restricted to data over 200 to $1000 \mathrm{~s}^{-1}$.

As point of reference, the apparent viscosity at $33 \mathrm{~s}^{-1}$ is derived from each measurement. The results are provided in Table 12. For each temperature, this reference point is determined from measurement data and from the fitting parameters provided in Table 11. Because the reference point appears to fall within a region of elastic deformation of the test material, the reference viscosities may not be truly representative of the material.

Table 12. Apparent viscosity of sample TI540-G5-R1 at $33 \mathrm{~s}^{-1}$.

\begin{tabular}{||c|c|c|c|c|c||}
\hline TEMPERATURE & \multirow{2}{*}{$\begin{array}{c}\eta_{\text {APP }}(\mathbf{C P}) \\
\text { FROM }\end{array}$} & \multicolumn{5}{|c||}{$\begin{array}{c}\eta_{\text {APP }} \text { (CP) } \\
\text { FROM FITTING PARAMETERS }\end{array}$} \\
\cline { 3 - 6 } & $\begin{array}{c}\text { MEASUREMENT } \\
\text { DATA }\end{array}$ & $\begin{array}{c}\text { Power- } \\
\text { Law }\end{array}$ & $\begin{array}{c}\text { Herschel- } \\
\text { Bulkley }\end{array}$ & $\begin{array}{c}\text { Bingham } \\
\text { Plastic* }\end{array}$ & $\begin{array}{c}\text { Herschel- } \\
\text { Bulkley* }\end{array}$ \\
\hline 25 & 56 & 38 & 56 & 72 & 70 \\
\hline 40 & 67 & 48 & 64 & 84 & 75 \\
\hline 60 & 71 & 52 & 70 & 87 & 82 \\
\hline
\end{tabular}

*Fits restricted to data over 200 to $1000 \mathrm{~s}^{-1}$.

In summary, the low concentration pre-leach group 5 slurry (sample TI540-G5-R1) is nonNewtonian. It shows a finite yield stress that falls between 1.4 and $2.7 \mathrm{~Pa}$ and that increases with slurry temperature. The flow curve evidences shear thinning over 0-200 s' result of elastic deformation during the early (and late) stages of flow curve testing. Beyond $200 \mathrm{~s}-1$, the flow curve is relatively linear and is consistent with a Bingham plastic fluid with a consistency ranging from 4.6 to $4.1 \mathrm{cP}$. Increases in slurry temperature serve to lower the consistency. 


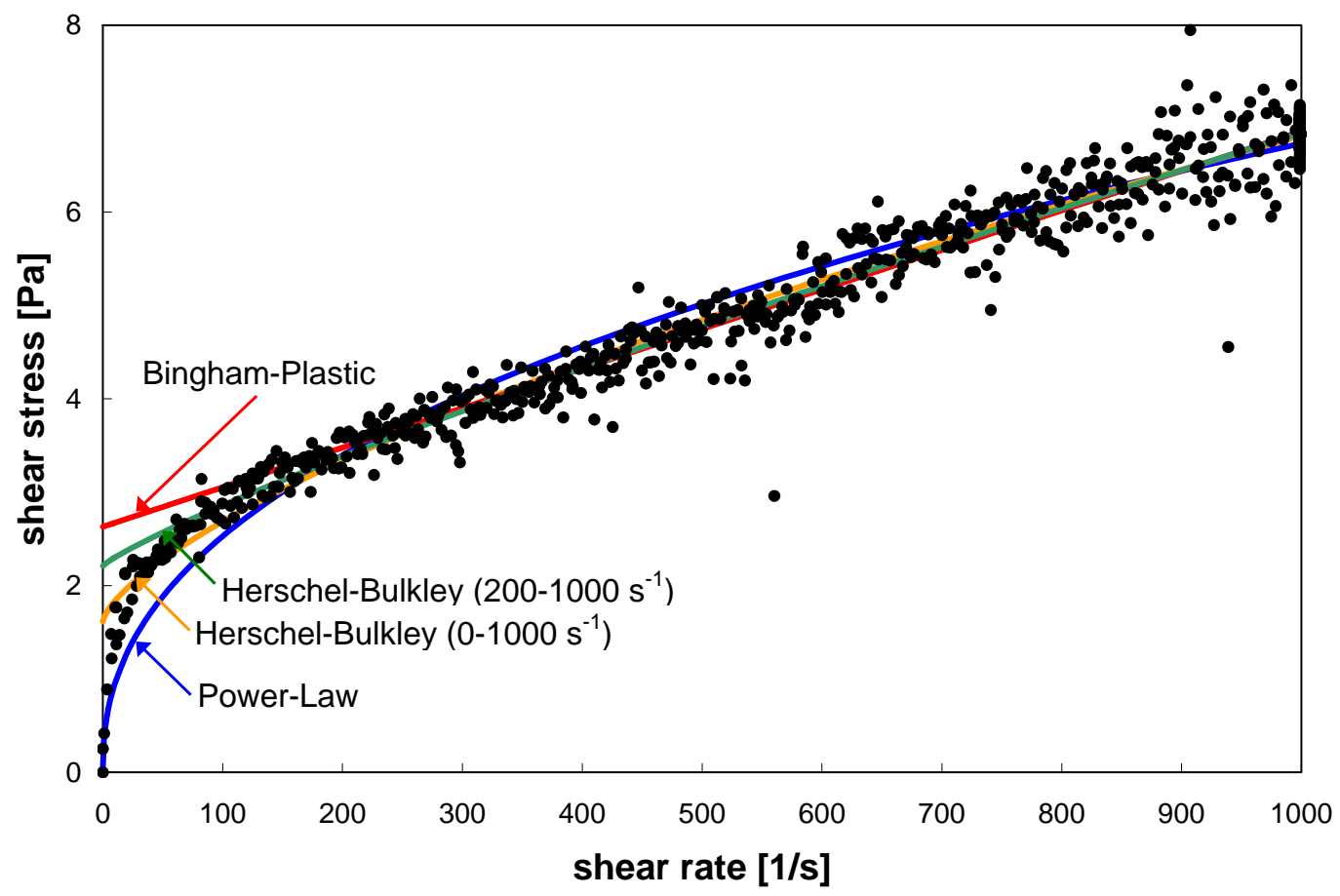

Figure 5. Model fits of flow curve data for Group 5 CUF slurry sample TI540-G5-R1 at $40^{\circ} \mathrm{C}$. Power-law model fit over 0-1000 s'. Bingham plastic model restricted to 200-1000 s-1. HershelBulkley considers both full and restricted ranges.

\section{Sample TI-540-G5-R2BN*: Pre-Caustic-Leach High Solids Matrix (15.5-wt\%)}

Figure 6 shows the results of flow curve testing for sample TI540-G5-R2BN*. This sample corresponds to the high concentration (15.5-wt\% solids) slurry that results from dewatering of the initial material loaded into the CUF. It should be noted that, chronologically, the 15.5-wt\% slurry was targeted after the 19 -wt\% slurry was found to be too thick for proper CUF operation. For this report, it is discussed before the 19-wt\% slurry because it is the second in the solids concentration series prior to leaching. In terms of material processing, the 15.5-wt\% waste slurry was circulated through ultrafiltration system for an extended period of time, dewatered to $19-\mathrm{wt} \%$, and subsequently diluted to 15.5 -wt $\%$ in the CUF system prior to sampling. Other than concentration and dilution, the waste slurry had not been subjected to any chemical treatments such as caustic leaching.

The flow curves for sample TI540-G5-R2BN* are similar to that for the source material.

Specifically, they show an apparent elastic deformation over the $0-200 \mathrm{~s}^{-1}$ range and significant hysteresis, with the down ramp showing larger viscous stress than the up-ramp. Like the source material, the flow curve at $25^{\circ} \mathrm{C}$ is linear (suggestive of Bingham Plastic behavior), whereas both of the higher temperature flow curves show slight to moderate shear thinning behavior. In addition, the 15.5-wt\% CUF sample shows increasing stress with increasing sample temperature. These similarities are expected, as the 15.5wt\% CUF sample has a similar solids concentration to the source material. It is likely that evaporation is the cause hysteresis and increasing stress with temperature for the current sample (as it was for the source material). 


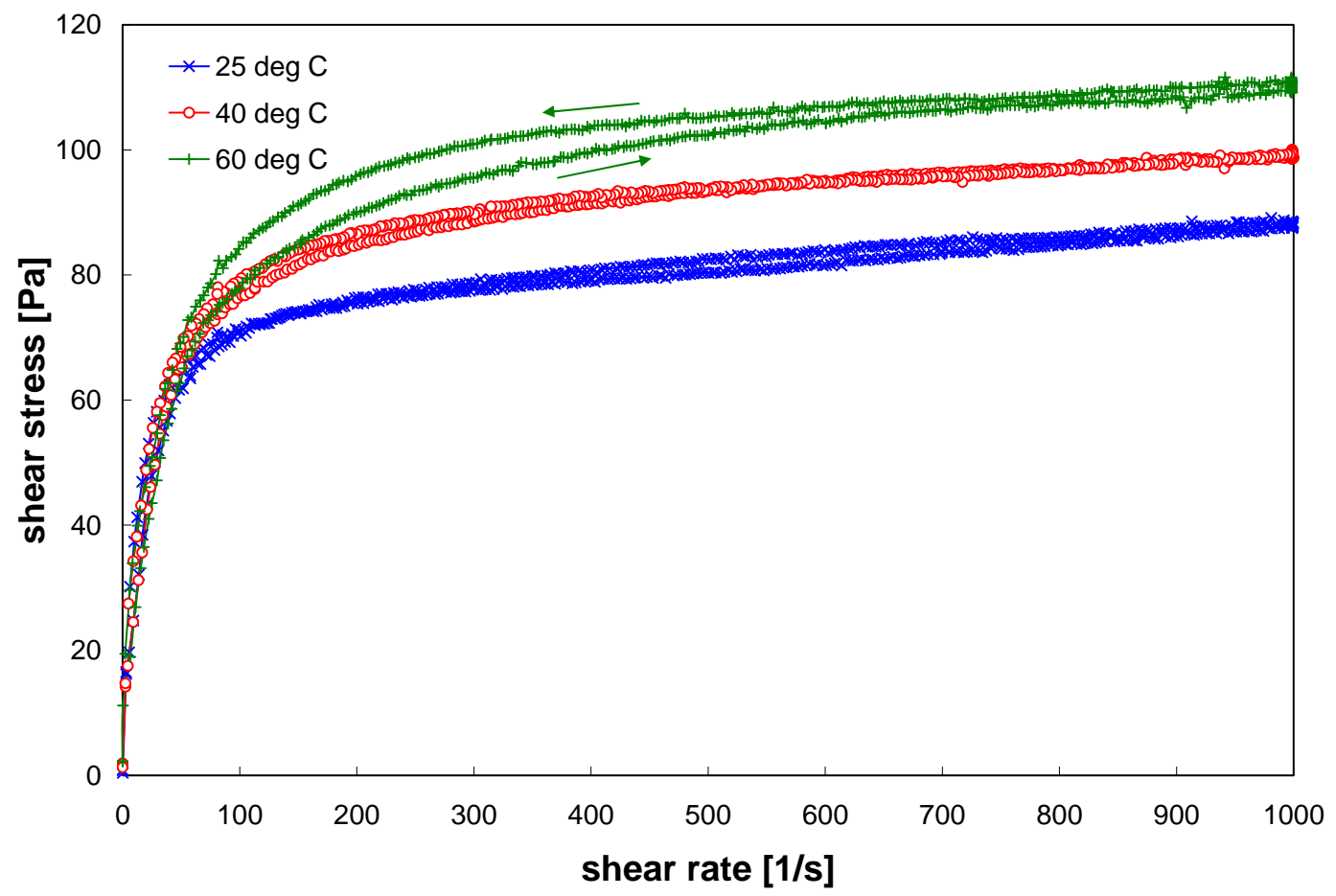

Figure 6. Flow curves for Group 5 CUF slurry sample TI540-G5-R2BN* at $25^{\circ} \mathrm{C}, 40^{\circ} \mathrm{C}$, and $60^{\circ} \mathrm{C}$. Sample corresponds to high concentration (15.5-wt\% solids) pre-caustic-leach slurry. Flow curve hysteresis only occurred at $60^{\circ} \mathrm{C}$; the arrows indicate the direction of the shear/rotational rate ramp.

In terms of relative magnitude, the viscous stress response of the 15.5-wt\% CUF sample to shear is about $20 \mathrm{~Pa}$ larger than that of the source material over all temperatures. The degree of viscous stress increase with temperature, $\sim 30 \mathrm{~Pa}$, is similar to that of the source material. This is unexpected, as the source material has the higher solids concentration. The larger viscous stress response for the 15.5 -wt $\%$ slurry sample could be the result of alteration of the material as a result of dilution to $4.3-\mathrm{wt} \%$ and subsequent CUF processing. Another cause may be segregation of higher solids material in the flow loop (because of poor mixing of recycled permeate in the CUF reservoir).

Table 13 summarizes the best-fit rheological parameters for flow curve data for sample TI540G5-R2BN*. Power-law, Bingham Plastic, and Herschel-Bulkley models were evaluated. As shown in Figure 7, many of the same difficulties in fitting the source material flow curves plague these fits as well. First, the models are not able to capture the sharp curvature of the $0-200 \mathrm{~s}^{-1}$ region. Beyond $200 \mathrm{~s}^{-1}$, the Bingham model tends to under-predict the slope of the flow curve, whereas the Power-law model tends to over-predict the slope. The Herschel-Bulkley model captures the flow curve behavior in the 200-1000 s-1 region, but the fitting parameters to lose physical significance with increasing temperature. For example, the best-fit Herschel-Bulkley yield stress decreases from $70 \mathrm{~Pa}$ at $25^{\circ} \mathrm{C}$ (which is reasonable) to $-18 \mathrm{~Pa}$ at $60^{\circ} \mathrm{C}$ (which is physically impossible). It should be noted that the negative yield at $60^{\circ} \mathrm{C}$ is a result of both the unusual behavior over the $0-200 \mathrm{~s}^{-1}$ region and restricting the Herschel-Bulkley fitting range to 200-1000 s $\mathrm{s}^{-1}$. In its region of applicability $\left(200-1000 \mathrm{~s}^{-1}\right)$, this fit adequately captures the data behavior and is physically meaningful. Application of the fit over the entire shear range would not necessary improve the estimate of Herschel-Bulkley yield stress because the model would still have difficulty fitting the sharp transition in flow curve data slope over 0-200 $\mathrm{s}^{-1}$. 
Table 13. Results of fitting analysis for rheology sample TI540-G5-R2BN*. This sample corresponds to a high concentration (15.5-wt\%) pre-caustic-leach slurry for group 5. Unless otherwise specified, analysis considered shear rates spanning 200 to $1000 \mathrm{~s}^{-1}$.

\begin{tabular}{|c|c|c|c|c|c|}
\hline MODEL & $\begin{array}{c}\text { TEMPERATURE } \\
{\left[{ }^{\circ} \mathrm{C}\right]}\end{array}$ & $\begin{array}{c}\text { YIELD } \\
\text { STRESS } \\
\text { [PA] }\end{array}$ & $\begin{array}{c}\text { CONSISTENCY } \\
{\left[\mathrm{PA} \cdot \mathrm{S}^{\mathrm{N}}\right]}\end{array}$ & $\begin{array}{l}\text { FLOW } \\
\text { INDEX }\end{array}$ & $\mathbf{R}$ \\
\hline \multirow[t]{3}{*}{ Power-Law* } & 25 & $\mathrm{n} / \mathrm{a}$ & 38 & 0.12 & 0.96 \\
\hline & 40 & $\mathrm{n} / \mathrm{a}$ & 41 & 0.13 & 0.94 \\
\hline & 60 & $\mathrm{n} / \mathrm{a}$ & 40 & 0.15 & 0.95 \\
\hline \multirow[t]{3}{*}{ Bingham-Plastic } & 25 & 74 & 0.014 & $\mathrm{n} / \mathrm{a}$ & 0.98 \\
\hline & 40 & 86 & 0.013 & $\mathrm{n} / \mathrm{a}$ & 0.97 \\
\hline & 60 & 94 & 0.016 & $\mathrm{n} / \mathrm{a}$ & 0.93 \\
\hline \multirow[t]{3}{*}{ Herschel-Bulkley } & 25 & 70 & 0.19 & 0.66 & 0.99 \\
\hline & 40 & 25 & 34 & 0.11 & 0.99 \\
\hline & 60 & -18 & 74 & 0.081 & 0.96 \\
\hline
\end{tabular}

*Fits applied to full range of shear (i.e., 0 to $1000 \mathrm{~s}^{-1}$ )

Because of these difficulties, there is some uncertainty in assigning a specific yield point for sample TI540-G5-R2BN*. As with other fits for previous samples, an upper bound of yield stress is provided by the Bingham plastic. For the current measurements, the yield stress is then bounded by 74 , 86, and $94 \mathrm{~Pa}$ at $25^{\circ}, 40^{\circ}$, and $60^{\circ} \mathrm{C}$, respectively. Based on the Herschel-Bulkley fit, the lower yield stress boundary is $70 \mathrm{~Pa}$ at $25^{\circ} \mathrm{C}$. Significant sample elasticity / slip and poor rotational sampling over 0 $200 \mathrm{~s}^{-1}$ renders Herschel-Bulkley estimates of the lower yield boundary physically meaningless at higher temperatures.

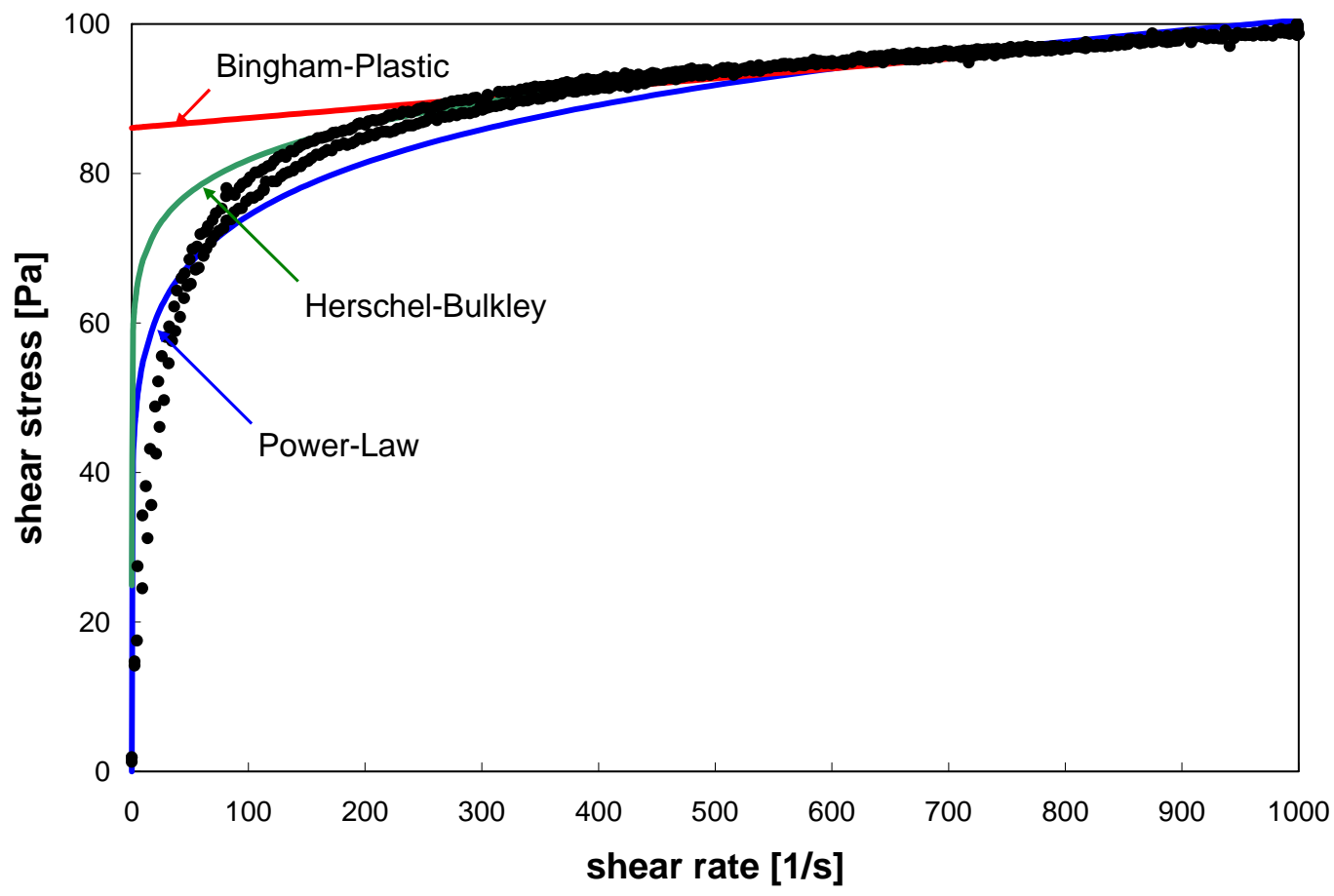

Figure 7. Model fits of flow curve data for Group 5 CUF slurry sample TI540-G5-R2BN* at $40^{\circ} \mathrm{C}$. Power-law model was fit over 0-1000 s${ }^{-1}$. Bingham plastic and Herschel-Bulkley models were restricted to $200-1000 \mathrm{~s}^{-1}$. 
The results shown in Table 13 confirm the temperature trends observed in Figure 6. With increasing temperature, the yield stress of the slurry increases dramatically as evidenced by the BinghamPlastic yield stresses. In contrast, temperature does not appear to influence the slope of the flow curve at high shear, as the best-fit Bingham consistency index increases only slightly from $25^{\circ}$ to $60^{\circ} \mathrm{C}$.

Apparent viscosities at $33 \mathrm{~s}^{-1}$ for sample TI540-G5-R2BN* are provided in Table 14. For each temperature, this reference point is determined from measurement data and from the fitting parameters provided in Table 13. Because the reference point appears to fall within a region of elastic deformation of the test material, the reference viscosities may not be truly representative of the material.

Table 14. Apparent viscosity of sample TI540-G5-R2BN* at $33 \mathrm{~s}^{-1}$.

\begin{tabular}{||c|c|c|c|c||}
\hline \hline TEMPERATURE & \multirow{2}{*}{$\begin{array}{c}\eta_{\text {APP }}(\mathrm{CP}) \\
\text { FROM }\end{array}$} & \multicolumn{3}{|c||}{$\eta_{\text {APP }}$ (CP) } \\
\cline { 3 - 5 } & $\begin{array}{c}\text { FROMOM FITTING PARAMETERS } \\
\text { MEAREMENT } \\
\text { DATA }\end{array}$ & Power-Law & $\begin{array}{c}\text { Bingham } \\
\text { Plastic }\end{array}$ & $\begin{array}{c}\text { Herschel- } \\
\text { Bulkley }\end{array}$ \\
\hline 25 & 1710 & 1770 & 2260 & 2170 \\
\hline 40 & 1760 & 1950 & 2620 & 2270 \\
\hline 60 & 1670 & 2050 & 2880 & 2410 \\
\hline
\end{tabular}

\section{Sample TI-540-G5-R2A: Pre-Caustic-Leach Very High Solids Matrix (19-wt\%)}

Figure 8 shows the results of flow curve testing for sample TI540-G5-R2A. This sample corresponds to the very high concentration (19-wt\% solids) slurry that was the initial result of slurry dewatering. In terms of material processing, the $19-w t \%$ waste slurry was circulated through ultrafiltration system for an extended period of time and then dewatered to 19 -wt\% solids prior to sampling. Other than concentration, the waste slurry had not been subjected to any chemical treatments such as caustic leaching.

The flow curves for sample TI540-G5-R2A appear to be more severe versions of the flow curve for the source material and 15.5-wt\% dewatered pre-leach slurry. All temperatures show an apparent elastic deformation over the $0-200 \mathrm{~s}^{-1}$ range and significant hysteresis. Flow curves show increasing stress with increasing sample temperature. One difference is that all flow curves appear to have some shear thinning behavior. In contrast, lower concentration slurries, including the source material and 15.5wt $\%$ sludge, showed Bingham Plastic behavior at $25^{\circ} \mathrm{C}$.

The viscous stress response of the 19-wt\% CUF sample to shear is larger than that of the source material at all temperatures. Considering the stress response at $1000 \mathrm{~s}^{-1}$ in the current sample against the source material, the 19 -wt $\%$ shows increases of $\sim 35, \sim 55$, and $\sim 65 \mathrm{~Pa}$ at $25^{\circ}, 40^{\circ}$, and $60^{\circ}$, respectively. These increases most likely result from a combination of 1) increased slurry concentration, 2) evaporation, or 3) poor sampling of rheology material. 


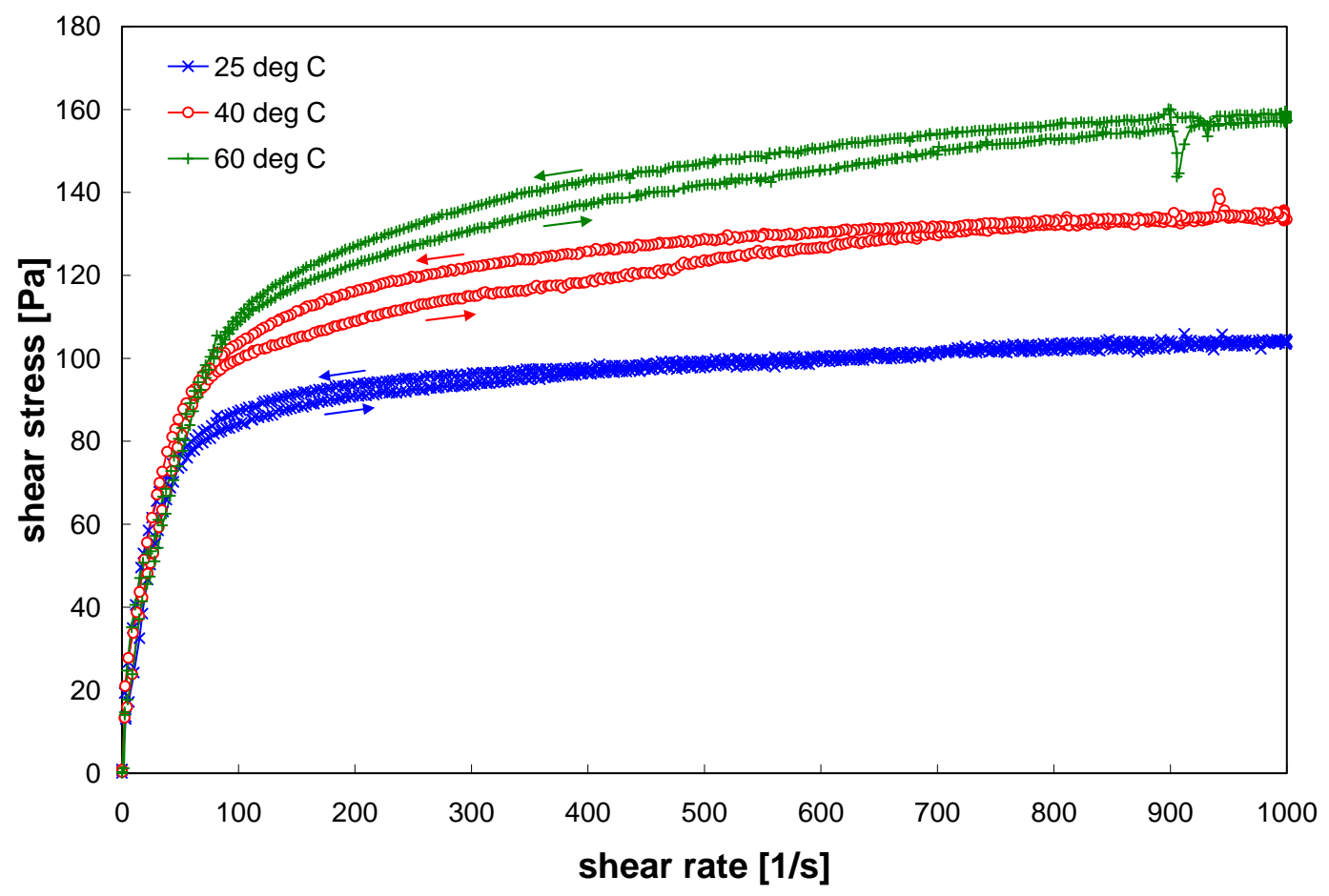

Figure 7. Flow curves for Group 5 CUF slurry sample TI540-G5-R2A at $25^{\circ} \mathrm{C}, 40^{\circ} \mathrm{C}$, and $60^{\circ} \mathrm{C}$. Sample corresponds to a very high concentration (19-wt\% solids) pre-caustic-leach slurry. The arrows indicate the direction of the shear/rotational rate ramp.

The behavior, like all group 5 pre-leach slurry samples, is non-Newtonian and difficult to characterize with the three models typically used for tank waste characterization (see the Background Section). As before, the flow curve data for each temperature is fit to the three models by optimizing the values of the model parameters for yield stress, consistency, and flow index where applicable. Power-law fits employed the entire range of shear rates whereas Bingham-Plastic and Herschel-Bulkley are restricted to 200 to $1000 \mathrm{~s}^{-1}$. The results of the fitting analysis are shown in Table 15. An example of the fitting quality is shown in Figure 8, which compares the flow curve data at $40^{\circ} \mathrm{C}$ to their corresponding fits. None of the rheological models appear to full capture the flow curve behavior observed. Similar results are obtained at $25^{\circ}$ and $60^{\circ} \mathrm{C}$.

As with the other concentrated pre-leach group 5 slurries, the exact yield point is for TI540-G5R2A is difficult to determine. Using the Bingham plastic fitting parameters, conservative upper bounds can be placed on the yield stress as a function of temperature. These are $92 \mathrm{~Pa}, 110 \mathrm{~Pa}$, and $130 \mathrm{~Pa}$ at $25^{\circ}$, $40^{\circ}$, and $60^{\circ} \mathrm{C}$, respectively. The increase in the best-fit Bingham yield with temperature is consistent with observed increased in the flow curve data (Figure 7) Herschel-Bulkley fits suggest a lower bound of $\sim 50 \mathrm{~Pa}$ at $25^{\circ}$ and $40^{\circ} \mathrm{C}$ for yield stress. The $60^{\circ} \mathrm{C}$ Herschel-Bulkley yield stress is physically meaningless. The best-fit Bingham-consistencies increase with temperature. Specifically, they are 0.012, 0.022 , and $0.034 \mathrm{~Pa} \cdot \mathrm{s}$ at $25^{\circ}, 40^{\circ}$, and $60^{\circ} \mathrm{C}$, respectively. This increase appears to be a result of increased shear thinning rather than an actual increase in slope of the high-shear rate data. 
Table 15. Results of fitting analysis for rheology sample TI540-G5-R2A. This sample corresponds to a concentrated (19-wt\%) pre-caustic-leach slurry for group 5. Unless otherwise specified, analysis considered shear rates spanning 200 to $1000 \mathrm{~s}^{-1}$.

\begin{tabular}{|c|c|c|c|c|c|}
\hline MODEL & $\begin{array}{c}\text { TEMPERATURE } \\
{\left[{ }^{\circ} \mathrm{C}\right]}\end{array}$ & $\begin{array}{c}\text { YIELD } \\
\text { STRESS } \\
\text { [PA] }\end{array}$ & $\begin{array}{c}\text { CONSISTENCY } \\
{\left[\mathrm{PA} \cdot \mathrm{S}^{\mathrm{N}}\right]}\end{array}$ & $\begin{array}{l}\text { FLOW } \\
\text { INDEX }\end{array}$ & $\mathbf{R}$ \\
\hline \multirow[t]{3}{*}{ Power-Law* } & 25 & $\mathrm{n} / \mathrm{a}$ & 47 & 0.12 & 0.93 \\
\hline & 40 & $\mathrm{n} / \mathrm{a}$ & 47 & 0.15 & 0.95 \\
\hline & 60 & $\mathrm{n} / \mathrm{a}$ & 43 & 0.17 & 0.96 \\
\hline \multirow[t]{3}{*}{ Bingham-Plastic } & 25 & 92 & 0.012 & $\mathrm{n} / \mathrm{a}$ & 0.96 \\
\hline & 40 & 110 & 0.022 & $\mathrm{n} / \mathrm{a}$ & 0.92 \\
\hline & 60 & 130 & 0.034 & $\mathrm{n} / \mathrm{a}$ & 0.95 \\
\hline \multirow[t]{3}{*}{ Herschel-Bulkley } & 25 & 49 & 20 & 0.15 & 0.98 \\
\hline & 40 & 46 & 28 & 0.17 & 0.95 \\
\hline & 65 & -64 & 110 & 0.097 & 0.98 \\
\hline
\end{tabular}

*Fits applied to full range of shear (i.e., 0 to $1000 \mathrm{~s}^{-1}$ )

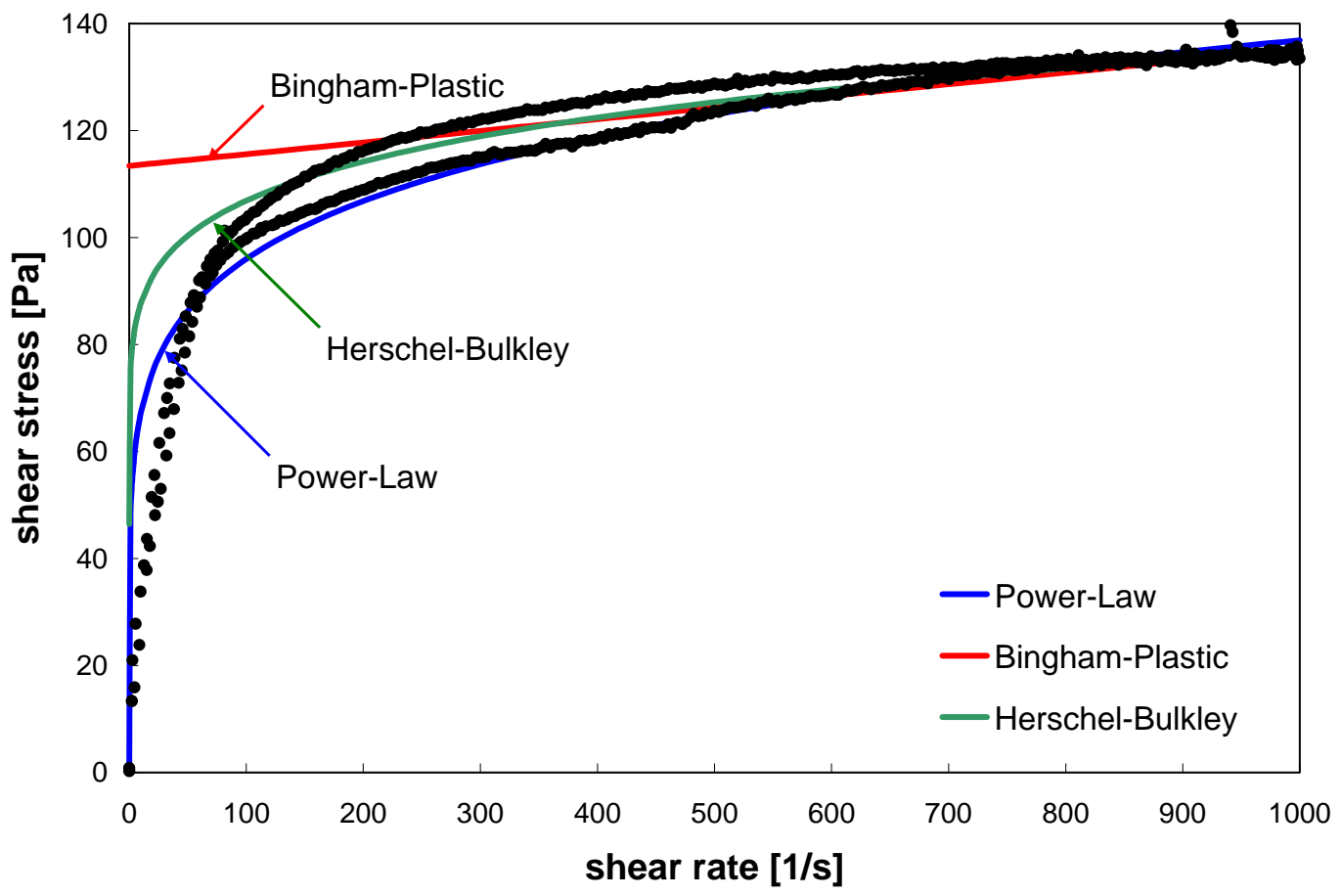

Figure 8. Model fits (curves) of flow curve data (closed circles) for Group 5 CUF slurry sample TI540-G5-R2A at $40^{\circ}$ C. Power-law model was fit over 0-1000 $\mathrm{s}^{-1}$. Bingham plastic and HerschelBulkley models were restricted to $200-1000 \mathrm{~s}^{-1}$.

Apparent viscosities at $33 \mathrm{~s}^{-1}$ for sample TI540-G5-R2A are provided in Table 16. For each temperature, this reference point is determined from measurement data and from the fitting parameters provided in Table 15. Because the reference point appears to fall within a region of elastic deformation of the test material, the reference viscosities may not be truly representative of the material. 
Table 16. Apparent viscosity of sample TI540-G5-R2A at $33 \mathrm{~s}^{-1}$.

\begin{tabular}{||c|c|c|c|c||}
\hline \hline TEMPERATURE & \multirow{2}{*}{$\begin{array}{c}\eta_{\text {APP }}(\mathrm{CP}) \\
\text { FROM }\end{array}$} & \multicolumn{3}{|c||}{$\begin{array}{c}\eta_{\text {APP }} \text { (CP) } \\
\text { FROM FITTING PARAMETERS }\end{array}$} \\
\cline { 3 - 5 } & $\begin{array}{c}\text { MEASUREMENT } \\
\text { DATA }\end{array}$ & Power-Law & $\begin{array}{c}\text { Bingham } \\
\text { Plastic }\end{array}$ & $\begin{array}{c}\text { Herschel- } \\
\text { Bulkley }\end{array}$ \\
\hline 25 & 1960 & 2150 & 2800 & 2490 \\
\hline 40 & 2000 & 2450 & 3460 & 2930 \\
\hline 60 & 1840 & 2550 & 3840 & 2910 \\
\hline
\end{tabular}

\section{Sample TI-540-G5-R3: Post-Leach Dewatered Slurry (13.5-wt\%)}

Figure 9 shows the results of flow curve testing for sample TI540-G5-R3. This sample corresponds to the dewatered 13.5 -wt $\%$ group 5 waste solids slurry that remains after caustic leaching for 24 hours at $100^{\circ} \mathrm{C}$. The flow curves for the post-leach, dewatered sample show a significant reduction in the range of stresses (5-27 Pa) experience over shear rates of 0-1000 $\mathrm{s}^{-1}$ relative to sample TI-540-G5R2BN* (15-100 Pa). It is suspected that the majority of this reduction is attributable to caustic leaching, although some of the change could also be a result of the difference in solids concentrations between the pre-leach (15.5-wt\%) and post-leach (13.5-wt\%) samples.

The post-leach sample still shows slip or elasticity over the $0-100 \mathrm{~s}^{-1}$ region. All curves appear to show non-Newtonian behavior consistent with the Bingham-plastic or Herschel-Bulkley constitutive equations. Although there is some shear-thinning behavior, it is difficult to discern without the aid of best-fit lines. Increases in slurry temperature appear to raise the apparent yield stress (likely through slurry evaporation and concentration) and lower the slope of the flow curve over the entire range of shear rates tested (likely through lowering of suspending phase viscosity -see discussion of post-leach supernatant behavior, sample TI-540-G5-Leach2).

To maintain consistency with previous analyses in this report, the flow curve data for TI540-G5R3 are fit to the three models by optimizing the values of the model parameters for yield stress, consistency, and flow index where applicable. Power-law fits employed the entire range of shear rates whereas Bingham-Plastic and Herschel-Bulkley are restricted to 200 to $1000 \mathrm{~s}^{-1}$. The results of the fitting analysis are shown in Table 17. An example of the fitting quality is shown in Figure 10, which compares the flow curve data at $40^{\circ} \mathrm{C}$ to their corresponding fits. All models seem to provide a reasonable approximation at shear rates greater than $200 \mathrm{~s}^{-1}$. As before, Bingham model appears to overpredict flow curve data in the $0-200 \mathrm{~s}^{-1}$ region, whereas the Power-law and Herschel-Bulkley slightly underpredict the data. Of all models, the Herschel-Bulkley provides the best fit of the data.

The fitting analysis suggests that the yield point for TI540-G5-R3 falls between $2.4-5.7 \mathrm{~Pa}$ at $25^{\circ} \mathrm{C}$, $2.6-7.8 \mathrm{~Pa}$ at $40^{\circ} \mathrm{C}$, and $5.6-8.7 \mathrm{~Pa}$ at $60^{\circ} \mathrm{C}$. Regressed values for yield stress confirm the observation of increasing stress with temperature in Figure 10. Analysis of the Bingham consistency also confirms the observation of decreasing flow curve slope with temperature. Specifically, the consistency decreases consistently from $0.022 \mathrm{~Pa} \cdot \mathrm{s}$ at $25^{\circ} \mathrm{C}$ to 0.012 at $60^{\circ} \mathrm{C}$. 


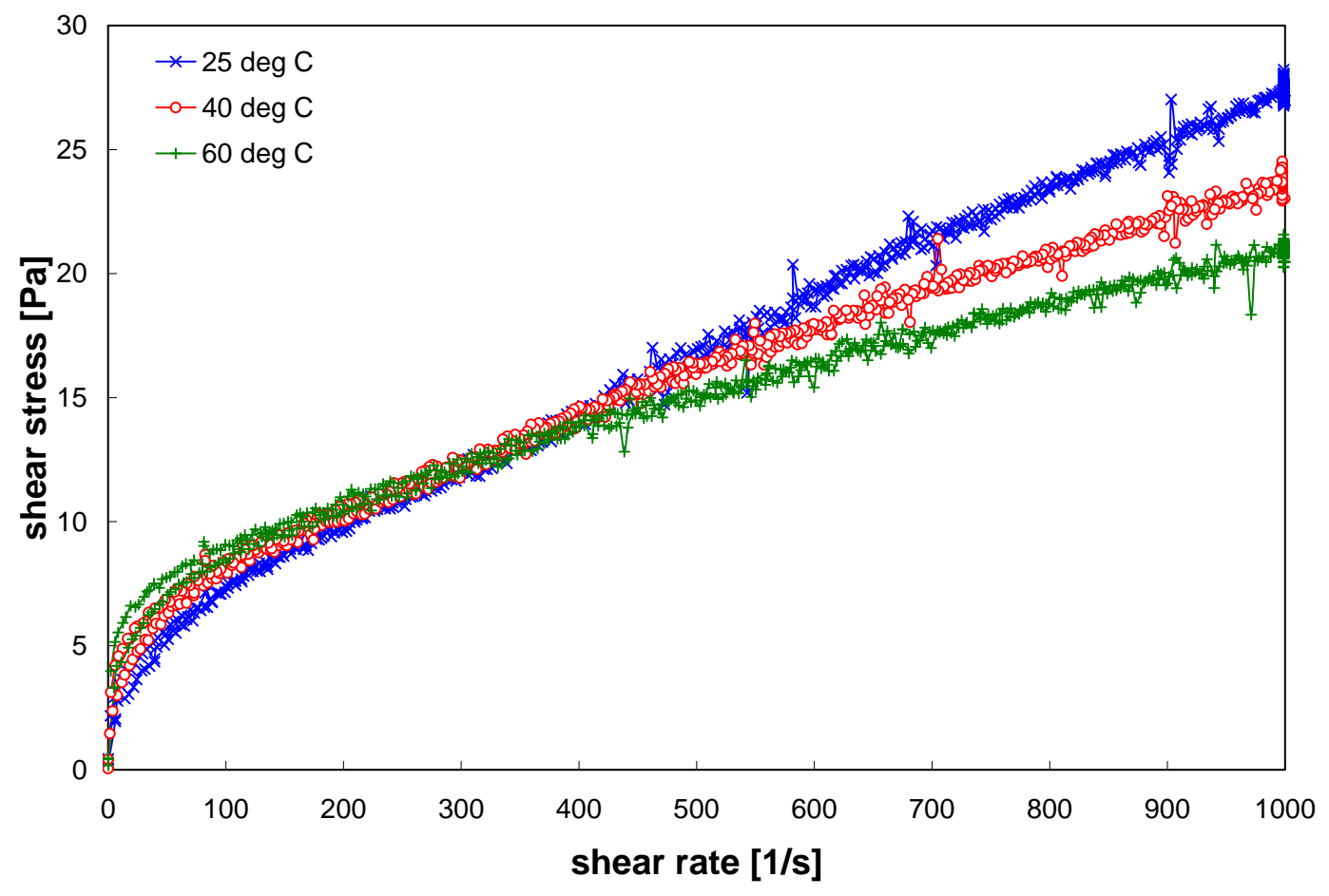

Figure 9. Flow curves for Group 5 CUF slurry sample TI540-G5-R3 at $25^{\circ} \mathrm{C}, 40^{\circ} \mathrm{C}$, and $60^{\circ} \mathrm{C}$. Sample corresponds to the post-caustic-leach dewatered slurry (13.5-wt\% solids).

Table 17. Results of fitting analysis for rheology sample TI540-G5-R3. This sample corresponds to a concentrated (13.5-wt\%) post-caustic-leach slurry for group 5. Unless otherwise specified, analysis considered shear rates spanning 200 to $1000 \mathrm{~s}^{-1}$.

\begin{tabular}{||c|c|c|c|c|c||}
\hline MODEL & $\begin{array}{c}\text { TEMPERATURE } \\
{\left[{ }^{\mathbf{C}} \mathbf{C}\right]}\end{array}$ & $\begin{array}{c}\text { YIELD } \\
\text { STRESS } \\
{[\mathbf{P A}]}\end{array}$ & $\begin{array}{c}\text { CONSISTENCY } \\
{\left[\mathbf{P A} \cdot \mathbf{S}^{\mathbf{N}}\right]}\end{array}$ & $\begin{array}{c}\text { FLOW } \\
\text { INDEX }\end{array}$ & $\mathbf{R}$ \\
\hline \multirow{3}{*}{ Power-Law* } & 25 & $\mathrm{n} / \mathrm{a}$ & 0.30 & 0.65 & 0.997 \\
\cline { 2 - 6 } & 40 & $\mathrm{n} / \mathrm{a}$ & 0.72 & 0.51 & 0.996 \\
\cline { 2 - 6 } & 60 & $\mathrm{n} / \mathrm{a}$ & 1.2 & 0.41 & 0.993 \\
\hline \multirow{3}{*}{ Bingham-Plastic } & 25 & 5.7 & 0.022 & $\mathrm{n} / \mathrm{a}$ & 0.998 \\
\cline { 2 - 7 } & 40 & 7.8 & 0.016 & $\mathrm{n} / \mathrm{a}$ & 0.996 \\
\cline { 2 - 7 } & 60 & 8.7 & 0.012 & $\mathrm{n} / \mathrm{a}$ & 0.996 \\
\hline Herschel-Bulkley & 25 & 2.4 & 0.11 & 0.79 & 0.998 \\
\cline { 2 - 7 } & 40 & 2.6 & 0.26 & 0.64 & 0.998 \\
\cline { 2 - 7 } & 65 & 5.6 & 0.12 & 0.70 & 0.997 \\
\hline
\end{tabular}

*Fits applied to full range of shear (i.e., 0 to $1000 \mathrm{~s}^{-1}$ ) 


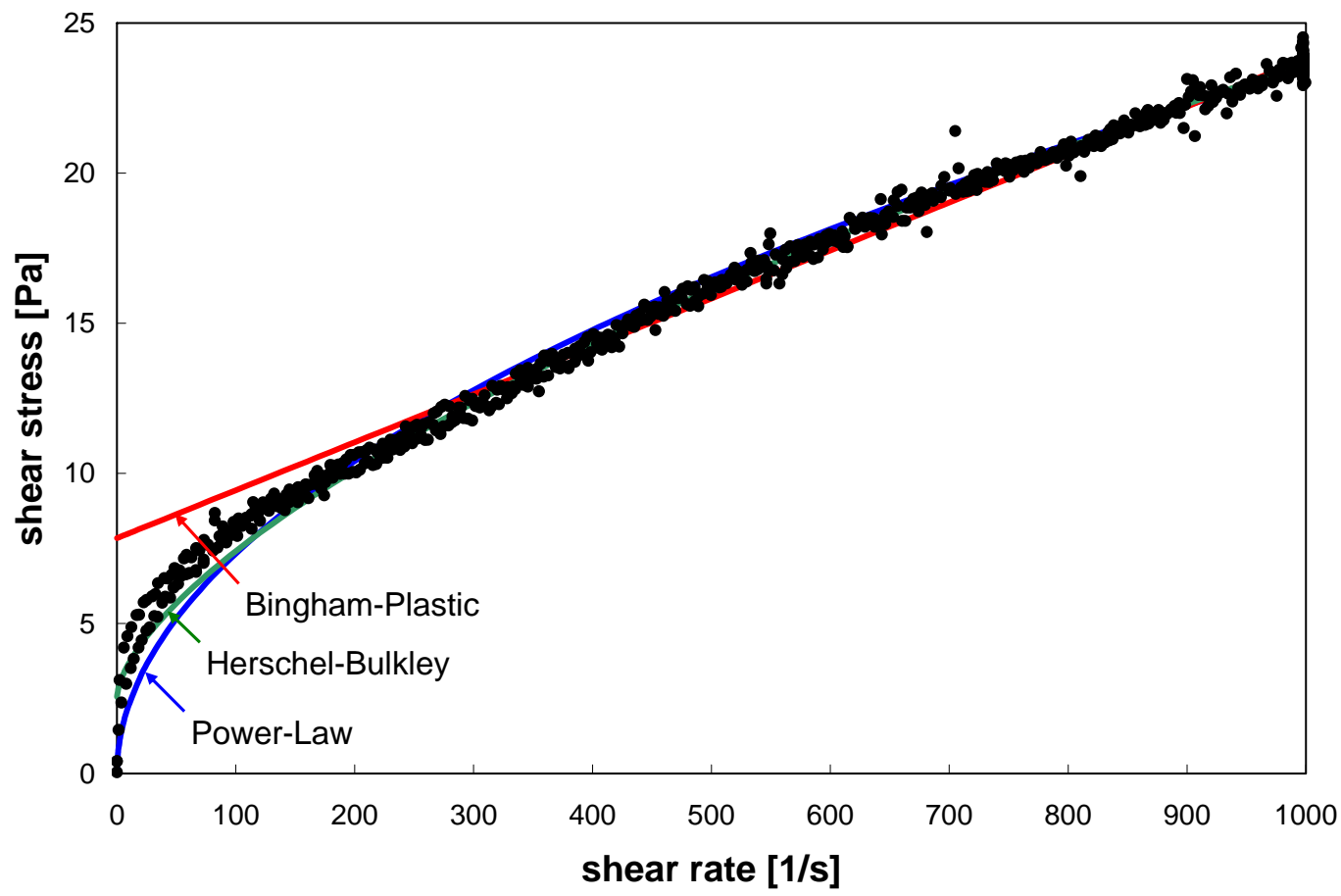

Figure 10. Model fits of flow curve data for Group 5 CUF slurry sample TI540-G5-R3 at $40^{\circ} \mathrm{C}$. Power-law model was fit over 0-1000 s $\mathrm{s}^{-1}$. Bingham plastic and Herschel-Bulkley models were restricted to $200-1000 \mathrm{~s}^{-1}$.

Apparent viscosities at $33 \mathrm{~s}^{-1}$ for sample TI540-G5-R3 are provided in Table 18. For each temperature, this reference point is determined from measurement data and from the fitting parameters provided in Table 17. Because the reference point falls within $0-100 \mathrm{~s}^{-1}$ and is influenced by slip, poor sampling, and time-dependent elasticity, the apparent viscosities may not be truly representative of the material. As with the fitting analysis, the Bingham-Plastic viscosities provide a conservative upper estimate of apparent viscosity at $33 \mathrm{~s}^{-1}$.

Table 18. Apparent viscosity of sample TI540-G5-R3 at $33 \mathrm{~s}^{-1}$.

\begin{tabular}{||c|c|c|c|c||}
\hline \hline TEMPERATURE & \multirow{2}{*}{$\begin{array}{c}\eta_{\text {APP }}(\mathbf{C P}) \\
\text { FROM }\end{array}$} & \multicolumn{3}{|c||}{$\begin{array}{c}\eta_{\text {APP }} \text { (CP) } \\
\text { FROM FITTING PARAMETERS }\end{array}$} \\
\cline { 3 - 5 } & $\begin{array}{c}\text { MEASUREMENT } \\
\text { DATA }\end{array}$ & Power-Law & $\begin{array}{c}\text { Bingham } \\
\text { Plastic }\end{array}$ & $\begin{array}{c}\text { Herschel- } \\
\text { Bulkley }\end{array}$ \\
\hline 25 & 140 & 89 & 200 & 120 \\
\hline 40 & 170 & 130 & 250 & 150 \\
\hline 60 & 200 & 160 & 280 & 210 \\
\hline
\end{tabular}

\section{Sample TI-540-G5-R4: Post-Leach Dewatered and Washed Slurry (4.1-wt\%)}

Figure 11 shows the results of flow curve testing for sample TI540-G5-R4. This sample corresponds to the post-caustic leach dewatered and washed slurry. The slurry has an approximate solids concentration of 4.1-wt\%. The flow curves for sample TI540-G5-R4 suggest that washing of the postleach dewatered slurry further reduces the waste rheology but does not alter its behavior. All curves show non-Newtonian behavior consistent with the Bingham-plastic or Herschel-Bulkley constitutive equations. 
The samples still show slip or elasticity over the $0-100 \mathrm{~s}^{-1}$ region. The apparent yield stress has decreased by (approximately) a factor of two relative to the dewatered post-leach slurry. Increases in slurry temperature do not appear to affect yield stress but do appear to lower the slope of the flow curve over the entire range of shear rates tested (likely through lowering of suspending phase viscosity). It should be noted that the stresses observed for these samples (2-8 Pa) are approaching the limiting of accuracy for the M5 measuring system $(\sim 0.5 \mathrm{~Pa})$ and may be significantly influenced by measurement noise at low shear rates.

Power-Law, Bingham-Plastic, and Herschel-Bulkley model parameters for sample TI540-G5-R4 are given in Table 19. As before, the Power-Law fit employed the entire range of shear rates whereas Bingham-Plastic and Herschel-Bulkley fits were restricted to 200 to $1000 \mathrm{~s}^{-1}$. In addition, a second Herschel-Bulkley fit was applied to the entire range of shear. An example of the fitting quality is shown in Figure 12, which compares the flow curve data at $40^{\circ} \mathrm{C}$ to their corresponding fits. All models seem to provide a reasonable approximation at shear rates greater than $200 \mathrm{~s}^{-1}$. The Power-law and HerschelBulkley fits using the entire range of shear provide an adequate representation of the $0-200 \mathrm{~s}^{-1}$ data. Out of all models, the Herschel-Bulkley best captures the full range of flow curve data.

Using the Bingham and Herschel-Bulkley fits as bounding points, the yield stress of TI540-G5R4 appears to fall between 1.6 and 3.3 at $25^{\circ} \mathrm{C}, 1.6$ and 3.4 at $40^{\circ} \mathrm{C}$, and 1.8 and 2.8 at $60^{\circ} \mathrm{C}$. The Herschel-Bulkley and Bingham-Plastic fits appear to confirm that yield stress does not change predictably with increasing temperature. In addition, the Bingham-Plastic consistency parameters decrease with increasing temperature, confirming the prior observation that the slope of the flow curve data decrease at higher temperatures.

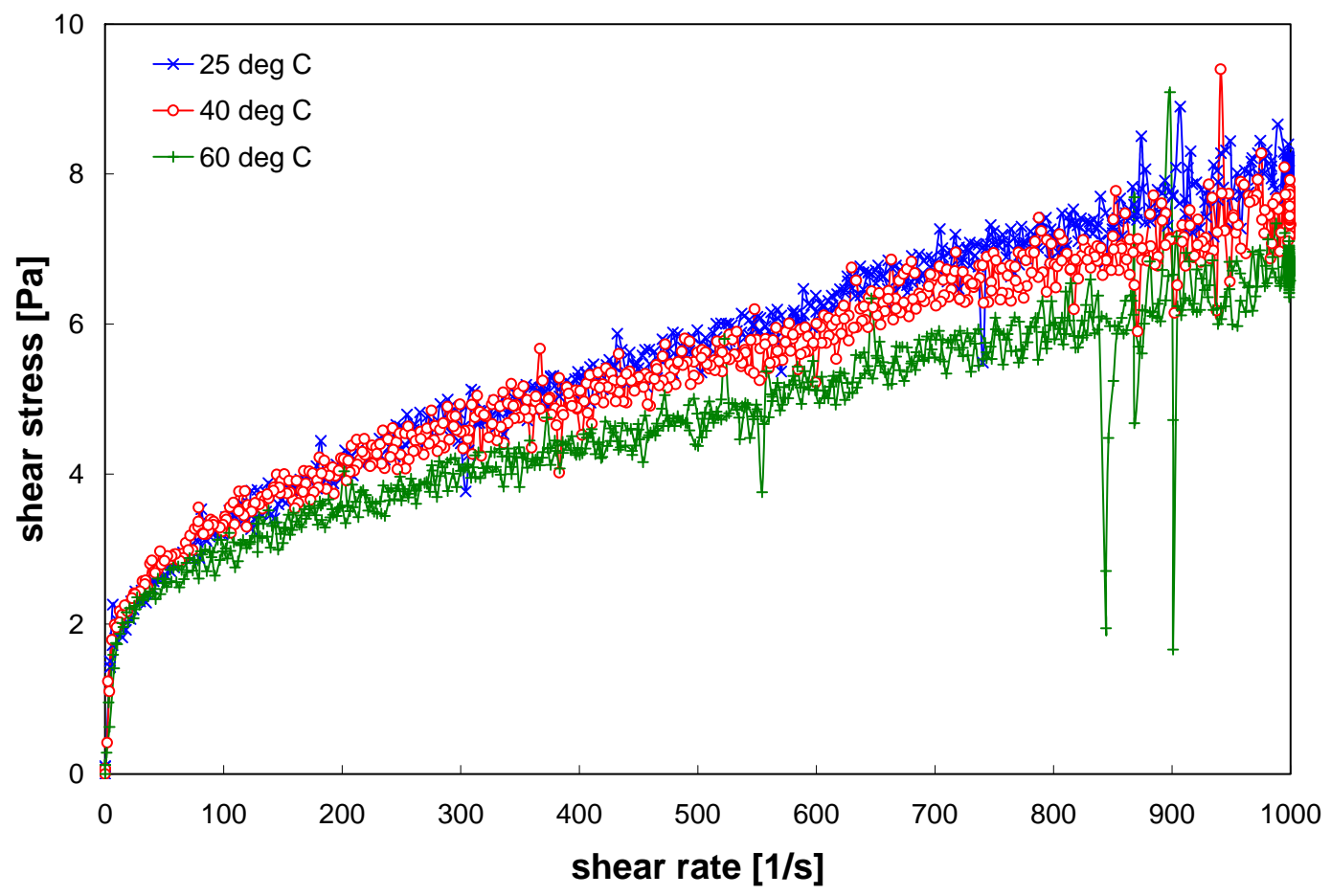

Figure 11. Flow curves for Group 5 CUF slurry sample TI540-G5-R4 at $25^{\circ} \mathrm{C}, 40^{\circ} \mathrm{C}$, and $60^{\circ} \mathrm{C}$. Sample corresponds to the post-caustic-leach dewatered and washed slurry (4.1-wt\% solids). 
Table 17. Results of fitting analysis for rheology sample TI540-G5-R4. This sample corresponds to the post-caustic leach dewatered and washed slurry (4.1-wt\%). Unless otherwise specified, analysis considered shear rates spanning 200 to $1000 \mathrm{~s}^{-1}$.

\begin{tabular}{|c|c|c|c|c|c|}
\hline MODEL & $\begin{array}{c}\text { TEMPERATURE } \\
{\left[{ }^{\circ} \mathrm{C}\right]}\end{array}$ & $\begin{array}{c}\text { YIELD } \\
\text { STRESS } \\
\text { [PA] }\end{array}$ & $\begin{array}{c}\text { CONSISTENCY } \\
{\left[P A \cdot S^{N}\right]}\end{array}$ & $\begin{array}{l}\text { FLOW } \\
\text { INDEX }\end{array}$ & $\mathbf{R}$ \\
\hline \multirow[t]{3}{*}{ Power-Law* } & 25 & $\mathrm{n} / \mathrm{a}$ & 0.46 & 0.41 & 0.990 \\
\hline & 40 & $\mathrm{n} / \mathrm{a}$ & 0.57 & 0.37 & 0.985 \\
\hline & 60 & $\mathrm{n} / \mathrm{a}$ & 0.44 & 0.39 & 0.964 \\
\hline \multirow[t]{3}{*}{ Bingham-Plastic } & 25 & 3.3 & 0.0047 & $\mathrm{n} / \mathrm{a}$ & 0.998 \\
\hline & 40 & 3.4 & 0.0041 & $\mathrm{n} / \mathrm{a}$ & 0.978 \\
\hline & 60 & 2.8 & 0.0039 & $\mathrm{n} / \mathrm{a}$ & 0.948 \\
\hline \multirow[t]{3}{*}{ Herschel-Bulkley } & 25 & 2.4 & 0.031 & 0.75 & 0.989 \\
\hline & 40 & 2.7 & 0.022 & 0.78 & 0.979 \\
\hline & 60 & 3.0 & 0.0018 & 1.1 & 0.945 \\
\hline \multirow[t]{3}{*}{ Herschel-Bulkley* } & 25 & 1.6 & 0.10 & 0.60 & 0.994 \\
\hline & 40 & 1.6 & 0.13 & 0.55 & 0.998 \\
\hline & 60 & 1.8 & 0.046 & 0.68 & 0.970 \\
\hline
\end{tabular}

*Fits applied to full range of shear (i.e., 0 to $1000 \mathrm{~s}^{-1}$ )

Apparent viscosities at $33 \mathrm{~s}^{-1}$ for sample TI540-G5-R3 are provided in Table 18. For each temperature, this reference point is determined from measurement data and from the fitting parameters provided in Table 17. Because the reference point falls within $0-100 \mathrm{~s}^{-1}$ believed to show slip, the reference viscosities may not be truly representative of the material. As with the fitting analysis, the Bingham-Plastic viscosities provide a conservative upper estimate of apparent viscosity at $33 \mathrm{~s}^{-1}$.

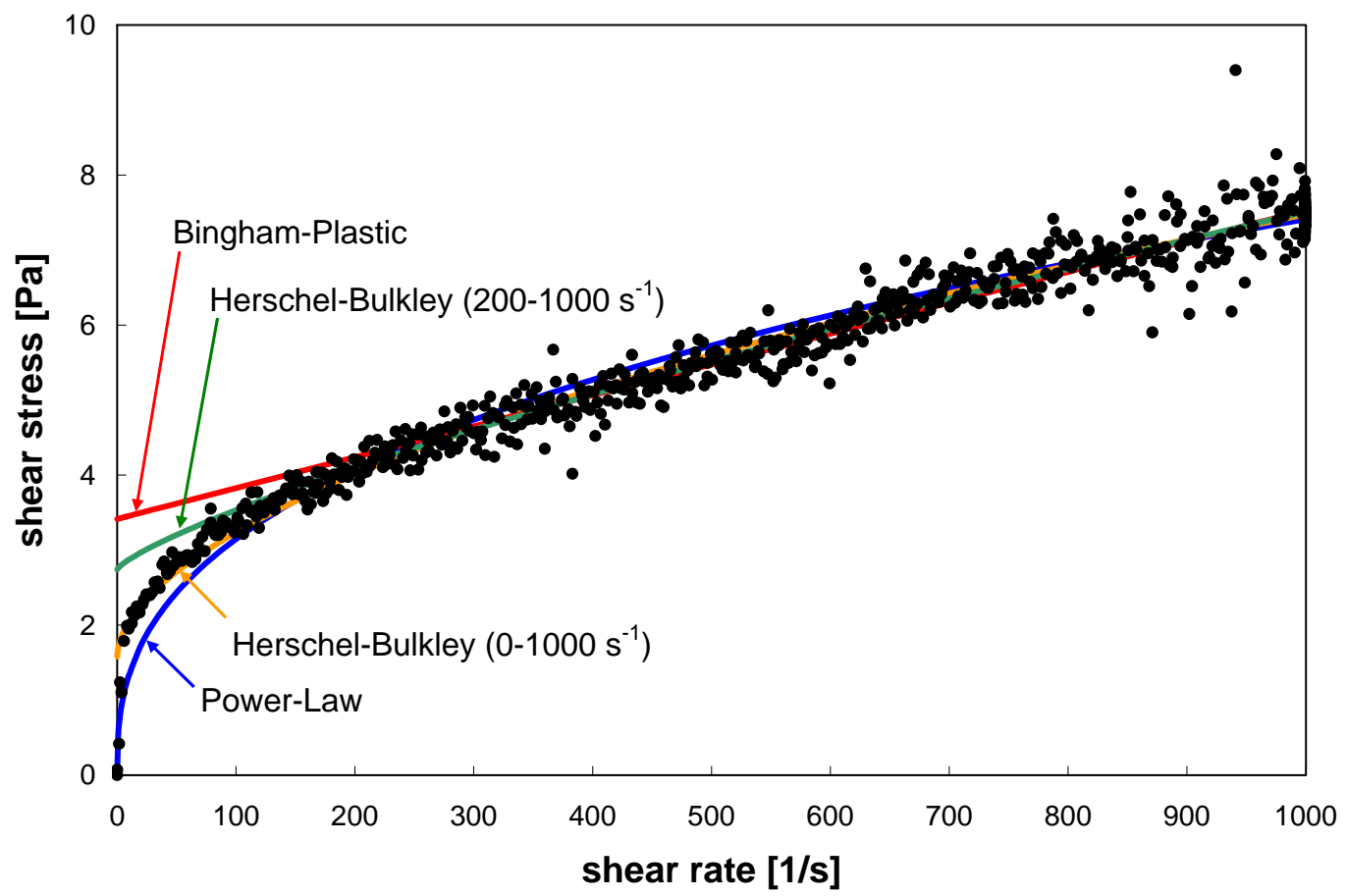

Figure 12. Model fits of flow curve data for Group 5 CUF slurry sample TI540-G5-R4 at $40^{\circ} \mathrm{C}$. Power-law model was fit over 0-1000 s ${ }^{-1}$. Bingham plastic and Herschel-Bulkley models were 
restricted to $200-1000 \mathrm{~s}^{-1}$.

Table 18. Apparent viscosity of sample TI540-G5-R4 at $33 \mathrm{~s}^{-1}$.

\begin{tabular}{||c|c|c|c|c|c||}
\hline \hline TEMPERATURE & \multirow{2}{*}{$\begin{array}{c}\eta_{\text {APP }}(\mathrm{CP}) \\
\text { FROM }\end{array}$} & \multicolumn{4}{|c||}{$\begin{array}{c}\eta_{\text {APP }}(\mathrm{CP}) \\
\text { FROM FITTING PARAMETERS }\end{array}$} \\
\cline { 3 - 7 } & $\begin{array}{c}\text { MEASUREMENT } \\
\text { DATA }\end{array}$ & $\begin{array}{c}\text { Power- } \\
\text { Law }\end{array}$ & $\begin{array}{c}\text { Herschel- } \\
\text { Bulkley }\end{array}$ & $\begin{array}{c}\text { Bingham } \\
\text { Plastic* }\end{array}$ & $\begin{array}{c}\text { Herschel- } \\
\text { Bulkley* }\end{array}$ \\
\hline 25 & 73 & 59 & 73 & 110 & 87 \\
\hline 40 & 77 & 63 & 75 & 110 & 93 \\
\hline 60 & 72 & 52 & 69 & 88 & 93 \\
\hline
\end{tabular}

*Fits restricted to data over 200 to $1000 \mathrm{~s}^{-1}$.

\section{Comparison of Slurry Rheology}

A comparison of group 5 CUF sample rheology at $25^{\circ} \mathrm{C}$ is given in Figure 13. Higher temperatures show similar trends. Because of the difference in magnitude between the concentrated precaustic leach slurries relative to the other slurries tested, the results have been separated out into weaker and stronger rheology results in Figures 13a and 13b, respectively. As a point of reference, the postcaustic leach dewatered slurry is shown on both graphs. All curves show non-Newtonian behavior. In order of increasing strength (as measured by the average magnitude of stress required to maintain flow over the range of shear), the slurries are:

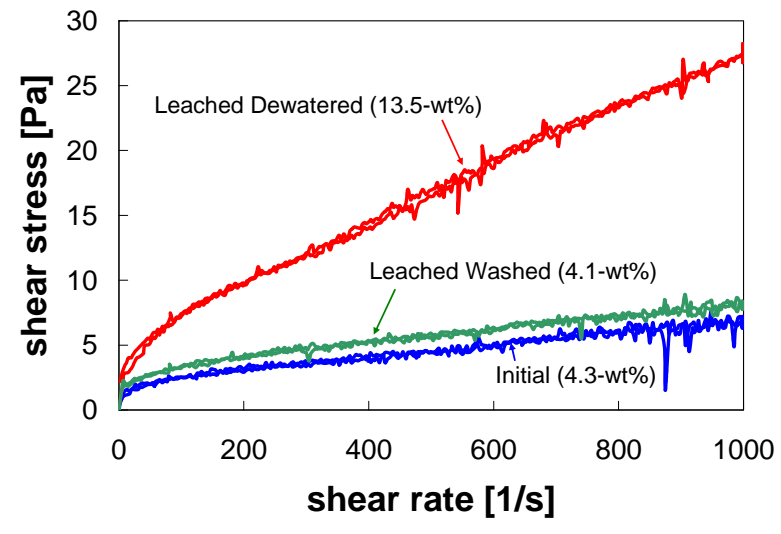

(a)

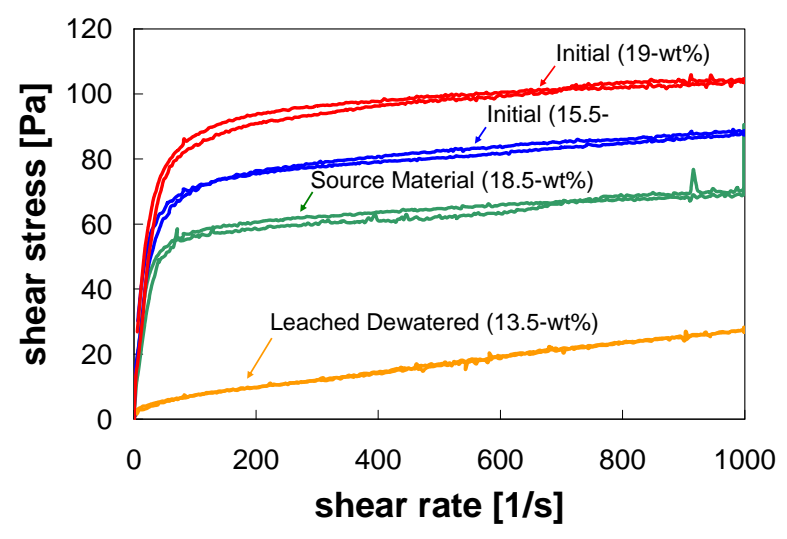

(b)

Figure 13. Comparison of group 5 CUF slurry flow curves at $25^{\circ} \mathrm{C}$, with (a) showing the weaker slurries and (b) showing the stronger slurries. The leached dewater [red curve in (a), amber curve in (b)] is included in both graphs as a point of reference.

1. initial (pre-caustic leach) slurry at 4.3-wt\% - TI540-G5-R1

2. leached, dewatered, and washed slurry at 4.1-wt\% - TI540-G5-R4

3. leached and dewatered slurry at 13.5-wt\% - TI540-G5-R3

4. source material at $18.5-\mathrm{wt} \%$ - G5-RH-2

5. initial (pre-caustic leach) slurry at 15.5-wt\% - TI540-G5-R2BN*

6. initial (pre-caustic leach) slurry at 19-wt\% - TI540-G5-R2A

The initial dilute CUF slurry and the final dewatered and washed slurry are more or less equal in terms of rheology. The post-leach, dewatered slurry is viscous relative to these two, but this is expected because of its concentration and because of the fact that the suspending phase contains all of the leaching products 
from caustic contact. All concentrated pre-leach slurries show stress magnitudes of 50 Pa or greater. Of the three concentrated pre-leach slurries, the source material for the CUF run shows the lowest rheology. As stated in previous sections, this is unexpected as the source material has a solids concentration of 18.5wt\%, which near to that of the most concentrated slurry tested (19-wt\%). The increased rheology of both pre-leach CUF samples over that of the source material may be a result of sample alterations caused by the dilution and subsequent concentration in the CUF. The 19-wt\% CUF sample is more viscous than the 15.5-wt\% sample. This result is expected because of the increased solids concentration.

The Bingham-Plastic model parameters determined by linear regression of the flow curve data provide a conservatively high estimate of yield stress as a function of slurry concentration and temperature. Figure 14 shows the Bingham-Plastic yield stress as a function of temperature for all slurries tested herein. As before, the results have been separated out into weak and strong rheology results in Figures 14a and 14b, respectively. The graphs show that, with exception of the post-caustic leach dewatered and washed slurry, the yield stress typically increases with slurry temperature. This could be a result of slurry concentration resulting from evaporation of the rheology sample. It could also be caused by temperature induced aggregation, which would be similar to and consistent with the observation of aggregation in samples subjected to sonication during particle size analysis. The increase in yield stress with temperature appears to show diminishing returns at higher temperatures, such that the increase as temperature is raised from $40^{\circ}$ to $60^{\circ} \mathrm{C}$ is typically less than the increase observed from $25^{\circ}$ to $40^{\circ} \mathrm{C}$.

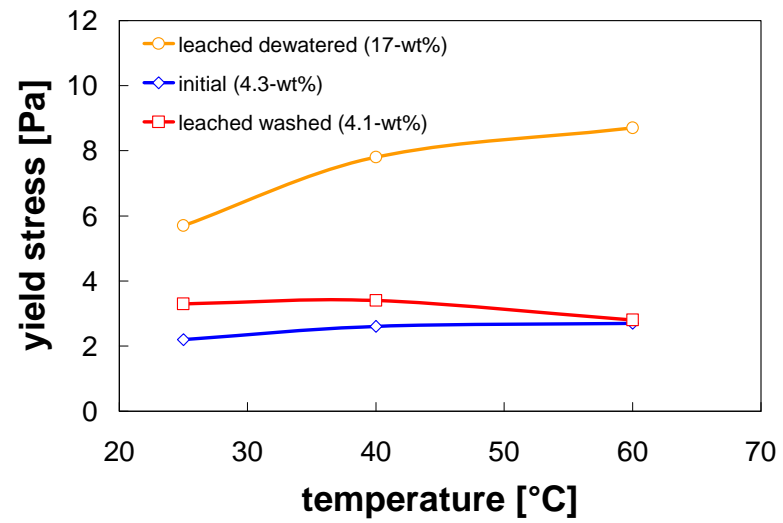

(a)

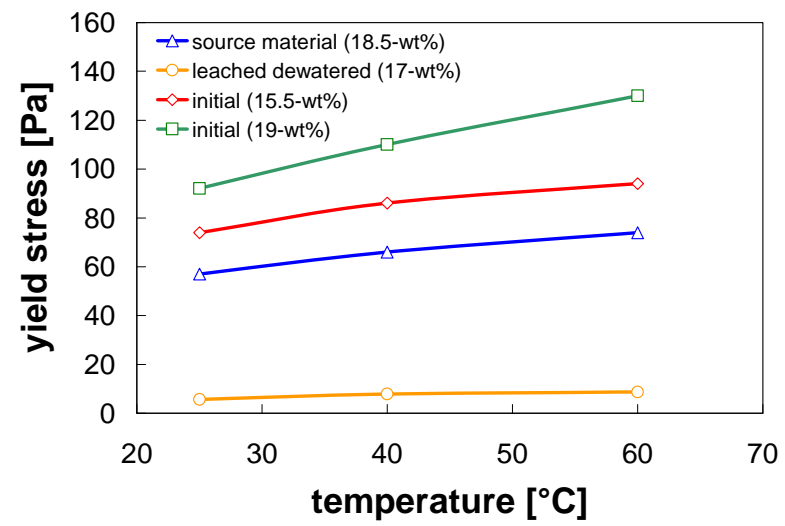

(b)

Figure 14. Comparison of group 5 CUF slurry Bingham-Plastic yield stress as a function of temperature, with (a) showing the weaker slurries and (b) showing the stronger slurries. The leached dewater [amber curve] is included in both graphs as a point of reference. 


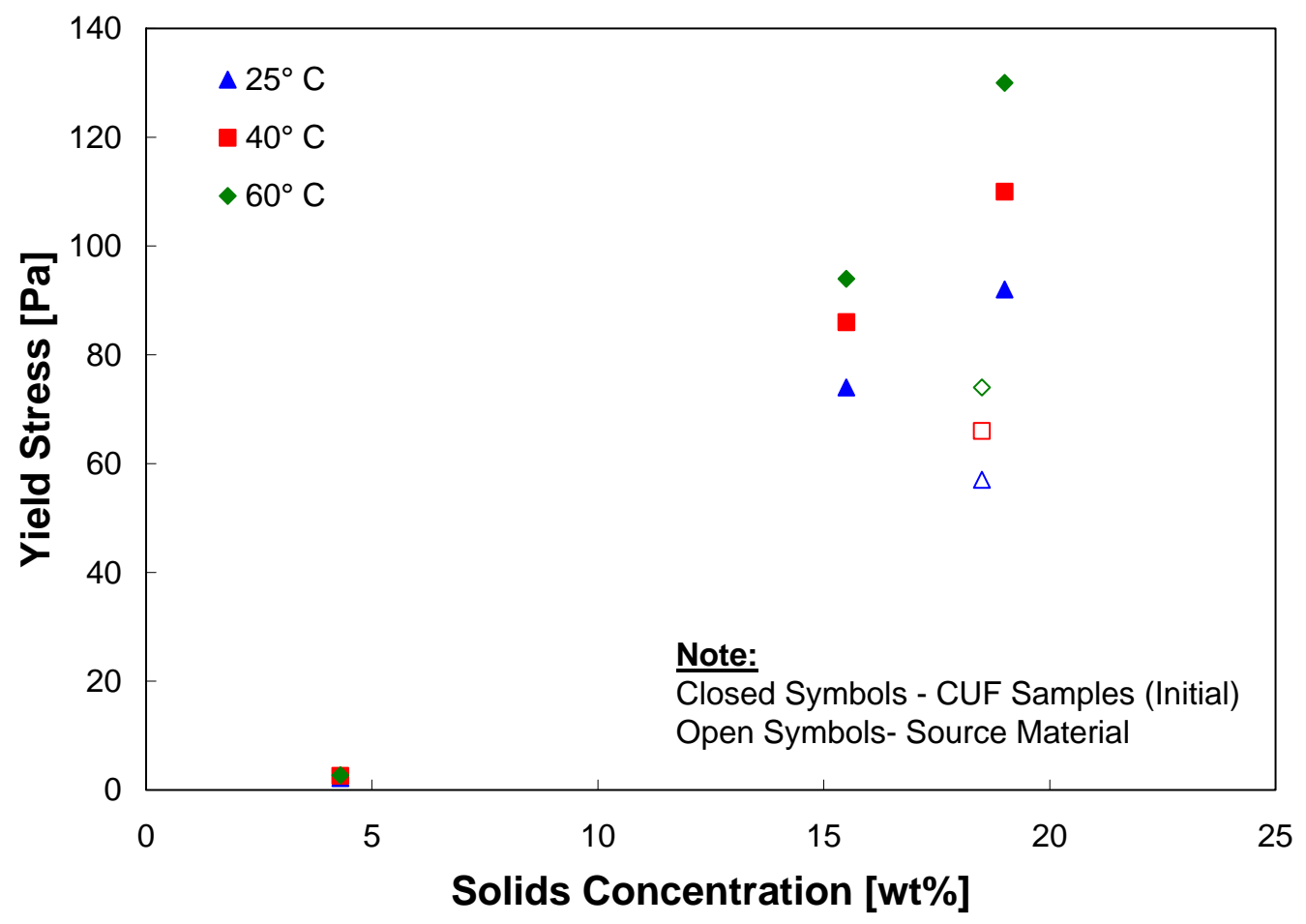

Figure 15. Bingham-Plastic yield stresses for the pre-caustic leach slurry samples (closed symbols) and the source material (open symbols) as a function of concentration.

Figure 15 shows the influence of slurry concentration on the yield stress. The figure is limited to only those samples with comparable chemistry, namely the source material and pre-caustic leach samples. It is clear from the graph that the CUF slurry yield stress (filled symbols) is higher than the source material yield stress (open symbols) at equivalent concentration. Although the materials should be of similar chemistry, it is believed that differences in material sampling for rheology or changes in sample chemistry upon dilution are the root cause of this disparity. Given the limited number of observations, the yield stresses for CUF slurries at $25^{\circ}, 40^{\circ}$, and $60^{\circ}$ appear to vary linearly with slurry concentration over 4- to $20-w t \%$. Without additional slurry concentration data points, it is difficult to say if the expected exponential increase in yield stress with increasing slurry concentration is absent.

Figure 16 shows the Bingham-Plastic consistency indexes for group 5 CUF slurry samples and source material as a function of temperature. In general, the most dilute slurries (i.e., the initial 4.3-wt\% and post-leached dewatered and washed slurry) show decreasing consistency with increasing temperature. The leached and dewatered slurry (13.5-wt\%) slurry also shows this behavior. The decrease in the Bingham consistency index is consistent with a decrease in the suspending phase viscosity with increased temperature and indicates the extent to which the suspending phase influences the bulk viscosity for these slurries. The dilute nature of the $\sim 4$-wt $\%$ slurries results in a significant suspending phase contribution to the bulk viscosity relative to the particle contribution. For the leached and dewatered slurry, the high concentration of dissolved solids in the suspending phase results in significant suspending phase viscosity, even with the high concentration of solids (13.5-wt\%). 


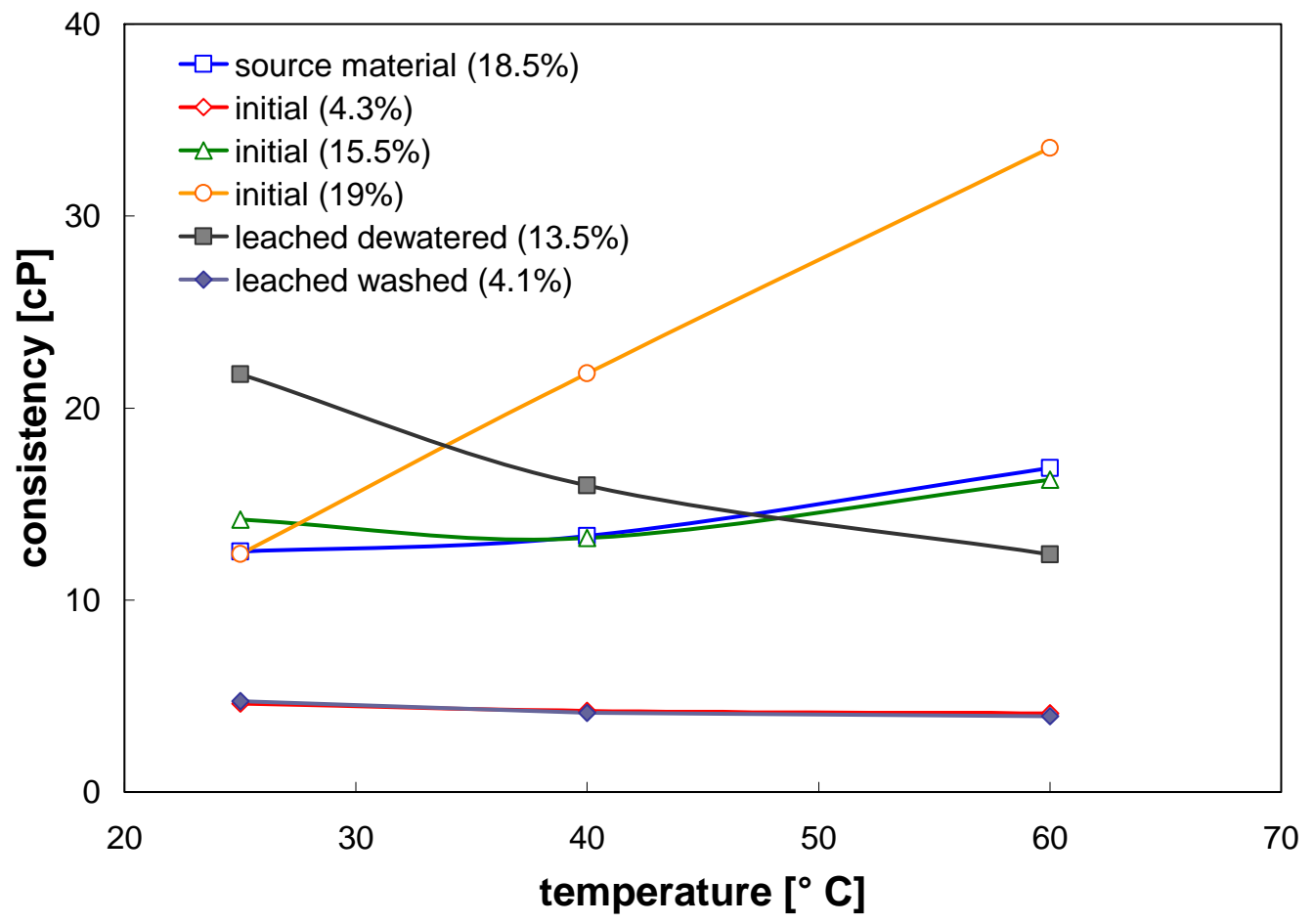

Figure 16. Bingham-Plastic consistency indexes for group 5 CUF slurry samples and source material as a function of temperature. Note: the initial (4.3-wt\%) and leached dewatered (13.5-wt\%) consistencies are similar such that their curves and data points lie on top of one another.

For the more concentrated slurries, including the source material and dewatered initial CUF slurries, the Bingham consistency index typically increases with increased slurry temperature. While it is still likely that the suspending phase viscosity is lowered with temperature, that behavior is masked by significant solid interactions in these slurries. As such, the bulk consistency is dictated by behavior of the suspended particles and particles aggregates. Increases in slurry consistency may be a result of particle aggregation. As stated in preceding paragraphs, sonication has been observed to aggregate particles in group 5 waste slurries. Increased slurry temperature is expected to have similar effects on the state of particle aggregation.

\section{Sample TI-540-G5-Dewater4: Pre-Caustic-Leach Permeate}

Figure 17 shows the results of flow curve testing for sample TI-540-G5-Dewater4. This sample corresponds to the permeate collected during the dewatering operation prior to caustic leaching. The flow curves are typical of a low-viscosity Newtonian fluid. The slurries show a high noise to signal ratio at low shear rates below $300 \mathrm{~s}^{-1}$. This is a result of the measured stresses being near the limit of detection for the instrument (practically $0.2 \mathrm{~Pa}$ ). At $300 \mathrm{~s}^{-1}$, there is a well-defined increase in the slope of all flow curves. The sudden nature of this increase and its reproducibility on the flow curve down-ramp are consistent with turbulent flow in the gap between the rotor and cup wall. 


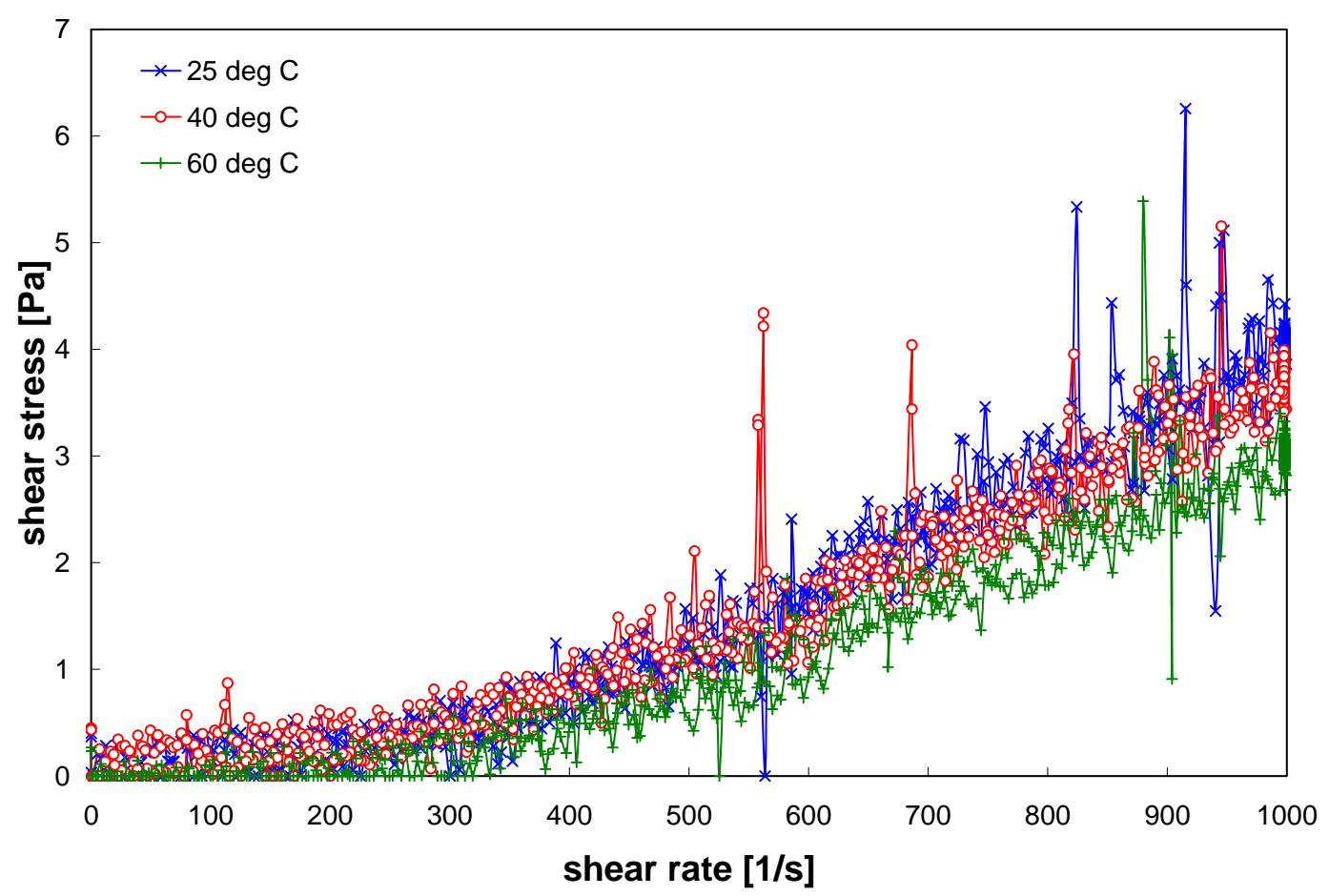

Figure 17. Flow curves for Group 5 CUF permeate sample TI-540-G5-Dewater 4 at $25^{\circ} \mathrm{C}, 40^{\circ} \mathrm{C}$, and $60^{\circ} \mathrm{C}$. Permeate is collected during the dewatering operations before caustic leaching of the slurry.

Rotational viscometry operates under the assumption of laminar flow. Because most rotational viscometers employ small gap sizes $(\sim 1 \mathrm{~mm})$ and because most tests fluids are non-Newtonian or are Newtonian with high viscosity (i.e., greater than $10 \mathrm{cP}$ ), flow conditions within the gap are typically laminar. However, turbulent flow conditions will be realized during flow curve measurement for low viscosity fluids. For example, flow curve measurements of water (which has a viscosity of $1 \mathrm{cP}$ ) in the MV1 measurement cup system show a transition from laminar to turbulent flow around $200 \mathrm{~s}^{-1}$. This transition point scales approximately with viscosity, such that prediction of transition points for higher viscosity fluids can be made simply by multiplying $200 \mathrm{~s}^{-1}$ by the ratio of the current viscosity to that of water. Thus, $5 \mathrm{cP}$ fluids should have a transition point around $1000 \mathrm{~s}^{-1}$, which is the measurement limit for the flow curves discussed herein. As such, laminar-to-turbulent flow transitions should not be observed for fluids with viscosities greater than $5 \mathrm{cP}$.

Turbulent flow dissipates more energy than laminar flow. As a result, more force is required to maintain constant rotation of the measurement systems in turbulent flow. This is observed in flow curve measurements as an increase in the slope of the shear stress versus shear rate curve (like observed in Figure 5). This increase is not predictable and cannot be analyzed to extract the actual viscosity of the test fluid. Thus, any flow curve data beyond the transition point is usually discarded.

For the current measurements, the break point of $300 \mathrm{~s}^{-1}$ suggests permeate viscosities of around $1.5 \mathrm{cP}$ [i.e., $\left(300 \mathrm{~s}^{-1} / 200 \mathrm{~s}^{-1}\right) *(1 \mathrm{cP})$ ]. Because of the substantial noise in the laminar flow data below 300 $\mathrm{s}^{-1}$, it is not possible to accurately determine viscosity through analysis of the flow curve slopes at each temperature. Instead, a separate measurement of viscosity at each temperature was derived by taking the average of the apparent viscosity measured during constant rotation mixing of the permeate sample. 
These measurements will be hereafter referred to as "constant rotation" viscosities. Implicit in these measurements is the assumption of Newtonian fluid behavior.

Table 19. Newtonian viscosities for permeate sample TI-540-G5-Dewater4 at $25^{\circ}$ $\mathrm{C}, 40^{\circ} \mathrm{C}$, and $60^{\circ} \mathrm{C}$ as determined by constant rotation at $200 \mathrm{~s}^{-1}$.

\begin{tabular}{||c|c|c||}
\hline \hline TEMPERATURE $\left[{ }^{\circ} \mathbf{C}\right]$ & MODEL & $\begin{array}{c}\text { VISCOSITY } \\
\text { [CP] }\end{array}$ \\
\hline 25 & Average (constant rotation) & $1.5 \pm 0.4$ \\
\hline 40 & Average (constant rotation) & $1.7 \pm 0.3$ \\
\hline 60 & Average (constant rotation) & $1.5 \pm 0.3$ \\
\hline
\end{tabular}

The results of the constant rotation analysis are shown in Table 19. Measurements were taken at $200 \mathrm{~s}^{-1}$, which is below the flow transition point observed in Figure 17. Each measurement consists of an average of at least 50 point measurements of viscosity during constant rotation and is reported with the sample standard deviation. The average viscosity of the permeate varies between 1.5 and $1.7 \mathrm{cP}$ and does not vary predictably with temperature within the limits of accuracy for the instrument. The measurements are consistent with the observed transition point at $300 \mathrm{~s}^{-1}$. For the current measurements, no apparent viscosity is given at $33 \mathrm{~s}^{-1}$ as the apparent viscosity of a Newtonian fluid is equal to its actual viscosity.

\section{Sample TI-540-G5-Leach2: Post-Leach Pre-Wash Permeate}

Figure 18 shows the results of flow curve testing for sample TI-540-G5-Leach2. This sample corresponds to the permeate collected during the dewatering operation after caustic leaching. All curves appear to show Newtonian flow behavior. Unlike the -Dewater4 sample, the post-leach permeate do not show transition points, suggesting viscosities near or above $5 \mathrm{cP}$ for at all temperatures. The slope of the flow curves decrease with increasing temperature. This decrease in viscosity with temperature is typical for liquid samples.

Newtonian viscosities as a function of temperature are derived by fitting the flow curve data (i.e., stress versus shear rate) to Eq. 4. The results are shown in Table 20. In addition, a single constant rotation viscosity measurement was made at $60^{\circ} \mathrm{C}$ to estimate measurement error and as a check of the method used to determine viscosity for sample TI-540-G5-Dewater4. It is also included in Table 20. The results show that the viscosities for the post-leach permeate decrease strongly as a function of temperature. Indeed, as the temperature is increased from $25^{\circ}$ to $60^{\circ}$, the viscosity decreases by more than a factor of 2 (i.e., 11 to $4.7 \mathrm{cP}$ ). In addition, the $25^{\circ} \mathrm{C}$ post-leach permeate viscosity is almost an order of magna are greater than the pre-leach permeate. This is a result of the presence of the leaching and dissolution products. At $60^{\circ} \mathrm{C}$, the viscosity derived from flow curve testing (4.7 $\mathrm{Pa}$ ) and that from constant rotation (4.4 Pa) are not significantly different relative to the sample standard deviation $( \pm 0.6$ $\mathrm{Pa}$ ). No apparent viscosity is given at $33 \mathrm{~s}^{-1}$ as the apparent viscosity of a Newtonian fluid is equal to its actual viscosity. 


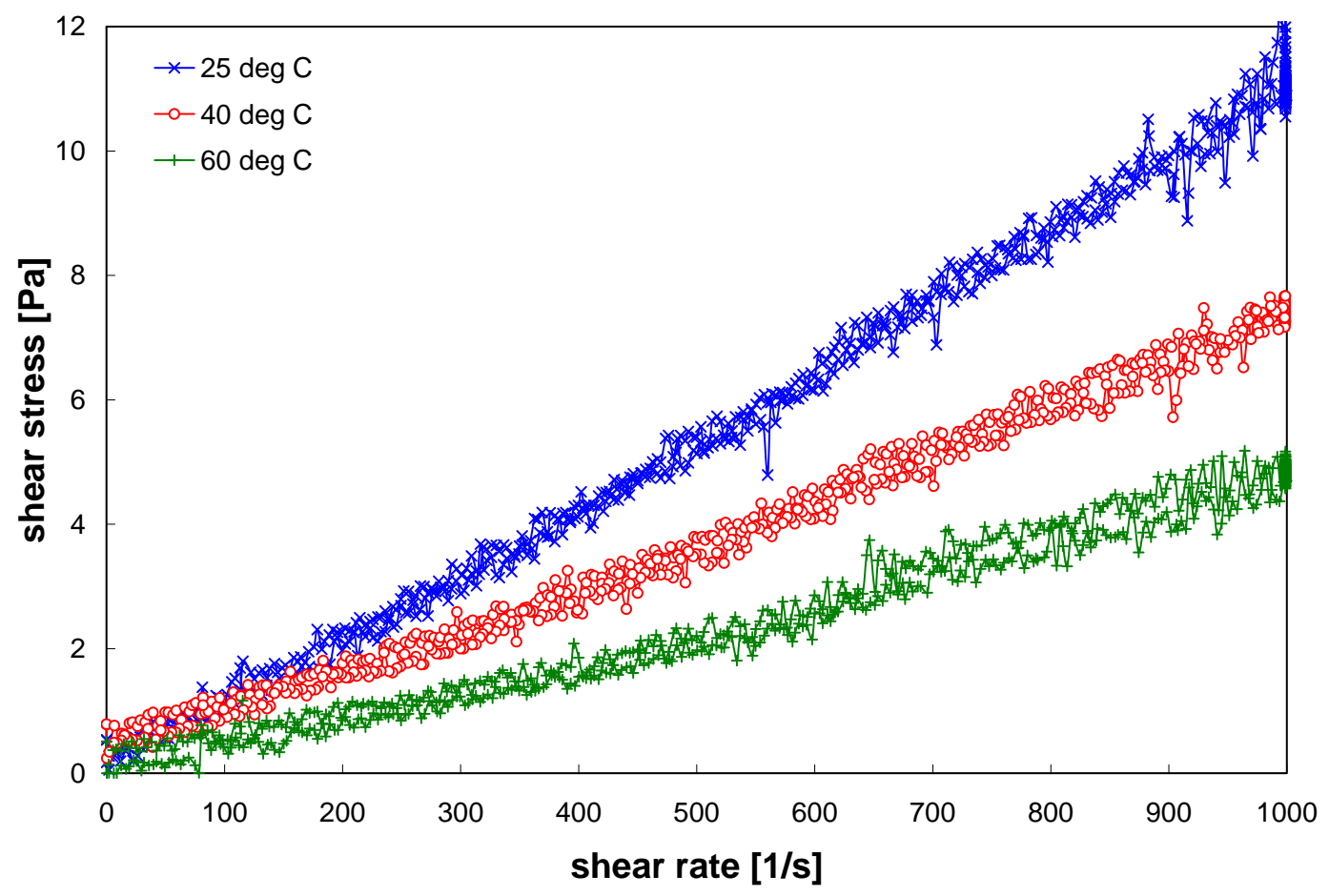

Figure 18. Flow curves for Group 5 CUF permeate sample TI-540-G5-Leach2 at $25^{\circ} \mathrm{C}, 40^{\circ} \mathrm{C}$, and $60^{\circ} \mathrm{C}$. Permeate is collected during the dewatering operations after caustic leaching of the slurry.

Table 19. Newtonian viscosities for permeate sample TI-540-G5-Leach2 at $25^{\circ} \mathrm{C}$, $40^{\circ} \mathrm{C}$, and $60^{\circ} \mathrm{C}$. Measurements are determined primarily by flow curve analysis. A second $60^{\circ} \mathrm{C}$ measurement was made using constant rotation at $500 \mathrm{~s}^{-1}$.

\begin{tabular}{||c|c|c||}
\hline \hline TEMPERATURE $\left[{ }^{\circ} \mathbf{C}\right.$ ] & MODEL & $\begin{array}{c}\text { VISCOSITY } \\
\text { [CP] }\end{array}$ \\
\hline 25 & Newtonian (flow curve) & 11 \\
\hline 40 & Newtonian (flow curve) & 7.4 \\
\hline 60 & Newtonian (flow curve) & 4.7 \\
\hline 60 & Average (constant rotation) & $4.4 \pm 0.6$ \\
\hline
\end{tabular}

\section{$\underline{\text { Conclusions }}$}

The rheology of group 5 tank waste slurries and permeates was examined as a function of CUF processing and temperature. All slurries exhibited non-Newtonian rheology that depended strongly on solids concentration, CUF processing, and temperature. The exact sample rheology was difficult to characterize in terms of the most common constitutive equations applied waste slurries (i.e., the PowerLaw, Bingham-Plastic, and Herschel-Bulkley models) because the group 5 waste slurries exhibit extreme shear thinning behavior in the $0-200 \mathrm{~s}^{-1}$ shear rate region. This behavior is may be an artifact of the measurement caused by slip between the sample and rotor, by a prolonged period of slurry elastic deformation, and/or by poor rotational sampling. It may also indicate additional break down of sample internal structure (such as aggregate or gel bridges) during the low shear region of the slurry.

Because of the difficulties in measuring the slurry in the low shear region, the model parameters derived from the group 5 flow curve data, such as yield stress and consistency, may not accurate represent 
the waste properties. On the other hand, the Bingham-Plastic model parameters appear to provide a reasonable upper bound of the flow curve behavior, and as such, may be useful when designing facilities to handle group 5 waste slurries. Using the Bingham parameters as a guide, the slurry rheology as a function of waste processing in the CUF may be described as follows:

1. Source material - this is concentrated (18.5-wt\%) slurry derived from homogenization of wastes from processing group 5 . It shows significant non-Newtonian rheology: as temperature is increased from $25^{\circ}$ to $60^{\circ} \mathrm{C}$, the yield stress increases from 57 to $74 \mathrm{~Pa}$ and the consistency increases from 13 to $17 \mathrm{cP}$.

2. Low-solids CUF slurry - the low-solids (4.3-wt\%) slurry is a diluted form of the source material for group 5 wastes. It shows a relatively weak non-Newtonian rheology: as temperature is increased from $25^{\circ}$ to $60^{\circ} \mathrm{C}$, the yield stress increases from 2.2 to $2.7 \mathrm{~Pa}$ and the consistency decreases from 4.6 to $4.1 \mathrm{cP}$.

3. High-solids CUF slurry - the high-solids (15.5-wt\%) slurry is the result of dewatering operations on the pre-caustic leach slurry in the CUF. It shows significant non-Newtonian rheology: as temperature is increased from $25^{\circ}$ to $60^{\circ} \mathrm{C}$, the yield stress increases from 74 to $94 \mathrm{~Pa}$ and the consistency increases slightly from 14 to $16 \mathrm{cP}$. It should be noted that despite its lower solids concentrations, the high-solids CUF slurry has a stronger rheology than the source material. This is believed to be a result of 1) chemical alterations caused by dilution and concentration in the CUF or 2) differences in source material and CUF slurry sampling.

4. Very high-solids CUF slurry - the very high-solids (15.5-wt\%) slurry is the result of dewatering operations on the pre-caustic leach slurry in the CUF. It shows significant non-Newtonian rheology: as temperature is increased from $25^{\circ}$ to $60^{\circ} \mathrm{C}$, the yield stress increases from 92 to 130 $\mathrm{Pa}$ and the consistency increases from 12 to $34 \mathrm{cP}$.

5. Leached and dewatered slurry - this 14.3 -wt\% slurry results after caustically leaching the initial group 5 waste slurry in the CUF for 24 hours at $100^{\circ} \mathrm{C}$. Relative to the previous samples, it shows moderate non-Newtonian rheology: as temperature is increased from $25^{\circ}$ to $60^{\circ} \mathrm{C}$, the yield stress increases from 5.7 to $8.7 \mathrm{~Pa}$ and the consistency decreases from 22 to $12 \mathrm{cP}$.

6. Leached, dewatered, and washed slurry - this 4.1-wt\% slurry results from washing of the leached and dewatered slurry. Relative to the previous samples, it shows weak non-Newtonian rheology: as temperature is increased from $25^{\circ}$ to $60^{\circ} \mathrm{C}$, the yield stress decreases from 3.3 to $2.8 \mathrm{~Pa}$ and the consistency decreases from 4.7 to $3.9 \mathrm{cP}$.

All permeate samples shows Newtonian behavior. Pre- and post-leach samples were collected from CUF dewater operations. Pre-leach samples showed viscosities between 1.5 and $1.7 \mathrm{cP}$ with an associated sampling error around 0.3 Pa. As the pre-leach viscosities were near the limit of detection of the instrument used, no significant temperature trends were detected (although permeate viscosity is expected to decrease with increasing temperature). Post-leach permeate shows a significant $11 \mathrm{cP}$ viscosity at $25^{\circ} \mathrm{C}$. As temperature is increased to $60^{\circ} \mathrm{C}$, the viscosity decreases to $4.7 \mathrm{cP}$. 


\section{Records}

Data records relating to rheological characterization of Group 5 CUF testing and initial characterization samples include original RheoWin data files, Test Data Packages (TDP), and LRBs:

- $\quad$ LRB BNW 59633 - Pages 24, 26-27, and 30-36

- CCP-WTPSP-376 - performance check results for August measurements

- CCP-WTPSP-377 - flow curve measurement data, results, and graphs for sample G5-RH-2

- CCP-WTPSP-399 - flow curve measurement data, results, and graphs for sample TI540-G5-R1

- CCP-WTPSP-404 - flow curve measurement data, results, and graphs for sample TI540-G5-R2A

- CCP-WTPSP-403 - flow curve measurement data, results, and graphs for sample TI540-G5-R2BN*

- CCP-WTPSP-400 - flow curve measurement data, results, and graphs for sample TI540-G5-R3

- CCP-WTPSP-401 - flow curve measurement data, results, and graphs for sample TI540-G5-R4

- CCP-WTPSP-402 - flow curve measurement data, results, and graphs for sample TI540-G5-Dewater4

- $\quad$ CCP-WTPSP-399 - flow curve measurement data, results, and graphs for sample TI540-G5-Leach2

- CCP-WTPSP-398 - flow curve comparisons and fitting parameter variation with slurry concentration and temperature 
Table 20 provides a complete list of the relevant RheoWin file.

Table 20 List of RheoWin files associated with Group 5 CUF Testing Rheology.

\begin{tabular}{|c|c|c|}
\hline File Name & $\begin{array}{c}\text { Type of } \\
\text { Measurement }\end{array}$ & Description \\
\hline 070807_201_a & Performance Check & Brookfield Fluid 10 at 25 deg C (9.6 cP) - 9.104 cP \\
\hline 070807_201_b & Performance Check & Brookfield Fluid 50 at 25 deg C (48.0 cP) - 45.85 cP \\
\hline 070808_201_b & Performance Check & Brookfield Fluid 100 at $25 \operatorname{deg}$ C $(96.0 \mathrm{cP})-88.49$ cP \\
\hline 070815_201_a & Flow Curve & $\begin{array}{l}\text { G5-RH-2 at } 25 \text { deg C, Group } 5 \text { Initial Characterization } \\
\text { Slurry }\end{array}$ \\
\hline 070815_201_b & Flow Curve & $\begin{array}{l}\text { G5-RH-2 at } 40 \text { deg C, Group } 5 \text { Initial Characterization } \\
\text { Slurry }\end{array}$ \\
\hline 070815_201_c & Flow Curve & $\begin{array}{l}\text { G5-RH-2 at } 60 \text { deg C, Group } 5 \text { Initial Characterization } \\
\text { Slurry }\end{array}$ \\
\hline 070820_201_a & Flow Curve & TI540-G5-R1 at 25 deg C, Group 5 CUF Slurry \\
\hline 070820_201_b & Flow Curve & TI540-G5-R1 at 40 deg C, Group 5 CUF Slurry \\
\hline 070820_201_c & Flow Curve & TI540-G5-R1 at 60 deg C, Group 5 CUF Slurry \\
\hline 070821_201_a & Flow Curve & TI540-G5-Dewater4 at 25 deg C, Group 5 CUF Slurry \\
\hline 070821_201_b & Constant Rotation & TI540-G5-Dewater4 at 25 deg C, Group 5 CUF Slurry \\
\hline 070821_201_c & Flow Curve & TI540-G5-Dewater4 at 40 deg C, Group 5 CUF Slurry \\
\hline 070821_201_d & Constant Rotation & TI540-G5-Dewater4 at 40 deg C, Group 5 CUF Slurry \\
\hline 070821_201_e & Flow Curve & TI540-G5-Dewater4 at 60 deg C, Group 5 CUF Slurry \\
\hline 070821_201_f & Constant Rotation & TI540-G5-Dewater4 at 60 deg C, Group 5 CUF Slurry \\
\hline 070821_201_g & Flow Curve & TI540-G5-R2A at 25 deg C, Group 5 CUF Slurry \\
\hline 070821_201_h & Flow Curve & TI540-G5-R2A at 40 deg C, Group 5 CUF Slurry \\
\hline 070821_201_i & Flow Curve & TI540-G5-R2A at 60 deg C, Group 5 CUF Slurry \\
\hline 070822_201_b & Flow Curve & TI540-G5-R2BN* at 25 deg C, Group 5 CUF Slurry \\
\hline 070822_201_c & Flow Curve & TI540-G5-R2BN* at 40 deg C, Group 5 CUF Slurry \\
\hline 070822_201_d & Flow Curve & TI540-G5-R2BN* at 60 deg C, Group 5 CUF Slurry \\
\hline 070824_201_a & Flow Curve & TI540-G5-R3 at 25 deg C, Group 5 Slurry \\
\hline 070824_201_b & Flow Curve & TI540-G5-R3 at 40 deg C, Group 5 Slurry \\
\hline 070824_201_c & Flow Curve & TI540-G5-R3 at 60 deg C, Group 5 Slurry \\
\hline 070825_201_a & Flow Curve & TI540-G5-R4 at 25 deg C, Group 5 Slurry \\
\hline 070825_201_b & Flow Curve & TI540-G5-R4 at 40 deg C, Group 5 Slurry \\
\hline 070825_201_c & Flow Curve & TI540-G5-R4 at 60 deg C, Group 5 Slurry \\
\hline 070828_201_a & Flow Curve & TI540-G5-Leach2 at 25 deg C, Group 5 Slurry \\
\hline 070828_201_c & Flow Curve & TI540-G5-Leach2 at 40 deg C, Group 5 Slurry \\
\hline 070828_201_d & Flow Curve & TI540-G5-Leach2 at 60 deg C, Group 5 Slurry \\
\hline
\end{tabular}




\section{References}

1. Doc. No. TP-RPP-WTP-467, Revision 0, "Characterization and Small Scale Testing of Hanford Wastes to Support the Development and Demonstration of Leaching and Ultrafiltration Pretreatment Processes,” SK Fiskum, Battelle - Pacific Northwest Division, February 2007.

2. Steffe JF, Rheological Methods in Food Process Engineering, Freeman Press, East Lansing (1992).

3. Doc. No. RPL-COLLOID-02, Revision 1, "Measurement of Physical and Rheological Properties of Solutions, Slurries and Sludges,” RC Daniel, Pacific Northwest National Laboratory, May 2007.

4. Doc. No. TDP-WTP-056, “Rheology of Waste Processing Group 5: Initial Characterization,” RC Daniel, Battelle - Pacific Northwest Division, November 2007. 


\section{Appendix A - Rheograms}

This appendix contains detailed rheograms (shear stress and apparent viscosity as a function of shear) for Group 5 initial characterization and CUF testing samples. No discussion of these results is provided.

\section{Sample G5-RH-2: Source Group 5 Material for CUF Testing}

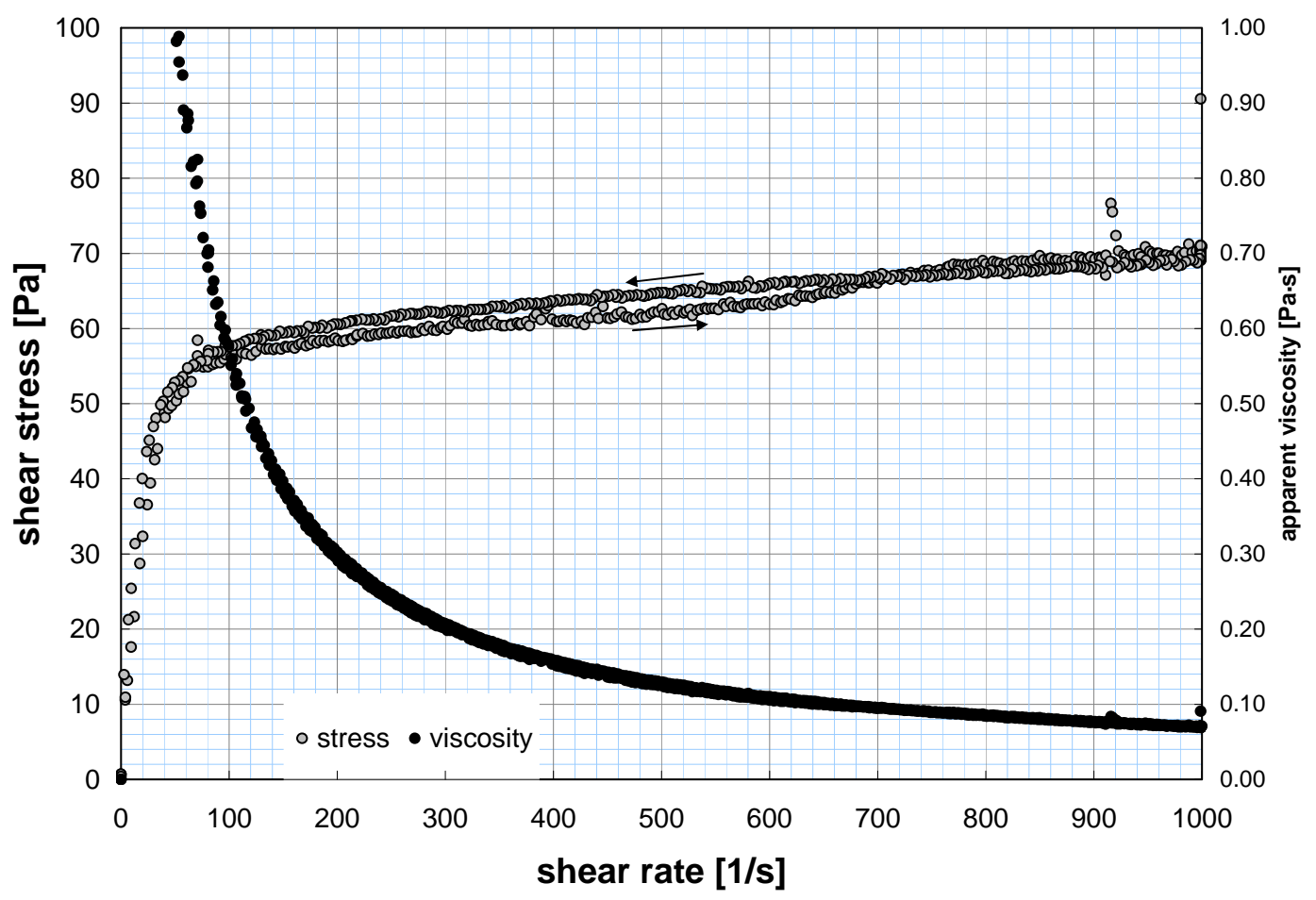

Figure A-1. Rheogram for G5-RH-2 at $25^{\circ} \mathrm{C}$. 


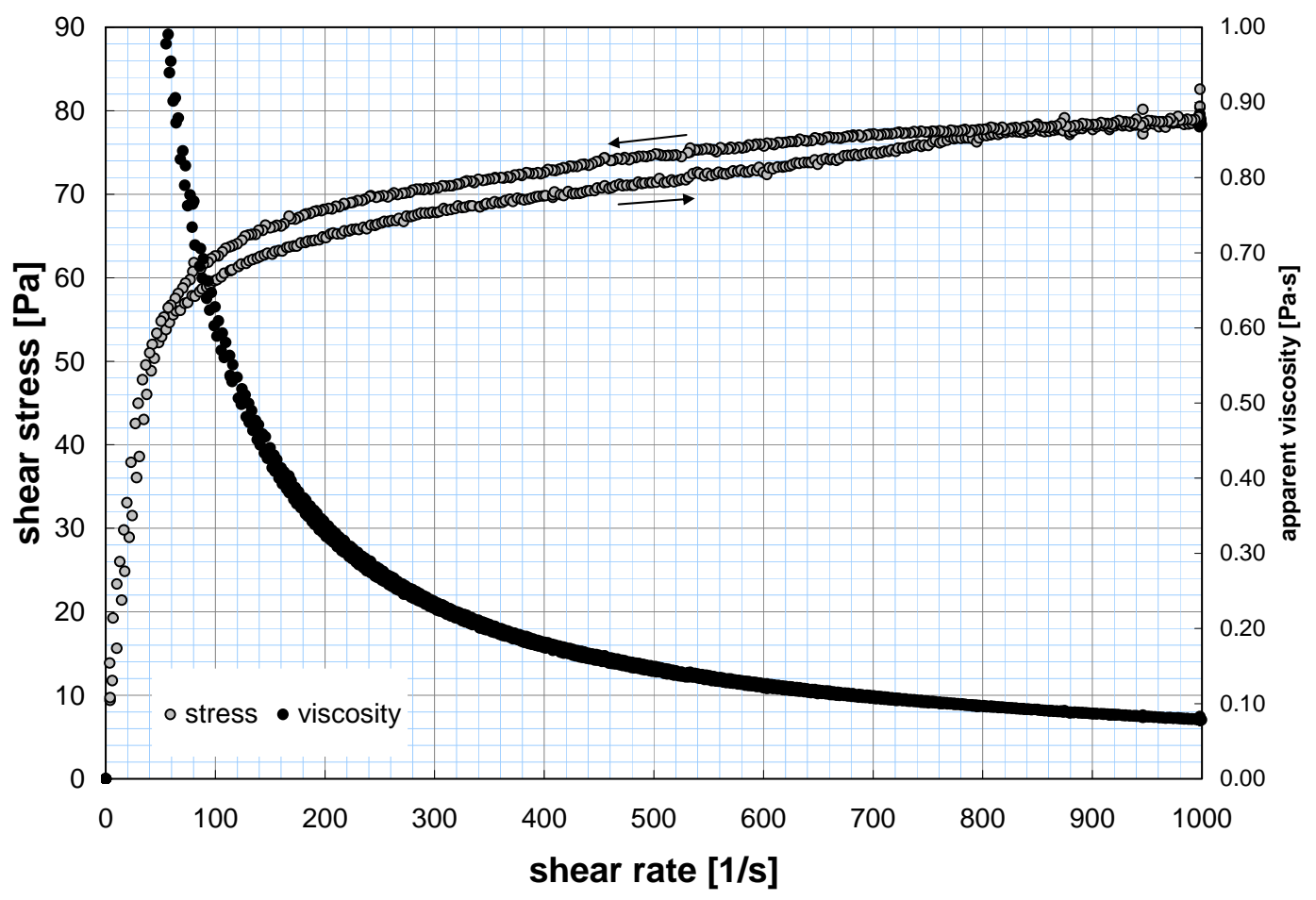

Figure A-2. Rheogram for G5-RH-2 at $40^{\circ} \mathrm{C}$.

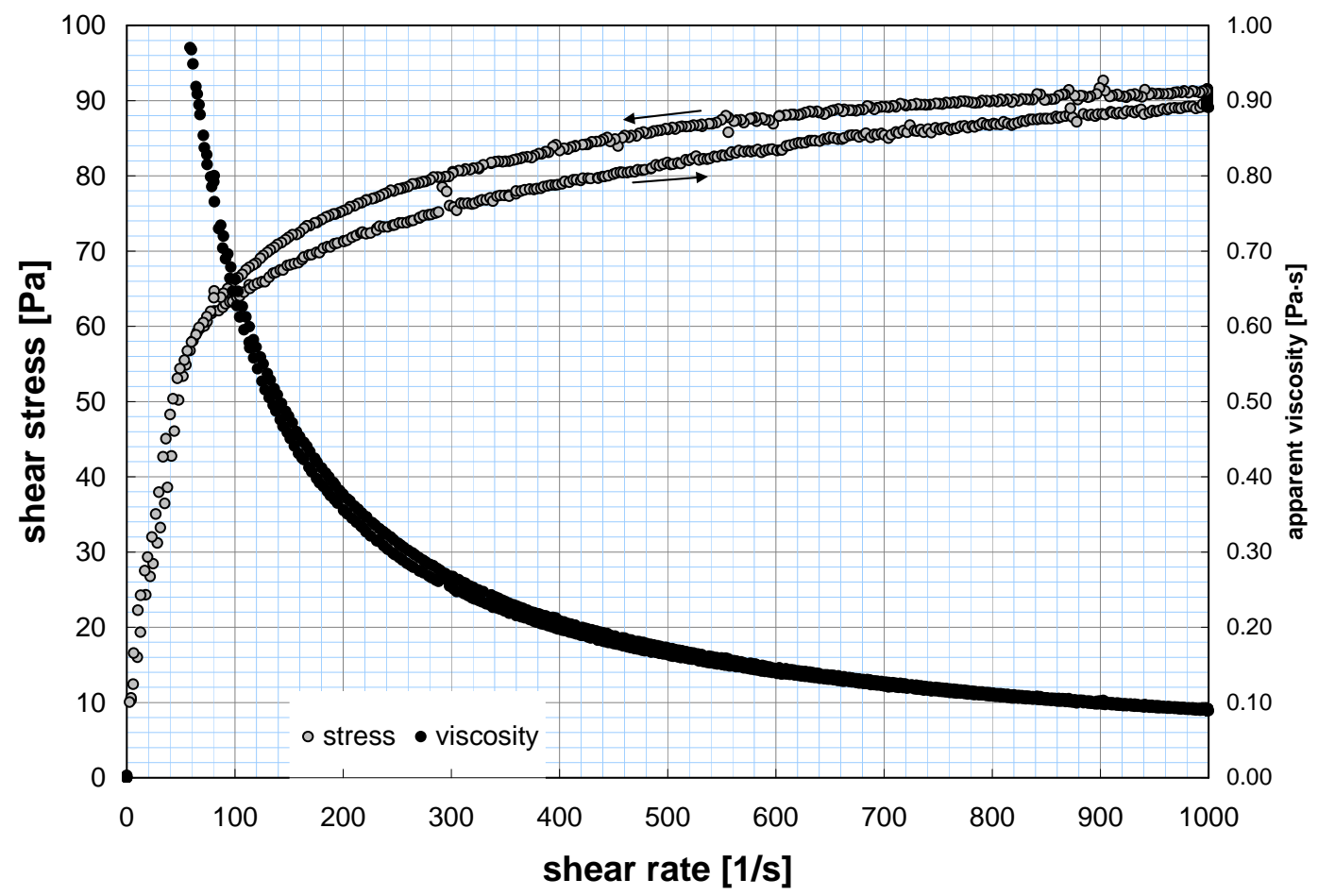

Figure A-3. Rheogram for G5-RH-2 at $60^{\circ} \mathrm{C}$. 
Sample TI540-G5-R1: Pre-Caustic-Leach Low Solids Matrix (4.3-wt\%)

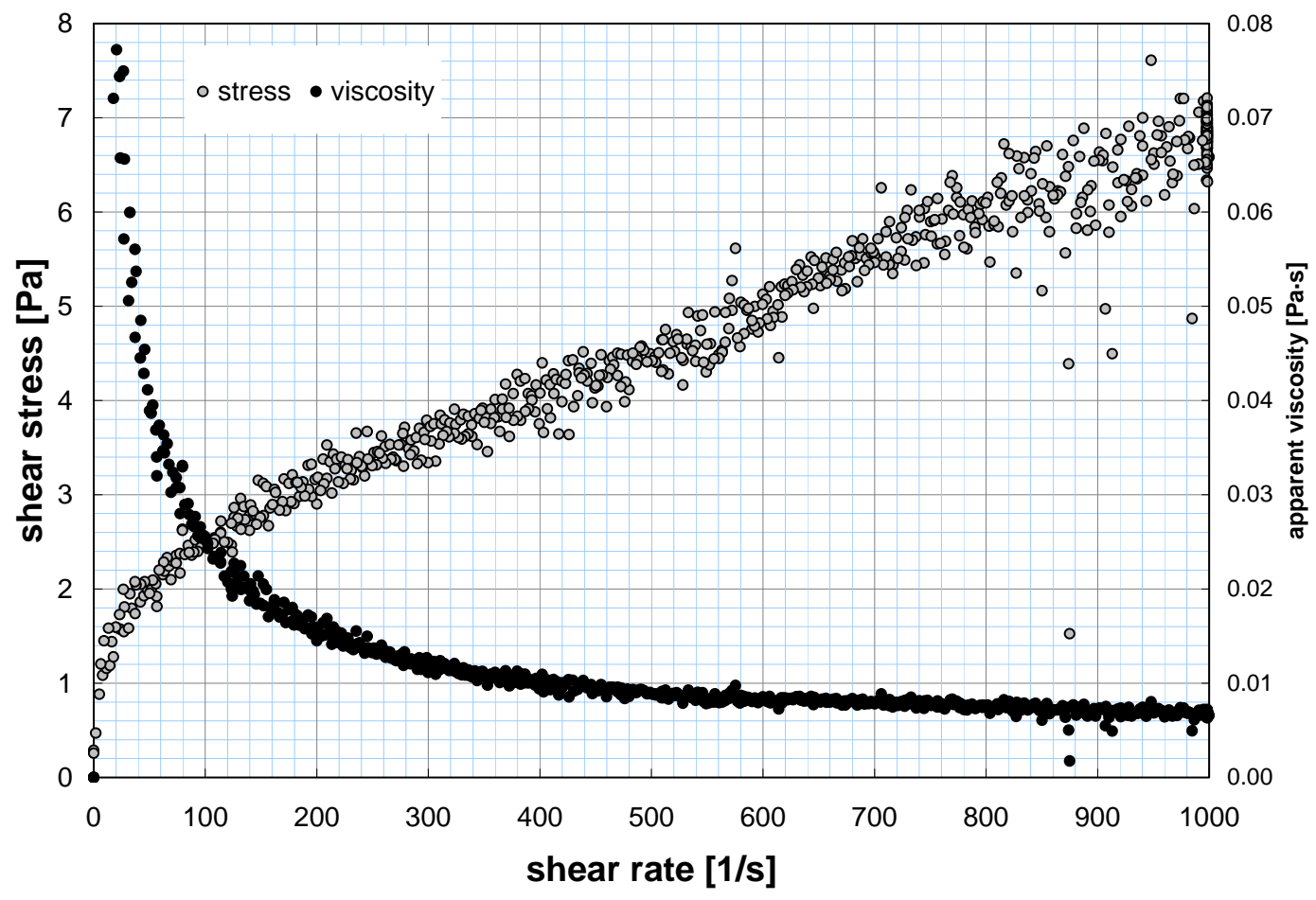

Figure A-4. Rheogram for TI540-G5-R1at $25^{\circ} \mathrm{C}$.

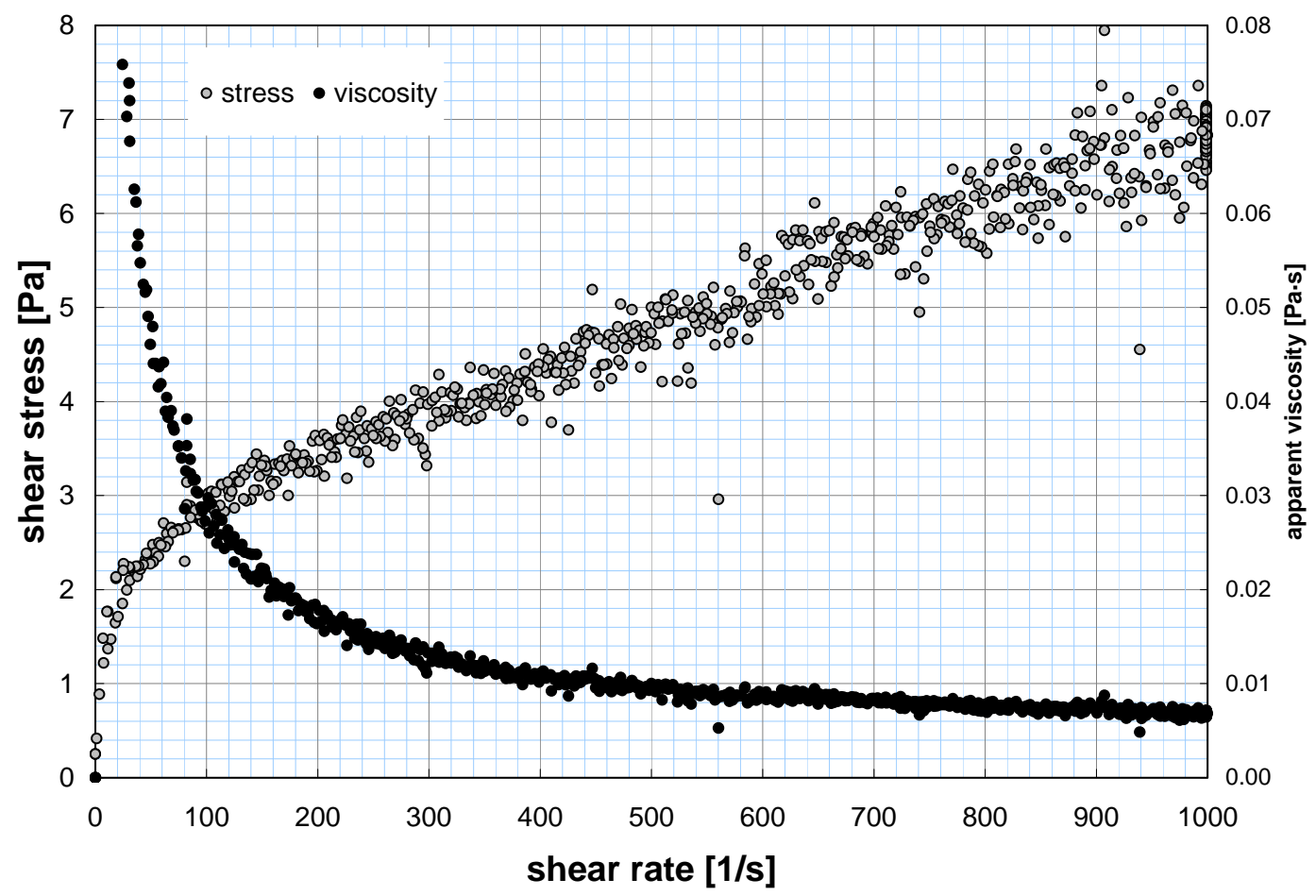

Figure A-5. Rheogram for TI540-G5-R1at $40^{\circ} \mathrm{C}$. 


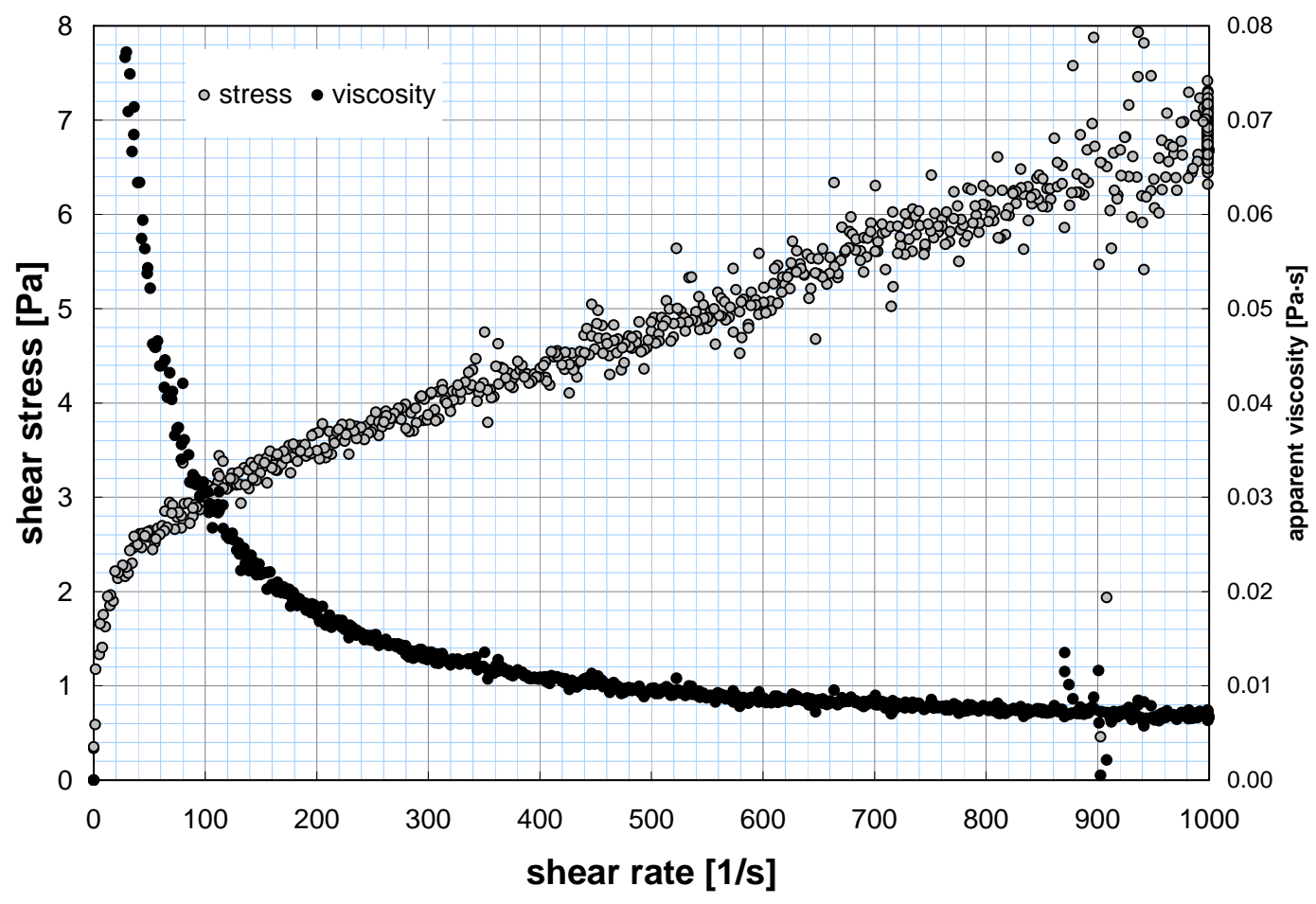

Figure A-6. Rheogram for TI540-G5-R1at $60^{\circ} \mathrm{C}$.

Sample TI-540-G5-R2BN*: Pre-Caustic-Leach High Solids Matrix (15.5-wt\%)

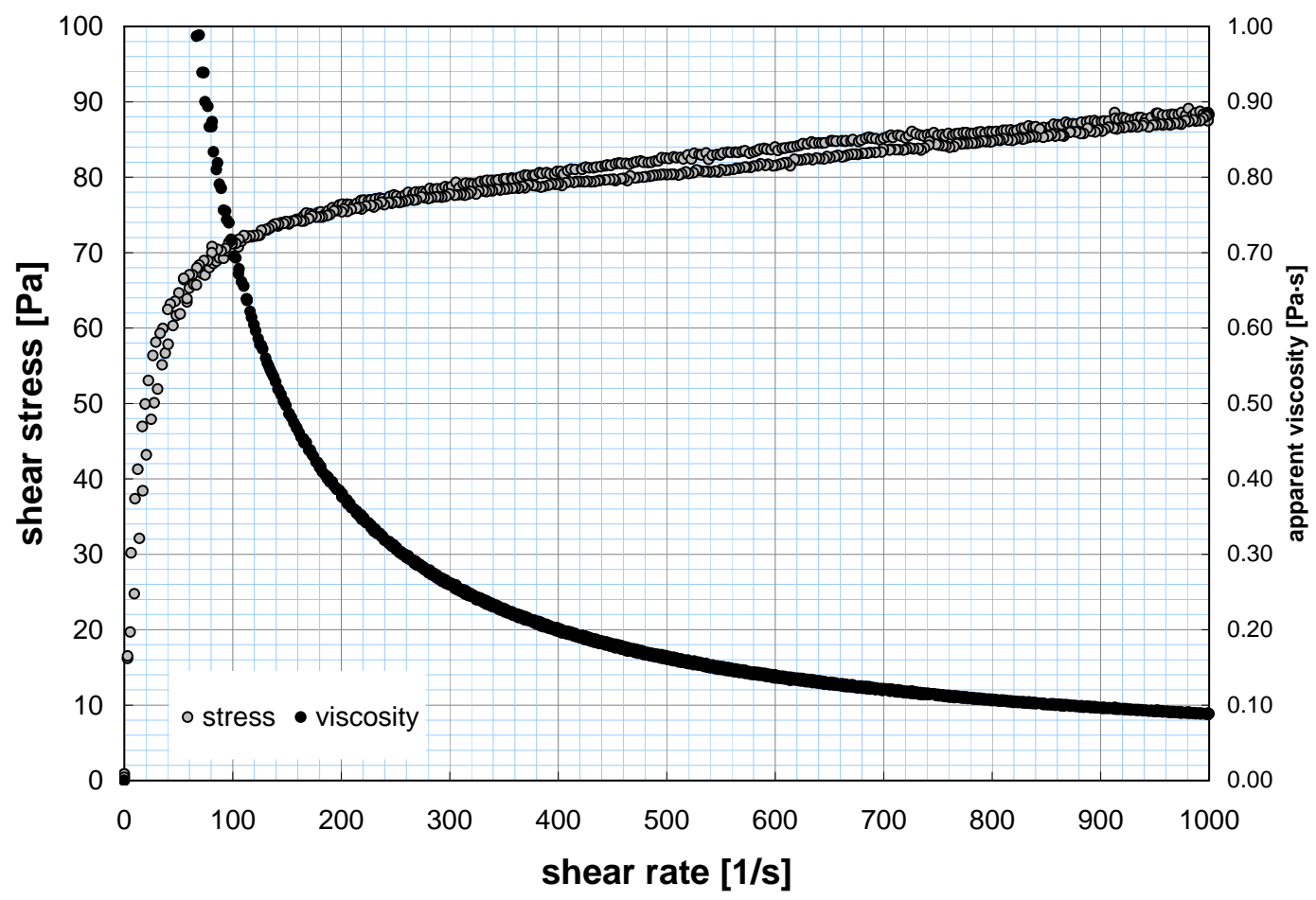

Figure A-7. Rheogram for TI540-G5-R2BN* at $25^{\circ} \mathrm{C}$. 


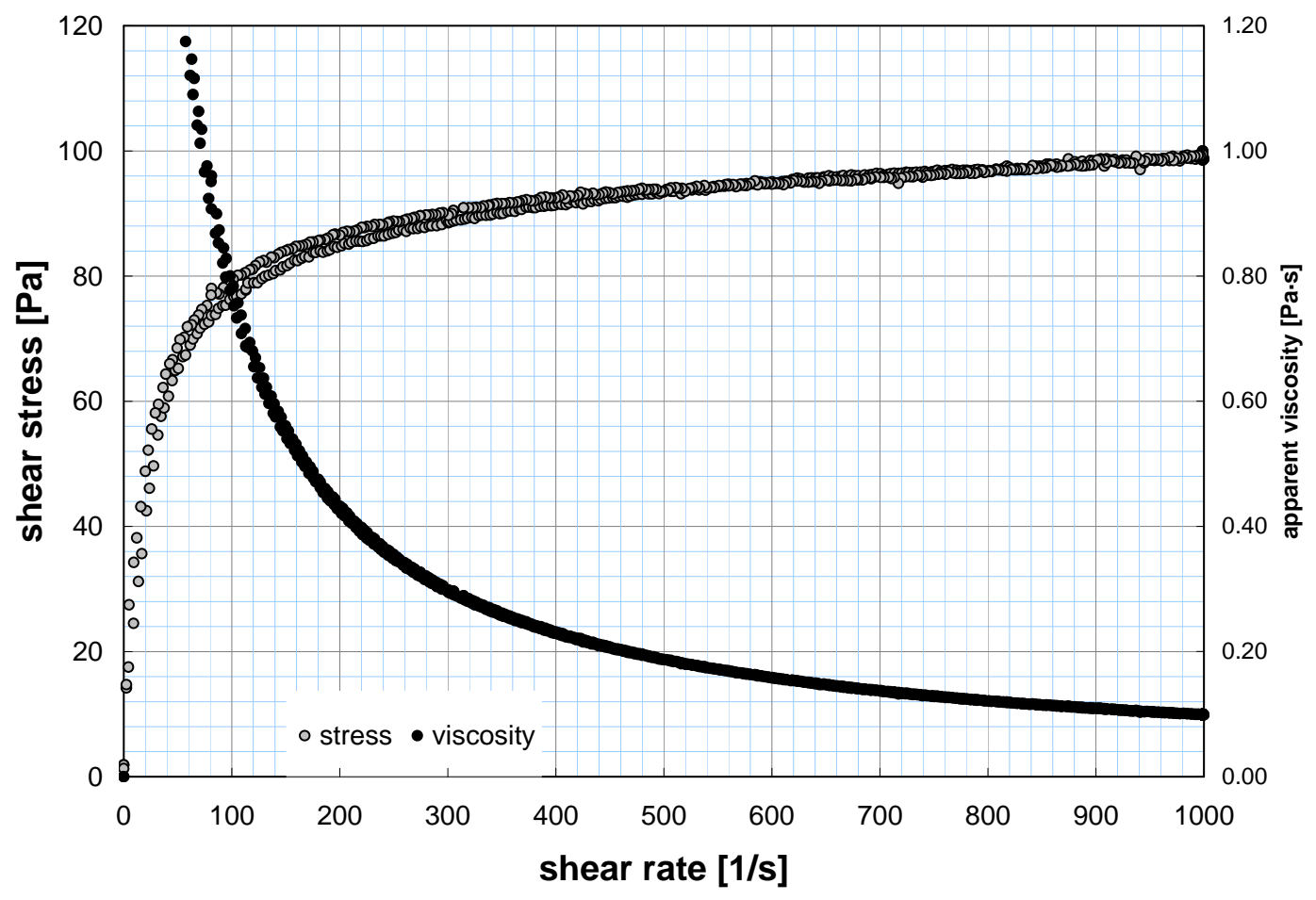

Figure A-8. Rheogram for TI540-G5-R2BN* at $40^{\circ} \mathrm{C}$.

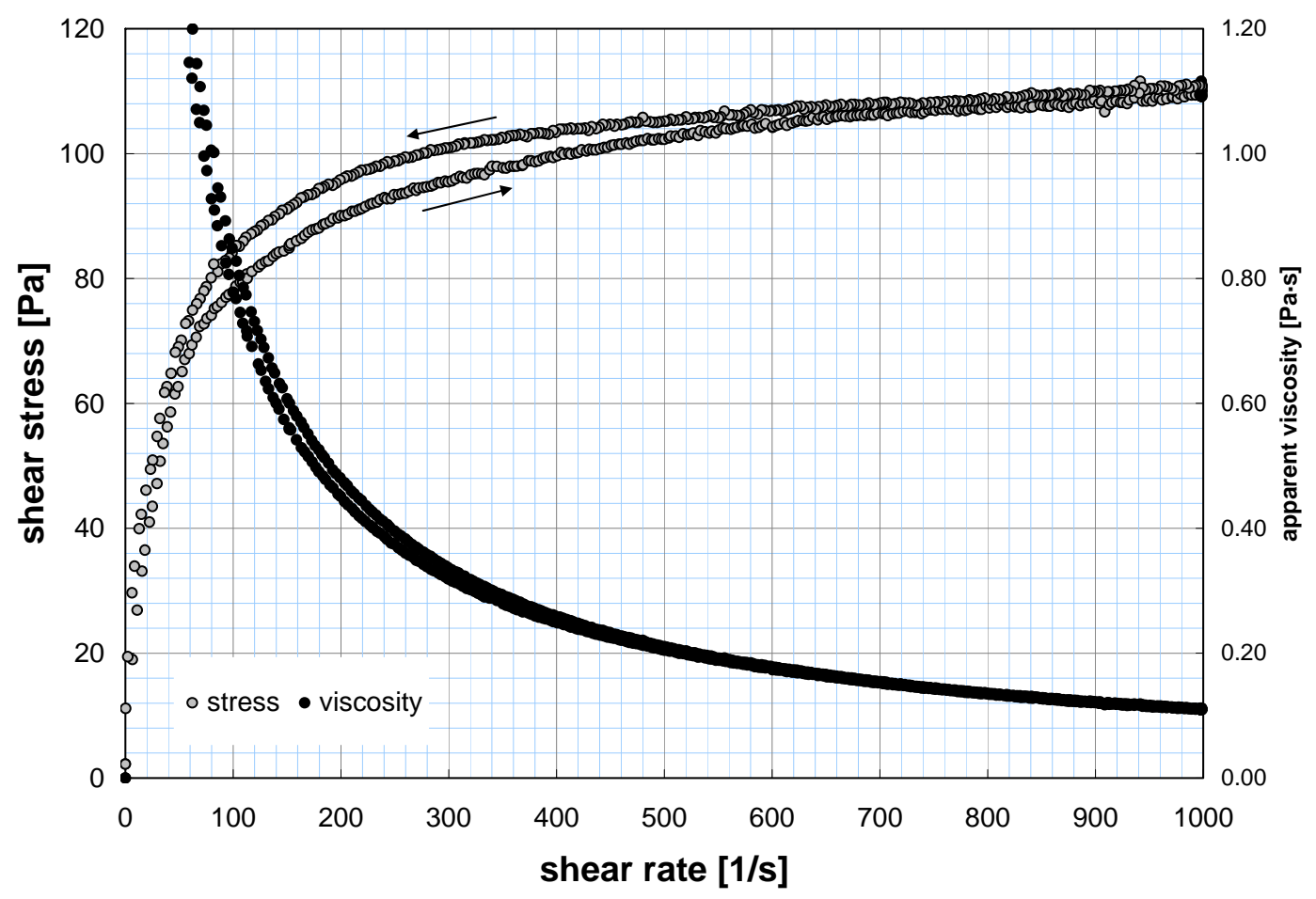

Figure A-9. Rheogram for TI540-G5-R2BN* at $60^{\circ} \mathrm{C}$. 
Sample TI-540-G5-R2A: Pre-Caustic-Leach Very High Solids Matrix (19-wt\%)

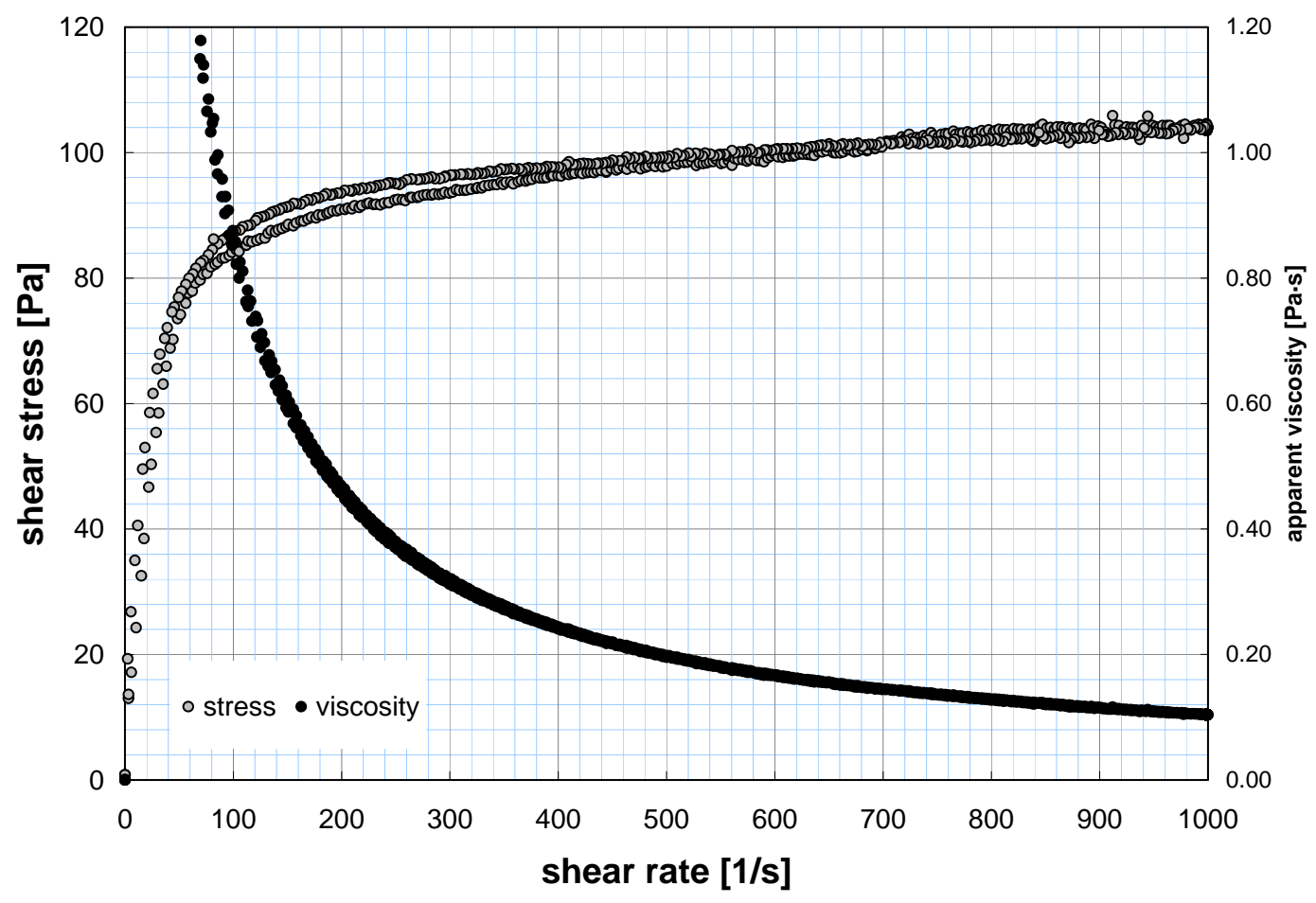

Figure A-10. Rheogram for TI540-G5-R2A at $25^{\circ} \mathrm{C}$.

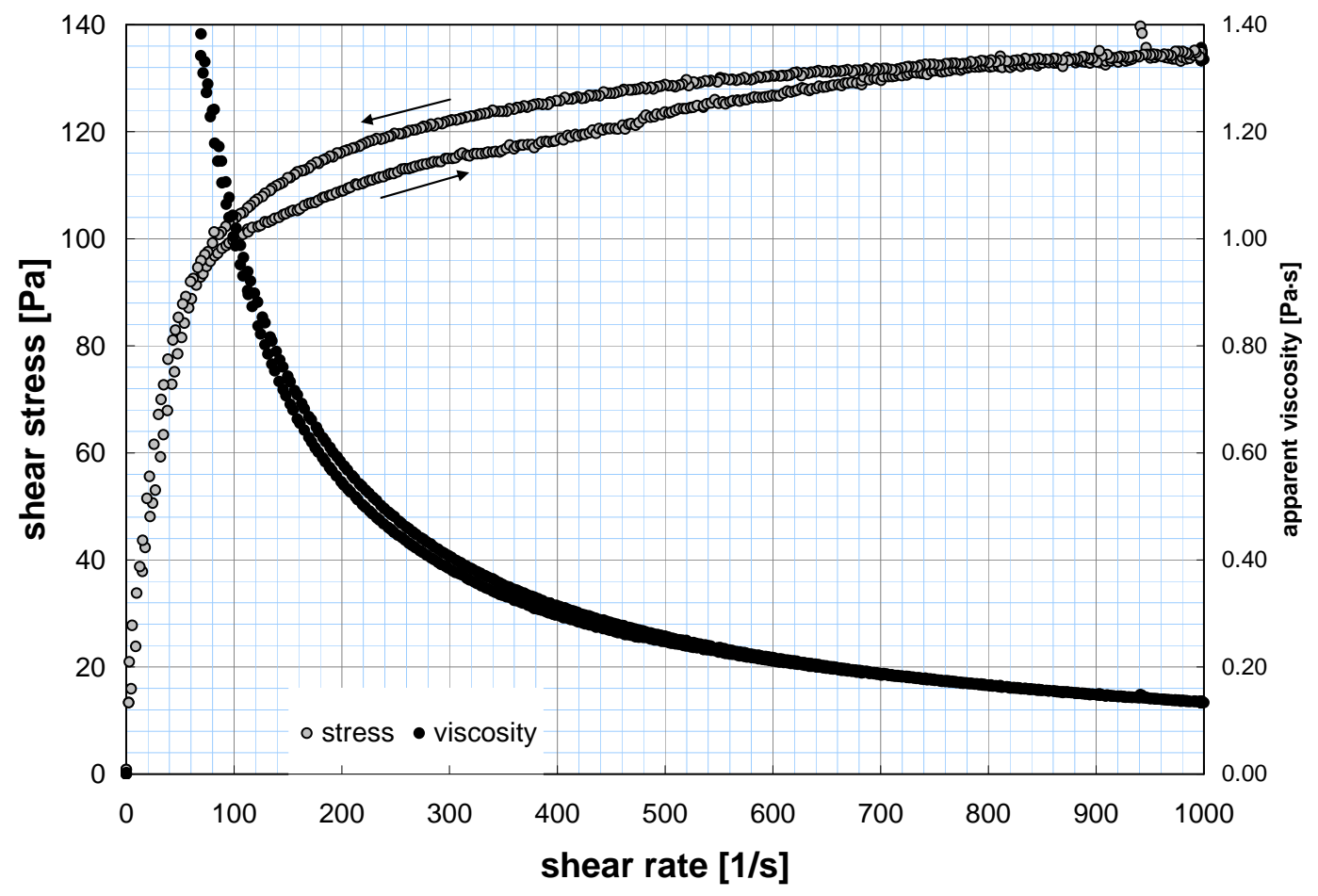

Figure A-11. Rheogram for TI540-G5-R2A at $40^{\circ} \mathrm{C}$. 


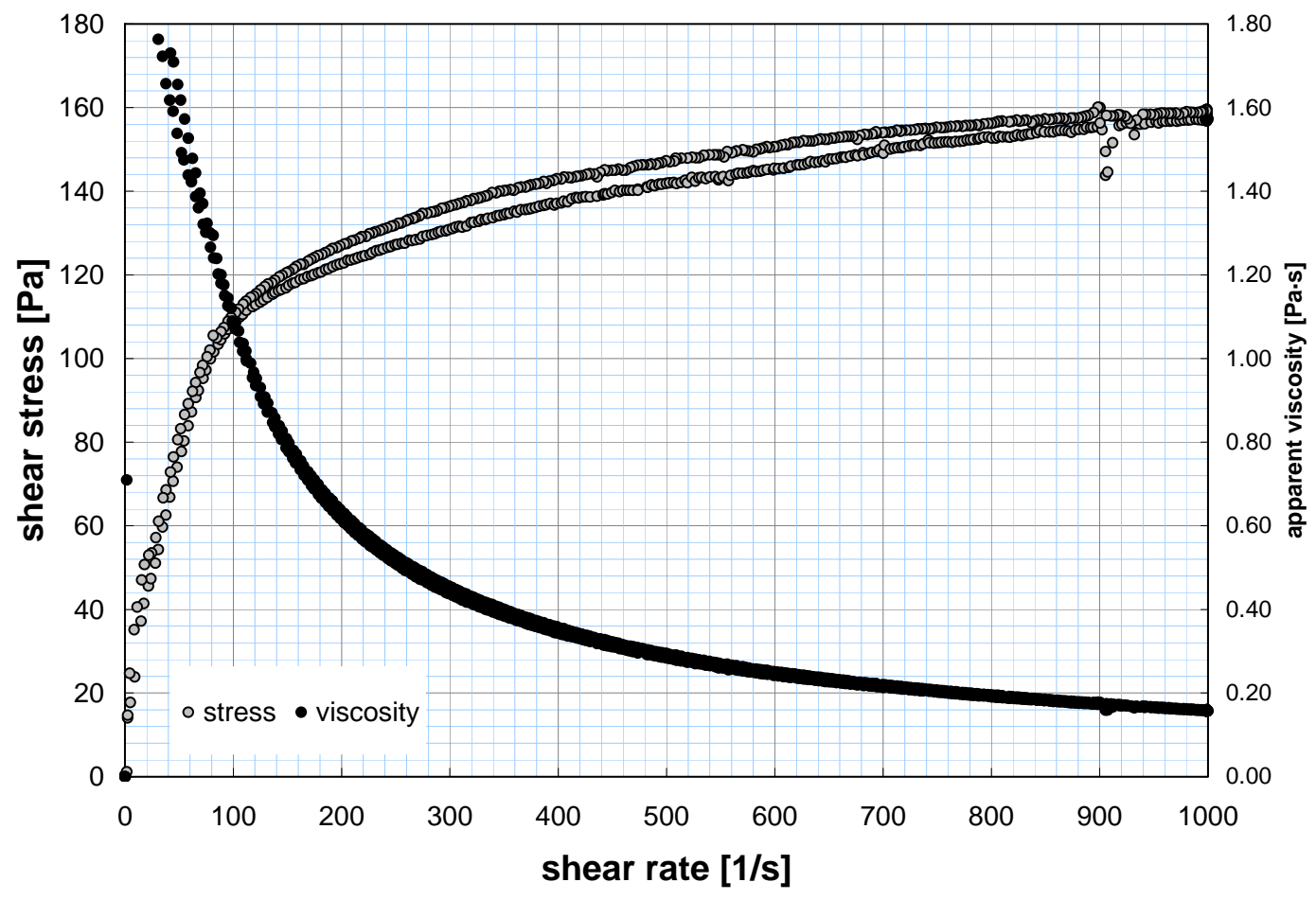

Figure A-12. Rheogram for TI540-G5-R2A at $60^{\circ} \mathrm{C}$.

Sample TI-540-G5-R3: Post-Leach Dewatered Slurry (13.5-wt\%)

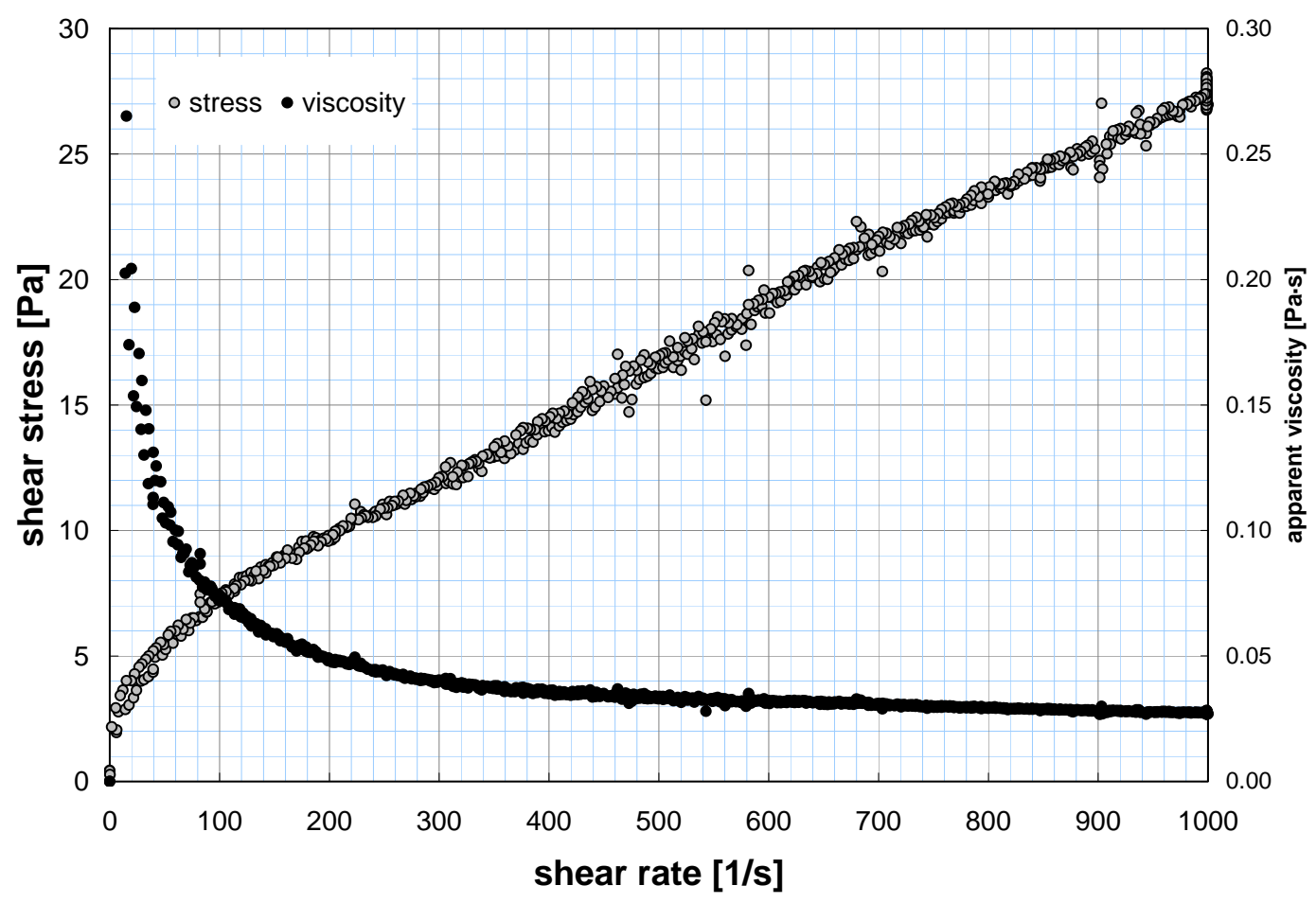

Figure A-13. Rheogram for TI540-G5-R3 at $25^{\circ} \mathrm{C}$. 


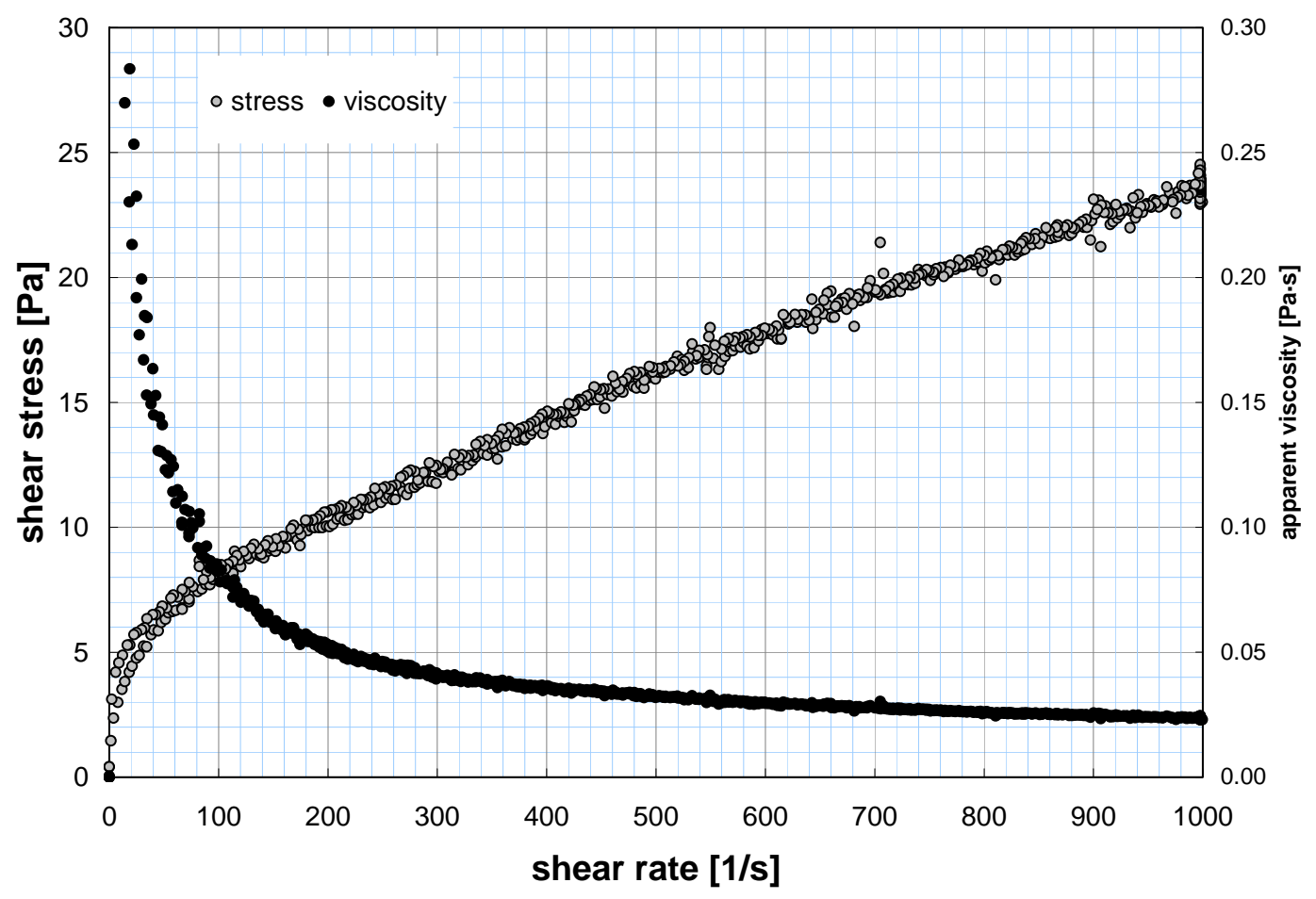

Figure A-14. Rheogram for TI540-G5-R3 at $40^{\circ} \mathrm{C}$.

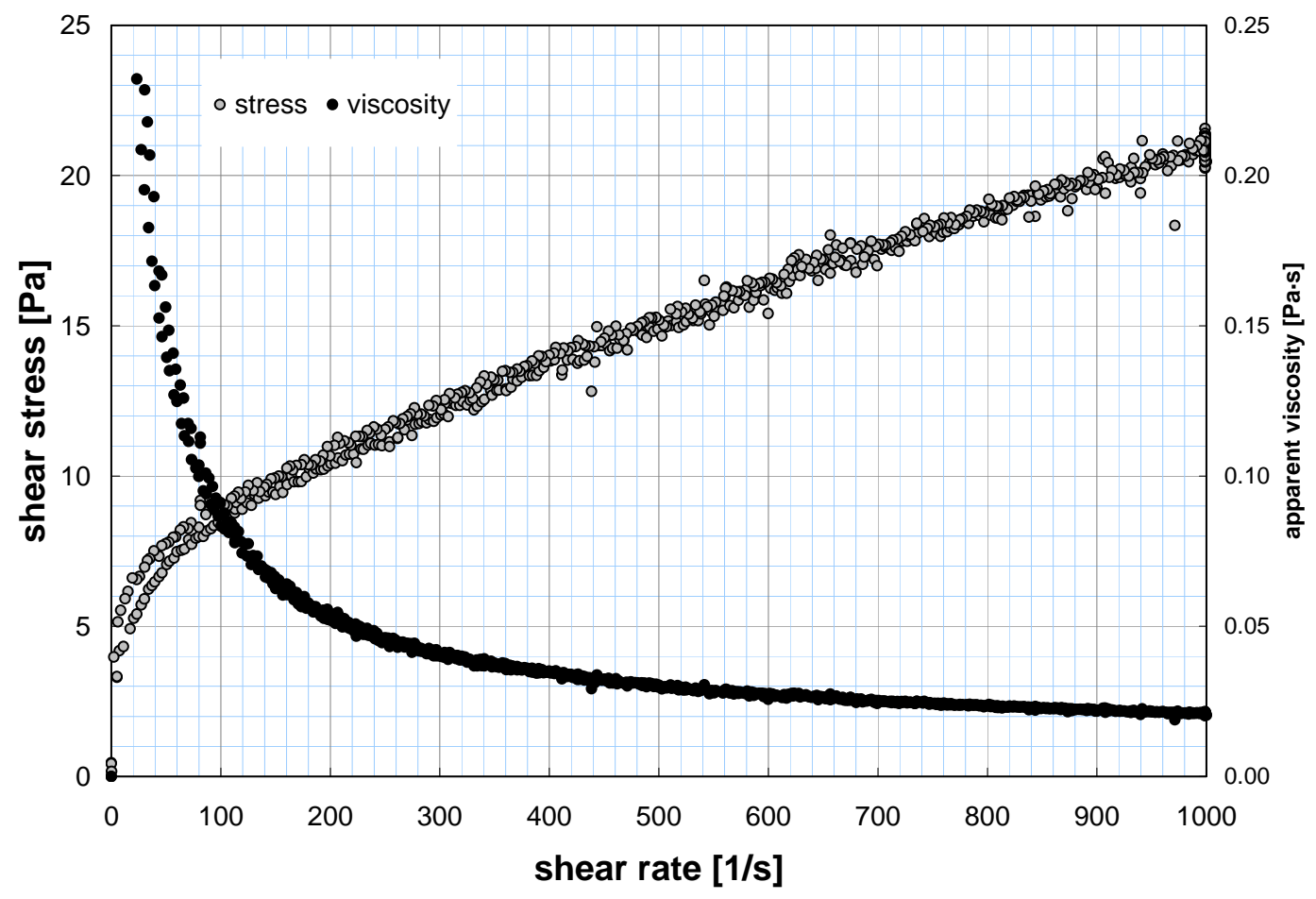

Figure A-15. Rheogram for TI540-G5-R3 at $60^{\circ} \mathrm{C}$. 
Sample TI-540-G5-R4: Post-Leach Dewatered and Washed Slurry (4.1-wt\%)

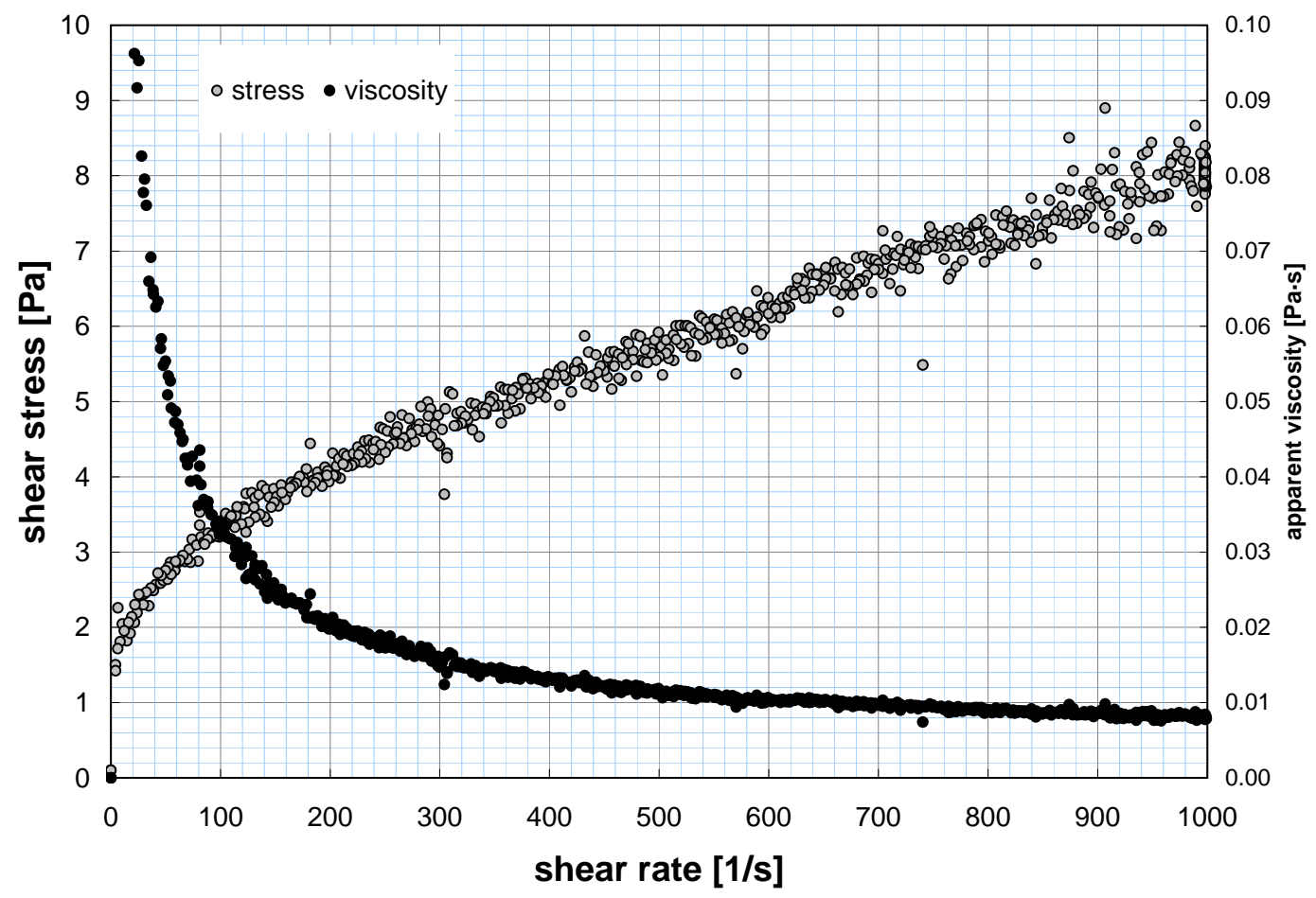

Figure A-16. Rheogram for TI540-G5-R4 at $25^{\circ} \mathrm{C}$.

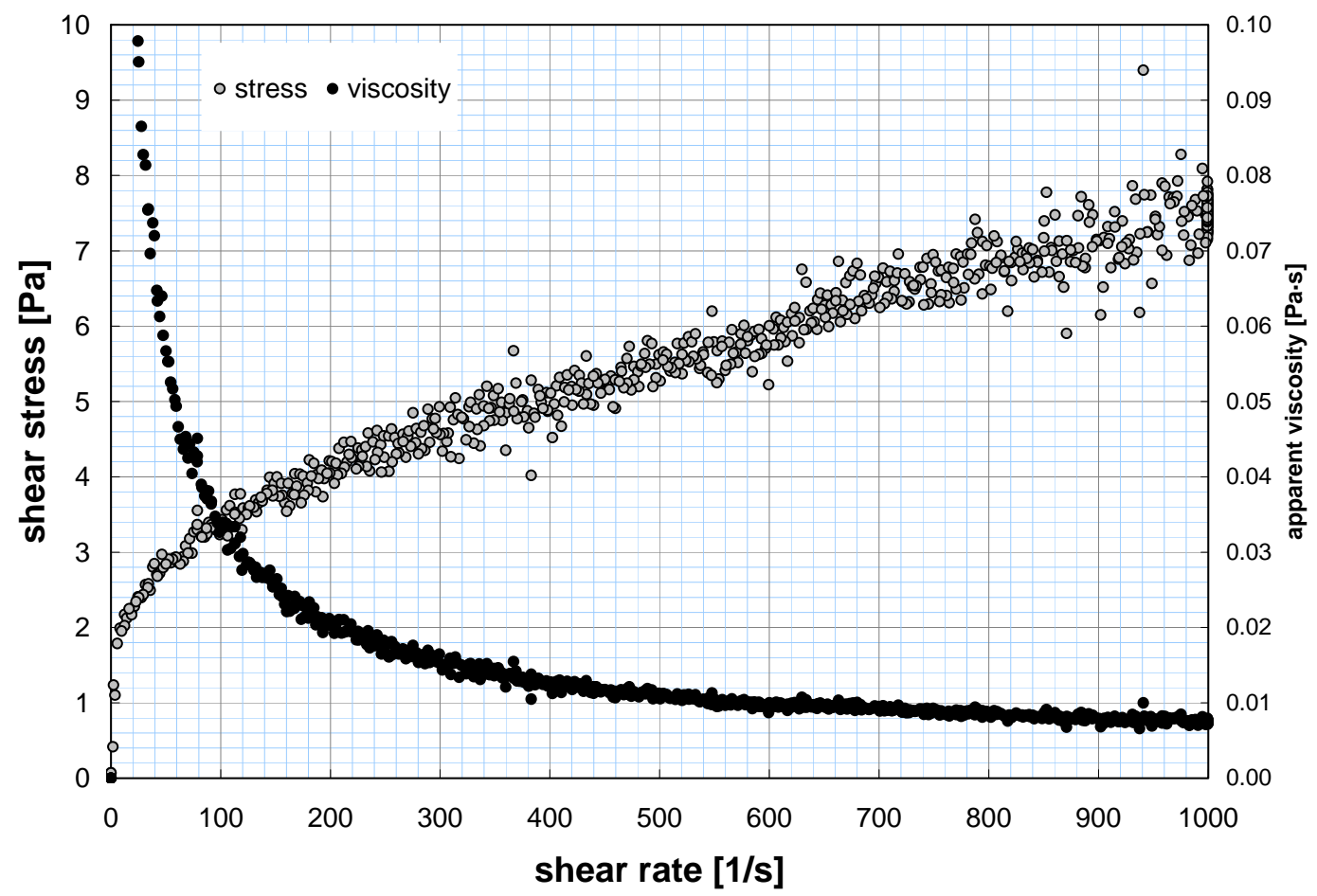

Figure A-17. Rheogram for TI540-G5-R4 at $40^{\circ} \mathrm{C}$. 


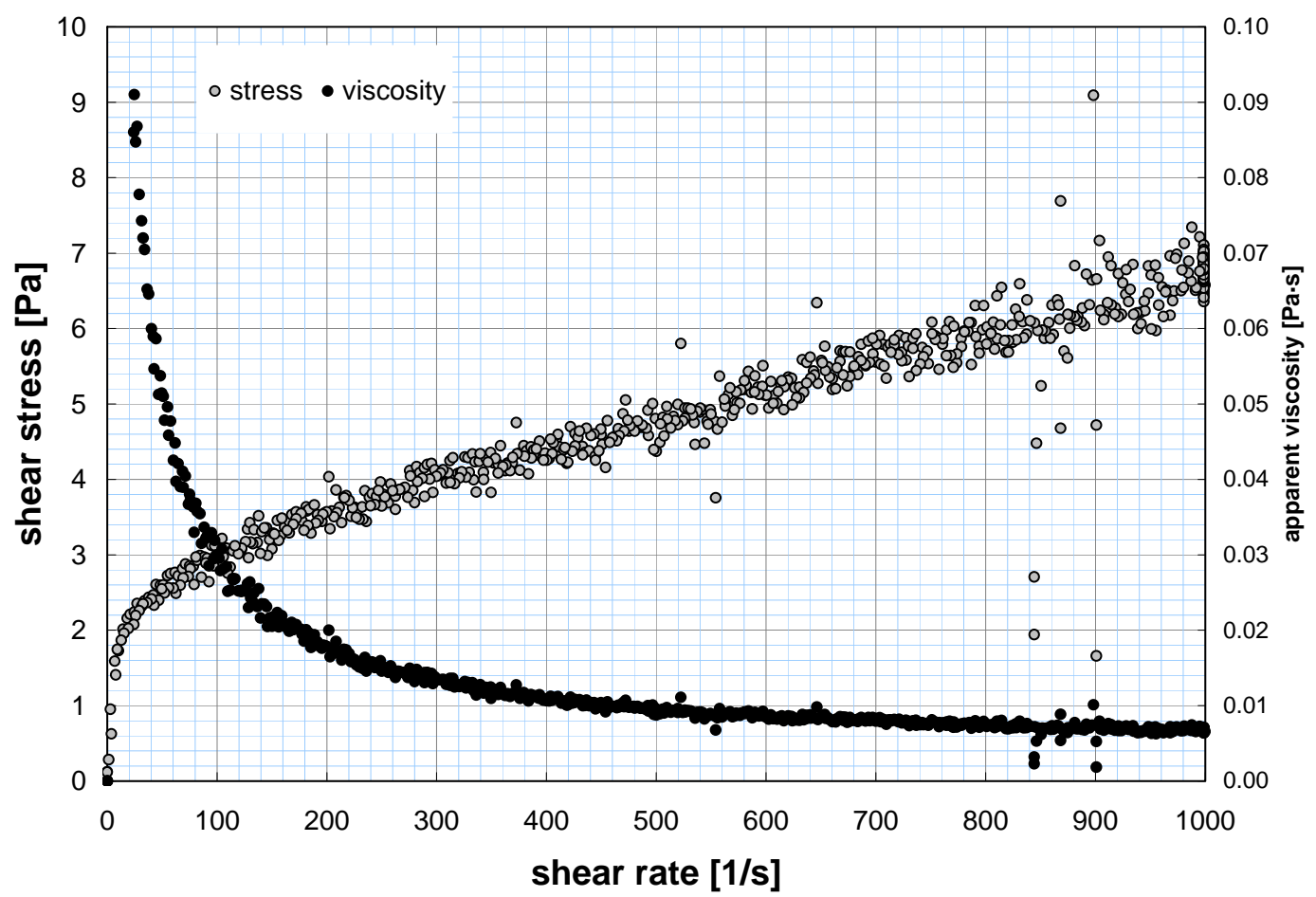

Figure A-18. Rheogram for TI540-G5-R4 at $60^{\circ} \mathrm{C}$.

\section{Sample TI-540-G5-Dewater4: Pre-Caustic-Leach Permeate}

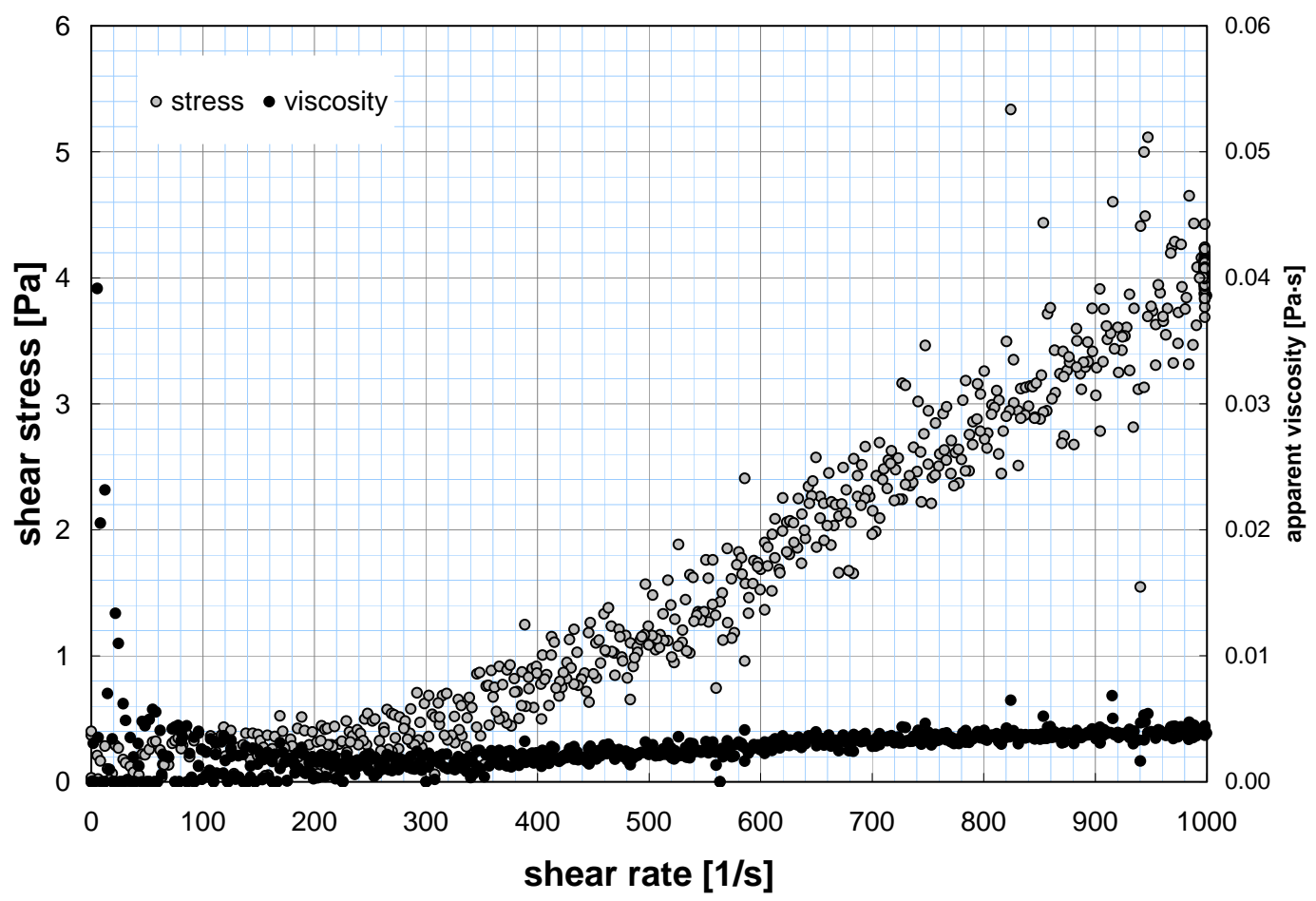

Figure A-19. Rheogram for TI540-G5-Dewater 4 at $25^{\circ} \mathrm{C}$. Measurements affected by Taylor vortices above $200 \mathrm{~s}^{-1}$. 


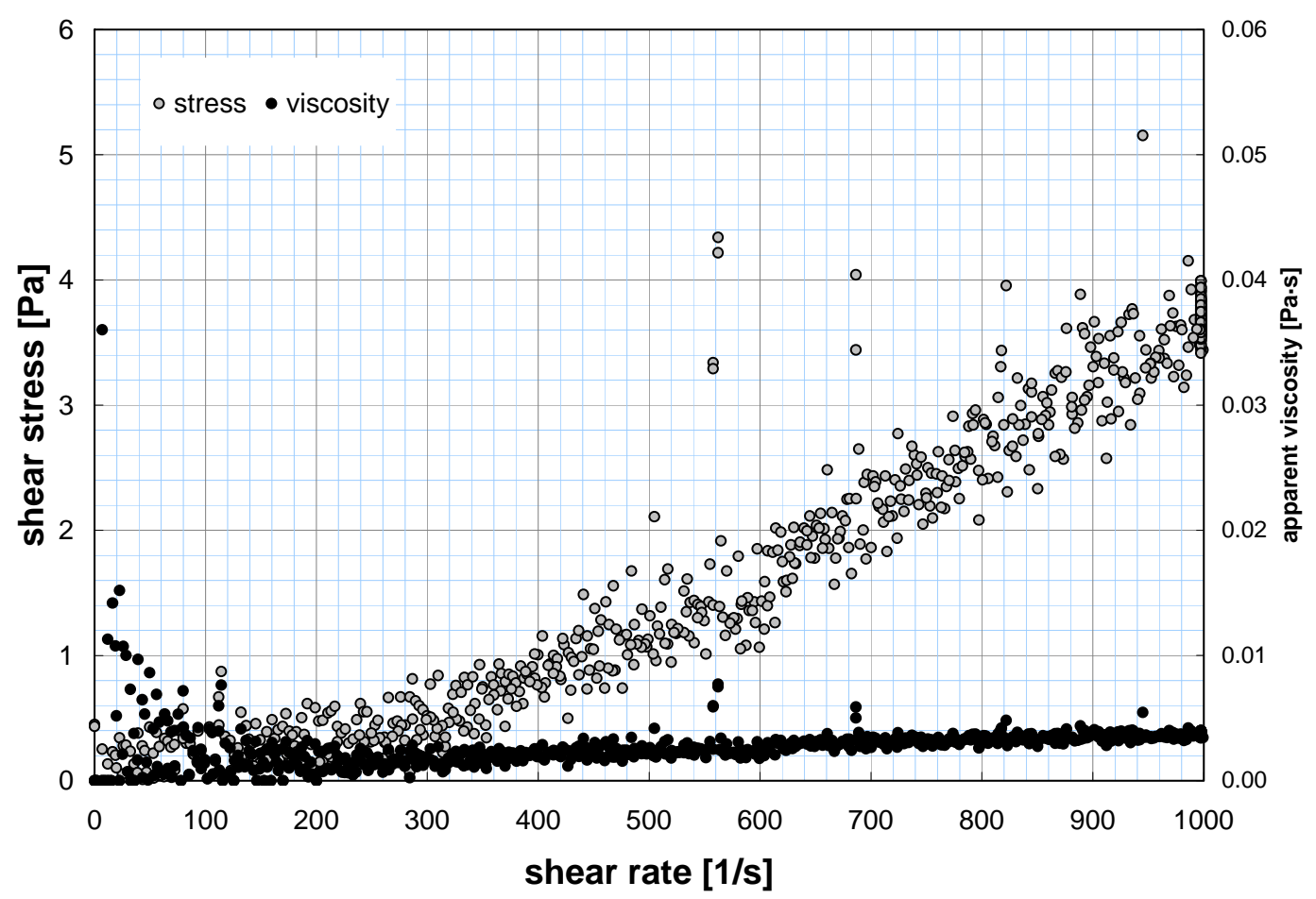

Figure A-20. Rheogram for TI540-G5-Dewater 4 at $40^{\circ} \mathrm{C}$. Measurements affected by Taylor vortices above $200 \mathrm{~s}^{-1}$.

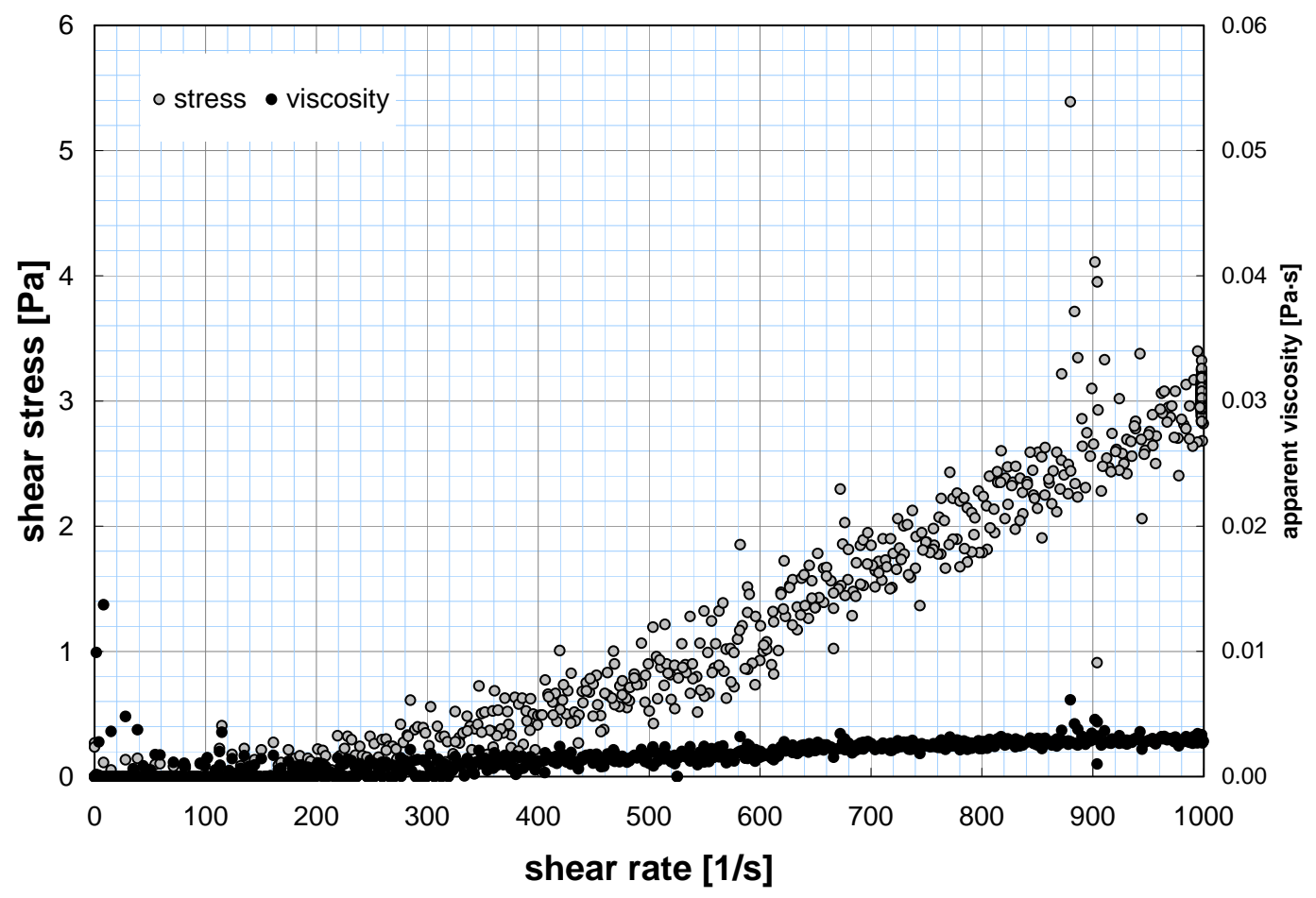

Figure A-21. Rheogram for TI540-G5-Dewater 4 at $60^{\circ} \mathrm{C}$. Measurements affected by Taylor vortices above $200 \mathrm{~s}^{-1}$. 
Sample TI-540-G5-Leach2: Post-Leach Pre-Wash Permeate

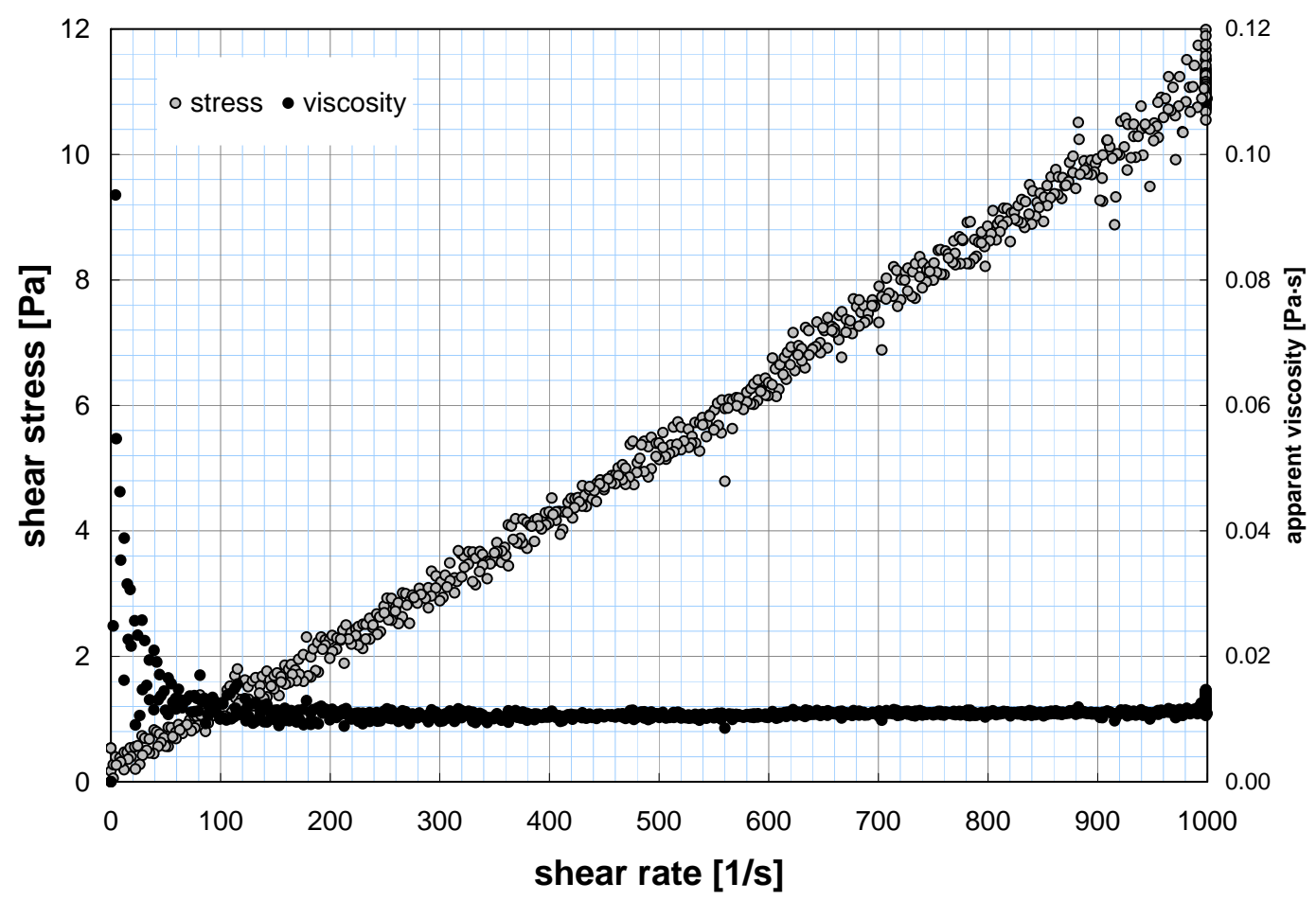

Figure A-22. Rheogram for TI540-G5-Leach2 at $25^{\circ} \mathrm{C}$.

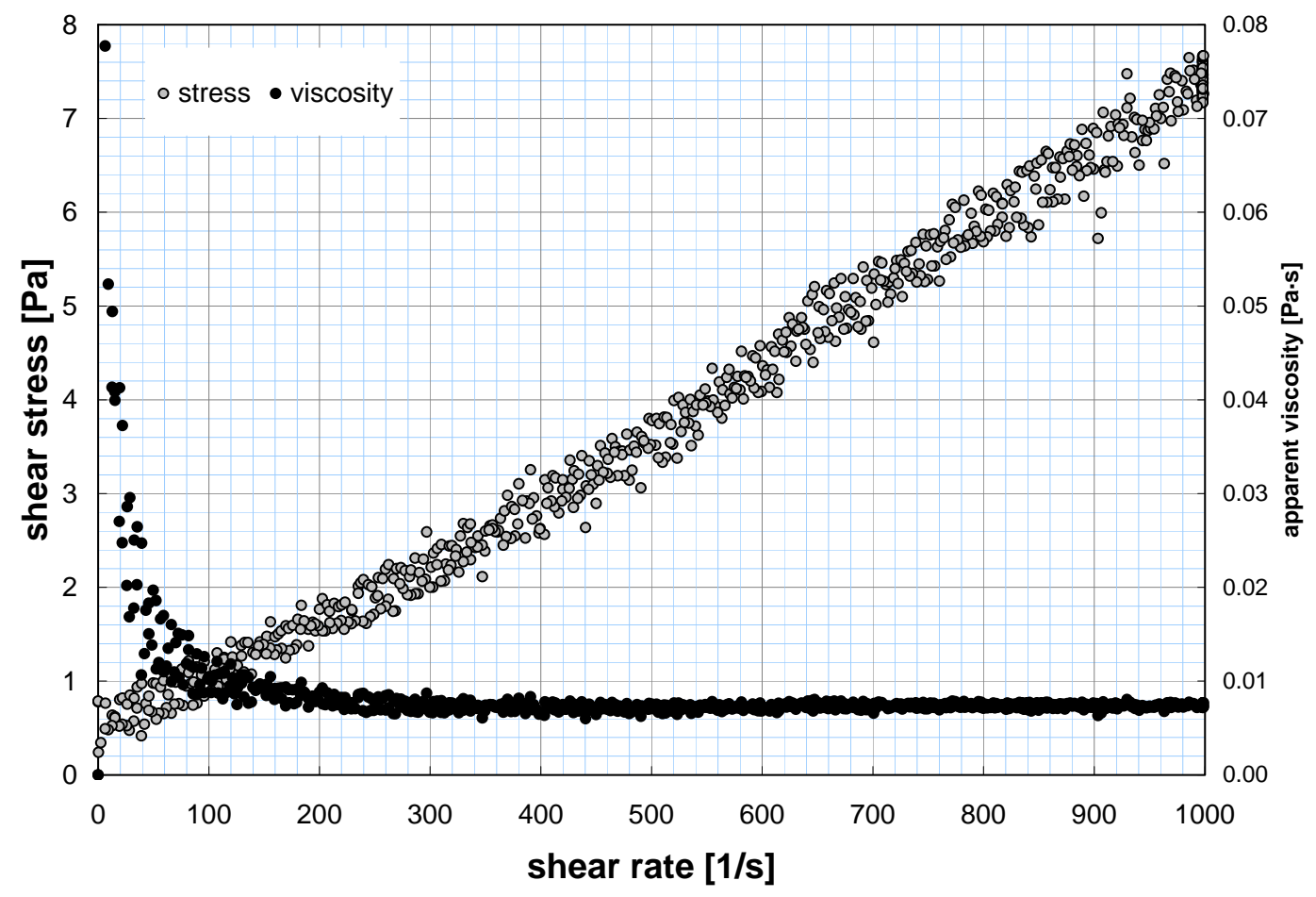

Figure A-23. Rheogram for TI540-G5- Leach2 at $40^{\circ} \mathrm{C}$. 


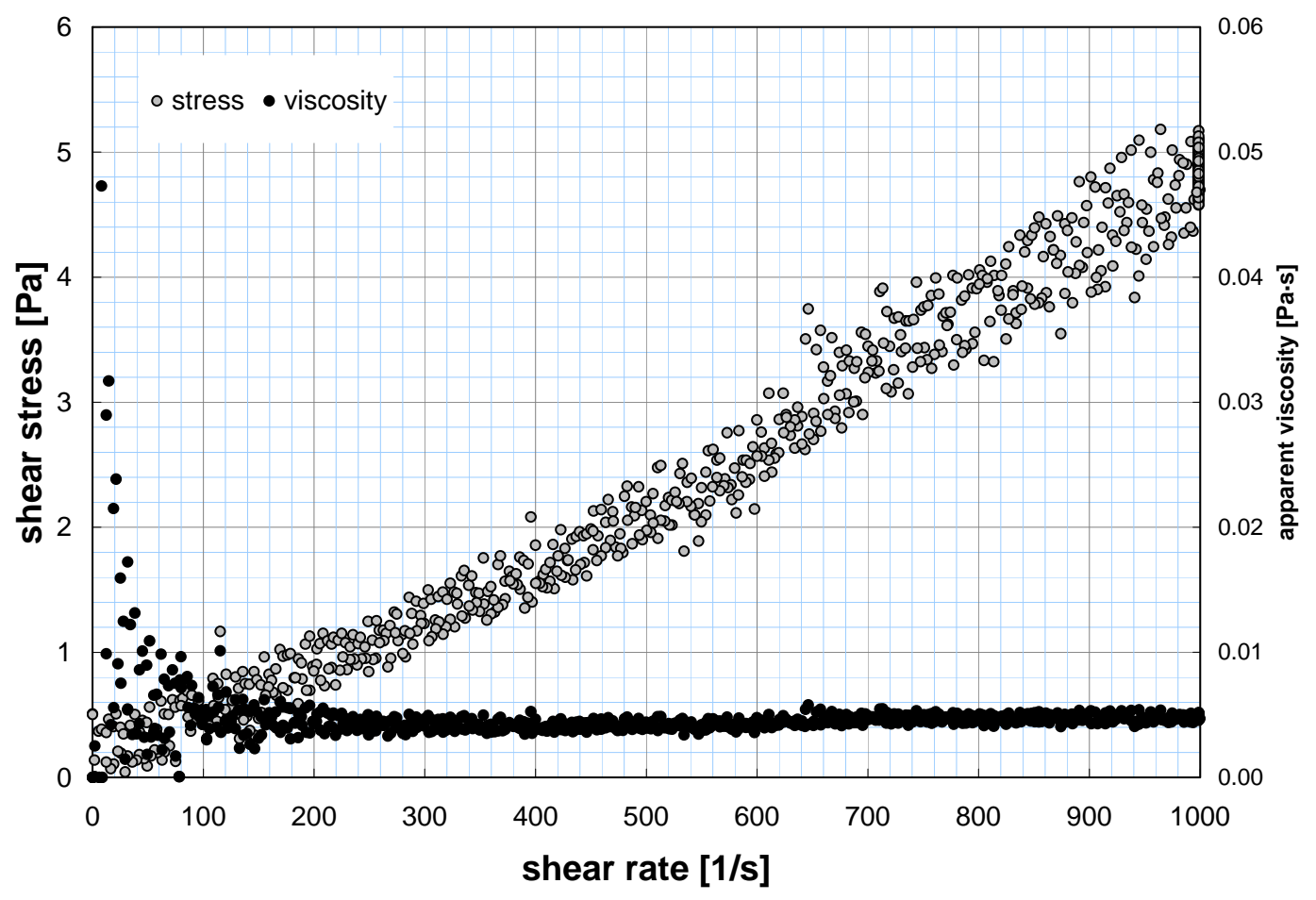

Figure A-24. Rheogram for TI540-G5- Leach2 at $60^{\circ} \mathrm{C}$. 
WTP-RPT-172, Rev 0

\section{Appendix $\mathbf{J}$}

\section{Group 6/5 CUF Rheology Analysis}




\section{Appendix J: Group 6/5 CUF Rheology Analysis}

\section{Battelle}

The Business of Innovation

$\begin{array}{ll}\text { Date } & \text { April 11, } 2008 \\ \text { To } & \text { Rick Shimskey } \\ \text { From } & \text { Richard Daniel } \\ \text { Subject } & \frac{\text { Rheology of Hanford Waste S-Saltcake Slurry (Group }}{\text { 6) and REDOX / S-Saltcake Sludge Slurry Mixtures }} \\ & \text { (Group 5/6): CUF Testing }\end{array}$

Internal Distribution

Rick Shimskey

Richard Daniel

\section{Acronyms and Abbreviations}

$\begin{array}{ll}\text { AV } & \text { Axial Velocity } \\ \text { CUF } & \text { Cells Unit Filter } \\ \text { DI } & \text { Deionized (water) } \\ \text { LRB } & \text { Laboratory Record Book } \\ \text { NIST } & \text { National Institute of Technology } \\ \text { RPL } & \text { Radiochemical Processing Laboratory } \\ \text { RPP } & \text { River Protection Project } \\ \text { SAL } & \text { Shielded Analytical Laboratory } \\ \text { TDP } & \text { Test Data Package } \\ \text { TMP } & \text { Transmembrane Pressure } \\ \text { WTP } & \text { Waste Treatment Plant (Support Program) }\end{array}$

\section{Introduction}

In fulfillment of the requirements of Test Plan TP-RPP-WTP-467 [1], the rheology of select Hanford tank waste samples was characterized at the Radiochemical Processing Laboratory (RPL). This interim characterization report presents rheology test results for two waste processing groups: Group 6 and Group 5/6 Cells Unit Filter (CUF) testing samples. Waste group 6 corresponds to S-Saltcake slurry; waste group 5/6 corresponds to mixtures of S-Saltcake slurry and REDOX (R) Sludge. The studies described herein will be limited to flow-curve testing of waste materials.

\section{Background}

Rheology is the science of material flow and deformation. For fluid systems, including pure liquids, mixtures of liquids, and suspensions of solids in liquids, the rheological properties of that system describe how it responds to an applied force or stress. When applied to solids, stress induces a strain or finite deformation in the material as long as the material yield is not exceeded. When applied to pure liquids, any stress causes a continuous deformation of the substance or, in simpler terms, fluid flow. Suspensions of solids in liquids or liquid mixtures with internal structure can show a combination of both 
solid- and liquid-like behavior. In addition, the response of materials to force and deformation may not be constant. Changes in internal structure of materials that occur as a result of mechanical and chemical processes, such as breakage, precipitation of solids, and gelation, may alter the macroscopic flow and deformation properties. For the current study, only non-elastic flow of tank waste slurries and supernatants is considered.

Non-elastic flow of tank waste slurries and supernatants is characterized with rotational viscometry. The goal of rotational viscometry is measurement of a material's flow curve (also known as a "rheogram"), which describes the shear stress response, $\tau$, as a function of applied shear rate, $\dot{\gamma}$ (also called the rate-of-strain). The result of a flow curve measurement is a set of $\tau$ versus $\dot{\gamma}$ measurements, which are called flow curve data. Flow curve data can be interpreted with several constitutive equations that relate viscous stress to shear-rate. Such analysis allows the flow behavior over a broad range of conditions to be described with just a few rheological descriptors such as viscosity, yield stress, consistency, and flow index.

A concentric cylinder rotational viscometer operated in controlled-rate mode will be used for flow curve testing of tank waste slurries and supernatants. These viscometers operate by placing a given volume of test sample into a measurement cup of known geometry. A cylindrical rotor attached to a torque sensor is then lowered into the sample until the slurry is even with, but does not cover, the top of the rotor. Both the radius and height of the rotor are known such that the gap distance between cup and rotor and surface area of fluid contact can be determined. In addition, the top and bottom of the rotor have recessed surfaces such that the fluid only contacts the radial surfaces of the rotor. A filled rotor-incup test geometry is shown in Figure 1. Determination of the fluid flow properties of the sample is made by spinning the rotor at a known rotational speed, $\Omega$, and measuring the resisting torque, $M$, acting on the rotor. Because fluid only contacts the rotor on the radial surfaces of rotation, all of the force resisting steady-state rotation can be ascribed to shearing of the fluid in the cup-rotor gap. Assuming an isotropic fluid and cup and rotor dimensions as shown in Figure 1, the torque acting on the rotor can be directly related to the shear stress at the rotor using the equation,

$$
\tau=\frac{M}{2 \pi H R_{I}^{2}}
$$

Shear stress has units of force per area $\left[\mathrm{N} / \mathrm{m}^{2}\right]$. Calculation of the fluid shear rate at the rotor is complicated by the fact that shear rate depends on both on the measurement system geometry and the fluid rheological properties. For the simplest fluids (i.e., Newtonian fluids) the shear rate of the fluid at the rotor can be calculated given the geometry of the cup rotor shear (see Figure 1) by using the equation,

$$
\dot{\gamma}=\left(\frac{2 R_{O}^{2}}{R_{O}^{2}-R_{I}^{2}}\right) \Omega
$$

Here, shear rate has units of inverse seconds [1/s]. Calculation of shear rate for materials showing more complex shear stress versus shear rate behavior (i.e., non-Newtonian fluids) requires input of flow curve parameters such as yield stress and degree of shear-thinning or shear-thickening. Because the required 
input parameters are typically not known prior to measurement, this requirement is typically circumvented by using a cup and rotor system with a small gap $(\sim 1 \mathrm{~mm})$ such that shear rate effects introduced by fluid properties are minimized. For these systems, Eq. 2 provides an accurate determination of shear rate for non-Newtonian materials.

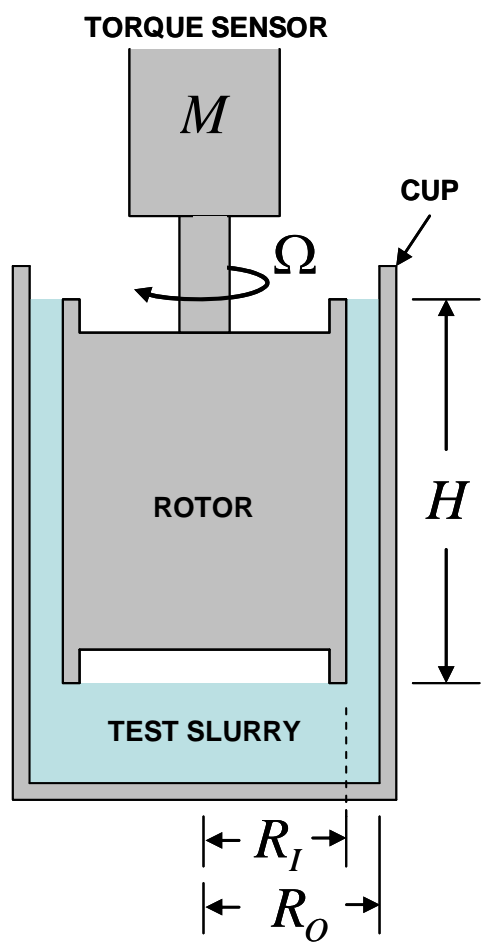

Figure 1. Rotor and cup geometry used in rotational viscometry testing.

Shear rates examined in this study will span approximately 1 to $1000 \mathrm{~s}^{-1}$ and are typical of the order of magnitude of shear rates experienced in pipeline flow [2]. Pipeline flows encountered in the Waste Treatment Plant may exceed the range studied herein. As such, mechanistic models of waste rheology shall be employed to fit shear stress versus shear rate data, allowing extension to shear rates beyond those studied herein.

The resistance of a fluid to flow can be described in terms of the fluid's apparent viscosity, $\eta_{a p p}$, which is defined as the ratio of the shear stress to shear rate:

$$
\eta_{a p p}=\frac{\tau}{\dot{\gamma}}
$$

Often the shear stress and viscosity vary as a function of shear rate. Since the viscosity is defined as the ratio of shear stress to shear rate, the units of the variable are Pa·s. Typically, viscosity is reported in units of centipoise (cP; where $1 \mathrm{cP}=1 \mathrm{mPa} \cdot \mathrm{s}$ ). 
Flow curve data are usually combined plots of $\tau$ and $\eta_{a p p}$ as a function of $\dot{\gamma}$. As stated above, flow curve data can be interpreted with several constitutive equations (i.e., flow curves), allowing characterization of that data with just a few rheological descriptors. The behavior of tank waste sludges, slurries, and supernatants can be described by four common flow curve equations. These are:

- $\quad$ Newtonian - Newtonian fluids flow as a result of any applied stress and show constant viscosity over all shear conditions. The flow curve for Newtonian fluids is,

$$
\tau=\eta \dot{\gamma}
$$

where $\eta$ is the Newtonian viscosity.

- Ostwald (Power Law) - Power law fluids flow as a result of any applied stress and have viscosities that either increase or decrease with increasing shear rate. The are described by,

$$
\tau=m \dot{\gamma}^{n}
$$

where $m$ is the power law consistency index and $n$ is the power law index. Power law fluids with $n<1$ are referred to as psuedoplastic (shear-thinning), whereas power law fluids with $n$ $>1$ are referred to as dilatant (shear-thickening).

- Bingham Plastic - Bingham plastics are fluids that show finite yield points. This stress (i.e., the yield stress) must be exceeded before these types of materials flow. Once flow is initiated, the stress response of the material is Newtonian over the rest of the shear rate range. Bingham plastics are described by,

$$
\tau=\tau_{O}^{B}+k_{B} \dot{\gamma}
$$

where $\tau_{O}^{B}$ is the Bingham yield index and $k_{B}$ is the Bingham consistency index.

- $\quad$ Herschel-Bulkley - Fluids that behave in accordance with a Herschel-Bulkley model show a finite yield followed by power-law behavior over the rest of the shear rate range. They are described by,

$$
\tau=\tau_{O}^{H}+k_{H} \dot{\gamma}^{b}
$$

where $\tau_{O}^{H}$ is the Herschel-Bulkley yield index, $k_{H}$ is the Herschel-Bulkley consistency index, and $\mathrm{b}$ is the Herschel-Bulkley power law index.

Power-law fluids, Bingham plastics, and Herschel-Bulkley fluids are referred to as non-Newtonian fluids. In generally, liquids without internal and/or interconnected structures (such as tank waste supernatants) are Newtonian. Sludges and slurries are typically non-Newtonian, but their exact behavior depends on 
the concentration of solids and suspending phase chemistry. Sufficiently dilute slurries may show Newtonian behavior.

For the purposes of data reporting herein, the model used to fit flow curve data will be reported. Values for $\tau_{O}^{B}$ and $\tau_{O}^{H}$ will then be collectively referred to as the yield stress. Values for $\eta, m, k_{B}$, and $k_{H}$, shall be collectively referred to as the consistency. Values for $n$ and $b$ shall be referred to as the flow index. .

\section{Samples}

Group 6 and 5/6 CUF rheology samples were derived as part of bench-scale crossflow ultrafiltration and leaching studies using actual tank waste. Source material for the studies included both Group 5 [REDOX] and Group 6 [S-Saltcake] solids. Initially, a low-concentration group 6 tank waste slurry (3.2-wt\% solids) was loaded into a CUF unit installed in SAL Cell 5 and subjected to the following operations (in order):

1. full-recycle ultrafiltration of the low-concentration (3.2-wt\% solids) waste slurry at various axial velocities (AV) and transmembrane pressures (TMP)

2. dewatering of group 6 slurry and mixing with group 5 waste solids to transform the lowconcentration (3.2-wt\% solids) group 6 slurry to a high-concentration (13.2-wt\% solids) group 5/6 mixture

3. full-recycle ultrafiltration of the high-concentration (13.2-wt\% solids) waste slurry at various AV and TMP

4. caustic leaching of the waste slurry with $5 \mathrm{M}$ sodium hydroxide for 24 hours at $100^{\circ} \mathrm{C}$

5. dewatering of the caustically leached slurry

6. washing of the caustically-leached slurry

7. oxidative leaching of the waste slurry with $1 \mathrm{M}$ sodium permanganate for 24 hours at $100^{\circ} \mathrm{C}$

8. washing of the oxidative-leached slurry

9. combination of the oxidative-leached group 5/6 mixture with caustically-leached group 5 solids from a previous CUF test

For CUF rheology testing, samples were derived from various points in the ultrafiltration process outlined above. With regard to slurry samples, rheology was tested after

- $\quad$ loading the sample into the CUF (i.e., during step 1),

- dewatering the initial slurry and mixing with group 5 solids (i.e. after step 2),

- after caustic leaching and dewatering (i.e., after step 5),

- after washing the caustic leached slurry (i.e., after step 6),

- after oxidative leaching and dewatering (i.e., after step 8),

- after combination of the oxidative-leached 5/6 slurry with the caustically-leached group 5 solids (i.e., after step 9),

A single waste permeate (i.e., supernatant) sample was collected during the dewatering step before caustic leaching. Table 1 provides a summary of the samples taken and their given sample identification number. 
Table 1. Samples associated with Group 6 and 5/6 CUF rheology testing.

\begin{tabular}{||l|l||}
\hline \hline Sample Jar ID & Description \\
\hline TI540-G5-R1 & Slurry - Low-solids matrix (3.2-wt\%) group 6 slurry before caustic leaching \\
\hline TI540-G5-R2 & $\begin{array}{l}\text { Slurry - High-solids matrix (13.2-wt\%) group 5/6 slurry before caustic } \\
\text { leaching }\end{array}$ \\
\hline TI540-G5-R3 & Slurry - Dewatered group 5/6 slurry after caustic leaching (8.9-wt\%) \\
\hline TI540-G5-R4 & Slurry - Washed group 5/6 slurry after caustic leaching (12.8-wt\%) \\
\hline TI540-G5-R5 & Slurry - Washed group 5/6 slurry after oxidative leaching (9.7-wt\%) \\
\hline TI540-G5-R6 & $\begin{array}{l}\text { Slurry - Combined leached solids from group 5/6 and group 5 tests (8.0- } \\
\text { wt\%) }\end{array}$ \\
\hline TI540-G5-R2S & $\begin{array}{l}\text { Permeate - pre-caustic leach permeate collected during initial dewatering } \\
\text { step }\end{array}$ \\
\hline \hline
\end{tabular}

\section{Analysis}

Flow curve testing of group 6 and 5/6 waste samples was performed in parallel with the ultrafiltration studies. Testing began on November 2 and finished on November 16, 2007. Flow curve testing produced the following reportable data for the group 6 and 5/6 CUF samples:

- flow curve data for group 6 and $5 / 6$ slurries at $25^{\circ} \mathrm{C}, 40^{\circ} \mathrm{C}$, and $60^{\circ} \mathrm{C}$ at various points in the ultrafiltration and leaching processes

- flow curve data for group $5 / 6$ supernatants at $25^{\circ} \mathrm{C}, 40^{\circ} \mathrm{C}$, and $60^{\circ} \mathrm{C}$ prior to caustic leaching

- best-fit Newtonian, Power-law, Bingham Plastic, and Herschel-Bulkley parameters for group 6 and $5 / 6$ waste slurries at $25^{\circ} \mathrm{C}, 40^{\circ} \mathrm{C}$, and $60^{\circ} \mathrm{C}$

- Newtonian viscosities for group 6 and $5 / 6$ permeates at $25^{\circ} \mathrm{C}, 40^{\circ} \mathrm{C}$, and $60^{\circ} \mathrm{C}$

\section{Instrumentation}

Rheological characterization was accomplished using a Rotovisco ${ }^{\circledR}$ RV20 Measuring System M equipped with an M5 measuring head and RC20 controller. These components were purchased from HAAKE Mess-Technik GmbH u. Co. (now the Thermo Electron Corporation, Madison, WI 53711). This system is installed in Cell 4 of the Shielded Analytical Laboratory (SAL) at the Radiochemical Processing Laboratory (RPL). The M5 measuring head (SN\# 902398) is a "Searle" type viscometer capable of producing rotational speeds up to $500 \mathrm{RPM}$ and measuring torques up to $0.049 \mathrm{~N} \cdot \mathrm{m}$. The minimum rotational speed and torque resolution achievable by this measuring head are 0.05 RPM and $0.49 \mathrm{mN} \cdot \mathrm{m}$, respectively. Table 2 summarizes the M5 measuring system information.

Table 2. Summary of Haake RV20 system with M5 measuring head.

\begin{tabular}{||l|l||}
\hline \hline Analyzer: & $\begin{array}{l}\text { Rotorvisco }{ }^{\circledR} \text { RV20 Measuring System M with M5 } \\
\text { Measuring Head. }\end{array}$ \\
\hline Measurement principle: & Controlled Rate \\
\hline Serial Number: & 902398 \\
\hline Torque Sensor Range & 0.49 to $49 \mathrm{mN} \cdot \mathrm{s}$ \\
\hline Rotational Rate Range & 0.05 to $500 \mathrm{RPM}$ \\
\hline Calibrated & May 23, 2007 \\
\hline Date Due & May 2008 \\
\hline
\end{tabular}


Flow curve measurements employed an MV1 stainless steel measuring cup and rotor. The dimensions of the MV1 and vane measuring systems are listed in Table 3.

Table 3. Vane and Cup and Rotor Measuring System Dimensions.

\begin{tabular}{||l|c|c|c|c||}
\hline Measuring System & $\begin{array}{c}\text { Vane/Rotor } \\
\text { Radius }\end{array}$ & $\begin{array}{c}\text { Vane/Rotor } \\
\text { Height }\end{array}$ & Cup Radius & Gap Width \\
\hline MV1 & $20.04 \mathrm{~mm}$ & $60 \mathrm{~mm}$ & $21 \mathrm{~mm}$ & $0.96 \mathrm{~mm}$ \\
\hline
\end{tabular}

Temperature control is achieved using a combination of the standard measuring system $\mathrm{M}$ temperature jacket and a Cole-Parmer ${ }^{\circledR}$ Polystat ${ }^{\circledR}$ Temperature-Controlled Recirculator, Model Number C-12920-00. This recirculator allows heating and cooling of recirculation fluid to the rheometer over $-5^{\circ}$ to $80^{\circ} \mathrm{C}$ with a stability of $\pm 0.5^{\circ} \mathrm{C}$. It connects the measuring head to the measuring system, centers the cup, and provides heat transfer area between cup and recirculating fluid. The recirculating unit is located next to, but outside, the SAL Cell 4. The recirculator is connected to the water jacket through a combination of stainless steel piping (outside of cell) and flexible fiber reinforced plastic hose (inside cell). The desired temperature is set using the digital control interface on the recirculating unit. Fluid is circulated between the recirculator and jacket until the desired temperature is achieved at the jacket. Jacket temperature is monitored using a Type-K thermocouple (Omega Model TJ36-CASS-116-G-6-CC) calibrated over $0^{\circ}$ to $100^{\circ} \mathrm{C}$ connected to a multichannel display unit located in the SAL Gallery. Details of the temperature measurement and display calibration are given in Table 4. It should be noted that only the first two channels of the temperature display were calibrated. All measurements taken herein employ channel 1.

Table 4. Calibration information for temperature measurement and display systems.

\begin{tabular}{||l|c|c|c|c|c||}
\hline System & Serial \# & $\begin{array}{c}\text { Calibratio } \\
\text { n Barcode }\end{array}$ & Range Calibrated & $\begin{array}{c}\text { Date } \\
\text { Calibrated }\end{array}$ & $\begin{array}{c}\text { Date } \\
\text { Due }\end{array}$ \\
\hline $\begin{array}{l}\text { Type-K } \\
\text { Thermocouple }\end{array}$ & $\mathrm{n} / \mathrm{a}$ & 22888 & $0^{\circ}$ to $100^{\circ} \mathrm{C}\left( \pm 2^{\circ} \mathrm{C}\right)$ & $5 / 4 / 2007$ & $5 / 4 / 2008$ \\
\hline $\begin{array}{l}\text { Temperature } \\
\text { Display }\end{array}$ & 6070759 & 22889 & $0^{\circ}$ to $100^{\circ} \mathrm{C}\left( \pm 2^{\circ} \mathrm{C}\right)$ & $5 / 7 / 2007$ & $5 / 7 / 2008$ \\
\hline \hline
\end{tabular}

Rheometer control and data acquisition are accomplished through remote computer connection using the RheoWin Pro Job Manager Software, Version 2.96. The RheoWin software serves as a central program for obtaining, processing, and recording to disk data from the RV20-M5 Measuring System. During measurement, the software automatically converted rotor torque readings into shear stresses based on the appropriate A-factor conversion, such that

$$
\tau=A M
$$

For the cup and rotor system, the A-factor is defined by 


$$
A=\frac{1}{2 \pi H R_{I}^{2}}
$$

The A-factor for the MV1 measuring system is $6570 \mathrm{~m}^{-3}$. For flow curve testing, the RheoWin software also automatically converted the rotational rate readings into shear rates based on a factory-set " $\mathrm{M}$ factor”, such that:

$$
\dot{\gamma}=M_{R} \Omega
$$

where $\Omega$ is the rotational rate in radians per second, and $M_{R}$ is the "M-factor". The M-factor is defined as

$$
M=\left(\frac{2 R_{O}^{2}}{R_{O}^{2}-R_{I}^{2}}\right)
$$

For the MV1 sensor system, the M-factor is 22.350. The RheoWin software also allows postmeasurement processing and interpretation of data. Specifically, it can be used to determine maxima points in shear strength testing and fit flow curve data to any flow curve model.

\section{Governing Test Plan, Procedure, and Test Instructions}

The test plan governing the physical characterizations for these samples is River Protection Project - Waste Treatment Plant Support Program (RPP-WTP) document number TP-RPP-WTP-467, Revision 0 [1]. Operation of the HAAKE RV20-M5 Measurement System is governed by RPLCOLLOID-02, Revision 1 [3].

\section{Experimental}

Waste slurries were generally tested "as-is". Specifically, no sample treatment was performed during the interval between sample extraction from the CUF and rheology testing, with exception of the mechanical agitation required to disperse any settled waste solids in each sample jar. To provide a consistent sampling approach and samples representative of material in-contact with the CUF filter element, all samples were collected from CUF valve port V5.

\section{Instrument Performance Check}

As required by RPL-COLLOID-02, the performance of the Haake M5 rheometer must be verified at the beginning of each series of analyses (with the period between performance checks not to exceed 30 days during use). Checks are performed using Newtonian viscosity standards certified by methods traceable to the United States National Institute of Standards and Technology (NIST). Checks verify that the Haake M5 rheometer can measure the standard's viscosity to within $10 \%$ for fluids of $10 \mathrm{cP}$ or greater and to within $15 \%$ for fluids less than $10 \mathrm{cP}$ at the temperature listed on the certificate of analysis.

For the measurements described in this report, the performance check employed General Purpose Silicone Fluids purchased from Brookfield Engineering Laboratories, Inc. (Middleboro, Massachusetts, USA, 02346). Silicone oils are single phase liquids and have no suspended solids. For testing, three 
standards were used: Brookfield Fluid 10 and Brookfield Fluid 100. Tables 5 and 6 provide a summary of each viscosity standard's properties. Standards are traceable back to their certificate of analysis through a unique lot number.

Table 5. Properties of Brookfield Fluid 10.

\begin{tabular}{||l|l||}
\hline \hline Fluid & 10 \\
\hline Viscosity & $9.6 \mathrm{cP}$ \\
\hline Temperature & 25 \\
\hline Lot Number & 121306 \\
\hline PNNL Barcode & 275359 \\
\hline Certificate Date & $12 / 14 / 2007$ \\
\hline
\end{tabular}

Table 6. Properties of Brookfield Fluid 50.

\begin{tabular}{||l|l||}
\hline Fluid & 100 \\
\hline Viscosity & $96.0 \mathrm{cP}$ \\
\hline Temperature & 25 \\
\hline Lot Number & 021507 \\
\hline PNNL Barcode & 275361 \\
\hline Calibration Date & $2 / 16 / 2007$ \\
\hline \hline
\end{tabular}

Performance checks consisted of temperature controlled flow curve measurements that employed the MV1 measuring cup and rotor. The instrument performance checks covering the period of testing were run on October $24^{\text {th }}$ and $25^{\text {th }}$, 2007. In both cases, execution of performance verifications was as follows:

1. The appropriate measurement rotor was installed on the measuring head

2. The temperature jacket was installed on the measuring head and the recirculator turned on and set to $25^{\circ} \mathrm{C}$. The jacket is allowed to achieve temperature equilibrium.

3. Approximately 40 to $50 \mathrm{~mL}$ of viscosity fluid was added to the MV1 cup.

4. The measuring cup was installed into the water jacket by slowly raising it on a laboratory jack stand. During installation, the cup slides into the base of the water jacket where it contacts and slides over the rotor. The rotor volume displaces the test material, forcing it to fill the gap between cup and rotor. While the cup was being raised, the liquid level relative to the top of the rotor was monitored through an opening in the top of the water jacket using a small digital video camera installed in-cell. The cup was raised until the test material was observed to spill over the top of the rotor. Before continuing, most of the excess viscosity standard on the upper recess of the rotor was removed using a plastic transfer pipette.

5. The viscosity standard was left undisturbed in the measuring system for 5 minutes to allow temperature equilibration.

6. The material flow curve data were measured. Rheological analysis was performed over a 15minute period, split into three 5-minute intervals. Over the first 5 minutes, the shear rate was gradually increased from zero to $1000 \mathrm{~s}^{-1}$. For the second 5 minutes, the shear rate was held constant at $1000 \mathrm{~s}^{-1}$. For the final 5-minutes, the shear rate was gradually reduced back to zero. During this time, the resisting torque and rotational rate was continuously monitored and recorded.

After the measurement, flow curve data were automatically fit to a Newtonian model (Eq. 4) by the RheoWin software. The regressed value was saved to the measurement file and was also transcribed into the LRB. The percent error, $E$, between the measured viscosity, $\eta_{\text {meas }}$, and that listed on the certificate of analysis, $\eta_{\text {list }}$, was calculated as: 


$$
E=\left(\frac{\eta_{\text {meas }}-\eta_{\text {list }}}{\eta_{\text {list }}}\right) \times 100 \%
$$

The performance check is considered acceptable if the absolute value of $E$, defined as $|E|$, was less than $10 \%$ for fluids with list viscosities greater than or equal to $10 \mathrm{cP}$ or was less than $15 \%$ for fluids with list viscosities less than $10 \mathrm{cP}$. Prior to start of any quality affecting work, the RV20-M5 was verified to be in acceptable performance.

Table 7 lists the results of each performance verification/check carried out in association with Group 6 and 5/6 CUF testing efforts. As indicated in the table, the RV20-M5 measuring system showed acceptable performance for both test fluids. All flow curves showed the expected Newtonian behavior for these standards.

Table 7. Results of rheometer performance checks.

\begin{tabular}{||l|c|c|c|c|c||}
\hline Test Fluid & $\begin{array}{c}\text { Performance } \\
\text { Date* }\end{array}$ & $\begin{array}{c}\text { List } \\
\text { Viscosity } \\
\text { (cP) }\end{array}$ & $\begin{array}{c}\text { Measured } \\
\text { Viscosity (cP) }\end{array}$ & $/ E /$ & Acceptable \\
\hline Brookfield Fluid 10 & $\begin{array}{c}\text { October 24, } \\
2007\end{array}$ & 9.6 & 8.9 & $7.0 \%$ & Yes \\
\hline Brookfield Fluid 100 & $\begin{array}{c}\text { October 25, } \\
2007\end{array}$ & 96.0 & 87.7 & $8.6 \%$ & Yes \\
\hline
\end{tabular}

*Period of performance extends for 30 days after the listed performance date.

Flow Curve Testing

Flow curve testing for both slurry and supernatant samples employed an MV1 cup and rotor. Each flow curve measurement was accomplished as follows:

1. The MV1 rotor was installed on the measuring head

2. The temperature jacket was installed and the recirculator turned on and set to $25^{\circ} \mathrm{C}$. The jacket is allowed to achieve temperature equilibrium.

3. The test sample was transferred from its source jar into the MV1 measurement cup. Sample was added to the cup until the fluid level was above the first (i.e., lowest) cup level marker but still below the second level marker. This typically required 40 to $50 \mathrm{~mL}$ of sample. Gross material transfer was accomplished by pouring the sample into the test container until a rough estimate of the required sample volume was obtained. Fine level adjustments were made by adding and removing material to and from the measuring cup using a plastic transfer pipette.

4. The measuring cup was installed into the water jacket by slowly raising it on a laboratory jack stand. The cup was raised until the test material was observed to spill over the top of the rotor. Before continuing, excess material was removed from the top of the rotor (to the extent possible) using a plastic transfer pipette. In most cases, there was approximately 1-3 $\mathrm{mL}$ of excess material that could not be removed from the upper rotor recess.

5. The moisture barrier was wetted and installed over the opening at the top of the temperature jacket. The moisture barrier is a stainless steel clamshell fitting lined with a sponge. It serves to 
minimize sample evaporation by blocking openings at the top of the water jacket (where the sample is exposed to air) and by humidifying the air space above the sample.

6. The sample was left undisturbed in the measuring system for 5 minutes to allow temperature equilibration.

7. The sample was sheared for 3 minutes at a rotational rate of 200 RPM (which corresponds to a shear rate of $470 \mathrm{~s}^{-1}$ ) to break sample structure, to attempt re-suspension any settled slurry particles, and to verify that the rotor was properly centered.

8. The material flow curve data were measured. Rheological analysis was performed over a 15minute period, split into three 5-minute intervals. Over the first 5 minutes, the shear rate was smoothly increased from zero to $1000 \mathrm{~s}^{-1}$. For the second 5 minutes, the shear rate was held constant at $1000 \mathrm{~s}^{-1}$. For the final 5-minutes, the shear rate was smoothly reduced back to zero. During this time, the resisting torque and rotational rate were continuously monitored and recorded.

9. The flow curve data for $25^{\circ} \mathrm{C}$ were saved using the RheoWin file format and a unique filename identifier. Sample information and the associated RheoWin filename were entered into the LRB.

10. The cup was raised so that fresh sludge/slurry filled the gap. Excess sludge was pipetted from the top. The moisture guard was, removed, re-wetted, and then re-installed

11. The flow curve at $25^{\circ} \mathrm{C}$ was re-measured as per steps 7 through 9 .

12. The temperature set point was set to $40^{\circ} \mathrm{C}$. Once the jacket had reached the temperature set point, the sample was allowed an additional 5 minutes to reach temperature equilibrium. The cup was raised so that fresh sludge/slurry filled the gap. Excess sludge was pipetted from the top. The moisture guard was, removed, re-wetted, and then re-installed

13. The flow curve at $40^{\circ} \mathrm{C}$ was measured as per steps 7 through 9 .

14. The temperature set point was set to $60^{\circ} \mathrm{C}$. Once the jacket had reached the temperature set point, the sample was allowed an additional 5 minutes to reach temperature equilibrium. The cup was raised so that fresh sludge/slurry filled the gap. Excess sludge was pipetted from the top. The moisture guard was removed, re-wetted, and then re-installed

15. The flow curve at $60^{\circ} \mathrm{C}$ was measured as per steps 7 through 9 .

16. At the end of testing, the measuring cup was removed from the system. The test material was returned to its original container. The measuring system was disassembled. Any slurry or precipitated salt solids remaining in the cup or rotor were cleaned-off using by rinsing with copious amounts of water and by wiping down with a damp cloth.

Visual inspection of the group 6 and 5/6 slurries prior to testing found no observable solids settling during transfer from sample jar to rheometer measurement cup. In addition, when performing step 7, the rotor torques measured while mixing were constant. This indicates that for short periods of time, such as the 3 minute mixing step or the time required to transfer the sample to the measuring cup ( $\sim 5$ minutes), settling and shear history effects were minimal for the Group 6 and 5/6 CUF slurry samples.

For the pre-caustic leach permeate sample (TI540-G6-R2S), the viscosity was too low to accurately determine by flow curve because of formation of Taylor Vortices (hereafter referred as flow vortices) in the gap between cup and rotor. To obtain viscosity as a function of temperature for this sample, constant rotation experiments were performed at a shear rate of $200 \mathrm{~s}^{-1}$, which is below that at which vortex formation was noted. It should be noted that Newtonian behavior is assumed such that the viscosity of the supernatant sample is equal to the apparent viscosity as determined by Eq. 3 . 
At the end of each flow curve or constant rotation measurement, all information relevant to the measurement, including raw and calculated measurement results and sample information, were saved to disk using the RheoWin file format and a unique filename identifier. The filename, temperature, start and end of temperature equilibration, and a basic sample identifier were recorded in a Laboratory Record Book (LRB). A separate data file was used for each flow curve measurement. Note: a summary of flow curve measurement results (including viscous stress and apparent viscosity as a function of shear rate) is provided in Appendix A of this report.

Post-measurement analysis and review of flow curve data were accomplished using the RheoWin Pro Data Manager software, Version 2.96. For each set of measurement data, the flow curve data was characterized by determining the best-fit parameters for the constitutive equation outlined in Section 2.0 of this report (i.e., the Newtonian, Power-Law, Bingham-Plastic, and Herschel-Bulkley flow models). This analysis utilized the least-squares data regression routine native to the RheoWin 2.96 software. Each regression analysis included both up- and down-ramp portions of the flow curve, resulting in an "average" set of model parameters for the total flow curve. In certain cases, model fits were limited to specific shear rate ranges to avoid flow curve anomalies such as Taylor Vortices (at high shear rates) and slip (at low shear rates). Alternate flow curve analyses, such as fits to constitutive models not listed herein or fits of specific portions of the flow (e.g., up-ramp only) are available on request.

\section{Results and Discussion}

The following sections discuss the results of flow curve testing for Group 6 and 5/6 CUF samples. Before discussing the results of CUF testing, flow curve measurements for the Group 5 and Group 6 source material, namely those derived from homogenization efforts, will be introduced and reviewed as a point-of-reference for discussion of CUF flow curves. Following that discussion, the slurry flow curves for each sample will be introduced and discussed one-by-one, with an emphasis on the temperature effects and flow curve behavior of each particular sample. After all flow curve measurement data has been presented, the results will be compared to one another to elucidate the effect of CUF processing on relative sample rheology. Next, a discussion of permeate rheology will be given. Finally, the results of flow curve testing will be summarized and the impacts on pre-treatment plant operations briefly discussed.

\section{Sample G5-RH-2: Source Group 5 Material for CUF Testing}

Sample G5-RH-2 represents Group 5 tank waste derived from homogenization efforts and is source material for the Group 6 and 5/6 CUF tests. This waste slurry has a concentration of 18.5-wt\% undissolved solids. It was tested as part of the initial characterization efforts that took place prior to CUF testing. The results have been previously reported in Test Data Package TDP-WTP-056 [4].

Flow curve testing results for the Group 5 source material are shown in Figure 2. Over shear rates of zero to $100 \mathrm{~s}^{-1}$, shear stress is observed to increase rapidly as a function of shear rate for all temperatures. The rate of increase appears to decrease with increasing temperature, with the $60{ }^{\circ} \mathrm{C}$ measurement showing the slowest response. Beyond $100 \mathrm{~s}^{-1}$, all flow curves level out and show a much slower increase in shear stress with shear rate. Over $100-1000 \mathrm{~s}^{-1}$, shear stress increases at $25^{\circ} \mathrm{C}$ are 
linear, whereas both 40 and $60^{\circ} \mathrm{C}$ measurements show slight to moderate downward curvature indicative of a shear thinning fluid.

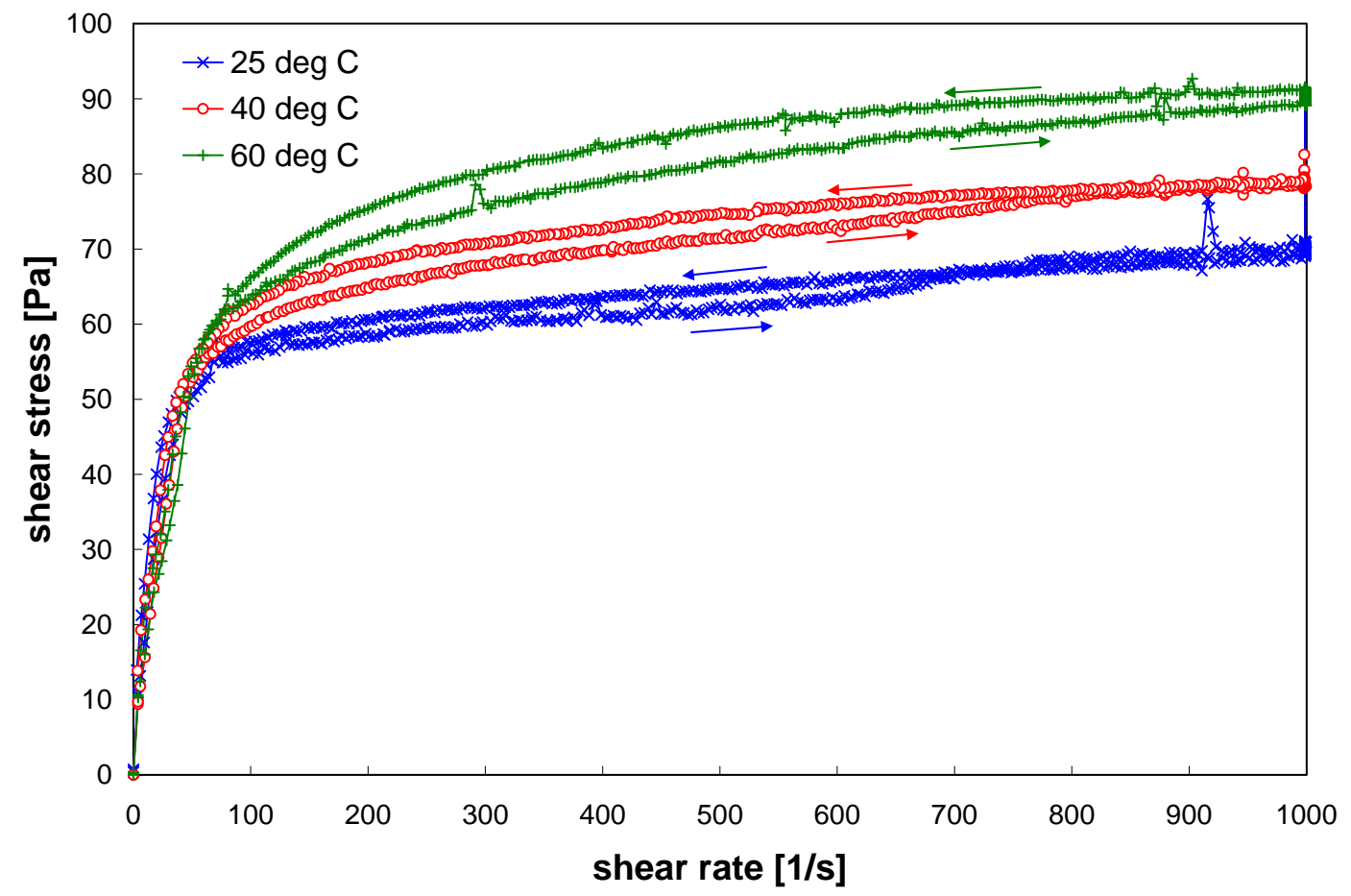

Figure 2. Flow curves for Group 5 initial characterization sample G5-RH-2 at $25^{\circ} \mathrm{C}, 40^{\circ} \mathrm{C}$, and $60^{\circ}$ C. Sample corresponds to the source material for CUF testing. The arrows indicate the direction of the shear/rotational rate ramp.

For all temperatures, the flow curves show hysteresis. Specifically, the shear stress measured during the ramp up to $1000 \mathrm{~s}^{-1}$ is always lower than that measured on the ramp back down to zero. Flow curve data hysteresis occurs as a result of sample alteration brought about by shear, chemical processes (such as precipitation), settling, or evaporation. Even though the sludge is sheared prior to measurement to mix the sample and eliminate structure, continued shearing of the sludge throughout each of the 15minute flow curve tests could continue to alter sample. However, shearing tends to break-up and eliminate particle aggregates, which in turn, lowers the force required to maintain fluid motion. As such, the observation of increased shear stress on all flow-curve down-ramps is not consistent with the expected shear induced hysteresis effects typically seen with tank waste. Settling effects are also unlikely, because the sludge is mixed immediately prior to testing to re-suspend settled solids and because phase separation was not observed when transferring the sample to the measurement cup.

Although chemical changes are also unlikely (as the jars from which the sample had been taken have at least one month to reach chemical equilibrium), it is possible that heating of the sample could alter particle-particle interactions. Particle size measurements of Group 5 Initial Characterization samples do show sample instability. Specifically, application of sonic energy appear to cause particle coagulation, as it is accompanied by an increase in the fraction of coarse particles and particle aggregates observed in Group 5 waste samples tested. This could be consistent with the observations in Figure 2, as formation of 
particle aggregates tends to increase the force required for fluid motion. Although particle coagulation can explain the shear stress hysteresis, evaporation of liquid (and the resulting increase in solids concentration it causes) is the most likely cause of the observed hysteresis. This is supported by the fact that separation between up-ramp and down-ramp stress curves increases with increasing temperature.

With regard to the temperature dependence of the flow curves, the measured range of shear stresses beyond $100 \mathrm{~s}^{-1}$ uniformly increases with increasing temperature. For example, an increase of 30 $\mathrm{Pa}$ is observed between the $25^{\circ} \mathrm{C}$ for and $60^{\circ} \mathrm{C}$ measurements at $1000 \mathrm{~s}^{-1}$. Like flow curve hysteresis, the increase in measured shear stress with temperature may be either coagulation of particles or evaporation. Because of volume limitations, the same Group 5 waste material was repeatedly tested. As such, evaporation is the most likely cause for the observed shear stress increase.

The flow curve behavior observed in Figure 2 is difficult to characterize. Altogether, the curves look highly pseudo-plastic. However, the sharp transition in slope that occurs around $\sim 100 \mathrm{~s}^{-1}$ is not wellcaptured by the Ostwald equation as shown in Figure 3. Although Figure 3 is restricted to flow curve data at $40^{\circ} \mathrm{C}$, Ostwald fits of $25^{\circ}$ and $60^{\circ} \mathrm{C}$ data show similar problems. The unusual stress versus strain-rate behavior over 0-100 s-1 might be an artifact caused by 1) slip between the test sample and sensor surfaces 2) sample elasticity, and 3) poor rotational sampling of material at low shear rates (i.e., very slow rotational speed of the rotor).

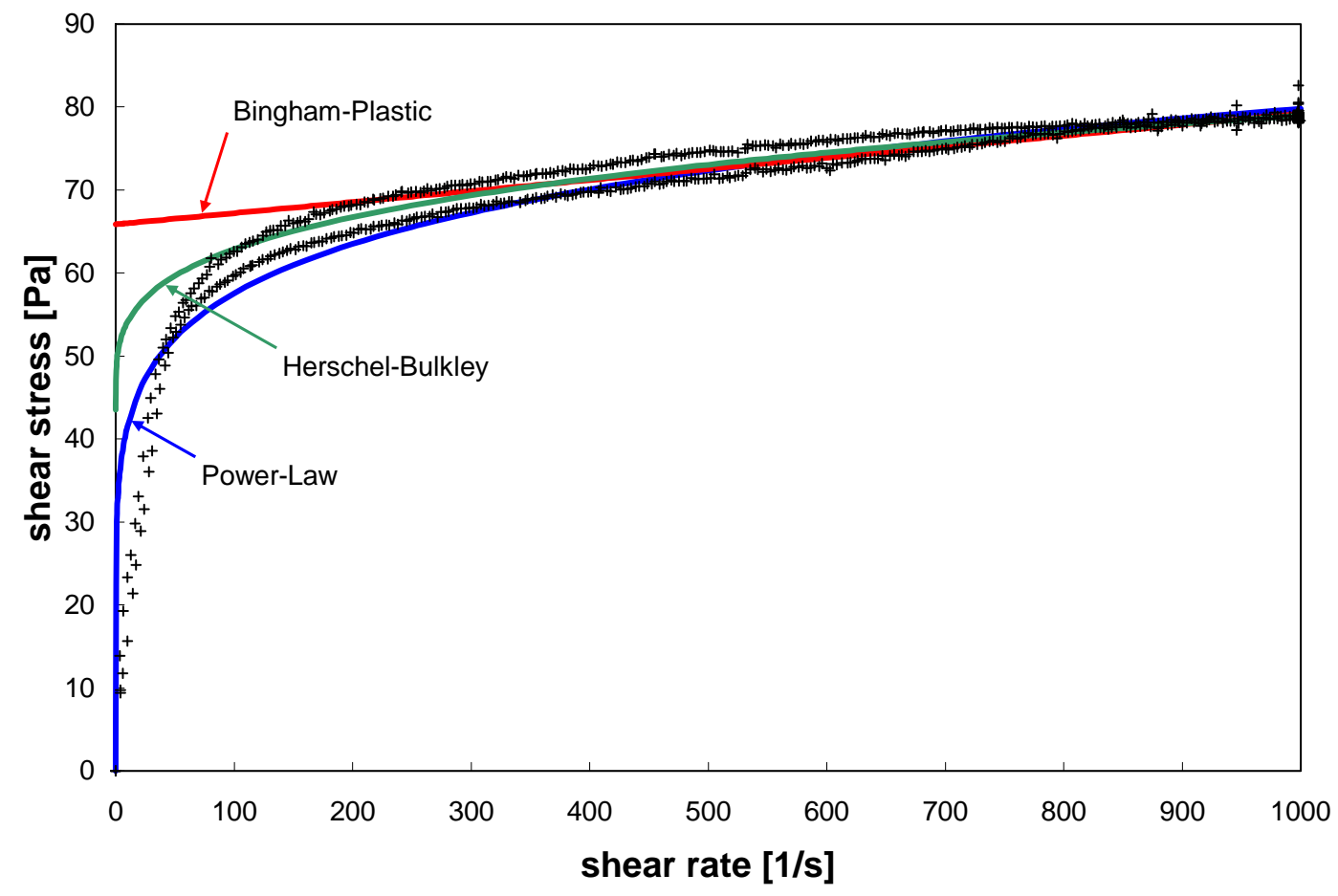

Figure 3. Flow curve fits for sample G5-RH-2 at $40^{\circ} \mathrm{C}$. The Ostwald fit is applied over 0-1000 s ${ }^{-1}$, whereas the Bingham-Plastic and Herschel-Bulkley fits are applied over 200-1000 s .

When attempting to analyze the data using Bingham-Plastic and Herschel-Bulkley models, flow curve data in the $0-100 \mathrm{~s}^{-1}$ skewed the curve fits at higher shear rates. To overcome this problem, 
regression analysis for Bingham-Plastic and Herschel-Bulkley models was limited to the 200-1000 s-1 shear rate region. The results of regression analysis for sample G5-RH-2 are shown in Table 8. Figure 3 shows the Bingham-Plastic and Herschel-Bulkley model fits for $40^{\circ} \mathrm{C}$; similar fits were obtained at $25^{\circ}$ and $60^{\circ} \mathrm{C}$. Based on the reported correlation coefficient, $R$, all analyses provide roughly the same fit of the data. It should be noted that although the power-law fit strictly does not have a yield stress, the flow index for the current fits is sufficiently low that the power law fit appears to fall back to a finite yield point for each fit.

Table 8. Best fit of select rheological models to Group 5 initial characterization flow curve data.

\begin{tabular}{|c|c|c|c|c|c||}
\hline MODEL & $\begin{array}{c}\text { TEMPERATURE } \\
{\left[{ }^{\circ} \mathbf{C}\right]}\end{array}$ & $\begin{array}{c}\text { YIELD } \\
\text { STRESS } \\
{[\mathbf{P A}]}\end{array}$ & $\begin{array}{c}\text { CONSISTENCY } \\
{\left[\text { PA· }{ }^{\mathbf{N}}\right]}\end{array}$ & $\begin{array}{c}\text { FLOW } \\
\text { INDEX }\end{array}$ & $\mathbf{R}^{*}$ \\
\hline \multirow{3}{*}{ Power-Law } & 25 & $\mathrm{n} / \mathrm{a}$ & 30 & 0.12 & 0.94 \\
\cline { 2 - 6 } & 40 & $\mathrm{n} / \mathrm{a}$ & 30 & 0.14 & 0.95 \\
\cline { 2 - 6 } & 60 & $\mathrm{n} / \mathrm{a}$ & 28 & 0.17 & 0.95 \\
\hline \multirow{3}{*}{ Bingham-Plastic } & 25 & 57 & 0.013 & $\mathrm{n} / \mathrm{a}$ & 0.94 \\
\cline { 2 - 6 } & 40 & 66 & 0.013 & $\mathrm{n} / \mathrm{a}$ & 0.95 \\
\cline { 2 - 6 } & 60 & 74 & 0.017 & $\mathrm{n} / \mathrm{a}$ & 0.92 \\
\hline Herschel-Bulkley & 25 & 56 & 0.044 & 0.83 & 0.94 \\
\cline { 2 - 6 } & 40 & 44 & 5.8 & 0.26 & 0.96 \\
\cline { 2 - 7 } & 60 & 26 & 19 & 0.18 & 0.94 \\
\hline
\end{tabular}

$* \mathrm{R}$ is the correlation coefficient of the fit

Because none of the fitting parameters and corresponding equations provides an accurate representation of the low-shear region, care must be taken when interpreting them. A general representation of the flow curve behavior changes with temperature may be derived from the BinghamPlastic model parameters. Here, the apparent yield stress increases from 57 to $74 \mathrm{~Pa}$ as the temperature is increased from $25^{\circ}$ to $60^{\circ} \mathrm{C}$. Likewise, the consistency of the fluid increases slightly from $13 \mathrm{cP}$ to 17 $\mathrm{cP}$. Whether these numbers are actually representative of the actual yield stress and consistency can not be ascertained from the flow curve measurements alone. Neglecting the unusual behavior between 0 and $100 \mathrm{~s}^{-1}$, examination of the fits in Figure 3 suggests that the Bingham-Plastic model overestimates the actual yield while the Herschel-Bulkley model underestimates the actual yield. Thus, the BinghamPlastic yield stress appears to place conservative upper bound on yield stress. A conservative lower bound is given by the Herschel-Bulkley yield stress.

As point of reference, the apparent viscosity at $33 \mathrm{~s}^{-1}$ is derived from each measurement. The results are provided in Table 9. For each temperature, this reference point is determined from the average of up-ramp and down-ramp flow curve measurement data and from the fitting parameters provided in Table 8. Because measurement data at all three temperatures show high shear stress $(\sim 30-75 \mathrm{~Pa})$, the apparent viscosities at $33 \mathrm{~s}^{-1}$ are all on the order of $1000 \mathrm{cP}$. Because the consistency of the material is low, apparent viscosities drop off rapidly. 
Table 9. Apparent viscosity of sample G5-RH2 at $33 \mathrm{~s}^{-1}$.

\begin{tabular}{|c|c|c|c|c|}
\hline \multirow[t]{2}{*}{$\begin{array}{l}\text { TEMPERATURE } \\
{\left[{ }^{\circ} \mathrm{C}\right]}\end{array}$} & \multirow{2}{*}{$\begin{array}{c}\eta_{\text {APP }}(\mathrm{CP}) \\
\text { FROM } \\
\text { MEASUREMENT } \\
\text { DATA }\end{array}$} & \multicolumn{3}{|c|}{$\begin{array}{c}\eta_{\text {APP }}(\mathrm{CP}) \\
\text { FROM FITTING PARAMETERS }\end{array}$} \\
\hline & & Power-Law & $\begin{array}{c}\text { Bingham } \\
\text { Plastic }\end{array}$ & $\begin{array}{l}\text { Herschel- } \\
\text { Bulkley }\end{array}$ \\
\hline 25 & 1320 & 1400 & 1750 & 1720 \\
\hline 40 & 1250 & 1490 & 2010 & 1760 \\
\hline 60 & 1060 & 1550 & 2260 & 1870 \\
\hline
\end{tabular}

Sample TI490-G6-AR-RH: Source Group 6 Material for CUF Testing

Sample TI490-G6-AR-RH represents Group 6 tank waste derived from homogenization efforts and is the source material for the Group 6 and 5/6 CUF tests. This waste slurry has an undissolved solids concentration of 14.7-wt\%. It was tested as part of the initial characterization efforts that took place before CUF testing. The results have been previously reported in Test Data Package TDP-WTP-061 [5].

Flow curve testing results for the Group 6 slurry sample, TI490-G6-AR-RH, are shown in Figure 4. The $25^{\circ}$ and $40^{\circ}$ measurements show Newtonian behavior (i.e., a linearly increase shear stress with shear rate and a zero intercept) over the entire measurement range of 0 to $1000 \mathrm{~s}^{-1}$. The up-ramp of the $25^{\circ} \mathrm{C}$ measurement suggests a small non-zero intercept; however, given the noise in the adjacent measurement data and possible inertial effects of the rotor, this intercept does not appear to be significantly different than zero. The $60^{\circ} \mathrm{C}$ measurement data show a slight down-ward curvature up to $600 \mathrm{~s}^{-1}$, but the curvature is not so severe that the behavior could not be characterized as Newtonian. At $600 \mathrm{~s}^{-1}$, there is a well-defined increase in the slope of the $60^{\circ} \mathrm{C}$ flow curve. The sudden nature of this increase and its reproducibility on the flow curve down-ramp are consistent with turbulent slurry flow in the gap between the rotor and cup wall. 


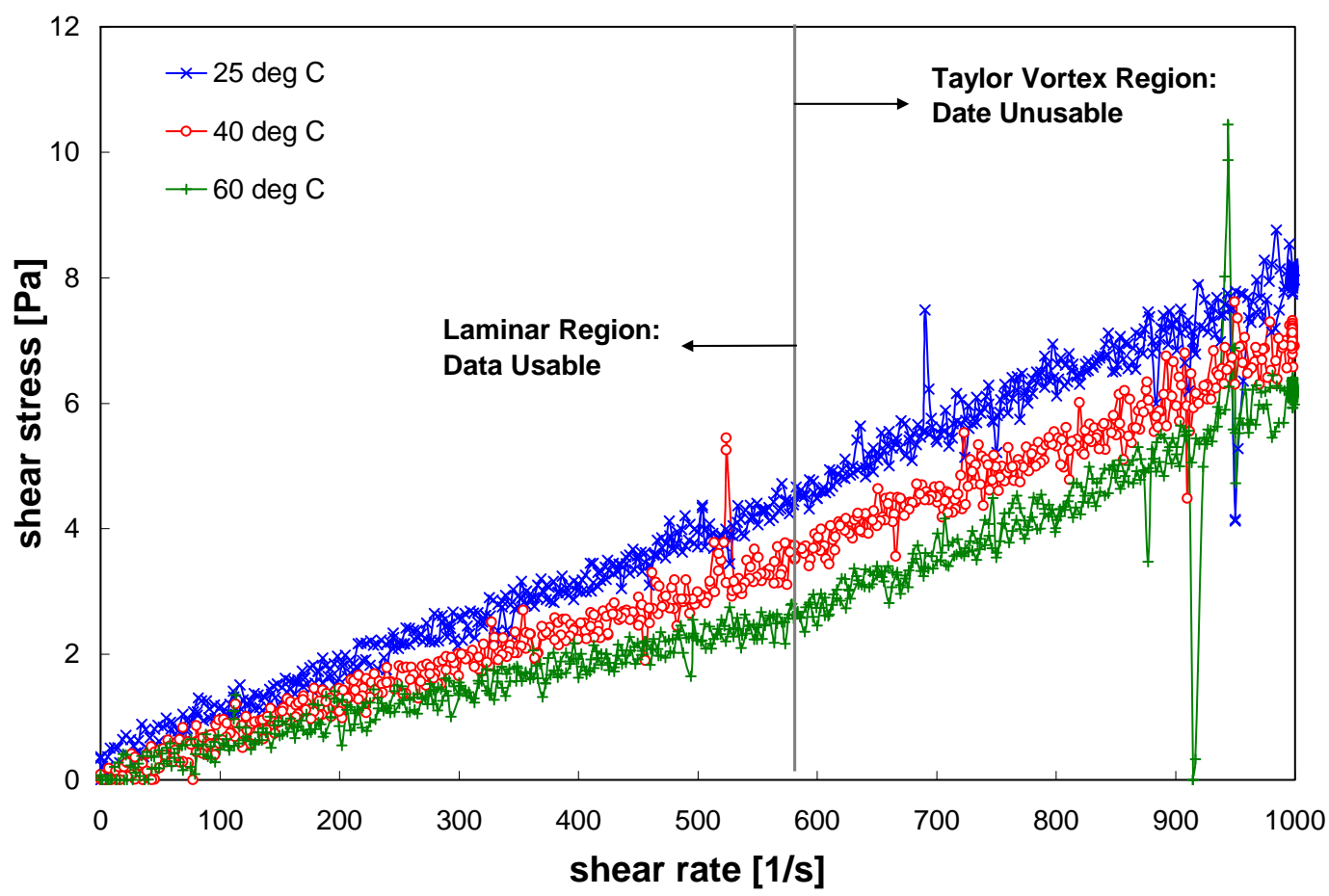

Figure 4. Flow curve (shear stress versus shear rate) for Group 6 Initial Characterization slurry sample TI490-G6-AR-RH at $25^{\circ} \mathrm{C}, 40^{\circ} \mathrm{C}$, and $60^{\circ} \mathrm{C}$ as measured using the MV1 cup and rotor. Note: the second repeat measurement for $25^{\circ} \mathrm{C}$ is shown here, as it is the closest to the $40^{\circ}$ and $60^{\circ} \mathrm{C}$ measurements in time.

Rotational viscometry operates under the assumption of laminar flow. Because most rotational viscometers employ small gap sizes $(\sim 1 \mathrm{~mm})$ and because most tests fluids are non-Newtonian or are Newtonian with high viscosity (i.e., greater than $10 \mathrm{cP}$ ), flow conditions within the gap are typically laminar. However, turbulent flow conditions will be realized during flow curve measurement for low viscosity fluids. For example, flow curve measurements of water (which has a viscosity of $1 \mathrm{cP}$ ) in the MV1 measurement cup system show a transition from laminar to turbulent flow around $200 \mathrm{~s}^{-1}$. This transition point scales approximately with viscosity, such that prediction of transition points for higher viscosity fluids can be made simply by multiplying $200 \mathrm{~s}^{-1}$ by the ratio of the current viscosity to that of water. Thus, $5 \mathrm{cP}$ fluids should have a transition point around $1000 \mathrm{~s}^{-1}$, which is the measurement limit for the flow curves discussed herein. As such, laminar-to-turbulent flow transitions should not be observed for fluids with viscosities greater than $5 \mathrm{cP}$.

Turbulent flow dissipates more energy than laminar flow. As a result, more force is required to maintain constant rotation of the measurement systems in turbulent flow. This is observed in flow curve measurements as an increase in the slope of the shear stress versus shear rate curve (like observed in Figure 4). This increase is not predictable and cannot be analyzed to extract the actual viscosity of the test fluid. Thus, any flow curve data beyond the transition point is usually discarded.

Based on the observations above, Newtonian viscosities for each flow curve measurement taken for the Group 6 slurry were calculated. The results are shown in Table 10 and indicate a slurry viscosity between 4 and $8 \mathrm{cP}$. Both initial and repeat measurements are shown for $25^{\circ} \mathrm{C}$. In addition, a separate 
measurement of viscosity at each temperature was derived by taking the average of the apparent viscosity measured during constant rotation shearing of the slurry prior to measurement (i.e., step 7 of the flow curve measurement outline in Section 7). These measurements will be hereafter referred to as "constant rotation” viscosities.

Table 10. Newtonian viscosities for Group 6 slurry sample TI490-G6-AR-RH. Reported viscosities are determined by least-squares analysis of flow curve data over 0-1000 $\mathrm{s}^{-1}$ unless noted otherwise.

\begin{tabular}{|c|c|c|c|}
\hline TEMPERATURE [ $\left.{ }^{\circ} \mathrm{C}\right]$ & MODEL & $\begin{array}{c}\text { VISCOSITY } \\
\text { [CP] }\end{array}$ & $\overline{\overline{\mathbf{R}^{\mathrm{A}}}}$ \\
\hline 25 (measurement 1 of 2 ) & Average (constant rotation) & $6.3 \pm 0.2$ & $\mathrm{n} / \mathrm{a}$ \\
\hline 25 (measurement 2 of 2 ) & Average (constant rotation) & $7.6 \pm 0.2$ & $\mathrm{n} / \mathrm{a}$ \\
\hline 40 & Average (constant rotation) & $5.7 \pm 0.3$ & $\mathrm{n} / \mathrm{a}$ \\
\hline 60 & Average (constant rotation) & $4.2 \pm 0.1$ & $\mathrm{n} / \mathrm{a}$ \\
\hline 25 (measurement 1 of 2 ) & Newtonian & 6.5 & 0.996 \\
\hline 25 (measurement 2 of 2 ) & Newtonian & 8.0 & 0.994 \\
\hline 40 & Newtonian & 6.9 & 0.991 \\
\hline 60 & Newtonian $^{\mathrm{c}}$ & 4.6 & 0.972 \\
\hline
\end{tabular}

${ }^{\mathrm{a}} \mathrm{R}$ is correlation coefficient of the fit

${ }^{\mathrm{b}}$ Viscosity determined by averaging apparent viscosity during constant rotor rotation at $470 \mathrm{~s}^{-1}$.

${ }^{\mathrm{c}}$ Least-squares analysis restricted to $0-600 \mathrm{~s}^{-1}$

Repeat rheology measurements for Group 6 waste slurries show a time-dependent increase in viscosity. In particular:

- The second measurement of viscosity at $25^{\circ} \mathrm{C}(8.0 \mathrm{cP})$ is significantly higher than the first (6.5 cP).

- Comparison of the flow curve data at $25^{\circ} \mathrm{C}$ also show a uniform increase at all shear rates on the second measurement (see Figure 5).

- Newtonian viscosities derived from flow curve data are always greater than the constant rotation viscosities determined from the shearing step immediately prior to flow curve testing at all temperatures. For example, average of the apparent viscosities measured during the shearing step at $60^{\circ} \mathrm{C}$ indicates a viscosity of $4.2 \pm 0.1 \mathrm{cP}$. The flow curve measured immediately after shearing found a best-fit Newtonian viscosity of $4.6 \mathrm{cP}$. While this observed difference may be a result of experimental error, viscosity measurements at all other temperatures mirror this increase.

The consistency of viscosity increase between each "repeat" measurement strongly suggests that this increase is potentially caused by a macroscopic change in the slurry sample. As discussed for the Group 5 initial characterization rheology samples, an actual increase in the viscosity of the slurry can occur as a result of sample alteration brought about by shear, chemical processes (such as precipitation), settling, or evaporation. 


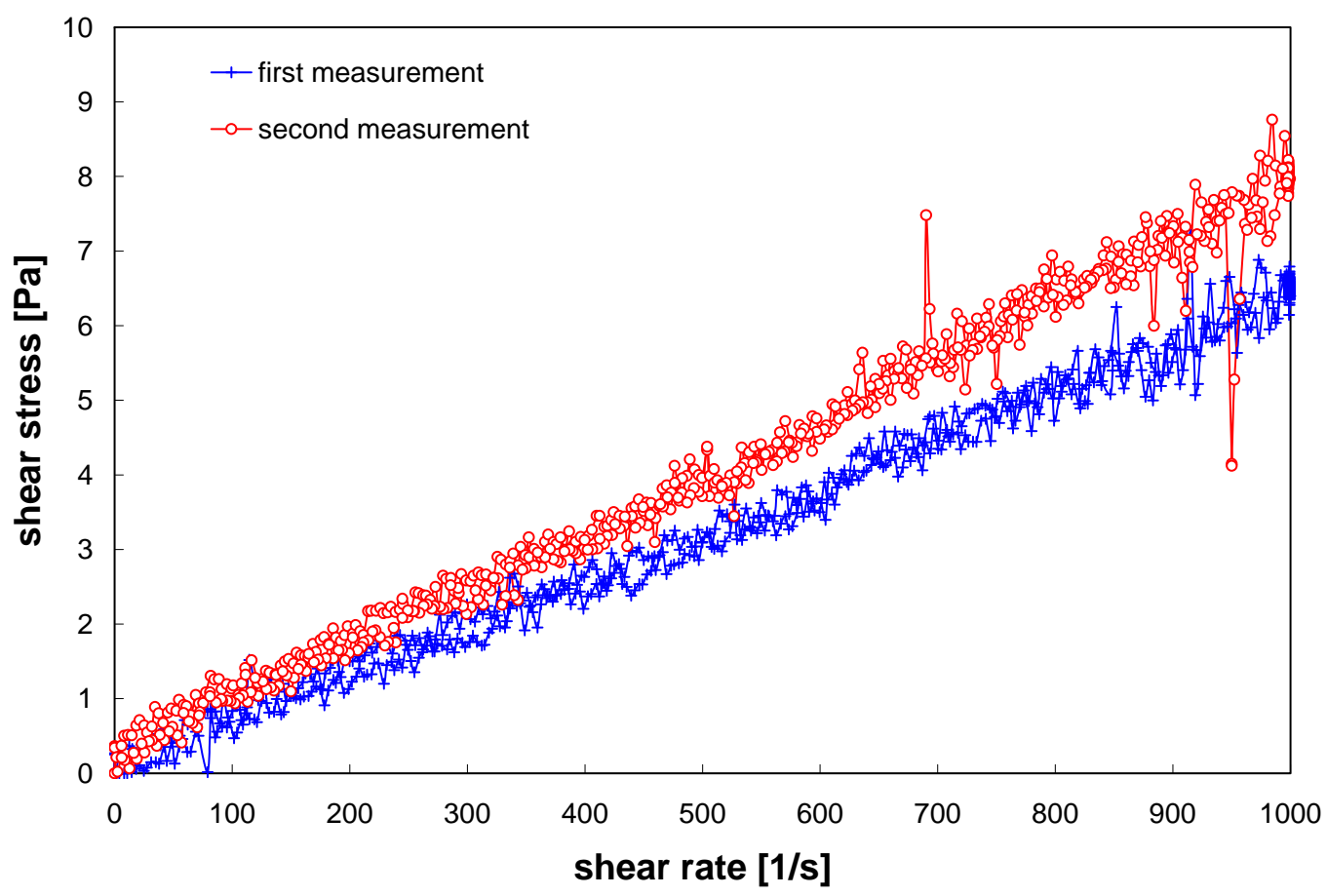

Figure 5. Two repeat measurements of the flow curve (shear stress versus shear rate) for Group 6 Initial Characterization sample TI490-G6-AR-RH at $25^{\circ} \mathrm{C}$ as measured using the MV1 cup and rotor.

For the current measurements, the viscosity increase is difficult to attribute to either macroscopic changes in the sample or changes to the measuring system. Shear effects, which typically lower tank waste viscosity, are not consistent with the increase in shear stress observed for Group 6 wastes. Settling effects do not appear to be the cause as 1) the sludge is mixed immediately prior to testing to re-suspend settled solids, 2) phase separation was not observed when transferring the sample to the measurement cup, and 3) no hysteresis between the up- and down-ramps of the flow curve is observed. Chemical changes are not likely because the slurry was aged one month prior to testing and because, in the current test, stress increase is observed at low-temperature. Although the time-dependent increase in slurry viscosity is consistent with slurry evaporation, significant evaporation should also be accompanied by flow curve hysteresis. Figures 5 and 6 show little to no hysteresis, even at higher temperatures where evaporation is expected be more severe.

Out of the potential causes listed, viscosity increase as a result of slurry evaporation is the most likely cause. An explanation for the lack of flow curve hysteresis is that slurry evaporation occurs only between flow curve measurements when the moisture barrier has been removed from the system. However, if evaporation only occurs when the moisture barrier is removed from the system, the mixing and flow curve viscosities shown in Table 10 should be similar (as flow curve measurements immediately follow mixing). Because of this inconsistency and lack of flow curve hysteresis, evaporation cannot be listed definitively as the cause of slurry viscosity increase. 
With regard to the temperature dependence of the flow curves, the measured slurry viscosity decreases with increasing temperature. Taking the three closest chronological measurements, the Newtonian viscosity decreases from $8.0 \mathrm{cP}$ to $6.9 \mathrm{cP}$ to $4.6 \mathrm{cP}$ as the temperature is increased from $25^{\circ}$ to $40^{\circ}$ to $60^{\circ} \mathrm{C}$, respectively. The viscosities measured by constant rotation show similar behavior. The decrease in slurry viscosity is consistent with the expected behavior. That is, dilute slurries typically show a decrease in apparent viscosity as a result of a decrease in the viscosity of the slurry's liquid suspending phase. Given that evaporation appears to increase viscosity in repeat measurements, the results in Table 10 most likely under-estimate the magnitude of viscosity decrease with temperature.

As point of reference, the apparent viscosity at $33 \mathrm{~s}^{-1}$ is usually provided for slurry samples. For the current measurements, such results would be highly unreliable because $33 \mathrm{~s}^{-1}$ occurs on the lower end of the shear rate range and the shear stresses measured there are close to the RV20-M5 measuring system's lower torque limit. As such, apparent viscosities derived from measurement data near $33 \mathrm{~s}^{-1}$ would be strongly affected by rotor noise and inertia, and for this reason, will not be reported herein. It should be noted that for Newtonian systems, the apparent viscosities as a function of temperature at $33 \mathrm{~s}^{-1}$ should be equivalent to the Newtonian viscosities listed in Table 10.

\section{Sample TI552-G6-R1: Initial Material Low Solids Matrix Slurry (3.2-wt\%)}

Figure 6 shows the results of flow curve testing for sample TI552-G6-R1. This sample corresponds to the low-solids matrix slurry and contains only Group 6 solids and has an undissolved solids concentration of 3.2-wt\%. The behavior of this dilute Group 6 solids slurry is consistent with that observed for the source Group 6 material (TI490-G6-AR-RH). Like the more concentrated Group 6 Initial Characterization sample (TI490-G6-AR-RH), sample TI552-G6-R1 is Newtonian and shows sharp transitions in slope near $600 \mathrm{~s}^{-1}$ that are consistent with the formation of Taylor vortices. In addition, increases in the sample temperature from $25^{\circ} \mathrm{C}$ to $40^{\circ} \mathrm{C}$ and from $40^{\circ} \mathrm{C}$ to $60^{\circ} \mathrm{C}$ cause reduce the slope of the flow curves, indicating a drop in slurry viscosity.

Newtonian viscosities as a function of temperature are derived by fitting the flow curve data (i.e., stress versus shear rate) to Eq. 4 . The range of shear rates analyzed was limited to 0 - $500 \mathrm{~s}^{-1}$ to exclude flow regions potentially effected by Taylor vortices. In addition, constant rotation viscosity measurements were derived from the constant rotational shearing step made prior to each measurement. Here, the viscous stress response of the fluid (sheared at $470 \mathrm{~s}^{-1}$ ) was converted to viscosity using Eq. 3 and time averaged over the duration of the shear step ( 3 minutes). The results of both analyses are shown in Table 11.

Relative to the source group 6 material, which showed viscosities of 4 - $8 \mathrm{cP}$ over the $25^{\circ}$ to $60^{\circ} \mathrm{C}$ test range, the viscosity of the low-solids matrix is reduced and shows only a 3 - $6 \mathrm{cP}$ over the same temperature range. The results in Table 11 also confirm that the viscosity of the low-solids matrix slurry decreases with increasing temperature. As was observed in the source Group 6 material, the repeat viscosity measurement at $25^{\circ} \mathrm{C}$ for sample TI522-G6-R1 shows a higher viscosity than the primary measurement. This may be a result of evaporation or changes to the solids structure as a result of shear on the previous tests. Evaporation is suspected in the current measurements, as it has been observed in all previous flow curve tests on actual waste samples (see References [4] and [5]). With regard to the consequence on the results reported in Table 11, evaporation would tend to increase slurry concentration 
and, as a result, increase the measured slurry viscosity. If this is the case, then the current studies will 1) over-estimate the actual viscosity of the slurry and 2) underestimate the drop in slurry viscosity with temperature.

The viscosities determined by 1) fitting the flow curve data to Eq. 4 and 2) by time-averaging the viscosity measured during constant rotation at $470 \mathrm{~s}^{-1}$ agree well with each other. Indeed, the difference between the results of the two approaches, which ranges from 0.1 to $0.3 \mathrm{cP}$, is almost equivalent to the standard deviation of each measurement, $\sim 0.2 \mathrm{cP}$. As such, it is suspected that any statistically treatment of these results would find differences between the fitting analysis and constant rotation measurement methods statistically insignificant.

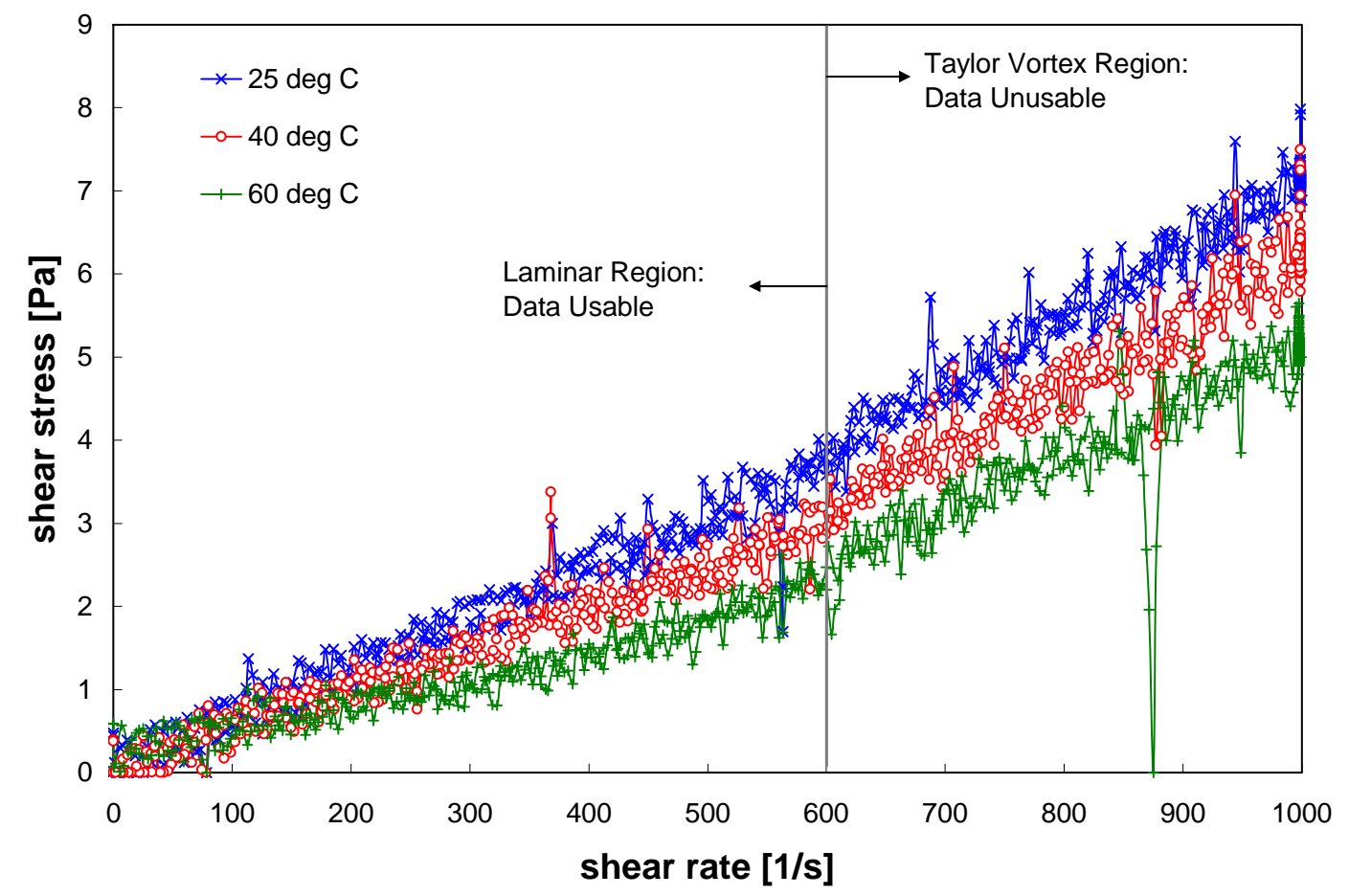

Figure 6. Flow curve (shear stress versus shear rate) for Group 5/6 low-solids matrix slurry sample TI552-G6-R1 at $25^{\circ} \mathrm{C}, 40^{\circ} \mathrm{C}$, and $60^{\circ} \mathrm{C}$ as measured using the MV1 cup and rotor. Note: the second repeat measurement for $25^{\circ} \mathrm{C}$ is shown here, as it is the closest to the $40^{\circ}$ and $60^{\circ} \mathrm{C}$ measurements in time. 
Table 11. Newtonian viscosities for Group 5/6 slurry sample TI552-G6-R1 at $25^{\circ} \mathrm{C}, 40^{\circ} \mathrm{C}$, and $60^{\circ} \mathrm{C}$. Note: the error reported for constant rotation is the standard deviation of stress over the 3 minute averaging period.

\begin{tabular}{|c|c|c|c|}
\hline TEMPERATURE [ $\left.{ }^{\circ} \mathrm{C}\right]$ & $\overline{\text { MODEL }}$ & $\begin{array}{c}\text { VISCOSITY } \\
\text { [CP] }\end{array}$ & $\overline{\overline{\mathbf{R}^{\mathbf{A}}}}$ \\
\hline 25 (measurement 1 of 2 ) & Average (constant rotation) $^{\mathrm{b}}$ & $5.1 \pm 0.2$ & $\mathrm{n} / \mathrm{a}$ \\
\hline 25 (measurement 2 of 2 ) & Average (constant rotation) $^{b}$ & $6.2 \pm 0.2$ & $\mathrm{n} / \mathrm{a}$ \\
\hline 40 & Average (constant rotation) $^{b}$ & $4.8 \pm 0.2$ & $\mathrm{n} / \mathrm{a}$ \\
\hline 60 & Average (constant rotation) $^{b}$ & $3.3 \pm 0.2$ & $\mathrm{n} / \mathrm{a}$ \\
\hline 25 (measurement 1 of 2 ) & Newtonian $^{c}$ & 5.2 & 0.979 \\
\hline 25 (measurement 2 of 2 ) & Newtonian $^{\mathrm{C}}$ & 6.2 & 0.975 \\
\hline 40 & Newtonian $^{c}$ & 5.0 & 0.958 \\
\hline 60 & Newtonian $^{c}$ & 3.0 & 0.941 \\
\hline
\end{tabular}

${ }^{\mathrm{a}} \mathrm{R}$ is correlation coefficient of the fit

${ }^{\mathrm{b}}$ Viscosity determined by averaging apparent viscosity during constant rotor rotation at $470 \mathrm{~s}^{-1}$.

${ }^{c}$ Least-squares analysis restricted to $0-500 \mathrm{~s}^{-1}$

As before, apparent viscosities derived from measurement data near $33 \mathrm{~s}^{-1}$ will not be reported herein. It is recommended that engineering design use the Newtonian viscosities listed in Table 11.

\section{Sample TI552-G6-R2: Initial Material High Solids Matrix Slurry (13.2-wt\%)}

Figure 7 shows the results of flow curve testing for sample TI552-G6-R2. This sample corresponds to the high-solids matrix slurry and contains both Group 5 and Group 6 solids and has an undissolved solids concentration of 13.2-wt\%. Sample TI552-G6-R2 shows non-Newtonian behavior at all temperatures studied, with the flow curves showing finite yield points and near-linear to slightly shearthinning stress behavior over 0 to $1000 \mathrm{~s}^{-1}$ depending on the measurement temperature. Flow curve hysteresis is absent in the $25^{\circ}$ and $40^{\circ} \mathrm{C}$ measurements. In contrast, measurable hysteresis is present in the $60^{\circ} \mathrm{C}$ flow curve, with the down-ramp showing a 1-2 Pa increase in stress over the range of shear rates.

The change observed in the flow curves with increasing temperature is not consistent. Specifically, the increase in temperature from $25^{\circ}$ to $40^{\circ} \mathrm{C}$ appears to have no impact on the slurry yield stress but does appear to lower its consistency (i.e., the slope of the near-linear portion of the flow curve). The decrease in consistency is comparable to the decrease in viscosity observed in the group 6 source material and low-solids matrix slurries. At $60^{\circ} \mathrm{C}$, the stress response of the material increases dramatically, with the range of stresses ranging from 8-20 Pa relative to the 3-15 Pa range observed over the same shear rate range $\left(0-1000 \mathrm{~s}^{-1}\right)$ at $40^{\circ} \mathrm{C}$.

The increase in shear stress described in the preceding paragraph is accompanied by flow curve hysteresis (as discussed in the preceding paragraph) and an increase in the downward curvature (i.e., shear-thinning behavior) of the flow curve. Because both stress increase and hysteresis occur at the highest measurement temperature, they are believed to be a result of evaporation of the slurry suspending phase and the resulting increase in slurry solids concentration it causes. It should be noted that the impact of solids concentration and evaporation effects on the high-solids matrix samples will be more 
severe than for the low-solids matrix (see discussion of Sample TI540-G5-R1 in Reference [6]) and could explain why hysteresis is not observed in the low-solids matrix samples.

On the other hand, the source material for group 6 is also free of hysteresis effects, and as such, concentration effects alone may not fully explain the origin of hysteresis observed in TI552-G6-R2. The high-solids matrix slurry is a mixture of Group 5 and Group 6 solids. Hysteresis has been commonly observed for slurries derived from waste processing group 5 (see Reference [6]), and as such, the hysteresis could also be purely a result of group 5 solids interactions in the slurry mixture.

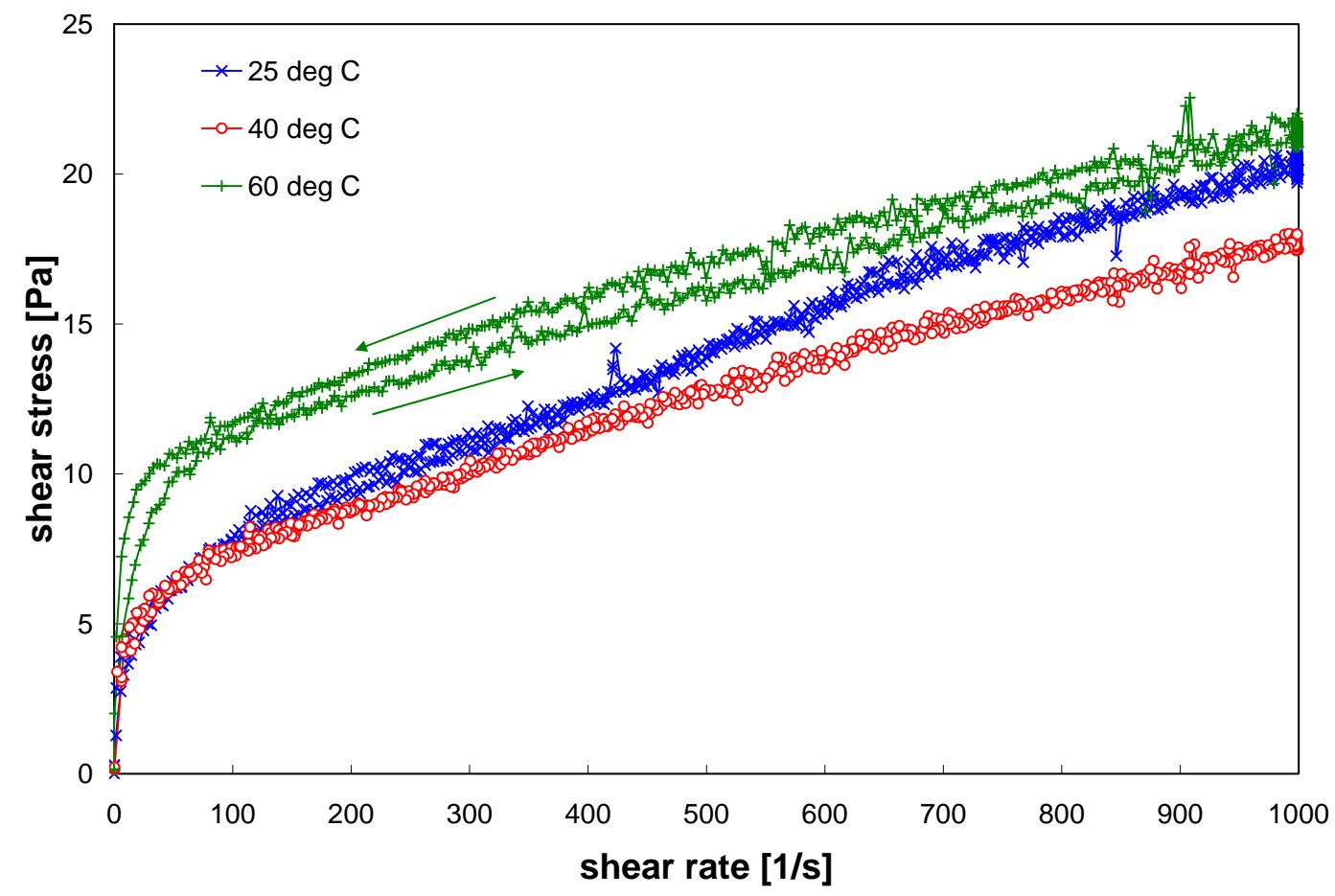

Figure 7. Flow curve (shear stress versus shear rate) for Group 5/6 low-solids matrix slurry sample TI552-G6-R2 at $25^{\circ} \mathrm{C}, 40^{\circ} \mathrm{C}$, and $60^{\circ} \mathrm{C}$ as measured using the MV1 cup and rotor. Note: the second repeat measurement for $25^{\circ} \mathrm{C}$ is shown here, as it is the closest to the $40^{\circ}$ and $60^{\circ} \mathrm{C}$ measurements in time.

Finally, it should be noted that the flow curves for TI552-G6-R2 are similar to group 5 slurry samples in that they show significant curvature in the $0-100 \mathrm{~s}^{-1}$ region. As before, this curvature is most likely a result of sample slip and elasticity as well as limited rotational sampling of the slurry. The degree to which these impact the measurement appears to be lessened (relative to Group 5 slurry samples) as high curvature is restricted to shear rates of $0-100 \mathrm{~s}^{-1}$ rather than $0-200 \mathrm{~s}^{-1}$ as observed in concentrated group 5 sample (cf. Reference [6]).

Table 12 summarizes the best-fit rheological parameters for flow curve data for sample TI5552G6-R2. Only Bingham-Plastic and Herschel-Bulkley models were evaluated. Bingham-Plastic analyses were restricted to a shear rate range of 200 to $1000 \mathrm{~s}^{-1}$ to avoid the highly non-linear region at shear rates approaching zero. Herschel-Bulkley analyses employ the full measurement range (0 to $\left.1000 \mathrm{~s}^{-1}\right)$. The 
Bingham-Plastic fitting results confirm the temperature behaviors observed in the flow curve.

Specifically, they show that 1 ) the yield points for the $25^{\circ} \mathrm{C}$ (2 of 2) and $40^{\circ} \mathrm{C}$ measurements are similar, 2) the consistency of $13 \mathrm{cP}$ at $25^{\circ} \mathrm{C}$ is slightly higher than the consistency of $11 \mathrm{cP}$ at $40^{\circ} \mathrm{C}$, and 3) that there is a large jump in yield (7.2 to $11 \mathrm{~Pa}$ ) as temperature is increased from 40 to $60^{\circ} \mathrm{C}$. In addition, the Herschel-Bulkley flow indices tend to decrease with increasing temperature, indicating the slurry is becoming more non-Newtonian as temperature is increased (as observed in Figure 7).

With regards to measurement repeatability, the two measurements at $25^{\circ} \mathrm{C}$ show similar consistency but different yield stress. Between repeat measurements, the yield stress increases from 6.1 to 7.4 Pa based on Bingham-Plastic fitting parameters. This increase is consistent with evaporation effects observed in both Group 5 and Group 6 slurries.

Table 12. Results of fitting analysis for rheology sample TI552-G6-R2. This sample corresponds to a high concentration (13.2-wt\%) pre-caustic-leach Group 5/6 slurry mixture.

\begin{tabular}{||c|c|c|c|c|c||}
\hline MODEL & $\begin{array}{c}\text { TEMPERATURE } \\
{\left[{ }^{\circ} \mathbf{C}\right]}\end{array}$ & $\begin{array}{c}\text { YIELD } \\
\text { STRESS } \\
{[\text { PA }]}\end{array}$ & $\begin{array}{c}\text { CONSISTENCY } \\
{\left[\mathbf{P A} \cdot \mathbf{S}^{\mathbf{N}}\right]}\end{array}$ & $\begin{array}{c}\text { FLOW } \\
\text { INDEX }\end{array}$ & $\mathbf{R}$ \\
\hline \multirow{3}{*}{$\begin{array}{c}\text { Bingham-Plastic } \\
\left(200-1000 \mathrm{~s}^{-1}\right)\end{array}$} & $25(1$ of 2$)$ & 6.1 & 0.014 & $\mathrm{n} / \mathrm{a}$ & 0.997 \\
\cline { 2 - 6 } & $25(2$ of 2$)$ & 7.4 & 0.013 & $\mathrm{n} / \mathrm{a}$ & 0.997 \\
\cline { 2 - 6 } & 40 & 7.2 & 0.011 & $\mathrm{n} / \mathrm{a}$ & 0.995 \\
\cline { 2 - 6 } & 60 & 11 & 0.010 & $\mathrm{n} / \mathrm{a}$ & 0.997 \\
\hline \multirow{3}{*}{$\begin{array}{c}\text { Herschel-Bulkley } \\
\left(0-1000 \mathrm{~s} \mathrm{~s}^{-1}\right)\end{array}$} & $25(1$ of 2$)$ & 3.7 & 0.083 & 0.768 & 0.996 \\
\cline { 2 - 6 } & $25(2$ of 2$)$ & 3.6 & 0.19 & 0.651 & 0.998 \\
\cline { 2 - 7 } & 40 & 4.0 & 0.16 & 0.646 & 0.987 \\
\cline { 2 - 7 } & 60 & 6.7 & 0.36 & 0.537 & 0.991 \\
\hline
\end{tabular}

The quality of the data fits is demonstrated in Figure 8, which shows both the Bingham-Plastic and Herschel-Bulkley fits applied to the flow curve at $40^{\circ} \mathrm{C}$. The Bingham-Plastic model provides a reasonable estimate of the shear rate behavior over 300 to $1000 \mathrm{~s}^{-1}$, but as expected, tends to over-predict the magnitude of the yield point. The Herschel-Bulkley accurately captures the shear rate behavior, including both the yield and flow curve curvature, over the entire range of shear rates.

Because of concerns with poor rotational sampling, slip, and elasticity, there is some uncertainty associated with the low-shear behavior of the slurry, namely the yield stress. As discussed previously for the Group 5 initial characterization sample G5-RH2, the actual yield can be roughly bounded by the yield points derived from Herschel-Bulkley and Bingham-Plastic fits, with the Herschel-Bulkley yield stress providing the lower bound and the Bingham-Plastic providing the upper bound. In this case, the yield stress for slurry TI552-G6-R2 can be reasonably expected to fall between 3.6 and $7.4 \mathrm{~Pa}$ at $25^{\circ} \mathrm{C}, 4.0$ and $7.2 \mathrm{~Pa}$ at $40^{\circ} \mathrm{C}$, and 6.7 and $11 \mathrm{~Pa}$ at $60^{\circ} \mathrm{C}$ when neglecting the effects of evaporation on the measured yield.

As point of reference, the apparent viscosity at $33 \mathrm{~s}^{-1}$ is derived from each measurement. The results are provided in Table 13. For each temperature, this reference point is determined from the average of up-ramp and down-ramp flow curve measurement data and from the fitting parameters provided in Table 12. 
Table 13. Apparent viscosity of sample TI552-G6-R2 at $33 \mathrm{~s}^{-1}$.

\begin{tabular}{||c|c|c|c||}
\hline \hline TEMPERATURE & \multirow{2}{*}{$\begin{array}{c}\eta_{\text {APP }}(\mathrm{CP}) \\
\text { FROM }\end{array}$} & \multicolumn{2}{|c|}{$\eta_{\text {APP }}$ (CP) } \\
\cline { 3 - 4 } & $\begin{array}{c}\text { MEASUREMENT } \\
\text { DATA }\end{array}$ & Bingham Plastic & Herschel-Bulkley \\
\cline { 3 - 4 } & 150 & 200 & 150 \\
\hline $25(1$ of 2$)$ & 170 & 240 & 160 \\
\hline $25(2$ of 2$)$ & 170 & 230 & 170 \\
\hline 40 & 290 & 360 & 270 \\
\hline 60 & \multicolumn{2}{|c}{} \\
\hline
\end{tabular}

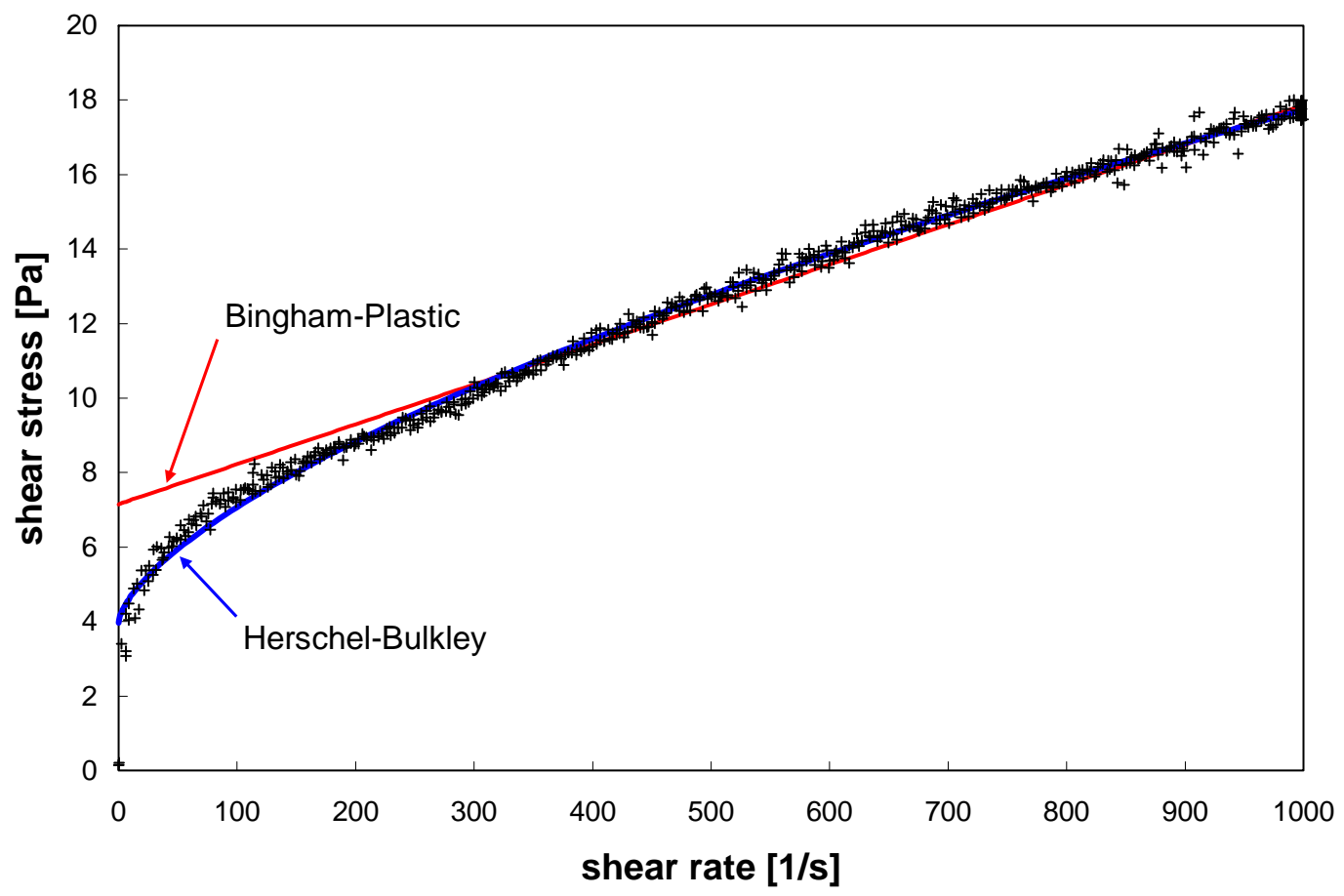

Figure 8. Model fits of flow curve data for Group 5/6 CUF slurry sample TI552-G6-R2 at $40^{\circ} \mathrm{C}$. Bingham plastic model is restricted to $200-1000 \mathrm{~s}^{-1}$. Hershel-Bulkley considers the full shear rate range of $0-1000 \mathrm{~s}^{-1}$.

Sample TI552-G6-R3: Caustic-Leached and Dewatered Slurry (8.9-wt\%)

Figure 9 shows the results of flow curve testing for sample TI552-G6-R3. This sample corresponds to a Group 5/6 slurry mixture that has been caustically leached for 24 hours at $100^{\circ} \mathrm{C}$ and subsequently dewatered in the cross-flow ultrafilter. It has an undissolved solids concentration of 8.9wt\%. Flow curves for sample TI552-G6-R3 show non-Newtonian behavior at all temperatures and are consistent with the pre-caustic leach high-solids matrix slurry. The current flow curves exhibit finite yield points, are shear-thinning over 0-200 s-1, and are near-linear beyond $200 \mathrm{~s}^{-1}$.

Hysteresis appears at specific shear regions for all flow curves for sample TI552-G6-R3. The regions of hysteresis for $25^{\circ} \mathrm{C}$ and $40^{\circ} \mathrm{C}$ flow curves are 200-600 s$~^{-1}$ and $800-1000 \mathrm{~s}^{-1}$, respectively, and 
most likely correspond to increased torque resulting from the transfer and shearing of excess slurry in the upper rotor recess to the wall. Because the driving force for transfer is the rotational inertia and the resisting force is the slurry yield point, transfer of material from the recess to the wall occurs at a specific rotor rotational rate for each test material. Transfer causes an increase in the observed torque because its effects an increase in the height of sheared material (i.e., increases the effective fluid-rotor contact area). Torque hysteresis results from material transfer because the material geometries associated with excess material transferring from recess to wall and with excess material sliding down the wall back into the recess are different. It should be noted that this form of flow curve hysteresis does not appear to effect the $60^{\circ} \mathrm{C}$ measurement. This discrepancy may result from differences in excess material removal during step 10 of the flow curve measurement procedure. On the other hand, the hysteresis observed at $60^{\circ} \mathrm{C}$ appears to be more consistent with temperature driven evaporation. Here, the hysteresis is greatest at low shear-rates (where the times differential between flow curve up- and down-ramps is greatest).

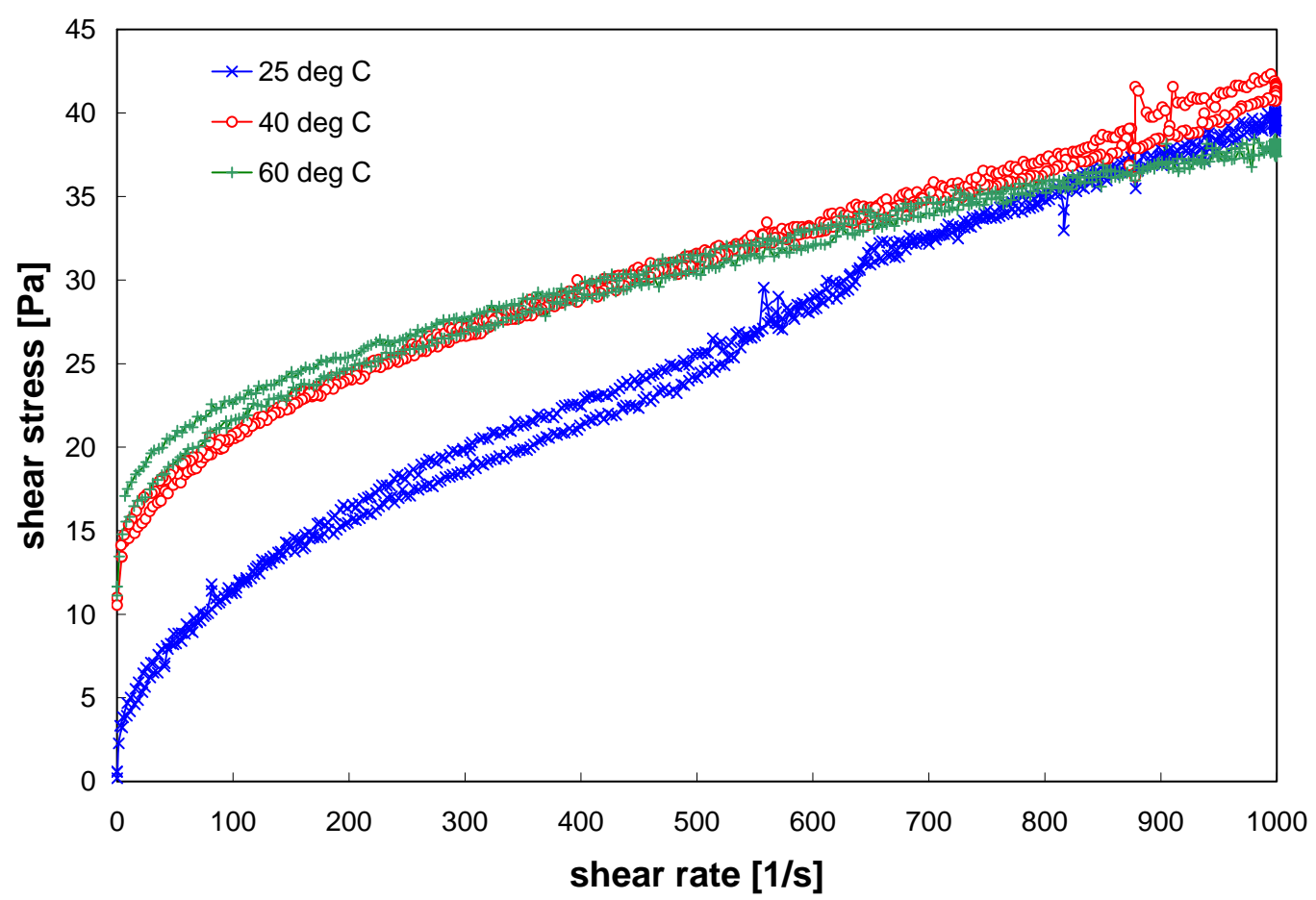

Figure 9. Flow curve (shear stress versus shear rate) for Group 5/6 caustic-leached and dewatered slurry sample TI552-G6-R3 at $25^{\circ} \mathrm{C}, 40^{\circ} \mathrm{C}$, and $60^{\circ} \mathrm{C}$ as measured using the MV1 cup and rotor. Note: the second repeat measurement for $25^{\circ} \mathrm{C}$ is shown here, as it is the closest to the $40^{\circ}$ and $60^{\circ} \mathrm{C}$ measurements in time.

The flow curve behavior with respect to increasing temperature is unusual. In particular, the higher temperature measurements $\left(40^{\circ}\right.$ and $\left.60^{\circ} \mathrm{C}\right)$ are both significantly higher than the $25^{\circ} \mathrm{C}$ at all shear rates but the highest $\left(800-1000 \mathrm{~s}^{-1}\right)$. That is, the yield point for the $25^{\circ} \mathrm{C}$ is only $3-5 \mathrm{~Pa}$, whereas those for the $40^{\circ}$ and $60^{\circ} \mathrm{C}$ measurements range from 15 to $20 \mathrm{~Pa}$. The consistency, as judged by the slope of the flow curve at shear rates greater than $200 \mathrm{~s}^{-1}$, appears to decrease as a function of temperature, with the $25^{\circ}$ show a much higher consistency than both 40 and $60^{\circ} \mathrm{C}$ measurements. With regards to the repeatability of the flow curve at $25^{\circ} \mathrm{C}$, both first and second flow curve measurements show similar yield 
points and flow curve slopes. As such, it is unknown if the dramatic change in flow curves from $25^{\circ}$ to $40^{\circ} \mathrm{C}$ is a result of a significant change in the bulk structure of this slurry sample or simply a result of an equipment error (such as rotor misalignment). It is interesting to note that a similar jump was observed in the flow curves for the pre-leach high-solids matrix slurry (sample TI552-G6-R2) as temperature was increased from $40^{\circ}$ to $60^{\circ} \mathrm{C}$. This suggests that there may be significant changes to the particle-particle interactions and internal slurry structure for group 5/6 slurry mixtures as they are heated and sheared.

Table 14 summarizes the best-fit rheology parameters for flow curve data for sample TI5552-G6R3. As with previous Group 5/6 CUF samples, only Bingham-Plastic and Herschel-Bulkley models were evaluated. Bingham-Plastic analyses were restricted to a shear rate range of 200 to $1000 \mathrm{~s}^{-1}$ to avoid the highly non-linear region at shear rates approaching zero. Herschel-Bulkley analyses employ the full measurement range ( 0 to $\left.1000 \mathrm{~s}^{-1}\right)$.

The Bingham-Plastic fitting results confirm the phenomena described in the preceding paragraphs with regards to temperature. Specifically, they show that 1 ) the both primary and repeat flow curve measurements show roughly the same yield stress and consistency, 2) a significant jump occurs in both yield stress ( $\sim 10 \mathrm{~Pa}$ increase) and consistency ( $\sim .010 \mathrm{~Pa} \cdot \mathrm{s}$ decrease) occurs between $25^{\circ}$ and $40^{\circ} \mathrm{C}$, and 3 ) a smaller but continued change occurs between 40 and $60^{\circ} \mathrm{C}$. In addition, the Herschel-Bulkley flow indices tend to decrease with increasing temperature, indicating the slurry is becoming more nonNewtonian as temperature is increased (as observed in Figure 7). Finally, with regards to measurement repeatability, the two measurements at $25^{\circ} \mathrm{C}$ show similar consistency but different yield stress. Between repeat measurements, the yield stress increases from 9.9 to 11 Pa based on Bingham-Plastic fitting parameters. This increase is consistent with evaporation effects observed in the previous sample (TI552G6-R2).

Table 14. Results of fitting analysis for rheology sample TI552-G6-R3. This sample corresponds to a caustic-leached and dewatered Group 5/6 slurry mixture (8.9-wt\%).

\begin{tabular}{||c|c|c|c|c|c||}
\hline \hline MODEL & $\begin{array}{c}\text { TEMPERATURE } \\
{\left[{ }^{\circ} \mathbf{C}\right]}\end{array}$ & $\begin{array}{c}\text { YIELD } \\
\text { STRESS } \\
{[\mathbf{P A}]}\end{array}$ & $\begin{array}{c}\text { CONSISTENCY } \\
{\left[\mathbf{P A} \cdot \mathbf{S}^{\mathbf{N}}\right]}\end{array}$ & $\begin{array}{c}\text { FLOW } \\
\text { INDEX }\end{array}$ & $\mathbf{R}$ \\
\hline \multirow{3}{*}{$\begin{array}{c}\text { Bingham-Plastic } \\
\left(200-1000 \mathrm{~s}^{-1}\right)\end{array}$} & $25(1$ of 2$)$ & 9.9 & 0.029 & $\mathrm{n} / \mathrm{a}$ & 0.984 \\
\cline { 2 - 6 } & $25(2$ of 2$)$ & 11 & 0.029 & $\mathrm{n} / \mathrm{a}$ & 0.996 \\
\cline { 2 - 6 } & 40 & 21 & 0.020 & $\mathrm{n} / \mathrm{a}$ & 0.997 \\
\cline { 2 - 6 } & 60 & 23 & 0.015 & $\mathrm{n} / \mathrm{a}$ & 0.992 \\
\hline \multirow{3}{*}{$\begin{array}{c}\text { Herschel-Bulkley } \\
\left(0-1000 \mathrm{~s} \mathrm{~s}^{-1}\right)\end{array}$} & $25(1$ of 2$)$ & 3.7 & 0.25 & 0.72 & 0.994 \\
\cline { 2 - 6 } & $25(2$ of 2$)$ & 3.8 & 0.29 & 0.70 & 0.998 \\
\cline { 2 - 7 } & 40 & 14 & 0.32 & 0.64 & 0.998 \\
\cline { 2 - 7 } & 60 & 14 & 0.86 & 0.48 & 0.997 \\
\hline
\end{tabular}

The quality of the data fits is demonstrated in Figure 10, which shows both the Bingham-Plastic and Herschel-Bulkley fits applied to the flow curve at $40^{\circ} \mathrm{C}$. The curve fits are comparable to those seen in the previous sample, TI552-G6-R3. Overall, the Herschel-Bulkley provides the closest fit of the data and is able to adequately capture both the magnitude and curvature of data over the entire shear rate range tested. Like before, the low-shear flow curve data are subject to measurement errors such as slip, elasticity, and poor rotational sampling, all of which may confound measurement of the true yield point. 
Based on the Herschel-Bulkley and Bingham-Plastic fits, the yield can reasonably be expected to range between 3.7 and $11 \mathrm{~Pa}$ at $25^{\circ} \mathrm{C}, 14$ and $21 \mathrm{~Pa}$ at $40^{\circ} \mathrm{C}$, and 14 and $23 \mathrm{~Pa}$ at $60^{\circ} \mathrm{C}$.

Finally, as point of reference, the apparent viscosity at $33 \mathrm{~s}^{-1}$ is derived from each measurement. The results are provided in Table 15. For each temperature, this reference point is determined from the average of up-ramp and down-ramp flow curve measurement data and from the fitting parameters provided in Table 14. As expected from the quality of the fit shown in Figure 10, the apparent viscosities determined from the measured data and that predicted by the Herschel-Bulkley fit match closely.

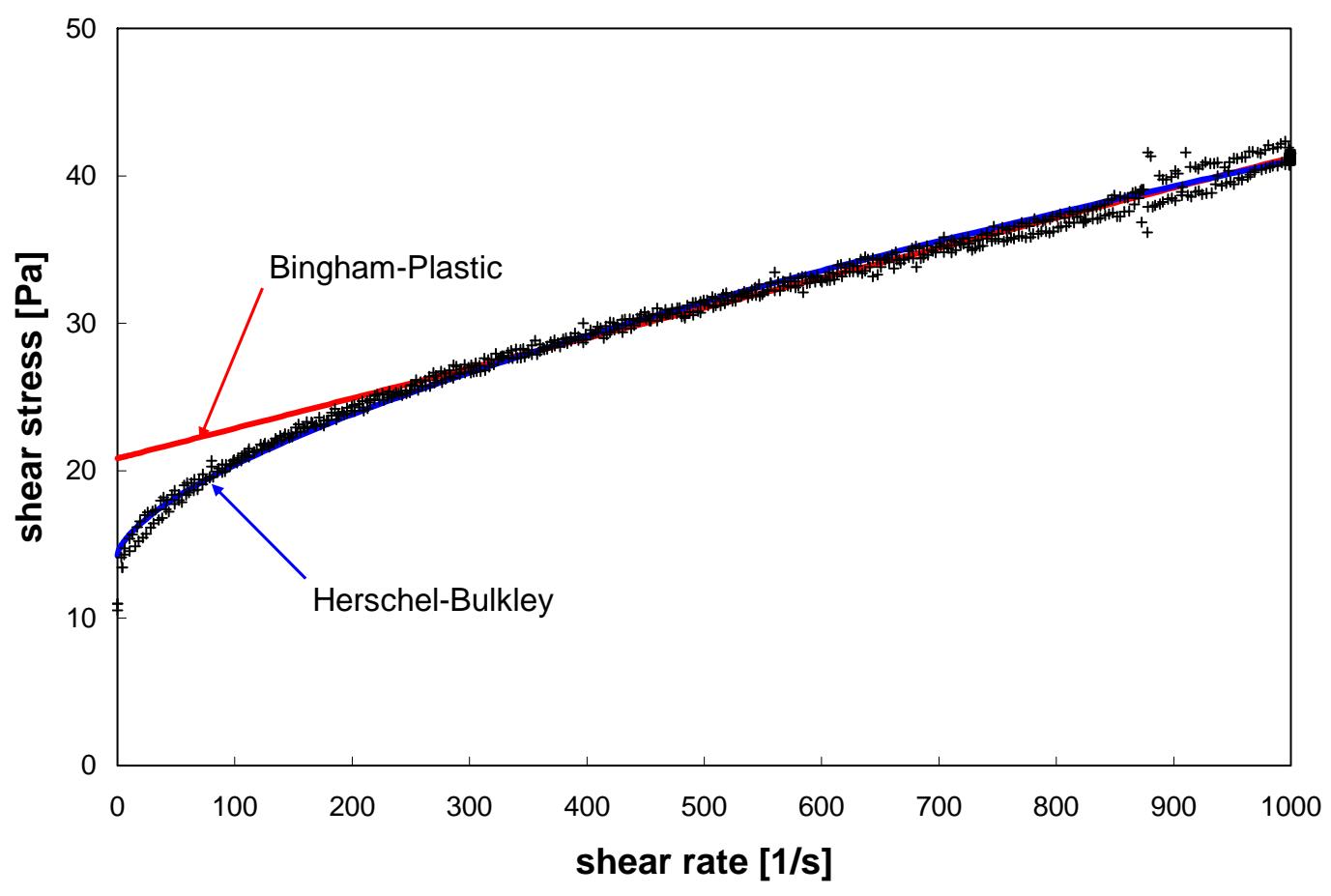

Figure 10. Model fits of flow curve data for Group 5/6 CUF slurry sample TI552-G6-R3 at $40^{\circ} \mathrm{C}$. Bingham plastic model is restricted to $200-1000 \mathrm{~s}^{-1}$. Hershel-Bulkley considers the full shear rate range of $0-1000 \mathrm{~s}^{-1}$.

Table 15. Apparent viscosity of sample TI552-G6-R3 at $33 \mathrm{~s}^{-1}$.

\begin{tabular}{||c|c|c|c||}
\hline \hline TEMPERATURE & \multirow{2}{*}{$\begin{array}{c}\eta_{\text {APP }}(\mathrm{CP}) \\
\text { FROM }\end{array}$} & \multicolumn{2}{|c||}{$\eta_{\text {APP }}$ (CP) } \\
\cline { 3 - 4 } & $\begin{array}{c}\text { FEASUREMENT } \\
\text { DATA }\end{array}$ & Bingham Plastic & Herschel-Bulkley \\
\cline { 3 - 4 } & 220 & 330 & 200 \\
\hline $25(1$ of 2$)$ & 210 & 360 & 220 \\
\hline $25(2$ of 2$)$ & 520 & 650 & 520 \\
\hline 40 & 570 & 720 & 570 \\
\hline 60 & \multicolumn{2}{|}{} \\
\hline
\end{tabular}


Sample TI552-G6-R4: Caustic-Leached, Dewatered, and Washed Slurry (12.8-wt\%)

Figure 11 shows the results of flow curve testing for sample TI552-G6-R4. This sample corresponds to a Group 5/6 slurry mixture that was caustically leached for 24 hours at $100^{\circ} \mathrm{C}$ and subsequently dewatered and washed in a cross-flow ultrafilter system. It has an undissolved solids concentration of 12.8-wt\%. Flow curves for sample TI552-G6-R4 show non-Newtonian behavior at all temperatures and are consistent with the pre-caustic leach high-solids matrix slurry. The current flow curves exhibit finite yield points and are shear-thinning over most of the shear rate range tested.

Flow curve hysteresis is absent in the $25^{\circ} \mathrm{C}$ measurement but is clearly evident in the $40^{\circ} \mathrm{C}$ and $60^{\circ} \mathrm{C}$ measurements. The degree of hysteresis increases with temperature, as the difference between stress observed in the up and down-ramp is much larger in the $60^{\circ} \mathrm{C}$ measurement $(\sim 3-5 \mathrm{~Pa})$ relative to the $40^{\circ} \mathrm{C}(\sim 1-2 \mathrm{~Pa})$. In all cases, the down-ramp shows the higher stress response, indicating an increase in slurry apparent viscosity with time. Based on these observations, it is likely that evaporation is the cause of flow curve hysteresis for sample TI552-G6-R4.

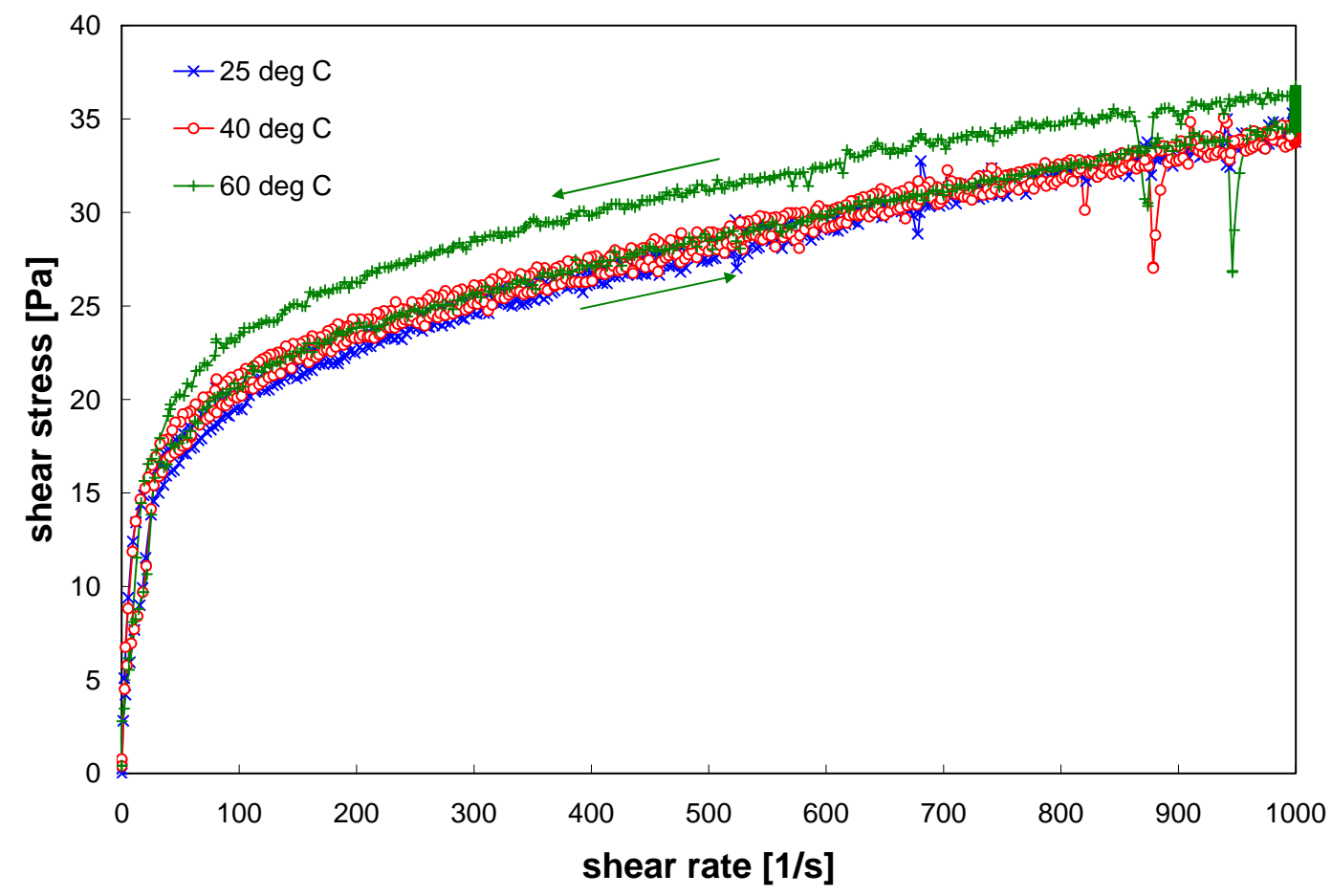

Figure 11. Flow curve (shear stress versus shear rate) for Group 5/6 caustic-leached, dewatered, and washed slurry sample TI552-G6-R4 at $25^{\circ} \mathrm{C}, 40^{\circ} \mathrm{C}$, and $60^{\circ} \mathrm{C}$ as measured using the MV1 cup and rotor. Note: the second repeat measurement for $25^{\circ} \mathrm{C}$ is shown here, as it is the closest to the $40^{\circ}$ and $60^{\circ} \mathrm{C}$ measurements in time.

Changes in flow curve behavior as sample temperature is increased from $25^{\circ}$ to $60^{\circ} \mathrm{C}$ are difficult to characterize, as they appear to show competing effects that tend to increase and lower apparent viscosity. Overall, an increase in the viscous stress response is observed with increasing temperature; however, this increase is associated entirely with flow curve hysteresis. Although difficult to distinguish from measurement noise, the hysteresis appears to be masking a slight decrease in slurry stress response 
with increase temperature. This is evidenced by the fact that the up-ramp at both $40^{\circ}$ and $60^{\circ} \mathrm{C}$ shows a lower viscous stress response relative to the down-ramp for the previous temperature set-point $\left(25^{\circ}\right.$ and $40^{\circ} \mathrm{C}$, respectively). Because the magnitude of the observed decrease is close the limit of instrument sensitivity ( $\sim .5 \mathrm{~Pa})$, it cannot be determined with confidence whether this decrease is real or an artifact of the measurement. It can be postulated that, if the effects causing flow curve hysteresis could be minimized, the decrease in slurry apparent viscosity may become more noticeable.

As stated before, hysteresis is believed to be caused by evaporation of the sample suspending phase, and subsequent increase in sample solids concentration that causes. To minimize evaporation and the change in rheology, a wetted moisture barrier is installed on the rheometer (see Step 5 of the flow curve testing description in Section 7 of this report for details). However, during the first of two flow curve measurements at $25^{\circ} \mathrm{C}$ for sample TI552-G6-R4, the moisture barrier was inadvertently left off the viscometer. To correct this, the second of the two measurements at $25^{\circ} \mathrm{C}$ was performed as usual, that is, with the moisture barrier installed. As such, flow curve testing at $25^{\circ} \mathrm{C}$ for TI552-G6-R4 provided a unique opportunity to confirm 1) that the moisture barrier was functioning as intended and 2) that the hysteresis typically observed in the flow curves is a result of evaporation. The results of the primary (without moisture barrier) and replicate (with moisture barrier) flow curve measurements at $25^{\circ} \mathrm{C}$ are show in Figure 12. The absence of the moisture barrier has a profound effect on flow curve hysteresis. For the test with the moisture barrier installed, hysteresis is almost absent. In contrast, the test without the moisture barrier shows hysteresis approaching that observed in the $60^{\circ} \mathrm{C}$ flow curve measurement for TI552-G6-R4. The effect observed here is not one of shear history, as the slurry between the cup-rotor gap was refreshed between tests. Based on these observations, hysteresis can be assigned to evaporative effects with a high degree of confidence.

Unlike samples previous Group 5/6 samples [i.e., TI552-G6-R1, -R2, and -R3], the flow curves for waste sample TI552-G6-R4 show rotor slip, sample elasticity, and poor sampling at low shear for all temperatures tested. These effects are evidenced by the poorly defined yield points. That is, whereas flow curves for previous samples meet the stress axis at finite values as zero shear is approached (see Figure 10), the flow curves for sample -R4 appear to curve strongly toward zero stress (similar to what would be expected from a highly shear-thinning Power-Law fluid) at zero shear. This behavior is reminiscent of the group 5 source material behavior at low shear and could indicate that post-caustic leach washing has removed most of the S-Saltcake solids and that the remaining group 5 solids now dominate the slurry rheology. 


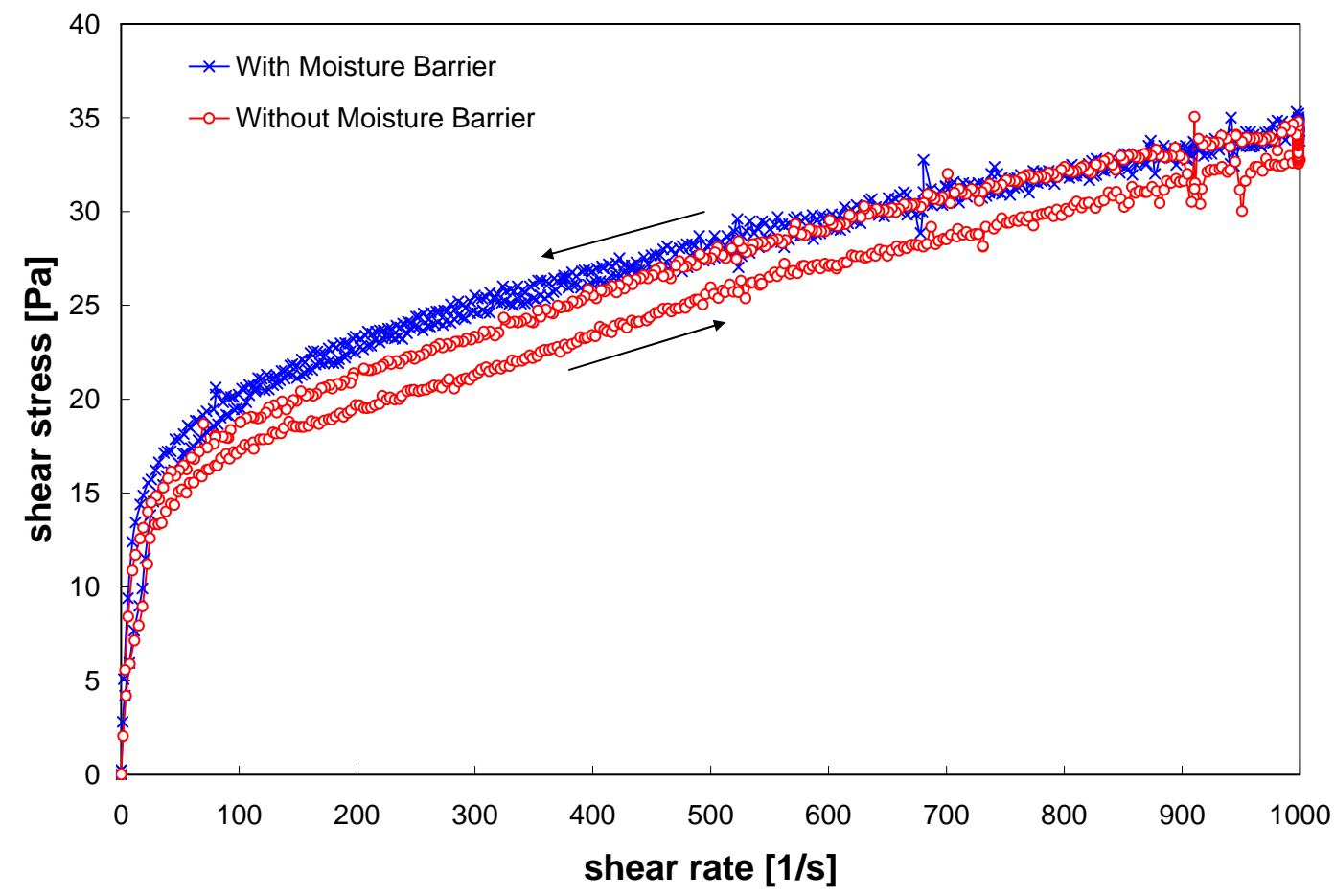

Figure 12. Two flow curve measurements of sample TI552-G6-R4 at $25^{\circ} \mathrm{C}$. Test show the effect of the moisture barrier on the flow curve measurement, with significant hysteresis (specifically, an increase in stress with time) being observed when the moisture barrier is not employed. This indicates that evaporation effects are likely the cause of hysteresis observed in previous flow curve measurements.

Table 16 summarizes the best-fit rheology parameters for flow curve data for sample TI5552-G6R4. As with previous Group 5/6 CUF samples, only Bingham-Plastic and Herschel-Bulkley models were evaluated. Bingham-Plastic analyses were restricted to a shear rate range of 200 to $1000 \mathrm{~s}^{-1}$ to avoid the highly non-linear region at shear rates approaching zero. Herschel-Bulkley analyses employ the full measurement range ( 0 to $\left.1000 \mathrm{~s}^{-1}\right)$.

Table 16. Results of fitting analysis for rheology sample TI552-G6-R4. This sample corresponds to a caustic-leached, dewatered, and washed Group 5/6 slurry mixture (12.8-wt\%).

\begin{tabular}{|c|c|c|c|c|c|}
\hline MODEL & $\begin{array}{c}\text { TEMPERATURE } \\
{\left[{ }^{\circ} \mathrm{C}\right]}\end{array}$ & $\begin{array}{c}\text { YIELD } \\
\text { STRESS } \\
\text { [PA] }\end{array}$ & $\begin{array}{c}\text { CONSISTENCY } \\
{\left[\text { PA }^{\mathrm{N}}\right]}\end{array}$ & $\begin{array}{l}\text { FLOW } \\
\text { INDEX }\end{array}$ & $\mathbf{R}$ \\
\hline \multirow{4}{*}{$\begin{array}{l}\text { Bingham-Plastic } \\
\left(200-1000 \mathrm{~s}^{-1}\right)\end{array}$} & 25 (1 of 2$)$ & 18 & 0.016 & $\mathrm{n} / \mathrm{a}$ & 0.974 \\
\hline & 25 (2 of 2$)$ & 21 & 0.013 & $\mathrm{n} / \mathrm{a}$ & 0.993 \\
\hline & 40 & 22 & 0.012 & $\mathrm{n} / \mathrm{a}$ & 0.985 \\
\hline & 60 & 24 & 0.012 & $\mathrm{n} / \mathrm{a}$ & 0.932 \\
\hline \multirow{4}{*}{$\begin{array}{l}\text { Herschel-Bulkley } \\
\qquad\left(0-1000 \mathrm{~s}^{-1}\right)\end{array}$} & 25 (1 of 2$)$ & 5.9 & 1.7 & 0.40 & 0.986 \\
\hline & 25 (2 of 2$)$ & 1.0 & 5.5 & 0.26 & 0.992 \\
\hline & 40 & -2.1 & 8.3 & 0.21 & 0.989 \\
\hline & 60 & -11 & 15 & 0.16 & 0.971 \\
\hline
\end{tabular}

Note: $\mathrm{R}$ is the correlation coefficient. 
The Bingham-Plastic and Herschel-Bulkley fitting results confirm the temperature effects described in the preceding paragraphs. First, the Bingham yield stress increases as a result of increased measurement temperature; however, this increase could also be as a result of evaporation of the sample with time as the replicate measurement at $25^{\circ} \mathrm{C}$ also shows a $\sim 3 \mathrm{~Pa}$ increase in yield over the first test. The increase in yield matches the overall increase in the viscous stress response of TI552-G6-R4 observed in Figure 11. Bingham consistency decreases with increasing temperature. This change in flow curve slope over $200-1000 \mathrm{~s}^{-1}$ is noticeable between the first and second flow curve measurements at $25^{\circ} \mathrm{C}$ (see Figure 12), but less so at the higher temperature measurements. Finally, increased flow curve hysteresis at the higher measurement temperatures can be observed in the decrease of the correlation coefficient with increasing temperature.

In addition to the temperature effects, a number of secondary phenomena described in the preceding paragraphs are also be confirmed by the fitting parameters. First, the flow curve hysteresis caused by not having the moisture guard in-place on the first $25^{\circ} \mathrm{C}$ flow curve is clear by the difference in correlation coefficients between the primary and replicate measurement. The high curvature at low shears associated with slip, sample elasticity, and poor rotational sampling manifest as unrealistically low Herschel-Bulkley yield stresses. Indeed, the curvature is so severe, that regression analysis derives negative, physically impossible, Herschel-Bulkley yield points when fitting the higher temperature measurements. It should be noted similar Herschel-Bulkley fit anomalies were obtained for Group 5 CUF samples (see Reference [6]) and are characteristic of the unusual low-shear behavior for these samples. Because the Herschel-Bulkley yield points are physically unreasonable, only an upper estimate of the yield stress for sample TI552-G6-R4 can be provided. Based on the Bingham-Plastic fits, this upper yield bound falls between $18-21 \mathrm{~Pa}$ at $25^{\circ} \mathrm{C}$, is $22 \mathrm{~Pa}$ at $40^{\circ} \mathrm{C}$, and is $24 \mathrm{~Pa}$ at $60^{\circ} \mathrm{C}$.

The quality of the $40^{\circ} \mathrm{C}$ fitting parameters is demonstrated in Figure 13. Despite having a physically unrealistic yield point, the Herschel-Bulkley fit provides an accurate representation of the flow curve data in terms of magnitude and curvature. The only weakness of the fit is its inability to fully capture the sharp transition in slope that occurs from 0 to $200 \mathrm{~s}^{-1}$, and even the degree of deviation here is slight such that the fit falls very close to the data. The Bingham-Plastic fit performs reasonably well beyond 200 s-1 (i.e., the region over which it is fit) and provides a rough first approximation of the flow curve behavior. Significant deviation between Bingham-Plastic fit and actual flow curve data is observed in the $0-200 \mathrm{~s}^{-1}$ region. Overall, the Bingham-Plastic fit highlights the shear-thinning nature of the curve. It should be noted that similar Bingham-Plastic and Herschel-Bulkley fits were obtained at $25^{\circ}$ and $60^{\circ} \mathrm{C}$. 


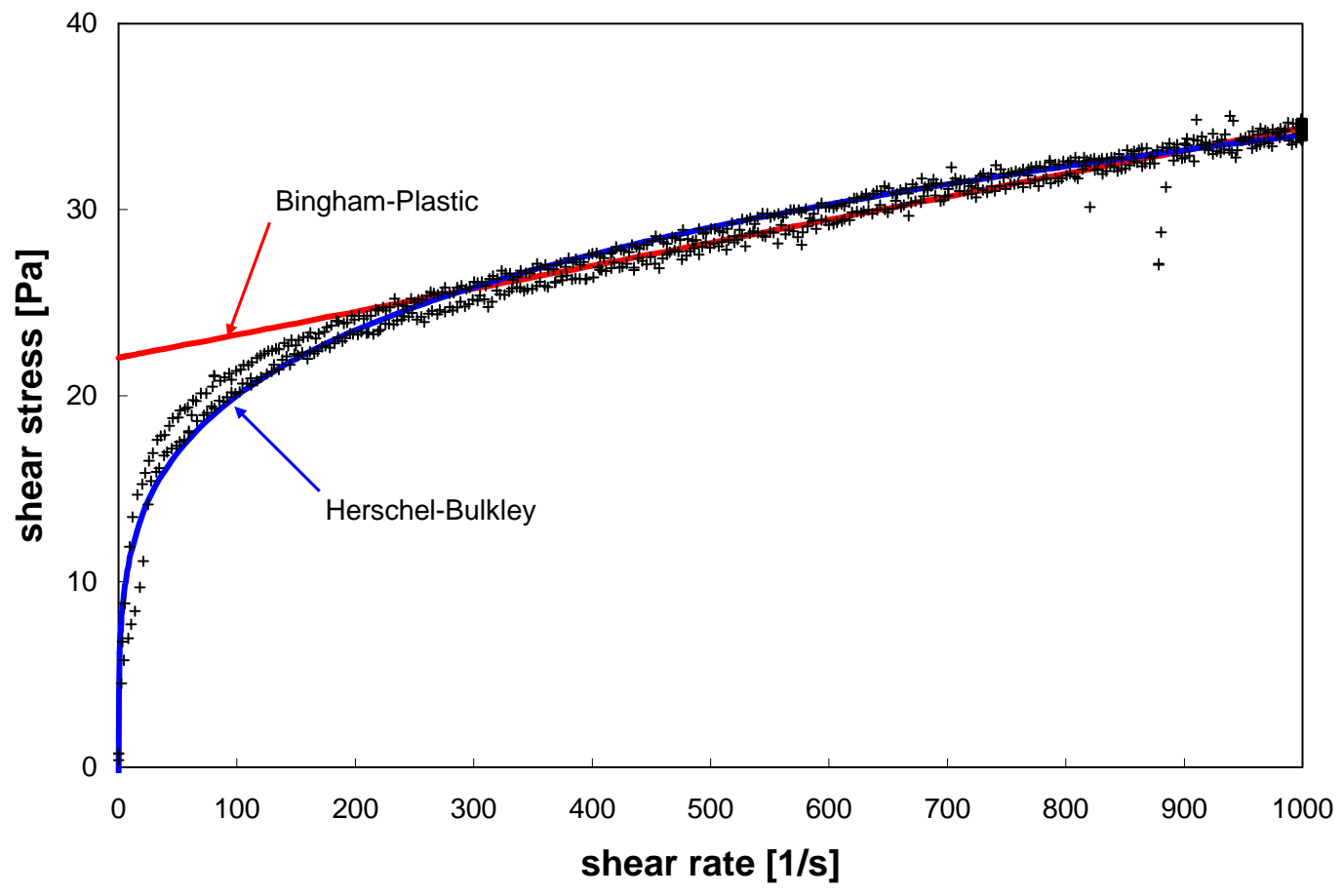

Figure 13. Model fits of flow curve data for Group 5/6 CUF slurry sample TI552-G6-R4 at $40^{\circ} \mathrm{C}$. Bingham plastic model is restricted to $200-1000 \mathrm{~s}^{-1}$. Hershel-Bulkley considers the full shear rate range of $0-1000 \mathrm{~s}^{-1}$.

Like with previous Group 5/6 samples the apparent viscosity at $33 \mathrm{~s}^{-1}$ is derived from each measurement as point of reference. The results are provided in Table 17. For each temperature, this reference point is determined from the average of up-ramp and down-ramp flow curve measurement data and from the fitting parameters provided in Table 16.

Table 17. Apparent viscosity of sample TI552-G6-R4 at $33 \mathrm{~s}^{-1}$.

\begin{tabular}{|c|c|c|c|}
\hline \multirow[t]{2}{*}{$\begin{array}{c}\text { TEMPERATURE } \\
{\left[{ }^{\circ} \mathrm{C}\right]}\end{array}$} & \multirow{2}{*}{$\begin{array}{c}\eta_{\text {APP }}(\mathrm{CP}) \\
\text { FROM } \\
\text { MEASUREMENT } \\
\text { DATA }\end{array}$} & \multicolumn{2}{|c|}{$\begin{array}{c}\eta_{\text {APP }}(\mathrm{CP}) \\
\text { FROM FITTING PARAMETERS }\end{array}$} \\
\hline & & Bingham Plastic & Herschel-Bulkley \\
\hline 25 (1 of 2$)$ & 430 & 570 & 390 \\
\hline 25 (2 of 2$)$ & 480 & 650 & 440 \\
\hline 40 & 510 & 680 & 460 \\
\hline 60 & 530 & 730 & 490 \\
\hline
\end{tabular}

\section{Sample TI552-G6-R5: Oxidative-Leached and Washed Slurry (9.7-wt\%)}

Figure 14 shows the results of flow curve testing for sample TI552-G6-R5. This sample corresponds to a Group 5/6 slurry mixture that was oxidative-leached for 24 hours at $100^{\circ} \mathrm{C}$ and subsequently washed in a cross-flow ultrafilter system. It has an undissolved solids concentration of 9.7wt\%. Flow curves for sample TI552-G6-R5 show slight non-Newtonian behavior at all temperature; however, relative to sample TI552-G6-R4, the range of viscous shear stress is reduced ( 0.5 to 6 Pa after 
oxidative leaching as compared to $\sim 5$ to 35 Pa before). The current flow curves exhibit finite yield stresses ranging from 0.5 to1.3 Pa that are near the limit of detection for the M5-viscometer. The samples are slightly shear thinning, and exhibit a sharp increase in flow curve slope at $500 \mathrm{~s}^{-1}$ that, for a Newtonian sample, would be associated with the formation of Taylor vortices. Given the magnitude of stress observed in the current measurements, it is likely that the transition observed at $500 \mathrm{~s}^{-1}$ is associated with turbulent slurry flow in the cup-rotor gap.

Flow curve data in Figure 14 suggest that slurry yield stress increases with increasing temperature and slurry consistency decreases with increasing temperature. Both observations are consistent with flow curve measurements for previous group 5, 6, and 5/6 mixture slurries. For the current measurements, there appears to be no temperature driven evaporation effects. Flow curve hysteresis is only observed in the $25^{\circ} \mathrm{C}$ measurement data, and is absent from the higher temperature measurements. The exact cause of the hysteresis at $25^{\circ} \mathrm{C}$ is unknown at this time; however, the difference in up- and down-ramp stresses observed at $25^{\circ} \mathrm{C}$ is comparable to the measurement noise.

Table 18 summarizes the best-fit rheology parameters for flow curve data for sample TI5552-G6R5. As with previous Group 5/6 CUF samples, only Bingham-Plastic and Herschel-Bulkley models were evaluated. Both analyses employ a shear rate range of 0 to $500 \mathrm{~s}^{-1}$ to avoid the vortex region at high shear. The absence of a highly shear-thinning region at low shear means that the Bingham-Plastic fit will not be biased by the inclusion shear stresses over the 0 to $200 \mathrm{~s}^{-1}$ region as with previous results. Based on the Bingham-Plastic and Herschel-Bulkley fitting results, the slurry yield stress falls between 0.4 to $0.8 \mathrm{~Pa}$ at $25^{\circ} \mathrm{C}, 0.4$ to $0.7 \mathrm{~Pa}$ at $40^{\circ} \mathrm{C}$, and 1.2 to $1.4 \mathrm{~Pa}$ at $60^{\circ} \mathrm{C}$. With exception of the $60^{\circ} \mathrm{C}$ measurement, all yield points fall within or on the limit of instrument sensitivity, and as such, are not substantially different from zero. With regards to consistency, Bingham-Plastic fitting parameters indicate a range of slurry consistency from $3 \mathrm{cP}$ (at higher temperatures) to $5 \mathrm{cP}$ (at $25^{\circ} \mathrm{C}$ ).

Table 18. Results of fitting analysis for rheology sample TI552-G6-R5. This sample corresponds to an oxidative-leached and washed Group 5/6 slurry mixture (9.7-wt\%).

\begin{tabular}{|c|c|c|c|c|c|}
\hline MODEL & $\begin{array}{c}\text { TEMPERATURE } \\
{\left[{ }^{\circ} \mathrm{C}\right]}\end{array}$ & $\begin{array}{c}\text { YIELD } \\
\text { STRESS } \\
\text { [PA] }\end{array}$ & $\begin{array}{c}\text { CONSISTENCY } \\
{\left[\mathrm{PA} \cdot \mathrm{S}^{\mathrm{N}}\right]}\end{array}$ & $\begin{array}{l}\text { FLOW } \\
\text { INDEX }\end{array}$ & $\overline{\overline{\mathbf{R}}}$ \\
\hline \multirow{4}{*}{$\begin{array}{l}\text { Bingham-Plastic } \\
\left(0-500 \mathrm{~s}^{-1}\right)\end{array}$} & 25 (1 of 2$)$ & 0.8 & 0.0052 & $\mathrm{n} / \mathrm{a}$ & 0.949 \\
\hline & 25 (2 of 2$)$ & 0.7 & 0.0050 & $\mathrm{n} / \mathrm{a}$ & 0.952 \\
\hline & 40 & 0.7 & 0.0031 & $\mathrm{n} / \mathrm{a}$ & 0.936 \\
\hline & 60 & 1.4 & 0.0031 & $\mathrm{n} / \mathrm{a}$ & 0.957 \\
\hline \multirow{4}{*}{$\begin{array}{l}\text { Herschel-Bulkley } \\
\quad\left(0-500 \mathrm{~s}^{-1}\right)\end{array}$} & 25 (1 of 2$)$ & 0.4 & 0.041 & 0.68 & 0.955 \\
\hline & 25 (2 of 2$)$ & 0.4 & 0.026 & 0.75 & 0.956 \\
\hline & 40 & 0.5 & 0.023 & 0.71 & 0.966 \\
\hline & 60 & 1.2 & 0.016 & 0.75 & 0.960 \\
\hline
\end{tabular}

Note: $\mathrm{R}$ is the correlation coefficient. 


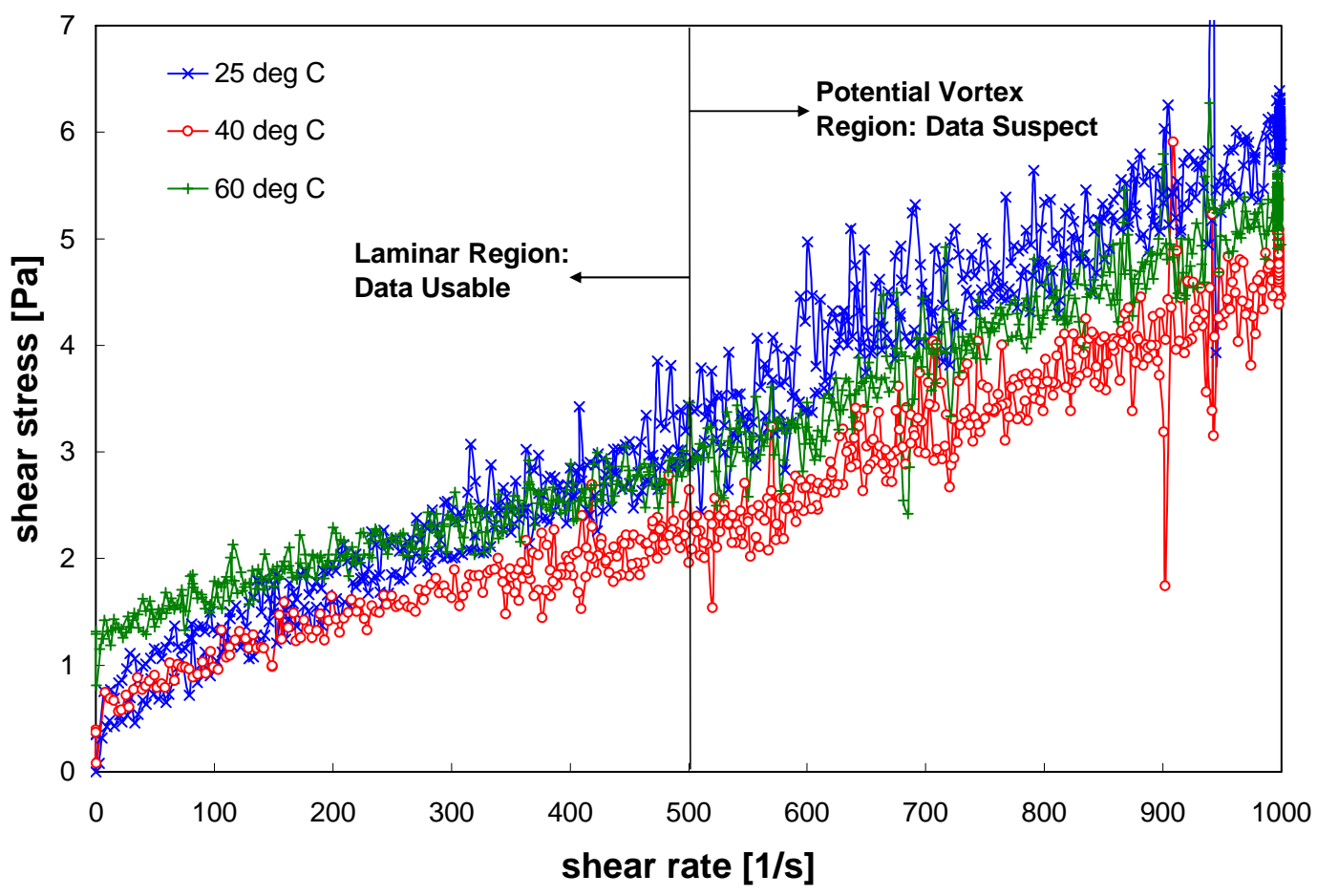

Figure 14. Flow curve (shear stress versus shear rate) for Group 5/6 caustic-leached, dewatered, and washed slurry sample TI552-G6-R5 at $25^{\circ} \mathrm{C}, 40^{\circ} \mathrm{C}$, and $60^{\circ} \mathrm{C}$ as measured using the MV1 cup and rotor. Note: the second repeat measurement for $25^{\circ} \mathrm{C}$ is shown here, as it is the closest to the $40^{\circ}$ and $60^{\circ} \mathrm{C}$ measurements in time.

Figure 15 shows the quality of the fit produced by regression analysis of the $40^{\circ} \mathrm{C}$ flow curve data for sample TI552-G6-R5. Up to the fitting analysis limit of $500 \mathrm{~s}^{-1}$, the Herschel-Bulkley model captures the slight shear-thinning behavior observed in the flow curve. However, based on the data scatter (which illustrates the $0.5 \mathrm{~Pa}$ limit of instrument sensitivity), differences in the Herschel-Bulkley and Bingham-Plastic model fits for the data are not significant. Similar fits are observed at $25^{\circ}$ and $60^{\circ} \mathrm{C}$.

As before, the apparent viscosity at $33 \mathrm{~s}^{-1}$ is derived from each measurement as point of reference. The results are provided in Table 19. For each temperature, this reference point is determined from the average of up-ramp and down-ramp flow curve measurement data and from the fitting parameters provided in Table 18.

Table 19. Apparent viscosity of sample TI552-G6-R5 at $33 \mathrm{~s}^{-1}$.

\begin{tabular}{||c|c|c|c||}
\hline \multirow{2}{*}{$\begin{array}{c}\text { TEMPERATURE } \\
{\left[{ }^{\circ} \mathbf{C}\right]}\end{array}$} & $\begin{array}{c}\eta_{\text {APP }}(\mathrm{CP}) \\
\text { FROM } \\
\end{array}$ & $\begin{array}{c}\text { MEASUREMENT } \\
\text { DATA }\end{array}$ & \multicolumn{2}{|c||}{$\eta_{\text {APP }}$ (CP) } \\
\cline { 3 - 4 } & 26 & Bingham Plastic & Herschel-Bulkley \\
\hline $25(1$ of 2$)$ & 23 & 30 & 26 \\
\hline $25(2$ of 2$)$ & 24 & 26 & 23 \\
\hline 40 & 44 & 25 & 43 \\
\hline 60 & 44 & 22 \\
\hline
\end{tabular}




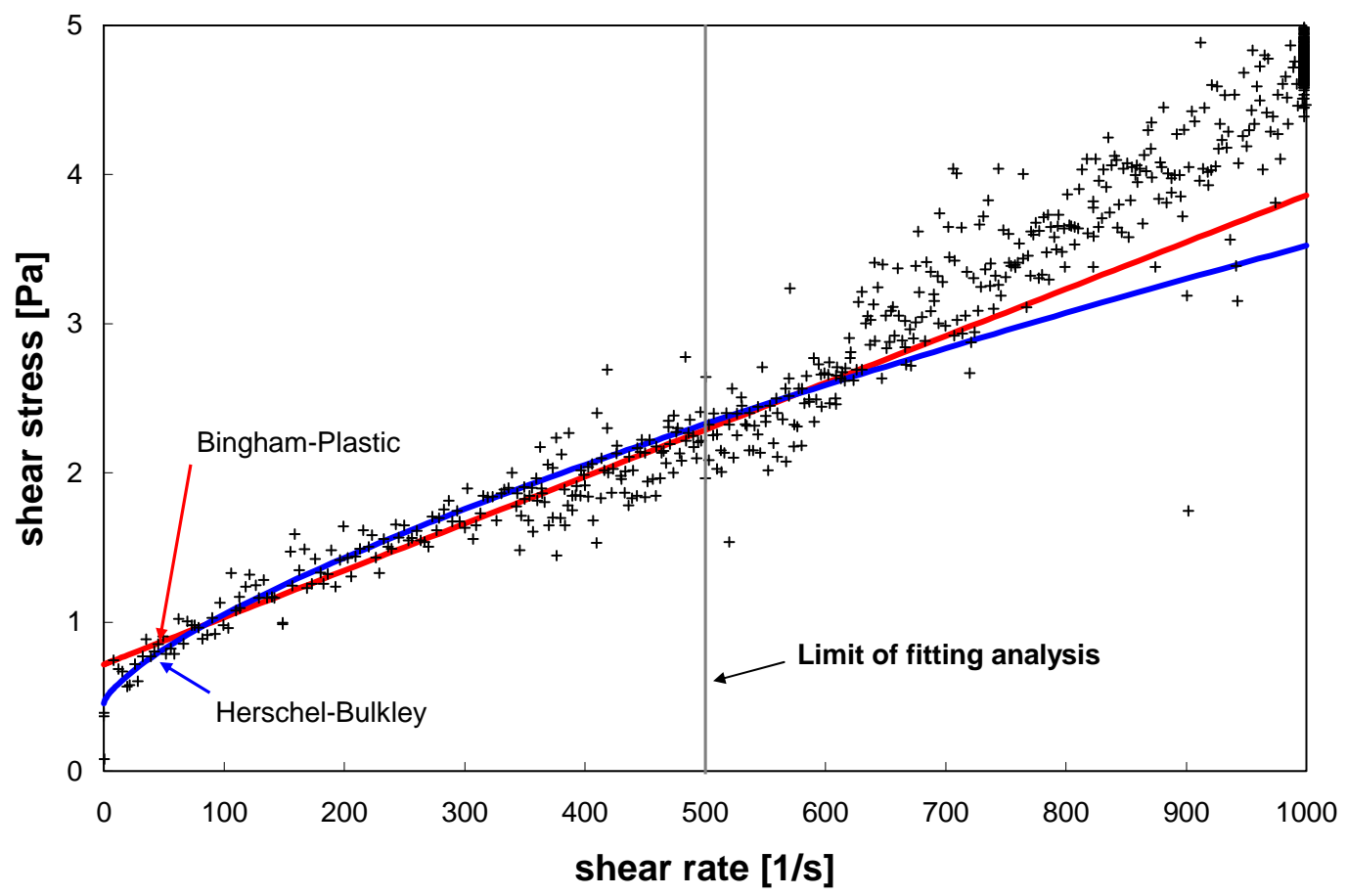

Figure 15. Model fits of flow curve data for Group 5/6 CUF slurry sample TI552-G6-R5 at $40^{\circ} \mathrm{C}$. Both fit analyses employ a shear rate range of $0-500 \mathrm{~s}^{-1}$.

\section{Sample TI552-G6-R6: Combined Leached Slurry (8.0-wt\%)}

Figure 16 shows the results of flow curve testing for sample TI552-G6-R6. This sample corresponds to a Group 5/6 slurry mixture formed by combining solids from sample TI552-G6-R5 (an oxidative-leached and washed Group 5/6 CUF sample) with caustically-leached Group 5 solids from a previous CUF study. This combined sample has an undissolved solids concentration of $8.0-\mathrm{wt} \%$. Flow curves for sample TI552-G6-R5 show non-Newtonian behavior at all temperatures. The range of viscous shear stresses observed for these samples is similar to sample TI552-G6-R5, Flow curves for TI552-G6R6 exhibit finite yield stresses near 1 Pa and do not appear to be shear-thinning over most of the shear rate range, with exception of the slight shear thinning behavior observed below $100 \mathrm{~s}^{-1}$. The yield stress does not vary noticeably with temperature; the flow curve slope appears to decrease slight as temperature is raised from $25^{\circ}$ to $40^{\circ} \mathrm{C}$, but remains relatively constant thereafter. Flow curve hysteresis is not observed and is either absent or falls within the measurement noise.

Table 20 summarizes the best-fit rheology parameters for flow curve data for sample TI5552-G6R6. As with previous Group 5/6 CUF samples, only Bingham-Plastic and Herschel-Bulkley models were evaluated. Bingham-Plastic regression analysis is limited to shear rates between 200 to $1000 \mathrm{~s}^{-1}$ to avoid bias from the data curvature below $100 \mathrm{~s}-1$. Herschel-Bulkley fits employ the full range of shear rates. Based on the Bingham-Plastic and Herschel-Bulkley fitting results, the slurry yield stress falls between 0.4 to $0.8 \mathrm{~Pa}$ at $25^{\circ} \mathrm{C}, 0.4$ to $0.7 \mathrm{~Pa}$ at $40^{\circ} \mathrm{C}$, and 1.2 to $1.4 \mathrm{~Pa}$ at $60^{\circ} \mathrm{C}$. With exception of the $60^{\circ} \mathrm{C}$ measurement, all yield points fall within or on the limit of instrument sensitivity, and as such, are not 
substantially different from zero. With regards to consistency, Bingham-Plastic fitting parameters indicate a range of slurry consistency from $3 \mathrm{cP}$ (at higher temperatures) to $5 \mathrm{cP}$ (at $25^{\circ} \mathrm{C}$ ).

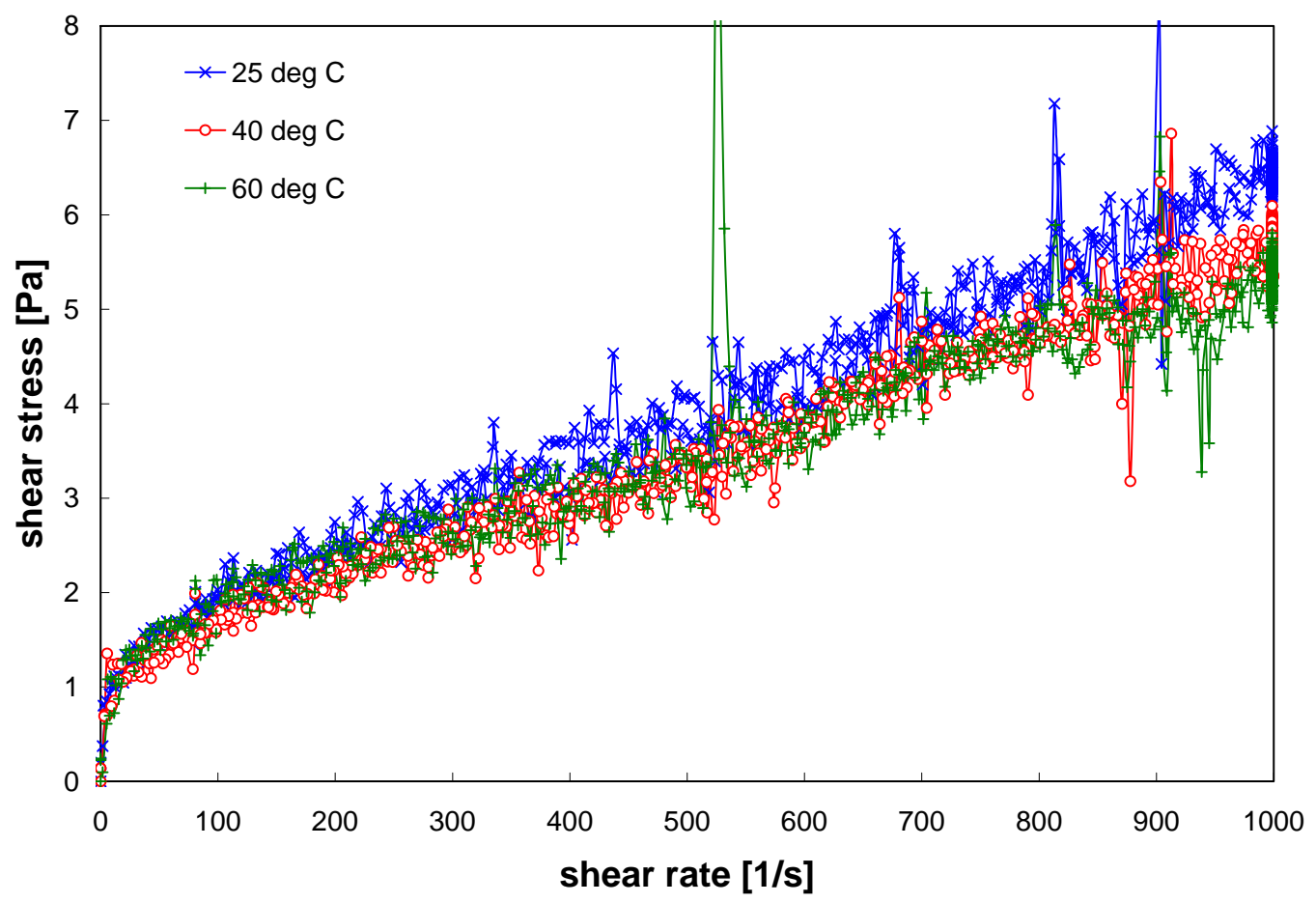

Figure 16. Flow curve (shear stress versus shear rate) for Group 5/6 caustic-leached, dewatered, and washed slurry sample TI552-G6-R6 at $25^{\circ} \mathrm{C}, 40^{\circ} \mathrm{C}$, and $60^{\circ} \mathrm{C}$ as measured using the MV1 cup and rotor. Note: the second repeat measurement for $25^{\circ} \mathrm{C}$ is shown here, as it is the closest to the $40^{\circ}$ and $60^{\circ} \mathrm{C}$ measurements in time.

Table 20. Results of fitting analysis for rheology sample TI552-G6-R6. This sample corresponds to the combined leached Group 5/6 slurry mixture (8.0-wt\%).

\begin{tabular}{|c|c|c|c|c|c|}
\hline MODEL & $\begin{array}{c}\text { TEMPERATURE } \\
{\left[{ }^{\circ} \mathrm{C}\right]}\end{array}$ & $\begin{array}{c}\text { YIELD } \\
\text { STRESS } \\
\text { [PA] }\end{array}$ & $\begin{array}{c}\text { CONSISTENCY } \\
{\left[\mathrm{PA}^{\mathrm{N}} \mathrm{S}^{\mathrm{N}}\right]}\end{array}$ & $\begin{array}{l}\text { FLOW } \\
\text { INDEX }\end{array}$ & $\mathbf{R}$ \\
\hline \multirow{4}{*}{$\begin{array}{l}\text { Bingham-Plastic } \\
\left(200-1000 \mathrm{~s}^{-1}\right)\end{array}$} & 25 (1 of 2$)$ & 0.9 & 0.0036 & $\mathrm{n} / \mathrm{a}$ & 0.967 \\
\hline & 25 (2 of 2$)$ & 1.3 & 0.0051 & $\mathrm{n} / \mathrm{a}$ & 0.981 \\
\hline & 40 & 1.1 & 0.0046 & $\mathrm{n} / \mathrm{a}$ & 0.985 \\
\hline & 60 & 1.6 & 0.0038 & $\mathrm{n} / \mathrm{a}$ & 0.908 \\
\hline \multirow{4}{*}{$\begin{array}{l}\text { Herschel-Bulkley } \\
\left(0-1000 \mathrm{~s}^{-1}\right)\end{array}$} & 25 (1 of 2$)$ & 0.8 & 0.0060 & 0.93 & 0.980 \\
\hline & 25 (2 of 2$)$ & 1.3 & 0.0058 & 0.98 & 0.989 \\
\hline & 40 & 1.2 & 0.0041 & 1.0 & 0.990 \\
\hline & 60 & 1.0 & 0.020 & 0.78 & 0.949 \\
\hline
\end{tabular}

Note: $\mathrm{R}$ is the correlation coefficient.

The Bingham-Plastic fitting parameters suggest that yield stress increases as a function of temperature. Visual inspection of the data (and their apparent yields) along with limited variance in the Herschel-Bulkley yield points do not confirm this increase; as such, the increase in Bingham yield is 
likely a result of the limited fitting range and the decrease in flow curve slope with increase temperature. When compared to the expected limit of accuracy of 0.5 Pa for the M5-measuring system, the differences in yield stress for both Herschel-Bulkley and Bingham-Plastic models do not appear significant. With regard to flow curve slope, the Bingham consistencies appear to confirm the observed decrease in slope as temperature is increased; however, the large difference in primary and replicate $25^{\circ} \mathrm{C}$ consistencies (nearly $2 \mathrm{cP}$ ) indicates that the change in consistency with temperature is not statistically significant. Based on this evaluation of the fit quality, it is reasonable to estimate the yield point and consistency for the combined leach slurry (TI552-G6-R6) at 1 Pa and $\sim 4 \mathrm{cP}$, respectively.

Figure 17 shows the quality of the fit produced by regression analysis of the $40^{\circ} \mathrm{C}$ flow curve data for sample TI552-G6-R6. Here, the Bingham-Plastic and Herschel-Bulkley curve are indistinguishable from one another. In terms of modeling the data, both provide equivalent fits of the flow curve at $40^{\circ} \mathrm{C}$. Similar fits are obtained at $25^{\circ}$ and $60^{\circ} \mathrm{C}$.

The apparent viscosity at $33 \mathrm{~s}^{-1}$ is derived from each measurement as point of reference. The results are provided in Table 21. For each temperature, this reference point is determined from the average of up-ramp and down-ramp flow curve measurement data and from the fitting parameters provided in Table 20.

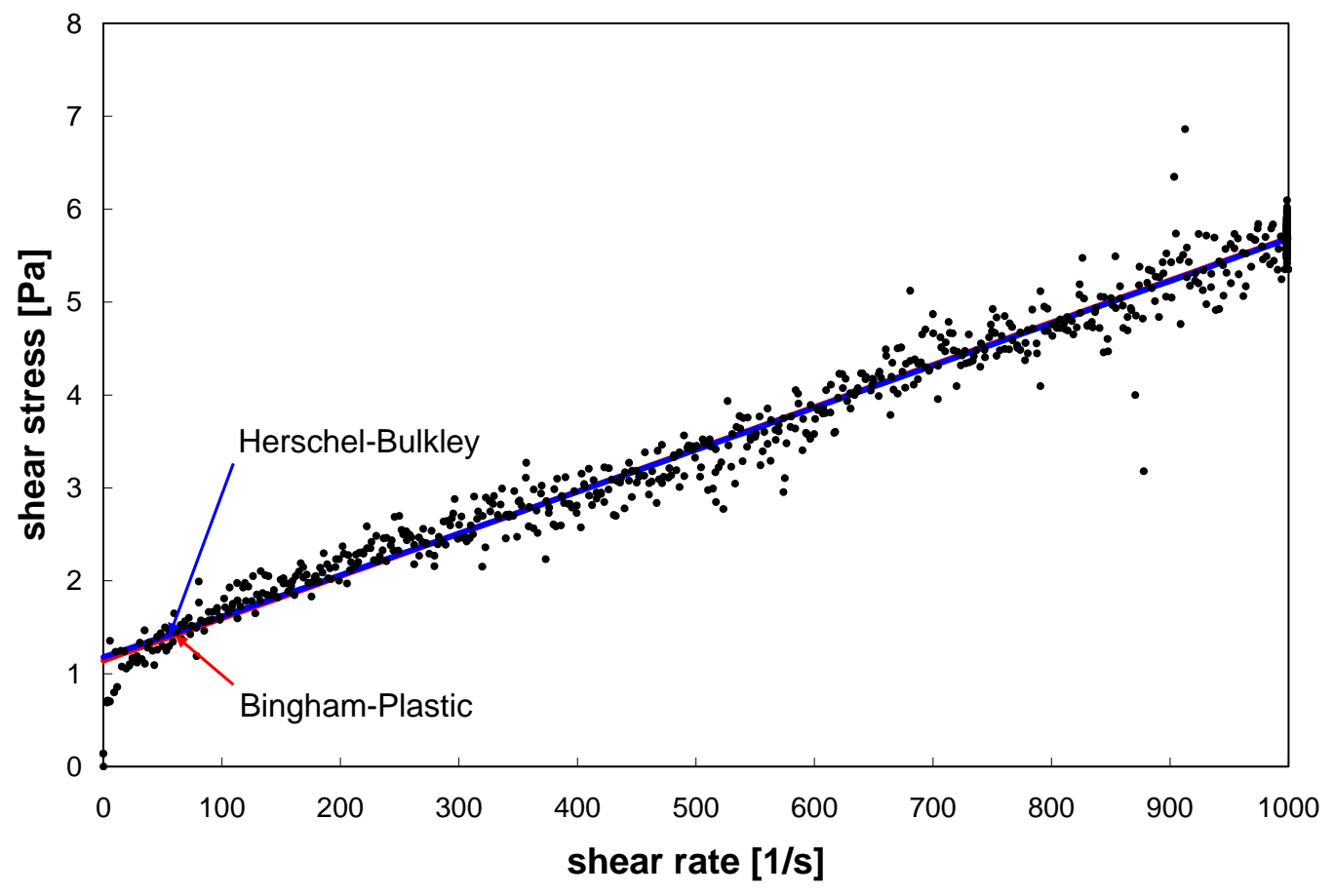

Figure 17. Model fits of flow curve data for Group 5/6 CUF slurry sample TI552-G6-R6 at $40^{\circ} \mathrm{C}$.

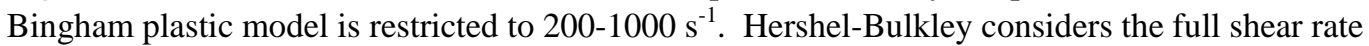
range of $0-1000 \mathrm{~s}^{-1}$. Bingham-Plastic and Herschel-Bulkley lie on top of one another. 
Table 21. Apparent viscosity of sample TI552-G6-R6 at $33 \mathrm{~s}^{-1}$.

\begin{tabular}{|c|c|c|c|}
\hline \multirow[t]{2}{*}{$\begin{array}{l}\text { TEMPERATURE } \\
{\left[{ }^{\circ} \mathrm{C}\right]}\end{array}$} & \multirow{2}{*}{$\begin{array}{c}\eta_{\text {APP }}(\mathrm{CP}) \\
\text { FROM } \\
\text { MEASUREMENT } \\
\text { DATA }\end{array}$} & \multicolumn{2}{|c|}{$\begin{array}{c}\eta_{\text {APP }}(\mathrm{CP}) \\
\text { FROM FITTING PARAMETERS }\end{array}$} \\
\hline & & Bingham Plastic & Herschel-Bulkley \\
\hline 25 (1 of 2$)$ & 28 & 32 & 29 \\
\hline 25 (2 of 2 ) & 42 & 45 & 44 \\
\hline 40 & 39 & 39 & 40 \\
\hline 60 & 41 & 52 & 40 \\
\hline
\end{tabular}

\section{Comparison of Slurry Rheology}

The following paragraphs discuss group 5/6 CUF sample rheology at $25^{\circ} \mathrm{C}$ to illustrate the effects of waste mixing and CUF processing on slurry rheology. It should be noted that, because the test material is a mixture of group 5 and 6 waste samples, the comparisons given herein are different from those previously reported for the Group 5 CUF test samples [6]. For example, the Group 5 comparisons were able to look at the effect of pre-leach solids concentration on slurry rheology. For the Group 5/6 CUF data, a similar comparison cannot be done because the pre-leach concentration is accompanied by mixing of the Group 6 solids with solids from Group 5.

Discussion in this section shall examine five aspects of the Group 5/6 CUF processing. These are

1. dilution of Group 6 source material with Group 6 supernatant

2. mixing of Group 6 slurry with source Group 5 material

3. caustic and oxidative leaching of the Group 5/6 slurry mixture

4. washing of the caustic-leached Group 5/6 slurry mixture

5. combining the Group 6 oxidative-leached and Group 5 caustic-leached slurries

To discuss the influence of each of these processes on the CUF slurry rheology, flow curve data along with best-fit Bingham-Plastic and Newtonian viscosities shall be employed. This section is concluded by a discussion of the effect of temperature on the best-fit Bingham-Plastic parameters for Group 5/6 CUF samples.

Figure 18 and Table 22 show the effect of dilution of the Group 6 source slurry (14.7-wt\%) with Group 6 permeate. Figure 18 compares the rheology of the Group 6 source slurry to the diluted slurry rheology (3.2-wt\%). Both measurements show Newtonian flow curve behavior and are similar in magnitude. As expected, the more concentrated shows higher stresses over the entire range of shear rates examined; however, but the magnitude of decrease upon dilution ( $1 \mathrm{~Pa})$ is relatively small given the 4-5 fold decrease in solids concentration. In terms of viscosity, dilution of the Group 6 slurry drops the viscosity from 8.0 to $6.2 \mathrm{cP}$. For comparison, concentration of the Group 5 waste slurry from 4.3 -wt\% to 15.5-wt\% effected an increase in consistency from 4.6 to $14 \mathrm{cP}$ and an increase in yield stress from 2.2 to $74 \mathrm{~Pa}$. From this comparison, it can be seen that a relatively similar change in solids concentration impacts Group 6 rheology differently than Group 5. The small change in Group 6 rheology could imply that the supernatant is dominating the slurry rheology; however, the measured viscosities for Group 6 source and diluted slurries are both significantly larger than the measured supernatant viscosity for the system $(1.5 \mathrm{cP})$, which indicates that the impact of Group 6 saltcake solids on the rheology is substantial. 
Table 22. Effect of dilution on Group 6 slurry rheology (at $25^{\circ} \mathrm{C}$ )

\begin{tabular}{||c|c|c|c||}
\hline DESCRIPTION & $\begin{array}{c}\text { SOLIDS } \\
\text { CONCENT } \\
\text { RATION }\end{array}$ & $\begin{array}{c}\text { RHEOLO } \\
\text { GY }\end{array}$ & $\begin{array}{c}\text { VISCOSIT } \\
\text { Y } \\
\text { [CP] }\end{array}$ \\
\hline $\begin{array}{c}\text { Group 6 Source } \\
\text { (TI490-G6-AR-RH) }\end{array}$ & $14.7-\mathrm{wt} \%$ & Newtonian & 8.0 \\
\hline $\begin{array}{c}\text { Group 6 Dilution } \\
\text { (TI552-G6-R1) }\end{array}$ & $3.2-\mathrm{wt} \%$ & Newtonian & 6.2 \\
\hline $\begin{array}{c}\text { Group 6 Supernatant } \\
\text { (TI488-G6-AR-J2) }\end{array}$ & $\mathrm{n} / \mathrm{a}$ & Newtonian & 1.5 \\
\hline
\end{tabular}

${ }^{\mathrm{a}}$ Taken from Reference [5]

Figure 19 and Table 23 show the influence of mixing the Group 6 slurry with Group 5 solids on the CUF process material rheology. The source waste groups show highly different rheologies. Group 5 is highly non-Newtonian, having a yield stress of $57 \mathrm{~Pa}$ and a consistency of $13 \mathrm{cP}$. In contrast, Group 6 is Newtonian and has a viscosity of $8 \mathrm{cP}$, which is slightly less than the Group 5 source material's consistency. The Group 5/6 mixture represented by sample TI552-G6-R2 is formed by combining roughly two parts Group 5 solids, one part Group 6 solids, one part Group 5 supernatant, and two parts Group 6 supernatant. The resulting mixture is non-Newtonian with a yield stress of 7.4 Pa and a consistency of $13 \mathrm{cP}$. From the flow curves presented in Figure 19, it is clear that the Group 5 solids have imparted some of their non-Newtonian behavior to the slurry combination. Although the mixture consistency is similar to that of Group 5, the yield stress of the 13.2-wt\% combined Group 5/6 slurry is much lower than that observed in pre-leach Group 5 CUF slurries of similar concentration. This indicates that the Group 6 solids may be impeding the structuring mechanism Group 5 solids impart to the slurry.

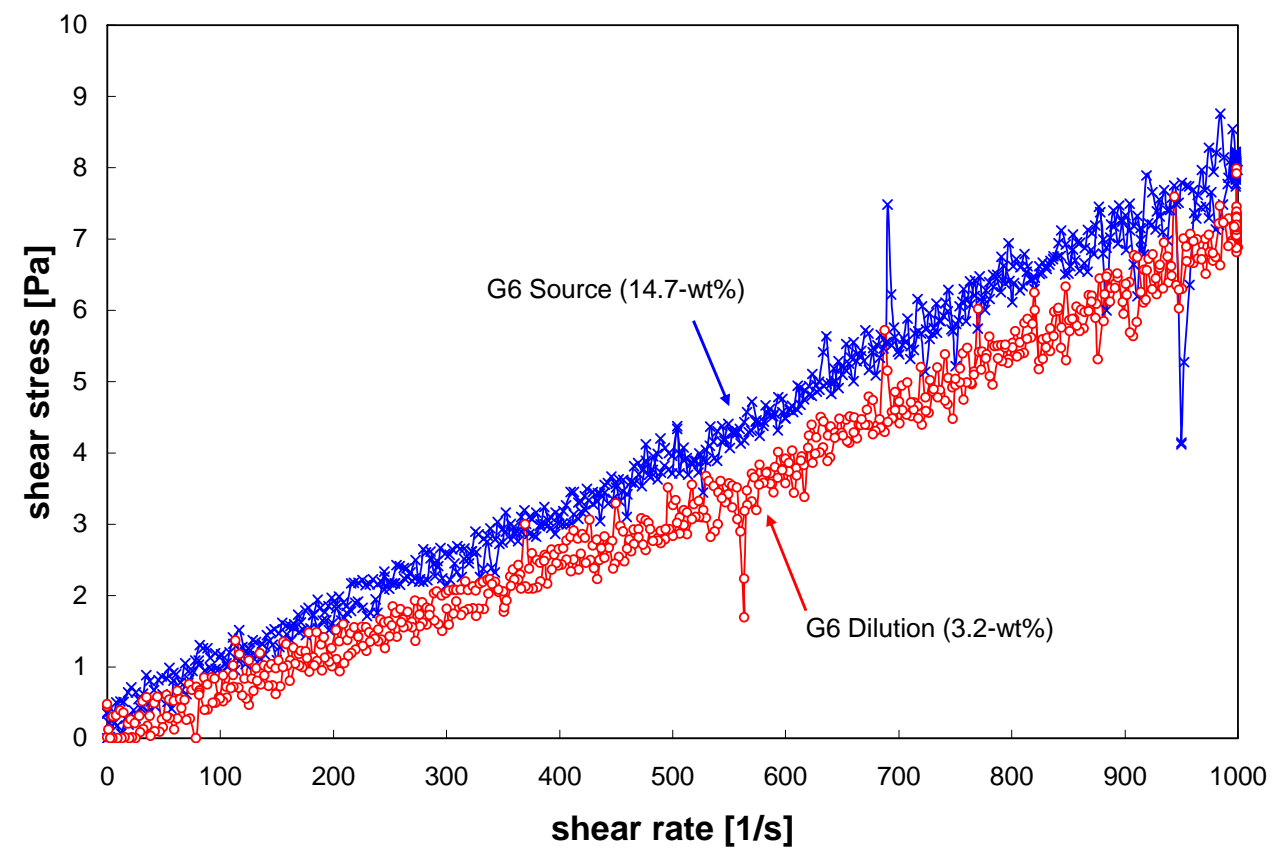

Figure 18. A comparison of Group 6 source material (sample TI490-G6-AR-RH) and Group 6 slurry diluted with Group 6 supernatant (sample TI552-G6-R1). Both measurements are at $25^{\circ} \mathrm{C}$. 
Table 23. Effect of mixing different waste slurries on Group 5/6 CUF rheology (at $25^{\circ} \mathrm{C}$ )

\begin{tabular}{||c|c|c|c|c||}
\hline DESCRIPTION & $\begin{array}{c}\text { SOLIDS } \\
\text { CONCENTRATION }\end{array}$ & RHEOLOGY & $\begin{array}{c}\text { YIELD } \\
\text { STRESS } \\
\text { [PA] }\end{array}$ & $\begin{array}{c}\text { CONSISTENCY } \\
\text { [CP] }\end{array}$ \\
\hline $\begin{array}{c}\text { Group 5 Source } \\
\text { (G5-RH-2) }\end{array}$ & $18.5-\mathrm{wt} \%$ & $\begin{array}{c}\text { Non- } \\
\text { Newtonian }\end{array}$ & 57 & 13 \\
\hline $\begin{array}{c}\text { Group 6 Source } \\
\text { (TI490-G6-AR- } \\
\text { RH) }\end{array}$ & $14.7-w \mathrm{wt} \%$ & Newtonian & $\mathrm{n} / \mathrm{a}$ & 8.0 \\
\hline $\begin{array}{c}\text { Group 5/6 } \\
\text { Mixture (TI552- } \\
\text { G6-R2) }\end{array}$ & $13.2-\mathrm{wt} \%$ & $\begin{array}{c}\text { Non- } \\
\text { Newtonian }\end{array}$ & 7.4 & 13 \\
\hline
\end{tabular}

Figure 20 and Table 24 show the influence of caustic and oxidative leaching on the Group 5/6 waste slurry. Both post-leach flow curves correspond to washed slurries. Before leaching, the slurry is non-Newtonian with a yield of $7.4 \mathrm{~Pa}$ and a consistency of $13 \mathrm{cP}$. After caustic leaching and washing, the slurry is still non-Newtonian. The caustic leaching and washing operations are accompanied by an increase in slurry yield stress from 7.4 to $21 \mathrm{~Pa}$; the slurry consistency did not change. The increase in yield stress with caustic leaching and washing could indicate that these operations have eliminated the Group 6 solids fraction, causing the slurry properties to more closely resemble those of Group 5.

However, as discussed in Ref. [5], the slurry rheology for Group 5 wastes is greatly reduced by caustic leaching, with the final leached and washed slurry having a yield of $3.3 \mathrm{~Pa}$ and a consistency of $4.7 \mathrm{cP}$ at $25^{\circ} \mathrm{C}$. Given these results, the rheology of the Group 5/6 slurry should be similar were the solids fraction dominated by Group 5 after leaching. As such, it is possible to infer that the caustic-leached, dewatered, and washed rheology for the Group 5/6 is governed in part by the behavior of caustic leached and washed Group 6 solids. 


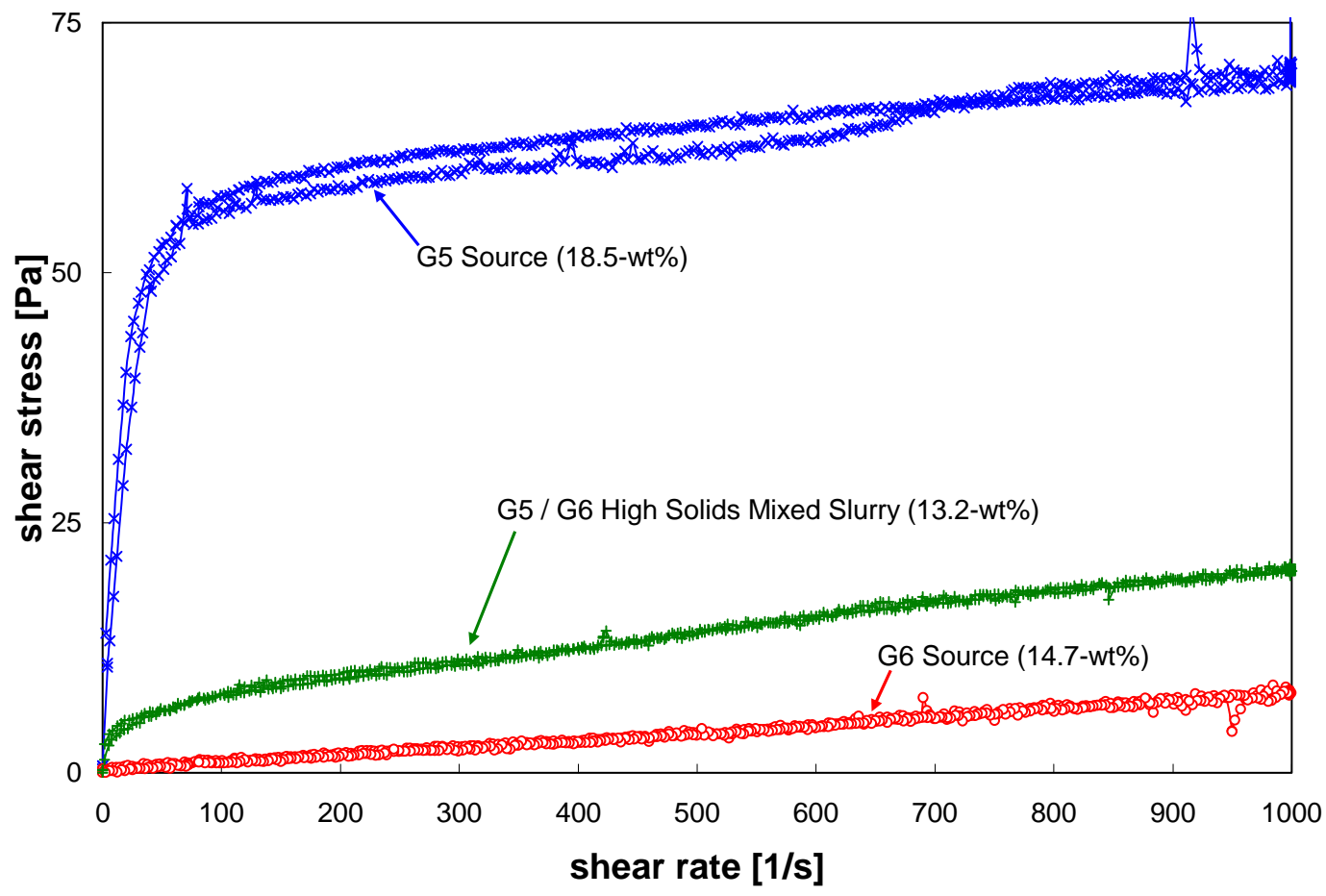

Figure 19. A comparison of Group 5, 6, and 5/6 rheologies highlighting the effect of mixing different waste materials. Flow curves correspond to the Group 5 source material (sample G5-RH-2), Group 6 source material (sample TI490-G6-AR-RH), and high-solids Group 5/6 slurry mixture (sample TI552G6-R2). All measurements are at $25^{\circ} \mathrm{C}$.

Subsequent oxidative-leaching of Group 5/6 slurry TI552-G6-R4 almost completely eliminates the non-Newtonian behavior of the Group 5/6 mixtures. The measured yield for the post-ox-leach slurry is $0.7 \mathrm{~Pa}$, which is at the limit of detection for the M5 measuring system ( $0.5 \mathrm{~Pa}$ ). Part of this lowering may be a result of lowered solids concentration; specifically, the 9.7-wt\% post-leach slurry is more dilute (on an undissolved solids basis) than the pre-leach and caustic-leached slurries. However, the consistency for the post-oxidative-leach slurry is only $5.0 \mathrm{cP}$ and is lower than that for the 3.2-wt\% Group 6 dilution presented in Figure 18 and Table $22(6.2 \mathrm{cP})$. As such, it is possible to attribute part of the reduction to oxidative and washing leaching alone.

Table 24. Effect of caustic / oxidative leaching on Group 5/6 CUF slurry rheology (at $25^{\circ} \mathrm{C}$ )

\begin{tabular}{||c|c|c|c|c||}
\hline DESCRIPTION & $\begin{array}{c}\text { SOLIDS } \\
\text { CONCENTRATION }\end{array}$ & RHEOLOGY & $\begin{array}{c}\text { YIELD } \\
\text { STRESS } \\
\text { [PA] }\end{array}$ & $\begin{array}{c}\text { CONSISTENCY } \\
\text { [CP] }\end{array}$ \\
\hline $\begin{array}{c}\text { Pre-leach slurry } \\
\text { (TI552-G6-R2) }\end{array}$ & $13.2-\mathrm{wt} \%$ & $\begin{array}{c}\text { Non- } \\
\text { Newtonian }\end{array}$ & 7.4 & 13 \\
\hline $\begin{array}{c}\text { Caustic-leached } \\
\text { (TI552-G6-R4) }\end{array}$ & $12.8-\mathrm{wt} \%$ & $\begin{array}{c}\text { Non- } \\
\text { Newtonian }\end{array}$ & 21 & 13 \\
\hline $\begin{array}{c}\text { Oxidative- } \\
\text { leached (TI552- } \\
\text { G6-R5) }\end{array}$ & $9.7-\mathrm{wt} \%$ & $\begin{array}{c}\text { Non- } \\
\text { Newtonian }\end{array}$ & 0.7 & 5.0 \\
\hline
\end{tabular}




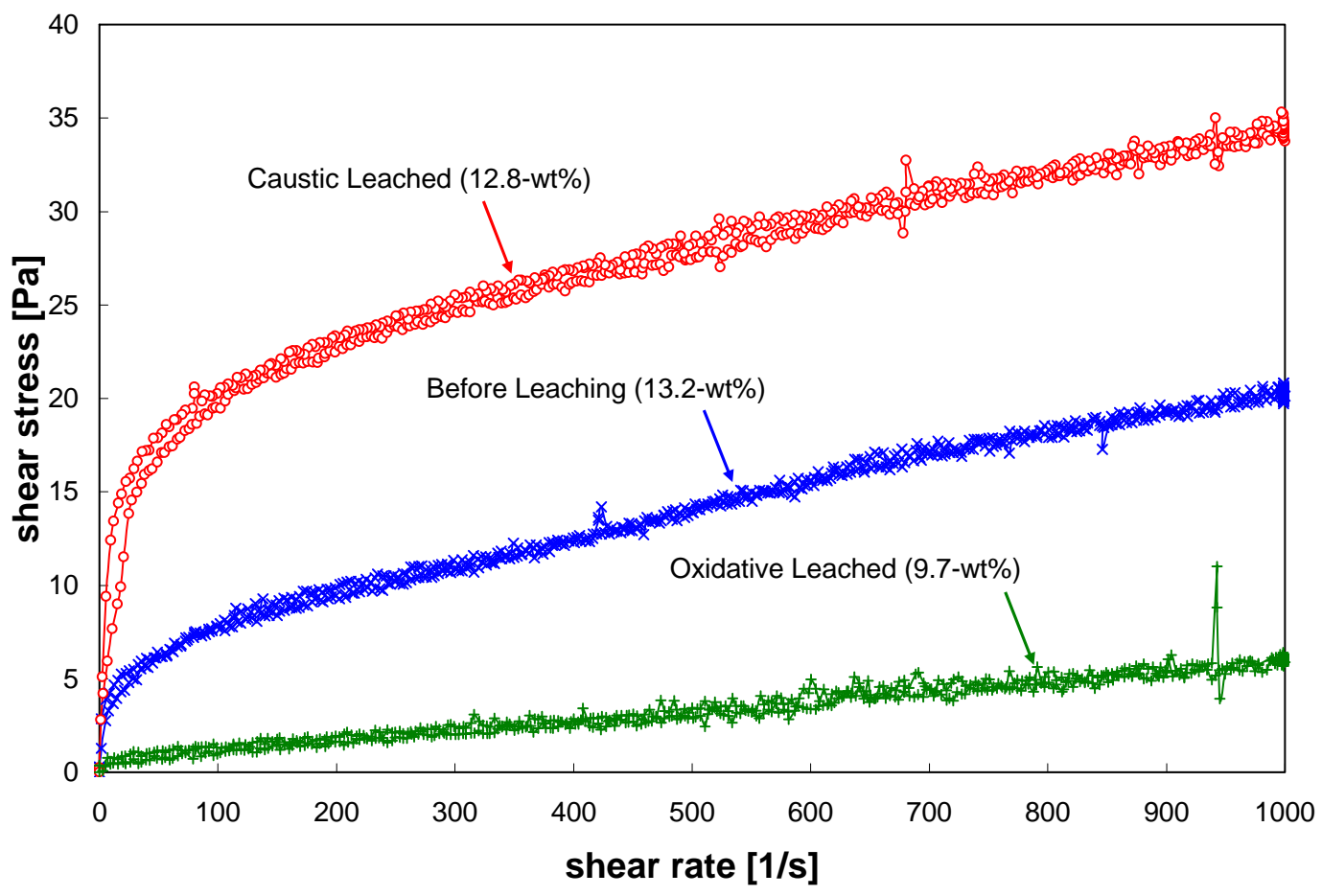

Figure 20. A comparison of Group 5/6 CUF slurries showing the effect of caustic leaching on rheology at $25^{\circ} \mathrm{C}$. Flow curves correspond to the pre-leach slurry (TI552-G6-R2), the caustic-leached, dewatered, washed slurry (sample TI552-G6-R4), and the oxidative-leached and washed slurry (TI552-G6-R5).

Table 25 and Figure 21 show the effect washing has on the Group 5/6 CUF material rheology. For washing, flow curve comparison is limited to post-caustic leach process (i.e., sample TI552-G6-R3 and -R4) as this was the only time pre- and post- washing samples were collected. Figure 21 indicates that washing both increased the yield stress of the slurry and decreased the consistency. These behaviors are confirmed by the Bingham-Plastic fitting parameters shown in Table 25: washing increases the yield point from 11 to $21 \mathrm{~Pa}$ while decreasing the consistency from 29 to $13 \mathrm{cP}$. Chemical changes in the solids species as a result of solids washing may cause the stress increase observed here and may also play a primary role in the increase between the pre- and post-leach samples TI552-G6-R2 and -R4 (as opposed to caustic-leaching effects alone). However, washing is accompanied by an increase in solids concentration from 8.9 to 12.8 -wt\%. It is likely that the increase in yield observed during washing is a combination of increased solids concentration and chemical changes caused by washing. The decrease in slurry consistency with washing can be attributed to a reduction in suspending phase viscosity as the chemical species dissolved during caustic leaching are washed out of the slurry. 
Table 25. Effect of washing on Group 5/6 CUF slurry rheology (at $25^{\circ} \mathrm{C}$ )

\begin{tabular}{||c|c|c|c|c||}
\hline DESCRIPTION & $\begin{array}{c}\text { SOLIDS } \\
\text { CONCENTRATION }\end{array}$ & RHEOLOGY & $\begin{array}{c}\text { YIELD } \\
\text { STRESS } \\
\text { [PA] }\end{array}$ & $\begin{array}{c}\text { CONSISTENCY } \\
\text { [CP] }\end{array}$ \\
\hline $\begin{array}{c}\text { Dewatered } \\
\text { (TI552-G6-R3) }\end{array}$ & $8.9-\mathrm{wt} \%$ & $\begin{array}{c}\text { Non- } \\
\text { Newtonian }\end{array}$ & 11 & 29 \\
\hline $\begin{array}{c}\text { Washed } \\
\text { (TI552-G6-R4) }\end{array}$ & $12.8-\mathrm{wt} \%$ & $\begin{array}{c}\text { Non- } \\
\text { Newtonian }\end{array}$ & 21 & 13 \\
\hline
\end{tabular}

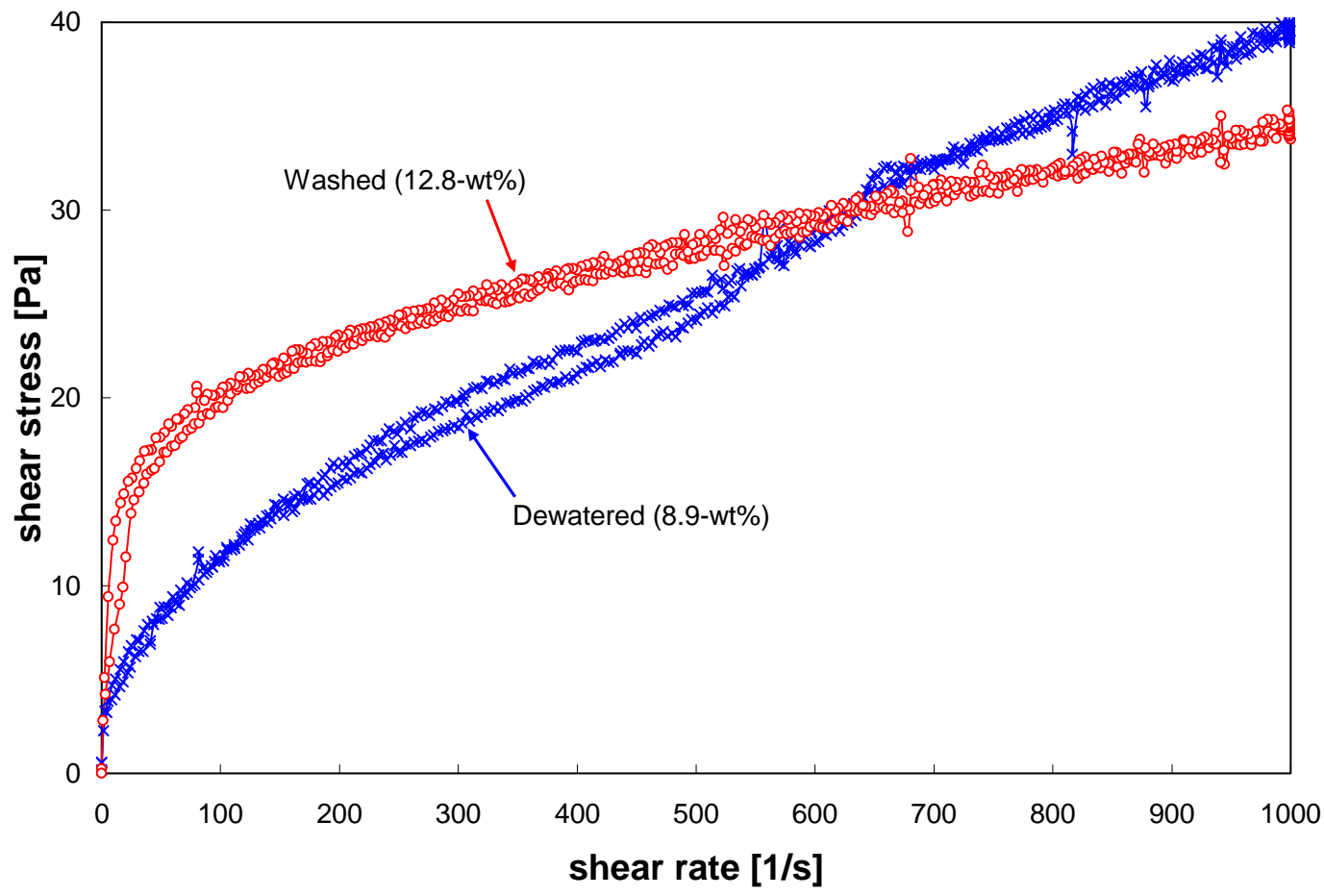

Figure 21. A comparison of Group 5/6 CUF slurries showing the effect of solids washing on rheology at $25^{\circ} \mathrm{C}$. Flow curves correspond to the caustic-leached and dewatered slurry (TI552-G6-R3) and to the caustic-leached, dewatered, washed slurry (sample TI552-G6-R4).

Table 26 and Figure 22 show the change in slurry rheology accomplished by mixing causticallyleached Group 5 solids (similar to sample TI540-G5-R4 in Ref [6]) into the post-oxidative-leach Group 5/6 slurry sample (TI552-G6-R5). The combined leach test sample (TI552-G6-R6) was created by mixing roughly 2 parts oxidative-leached Group 5/6 solids with 1 part caustically leached Group 5 solids. These solids were diluted with inhibited water during the mixing process. Exact mixing details for sample TI552-G6-R6 shall be provided in the CUF testing report that this interim rheology report supports.

The flow curves for the individual Group 5 and 5/6 leached slurries and combined 5 and 5/6 leach slurry are presented in Figure 22. This figure indicates that the only impact addition of the Group 5 caustic-leached solids has on the Group 5/6 slurry rheology is to increase the yield stress of the slurry. This observation can be rationalized by Group 5 solids adding to the strength of sample internal structure and is consistent with the behavior seen upon addition of un-leached Group 5 solids into un-leached 
Group 6 solids (cf. Figure 19). It should be noted that an increase in yield strength occurs despite the slight dilution from 9.7 to $8.0 \mathrm{wt}-\%$ undissolved solids that occurs as a result of leached slurry combination. The observation is confirmed by the fitting parameters given in Table 26. The table shows that addition of Group 5 solids to the leached 5/6 slurry increases the yield from 0.7 to $1.3 \mathrm{~Pa}$; however, this increase is very near the instruments limit of sensitivity ( $0.5 \mathrm{~Pa})$ and may not be statistically significant. The observed increase in slurry consistency of $0.1 \mathrm{cP}$ is not statistically significant even considering the lowest observed measurement errors for all Group 5/6 CUF testing rheology samples (i.e., the 0.1 to $0.2 \mathrm{cP}$ standard deviations on the Newtonian slurries).

Table 26. Changes in Group 5/6 CUF slurry rheology as a result of leached slurry combination (at $25^{\circ} \mathrm{C}$ )

\begin{tabular}{|c|c|c|c|c|}
\hline DESCRIPTION & $\begin{array}{c}\text { SOLIDS } \\
\text { CONCENTRATION }\end{array}$ & RHEOLOGY & $\begin{array}{c}\text { YIELD } \\
\text { STRESS } \\
\text { [PA] }\end{array}$ & $\begin{array}{c}\text { CONSISTENCY } \\
\text { [CP] }\end{array}$ \\
\hline $\begin{array}{c}\text { Group } 5 \\
\text { Leached }^{\mathrm{a}} \\
\text { (TI540-G5-R4) }^{\text {(TI }}\end{array}$ & 4.1-wt\% & $\begin{array}{c}\text { Non- } \\
\text { Newtonian }\end{array}$ & 3.3 & 4.7 \\
\hline $\begin{array}{c}\text { Group 5/6 } \\
\text { Leached } \\
\text { (TI552-G6-R5) } \\
\end{array}$ & 9.7-wt\% & $\begin{array}{c}\text { Non- } \\
\text { Newtonian }\end{array}$ & 0.7 & 5.0 \\
\hline $\begin{array}{l}\text { Combined Leach } \\
\text { (TI552-G6-R6) }\end{array}$ & 8.0-wt\% & $\begin{array}{c}\text { Non- } \\
\text { Newtonian }\end{array}$ & 1.3 & 5.1 \\
\hline
\end{tabular}

${ }^{\mathrm{a}}$ Rheology parameters taken from Ref. [6]

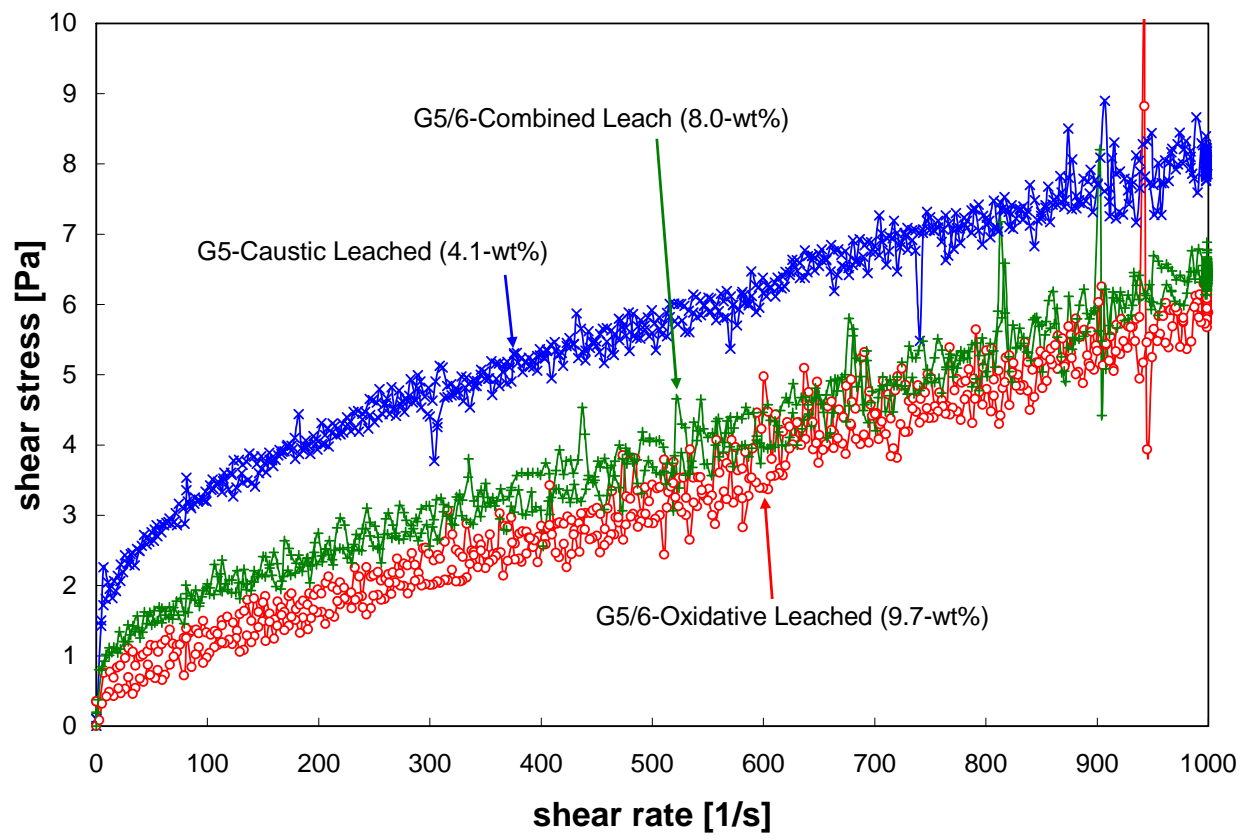

Figure 22. A comparison of Group 5, and 5/6 rheologies showing the effect of combining leached sludges. Flow curves correspond to the Group 5 caustic-leached material (similar to sample TI540G5-R4 in Ref [6]), Group 5/6 oxidative-leached material (sample TI552-G6-R5), and the combined leach slurry (sample TI552-G6-R6). All measurements are at $25^{\circ} \mathrm{C}$. 
Figure 23 shows the effect of temperature on the Bingham-Plastic fitting parameters derived from flow curve data of Group 5/6 samples. This figure shows that 1 ) slurry yield stress typically increases with increasing temperature (likely a result of solids concentration caused by evaporation of the suspending phase) and that 2) slurry consistency generally decrease with increasing temperature. The latter observation is consistent with a decreased suspending phase viscosity that occurs when heating liquids. Slurry consistency temperature trends are complex, and as such, there may be other chemical and physical sample changes driving down slurry consistency with increasing temperature.

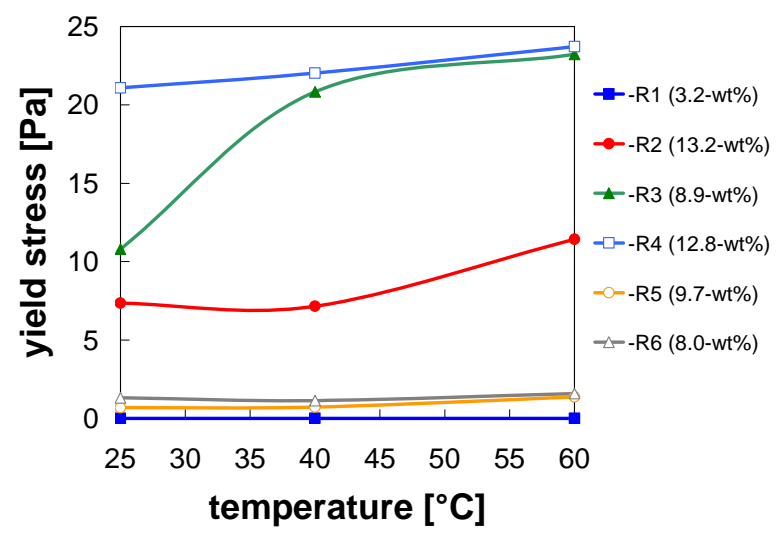

(a)

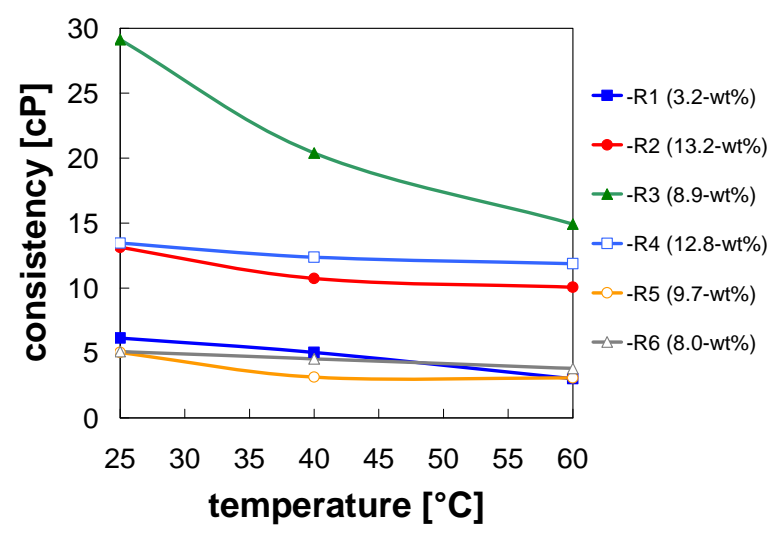

(b)

Figure 23. Comparison of group 5/6 CUF slurry Bingham-Plastic yield stress (a) and consistency (b) as a function of temperature. Slurries are label in accordance with Table 1. Sample TI552-G6-R1 is Newtonian, and as such, has a zero yield stress at all temperature. Sample -R1's reported consistency is its Newtonian viscosity.

\section{Sample TI552-G6-R2S: Pre-Caustic-Leach Permeate}

Figure 24 shows the results of flow curve testing for sample TI522-G6-R2S. This sample corresponds to permeate collected during the pre-caustic leach dewatering operation. The flow curves are typical of a low-viscosity Newtonian fluid. The slurries show a high noise to signal ratio and exhibit increase in the slope near $500 \mathrm{~s}^{-1}$ that is consistent with the formation of Taylor Vortices. In addition to vortex formation, the flow curves are also substantially effected by hysteresis. For low viscosity measurements, hysteresis is normally a result of rotor inertia. Both measurement noise resulting from mechanical friction and rotor inertia are physical limitations of the M5 measuring system and cannot be corrected or further minimized.

Flow curve data at $25^{\circ}$ and $40^{\circ} \mathrm{C}$ are acceptable for data analysis. The torque offset on the $60^{\circ} \mathrm{C}$ measurement appears to have been set too low, such that the combination of rotor inertia and measurement noise on the down-ramp result in a number of the measurement points falling below zero. Because the M5-measuring system records negative torques as zero, a significant number of down-ramp data below $300 \mathrm{~s}^{-1}$ at $60^{\circ} \mathrm{C}$ were set to zero. Overall, this does not impede determination of viscosity from the current set of measurement data because 1) the up-ramp data are still usable and 2) the flow curve is supplemented by the constant rotation measurements. As such, no corrective action was taken to improve the $60^{\circ} \mathrm{C}$ flow curve measurement. 
Newtonian viscosities as a function of temperature are derived by fitting the flow curve data presented in Figure 24 to Eq. 4. The range of shear rates analyzed was limited to $0-400 \mathrm{~s}^{-1}$ to exclude flow regions potentially effected by Taylor vortices. In addition, constant rotation viscosity measurements were derived from the constant rotational shearing step made prior to each measurement. Here, the viscous stress response of the fluid (sheared at $470 \mathrm{~s}^{-1}$ ) was converted to viscosity using Eq. 3 and time averaged over the duration of the shear step ( 3 minutes). The results of both analyses are shown in Table 27. Analysis finds a permeate viscosities ranging from 3.8 to $4.1 \mathrm{cP}$ at $25^{\circ} \mathrm{C}$, from 2.9 to $3.1 \mathrm{cP}$ at $40^{\circ} \mathrm{C}$, and from 1.7 to $2.1 \mathrm{cP}$ at $60^{\circ} \mathrm{C}$.

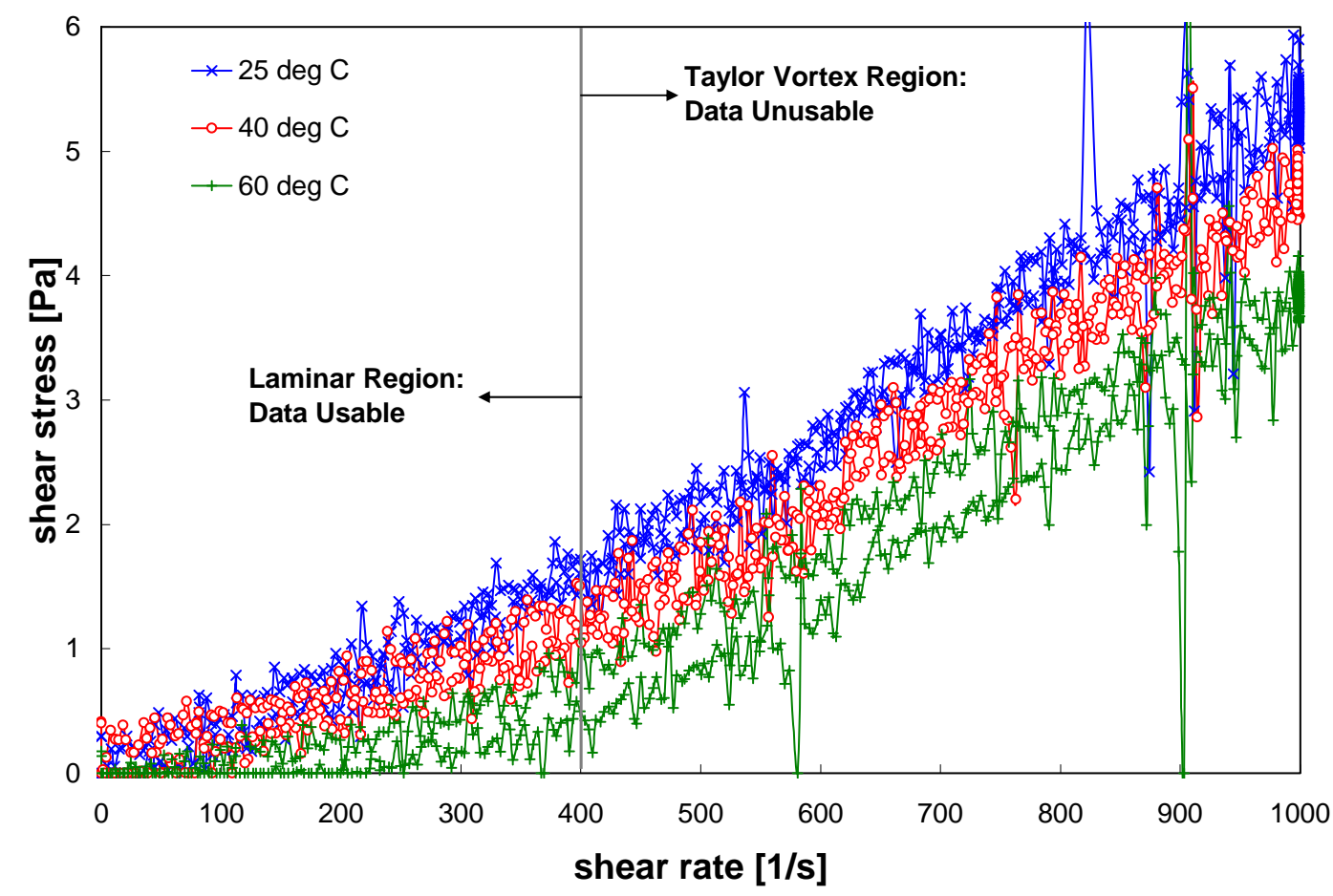

Figure 24. Flow curve (shear stress versus shear rate) for Group 5/6 pre-leach permeate, TI552-G6R2S at $25^{\circ} \mathrm{C}, 40^{\circ} \mathrm{C}$, and $60^{\circ} \mathrm{C}$ as measured using the MV1 cup and rotor. Note: the second repeat measurement for $25^{\circ} \mathrm{C}$ is shown here, as it is the closest to the $40^{\circ}$ and $60^{\circ} \mathrm{C}$ measurements in time.

The Newtonian viscosities calculated by constant rotation and flow-curve regression compare well. Measurements at $25^{\circ}$ and $40^{\circ} \mathrm{C}$ match within the standard deviation of the constant rotation viscosities alone (i.e., without even considering experimental and fitting errors in the viscosities determined by regression analysis). There is a $0.4 \mathrm{cP}$ deviation between viscosities measured by regression and constant rotation at $60^{\circ} \mathrm{C}$. Relative to the overall expected sensitivity of $0.5 \mathrm{cP}$ for the M5 measuring system, this deviation is still acceptable. It should be noted that the constant rotation viscosities at each temperature are either equal to or greater than their respective viscosities determined by regression analysis. This difference is inconsistent with the majority of other Newtonian viscosity determinations by this method, where the constant rotation measurement is typically lower than the regressed value (cf. Table 10 and 11). For the current measurements, the exact shear stress at which Taylor Vortices form is not distinct and may start somewhere between 400 to $500 \mathrm{~s}^{-1}$. As such, the constant rotation viscosities, which employ a shear rate above that used in the regression analysis, could 
be effected weakly by turbulent flow in the gap and show slightly larger values than regression as a result. However, as stated before, the difference is not large enough to be significant and falls within the measurement noise of the system.

Table 27. Newtonian viscosities for Group 5/6 permeate sample TI552-G6-R2S at $25^{\circ} \mathrm{C}, 40^{\circ} \mathrm{C}$, and $60^{\circ} \mathrm{C}$. Note: the error reported for constant rotation is the standard deviation of stress over the 3 minute averaging period.

\begin{tabular}{|c|c|c|c|}
\hline TEMPERATURE [ $\left.{ }^{\circ} \mathrm{C}\right]$ & MODEL & $\begin{array}{c}\text { VISCOSITY } \\
\text { [CP] }\end{array}$ & $\overline{\overline{\mathbf{R}^{\mathbf{A}}}}$ \\
\hline 25 (measurement 1 of 2 ) & Average (constant rotation) $^{\mathrm{b}}$ & $3.8 \pm 0.1$ & $\mathrm{n} / \mathrm{a}$ \\
\hline 25 (measurement 2 of 2 ) & Average (constant rotation) $^{b}$ & $4.1 \pm 0.2$ & $\mathrm{n} / \mathrm{a}$ \\
\hline 40 & Average (constant rotation) $^{\mathrm{b}}$ & $3.1 \pm 0.2$ & $\mathrm{n} / \mathrm{a}$ \\
\hline 60 & Average (constant rotation) $^{b}$ & $2.1 \pm 0.1$ & $\mathrm{n} / \mathrm{a}$ \\
\hline 25 (measurement 1 of 2 ) & Newtonian $^{c}$ & 3.8 & 0.938 \\
\hline 25 (measurement 2 of 2 ) & Newtonian $^{c}$ & 3.9 & 0.943 \\
\hline 40 & Newtonian $^{\mathrm{C}}$ & 2.9 & 0.870 \\
\hline 60 & Newtonian ${ }^{\mathrm{c}, \mathrm{d}}$ & 1.7 & 0.891 \\
\hline
\end{tabular}

${ }^{\mathrm{a}} \mathrm{R}$ is correlation coefficient of the fit

${ }^{\mathrm{b}}$ Time-average viscosity at a constant rate of $470 \mathrm{~s}^{-1}$ over 3 minutes

${ }^{\mathrm{c}}$ Fit of flow curve data to Eq. 4 over 0 to $400 \mathrm{~s}^{-1}$

${ }^{\mathrm{d}}$ Up-ramp fit only

Because of the measurement limitations outlined above with respect to noise and rotor inertia, apparent viscosities at $33 \mathrm{~s}^{-1}$ derived from interpolation of data points bounding $33 \mathrm{~s}^{-1}$ will not be reported. In terms of calculated apparent viscosities, the Newtonian results reported in Table 27 represent the apparent viscosity over the entire range of shear. It is recommended that engineering design use these results.

\section{$\underline{\text { Conclusions }}$}

The preceding sub-sections detail the rheology of Group 5/6 tank waste slurries and permeates as a function of CUF processing and temperature. CUF samples containing only Group 6 (S-Saltcake) solids were Newtonian. All Group 5/6 slurry mixtures containing both S-Saltcake and REDOX (R) solids exhibited non-Newtonian rheology of varying degrees. As expected, slurry rheology was found to depend on the concentration of undissolved solids and on CUF processing. The flow curve behavior for most non-Newtonian slurries was best described with the Herschel-Bulkley constitutive equation. The Bingham-Plastic equation provided acceptable characterization of the flow curve data above shear rates of $100 \mathrm{~s}^{-1}$, but shear-thinning behavior in the 0 to $100 \mathrm{~s}^{-1}$ shear rate range prevented it from accurately capture low-shear stress behavior.

It is not known if the shear-thinning behavior observed in most non-Newtonian samples is true or if it is indicative of slip, sample elasticity, and poor rotational sampling, as the degree of shear-thinning is much less than observed in the Group 5 CUF testing samples (see Ref [6]). There is one exception; sample TI552-G6-R4, which corresponds to a caustically-leached, dewatered, and washed Group 5/6 slurry, showed severe shear-thinning reminiscent of concentrated Group 5 CUF slurries. Observation of this behavior in the flow curve data was confirmed by physically un-realistic Herschel-Bulkley 
parameters. For this particular sample, it is likely that slip, elasticity, and poor sampling influenced the measurement.

Apparent time-dependencies (i.e., hysteresis) were observed in the flow curve data for certain CUF testing samples. Effected samples include TI552-G6-R2 (high-solids matrix), -R3 (caustic-leached and dewatered), -R4 (caustic-leached, dewatered, and washed), and -R5 (oxidative-leached and washed). For sample -R2 and -R4, hysteresis is believed to result from evaporation of the suspending phase and the increase in solids concentration it causes. Increases in samples -R3 and -R5 are believed to be the result of measurement equipment limitations, such as rotor inertia.

The Bingham-Plastic model parameters to provide a reasonable description of flow curve behavior. Using the these parameters as a guide, the slurry rheology as a function of waste processing in the CUF may be described as follows:

1. Group 5 Source Material (G5-RH-2) - this is a concentrated (18.5-wt\%) slurry derived from homogenization of wastes from processing group 5 . It shows significant non-Newtonian rheology: as temperature is increased from $25^{\circ}$ to $60^{\circ} \mathrm{C}$, the slurry's yield stress increases from 57 to $74 \mathrm{~Pa}$ while its consistency increases from 13 to $17 \mathrm{cP}$.

2. Group 6 Source Material (TI490-G6-AR-RH) - this is a concentrated (14.7-wt\%) slurry derived from homogenization of wastes from processing group 6 . Its behavior is Newtonian: as temperature is increased from $25^{\circ}$ to $60^{\circ} \mathrm{C}$, the slurry's Newtonian viscosity decreases from $\sim 8$ to $\sim 4 \mathrm{cP}$.

3. Group 6 Dilution (TI552-G6-R1) - this is a low solids concentration Group 6 slurry (3.2-wt\%) created by diluting Group 6 source material with Group 6 supernatant. Its behavior is Newtonian: as temperature is increased from $25^{\circ}$ to $60^{\circ} \mathrm{C}$, the slurry's Newtonian viscosity decreases from $\sim 6$ to $\sim 3 \mathrm{cP}$.

4. Group 5/6 Pre-Leach Mixture (TI552-G6-R2) - this is a high solids Group 5/6 mixed slurry (13.2-wt\%) created by adding Group 5 source material to the Group 6 dilution and subsequently dewatering that mixture. It shows non-Newtonian rheology: as temperature is increased from $25^{\circ}$ to $60^{\circ} \mathrm{C}$, the slurry's yield stress increases from $\sim 7$ to $\sim 11$ Pa whereas its consistency decreases from 13 to $10 \mathrm{cP}$.

5. Group 5/6 Caustic-Leached and Dewatered Slurry (TI552-G6-R3) - this 8.9-wt\% slurry results from caustically leaching and dewatering the Group 5/6 slurry mixture represented by sample TI552-G6-R2. Leaching is carried out in the CUF for 24 hours at $100^{\circ} \mathrm{C}$. It shows nonNewtonian rheology: as temperature is increased from $25^{\circ}$ to $60^{\circ} \mathrm{C}$, this slurry's yield stress increases from $\sim 11$ to $\sim 23 \mathrm{~Pa}$ whereas the consistency decreases from $\sim 29$ to $\sim 15 \mathrm{cP}$.

6. Group 5/6 Caustic-Leached, Dewatered, and Washed Slurry (TI552-G6-R4) - this 12.8-wt\% slurry results from washing of the caustic-leached and dewatered slurry. It shows non-Newtonian rheology: as temperature is increased from $25^{\circ}$ to $60^{\circ} \mathrm{C}$, the slurry's yield stress increases slightly from $\sim 21$ to $\sim 24 \mathrm{~Pa}$ while its consistency decreases slightly from $\sim 13$ to $\sim 12 \mathrm{cP}$. 
7. Group 5/6 Oxidative-Leached and Washed Slurry (TI552-G6-R5) - this 9.7-wt\% slurry results from oxidative leaching and subsequently washing the caustic-leached, dewatered, and washed slurry. It shows weak non-Newtonian rheology: as temperature is increased from $25^{\circ}$ to $60^{\circ} \mathrm{C}$, the yield stress increases from 0.7 to $1.4 \mathrm{~Pa}$ whereas the consistency decreases from $\sim 5$ to $\sim 3 \mathrm{cP}$.

8. Group 5/6 Combined Leach Slurry (TI552-G6-R6) - this 8.0-wt\% slurry results from mixing the oxidative-leached and washed slurry with caustic-leached solids from waste processing group 5. It shows weak non-Newtonian rheology: as temperature is increased from $25^{\circ}$ to $60^{\circ} \mathrm{C}$, the yield stress decreases from 1.3 to $1.6 \mathrm{~Pa}$ whereas the consistency decreases slightly from $\sim 5$ to $\sim 4 \mathrm{cP}$.

The single pre-leach permeate sample collected during dewatering of the initial Group 5/6 waste mixture (i.e., sample TI552-G6-R2S) is Newtonian as expected. It has a viscosity that ranges from $4 \mathrm{cP}$ at $25^{\circ} \mathrm{C}$ to $2 \mathrm{cP}$ at $60^{\circ} \mathrm{C}$.

\section{Records}

Data records relating to rheological characterization of Group 6 and Group 5/6 Initial Characterization and CUF Testing samples include original RheoWin data files, Test Data Packages (TDPs), and LRBs:

- $\quad$ LRB BNW 59633 - Pages 62-68

- CCP-WTPSP-377 - flow curve measurement data, results, and graphs for sample G5-RH-2

- CCP-WTPSP-384 - performance check results for October measurements

- CCP-WTPSP-385 - flow curve measurement data, results, and graphs for sample TI490-G6-AR-RH

- CCP-WTPSP-407 - flow curve measurement data, results, and graphs for sample TI552-G6-R1

- CCP-WTPSP-410 - flow curve measurement data, results, and graphs for sample TI540-G6-R2S

- CCP-WTPSP-411 - flow curve measurement data, results, and graphs for sample TI540-G6-R2

- CCP-WTPSP-412 - flow curve measurement data, results, and graphs for sample TI540-G6-R3

- CCP-WTPSP-413 - flow curve measurement data, results, and graphs for sample TI540-G6-R4

- CCP-WTPSP-414 - flow curve measurement data, results, and graphs for sample TI540-G6-R5

- CCP-WTPSP-415 - flow curve measurement data, results, and graphs for sample TI540-G6-R6

- CCP-WTPSP-421 - flow curve comparisons and fitting parameter variation with slurry concentration and temperature

Table 28 provides a complete list of the relevant RheoWin file.

Table 28 List of RheoWin files associated with Group 6 CUF Testing Rheology.

\begin{tabular}{||c|c|c||}
\hline File Name & $\begin{array}{c}\text { Type of } \\
\text { Measurement }\end{array}$ & Description \\
\hline $071024 \_201 \_b$ & $\begin{array}{c}\text { Performance } \\
\text { Check }\end{array}$ & Brookfield Fluid 10 at $25^{\circ} \mathrm{C}(9.6 \mathrm{cP})-8.9 \mathrm{cP}$ \\
\hline 071024_201_c & $\begin{array}{c}\text { Performance } \\
\text { Check }\end{array}$ & Brookfield Fluid 100 at $25^{\circ} \mathrm{C}(96.0 \mathrm{cP})-87.7 \mathrm{cP}$ \\
\hline
\end{tabular}


Table 28 List of RheoWin files associated with Group 6 CUF Testing Rheology.

\begin{tabular}{|c|c|c|}
\hline File Name & $\begin{array}{c}\text { Type of } \\
\text { Measurement }\end{array}$ & Description \\
\hline 071031_201_c & Constant Rotation & $\begin{array}{l}\text { TI490-G6-AR-RH at } 25^{\circ} \mathrm{C} \text {, Group } 6 \text { Initial Characterization } \\
\text { Slurry }\end{array}$ \\
\hline 071031_201_d & Flow Curve & $\begin{array}{l}\text { TI490-G6-AR-RH at } 25^{\circ} \mathrm{C} \text {, Group } 6 \text { Initial Characterization } \\
\text { Slurry }\end{array}$ \\
\hline 071031_201_e & Constant Rotation & $\begin{array}{l}\text { TI490-G6-AR-RH at } 25^{\circ} \mathrm{C} \text {, Group } 6 \text { Initial Characterization } \\
\text { Slurry }\end{array}$ \\
\hline 071031_201_f & Flow Curve & $\begin{array}{l}\text { TI490-G6-AR-RH at } 25^{\circ} \mathrm{C} \text {, Group } 6 \text { Initial Characterization } \\
\text { Slurry }\end{array}$ \\
\hline 071031_201_g & Constant Rotation & $\begin{array}{l}\text { TI490-G6-AR-RH at } 40^{\circ} \mathrm{C} \text {, Group } 6 \text { Initial Characterization } \\
\text { Slurry }\end{array}$ \\
\hline 071031_201_h & Flow Curve & $\begin{array}{l}\text { TI490-G6-AR-RH at } 40^{\circ} \mathrm{C} \text {, Group } 6 \text { Initial Characterization } \\
\text { Slurry }\end{array}$ \\
\hline 071031_201_i & Constant Rotation & $\begin{array}{l}\text { TI } 490-G 6-A R-R H \text { at } 60^{\circ} \mathrm{C} \text {, Group } 6 \text { Initial Characterization } \\
\text { Slurry }\end{array}$ \\
\hline 071031_201_j & Flow Curve & $\begin{array}{l}\text { TI } 490-G 6-A R-R H \text { at } 60^{\circ} \mathrm{C} \text {, Group } 6 \text { Initial Characterization } \\
\text { Slurry }\end{array}$ \\
\hline 071105_201_a & Constant Rotation & TI552-G6-R1 at $25^{\circ} \mathrm{C}$, Group 6 CUF Slurry \\
\hline 071105_201_b & Flow Curve & TI552-G6-R1 at $25^{\circ} \mathrm{C}$, Group 6 CUF Slurry \\
\hline 071105_201_c & Constant Rotation & TI552-G6-R1 at $25^{\circ} \mathrm{C}$, Group 6 CUF Slurry \\
\hline 071105_201_d & Flow Curve & TI552-G6-R1 at $25^{\circ} \mathrm{C}$, Group 6 CUF Slurry \\
\hline 071105_201_e & Constant Rotation & TI552-G6-R1 at $40^{\circ} \mathrm{C}$, Group 6 CUF Slurry \\
\hline 071105_201_f & Flow Curve & TI552-G6-R1 at $40^{\circ} \mathrm{C}$, Group 6 CUF Slurry \\
\hline 071105_201_g & Constant Rotation & TI552-G6-R1 at $60^{\circ} \mathrm{C}$, Group 6 CUF Slurry \\
\hline 071105_201_h & Flow Curve & TI552-G6-R1 at $60^{\circ} \mathrm{C}$, Group 6 CUF Slurry \\
\hline 071106_201_a & Constant Rotation & TI552-G6-R2 at $25^{\circ} \mathrm{C}$, Group 5/6 CUF Slurry \\
\hline 071106_201_b & Flow Curve & TI552-G6-R2 at $25^{\circ} \mathrm{C}$, Group 5/6 CUF Slurry \\
\hline 071106_201_c & Constant Rotation & TI552-G6-R2 at $25^{\circ} \mathrm{C}$, Group 5/6 CUF Slurry \\
\hline 071106_201_d & Flow Curve & TI552-G6-R2 at $25^{\circ} \mathrm{C}$, Group 5/6 CUF Slurry \\
\hline 071106_201_e & Constant Rotation & TI552-G6-R2 at $40^{\circ} \mathrm{C}$, Group 5/6 CUF Slurry \\
\hline 071106_201_f & Flow Curve & TI552-G6-R2 at $40^{\circ} \mathrm{C}$, Group 5/6 CUF Slurry \\
\hline 071106_201_j & Constant Rotation & TI552-G6-R2 at $60^{\circ} \mathrm{C}$, Group 5/6 CUF Slurry \\
\hline 071106_201_k & Flow Curve & TI552-G6-R2 at $60^{\circ} \mathrm{C}$, Group 5/6 CUF Slurry \\
\hline 071108_201_a & Constant Rotation & TI552-G6-R3 at $25^{\circ} \mathrm{C}$, Group 5/6 CUF Slurry \\
\hline 071108_201_b & Flow Curve & TI552-G6-R3 at $25^{\circ} \mathrm{C}$, Group 5/6 CUF Slurry \\
\hline 071108_201_c & Constant Rotation & TI552-G6-R3 at $25^{\circ} \mathrm{C}$, Group 5/6 CUF Slurry \\
\hline 071108_201_d & Flow Curve & TI552-G6-R3 at $25^{\circ} \mathrm{C}$, Group 5/6 CUF Slurry \\
\hline 071108_201_e & Constant Rotation & TI552-G6-R3 at $40^{\circ} \mathrm{C}$, Group 5/6 CUF Slurry \\
\hline 071108_201_f & Flow Curve & TI552-G6-R3 at $40^{\circ} \mathrm{C}$, Group 5/6 CUF Slurry \\
\hline 071108_201_g & Constant Rotation & TI552-G6-R3 at $60^{\circ} \mathrm{C}$, Group 5/6 CUF Slurry \\
\hline 071108_201_h & Flow Curve & TI552-G6-R3 at $60^{\circ} \mathrm{C}$, Group 5/6 CUF Slurry \\
\hline 071108_201_i & Constant Rotation & TI552-G6-R4 at $25^{\circ} \mathrm{C}$, Group 5/6 CUF Slurry \\
\hline 071108_201_j & Flow Curve & TI552-G6-R4 at $25^{\circ} \mathrm{C}$, Group 5/6 CUF Slurry \\
\hline 071108_201_k & Constant Rotation & TI552-G6-R4 at $25^{\circ} \mathrm{C}$, Group 5/6 CUF Slurry \\
\hline
\end{tabular}


Table 28 List of RheoWin files associated with Group 6 CUF Testing Rheology.

\begin{tabular}{|c|c|c|}
\hline File Name & $\begin{array}{c}\text { Type of } \\
\text { Measurement }\end{array}$ & Description \\
\hline 071108_201_l & Flow Curve & TI552-G6-R4 at $25^{\circ} \mathrm{C}$, Group 5/6 CUF Slurry \\
\hline 071109_201_a & Constant Rotation & TI552-G6-R4 at $40^{\circ} \mathrm{C}$, Group 5/6 CUF Slurry \\
\hline 071109_201_b & Flow Curve & TI552-G6-R4 at $40^{\circ} \mathrm{C}$, Group 5/6 CUF Slurry \\
\hline 071109_201_c & Constant Rotation & TI552-G6-R4 at $60^{\circ} \mathrm{C}$, Group 5/6 CUF Slurry \\
\hline 071109_201_d & Flow Curve & TI552-G6-R4 at $60^{\circ} \mathrm{C}$, Group 5/6 CUF Slurry \\
\hline 071109_201_e & Constant Rotation & TI552-G6-R5 at $25^{\circ} \mathrm{C}$, Group 5/6 CUF Slurry \\
\hline 071109_201_f & Flow Curve & TI552-G6-R5 at $25^{\circ} \mathrm{C}$, Group 5/6 CUF Slurry \\
\hline 071109_201_g & Constant Rotation & TI552-G6-R5 at $25^{\circ} \mathrm{C}$, Group 5/6 CUF Slurry \\
\hline 071109_201_h & Flow Curve & TI552-G6-R5 at $25^{\circ} \mathrm{C}$, Group 5/6 CUF Slurry \\
\hline 071109_201_i & Constant Rotation & TI552-G6-R5 at $40^{\circ} \mathrm{C}$, Group 5/6 CUF Slurry \\
\hline 071109_201_j & Flow Curve & TI552-G6-R5 at $40^{\circ} \mathrm{C}$, Group 5/6 CUF Slurry \\
\hline 071109_201_k & Constant Rotation & TI552-G6-R5 at $60^{\circ} \mathrm{C}$, Group 5/6 CUF Slurry \\
\hline 071109_201_l & Flow Curve & TI552-G6-R5 at $60^{\circ} \mathrm{C}$, Group 5/6 CUF Slurry \\
\hline 071113_201_a & Constant Rotation & TI552-G6-R6 at $25^{\circ} \mathrm{C}$, Group 5/6 CUF Slurry \\
\hline 071113_201_b & Flow Curve & TI552-G6-R6 at $25^{\circ} \mathrm{C}$, Group 5/6 CUF Slurry \\
\hline 071113_201_c & Constant Rotation & TI552-G6-R6 at $25^{\circ} \mathrm{C}$, Group 5/6 CUF Slurry \\
\hline 071113_201_d & Flow Curve & TI552-G6-R6 at $25^{\circ} \mathrm{C}$, Group 5/6 CUF Slurry \\
\hline 071113_201_e & Constant Rotation & TI552-G6-R6 at $40^{\circ} \mathrm{C}$, Group 5/6 CUF Slurry \\
\hline 071113_201_f & Flow Curve & TI552-G6-R6 at $40^{\circ} \mathrm{C}$, Group 5/6 CUF Slurry \\
\hline 071113_201_g & Constant Rotation & TI552-G6-R6 at $60^{\circ} \mathrm{C}$, Group 5/6 CUF Slurry \\
\hline 071113_201_h & Flow Curve & TI552-G6-R6 at $60^{\circ} \mathrm{C}$, Group 5/6 CUF Slurry \\
\hline 071116_201_a & Constant Rotation & TI552-G6-R2S at 25ㅇ, Group 5/6 CUF Permeate \\
\hline 071116_201_b & Flow Curve & TI552-G6-R2S at $25^{\circ} \mathrm{C}$, Group 5/6 CUF Permeate \\
\hline 071116_201_c & Constant Rotation & TI552-G6-R2S at 25², Group 5/6 CUF Permeate \\
\hline 071116_201_d & Flow Curve & TI552-G6-R2S at 25ㅇ, Group 5/6 CUF Permeate \\
\hline 071116_201_e & Constant Rotation & TI552-G6-R2S at $40^{\circ} \mathrm{C}$, Group 5/6 CUF Permeate \\
\hline 071116_201_f & Flow Curve & TI552-G6-R2S at $40^{\circ} \mathrm{C}$, Group 5/6 CUF Permeate \\
\hline 071116_201_g & Constant Rotation & TI552-G6-R2S at $60^{\circ} \mathrm{C}$, Group 5/6 CUF Permeate \\
\hline 071116_201_h & Flow Curve & TI552-G6-R2S at $60^{\circ} \mathrm{C}$, Group 5/6 CUF Permeate \\
\hline
\end{tabular}

\section{References}

1. Doc. No. TP-RPP-WTP-467, Revision 0, "Characterization and Small Scale Testing of Hanford Wastes to Support the Development and Demonstration of Leaching and Ultrafiltration Pretreatment Processes,” SK Fiskum, Battelle - Pacific Northwest Division, February 2007.

2. Steffe JF, Rheological Methods in Food Process Engineering, Freeman Press, East Lansing (1996).

3. Doc. No. RPL-COLLOID-02, Revision 1, "Measurement of Physical and Rheological Properties of Solutions, Slurries and Sludges,” RC Daniel, Pacific Northwest National Laboratory, May 2007.

4. Doc. No. TDP-WTP-056, “Rheology of Waste Processing Group 5: Initial Characterization,” RC Daniel, Battelle - Pacific Northwest Division, November 2007. 
5. Doc. No. TDP-WTP-061, “Rheology of Waste Processing Group 6: Initial Characterization,” RC Daniel, Battelle - Pacific Northwest Division, January 2008.

6. Doc. No. TDP-WTP-070, "Rheology of Hanford Waste REDOX Sludge (Waste Processing Group 5): CUF Testing,” RC Daniel, Battelle - Pacific Northwest Division, April 2008. 


\section{Appendix A - Rheograms}

This appendix contains detailed rheograms (shear stress and apparent viscosity as a function of shear) for Group 5 and Group 6 initial characterization samples and well as Group 5/6 CUF testing samples. No discussion of these results is provided.

Sample G5-RH-2: Source Group 5 Material for CUF Testing (18.5-wt\%)

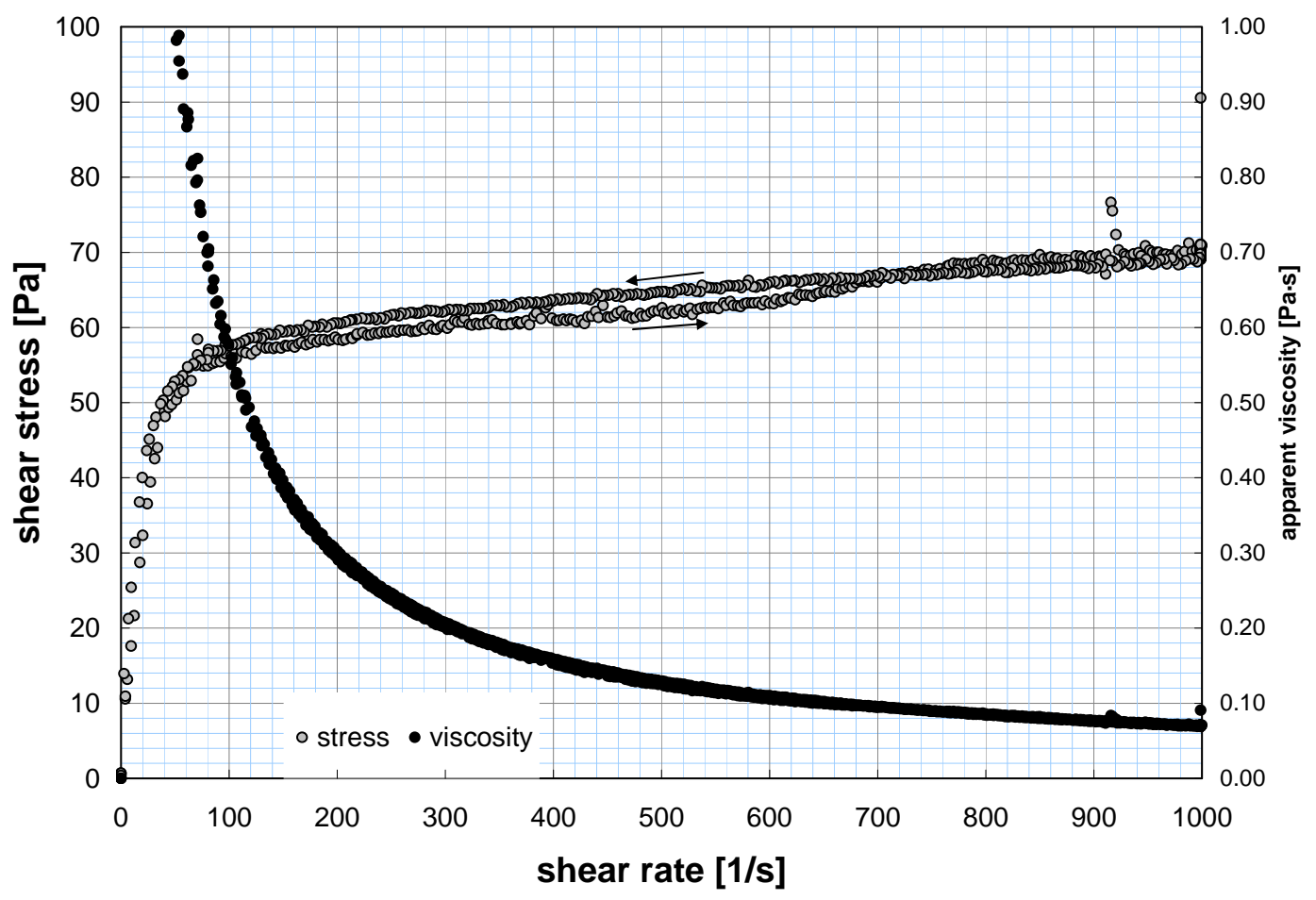

Figure A-1. Rheogram for G5-RH-2 at $25^{\circ} \mathrm{C}$. 


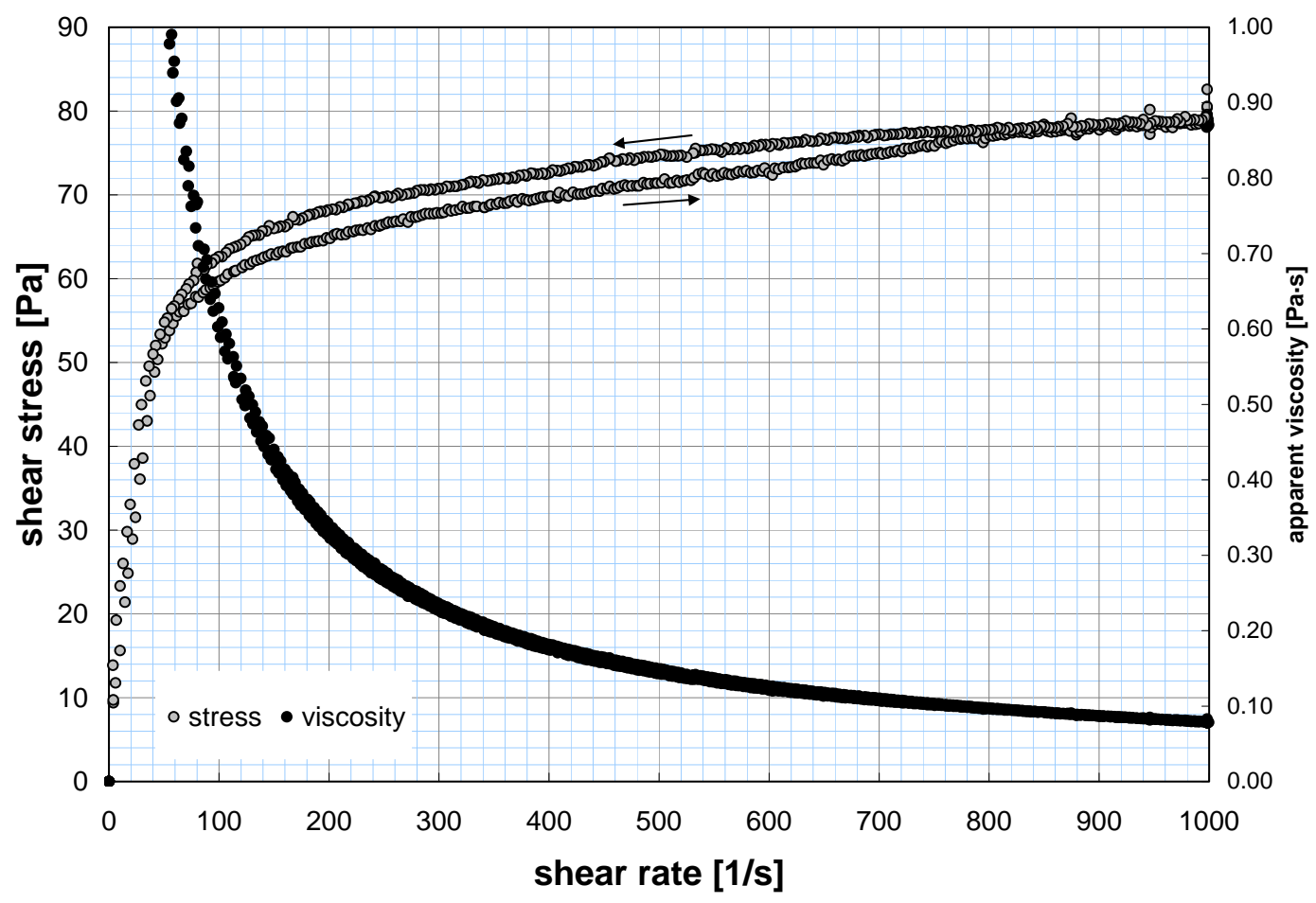

Figure A-2. Rheogram for G5-RH-2 at $40^{\circ} \mathrm{C}$.

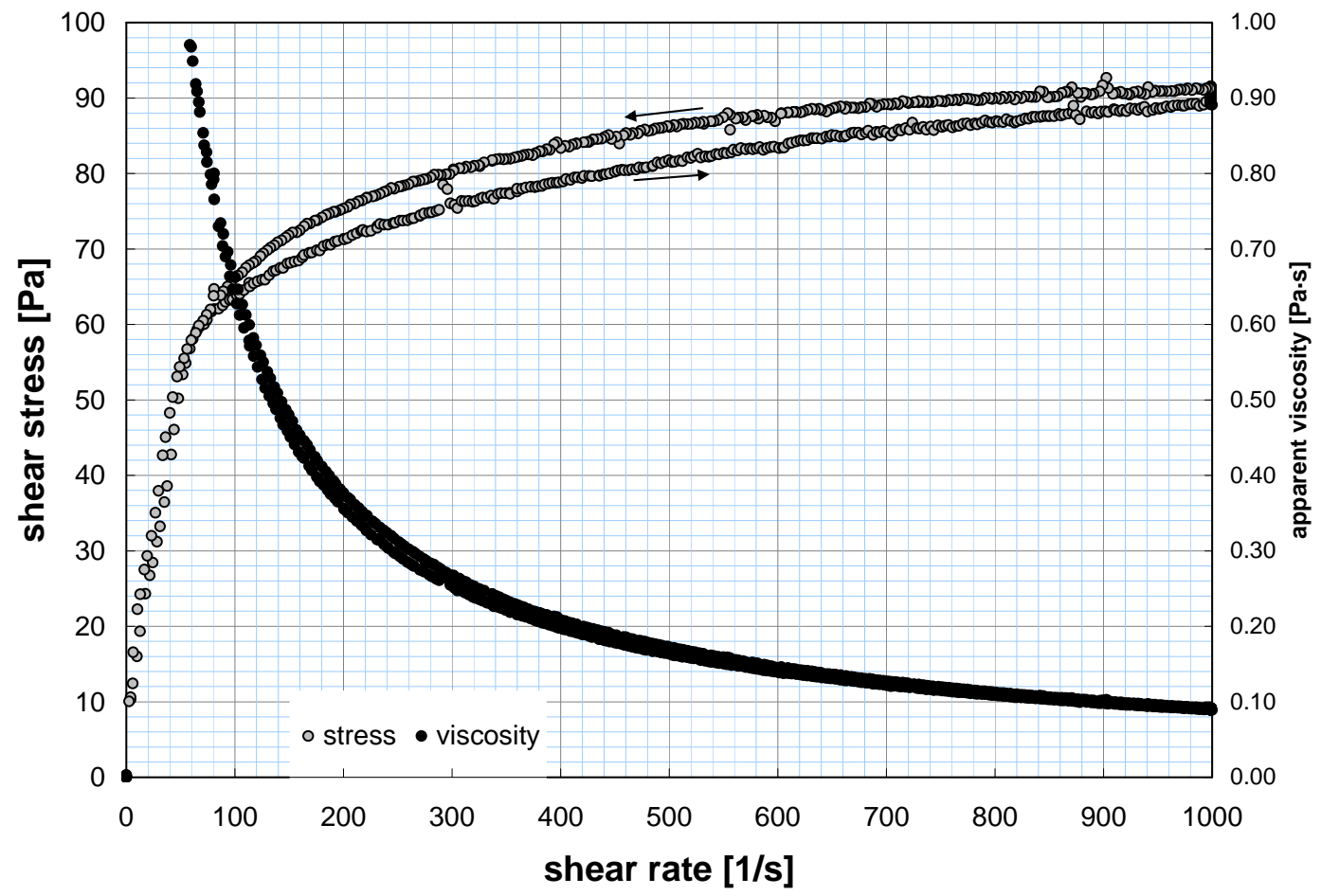

Figure A-3. Rheogram for G5-RH-2 at $60^{\circ} \mathrm{C}$. 
Sample TI490-G6-AR-RH: Source Group 6 Material for CUF Testing (14.7-wt\%)

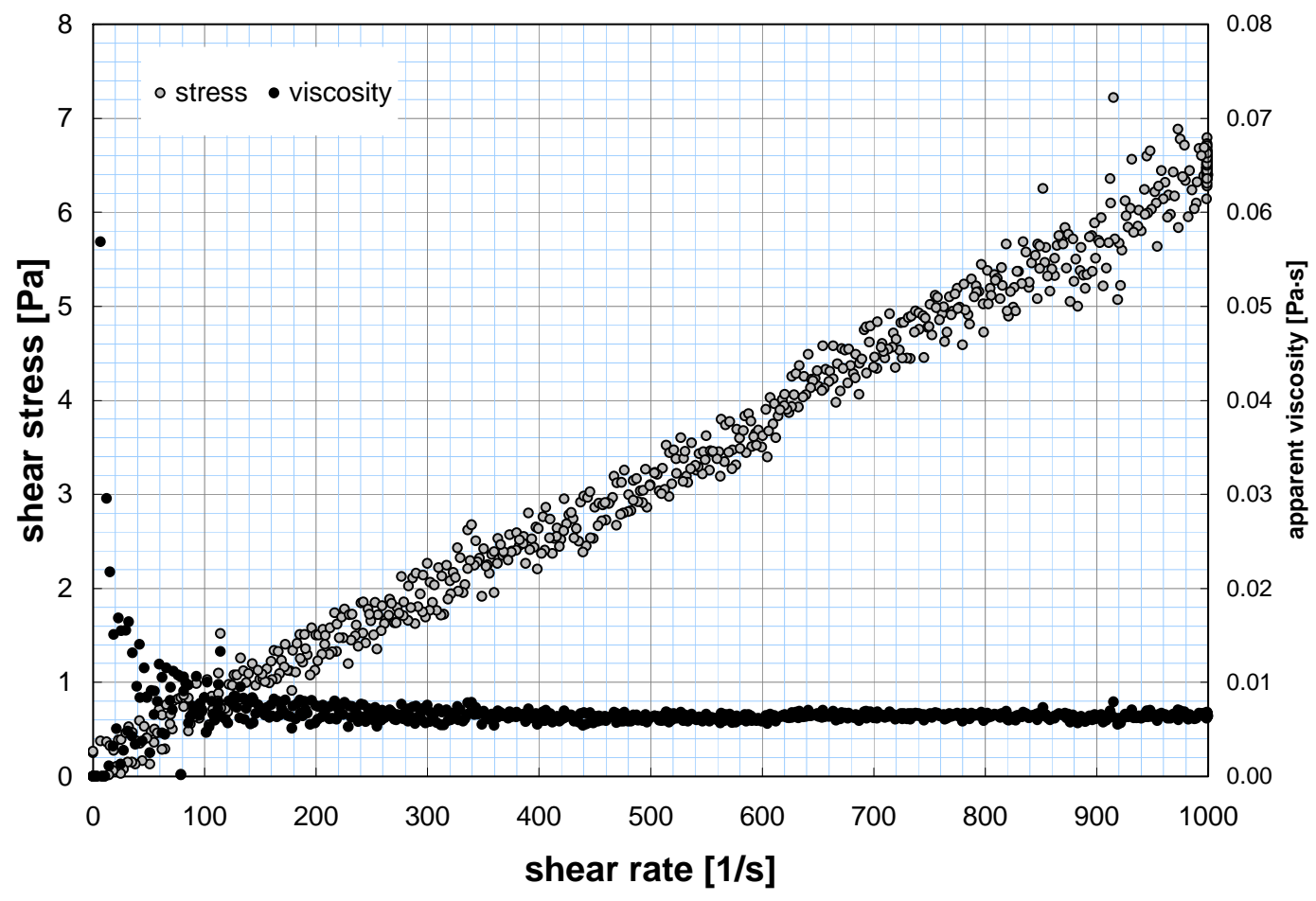

Figure A-4. Rheogram for TI490-G6-AR-RH at $25^{\circ} \mathrm{C}$ (measurement 1 of 2).

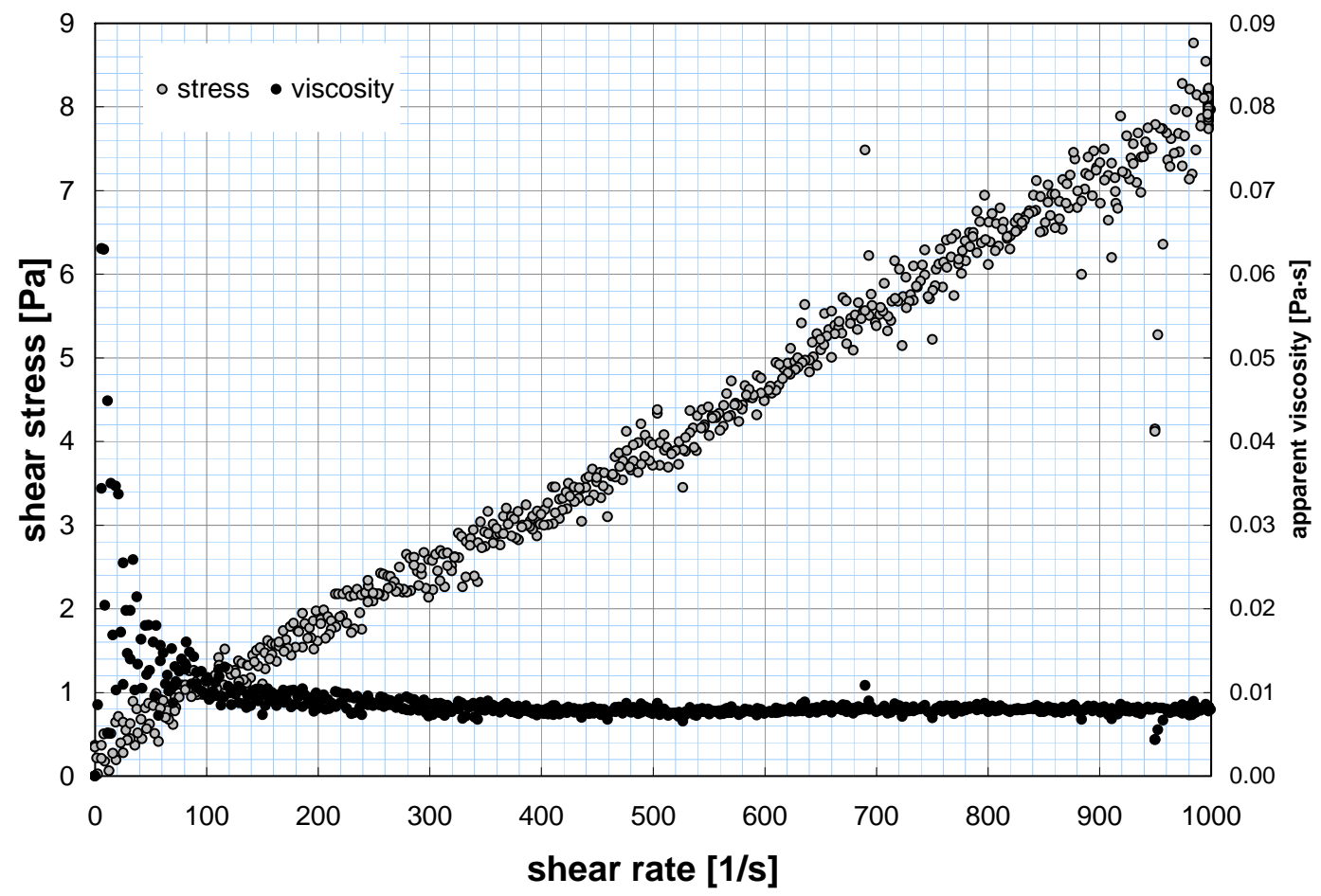

Figure A-5. Rheogram for TI490-G6-AR-RH at $25^{\circ} \mathrm{C}$ (measurement 2 of 2). 


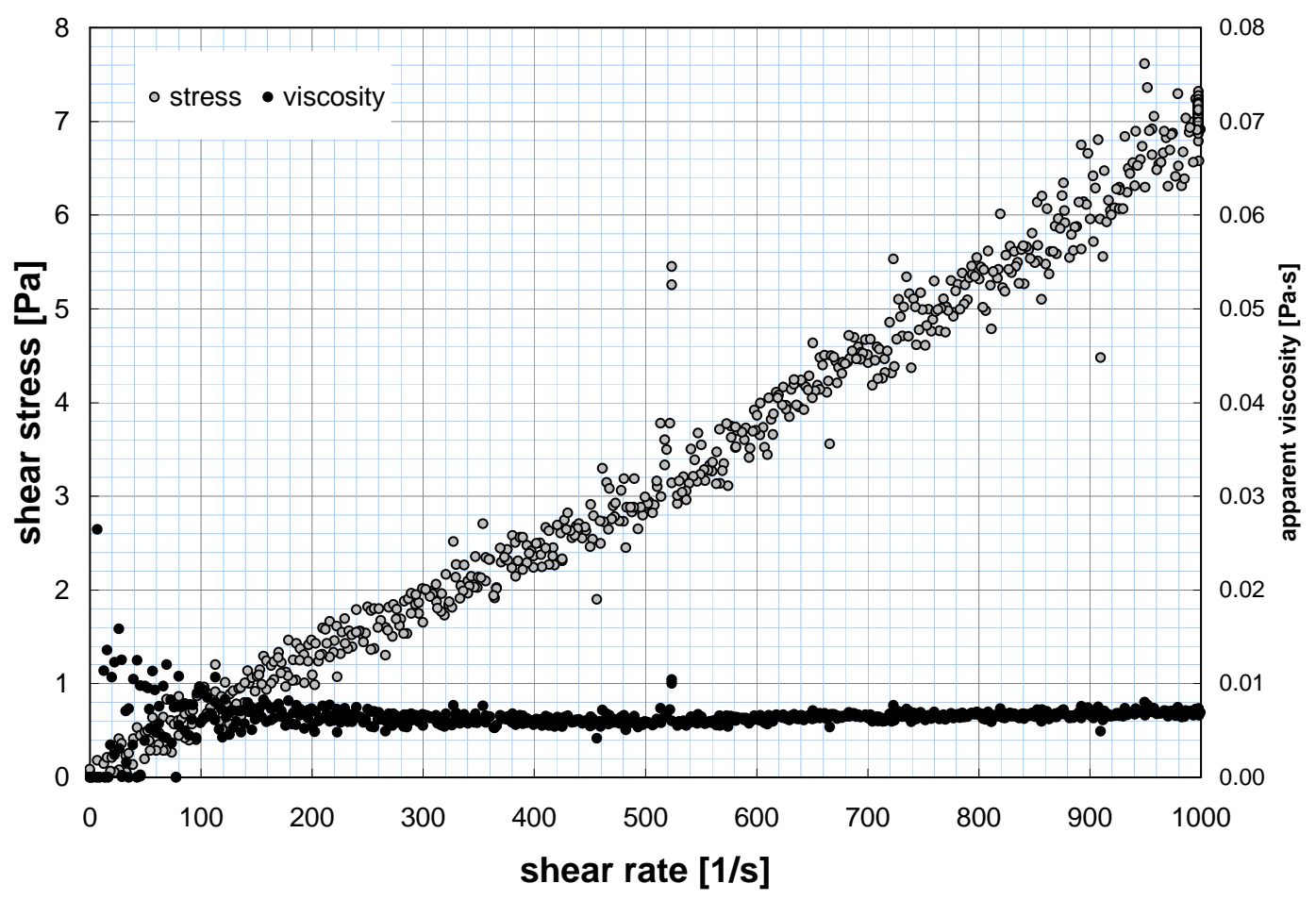

Figure A-6. Rheogram for TI490-G6-AR-RH at $40^{\circ} \mathrm{C}$.

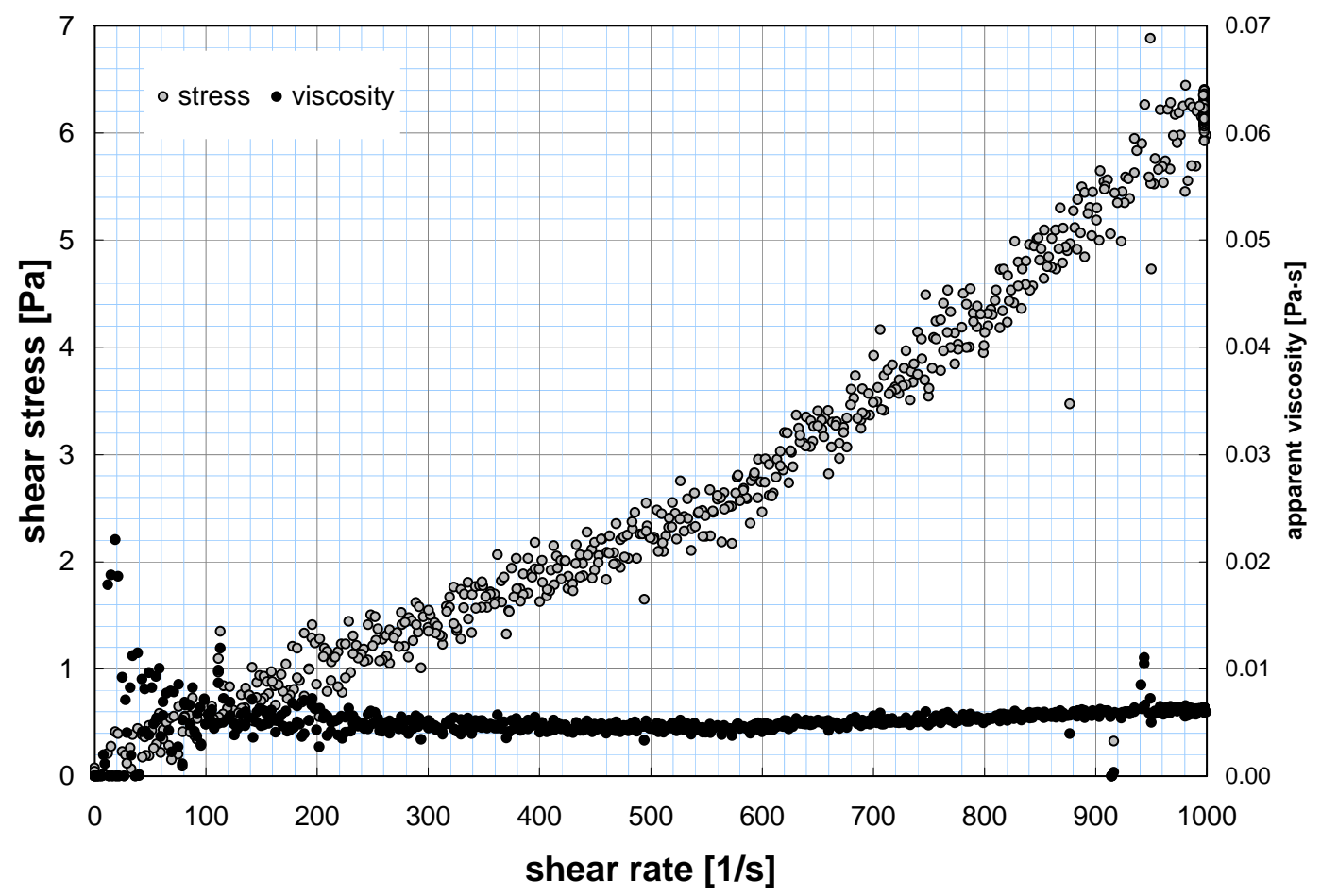

Figure A-7. Rheogram for TI490-G6-AR-RH at $60^{\circ} \mathrm{C}$. 
Sample TI5552-G6-R1: Pre-Leach Low Solids Matrix (3.2-wt\%)

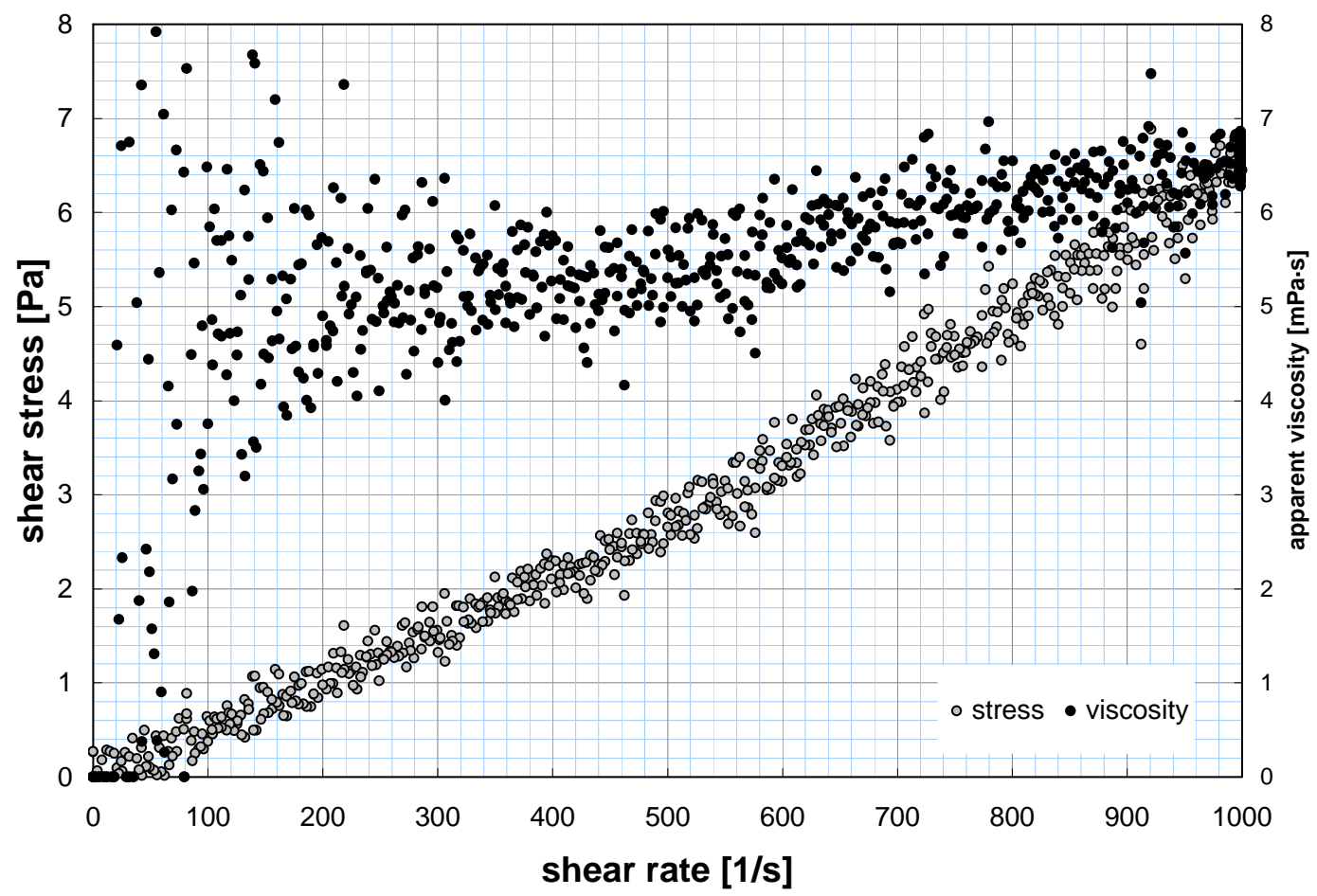

Figure A-8. Rheogram for TI5552-G6-R1 at $25^{\circ} \mathrm{C}$ (measurement 1 of 2).

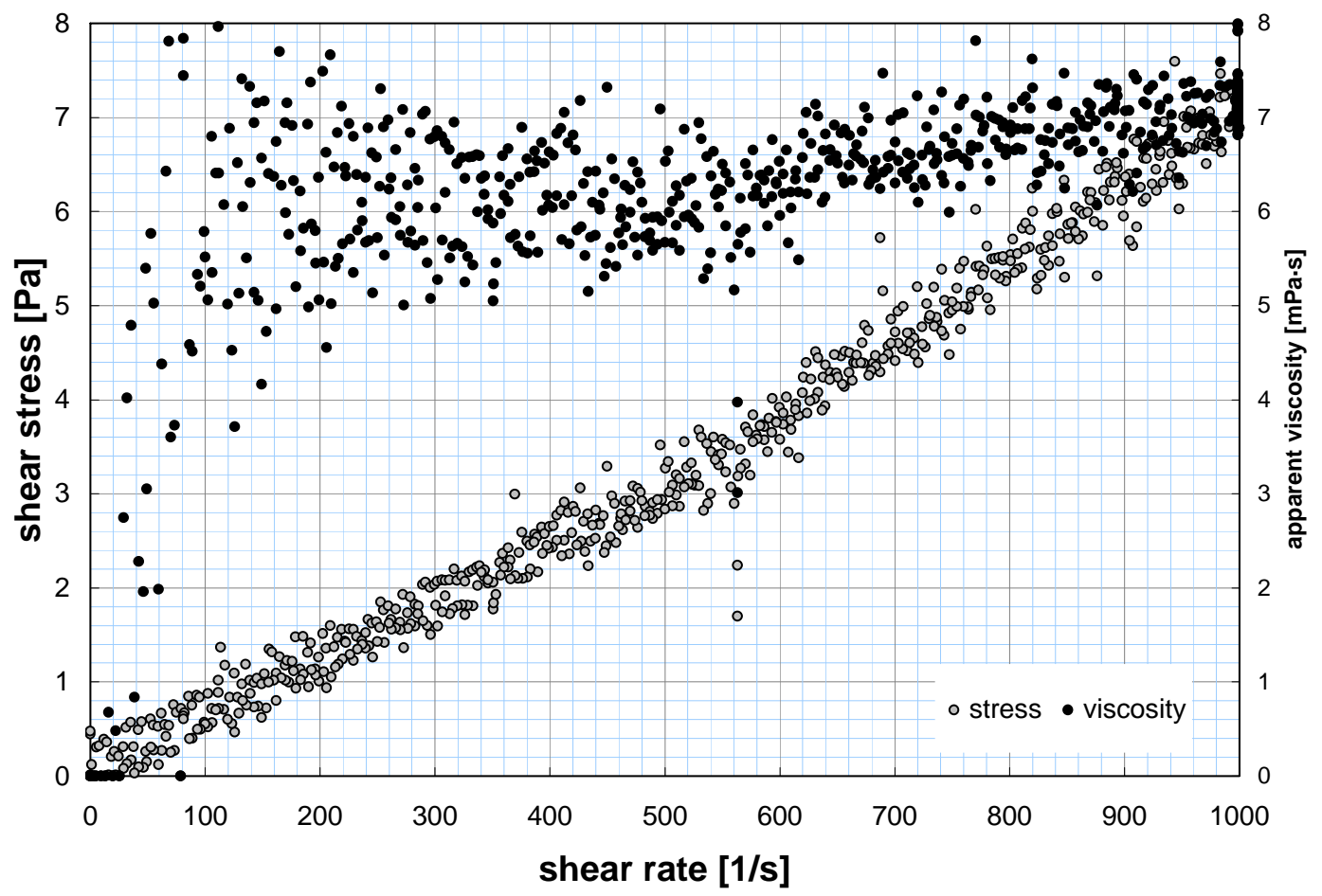

Figure A-9. Rheogram for TI5552-G6-R1 at $25^{\circ} \mathrm{C}$ (measurement 2 of 2). 


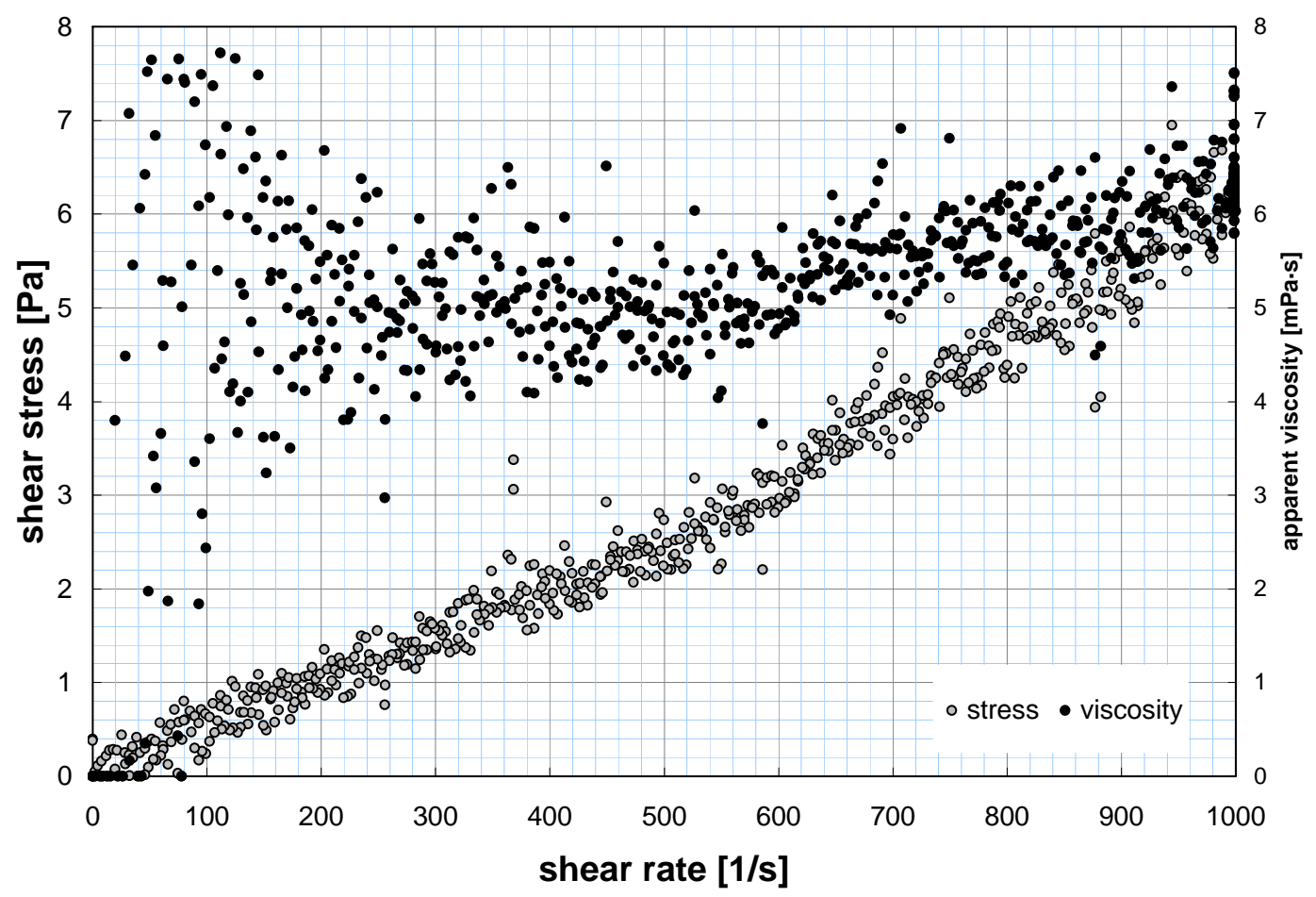

Figure A-10. Rheogram for TI5552-G6-R1 at $40^{\circ} \mathrm{C}$.

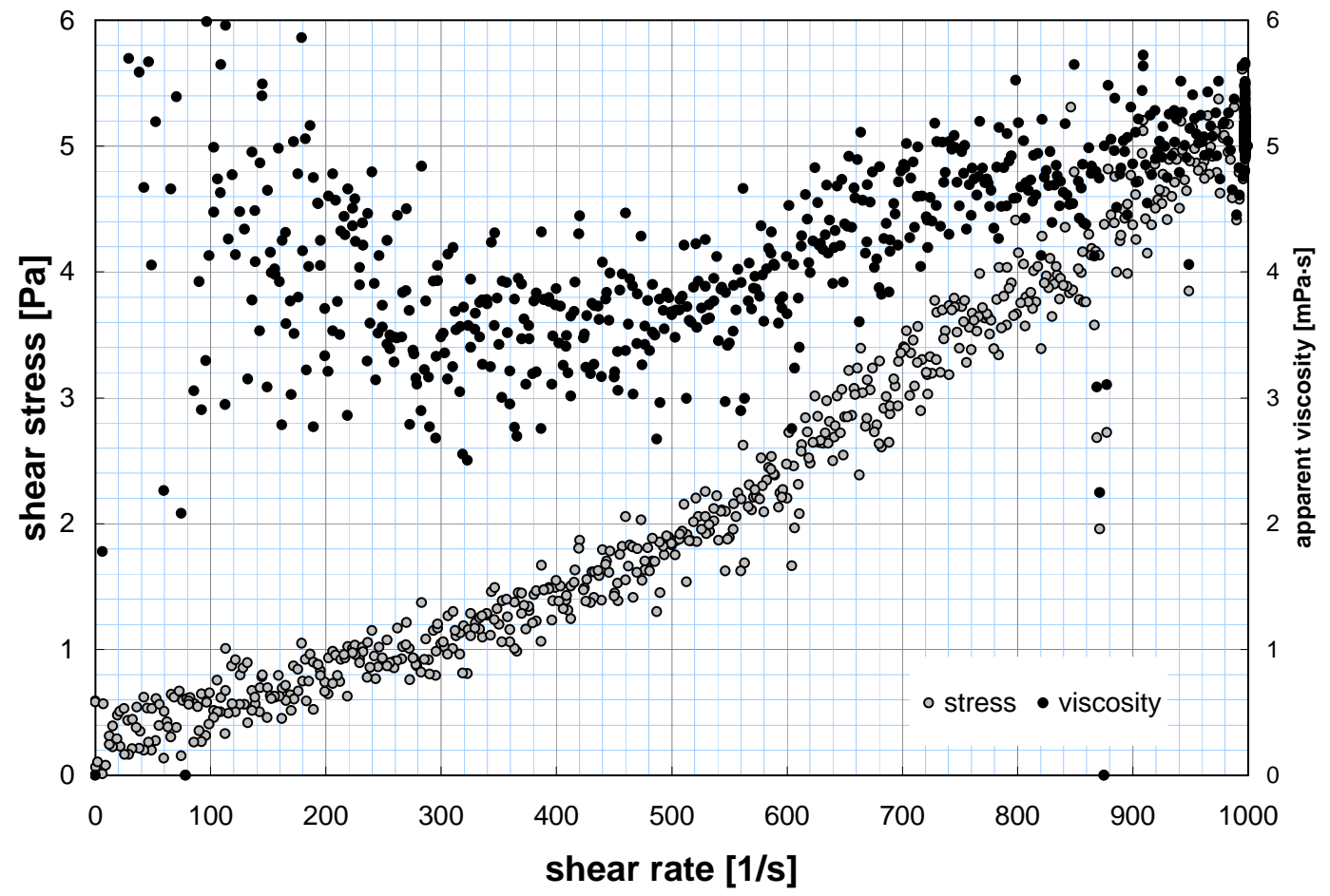

Figure A-11. Rheogram for TI5552-G6-R1 at $60^{\circ} \mathrm{C}$. 
Sample TI5552-G6-R2: Pre-Leach High Solids Matrix (13.2-wt\%)

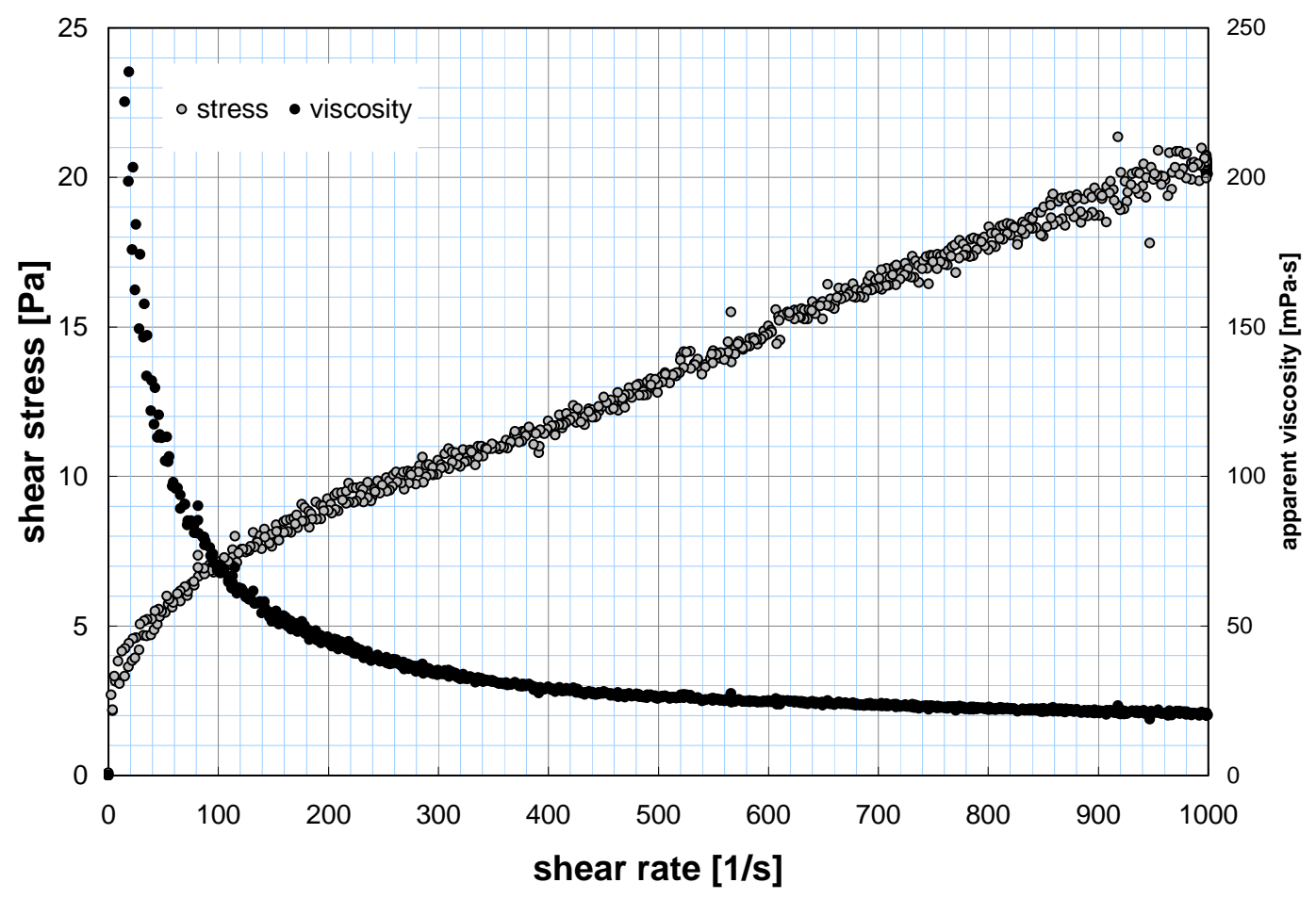

Figure A-12. Rheogram for TI5552-G6-R2 at $25^{\circ} \mathrm{C}$ (measurement 1 of 2).

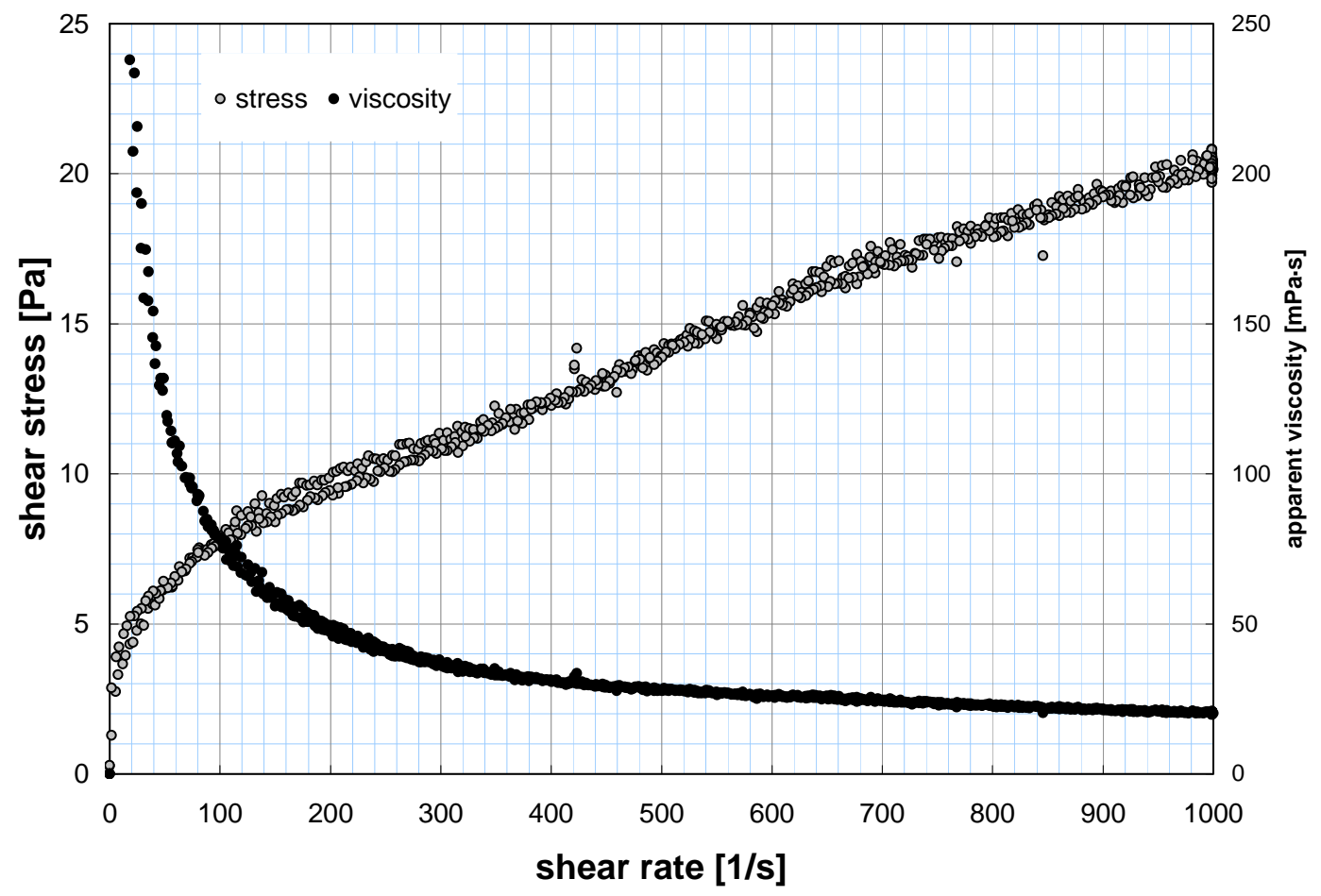

Figure A-13. Rheogram for TI5552-G6-R2 at $25^{\circ} \mathrm{C}$ (measurement 2 of 2). 


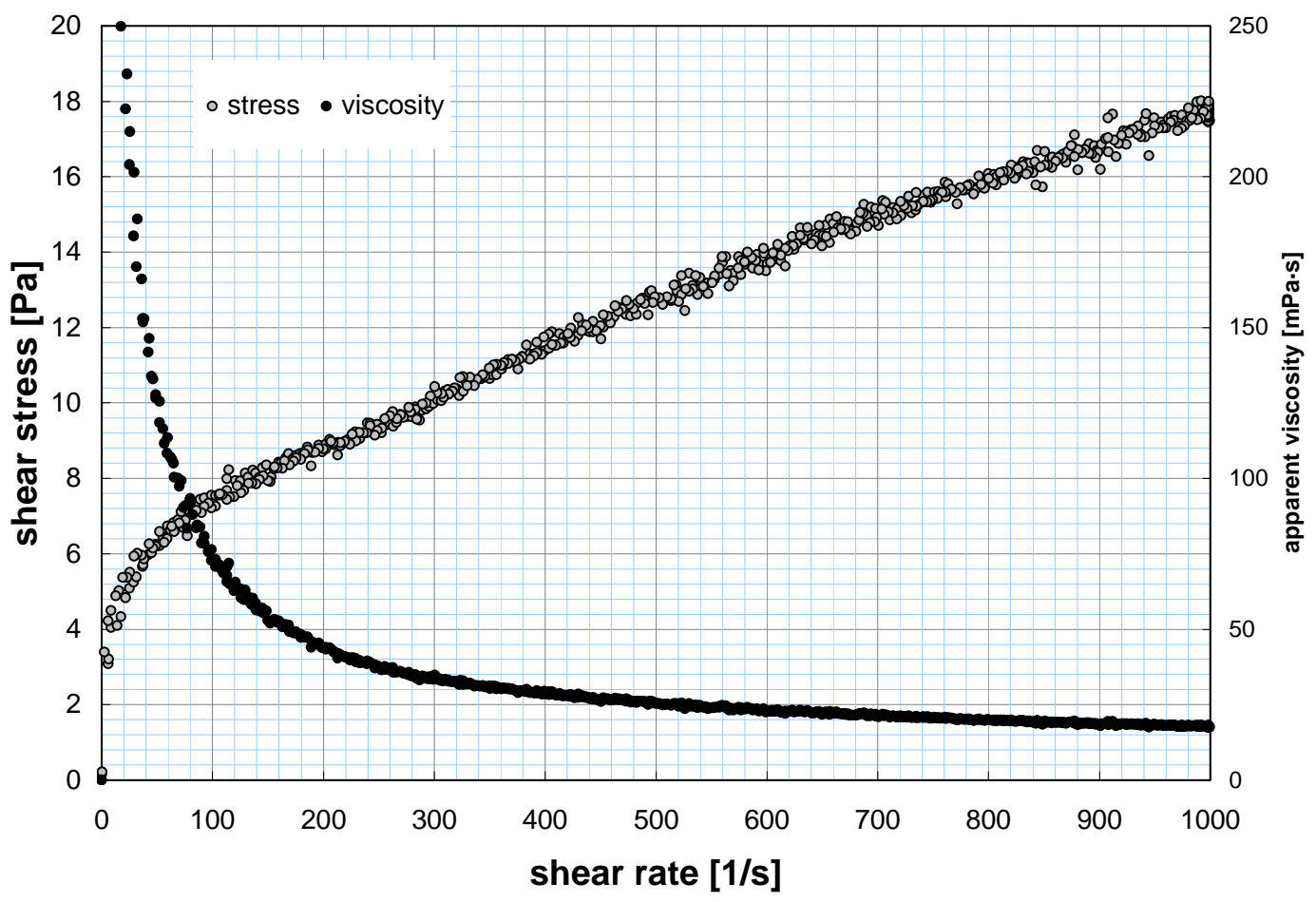

Figure A-14. Rheogram for TI5552-G6-R2 at $40^{\circ} \mathrm{C}$.

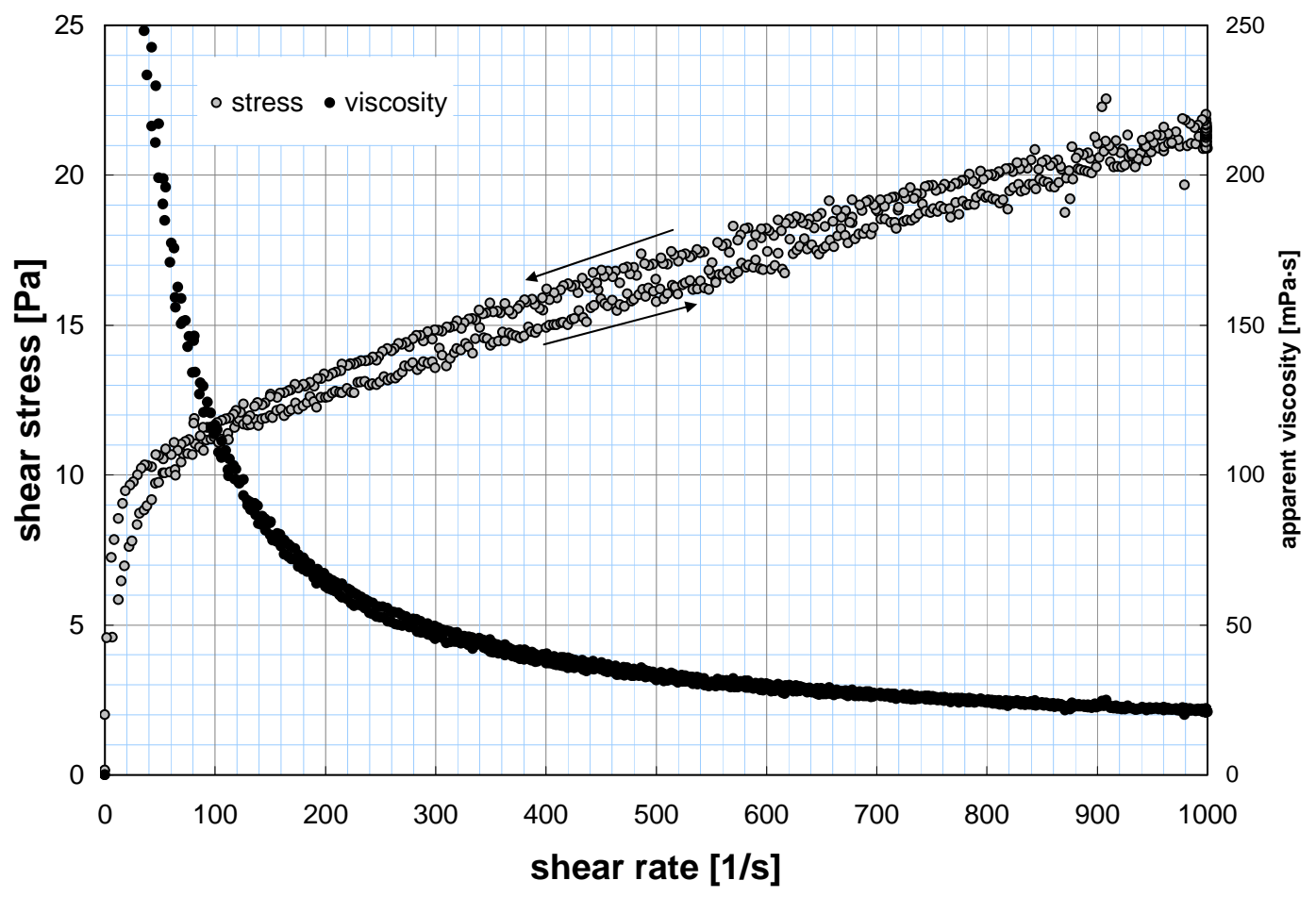

Figure A-15. Rheogram for TI5552-G6-R2 at $60^{\circ} \mathrm{C}$. 
Sample TI5552-G6-R3: Caustic-Leached and Dewatered Slurry (8.9-wt\%)

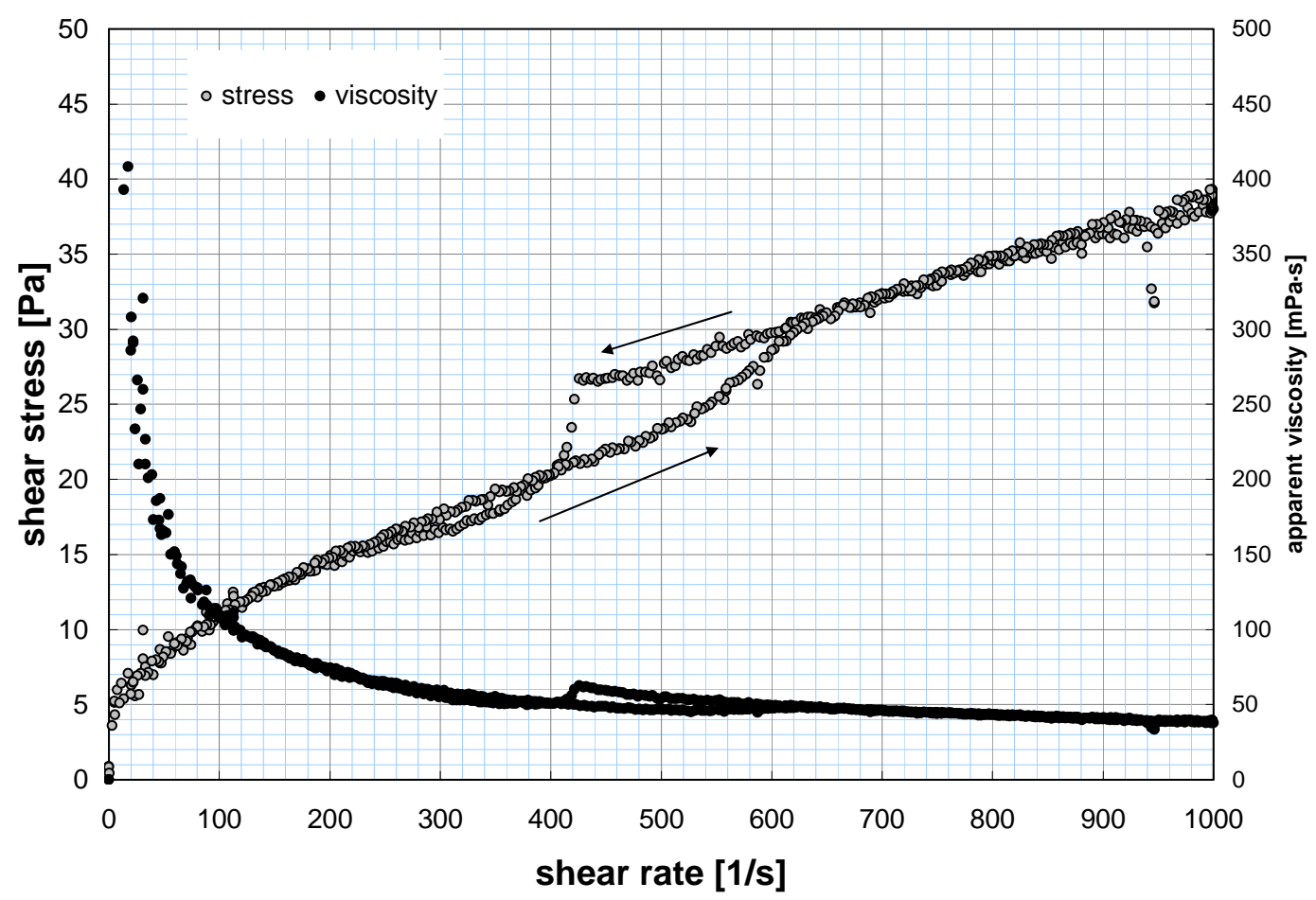

Figure A-16. Rheogram for TI5552-G6-R3 at $25^{\circ} \mathrm{C}$ (measurement 1 of 2).

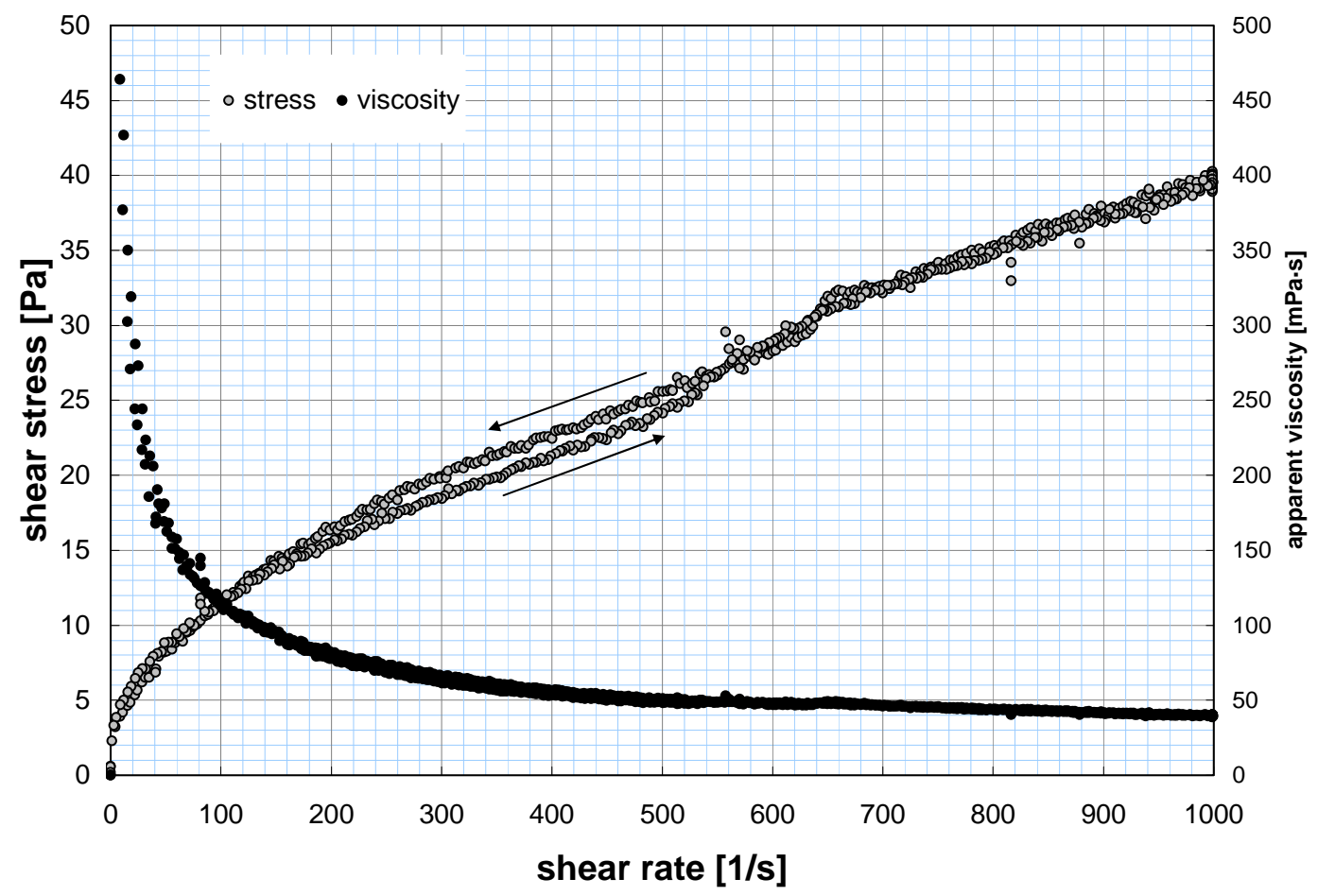

Figure A-17. Rheogram for TI5552-G6-R3 at $25^{\circ} \mathrm{C}$ (measurement 2 of 2). 


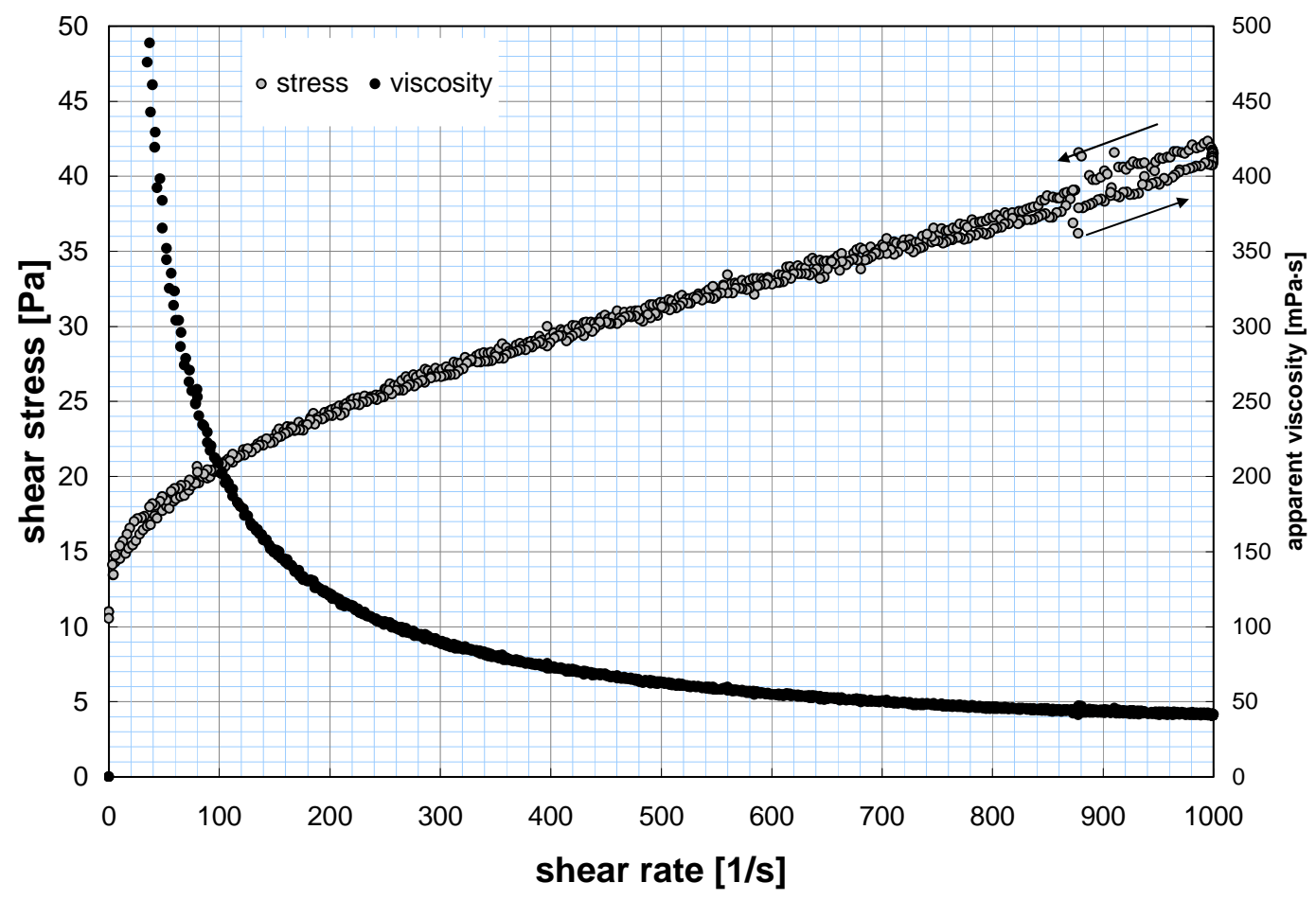

Figure A-18. Rheogram for TI5552-G6-R3 at $40^{\circ} \mathrm{C}$.

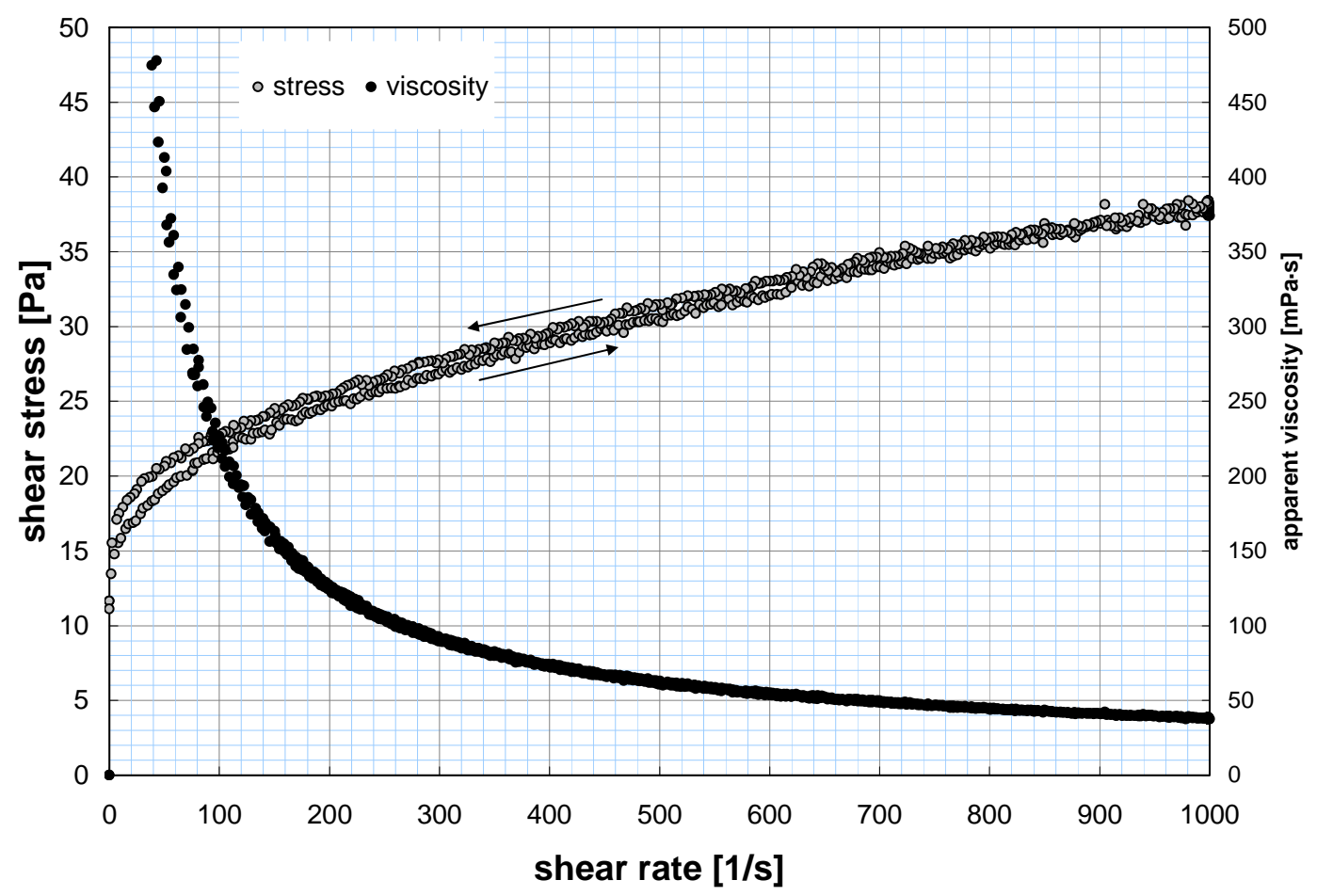

Figure A-19. Rheogram for TI5552-G6-R3 at $60^{\circ} \mathrm{C}$. 
Sample TI5552-G6-R4: Caustic-Leached, Dewatered, and Washed Slurry (12.8-wt\%)

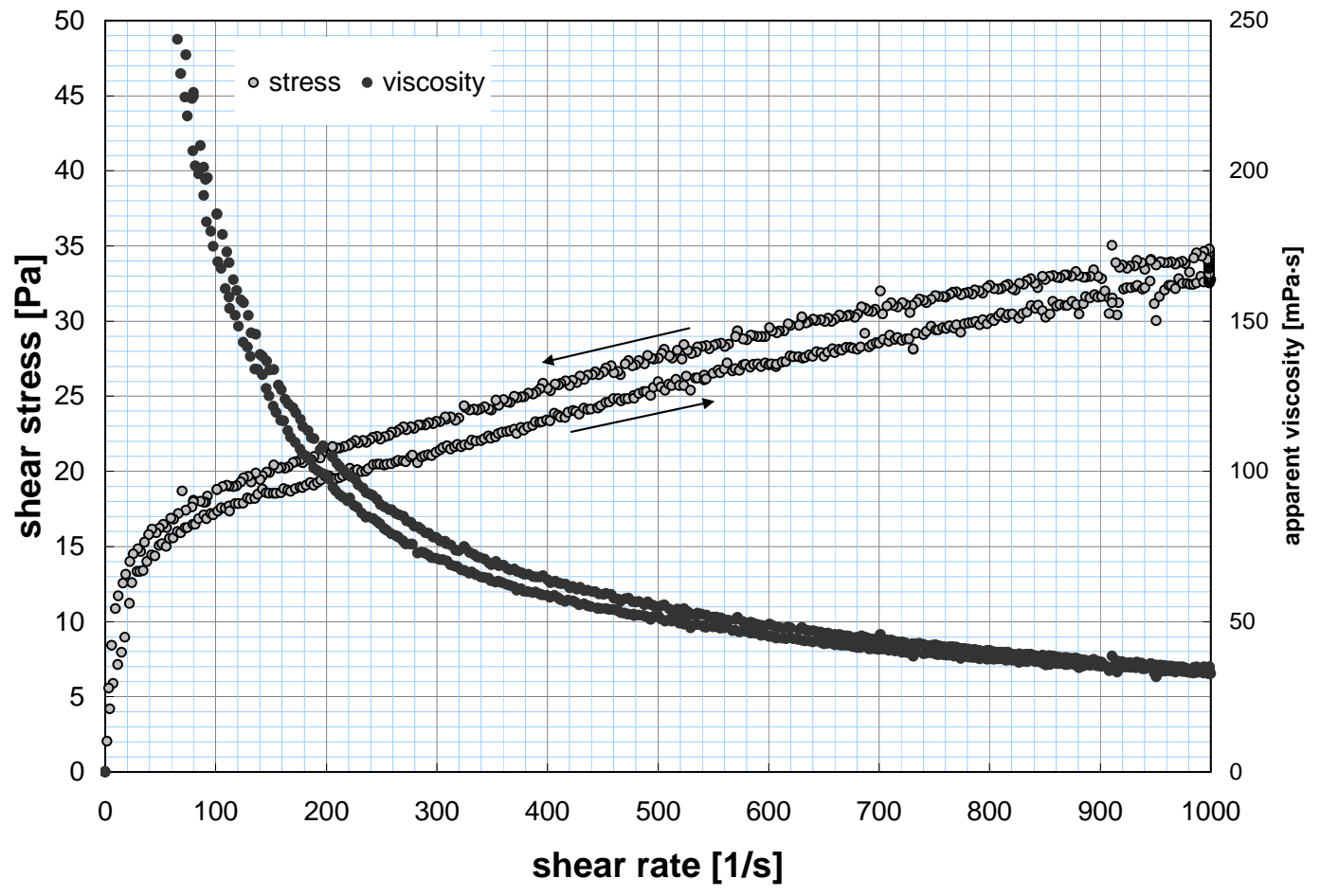

Figure A-20. Rheogram for TI5552-G6-R4 at $25^{\circ} \mathrm{C}$ (measurement 1 of 2).

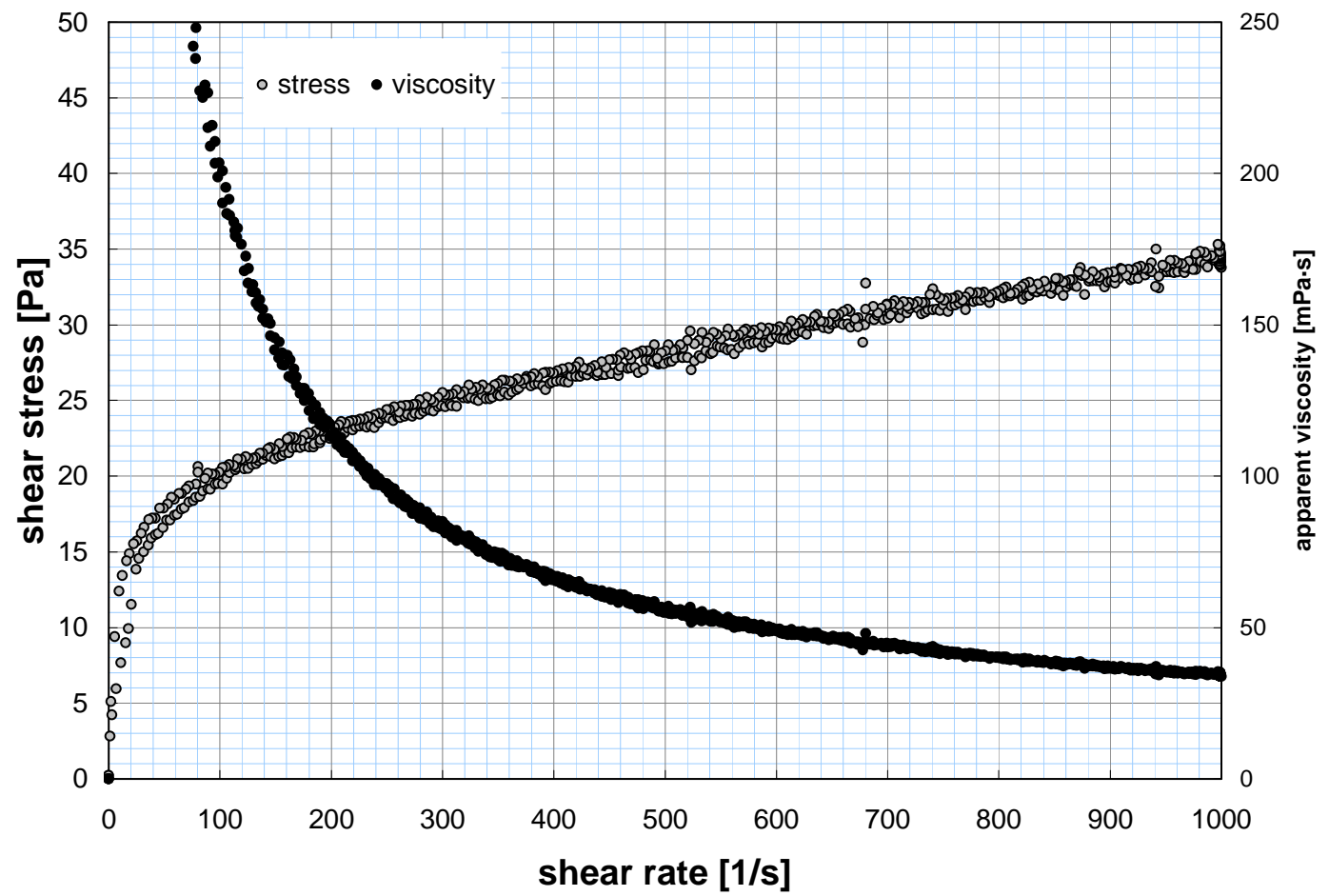

Figure A-21. Rheogram for TI5552-G6-R4 at $25^{\circ} \mathrm{C}$ (measurement 2 of 2). 


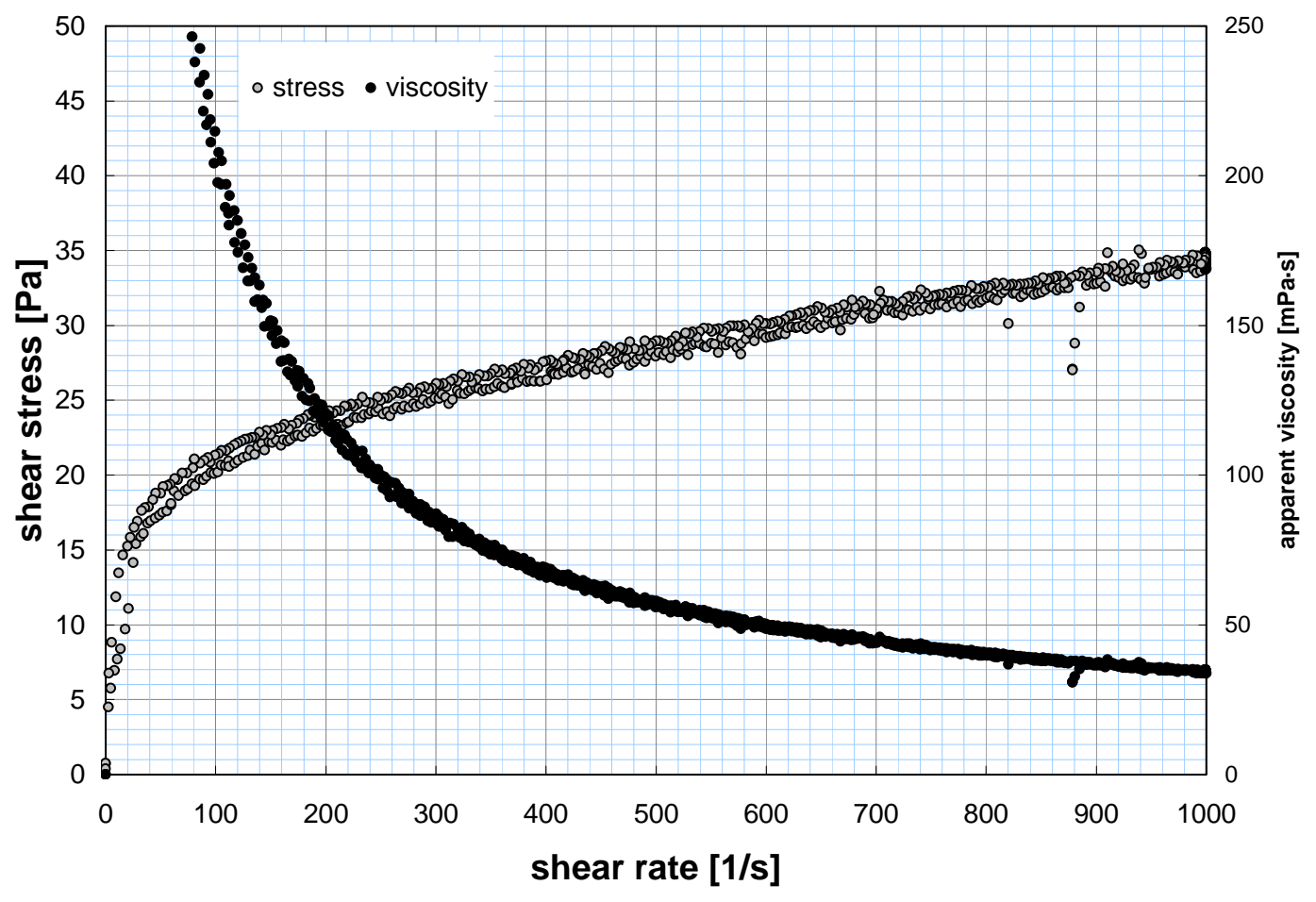

Figure A-22. Rheogram for TI5552-G6-R4 at $40^{\circ} \mathrm{C}$.

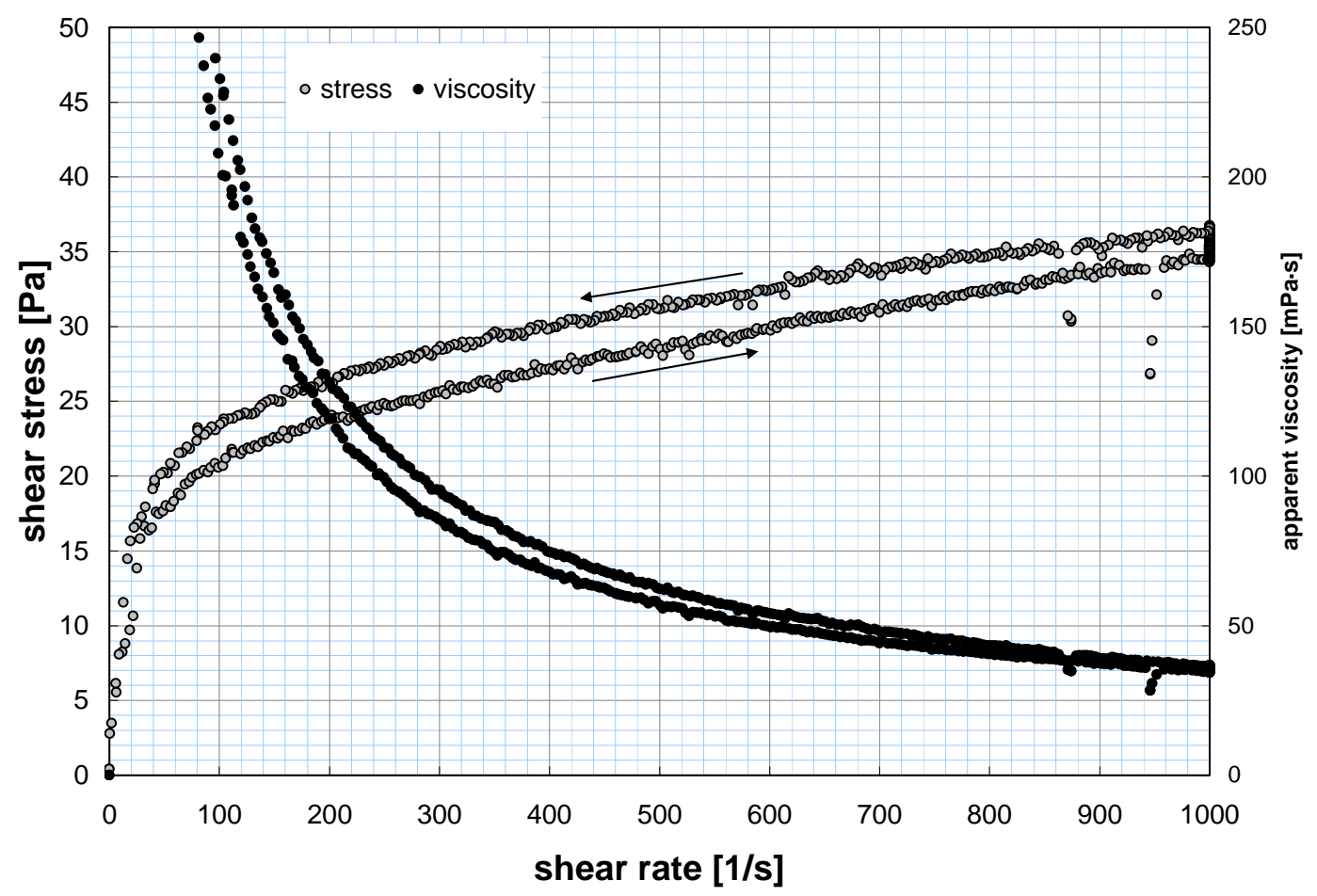

Figure A-23. Rheogram for TI5552-G6-R4 at $60^{\circ} \mathrm{C}$. 
Sample TI5552-G6-R5: Oxidative-Leached and Washed Slurry (9.7-wt\%)

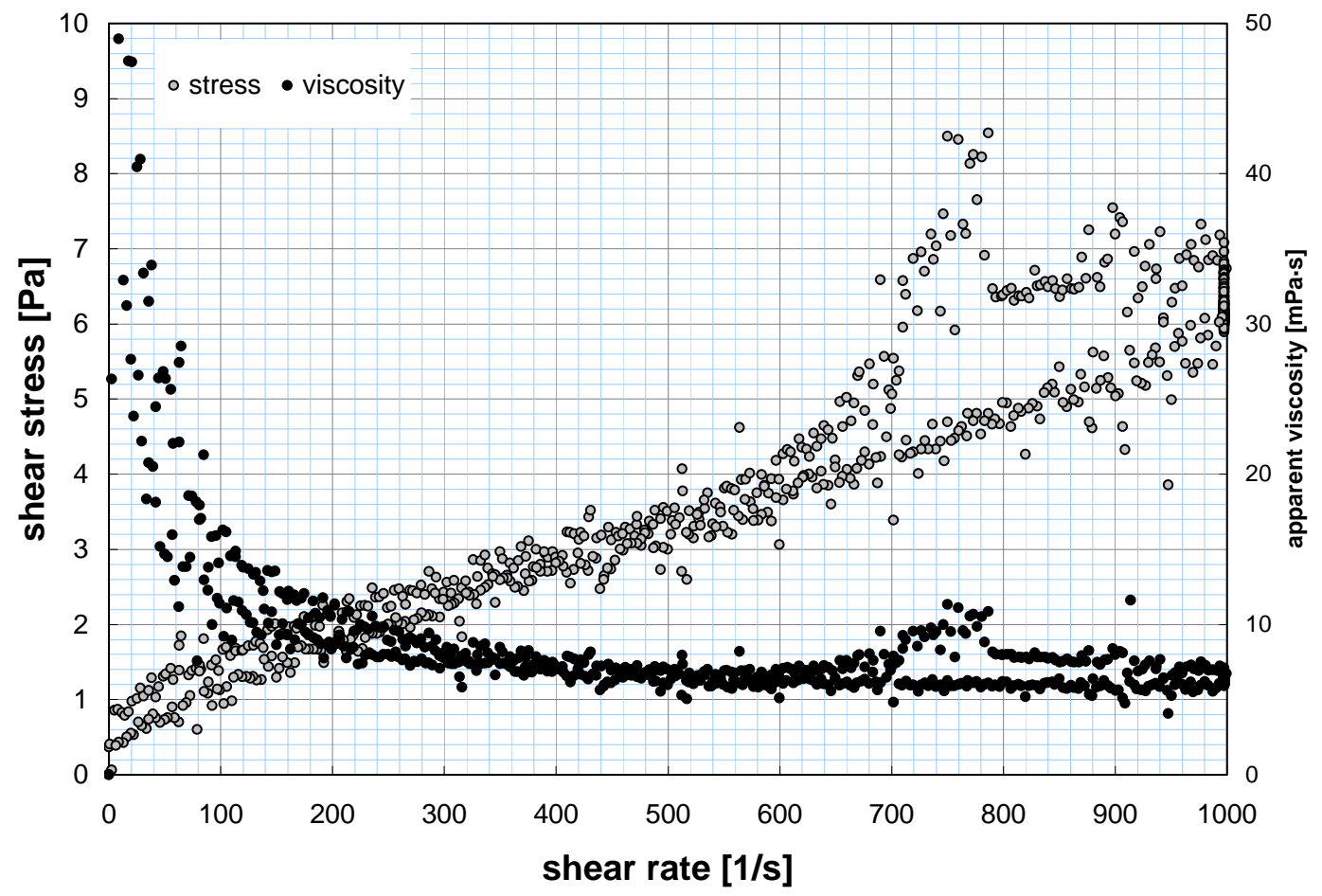

Figure A-24. Rheogram for TI5552-G6-R5 at $25^{\circ} \mathrm{C}$ (measurement 1 of 2).

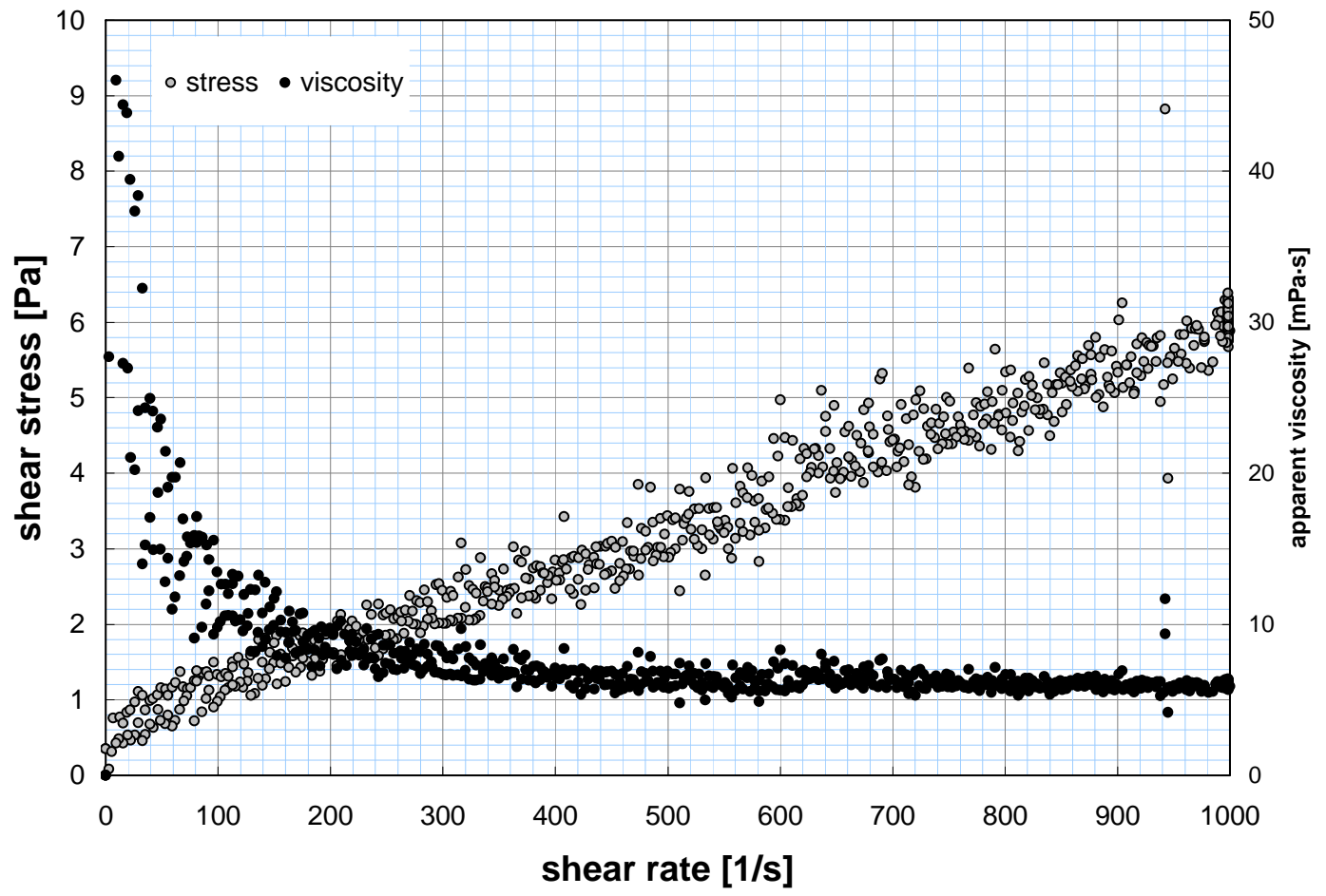

Figure A-25. Rheogram for TI5552-G6-R5 at $25^{\circ} \mathrm{C}$ (measurement 2 of 2). 


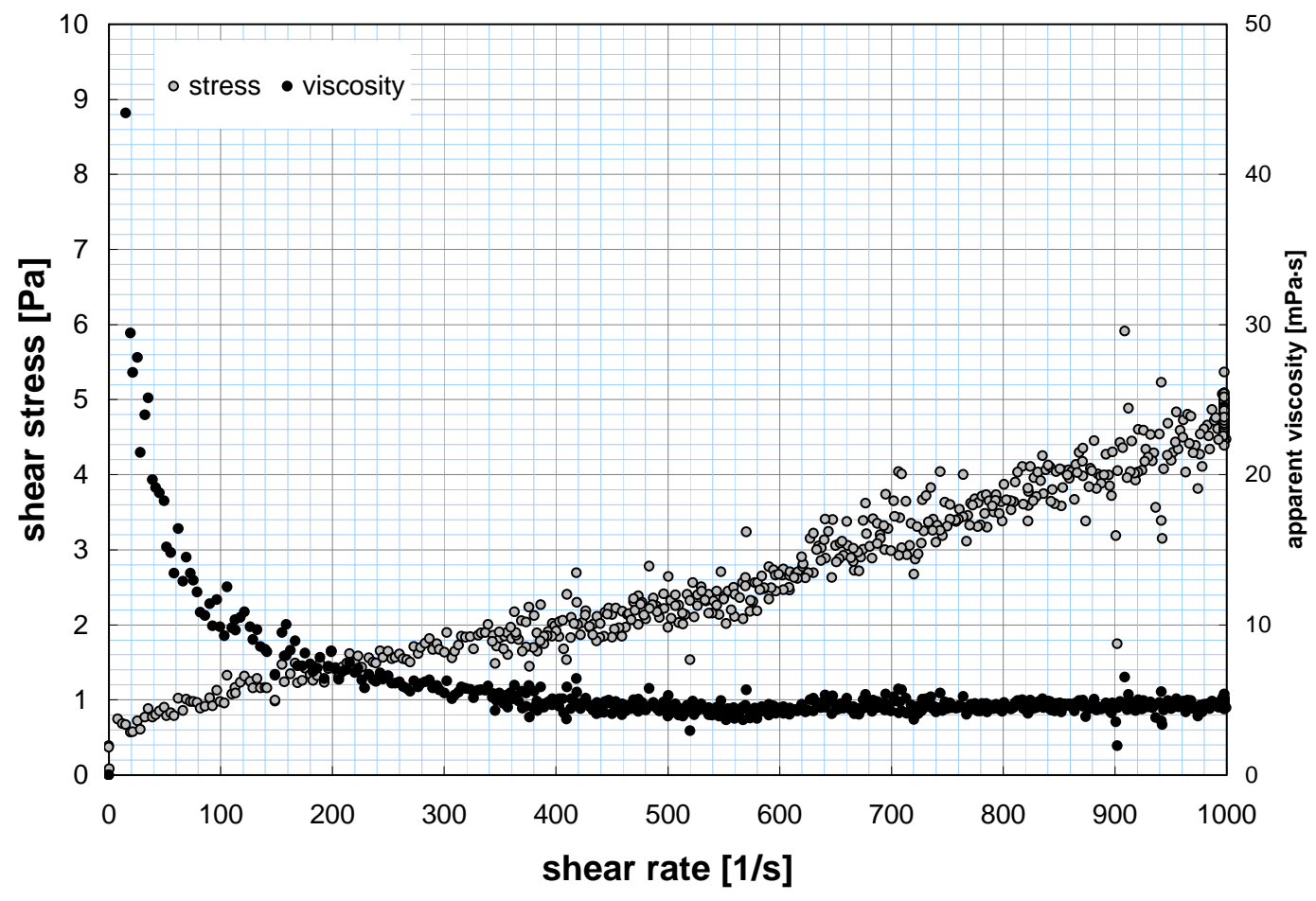

Figure A-26. Rheogram for TI5552-G6-R5 at $40^{\circ} \mathrm{C}$.

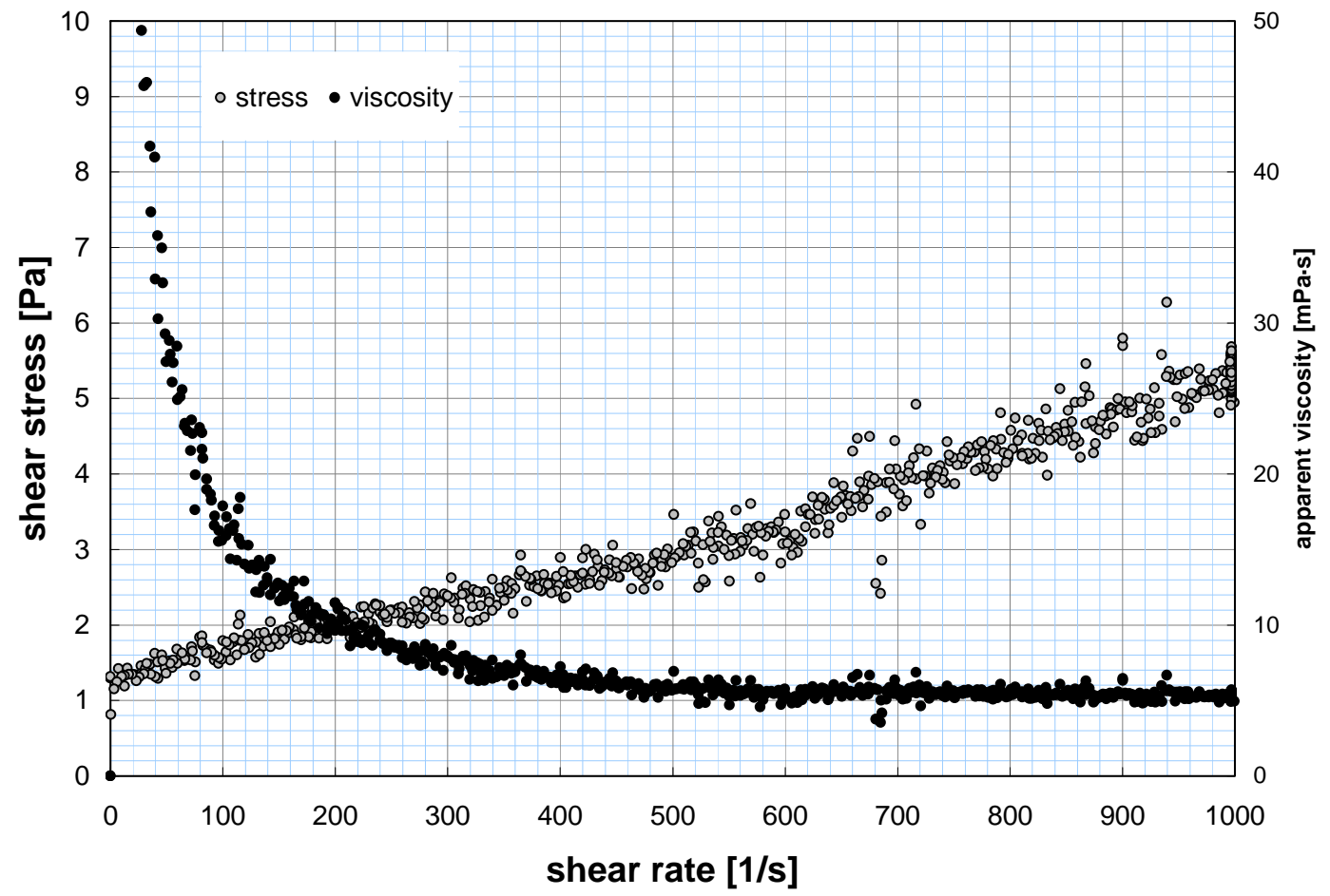

Figure A-27. Rheogram for TI5552-G6-R5 at $60^{\circ} \mathrm{C}$. 
Sample TI5552-G6-R6: Combined Leach Slurry (9.7-wt\%)

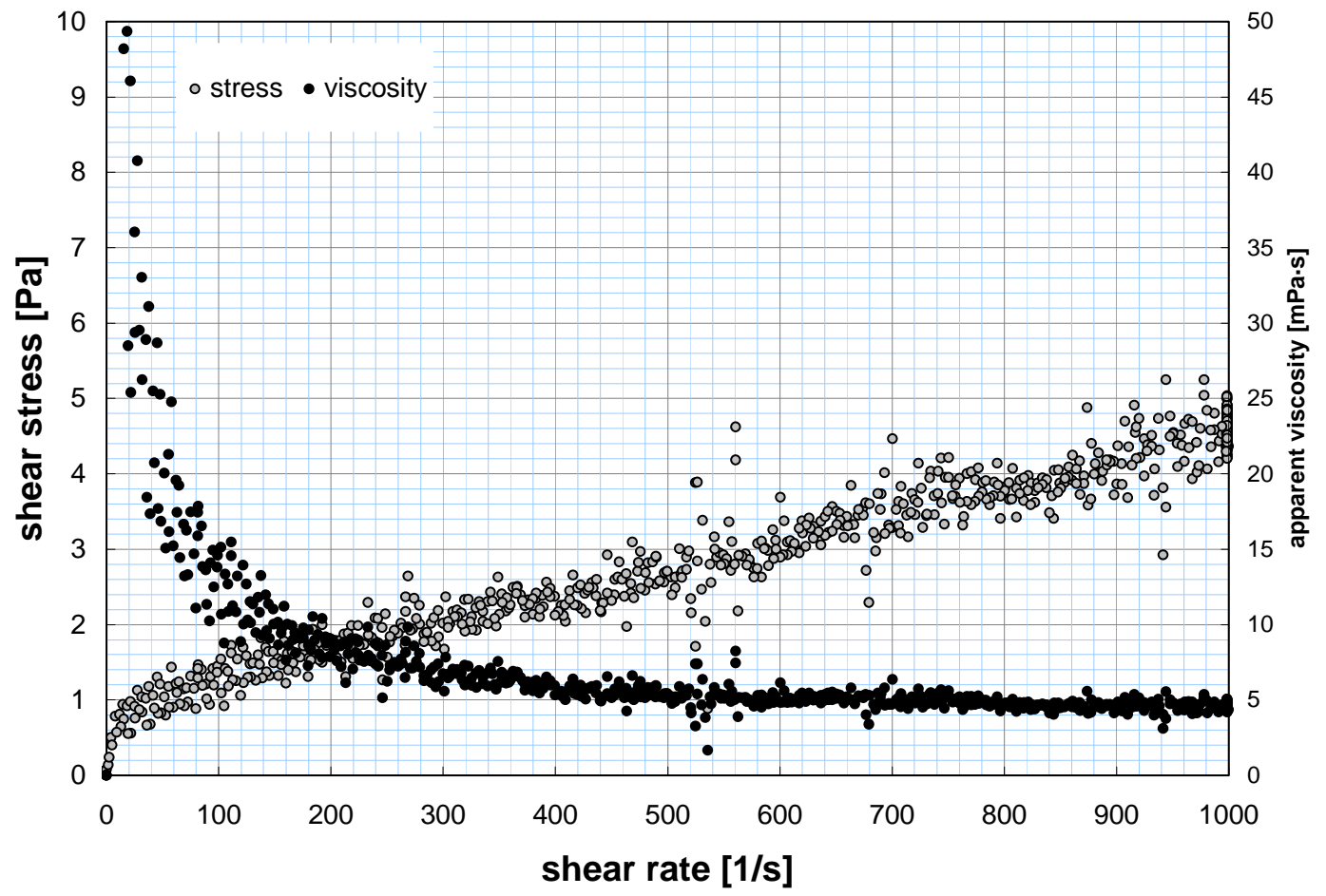

Figure A-28. Rheogram for TI5552-G6-R6 at $25^{\circ} \mathrm{C}$ (measurement 1 of 2).

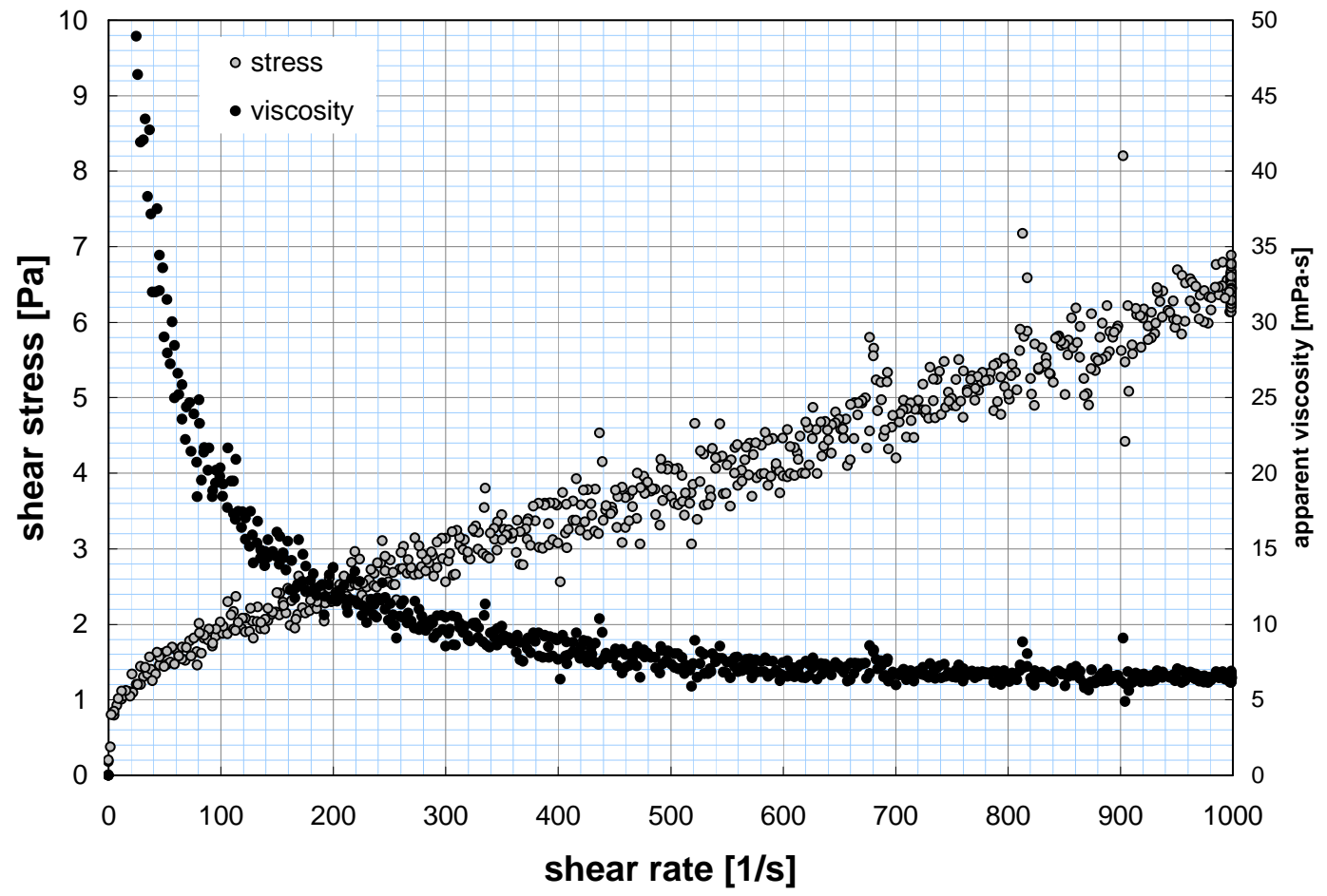

Figure A-29. Rheogram for TI5552-G6-R6 at $25^{\circ} \mathrm{C}$ (measurement 2 of 2). 


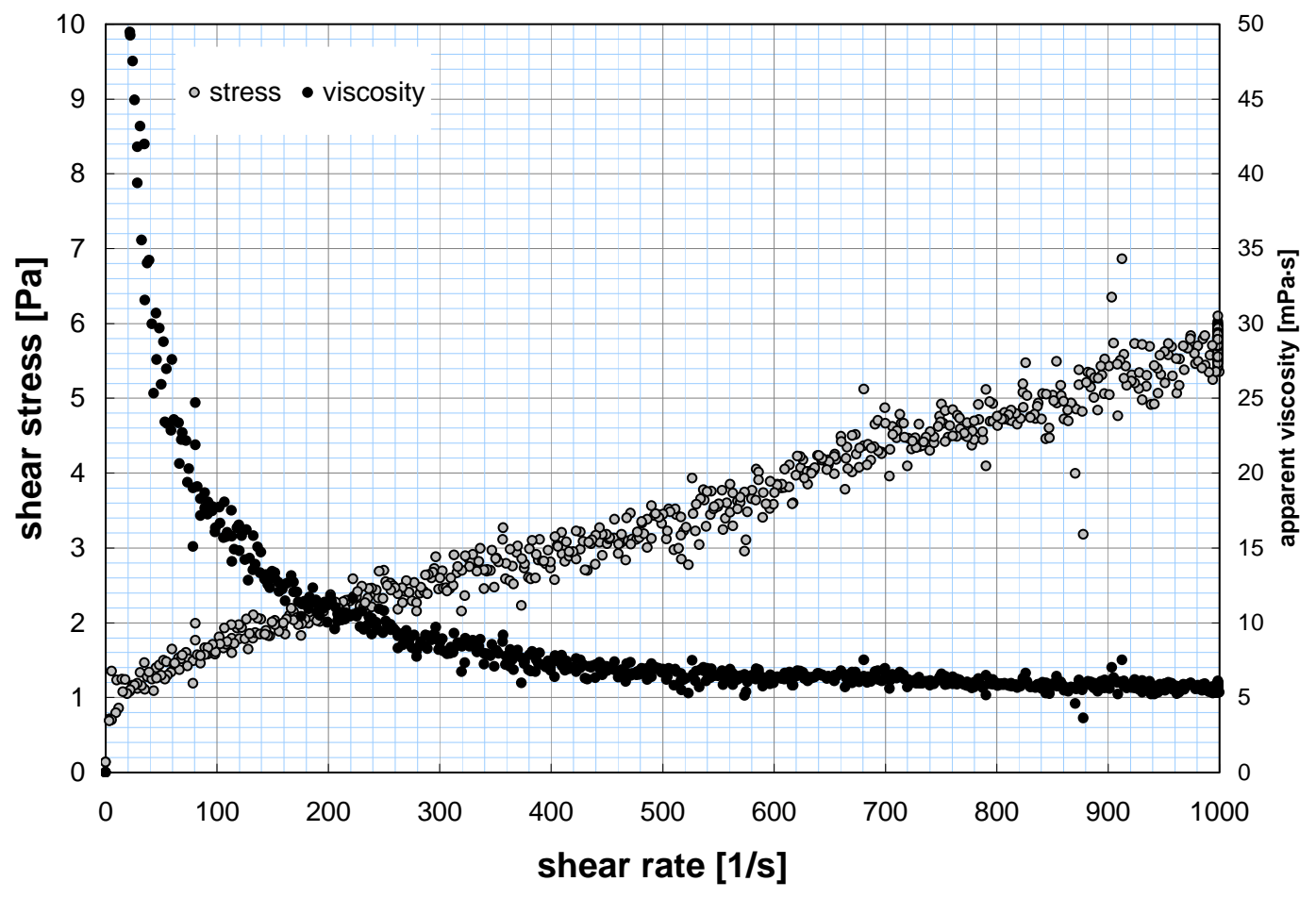

Figure A-30. Rheogram for TI5552-G6-R6 at $40^{\circ} \mathrm{C}$.

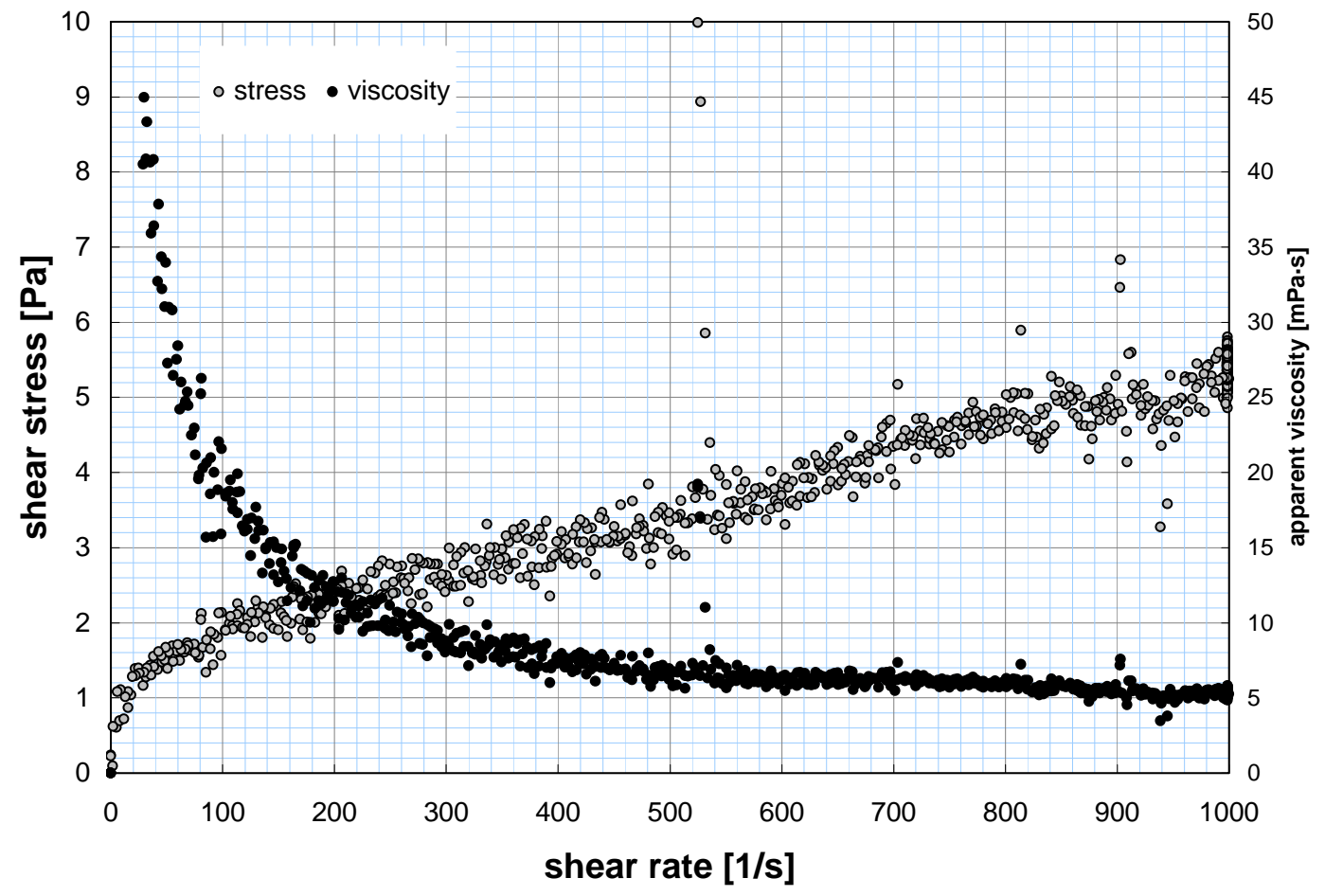

Figure A-31. Rheogram for TI5552-G6-R6 at $60^{\circ} \mathrm{C}$. 
Sample TI5552-G6-R2S: Pre-Leach Permeate

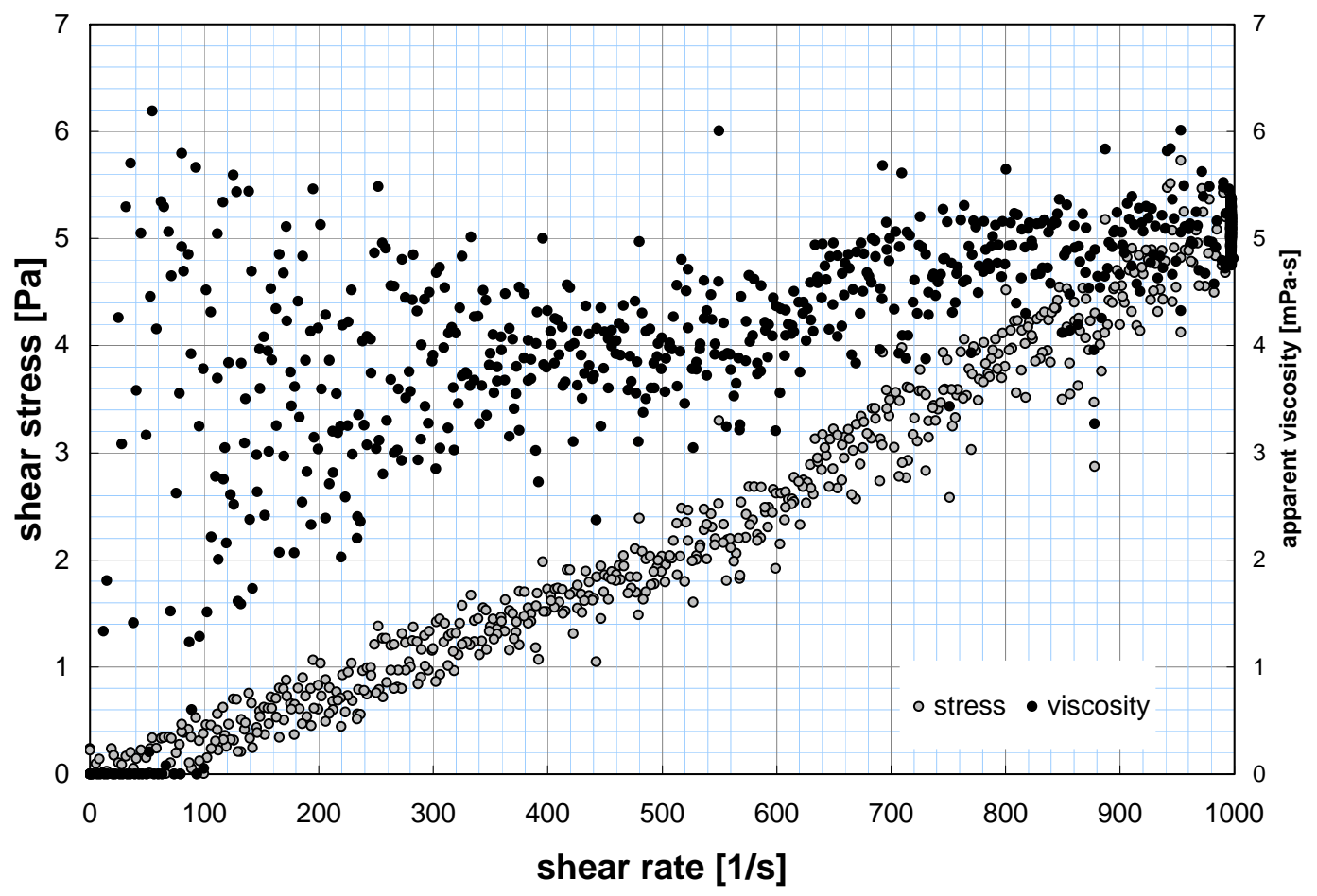

Figure A-32. Rheogram for TI5552-G6-R2S at $25^{\circ} \mathrm{C}$ (measurement 1 of 2).

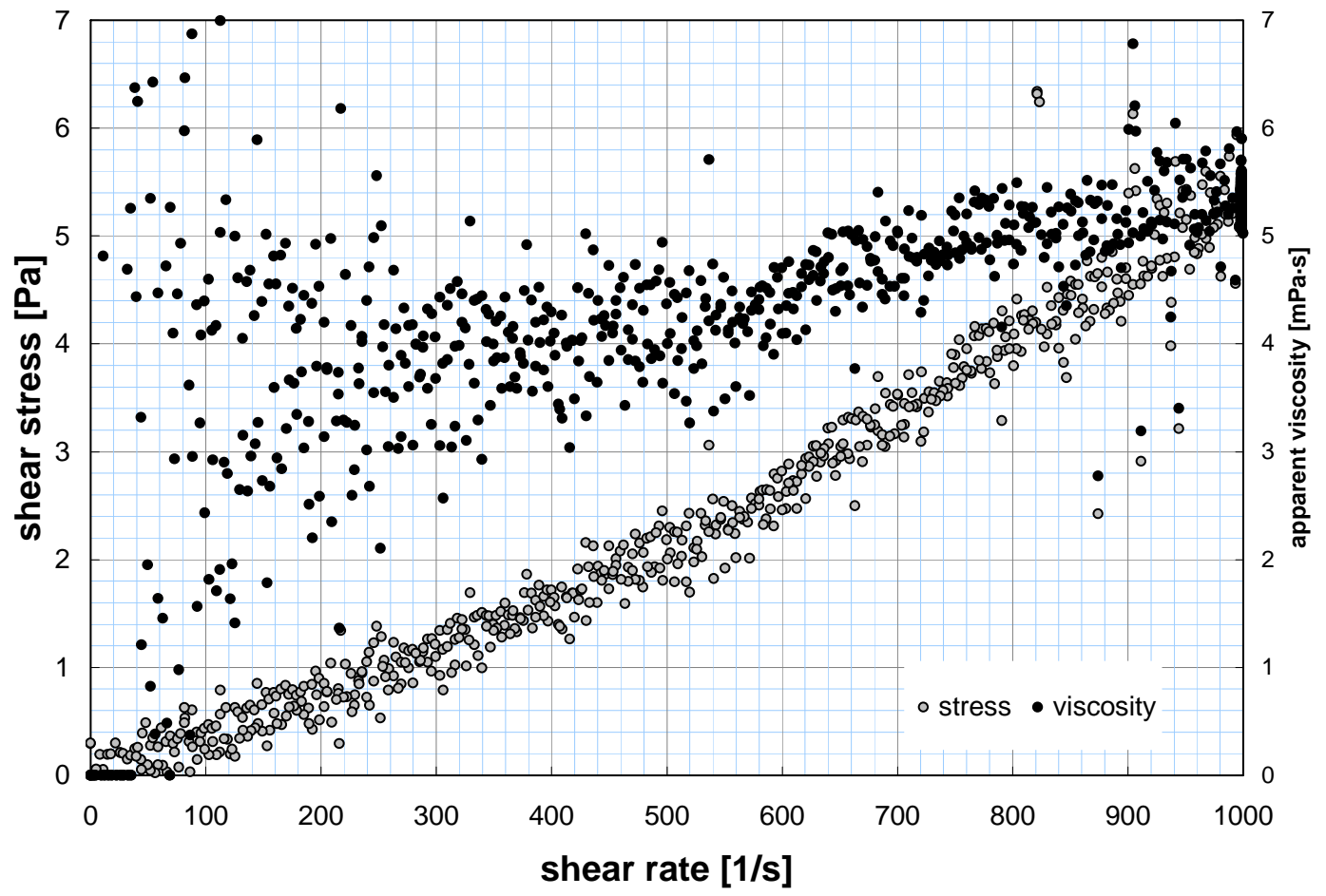

Figure A-33. Rheogram for TI5552-G6-R2S at $25^{\circ} \mathrm{C}$ (measurement 2 of 2). 


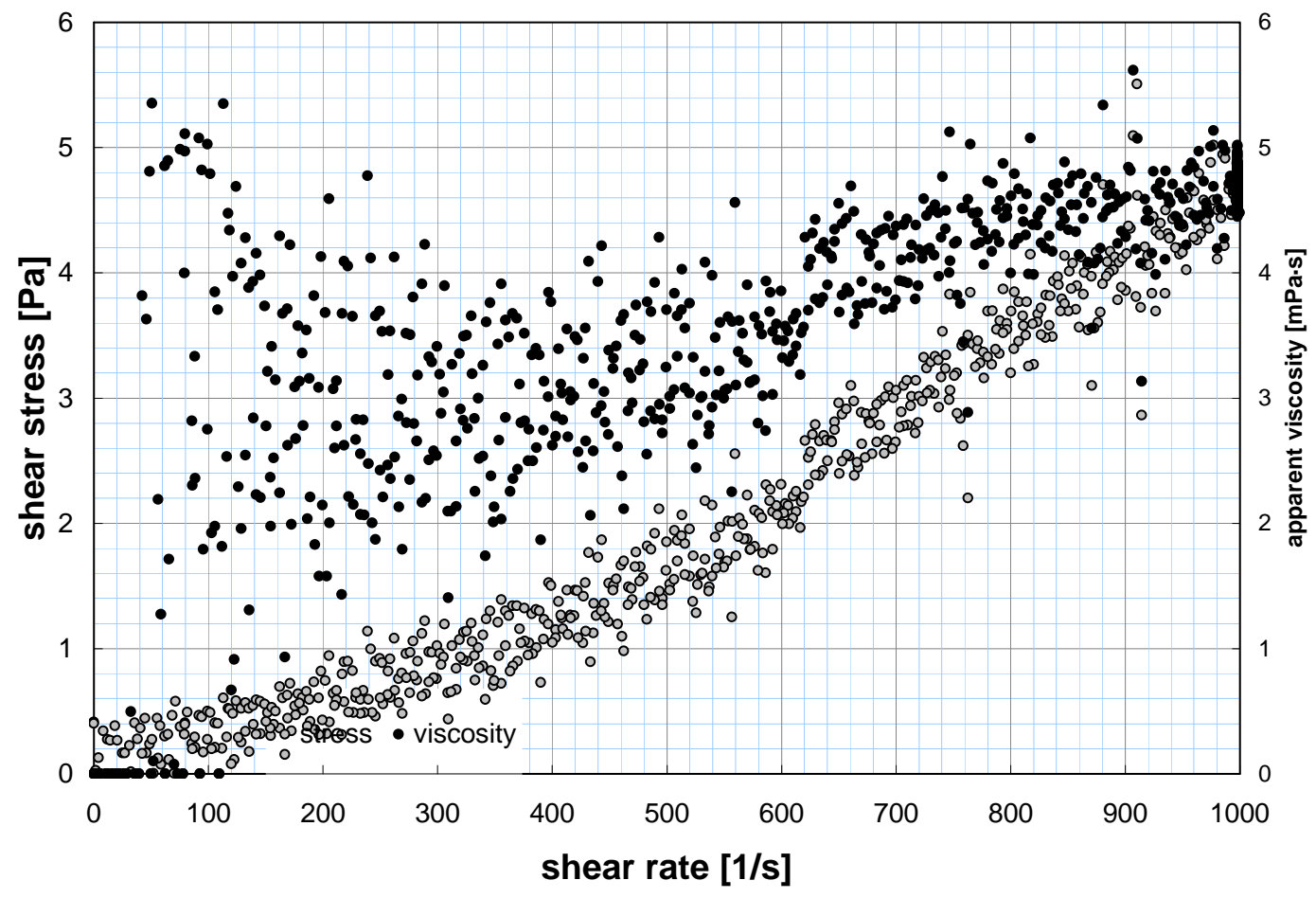

Figure A-34. Rheogram for TI5552-G6-R2S at $40^{\circ} \mathrm{C}$.

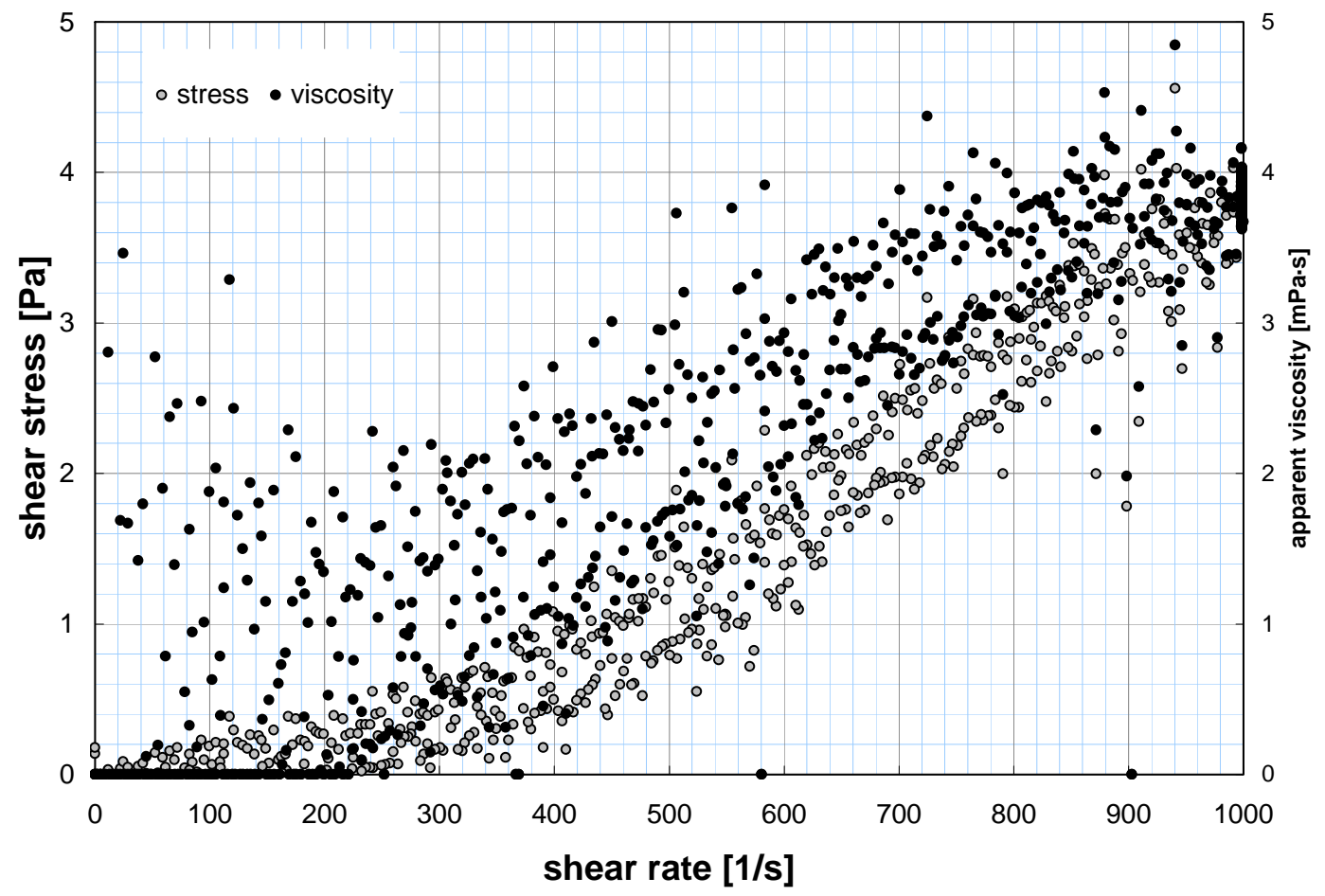

Figure A-35. Rheogram for TI5552-G6-R2S at $60^{\circ} \mathrm{C}$. 


\section{Appendix K}

\section{Group 5 CUF Analytical Results}




\title{
Appendix K: Group 5 CUF Analytical Results
}

\author{
Special Instructions for \\ CUF Group 5 REDOX Sludge Treatablility Study \\ Analysis Requirements (ASR 7998)
}

The start date for this treatability study is August 20, 2007.

A composite material containing liquid and sludge from Hanford waste tanks S-101, S-107, S110, and SX-103 was subjected to CUF process as per TI-RPP-WTP-540. The processing and analysis schematic is shown on the following page, the ASO-required analysis indicated by highlighted blocks. The aqueous samples are ready to directly sub-sample for analysis and acid digestion. The solid slurry sample has been aliquoted into crucibles and dried; the sub-samples are ready for fusion.

Table 1. Cross-Reference of Process component, Sample ID, and RPL ID

\begin{tabular}{|l|l|l|}
\hline Component & Sample ID & ASO ID \\
\hline 20 wt\% Slurry & TI540-G5-7 & $\mathbf{0 7 - 0 1 7 8 3}$ \\
\hline 20 wt\% Slurry & TI540-G5-8 & $\mathbf{0 7 - 0 1 7 8 4}$ \\
\hline Dewater filtrate & TI540-G5-A & $\mathbf{0 7 - 0 1 7 7 9}$ \\
\hline $\begin{array}{l}\text { Caustic leach filtrates, } 0 \\
\text { hours }\end{array}$ & TI540-G5-C & $\mathbf{0 7 - 0 1 7 7 3}$ \\
\hline $\begin{array}{l}\text { Caustic leach filtrates, } 4 \\
\text { hours }\end{array}$ & TI540-G5-D & $\mathbf{0 7 - 0 1 7 7 4}$ \\
\hline $\begin{array}{l}\text { Caustic leach filtrates, } 8 \\
\text { hours }\end{array}$ & TI540-G5-E & $\mathbf{0 7 - 0 1 7 7 5}$ \\
\hline $\begin{array}{l}\text { Caustic leach filtrates, } \\
12 \text { hours }\end{array}$ & TI540-G5-F & $\mathbf{0 7 - 0 1 7 7 6}$ \\
\hline Caustic leach slurry & TI540-G5-12 & $\mathbf{0 7 - 0 1 7 8 6}$ \\
\hline Caustic leach permeate & TI540-G5-G & $\mathbf{0 7 - 0 1 7 8 0}$ \\
\hline Caustic wash 1 permeate & TI540-G5-I & $\mathbf{0 7 - 0 1 7 7 7}$ \\
\hline Caustic wash 2 permeate & TI540-G5-K & $\mathbf{0 7 - 0 1 7 7 8}$ \\
\hline Caustic wash 3 permeate & TI540-G5-M & $\mathbf{0 7 - 0 1 7 8 1}$ \\
\hline $\begin{array}{l}\text { Combined caustic } \\
\text { washes }\end{array}$ & TI540-G5-O & $\mathbf{0 7 - 0 1 7 8 2}$ \\
\hline $\begin{array}{l}\text { Caustic leached and } \\
\text { washed slurry }\end{array}$ & TI540-G5-17 & $\mathbf{0 7 - 0 1 7 8 5}$ \\
\hline
\end{tabular}

\section{SAL Preparation/Analysis}

Record both the nominal volume and actual weight distributions of aqueous sample material for various analyses. This may require weighing vials following exit from the hot cell. This is intended to assure significant evaporation did not occur between aliquoting and capping in the cell and will address issues of potential sample hold-up volume in the pipet tip.

Observations associated with the dissolution preparations shall be reported. If any residual solids remain after any of the fusion and acid digestions, note on the bench sheet (include estimated quantity, color, texture, etc.) and contact RW Shimskey or MK Edwards for further instruction prior to distribution. 
Addition of Group 5 Slurry

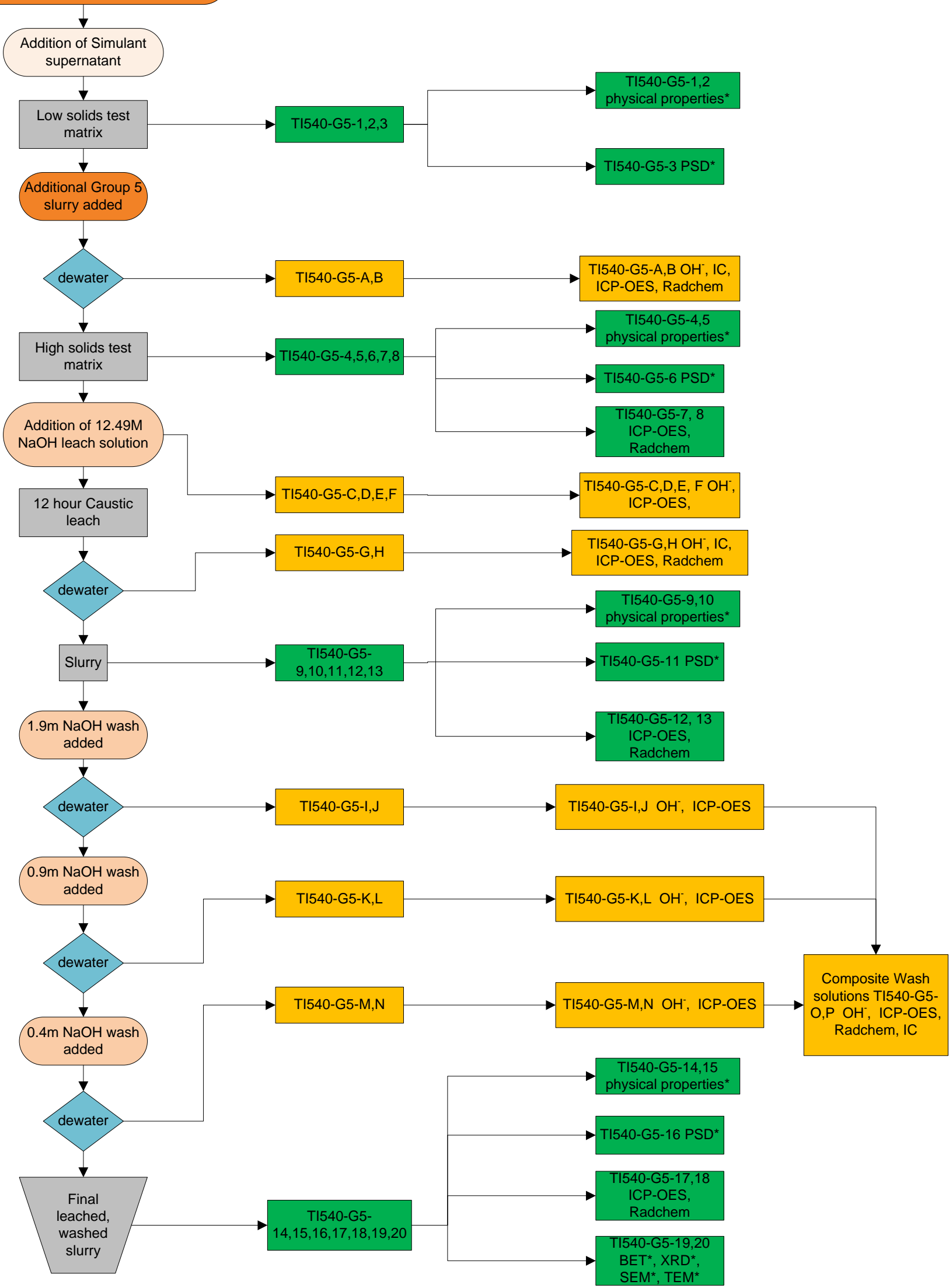

*Analyses not performed by ASO 


\section{Archive of SAL Fusion Preparation Samples}

The fusion preparations will result in a $100-\mathrm{mL}$ volume. This solution will be apportioned to the laboratory as needed to conduct work-station-specific analyses. A 15-mL aliquot from each preparation will need to be prepared as an archive sample. The vials need to be labeled inclusive of the following: date, ASO-ID, matrix, treatablility study, hazard, fusion prep (if applicable). The vial tare, gross masses, and IDs need to be recorded and submitted to RW Shimskey or MK Edwards. The vials may be removed from the hot cells for storage. The remaining portions of the fusion preparations may be disposed of.

\section{Laboratory Analysis}

The required sample analyses are shown in Table 2.

Table 2 Filtration and Leach Testing Characterization Plan

\begin{tabular}{|c|c|}
\hline Process Step & Analyte \\
\hline \multirow[t]{3}{*}{ Dewatered slurry (TI540-G5-7, TI540-G5-8) } & HF assisted Acid digestion \\
\hline & - ICP metals (Table 3) \\
\hline & $\begin{array}{l}\text { KOH fusion } \\
\text { - ICP metals (Table 3) } \\
\text { - GEA } \\
\text { - Total alpha } \\
\text { - }{ }^{238} \mathrm{Pu},{ }^{239+240} \mathrm{Pu} \\
\text { - U/KPA } \\
\text { - }{ }^{90} \mathrm{Sr} \\
\text { - Total beta }\end{array}$ \\
\hline \multirow[t]{2}{*}{ Dewater filtrate (TI540-G5-A) } & $\begin{array}{l}\text { Direct distribution } \\
\text { - Anions (Table 3) } \\
\text { - Free hydroxide } \\
\text { - Density } \\
\end{array}$ \\
\hline & $\begin{array}{l}\text { Acid digestion } \\
\text { - ICP metals (Table 3) } \\
\text { - GEA } \\
\text { - Total alpha } \\
\text { - }{ }^{238} \mathrm{Pu},{ }^{239+240} \mathrm{Pu} \\
\text { - }{ }^{90} \mathrm{Sr} \\
\text { - Total beta }\end{array}$ \\
\hline
\end{tabular}




\begin{tabular}{|c|c|}
\hline Process Step & Analyte \\
\hline $\begin{array}{c}\text { Time interval Leach filtrates } \\
\text { (TI540-G5-C, TI540-G5-D, TI540-G5-E, TI540- } \\
\text { G5-F) }\end{array}$ & $\begin{array}{l}\text { Direct distribution } \\
\text { - Free hydroxide } \\
\text { - Density } \\
\text { Acid digestion } \\
\text { - ICP metals (Table 3) }\end{array}$ \\
\hline \multirow[t]{2}{*}{ Caustic-leached permeate (TI540-G5-G) } & $\begin{array}{l}\text { Direct distribution } \\
\text { - Anions (Table 3) } \\
\text { - Free hydroxide } \\
\text { - Density } \\
\end{array}$ \\
\hline & $\begin{array}{l}\text { Acid digestion } \\
\text { - ICP metals (Table 3) } \\
\text { - GEA } \\
\text { - Total alpha } \\
\text { - }{ }^{238} \mathrm{Pu},{ }^{239+240} \mathrm{Pu} \\
\text { - }{ }^{90} \mathrm{Sr} \\
\text { - Total beta } \\
\text { - U (KPA) }\end{array}$ \\
\hline Caustic-leached slurry (TI540-G5-12) & $\begin{array}{l}\text { KOH fusion } \\
\text { - ICP metals (Table 3) } \\
\text { - GEA } \\
\text { - Total alpha } \\
\text { - }{ }^{238} \mathrm{Pu},{ }^{239+240} \mathrm{Pu} \\
\text { - U/KPA } \\
\text { - }{ }^{90} \mathrm{Sr} \\
\text { - Total beta }\end{array}$ \\
\hline $\begin{array}{l}\text { First and second washes following caustic leach } \\
\text { (TI540-G5-I, TI540-G5-K) }\end{array}$ & $\begin{array}{l}\text { Direct distribution } \\
\text { - Free hydroxide } \\
\text { - Density } \\
\text { Acid digestion } \\
\text { - ICP metals (Table 3) }\end{array}$ \\
\hline \multirow[t]{2}{*}{$\begin{array}{l}\text { Third wash following caustic leach (TI540-G5- } \\
\text { M) }\end{array}$} & $\begin{array}{l}\text { Direct distribution } \\
\text { - Anions (Table 3) } \\
\text { - Free hydroxide } \\
\text { - Density } \\
\end{array}$ \\
\hline & $\begin{array}{l}\text { Acid digestion } \\
\text { - ICP metals (Table 3) } \\
\text { - GEA } \\
\text { - Total alpha } \\
\text { - }{ }^{238} \mathrm{Pu},{ }^{239+240} \mathrm{Pu} \\
\text { - }{ }^{90} \mathrm{Sr} \\
\text { - Total beta }\end{array}$ \\
\hline
\end{tabular}




\begin{tabular}{|c|c|}
\hline Process Step & Analyte \\
\hline \multirow[t]{2}{*}{ Combined washes (G5-O) } & $\begin{array}{l}\text { Direct distribution } \\
\text { - Anions (Table 3) } \\
\text { - Free hydroxide } \\
\text { - Density }\end{array}$ \\
\hline & $\begin{array}{l}\text { Acid digestion } \\
\text { - ICP metals (Table 3) } \\
\text { - GEA } \\
\text { - Total alpha } \\
\text { - }{ }^{238} \mathrm{Pu},{ }^{239+240} \mathrm{Pu} \\
\text { - }{ }^{90} \mathrm{Sr} \\
\text { - Total beta }\end{array}$ \\
\hline \multirow[t]{5}{*}{ Caustic-leached and washed slurry (G5-17) } & Direct distribution \\
\hline & $\begin{array}{l}\text { - Water leachable IC } \\
\text { anions } \\
\end{array}$ \\
\hline & HF assisted Acid digestion \\
\hline & - ICP metals (Table 3) \\
\hline & $\begin{array}{l}\text { KOH fusion } \\
\text { - ICP metals (Table 3) } \\
\text { - GEA } \\
\text { - Total alpha } \\
\text { - }{ }^{238} \mathrm{Pu},{ }^{239+240} \mathrm{Pu} \\
\text { - U/KPA } \\
\text { - }{ }^{90} \mathrm{Sr} \\
\text { - Total beta }\end{array}$ \\
\hline
\end{tabular}

All analyses are to be conducted per approved PNNL procedures or test plans with the QC defined in the QC information Section. Table 3 defines the analytes of interest, the required detection limits, and analysis methods.

\section{Quality Control}

All work is to be conducted according to RPP-WTP-QA-005, Rev. 0.

Preparative or sample analysis QC is to include a preparation blank, sample, sample duplicate, matrix spike, and a LCS or BS. The ASO is responsible for preparing the QC samples. The samples submitted for fusion are sub-aliquoted into fusion vessels in duplicate (sample, sample duplicate-note that ASO needs to provide the LCS material). If possible, the matrix spike and LCS/BS are to include all the analytes of interest to be reported for the specific analysis.

The duplicate, LCS/BS, and MS QC acceptance criteria for the aqueous phases and solid phases are provided in Table 4. The preparation blank (PB) analyte concentration shall be less than the estimated quantitation limit (EQL) or the minimum detectable activity (MDA) of the associated sample. When the PB concentration is equal to or exceeds the EQL, then the PB concentration shall not exceed $5 \%$ of the measured concentration present in the sample. Failure of the PB, and/or duplicates, and/or LCS/BS to meet the acceptance criteria requires that affected samples in the processing batch be re-prepared and re-analyzed for the failed analytes, availability of samples permitting, at ASO expense. 
In the case of multi-elemental methods (IC and ICP-OES), isolated QC failure(s) may be communicated to RW Shimskey or MK Edwards for an assessment of the impact on data interpretation. If the data are acceptable as-is, RW Shimskey or MK Edwards will indicate in writing (e.g., e-mail message) that the data may be reported, and the resulting limitations on the data from the QC sample failure(s) shall be included in the final report.

When the MS fails to meet the acceptance criteria, the results shall be investigated for potential sources of error. When the sources of error cannot be identified, the failure of the MS and any resulting limitations on the data shall be included in the report.

Note that in some cases BS and MS are requested for U/KPA as well as ICP metals in solution analysis. Because the broad suite of ICP BS metals will interfere with the U KPA analysis, two MS and BS samples (one supporting each technique) will need to be prepared as part of the acid digestion.

\section{Reporting Units}

Report aqueous sample results in units of $\mathrm{ug} / \mathrm{mL}$ or $\mathrm{uCi} / \mathrm{mL}$. Report solids sample results as ug/g or uCi/g; the initial dry mass of solids (as measured in each fusion crucible) will be provided. For radiochemistry, the reference date of August 1, 2007 shall be applied. Report the hydroxide concentration in units of molarity and $\mathrm{ug} / \mathrm{mL}$.

\section{Reporting}

The analytical data report shall be prepared in accordance with PNL-ASO-058, Rev. 0, Section 5.3, Comprehensive Data Report. Please be sure to include action taken with respect to any identified unexpected results and discrepancies.

The following elements may be included in the final report or be traceable to the test results (usually by entry in the LRB, Test Instruction, or data sheet) and be maintained as lifetime records:

- identification of standards used

- identification of M\&TE used

- reference to the Test Plan (identified on page 1 of the ASR)

- signature and date of person who performed the test and recorded the data

- hand calculation review documentation. 
Analytical results shall be reported both in hard copy and electronically. Preliminary data reports and electronic files shall be provided as soon as practical after completion of analysis. The final ASR data report shall be provided no later than the commitment date on the ASR.

Table 3. Method Detection Limits for Solids and Supernatants

\begin{tabular}{|c|c|c|c|}
\hline Analyte & Solids & Solutions & Analysis Method \\
\hline & $\mu \mathrm{Ci} / \mathrm{g}^{(\mathrm{a})}$ & $\mu \mathrm{Ci} / \mathrm{ml}$ & \\
\hline${ }^{137} \mathrm{Cs}$ & $6.0 \mathrm{E}-02$ & $1.0 \mathrm{E}-02$ & \multirow{5}{*}{$\mathrm{GEA}^{\mathrm{c}}$} \\
\hline${ }^{60} \mathrm{Co}$ & 3.0E-02 & $1.0 \mathrm{E}-02$ & \\
\hline${ }^{154} \mathrm{Eu}$ & 5.0E-03 & $4.0 \mathrm{E}-04$ & \\
\hline${ }^{155} \mathrm{Eu}$ & 8.0E-03 & $4.0 \mathrm{E}-04$ & \\
\hline${ }^{241} \mathrm{Am}$ & 3.0E-03 & $2.0 \mathrm{E}-03$ & \\
\hline $\mathrm{Pu}$ & $1.0 \mathrm{E}-03$ & $1.0 \mathrm{E}-04$ & ${ }^{239+240} \mathrm{Pu}$ and ${ }^{238} \mathrm{Pu}$ by AEA \\
\hline Total alpha & $1.0 \mathrm{E}-02$ & $4.0 \mathrm{E}-03$ & Proportional counting \\
\hline Total beta & $1.0 \mathrm{E}-02$ & $1.0 \mathrm{E}-03$ & Proportional counting \\
\hline \multirow[t]{2}{*}{${ }^{90} \mathrm{Sr}$} & $1.0 \mathrm{E}-02$ & $1.0 \mathrm{E}-03$ & Separation and proportional counting \\
\hline & $\mu \mathrm{g} / \mathrm{g}$ & $\mu \mathrm{g} / \mathrm{ml}$ & \\
\hline $\mathrm{Al}$ & $3.0 \mathrm{E}+02$ & $7.5 \mathrm{E}+01$ & \multirow{16}{*}{ ICP-OES } \\
\hline $\mathrm{B}$ & $2.0 \mathrm{E}+02$ & $7.5 \mathrm{E}+01$ & \\
\hline $\mathrm{Bi}$ & $4.0 \mathrm{E}+02$ & $3.0 \mathrm{E}+01$ & \\
\hline $\mathrm{Cd}$ & $7.5 \mathrm{E}+01$ & $7.5 \mathrm{E}+01$ & \\
\hline $\mathrm{Cr}$ & $1.2 \mathrm{E}+02$ & $1.5 \mathrm{E}+01$ & \\
\hline $\mathrm{Fe}$ & $3.0 \mathrm{E}+02$ & $7.5 \mathrm{E}+01$ & \\
\hline $\mathrm{K}$ & $1.0 \mathrm{E}+03^{(\mathrm{b})}$ & $5.0 \mathrm{E}+01$ & \\
\hline $\mathrm{Mn}$ & $3.0 \mathrm{E}+02$ & $1.5 \mathrm{E}+01$ & \\
\hline $\mathrm{Na}$ & $3.0 \mathrm{E}+03$ & $7.5 \mathrm{E}+01$ & \\
\hline $\mathrm{Ni}$ & $1.6 \mathrm{E}+02^{(\mathrm{b})}$ & $3.0 \mathrm{E}+01$ & \\
\hline S & $1.5 \mathrm{E}+03$ & $2.0 \mathrm{E}+2$ & \\
\hline $\mathrm{Si}$ & $3.0 \mathrm{E}+03$ & $7.5 \mathrm{E}+01$ & \\
\hline $\mathrm{Sr}$ & $3.0 \mathrm{E}+02$ & $7.5 \mathrm{E}+01$ & \\
\hline $\mathrm{Zn}$ & $3.0 \mathrm{E}+02$ & $7.5 \mathrm{E}+01$ & \\
\hline $\mathrm{Zr}$ & $3.0 \mathrm{E}+02$ & $7.5 \mathrm{E}+01$ & \\
\hline $\mathrm{U}$ & $2.5 \mathrm{E}+03$ & $7.5 \mathrm{E}+01$ & \\
\hline $\mathrm{U}$ & $6.0 \mathrm{E}+01$ & $6.0 \mathrm{E}+01$ & Kinetic Phosphorescence \\
\hline Fluoride & $2.5 \mathrm{E}+02$ & $1.2 \mathrm{E}+02$ & \multirow{6}{*}{$\begin{array}{l}\text { Ion Chromatography } \\
\text { (water-soluble species) }\end{array}$} \\
\hline Nitrite & $2.5 \mathrm{E}+02$ & $1.2 \mathrm{E}+02$ & \\
\hline Nitrate & $2.5 \mathrm{E}+02$ & $1.2 \mathrm{E}+02$ & \\
\hline Phosphate & $2.5 \mathrm{E}+02$ & $1.2 \mathrm{E}+02$ & \\
\hline Sulfate & $2.5 \mathrm{E}+02$ & $1.2 \mathrm{E}+02$ & \\
\hline Oxalate & $8.0 \mathrm{E}+02$ & $4.0 \mathrm{E}+02$ & \\
\hline Hydroxide & NA & 1E-01 M & Titration \\
\hline Total organic carbon & NA & $4.0 \mathrm{E}+02$ (as C) & \multirow{2}{*}{ Hot persulfate method } \\
\hline Total inorganic carbon & NA & $2.0 \mathrm{E}+02$ (as C) & \\
\hline $\begin{array}{l}\text { (a) KOH fusion for soli } \\
\text { (b) The Ni and K canno } \\
\text { assessed from a separat } \\
\text { (c) Please provide Mn- } 5\end{array}$ & $\begin{array}{l}\text { samples. } \\
\text { be measurec } \\
\text { HF-assisted } \\
\text { data. }\end{array}$ & $\begin{array}{l}\text { KOH fusion whic } \\
\text { tion. }\end{array}$ & es a Ni crucible. The Ni and K will be \\
\hline
\end{tabular}


츨

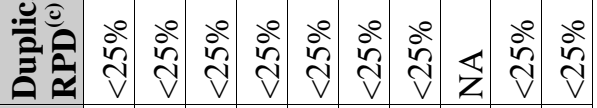

悹

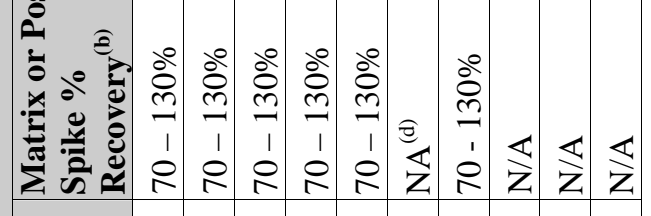

o

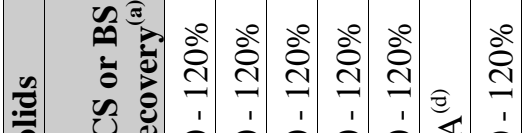

की

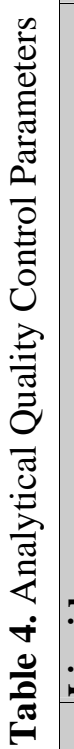

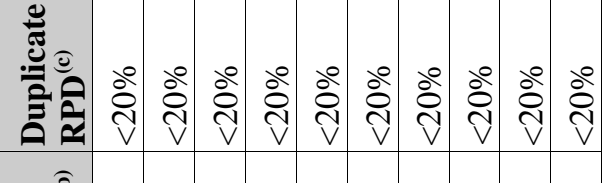

帘

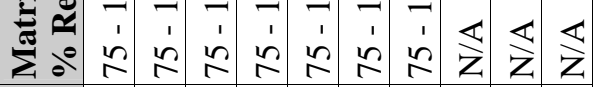

do

m

今े సి

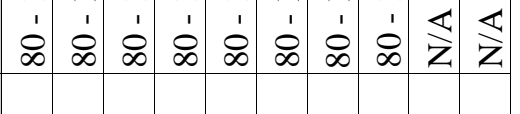

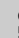

.0.

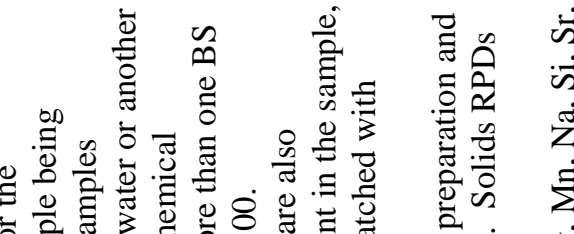

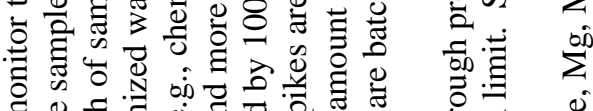

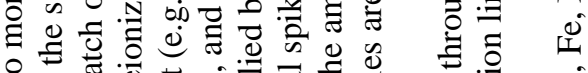

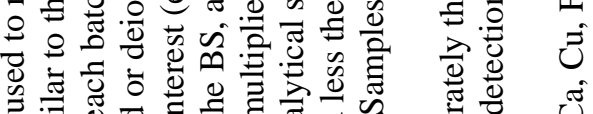

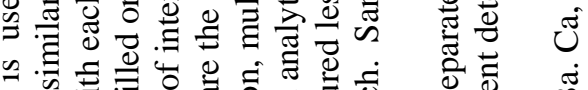

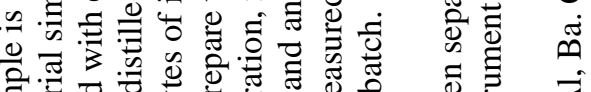

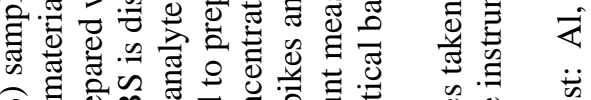

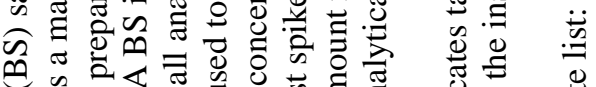

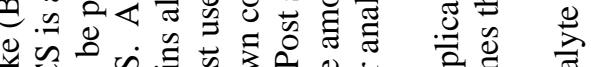

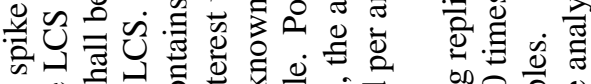

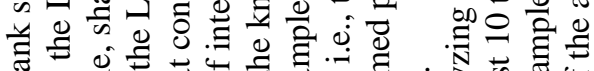

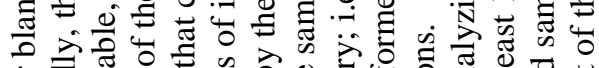
。

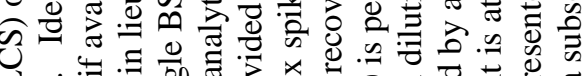

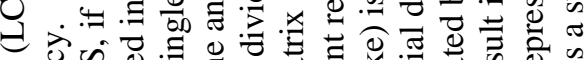

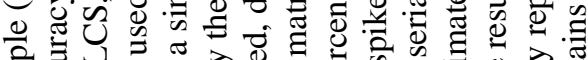

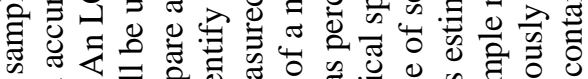

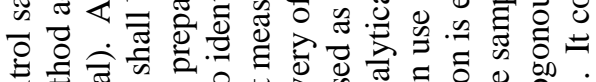

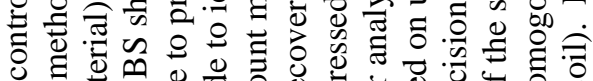

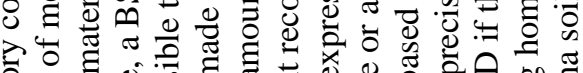

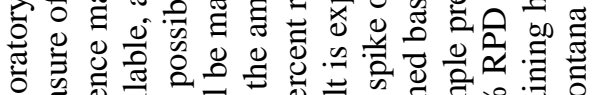

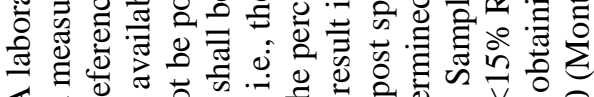

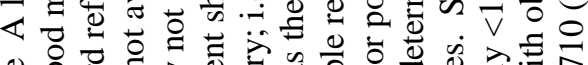

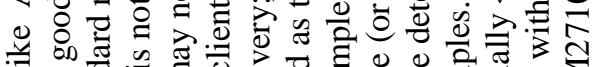

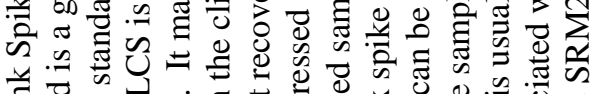

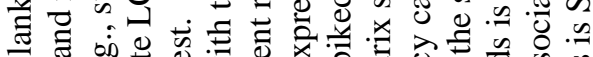

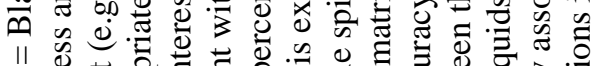

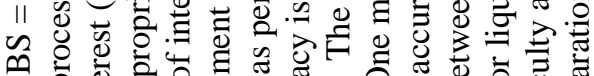

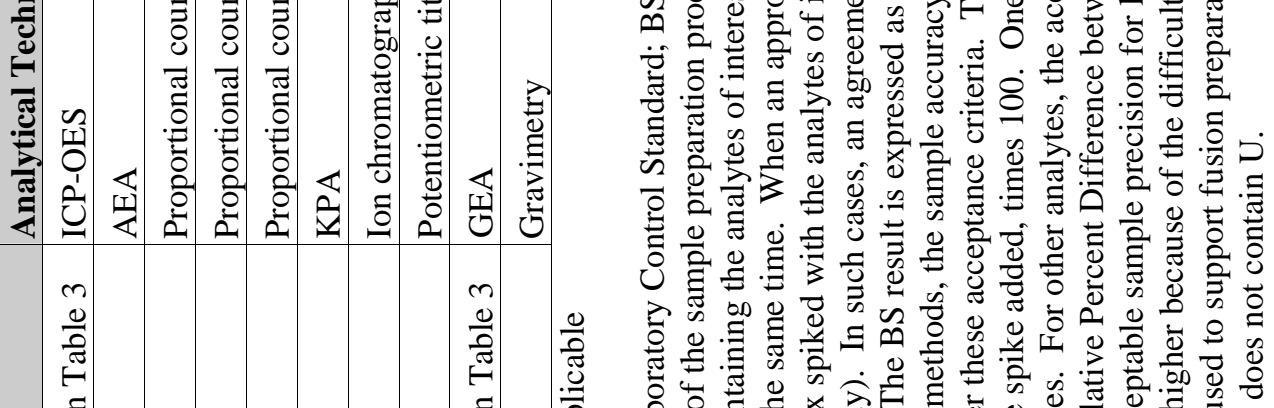

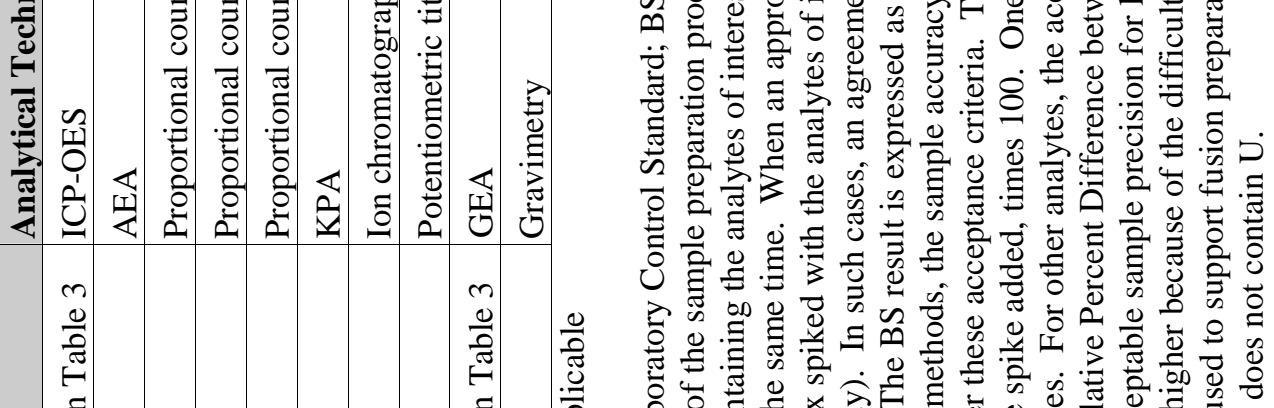

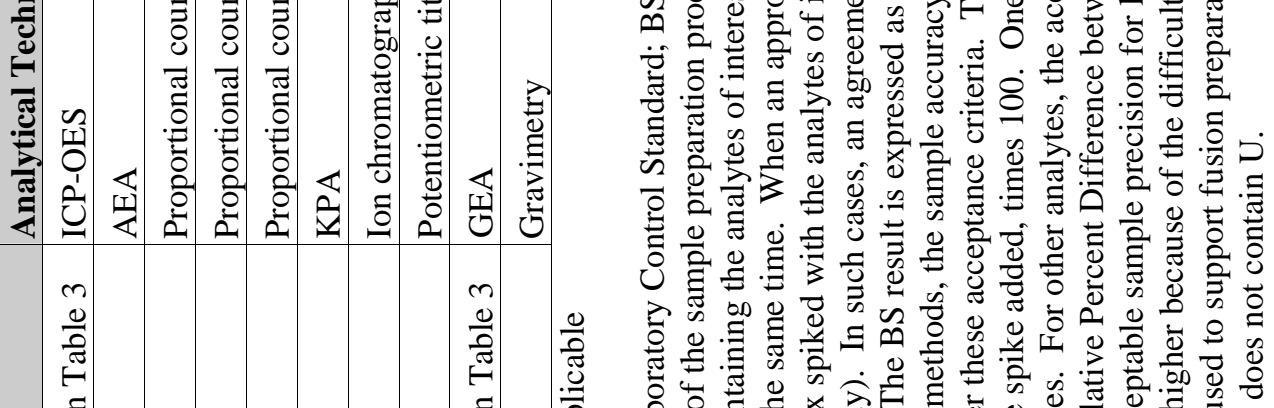

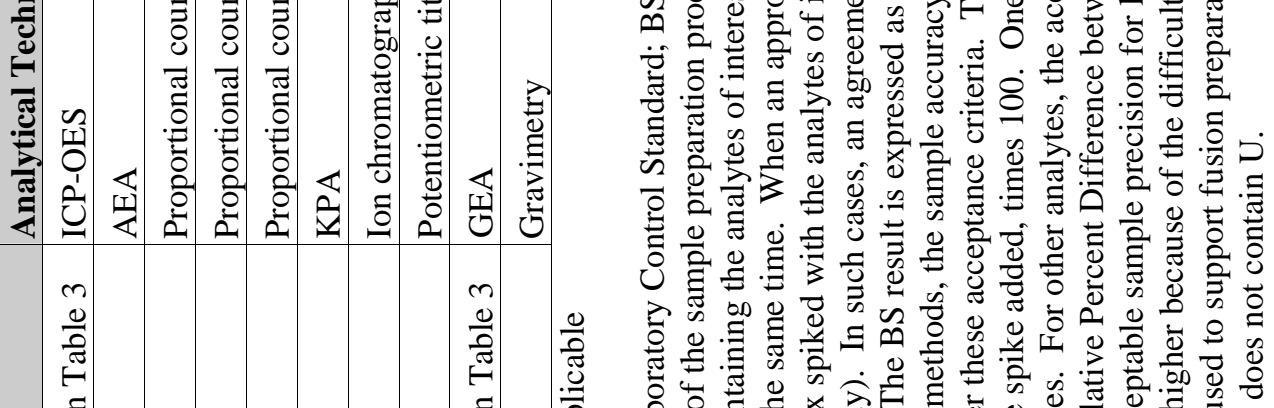

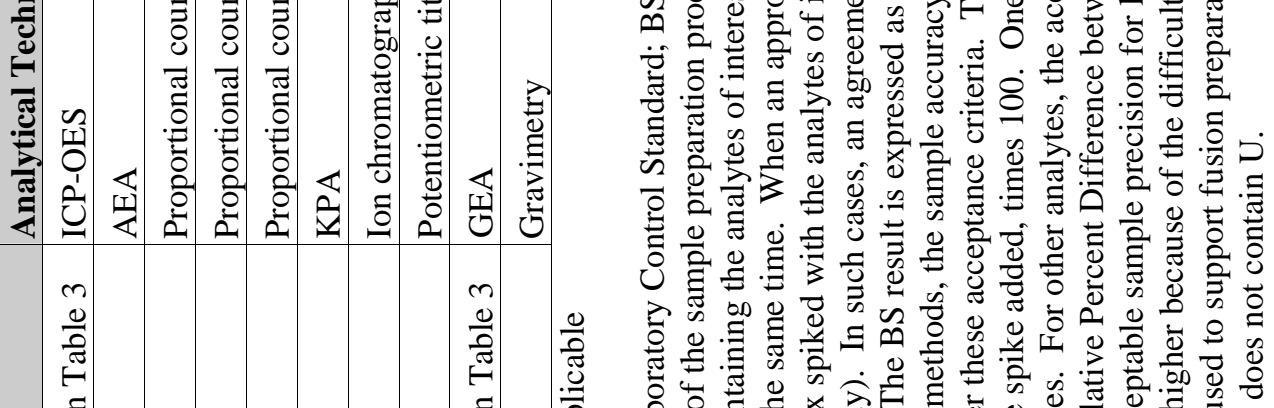

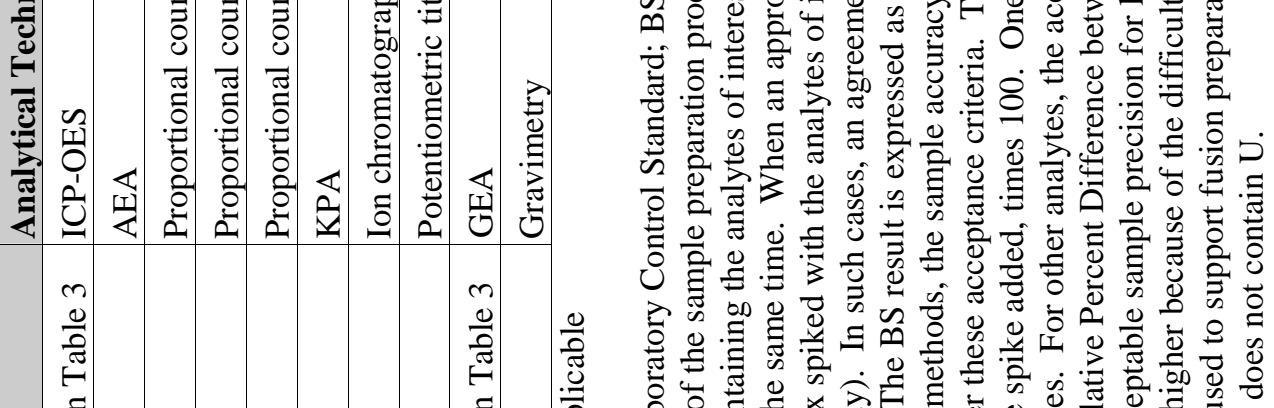

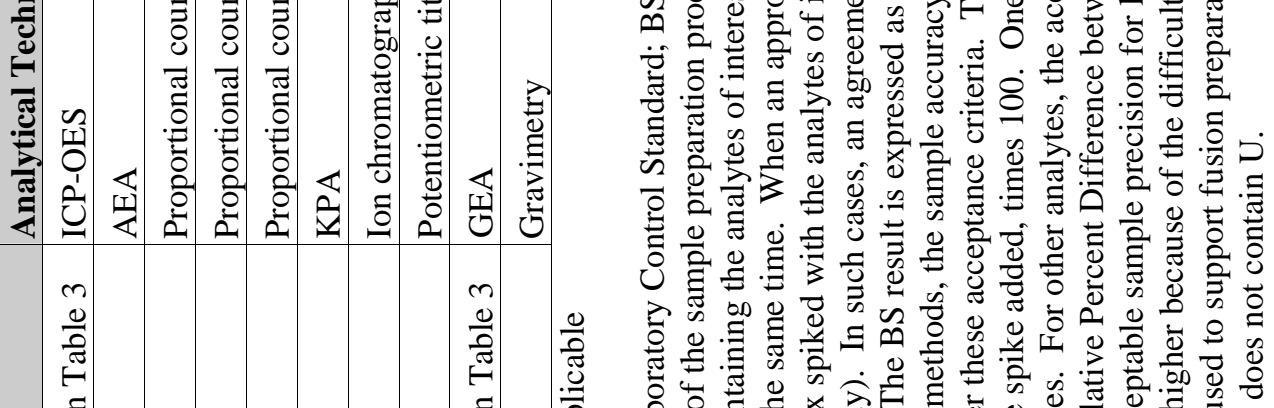

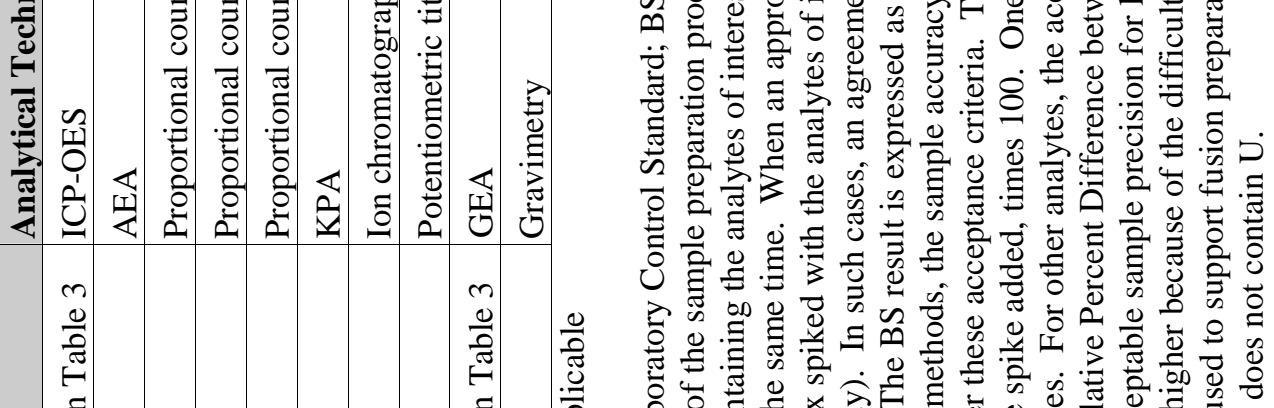

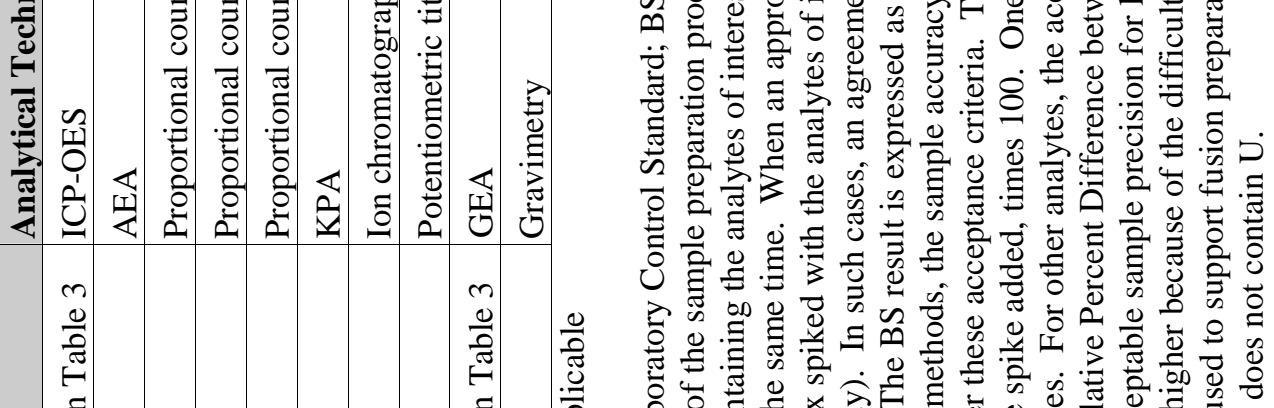

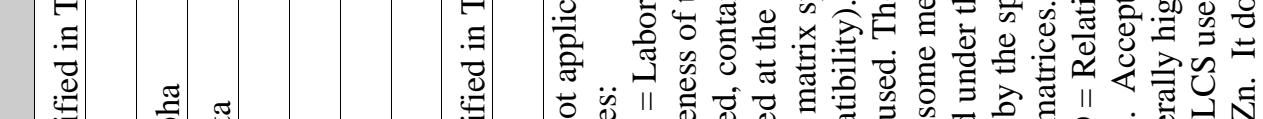
ะ

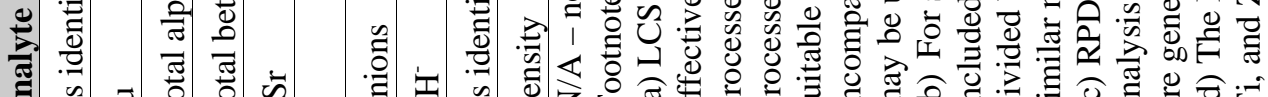

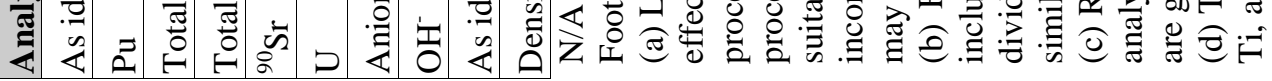


Requestor -- Complete all fields on this COVER PAGE, unless specified as optional or ASR is a revision

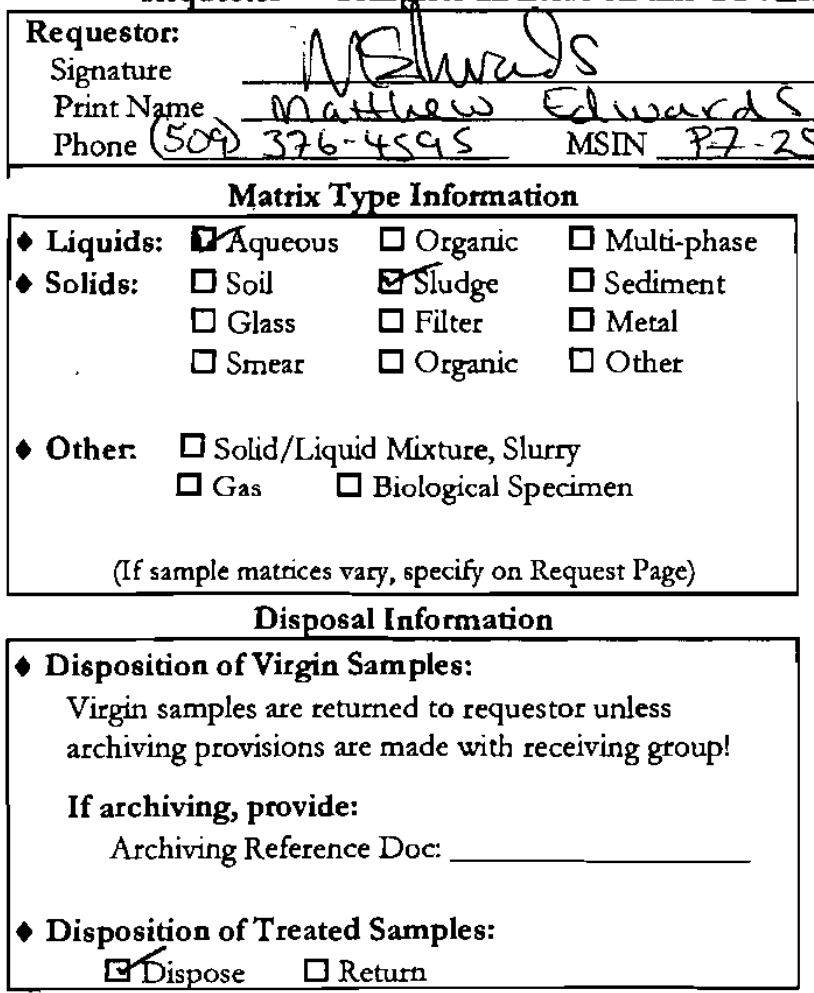

Project Number:

Work Package:

\section{QA/Special Requirements} DASO-QAP-001, Rev. 6 (Equivalent to HASQARD)

Additional QA Requirements, List Document Below:

Reference Doc Number._RPP_WTP-QA-005, Rev. 2_

- Field COC Submitted? $\mathbb{\text { WNo }} \square$ Yes

- Lab COC Required? $\square$ No $\square$ Yes

- Sample/Container Inspection Documentation Required? QTo $\square$ Yes

- Hold Time: 田No $\square$ Yes

If Yes,

Contact ASO

Lead before

submitting

$\square$ Use SW 846 (PNL-ASO-071, identify

analytes/methods where holding times apply)

Samples

- Special Storage Requirements:

$\square$ Wone $\square$ Refrigerate $\square$ Other, Specify:

- Data Requires ASO Quality Engineer Review? অTo $\square$ Yes Data Reporting Information

Is Work Associated with a Fee-Based
Milestone? $\square$ No $\square-$ Yes
If yes, milestone due date:
$1+2008$

- Preliminary Results Requested, As Available? $\square$ No $\square$ Yes

\section{- Data Reporting Level \\ $\square$ ASO-QAP-001 (Equivalent to HASQARD). \\ $\square$ Minimum data report. \\ Project Specific Requirements: \\ Contact $A S O$ Lead or List Reference \\ Document: Attached}

- Requested Anglytical Work Completion Date:
$\frac{9 / 30 / 2007}{\text { (Note: Priority rate charge for < } 10 \text { busineas day tum-around time) }}$
- Negotiated Commitment Date:
$\frac{16 / 8 / 07}{\text { (To be completed by ASO Lead) }}$ IRD, $M J S, R G S$
- Sample Information Check List Attached? \No $\square$ Yes

If no, Reference Doc Attached:

or, Previous ASR Number:

or, Previous RPL Number:
Does the Waste Designation Documentation Indicate Presence of PCBs? $\square$ No $\square$ Yes

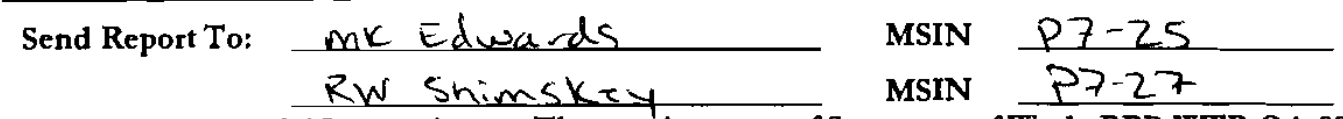

Additional or Special Instructions _The requirements of Statement of Work, RPP-WTP-QA-005, Rev, 2, apply to this work. Task-specific Quality Control criteria are attached. Reference Document (i.e., TP-RPP-WTP- 4 7):

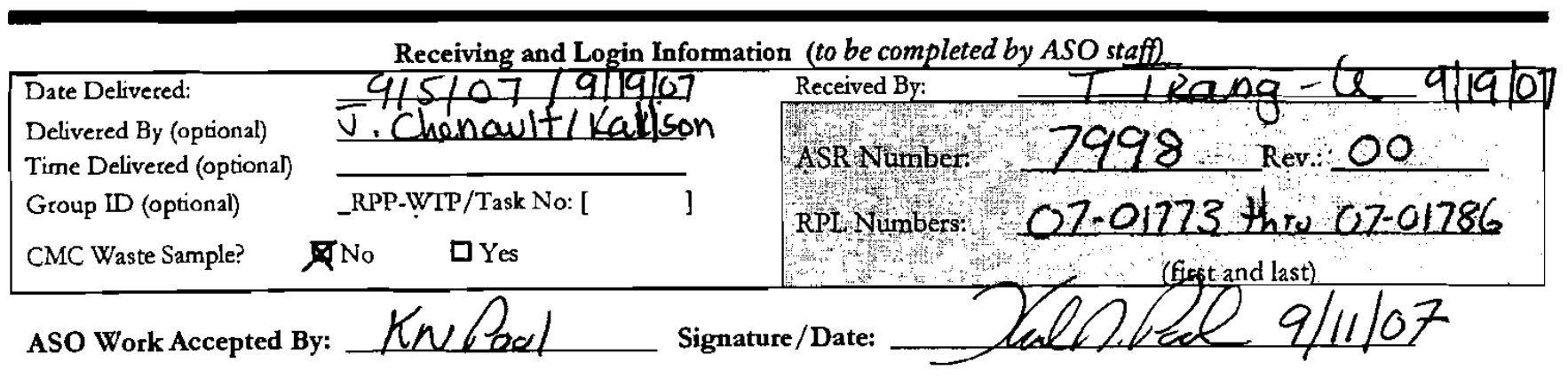


WTP-RPT-172, Rev 0

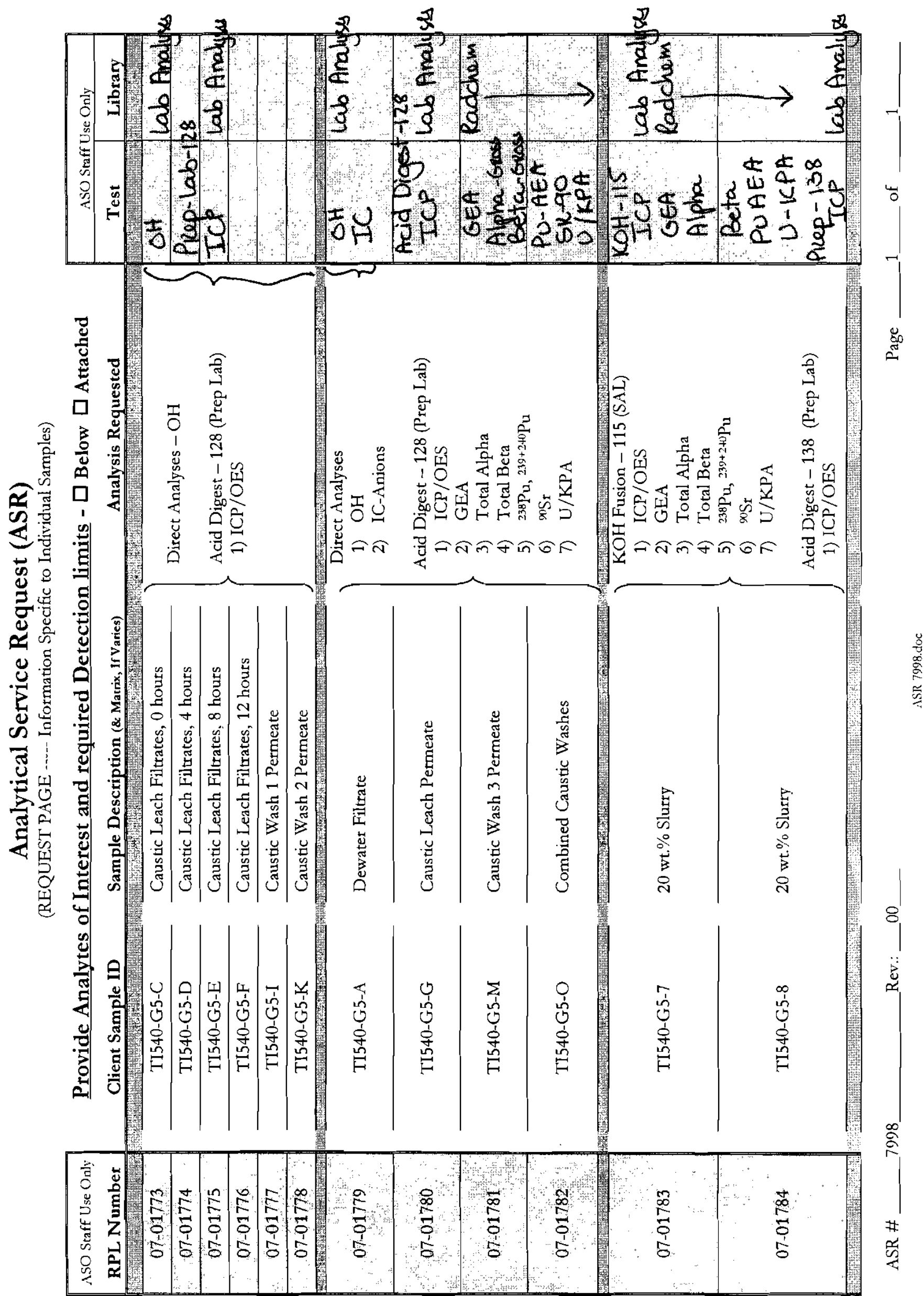



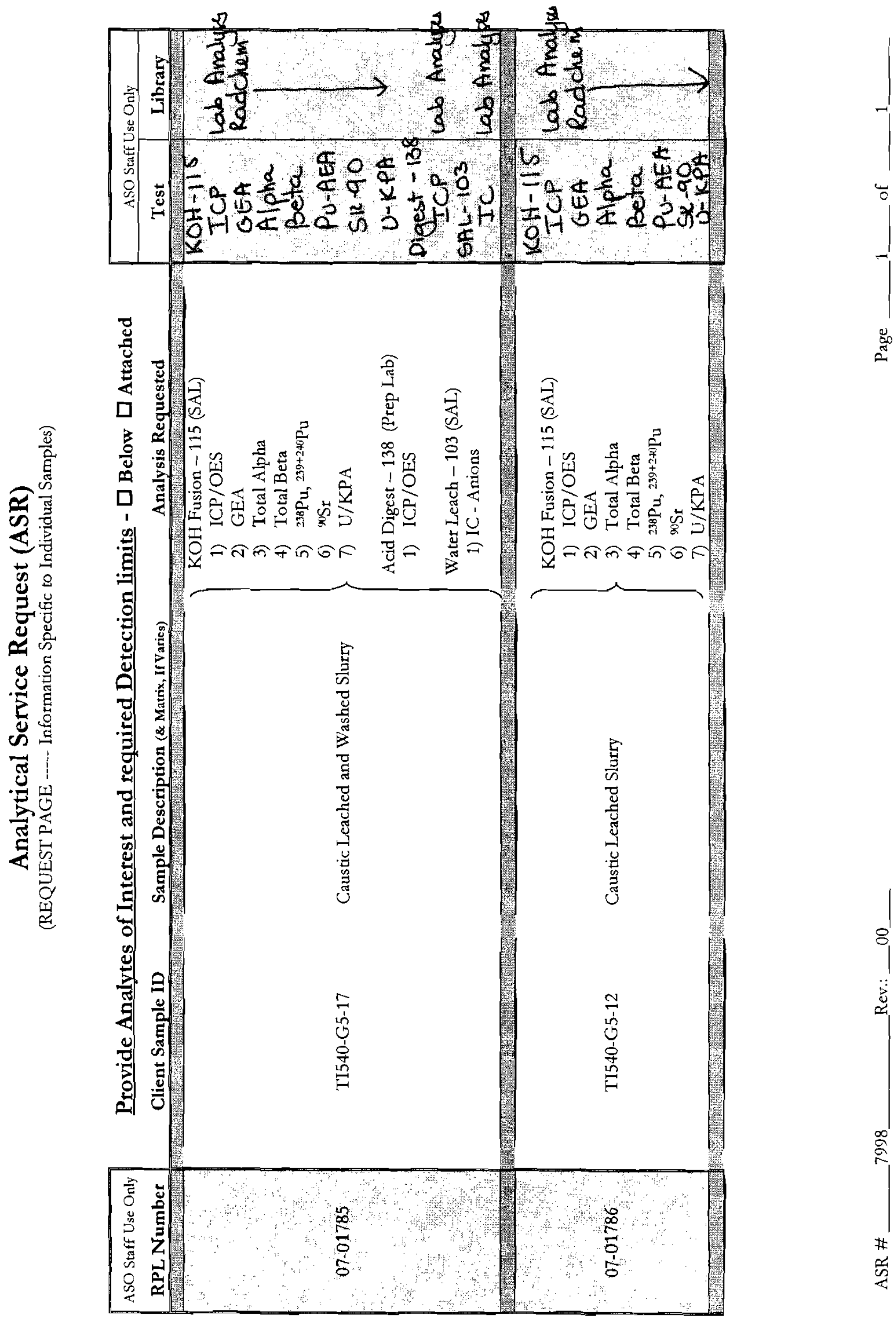
Battelle PNNL/RS\&E/Inorganic Analysis ... ICPOES Analysis Report PO Box 999, Richland, Washington 99352

$\begin{array}{ll}\text { Project / WP\#: } & 52964 \text { / F99189 } \\ \text { ASR\#: } & 7998 \\ \text { Client: } & \text { M. Edwards } \\ \text { Total Samples: } & 4 \text { (solid) }\end{array}$

\begin{tabular}{|l|c|c|}
\hline \multicolumn{3}{|c|}{ First } \\
\hline RPL\#: & $07-01783$ & Last \\
\hline Client ID: & TI540-G5-7 & TI-01786 \\
\hline $\begin{array}{l}\text { Sample Preparation: PNL-ALO-115, "Solubilization of Metals from Solids } \\
\text { using a KOH-KNO }\end{array}$ Fusion", 9/19/07 (SAL/dk). & \\
\hline
\end{tabular}

Procedure: $\quad$ RPG-CMC-211, "Determination of Elemental Composition by Inductively Coupled Argon Plasma Optical Emission Spectrometry (ICPOES)", Rev 1.

Analyst: $\quad \underline{\text { J.K. Deschane }}$

Analysis Date (File): $\quad \underline{9-24-2007}$ (C0063)

See Chemical Measurement Center 98620 file: $\underline{\text { ICP-325-405-3 }}$

(Calibration and Maintenance Records)

M\&TE Number: $\quad$ N827583 (ICPOES instrument)

M19445 (Mettler AT400 Balance)

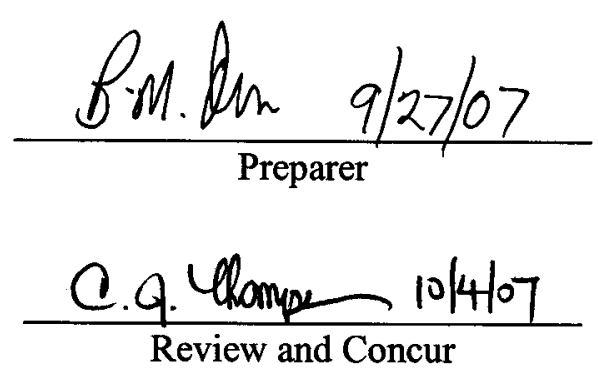




\section{Battelle PNNL/RS\&E/Inorganic Analysis ... ICPOES Analysis Report}

Four samples submitted under Analytical Service Request (ASR) 7998 were analyzed by ICPOES. The samples were prepared following RPL fusion procedure PNL-ALO-115 using a nominal 0.2 grams of sample. The samples were dried to constant mass prior to undergoing fusion and were diluted to a final volume of $100 \mathrm{~mL}$.

Analytes of interest (AOIs) were specified in the ASR, and are listed in the upper section of the attached ICPOES Data Report. The quality control (QC) results for these AOIs have been evaluated and are presented below. Analytes other than AOIs are reported in the bottom section of the report, but have not been fully evaluated for QC performance. The results are given as $\mu \mathrm{g} / \mathrm{g}$ for each detected analyte, and have been adjusted for all laboratory processing factors and instrument dilutions.

Calibration of the ICPOES was done following the manufacturer's recommended calibration procedure and using multi-analyte custom standard solutions traceable to the National Institute of Standards and Technology (NIST). Midrange calibration verification standards (MCVA and $\mathrm{MCVB}$ ) were used to verify acceptance of the two-point calibration curves obtained for each analyte, and also used for continuing calibration verification.

Minimum Method Detection Limit (MDL) values were specified in the ASR. Except for sodium, MDL levels were met for all AOIs. Because of known impurities of sodium in the 115 fusion flux, the MDL for this analyte has been set artificially high to account for this expected impurity level. However, the observed concentration of sodium in the samples exceeded the requested MDL level.

The controlling documents are ASO-QAP-001, and the client supplied RPP-WTP-QA-005, Rev. 2 and "ASR 7998 Special Instructions". Instrument calibrations, QC checks and blanks (e.g., ICV/ICB, CCV/CCB, LLS, ICS), post-spike, laboratory control standard (LCS), duplicate, and serial dilution were conducted during the analysis run. The LCS was prepared using a nominal 0.2 grams of SRM-2710 (Montana Soil).

\section{Preparation Blank (PB):}

A preparation blank (reagents only) was prepared for the fusion process. The concentrations of all AOIs were within the acceptance criteria of $\leq \mathrm{EQL}$ (estimated quantitation level) or less than $\leq 5 \%$ of the concentration in the sample.

\section{Blank Spike (BS)/Laboratory Control Sample (LCS):}

An LCS (Montana Soil) was prepared for the fusion process. Recovery values are listed for all analytes included in the spike that were measured at or above the EQL. The recovery values were within the acceptance criterion of $80 \%$ to $120 \%$ for all AOIs meeting the above requirement.

\section{Matrix-Spiked Sample:}

No matrix spike sample was provided for analysis. 


\section{Battelle PNNL/RS\&E/Inorganic Analysis ... ICPOES Analysis Report}

\section{Duplicate Relative Percent Difference (RPD):}

A duplicate was prepared for the fusion process. RPDs are listed for all analytes that were measured at or above the EQL. The RPDs were within the client acceptance criterion of $\leq 25 \%$ for all AOIs meeting the above requirement.

\section{Post-Spike/Analytical Spike Sample (Spike A Elements):}

An analytical spike (A component) was conducted for the fusion process. Recovery values are listed for all analytes in the spike that were measured at or above the EQL, and that had a spike concentration $\geq 25 \%$ of that in the sample. The recovery values were within the client acceptance criterion of $70 \%$ to $130 \%$ for all AOIs meeting the above requirements.

\section{Post Spike/Analytical Spike Sample (B Component):}

An analytical spike (B component) was conducted for the fusion process. Recovery values are listed for all analytes in the spike that were measured at or above the EQL, and that had a spike concentration $\geq 25 \%$ of that in the sample. The recovery values were within the client acceptance criterion of $70 \%$ to $130 \%$ for all AOIs meeting the above requirements.

\section{Serial dilution:}

Five-fold serial dilution was conducted for the fusion process. Percent differences (\%Ds) are listed for all analytes that had a concentration at or above the EQL in the diluted sample. The $\%$ Ds were within the acceptance criterion of $\leq 10 \%$ for all AOIs meeting the above requirement.

\section{Other QC:}

All other instrument-related QC tests for the AOIs passed within the appropriate acceptance criteria.

\section{Comments:}

1) The "Final Results" have been corrected for all laboratory dilutions performed on the samples during processing and analysis, unless specifically noted.

2) Instrument detection limits (IDL) and estimated quantitation limits (EQL) shown are for acidified water. Detection limits for other matrices may be determined if requested. Method detection limits (MDL) can be estimated by multiplying the IDL by the "Multiplier". The estimated quantitation limit (EQL) for each concentration value can be obtained by multiplying the EQL by the "Multiplier".

3) Routine precision and bias is typically $\pm 15 \%$ or better for samples in dilute, acidified water (e.g. $2 \% \mathrm{v} / \mathrm{v}$ $\mathrm{HNO}_{3}$ or less) at analyte concentrations $>$ EQL up to the upper calibration level. This also presumes that the total dissolved solids concentration in the sample is less than $5000 \mu \mathrm{g} / \mathrm{mL}(0.5$ per cent by weight). Note that bracketed values listed in the data report are within the MDL and the EQL, and have potential uncertainties greater than $15 \%$. Concentration values < MDL are listed as "..". Note, that calibration and QC standards are validated to a precision of $\pm 10 \%$.

4) Absolute precision, bias and detection limits may be determined on each sample if required by the client. The maximum number of significant figures for all ICP measurements is two.

5) Analytes included in the spike A component (for the AS/PS) are; $\mathrm{Ag}, \mathrm{Al}, \mathrm{As}, \mathrm{B}, \mathrm{Ba}, \mathrm{Be}, \mathrm{Bi}, \mathrm{Ca}, \mathrm{Cd}, \mathrm{Co}, \mathrm{Cr}$, $\mathrm{Cu}, \mathrm{Fe}, \mathrm{K}, \mathrm{Li}, \mathrm{Mg}, \mathrm{Mn}, \mathrm{Mo}, \mathrm{Na}, \mathrm{Ni}, \mathrm{P}, \mathrm{Pb}, \mathrm{S}, \mathrm{Sb}, \mathrm{Se}, \mathrm{Si}, \mathrm{Sn}, \mathrm{Sr}, \mathrm{Ta}, \mathrm{Ti}, \mathrm{Tl}, \mathrm{V}, \mathrm{W}, \mathrm{Y}, \mathrm{Zn}$, and Zr. Analytes included in the spike $\mathrm{B}$ component are; Ce, $\mathrm{Dy}, \mathrm{Eu}, \mathrm{La}, \mathrm{Nd}, \mathrm{Pd}, \mathrm{Rh}, \mathrm{Ru}, \mathrm{Te}, \mathrm{Th}$, and $\mathrm{U}$. 


\begin{tabular}{|c|c|c|c|c|c|c|c|c|}
\hline & Run Date > & 9/24/2007 & 9/24/2007 & 9/24/2007 & 9/24/2007 & 9/24/2007 & 9/24/2007 \\
\hline & & Multiplier > & 3023.0 & 3168.6 & 2890.2 & 3082.6 & 3335.6 & 3225.8 \\
\hline & & & 07-01783-115 & 07-01783-115 & 07-01783-115 & 07-01784-115- & $07-01785-115$ & 07-01786-115- \\
\hline & & RPLLAB > & B @5 & S @5 & D@5 & S@5 & S@5 & S @5 \\
\hline $\begin{array}{l}\text { Instr. Det. } \\
\text { Limit (IDL) }\end{array}$ & $\begin{array}{l}\text { Est. Quant. } \\
\text { Limit (EQL) }\end{array}$ & Client ID > & 07-01783-PB & \multicolumn{2}{|c|}{$\underline{T 1540-\mathrm{G} 5-7}$} & T1540-G5-8 & T54005-17 & T540-G5-12 \\
\hline$(\mu \mathrm{g} / \mathrm{mL})$ & $(\mu \mathrm{g} / \mathrm{mL})$ & (Analyte) & $(\mu \mathrm{g} / \mathrm{g})$ & $(\mu \mathrm{g} / \mathrm{g})$ & $(\mu \mathrm{g} / \mathrm{g})$ & $(\mu \mathrm{g} / \mathrm{g})$ & $(\mu \mathrm{g} / \mathrm{g})$ & $(\mu \mathrm{g} / \mathrm{g})$ \\
\hline 0.0459 & 0.459 & Al & 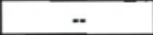 & 183,000 & 187,000 & 181,000 & 112,000 & 96,400 \\
\hline 0.0273 & 0.273 & B & .. & [110] & [120] & [92] & - & 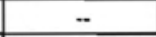 \\
\hline 0.0461 & 0.461 & $\mathrm{Bi}$ & - &. & -. & .- & - & .. \\
\hline 0.0024 & 0.024 & $\mathrm{Cd}$ &. & .- &.. & -. & .. & - \\
\hline 0.0049 & 0.049 & $\mathrm{Cr}$ & [26] & 3,620 & 3,700 & 3,760 & 4,840 & 2,740 \\
\hline 0.0247 & 0.247 & $\mathrm{Fe}$ & {$[260]$} & 6,370 & 5,980 & 5,870 & 18,000 & 7,510 \\
\hline 10.7000 & 107.000 & $\mathrm{~K}$ & na & na & na & na & na & na \\
\hline 0.0077 & 0.077 & $\mathrm{Mn}$ & [160] & 2,640 & 2,570 & 2,550 & 6,990 & 3,120 \\
\hline 3.8000 & 38.000 & $\mathrm{Na}$ & - & 162,000 & 166,000 & 170,000 & 244,000 & 286,000 \\
\hline 0.0144 & 0.144 & $\mathrm{Ni}$ & na & na & na & na & na & na \\
\hline 0.2239 & 2.239 & $\mathbf{s}$ &. & [730] &. & [700] &.. & - \\
\hline 0.1299 & 1.299 & $\mathrm{Si}$ & - & 5,410 & 5,320 & 5,020 & 13,600 & 6,170 \\
\hline 0.0032 & 0.032 & $\mathrm{Sr}$ &. & 673 & 687 & 670 & 2,020 & 813 \\
\hline 0.3893 & 3.893 & u & . & {$[8,600]$} & {$[8,900]$} & {$[8,700]$} & 28,000 & {$[11,000]$} \\
\hline 0.0156 & 0.156 & $\mathrm{Zn}$ & .. & - & -. & $\ddot{-}$ & - & - \\
\hline 0.0182 & 0.182 & $\mathrm{Zr}$ &.. & - &.- & .. & [170] & -- \\
\hline
\end{tabular}

Other Analytes

\begin{tabular}{|c|c|c|c|c|c|c|c|c|}
\hline 0.0052 & 0.052 & $\mathrm{Ag}$ & .. & 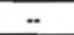 &.. & .. & - &.- \\
\hline 0.0835 & 0.835 & As &.- &. &.. & .. &. &.- \\
\hline 0.0124 & 0.124 & $\mathrm{Ba}$ & - & {$[110]$} & {$[56]$} & {$[51]$} & [150] & [59] \\
\hline 0.0003 & 0.003 & $\mathrm{Be}$ &.- & 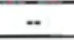 & -- & -- & - & - \\
\hline 0.9500 & 9.500 & $\mathrm{Ca}$ & - & 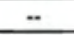 & - & - & - & - \\
\hline 0.0625 & 0.625 & $\mathrm{Ce}$ & 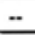 &. &. &. & - & - \\
\hline 0.0064 & 0.064 & Co & - & - & 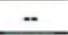 & .. & $\ddot{-}$ & 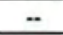 \\
\hline 0.0087 & 0.087 & $\mathrm{Cu}$ &.- & {$[29]$} & {$[27]$} &. & {$[59]$} & [45] \\
\hline 0.0160 & 0.160 & Dy & 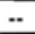 &.. & .- & 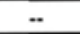 & - & - \\
\hline 0.0051 & 0.051 & Eu &. & 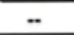 & 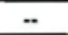 & .. & - &.- \\
\hline 0.0033 & 0.033 & La &.. & [11] &. &.. & {$[27]$} & 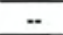 \\
\hline 0.0099 & 0.099 & $\mathrm{Li}$ & .. &.. & .. &.. &.- & .. \\
\hline 0.0479 & 0.479 & $\mathrm{Mg}$ &.- & 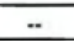 & [150] &.. & [380] & [170] \\
\hline 0.0092 & 0.092 & Mo & -. &.. & .. & -. & [35] &.- \\
\hline 0.0963 & 0.963 & $\mathrm{Nd}$ &. & .. & .. & .. & .. & .. \\
\hline 0.0486 & 0.486 & $\mathrm{P}$ &.- & [790] & [750] & {$[800]$} & [330] & [210] \\
\hline 0.0279 & 0.279 & $\mathrm{~Pb}$ & 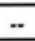 &.. & 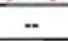 & 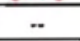 & .. &.- \\
\hline 0.0568 & 0.568 & $\mathrm{Pd}$ & 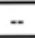 & -- & - &.. & .. &.. \\
\hline 0.0372 & 0.372 & Rh & 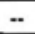 & -. & .- &.- &.. & 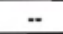 \\
\hline 0.0160 & 0.160 & $\mathrm{Ru}$ & 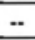 & -- &.- &.- & - & - \\
\hline 0.0529 & 0.529 & $\mathrm{Sb}$ & .. &.. &.- &.- & -- & - \\
\hline 0.0902 & 0.902 & Se &.. &.- &.- &.- &.. &.. \\
\hline 0.0844 & 0.844 & Sn &.. & 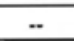 &.- &.- & -- & - \\
\hline 0.0182 & 0.182 & $\mathrm{Ta}$ & 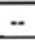 & 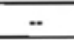 &.- &.. &.- & - \\
\hline 0.0716 & 0.716 & $\mathrm{Te}$ &.. & 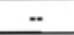 &. & - & $\because$ & - \\
\hline 0.0558 & 0.558 & Th & - & 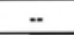 &.. &.. & .. &.. \\
\hline 0.0084 & 0.084 & $\mathrm{Ti}$ & - & 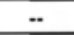 &.. &.. & [43] &. \\
\hline 0.0649 & 0.649 & $\mathrm{TI}$ & - & - &. &.. & - & -- \\
\hline 0.0042 & 0.042 & v & 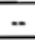 &.- & 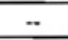 &.. &.- & - \\
\hline 0.0284 & 0.284 & $w$ & - &.. & - &.. & 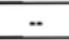 & 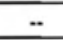 \\
\hline 0.0061 & 0.061 & $Y$ & - &.. &.. &.- & - & - \\
\hline
\end{tabular}

1) "-." indicates the value is $<$ MDL. The method detection limit (MDL) $=I D L$ times the "multiplier" near the top of each column. The estimated sample quantitation limit $=E Q L$ (in Column 2)

times the "multiplier". Overall error for values $\geq E Q L$ is estimated to be within $\pm 15 \%$.

2) Values in brackets [ ] are $\geq$ MOL but < EQL, with errors likely to exceed $15 \%$.

$n a=$ not applicable; $\mathrm{KOH}$ flux and $\mathrm{Ni}$ crucible or $\mathrm{Na}_{2} \mathrm{O}_{2}$ flux and $\mathrm{Zr}$ crucible used for preparing samples. 
QC Performance 9/24/2007

\begin{tabular}{|c|c|c|c|c|c|c|}
\hline Criteria > & $\leq 25 \%$ & $80 \%-120 \%$ & $70 \%-130 \%$ & $70 \%-130 \%$ & $70 \%-130 \%$ & $\leq 10 \%$ \\
\hline$Q C I D>$ & $\begin{array}{c}\text { 07-01783 } \\
\text { Dup }\end{array}$ & LCS/BS & MS (none) & $\begin{array}{c}07-01783+ \\
\text { AS-A }\end{array}$ & $\begin{array}{c}07-01783+ \\
\text { AS-B }\end{array}$ & $\begin{array}{c}07-01783 \\
5 \text {-fold } \\
\text { Serial Dil }\end{array}$ \\
\hline Analytes & RPD (\%) & $\%$ Rec & \%Rec & \%Rec & $\% \operatorname{Rec}$ & $\%$ Diff \\
\hline Al & 2.2 & 93 & & 97 & & 1.8 \\
\hline B & & & & 102 & & \\
\hline $\mathrm{Bi}$ & & & & 94 & & \\
\hline$\overline{C d}$ & & & & 96 & & \\
\hline $\mathrm{Cr}$ & 2.1 & & & 94 & & 2.0 \\
\hline $\mathrm{Fe}$ & 6.4 & 90 & & 95 & & 3.5 \\
\hline$K$ & na & na & na & na & na & na \\
\hline $\mathrm{Mn}$ & 2.7 & 96 & & 98 & & 8.7 \\
\hline $\mathrm{Na}$ & 1.9 & & & 96 & & \\
\hline $\mathbf{N i}$ & na & na & na & na & na & na \\
\hline $\mathbf{s}$ & & & & 97 & & \\
\hline Si & 1.8 & 82 & & 100 & & \\
\hline $5 r$ & 2.0 & 89 & & 96 & & 1.5 \\
\hline $\mathbf{U}$ & & & & & 93 & \\
\hline $\mathrm{Zn}$ & & 87 & & 92 & & \\
\hline $\mathbf{Z r}$ & & & & 97 & & \\
\hline
\end{tabular}

Other Analytes

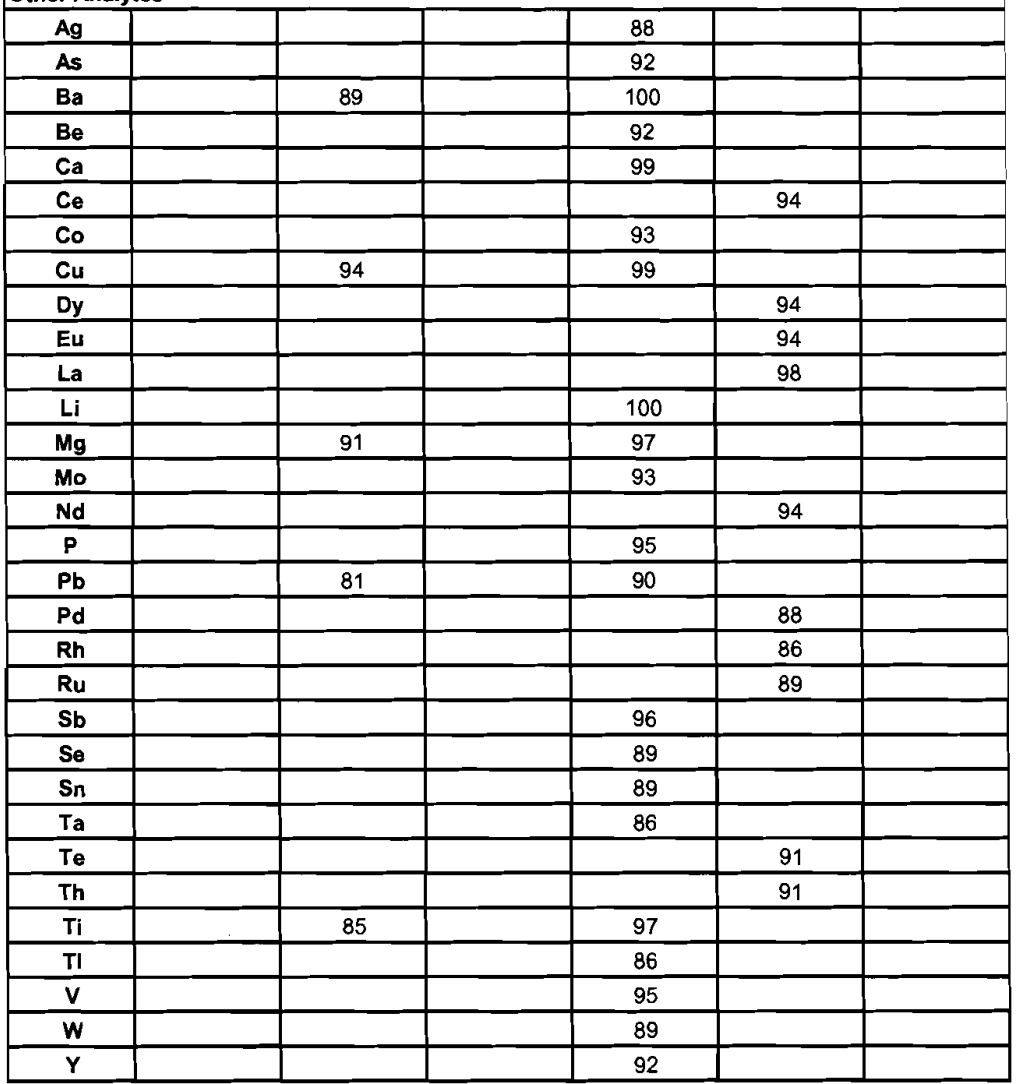

Shaded results are outside the acceptance criteria.

$n r=$ not recovered; spike concentration less than $25 \%$ of sample concentration.

na = not applicable; $\mathrm{KOH}$ flux and Ni crucible or $\mathrm{Na}_{2} \mathrm{O}_{2}$ flux and $\mathrm{Zr}$ crucible used for preparing samples. 
Battelle PNNL/RS\&E/Inorganic Analysis ... ICPOES Analysis Report PO Box 999, Richland, Washington 99352

$\begin{array}{ll}\text { Project / WP\#: } & 52964 \text { / F99189 } \\ \text { ASR\#: } & 7998 \\ \text { Client: } & \text { M. Edwards } \\ \text { Total Samples: } & 10 \text { (liquid) }\end{array}$

\begin{tabular}{|l|c|c|}
\hline \multicolumn{3}{|c|}{ First } \\
\hline RPL\#: & $07-01773$ & Last \\
\hline Client ID: & TI540-G5-C & TI540-G5-O \\
\hline Sample Preparation: RPG-CMC-128, "HNO & -HCl Acid Extraction of \\
Liquids for Metals Analysis Using a Dry-Block Heater", 9/21/07 (SRPL/ld). \\
\hline
\end{tabular}

Procedure: $\quad$ RPG-CMC-211, "Determination of Elemental Composition by Inductively Coupled Argon Plasma Optical Emission Spectrometry (ICPOES)", Rev 1.

Analyst: $\quad \underline{\text { J. K. Deschane \& B. M. Oliver }}$

Analysis Date (File): $\quad$ 9-28-2007 (C0064)

See Chemical Measurement Center 98620 file: $\quad$ ICP-325-405-3

(Calibration and Maintenance Records)

M\&TE Number: $\quad \underline{\text { N827583 }}$ (ICPOES instrument) $\underline{\text { M19445 }}$ (Mettler AT400 Balance)

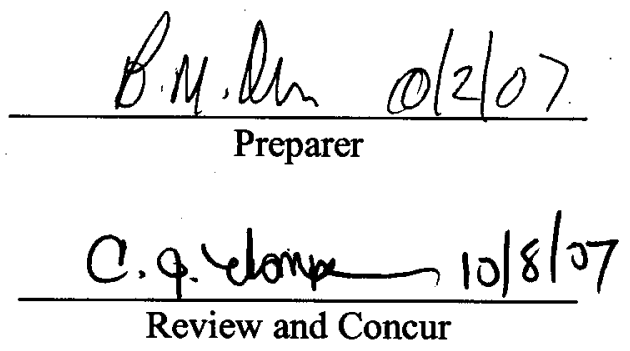




\section{Battelle PNNL/RS\&E/Inorganic Analysis ... ICPOES Analysis Report}

Ten samples submitted under Analytical Service Request (ASR) 7998 were analyzed by ICPOES. The samples were prepared following RPL procedure RPG-CMC-128 using $1 \mathrm{~mL}$ of sample and diluting to a final volume of $25 \mathrm{~mL}$.

Analytes of interest (AOIs) were specified in the ASR, and are listed in the upper section of the attached ICPOES Data Report. The quality control (QC) results for these AOIs have been evaluated and are presented below. Analytes other than AOIs are reported in the bottom section of the report, but have not been fully evaluated for QC performance. The results are given as $\mu \mathrm{g} / \mathrm{mL}$ for each detected analyte, and have been adjusted for all laboratory processing factors and instrument dilutions.

Calibration of the ICPOES was done following the manufacturer's recommended calibration procedure and using multi-analyte custom standard solutions traceable to the National Institute of Standards and Technology (NIST). Midrange calibration verification standards (MCVA and MCVB) were used to verify acceptance of the two-point calibration curves obtained for each analyte, and also used for continuing calibration verification.

Minimum Method Detection Limit (MDL) values were specified in the ASR. Except for potassium in several of the samples, MDL levels were met for all AOIs. As mitigation, however, the measured potassium levels in these samples exceeded the requested MDL.

The controlling documents are ASO-QAP-001, and the client supplied RPP-WTP-QA-005, Rev. 2 and "ASR 7998 Special Instructions". Instrument calibrations, QC checks and blanks (e.g., ICV/ICB, CCV/CCB, LLS, ICS), postspike, blank spike, matrix spike, duplicate, and serial dilution were conducted during the analysis run. The blank spike and matrix spike were prepared using $1.5 \mathrm{~mL}$ each of BPNL-QC-1 A, $-2 \mathrm{~A}$, and -3 solutions.

\section{Preparation Blank (PB):}

A preparation blank (reagents only) was prepared for the extraction process. Except for $\mathrm{Si}$ $(5.43 \mu \mathrm{g} / \mathrm{mL})$ and $\mathrm{Sr}(0.130 \mathrm{ug} / \mathrm{mL})$, the concentrations of all AOIs were within the acceptance criteria of $\leq \mathrm{EQL}$ (estimated quantitation level) or less than $\leq 5 \%$ of the concentration in the sample. The $\mathrm{Si}$ and $\mathrm{Sr}$ are presumed to be from impurity issues in the water used during sample preparation. Silicon and strontium were also detected in a separate preparation blank for ASR-7985 which was prepared in the SRPL on the same day.

\section{Blank Spike (BS)/Laboratory Control Sample (LCS):}

A blank spike was prepared for the extraction process. Recovery values are listed for all analytes included in the spike that were measured at or above the EQL. Except for bismuth, the recovery values were within the acceptance criterion of $80 \%$ to $120 \%$ for all AOIs meeting the above requirement. Bismuth was under-recovered in both the blank spike and matrix spike (see below). Direct analysis of the spike solution indicated a loss of bismuth of about $25 \%$, contributing partly to the observed under-recovery. The additional under-recovery is attributed to potential sample preparation issues (e.g., precipitation). As mitigation, however, bismuth was not detected above EQL in the client samples. 


\section{Battelle PNNL/RS\&E/Inorganic Analysis ... ICPOES Analysis Report}

Matrix-Spiked Sample:

A matrix spike was prepared for the extraction process. Recovery values are listed for all analytes included in the spike that were measured at or above the EQL. Except for bismuth as noted above, the recovery values were within the acceptance criterion of $75 \%$ to $125 \%$ for all AOIs meeting the above requirement. As discussed above, the under-recovery for bismuth is presumed to be from loss of bismuth in the BPNL spike solution and other potential sample preparation issues.

\section{Duplicate Relative Percent Difference (RPD):}

A duplicate was prepared for the extraction process. RPDs are listed for all analytes that were measured at or above the EQL. The RPDs were within the acceptance criterion of $\leq 20 \%$ for all AOIs meeting the above requirement.

\section{Post-Spike/Analytical Spike Sample (Spike A Elements):}

For purposes of QC evaluation of the extraction process, a post spike (A component) was conducted on Sample 07-01714 (ASR-7985). Recovery values are listed for all analytes in the spike that were measured at or above the EQL, and that had a spike concentration $\geq 25 \%$ of that in the sample. The recovery values were within the acceptance criterion of $75 \%$ to $125 \%$ for all AOIs meeting the above requirements.

\section{Post Spike/Analytical Spike Sample (B Component):}

For purposes of $\mathrm{QC}$ evaluation of the extraction process, a post spike (B component) was conducted on Sample 07-01714 (ASR-7985). Recovery values are listed for all analytes in the spike that were measured at or above the EQL, and that had a spike concentration $\geq 25 \%$ of that in the sample. The recovery values were within the acceptance criterion of $75 \%$ to $125 \%$ for all AOIs meeting the above requirements.

\section{Serial dilution:}

For purposes of QC evaluation of the extraction process, five-fold serial dilution was conducted on Sample 07-01714 (ASR-7985). Percent differences (\%Ds) are listed for all analytes that had a concentration at or above the EQL in the diluted sample. The \%Ds were within the acceptance criterion of $\leq 10 \%$ for all AOIs meeting the above requirement.

\section{Other QC:}

All other instrument-related QC tests for the AOIs passed within the appropriate acceptance criteria.

\section{Comments:}

1) The "Final Results" have been corrected for all laboratory dilutions performed on the samples during processing and analysis, unless specifically noted.

2) Instrument detection limits (IDL) and estimated quantitation limits (EQL) shown are for acidified water. Detection limits for other matrices may be determined if requested. Method detection limits (MDL) can be estimated by multiplying the IDL by the "Multiplier". The estimated quantitation limit (EQL) for each concentration value can be obtained by multiplying the EQL by the "Multiplier". 


\section{Battelle PNNL/RS\&E/Inorganic Analysis ... ICPOES Analysis Report}

3) Routine precision and bias is typically $\pm 15 \%$ or better for samples in dilute, acidified water (e.g. $2 \%$ v/v $\mathrm{HNO}_{3}$ or less) at analyte concentrations $>$ EQL up to the upper calibration level. This also presumes that the total dissolved solids concentration in the sample is less than $5000 \mu \mathrm{g} / \mathrm{mL}(0.5$ per cent by weight). Note that bracketed values listed in the data report are within the MDL and the EQL, and have potential uncertainties greater than $15 \%$. Concentration values $<$ MDL are listed as "-.". Note, that calibration and QC standards are validated to a precision of $\pm 10 \%$.

4) Absolute precision, bias and detection limits may be determined on each sample if required by the client. The maximum number of significant figures for all ICP measurements is two.

5) Analytes included in the spike A component (for the AS/PS) are; $\mathrm{Ag}, \mathrm{Al}, \mathrm{As}, \mathrm{B}, \mathrm{Ba}, \mathrm{Be}, \mathrm{Bi}, \mathrm{Ca}, \mathrm{Cd}, \mathrm{Co}, \mathrm{Cr}$, $\mathrm{Cu}, \mathrm{Fe}, \mathrm{K}, \mathrm{Li}, \mathrm{Mg}, \mathrm{Mn}, \mathrm{Mo}, \mathrm{Na}, \mathrm{Ni}, \mathrm{P}, \mathrm{Pb}, \mathrm{S}, \mathrm{Sb}, \mathrm{Se}, \mathrm{Si}, \mathrm{Sn}, \mathrm{Sr}, \mathrm{Ta}, \mathrm{Ti}, \mathrm{Tl}, \mathrm{V}, \mathrm{W}, \mathrm{Y}, \mathrm{Zn}$, and Zr. Analytes included in the spike $\mathrm{B}$ component are; $\mathrm{Ce}, \mathrm{Dy}, \mathrm{Eu}, \mathrm{La}, \mathrm{Nd}, \mathrm{Pd}, \mathrm{Rh}, \mathrm{Ru}, \mathrm{Te}, \mathrm{Th}$, and $\mathrm{U}$. 


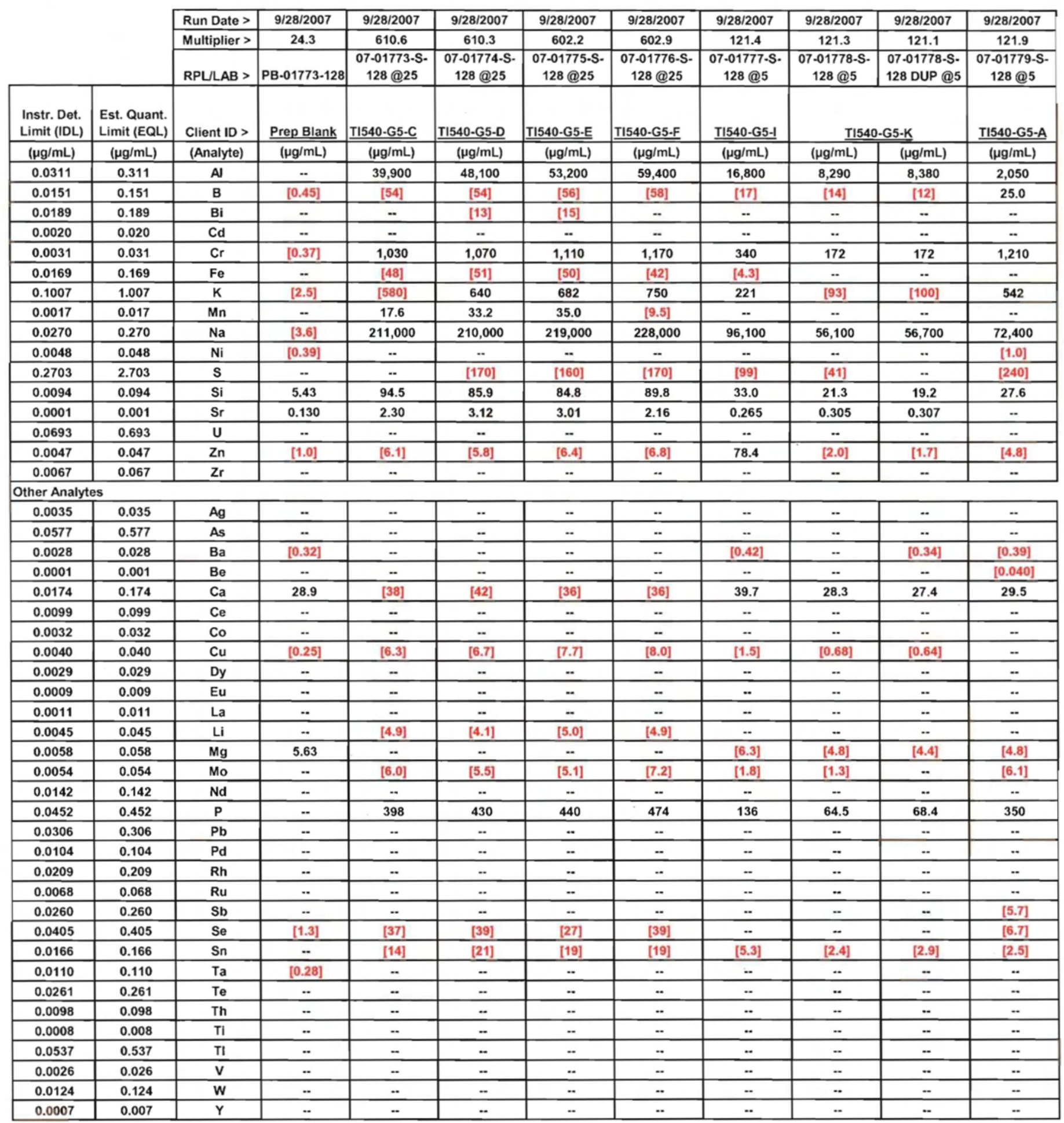

1) "-." indicates the value is $<M D L$. The method detection limit $(M D L)=I D L$ times the "multiplier" near the top of each column. The estimated sample quantitation limit $=E Q L$ (in Column 2) times the "multiplier". Overall error for values $2 E Q L$ is estimated to be within $\pm 15 \%$. 2) Values in brackets [ ] are $\geq M D L$ but $<E Q L$, with errors likely to exceed $15 \%$. 


\begin{tabular}{|c|c|c|c|c|}
\hline Run Date > & $9 / 28 / 2007$ & $9 / 28 / 2007$ & $9 / 28 / 2007$ & $9 / 28 / 2007$ \\
\hline Multiplier > & 122.2 & 611.1 & 121.4 & 122.1 \\
\hline RPL/LAB > & $\begin{array}{c}\text { 07-01780-S- } \\
128 \text { @5 } \\
\end{array}$ & $\begin{array}{c}\text { 07-01780-S- } \\
128 \text { @25 } \\
\end{array}$ & $\begin{array}{c}\text { 07-01781-S- } \\
128 \text { @5 }\end{array}$ & $\begin{array}{c}07-01782-S- \\
128 @ 5 \\
\end{array}$ \\
\hline Client ID > & \multicolumn{2}{|c|}{ TI540-G5-G } & TI540-G5-M & TI540-G5.O \\
\hline (Analyte) & $(\mu \mathrm{g} / \mathrm{mL})$ & $(\mu \mathrm{g} / \mathrm{mL})$ & $(\mu \mathrm{g} / \mathrm{mL})$ & $(\mu \mathrm{g} / \mathrm{mL})$ \\
\hline Al & 33,900 & & 4,230 & 9,840 \\
\hline B & 31.3 & & [6.3] & [11] \\
\hline $\mathrm{Bi}$ & [3.5] & & .. & - \\
\hline Cd & - & & 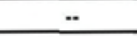 & - \\
\hline $\mathrm{Cr}$ & 663 & & 93.5 & 202 \\
\hline $\mathrm{Fe}$ & [7.4] & & $\ddot{*}$ & $\ldots$ \\
\hline $\mathrm{K}$ & 410 & & [100] & 154 \\
\hline $\mathrm{Mn}$ & [0.39] & & - & 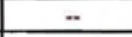 \\
\hline $\mathrm{Na}$ & over-range & 152,000 & 33,000 & 61,100 \\
\hline $\mathrm{Ni}$ & $\cdots$ & & $\cdots$ & $-\cdot$ \\
\hline $\mathrm{s}$ & [130] & & $\ddot{*}$ & [38] \\
\hline $\mathrm{Si}$ & 60.3 & & 12.5 & 20.2 \\
\hline $\mathrm{Sr}$ & {$[0.097]$} & & 0.326 & 0.289 \\
\hline$U$ & - & & .. & .. \\
\hline $\mathrm{Zn}$ & 8.49 & & [1.5] & [1.7] \\
\hline $\mathrm{Zr}$ & - & & $*$ & - \\
\hline
\end{tabular}

\begin{tabular}{|c|c|c|c|}
\hline $\mathrm{Ag}$ & - & - &.. \\
\hline As & - & 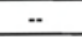 & - \\
\hline $\mathrm{Ba}$ & .. & $*$ & {$[0.47]$} \\
\hline $\mathrm{Be}$ & .. & - & .. \\
\hline $\mathrm{Ca}$ & 27.7 & 29.2 & 27.2 \\
\hline $\mathrm{Ce}$ & $*$ & $*$ & 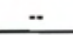 \\
\hline Co &. & - & 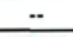 \\
\hline $\mathrm{Cu}$ & [3.0] & $=$ & {$[0.86]$} \\
\hline Dy & .. & - & 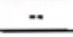 \\
\hline $\mathrm{Eu}$ & $\cdots$ & $\cdots$ & 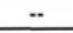 \\
\hline La & 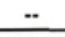 &. & - \\
\hline $\mathrm{Li}$ & .. & {$[0.87]$} &. \\
\hline $\mathrm{Mg}$ & [4.5] & [4.8] & {$[4.5]$} \\
\hline Mo & [3.7] & - & {$[0.82]$} \\
\hline $\mathrm{Nd}$ & - & - & - \\
\hline $\mathrm{P}$ & 273 & [37] & 79.5 \\
\hline $\mathrm{Pb}$ & [4.8] & - &.. \\
\hline Pd & - & $=$ & - \\
\hline Rh & - & .. & - \\
\hline $\mathbf{R u}$ & - & - & - \\
\hline $\mathrm{Sb}$ & - & $*$ & - \\
\hline Se & [5.6] & {$[5.6]$} & {$[6.2]$} \\
\hline Sn & [12] & - & {$[2.8]$} \\
\hline $\mathrm{Ta}$ &. & - &. \\
\hline $\mathrm{Te}$ &. & - & 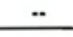 \\
\hline Th & - & - & $\cdots$ \\
\hline $\mathrm{Ti}$ &. &.- & .. \\
\hline $\mathrm{TI}$ & 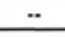 & - & .. \\
\hline v &. & $\cdots$ & 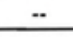 \\
\hline w & 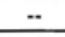 & 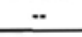 & $\cdots$ \\
\hline$Y$ & .. & .. & - \\
\hline
\end{tabular}


QC Performance 9/28/2007

\begin{tabular}{|c|c|c|c|c|c|c|}
\hline Criteria > & $\leq 25 \%$ & $80 \%-120 \%$ & $75 \%-125 \%$ & $75 \%-125 \%$ & $75 \%-125 \%$ & $\leq 10 \%$ \\
\hline$Q C I D>$ & $\begin{array}{c}\text { 07-01778 } \\
\text { Dup }\end{array}$ & BS-1773 & $\begin{array}{c}07-01778 \\
\text { MS }\end{array}$ & $\begin{array}{c}07-01714+ \\
\text { PS-A }\end{array}$ & $\begin{array}{c}07-01714+ \\
\text { PS-B }\end{array}$ & $\begin{array}{c}07-01714 \\
5 \text {-fold } \\
\text { Serial Dil }\end{array}$ \\
\hline Analytes & RPD (\%) & \%Rec & $\%$ Rec & $\%$ Rec & $\%$ Rec & $\%$ Diff \\
\hline Al & 1.1 & 96 & 94 & 97 & & \\
\hline B & & 100 & 103 & 107 & & \\
\hline $\mathrm{Bi}$ & & 41 & 45 & 91 & & \\
\hline $\mathrm{Cd}$ & & 97 & 97 & 100 & & \\
\hline $\mathrm{Cr}$ & 0.1 & 92 & 92 & 95 & & 6.6 \\
\hline $\mathrm{Fe}$ & & 97 & 99 & 99 & & \\
\hline $\mathbf{K}$ & & 95 & 99 & 100 & & \\
\hline $\mathrm{Mn}$ & & 96 & 98 & 99 & & \\
\hline $\mathrm{Na}$ & 1.0 & 97 & $\mathrm{nr}$ & $\mathrm{nr}$ & & 4.9 \\
\hline $\mathrm{NI}$ & & 95 & 96 & 95 & & \\
\hline $\mathbf{S}$ & & & & 102 & & 4.7 \\
\hline $\mathrm{Si}$ & 10.2 & 93 & 99 & 98 & & \\
\hline $\mathrm{Sr}$ & 0.6 & 93 & 94 & 96 & & \\
\hline U & & 92 & 91 & & 93 & \\
\hline $\mathrm{Zn}$ & & 95 & 100 & 95 & & \\
\hline $\mathrm{Zr}$ & & 116 & 115 & 98 & & \\
\hline
\end{tabular}

Other Analytes

\begin{tabular}{|c|c|c|c|c|c|c|}
\hline $\mathrm{Ag}$ & & 99 & 100 & 92 & & \\
\hline As & & & & 94 & & \\
\hline $\mathrm{Ba}$ & & 96 & 97 & 98 & & \\
\hline $\mathrm{Be}$ & & 93 & 94 & 94 & & \\
\hline $\mathrm{Ca}$ & 3.3 & 96 & 97 & 99 & & \\
\hline $\mathrm{Ce}$ & & 94 & 96 & & 100 & \\
\hline Co & & & & 94 & & \\
\hline $\mathrm{Cu}$ & & 99 & 102 & 99 & & \\
\hline Dy & & & & & 94 & \\
\hline Eu & & & & & 93 & \\
\hline La & & 96 & 96 & & 99 & \\
\hline Li & & 99 & 99 & 100 & & \\
\hline $\mathrm{Mg}$ & & 96 & 98 & 99 & & \\
\hline Mo & & 94 & 96 & 95 & & \\
\hline Nd & & 91 & 91 & & 94 & \\
\hline $\mathbf{P}$ & 5.9 & 93 & 94 & 112 & & 4.2 \\
\hline $\mathrm{Pb}$ & & 94 & 94 & 93 & & \\
\hline $\mathrm{Pd}$ & & & & & 93 & \\
\hline Rh & & & & & 87 & \\
\hline$R u$ & & & & & 93 & \\
\hline Sb & & & & 96 & & \\
\hline $\mathrm{Se}$ & & & & 92 & & \\
\hline Sn & & & & 91 & & \\
\hline $\mathrm{Ta}$ & & & & 89 & & \\
\hline $\mathrm{Te}$ & & & & & 93 & \\
\hline Th & & 91 & 92 & & 93 & \\
\hline $\mathrm{Ti}$ & & 97 & 97 & 99 & & \\
\hline TI & & & & 88 & & \\
\hline $\mathrm{V}$ & & 103 & 104 & 93 & & \\
\hline w & & 87 & 76 & 89 & & \\
\hline$Y$ & & & & 95 & & \\
\hline
\end{tabular}

Shaded results are outside the acceptance criteria.

$n r=$ not recovered; spike concentration less than $25 \%$ of sample concentration. 
Battelle PNNL/RS\&E/Inorganic Analysis ... ICPOES Analysis Report

PO Box 999, Richland, Washington 99352

$\begin{array}{ll}\text { Project / WP\#: } & \text { 52964 / F99189 } \\ \text { ASR\#: } & 7998 \\ \text { Client: } & \text { M. Edwards } \\ \text { Total Samples: } & \text { 3 (solid) }\end{array}$

\begin{tabular}{|c|c|c|}
\hline & First & Last \\
\hline RPL\#: & $07-01783$ & $07-01785$ \\
\hline Client ID: & TI540-G5-7 & TI540-G5-17 \\
\hline
\end{tabular}

Procedure: $\quad$ RPG-CMC-211, "Determination of Elemental Composition by Inductively Coupled Argon Plasma Optical Emission Spectrometry (ICPOES)", Rev 1.

Analyst: $\quad$ J. K. Deschane

Analysis Date (File): $\quad \underline{10-2-2007}$ (C0065)

See Chemical Measurement Center 98620 file: $\quad \underline{\text { ICP-325-405-3 }}$

(Calibration and Maintenance Records)

M\&TE Number: $\quad$ N827583 (ICPOES instrument) $\underline{\text { M19445 }}$ (Mettler AT400 Balance)

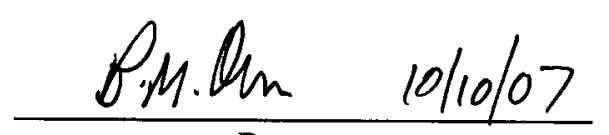

Preparer

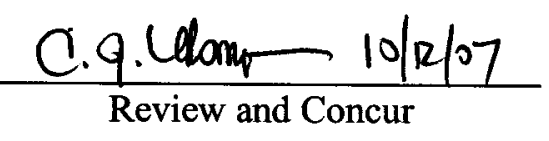


Three samples submitted under Analytical Service Request (ASR) 7998 were analyzed by ICPOES. The samples were prepared following RPL digestion procedure RPG-CMC-138 using a nominal 0.2 grams of sample and diluting to a final volume of approximately $50 \mathrm{~mL}$. Because of uncertainties in the dry mass measurements taken during preparation, wt.\% solids values from the $\mathrm{KOH}$ fusion preparation (reported separately) were applied to the wet mass data in order to determine final dry mass values for the samples. As a result, the reported data are indicated as estimated ("J").

Analytes of interest (AOIs) were specified in the ASR, and are listed in the upper section of the attached ICPOES Data Report. The quality control (QC) results for these AOIs have been evaluated and are presented below. Analytes other than AOIs are reported in the bottom section of the report, but have not been fully evaluated for QC performance. The results are given as $\mu \mathrm{g} / \mathrm{g}$ for each detected analyte, and have been adjusted for all laboratory processing factors and instrument dilutions.

Calibration of the ICPOES was done following the manufacturer's recommended calibration procedure and using multi-analyte custom standard solutions traceable to the National Institute of Standards and Technology (NIST). Midrange calibration verification standards (MCVA and MCVB) were used to verify acceptance of the two-point calibration curves obtained for each analyte, and also used for continuing calibration verification.

Minimum Method Detection Limit (MDL) values were specified in the ASR. MDL levels were met for all AOIs.

The controlling documents are ASO-QAP-001, and the client supplied RPP-WTP-QA-005, Rev. 2 and "ASR 7998 Special Instructions". Instrument calibrations, QC checks and blanks (e.g., ICV/ICB, CCV/CCB, LLS, ICS), post-spike, laboratory control standard (LCS), duplicate, and serial dilution were conducted during the analysis run. The LCS was prepared using a nominal 0.2 grams of SRM-2710 (Montana Soil).

Preparation Blank (PB):

A preparation blank (reagents only) was prepared for the digestion process. The concentrations of all AOIs were within the acceptance criteria of $\leq \mathrm{EQL}$ (estimated quantitation level) or less than $\leq 5 \%$ of the concentration in the sample.

Blank Spike (BS)/Laboratory Control Sample (LCS):

An LCS (Montana Soil) was prepared for the digestion process. Recovery values are listed for all analytes included in the spike that were measured at or above the EQL. The recovery values were within the acceptance criterion of $80 \%$ to $120 \%$ for all AOIs meeting the above requirement.

Matrix-Spiked Sample:

No matrix spike sample was provided for analysis. 


\section{Battelle PNNL/RS\&E/Inorganic Analysis ... ICPOES Analysis Report}

Duplicate Relative Percent Difference (RPD):

A duplicate was prepared for the digestion process. RPDs are listed for all analytes that were measured at or above the EQL. The RPDs were within the client acceptance criterion of $\leq 25 \%$ for all AOIs meeting the above requirement.

\section{Post-Spike/Analytical Spike Sample (Spike A Elements):}

An analytical spike (A component) was conducted for the digestion process. Recovery values are listed for all analytes in the spike that were measured at or above the EQL, and that had a spike concentration $\geq 25 \%$ of that in the sample. The recovery values were within the client acceptance criterion of $70 \%$ to $130 \%$ for all AOIs meeting the above requirements.

\section{Post Spike/Analytical Spike Sample (B Component):}

An analytical spike (B component) was conducted for the digestion process. Recovery values are listed for all analytes in the spike that were measured at or above the EQL, and that had a spike concentration $\geq 25 \%$ of that in the sample. The recovery values were within the client acceptance criterion of $70 \%$ to $130 \%$ for all AOIs meeting the above requirements.

\section{Serial dilution:}

Five-fold serial dilution was conducted on Sample 07-01716 for the digestion process. Percent differences (\%Ds) are listed for all analytes that had a concentration at or above the EQL in the diluted sample. Except for zinc (34\%), the \%Ds were within the acceptance criterion of $\leq 10 \%$ for all AOIs meeting the above requirement. The reason for this high $\% \mathrm{D}$ is not completely understood; however, examination of the available data would suggest that the $5 \mathrm{x}$ diluted sample is perhaps biased high. It should be noted that zinc was detected above the EQL in only one of the samples (07-01785) at a level of $56 \mu \mathrm{g} / \mathrm{g}$, which was close to the EQL for that particular analysis of $\sim 54 \mu \mathrm{g} / \mathrm{g}$.

\section{Other QC:}

All other instrument-related QC tests for the AOIs passed within the appropriate acceptance criteria.

\section{Comments:}

1) The "Final Results" have been corrected for all laboratory dilutions performed on the samples during processing and analysis, unless specifically noted.

2) Instrument detection limits (IDL) and estimated quantitation limits (EQL) shown are for acidified water. Detection limits for other matrices may be determined if requested. Method detection limits (MDL) can be estimated by multiplying the IDL by the "Multiplier". The estimated quantitation limit (EQL) for each concentration value can be obtained by multiplying the EQL by the "Multiplier".

3) Routine precision and bias is typically $\pm 15 \%$ or better for samples in dilute, acidified water (e.g. $2 \% \mathrm{v} / \mathrm{v}$ $\mathrm{HNO}_{3}$ or less) at analyte concentrations > EQL up to the upper calibration level. This also presumes that the total dissolved solids concentration in the sample is less than $5000 \mu \mathrm{g} / \mathrm{mL}(0.5$ per cent by weight). Note that bracketed values listed in the data report are within the MDL and the EQL, and have potential uncertainties greater than $15 \%$. Concentration values $<$ MDL are listed as ".-.". Note, that calibration and QC standards are validated to a precision of $\pm 10 \%$. 


\section{Battelle PNNL/RS\&E/Inorganic Analysis ... ICPOES Analysis Report}

4) Absolute precision, bias and detection limits may be determined on each sample if required by the client. The maximum number of significant figures for all ICP measurements is two.

5) Analytes included in the spike A component (for the AS/PS) are; $\mathrm{Ag}, \mathrm{Al}, \mathrm{As}, \mathrm{B}, \mathrm{Ba}, \mathrm{Be}, \mathrm{Bi}, \mathrm{Ca}, \mathrm{Cd}, \mathrm{Co}, \mathrm{Cr}$, $\mathrm{Cu}, \mathrm{Fe}, \mathrm{K}, \mathrm{Li}, \mathrm{Mg}, \mathrm{Mn}, \mathrm{Mo}, \mathrm{Na}, \mathrm{Ni}, \mathrm{P}, \mathrm{Pb}, \mathrm{S}, \mathrm{Sb}, \mathrm{Se}, \mathrm{Si}, \mathrm{Sn}, \mathrm{Sr}, \mathrm{Ta}, \mathrm{Ti}, \mathrm{Tl}, \mathrm{V}, \mathrm{W}, \mathrm{Y}, \mathrm{Zn}$, and Zr. Analytes included in the spike B component are; Ce, $\mathrm{Dy}, \mathrm{Eu}, \mathrm{La}, \mathrm{Nd}, \mathrm{Pd}, \mathrm{Rh}, \mathrm{Ru}, \mathrm{Te}, \mathrm{Th}$, and $\mathrm{U}$. 


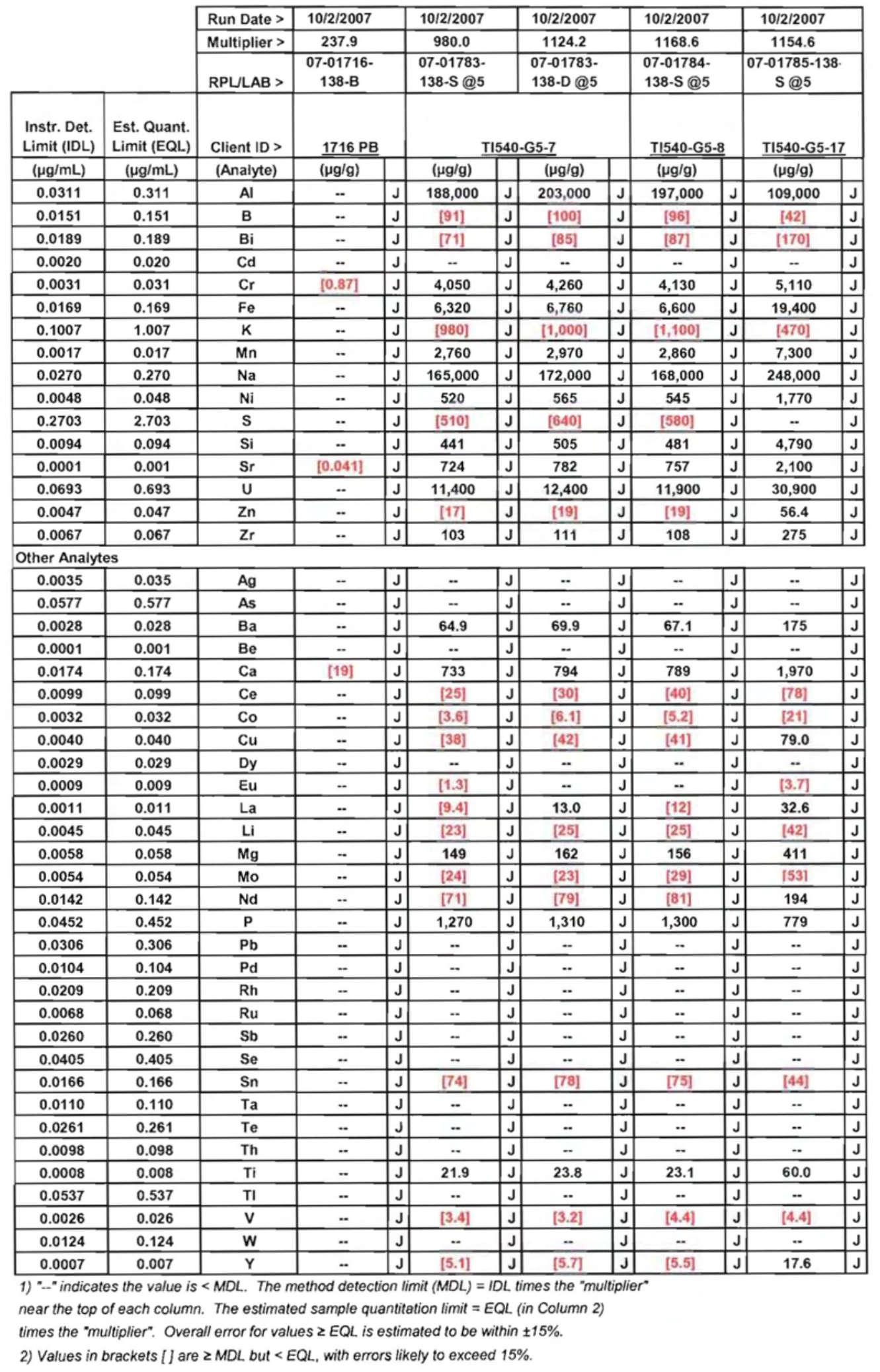




\begin{tabular}{|c|c|c|c|c|c|c|}
\hline Criteria > & $\leq 25 \%$ & $80 \%-120 \%$ & $70 \%-130 \%$ & $70 \%-130 \%$ & $70 \%-130 \%$ & $\leq 10 \%$ \\
\hline QC ID > & $\begin{array}{c}\text { 07-01783 } \\
\text { Dup }\end{array}$ & $\begin{array}{l}\text { 07-01716 } \\
\text { LCS/BS }\end{array}$ & MS (none) & $\begin{array}{c}07-01716+ \\
\text { AS-A }\end{array}$ & $\begin{array}{c}07-01716+ \\
\text { AS-B }\end{array}$ & $\begin{array}{c}07-01716 \\
5 \text {-fold } \\
\text { Serial Dil }\end{array}$ \\
\hline Analytes & RPD (\%) & $\%$ Rec & $\% \operatorname{Rec}$ & $\% \operatorname{Rec}$ & $\%$ Rec & $\%$ Diff \\
\hline Al & 7.5 & 99 & & 98 & & 0.5 \\
\hline $\mathrm{B}$ & & & & 109 & & \\
\hline $\mathrm{Bi}$ & & & & 92 & & 0.7 \\
\hline $\mathrm{Cd}$ & & & & 104 & & \\
\hline $\mathrm{Cr}$ & 5.1 & & & 95 & & 0.5 \\
\hline $\mathrm{Fe}$ & 6.9 & 99 & & 109 & & 0.9 \\
\hline $\mathrm{K}$ & & & & 100 & & \\
\hline $\mathrm{Mn}$ & 7.1 & 102 & & 103 & & 1.0 \\
\hline $\mathrm{Na}$ & 4.2 & 97 & & 101 & & 0.2 \\
\hline $\mathrm{Ni}$ & 8.3 & & & 105 & & 3.2 \\
\hline $\mathrm{S}$ & & & & 104 & & \\
\hline $\mathrm{Si}$ & 13.4 & & & 99 & & 0.0 \\
\hline $\mathrm{Sr}$ & 7.6 & 98 & & 103 & & 0.3 \\
\hline $\mathrm{U}$ & 8.4 & & & & 95 & 7.8 \\
\hline $\mathrm{Zn}$ & & 94 & & 98 & & 33.6 \\
\hline $\mathrm{Zr}$ & 7.6 & & & 102 & & \\
\hline \multicolumn{7}{|c|}{ Other Analytes } \\
\hline $\mathrm{Ag}$ & & & & 73 & & \\
\hline As & & & & 101 & & \\
\hline $\mathrm{Ba}$ & 7.5 & 99 & & 102 & & \\
\hline $\mathrm{Be}$ & & & & 99 & & \\
\hline $\mathrm{Ca}$ & 8.0 & 100 & & 105 & & 1.8 \\
\hline $\mathrm{Ce}$ & & & & & 107 & \\
\hline Co & & & & 103 & & \\
\hline $\mathrm{Cu}$ & & 97 & & 101 & & \\
\hline Dy & & & & & 101 & \\
\hline Eu & & & & & 100 & \\
\hline La & & 81 & & & 112 & \\
\hline $\mathrm{Li}$ & & & & 103 & & \\
\hline $\mathrm{Mg}$ & 8.5 & 98 & & 102 & & 7.0 \\
\hline Mo & & & & 102 & & \\
\hline $\mathrm{Nd}$ & & & & & 101 & \\
\hline $\mathbf{P}$ & 3.6 & & & $\mathrm{nr}$ & & 4.2 \\
\hline $\mathrm{Pb}$ & & 93 & & 101 & & \\
\hline $\mathrm{Pd}$ & & & & & 96 & \\
\hline $\mathrm{Rh}$ & & & & & 100 & \\
\hline $\mathrm{Ru}$ & & & & & 103 & \\
\hline $\mathrm{Sb}$ & & & & 104 & & \\
\hline Se & & & & 104 & & \\
\hline Sn & & & & 101 & & \\
\hline $\mathrm{Ta}$ & & & & 98 & & \\
\hline $\mathrm{Te}$ & & & & & 97 & \\
\hline Th & & & & & 99 & \\
\hline $\mathrm{Ti}$ & 8.3 & 94 & & 103 & & 6.1 \\
\hline $\mathrm{TI}$ & & & & 98 & & \\
\hline V & & 85 & & 98 & & \\
\hline$w$ & & & & 100 & & \\
\hline$Y$ & & 77 & & 97 & & \\
\hline
\end{tabular}

Shaded results are outside the acceptance criteria.

$n r=$ not recovered; spike concentration less than $25 \%$ of sample concentration. 


\section{Battelle - Pacific Northwest National Laboratory Analytical Support Operations - IC Report PO Box 999, Richland, Washington 99352}

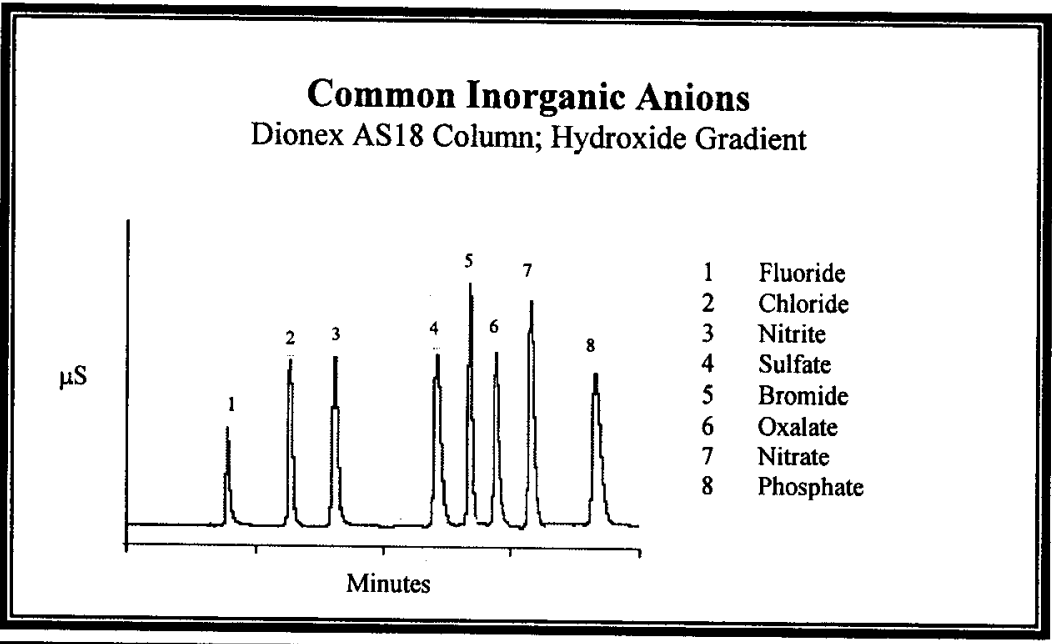

$\begin{array}{llll}\text { Client: } & \text { M. Edwards } & \text { ASR \#: } & 7998 \\ \text { Project \#: } & \text { \# Samples: } & \text { 4 Liquids/ 1 Solid } \\ \text { Charge Code: } & \text { F99189 } & \end{array}$

\section{*** RPL Numbers (Liquids): 07-01779 through 07-01782 *** *** RPL Number (Solid): 07-01785***}

Procedure, Analysis, System, and Records Information

\begin{tabular}{|l|l|}
\hline Analysis Procedure & PNL-ALO-212, "Determination of Inorganic Anions by Ion Chromatography" \\
\hline Prep Procedure & $\begin{array}{l}\text { Water leach performed in SAL Hot Cells (DRK 09/25/07) } \\
\text { Bench dilutions performed in lab 400 (MJS 09/23/2007,09/26/07, 10/10/07) }\end{array}$ \\
\hline Analyst & MJ Steele \\
\hline Analysis Dates & $09 / 25 / 07,09 / 26 / 07,10 / 10 / 07$ \\
\hline Calibration Date & $09 / 24 / 07$ \\
\hline Cal/Ver Stds Prep Date & Cal 9/21/07; Ver 09/21/07, 10/10/07 \\
\hline Excel Data File & 7998 Results Edwards.xls \\
\hline \multirow{2}{*}{ \&\&TE Numbers } & IC System (M\&TE) N830443 N830444 \\
\cline { 2 - 2 } & Balances: 360-06-01-031/1113052270 \\
\hline All Analysis Records & Chemical Measurement Center 98620: RIDS IC System File (IC-0142) \\
\hline
\end{tabular}

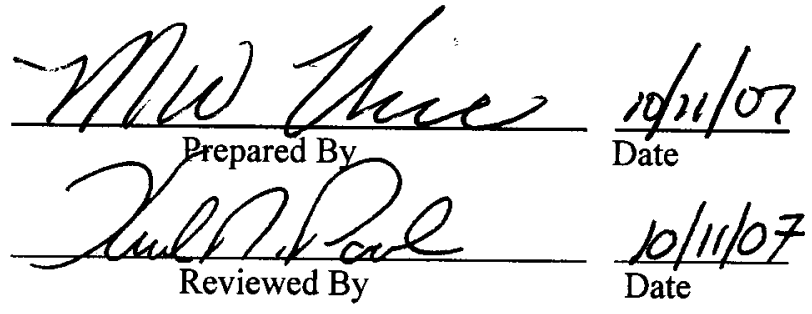




\section{IC Report}

\section{Liquid Sample Results}

See Table 1 for Liquid Sample Results.

\section{Sample Analysis/Results Discussion}

Four liquid samples were submitted to the ASO for analysis. The samples were prepared for analysis using dilutions at the bench, which included the preparation of analytical spikes and a sample replicate. The dilutions were prepared in deionized water and the water was analyzed as the process dilution sample. All sample results are reported as $\mu \mathrm{g} / \mathrm{mL}$.

After screening the samples, the final analysis was performed using a range of additional dilution factors from $\sim 20$ to $\sim 10,000 \mathrm{x}$ in order to obtain valid anion results within the calibration range. All results have been adjusted for all analytical dilutions. The prep dilution blank (water used to dilute samples at the IC workstation) is reported as analyzed, no dilution factors were applied to this sample. The estimated method detection limits (MDL) are provided, and are based on the estimated quantitation limit (EQL), which is one-tenth of the lowest calibration standard (adjusted for the dilutions used for reporting the results).

\section{Quality Control Discussion}

The method performance is evaluated against the acceptance criteria established by Analytical Support Operations QA Plan ASO-QAP-001 and the client specified special instructions, RPP-WTP-QA-005 Rev. 2, which has the same specification as the QA Plan.

Processing Blanks: (Dilution) A process dilution blank (deionized water) was analyzed with the sample set. There were no anions detected above the MDL. Thus, the processing blank met the acceptance criteria for all analytes of interest.

Duplicate (Precision): One duplicate dilution was prepared and analyzed. The relative percent difference (RPD) ranged from $0 \%$ to $1 \%$ for all analytes of interest except for the J-flagged fluoride results. The measured RPD was within acceptance criterion of $<20 \%$.

Processing Laboratory Control/Blank Spike (Lab LCS - Accuracy): Two routine instrument blank spikes were analyzed with the run and had recoveries ranging from $98 \%$ to $104 \%$ for the analytes of interest. These recoveries meet the acceptance criteria of $80 \%$ to $120 \%$ recovery.

Matrix Spike (Accuracy): None prepared. Liquid samples did not undergo sample preparation; therefore, an analytical spike was prepared and analyzed.

Analytical Spike (Accuracy): Analytical spikes, standard added during dilution, were prepared for sample 07-01780 and analyzed. Analytical spikes for samples diluted 4000x or greater show excellent recoveries ranging from $97 \%$ to $105 \%$. Analytical spikes diluted less than $4000 \mathrm{x}$ appear to show matrix effect from high sample contribution or are over-range. Analytical spikes for samples diluted $4000 \mathrm{x}$ or greater meet the spike recovery acceptance criteria of $75 \%$ to $125 \%$. 


\section{IC Report}

\section{Solid Sample Results}

See Table 2 for Solid Sample Results.

\section{Sample Analysis/Results Discussion}

One solid sample was submitted to the ASO for analysis. The samples were prepared for analysis by leaching in water at about 10 parts water to 1 part sample, using procedure RPG-CMS-103. Along with the sample, a duplicate, matrix spike, laboratory control sample (blank spike) and process blank were prepared in like manner to the sample. For analysis, further dilutions were prepared in deionized water (the same water used for diluting the liquid samples). The sample results are reported as $\mu \mathrm{g} / \mathrm{g}$.

After screening the sample, the final analysis was performed using a range of additional dilution factor from $\sim 5$ to $\sim 125 \mathrm{x}$ in order to obtain valid anion results within the calibration range. All results have been adjusted for all analytical and processing dilutions. The preparation blank (from leach processing) has been adjusted using the sample leaching factor and reported as $\mu \mathrm{g} / \mathrm{g}$. The MDLs are provided, and are based on the EQL, which is one-tenth of the lowest calibration standard (adjusted for the dilutions used for reporting the results).

\section{Quality Control Discussion}

The method performance is evaluated against the acceptance criteria established by Analytical Support Operations QA Plan ASO-QAP-001 and the client specified special instructions, RPP-WTP-QA-005 Rev. 2, which has the same specification as the QA Plan.

Water Leach Processing Blanks: A process blank (deionized water) was prepared and analyzed. There were no anions detected above the MDL. Thus, the processing blank met the acceptance criteria for all analytes of interest.

Water Leach Duplicate (Precision): A duplicate was prepared and analyzed. The relative percent difference (RPD) ranged from 0 to $2 \%$ for all analytes of interest except for the J-flagged fluoride results. The measured RPD was within acceptance criterion of $<20 \%$.

Laboratory Control Sample/Blank Spike (LCS/BS): An LCS/BS was processed with the sample batch and analyzed at two dilutions. The LCS/BS demonstrated recoveries ranging of $101 \%$ to $106 \%$ for the analytes of interest. These recoveries meet the acceptance criteria of $80 \%$ to $120 \%$ recovery.

Matrix Spike (Accuracy): A matrix spike was processed with the sample batch and analyzed two dilutions. Except for sulfate and phosphate, the matrix spikes were either not recovered or demonstrated erratic recoveries. Fluoride at low dilutions $(5 \mathrm{x})$ and oxalate at higher dilution $(25 \mathrm{x})$ do not meet the acceptance criteria of $70 \%$ to $130 \%$ recovery, and nitrate and nitrite could not be recovered due to high sample concentrations. Fluoride recovery appears to be matrix related, whereas the oxalate recovery appears to be concentration related (near eluting nitrate is orders of magnitude higher in concentration; impacting separation and baseline fitting). 


\section{IC Report}

Post Spike (Accuracy): Post spikes, standard added during dilution, were prepared from the leached solid sample and analyzed. For results not over range, post spike recoveries ranged from $86 \%$ to $105 \%$; meeting the spike recovery acceptance criteria of $75 \%$ to $125 \%$.

\section{Liquid and Solid Sample Results}

\section{Deviations from Procedure}

None

\section{Additional Quality Control Discussion}

IC System QC Samples: Numerous calibration verification standards and calibration verification blanks were analyzed with each run day. For all data reported, the IC System QC bounding the sample analyses produced results for all analytes were within the acceptance criterion of the ASO's QA Plan (i.e., $90 \%$ to $110 \%$ recovery for verification standards and verification blank results $\angle \mathrm{EQL}$ or $\angle 5 \%$ of reported sample result).

\section{General Comments}

- The reported "Final Results" have been corrected for all dilutions performed on the sample during processing or analysis.

- The MDL is set at the concentration of the lowest calibrations standard divided by 10 . The EQL is defined as the concentration of the lowest calibration standards times the sample dilution factors (processing and analysis) and assumes non-complex aqueous matrices. Matrix-specific MDLs or EQLs may be determined, if requested.

- Routine precision and bias are typically $\pm 15 \%$ or better for non-complex aqueous samples that are free of interference. 
IC Report

Table 1: Liquid Sample Results ASR 7998

Results

\begin{tabular}{|c|c|c|c|c|c|c|c|c|c|c|}
\hline RPL Number & Client Sample ID & $\begin{array}{c}F \\
M D L \\
\mu \mathrm{g} / \mathrm{mL}\end{array}$ & $\begin{array}{c}\mathrm{F} \\
\text { Result } \\
\mu \mathrm{g} / \mathrm{mL}\end{array}$ & DF & $\begin{array}{r}\mathrm{NO}_{2} \\
\mathrm{MDL} \\
\mu \mathrm{g} / \mathrm{mL}\end{array}$ & $\begin{array}{c}\mathrm{NO}_{2} \\
\text { Result } \\
\mu \mathrm{g} / \mathrm{mL}\end{array}$ & DF & $\begin{array}{r}\mathrm{SO}_{4} \\
\mathrm{MDL} \\
\mu \mathrm{g} / \mathrm{mL}\end{array}$ & $\begin{array}{c}\mathrm{SO}_{4} \\
\text { Result } \\
\mu \mathrm{g} / \mathrm{mL}\end{array}$ & DF \\
\hline 07-01779 & TI540-G5-A Dewater Filtrate & 3.1 & 23.0 & $\mathrm{~J}$ & 250 & 26,500 & & 7.5 & 696 & \\
\hline $07-01780$ & TI450-G5-G Caustic Leach Perm. & 3.1 & 3.1 & $\mathrm{U}$ & 50 & 13,800 & & 7.5 & 334 & \\
\hline $07-01781$ & TI450-G5-M Caustic Wash 3 Perm. & 0.31 & $0.3 \mathrm{I}$ & $\mathrm{U}$ & 5.0 & 1,720 & & 0.75 & 39.4 & \\
\hline $07-01782$ & TI450-G5-O Comb. Caustic Wash & 0.31 & 0.31 & $\underline{U}$ & 50 & 3,960 & & 0.75 & 15.7 & \\
\hline DB ASR 7998 & Dilution Blank 9-23-07 & 0.016 & 0.016 & $\mathrm{U}$ & 0.025 & 0.025 & $\mathrm{U}$ & 0.037 & 0.037 & $\mathrm{U}$ \\
\hline RPL Number & Client Sample ID & $\begin{array}{r}\mathrm{C}_{2} \mathrm{O}_{4} \\
\mathrm{MDL} \\
\mu \mathrm{g} / \mathrm{mL}\end{array}$ & $\begin{array}{l}\mathrm{C}_{2} \mathrm{O}_{4} \\
\text { Result } \\
\mu \mathrm{g} / \mathrm{mL}\end{array}$ & DF & $\begin{array}{r}\mathrm{NO}_{3} \\
\mathrm{MDL} \\
\mu \mathrm{g} / \mathrm{mL}\end{array}$ & $\begin{array}{c}\mathrm{NO}_{3} \\
\text { Result } \\
\mu \mathrm{g} / \mathrm{mL}\end{array}$ & DF & $\begin{array}{r}\mathrm{PO}_{4} \\
\mathrm{MDL} \\
\mu \mathrm{g} / \mathrm{mL}\end{array}$ & $\begin{array}{c}\mathrm{PO}_{4} \\
\text { Result } \\
\mu \mathrm{g} / \mathrm{mL}\end{array}$ & DF \\
\hline $07-01779$ & TI540-G5-A Dewater Filtrate & 5.0 & 1,120 & & 500 & 95,000 & & 6.0 & 1,160 & \\
\hline $07-01780$ & TI450-G5-G Caustic Leach Perm. & 5.0 & 133 & & 500 & 49,800 & & 6.0 & 812 & \\
\hline 07-01781 & TI450-G5-M Caustic Wash 3 Perm. & 0.50 & 116 & & 100 & 6,290 & & 0.60 & 95.4 & \\
\hline 07-01782 & TI450-G5-O Comb. Caustic Wash & 0.50 & 38.1 & & 100 & 14,100 & & 0.60 & 101 & \\
\hline DB ASR 7998 & Dilution Blank 9-23-07 & 0.025 & 0.025 & $\mathrm{U}$ & 0.050 & 0.050 & $\mathrm{U}$ & 0.030 & 0.030 & $\mathrm{U}$ \\
\hline
\end{tabular}

\section{QC Sample Results (precision)}

\begin{tabular}{|c|c|c|c|c|c|c|c|}
\hline RPL Number & Sample ID & $\begin{array}{c}\mathrm{F} \\
\mu \mathrm{g} / \mathrm{mL}\end{array}$ & RPD & $\begin{array}{c}\mathrm{NO}_{2} \\
\mu \mathrm{g} / \mathrm{mL}\end{array}$ & RPD & $\begin{array}{c}\mathrm{SO}_{4} \\
\mu \mathrm{g} / \mathrm{mL}\end{array}$ & RPD \\
\hline 07-01779 & Sample & $\mathrm{J}$ & \multirow{2}{*}{ (a) } & 26,500 & \multirow{2}{*}{0} & 696 & \multirow{2}{*}{ I } \\
\hline 07-01779DUP & Duplicate & $\mathrm{J}$ & & 26,500 & & 703 & \\
\hline RPL Number & Sample ID & $\begin{array}{r}\mathrm{C}_{2} \mathrm{O}_{4} \\
\mu \mathrm{g} / \mathrm{mL}\end{array}$ & RPD & $\begin{array}{c}\mathrm{NO}_{3} \\
\mu \mathrm{g} / \mathrm{mL}\end{array}$ & RPD & $\begin{array}{c}\mathrm{PO}_{4} \\
\mu \mathrm{g} / \mathrm{mL}\end{array}$ & RPD \\
\hline 07-01779 & Sample & 1,120 & \multirow{2}{*}{0} & 95,000 & \multirow{2}{*}{0} & 1,160 & \multirow{2}{*}{0} \\
\hline 07-01779DUP & Duplicate & 1,120 & & 94,700 & & 1,160 & \\
\hline
\end{tabular}

\section{QC Sample results (accuracy); At IC Workstation}

\begin{tabular}{|l|l|c|c|c|c|c|c|}
\hline \multirow{2}{*}{ RPL Number } & \multicolumn{5}{|c|}{$\%$ Recovery } \\
\cline { 2 - 8 } & Sample ID & $\mathbf{F}$ & $\mathbf{N O}_{2}$ & $\mathbf{S O}_{4}$ & $\mathbf{C}_{2} \mathbf{O}_{4}$ & $\mathbf{N O}_{3}$ & $\mathbf{P O}_{4}$ \\
\hline $07-01780(20,000 x)$ & Analytical Spike & 102 & 104 & 101 & 104 & 101 & 104 \\
\hline $07-01780(4,000 x)$ & Analytical Spike & 100 & 105 & 100 & 97 & 101 & 100 \\
\hline $07-01780(400 x)$ & Analytical Spike & 48 & $(b)$ & 101 & 86 & $($ b) & 95 \\
\hline LCS 092407 & Lab LCS 9/25/2007 12:03:53 AM & 101 & 103 & 101 & 100 & 98.5 & 99.8 \\
\hline LCS 092507 & Lab LCS 9/25/2007 10:19:07 PM & 101 & 104 & 102 & 104 & 101 & 100 \\
\hline
\end{tabular}

(a) \%RPD is not calculated for results which are below the EQL (i.e., J-flagged)

(b) \%Rec not reported; AS over-range

DF $=$ Data Quality Flag

RPD $=$ Relative Percent Difference

$\mathrm{U}=$ Not Detected Above Method Detection Limit

$\mathrm{J}=$ Detected, Result are Qualitative: Result $>\mathrm{MDL}$ but $<\mathrm{EQL}$ 


\section{IC Report}

\section{Table 2: Solid Sample -- ASR 7998}

Results

\begin{tabular}{|c|c|c|c|c|c|c|c|c|c|c|}
\hline RPL Number & Client Sample ID & $\begin{array}{c}\text { F } \\
\text { MDL } \\
\mu \mathrm{g} / \mathrm{g}\end{array}$ & $\begin{array}{c}\text { F } \\
\text { Result } \\
\mu \mathrm{g} / \mathrm{g}\end{array}$ & DF & $\begin{array}{c}\mathrm{NO}_{2} \\
\mathrm{MDL} \\
\mu \mathrm{g} / \mathrm{g}\end{array}$ & $\begin{array}{c}\mathrm{NO}_{2} \\
\text { Result } \\
\mu \mathrm{g} / \mathrm{g}\end{array}$ & DF & $\begin{array}{c}\mathrm{SO}_{4} \\
\mathrm{MDL} \\
\mu \mathrm{g} / \mathrm{g}\end{array}$ & $\begin{array}{c}\mathrm{SO}_{4} \\
\text { Result } \\
\mu \mathrm{g} / \mathrm{g}\end{array}$ & DF \\
\hline $07-01785$ & TI450-G5-17 - water leach & 0.80 & 0.80 & $\mathrm{U}$ & 32 & 4,200 & & 1.9 & 112 & \\
\hline $07-01785 \mathrm{~PB}$ & SAL Prep Blank & 0.16 & 0.16 & $\mathrm{U}$ & 0.26 & 0.26 & $\mathrm{U}$ & 0.38 & 0.38 & $\mathrm{U}$ \\
\hline RPL Number & Client Sample ID & $\begin{array}{c}\mathrm{C} 2 \mathrm{O4} \\
\mathrm{MDL} \\
\mu \mathrm{g} / \mathrm{g}\end{array}$ & $\begin{array}{c}\mathrm{C} 2 \mathrm{O} 4 \\
\text { Result } \\
\mu \mathrm{g} / \mathrm{g}\end{array}$ & DF & $\begin{array}{c}\mathrm{NO} 3 \\
\mathrm{MDL} \\
\mu \mathrm{g} / \mathrm{g}\end{array}$ & $\begin{array}{c}\mathrm{NO} 3 \\
\text { Result } \\
\mu \mathrm{g} / \mathrm{g}\end{array}$ & DF & $\begin{array}{l}\mathrm{PO4} \\
\mathrm{MDL} \\
\mu \mathrm{g} / \mathrm{g}\end{array}$ & $\begin{array}{c}\text { PO4 } \\
\text { Result } \\
\mu \mathrm{g} / \mathrm{g}\end{array}$ & DF \\
\hline $07-01785$ & TI450-G5-17 - water leach & 1.3 & 243 & & 64 & 15,300 & & 1.5 & 216 & \\
\hline 07-01785PB & SAL Prep Blank & 0.26 & 0.26 & $\mathrm{U}$ & 0.51 & 0.51 & $\mathrm{U}$ & 0.31 & 0.31 & $\mathrm{U}$ \\
\hline
\end{tabular}

QC Sample Results (precision); Preparative

Batch

\begin{tabular}{|c|c|c|c|c|c|c|c|}
\hline RPL Number & Sample ID & $\begin{array}{c}\mathbf{F} \\
\mu \mathrm{g} / \mathrm{g}\end{array}$ & RPD & $\begin{array}{l}\mathrm{NO}_{2} \\
\mu \mathrm{g} / \mathrm{g}\end{array}$ & RPD & $\begin{array}{r}\mathrm{SO}_{4} \\
\mu \mathrm{g} / \mathrm{g}\end{array}$ & RPD \\
\hline $07-01785$ & Sample & $\mathrm{U}$ & \multirow{2}{*}{ (a) } & 4,210 & \multirow{2}{*}{1} & 112 & \multirow{2}{*}{1} \\
\hline 07-01785DUP & Duplicate & $\mathrm{U}$ & & 4,270 & & 113 & \\
\hline RPL Number & Sample ID & $\begin{array}{l}\mathrm{C}_{2} \mathrm{O}_{4} \\
\mu \mathrm{g} / \mathrm{g}\end{array}$ & RPD & $\begin{array}{l}\mathrm{NO}_{3} \\
\mu \mathrm{g} / \mathrm{g}\end{array}$ & RPD & $\begin{array}{r}\mathrm{PO}_{4} \\
\mu \mathrm{g} / \mathrm{g}\end{array}$ & RPD \\
\hline $07-01785$ & Sample & 243 & \multirow{2}{*}{2} & 15,300 & \multirow{2}{*}{0} & 216 & \multirow{2}{*}{1} \\
\hline 07-01785DUP & Duplicate & 239 & & 15,400 & & 214 & \\
\hline
\end{tabular}

QC Sample Results (accuracy); Preparative Batch

\begin{tabular}{|l|l|c|c|c|c|c|c|}
\hline \multirow{2}{*}{ RPL Number } & \multirow{5}{*}{ Q } & \multicolumn{5}{|c|}{$\%$ Recovery } \\
\cline { 3 - 8 } & Sample ID & $\mathbf{F}$ & $\mathbf{N O}_{2}$ & $\mathbf{S O}_{4}$ & $\mathbf{C}_{2} \mathbf{O}_{4}$ & $\mathbf{N O}_{3}$ & $\mathbf{P O}_{4}$ \\
\hline $07-01785 B S(5 x)$ & LCS/BS & 104 & 106 & 103 & 103 & 105 & 101 \\
\hline $07-01785$ MS (5x) & Matrix Spiked Sample & 63 & (b) & 95 & 85 & (b) & 89 \\
\hline $07-01785 \mathrm{MS}(25 \mathrm{x})$ & Matrix Spiked Sample & 99 & (b) & 95 & 142 & (b) & 94 \\
\hline
\end{tabular}

QC Sample results (accuracy); At IC Workstation

\begin{tabular}{|l|l|c|c|c|c|c|c|}
\hline \multirow{2}{*}{ RPL Number } & \multicolumn{9}{|c|}{$\%$ Recovery } \\
\cline { 3 - 9 } & Sample ID & $\mathbf{F}$ & $\mathbf{N O}_{2}$ & $\mathbf{S O}_{4}$ & $\mathbf{C}_{2} \mathbf{O}_{4}$ & $\mathbf{N O}_{3}$ & $\mathbf{P O}_{4}$ \\
\hline $07-01785(10 x)$ & Post Spiked Sample & 86 & $(b)$ & 99 & 101 & (b) & 99 \\
\hline $07-01785(50 x)$ & Post Spiked Sample & 102 & 86 & 101 & 105 & (b) & 101 \\
\hline $07-01785(250 x)$ & Post Spiked Sample (on DUP) & 104 & 103 & 102 & 105 & 100 & 100 \\
\hline
\end{tabular}

(a) \%RPD is not calculated for results which are below the EQL (i.e., J-flagged)

(b) $\% \operatorname{Rec}$ not reported; over-range or spike concentration $<20 \%$ of sample concentration

LCS/BS = Laboratory Control Sample: Spike added prior to leaching solids.

$\mathrm{DF}=$ Data Quality Flag

RPD $=$ Relative Percent Difference

$\mathrm{U}=$ Not Detected Above Method Detection Limit

$\mathrm{J}=$ Detected, Result are Qualitative: Result $>$ MDL but $<\mathrm{EQL}$ 
Client:

Subject:

ASR:

Sample ID.
Matt Edwards

Rick Shimskey

Hydroxide Analyses for:
Report Date: 9/19/2007

Analysis Date: $9 / 18 / 2007$

CUF Group 5 Caustic Leach Study

Procedure: RPG-CMC-228-Rev 1

Direct sample aliquots of CUF Group 5 Caustic Leach Study samples (07-01773 thru 07-01782), 10 samples total were analyzed in duplicate for the base constituents content following procedure RPG-CMC228 , and using a Brinkman 636 Auto-Titrator. The titrant used was $0.2176 \mathrm{M} \mathrm{HCl}$ and the base standard, $0.1023 \mathrm{M} \mathrm{NaOH}$ was used for QC verification standards and matrix spike. - See Chemrec_123 pdf imbedded in the result report.

The hydroxide Standard recovery was $95 \%$. The two matrix spike recoveries were $96 \%$ and $97 \%$; all well within the allowed $\pm 20 \%$ recovery range. No hydroxide was detected in the reagent blank. The sample volumes analyzed were supported by weight verification, hence density information in duplicate is available for these samples.

The initial pH is reported on attached Report Summary along with the free hydroxide (1st inflection point) and the total hydroxide (2nd inflection point) molarities. These results showed excellent Relative Percent Deviation (RPD) on all samples, well within $\pm 20 \%$ allowed range .

A third inflection point around $\mathrm{pH} 5-6$ was noted on the curve, but in most cases the actual plotted data did not show any visible slope change. Hence, the third inflection point should be considered informational only and the RPD for these samples only used to judge the possible existence of a base constituent around the $\mathrm{pH}$ range. One exception is sample $07-1779$, where the 3 rd inflection point did show a slope change at $\mathrm{pH}$ of $\sim 4.6-4.8$.

The autotitrator in most cases also indicated erattic behavior at $\mathrm{pH} 4$ and below as evident from the curve data, and likely involved the precipitation formation dissolution as the $0.2 \mathrm{M} \mathrm{HCl}$ was added. Therefore, these points on the curve data were ignored.

The best estimate of the MDL for this method is obtained from the reagent blank which did not show any inflection points and is consistent with a value of 0 within our measurement sensitivity. All samples molarities were well above the MDL $(0.001 \mathrm{M})$ for this analysis. The results are accepted based on the QC data meeting the acceptance criteria as specified in the ASR.

Following is the report summary, the sample results calculated from the raw data, and the record file for the standardized acid and base used. The sample aliquots were mostly consumed in the titration process and any remaining fractions will be disposed of upon acceptance of this report.

Copies of the titration curves are available upon request.

Prepared by:

Reviewed by:

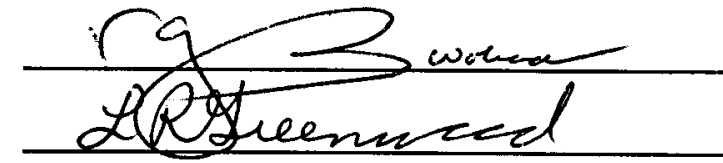

Date:

Date:

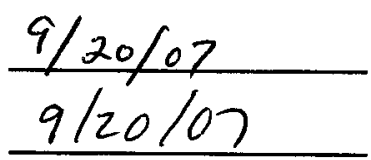


Battelle Pacific Northwest Laboratory

Radiochemical Processing Group-325 Building

Chemical Measurements Center

Hydroxide and Alkalinity Determination

Procedure: RPG-CMC-228-Rev 1

\section{ASR \# 7998}

WP\# F99189

$$
\begin{array}{rl|l|}
\text { Report Summary for ASR \# -- } 7998 & \begin{array}{r}
\text { Report Date: } \\
\text { Revision } \# \text { Rev-0 } \\
\text { Analysis Date: }
\end{array} \text { 9/18/2007 } \\
\hline
\end{array}
$$

Equip \# WB76843

\begin{tabular}{|c|c|c|c|c|c|c|c|c|c|}
\hline \multirow[b]{2}{*}{$\underline{\text { RPG \# }}$} & \multirow[b]{2}{*}{ Client ID } & \multirow[b]{2}{*}{$\begin{array}{c}\text { Initial } \\
\text { pH }\end{array}$} & \multirow[b]{2}{*}{$\begin{array}{c}\text { OH conc } \\
\text { ug } / \mathrm{mL}\end{array}$} & \multirow{2}{*}{$\begin{array}{l}\text { First Point } \\
\text { Molarity }\end{array}$} & \multirow[b]{2}{*}{ RPD } & \multicolumn{2}{|l|}{ Second Point } & \multicolumn{2}{|c|}{ Third Point } \\
\hline & & & & & & Molarity & RPD & Molarity & RPD \\
\hline $07-01773$ & TI540-G5-C & 12.76 & $1.00 \mathrm{E}+05$ & 5.90 & & 2.08 & 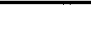 & 0.27 & \\
\hline 07-01773-Dup & TI540-G5-C & 12.79 & $9.68 \mathrm{E}+04$ & 5.70 & $3.5 \%$ & 2.11 & $1.0 \%$ & 0.28 & $3 \%$ \\
\hline $07-01774$ & TI540-G5-D & 12.79 & $9.60 \mathrm{E}+04$ & 5.64 & & 2.49 & & 0.27 & \\
\hline 07-01774-Dup & TI540-G5-D & 12.65 & $9.53 \mathrm{E}+04$ & 5.61 & $0.7 \%$ & 2.39 & $4.0 \%$ & 0.26 & $2 \%$ \\
\hline $07-01775$ & TI540-G5-E & 12.68 & $9.42 \mathrm{E}+04$ & 5.54 & & 2.54 & & 0.25 & \\
\hline 07-01775-Dup & TI540-G5-E & 12.74 & $9.42 \mathrm{E}+04$ & 5.54 & $0.0 \%$ & 2.61 & $3.0 \%$ & 0.28 & $11 \%$ \\
\hline $07-01776$ & TI540-G5-F & 12.59 & $1.01 \mathrm{E}+05$ & 5.94 & & 2.75 & & 0.31 & \\
\hline 07-01776-Dup & TI540-G5-F & 12.77 & $9.92 \mathrm{E}+04$ & 5.84 & $1.8 \%$ & 2.75 & $0.2 \%$ & 0.33 & $5 \%$ \\
\hline $07-01777$ & TI540-G5-I & 12.71 & $4.57 \mathrm{E}+04$ & 2.69 & & 0.91 & & 0.13 & \\
\hline 07-01777-Dup & TI540-G5-I & 12.72 & $4.57 \mathrm{E}+04$ & 2.69 & $0.0 \%$ & 0.90 & $1.1 \%$ & 0.14 & $6 \%$ \\
\hline $07-01778$ & TI540-G5-K & 12.66 & $3.02 \mathrm{E}+04$ & 1.78 & & 0.47 & & 0.03 & \\
\hline 07-01778-Dup & TI540-G5-K & 12.59 & $3.00 \mathrm{E}+04$ & 1.76 & $0.9 \%$ & 0.48 & $2.8 \%$ & 0.04 & $28 \%$ \\
\hline $07-01779$ & TI540-G5-A & 11.74 & $2.66 \mathrm{E}+03$ & 0.16 & & 0.57 & & 0.46 & \\
\hline 07-01779-Dup & TI540-G5-A & 12.06 & $2.63 E+03$ & 0.15 & $1.4 \%$ & 0.55 & $2.6 \%$ & 0.49 & $5 \%$ \\
\hline & & & $\begin{array}{c}\mu \mathrm{g} / \mathrm{ml} \text { or } \\
\mathrm{mg} / \mathrm{L}\end{array}$ & Molarity & & & & & \\
\hline $\begin{array}{l}\mathrm{OH} \text { conc }(\mathrm{mg} / \mathrm{L})=\mathrm{N} \\
\text { free } \mathrm{OH} \text { as spe }\end{array}$ & $(\mathrm{g} / \mathrm{L}) * 17,000$ & & MDL & $\mathrm{MDL}$ & & Required RPD & & & \\
\hline free $\mathrm{OH}$ as spe & cified in ASR & & $1.70 \mathrm{E}+01$ & 0.001 & & $+1-15 \%$ & & & \\
\hline
\end{tabular}

Concentration, moles / Liter

Reag. BIk.1

Standard 1

07-01779MS Matrix spike
12.58

12.53
Allowed Recovery Range

0

$95.0 \%$

$+/-25 \%$

$96 \%$

Note: Results are presented for the first, second, and third inflection points on the titration curves, as applicable. The first inflection point is generally associated with the free hydroxide concentration. The second inflection point generally represents total hydroxide, or carbonate or a combination of aluminate and carbonate. The third inflection point is usually indicative of bicarbonate or other weak acids or possibly the continued protonation of alumina.

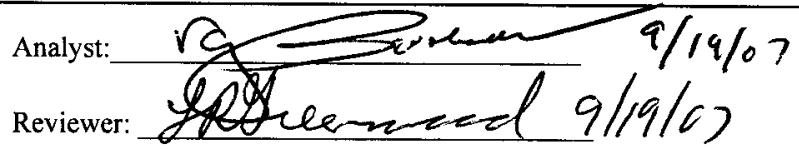


Battelle Pacific Northwest Laboratory

Radiochemical Processing Group-325 Building

Chemical Measurements Center
ASR \# 7998

WP\# F99189

Hydroxide and Alkalinity Determination

Procedure: RPG-CMC-228-Rev 1

Equip \# WB76843

\begin{tabular}{r|r|} 
Report Date: & $9 / 19 / 2007$ \\
Analysis Date: & $9 / 18 / 2007$
\end{tabular}

Concentration, moles / Liter

\begin{tabular}{|c|c|c|c|c|c|c|c|c|c|}
\hline \multirow[b]{2}{*}{ RPG \# } & \multirow[b]{2}{*}{ Client ID } & \multirow{2}{*}{$\begin{array}{c}\text { Initial } \\
\text { pH }\end{array}$} & \multirow{2}{*}{$\begin{array}{c}\text { OH conc } \\
\mathrm{ug} / \mathrm{mL}\end{array}$} & \multirow{2}{*}{$\begin{array}{l}\text { First Point } \\
\text { Molarity }\end{array}$} & \multirow[b]{2}{*}{ RPD } & \multicolumn{2}{|c|}{ Second Point } & \multicolumn{2}{|l|}{ Third Point } \\
\hline & & & & & & Molarity & RPD & Molarity & RPD \\
\hline $07-01780$ & TI540-G5-G & 13.00 & $6.38 \mathrm{E}+04$ & 3.75 & & 1.82 & & 0.23 & \\
\hline 07-01780-Dup & TI540-G5-G & 12.37 & $6.36 \mathrm{E}+04$ & 3.74 & $0.4 \%$ & 1.80 & $1.0 \%$ & 0.22 & $3 \%$ \\
\hline $07-01781$ & TI540-G5-M & 12.44 & $1.81 \mathrm{E}+04$ & 1.07 & & 0.23 & & 0.04 & \\
\hline 07-01781-Dup & TI540-G5-M & 12.53 & $1.82 \mathrm{E}+04$ & 1.07 & $0.6 \%$ & 0.22 & $5.1 \%$ & 0.04 & $8 \%$ \\
\hline $07-01782$ & TI540-G5-O & 12.61 & $3.08 E+04$ & 1.81 & & 0.53 & & 0.07 & \\
\hline 07-01782-Dup & TI540-G5-O & 12.60 & $3.06 \mathrm{E}+04$ & 1.80 & $0.6 \%$ & 0.55 & $2.8 \%$ & 0.06 & $10 \%$ \\
\hline
\end{tabular}

$\mathrm{OH}$ conc $(\mathrm{mg} / \mathrm{L})=\mathrm{M}(\mathrm{g} / \mathrm{L}) * 17,000$

free $\mathrm{OH}$ as specified in $\mathrm{ASR}$

Reag. Blk. 1

Standard 1

MS

Matrix spike
12.58

12.60

\begin{tabular}{|cc}
\multicolumn{1}{c}{$\begin{array}{c}\mathrm{g} / \mathrm{ml} \text { or } \\
\mathrm{mg} / \mathrm{L}\end{array}$} & Molarity \\
$\mathrm{MDL}$ & MDL \\
\hline $1.70 \mathrm{E}+01$ & $\mathbf{0 . 0 0 1}$ \\
\hline
\end{tabular}

0

$95 \%$

$97 \%$
Required RPD

$+/-15 \%$

Allowed Recovery Range

$+/-25 \%$

$+/-20 \%$

Note: Results are presented for the first, second, and third inflection points on the titration curves, as applicable. The first inflection point is generally associated with the free hydroxide concentration. The second inflection point generally represents carbonate or a combination of aluminate and carbonate. The third inflection point is usually indicative of bicarbonate or other weak acids or possibly the continued protonation of alumina.

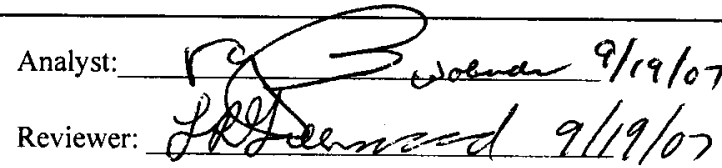


各

細

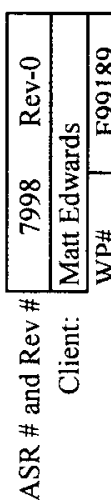

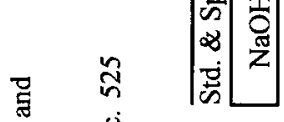

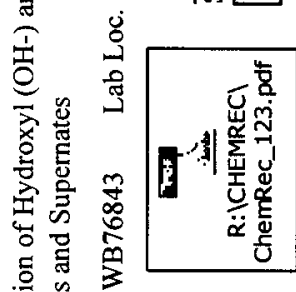

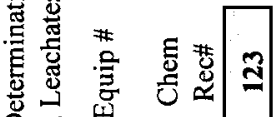

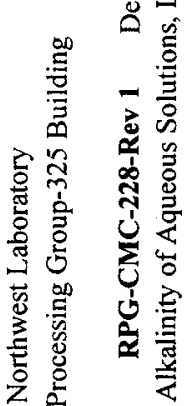

宽

흥

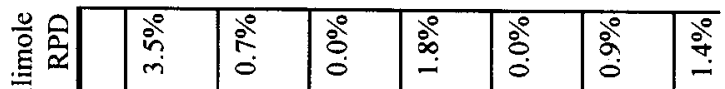

言

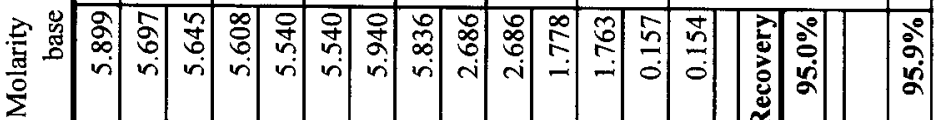

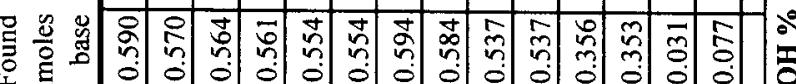
言

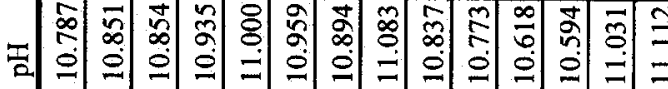

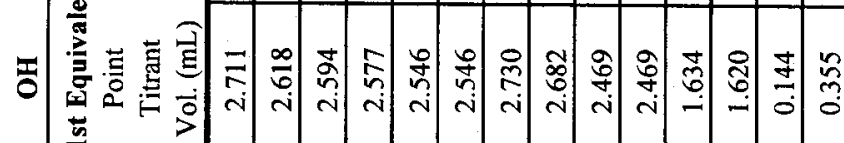

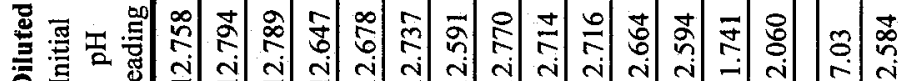

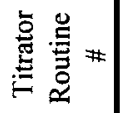

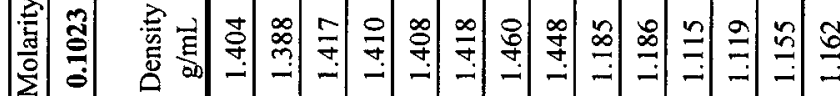

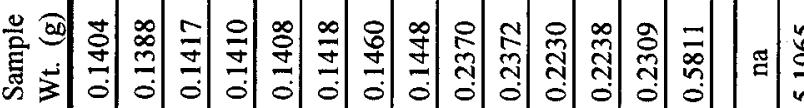

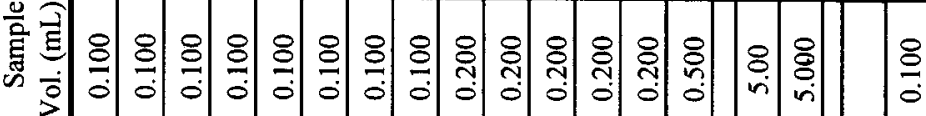

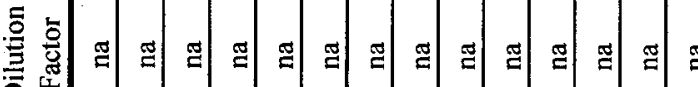
言部

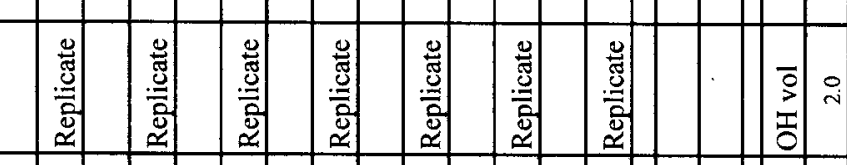

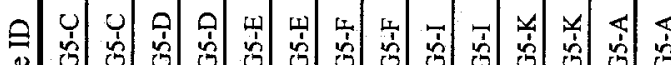

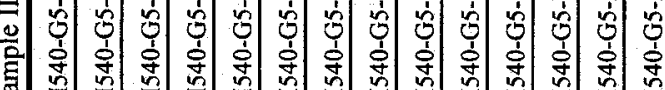

彭

衰

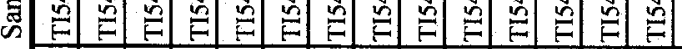

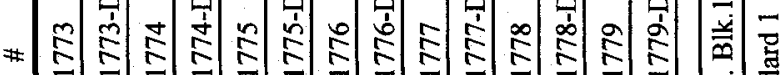

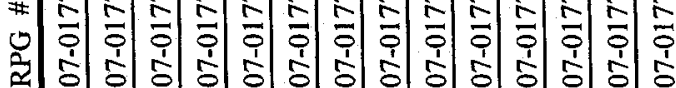

ปั่

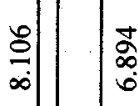

$m$

홍

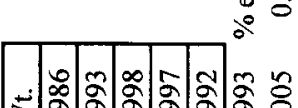

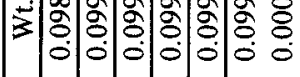

oิ

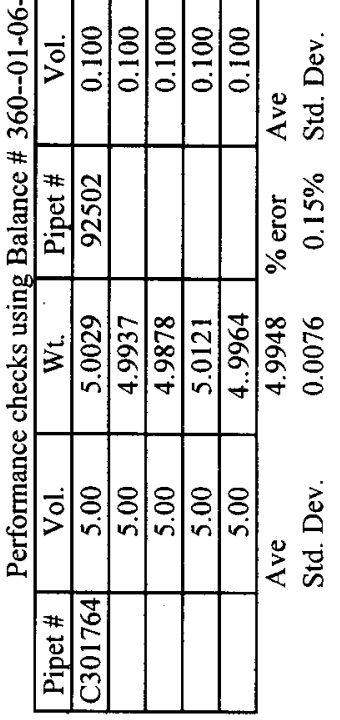

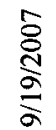

产 京
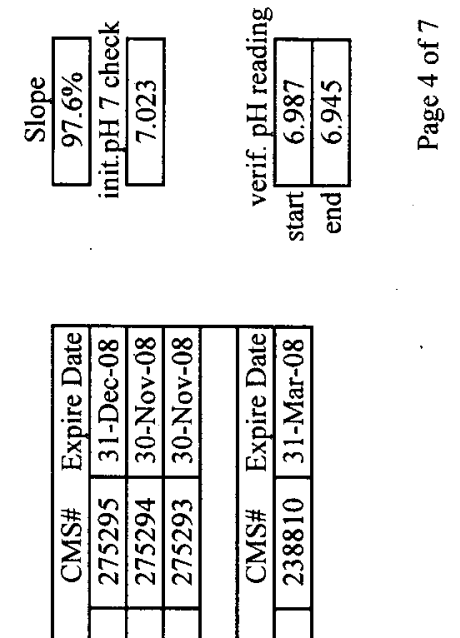

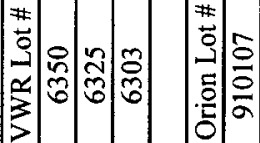

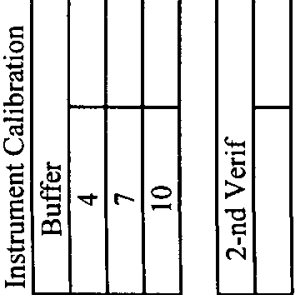




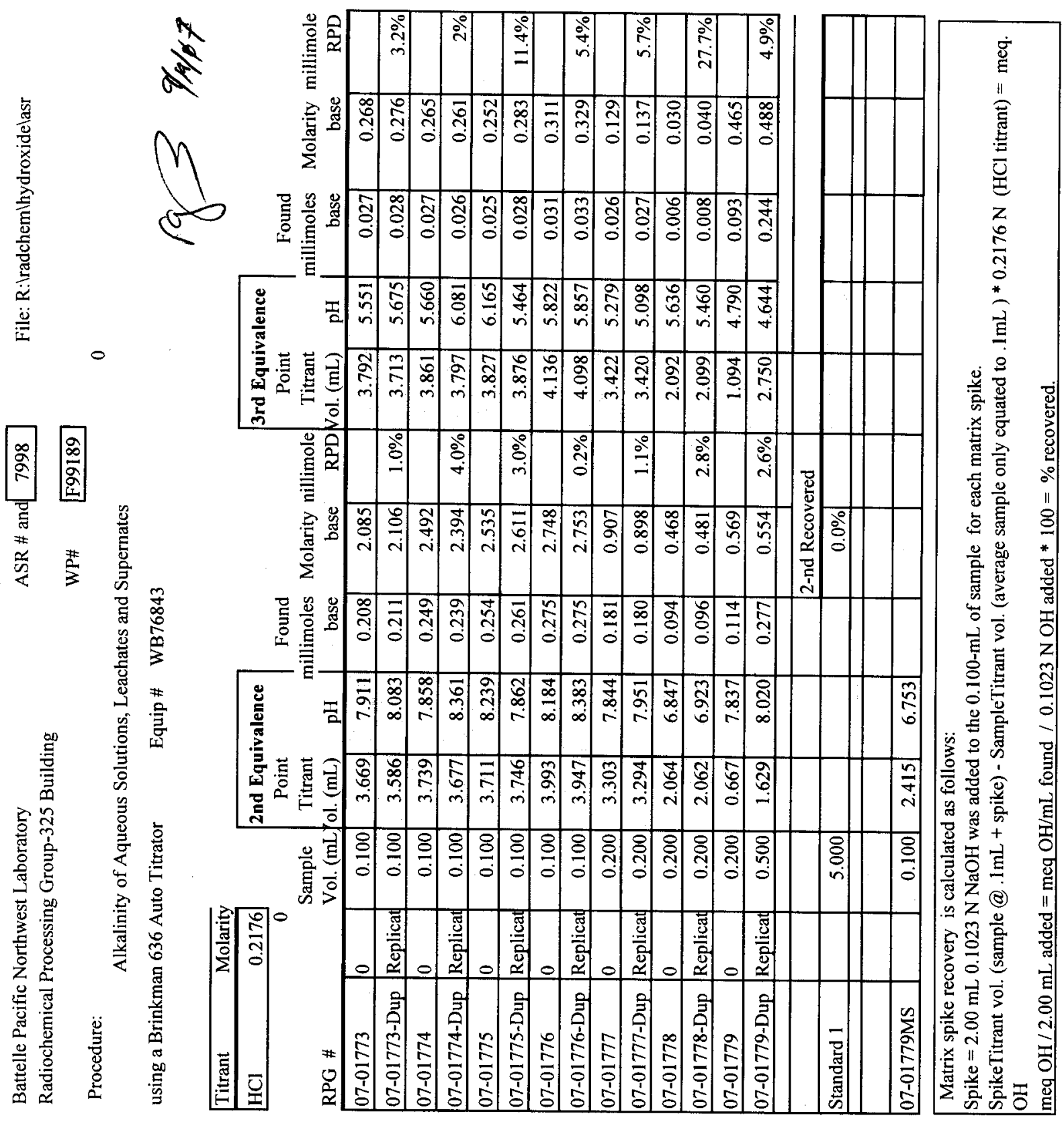




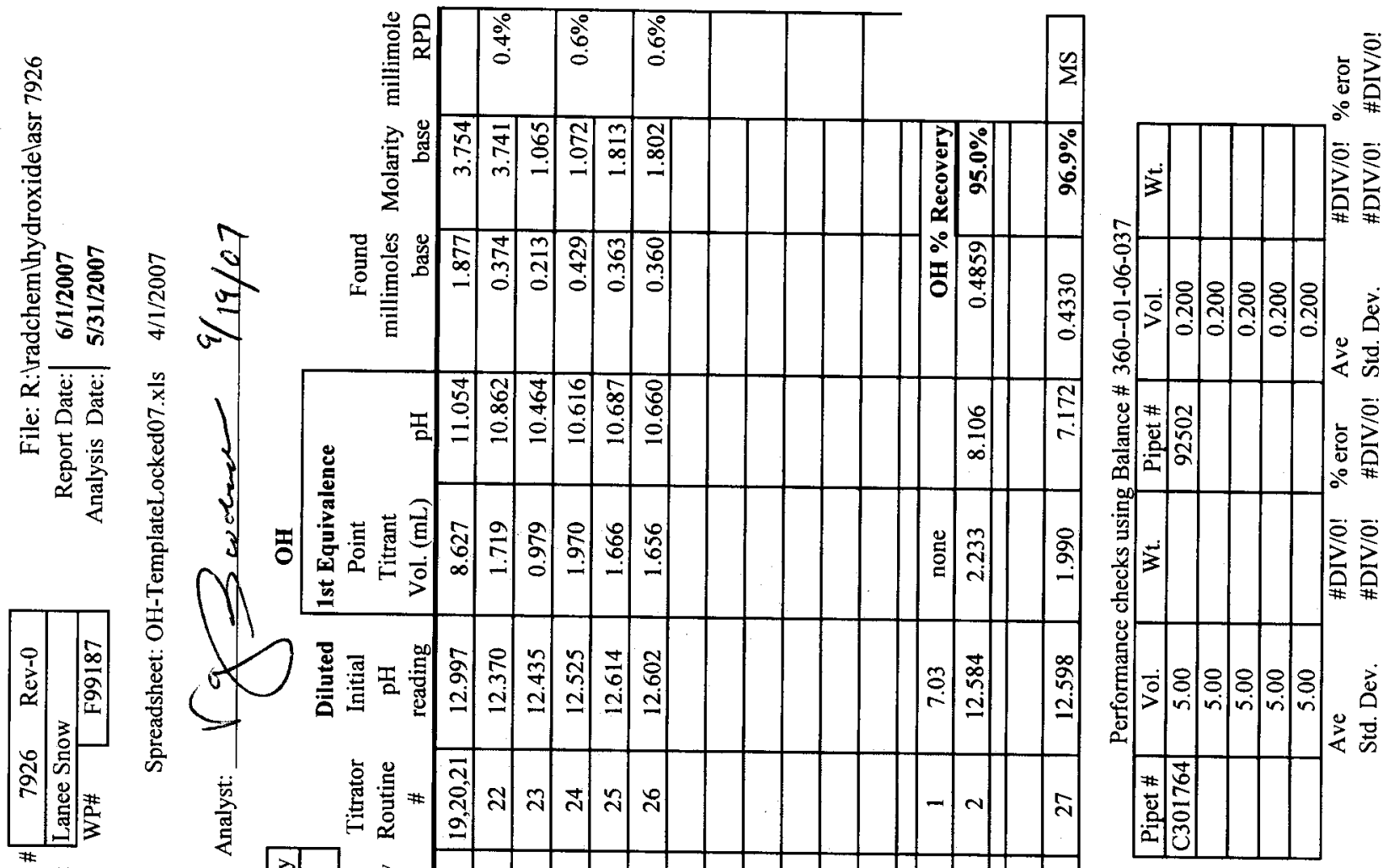

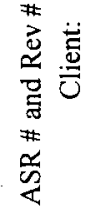
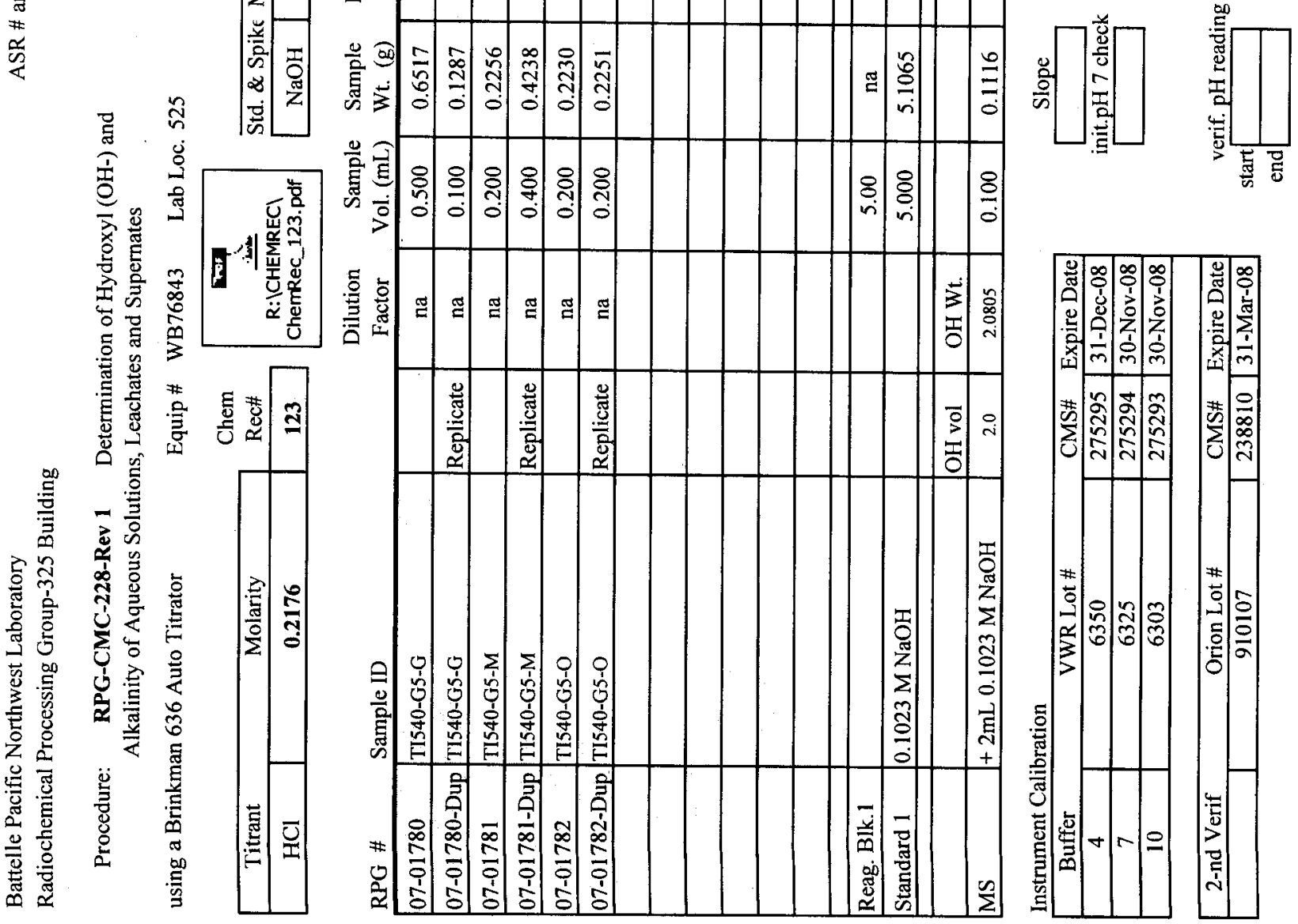

ثै
0
0
0
0
0 


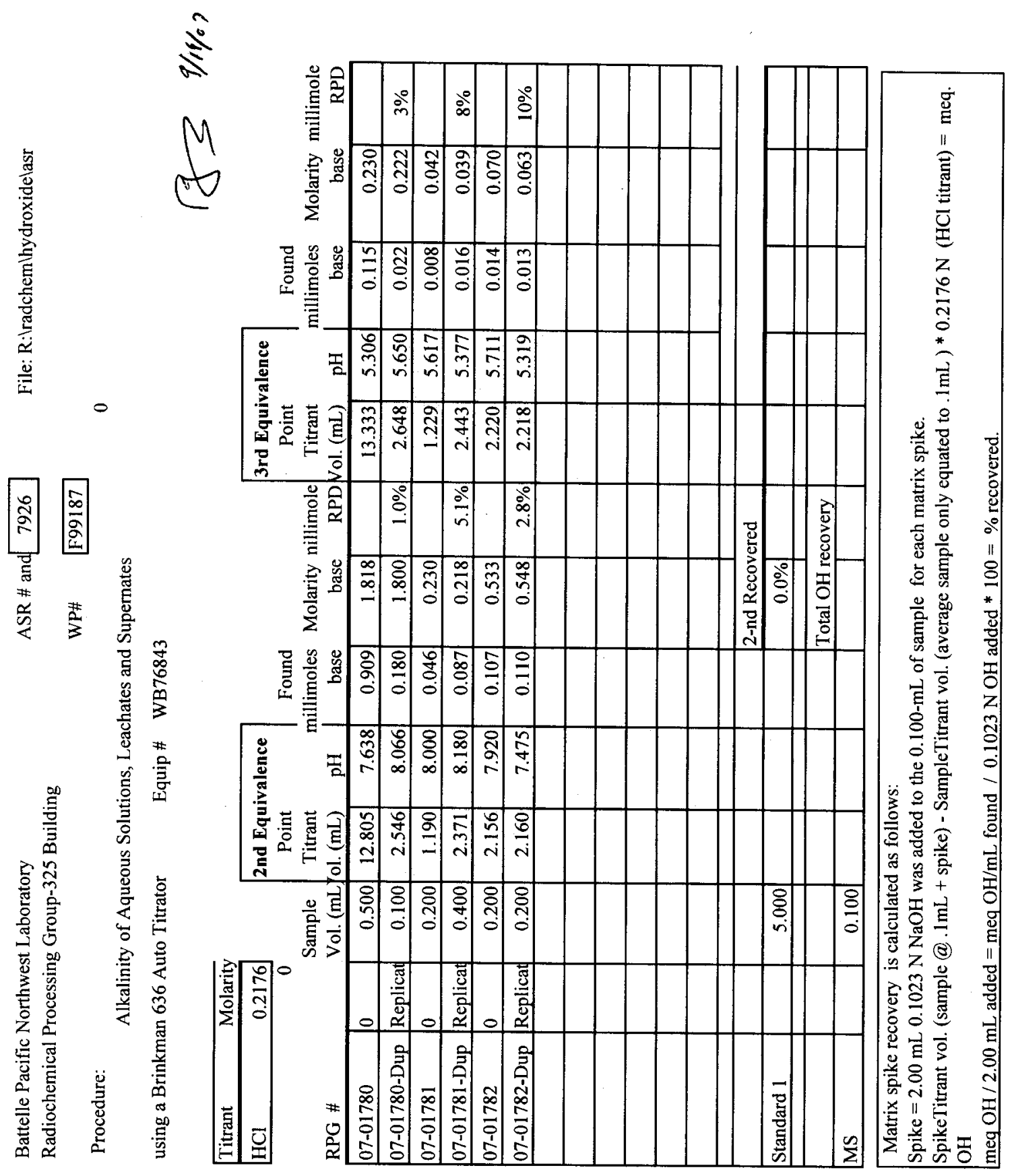



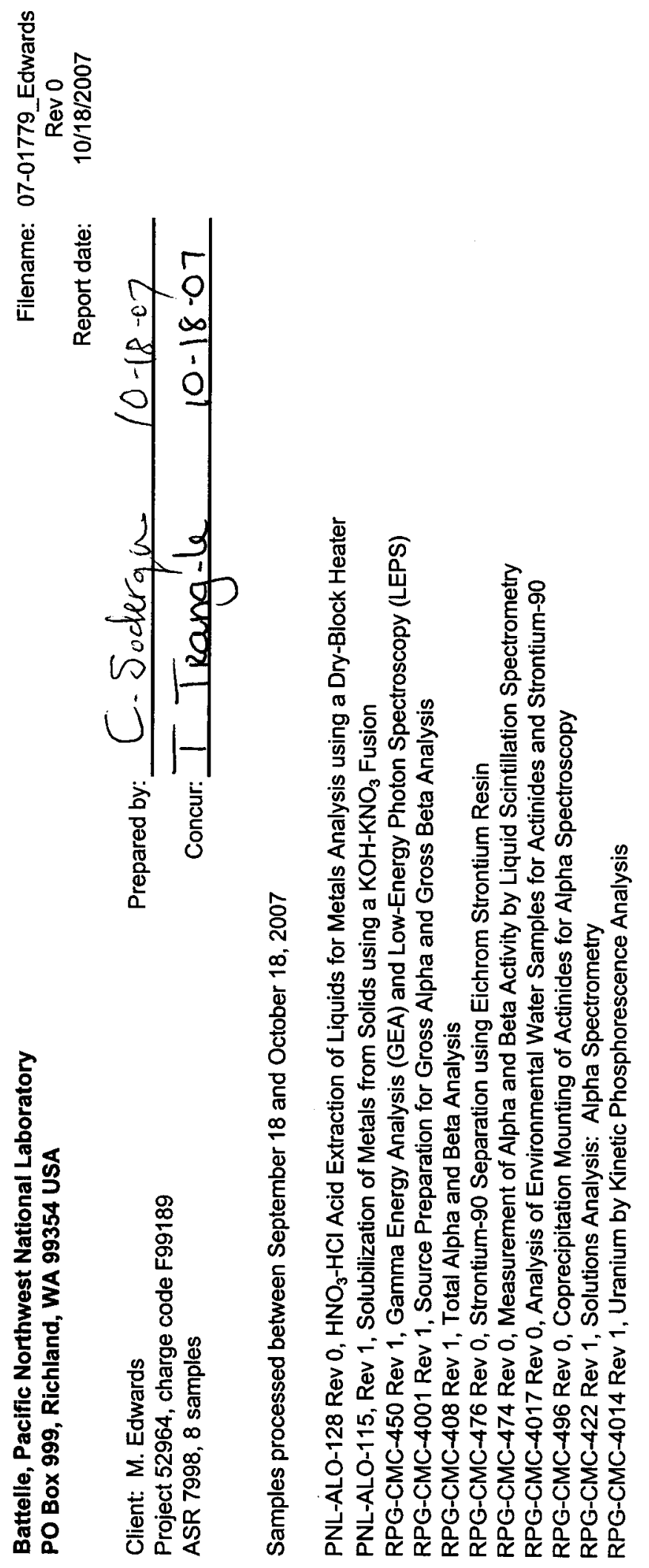

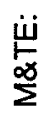

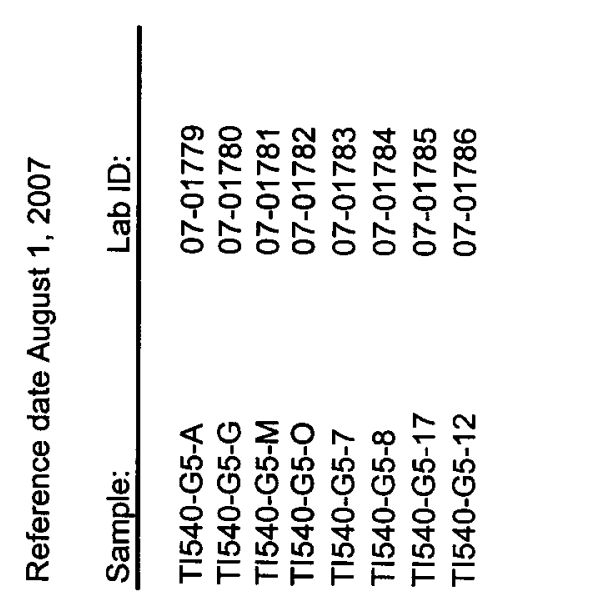




\section{Battelle, Pacific Northwest National Laboratory PO Box 999, Richland, WA 99354 USA}

Filename: 07-01779_Edwards

Rev 0

Report date: $10 / 18 / 2007$

Client: M. Edwards

Project 52964, charge code F99189

ASR 7998, 8 samples

\section{The Samples}

These samples are various caustic liquids and slurries and were delivered to the analytical lab in September 2007. Only the radiochemical data appears in this report; the inorganic analytes are reported separately.

\section{Sample Preparation}

The liquid samples were digested in dilute nitric acid, then adjusted to known volume for further analysis (procedure PNL-ALO-128). The acid digestion was done in a laboratory fume hood, not a hot cell. The slurries were weighed, dried to constant weight, weighed again, and then fused with $\mathrm{KOH}$ (procedure PNL-ALO-115). The KOH fusion was dissolved in water, acidified, and diluted to volume. The $\mathrm{KOH}$ fusions were done in a hot cell. All analytical data from the $\mathrm{KOH}$ fusions is reported per gram of dry sample, not raw wet sample.

All of the radiochemical analyses on this report used the acid digestions and $\mathrm{KOH}$ fusion solutions. No analyses were run on raw sample.

\section{Quality Control Results}

All of the detection limits were met except certain gamma emitters, as explained below. The blanks are negligible for everything except $\mathrm{Co}-60$ and Pu-238 in the hot cell fusion. The $\mathrm{Co}-60$ in these samples is probably all hot cell contamination, and the Pu- 238 in the solids may be $20 \%$ hot cell contamination.

The duplicates agree well in every case. (The Am-241 results for sample TI540-G5-7 agree well, considering their high counting uncertainties.) The spike results ranged from $96 \%$ to $106 \%$ of expected.

\section{Gamma Emitters (procedure RPG-CMC-450)}

The samples were counted for gamma emitters using a 2-mL geometry in a glass liquid scintillation vial. Because of high Cs-137 activity in the samples, not all of the detection limits could be met. The Compton background from the Cs-137 made it impossible to reach the requested detection limits for Eu-155 and Am-241 for several of the samples.

The acid digestion blank had no detectable gamma emitters, but the $\mathrm{KOH}$ fusion blank has about as much $\mathrm{Co}-60$ as was found in the samples. The $\mathrm{KOH}$ fusion blank also has about $3 \%$ as much Cs137 as any one of the accompanying samples.

Because gamma emitters are measured without any chemical separations, no spikes are counted. 
Battelle, Pacific Northwest National Laboratory PO Box 999, Richland, WA 99354 USA
Filename: 07-01779_Edwards

Rev 0

Report date: $10 / 18 / 2007$

\section{Gross Alpha and Gross Beta (procedures RPG-CMC-4001 and -408)}

To measure gross alpha and gross beta, the acid digestions and $\mathrm{KOH}$ fusion solutions were evaporated onto planchets. Gross beta was measured using a gas proportional counter, and gross alpha was measured using a Ludlum alpha counter.

The measured gross beta activity is equal to the Cs- $137+\mathrm{Sr}-90+Y-90$ activity, within expected uncertainty. (Y-90 is in equilibrium with $\mathrm{S} r-90$ in these samples.) These three beta emitters make up essentially all the beta activity in the samples.

Strontium-90 Analysis (procedures RPG-CMC-476 and -474)

Strontium was chemically separated from the acid digestion and $\mathrm{KOH}$ fusion solutions using Eichrom strontium resin. The separated $\mathrm{Sr}-90$ was counted for beta activity using liquid scintillation.

Nearly all of the beta activity in the solids is Sr-90 and its daughter Y-90. The beta activity in the liquid samples is mostly Cs-137.

Plutonium (procedures RPG-CMC-4017, -496, and -408)

Plutonium was separated from the acid digestion and $\mathrm{KOH}$ fusion sample preparations by anion exchange in hydrochloric acid, then mounted for counting by coprecipitation, then counted by alpha spectrometry.

Plutonium was found in every sample, although at a low concentration in the liquids. The Pu-238 results in the solids are biased high, mayby $20 \%$, by hot cell contamination.

Uranium (procedures RPG-CMC-4017 and -4014)

Uranium was separated from the sample solutions by anion exchange in hydrochloric acid, then measured by kinetic phosphorescence analysis. The lab blank has measurable uranium (samples handled in glassware always do), but the blank is small compared the lowest sample concentration and negligible compared to the highest samples.

A reagent spike and matrix spike were prepared during the acid digestion. No hot cell fusion uranium spikes were prepared, since an inordinate amount of spike would be required.

All of the samples have easily measurable uranium, particularly the solid samples, which are over 1 weight percent uranium. 


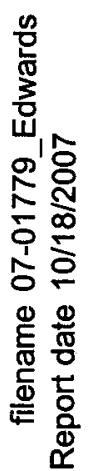

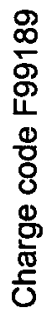

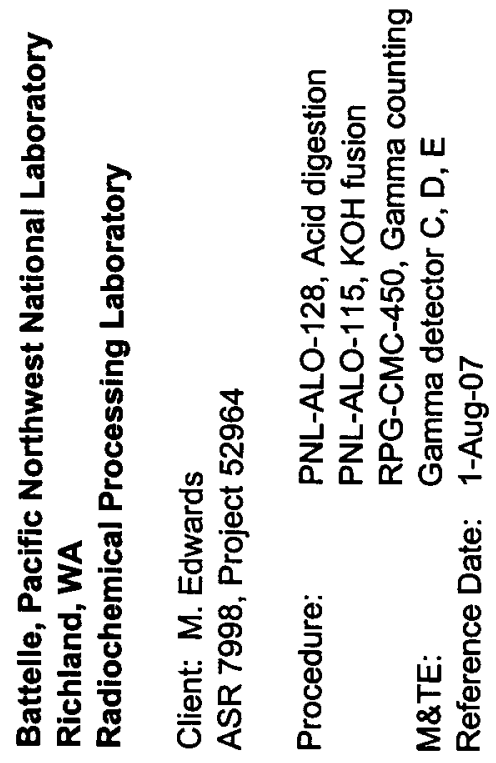

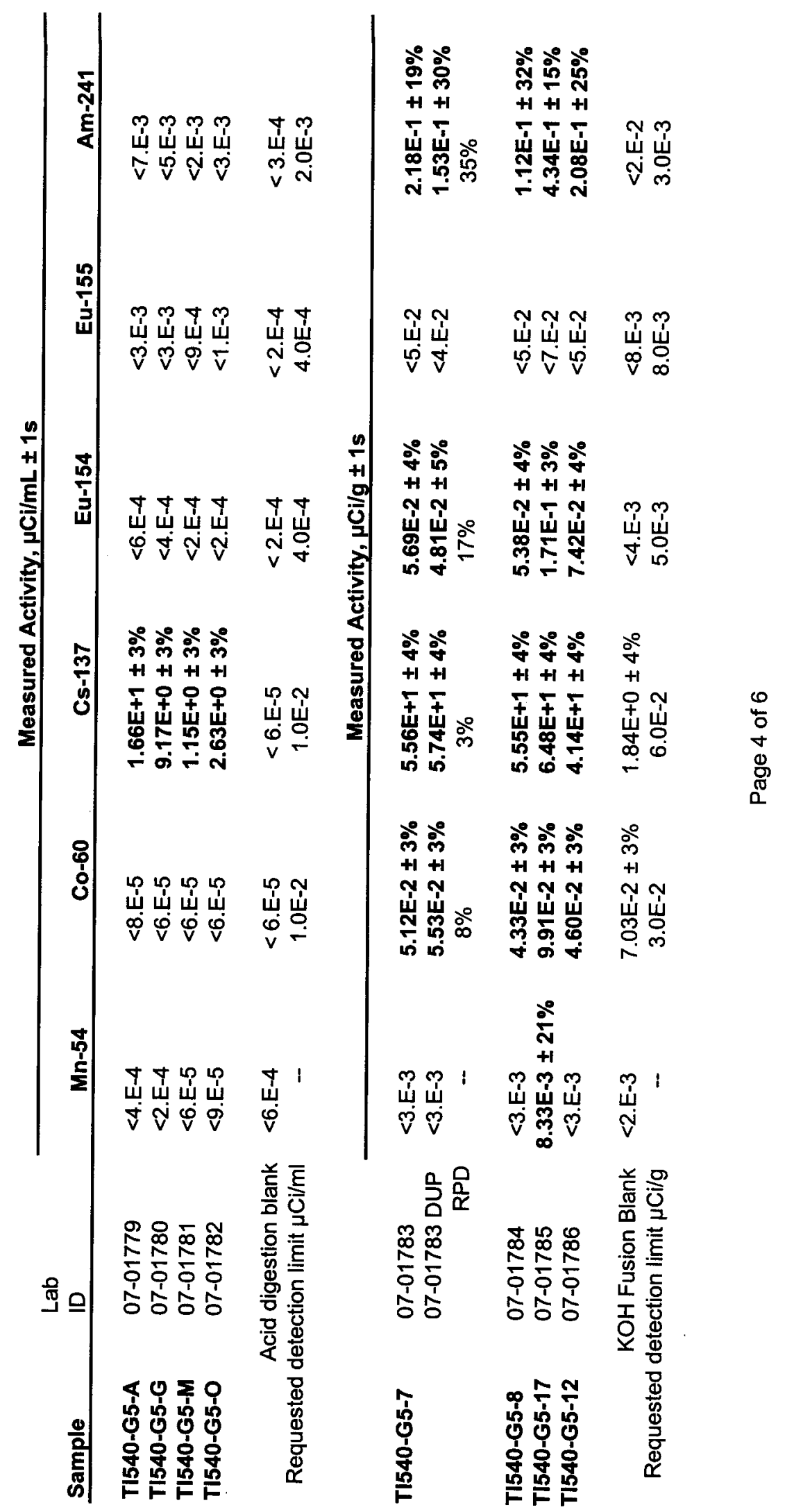



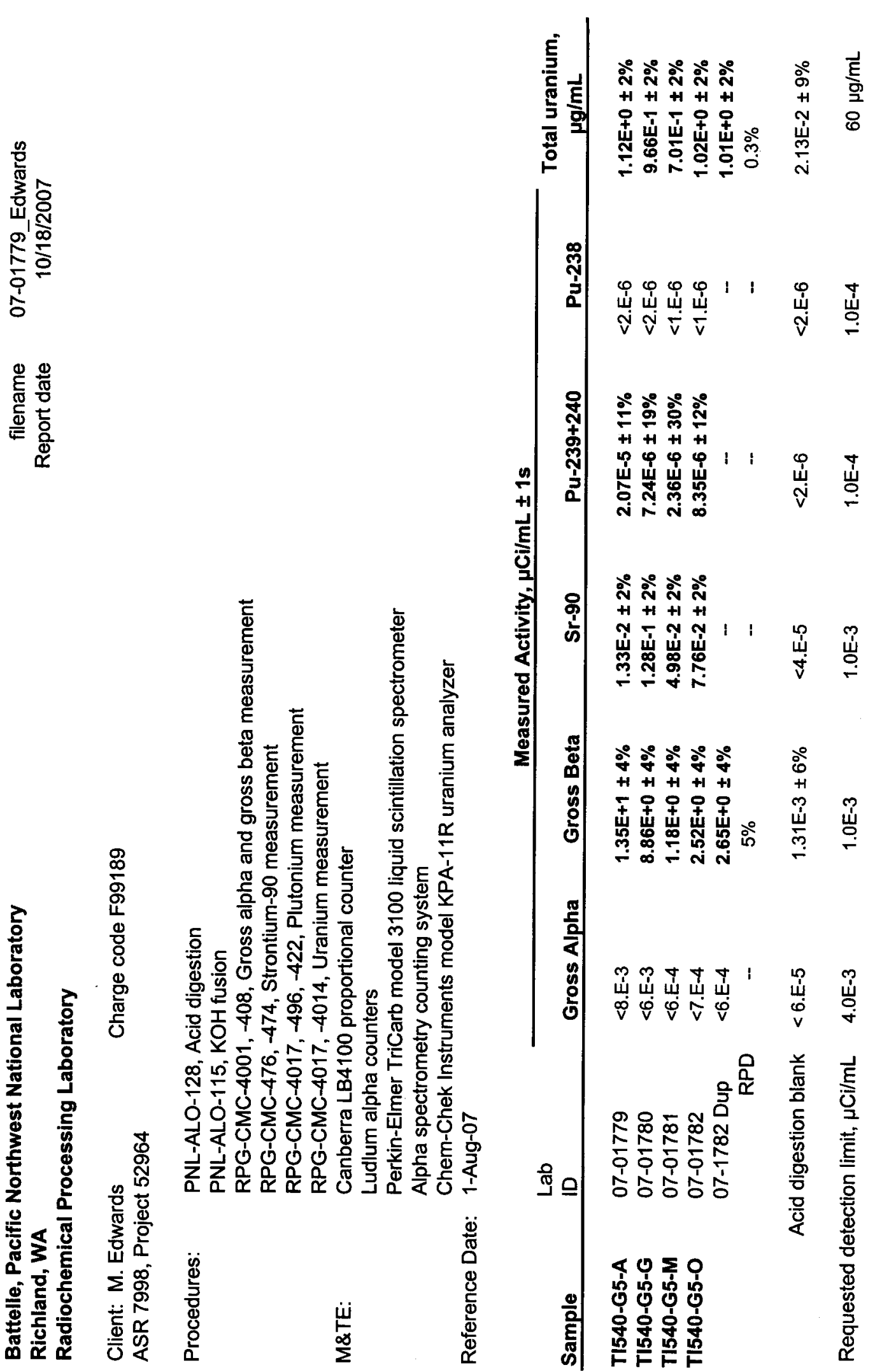

0
4
0
10
0
0
0
0

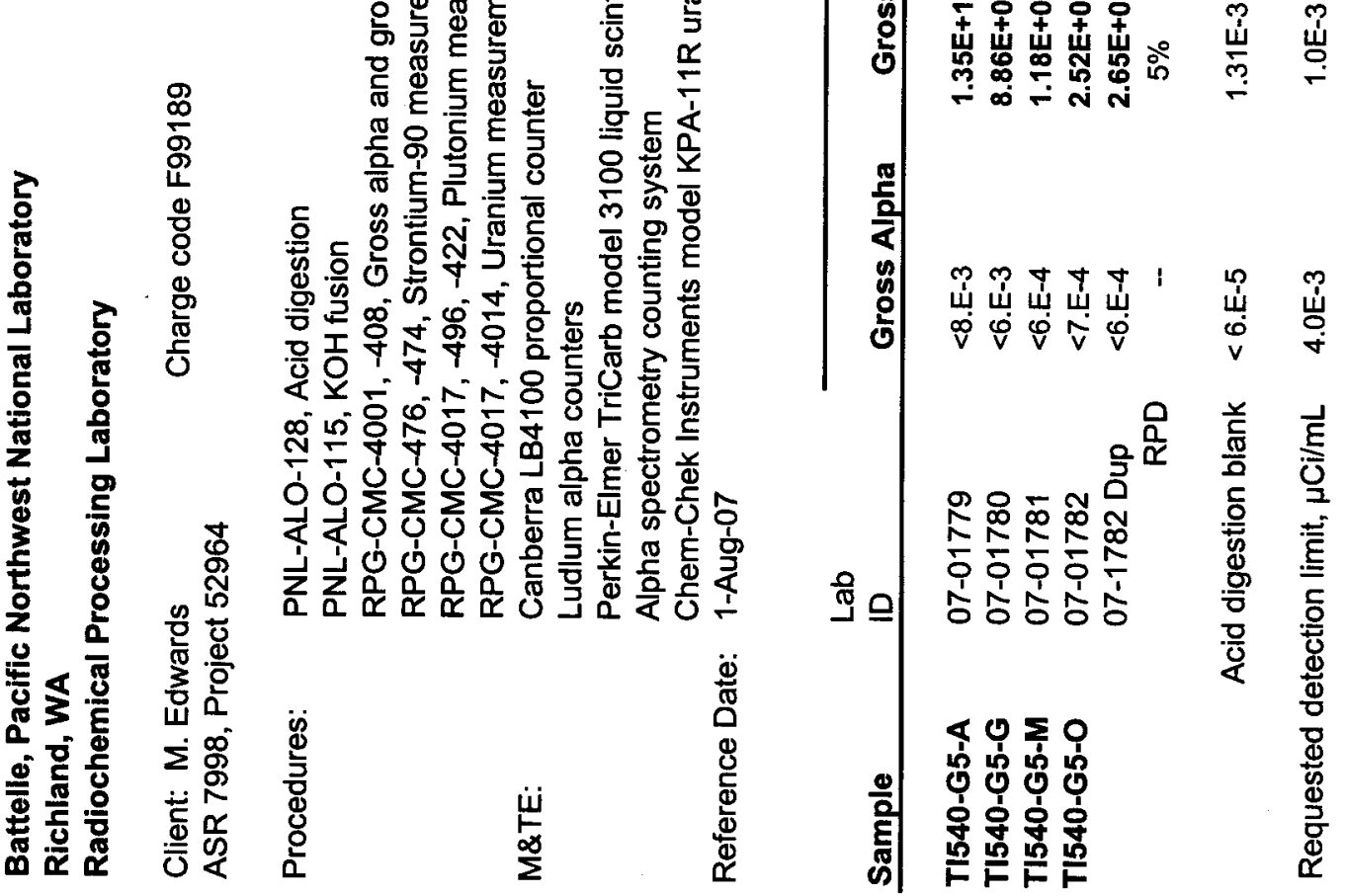




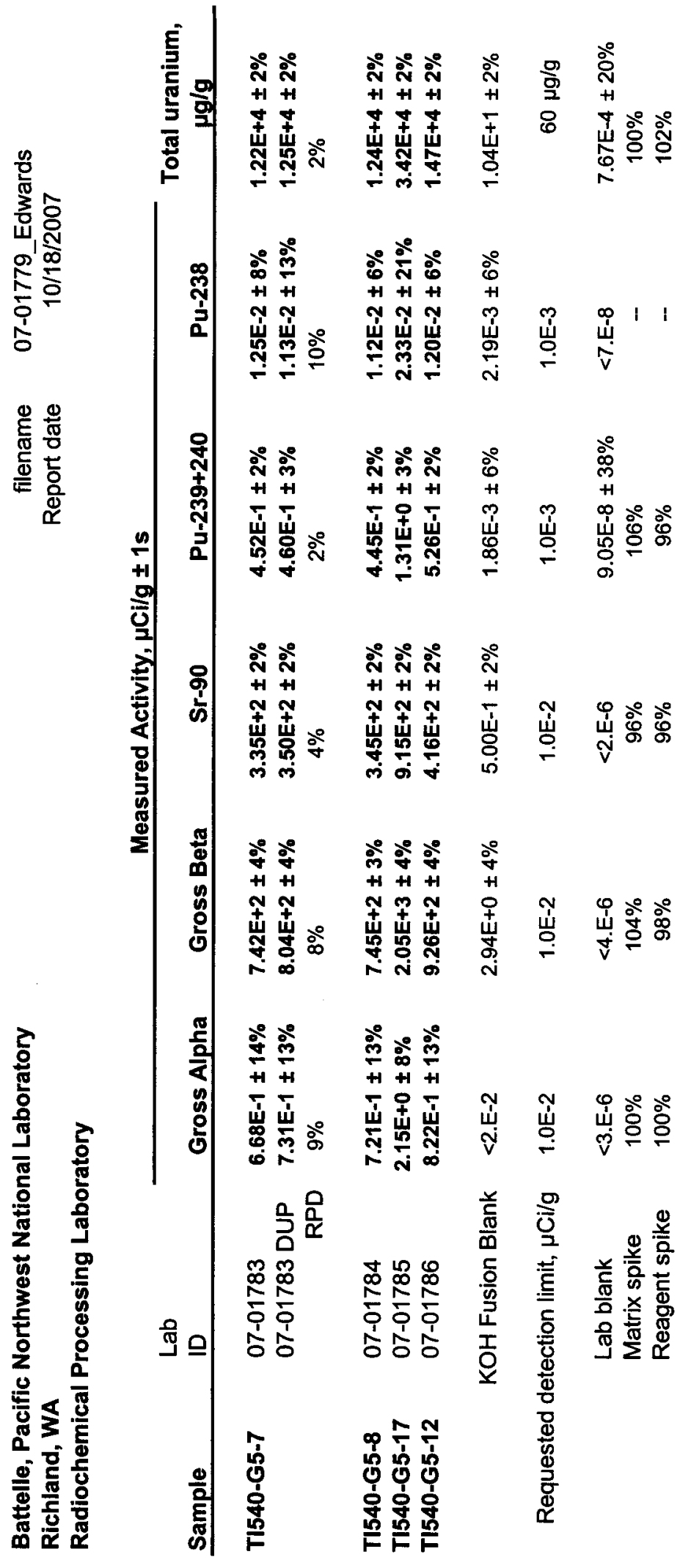




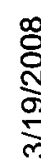

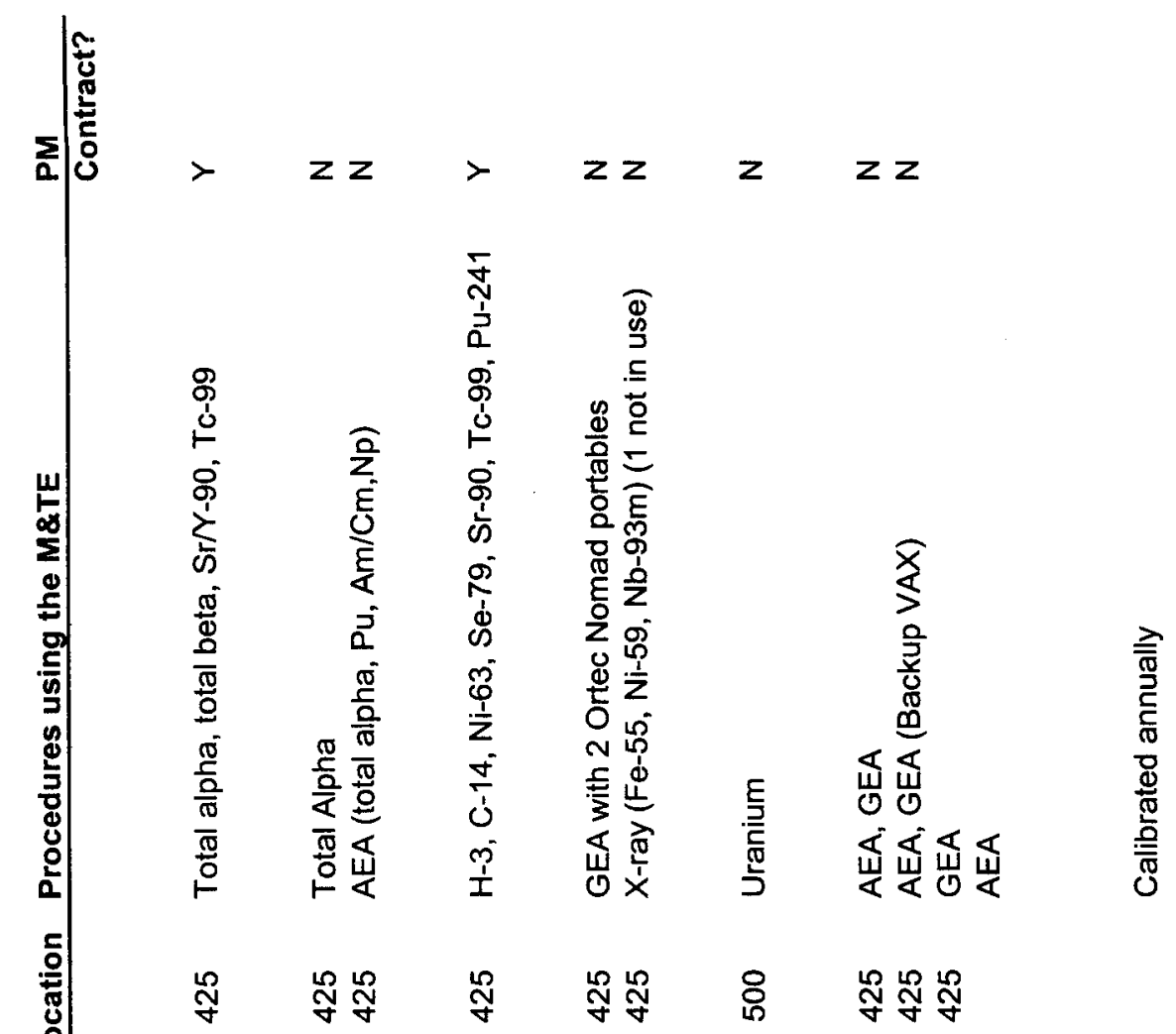

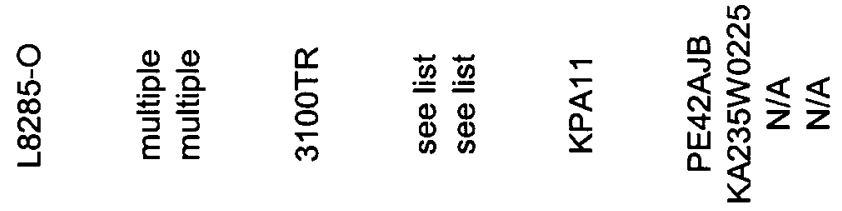

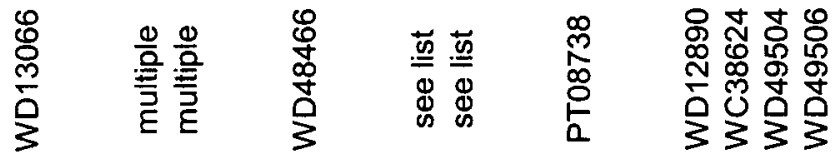

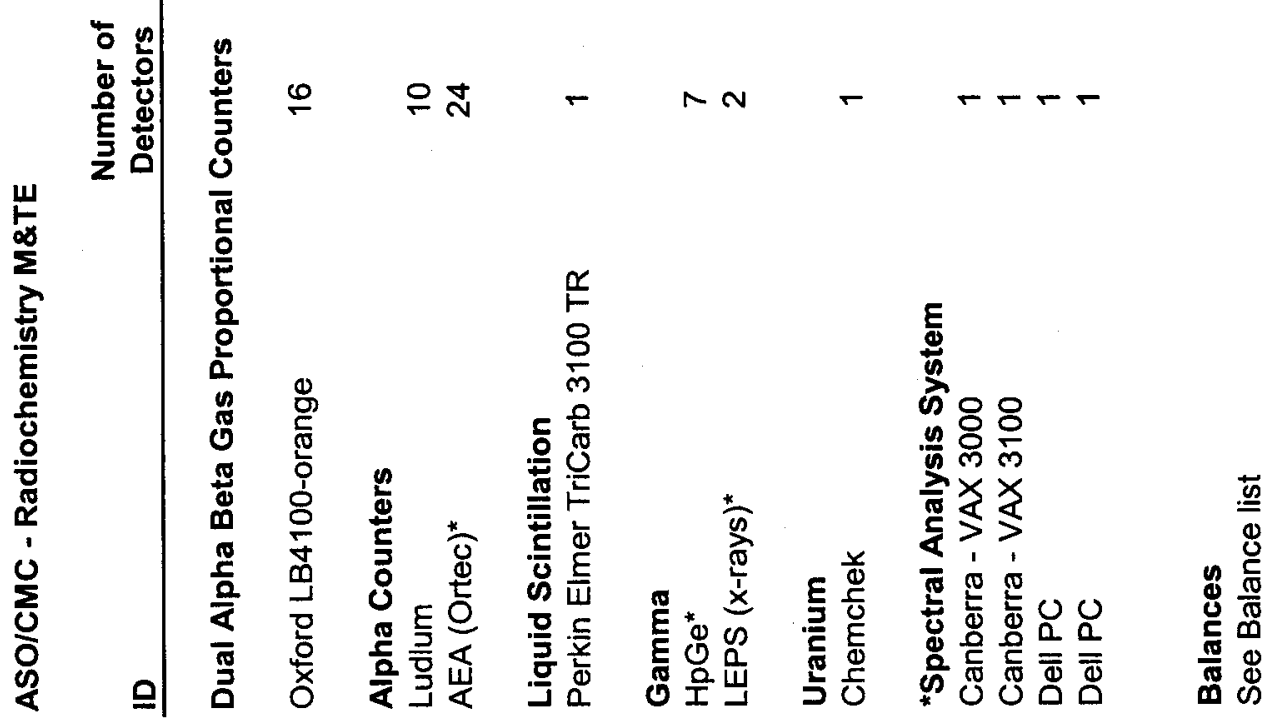




\section{Appendix L}

\section{Group 6/5 CUF Analytical Results}




\title{
Appendix L: Group 6/5 CUF Analytical Results
}

\author{
Special Instructions for \\ CUF Group 6/5 REDOX Sludge/s-saltcake Treatablility Study \\ Analysis Requirements
}

The start date for this treatability study is November 5th, 2007. Color code: Brilliant Lime.

A composite material containing liquid and sludge from Hanford waste tanks S-106, S-111, SX102, SX-105, SX-106, SY-103, U-103, and U-108 (s-saltcake) and S-101, S-107, S-110, and SX103(REDOX sludge) was subjected to CUF process as per TI-RPP-WTP-552. The processing and analysis schematic is shown by Figure 1 and Table 1 . The aqueous samples are ready to directly sub-sample for analysis and acid digestion. The solid slurry sample has been aliquoted into crucibles and dried; the sub-samples are ready for fusion.

\section{SAL Preparation/Analysis}

Record both the nominal volume and actual weight distributions of aqueous sample material for various analyses.

Please record observations associated with the dissolution preparations. If any residual solids remain after any of the fusion and acid digestions, note on the bench sheet (include estimated quantity, color, texture, etc.) and contact RW Shimskey or MK Edwards for further instruction prior to distribution.

\section{Archive of SAL Fusion Preparation Samples}

The fusion preparations will result in a $100-\mathrm{mL}$ volume. This solution will be apportioned to the laboratory as needed to conduct work-station-specific analyses. Please prepare a 15-mL aliquot from each preparation as an archive sample. The vials need to be labeled with the following: date, ASO-ID, matrix, treatablility study, hazard, fusion prep (if applicable) and their tare, gross masses, and IDs provided to RW Shimskey or MK Edwards. The vials may be removed from the hot cells for storage. The remaining portions of the fusion preparations may be disposed of.

\section{Quality Control}

All work is to be conducted according to RPP-WTP-QA-005, Rev. 2.

Preparative or sample analysis QC includes a preparation blank, sample, sample duplicate, matrix spike, and a LCS or BS. The samples submitted for fusion are sub-aliquoted into fusion vessels in duplicate (sample, sample duplicate). If possible, the matrix spike and LCS/BS need to include all the analytes of interest to be reported for the specific analysis.

The duplicate, LCS/BS, and MS QC acceptance criteria for the aqueous phases and solid phases are provided in Table 4 . The preparation blank (PB) analyte concentration shall be less than the estimated quantitation limit (EQL) or the minimum detectable activity (MDA) of the associated sample. When the PB concentration is equal to or exceeds the EQL, then the PB concentration shall not exceed $5 \%$ of the measured concentration present in the sample. Failure of the PB, and/or duplicates, and/or LCS/BS to meet the acceptance criteria requires that affected samples in 
the processing batch be re-prepared and re-analyzed for the failed analytes, availability of samples permitting, at ASO expense.

In the case of multi-elemental methods (IC and ICP-OES), isolated QC failure(s) may be communicated to RW Shimskey or MK Edwards for an assessment of the impact on data interpretation. If the data are acceptable, RW Shimskey or MK Edwards will indicate, in writing, that the data may be reported, and the resulting limitations on the data from the QC sample failure(s) shall be included in the final report.

When the MS fails to meet the acceptance criteria, the results shall be investigated for potential sources of error. When the sources of error cannot be identified, the failure of the MS and any resulting limitations on the data shall be included in the report.

Note that in some cases BS and MS are requested for U/KPA as well as ICP metals in solution analysis. Because the broad suite of ICP BS metals will interfere with the U KPA analysis, two MS and BS samples (one supporting each technique) will need to be prepared as part of the acid digestion.

\section{Reporting Units}

Report aqueous sample results in units of $\mathrm{ug} / \mathrm{mL}$ or $\mathrm{uCi} / \mathrm{mL}$. Report solids sample results as ug/g or $\mathrm{uCi} / \mathrm{g}$; the initial dry mass of solids (as measured in each fusion crucible) will be provided. For radiochemistry, the reference date of November 5, 2007 shall be applied. Report the hydroxide concentration in units of molarity and ug/mL.

\section{Reporting}

Please prepare the analytical data report in accordance with PNL-ASO-058, Rev. 0, Section 5.3, Comprehensive Data Report. Please be sure to include action taken with respect to any identified unexpected results and discrepancies.

The following elements may be included in the final report or be traceable to the test results (usually by entry in the LRB, Test Instruction, or data sheet) and be maintained as lifetime records:

- identification of standards used

- identification of M\&TE used

- reference to the Test Plan (identified on page 1 of the ASR)

- $\quad$ signature and date of person who performed the test and recorded the data

- hand calculation review documentation.

Analytical results shall be reported both in hard copy and electronically. Preliminary data reports and electronic files shall be provided as soon as practical after completion of analysis. The final ASR data report shall be provided no later than the commitment date on the ASR. 
Table 1. Cross-Reference of Process component, Sample ID, and RPL ID

\begin{tabular}{|c|c|c|}
\hline Component & Sample ID & ASO ID \\
\hline Dewater filtrate & TI552-G6-A & $08-00218$ \\
\hline Dewater filtrate & TI552-G6-B & $08-00219$ \\
\hline Leach permeate & TI552-G6-D & $08-00220$ \\
\hline wash 6 permeate & TI552-G6-J & $08-00221$ \\
\hline Combined permeate & TI552-G6-K & $08-00222$ \\
\hline $\begin{array}{l}\text { Oxidative wash } 3 \\
\text { permeate }\end{array}$ & TI552-G6-O & $08-00223$ \\
\hline Combined wash & TI552-G6-P & 08-00224 \\
\hline 0.5 hr oxidative leach & TI552-G6-L1 & $08-00225$ \\
\hline 1 hr oxidative leach & TI552-G6-L2 & $08-00226$ \\
\hline 2 hr oxidative leach & TI552-G6-L3 & $08-00227$ \\
\hline 4 hr oxidative leach & TI552-G6-L4 & $08-00228$ \\
\hline $6 \mathrm{hr}$ oxidative leach & TI552-G6-L5 & $08-00229$ \\
\hline $\begin{array}{l}\text { Caustic leach filtrate, } 1 \\
\text { hour heat up }\end{array}$ & TI552-G6-C1 & $08-00230$ \\
\hline $\begin{array}{l}\text { Caustic leach filtrate, } 3 \\
\text { hour heat up }\end{array}$ & TI552-G6-C2 & $08-00231$ \\
\hline $\begin{array}{l}\text { Caustic leach filtrate, } 0 \\
\text { hour leach }\end{array}$ & TI552-G6-C3 & $08-00232$ \\
\hline $\begin{array}{l}\text { Caustic leach filtrate, } 4 \\
\text { hour leach }\end{array}$ & TI552-G6-C4 & $08-00233$ \\
\hline $\begin{array}{l}\text { Caustic leach filtrate, } 8 \\
\text { hour leach }\end{array}$ & TI552-G6-C5 & $08-00234$ \\
\hline wash 1 permeate & TI552-G6-E & $08-00235$ \\
\hline wash 2 permeate & TI552-G6-F & $08-00236$ \\
\hline wash 3 permeate & TI552-G6-G & $08-00237$ \\
\hline wash 4 permeate & TI552-G6-H & $08-00238$ \\
\hline wash 5 permeate & TI552-G6-I & $08-00239$ \\
\hline $\begin{array}{l}\text { Oxidative wash } 1 \\
\text { permeate }\end{array}$ & TI552-G6-M & $08-00240$ \\
\hline $\begin{array}{l}\text { Oxidative wash } 2 \\
\text { permeate }\end{array}$ & TI552-G6-N & $08-00241$ \\
\hline 16 wt\% slurry & TI552-G6-7 & $08-00242$ \\
\hline Leach slurry & TI552-G6-12 & $08-00243$ \\
\hline $\begin{array}{l}\text { Leached and washed } \\
\text { slurry }\end{array}$ & TI552-G6-17 & $08-00244$ \\
\hline $\begin{array}{l}\text { Leached and washed } \\
\text { slurry }\end{array}$ & TI552-G6-22 & $08-00245$ \\
\hline $\begin{array}{l}\text { Leached and washed } \\
\text { slurry }\end{array}$ & TI552-G6-27 & $08-00246$ \\
\hline
\end{tabular}


Figure 1. Sample analysis flow chart

CUF Operation

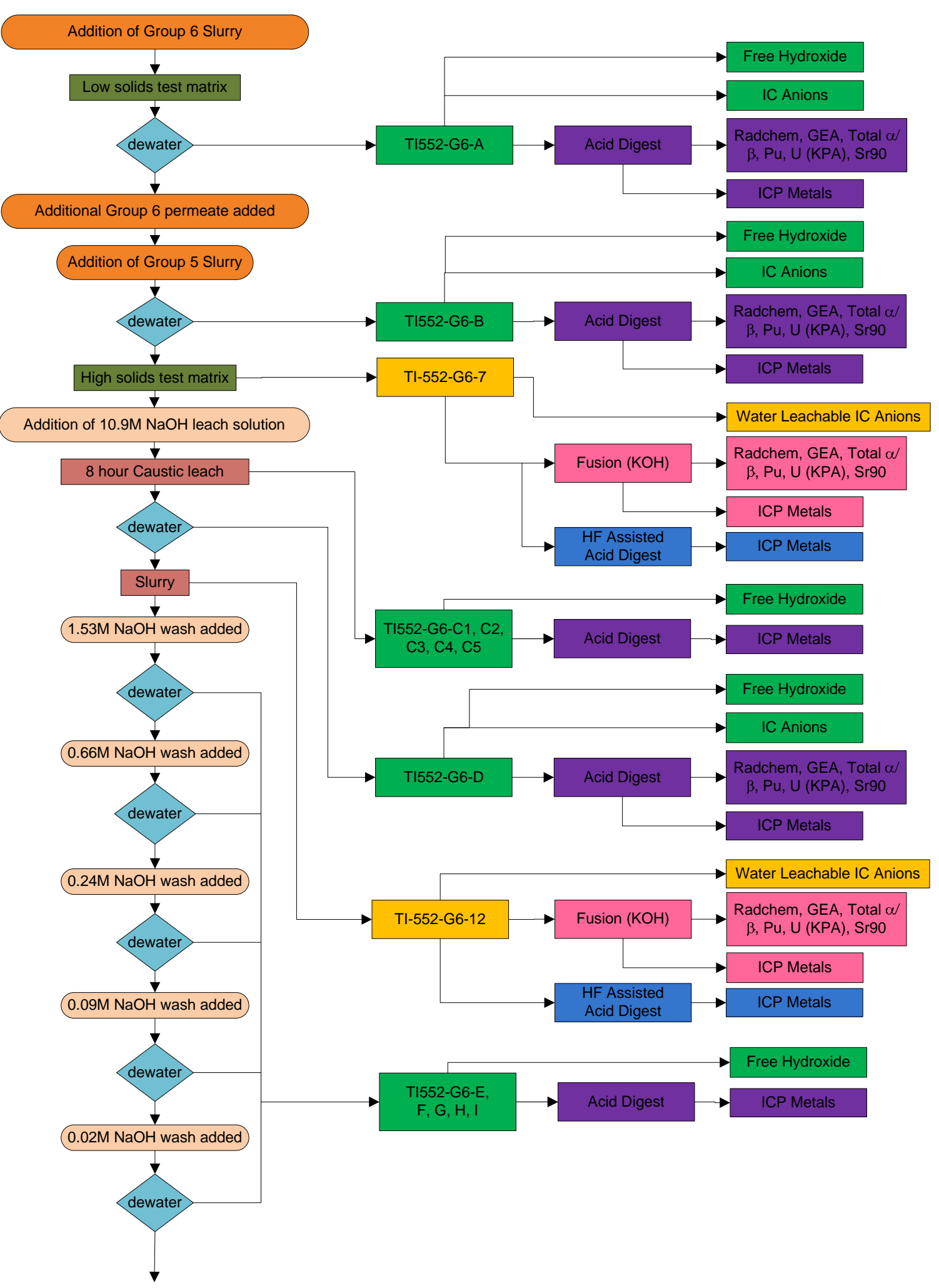




\section{Figure 1. Sample analysis flow chart, continued}

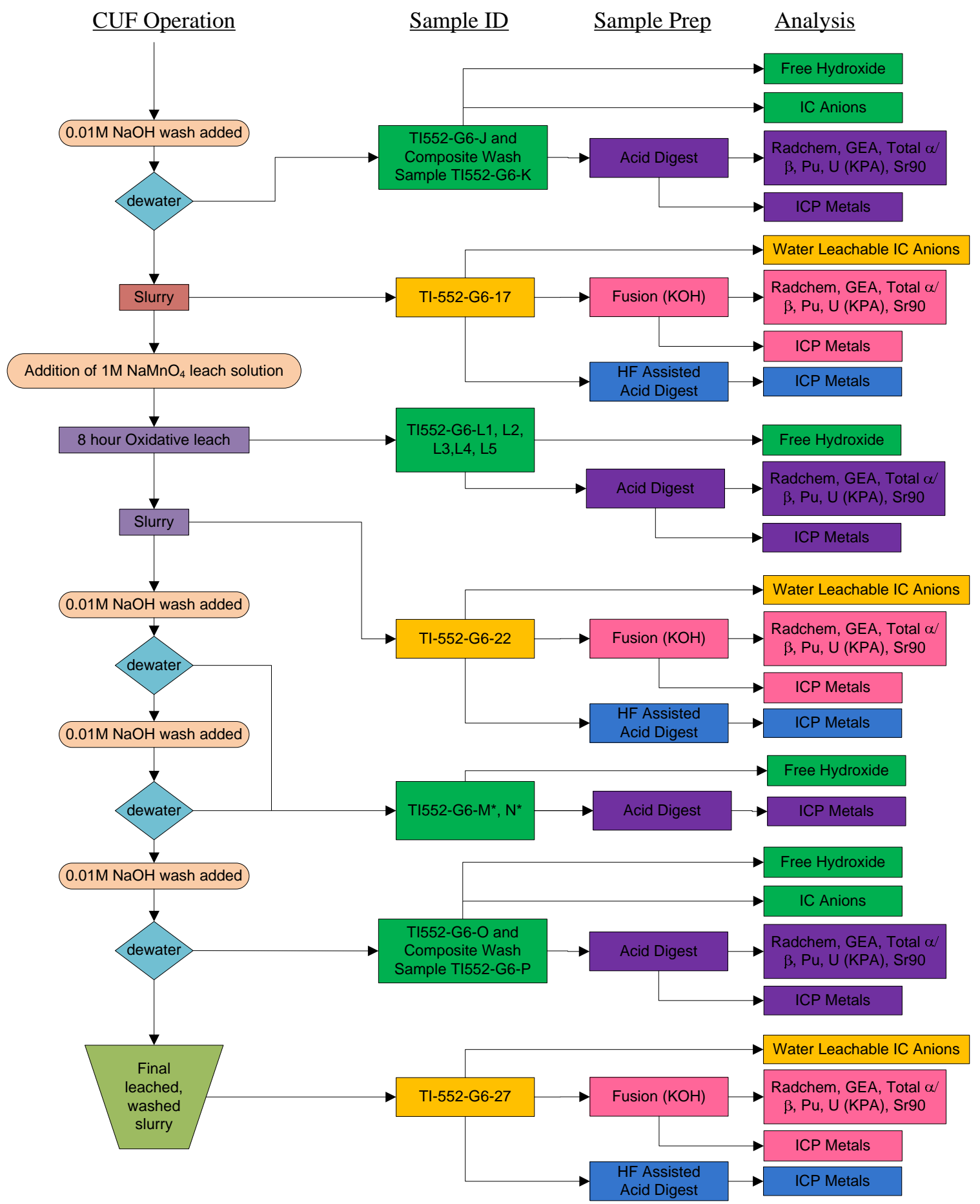

*Samples TI-552-G6-M \& N sent for radchem analysis, ASR 8108 


\section{Laboratory Analysis}

The required sample analyses are shown in Table 2 Filtration and Leach Testing Characterization Plan.

Table 2 Filtration and Leach Testing Characterization Plan

\begin{tabular}{|c|c|}
\hline Process Step & Analyte \\
\hline \multirow[t]{3}{*}{ Dewatered slurry (TI552-G6-7) } & $\begin{array}{r}\text { HF assisted Acid digestion } \\
\bullet \text { ICP metals (Table 3) }\end{array}$ \\
\hline & $\begin{array}{l}\text { KOH fusion } \\
\text { - ICP metals (Table 3) } \\
\text { - GEA } \\
\text { - Total alpha } \\
\text { - }{ }^{238} \mathrm{Pu},{ }^{239+240} \mathrm{Pu} \\
\text { - } \mathrm{U} / \mathrm{KPA} \\
\text { - }{ }^{90} \mathrm{Sr} \\
\text { - Total beta }\end{array}$ \\
\hline & $\begin{array}{l}\text { Water Leach } \\
\text { - Anions (Table 3) }\end{array}$ \\
\hline \multirow[t]{2}{*}{ Dewater filtrates (TI552-G6-A, TI552-G6-B) } & $\begin{array}{l}\text { Direct distribution } \\
\text { - Anions (Table 3) } \\
\text { - Free hydroxide } \\
\end{array}$ \\
\hline & $\begin{array}{l}\text { Acid digestion } \\
\text { - ICP metals (Table 3) } \\
\text { - GEA } \\
\text { - Total alpha } \\
\text { - }{ }^{238} \mathrm{Pu},{ }^{239+240} \mathrm{Pu} \\
\text { - } \mathrm{U} / \mathrm{KPA} \\
\text { - }{ }^{90} \mathrm{Sr} \\
\text { - Total beta }\end{array}$ \\
\hline \multirow{2}{*}{$\begin{array}{c}\text { Time interval Caustic Leach filtrates } \\
\text { (TI552-G6-C1, TI552-G6-C2, TI552-G6-C3, } \\
\text { TI552-G6-C4, TI552-G6-C5) }\end{array}$} & $\begin{array}{l}\text { Direct distribution } \\
\text { • Free hydroxide }\end{array}$ \\
\hline & $\begin{array}{l}\text { Acid digestion } \\
\text { • ICP metals (Table 3) }\end{array}$ \\
\hline \multirow[t]{2}{*}{ Caustic-leached permeate (TI552-G6-D) } & $\begin{array}{l}\text { Direct distribution } \\
\text { - Anions (Table 3) } \\
\text { - Free hydroxide } \\
\end{array}$ \\
\hline & $\begin{array}{l}\text { Acid digestion } \\
\text { - ICP metals (Table 3) } \\
\text { - GEA } \\
\text { - Total alpha } \\
\text { - }{ }^{238} \mathrm{Pu},{ }^{239+240} \mathrm{Pu} \\
\text { - } \mathrm{U} / \mathrm{KPA} \\
\text { - }{ }^{90} \mathrm{Sr} \\
\text { - Total beta }\end{array}$ \\
\hline
\end{tabular}




\begin{tabular}{|c|c|}
\hline Caustic-leached slurry (TI552-G6-12) & $\begin{array}{l}\text { HF assisted Acid digestion } \\
\quad \text { • ICP metals (Table 3) }\end{array}$ \\
\hline & $\begin{array}{l}\text { KOH fusion } \\
\text { - ICP metals (Table 3) } \\
\text { - GEA } \\
\text { - Total alpha } \\
\text { - }{ }^{238} \mathrm{Pu},{ }^{239+240} \mathrm{Pu} \\
\text { - U/KPA } \\
\text { - }{ }^{90} \mathrm{Sr} \\
\text { - Total beta }\end{array}$ \\
\hline & $\begin{array}{l}\text { Water Leach } \\
-\quad \text { Anions (Table 3) }\end{array}$ \\
\hline $\begin{array}{l}\text { First through fifth washes following caustic leach } \\
\text { (TI552-G6-E, TI552-G6-F, TI552-G6-G, TI552- }\end{array}$ & $\begin{array}{l}\text { Direct distribution } \\
\text { • Free hydroxide }\end{array}$ \\
\hline G6-H, TI552-G6-I) & $\begin{array}{l}\text { Acid digestion } \\
\quad \text { - ICP metals (Table 3) }\end{array}$ \\
\hline $\begin{array}{l}\text { Sixth wash and combined washes following } \\
\text { caustic leach (TI552-G6-J, TI552-G6-K) }\end{array}$ & $\begin{array}{l}\text { Direct distribution } \\
\text { - Anions (Table 3) } \\
\text { - Free hydroxide }\end{array}$ \\
\hline & $\begin{array}{l}\text { Acid digestion } \\
\text { - ICP metals (Table 3) } \\
\text { - GEA } \\
\text { - Total alpha } \\
\text { - }{ }^{238} \mathrm{Pu},{ }^{239+240} \mathrm{Pu} \\
\text { - } \mathrm{U} / \mathrm{KPA} \\
\text { - }{ }^{90} \mathrm{Sr} \\
\text { - Total beta } \\
\end{array}$ \\
\hline $\begin{array}{l}\text { Caustic-leached and washed slurry (TI552-G6- } \\
\text { 17) }\end{array}$ & $\begin{array}{l}\text { HF assisted Acid digestion } \\
\text { - ICP metals (Table 3) }\end{array}$ \\
\hline & $\begin{array}{l}\text { KOH fusion } \\
\text { - ICP metals (Table 3) } \\
\text { - GEA } \\
\text { - Total alpha } \\
\text { - }{ }^{238} \mathrm{Pu},{ }^{239+240} \mathrm{Pu} \\
\text { - } \mathrm{U} / \mathrm{KPA} \\
\text { - }{ }^{90} \mathrm{Sr} \\
\text { - Total beta }\end{array}$ \\
\hline & $\begin{array}{l}\text { Water Leach } \\
\text { - } \quad \text { Anions (Table 3) } \\
\text { - } \quad \text { TIC/TOC }\end{array}$ \\
\hline $\begin{array}{c}\text { Time interval Oxidative Leach filtrates } \\
\text { (TI552-G6-L1, TI552-G6-L2, TI552-G6-L3, }\end{array}$ & $\begin{array}{l}\text { Direct distribution } \\
\text { • Free hydroxide } \\
\end{array}$ \\
\hline TI552-G6-L4, TI552-G6-L5) & $\begin{array}{l}\text { Acid digestion } \\
\text { - ICP metals (Table 3) } \\
\text { - GEA } \\
\text { - Total alpha } \\
\text { - }{ }^{238} \mathrm{Pu},{ }^{239+240} \mathrm{Pu} \\
\text { - } \mathrm{U} / \mathrm{KPA} \\
\text { - }{ }^{90} \mathrm{Sr} \\
\text { - Total beta }\end{array}$ \\
\hline
\end{tabular}




\begin{tabular}{|c|c|}
\hline \multirow[t]{3}{*}{ Oxidative leach slurry (TI552-G6-22) } & $\begin{array}{r}\text { HF assisted Acid digestion } \\
\text { - ICP metals (Table 3) }\end{array}$ \\
\hline & $\begin{array}{l}\text { KOH fusion } \\
\text { - ICP metals (Table 3) } \\
\text { - GEA } \\
\text { - Total alpha } \\
\text { - }{ }^{238} \mathrm{Pu},{ }^{239+240} \mathrm{Pu} \\
\text { - } \mathrm{U} / \mathrm{KPA} \\
\text { - }{ }^{90} \mathrm{Sr} \\
\text { - Total beta }\end{array}$ \\
\hline & $\begin{array}{l}\text { Water Leach } \\
\text { - } \quad \text { Anions (Table 3) } \\
\text { - } \quad \text { TIC/TOC } \\
\end{array}$ \\
\hline \multirow[t]{2}{*}{$\begin{array}{c}\text { First and second washes following oxidative } \\
\text { leach (TI552-G6-M, TI552-G6-N) }\end{array}$} & $\begin{array}{l}\text { Direct distribution } \\
\text { - Free hydroxide }\end{array}$ \\
\hline & $\begin{array}{l}\text { Acid digestion } \\
\text { • ICP metals (Table 3) }\end{array}$ \\
\hline \multirow[t]{2}{*}{$\begin{array}{l}\text { Third wash and combined washes following } \\
\text { oxidative leach (TI552-G6-O, TI552-G6-P) }\end{array}$} & $\begin{array}{l}\text { Direct distribution } \\
\text { - Anions (Table 3) } \\
\text { - Free hydroxide }\end{array}$ \\
\hline & $\begin{array}{l}\text { Acid digestion } \\
\text { - ICP metals (Table 3) } \\
\text { - GEA } \\
\text { - Total alpha } \\
\text { - }{ }^{238} \mathrm{Pu},{ }^{239+240} \mathrm{Pu} \\
\text { - } \mathrm{U} / \mathrm{KPA} \\
\text { - }{ }^{90} \mathrm{Sr} \\
\text { - Total beta }\end{array}$ \\
\hline \multirow[t]{3}{*}{$\begin{array}{l}\text { Oxidatively leached and washed slurry (TI552- } \\
\text { G6-27) }\end{array}$} & $\begin{array}{r}\text { HF assisted Acid digestion } \\
\text { - ICP metals (Table 3) } \\
\end{array}$ \\
\hline & $\begin{array}{l}\text { KOH fusion } \\
\text { - ICP metals (Table 3) } \\
\text { - GEA } \\
\text { - Total alpha } \\
\text { - }{ }^{238} \mathrm{Pu},{ }^{239+240} \mathrm{Pu} \\
\text { - } \mathrm{U} / \mathrm{KPA} \\
\text { - }{ }^{90} \mathrm{Sr} \\
\text { - Total beta } \\
\end{array}$ \\
\hline & $\begin{array}{l}\text { Water Leach } \\
\text { - Anions (Table 3) }\end{array}$ \\
\hline
\end{tabular}

All analyses are to be conducted per approved PNNL procedures or test plans with the QC defined in the QC information Section. Table 3 defines the analytes of interest, the required detection limits, and analysis methods. 
Table 3. Method Detection Limits for Solids and Supernatants

\begin{tabular}{|c|c|c|c|}
\hline Analyte & Solids & Solutions & Analysis Method \\
\hline & $\mu \mathrm{Ci} / \mathrm{g}^{(\mathrm{a})}$ & $\overline{\mu \mathrm{Ci} / \mathrm{ml}}$ & \\
\hline${ }^{137} \mathrm{Cs}$ & $6.0 \mathrm{E}-02$ & $1.0 \mathrm{E}-02$ & \multirow{5}{*}{$\mathrm{GEA}^{\mathrm{c}}$} \\
\hline${ }^{60} \mathrm{Co}$ & $3.0 \mathrm{E}-02$ & $1.0 \mathrm{E}-02$ & \\
\hline${ }^{154} \mathrm{Eu}$ & 5.0E-03 & $4.0 \mathrm{E}-04$ & \\
\hline${ }^{155} \mathrm{Eu}$ & 8.0E-03 & $4.0 \mathrm{E}-04$ & \\
\hline${ }^{241} \mathrm{Am}$ & $3.0 \mathrm{E}-03$ & $2.0 \mathrm{E}-03$ & \\
\hline $\mathrm{Pu}$ & $1.0 \mathrm{E}-03$ & $1.0 \mathrm{E}-04$ & ${ }^{239+240} \mathrm{Pu}$ and ${ }^{238} \mathrm{Pu}$ by AEA \\
\hline Total alpha & $1.0 \mathrm{E}-02$ & $4.0 \mathrm{E}-03$ & Proportional counting \\
\hline Total beta & $1.0 \mathrm{E}-02$ & $1.0 \mathrm{E}-03$ & Proportional counting \\
\hline \multirow[t]{2}{*}{${ }^{90} \mathrm{Sr}$} & $1.0 \mathrm{E}-02$ & $1.0 \mathrm{E}-03$ & Separation and proportional counting \\
\hline & $\mu \mathrm{g} / \mathrm{g}$ & $\mu \mathrm{g} / \mathrm{ml}$ & \\
\hline $\mathrm{Al}$ & $3.0 \mathrm{E}+02$ & $7.5 \mathrm{E}+01$ & \multirow{17}{*}{ ICP-OES } \\
\hline $\mathrm{B}$ & $2.0 \mathrm{E}+02$ & $7.5 \mathrm{E}+01$ & \\
\hline $\mathrm{Bi}$ & $4.0 \mathrm{E}+02$ & $3.0 \mathrm{E}+01$ & \\
\hline $\mathrm{Cd}$ & $7.5 \mathrm{E}+01$ & $7.5 \mathrm{E}+01$ & \\
\hline $\mathrm{Cr}$ & $1.2 \mathrm{E}+02$ & $1.5 \mathrm{E}+01$ & \\
\hline $\mathrm{Fe}$ & $3.0 \mathrm{E}+02$ & $7.5 \mathrm{E}+01$ & \\
\hline $\mathrm{K}$ & $1.0 \mathrm{E}+03^{(\mathrm{b})}$ & $5.0 \mathrm{E}+01$ & \\
\hline $\mathrm{Mn}$ & $3.0 \mathrm{E}+02$ & $1.5 \mathrm{E}+01$ & \\
\hline $\mathrm{Na}$ & $3.0 \mathrm{E}+03$ & $7.5 \mathrm{E}+01$ & \\
\hline $\mathrm{Ni}$ & $1.6 \mathrm{E}+02^{(\mathrm{b})}$ & $3.0 \mathrm{E}+01$ & \\
\hline $\mathrm{P}$ & $2.0 \mathrm{E}+02$ & $1.0 \mathrm{E}+01$ & \\
\hline $\mathrm{S}$ & $1.5 \mathrm{E}+03$ & $2.0 \mathrm{E}+2$ & \\
\hline $\mathrm{Si}$ & $3.0 \mathrm{E}+03$ & $7.5 \mathrm{E}+01$ & \\
\hline $\mathrm{Sr}$ & $3.0 \mathrm{E}+02$ & $7.5 \mathrm{E}+01$ & \\
\hline $\mathrm{Zn}$ & $3.0 \mathrm{E}+02$ & $7.5 \mathrm{E}+01$ & \\
\hline $\mathrm{Zr}$ & $3.0 \mathrm{E}+02$ & $7.5 \mathrm{E}+01$ & \\
\hline $\mathrm{U}$ & $2.5 \mathrm{E}+03$ & $7.5 \mathrm{E}+01$ & \\
\hline $\mathrm{U}$ & $6.0 \mathrm{E}+01$ & $6.0 \mathrm{E}+01$ & Kinetic Phosphorescence \\
\hline Fluoride & $2.5 \mathrm{E}+02$ & $1.2 \mathrm{E}+02$ & \multirow{6}{*}{$\begin{array}{l}\text { Ion Chromatography } \\
\text { (water-soluble species) }\end{array}$} \\
\hline Nitrite & $2.5 \mathrm{E}+02$ & $1.2 \mathrm{E}+02$ & \\
\hline Nitrate & $2.5 \mathrm{E}+02$ & $1.2 \mathrm{E}+02$ & \\
\hline Phosphate & $2.5 \mathrm{E}+02$ & $1.2 \mathrm{E}+02$ & \\
\hline Sulfate & $2.5 \mathrm{E}+02$ & $1.2 \mathrm{E}+02$ & \\
\hline Oxalate & $8.0 \mathrm{E}+02$ & $4.0 \mathrm{E}+02$ & \\
\hline Hydroxide & NA & 1E-01 M & Titration \\
\hline Total organic carbon & NA & $4.0 \mathrm{E}+02$ (as C) & \multirow{2}{*}{ Hot persulfate method } \\
\hline Total inorganic carbon & NA & $2.0 \mathrm{E}+02$ (as C) & \\
\hline
\end{tabular}


ฮั้

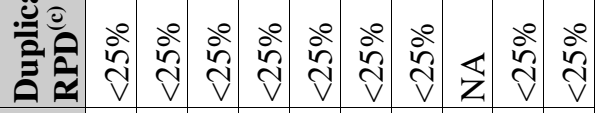

s.

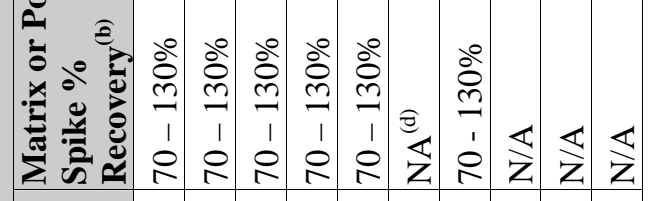

o

n

- $\quad$ bे

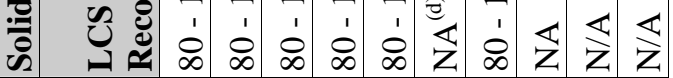

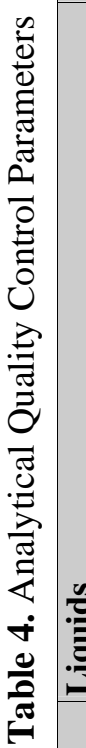

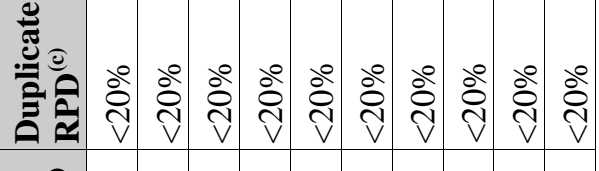

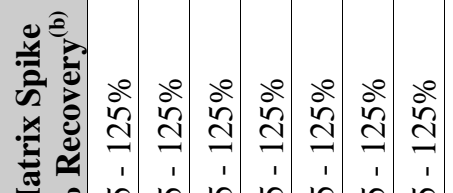

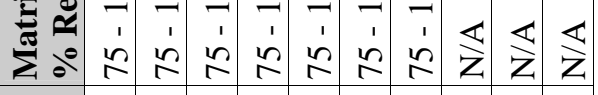

de

m

空

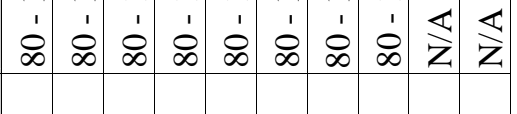

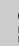

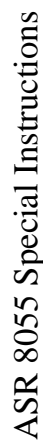

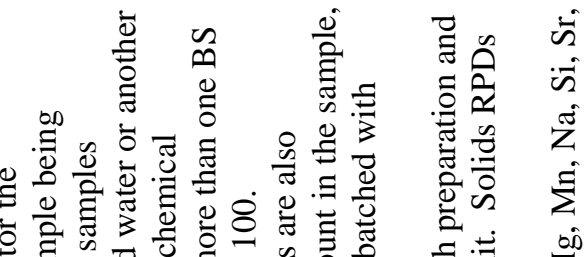

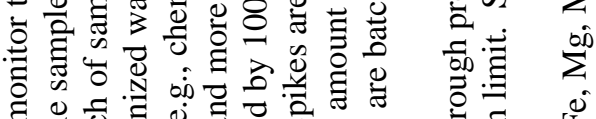

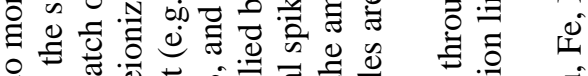

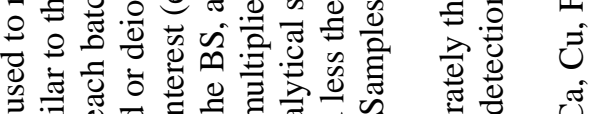

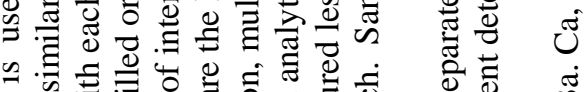

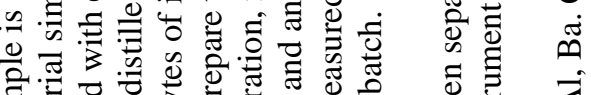

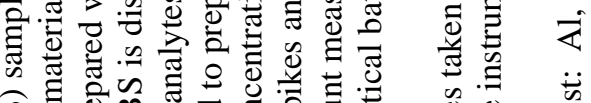

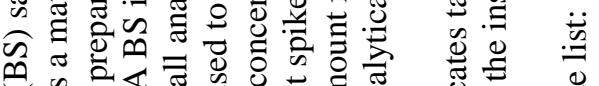

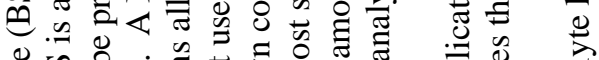

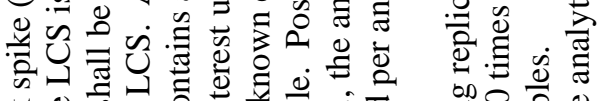

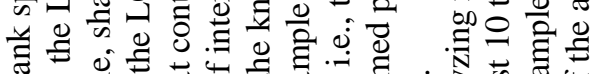

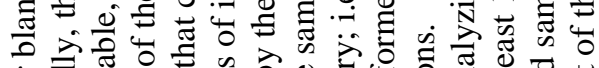
。

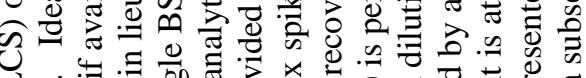

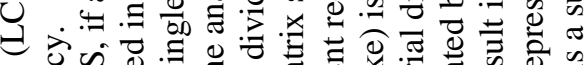

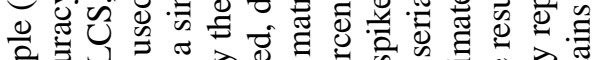

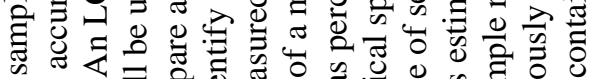

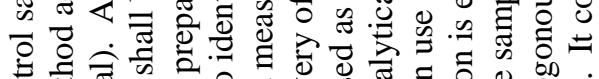

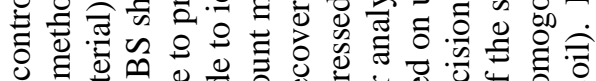
入

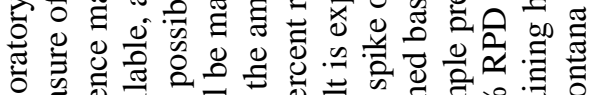

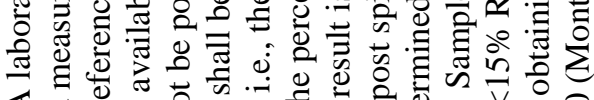

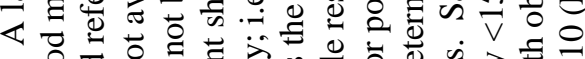

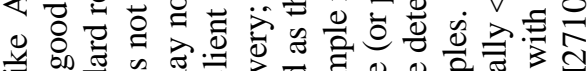

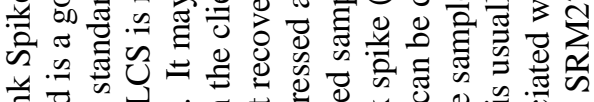

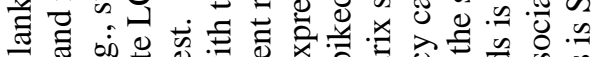
$\vec{m}$ 药

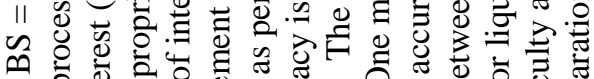

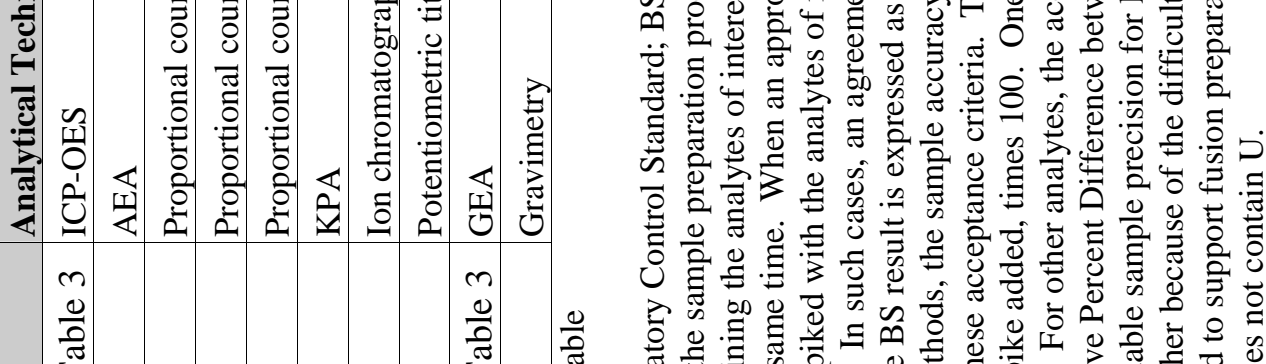

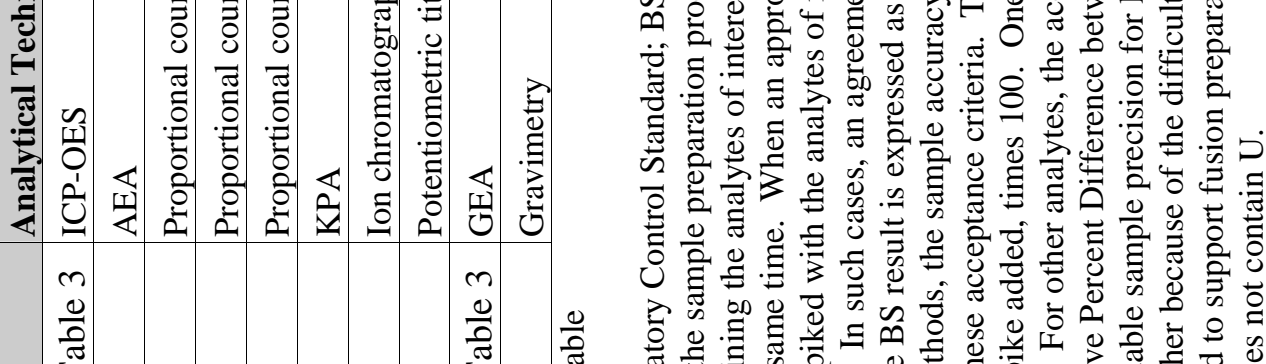

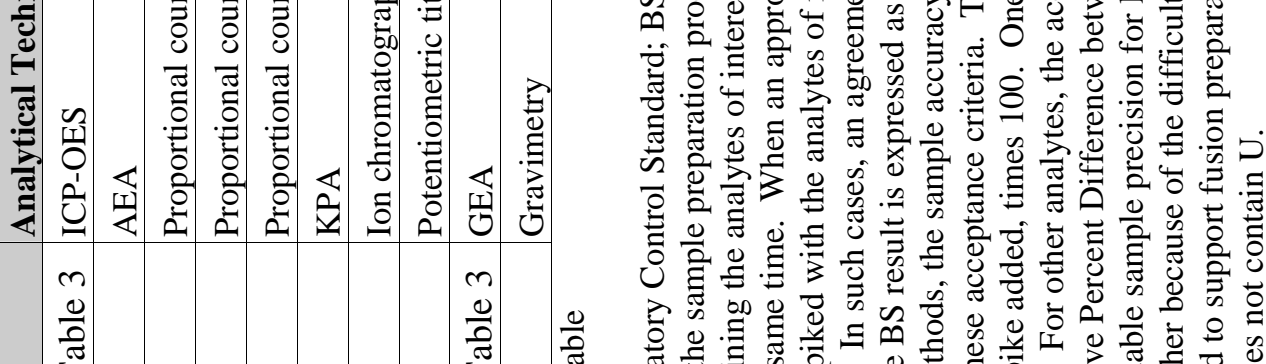

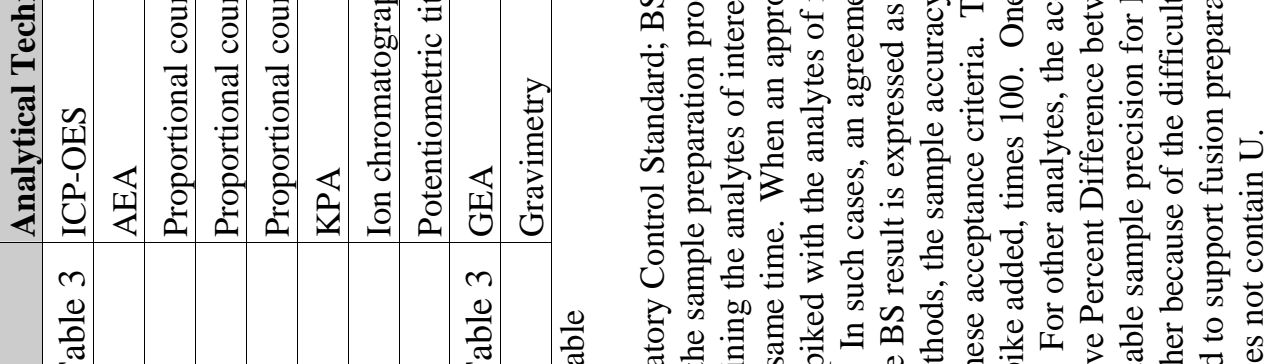

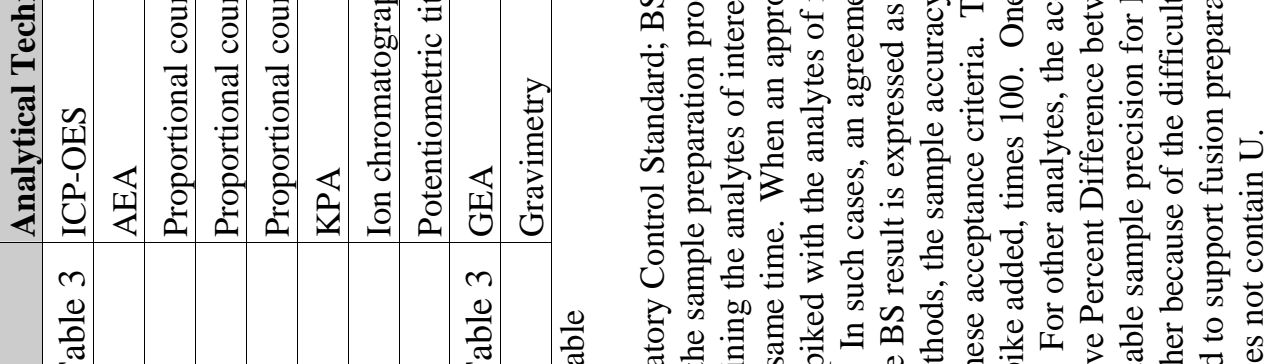

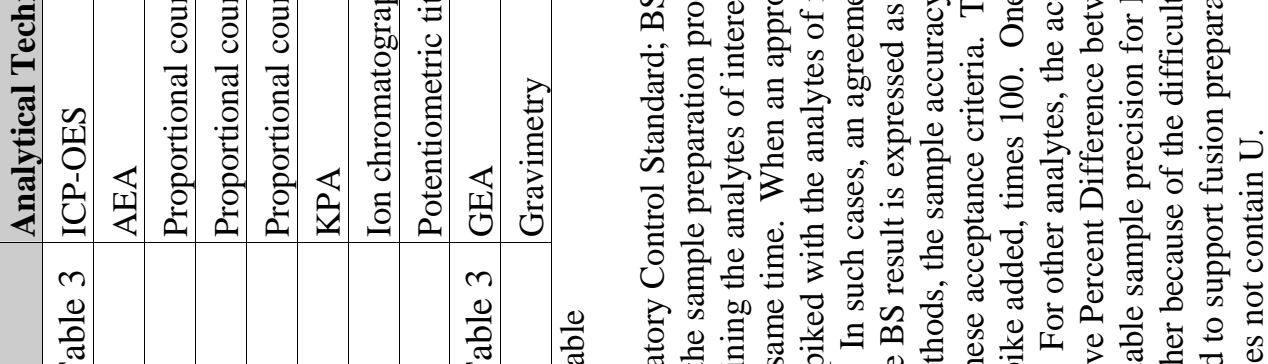

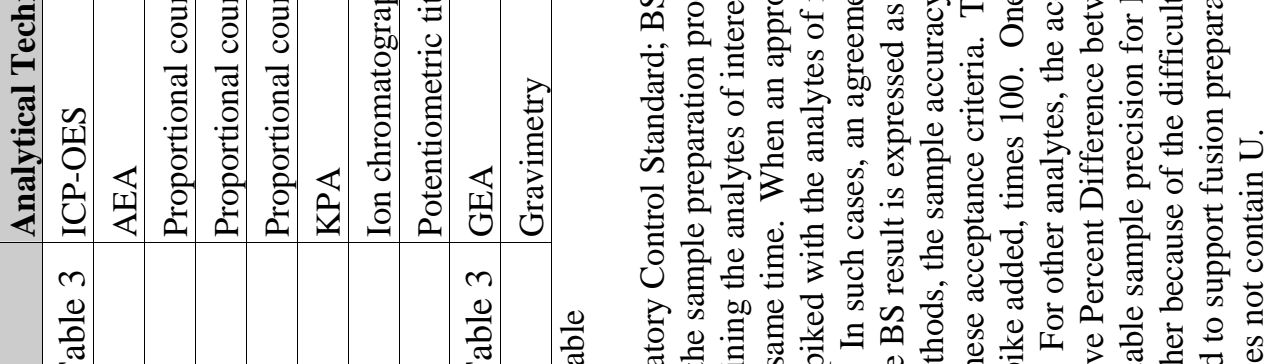

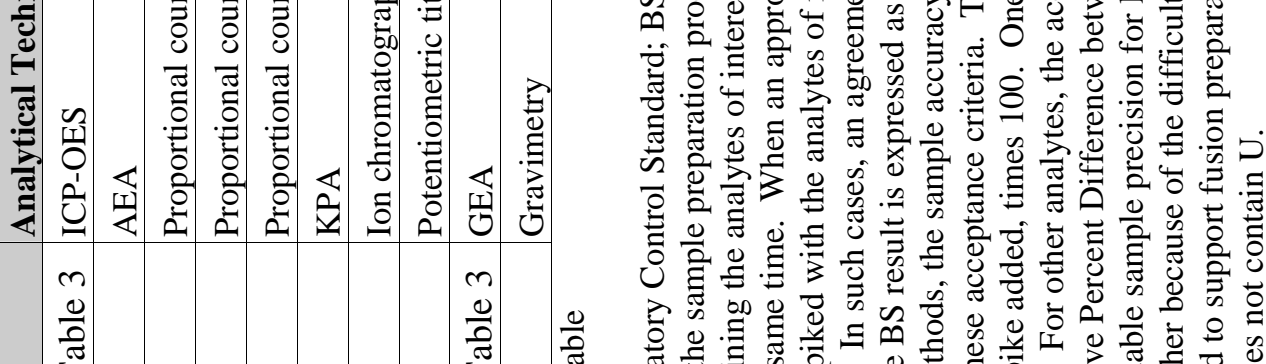

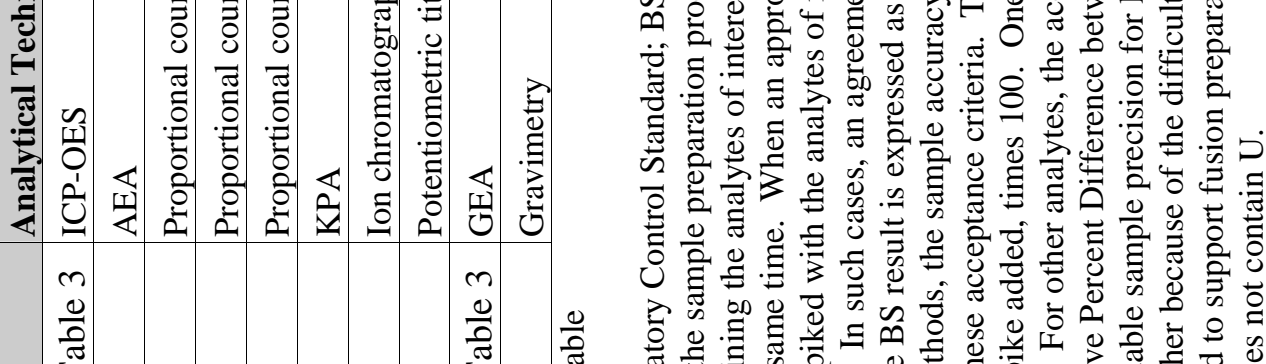

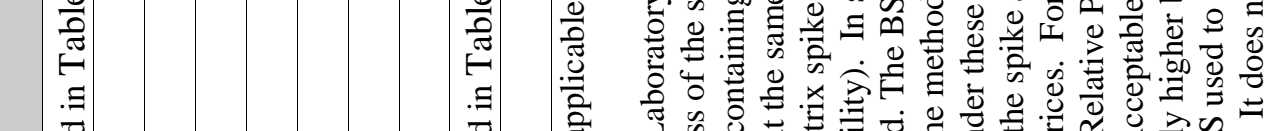

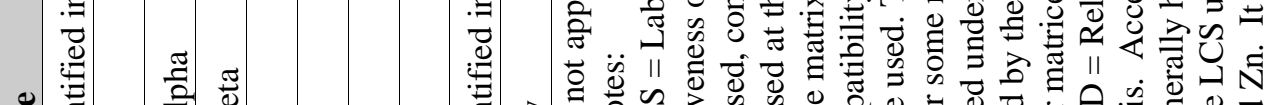

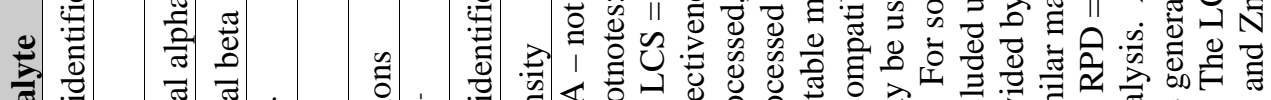

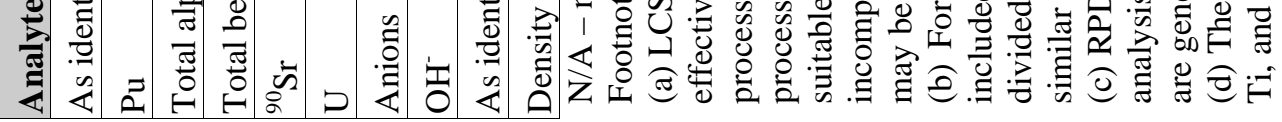


Requestor --- Complete all fields on this COVER PAGE, unless specified as optional or ASR is a revision

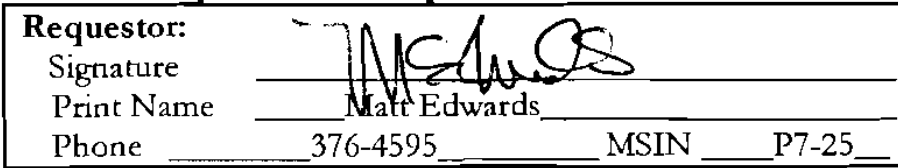

Matrix Type Information

\begin{tabular}{llll}
\hline Liquids: & X Aqueous & $\square$ Organic & $\square$ Multi-phase \\
Solids: & $\square$ Soil & X Sludge & $\square$ Sediment \\
& $\square$ Glass & $\square$ Filter & $\square$ Metal \\
& $\square$ Smear & $\square$ Organic & $\square$ Other
\end{tabular}

- Other: $\square$ Solid/Liquid Mixture, Slurry $\square$ Gas $\square$ Biological Specimen

(If sample matrices vary, specify on Request Page)

\section{Disposal Information}

- Disposition of Virgin Samples:

Virgin samples are returned to requestor unless archiving provisions are made with receiving group!

If archiving, provide:

Archiving Reference Doc:

- Disposition of Treated Samples:

$$
\text { X Dispose } \square \text { Return }
$$

- Is Work Associated with a Fee-Based Milestone? X No $\square$ Yes If yes, milestone due date:

- Preliminary Results Requested, As Available? $\square$ No X Yes
Project Number:
52964
Work Package:
F99189

QA/Special Requirements

\section{- QA Plan: \\ X ASO-QAP-001, Rev. 6 (Equivalent to HASQARD)}

$\mathbf{X}$ Additional QA Requirements, List Document Below:

Reference Doc Number:_RPP_WTP-QA-005, Rev. 2_

- Field COC Submitted? X No $\square$ Yes

- Lab COC Required? X No $\square$ Yes

- Sample/Container Inspection Documentation Required? $\mathrm{X}$ No $\square$ Yes

- Hold Time: X No $\square$ Yes

If Yes,

Contact ASO

Lead before

submitting

Samples

Use SW 846 (PNL-ASO-071, identify analytes/methods where holding times apply)

- Special Storage Requirements: X None $\square$ Refrigerate $\square$ Other, Specify:

- Data Requires ASO Quality Engineer Review? X No $\square$ Yes Data Reporting Information
- Data Reporting Level
X ASO-QAP-001 (Equivalent to HASQARD).
$\square$ Minimum data report.
$\square$ Project Specific Requirements:
Contact ASO Lead or List Reference
Document:

- Requested Analytical Work Completion Date:

(Note: Priority rate charge for $<10$ business day curn-arouud time)

- Negotiated Commitment Date: $1 / 1410 \%$ (To be completed by ASO Lead) $P$ LRG KKT MJS JRD Waste Designation Information PKB , CZS, KGS, LPP, KJC

- Sample Information Check List Attached? X No $\square$ Yes If no, Reference Doc Attached: or, Previous ASR Number: 7918
Does the Waste Designation Documentation Indicate Presence of $P C B$ s? $\mathrm{X}$ No $\square$ Yes or, Previous RPL Number:

Send Report To: Matt Edwards MSIN P7-25 Sandy Fiskum MSIN P7-22

Additional or Special Instructions _The requirements of Statement of Work, RPP-WTP-QA-005, Rev. 2, apply to this work. Task-specific Quality Control criteria are attached. Reference Document (i.e., TP-RPP-WTP-

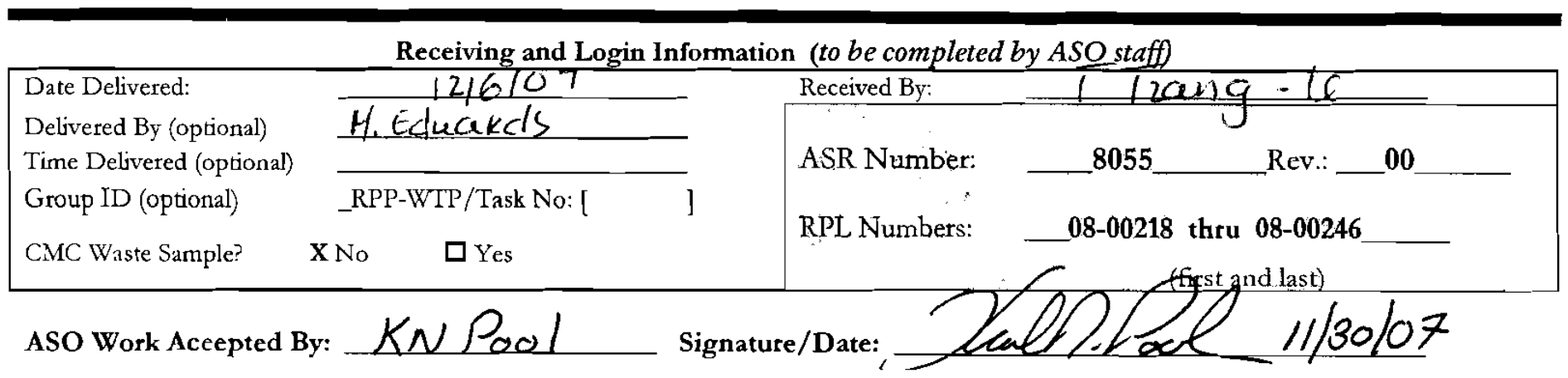




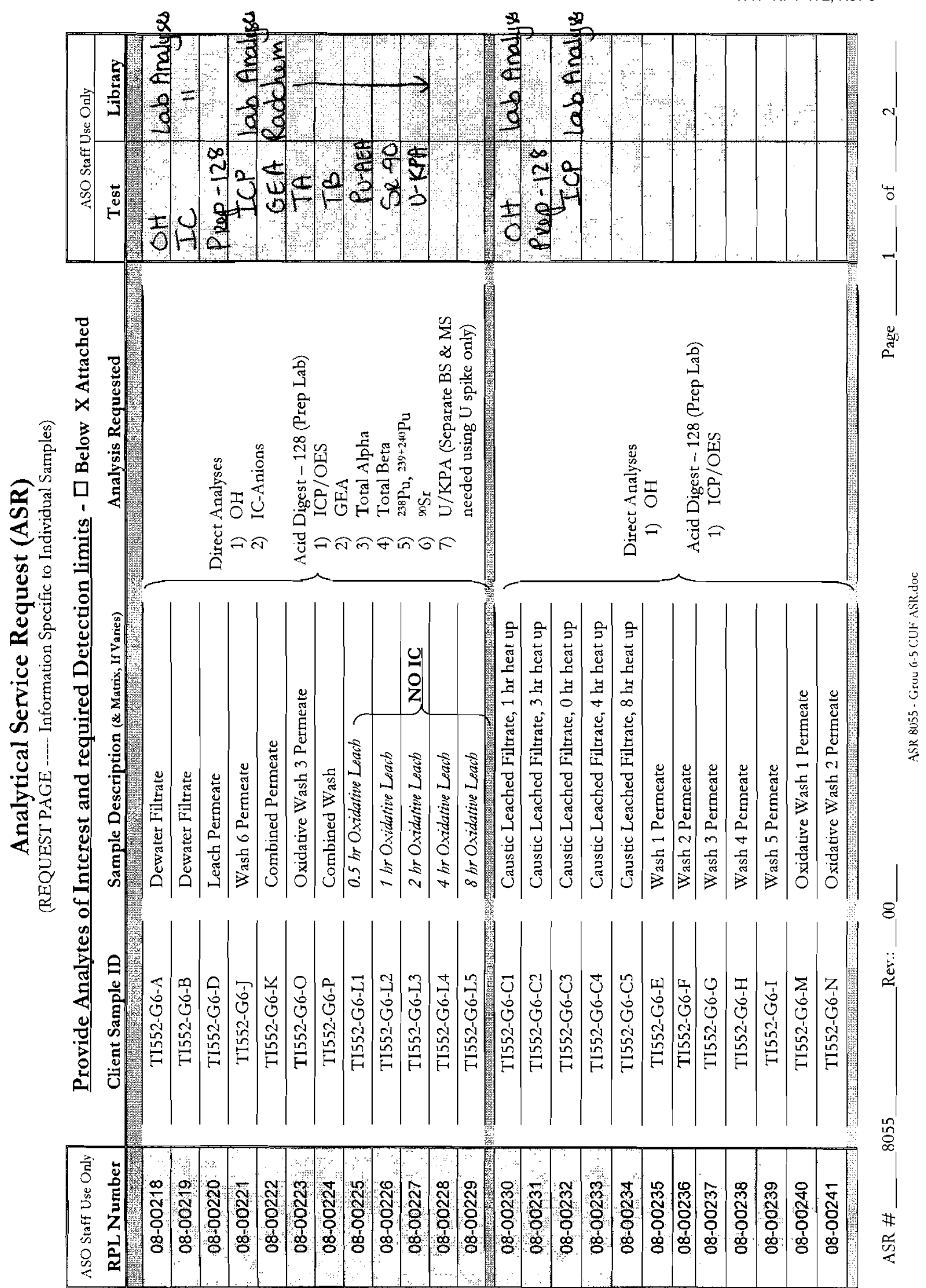


WTP-RPT-172, Rev 0
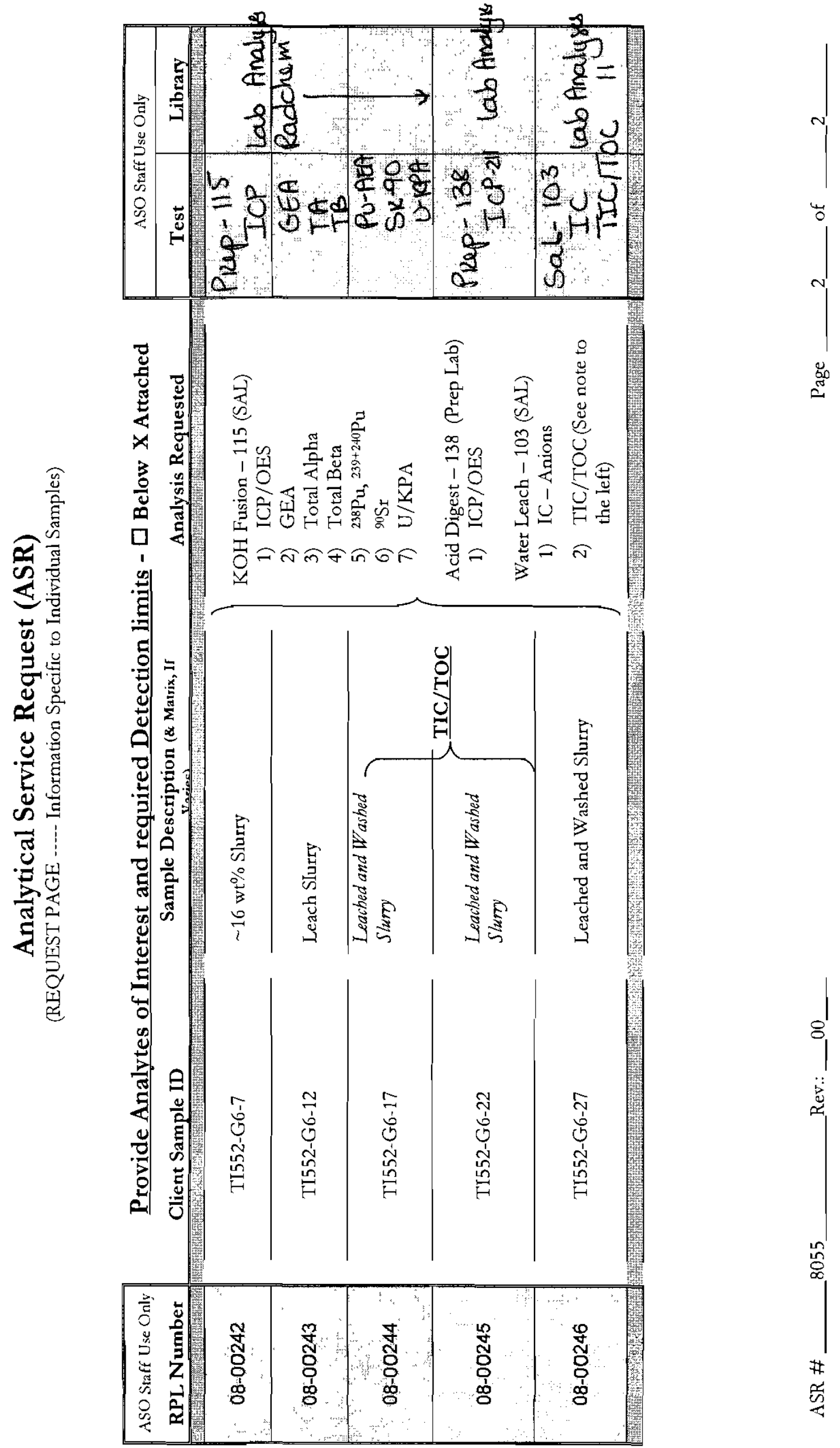

| 
Battelle PNNL/RS\&E/Inorganic Analysis ... ICPOES Analysis Report PO Box 999, Richland, Washington 99352

Project / WP\#: 52964 / F99189

ASR\#: $\quad 8055$

Client: $\quad$ M. Edwards

Total Samples: 5 (solid)

\begin{tabular}{|l|c|c|}
\hline \multicolumn{2}{|c|}{ First } & Last \\
\hline RPL\#: & $08-00242$ & $08-00246$ \\
\hline Client ID: & TI552-G6-7 & TI552-G6-27 \\
\hline $\begin{array}{l}\text { Sample Preparation: PNL-ALO-115, “Solubilization of Metals from Solids } \\
\text { using a KOH-KNO }\end{array}$ Fusion", 12/06/07 (SAL/dk). \\
\hline
\end{tabular}

Procedure: $\quad$ RPG-CMC-211, "Determination of Elemental Composition by Inductively Coupled Argon Plasma Optical Emission Spectrometry (ICPOES)", Rev 1.

Analyst: $\quad$ J. Deschane

Analysis Date (File): $\quad \underline{12-12-2007}$ (C0081)

See Chemical Measurement Center 98620 file: ICP-325-405-3

(Calibration and Maintenance Records)

M\&TE Number: $\quad \underline{\text { N827583 }}$ (ICPOES instrument)

M19445 (Mettler AT400 Balance)

$$
\begin{aligned}
& \frac{\text { S.M. Whn } 12 / 18 / 07}{\text { Preparer }} \\
& \frac{\text { C.9. Ulomy } 12 / 18 / 07}{\text { Review and Concur }}
\end{aligned}
$$




\section{Battelle PNNL/RS\&E/Inorganic Analysis ... ICPOES Analysis Report}

Five samples submitted under Analytical Service Request (ASR) 8055 were analyzed by ICPOES. The samples were prepared following RPL fusion procedure PNL-ALO-115 using a nominal 0.2 grams of sample. The samples were dried to constant mass prior to undergoing fusion and were diluted to a final volume of $100 \mathrm{~mL}$.

Analytes of interest (AOIs) were specified in the ASR, and are listed in the upper section of the attached ICPOES Data Report. The quality control (QC) results for these AOIs have been evaluated and are presented below. Analytes other than AOIs are reported in the bottom section of the report, but have not been fully evaluated for $\mathrm{QC}$ performance. The results are given as $\mu \mathrm{g} / \mathrm{g}$ for each detected analyte, and have been adjusted for all laboratory processing factors and instrument dilutions.

Calibration of the ICPOES was done following the manufacturer's recommended calibration procedure and using multi-analyte custom standard solutions traceable to the National Institute of Standards and Technology (NIST). Midrange calibration verification standards (MCVA and MCVB) were used to verify acceptance of the two-point calibration curves obtained for each analyte, and also used for continuing calibration verification.

Minimum Method Detection Limit (MDL) values were specified in the ASR. Except for sodium, MDL levels were met for all AOIs. Because of known impurities of sodium in the 115 fusion flux, the MDL for this analyte has been set artificially high to account for this expected impurity level. Measured levels of sodium in the samples, however, exceeded the requested MDL level.

The controlling documents are ASO-QAP-001, and the client supplied RPP-WTP-QA-005, Rev. 2 and "ASR 8055 Special Instructions". Instrument calibrations, QC checks and blanks (e.g., ICV/ICB, CCV/CCB, LLS, ICS), post-spike, laboratory control standard (LCS), duplicate, and serial dilution were conducted during the analysis run. The LCS was prepared using a nominal 0.2 grams of SRM-2710 (Montana Soil).

\section{Preparation Blank (PB):}

A preparation blank (reagents only) was prepared for the fusion process. Except for manganese, the concentrations of all AOIs were within the acceptance criteria of $\leq \mathrm{EQL}$ (estimated quantitation level) or less than $\leq 5 \%$ of the concentration in the sample. Manganese was measured at a level of $123 \mu \mathrm{g} / \mathrm{g}$ in the blank which exceeded the $5 \%$ criteria in three of the five samples (08-00242, 08-00243, and 08-00244). The manganese is presumed to have occurred from cross contamination in the SAL during sample preparation.

\section{Blank Spike (BS)/Laboratory Control Sample (LCS):}

An LCS (Montana Soil) was prepared for the fusion process. Recovery values are listed for all analytes included in the spike that were measured at or above the EQL. The recovery values were within the acceptance criterion of $80 \%$ to $120 \%$ for all AOIs meeting the above requirement. 


\section{Battelle PNNL/RS\&E/Inorganic Analysis ... ICPOES Analysis Report}

\section{Matrix-Spiked Sample:}

No matrix spike sample was provided for analysis.

\section{Duplicate Relative Percent Difference (RPD):}

A duplicate was prepared for the fusion process. RPDs are listed for all analytes that were measured at or above the EQL. The RPDs were within the client acceptance criterion of $\leq 25 \%$ for all AOIs meeting the above requirement.

\section{Post-Spike/Analytical Spike Sample (A Component):}

An analytical spike (A component) was conducted for the fusion process. Recovery values are listed for all analytes in the spike that were measured at or above the EQL, and that had a spike concentration $\geq 25 \%$ of that in the sample. The recovery values were within the client acceptance criterion of $70 \%$ to $130 \%$ for all AOIs meeting the above requirements.

\section{Post Spike/Analytical Spike Sample (B Component):}

An analytical spike (B component) was conducted for the fusion process. Recovery values are listed for all analytes in the spike that were measured at or above the EQL, and that had a spike concentration $\geq 25 \%$ of that in the sample. The recovery values were within the client acceptance criterion of $70 \%$ to $130 \%$ for all AOIs meeting the above requirements.

\section{Serial dilution:}

Five-fold serial dilution was conducted for the fusion process. Percent differences (\%Ds) are listed for all analytes that had a concentration at or above the EQL in the diluted sample. The $\%$ Ds were within the acceptance criterion of $\leq 10 \%$ for all AOIs meeting the above requirement.

\section{Other QC:}

All other instrument-related QC tests for the AOIs passed within the appropriate acceptance criteria.

\section{Comments:}

1) The "Final Results" have been corrected for all laboratory dilutions performed on the samples during processing and analysis, unless specifically noted.

2) Instrument detection limits (IDL) and estimated quantitation limits (EQL) shown are for acidified water. Detection limits for other matrices may be determined if requested. Method detection limits (MDL) can be estimated by multiplying the IDL by the "Multiplier". The estimated quantitation limit (EQL) for each concentration value can be obtained by multiplying the EQL by the "Multiplier".

3) Routine precision and bias is typically $\pm 15 \%$ or better for samples in dilute, acidified water (e.g. $2 \% \mathrm{v} / \mathrm{v}$ $\mathrm{HNO}_{3}$ or less) at analyte concentrations $>$ EQL up to the upper calibration level. This also presumes that the total dissolved solids concentration in the sample is less than $5000 \mu \mathrm{g} / \mathrm{mL}(0.5$ per cent by weight). Note that bracketed values listed in the data report are within the MDL and the EQL, and have potential uncertainties greater than $15 \%$. Concentration values < MDL are listed as "-.". Note, that calibration and QC standards are validated to a precision of $\pm 10 \%$.

4) Absolute precision, bias and detection limits may be determined on each sample if required by the client. The maximum number of significant figures for all ICP measurements is two.

5) Analytes included in the spike A component (for the AS/PS) are; $\mathrm{Ag}, \mathrm{Al}, \mathrm{As}, \mathrm{B}, \mathrm{Ba}, \mathrm{Be}, \mathrm{Bi}, \mathrm{Ca}, \mathrm{Cd}, \mathrm{Co}, \mathrm{Cr}$, $\mathrm{Cu}, \mathrm{Fe}, \mathrm{K}, \mathrm{Li}, \mathrm{Mg}, \mathrm{Mn}, \mathrm{Mo}, \mathrm{Na}, \mathrm{Ni}, \mathrm{P}, \mathrm{Pb}, \mathrm{S}, \mathrm{Sb}, \mathrm{Se}, \mathrm{Si}, \mathrm{Sn}, \mathrm{Sr}, \mathrm{Ta}, \mathrm{Ti}, \mathrm{Tl}, \mathrm{V}, \mathrm{W}, \mathrm{Y}, \mathrm{Zn}$, and Zr. Analytes included in the spike $\mathrm{B}$ component are; $\mathrm{Ce}, \mathrm{Dy}, \mathrm{Eu}, \mathrm{La}, \mathrm{Nd}, \mathrm{Pd}, \mathrm{Rh}, \mathrm{Ru}, \mathrm{Te}, \mathrm{Th}$, and $\mathrm{U}$. 


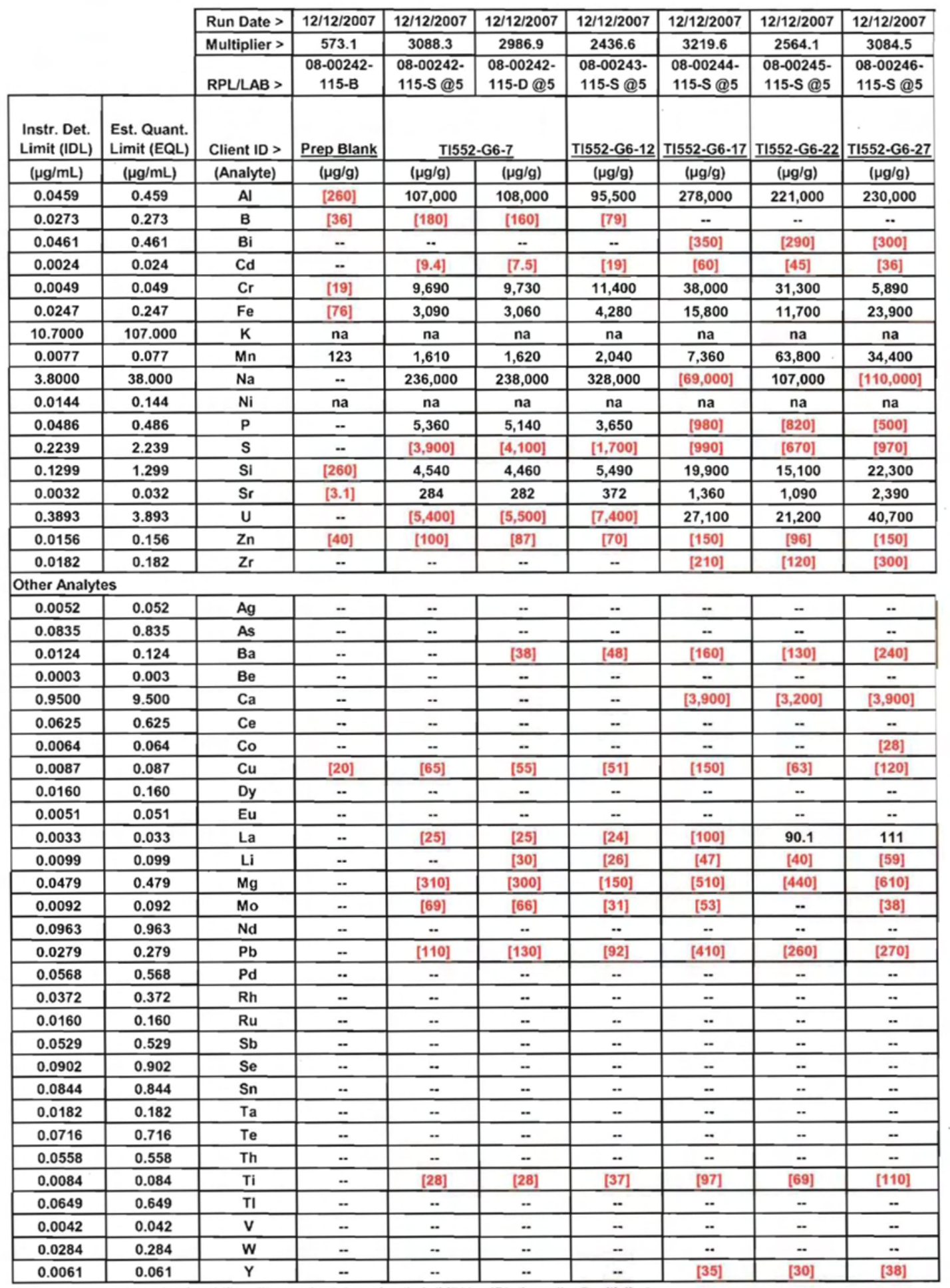

1) "-." indicates the value is $<$ MDL. The method detection limit (MDL) =IDL times the "multiplier" near the top of each column. The estimated sample quantitation limit $=E Q L$ (in Column 2) times the "multiplier". Overall error for values $\geq E Q L$ is estimated to be within $\pm 15 \%$.

2) Values in brackets [] are $\geq M D L$ but $<E Q L$, with errors likely to exceed $15 \%$. 
QC Performance 12/12/07

\begin{tabular}{|c|c|c|c|c|c|c|}
\hline Criteria > & $\leq 25 \%$ & $80 \%-120 \%$ & $70 \%-130 \%$ & $70 \%-130 \%$ & $70 \%-130 \%$ & $\leq 10 \%$ \\
\hline$Q C I D>$ & $\begin{array}{c}08-00242 \\
\text { Dup }\end{array}$ & LCS/BS & MS (none) & $\begin{array}{c}\text { 08-00242 + } \\
\text { PS.A }\end{array}$ & $\begin{array}{c}\text { 08-00242 + } \\
\text { PS-B } \\
\end{array}$ & $\begin{array}{c}08-00242 \\
5 \text {-fold } \\
\text { Serial Dil }\end{array}$ \\
\hline Analytes & RPD (\%) & $\%$ Rec & $\% \operatorname{Rec}$ & $\% \operatorname{Rec}$ & $\%$ Rec & $\%$ Diff \\
\hline Al & 1.4 & 96 & & 104 & & 5.4 \\
\hline B & & & & 106 & & \\
\hline$B i$ & & & & 100 & & \\
\hline $\mathrm{Cd}$ & & & & 101 & & \\
\hline $\mathrm{Cr}$ & 0.5 & & & 106 & & 6.7 \\
\hline $\mathrm{Fe}$ & 0.8 & 98 & & 104 & & \\
\hline $\mathrm{K}$ & na & na & na & na & na & na \\
\hline $\mathrm{Mn}$ & 0.7 & 102 & & 104 & & 6.9 \\
\hline $\mathrm{Na}$ & 0.8 & & & 103 & & \\
\hline $\mathrm{Ni}$ & na & na & na & na & na & na \\
\hline $\mathbf{P}$ & 4.2 & & & 105 & & \\
\hline $\mathbf{s}$ & & & & 107 & & \\
\hline Si & 1.8 & 89 & & 106 & & \\
\hline Sr & 0.5 & 96 & & 102 & & \\
\hline$u$ & & & & & 95 & \\
\hline $\mathrm{Zn}$ & & 94 & & 104 & & \\
\hline $\mathrm{Zr}$ & & & & 103 & & \\
\hline \multicolumn{7}{|c|}{ Other Analytes } \\
\hline $\mathrm{Ag}$ & & & & 93 & & \\
\hline As & & & & 105 & & \\
\hline Ba & & 95 & & 103 & & \\
\hline $\mathrm{Be}$ & & & & 100 & & \\
\hline $\mathrm{Ca}$ & & & & 107 & & \\
\hline $\mathrm{Ce}$ & & & & & 95 & \\
\hline Co & & & & 102 & & \\
\hline $\mathrm{Cu}$ & & 96 & & 105 & & \\
\hline Dy & & & & & 97 & \\
\hline Eu & & & & & 95 & \\
\hline La & & & & & 97 & \\
\hline Li & & & & 103 & & \\
\hline $\mathrm{Mg}$ & & 94 & & 103 & & \\
\hline Mo & & & & 102 & & \\
\hline $\mathrm{Nd}$ & & & & & 103 & \\
\hline $\mathrm{Pb}$ & & 91 & & 104 & & \\
\hline Pd & & & & & 90 & \\
\hline $\mathbf{R h}$ & & & & & 94 & \\
\hline Ru & & & & & 97 & \\
\hline Sb & & & & 104 & & \\
\hline Se & & & & 103 & & \\
\hline Sn & & & & 100 & & \\
\hline Ta & & & & 100 & & \\
\hline Te & & & & & 95 & \\
\hline Th & & & & & 98 & \\
\hline $\mathrm{Ti}$ & & 91 & & 104 & & \\
\hline $\mathrm{TI}$ & & & & 97 & & \\
\hline $\mathrm{v}$ & & & & 101 & & \\
\hline w & & & & 100 & & \\
\hline $\mathrm{Y}$ & & & & 101 & & \\
\hline
\end{tabular}

Shaded results are outside the acceptance criteria.

$n r=$ not recovered; spike concentration less than $25 \%$ of sample concentration.

na $=$ not applicable; $\mathrm{KOH}$ flux and Ni crucible or $\mathrm{Na}_{2} \mathrm{O}_{2}$ flux and $\mathrm{Zr}$ crucible used for preparing sample 
Battelle PNNL/RS\&E/Inorganic Analysis ... ICPOES Analysis Report PO Box 999, Richland, Washington 99352

Project / WP\#: $\quad 52964$ / F99189

ASR\#: $\quad 8055$

Client: $\quad$ M. Edwards

Total Samples: 24 (liquid)

\begin{tabular}{|c|c|c|}
\hline & First & Last \\
\hline RPL\#: & $08-00218$ & $08-00241$ \\
\hline Client ID: & TI552-G6-A & TI552-G6-N \\
\hline
\end{tabular}

Procedure: $\quad$ RPG-CMC-211, "Determination of Elemental Composition by Inductively Coupled Argon Plasma Optical Emission Spectrometry (ICPOES)", Rev 1.

Analyst: $\quad \underline{\text { P. Berry \& B. Oliver }}$

Analysis Date (File): $\quad \underline{01-07-2008}(\mathrm{C} 0087)$

$\underline{01-09-2007}(\mathrm{C} 0089)$

See Chemical Measurement Center 98620 file: $\underline{\text { ICP-325-405-3 }}$

(Calibration and Maintenance Records)

M\&TE Number: $\quad \underline{\text { N827583 }}$ (ICPOES instrument) $\underline{\text { M19445 (Mettler AT400 Balance) }}$
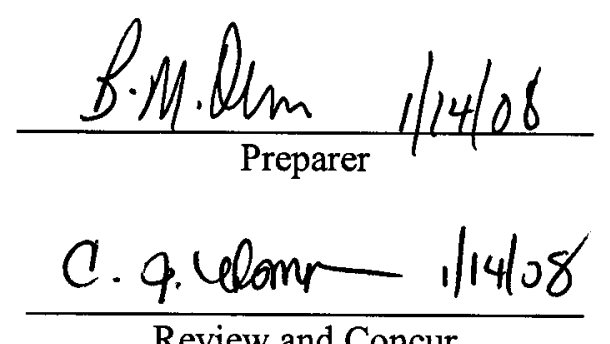

Review and Concur 


\section{Battelle PNNL/RS\&E/Inorganic Analysis ... ICPOES Analysis Report}

Twenty-four samples submitted under Analytical Service Request (ASR) 8055 were analyzed by ICPOES. The samples were prepared following RPL procedure RPG-CMC-128 using $1 \mathrm{~mL}$ of sample and diluting to a final volume of $25 \mathrm{~mL}$. Both sample preparation and analysis was done in two separate batches.

Analytes of interest (AOIs) were specified in the ASR, and are listed in the upper section of the attached ICPOES Data Report. The quality control (QC) results for these AOIs have been evaluated and are presented below. Analytes other than AOIs are reported in the bottom section of the report, but have not been fully evaluated for QC performance. The results are given as $\mu \mathrm{g} / \mathrm{mL}$ for each detected analyte, and have been adjusted for all laboratory processing factors and instrument dilutions.

Calibration of the ICPOES was done following the manufacturer's recommended calibration procedure and using multi-analyte custom standard solutions traceable to the National Institute of Standards and Technology (NIST). Midrange calibration verification standards (MCVA and MCVB) were used to verify acceptance of the two-point calibration curves obtained for each analyte, and also used for continuing calibration verification.

Minimum Method Detection Limit (MDL) values were specified in the ASR. Except for potassium in one sample, MDL levels were met for all AOIs.

The controlling documents are ASO-QAP-001, and the client supplied RPP-WTP-QA-005, Rev. 2 and "ASR 8055 Special Instructions". Instrument calibrations, QC checks and blanks (e.g., ICV/ICB, CCV/CCB, LLS, ICS), post-spike, blank spike, matrix spike, duplicate, and serial dilution were conducted during the analysis run. The blank spike and matrix spike were prepared using $1.5 \mathrm{~mL}$ each of BPNL-QC-1A, and $-2 \mathrm{~A}$ solutions.

\section{Preparation Blank (PB):}

A preparation blank (reagents only) was prepared for the extraction process for both sample batches. The concentrations of all AOIs were within the acceptance criteria of $\leq$ EQL (estimated quantitation level) or less than $\leq 5 \%$ of the concentration in the sample.

\section{Blank Spike (BS)/Laboratory Control Sample (LCS):}

A blank spike was prepared for the extraction process for both sample batches. Recovery values are listed for all analytes included in the spike that were measured at or above the EQL. The recovery values were within the acceptance criterion of $80 \%$ to $120 \%$ for all AOIs meeting the above requirement.

\section{Matrix-Spiked Sample:}

A matrix spike was prepared for the extraction process for both sample batches. Recovery values are listed for all analytes included in the spike that were measured at or above the EQL. The recovery values were within the acceptance criterion of $75 \%$ to $125 \%$ for all AOIs meeting the above requirement. 


\section{Battelle PNNL/RS\&E/Inorganic Analysis ... ICPOES Analysis Report}

\section{Duplicate Relative Percent Difference (RPD):}

A duplicate was prepared for the extraction process for both sample batches. RPDs are listed for all analytes that were measured at or above the EQL. Except for silicon ( 28\%) in the first analysis batch, the RPDs were within the acceptance criterion of $\leq 20 \%$ for all AOIs meeting the above requirement.

Post-Spike/Analytical Spike Sample (Spike A Elements):

A post spike (A component) was conducted on Sample 08-00218. Recovery values are listed for all analytes in the spike that were measured at or above the EQL, and that had a spike concentration $\geq 25 \%$ of that in the sample. Except for $\mathrm{Si}$ and $\mathrm{Zn}$, the recovery values were within the acceptance criterion of $75 \%$ to $125 \%$ for all AOIs meeting the above requirements. Note, however, that the post-spike was not used for QC evaluation, as a matrix spike was prepared and analyzed for the sample (see below).

\section{Post Spike/Analytical Spike Sample (B Component):}

A post spike (B component) was conducted on Sample 08-00218. Recovery values are listed for all analytes in the spike that were measured at or above the EQL, and that had a spike concentration $\geq 25 \%$ of that in the sample. The recovery values were within the acceptance criterion of $75 \%$ to $125 \%$ for all AOIs meeting the above requirements. Note, however, that the post-spike was not used for QC evaluation, as a matrix spike was prepared and analyzed for the sample (see below).

\section{Serial dilution:}

Five-fold serial dilution was conducted on Samples 08-00219 (Batch 1) and 08-00230

(Batch 2). Percent differences (\%Ds) are listed for all analytes that had a concentration at or above the EQL in the diluted sample. The \%Ds were within the acceptance criterion of $\leq 10 \%$ for all AOIs meeting the above requirement.

\section{Other QC:}

Strontium was very slightly outside the EQL tolerance $( \pm 0.001 \mu \mathrm{g} / \mathrm{mL})$ for the Interference Check Standard (ICS) analyzed with Batch 2. The major contributor to interference in $\mathrm{Sr}$ is $U$ which is present at a level of $100 \mu \mathrm{g} / \mathrm{mL}$ in the ICS solution. Uranium levels in the current samples did not exceed $0.08 \mu \mathrm{g} / \mathrm{mL}$ at the instrument, thus, any effects from this slight over-correction are entirely negligible. All other instrument-related QC tests for the AOIs passed within the appropriate acceptance criteria.

\section{Comments:}

1) The "Final Results" have been corrected for all laboratory dilutions performed on the samples during processing and analysis, unless specifically noted.

2) Instrument detection limits (IDL) and estimated quantitation limits (EQL) shown are for acidified water. Detection limits for other matrices may be determined if requested. Method detection limits (MDL) can be estimated by multiplying the IDL by the "Multiplier". The estimated quantitation limit (EQL) for each concentration value can be obtained by multiplying the EQL by the "Multiplier".

3) Routine precision and bias is typically $\pm 15 \%$ or better for samples in dilute, acidified water (e.g. $2 \% \mathrm{v} / \mathrm{v}$ $\mathrm{HNO}_{3}$ or less) at analyte concentrations $>$ EQL up to the upper calibration level. This also presumes that the total dissolved solids concentration in the sample is less than $5000 \mu \mathrm{g} / \mathrm{mL}$ ( 0.5 per cent by weight). Note 


\section{Battelle PNNL/RS\&E/Inorganic Analysis ... ICPOES Analysis Report}

that bracketed values listed in the data report are within the MDL and the EQL, and have potential uncertainties greater than $15 \%$. Concentration values < MDL are listed as "- -". Note, that calibration and QC standards are validated to a precision of $\pm 10 \%$.

4) Absolute precision, bias and detection limits may be determined on each sample if required by the client. The maximum number of significant figures for all ICP measurements is two.

5) Analytes included in the spike A component (for the AS/PS) are; $\mathrm{Ag}, \mathrm{Al}, \mathrm{As}, \mathrm{B}, \mathrm{Ba}, \mathrm{Be}, \mathrm{Bi}, \mathrm{Ca}, \mathrm{Cd}, \mathrm{Co}, \mathrm{Cr}$, $\mathrm{Cu}, \mathrm{Fe}, \mathrm{K}, \mathrm{Li}, \mathrm{Mg}, \mathrm{Mn}, \mathrm{Mo}, \mathrm{Na}, \mathrm{Ni}, \mathrm{P}, \mathrm{Pb}, \mathrm{S}, \mathrm{Sb}, \mathrm{Se}, \mathrm{Si}, \mathrm{Sn}, \mathrm{Sr}, \mathrm{Ta}, \mathrm{Ti}, \mathrm{Tl}, \mathrm{V}, \mathrm{W}, \mathrm{Y}, \mathrm{Zn}$, and Zr. Analytes included in the spike $\mathrm{B}$ component are; $\mathrm{Ce}, \mathrm{Dy}, \mathrm{Eu}, \mathrm{La}, \mathrm{Nd}, \mathrm{Pd}, \mathrm{Rh}, \mathrm{Ru}, \mathrm{Te}, \mathrm{Th}$, and $\mathrm{U}$. 


\begin{tabular}{|c|c|c|c|c|c|c|c|c|c|c|c|}
\hline & Run Date > & $1 / 7 / 2008$ & $1 / 7 / 2008$ & $1 / 7 / 2008$ & $1 / 7 / 2008$ & $1 / 7 / 2008$ & $1 / 7 / 2008$ & $1 / 7 / 2008$ & $1 / 7 / 2008$ & $1 / 7 / 2008$ \\
\hline & & Multiplier > & 23.9 & 596.7 & 600.4 & 120.6 & 238.2 & 122.4 & 119.9 & 118.7 & 116.5 \\
\hline & & RPL/LAB > & PB-00218 & $\begin{array}{c}08-00218 \\
\text { @25 } \\
\end{array}$ & $\begin{array}{l}08-00218 \\
\text { Dup @25 } \\
\end{array}$ & $\begin{array}{c}08-00219 \\
\text { @5 }\end{array}$ & $\begin{array}{c}08-00220 \\
\text { @10 }\end{array}$ & $\begin{array}{c}08-00221 \\
\text { @5 }\end{array}$ & $\begin{array}{c}\text { 08-00222 } \\
\text { @5 }\end{array}$ & $\begin{array}{c}08-00223 \\
\text { @5 }\end{array}$ & $\begin{array}{c}08-00224 \\
\text { @5 }\end{array}$ \\
\hline $\begin{array}{l}\text { Instr. Det. } \\
\text { Limit (IDL) }\end{array}$ & $\begin{array}{l}\text { Est. Quant. } \\
\text { Limit (EQL) } \\
\end{array}$ & Client ID > & Prep. Blank & \multicolumn{2}{|c|}{ TI552-G6-A } & TI552-G6-B & TI552-G6-D & $\underline{T \mid 552-G 6-J}$ & TI552-G6-K & TI552-G6-O & TI552-G6-P \\
\hline$(\mu \mathrm{g} / \mathrm{mL})$ & $(\mu \mathrm{g} / \mathrm{mL})$ & (Analyte) & $(\mu \mathrm{g} / \mathrm{mL})$ & $(\mu \mathrm{g} / \mathrm{mL})$ & $(\mu \mathrm{g} / \mathrm{mL})$ & $(\mu \mathrm{g} / \mathrm{mL})$ & $(\mu \mathrm{g} / \mathrm{mL})$ & $(\mu \mathrm{g} / \mathrm{mL})$ & $(\mu \mathrm{g} / \mathrm{mL})$ & $(\mu \mathrm{g} / \mathrm{mL})$ & $(\mu \mathrm{g} / \mathrm{mL})$ \\
\hline 0.0311 & 0.311 & Al & - & 8,340 & 8,160 & 6,310 & 13,400 & 262 & 2,510 & 253 & 60.7 \\
\hline 0.0151 & 0.151 & 8 &. & [23] & [16] & 30.2 & [20] & -- & {$[2.5]$} &.- & 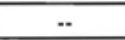 \\
\hline 0.0189 & 0.189 & $\mathrm{Bi}$ & - & - &.. & $\because$ & 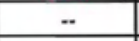 & [2.6] & 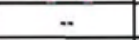 & 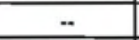 & .. \\
\hline 0.0020 & 0.020 & $\mathrm{Cd}$ &.- &.- & [1.3] & - & 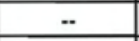 & -- &.- & [0.24] &.. \\
\hline 0.0031 & 0.031 & $\mathrm{Cr}$ &.- & 616 & 599 & 729 & 378 & 17.8 & 103 & 727 & 1,380 \\
\hline 0.0169 & 0.169 & $\mathrm{Fe}$ &.- & - &.. &.- & [11] & .. &.. &.- &.. \\
\hline 0.1007 & 1.007 & $K$ &.- & 1,110 & 1,050 & 954 & 470 & - & [75] & [19] & [42] \\
\hline 0.0017 & 0.017 & $\mathrm{Mn}$ &.- & - &.. & - &.. &.. &.. & 902 & 1,220 \\
\hline 0.0270 & 0.270 & $\mathrm{Na}$ &.- & 126,000 & 123,000 & 109,000 & 185,000 & 5,720 & 43,900 & 2,380 & 3,920 \\
\hline 0.0048 & 0.048 & $\mathrm{Ni}$ & 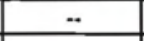 & [4.4] &.- & [2.5] &.. &. & 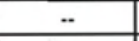 &.- &. \\
\hline 0.0452 & 0.452 & $\mathbf{P}$ & .- & 2,640 & 2,710 & 2,520 & 766 & [54] & 353 & {$[36]$} & [23] \\
\hline 0.2703 & 2.703 & $\mathbf{s}$ & $\cdot \cdot$ & 2,290 & 2,180 & 1,640 & 766 &.- & [140] & -- &.. \\
\hline 0.0094 & 0.094 & $\mathrm{Si}$ & 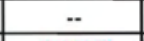 & 89.5 & 67.3 & 52.0 & 53.2 & [3.9] & 11.6 & [6.4] &. \\
\hline 0.0001 & 0.001 & $\mathrm{Sr}$ & {$[0.004]$} & {$[0.086]$} & 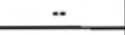 & {$[0.032]$} & {$[0.046]$} & .. & .. & .. & .. \\
\hline 0.0693 & 0.693 & $u$ & .. & .. &. & - & .. & .. &.- & -- & .. \\
\hline 0.0047 & 0.047 & $\mathrm{Zn}$ & {$[1.0]$} & .. & .. & .. & [8.7] & {$[0.59]$} & {$[1.3]$} & - & .. \\
\hline 0.0067 & 0.067 & $\mathrm{Zr}$ & .. & .. & .. & - & {$[1.8]$} & .. & $-\cdot$ & - & -. \\
\hline \multicolumn{12}{|c|}{\begin{tabular}{|l|} 
Other Analytes \\
\end{tabular}} \\
\hline 0.0035 & 0.035 & $\mathrm{Ag}$ & 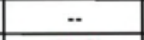 & $\ddot{*}$ & 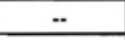 & -- & 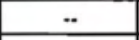 & $\ddot{*}$ & 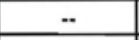 &.- & $\ddot{*}$ \\
\hline 0.0577 & 0.577 & As & [1.4] & $\ddot{*}$ & $\ddot{*}$ & - &.- &.. & 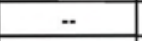 & - & $\ddot{*}$ \\
\hline 0.0028 & 0.028 & $\mathrm{Ba}$ &.- &.. & $\ddot{*}$ & 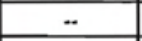 & $\begin{array}{l}-- \\
-\end{array}$ & $\ddot{*}$ & 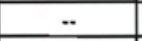 & 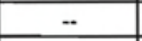 &.. \\
\hline 0.0001 & 0.001 & $8 e$ & 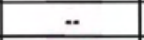 & [0.083] & {$[0.064]$} &.- & {$[0.086]$} &.- & {$[0.018]$} & -- & $\ldots$ \\
\hline 0.0174 & 0.174 & $\mathrm{Ca}$ & [2.3] & [41] & [58] & [20] & [17] & [3.3] & [5.2] & [4.0] & {$[2.3]$} \\
\hline 0.0099 & 0.099 & $\mathrm{Ce}$ & $\because$ & $\ddot{*}$ &.. &.. & -- & $\begin{array}{l}.- \\
-\end{array}$ &.- & - &.. \\
\hline 0.0032 & 0.032 & Co &.- & $\ddot{*}$ &.- & 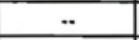 & 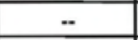 & 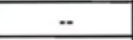 & 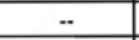 &.- & .. \\
\hline 0.0040 & 0.040 & $\mathrm{Cu}$ & 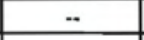 & 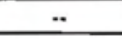 &.. &.. & - & 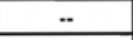 &.- & -- & $\because$ \\
\hline 0.0029 & 0.029 & Dy & - &.. &.. &.. &.. & $\because$ &.. & -- & -- \\
\hline 0.0009 & 0.009 & $\mathrm{Eu}$ & -- &.. & 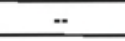 &.. & -- &.- &.- & -- & 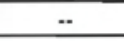 \\
\hline 0.0011 & 0.011 & La & $\approx$ & {$[0.68]$} & .. & {$[0.20]$} &.- & 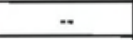 & {$[0.17]$} & -- &.- \\
\hline 0.0045 & 0.045 & $\mathrm{Li}$ & .. & .. & .. & .. & {$[1.7]$} & .- & $*$ & - &.. \\
\hline 0.0058 & 0.058 & $\mathrm{Mg}$ & -. &.. & -. & 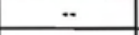 & - & -. & .. &.- &.. \\
\hline 0.0054 & 0.054 & Mo & {$[0.13]$} & 40.1 & 35.9 & 30.5 & 16.3 & {$[0.83]$} & [3.1] & [0.94] & [1.5] \\
\hline 0.0142 & 0.142 & Nd & -. & .. & .. & .. & - & 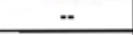 & .. & - & 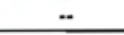 \\
\hline 0.0306 & 0.306 & $\mathrm{~Pb}$ & .. & .. & .. & -. & [25] & 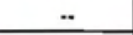 & .- & .- & - \\
\hline 0.0104 & 0.104 & $\mathrm{Pd}$ & - & $-\cdot$ &. & [1.7] &.- &.. &.. &.- &.. \\
\hline 0.0209 & 0.209 & $\mathbf{R h}$ &.. &.. & $\ddot{*}$ &. & -- &.. & 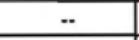 &.. &.- \\
\hline 0.0068 & 0.068 & $\mathrm{Ru}$ &.- &.. & [6.9] & [3.8] & [3.5] &.. &.. & 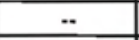 &.- \\
\hline 0.0260 & 0.260 & Sb &.- &.. &.. & 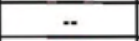 & - &.- & .. &.. & -- \\
\hline 0.0405 & 0.405 & Se & {$[3.4]$} & [97] & [110] & {$[8.0]$} & [9.9] & [27] & [29] & [21] & [22] \\
\hline 0.0166 & 0.166 & Sn & - &.. &. & [3.2] & - &.- & 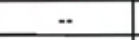 &.. & $\because$ \\
\hline 0.0110 & 0.110 & $\mathrm{Ta}$ &.- &.- &.. &.. &.- &.. &.. & [1.5] & -- \\
\hline 0.0261 & 0.261 & $\mathrm{Te}$ &.. &.. &.. &.. & -- &.. &.. &.- & -- \\
\hline 0.0098 & 0.098 & Th & - & [9.8] & 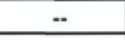 & - & - & 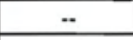 & 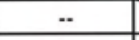 & 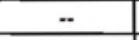 &.- \\
\hline 0.0008 & 0.008 & $\mathrm{Ti}$ & - &.. & 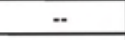 &. & - &.- &.. &.. & 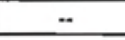 \\
\hline 0.0537 & 0.537 & $\mathrm{TI}$ & $*$ &.. &.. &.. &.- &.. & [8.2] &.. &.. \\
\hline 0.0026 & 0.026 & $\mathrm{v}$ &.- &.. & [1.7] & [1.6] & {$[0.75]$} & {$[0.36]$} & {$[0.40]$} & {$[0.37]$} & {$[0.33]$} \\
\hline 0.0124 & 0.124 & $w$ & {$[0.62]$} & [73] & 78.1 & 52.9 & [28] &.. & {$[6.5]$} &.- & - \\
\hline 0.0007 & 0.007 & $Y$ &.- & .. &.. &.. & - & 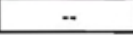 & .. &.- & -- \\
\hline
\end{tabular}

1) "--" indicates the value is $<M D L$. The method detection limit (MDL) =IDL times the "multiplier" near the top of each column. The estimated sample quantitation limit $=E Q L$ (in Column 2) times the "multiplier". Overall error for values $\geq E Q L$ is estimated to be within $\pm 15 \%$. 2) Values in brackets [] are $\geq M D L$ but $<E Q L$, with errors likely to exceed $15 \%$. 


\begin{tabular}{|c|c|c|c|c|c|}
\hline Run Date > & $1 / 7 / 2008$ & $1 / 7 / 2008$ & $1 / 7 / 2008$ & $1 / 7 / 2008$ & $1 / 7 / 2008$ \\
\hline Multiplier > & 120.2 & 120.0 & 120.6 & 234.0 & 241.3 \\
\hline RPLLAB > & $\begin{array}{c}08-00225 \\
\text { @5 }\end{array}$ & $\begin{array}{c}08-00226 \\
\text { @5 }\end{array}$ & $\begin{array}{c}08-00227 \\
@ 5\end{array}$ & $\begin{array}{c}08-00228 \\
\text { @10 }\end{array}$ & $\begin{array}{c}\text { 08-00229 } \\
\text { @10 }\end{array}$ \\
\hline Client ID > & TI552-G6-L1 & TI552-G6-L2 & II552-G6-L3 & II552-G6-L4 & TI552-G6-L5 \\
\hline (Analyte) & $(\mu \mathrm{g} / \mathrm{mL})$ & $(\mu \mathrm{g} / \mathrm{mL})$ & $(\mu \mathrm{g} / \mathrm{mL})$ & $(\mu \mathrm{g} / \mathrm{mL})$ & $(\mu \mathrm{g} / \mathrm{mL})$ \\
\hline Al & 491 & 333 & 393 & 423 & 357 \\
\hline B & 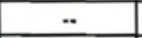 &.- & - & 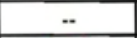 & - \\
\hline $\mathrm{Bi}$ & [6.3] & [2.9] & [12] & [13] & $=$ \\
\hline Cd & 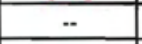 & $*$ & $=$ & $=$ & $*$ \\
\hline $\mathrm{Cr}$ & 5,060 & 3,390 & 4,970 & 3,960 & 3,520 \\
\hline $\mathrm{Fe}$ & -. & - & - & - & -. \\
\hline $\mathrm{K}$ & [110] & [93] & 124 & [100] & [100] \\
\hline $\mathrm{Mn}$ & 2,500 & 4,710 & 5,650 & 4,270 & 3,250 \\
\hline $\mathrm{Na}$ & 12,100 & 9,010 & 13,100 & 9,670 & 8,680 \\
\hline $\mathrm{Ni}$ & - & - &.. & - & $\ldots$ \\
\hline $\mathbf{P}$ & 98.5 & 59.7 & 67.7 & [53] & [64] \\
\hline $\mathrm{s}$ & [44] & - & [59] & $*$ & - \\
\hline Si & [7.7] & [3.5] & {$[4.0]$} & - & - \\
\hline $\mathrm{Sr}$ & {$[0.048]$} & {$[0.030]$} & {$[0.043]$} & {$[0.047]$} & $=$ \\
\hline U & .. & - & - & .. & - \\
\hline $\mathrm{Zn}$ & - & - & - & .. & $-\cdot$ \\
\hline $\mathrm{Zr}$ &. & .. & $\ldots$ & .. & .. \\
\hline
\end{tabular}

\begin{tabular}{|c|c|c|c|c|c|}
\hline $\mathrm{Ag}$ &. & .. & {$[0.47]$} & - & $\ldots$ \\
\hline As & 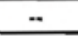 & .. &.. & .. & .. \\
\hline $\mathrm{Ba}$ & 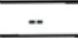 & .. & {$[0.66]$} & .. & .. \\
\hline $\mathrm{Be}$ & $*$ & .. &. & -. & .. \\
\hline $\mathrm{Ca}$ & {$[5.8]$} & {$[6.6]$} & {$[5.4]$} & [12] & {$[5.8]$} \\
\hline $\mathrm{Ce}$ & - & - & - &.. & .. \\
\hline Co & $*$ & - &.. &. & - \\
\hline $\mathrm{Cu}$ & $*$ & - & - & - &.- \\
\hline Dy & .. & - & - & .. & - \\
\hline $\mathrm{Eu}$ & .. & - & - & .. & $*$ \\
\hline La & {$[0.21]$} & {$[0.29]$} & {$[0.15]$} &. & - \\
\hline $\mathrm{Li}$ & .. &.- & -. & .. & $\cdots$ \\
\hline $\mathrm{Mg}$ &.. &. & .. & .. & 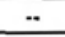 \\
\hline Mo & {$[0.97]$} & [1.1] & - & .. & 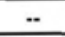 \\
\hline $\mathrm{Nd}$ &. & 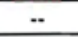 & 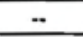 & -. & $\cdots$ \\
\hline $\mathrm{Pb}$ &.. &. & 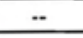 & - &.. \\
\hline $\mathbf{P d}$ &. & .. & .. & - & .. \\
\hline Rh & - &. & .. & -. &. \\
\hline $\mathrm{Ru}$ & -. & .. & .. & 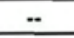 &. \\
\hline $\mathrm{Sb}$ & [9.1] & {$[4.8]$} & [8.9] & - & $-\cdot$ \\
\hline $\mathrm{Se}$ & [13] & [19] & [12] & [53] & [58] \\
\hline $\mathrm{Sn}$ & - & - & -. &.. & - \\
\hline $\mathrm{Ta}$ & - & .. & .. &. & - \\
\hline $\mathrm{Te}$ & - & $\ldots$ & .. & $*$ & - \\
\hline Th & - & - & -. & .. & $*$ \\
\hline $\mathrm{Ti}$ & 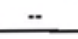 & - &. &.. & $*$ \\
\hline $\mathrm{TI}$ &.$\cdot$ & - &.- &.- & - \\
\hline $\mathrm{V}$ & {$[0.44]$} & {$[0.46]$} & {$[0.59]$} & {$[0.72]$} & - \\
\hline W & .. &.. & .. & 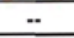 & - \\
\hline$Y$ &. & .. & $*$ &.. & $\cdots$ \\
\hline
\end{tabular}


QC Performance 1/7/08

\begin{tabular}{|c|c|c|c|c|c|c|}
\hline Criteria > & $\leq 20 \%$ & $80 \%-120 \%$ & $75 \%-125 \%$ & $75 \%-125 \%$ & $75 \%-125 \%$ & $\leq 10 \%$ \\
\hline$Q C I D>$ & $\begin{array}{c}08-00218 \\
\text { Dup }\end{array}$ & LCS/BS & $\begin{array}{c}08-00218 \\
M S\end{array}$ & $\begin{array}{c}08-00218+ \\
\text { PS-A }\end{array}$ & $\begin{array}{c}08-00218+ \\
\text { PS-B }\end{array}$ & $\begin{array}{c}08-00219 \\
\text { 5-fold } \\
\text { Serial Dil }\end{array}$ \\
\hline Analytes & RPD (\%) & $\%$ Rec & $\%$ Rec & $\% \operatorname{Rec}$ & $\% \operatorname{Rec}$ & \%Diff \\
\hline Al & 2.2 & 96 & 100 & 104 & & 0.4 \\
\hline B & & 102 & 103 & 100 & & \\
\hline $\mathrm{Bi}$ & & 86 & 89 & 99 & & \\
\hline $\mathrm{Cd}$ & & 95 & 97 & 102 & & \\
\hline $\mathrm{Cr}$ & 2.9 & 93 & $\mathrm{nr}$ & 103 & & 1.8 \\
\hline $\mathrm{Fe}$ & & 94 & 102 & 102 & & \\
\hline $\mathrm{K}$ & 5.6 & 96 & 104 & 103 & & 8.5 \\
\hline $\mathrm{Mn}$ & & 96 & 101 & 102 & & \\
\hline $\mathrm{Na}$ & 2.3 & 96 & $\mathrm{nr}$ & $\mathrm{nr}$ & & 2.4 \\
\hline $\mathrm{Ni}$ & & 93 & 99 & 101 & & \\
\hline$P$ & 2.7 & 96 & 102 & 101 & & 3.0 \\
\hline $\mathrm{s}$ & 4.9 & 98 & 106 & 102 & & 0.4 \\
\hline $\mathrm{Si}$ & 28.4 & 97 & 98 & 148 & & \\
\hline $\mathrm{Sr}$ & & 96 & 99 & 101 & & \\
\hline U & & 94 & 96 & & 96 & \\
\hline $\mathrm{Zn}$ & & 93 & 98 & 203 & & \\
\hline $\mathrm{Zr}$ & & 93 & 99 & 101 & & \\
\hline
\end{tabular}

Other Analytes

\begin{tabular}{|c|c|c|c|c|c|c|}
\hline $\mathrm{Ag}$ & & & & 94 & & \\
\hline As & & & & 103 & & \\
\hline $\mathrm{Ba}$ & & 95 & 99 & 100 & & \\
\hline $\mathrm{Be}$ & & 90 & 96 & 98 & & \\
\hline $\mathrm{Ca}$ & & 97 & 102 & 105 & & \\
\hline $\mathrm{Ce}$ & & 92 & 97 & & 97 & \\
\hline Co & & & & 100 & & \\
\hline $\mathrm{Cu}$ & & 94 & 96 & 100 & & \\
\hline Dy & & & & & 98 & \\
\hline $\mathrm{Eu}$ & & & & & 97 & \\
\hline La & & 92 & 96 & & 99 & \\
\hline $\mathrm{Li}$ & & 99 & 100 & 102 & & \\
\hline $\mathrm{Mg}$ & & 95 & 98 & 101 & & \\
\hline Mo & 11.1 & 96 & 100 & 100 & & \\
\hline $\mathrm{Nd}$ & & 96 & 99 & & 106 & \\
\hline $\mathrm{Pb}$ & & 95 & 99 & 102 & & \\
\hline $\mathrm{Pd}$ & & & & & 94 & \\
\hline Rh & & & & & 93 & \\
\hline Ru & & & & & 98 & \\
\hline $\mathrm{Sb}$ & & & & 103 & & \\
\hline Se & & & & 110 & & \\
\hline $\mathrm{Sn}$ & & & & 97 & & \\
\hline $\mathrm{Ta}$ & & & & 99 & & \\
\hline $\mathrm{Te}$ & & & & & 100 & \\
\hline Th & & 61 & 97 & & 98 & \\
\hline $\mathrm{Ti}$ & & 98 & 102 & 101 & & \\
\hline $\mathrm{TI}$ & & & & 98 & & \\
\hline $\mathrm{V}$ & & 78 & 81 & 98 & & \\
\hline w & & 93 & 94 & 95 & & \\
\hline $\mathrm{Y}$ & & & & 98 & & \\
\hline
\end{tabular}

Shaded results are outside the acceptance criteria.

$n r=$ not recovered; spike concentration less than $25 \%$ of sample concentration. 


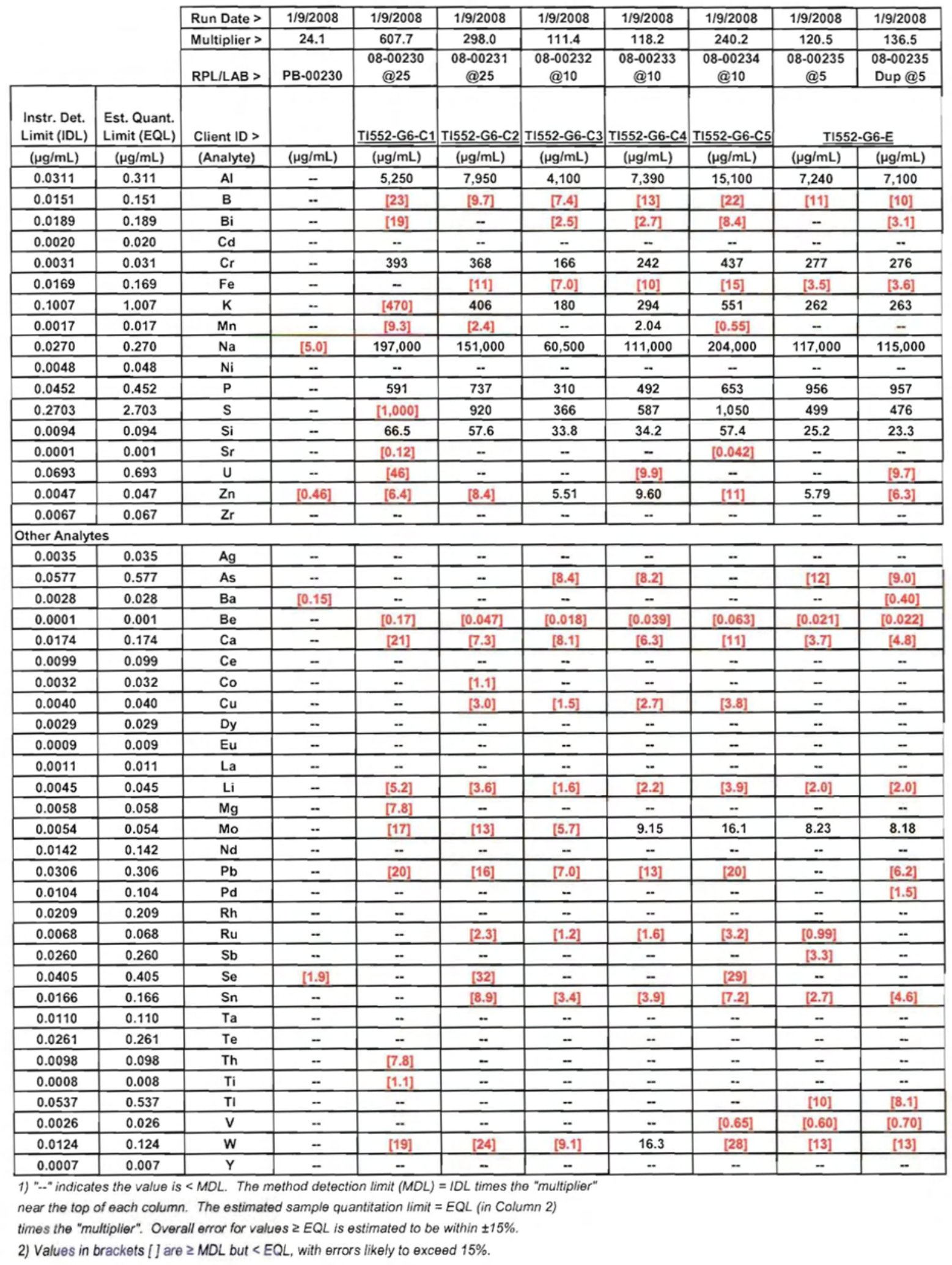




\begin{tabular}{|c|c|c|c|c|c|c|}
\hline Run Date > & 1/9/2008 & 1/9/2008 & $1 / 9 / 2008$ & $1 / 9 / 2008$ & $1 / 9 / 2008$ & $1 / 9 / 2008$ \\
\hline Multiplier > & 119.5 & 118.4 & 122.5 & 120.9 & 117.0 & 121.2 \\
\hline RPL/LAB > & $\begin{array}{c}08-00236 \\
@ 5\end{array}$ & $\begin{array}{c}08-00237 \\
\text { @5 }\end{array}$ & $\begin{array}{c}08-00238 \\
\text { @5 }\end{array}$ & $\begin{array}{c}08-00239 \\
\text { @5 } \\
\end{array}$ & $\begin{array}{c}08-00240 \\
\text { @5 }\end{array}$ & $\begin{array}{c}08-00241 \\
\text { @5 }\end{array}$ \\
\hline Client ID > & TI552-G6-F & TI552-G6-G & II552-G6-H & T1552-G6-I & TI552-G6-M & T1552-G6-N \\
\hline (Analyte) & $(\mu \mathrm{g} / \mathrm{mL})$ & $(\mu \mathrm{g} / \mathrm{mL})$ & $(\mu \mathrm{g} / \mathrm{mL})$ & $(\mu \mathrm{g} / \mathrm{mL})$ & $(\mu \mathrm{g} / \mathrm{mL})$ & $(\mu \mathrm{g} / \mathrm{mL})$ \\
\hline Al & 4,120 & 2,150 & 996 & 532 & 219 & 196 \\
\hline B & {$[6.4]$} & {$[2.7]$} & 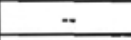 & - & - & $=$ \\
\hline $\mathrm{Bi}$ & - & $\ddot{*}$ &.- & - & [4.4] & - \\
\hline $\mathrm{Cd}$ & - & - & - &. &. & 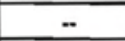 \\
\hline $\mathrm{Cr}$ & 165 & 89.3 & 45.0 & 26.4 & 2,340 & 1,470 \\
\hline $\mathrm{Fe}$ & - & - & - & - & - & - \\
\hline $\mathrm{K}$ & 152 & [74] & [34] & [23] & [58] & [49] \\
\hline $\mathrm{Mn}$ & - & - & - & - & 2,580 & 1,630 \\
\hline $\mathrm{Na}$ & 73,000 & 42,000 & 21,100 & 11,500 & 6,490 & 4,270 \\
\hline $\mathrm{Ni}$ & - & - & - & - & - & - \\
\hline$P$ & 536 & 280 & 136 & 89.9 & [46] & [39] \\
\hline $\mathrm{s}$ & {$[280]$} & [140] & {$[60]$} & [36] & $\ldots$ & - \\
\hline $\mathrm{Si}$ & 15.0 & {$[5.0]$} & [2.5] & - & - & $*$ \\
\hline $\mathrm{Sr}$ & - & - & - & - &.- & - \\
\hline$U$ & $=$ & - & - & - & - & - \\
\hline $\mathrm{Zn}$ & [2.5] & [1.3] & {$[1.4]$} & {$[1.4]$} & - & -. \\
\hline$Z_{r}$ & - & - &.- & - & - & 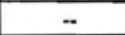 \\
\hline
\end{tabular}

\begin{tabular}{|c|c|c|c|c|c|c|}
\hline $\mathrm{Ag}$ & 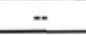 &.- &. & - & -- & - \\
\hline As & - & -. & - & 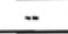 & - & - \\
\hline $\mathrm{Ba}$ & - & .- &. &.- & -. & - \\
\hline $\mathrm{Be}$ & {$[0.022]$} & - & - &.- & -- & - \\
\hline $\mathrm{Ca}$ & {$[2.5]$} & {$[2.7]$} & - & - & [3.1] & {$[2.3]$} \\
\hline $\mathrm{Ce}$ & -- & - & - &.- & - &.- \\
\hline Co & - & {$[0.42]$} & {$[0.42]$} & - & - & 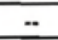 \\
\hline $\mathrm{Cu}$ & - & - & $=$ & - & - & - \\
\hline Dy & $\because$ & -- & -- & - & - & - \\
\hline $\mathrm{Eu}$ &.- & -- & . & - & - & 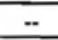 \\
\hline La & -- &.- & -- & $\because$ & {$[0.20]$} & - \\
\hline $\mathrm{Li}$ & {$[1.5]$} & {$[1.3]$} & [0.61] & -- & {$[0.80]$} & - \\
\hline $\mathrm{Mg}$ & - & - & - &.- & $=$ & -- \\
\hline Mo & [4.5] & {$[2.8]$} & {$[1,4]$} & {$[1.3]$} & {$[0.87]$} & - \\
\hline $\mathrm{Nd}$ & - & - & - & - & $\ldots$ & - \\
\hline $\mathrm{Pb}$ & -- & - & - & - & -- & -- \\
\hline $\mathrm{Pd}$ & -- & - & - & - & - &.- \\
\hline $\mathrm{Rh}$ & -- & $\ldots$ & - & - &.- & - \\
\hline $\mathrm{Ru}$ & -- & - & -- & -- & - & - \\
\hline $\mathrm{Sb}$ &.- &.- & -- & -- & [10] & {$[7.6]$} \\
\hline $\mathrm{Se}$ & {$[12]$} & - & - & - & - & {$[6.1]$} \\
\hline $\mathrm{Sn}$ & {$[4.9]$} &. & -. & [4.2] & {$[4,1]$} & [3.1] \\
\hline $\mathrm{Ta}$ & - & $-\cdot$ & .. & - & 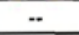 & - \\
\hline $\mathrm{Te}$ & - & - & -- & - & -- & - \\
\hline Th & - & -- & - & -- & $\ddot{*}$ & - \\
\hline $\mathrm{Ti}$ & -- & - & - & - & - & $\ldots$ \\
\hline $\mathrm{TI}$ & -- & - & - & - & - & - \\
\hline $\mathrm{v}$ & {$[0.51]$} & - & - & - & -- & 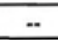 \\
\hline$w$ & {$[7.6]$} & {$[5.5]$} & {$[2.1]$} & - & - & - \\
\hline$Y$ & -. & - & - & -- & - & - \\
\hline
\end{tabular}




\begin{tabular}{|c|c|c|c|c|c|c|}
\hline Criteria > & $\leq 20 \%$ & $80 \%-120 \%$ & $75 \%-125 \%$ & $75 \%-125 \%$ & $75 \%-125 \%$ & $\leq 10 \%$ \\
\hline$Q C I D>$ & $\begin{array}{c}\text { 08-00235 } \\
\text { Dup }\end{array}$ & BS & $\begin{array}{c}08-00235 \\
\text { MS }\end{array}$ & PS-A (none) & PS-B (none) & $\begin{array}{c}08-00230 \\
5 \text {-fold } \\
\text { Serial Dil }\end{array}$ \\
\hline Analytes & RPD (\%) & $\%$ Rec & $\% \operatorname{Rec}$ & $\%$ Rec & $\%$ Rec & \%Diff \\
\hline Al & 1.9 & 100 & 101 & & & 2.3 \\
\hline $\mathrm{B}$ & & 105 & 108 & & & \\
\hline $\mathrm{Bi}$ & & 85 & 87 & & & \\
\hline Cd & & 96 & 96 & & & \\
\hline $\mathrm{Cr}$ & 0.5 & 97 & 101 & & & 3.5 \\
\hline $\mathrm{Fe}$ & & 98 & 102 & & & \\
\hline $\mathrm{K}$ & 0.5 & 100 & 106 & & & \\
\hline $\mathrm{Mn}$ & & 100 & 101 & & & \\
\hline $\mathrm{Na}$ & 1.4 & 99 & $\mathrm{nr}$ & & & 2.0 \\
\hline $\mathrm{Ni}$ & & 98 & 99 & & & \\
\hline $\mathbf{P}$ & 0.1 & 99 & 98 & & & \\
\hline $\mathrm{s}$ & 4.7 & 97 & 99 & & & \\
\hline Si & 8.1 & 96 & 103 & & & \\
\hline $\mathrm{Sr}$ & & 98 & 98 & & & \\
\hline$\underline{U}$ & & 95 & 95 & & & \\
\hline $\mathrm{Zn}$ & - & 96 & 96 & & & \\
\hline $\mathrm{Zr}$ & & 97 & 109 & & & \\
\hline \multicolumn{7}{|c|}{ Other Analytes } \\
\hline \multicolumn{7}{|l|}{$\mathrm{Ag}$} \\
\hline \multicolumn{7}{|l|}{ As } \\
\hline $\mathrm{Ba}$ & & 99 & 100 & & & \\
\hline $\mathrm{Be}$ & & 94 & 96 & & & \\
\hline $\mathrm{Ca}$ & & 100 & 103 & & & \\
\hline $\mathrm{Ce}$ & & 92 & 95 & & & \\
\hline \multicolumn{7}{|l|}{ Co } \\
\hline $\mathrm{Cu}$ & & 98 & 95 & & & \\
\hline \multicolumn{7}{|l|}{ Dy } \\
\hline \multicolumn{7}{|l|}{ Eu } \\
\hline La & & 96 & 99 & & & \\
\hline $\mathrm{Li}$ & & 102 & 106 & & & \\
\hline $\mathrm{Mg}$ & & 99 & 100 & - & & \\
\hline Mo & 0.6 & 99 & 100 & & & \\
\hline $\mathrm{Nd}$ & & 101 & 103 & & & \\
\hline $\mathrm{Pb}$ & & 98 & 100 & & & \\
\hline \multicolumn{7}{|l|}{ Pd } \\
\hline \multicolumn{7}{|l|}{ Rh } \\
\hline \multicolumn{7}{|l|}{$\mathrm{Ru}$} \\
\hline \multicolumn{7}{|l|}{$\mathrm{Sb}$} \\
\hline \multicolumn{7}{|l|}{$\mathrm{Se}$} \\
\hline \multicolumn{7}{|l|}{$\mathrm{Sn}$} \\
\hline \multicolumn{7}{|l|}{$\mathrm{Ta}$} \\
\hline \multicolumn{7}{|l|}{$\mathrm{Te}$} \\
\hline Th & & 32 & 99 & & & \\
\hline $\mathrm{Ti}$ & & 102 & 103 & & & \\
\hline \multicolumn{7}{|l|}{$\mathrm{TI}$} \\
\hline V & & 84 & 84 & & & \\
\hline$W$ & & 97 & 116 & & & \\
\hline $\mathbf{Y}$ & & 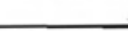 & 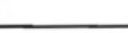 & & & \\
\hline
\end{tabular}

Shaded results are outside the acceptance criteria.

$n r=$ not recovered; spike concentration less than $25 \%$ of sample concentration. 
Battelle PNNL/RS\&E/Inorganic Analysis ... ICPOES Analysis Report PO Box 999, Richland, Washington 99352

$\begin{array}{ll}\text { Project / WP\#: } & 52964 \text { / F99189 } \\ \text { ASR\#: } & 8055 \\ \text { Client: } & \text { M. Edwards } \\ \text { Total Samples: } & \text { 5 (solid) }\end{array}$

\begin{tabular}{|l|c|c|}
\hline \multicolumn{2}{|c|}{ First } & Last \\
\hline RPL\#: & $08-00242$ & $08-00246$ \\
\hline Client ID: & TI552-G6-7 & TI552-G6-27 \\
\hline Sample Preparation: RPG-CMC-138, “HNO & -HF-HC1 Acid Digestion of \\
Solids for Metals Analysis Using a Dry-Block Heater", 01/04/08 (SRPL/ld). \\
\hline
\end{tabular}
Procedure: $\quad$ RPG-CMC-211, "Determination of Elemental Composition by Inductively Coupled Argon Plasma Optical Emission Spectrometry (ICPOES)", Rev 1.
Analyst: $\quad \underline{\text { P. Berry \& B. Oliver }}$

Analysis Date (File): $\quad \underline{01-09-2008}$ (C0089)

See Chemical Measurement Center 98620 file: $\underline{\text { ICP-325-405-3 }}$

(Calibration and Maintenance Records)

M\&TE Number: $\quad \underline{\text { N827583 }}$ (ICPOES instrument) M19445 (Mettler AT400 Balance)

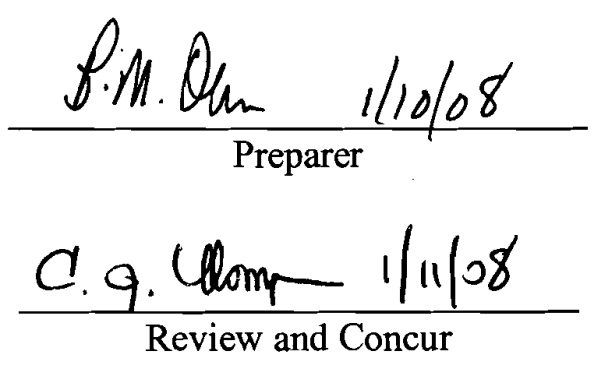




\section{Battelle PNNL/RS\&E/Inorganic Analysis ... ICPOES Analysis Report}

Five samples submitted under Analytical Service Request (ASR) 8055 were analyzed by ICPOES. The samples were prepared following RPL digestion procedure RPG-CMC-138 using from approximately 0.1 to 2 grams of sample and diluting to a final nominal volume of $50 \mathrm{~mL}$.

Analytes of interest (AOIs) were specified in the ASR, and are listed in the upper section of the attached ICPOES Data Report. The quality control (QC) results for these AOIs have been evaluated and are presented below. Analytes other than AOIs are reported in the bottom section of the report, but have not been fully evaluated for QC performance. The results are given as $\mu \mathrm{g} / \mathrm{g}$ for each detected analyte, and have been adjusted for all laboratory processing factors and instrument dilutions.

Calibration of the ICPOES was done following the manufacturer's recommended calibration procedure and using multi-analyte custom standard solutions traceable to the National Institute of Standards and Technology (NIST). Midrange calibration verification standards (MCVA and MCVB) were used to verify acceptance of the two-point calibration curves obtained for each analyte, and also used for continuing calibration verification.

Minimum Method Detection Limit (MDL) values were specified in the ASR. MDL levels were met for all AOIs.

The controlling documents are ASO-QAP-001, and the client supplied RPP-WTP-QA-005, Rev. 2, and "ASR 8055 Special Instructions". Instrument calibrations, QC checks and blanks (e.g., ICV/ICB, CCV/CCB, LLS, ICS), post-spike, laboratory control standard (LCS), duplicate, and serial dilution were conducted during the analysis run. The LCS was prepared using a nominal 0.1 grams of SRM-2710 (Montana Soil).

\section{Preparation Blank (PB):}

A preparation blank (reagents only) was prepared for the digestion process. The concentrations of all AOIs were within the acceptance criteria of $\leq \mathrm{EQL}$ (estimated quantitation level) or less than $\leq 5 \%$ of the concentration in the sample.

Blank Spike (BS)/Laboratory Control Sample (LCS):

An LCS (Montana Soil) was prepared for the digestion process. Recovery values are listed for all analytes included in the spike that were measured at or above the EQL. The recovery values were within the acceptance criterion of $80 \%$ to $120 \%$ for all AOIs meeting the above requirement.

\section{Matrix-Spiked Sample:}

No matrix spike sample was provided for analysis.

Duplicate Relative Percent Difference (RPD):

A duplicate was prepared for the digestion process. RPDs are listed for all analytes that were measured at or above the EQL. The RPDs were within the client acceptance criterion of $\leq 25 \%$ for all AOIs meeting the above requirement. 


\section{Battelle PNNL/RS\&E/Inorganic Analysis ... ICPOES Analysis Report}

\section{Post-Spike/Analytical Spike Sample (A Component):}

An analytical spike (A component) was conducted for the digestion process. Recovery values are listed for all analytes in the spike that were measured at or above the EQL, and that had a spike concentration $\geq 25 \%$ of that in the sample. The recovery values were within the client acceptance criterion of $70 \%$ to $130 \%$ for all AOIs meeting the above requirements.

\section{Post Spike/Analytical Spike Sample (B Component):}

An analytical spike (B component) was conducted for the digestion process. Recovery values are listed for all analytes in the spike that were measured at or above the EQL, and that had a spike concentration $\geq 25 \%$ of that in the sample. The recovery values were within the client acceptance criterion of $70 \%$ to $130 \%$ for all AOIs meeting the above requirements.

\section{Serial dilution:}

Five-fold serial dilution was conducted for the digestion process. Percent differences (\%Ds) are listed for all analytes that had a concentration at or above the EQL in the diluted sample. The $\%$ Ds were within the acceptance criterion of $\leq 10 \%$ for all AOIs meeting the above requirement.

\section{Other QC:}

Strontium was very slightly outside the EQL tolerance $( \pm 0.001 \mu \mathrm{g} / \mathrm{mL})$ for the Interference Check Standard (ICS) analyzed with Batch 2. The major contributor to interference in $\mathrm{Sr}$ is $U$ which is present at a level of $100 \mu \mathrm{g} / \mathrm{mL}$ in the ICS solution. Uranium levels in the current samples did not exceed approximately $25 \mu \mathrm{g} / \mathrm{mL}$ at the instrument, thus, any effects from this slight over-correction are negligible. All other instrument-related QC tests for the AOIs passed within the appropriate acceptance criteria.

\section{Comments:}

1) The "Final Results" have been corrected for all laboratory dilutions performed on the samples during processing and analysis, unless specifically noted.

2) Instrument detection limits (IDL) and estimated quantitation limits (EQL) shown are for acidified water. Detection limits for other matrices may be determined if requested. Method detection limits (MDL) can be estimated by multiplying the IDL by the "Multiplier". The estimated quantitation limit (EQL) for each concentration value can be obtained by multiplying the EQL by the "Multiplier".

3) Routine precision and bias is typically $\pm 15 \%$ or better for samples in dilute, acidified water (e.g. $2 \% \mathrm{v} / \mathrm{v}$ $\mathrm{HNO}_{3}$ or less) at analyte concentrations $>\mathrm{EQL}$ up to the upper calibration level. This also presumes that the total dissolved solids concentration in the sample is less than $5000 \mu \mathrm{g} / \mathrm{mL}$ ( 0.5 per cent by weight). Note that bracketed values listed in the data report are within the MDL and the EQL, and have potential uncertainties greater than $15 \%$. Concentration values $<$ MDL are listed as "- -". Note, that calibration and $\mathrm{QC}$ standards are validated to a precision of $\pm 10 \%$.

4) Absolute precision, bias and detection limits may be determined on each sample if required by the client. The maximum number of significant figures for all ICP measurements is two.

5) Analytes included in the spike $\mathrm{A}$ component (for the $\mathrm{AS} / \mathrm{PS}$ ) are; $\mathrm{Ag}, \mathrm{Al}, \mathrm{As}, \mathrm{B}, \mathrm{Ba}, \mathrm{Be}, \mathrm{Bi}, \mathrm{Ca}, \mathrm{Cd}, \mathrm{Co}, \mathrm{Cr}$, $\mathrm{Cu}, \mathrm{Fe}, \mathrm{K}, \mathrm{Li}, \mathrm{Mg}, \mathrm{Mn}, \mathrm{Mo}, \mathrm{Na}, \mathrm{Ni}, \mathrm{P}, \mathrm{Pb}, \mathrm{S}, \mathrm{Sb}, \mathrm{Se}, \mathrm{Si}, \mathrm{Sn}, \mathrm{Sr}, \mathrm{Ta}, \mathrm{Ti}, \mathrm{Tl}, \mathrm{V}, \mathrm{W}, \mathrm{Y}, \mathrm{Zn}$, and $\mathrm{Zr}$. Analytes included in the spike $\mathrm{B}$ component are; $\mathrm{Ce}, \mathrm{Dy}, \mathrm{Eu}, \mathrm{La}, \mathrm{Nd}, \mathrm{Pd}, \mathrm{Rh}, \mathrm{Ru}, \mathrm{Te}, \mathrm{Th}$, and $\mathrm{U}$. 


\begin{tabular}{|c|c|c|c|c|c|c|c|c|c|}
\hline & & Run Date $>$ & $1 / 9 / 2008$ & 1/9/2008 & 1/9/2008 & 1/9/2008 & 1/9/2008 & 1/9/2008 & 1/9/2008 \\
\hline & & Multiplier > & 32.7 & 369.5 & 347.2 & 139.8 & 160.2 & 254.7 & 181.0 \\
\hline & & RPL/LAB > & PB-00242 & $\begin{array}{c}08-00242 \\
@ 5\end{array}$ & $\begin{array}{c}\text { 08-00242 } \\
\text { Dup @5 } \\
\end{array}$ & $\begin{array}{c}08-00243 \\
@ 5\end{array}$ & $\begin{array}{c}08-00244 \\
@ 5\end{array}$ & $\begin{array}{c}\text { 08-00245 } \\
\text { @11 }\end{array}$ & $\begin{array}{c}08-00246 \\
@ 5\end{array}$ \\
\hline $\begin{array}{l}\text { Instr. Det. } \\
\text { Limit (IDL) } \\
\end{array}$ & $\begin{array}{l}\text { Est. Quant. } \\
\text { Limit (EQL) }\end{array}$ & Client ID > & & \multicolumn{2}{|c|}{ II552-G6-7 } & T1552-G6-12 & T1552-G6-17 & TI552-G6-22 & T1552-G6-27 \\
\hline$(\mu \mathrm{g} / \mathrm{mL})$ & $(\mu \mathrm{g} / \mathrm{mL})$ & (Analyte) & $(\mu \mathrm{g} / \mathrm{g})$ & $(\mu \mathrm{g} / \mathrm{g})$ & $(\mu \mathrm{g} / \mathrm{g})$ & $(\mu \mathrm{g} / \mathrm{g})$ & $(\mu \mathrm{g} / \mathrm{g})$ & $(\mu \mathrm{g} / \mathrm{g})$ & $(\mu \mathrm{g} / \mathrm{g})$ \\
\hline 0.0311 & 0.311 & Al & $-\cdot$ & 76,300 & 79,100 & 29,300 & 47,300 & 25,400 & 46,000 \\
\hline 0.0151 & 0.151 & B & 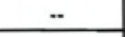 & [30] & [31] & [12] & - & $\ddot{*}$ & 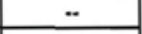 \\
\hline 0.0189 & 0.189 & $\mathrm{Bi}$ & $\ddot{-}$ & [58] & 66.0 & 37.3 & 60.4 & [35] & 58.2 \\
\hline 0.0020 & 0.020 & Cd &.- & 8.32 & 9.40 & 7.12 & 9.99 & [5.1] & 7.00 \\
\hline 0.0031 & 0.031 & $\mathrm{Cr}$ & .. & 6,590 & 6,710 & 4,560 & 6,590 & 3,330 & 1,130 \\
\hline 0.0169 & 0.169 & $\mathrm{Fe}$ & {$[0.58]$} & 2,250 & 2,310 & 1,560 & 2,630 & 1,380 & 4,600 \\
\hline 0.1007 & 1.007 & $\mathrm{~K}$ &.- & 619 & 627 & 306 & 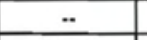 & [120] & [51] \\
\hline 0.0017 & 0.017 & $\mathrm{Mn}$ & -. & 1,120 & 1,160 & 771 & 1,240 & 10,100 & 6,910 \\
\hline 0.0270 & 0.270 & $\mathrm{Na}$ & -- & 83,400 & 83,300 & 124,000 & 14,200 & 12,400 & 20,500 \\
\hline 0.0048 & 0.048 & $\mathrm{Ni}$ & .. & 151 & 158 & 126 & 186 & 97.1 & 390 \\
\hline 0.0452 & 0.452 & $\mathbf{P}$ & -- & 1,920 & 1,920 & 1,600 & 199 & [99] & 98.2 \\
\hline 0.2703 & 2.703 & $\mathrm{~s}$ & - & 1,410 & 1,440 & 683 & [74] & [73] & - \\
\hline 0.0094 & 0.094 & $\mathrm{Si}$ & 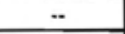 & 441 & 549 & 2,280 & 224 & 88.8 & 216 \\
\hline 0.0001 & 0.001 & $\mathrm{Sr}$ & - & 208 & 217 & 55.9 & 235 & 126 & 485 \\
\hline 0.0693 & 0.693 & $u$ & -- & 3,980 & 4,100 & 3,070 & 4,500 & 2,420 & 7,710 \\
\hline 0.0047 & 0.047 & $\mathrm{Zn}$ & -. & 26.8 & 32.8 & 10.9 & 12.7 & [6.1] & 16.6 \\
\hline 0.0067 & 0.067 & $\mathrm{Zr}$ & 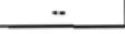 & 57.6 & 59.8 & 35.6 & 62.4 & 32.9 & 81.8 \\
\hline \multicolumn{10}{|c|}{ Other Analytes } \\
\hline 0.0035 & 0.035 & $\mathrm{Ag}$ & 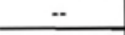 & 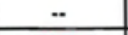 & 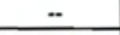 & -- & 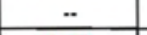 & 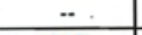 & - \\
\hline 0.0577 & 0.577 & As & - & [73] & {$[80]$} & [25] & [35] & [21] & [39] \\
\hline 0.0028 & 0.028 & $\mathrm{Ba}$ & -- & 25.5 & 26.1 & 12.3 & 29.1 & 15.7 & 45.9 \\
\hline 0.0001 & 0.001 & $\mathrm{Be}$ & - & {$[0.15]$} & {$[0.11]$} & {$[0.028]$} & {$[0.018]$} & - & -. \\
\hline 0.0174 & 0.174 & $\mathrm{Ca}$ & {$[1.6]$} & 593 & 597 & 366 & 656 & 351 & 725 \\
\hline 0.0099 & 0.099 & $\mathrm{Ce}$ & -- & {$[24]$} & {$[24]$} & {$[9.2]$} & 25.4 & {$[8.4]$} & 27.5 \\
\hline 0.0032 & 0.032 & Co & 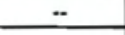 & [3.3] & {$[2.3]$} & {$[2.0]$} & {$[2.7]$} & {$[0.82]$} & [4.8] \\
\hline 0.0040 & 0.040 & $\mathrm{Cu}$ & 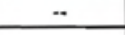 & [13] & 14.7 & 6.60 & 9.39 & {$[4.5]$} & 17.7 \\
\hline 0.0029 & 0.029 & Dy & 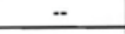 & $\ddot{*}$ & 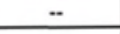 & $\ddot{-}$ &.. & 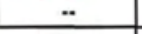 & - \\
\hline 0.0009 & 0.009 & Eu & .. & -- &.- & {$[0.14]$} & {$[0.89]$} & 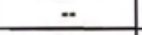 & {$[0.74]$} \\
\hline 0.0011 & 0.011 & La & .- & 22.0 & 22.8 & 7.60 & 25.1 & 13.2 & 27.6 \\
\hline 0.0045 & 0.045 & $\mathrm{Li}$ &.. & 16.9 & 16.8 & 7.69 & 7.44 & [4.8] & 10.7 \\
\hline 0.0058 & 0.058 & $\mathrm{Mg}$ &. & 83.7 & 86.6 & 56.7 & 98.6 & 50.6 & 125 \\
\hline 0.0054 & 0.054 & Mo &.- & 22.0 & 24.1 & 12.3 & {$[4.9]$} & {$[2.0]$} & [8.8] \\
\hline 0.0142 & 0.142 & $\mathrm{Nd}$ & - & [52] & 51.4 & 24.0 & 58.5 & [29] & 65.2 \\
\hline 0.0306 & 0.306 & $\mathrm{~Pb}$ & - & {$[100]$} & 110 & 49.0 & 79.8 & [42] & 60.3 \\
\hline 0.0104 & 0.104 & Pd & -- & 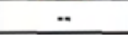 &.. &.- & - & - &.. \\
\hline 0.0209 & 0.209 & $\mathrm{Rh}$ & 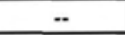 &. &. & - & 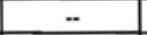 & - & 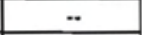 \\
\hline 0.0068 & 0.068 & Ru & 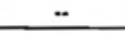 & [3.7] & {$[3.4]$} & {$[1.3]$} & - & - & 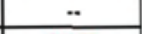 \\
\hline 0.0260 & 0.260 & Sb & 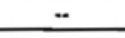 & {$[28]$} & [28] & [26] & [33] & [19] & {$[6.7]$} \\
\hline 0.0405 & 0.405 & Se & -- & [64] & [35] &.- & [15] & [31] & [12] \\
\hline 0.0166 & 0.166 & Sn & 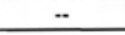 & [15] & [10] & {$[3.3]$} & - & 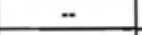 & - \\
\hline 0.0110 & 0.110 & Ta & .. & - & [5.6] & 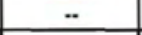 & {$[5.8]$} & 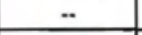 & {$[3.4]$} \\
\hline 0.0261 & 0.261 & $\mathrm{Te}$ & 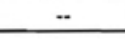 & - & - & 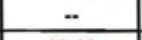 &.. & 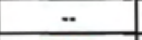 & - \\
\hline 0.0098 & 0.098 & Th & .. & [16] & [18] & [7.2] & 23.3 & {$[7.7]$} & {$[7.8]$} \\
\hline 0.0008 & 0.008 & $\mathrm{Ti}$ &. & 11.8 & 11.7 & 9.03 & 13.4 & 7.19 & 18.2 \\
\hline 0.0537 & 0.537 & $\mathrm{TI}$ &.. & - & 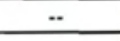 & [13] & 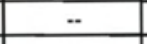 &.. & 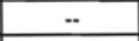 \\
\hline 0.0026 & 0.026 & v & 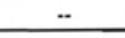 &. & - & - & .. & $\ddot{*}$ & -- \\
\hline 0.0124 & 0.124 & w & 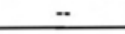 &.$*$ & -- & $\ddot{*}$ & 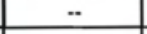 & -- & $-\cdot$ \\
\hline 0.0007 & 0.007 & $Y$ & .. & 6.08 & 6.34 & 3.40 & 7.06 & 3.58 & 7.51 \\
\hline
\end{tabular}


QC Performance 1/9/08

\begin{tabular}{|c|c|c|c|c|c|c|c|}
\hline Criteria > & $\leq 25 \%$ & $80 \%-120 \%$ & $80 \%-120 \%$ & $70 \%-130 \%$ & $70 \%-130 \%$ & $70 \%-130 \%$ & $\leq 10 \%$ \\
\hline$Q C|D\rangle$ & $\begin{array}{c}08-00242 \\
\text { Dup }\end{array}$ & BS (none) & LCS & MS (none) & $\begin{array}{c}08-00242+ \\
\text { PS-A }\end{array}$ & $\begin{array}{c}08-00242+ \\
\text { PS-B }\end{array}$ & $\begin{array}{c}08-00242 \\
5 \text {-fold } \\
\text { Serial Dil }\end{array}$ \\
\hline Analytes & RPD (\%) & $\%$ Rec & $\% \operatorname{Rec}$ & $\%$ Rec & $\%$ Rec & $\%$ Rec & $\%$ Diff \\
\hline Al & 3.7 & & 98 & & $\mathrm{nr}$ & & 2.0 \\
\hline B & & & & & 105 & & \\
\hline$B i$ & & & & & 98 & & \\
\hline $\mathrm{Cd}$ & 12.2 & & 100 & & 103 & & \\
\hline $\mathrm{Cr}$ & 1.9 & & 82 & & $\mathrm{nr}$ & & 0.7 \\
\hline $\mathrm{Fe}$ & 2.7 & & 95 & & 100 & & 0.8 \\
\hline $\mathrm{K}$ & 1.2 & & & & 100 & & \\
\hline $\mathrm{Mn}$ & 3.2 & & 99 & & 92 & & 0.8 \\
\hline $\mathrm{Na}$ & 0.1 & & 96 & & 103 & & 1.4 \\
\hline $\mathrm{Ni}$ & 4.5 & & & & 101 & & 0.4 \\
\hline $\mathbf{P}$ & 0.0 & & 81 & & 101 & & 5.4 \\
\hline s & 2.5 & & & & 98 & & \\
\hline $\mathrm{Si}$ & 21.8 & & $\mathrm{nr}$ & & 102 & & \\
\hline $\mathrm{Sr}$ & 3.9 & & 97 & & 103 & & 1.6 \\
\hline$u$ & 3.1 & & & & & 95 & 0.8 \\
\hline $\mathrm{Zn}$ & 20.0 & & 91 & & 99 & & \\
\hline $\mathrm{Zr}$ & 3.8 & & & & 99 & & \\
\hline
\end{tabular}

\begin{tabular}{|c|c|c|c|c|c|}
\hline $\mathrm{Ag}$ & & 50 & 89 & & \\
\hline As & & 99 & 110 & & \\
\hline $\mathrm{Ba}$ & 2.1 & 96 & 100 & & \\
\hline $\mathrm{Be}$ & & & 95 & & \\
\hline $\mathrm{Ca}$ & 0.8 & 98 & 102 & & 1.3 \\
\hline $\mathrm{Ce}$ & & 69 & & 98 & \\
\hline Co & & & 100 & & \\
\hline $\mathrm{Cu}$ & & 95 & 102 & & \\
\hline Dy & & & & 100 & \\
\hline $\mathrm{Eu}$ & & & & 98 & \\
\hline La & 3.5 & 150 & & 100 & 7.0 \\
\hline $\mathrm{Li}$ & 0.2 & & 101 & & \\
\hline $\mathrm{Mg}$ & 3.3 & 97 & 101 & & \\
\hline Mo & 9.0 & & 99 & & \\
\hline $\mathrm{Nd}$ & & & & 112 & \\
\hline $\mathrm{Pb}$ & & 95 & 108 & & \\
\hline $\mathbf{P d}$ & & & & 92 & \\
\hline $\mathrm{Rh}$ & & & & 93 & \\
\hline $\mathrm{Ru}$ & & & & 97 & \\
\hline $\mathrm{Sb}$ & & & 103 & & \\
\hline $\mathrm{Se}$ & & & 105 & & \\
\hline $\mathrm{Sn}$ & & & 98 & & \\
\hline $\mathrm{Ta}$ & & & 99 & & \\
\hline $\mathrm{Te}$ & & & & 97 & \\
\hline Th & & & & 100 & \\
\hline $\mathrm{Ti}$ & 0.9 & 93 & 100 & & \\
\hline $\mathrm{TI}$ & & & 97 & & \\
\hline $\mathrm{v}$ & & 91 & 95 & & \\
\hline$w$ & & 86 & 98 & & \\
\hline $\mathrm{Y}$ & 4.2 & 77 & 96 & & \\
\hline
\end{tabular}




\section{Battelle - Pacific Northwest National Laboratory Analytical Support Operations - IC Report \\ PO Box 999, Richland, Washington 99352}

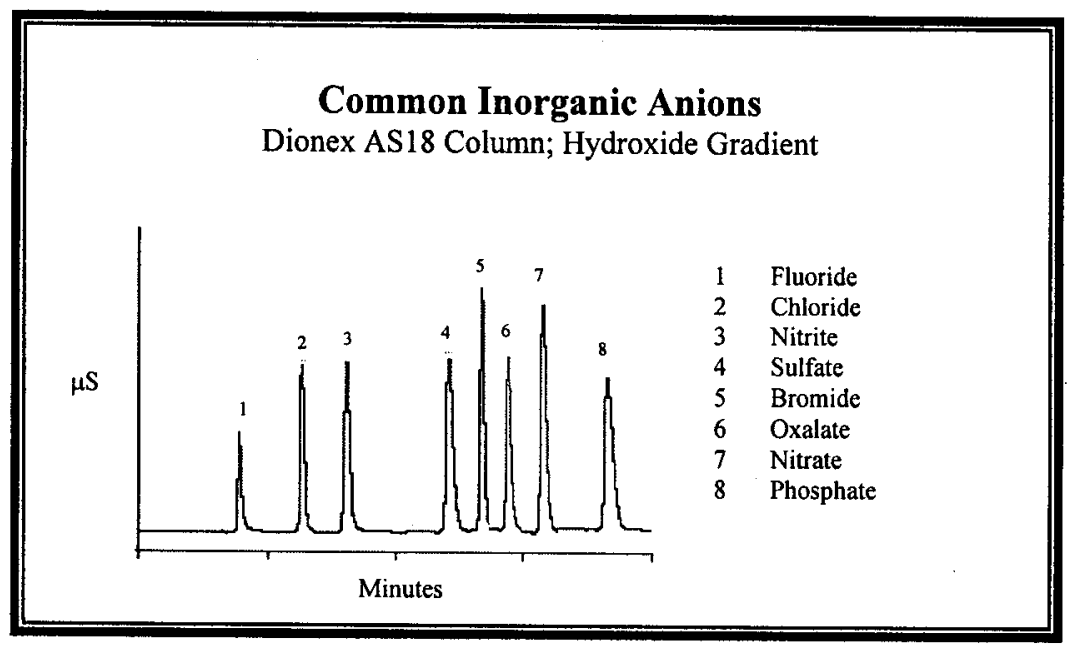

\section{Client:}

Project \#:

M. Edwards

Charge Code: 52964

F99189

\section{*** RPL Numbers: 08-00218 through 08-00224***}

Procedure, Analysis, System, and Records Information

\begin{tabular}{|l|l|}
\hline Analysis Procedure & PNL-ALO-212, "Determination of Inorganic Anions by Ion Chromatography" \\
\hline Prep Procedure & Bench Dilution performed in lab 400 (MJS 01/04/08, 01/05/08, 01/06/08) \\
\hline Analyst & MJ Steele \\
\hline Analysis Dates & $01 / 05 / 08,01 / 06 / 08$ \\
\hline Calibration Date & $1 / 05 / 08$ \\
\hline Cal/Ver Stds Prep Date & Cal 12/06/07; Ver 1/05/08 \\
\hline Excel Data File & Results ASR 8055 Edwards.xls \\
\hline \multirow{2}{*}{ M\&TE Numbers } & IC System (M\&TE) N830443 N830444 \\
\cline { 2 - 2 } & Balances: 360-06-01-031/1113052270 \\
\hline All Analysis Records & Chemical Measurement Center 98620: RIDS IC System File (IC-0149) \\
\hline
\end{tabular}

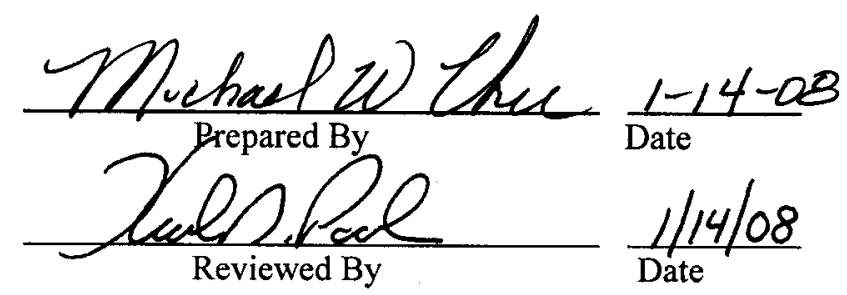




\section{IC Report}

\section{Sample Results}

See Attachment: Direct Liquid Sample Results ASR 8055

\section{Sample Analysis/Results Discussion}

Seven liquid samples were submitted to the ASO for analysis under ASR 8055. The specified analytes of are fluoride, nitrite, nitrate, sulfate, oxalate and phosphate. The sample was prepared for analysis using dilutions at the bench, which included the preparation of analytical spikes and sample replicates. The dilutions were prepared in deionized water and the water was analyzed as the process dilution sample. All sample results are reported as $\mu \mathrm{g} / \mathrm{mL}$.

After screening the sample, the final analysis was performed using additional dilution factors ranging from 1 to 15,000 . All results have been adjusted for all analytical dilutions. The prep dilution blank (water used to dilute samples at the IC workstation) is reported as analyzed, no dilution factors were applied to this sample. The estimated method detection limits (MDL) are provided, and are based on the estimated quantitation limit (EQL), which is one-tenth of the lowest calibration standard (adjusted for the dilutions used for reporting the results).

\section{Data Limitations}

None

\section{Quality Control Discussion}

The method performance is evaluated against the acceptance criteria established by Analytical Support Operations QA Plan ASO-QAP-001.

Processing Blanks: (Dilution) A process dilution blank (deionized water) was analyzed with the sample set. There were no anions detected above the method detection limit (MDL). The processing blank met the QA Plan acceptance criteria for all analytes of interest.

Duplicate (Precision): Sample 08-00218 was analyzed in duplicate. The relative percent difference is reported for all analytes which were measured at or above the EQL. The reported RPDs ranged from 1 to $2 \%$ for all analytes of interest, which meets the Project acceptance criteria (Table 4 of ASR) of $<20 \%$.

Laboratory Control Sample/Blank Spike (LCS/BS): The routine instrument LCS/blank spike was analyzed with the data set and had recoveries ranging from $105 \%$ to $113 \%$ for the analytes of interest. These recoveries meet the Project acceptance criteria (Table 4 of ASR) of $80 \%$ to $120 \%$ recovery.

Matrix Spike: (Accuracy) None prepared. Sample did not undergo sample preparation; therefore, an analytical post spike was prepared and analyzed.

Post Spike: (Accuracy) Multiple analytical spikes (i.e., standard added during dilution) were prepared for sample 08-00218 and analyzed. Sample 08-00218 was diluted by 400,2000 , and 30000 in order to obtain spikes concentrations at least $20 \%$ greater than measured sample 


\section{IC Report}

concentration. The recoveries range was from $98 \%$ to $114 \%$ for all analytes of interest, which meets the QA Plan post spike recovery acceptance criteria of $75 \%$ to $125 \%$.

IC System QC Samples: Numerous calibration verification standards and calibration verification blanks were analyzed with each run day. For all data reported, the IC System QC bounding the sample analyses produced results for all analytes were within the acceptance criterion of the ASO's QA Plan (i.e., 90\% to $110 \%$ recovery for verification standards and verification blank results $<\mathrm{EQL}$ or $<5 \%$ of reported sample result).

\section{Deviations from Procedure}

None

\section{General Comments}

- The reported "Final Results" have been corrected for all dilutions performed on the sample during processing or analysis.

- The MDL is set at the concentration of the lowest calibrations standard divided by 10 . The $\mathrm{EQL}$ is defined as the concentration of the lowest calibration standards times the sample dilution factors (processing and analysis) and assumes non-complex aqueous matrices. Matrix-specific MDLs or EQLs may be determined, if requested.

- Routine precision and bias are typically $\pm 15 \%$ or better for non-complex aqueous samples that are free of interference. 


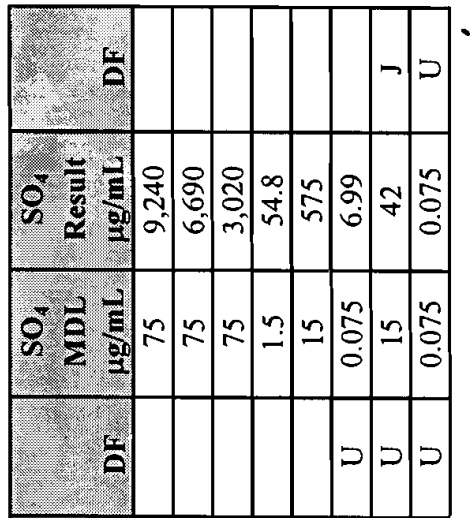

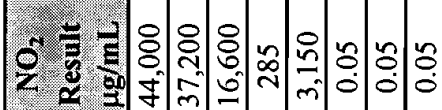

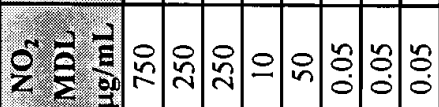

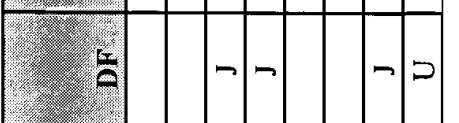

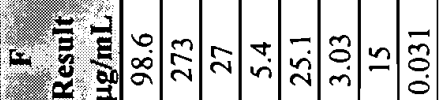

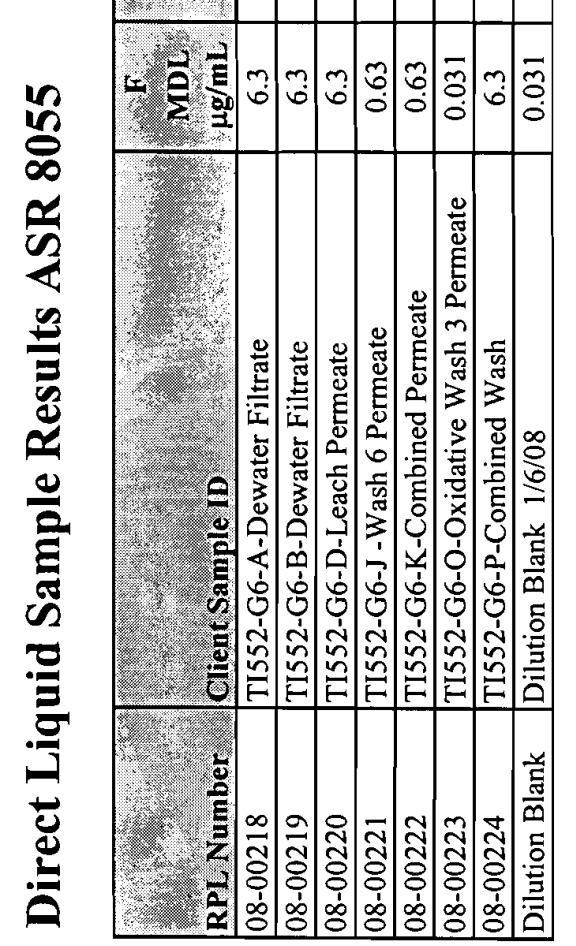

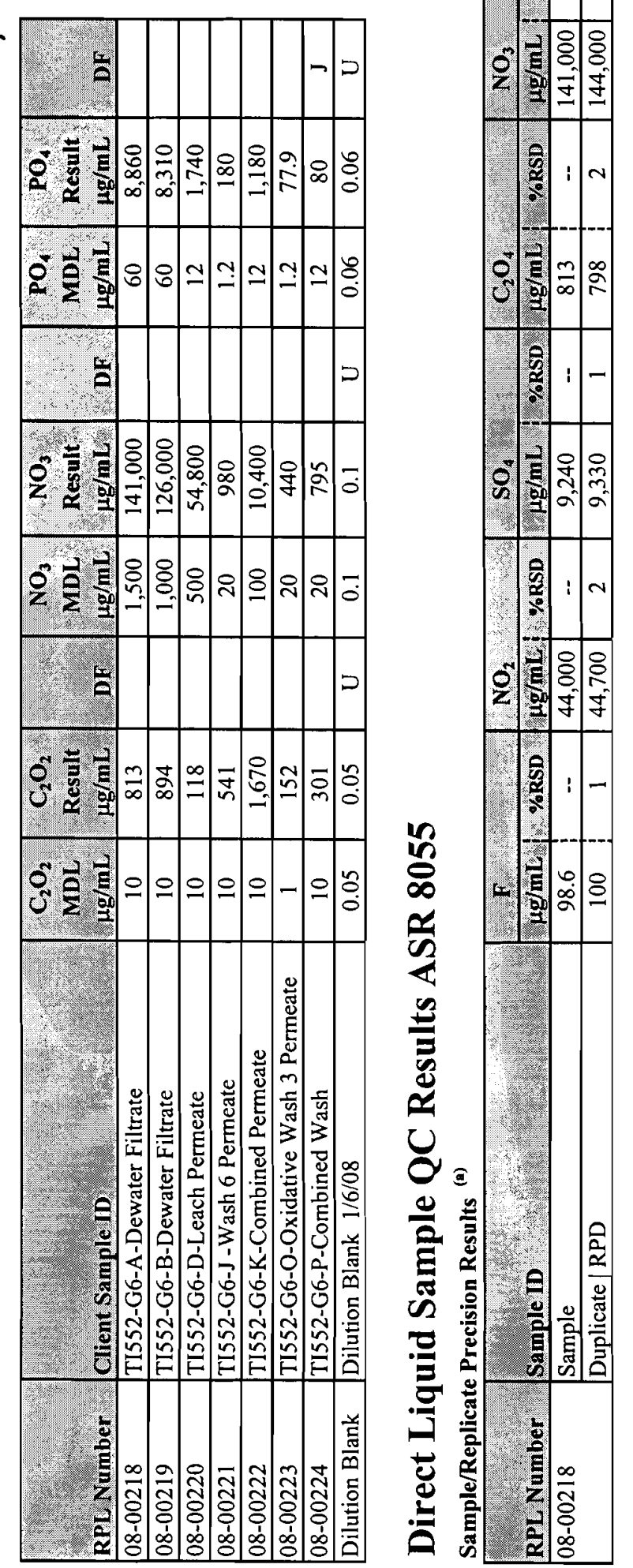

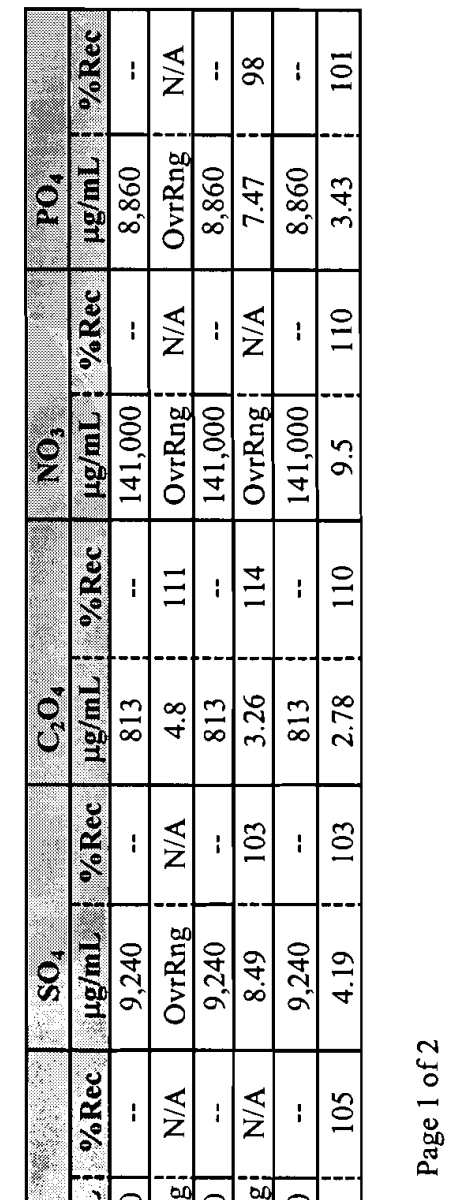

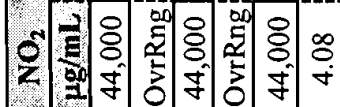
웅 : 호 : 의: :

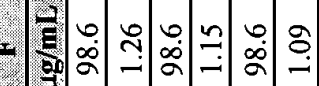

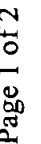




\section{Battelle - Pacific Northwest National Laboratory \\ Analytical Support Operations - IC Report \\ PO Box 999, Richland, Washington 99352}

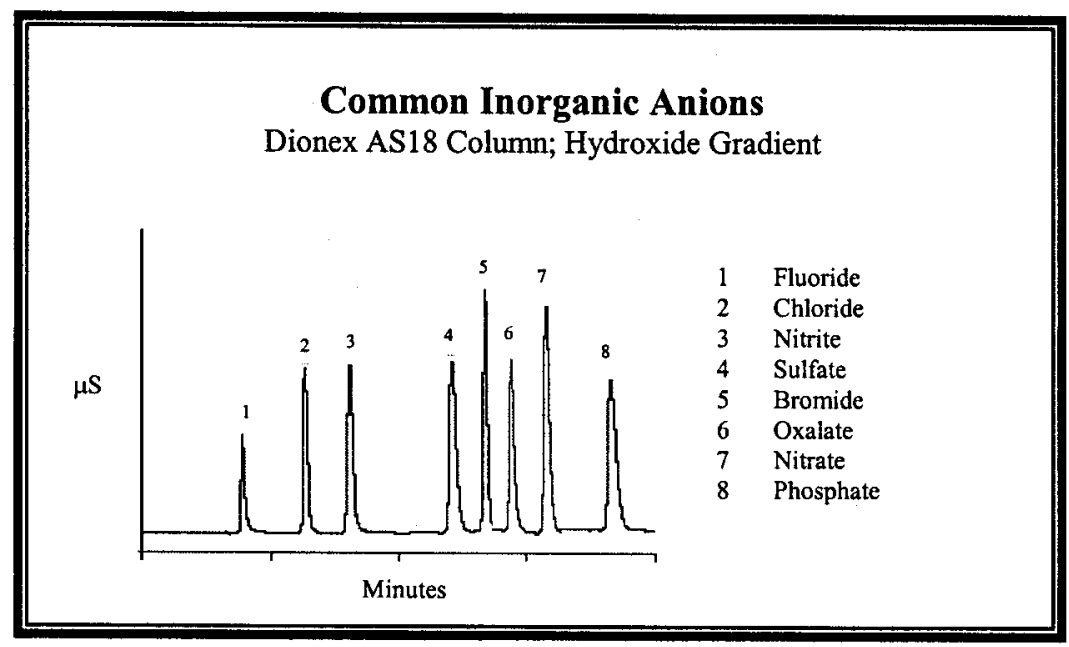

\section{Client: \\ M. Edwards \\ Project \#: 52964 \\ Charge Code: $\quad$ F99189}

ASR \#: $\quad 8055$

\# Samples: 5 Solids

*** RPL Numbers: 08-00242 through 08-00246***

Procedure, Analysis, System, and Records Information

\begin{tabular}{|l|l|}
\hline Analysis Procedure & PNL-ALO-212, "Determination of Inorganic Anions by Ion Chromatography" \\
\hline Prep Procedure & $\begin{array}{l}\text { Bench Dilution performed in lab 400 (MJS 01/04/08, 01/05/08, 01/06/08) } \\
\text { Water leach in SAL - RPG-CMC-103 (01/03/08) }\end{array}$ \\
\hline Analyst & MJ Steele \\
\hline Analysis Dates & $01 / 05 / 08,01 / 06 / 08$ \\
\hline Calibration Date & $1 / 05 / 08$ \\
\hline Cal/Ver Stds Prep Date & Cal 12/06/07; Ver 1/05/08 \\
\hline Excel Data File & Results ASR 8055 Edwards.xls \\
\hline \multirow{2}{*}{ M\&TE Numbers } & IC System (M\&TE) N830443 N830444 \\
\cline { 2 - 2 } & Balances: 360-06-01-031/1113052270 \\
\hline All Analysis Records & Chemical Measurement Center 98620: RIDS IC System File (IC-0149) \\
\hline
\end{tabular}

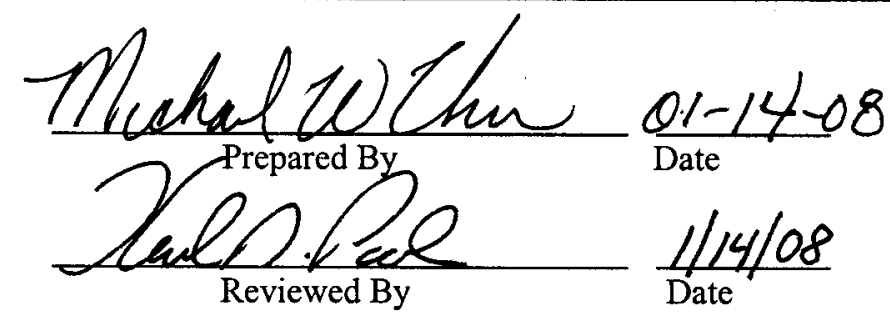




\section{IC Report}

\section{Sample Results}

See Attachment: Solid Sample Results ASR 8055

\section{Sample Analysis/Results Discussion}

Five solid/slurry samples were submitted to the ASO for analysis under ASR 8055. The specified analytes of are fluoride, nitrite, nitrate, sulfate, oxalate and phosphate. The sample was prepared for IC analysis by leaching the solids/slurry ( 1 $\mathrm{g}$ sample/slurry to $10 \mathrm{~mL}$ of deionized water), which included the preparation of matix spikes and sample replicates. Following leaching the samples were further diluted to bring each analyte within the calibration range. The dilutions were prepared in deionized water. Both the deionized water used to leach the solids/slurries and make further dilutions were analyzed as the process sample. All sample results are reported as $\mu \mathrm{g} / \mathrm{g}$; the leach deionized water samples have been normalized to the average solid/slurry processing factor of 8.16 .

After screening the sample, the final analysis was performed using additional dilution factors ranging from 1 to 750 . All results have been adjusted for all leaching and analytical dilution factors. The estimated method detection limits (MDL) are provided, and are based on the estimated quantitation limit (EQL), which is one-tenth of the lowest calibration standard (adjusted for the dilutions used for reporting the results).

\section{Data Limitations}

The Laboratory Control Sample (Blank Spike) processed through the leaching process failed for oxalate (only $12 \%$ of the oxalate was recovered). This is not uncommon for leaches performed in the hot cell; however, the loss mechanism is unknown. Based on the leached LCS recovery, oxalate results for all samples have been manually J-flagged (indicating that the oxalate results are qualitative estimates only).

\section{Quality Control Discussion}

The method performance is evaluated against the acceptance criteria established by Analytical Support Operations QA Plan ASO-QAP-001.

Dilution Blank: (Analytical Dilution) A dilution blank (deionized water) was analyzed with the sample set. There were no anions detected above the method detection limit (MDL). The processing blank meets the QA Plan acceptance criteria for all analytes of interest.

Process Blank: (Leach Dilution) A process blank (deionized water subjected to the same handling as the leached solid/slurry samples) was analyzed with the sample set. Of the analytes of interest, only nitrate was detected. However, the nitrate result is less than the EQL and meets the QA Plan acceptance criteria.

Duplicate (Precision): Sample 08-00244 was analyzed in duplicate. The relative percent difference is reported for all analytes which were measured at or above the EQL. The reported 


\section{IC Report}

RPDs ranged from 1 to $15 \%$ for all analytes of interest, which meets the Project acceptance criteria (Table 4 of ASR) of $<25 \%$.

Processing Laboratory Control/Blank Spike (LCS/BS): The leaching process LCS/blank spike was analyzed with the data set and, except for oxalate (See Data Limitations), had a recoveries ranging from $107 \%$ to $115 \%$ for the analytes of interest. These recoveries meet the Project acceptance criteria (Table 4 of ASR) of $80 \%$ to $120 \%$ recovery. Since oxalate only recovered at $12 \%$, all oxalate results have been J-flagged)

Matrix Spike: (Accuracy) A matrix spike was prepared for Sample 08-00242. However, no recoveries are reported since concentrations of all analytes of interest are greater than five times the (added) spike concentration. Post spikes were performed to evaluate accuracy.

Post Spike: (Accuracy) Multiple post spikes (i.e., standard added after leaching) were prepared for sample $08-00242$ and analyzed. Sample $08-00242$ was diluted by 100,500 , and 1500 in order to obtain spikes concentrations at least $20 \%$ greater than measured sample concentration. The recoveries range was from $95 \%$ to $109 \%$ for all analytes of interest (including oxalate), which meets the QA Plan post spike recovery acceptance criteria of $75 \%$ to $125 \%$.

IC System QC Samples: Numerous calibration verification standards and calibration verification blanks were analyzed with each run day. For all data reported, the IC System QC bounding the sample analyses produced results for all analytes were within the acceptance criterion of the ASO's QA Plan (i.e., $90 \%$ to $110 \%$ recovery for verification standards and verification blank results $<\mathrm{EQL}$ or $<5 \%$ of reported sample result).

\section{Deviations from Procedure}

None

\section{General Comments}

- The reported "Final Results" have been corrected for all dilutions performed on the sample during processing or analysis.

- The MDL is set at the concentration of the lowest calibrations standard divided by 10 . The $\mathrm{EQL}$ is defined as the concentration of the lowest calibration standards times the sample dilution factors (processing and analysis) and assumes non-complex aqueous matrices. Matrix-specific MDLs or EQLs may be determined, if requested.

- Routine precision and bias are typically $\pm 15 \%$ or better for non-complex aqueous samples that are free of interference. 


\begin{tabular}{|c|c|c|c|c|c|c|c|c|}
\hline$\stackrel{5}{0}$ & & & & & $\supset$ & $\stackrel{4}{0}$ & & $\supset$ \\
\hline 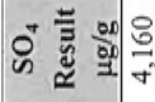 & & $\frac{\dot{亠}}{\infty}$ & $\underset{\infty}{\infty}$ & & $\overrightarrow{0}$ & 흘 & & ؛̃ \\
\hline 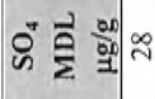 & & 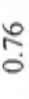 & $\stackrel{f}{\dot{f}}$ & & $\overrightarrow{\mid}$ & & & 5 \\
\hline & & & & & 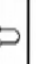 & & & כ \\
\hline
\end{tabular}

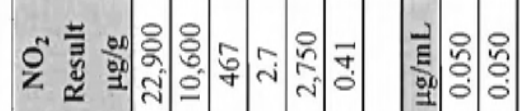

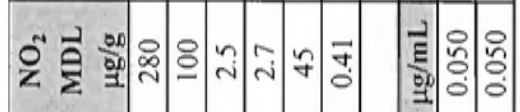

म

L

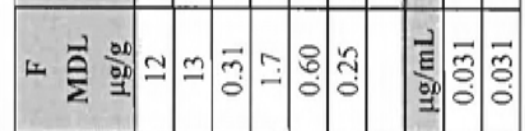

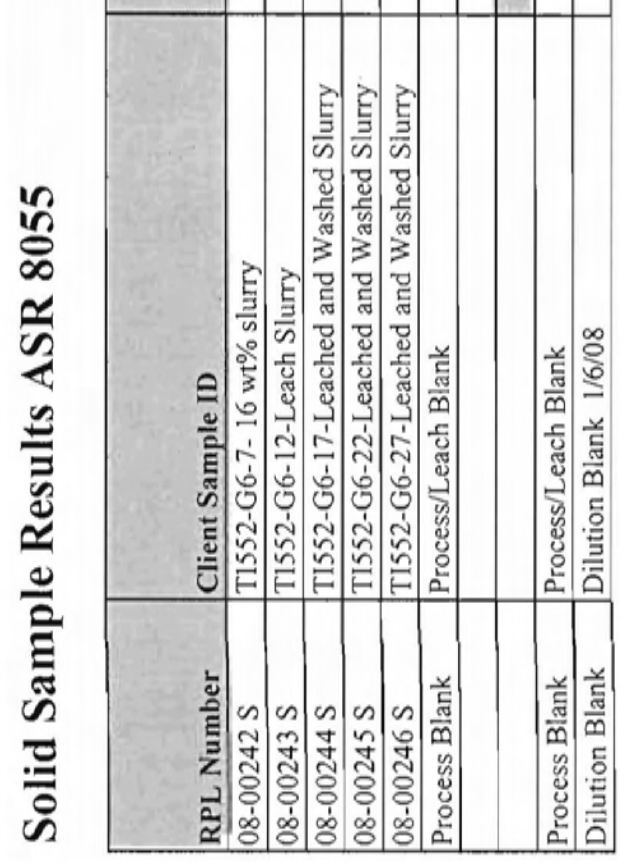

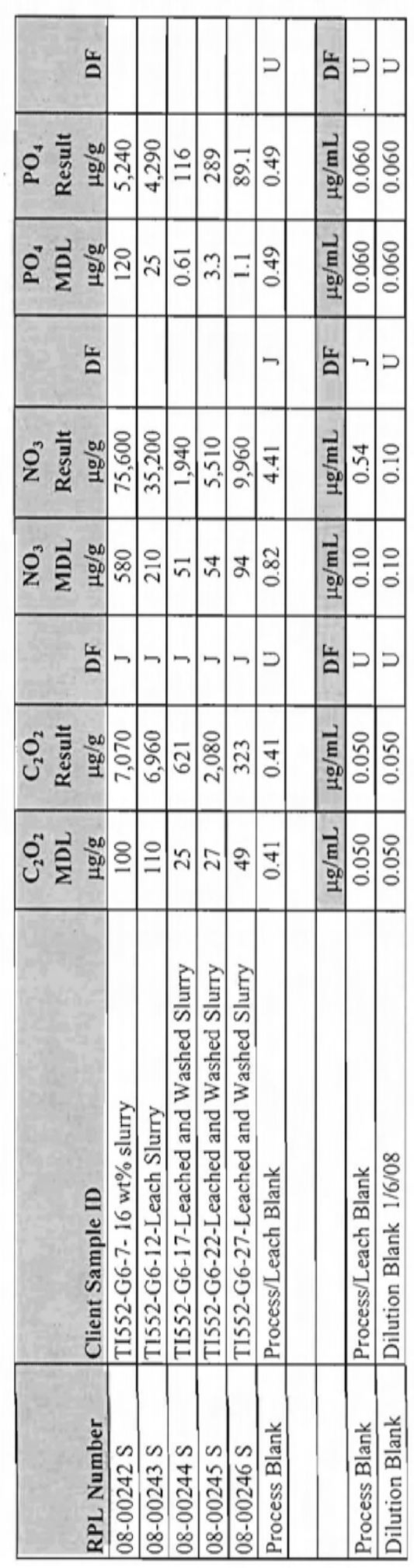



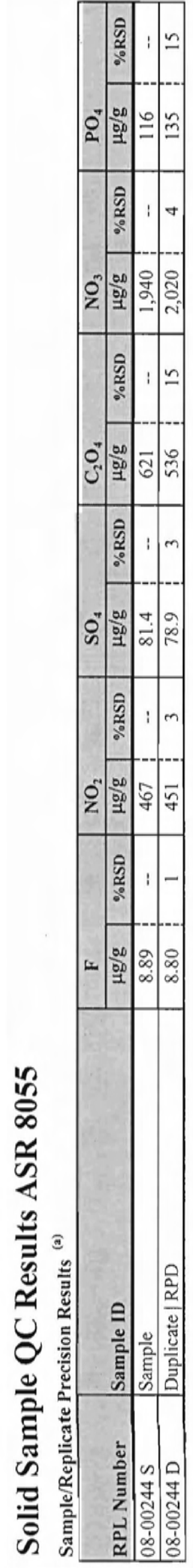

\begin{tabular}{|c|c|c|c|c|c|c|}
\hline $5^{\circ}$ & 의: & $\mathbf{z}$ & 으 & & & $\approx$ \\
\hline & & 讋 & 声 & & $\mathscr{B}$ & 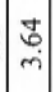 \\
\hline 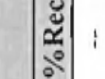 & & $\leqslant$ & $\widehat{z}$ & & 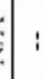 & $\stackrel{\infty}{=}$ \\
\hline & & & & & $\underset{\infty}{\infty}$ & $\stackrel{m}{=}$ \\
\hline & & $z$ & $\widehat{\Sigma}$ & & $:$ & : \\
\hline & & 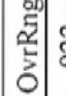 & $\frac{2}{5}$ & & & $\stackrel{m}{m}$ \\
\hline$\frac{2}{\circ}$ & 을 & $\mid \widehat{z}$ & 2 & & : & $\stackrel{0}{-}$ \\
\hline & & & & & 18 & 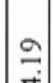 \\
\hline
\end{tabular}

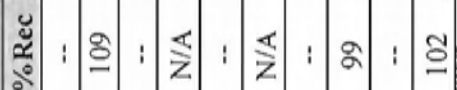

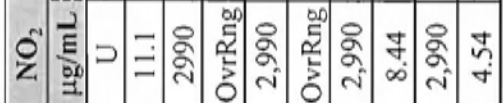
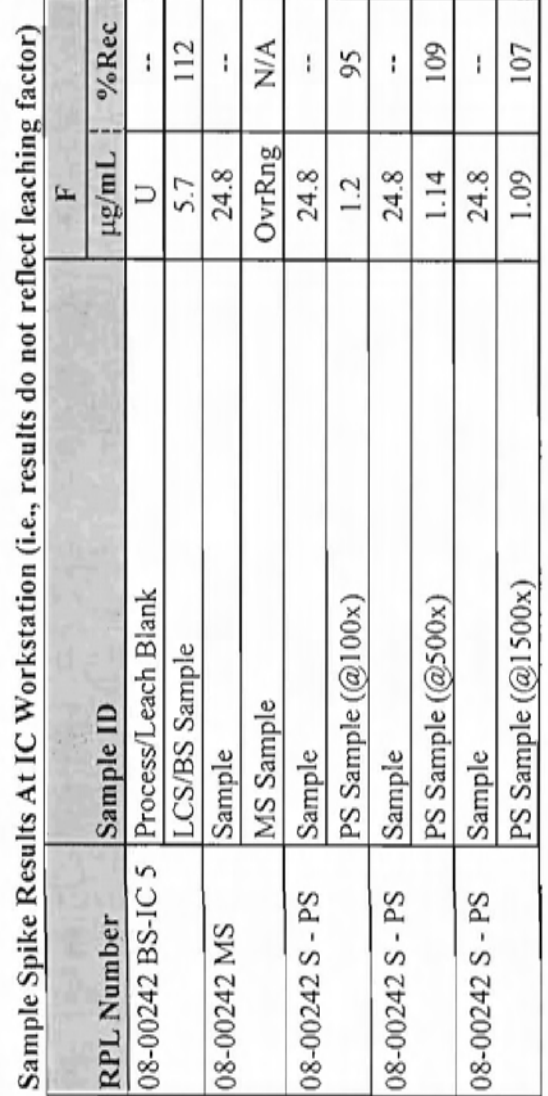

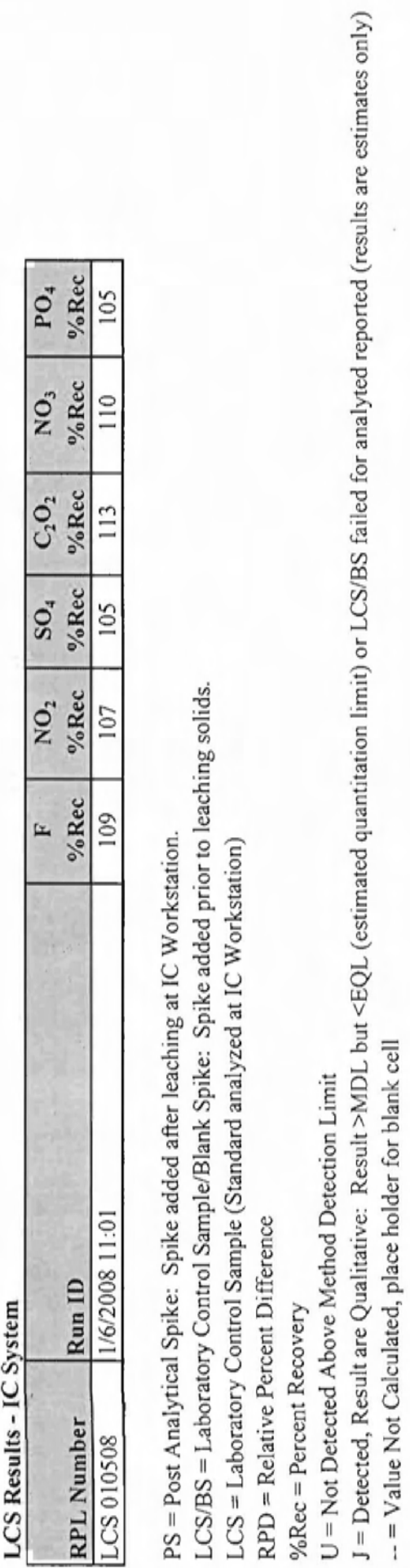




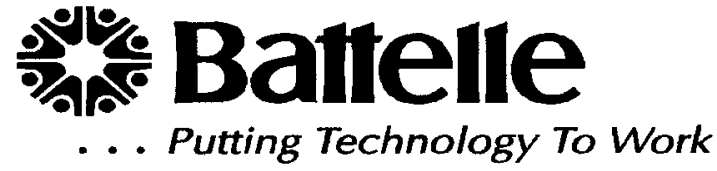

Client: Matt Edwards

Rick Shimskey

Subject:

ASR:

Sample ID.
Hydroxide Analyses for:

8055

$08-0218$
Rev-0

thru

\begin{tabular}{r|c|} 
Report Date: & $1 / 9 / 2008$ \\
Analysis Date: & $1 / 8 / 2008$ \\
\hline
\end{tabular}

CUF Group 6/5 Caustic Leach Study

Procedure: RPG-CMC-228-Rev 1

Direct sample aliquots of CUF Group 6/5 Caustic Leach Study samples (08-0218 thru 07-0241), except for 08-231-233, which were cancelled due to insufficient sample for hydroxide analysis. A total of 21 samples were analyzed in duplicate for the base constituents content following procedure RPG-CMC-228, and using a Brinkman 636 Auto-Titrator. The titrant used was $0.1016 \mathrm{M} \mathrm{HCl}$ and the base standard, $0.1118 \mathrm{M} \mathrm{NaOH}$ was used for QC verification standards and matrix spike. -- See Chemrec_139 pdf imbedded in the result report.

The hydroxide Standard recovery was $94 \%$. The three matrix spike recoveries were $98 \%, 97 \%$ and $102 \%$; all well within the allowed $\pm 20 \%$ recovery range. No hydroxide was detected in the reagent blank.

The initial $\mathrm{pH}$ is reported on attached Report Summary along with the free hydroxide molarity (generally the 1st inflection point), whenever the initial pH is 12 or more. In such cases, generally the 2 nd inflection point around $\mathrm{pH} 7-8$, indicates the total hydroxide molarity. These results showed excellent Relative Percent Deviation (RPD) on all samples for the first inflection point, well within $\pm 20 \%$ allowed range.

Most samples indicated a third inflection point around pH 5-6 as noted on the curve, and the RPD's were acceptable for those samples where the volume analyzed was within reasonable titration range of the $0.1 \mathrm{M}$ $\mathrm{HCl}$. Sample size provided for analysis was minimal, less than a mililiter for nearly all samples. This volume was insufficient for those samples having an initial $\mathrm{pH}$ of less than 10 but they still had acceptable RPD's. Wherever the RPD on the 2 nd or 3rd inflection point fell outside the $\pm 20 \%$ allowed range, the actual curve does not define these inflection points clearly meaning there is minimal evidence of this constiuent, thus contributing to the larger RPD. Basically, the sample size needed to be larger than what was provided.

The best estimate of the MDL for this method is obtained from the reagent blank which did not show any inflection points and is consistent with a value of 0 within our measurement sensitivity. All samples molarities were well above the MDL $(0.001 \mathrm{M})$ for this analysis. The results are accepted based on the QC data meeting the acceptance criteria as specified in the ASR.

Following is the report summary, the sample results calculated from the raw data, and the record file for the standardized acid and base used. The sample aliquots were consumed in the titration process.

Copies of the titration curves are available upon request.

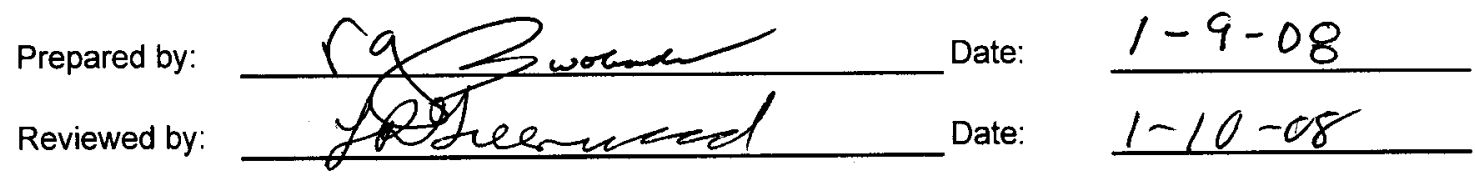


Battelle Pacific Northwest Laboratory

Radiochemical Processing Group-325 Building

Chemical Measurements Center

Hydroxide and Alkalinity Determination

Procedure: RPG-CMC-228-Rev 1

\section{ASR \# $\mathbf{8 0 5 5}$}

WP\# F99189

\begin{tabular}{rl|l|} 
Report Summary for ASR \# -- $\mathbf{8 0 5 5}$ & $\begin{array}{r}\text { Report Date: } \\
\text { Revision \# }\end{array}$ Rev-0 \\
Analysis Date: & $1 / 8 / 2008$ \\
\hline
\end{tabular}

\begin{tabular}{|c|c|c|c|c|c|c|c|c|c|}
\hline \multirow[b]{3}{*}{ RPG \# } & \multirow[b]{3}{*}{ Client ID } & \multirow[b]{3}{*}{$\begin{array}{c}\text { Initial } \\
\mathbf{p H}\end{array}$} & \multirow[b]{3}{*}{$\begin{array}{c}\text { OH conc } \\
\mathrm{ug} / \mathrm{mL}\end{array}$} & \multicolumn{5}{|c|}{ Concentration, moles / Liter } & \multirow[b]{3}{*}{ RPD } \\
\hline & & & & \multirow{2}{*}{$\begin{array}{c}\text { First Point } \\
\text { Molarity } \\
\end{array}$} & \multirow[b]{2}{*}{ RPD } & \multicolumn{2}{|c|}{ Second Point } & \multirow{2}{*}{$\begin{array}{l}\text { Third Poin } \\
\text { Molarity } \\
\end{array}$} & \\
\hline & & & & & & Molarity & RPD & & \\
\hline 08-0218 & TI552-G6-A & 11.93 & $1.06 \mathrm{E}+04$ & 0.62 & & 1.21 & & 0.79 & \\
\hline 08-0218-Dup & TI552-G6-A & 12.00 & $1.12 \mathrm{E}+04$ & 0.66 & $5.9 \%$ & 1.20 & $0.4 \%$ & 0.78 & $0 \%$ \\
\hline 08-0219 & TI552-G6-B & 12.04 & $1.07 \mathrm{E}+04$ & 0.63 & & 0.94 & & 0.66 & \\
\hline 08-0219-Dup & TI552-G6-B & 11.96 & $1.05 \mathrm{E}+04$ & 0.62 & $1.6 \%$ & 0.95 & $0.5 \%$ & 0.66 & $1 \%$ \\
\hline $08-0220$ & TI552-G6-D & 12.63 & $1.06 \mathrm{E}+05$ & 6.26 & & 0.97 & & 0.27 & \\
\hline 08-0220-Dup & TI552-G6-D & 12.69 & $1.03 \mathrm{E}+05$ & 6.06 & $3.4 \%$ & 0.96 & $1.9 \%$ & 0.30 & $14 \%$ \\
\hline 08-0221 & T1552-G6-J & 12.15 & $2.95 \mathrm{E}+03$ & 0.17 & & 0.03 & & 0.02 & \\
\hline 08-0221-Dup & TI552-G6-J & 12.12 & $2.95 \mathrm{E}+03$ & 0.17 & $0.1 \%$ & 0.03 & $0.8 \%$ & 0.02 & $5 \%$ \\
\hline 08-0222 & TI552-G6-K & 12.79 & $2.70 \mathrm{E}+04$ & 1.59 & & 0.22 & & 0.07 & \\
\hline 08-0222-Dup & TI552-G6-K & 12.50 & $2.65 \mathrm{E}+04$ & 1.56 & $1.5 \%$ & 0.23 & $6.3 \%$ & 0.08 & $3 \%$ \\
\hline $08-0223$ & TI552-G6-O & 9.83 & $2.07 \mathrm{E}+02$ & 0.01 & & 0.06 & & & \\
\hline 08-0223-Dup & T1552-G6-O & 9.93 & $2.37 \mathrm{E}+02$ & 0.01 & $13.3 \%$ & 0.06 & $0.4 \%$ & & \\
\hline 08-0224 & T1552-G6-P & 10.24 & $4.92 \mathrm{E}+02$ & 0.03 & & 0.09 & & & \\
\hline 08-0224-Dup & TI552-G6-P & 10.27 & $4.59 \mathrm{E}+02$ & 0.03 & $6.9 \%$ & 0.08 & $5.3 \%$ & & \\
\hline $\mathrm{OH} \operatorname{conc}(\mathrm{mg} / \mathrm{L})=$ & $M(g / L) * 17,000$ & & $\begin{array}{c}\mu \mathrm{g} / \mathrm{ml} \text { or } \\
\mathrm{mg} / \mathrm{L} \\
\mathrm{MDL}\end{array}$ & $\begin{array}{l}\text { Molarity } \\
\text { MDL }\end{array}$ & & Required RP & & & \\
\hline free $\mathrm{OH}$ as $\mathrm{sp}$ & cified in ASR & & $1.70 \mathrm{E}+01$ & 0.001 & & $+/-15 \%$ & & & \\
\hline & & & & & Allow & wed Recovery & Range & & \\
\hline Reag. Blk.1 & & & & $\mathbf{0}$ & & & & & \\
\hline Standard 1 & & 12.47 & & $94.1 \%$ & & $+/-25 \%$ & & & \\
\hline 08-0218MS & Matrix spike & 12.51 & & $98 \%$ & & $+/-20 \%$ & & & \\
\hline
\end{tabular}

Note: Results are presented for the first, second, and third inflection points on the titration curves, as applicable. The first inflection point is generally associated with the free hydroxide concentration. The second inflection point generally represents total hydroxide, or carbonate or a combination of aluminate and carbonate. The third inflection point is usually indicative of bicarbonate or other weak acids or possibly the continued protonation of alumina.

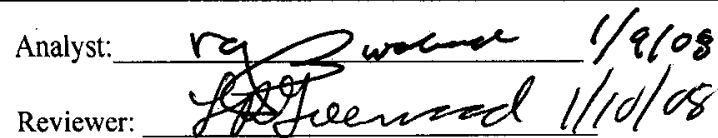


Battelle Pacific Northwest Laboratory

Radiochemical Processing Group-325 Building

Chemical Measurements Center

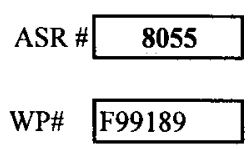

Equip \# WB76843

Hydroxide and Alkalinity Determination

Procedure: RPG-CMC-228-Rev 1

\begin{tabular}{rl|} 
Report Summary for ASR \# -- 8055 \\
Revision \# Rev-0
\end{tabular}

\begin{tabular}{r|r|}
$\begin{array}{r}\text { Report Date: } \\
\text { Analysis Date: }\end{array} 1 / 9 / 2008$ \\
\hline
\end{tabular}

Concentration, moles / Liter

\begin{tabular}{|c|c|c|c|c|c|c|c|c|c|}
\hline \multirow[b]{2}{*}{ RPG \# } & \multirow[b]{2}{*}{ Client ID } & \multirow{2}{*}{$\begin{array}{c}\text { Initial } \\
\mathrm{pH}\end{array}$} & \multirow{2}{*}{$\begin{array}{l}\text { OH conc } \\
\text { ug/mL }\end{array}$} & \multirow{2}{*}{$\begin{array}{c}\text { First Point } \\
\text { Molarity }\end{array}$} & \multirow[b]{2}{*}{ RPD } & \multicolumn{2}{|c|}{ Second Point } & \multicolumn{2}{|l|}{ Third Point } \\
\hline & & & & & & Molarity & RPD & Molarity & RPD \\
\hline $08-0225$ & TI552-G6-L1 & 10.32 & $1.60 \mathrm{E}+03$ & 0.09 & & 0.28 & & & \\
\hline 08-0225-Dup & TI552-G6-L1 & 10.29 & $1.61 \mathrm{E}+03$ & 0.09 & $0.9 \%$ & 0.27 & $5.3 \%$ & & \\
\hline $08-0226$ & TI552-G6-L2 & 11.09 & $1.60 \mathrm{E}+03$ & 0.09 & & 0.13 & & & \\
\hline 08-0226-Dup & TI552-G6-L2 & 11.18 & $1.50 \mathrm{E}+03$ & 0.09 & $6.4 \%$ & 0.14 & $5.2 \%$ & & \\
\hline $08-0227$ & TI552-G6-L3 & 10.33 & $1.49 \mathrm{E}+03$ & 0.09 & & 0.25 & & & \\
\hline 08-0227-Dup & TI552-G6-L3 & 10.25 & $1.46 \mathrm{E}+03$ & 0.09 & $1.6 \%$ & 0.25 & $0.4 \%$ & & \\
\hline $08-0228$ & TI552-G6-L4 & 10.47 & $1.15 \mathrm{E}+03$ & 0.07 & & 0.19 & & & \\
\hline 08-0228-Dup & TI552-G6-L4 & 10.38 & $1.23 \mathrm{E}+03$ & 0.07 & $6.8 \%$ & 0.18 & $4.2 \%$ & & \\
\hline 08-0229 & TI552-G6-L5 & 11.03 & $1.57 \mathrm{E}+03$ & 0.09 & & 0.15 & & & \\
\hline 08-0229-Dup & TI552-G6-L5 & 11.09 & $1.33 \mathrm{E}+03$ & 0.08 & $17.0 \%$ & 0.12 & $18.1 \%$ & & \\
\hline 08-0230 & TI552-G6-C1 & 12.60 & $1.20 \mathrm{E}+05$ & 7.03 & & 0.34 & & 0.62 & \\
\hline 08-0230-Dup & TI552-G6-C1 & 12.54 & $1.13 \mathrm{E}+05$ & 6.66 & $5.4 \%$ & 0.62 & $57.1 \%$ & 0.29 & $73 \%$ \\
\hline $08-0234$ & TI552-G6-C5 & 12.49 & $1.10 \mathrm{E}+05$ & 6.47 & & 1.12 & & 0.43 & \\
\hline 08-0234-Dup & TI552-G6-C5 & 12.60 & $1.00 \mathrm{E}+05$ & 5.91 & $9.1 \%$ & 1.14 & $1.8 \%$ & 0.33 & $28 \%$ \\
\hline
\end{tabular}

$\mathrm{OH}$ conc $(\mathrm{mg} / \mathrm{L})=\mathrm{M}(\mathrm{g} / \mathrm{L}) * 17,000$

free $\mathrm{OH}$ as specified in ASR

Reag. Blk.1

Standard 1

08-0227MS Matrix spike

\begin{tabular}{cc}
$\mu \mathrm{g} / \mathrm{ml}$ or \\
$\mathrm{mg} / \mathrm{L}$ & Molarity \\
$\mathrm{MDL}$ & MDL \\
\hline $1.70 \mathrm{E}+01$ & $\mathbf{0 . 0 0 1}$ \\
\hline
\end{tabular}

0

12.47

12.41
$94 \%$

$97 \%$
Required RPD $+/-15 \%$

Allowed Recovery Range

$+/=25 \%$

$+/-20 \%$

Note: Results are presented for the first, second, and third inflection points on the titration curves, as applicable. The first inflection point is generally associated with the free hydroxide concentration. The second inflection point generally represents carbonate or a combination of aluminate and carbonate. The third inflection point is usually indicative of bicarbonate or other weak acids or possibly the continued protonation of alumina.

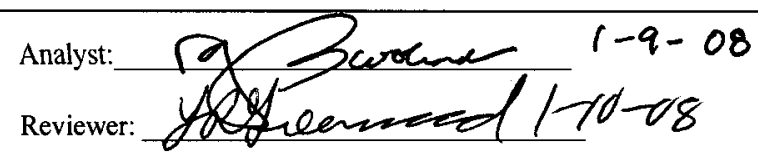


Battelle Pacific Northwest Laboratory

Radiochemical Processing Group-325 Building

Chemical Measurements Center

Hydroxide and Alkalinity Determination

Procedure: RPG-CMC-228-Rev 1

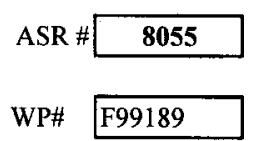

Equip \# WB76843

$$
\begin{array}{rl|l|}
\text { Report Summary for ASR \# -- } & \mathbf{8 0 5 5} \\
\text { Revision } \# \text { Rev-0 } & \begin{array}{r}
\text { Report Date: } \\
\text { Analysis Date: }
\end{array} 1 / 2 / 2008 \\
\hline
\end{array}
$$

\begin{tabular}{|c|c|c|c|c|c|c|c|c|c|}
\hline \multirow[b]{2}{*}{ RPG \# } & \multirow[b]{2}{*}{ Client ID } & \multirow{2}{*}{$\begin{array}{c}\text { Initial } \\
\text { pH }\end{array}$} & \multirow{2}{*}{$\begin{array}{c}\text { OH conc } \\
\text { ug/mL }\end{array}$} & \multirow{2}{*}{$\begin{array}{l}\text { First Point } \\
\text { Molarity }\end{array}$} & \multirow[b]{2}{*}{ RPD } & \multicolumn{2}{|c|}{ Second Point } & \multicolumn{2}{|c|}{ Third Point } \\
\hline & & & & & & Molarity & RPD & Molarity & RPD \\
\hline 08-0235 & TI552-G6-E & 12.60 & $6.99 \mathrm{E}+04$ & 4.11 & & 0.56 & & 0.18 & \\
\hline 08-0235-Dup & TI552-G6-E & 12.43 & $6.44 \mathrm{E}+04$ & 3.79 & $8.2 \%$ & 0.56 & $0.2 \%$ & 0.14 & $21.7 \%$ \\
\hline 08-0236 & TI552-G6-F & 12.19 & $4.17 \mathrm{E}+04$ & 2.45 & & 0.43 & & & \\
\hline 08-0236-Dup & TI552-G6-F & 12.22 & $4.02 \mathrm{E}+04$ & 2.37 & $3.5 \%$ & 0.50 & $13.1 \%$ & & \\
\hline 08-0237 & TI552-G6-G & 11.99 & $2.34 \mathrm{E}+04$ & 1.38 & & 0.16 & & 0.14 & \\
\hline 08-0237-Dup & TI552-G6-G & 12.21 & $2.27 \mathrm{E}+04$ & 1.34 & $3.0 \%$ & 0.17 & $4.3 \%$ & 0.09 & $44.2 \%$ \\
\hline 08-0238 & TI552-G6-H & 12.06 & $1.24 \mathrm{E}+04$ & 0.73 & & 0.08 & & 0.05 & \\
\hline 08-0238-Dup & TI552-G6-H & 12.16 & $1.24 \mathrm{E}+04$ & 0.73 & $0.1 \%$ & 0.08 & $4.4 \%$ & 0.04 & $18.6 \%$ \\
\hline 08-0239 & TI552-G6-I & 12.06 & $6.62 \mathrm{E}+03$ & 0.39 & & 0.04 & & 0.04 & \\
\hline 08-0239-Dup & TI552-G6-I & 12.23 & $6.41 \mathrm{E}+03$ & 0.38 & $3.2 \%$ & 0.06 & $36.7 \%$ & 0.03 & $31.2 \%$ \\
\hline $08-0240$ & TI552-G6-M & 10.33 & $8.46 \mathrm{E}+02$ & 0.05 & & 0.14 & & & \\
\hline 08-0240-Dup & TI552-G6-M & 10.29 & $8.38 \mathrm{E}+02$ & 0.05 & $1.0 \%$ & 0.13 & $7.8 \%$ & & \\
\hline 08-0241 & TI552-G6-N & 10.07 & $5.01 \mathrm{E}+02$ & 0.03 & & 0.10 & & & \\
\hline 08-0241-Dup & TI552-G6-N & 10.02 & $4.49 \mathrm{E}+02$ & 0.03 & $10.9 \%$ & 0.09 & $3.7 \%$ & & \\
\hline $\begin{array}{l}\mathrm{OH} \operatorname{conc}(\mathrm{mg} / \mathrm{L})= \\
\text { free } \mathrm{OH} \text { as sp }\end{array}$ & $\begin{array}{l}M(g / L) * 17,000 \\
\text { cified in ASR }\end{array}$ & & $\begin{array}{c}\mu \mathrm{g} / \mathrm{ml} \text { or } \\
\mathrm{mg} / \mathrm{L} \\
\mathrm{MDL}\end{array}$ & $\begin{array}{c}\text { Molarity } \\
\text { MDL } \\
\mathbf{0 . 0 0 1}\end{array}$ & & $\begin{array}{l}\text { Required RPI } \\
\begin{array}{|c|}+1-15 \% \\
\end{array}\end{array}$ & & & \\
\hline Reag. Blk.1 & & & & 0 & Allov & ved Recover & Range & & \\
\hline Standard 1 & & 12.47 & & $94 \%$ & & $+/-25 \%$ & & & \\
\hline 08-0238MS & Matrix spike & 12.45 & & $102 \%$ & & $+/-20 \%$ & & & \\
\hline
\end{tabular}

Concentration, moles / Liter

Note: Results are presented for the first, second, and third inflection points on the titration curves, as applicable. The first inflection point is generally associated with the free hydroxide concentration. The second inflection point generally represents carbonate or a combination of aluminate and carbonate.

The third inflection point is usually indicative of bicarbonate or other weak acids or possibly the continued protonation of alumina.

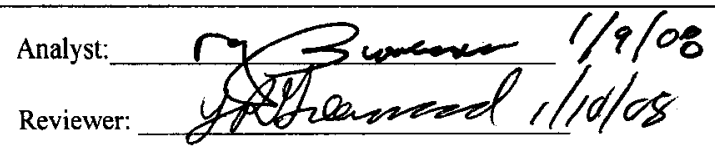




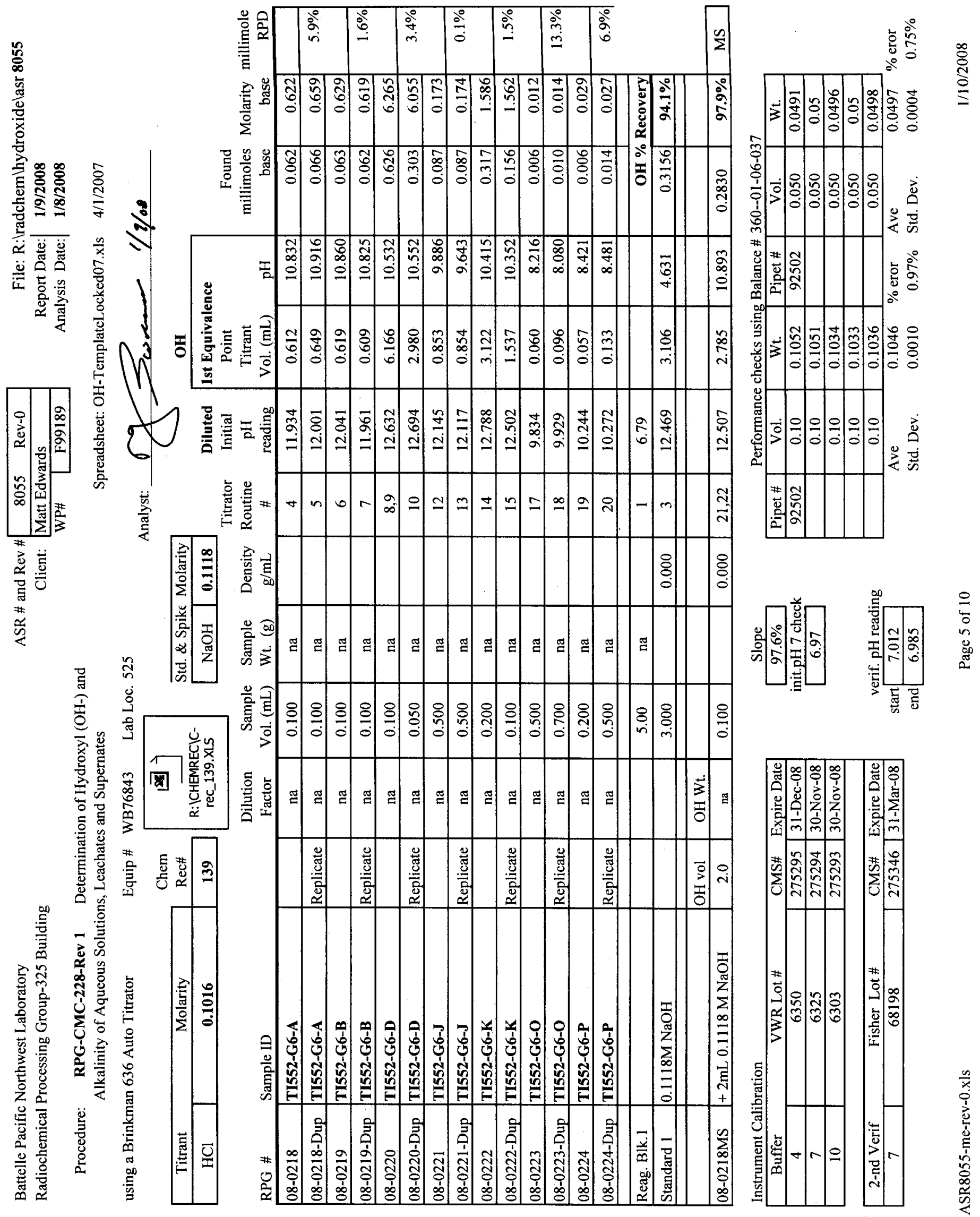




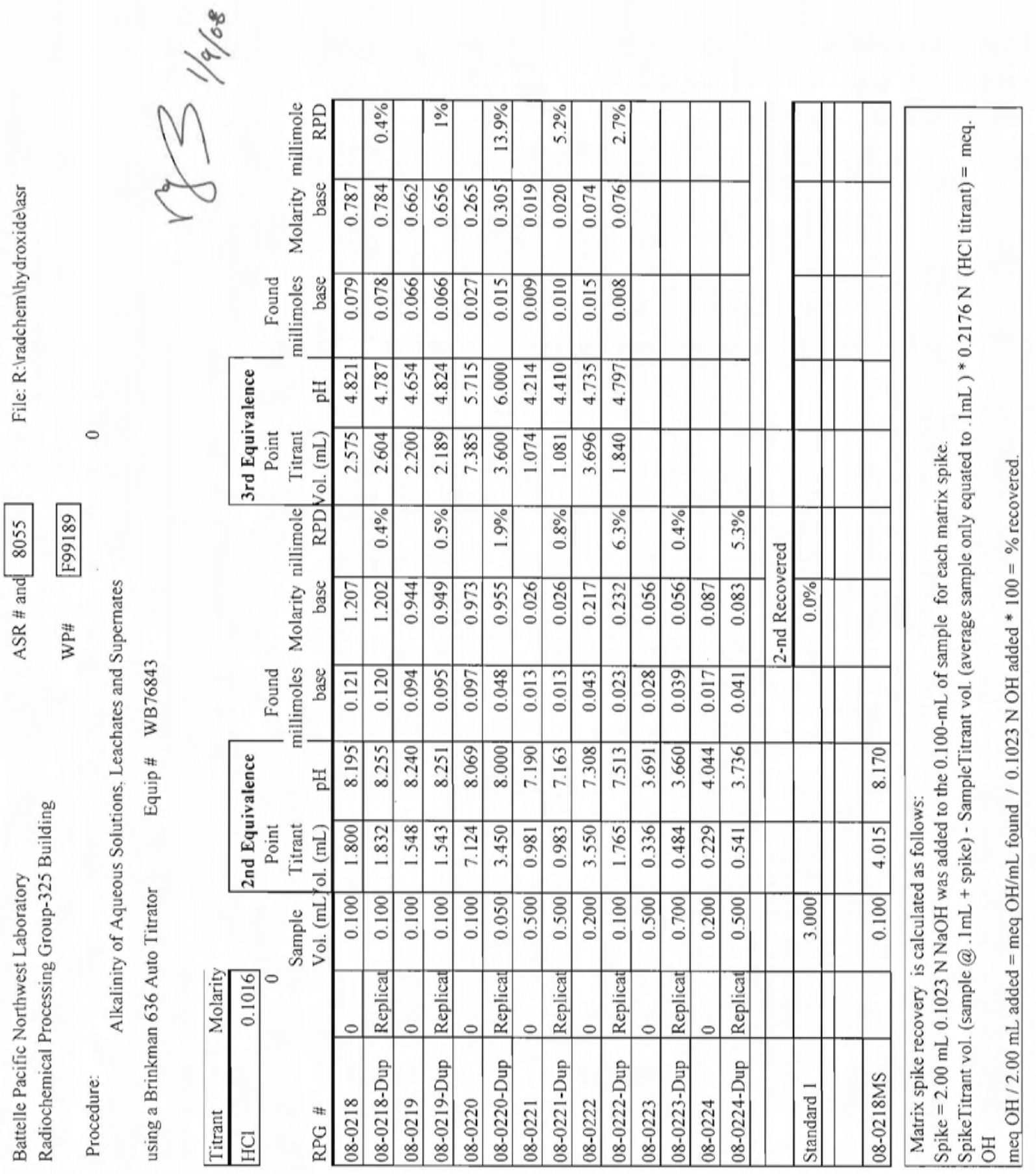

0
음
0
0
0
0
0 


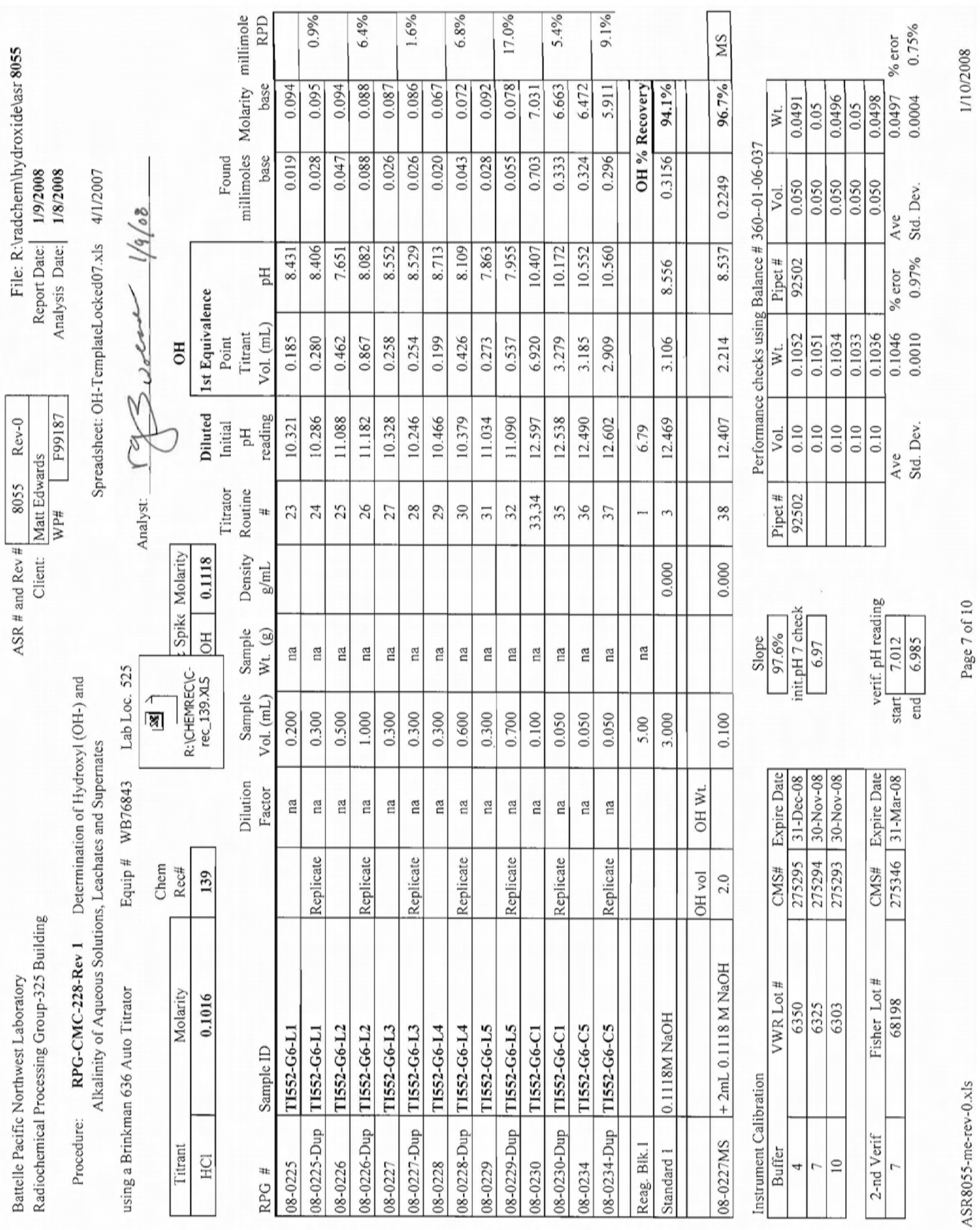




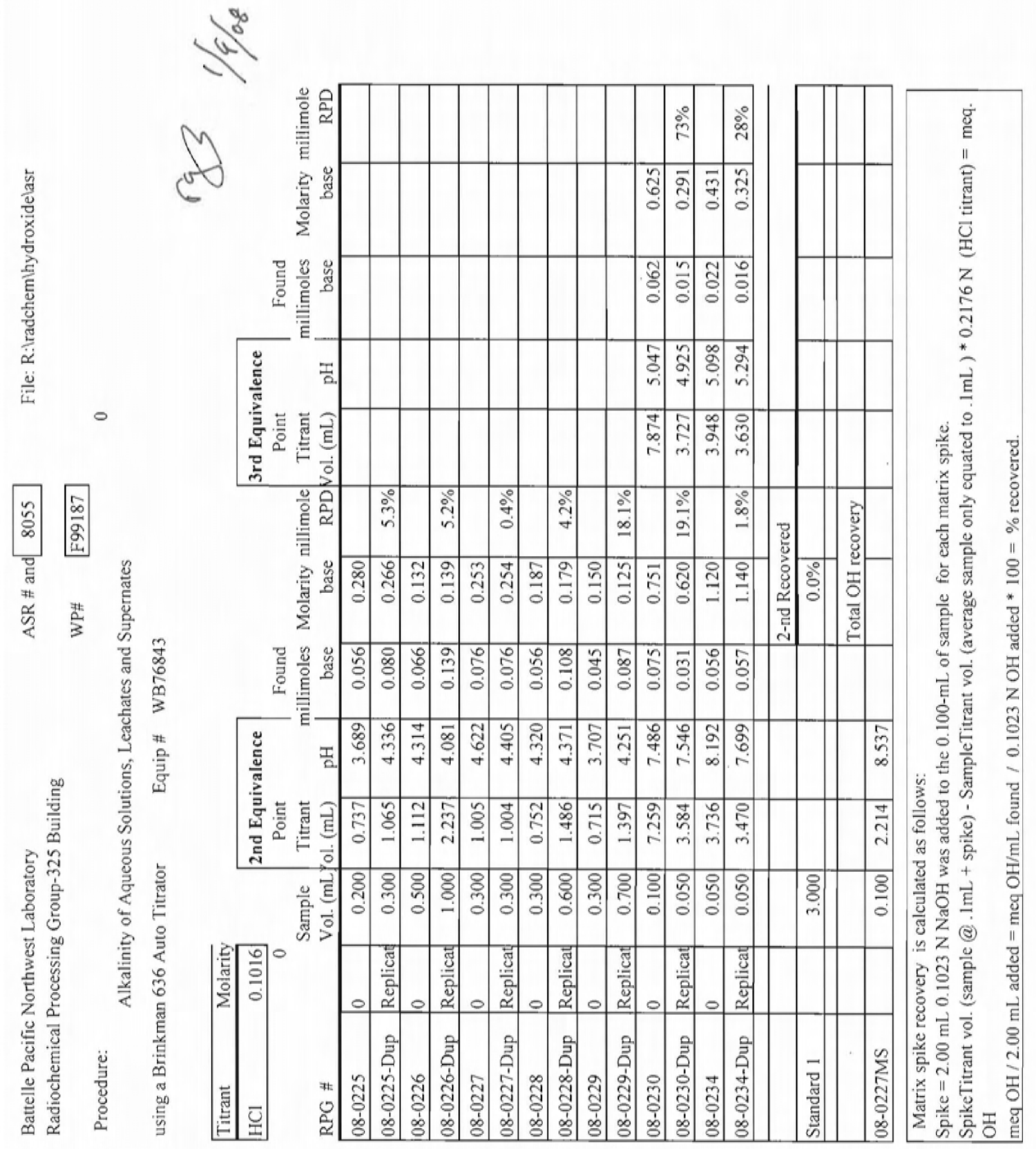




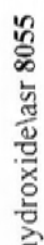

产

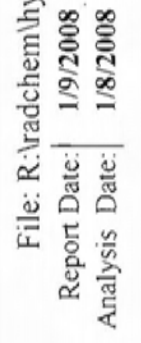

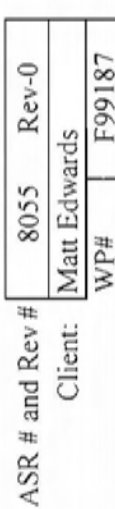

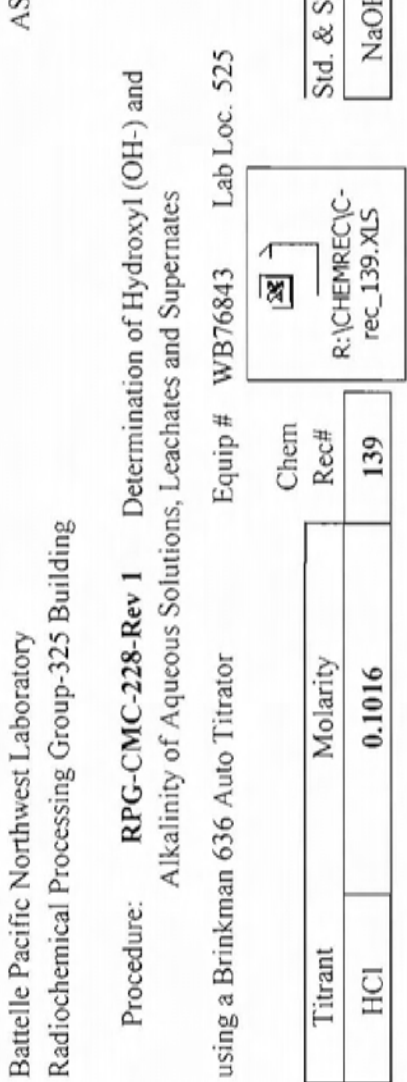

蕞

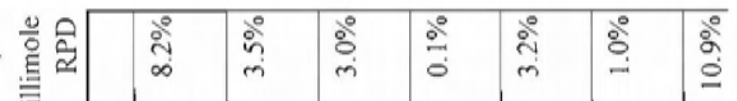

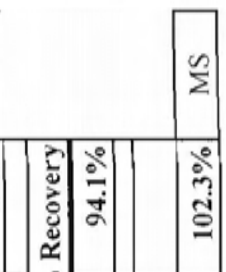

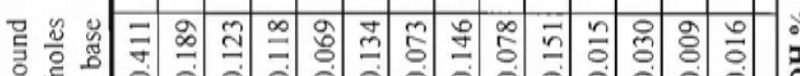

등

商

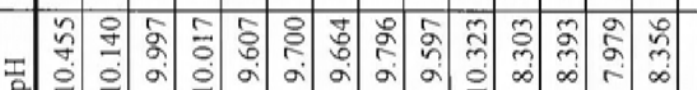

总

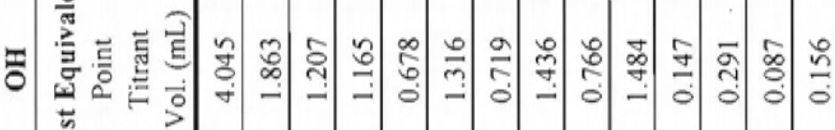

$\stackrel{8}{\circ}$

ते

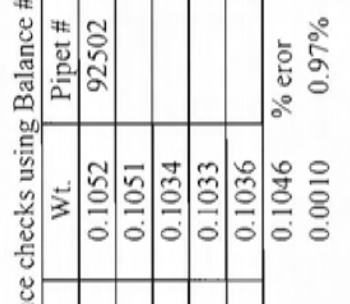

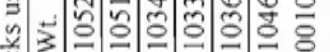

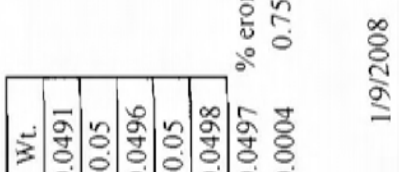

$0: 00$
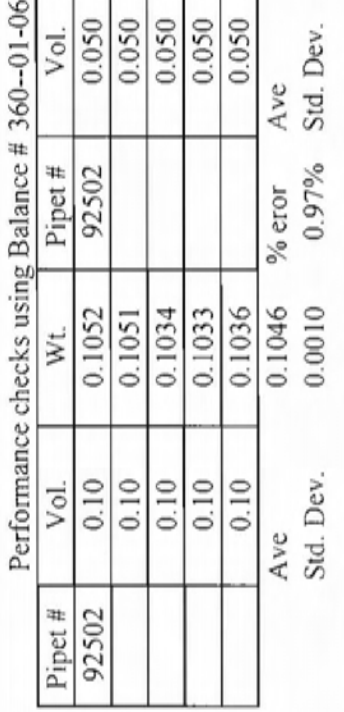

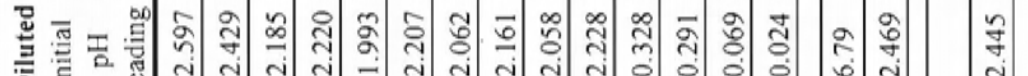

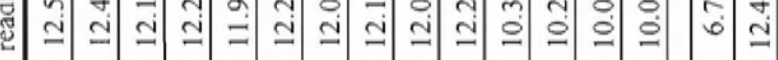

(1)

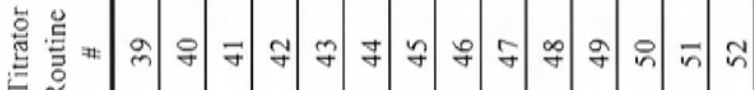

$\simeq$

总额

믈 영

空

青金응 웅

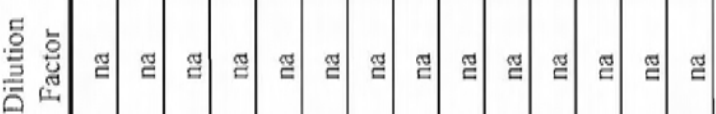

离

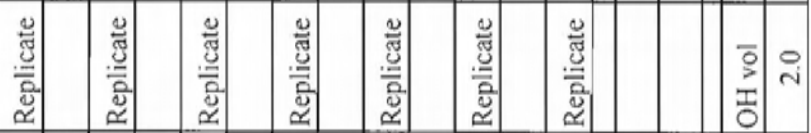

(⿻)

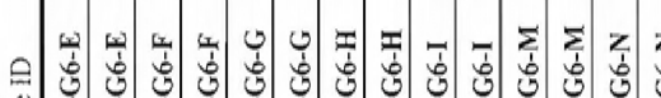

言究

罂

(1)

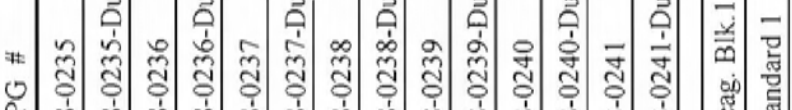
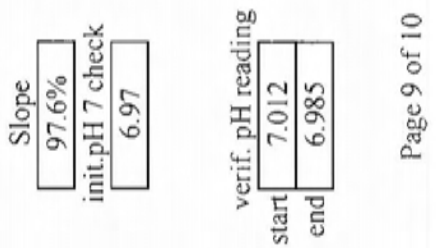

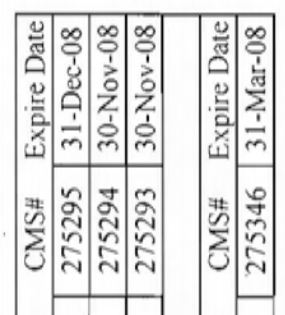

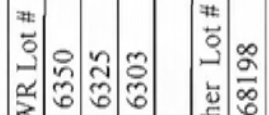

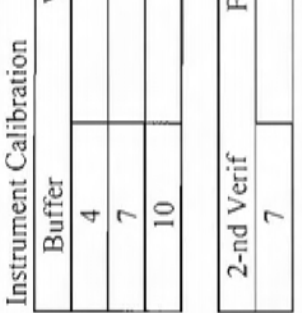

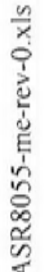




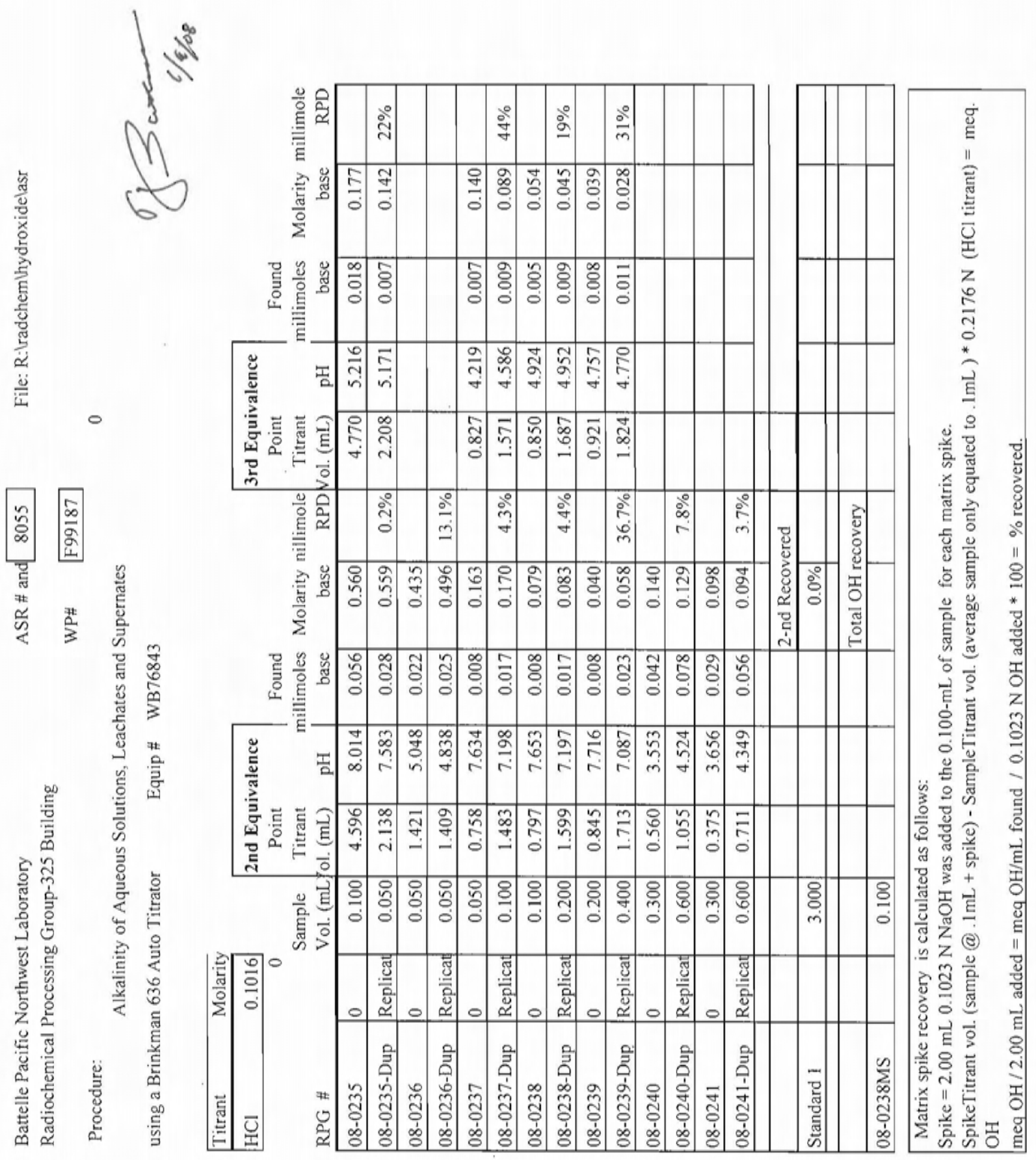

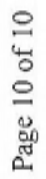



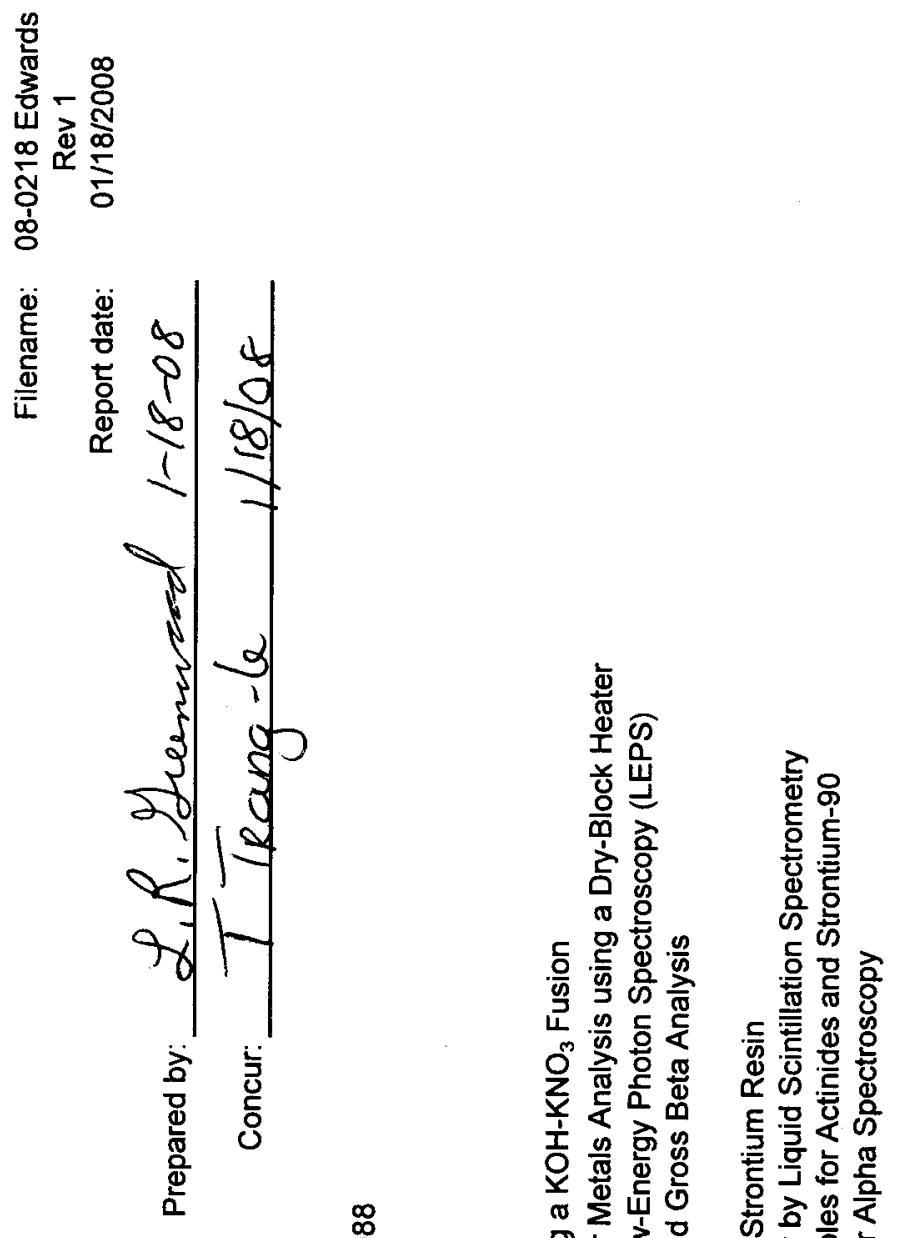

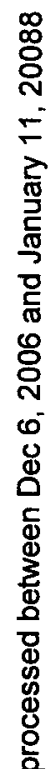
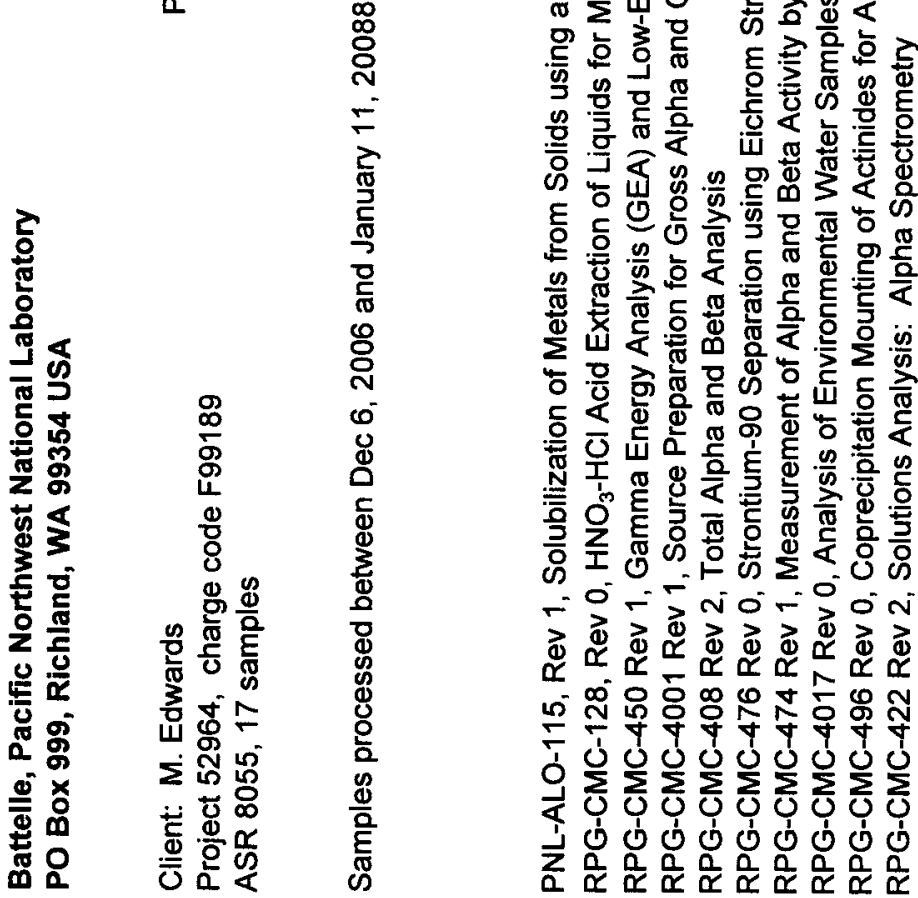

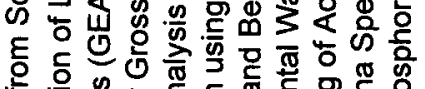

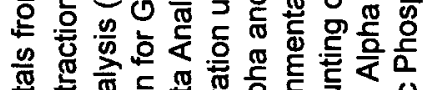

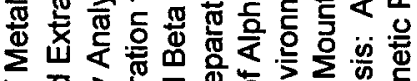

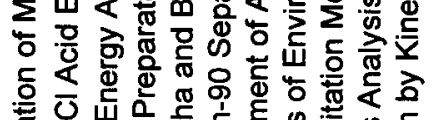

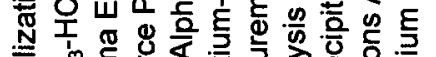

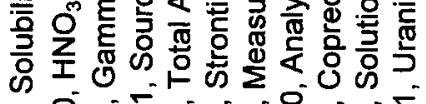

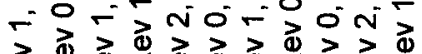

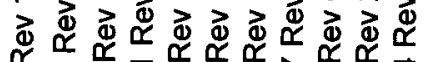
ம⿻

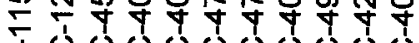

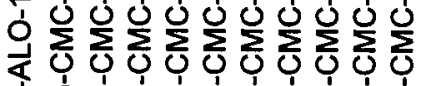
2
$z$

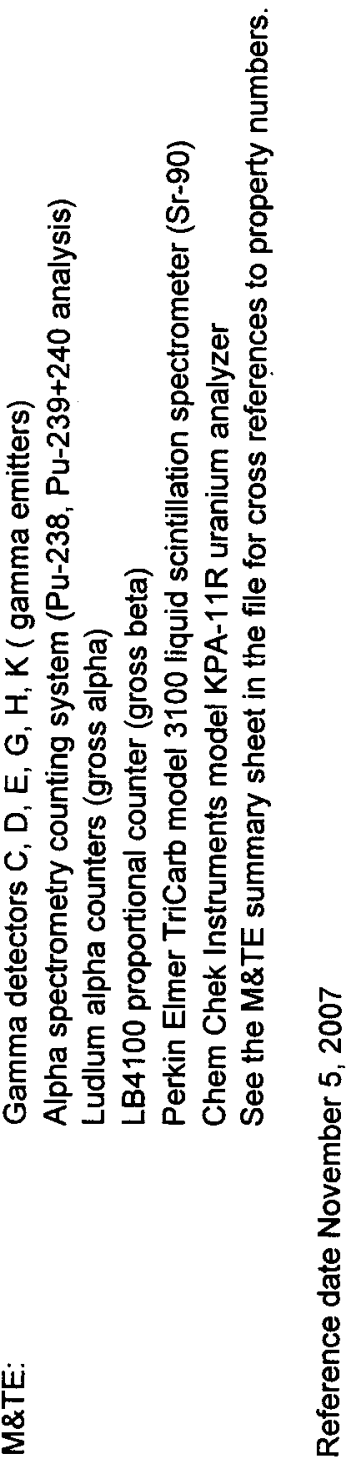



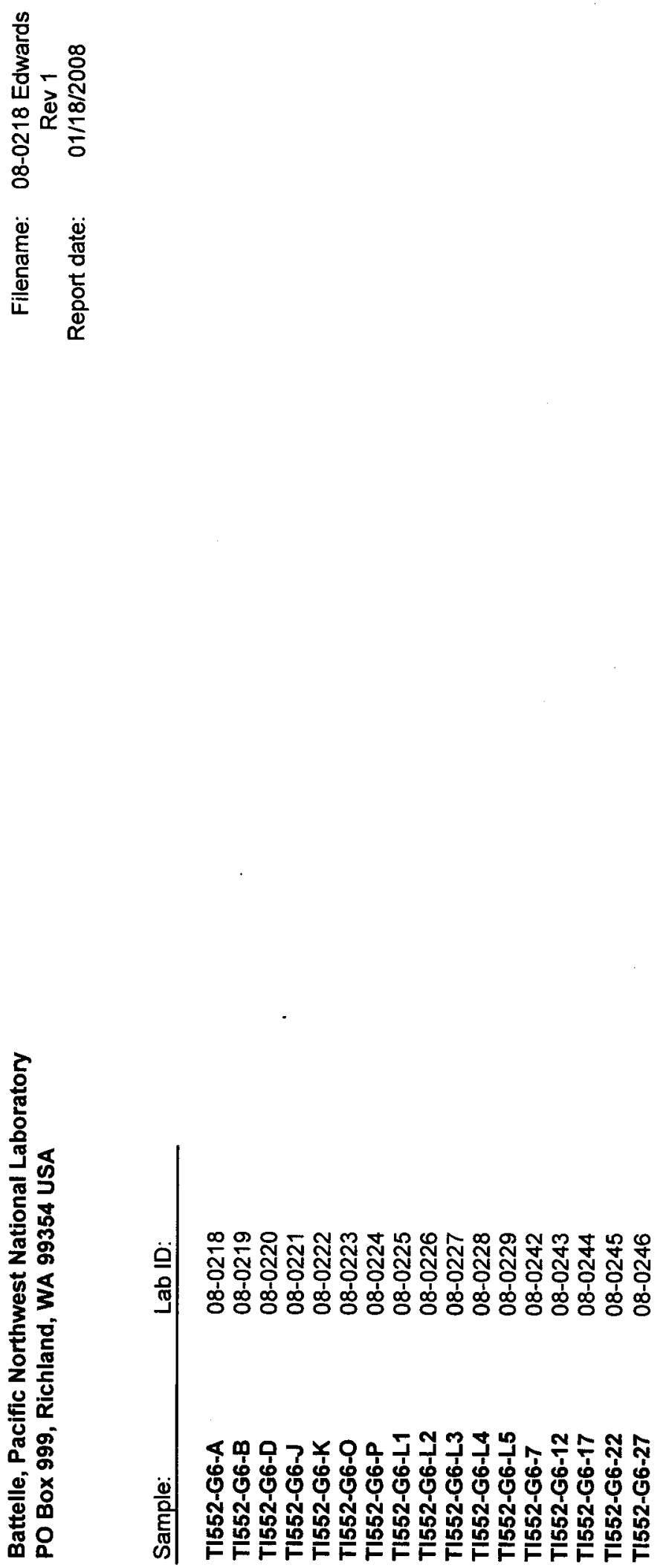


\author{
Battelle, Pacific Northwest National Laboratory \\ Richland, WA \\ Radiochemical Sciences and Engineering Group
}

filename $08-0218$ Edwards

Rev. 1

\section{Client: M. Edwards \\ ASR 8055}

Revision 1: The report was only revised for the plutonium results on sample TI552-G6-7 (080242). The duplicate for this sample was not included in the original analysis. The reanalysis of this sample and duplicate indicated an aliquot error on the original result. The entire batch of plutonium samples were subsequently reanalyzed and all of the results agree with the original analyses within the reported uncertainties except for sample TI552-G6-7 (08-0242).

\section{The Samples}

These samples were delivered to the analytical lab in early December 2007 . The samples required analysis of metals by ICPOES, anions by IC, hydroxide measurement, and several radionuclides. Only the radiochemistry data is reported here; the inorganic analytes are reported separately.

\section{Sample Preparation}

The liquid samples were digested in dilute nitric acid, hydrochloric acid (procedure RPG-CMC128). The acid digestion solution was used for radiochemistry. No raw sample was used for radiochemistry analysis.

The solid samples were fused with potassium hydroxide in cell (procedure PNL-ALO-115). The fusion solutions were removed from cell and delivered to the analytical lab for analysis. The radiochemistry analyses used the fusion solutions.

\section{Quality Control Results}

Most of the quality control results fell well within the limits prescribed by the project, with the exception of some of the gamma counting detection limits, and two special cases. Certain gamma emitters did not meet the requested detection limit because of high Compton background caused by $\mathrm{Cs}-137$ in the sample. Some of the gross alpha results are non-detects which are unavoidably higher than the requested detection limit, because of high dissolved solids in the liquid samples. All of the other detection limits were met. The blanks, including the hot cell potassium hydroxide fusion blank, are all negligible compared to the samples.

The spike results all fell within the limits requested by the project. The gross beta matrix spike result, $118 \%$, is within limits but has high uncertainty because the spike activity was much smaller than the sample activity. No matrix spike result for uranium could be reported because the spike was so much smaller than the sample uranium concentration.

All pairs of duplicates agree within expected uncertainty ( $9 \%$ RPD or less), with the exception of Co 60 . The Co-60 reported in these samples is probably largely hot cell contamination and is consequently not very reproducible. 


\section{Gamma Emitters (procedure RPG-CMC-450)}

Gamma emitters were measured by directly counting 2-mL aliquots of the acid digestion and fusion sample preparations. All gamma emitters that were detected were reported, except for potassium-40, which is naturally occurring. Because no sample preparation or separation is done for gamma counting, no spikes are prepared.

\section{Gross Alpha and Gross Beta (procedures RPG-CMC-4001 and -408)}

To measure gross alpha, a small volume of each sample solution (the acid digestion or fusion) was dried onto a steel disk and counted on a Ludlum solid scintillation alpha counter. Many of the samples have high dissolved solids, which limits the amount of material on the counting disk to a small volume. (If a larger volume were used, the resulting solids on the counting disk would absorb its own alpha emission and cause a low-biased result.) Because only small volumes can be counted this way, the attained detection limit for several samples is not as low as the project requested

To measure gross beta, a small volume of each sample solution was evaporated onto a planchet and counted on a gas proportional counter. Nearly all the activity is beta, not alpha, and crosstalk corrections were not necessary. Solids loading on the counting planchets was too small to affect the data.

The gross alpha for the solid samples agrees well with the sum of Pu-239+240, Pu-238, and Am241. (Gross alpha was not measurable in the liquid samples.) The gross beta results on all the samples equals the sum of $\mathrm{Sr}-90$ (with $\mathrm{Y}-90$ in equilibrium) and $\mathrm{Cs}-137$, within expected uncertainty.

\section{Strontium-90 (procedures RPG-CMC-476 and -474)}

Strontium was chemically separated from the acid digestion and fusion sample preparations, then measured by liquid scintillation. The solid samples have high $\mathrm{Sr}-90$ activity. Most of the gross beta activity in the solid samples is from SrY-90. The liquid samples have much lower Sr-90 activity, and much less SrY-90 than Cs-137.

Plutonium (procedures RPG-CMC-4017, -496 , and -422)

Plutonium was separated from the sample solutions by anion exchange in hydrochloric acid, then mounted for alpha spectroscopy by coprecipitation, then measured using alpha spectrometry.

Uranium (procedures RPG-CMC-4017 and -4014)

Uranium was chemically separated from the samples by anion exchange in hydrochloric acid, then measured by kinetic phosphorescence. The liquid samples have a very low concentration of uranium - far below the $60 \mu \mathrm{g} / \mathrm{mL}$ detection limit requested by the project. The solid samples are high in uranium, up to several percent by weight.

The blanks all show uranium, but at a small concentration compared to the samples. 


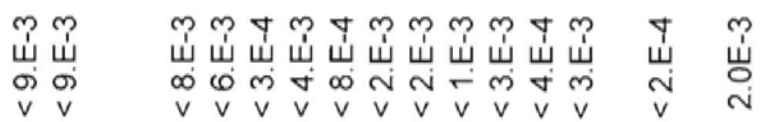

N

iे

の่

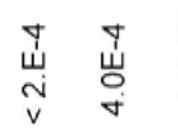

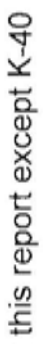

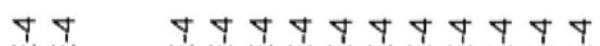

ய

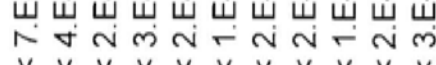

V V

$\vee \vee \vee \vee v \vee v \vee v \vee v$

$\underset{v}{\stackrel{⿰}{v}}$

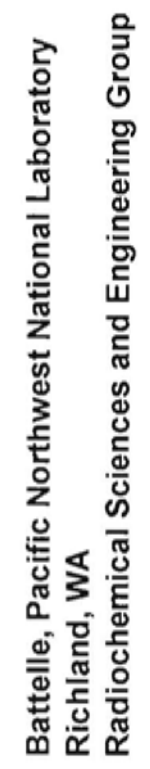

今゚ \%ำ

オ オஃ゚ प オ

ய山ำ щய

ถึ่

今̊

둥

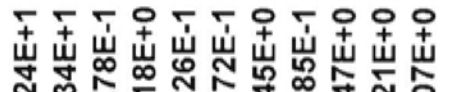

ஸั ণั

ஸุ mे

オ

$\stackrel{\oplus}{\leftrightarrows}$

을

षن

$\infty$ 茴

กับ

올윰

$\stackrel{\infty}{\check{\infty}}$

ธัธ

$\vee \vee v \vee v \vee v \vee v \vee v$

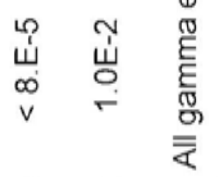

오ำ

ơ ô

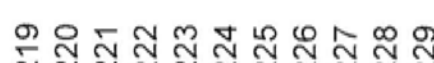

สิสัปสิ

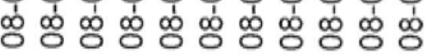

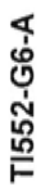

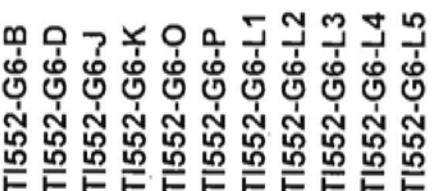

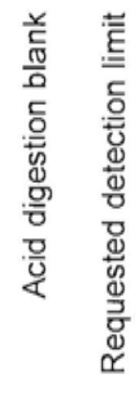




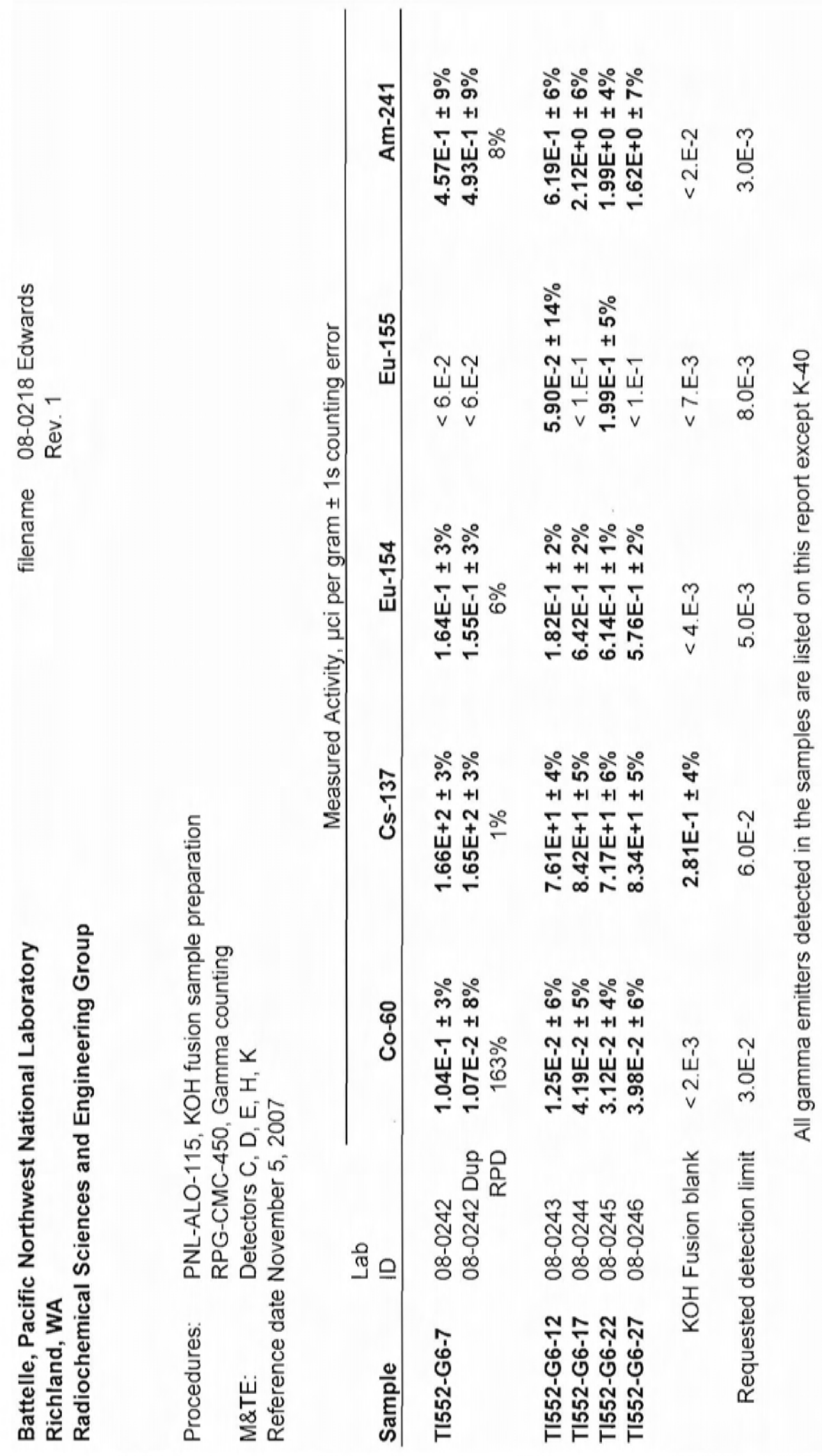


WTP-RPT-172, Rev 0
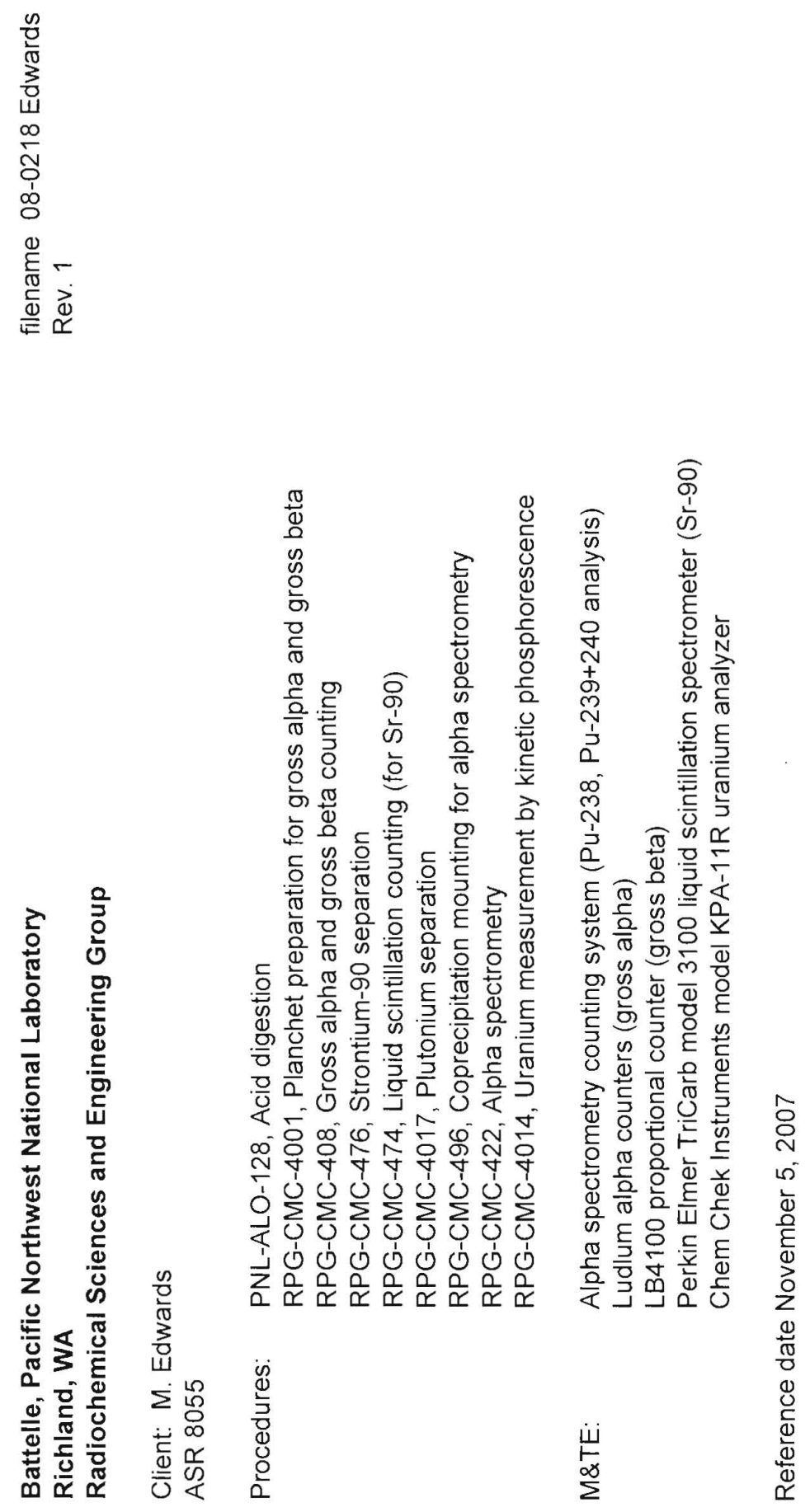

0
4
0
0
0
0
0 


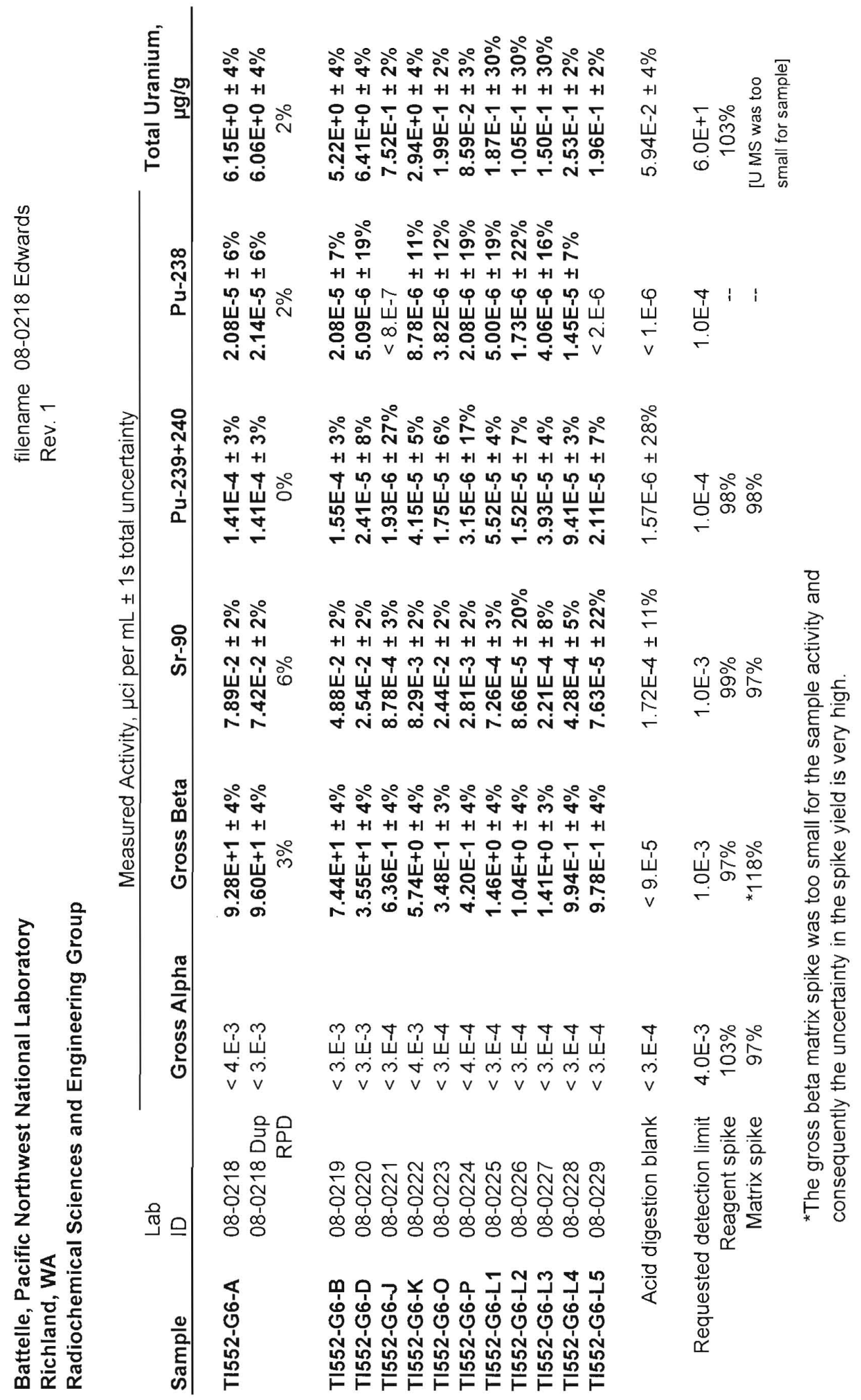

0
4
4
$\infty$
0
0
0
0 


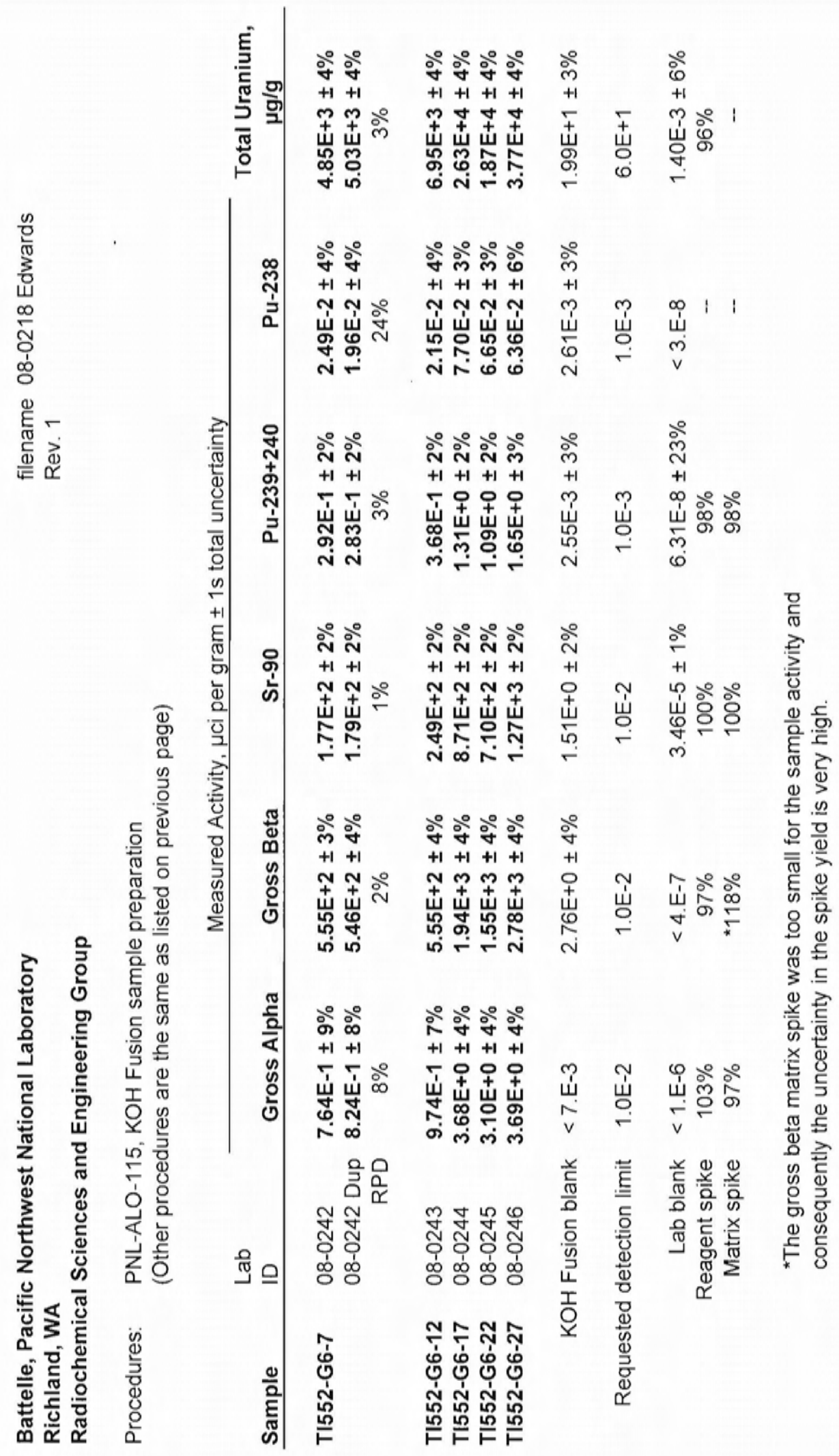




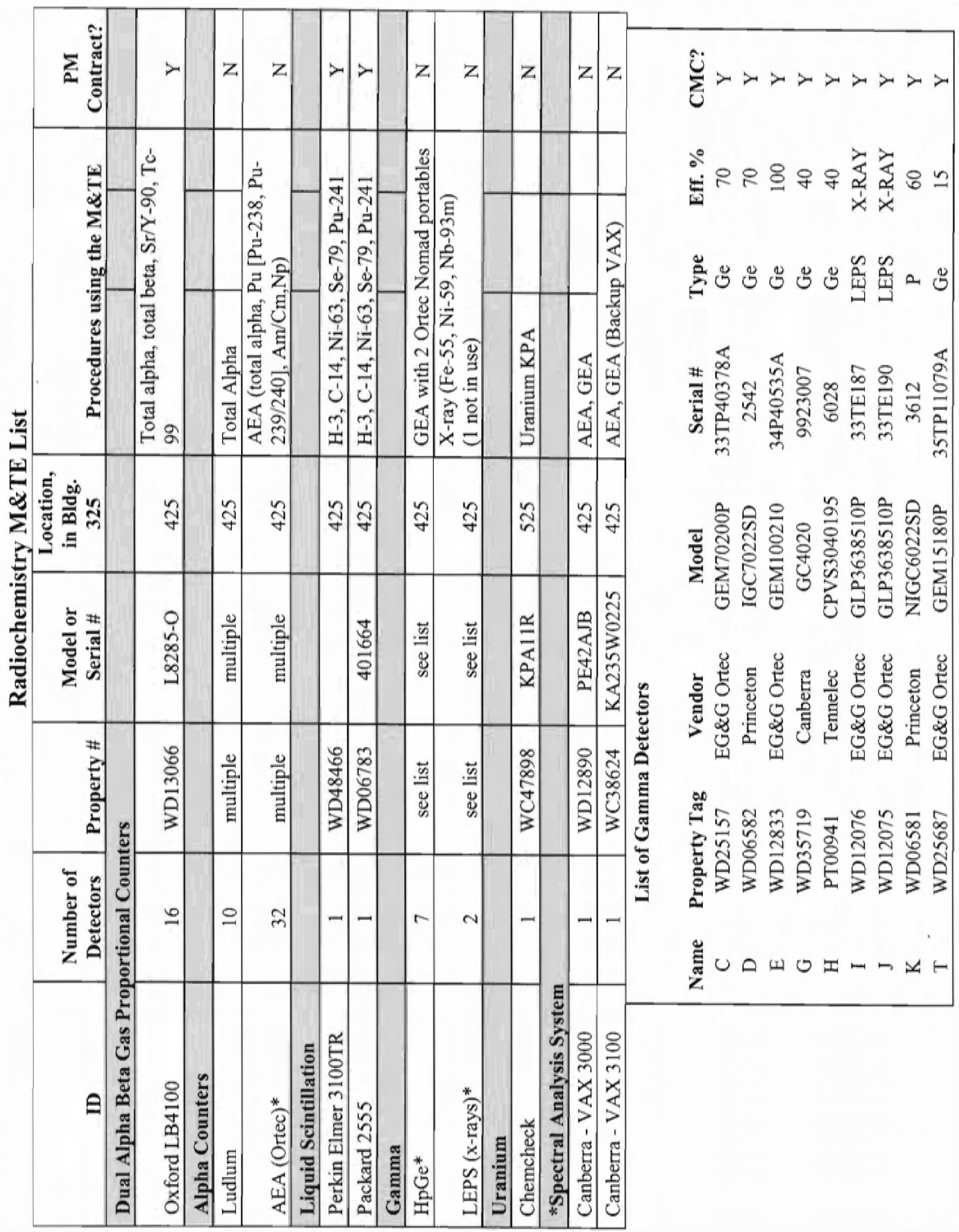




\section{Battelle - Pacific Northwest National Laboratory \\ Radiochemical Science and Technology \\ TIC/TOC Report - Hot Persulfate Method \\ PO Box 999, Richland, Washington 99352}

$\begin{array}{ll}\text { Project Number: } & 52964 \\ \text { Charge Code: } & \text { F99189 } \\ \text { ASR Number: } & 8055 \\ \text { Client: } & \text { MK Edwards } \\ \text { Total Samples: } & 2\end{array}$

\begin{tabular}{|c|c|}
\hline & Sample \\
\hline $\begin{array}{l}\text { RPL } \\
\text { Numbers }\end{array}$ & $08-00244$ and $08-00245$ \\
\hline Client IDs & TI552-G6-17 and TI552-G6-22 \\
\hline
\end{tabular}

\begin{tabular}{|l|l|}
\hline Analysis Procedure & $\begin{array}{l}\text { RPG-CMC-385 Rev. 0, "Carbon Measured in Solids, } \\
\text { Sludge, and Liquid Matrices" }\end{array}$ \\
\hline Prep Procedure & $\begin{array}{l}\text { RPG-CMC-103 "Water Leach of Sludge, Soil and Other } \\
\text { Solids" }\end{array}$ \\
\hline Analyst & M. Steele \\
\hline Analysis Date & January 11, 2008 \\
\hline CCV Standards & TOC CMS-218954 TIC CMS-239430 \\
\hline BS/LCS/MS Standards & TOC CMS-239432 TIC CMS-239496 \\
\hline Excel Data File & ASR 8055 HP Edwards .xls \\
\hline \multirow{2}{*}{ M\&TE Numbers } & Carbon System (WC01713-701) \\
\cline { 2 - 2 } & Balance (360-06-01-023) \\
\hline All Analysis Records & System File TC-08-004 \\
\hline
\end{tabular}

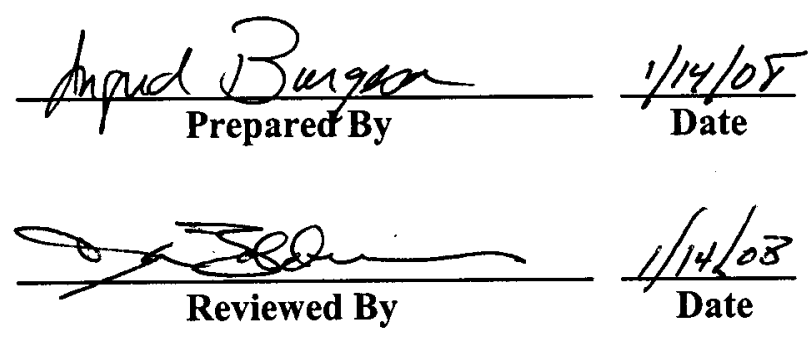




\section{TIC/TOC Report - Hot Persulfate Method}

Table 1: Carbon Final Results

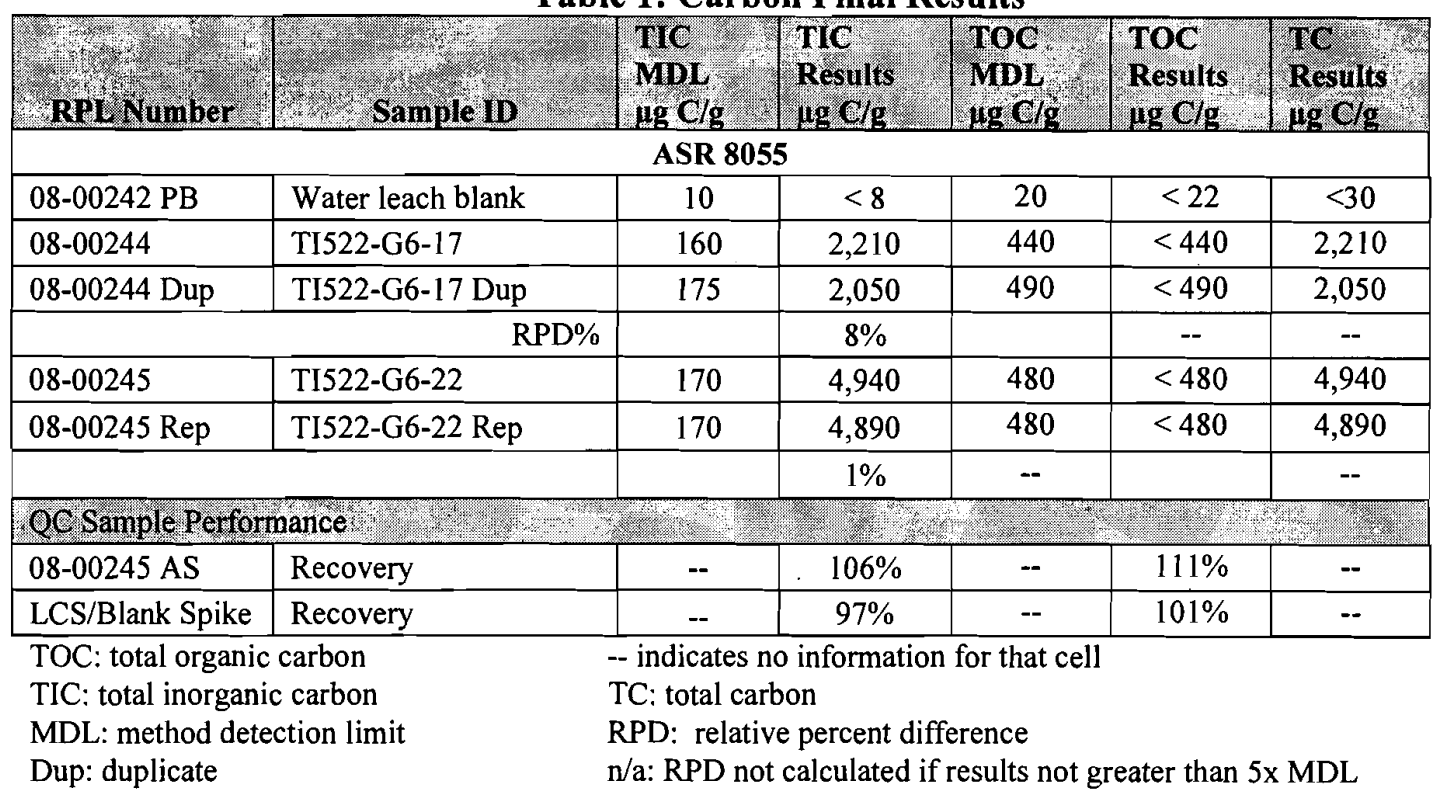

\section{Sample Analysis/Results Discussion}

The TIC/TOC analyses of two slurry samples submitted under Analytical Service Request (ASR) 8055 were performed on the water leach of each sample using the hot persulfate wet oxidation method, with the results reported in Table 1 . The hot persulfate method uses acid decomposition for TIC and silver catalyzed acidic potassium persulfate oxidation at $92-95^{\circ} \mathrm{C}$ for $\mathrm{TOC}$, all on the same sample, with TC being the sum of the TIC and TOC. The analyses were performed following the QA Plan ASO-QAP-001 and the client document RPP-WTP-QA-005 Rev. 2.

Table 1 above shows the results from the analysis. The samples were analyzed in duplicate. Sample 08-00244 was leached in duplicate; the analysis reflects duplicate processing. Sample 0800245 was analyzed in replicate. All sample results are corrected for average percent recovery of system calibration standards and are also corrected for contribution from the blank, as per procedure RPG-CMC-385, Rev. 0. All data are reported as $\mu \mathrm{g} \mathrm{C/g}$ sample.

\section{Quality Control Discussion}

The calibration and QC standards for TOC and TIC analyses are a solid pure chemical, alpha-D glucose and solid calcium carbonate. The identification of the standards and their Chemical Management System (CMS) numbers are included on the raw data benchsheets for traceability.

The QC for the method involves calibration blanks, sample duplicate (laboratory), laboratory control sample/blank spike (LCS/BS), and analytical spike (AS). The work was performed in one batch.

Calibration Check Standards: The calibration of the coulometer analysis system was checked by calibration check standards analyzed at the beginning and end of the analysis run. The average recovery from the calibration check standards is applied as a correction factor to the 'raw data' results obtained for the samples. The average recovery for the batch was $99 \%$ for TIC and $98 \%$ for TOC. 


\section{TIC/TOC Report - Hot Persulfate Method}

Laboratory Control Sample/Blank Spike: An LCS/BS was analyzed with the samples. With a recovery of $97 \%$ for TIC and $101 \%$ for TOC, the LCS/BS recovery is within acceptance criterion of $80 \%$ to $120 \%$.

Duplicate: Precision of the carbon measurements is demonstrated by the RPD between sample and duplicate. No duplicate sample was provided by the client. For this work, a process duplicate was prepared during leaching and a laboratory duplicate were analyzed. The precision result range for TIC (1-12\%), was within the acceptance criterion of $\leq 20 \%$. Note: the RPD is only calculated if both the sample and duplicate result exceed 5xMDL, otherwise it is reported as 'na'.

Analytical Spike: The accuracy of the carbon measurements can be estimated by the recovery results from the AS. The sample TIC AS recovery for the sample was 106\% and the TOC recovery was $111 \%$, both within the acceptance criterion of $75 \%$ to $125 \%$ recovery.

\section{Deviation from Procedure}

None.

\section{General Comments}

1) Routine precision and bias are typically $\pm 15 \%$ or better for non-complex samples that are free of interferences.

2) The estimated quantitation limit (EQL) is defined as 10 times the MDL. Results $<10 x M D L$ have higher uncertainties, and RPDs (or RSDs, if applicable) are not calculated if the results are $<5 \mathrm{xMDL}$.

3) For the TIC/TOC, the analysis MDL is based on the standard deviation calculated from the number ( $\mathrm{n}$ ) of system blanks analyzed with the batch of samples, with the standard deviation multiplied by the Student's $t$ values for $n-1$ degrees of freedom to establish the daily analysis.

4) The reported "Final Results" have been corrected for the lack of dilution performed on the sample during preparation. 


\section{Appendix M}

\section{Group 6/5 CUF UFP1/UFP2 Caustic Leaching Analytical Results}




\section{Special Instructions for \\ Parametric Testing of UFP1/UFP2 Caustic Leaching of Group 6/5 REDOX Sludge/S-Salt Cake Tank Waste (Treatability Study) Analysis Requirements}

The start date for this treatability study is December 13, 2007, under test instruction TI-RPPWTP-565. This treatability study follows the Group 6 study and uses the fluorescent green labels.

A composite material containing liquid and sludge from Hanford waste tanks S-106, S-111, SX102 , SX-105, SX-106, SY-103, U-103, and U-108 (S-saltcake) and S-101, S-107, S-110, and SX103(REDOX sludge) was blended together. After grabbing an initial slurry sample for analysis, the remainder was separated into two samples. One of the samples was diluted with excess supernate from the Group 6/5 CUF run to an un-dissolved solid concentration of $\sim 4 \mathrm{wt} \%$, the expected solid concentration in the UFP1 Pre-treatment vessel. The other sample was left as is at an un-dissolved solid concentration of $16-18 \mathrm{wt} \%$, the expected solid concentration in the UFP2 Pre-treatment vessel. In both cases a known amount of sodium hydroxide and excess water was added to simulate leaching conditions if they occurred in UFP1/UFP2. Both samples were then heated to $100^{\circ} \mathrm{C}$ and sampled at a periodic rate to understand how the kinetics differ between the two samples. Solids samples of the leached material were washed afterwards to estimate final dissolution factor. The sample processing and analysis schematic is shown in Figure 1. Test instruction sample ID's are cross referenced to ASO sample ID's in Table 1. The aqueous samples are ready to aliquot for direct analyses and acid digestion. The acid digestion of aqueous samples will be preparation in cell. The solid/slurry samples are ready to be sub-samples for an $\mathrm{HF}$ assisted acid digestion preparation in cell. Note: There is no radiochemical analysis required for any of these samples.

\section{SAL Preparation/Analysis}

Record both the nominal volume and actual weight distributions of aqueous sample material for various analyses.

Please record observations associated with the dissolution preparations. If any residual solids remain after any of the fusion and acid digestions, note on the bench sheet (include estimated quantity, color, texture, etc.) and contact RW Shimskey for further instruction prior to distribution.

\section{Archive of SAL Fusion Preparation Samples}

The fusion preparations will result in a $100-\mathrm{mL}$ volume. This solution will be apportioned to the laboratory as needed to conduct work-station-specific analyses. Please prepare a $15-\mathrm{mL}$ aliquot from each preparation as an archive sample. The vials need to be labeled with the following: date, ASO-ID, matrix, treatability study, hazard, fusion prep (if applicable) and their tare, gross masses, and IDs provided to RW Shimskey. The vials may be removed from the hot cells for storage. The remaining portions of the fusion preparations may be disposed of. 


\section{Quality Control}

All work is to be conducted according to RPP-WTP-QA-005, Rev.2.

Preparative or sample analysis QC includes a preparation blank, sample, sample duplicate, matrix spike, and a LCS or BS. The samples submitted for fusion are sub-aliquoted into fusion vessels in duplicate (sample, sample duplicate). If possible, the matrix spike and LCS/BS need to include all the analytes of interest to be reported for the specific analysis.

The duplicate, LCS/BS, and MS QC acceptance criteria for the aqueous phases and solid phases are provided in Table 4 . The preparation blank (PB) analyte concentration shall be less than the estimated quantitation limit (EQL) or the minimum detectable activity (MDA) of the associated sample. When the PB concentration is equal to or exceeds the EQL, then the PB concentration shall not exceed $5 \%$ of the measured concentration present in the sample. Failure of the PB, and/or duplicates, and/or LCS/BS to meet the acceptance criteria requires that affected samples in the processing batch be re-prepared and re-analyzed for the failed analytes, availability of samples permitting, at ASO expense.

In the case of multi-elemental methods (IC and ICP-OES), isolated QC failure(s) may be communicated to RW Shimskey for an assessment of the impact on data interpretation. If the data are acceptable, RW Shimskey will indicate, in writing, that the data may be reported, and the resulting limitations on the data from the QC sample failure(s) shall be included in the final report.

When the MS fails to meet the acceptance criteria, the results shall be investigated for potential sources of error. When the sources of error cannot be identified, the failure of the MS and any resulting limitations on the data shall be included in the report.

\section{Reporting Units}

Report aqueous sample results in units of $u g / \mathrm{mL}$. Report solids sample results as $u g / g$; the initial dry mass of solids (as measured in each fusion crucible) will be provided.

\section{Reporting}

Please prepare the analytical data report in accordance with PNL-ASO-058, Rev. 0, Section 5.3, Comprehensive Data Report. Please be sure to include action taken with respect to any identified unexpected results and discrepancies.

The following elements may be included in the final report or be traceable to the test results (usually by entry in the LRB, Test Instruction, or data sheet) and be maintained as lifetime records:

- identification of standards used

- identification of M\&TE used

- reference to the Test Plan (identified on page 1 of the ASR)

- signature and date of person who performed the test and recorded the data

- hand calculation review documentation. 
Analytical results shall be reported both in hard copy and electronically. Preliminary data reports and electronic files shall be provided as soon as practical after completion of analysis. The final ASR data report shall be provided no later than the commitment date on the ASR.

Blend Group 6 (S-Saltcake)

\& Group 5 (REDOX Sludge

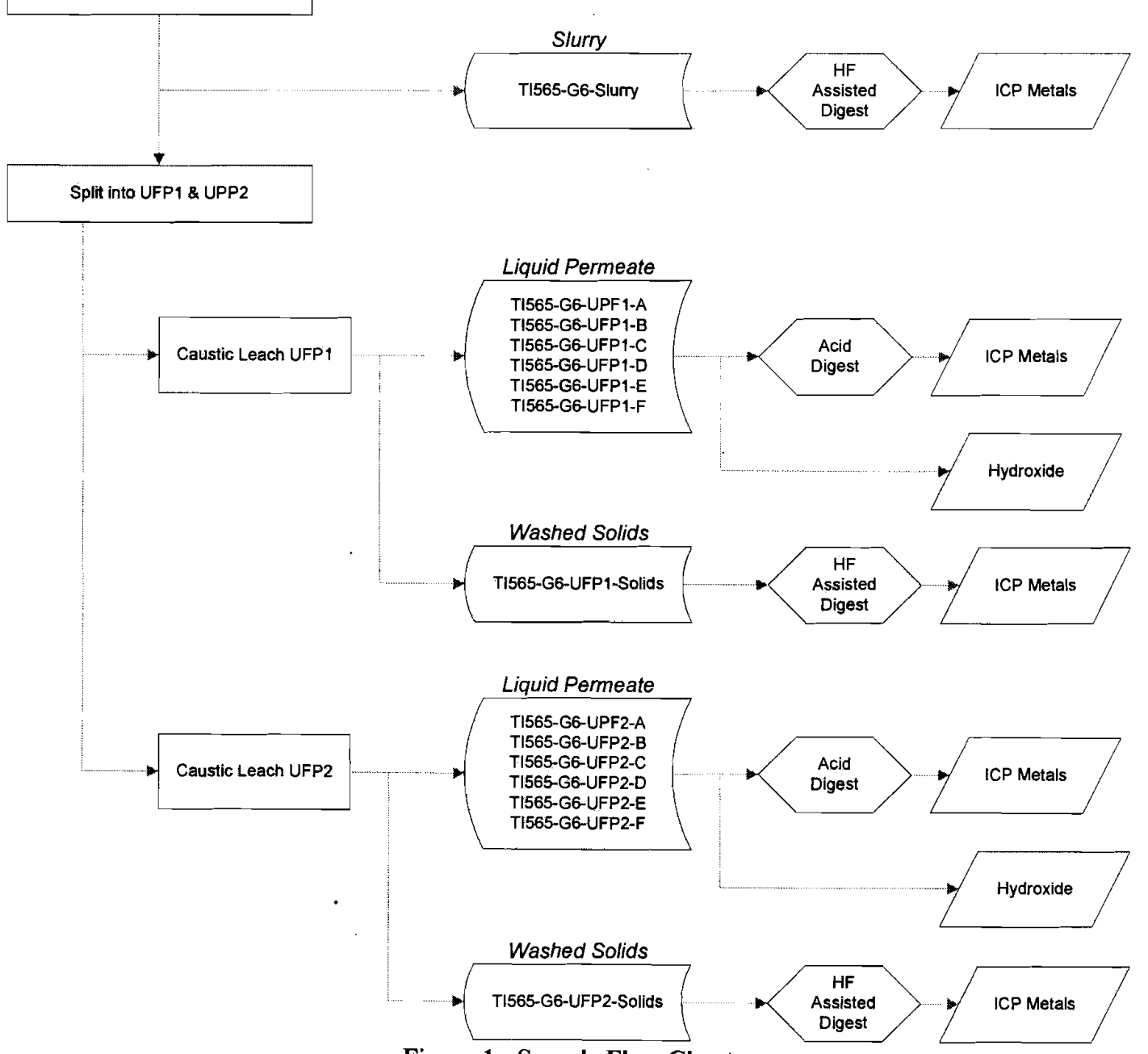

Figure 1: Sample Flow Chart 
Table 1. Cross-Reference of Process component, Sample ID, and RPL ID

\begin{tabular}{|l|l|l|}
\hline Component & Sample ID & ASO ID \\
\hline UFP1 Leach Permeate Time @ 0 hr & TI565-G6-UFP1-A & $08-00774$ \\
\hline UFP1 Leach Permeate Time @ 1 hr & TI565-G6-UFP1-B & $08-00775$ \\
\hline UFP1 Leach Permeate.Time @ 2 hr & TI565-G6-UFP1-C & $08-00776$ \\
\hline UFP1 Leach Permeate Time @ 4 hr & TI565-G6-UFP1-D & $08-00777$ \\
\hline UFP1 Leach Permeate Time @ 8 hr & TI565-G6-UFP1-E & $08-00778$ \\
\hline UFP1 Leach Permeate Final Sample & TI565-G6-UFP1-F & $08-00779$ \\
\hline UFP2 Leach Permeate Time @ 0 hr & TI565-G6-UFP2-A & $08-00780$ \\
\hline UFP2 Leach Permeate Time @ 1 hr & TI565-G6-UFP2-B & $08-00781$ \\
\hline UFP2 Leach Permeate Time @ 2 hr & TI565-G6-UFP2-C & $08-00782$ \\
\hline UFP2 Leach Permeate Time @ 4 hr & TI565-G6-UFP2-D & $08-00783$ \\
\hline UFP2 Leach Permeate Time @ 8 hr & TI565-G6-UFP2-E & $08-00784$ \\
\hline UFP2 Leach Permeate Final Sample & TI565-G6-UFP2-F & $08-00785$ \\
\hline Initial Slurry & TI565-G6-Slurry & $08-00786$ \\
\hline UPF1 Leached Solids (TripleWashed) & TI565-G6-UFP1-Solids & $08-00787$ \\
\hline UPF2 Leached Solids (Triple Washed) & TI565-G6-UFP2-Solids & $08-00788$ \\
\hline
\end{tabular}




\section{Laboratory Analysis}

The required sample analyses are shown below in Table $\mathbf{2}$.

Table 2: Filtration and Leach Testing Characterization Plan

\begin{tabular}{|c|c|}
\hline \multirow{2}{*}{$\begin{array}{l}\text { Initial slurry. } \\
\text { TI565-G6-Slurry }\end{array}$} & HF assisted Acid digestion \\
\hline & - ICP metals (Table 3) \\
\hline $\begin{array}{c}\text { Time interval Caustic Leach filtrates } \\
T I 565-G 6-U F P 1-A, B, C, D, E, F \\
T 1565-G 6-U F P 2-A, B, C, D, E, F\end{array}$ & $\begin{array}{l}\text { Direct distribution } \\
\text { - Free hydroxide } \\
\text { Acid digestion } \\
\text { - ICP metals }\end{array}$ \\
\hline $\begin{array}{c}\text { Washed, Caustic-leached Solids } \\
\text { TI565-G6-UFP1-Solids } \\
\text { TI565-G6-UFP2-Solids }\end{array}$ & $\begin{array}{l}\text { HF assisted Acid digestion } \\
- \text { ICP metals (Table 3) }\end{array}$ \\
\hline
\end{tabular}

All analyses are to be conducted per approved PNNL procedures or test plans with the QC defined in the QC information Section. Table 3 defines the analytes of interest, the required detection limits, and analysis methods. 
Table 3: Method Detection Limits for Solids and Supernatants

\begin{tabular}{|c|c|c|c|}
\hline Analyte : & Solids & Solutions & Analysis Method \\
\hline & $\mu \mathrm{Ci} / \mathrm{g}^{(\mathrm{a})}$ & $\mu \mathrm{Ci} / \mathrm{ml}$ & \\
\hline${ }^{137} \mathrm{Cs}$ & $6.0 \mathrm{E}-02$ & $1.0 \mathrm{E}-02$ & \multirow{5}{*}{$\mathrm{GEA}^{\mathrm{c}}$} \\
\hline${ }^{60} \mathrm{Co}$ & $3.0 \mathrm{E}-02$ & $1.0 \mathrm{E}-02$ & \\
\hline${ }^{154} \mathrm{Eu}$ & $5.0 \mathrm{E}-03$ & $4.0 \mathrm{E}-04$ & \\
\hline${ }^{155} \mathrm{Eu}$ & $8.0 \mathrm{E}-03$ & $4.0 \mathrm{E}-04$ & \\
\hline${ }^{241} \mathrm{Am}$ & $3.0 \mathrm{E}-03$ & $2.0 \mathrm{E}-03$ & \\
\hline $\mathrm{Pu}$ & $1.0 \mathrm{E}-03$ & $1.0 \mathrm{E}-04$ & ${ }^{239+240} \mathrm{Pu}$ and ${ }^{238} \mathrm{Pu}$ by AEA \\
\hline Total alpha & $1.0 \mathrm{E}-02$ & $4.0 \mathrm{E}-03$ & Proportional counting \\
\hline Total beta & $1.0 \mathrm{E}-02$ & $1.0 \mathrm{E}-03$ & Proportional counting \\
\hline \multirow[t]{2}{*}{${ }^{90} \mathrm{Sr}$} & $1.0 \mathrm{E}-02$ & $1.0 \mathrm{E}-03$ & Separation and proportional counting \\
\hline & $\mu \mathrm{g} / \mathrm{g}$ & $\mu \mathrm{g} / \mathrm{ml}$ & \\
\hline $\mathrm{Al}$ & $3.0 \mathrm{E}+02$ & $7.5 \mathrm{E}+01$ & \multirow{16}{*}{ ICP-OES } \\
\hline $\mathrm{B}$ & $2.0 \mathrm{E}+02$ & $7.5 \mathrm{E}+01$ & \\
\hline$\overline{\mathrm{Bi}}$ & $4.0 \mathrm{E}+02$ & $3.0 \mathrm{E}+01$ & \\
\hline $\mathrm{Cd}$ & $7.5 \mathrm{E}+01$ & $7.5 \mathrm{E}+01$ & \\
\hline $\mathrm{Cr}$ & $1.2 \mathrm{E}+02$ & $1.5 \mathrm{E}+01$ & \\
\hline $\mathrm{Fe}$ & $3.0 \mathrm{E}+02$ & $7.5 \mathrm{E}+01$ & \\
\hline $\mathrm{K}$ & $1.0 \mathrm{E}+03^{(\mathrm{b})}$ & $5.0 \mathrm{E}+01$ & \\
\hline $\mathrm{Mn}$ & $3.0 \mathrm{E}+02$ & $1.5 \mathrm{E}+01$ & \\
\hline $\mathrm{Na}$ & $3.0 \mathrm{E}+03$ & $7.5 \mathrm{E}+01$ & \\
\hline $\mathrm{Ni}$ & $1.6 \mathrm{E}+02^{(\mathrm{b})}$ & $3.0 \mathrm{E}+01$ & \\
\hline $\mathrm{S}$ & $1.5 \mathrm{E}+03$ & $2.0 \mathrm{E}+2$ & \\
\hline $\mathrm{Si}$ & $3.0 \mathrm{E}+03$ & $7.5 \mathrm{E}+01$ & \\
\hline $\mathrm{Sr}$ & $3.0 \mathrm{E}+02$ & $7.5 \mathrm{E}+01$ & \\
\hline $\mathrm{Zn}$ & $3.0 \mathrm{E}+02$ & $7.5 \mathrm{E}+01$ & \\
\hline $\mathrm{Zr}$ & $3.0 \mathrm{E}+02$ & $7.5 \mathrm{E}+01$ & \\
\hline $\mathrm{U}$ & $2.5 \mathrm{E}+03$ & $7.5 \mathrm{E}+01$ & \\
\hline $\mathrm{U}$ & $6.0 \mathrm{E}+01$ & $6.0 \mathrm{E}+01$ & Kinetic Phosphorescence \\
\hline Fluoride & $2.5 \mathrm{E}+02$ & $1.2 \mathrm{E}+02$ & \multirow{6}{*}{$\begin{array}{l}\text { Ion Chromatography } \\
\text { (water-soluble species) }\end{array}$} \\
\hline Nitrite & $2 . \overline{\mathrm{E}+02}$ & $1.2 \mathrm{E}+02$ & \\
\hline Nitrate & $2.5 \mathrm{E}+02$ & $1.2 \mathrm{E}+02$ & \\
\hline Phosphate & $2.5 \mathrm{E}+02$ & $1.2 \mathrm{E}+02$ & \\
\hline Sulfate & $2.5 \mathrm{E}+02$ & $1.2 \mathrm{E}+02$ & \\
\hline Oxalate & $8.0 \mathrm{E}+02$ & $4.0 \mathrm{E}+02$ & \\
\hline Hydroxide & NA & $1 \mathrm{E}-01 \mathrm{M}$ & Titration \\
\hline Total organic carbon & NA & $4.0 \mathrm{E}+02$ (as C) & \multirow{2}{*}{ Hot persulfate method } \\
\hline Total inorganic carbon & NA & $2.0 \mathrm{E}+02($ as C) & \\
\hline \multicolumn{4}{|c|}{$\begin{array}{l}\text { (a) } \mathrm{KOH} \text { fusion for solid samples. } \\
\text { (b) The Ni and } \mathrm{K} \text { cannot be measured from the } \mathrm{KOH} \text { fusion which uses a Ni crucible. The Ni and } \mathrm{K} \text { will be } \\
\text { assessed from a separate } \mathrm{HF} \text {-assisted acid digestion. } \\
\text { (c) Please provide } \mathrm{Mn}-54 \text { data. }\end{array}$} \\
\hline
\end{tabular}



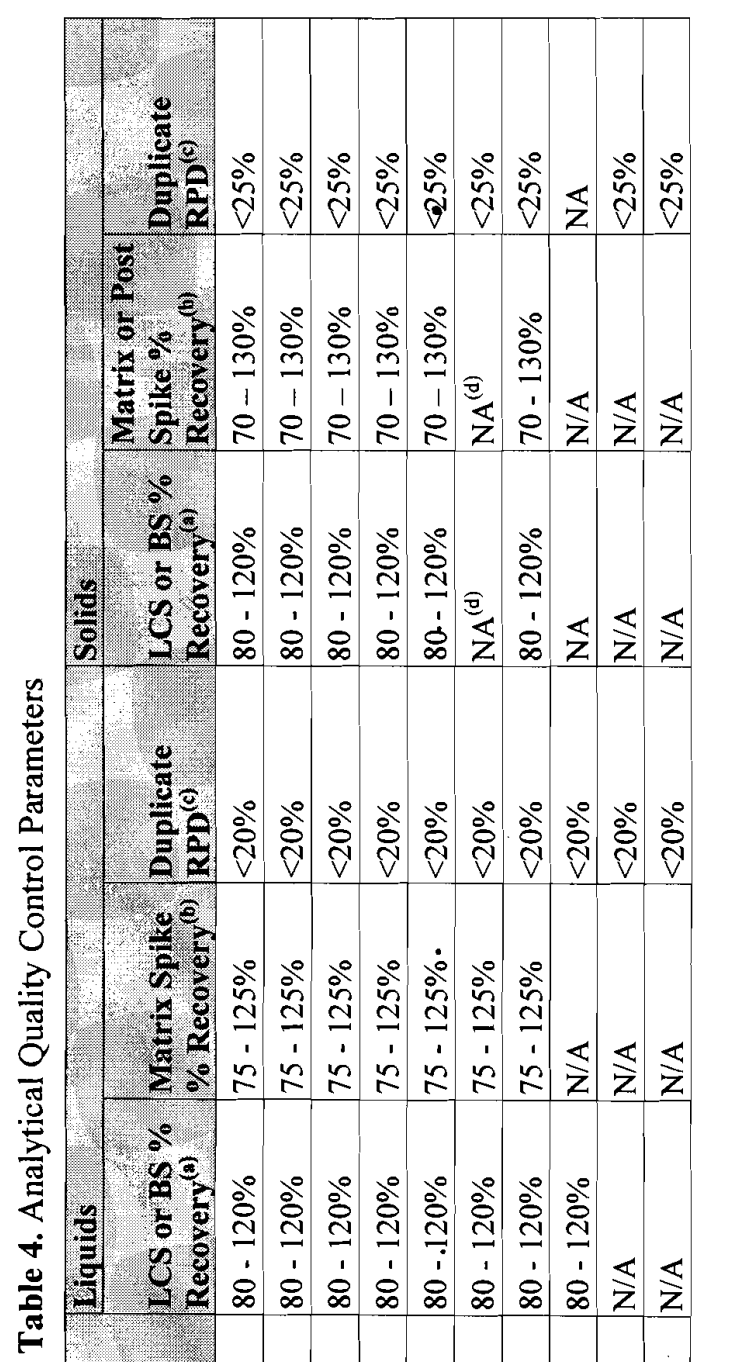

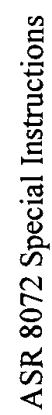

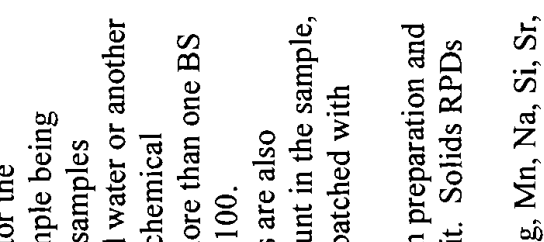

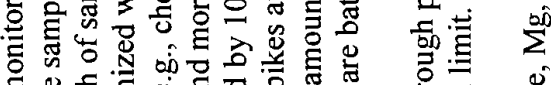

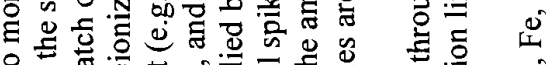

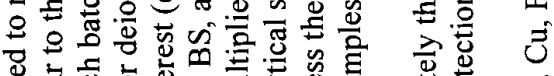

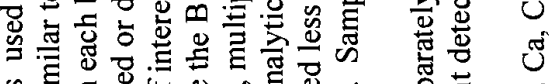
늘

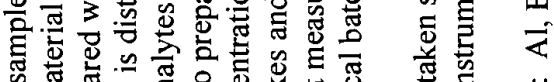

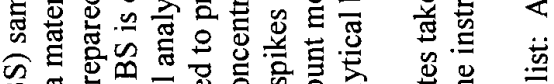

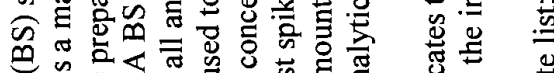

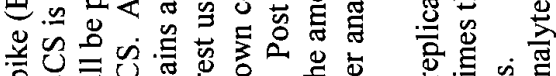

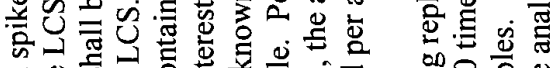

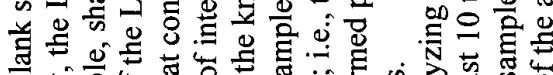

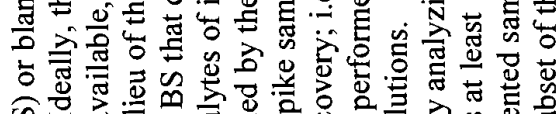

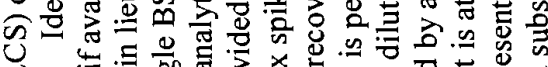

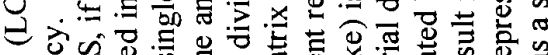

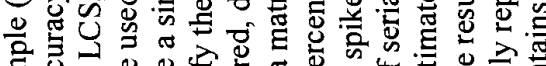

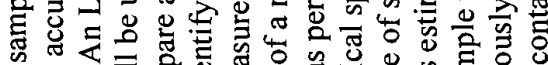

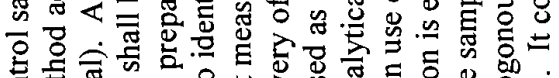

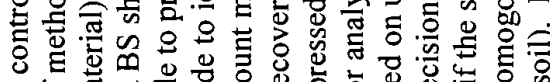

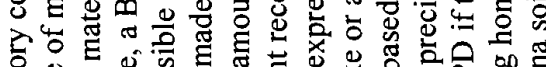

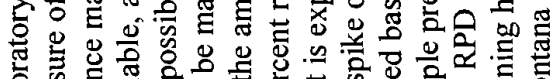

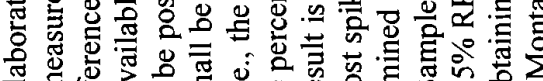

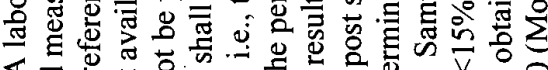

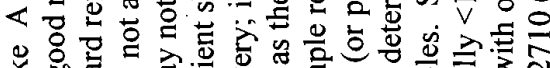

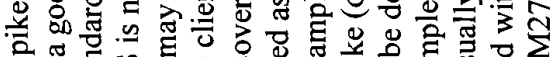
क

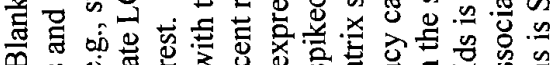
川

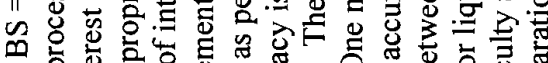

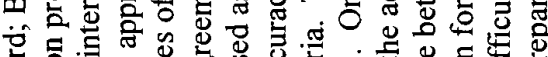

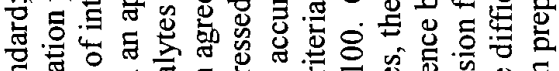

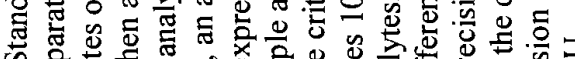

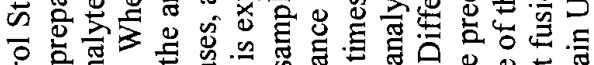
每

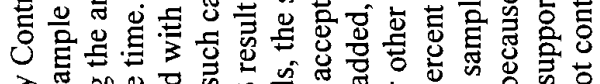
不

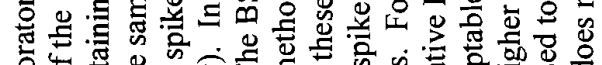

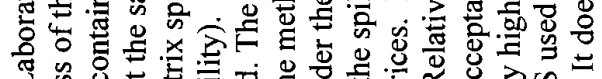

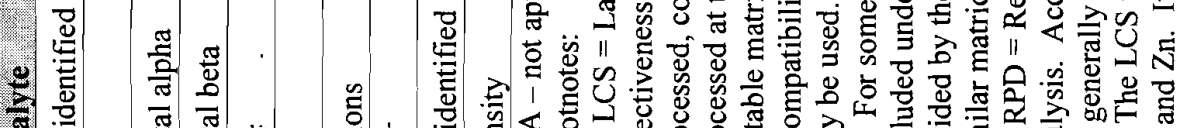

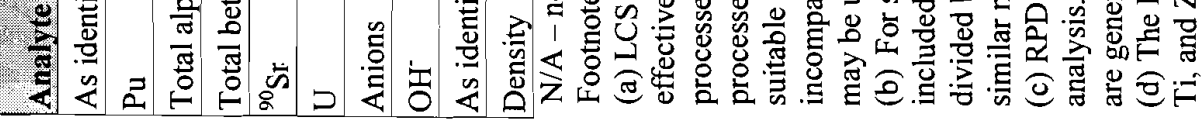


Requestor --- Complete all fieldy on this COVER PAGE, unless specified as optional or ASR is a revision

Requestor:
Signature
Print Name
Phone

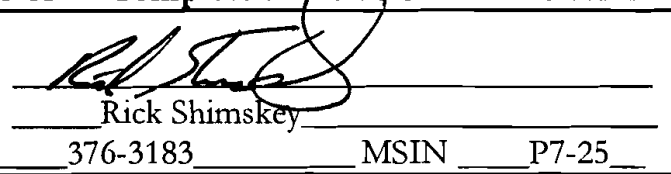

Matrix Type Information

- Liquids: X Aqueous

Solids:

$\square$ Soil
$\square$ Glass
$\square$ Smear

$\square$ Organic

$\mathbf{X}$ Sludge

$\square$ Filter

$\square$ Organic

$\square$ Multi-phase

$\square$ Sediment

$\square$ Metal

$\square$ Other

Other: $\square$ Solid/Liquid Mixture, Slurry

$\square$ Gas $\quad \square$ Biological Specimen

(If sample matrices vary, specify on Request Page)

\section{Disposal Information}

\section{- Disposition of Virgin Samples:}

Virgin samples are returned to requestor unless archiving provisions are made with receiving group!

If archiving, provide:

Archiving Reference Doc:

- Disposition of Treated Samples:

X Dispose $\square$ Return

Data Reporting Information

\begin{tabular}{l} 
Is Work Associated with a Fee-Based \\
Milestone? X No $\square$ Yes \\
If yes, milestone due date: \\
\hline Preliminary Results Requested, As \\
Available? $\square$ No X Yes
\end{tabular}

Available? $\square$ No X Yes

- QA Plan: $\mathbf{X}$ No $\square$ Yes

If Yes,

Contact ASO

Lead before

submitting

Samples
Project Number:

Work Package:
52964

F99187

\section{QA/Special Requirements}

X ASO-QAP-001, Rev. 6 (Equivalent to HASQARD)

$\mathbf{X}$ Additional QA Requirements, List Document Below:

Reference Doc Number:_RPP_WTP-QA-005, Rev. 2

- Field COC Submitted? X No $\square$ Yes

- Lab COC Required? X No $\square$ Yes

- Sample/Container Inspection Documentation Required?

- Hold Time: X No $\square$ Yes

$\square$ Use SW 846 (PNL-ASO-071, identify analytes/methods where holding times apply)

- Special Storage Requirements:

X None $\square$ Refrigerate $\square$ Other, Specify:

- Data Requires ASO Quality Engineer Review? X No $\square$ Yes

\section{Waste Designation Information}

\begin{tabular}{|c|c|}
\hline \multirow{4}{*}{$\begin{array}{l}\text { Data Reporting Level } \\
\text { X ASO-QAP-001 (Equivalent to } \\
\text { HASQARD). } \\
\square \text { Minimuin data report. } \\
\square \text { Project Specific Requirements: } \\
\text { Contact ASO Lead or List Reference } \\
\text { Document: }\end{array}$} & Date: \\
\hline & 0 business day turn-around time) \\
\hline & $\bullet$ Negotiated Cg \\
\hline & $K N P^{\text {To be completed by asO Le }}$ RGS BMO \\
\hline
\end{tabular}

- Sample Information Check List Attached? X No $\square$ Yes

If no, Reference Doc Attached:

or, Previous ASR Number: 7918
Does the Waste Designation Documentation

Indicate Presence of PCBs?

$\mathrm{X}$ No $\square$ Yes

or, Previous RPL Number:

Send Report To: Matt Edwards MSIN P7-25

Sandy Fiskum

MSIN

P7-22

Additional or Special Instructions _The requirements of Statement of Work, RPP-WTP-QA-005, Rev. 2, apply to this work. Task-specific Quality Control criteria are attached. Reference Document (i.e., TP-RPP-WTP-___):

\begin{tabular}{|c|c|c|}
\hline \multicolumn{3}{|c|}{ Receiving and Login Information (to be completed by ASO staff) } \\
\hline Date Delivered: & InSAL $12 / 20 / 07$ & Received By: T IRa \\
\hline Delivered By (optional) & & \\
\hline Time Delivered (optional) & & ASR Number: $\quad \quad \mathbf{8 0 7 2} \quad$ Rev.: $\_00$ \\
\hline Group ID (optional) & _RPP-WTP/Task No: [ & DDT \\
\hline CMC Waste Sample? & $\square$ Yes & KPL Numbers: \\
\hline
\end{tabular}



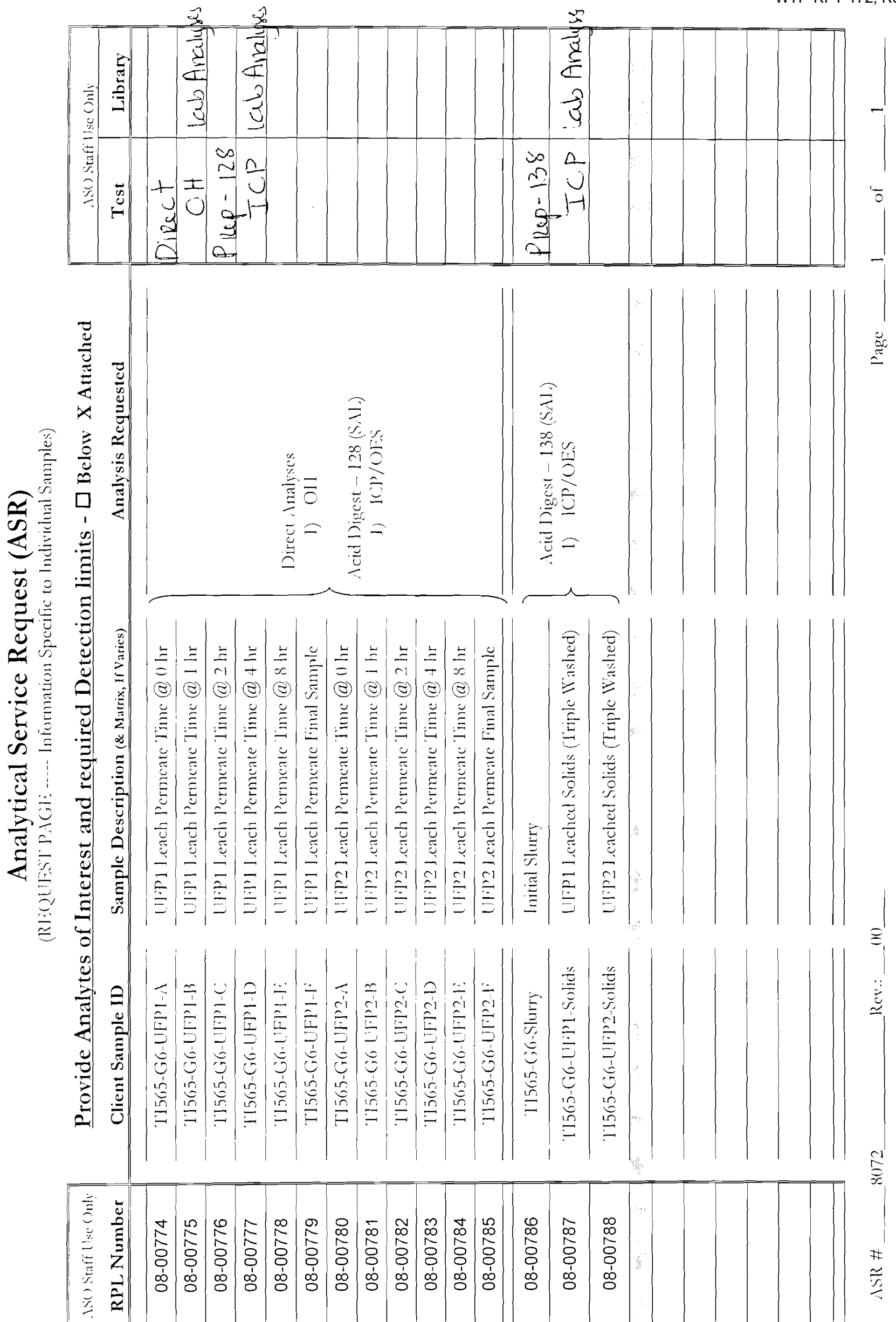

$\stackrel{\varrho}{\xi}$ 
Battelle PNNL/RS\&E/Inorganic Analysis ... ICPOES Analysis Report PO Box 999, Richland, Washington 99352

$\begin{array}{ll}\text { Project / WP\#: } & 52964 \text { / F99187 } \\ \text { ASR\#: } & 8072 \\ \text { Client: } & \text { R. Shimskey } \\ \text { Total Samples: } & 12 \text { (liquid) }\end{array}$

\begin{tabular}{|c|c|c|}
\hline & First & Last \\
\hline RPL\#: & $08-00774$ & $08-00785$ \\
\hline Client ID: & TI565-G6-UFP1-A & TI565-G6-UFP2-F \\
\hline
\end{tabular}

Procedure: RPG-CMC-211, "Determination of Elemental Composition by Inductively Coupled Argon Plasma Optical Emission Spectrometry (ICPOES)", Rev 1.

Analyst: $\quad \underline{\text { P. Berry }}$

Analysis Date (File): $\quad \underline{01-21-2008}$ (C0092)

See Chemical Measurement Center 98620 file: ICP-325-405-3

(Calibration and Maintenance Records)

M\&TE Number: $\quad \underline{\text { N827583 }}$ (ICPOES instrument) M19445 (Mettler AT400 Balance)

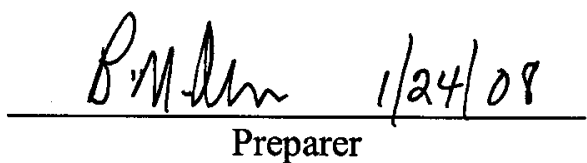

C. $9.4000-13108$

Review and Concur 


\section{Battelle PNNL/RS\&E/Inorganic Analysis ... ICPOES Analysis Report}

Twelve samples submitted under Analytical Service Request (ASR) 8072 were analyzed by ICPOES. The samples were prepared in the Shielded Analytical Laboratory (SAL) following RPL procedure RPG-CMC-128 using $1 \mathrm{~mL}$ of sample and diluting to a final volume of $25 \mathrm{~mL}$.

Analytes of interest (AOIs) were specified in the ASR, and are listed in the upper section of the attached ICPOES Data Report. The quality control (QC) results for these AOIs have been evaluated and are presented below. Analytes other than AOIs are reported in the bottom section of the report, but have not been fully evaluated for QC performance. The results are given as $\mu \mathrm{g} / \mathrm{mL}$ for each detected analyte, and have been adjusted for all laboratory processing factors and instrument dilutions.

Calibration of the ICPOES was done following the manufacturer's recommended calibration procedure and using multi-analyte custom standard solutions traceable to the National Institute of Standards and Technology (NIST). Midrange calibration verification standards (MCVA and MCVB) were used to verify acceptance of the two-point calibration curves obtained for each analyte, and also used for continuing calibration verification.

Minimum Method Detection Limit (MDL) values were specified in the ASR. MDL levels were met for all AOIs.

The controlling documents are ASO-QAP-001, and the client supplied RPP-WTP-QA-005, Rev. 2 and "ASR 8072 Special Instructions". Instrument calibrations, QC checks and blanks (e.g., ICV/ICB, CCV/CCB, LLS, ICS), post-spike, blank spike, matrix spike, duplicate, and serial dilution were conducted during the analysis run. The blank spike and matrix spike were prepared using $1.5 \mathrm{~mL}$ each of BPNL-QC-1A, and $-2 \mathrm{~B}$ solutions.

Several QC issues were noted in the analyses as discussed below. These issues have been discussed with the client, and the client accepts the data as reported.

\section{Preparation Blank (PB):}

A preparation blank (reagents only) was prepared for the extraction process. Except for zinc, the concentrations of all AOIs were within the acceptance criteria of $\leq \mathrm{EQL}$ (estimated quantitation level) or less than $\leq 5 \%$ of the concentration in the sample. Zinc was detected at a level of $\sim 1 \mu \mathrm{g} / \mathrm{mL}$, which was $>\mathrm{EQL}$ and $>5 \%$ of that observed in the samples $(\sim 8$ to $15 \mu \mathrm{g} / \mathrm{mL}$ ).

\section{Blank Spike (BS)/Laboratory Control Sample (LCS):}

A blank spike was prepared for the extraction process. Recovery values are listed for all analytes included in the spike that were measured at or above the EQL. Except for silicon (12\%), the recovery values were within the acceptance criterion of $80 \%$ to $120 \%$ for all AOIs meeting the above requirement.

\section{Matrix-Spiked Sample:}

A matrix spike was prepared for the extraction process. Recovery values are listed for all analytes included in the spike that were measured at or above the EQL. Except for silicon 


\section{Battelle PNNL/RS\&E/Inorganic Analysis ... ICPOES Analysis Report}

(64\%), the recovery values were within the acceptance criterion of $75 \%$ to $125 \%$ for all AOIs meeting the above requirement. The under-recoveries for silicon in both the BS and MS are not completely understood, but could relate to sample preparation.

\section{Duplicate Relative Percent Difference (RPD):}

A duplicate was prepared for the extraction process. RPDs are listed for all analytes that were measured at or above the EQL. Except for manganese ( 26\%), the RPDs were within the acceptance criterion of $\leq 20 \%$ for all AOIs meeting the above requirement.

\section{Post-Spike/Analytical Spike Sample (Spike A Elements):}

A post spike (A component) was conducted on the analysis batch. Recovery values are listed for all analytes in the spike that were measured at or above the EQL, and that had a spike concentration $\geq 25 \%$ of that in the sample. The recovery values were within the acceptance criterion of $75 \%$ to $125 \%$ for all AOIs meeting the above requirements.

\section{Post Spike/Analytical Spike Sample (B Component):}

A post spike (B component) was conducted on the analysis batch. Recovery values are listed for all analytes in the spike that were measured at or above the EQL, and that had a spike concentration $\geq 25 \%$ of that in the sample. The recovery values were within the acceptance criterion of $75 \%$ to $125 \%$ for all AOIs meeting the above requirements.

\section{Serial dilution:}

Five-fold serial dilution was conducted on the analysis batch. Percent differences (\%Ds) are listed for all analytes that had a concentration at or above the EQL in the diluted sample. The $\%$ Ds were within the acceptance criterion of $\leq 10 \%$ for all AOIs meeting the above requirement.

\section{Other QC:}

All other instrument-related QC tests for the AOIs passed within the appropriate acceptance criteria.

\section{Comments:}

1) The "Final Results" have been corrected for all laboratory dilutions performed on the samples during processing and analysis, unless specifically noted.

2) Instrument detection limits (IDL) and estimated quantitation limits (EQL) shown are for acidified water. Detection limits for other matrices may be determined if requested. Method detection limits (MDL) can be estimated by multiplying the IDL by the "Multiplier". The estimated quantitation limit (EQL) for each concentration value can be obtained by multiplying the EQL by the "Multiplier".

3) Routine precision and bias is typically $\pm 15 \%$ or better for samples in dilute, acidified water (e.g. $2 \% \mathrm{v} / \mathrm{v}$ $\mathrm{HNO}_{3}$ or less) at analyte concentrations $>E Q L$ up to the upper calibration level. This also presumes that the total dissolved solids concentration in the sample is less than $5000 \mu \mathrm{g} / \mathrm{mL}(0.5$ per cent by weight). Note that bracketed values listed in the data report are within the MDL and the EQL, and have potential uncertainties greater than $15 \%$. Concentration values $<\mathrm{MDL}$ are listed as "- .". Note, that calibration and QC standards are validated to a precision of $\pm 10 \%$.

4) Absolute precision, bias and detection limits may be determined on each sample if required by the client. The maximum number of significant figures for all ICP measurements is two. 
Battelle PNNL/RS\&E/Inorganic Analysis ... ICPOES Analysis Report

5) Analytes included in the spike A component (for the AS/PS) are; $\mathrm{Ag}, \mathrm{Al}, \mathrm{As}, \mathrm{B}, \mathrm{Ba}, \mathrm{Be}, \mathrm{Bi}, \mathrm{Ca}, \mathrm{Cd}, \mathrm{Co}, \mathrm{Cr}$, $\mathrm{Cu}, \mathrm{Fe}, \mathrm{K}, \mathrm{Li}, \mathrm{Mg}, \mathrm{Mn}, \mathrm{Mo}, \mathrm{Na}, \mathrm{Ni}, \mathrm{P}, \mathrm{Pb}, \mathrm{S}, \mathrm{Sb}, \mathrm{Se}, \mathrm{Si}, \mathrm{Sn}, \mathrm{Sr}, \mathrm{Ta}, \mathrm{Ti}, \mathrm{Tl}, \mathrm{V}, \mathrm{W}, \mathrm{Y}, \mathrm{Zn}$, and Zr. Analytes included in the spike $\mathrm{B}$ component are; $\mathrm{Ce}, \mathrm{Dy}, \mathrm{Eu}, \mathrm{La}, \mathrm{Nd}, \mathrm{Pd}, \mathrm{Rh}, \mathrm{Ru}, \mathrm{Te}, \mathrm{Th}$, and $\mathrm{U}$. 


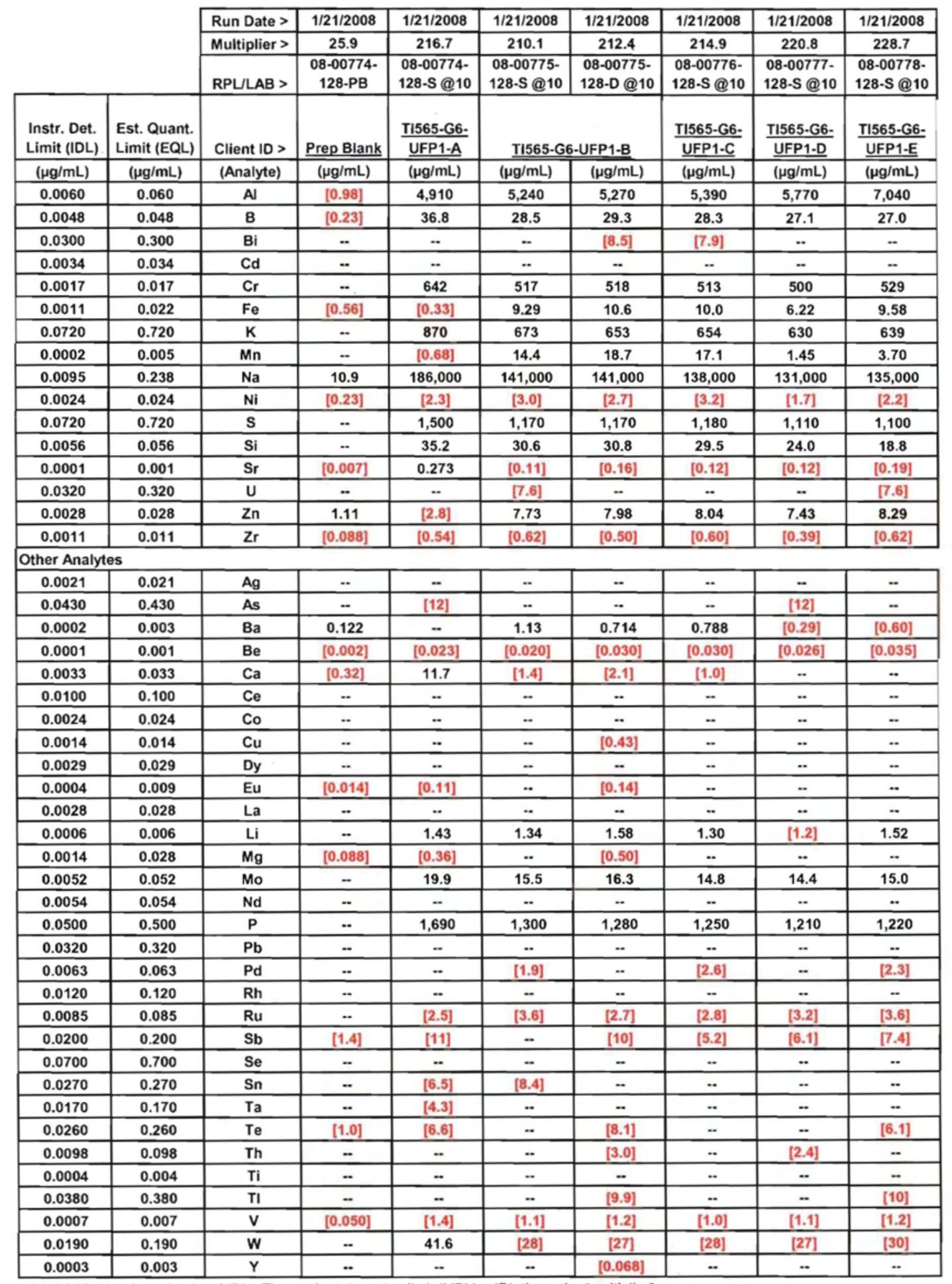

1) "--" indicates the value is $<M D L$. The method detection limit $(M D L)=I D L$ times the "multiplier" near the top of each column. The estimated sample quantitation limit $=E Q L$ (in Column 2) times the "multiplier". Overall error for values z EQL is estimated to be within $\pm 15 \%$.

2) Values in brackets [ ] are $\geq M D L$ but $<E Q L$, with errors likely to exceed $15 \%$. 


\begin{tabular}{|c|c|c|c|c|c|c|c|}
\hline Run Date > & $1 / 21 / 2008$ & $1 / 21 / 2008$ & $1 / 21 / 2008$ & $1 / 21 / 2008$ & $1 / 21 / 2008$ & $1 / 21 / 2008$ & $1 / 21 / 2008$ \\
\hline Multiplier > & 247.9 & 245.5 & 260.0 & 252.8 & 255.9 & 257.6 & 248.1 \\
\hline RPL/LAB > & $\begin{array}{l}08-00779- \\
128-S @ 10\end{array}$ & $\begin{array}{c}08-00780- \\
128-S @ 10\end{array}$ & $\begin{array}{c}08-00781- \\
\text { 128-S @10 }\end{array}$ & $\begin{array}{c}08-00782- \\
128-S \text { @10 }\end{array}$ & $\begin{array}{c}\text { 08-00783- } \\
\text { 128-S @10 }\end{array}$ & $\begin{array}{l}08-00784- \\
128-\text { S @10 }\end{array}$ & $\begin{array}{c}08-00785- \\
128-5 @ 10\end{array}$ \\
\hline Client ID > & $\frac{\text { TI565.G6- }}{\text { UFP1.F }}$ & $\frac{\text { T1565.G6- }}{\text { UFP2-A }}$ & $\frac{\text { T1565-G6- }}{\text { UFP2-B }}$ & $\frac{\text { T1565-G6- }}{\text { UFP2-C }}$ & $\frac{\text { T1565-G6- }}{\text { UFP2-D }}$ & $\frac{\text { T1565-G6: }}{\text { UFP2-E }}$ & $\frac{\text { T1565-G6- }}{\text { UFP2-F }}$ \\
\hline (Analyte) & $(\mu \mathrm{g} / \mathrm{mL})$ & $(\mu \mathrm{g} / \mathrm{mL})$ & $(\mu \mathrm{g} / \mathrm{mL})$ & $(\mu \mathrm{g} / \mathrm{mL})$ & $(\mu \mathrm{g} / \mathrm{mL})$ & $(\mu \mathrm{g} / \mathrm{mL})$ & $(\mu \mathrm{g} / \mathrm{mL})$ \\
\hline Al & 7,180 & 4,370 & 8,100 & 7,560 & 9,350 & 17,700 & 12,000 \\
\hline$B$ & 27.3 & 110 & 103 & 85.4 & 86.0 & 126 & 89.3 \\
\hline $\mathrm{Bi}$ & - & -. & {$[8.3]$} & - & 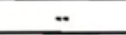 & - & - \\
\hline $\mathrm{Cd}$ & - & $\ddot{*}$ &. & - & {$[0.89]$} & {$[0.94]$} & - \\
\hline $\mathrm{Cr}$ & 544 & 609 & 629 & 527 & 527 & 799 & 540 \\
\hline $\mathrm{Fe}$ & {$[4.4]$} & {$[0.79]$} & 32.6 & 25.0 & 22.4 & 46.5 & 6.47 \\
\hline K & 663 & 739 & 708 & 592 & 592 & 827 & 567 \\
\hline $\mathrm{Mn}$ & .. & 9.96 & 52.7 & 33.4 & 9.19 & 24.0 & 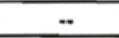 \\
\hline $\mathrm{Na}$ & 140,000 & 229,000 & 237,000 & 195,000 & 195,000 & 252,000 & 189,000 \\
\hline $\mathrm{Ni}$ & {$[2.2]$} & {$[2.2]$} & {$[1.5]$} & [1.9] & {$[1.8]$} & {$[1.4]$} & {$[1,3]$} \\
\hline $\mathrm{s}$ & 1,150 & 645 & 663 & 466 & 511 & 738 & 492 \\
\hline $\mathrm{Si}$ & 18.8 & 548 & 174 & 106 & 68.1 & 58.6 & 56.2 \\
\hline $\mathrm{Sr}$ & {$[0.20]$} & {$[0.23]$} & {$[0.25]$} & {$[0.20]$} & [0.15] & {$[0.22]$} & {$[0.17]$} \\
\hline$u$ & - & [12] & [9.1] & . & $\ddot{*}$ & {$[8.5]$} & $\ddot{*}$ \\
\hline $\mathrm{Zn}$ & 9.35 & 11.3 & 15.1 & 13.3 & 11.7 & 15.2 & 14.0 \\
\hline $\mathrm{Zr}$ & {$[0.53]$} & {$[0.80]$} & {$[0.53]$} & {$[0.85]$} & {$[1.4]$} & {$[1.2]$} & [1.1] \\
\hline
\end{tabular}

\begin{tabular}{|c|c|c|c|c|c|c|c|}
\hline $\mathrm{Ag}$ &.- &.. & - &.- &.- &.- &.. \\
\hline As & - &.. &.. & .. & .. & .. & .. \\
\hline $\mathrm{Ba}$ & {$[0.43]$} & {$[0.20]$} & 1.79 & 2.00 & {$[0.61]$} & {$[0.78]$} & 1.57 \\
\hline $\mathrm{Be}$ & {$[0.025]$} & {$[0.050]$} & {$[0.060]$} & {$[0.058]$} & {$[0.049]$} & {$[0.072]$} & [0.061] \\
\hline $\mathrm{Ca}$ & {$[1.1]$} & - & {$[1.1]$} & - & - & $*$ & - \\
\hline $\mathrm{Ce}$ & .. & 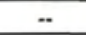 & - &. & - &.. &.$\cdot$ \\
\hline Co &. & - & - & - & - &.- & $\ddot{*}$ \\
\hline $\mathrm{Cu}$ &. & - & {$[3.1]$} & {$[2.0]$} & {$[2.4]$} & 4.56 & 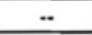 \\
\hline Dy & . &. & 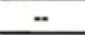 &. & - &. & - \\
\hline $\mathrm{Eu}$ &.. & {$[0.41]$} & {$[0.17]$} &.. &.. & - & {$[0.26]$} \\
\hline La &. & - & 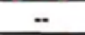 &.- & - & 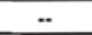 & - \\
\hline $\mathrm{Li}$ & {$[1.5]$} & 4.18 & 3.84 & 3.61 & 2.10 & 3.60 & 2.77 \\
\hline $\mathrm{Mg}$ & 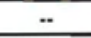 & {$[0.66]$} & - &. & - & - & {$[0.47]$} \\
\hline Mo & 15.0 & {$[10]$} & [10] & {$[7.5]$} & {$[7.7]$} & [10] & {$[8.1]$} \\
\hline $\mathrm{Nd}$ & .. & -. & -. & .. & .. & -. & .. \\
\hline$P$ & 1,240 & 677 & 645 & 533 & 533 & 766 & 528 \\
\hline $\mathrm{Pb}$ & .. & {$[9.8]$} & [21] & [16] & [18] & [25] & [15] \\
\hline $\mathrm{Pd}$ & {$[3.2]$} & {$[2.5]$} & {$[2.0]$} & [2.3] & - & - & {$[2.8]$} \\
\hline $\mathbf{R h}$ & - & - & - & .. &.- &.- & 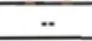 \\
\hline $\mathrm{Ru}$ & {$[2,4]$} & - & {$[2.8]$} &.. & [3.6] & [4.2] & 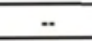 \\
\hline $\mathrm{Sb}$ & [11] & {$[7.9]$} & - &. &. & [14] & {$[9.7]$} \\
\hline $\mathrm{Se}$ & - & 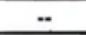 & - & - &. & - & 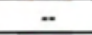 \\
\hline Sn & - & 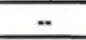 &.- &.- & 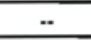 &.- & {$[9.2]$} \\
\hline $\mathrm{Ta}$ & - &.- & - &.- &.. & 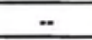 & 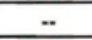 \\
\hline $\mathrm{Te}$ & [9.7] & [7.9] & {$[7.8]$} &.- &.- &.- & [12] \\
\hline Th & - & [4.4] & {$[2.8]$} &.. & -- & [2.6] & {$[4.8]$} \\
\hline $\mathrm{Ti}$ &. & {$[0.13]$} & {$[0.14]$} & .. &.. &.. &.- \\
\hline $\mathrm{TI}$ & -. & .. & .. & .. & .. & .. & -. \\
\hline $\mathrm{v}$ & {$[1.3]$} & {$[1.3]$} & {$[1.3]$} & {$[1.2]$} & {$[0.80]$} & {$[1.5]$} & {$[1.2]$} \\
\hline$w$ & [30] & [17] & [17] & [13] & [13] & [24] & [15] \\
\hline$Y$ & .. & {$[0.13]$} & .. & .- & -. & .. & {$[0.13]$} \\
\hline
\end{tabular}


QC Performance 1/21/2008

\begin{tabular}{|c|c|c|c|c|c|c|}
\hline Criteria > & $\leq 20 \%$ & $80 \%-120 \%$ & $75 \%-125 \%$ & $75 \%-125 \%$ & $75 \%-125 \%$ & $\leq 10 \%$ \\
\hline$Q C I D>$ & $\begin{array}{c}\text { 08-00775 } \\
\text { Dup }\end{array}$ & LCS/BS & $\begin{array}{c}08-00785 \\
\text { MS }\end{array}$ & $\begin{array}{c}08-00785+ \\
\text { PS-A }\end{array}$ & $\begin{array}{c}08-00785+ \\
\text { PS-B }\end{array}$ & $\begin{array}{c}08-00774 \\
5 \text {-fold } \\
\text { Serial Dil }\end{array}$ \\
\hline Analytes & RPD (\%) & $\%$ Rec & $\%$ Rec & $\%$ Rec & \%Rec & $\%$ Diff \\
\hline Al & 0.4 & 98 & 111 & 105 & & 3.7 \\
\hline B & 2.9 & 100 & 99 & 103 & & \\
\hline$B i$ & & 94 & 105 & 98 & & \\
\hline Cd & & 96 & 97 & 96 & & \\
\hline $\mathrm{Cr}$ & 0.3 & 100 & $\mathrm{nr}$ & 105 & & 4.1 \\
\hline $\mathrm{Fe}$ & 13.0 & 97 & 99 & 102 & & \\
\hline $\mathrm{K}$ & 3.1 & 99 & 102 & 102 & & 4.0 \\
\hline $\mathrm{Mn}$ & 25.9 & 98 & 98 & 102 & & \\
\hline $\mathrm{Na}$ & 0.4 & 104 & $\mathrm{nr}$ & $\mathrm{nr}$ & & 2.9 \\
\hline $\mathrm{Ni}$ & & 98 & 101 & 104 & & \\
\hline $\mathrm{s}$ & 0.5 & 90 & 96 & & 100 & 5.6 \\
\hline Si & 0.6 & 12 & 64 & 106 & & \\
\hline $\mathrm{Sr}$ & & 99 & 100 & 104 & & \\
\hline $\mathrm{U}$ & & 96 & 98 & & 98 & \\
\hline $\mathrm{Zn}$ & 3.2 & 98 & 96 & 103 & & \\
\hline $\mathrm{Zr}$ & & 85 & 87 & 102 & & \\
\hline
\end{tabular}

Other Analytes

\begin{tabular}{|c|c|c|c|c|c|c|}
\hline $\mathrm{Ag}$ & & & & 84 & & \\
\hline As & & & & 103 & & \\
\hline $\mathrm{Ba}$ & 44.7 & 96 & 98 & 101 & & \\
\hline $\mathrm{Be}$ & & 96 & 98 & 101 & & \\
\hline $\mathrm{Ca}$ & & 98 & 99 & 102 & & \\
\hline $\mathrm{Ce}$ & & 85 & 97 & & 99 & \\
\hline Co & & & & 100 & & \\
\hline $\mathrm{Cu}$ & & 96 & 96 & 103 & & \\
\hline Dy & & & & & 98 & \\
\hline Eu & & & & & 97 & \\
\hline La & & 82 & 94 & & 96 & \\
\hline Li & 16.7 & 99 & 99 & 102 & & \\
\hline $\mathrm{Mg}$ & & 99 & 99 & 102 & & \\
\hline Mo & 5.4 & 96 & 101 & 102 & & \\
\hline Nd & & 83 & 93 & & 93 & \\
\hline $\mathbf{P}$ & 1.8 & 96 & 99 & 101 & & 2.1 \\
\hline $\mathrm{Pb}$ & & 95 & 97 & 100 & & \\
\hline $\mathbf{P d}$ & & & & & 92 & \\
\hline Rh & & & & & 98 & \\
\hline Ru & & & & & 97 & \\
\hline $\mathrm{Sb}$ & & & & 103 & & \\
\hline $\mathrm{Se}$ & & & & 103 & & \\
\hline Sn & & & & 99 & & \\
\hline $\mathbf{T a}$ & & & & 101 & & \\
\hline $\mathrm{Te}$ & & & & & 100 & \\
\hline Th & & 23 & 96 & & 97 & \\
\hline $\mathrm{TI}$ & & 98 & 99 & 101 & & \\
\hline $\mathrm{TI}$ & & & & 99 & & \\
\hline V & & 95 & 96 & 102 & & \\
\hline W & & 95 & 112 & 100 & & \\
\hline$Y$ & & & & 101 & & \\
\hline
\end{tabular}

Shaded results are outside the acceptance criteria.

$n r=$ not recovered; spike concentration less than $25 \%$ of sample concentration. 
Battelle PNNL/RS\&E/Inorganic Analysis ... ICPOES Analysis Report PO Box 999, Richland, Washington 99352

Project / WP\#: $\quad 52964$ / F99187

ASR\#: $\quad 8072$

Client: $\quad$ R. Shimskey

Total Samples: $\quad 3$ (solid)

\begin{tabular}{|l|c|c|}
\hline \multicolumn{3}{|c|}{ First } \\
\hline RPL\#: & $08-00786$ & Last \\
\hline Client ID: & TI565-G6-Slurry & TI565-G6-UFP2-Solids \\
\hline Sample Preparation: & RPG-CMC-138, "HNO & -HF-HCl Acid Digestion of \\
Solids for Metals Analysis Using a Dry-Block Heater", 01/25/08 (SAL/dk). \\
\hline
\end{tabular}

Procedure: $\quad$ RPG-CMC-211, "Determination of Elemental Composition by Inductively Coupled Argon Plasma Optical Emission Spectrometry (ICPOES)", Rev 2.

Analyst: $\quad \underline{\text { P. Berry }}$

Analysis Date (File): $\quad \underline{01-29-2008}$ (C0095)

See Chemical Measurement Center 98620 file: $\underline{\text { ICP-325-405-3 }}$

(Calibration and Maintenance Records)

M\&TE Number: $\quad \underline{\text { N827583 }}$ (ICPOES instrument)

$\underline{\text { M19445 }}$ (Mettler AT400 Balance)
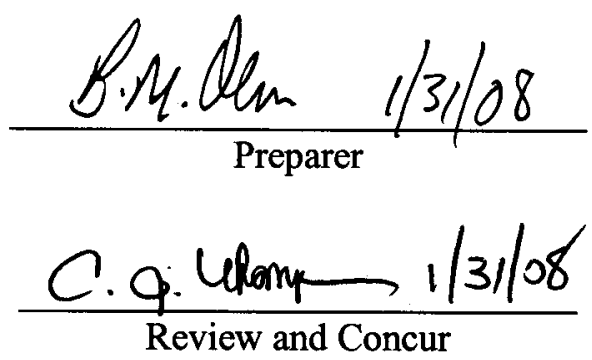


\section{Battelle PNNL/RS\&E/Inorganic Analysis ... ICPOES Analysis Report}

Three samples submitted under Analytical Service Request (ASR) 8072 were analyzed by ICPOES. The samples were prepared in the Shielded Analytical Laboratory (SAL) following digestion procedure RPG-CMC-138 using from approximately 0.1 to 0.2 grams of sample and diluting to a final volume of $100 \mathrm{~mL}$.

Analytes of interest (AOIs) were specified in the ASR, and are listed in the upper section of the attached ICPOES Data Report. The quality control (QC) results for these AOIs have been evaluated and are presented below. Analytes other than AOIs are reported in the bottom section of the report, but have not been fully evaluated for QC performance. The results are given as $\mu \mathrm{g} / \mathrm{g}$ for each detected analyte, and have been adjusted for all laboratory processing factors and instrument dilutions.

Calibration of the ICPOES was done following the manufacturer's recommended calibration procedure and using multi-analyte custom standard solutions traceable to the National Institute of Standards and Technology (NIST). Midrange calibration verification standards (MCVA and $\mathrm{MCVB}$ ) were used to verify acceptance of the two-point calibration curves obtained for each analyte, and also used for continuing calibration verification.

Minimum Method Detection Limit (MDL) values were specified in the ASR. Except for Al in Sample 08-00787 and Na in all samples, MDL levels were met for all AOIs. It should be noted that the $\mathrm{Al}$ and $\mathrm{Na}$ levels exceeded the requested MDL thereby mitigating the MDL requirement.

The controlling documents are ASO-QAP-001, and the client supplied RPP-WTP-QA-005, Rev. 2, and "ASR 8072 Special Instructions". Instrument calibrations, QC checks and blanks (e.g., ICV/ICB, CCV/CCB, LLS, ICS), post-spike, laboratory control standard (LCS), duplicate, and serial dilution were conducted during the analysis run. The LCS was prepared using a nominal 0.2 grams of SRM-2710 (Montana Soil).

Several QC issues were noted in the analyses as discussed below. These issues have been discussed with the client, and the client accepts the data as reported.

\section{Preparation Blank (PB):}

A preparation blank (reagents only) was prepared for the digestion process. Except for zinc, the concentrations of all AOIs were within the acceptance criteria of $\leq E Q L$ (estimated quantitation level) or less than $\leq 5 \%$ of the concentration in the sample. Zinc was measured at a level of $55 \mu \mathrm{g} / \mathrm{g}$ in the preparation blank, which exceeded the EQL and $5 \%$ of that measured in the samples. The zinc is suspected to be from contamination in the SAL; thus, the measured zinc levels are highly suspect.

Blank Spike (BS)/Laboratory Control Sample (LCS):

An LCS (Montana Soil) was prepared for the digestion process. Recovery values are listed for all analytes included in the spike that were measured at or above the EQL. The recovery values were within the acceptance criterion of $80 \%$ to $120 \%$ for all AOIs meeting the above requirement. 


\section{Battelle PNNL/RS\&E/Inorganic Analysis ... ICPOES Analysis Report}

\section{Matrix-Spiked Sample:}

No matrix spike sample was provided for analysis.

\section{Duplicate Relative Percent Difference (RPD):}

A duplicate was prepared for the digestion process. RPDs are listed for all analytes that were measured at or above the EQL. Except for zinc, the RPDs were within the client acceptance criterion of $\leq 25 \%$ for all AOIs meeting the above requirement. The high RPD for $\mathrm{Zn}$ is suspected to be from variable contamination in the SAL (see discussion for Preparation Blank).

\section{Post-Spike/Analytical Spike Sample (A Component):}

An analytical spike (A component) was conducted for the digestion process. Recovery values are listed for all analytes in the spike that were measured at or above the EQL, and that had a spike concentration $\geq 25 \%$ of that in the sample. The recovery values were within the client acceptance criterion of $70 \%$ to $130 \%$ for all AOIs meeting the above requirements.

\section{Post Spike/Analytical Spike Sample (B Component):}

An analytical spike (B component) was conducted for the digestion process. Recovery values are listed for all analytes in the spike that were measured at or above the EQL, and that had a spike concentration $\geq 25 \%$ of that in the sample. The recovery values were within the client acceptance criterion of $70 \%$ to $130 \%$ for all AOIs meeting the above requirements.

\section{Serial dilution:}

Five-fold serial dilution was conducted for the digestion process. Percent differences (\%Ds) are listed for all analytes that had a concentration at or above the EQL in the diluted sample. Except for zinc, the \%Ds were within the acceptance criterion of $\leq 10 \%$ for all AOIs meeting the above requirement. The high $\% \mathrm{D}$ for $\mathrm{Zn}$ is due to a large interference correction from high levels of $\mathrm{Cr}$ in the samples. However, as zinc is suspected to be from contamination in the SAL, this result has no significant effect on the reported data.

\section{Other QC:}

All other instrument-related QC tests for the AOIs passed within the appropriate acceptance criteria.

\section{Comments:}

1) The "Final Results" have been corrected for all laboratory dilutions performed on the samples during processing and analysis, unless specifically noted.

2) Instrument detection limits (IDL) and estimated quantitation limits (EQL) shown are for acidified water. Detection limits for other matrices may be determined if requested. Method detection limits (MDL) can be estimated by multiplying the IDL by the "Multiplier". The estimated quantitation limit (EQL) for each concentration value can be obtained by multiplying the EQL by the "Multiplier".

3) Routine precision and bias is typically $\pm 15 \%$ or better for samples in dilute, acidified water (e.g. $2 \% \mathrm{v} / \mathrm{v}$ $\mathrm{HNO}_{3}$ or less) at analyte concentrations $>\mathrm{EQL}$ up to the upper calibration level. This also presumes that the total dissolved solids concentration in the sample is less than $5000 \mu \mathrm{g} / \mathrm{mL}(0.5$ per cent by weight). Note 


\section{Battelle PNNL/RS\&E/Inorganic Analysis ... ICPOES Analysis Report}

that bracketed values listed in the data report are within the MDL and the EQL, and have potential uncertainties greater than $15 \%$. Concentration values < MDL are listed as "-.". Note, that calibration and QC standards are validated to a precision of $\pm 10 \%$.

4) Absolute precision, bias and detection limits may be determined on each sample if required by the client. The maximum number of significant figures for all ICP measurements is two.

5) Analytes included in the spike A component (for the AS/PS) are; $\mathrm{Ag}, \mathrm{Al}, \mathrm{As}, \mathrm{B}, \mathrm{Ba}, \mathrm{Be}, \mathrm{Bi}, \mathrm{Ca}, \mathrm{Cd}, \mathrm{Co}, \mathrm{Cr}$, $\mathrm{Cu}, \mathrm{Fe}, \mathrm{K}, \mathrm{Li}, \mathrm{Mg}, \mathrm{Mn}, \mathrm{Mo}, \mathrm{Na}, \mathrm{Ni}, \mathrm{P}, \mathrm{Pb}, \mathrm{S}, \mathrm{Sb}, \mathrm{Se}, \mathrm{Si}, \mathrm{Sn}, \mathrm{Sr}, \mathrm{Ta}, \mathrm{Ti}, \mathrm{Tl}, \mathrm{V}, \mathrm{W}, \mathrm{Y}, \mathrm{Zn}$, and Zr. Analytes included in the spike B component are; $\mathrm{Ce}, \mathrm{Dy}, \mathrm{Eu}, \mathrm{La}, \mathrm{Nd}, \mathrm{Pd}, \mathrm{Rh}, \mathrm{Ru}, \mathrm{Te}, \mathrm{Th}$, and $\mathrm{U}$. 


\begin{tabular}{|c|c|c|c|c|c|c|c|}
\hline & Run Date > & 1/29/2008 & $1 / 29 / 2008$ & $1 / 29 / 2008$ & 1/29/2008 & $1 / 29 / 2008$ \\
\hline & & Multiplier > & 693.2 & 580.0 & 560.2 & 1041.7 & 768.6 \\
\hline & & RPLLAB > & $\begin{array}{c}08-00786- \\
138-\mathrm{B}\end{array}$ & $\begin{array}{c}\text { 08-00786- } \\
138-\mathrm{S}\end{array}$ & $\begin{array}{c}\text { 08-00786- } \\
\text { 138-D }\end{array}$ & $\begin{array}{c}08-00787- \\
138-\mathrm{S}\end{array}$ & $\begin{array}{c}08-00788- \\
138-\mathrm{S}\end{array}$ \\
\hline $\begin{array}{l}\text { Instr. Det. } \\
\text { Limit (IDL) } \\
\end{array}$ & $\begin{array}{l}\text { Est. Quant. } \\
\text { Limit (EQL) }\end{array}$ & Client ID > & Prep. Blank & \multicolumn{2}{|c|}{ TI565-G6-Slurry } & U1565-G6- & $\begin{array}{l}\text { T1565-G6- } \\
\text { UFP2-Solids }\end{array}$ \\
\hline$(\mu \mathrm{g} / \mathrm{mL})$ & $(\mu \mathrm{g} / \mathrm{mL})$ & (Analyte) & $(\mu \mathrm{g} / \mathrm{g})$ & $(\mu \mathrm{g} / \mathrm{g})$ & $(\mu \mathrm{g} / \mathrm{g})$ & $(\mu \mathrm{g} / \mathrm{g})$ & $(\mu \mathrm{g} / \mathrm{g})$ \\
\hline 0.2900 & 2.900 & Al & 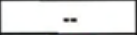 & 173,000 & 166,000 & 372,000 & 348,000 \\
\hline 0.0077 & 0.077 & B & [13] & 113 & 113 & [44] & 221 \\
\hline 0.0240 & 0.240 & $\mathrm{Bi}$ & -- & [81] & [98] & 301 & 270 \\
\hline 0.0029 & 0.029 & $\mathrm{Cd}$ &.. & [12] & [12] & 37.8 & 35.9 \\
\hline 0.0024 & 0.024 & $\mathrm{Cr}$ & 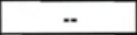 & 9,140 & 9,020 & 18,700 & 18,800 \\
\hline 0.1800 & 1.800 & $\mathrm{Fe}$ & 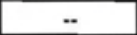 & 3,970 & 3,850 & 13,200 & 12,200 \\
\hline 4.0000 & 40.000 & $\mathrm{~K}$ & .. & -- & -. & .. & -- \\
\hline 0.0011 & 0.011 & $\mathrm{Mn}$ & -. & 2,540 & 2,490 & 8,490 & 7,420 \\
\hline 1.9000 & 19.000 & $\mathrm{Na}$ & 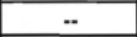 & 203,000 & 197,000 & 20,300 & 33,300 \\
\hline 0.0400 & 0.400 & $\mathrm{Ni}$ & 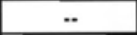 & 260 & 246 & 845 & 809 \\
\hline 0.1600 & 1.600 & $\mathbf{s}$ & 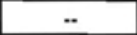 & 2,480 & 2,420 & .. & .. \\
\hline 0.2300 & 2.300 & Si & .. & [670] & {$[710]$} & [890] & [900] \\
\hline 0.0003 & 0.005 & $\mathrm{Sr}$ & 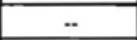 & 560 & 539 & 2,150 & 1,890 \\
\hline 0.0410 & 0.820 & $u$ & - & 10,200 & 10,000 & 37,500 & 34,100 \\
\hline 0.0032 & 0.032 & $\mathrm{Zn}$ & 55.0 & 81 (a) & $105(a)$ & 156 (a) & 135 (a) \\
\hline 0.0035 & 0.035 & $\mathrm{Zr}$ & .. & 118 & 115 & 395 & 371 \\
\hline
\end{tabular}

\section{Other Analytes}

\begin{tabular}{|l|l|l|l|l|l|l|l|}
\hline 0.0015 & 0.015 & $\mathrm{Ag}$ & - & {$[4.2]$} & {$[3.5]$} & 18.6 & 14.9 \\
\hline
\end{tabular}

\begin{tabular}{|l|l|l|l}
\hline 0.0390 & 0.390 & \\
\hline 0.0005 & 0.010 & \\
\hline 0.0000 & 0.000 & & \\
\hline
\end{tabular}

\begin{tabular}{|c|c|c|}
\hline 0.0005 & 0.010 & \\
\hline 0.0000 & 0.000 & \\
\hline 1.1000 & 11.000 & \\
\hline 0.0083 & 0.083 & \\
\hline
\end{tabular}

\begin{tabular}{|c|c|}
\hline 0.0083 & 0.083 \\
\hline 0.0027 & 0.027 \\
\hline 0.0020 & 0.020 \\
\hline
\end{tabular}

\begin{tabular}{|c|c|}
\hline 0.0029 & 0.029 \\
\hline 0.0004 & 0.004 \\
\hline 0.0027 & 0.027 \\
\hline
\end{tabular}

\begin{tabular}{|l|l|l|}
\hline 0.0027 & 0.027 & \\
\hline 0.0019 & 0.019 & \\
\hline 0.0052 & 0.052 & \\
\hline 0.0072 & 0.072 & \\
\hline 0.0062 & 0.062 & \\
\hline
\end{tabular}

\begin{tabular}{|l|l|l|}
\hline 0.0072 & 0.072 & \\
\hline 0.0062 & 0.062 & $\mathrm{Nd}$ \\
\hline 0.0540 & 0.540 & \\
\hline 0.0320 & 0.320 & $\mathrm{~Pb}$ \\
\hline
\end{tabular}

\begin{tabular}{|c|c|c|c|c|c|c|c|}
\hline 0.0540 & 0.540 & $\mathbf{P}$ & $*$ & 3,160 & 3,070 & 638 & 417 \\
\hline 0.0320 & 0.320 & $\mathrm{~Pb}$ & $\cdots$ & {$[120]$} & [110] & {$[270]$} & [230] \\
\hline 0.0064 & 0.064 & $\mathrm{Pd}$ & $*$ & - & - & 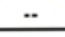 & - \\
\hline 0.0130 & 0.130 & Rh &. & - & - & -. & $\cdots$ \\
\hline 0.0067 & 0.067 & Ru & 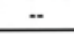 & {$[8.4]$} & [13] & 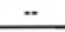 & - \\
\hline 0.0310 & 0.310 & Sb & 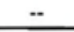 & 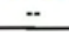 &.. & 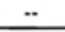 & - \\
\hline 0.1100 & 1.100 & Se & -. & 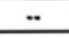 & .. &.. &. \\
\hline 0.0250 & 0.250 & Sn & $=$ & - & - & 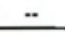 & - \\
\hline 0.0200 & 0.200 & $\mathrm{Ta}$ &. & - & - &. & - \\
\hline 0.0260 & 0.260 & $\mathrm{Te}$ & {$[20]$} & - & - & [83] & {$[43]$} \\
\hline 0.0084 & 0.084 & Th & {$[7.9]$} & 49.2 & {$[47]$} & 165 & 129 \\
\hline 0.0005 & 0.005 & $\mathrm{Ti}$ & {$[0.61]$} & 21.0 & 19.3 & 171 & 64.8 \\
\hline 0.0300 & 0.300 & TI &.. & [22] & - & [54] & [25] \\
\hline 0.0032 & 0.032 & $\mathrm{v}$ & .. & [5.9] & [5.4] & - & - \\
\hline 0.0210 & 0.210 & $w$ & $*$ & [110] & {$[100]$} & [26] & [22] \\
\hline 0.0003 & 0.003 & $\mathbf{Y}$ & $\cdots$ & 11.8 & 11.5 & 42.2 & 38.1 \\
\hline
\end{tabular}

1) "-- indicates the value is $<$ MDL. The method detection limit (MDL) $=$ IDL. times the "multiplier"

near the top of each column. The estimated sample quantitation limit $=E Q L$ (in Column 2) times the "multiplier". Overall error for values $\geq E Q L$ is estimated to be within $\pm 15 \%$.

2) Values in brackets [] are $\geq$ MDL but $<E Q L$, with errors likely to exceed $15 \%$.

(a) Suspect value due to $\mathrm{Zn}$ contamination in the preparation blank. 
QC Performance 1/29/2008

\begin{tabular}{|c|c|c|c|c|c|c|}
\hline Criteria > & $\leq 25 \%$ & $80 \%-120 \%$ & $70 \%-130 \%$ & $70 \%-130 \%$ & $70 \%-130 \%$ & $\leq 10 \%$ \\
\hline QC ID > & $\begin{array}{c}\text { 08-00786 } \\
\text { Dup }\end{array}$ & LCS/BS & MS (none) & $\begin{array}{c}\text { 08-00786 + } \\
\text { AS-A }\end{array}$ & $\begin{array}{c}08-00786+ \\
\text { AS-B }\end{array}$ & $\begin{array}{c}08-00786 \\
5-f o l d \\
\text { Serial Dil }\end{array}$ \\
\hline Analytes & RPD (\%) & $\%$ Rec & $\%$ Rec & $\%$ Rec & $\%$ Rec & \%Diff \\
\hline Al & 3.9 & 105 & & $\mathrm{nr}$ & & 2.1 \\
\hline B & 0.3 & & & 104 & & \\
\hline $\mathrm{Bi}$ & & & & 98 & & \\
\hline Cd & & 91 & & 100 & & \\
\hline $\mathrm{Cr}$ & 1.4 & & & $\mathrm{nr}$ & & 2.8 \\
\hline $\mathrm{Fe}$ & 3.2 & 103 & & 101 & & \\
\hline $\mathrm{K}$ & & & & 104 & & \\
\hline Mn & 1.8 & 107 & & $\mathrm{nr}$ & & 2.4 \\
\hline $\mathrm{Na}$ & 2.9 & 101 & & 99 & & 1.5 \\
\hline $\mathrm{Ni}$ & 5.3 & & & 103 & & \\
\hline $\mathrm{s}$ & 2.5 & 85 & & & 101 & \\
\hline Si & & & & 104 & & \\
\hline $\mathrm{Sr}$ & 3.8 & & & 102 & & 1.8 \\
\hline $\mathbf{U}$ & 1.9 & & & & 96 & 3.9 \\
\hline $\mathrm{Zn}$ & 27 (a) & 103 & & 103 & & $32(b)$ \\
\hline $\mathrm{Zr}$ & 2.7 & & & 101 & & 1.1 \\
\hline \multicolumn{7}{|c|}{ Other Analytes } \\
\hline $\mathrm{Ag}$ & & 100 & & 93 & & \\
\hline As & & 93 & & 101 & & \\
\hline $\mathrm{Ba}$ & 2.9 & 103 & & 101 & & 3.5 \\
\hline $\mathrm{Be}$ & & - & & 98 & & \\
\hline $\mathrm{Ca}$ & & 103 & & 107 & & \\
\hline $\mathrm{Ce}$ & & & & & 100 & \\
\hline Co & & & & 103 & & \\
\hline $\mathrm{Cu}$ & 0.6 & & & 102 & & \\
\hline Dy & & & & & 97 & \\
\hline Eu & & & & & 100 & \\
\hline La & 0.5 & & & & 96 & \\
\hline Li & 0.6 & & & 103 & & \\
\hline $\mathrm{Mg}$ & 5.4 & 103 & & 101 & & 1.5 \\
\hline Mo & 13.0 & & & 102 & & \\
\hline $\mathrm{Nd}$ & 1.2 & & & & 95 & \\
\hline $\mathbf{P}$ & 3.0 & 96 & & 101 & & 2.8 \\
\hline $\mathrm{Pb}$ & & 105 & & 106 & & \\
\hline Pd & & & & & 91 & \\
\hline Rh & & & & & 99 & \\
\hline Ru & & & & & 98 & \\
\hline Sb & & & & 101 & & \\
\hline Se & & & & 95 & & \\
\hline Sn & & & & 99 & & \\
\hline $\mathrm{Ta}$ & & & & 103 & & \\
\hline $\mathrm{Te}$ & & & & & 100 & \\
\hline Th & & & & & 99 & \\
\hline $\mathrm{Ti}$ & 8.8 & 99 & & 100 & & 5.8 \\
\hline $\mathrm{TI}$ & & 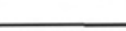 & & 100 & & \\
\hline$v$ & & 99 & & 99 & & \\
\hline$w$ & & & & 104 & & \\
\hline $\mathbf{Y}$ & 2.3 & & & 98 & & 1.5 \\
\hline
\end{tabular}

Shaded results are outside the acceptance criteria.

$n r=$ not recovered; spike concentration less than $25 \%$ of sample concentration.

(a) Suspect value due to $\mathrm{Zn}$ contamination in the preparation blank.

(b) Suspect value due to inter-element interference from high $\mathrm{Cr}$ levels in the sample. 


\section{के० Battelle \\ ...Putting Technology To Work}

Client: $\quad$ Rick Shimskey

\begin{tabular}{r|r|} 
Report Date: & $1 / 28 / 2008$ \\
Analysis Date: & $1 / 25 / 2008$ \\
\hline
\end{tabular}

Subject: $\quad$ Hydroxide Analyses for:

UFP1/UFP2 Caustic Leaching of

Group 6/5 REDOX Treatability Study

ASR: $\quad \mathbf{8 0 7 2} \quad$ Rev-0

Procedure: RPG-CMC-228-Rev 1

Sample ID. $\quad 08-0774 \quad$ thru $\quad 08-0785$

Direct sample aliquots of UFP1/UFP2 Caustic Leaching of Group 6/5 Caustic Treatablity Study samples (08-0774 thru 07-0785), a total of 12 samples were analyzed in duplicate for the base constituents content following procedure RPG-CMC-228, and using a Brinkman 636 Auto-Titrator. The titrant used was 0.1016 $\mathrm{M} \mathrm{HCl}$ and the base standard, $0.1118 \mathrm{M} \mathrm{NaOH}$ was used for $\mathrm{QC}$ verification standards and matrix spike. -See Chemrec_139 pdf imbedded in the result report.

The hydroxide Standard recovery was $100 \%$. The two matrix spike recoveries were $107 \%$, and $98 \%$; all well within the allowed $\pm 20 \%$ recovery range. No hydroxide was detected in the reagent blank.

The initial diluted $\mathrm{pH}$ is reported on attached Report Summary along with the free hydroxide molarity (generally the 1 st inflection point whenever the initial pH is 12 or more). In such cases, generally the 2 nd inflection point around $\mathrm{pH} 7-8$, indicates the total hydroxide molarity. Even though the analysis used very small volumes $(0.05 \mathrm{ml})$ due to high caustic and many samples had visible undissolved $\mathrm{MnO}$, these results showed excellent Relative Percent Deviation (RPD) for the first and second inflection point, well within \pm $20 \%$ allowed range.

The samples also indicated a third inflection point around pH 4-5, and most RPD's were within $\pm 20 \%$ allowed range. Again this is very acceptable considering the small sample size, undissolved species, and the fact that these molarities were very miminal compared to the hydroxide, i.e. the actual plotted data showed hardly any visible slope change.

The best estimate of the MDL for this method is obtained from the reagent blank which did not show any inflection points and is consistent with a value of 0 within our measurement sensitivity. All samples molarities were well above the MDL $(0.001 \mathrm{M})$ for this analysis. The results are accepted based on the QC data meeting the acceptance criteria as specified in the ASR.

Following is the report summary, the sample results calculated from the raw data, and the record file for the standardized acid and base used. The sample aliquots were consumed in the titration process.

Copies of the titration curves are available upon request.

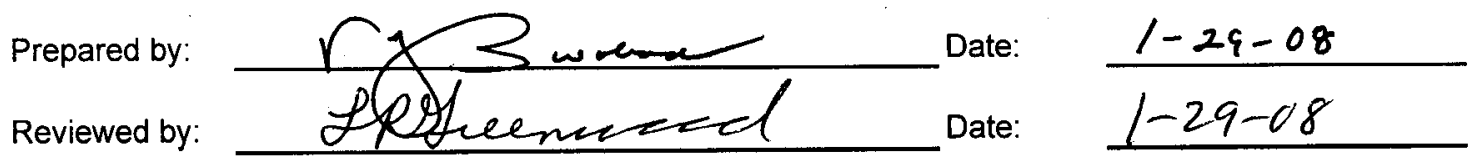


Battelle Pacific Northwest Laboratory

Radiochemical Processing Group-325 Building

Chemical Measurements Center

Hydroxide and Alkalinity Determination

Procedure: RPG-CMC-228-Rev 1

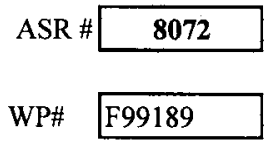

Equip \# WB76843

$$
\begin{array}{r|r|}
\text { Report Summary for ASR \# -- } 8072 & \begin{array}{r}
\text { Report Date: } \\
\text { Revision } \# \text { Rev-0 } \\
\text { Analysis Date: }
\end{array} 1 / 25 / 2008 \\
\hline
\end{array}
$$

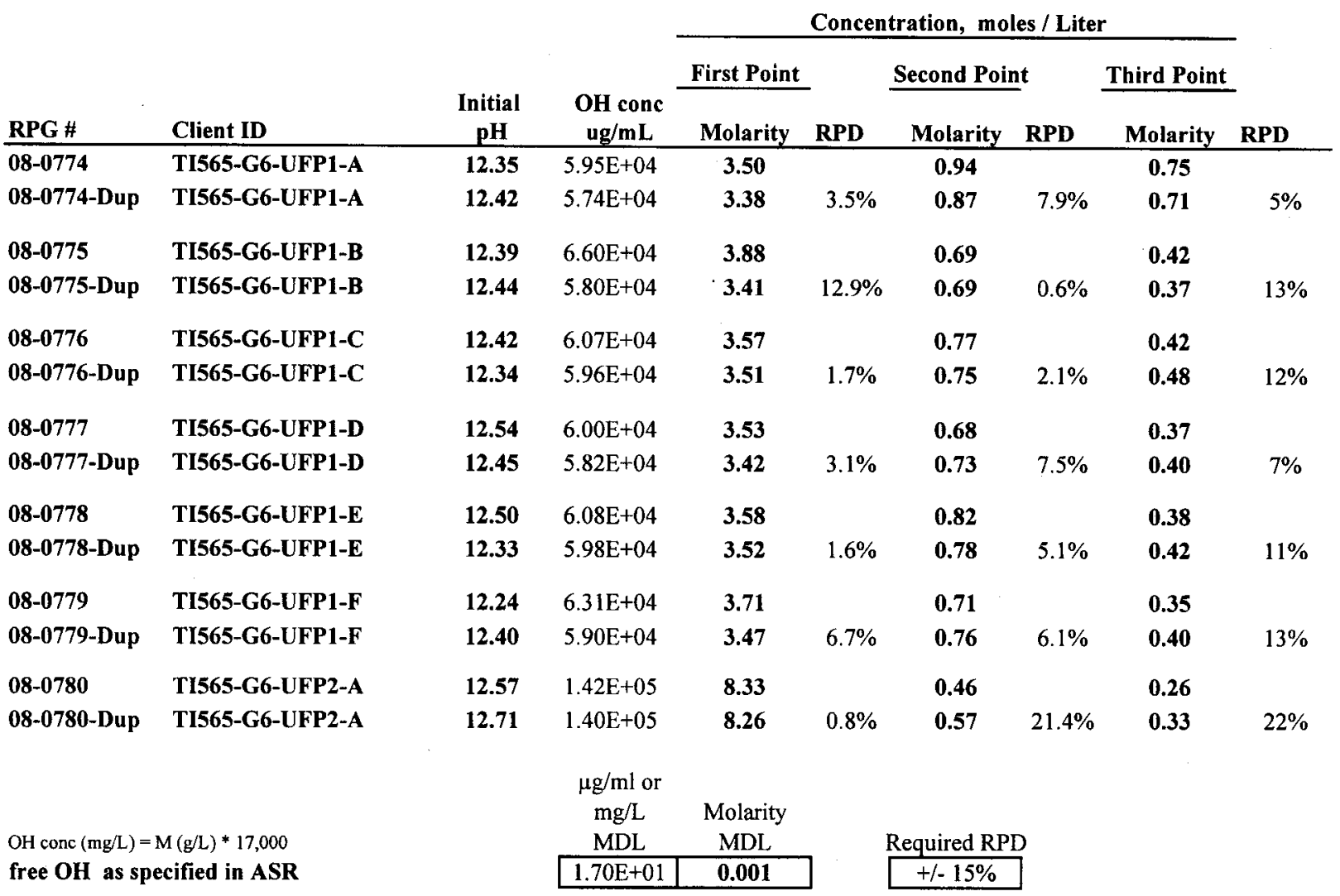

Reag. Blk.1

0

12.55

12.56
Allowed Recovery Range

$99.6 \%$

$107 \%$
$+/-25 \%$

$+/-20 \%$

Note: Results are presented for the first, second, and third inflection points on the titration curves, as applicable. The first inflection point is generally associated with the free hydroxide concentration. The second inflection point generally represents total hydroxide, or carbonate or a combination of aluminate and carbonate. The third inflection point is usually indicative of bicarbonate or other weak acids or possibly the continued protonation of alumina.

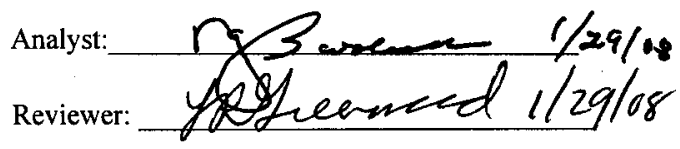


Battelle Pacific Northwest Laboratory

Radiochemical Processing Group-325 Building

Chemical Measurements Center
ASR \# $\mathbf{8 0 7 2}$

WP\# F99189

Hydroxide and Alkalinity Determination

Procedure: RPG-CMC-228-Rev 1

Equip \# WB76843

\begin{tabular}{r|r|} 
Report Date: & $1 / 28 / 2008$ \\
Analysis Date: & $1 / 25 / 2008$ \\
\hline
\end{tabular}

Concentration, moles / Liter

\begin{tabular}{|c|c|c|c|c|c|c|c|c|c|}
\hline \multirow[b]{2}{*}{ RPG \# } & \multirow[b]{2}{*}{ Client ID } & \multirow{2}{*}{$\begin{array}{c}\text { Initial } \\
\text { pH }\end{array}$} & \multirow{2}{*}{$\begin{array}{c}\text { OH conc } \\
\text { ug/mL }\end{array}$} & \multicolumn{2}{|l|}{ First Point } & \multicolumn{2}{|c|}{ Second Point } & \multicolumn{2}{|c|}{ Third Point } \\
\hline & & & & Molarity & RPD & Molarity & RPD & Molarity & RPD \\
\hline 08-0781 & TI565-G6-UFP2-B & 12.49 & $1.37 \mathrm{E}+05$ & 8.07 & & 0.70 & & 0.25 & \\
\hline 08-0781-Dup & TI565-G6-UFP2-B & 12.48 & $1.29 \mathrm{E}+05$ & 7.56 & $6.6 \%$ & 0.67 & $3.6 \%$ & 0.25 & $2.4 \%$ \\
\hline 08-0782 & TI565-G6-UFP2-C & 12.56 & $1.11 \mathrm{E}+05$ & 6.54 & & 0.63 & & 0.24 & \\
\hline 08-0782-Dup & TI565-G6-UFP2-C & 12.54 & $1.09 \mathrm{E}+05$ & 6.42 & $1.8 \%$ & 0.68 & $7.8 \%$ & 0.28 & $13.2 \%$ \\
\hline 08-0783 & TI565-G6-UFP2-D & 12.57 & $1.15 \mathrm{E}+05$ & 6.75 & & 0.78 & & 0.22 & \\
\hline 08-0783-Dup & TI565-G6-UFP2-D & 12.58 & $1.13 \mathrm{E}+05$ & 6.64 & $1.7 \%$ & 0.84 & $8.0 \%$ & 0.28 & $24.9 \%$ \\
\hline $08-0784$ & TI565-G6-UFP2-E & 12.61 & $1.37 \mathrm{E}+05$ & 8.05 & & 0.96 & & 0.17 & \\
\hline 08-0784-Dup & TI565-G6-UFP2-E & 12.65 & $1.44 \mathrm{E}+05$ & 8.48 & $5.2 \%$ & 1.13 & $16.7 \%$ & 0.18 & $4.6 \%$ \\
\hline $08-0785$ & TI565-G6-UFP2-F & 11.80 & $1.14 \mathrm{E}+05$ & 6.70 & & 0.86 & & 0.25 & \\
\hline 08-0785-Dup & TI565-G6-UFP2-F & 12.58 & $1.13 \mathrm{E}+05$ & 6.62 & $1.3 \%$ & 0.93 & $7.5 \%$ & 0.31 & $21.9 \%$ \\
\hline
\end{tabular}

$\mathrm{OH}$ conc $(\mathrm{mg} / \mathrm{L})=\mathrm{M}(\mathrm{g} / \mathrm{L}) * 17,000$ free $\mathrm{OH}$ as specified in $\mathrm{ASR}$

Reag. Blk.1

Standard 1

08-0783MS Matrix spike

\begin{tabular}{|c|c|}
$\mu \mathrm{g} / \mathrm{ml}$ or & \\
$\mathrm{mg} / \mathrm{L}$ & Molarity \\
$\mathrm{MDL}$ & $\mathrm{MDL}$ \\
\hline $1.70 \mathrm{E}+01$ & $\mathbf{0 . 0 0 1}$ \\
\hline
\end{tabular}

0

12.55

12.54
$100 \%$

$98 \%$
Required RPD

$+/-15 \%$

Allowed Recovery Range

$+1-25 \%$

$+/-20 \%$

Note: Results are presented for the first, second, and third inflection points on the titration curves, as applicable. The first inflection point is generally associated with the free hydroxide concentration. The second inflection point generally represents carbonate or a combination of aluminate and carbonate. The third inflection point is usually indicative of bicarbonate or other weak acids or possibly the continued protonation of alumina.

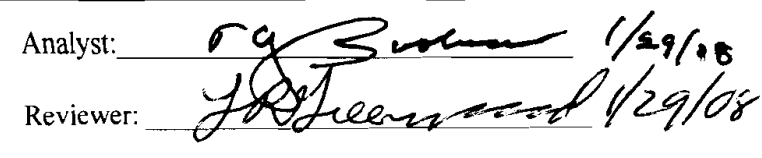




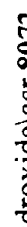

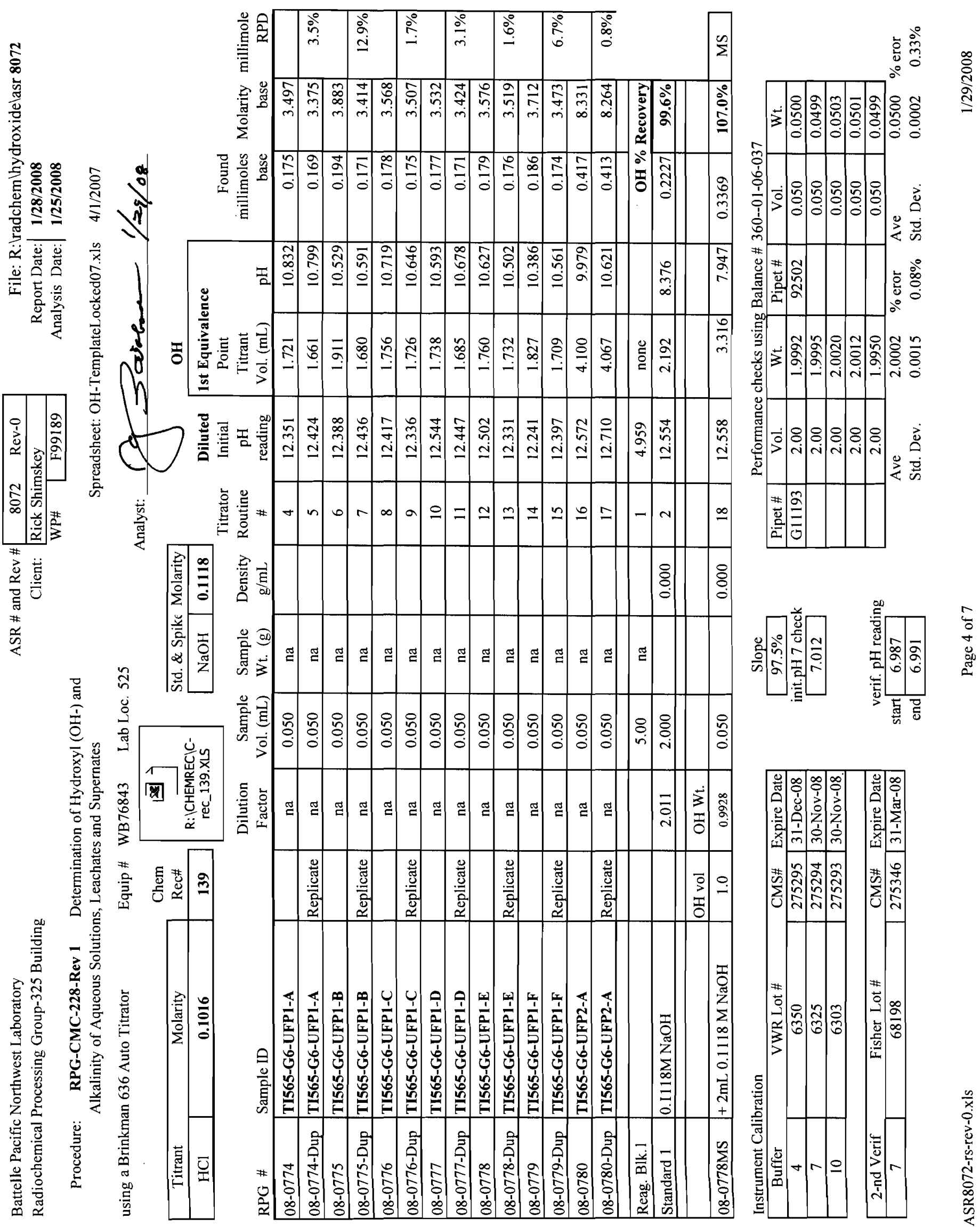




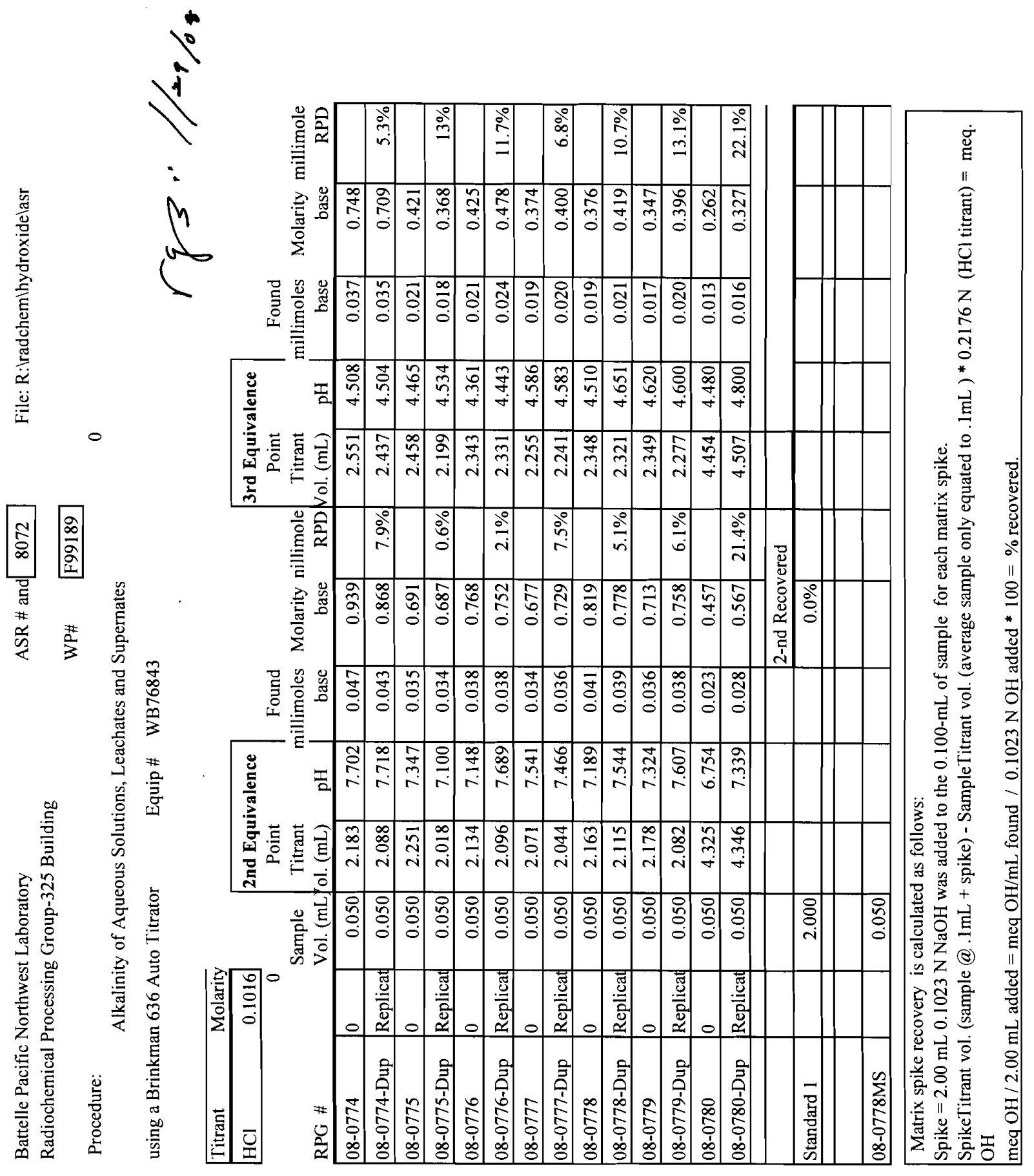

$n$
0
0
0
0
0
0
0 


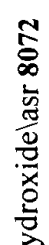

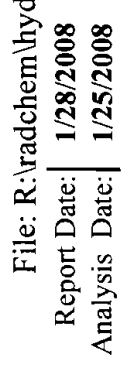

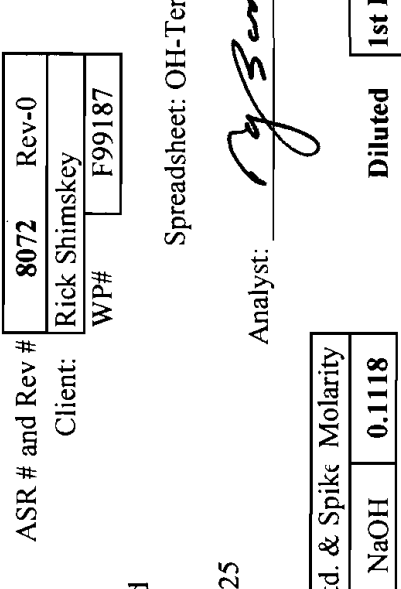
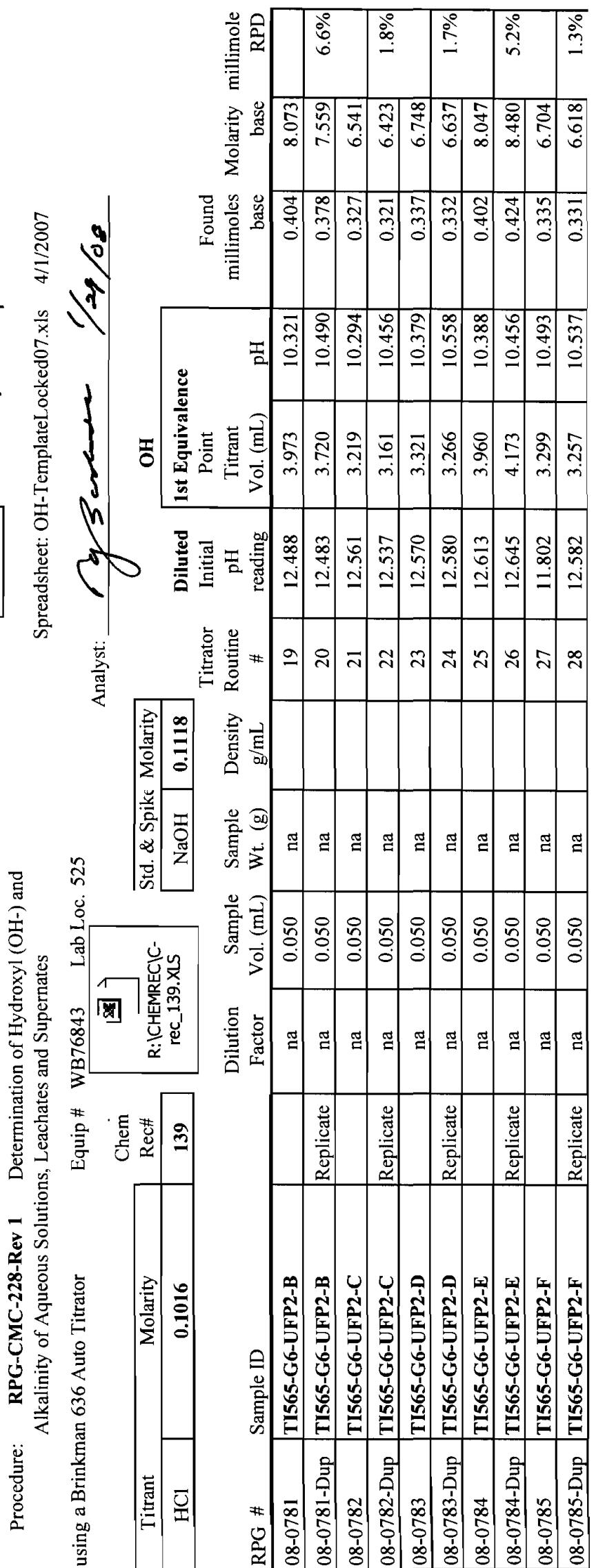

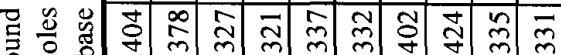

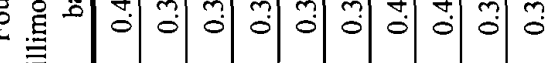

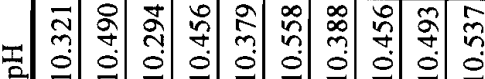

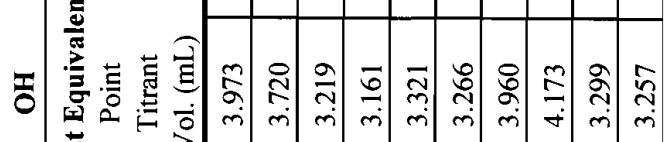
$\underline{\underline{n}}>m(m) m m m m$

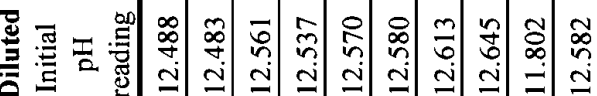

急 亳

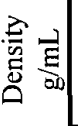

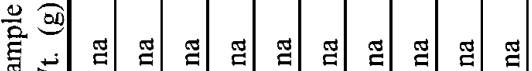

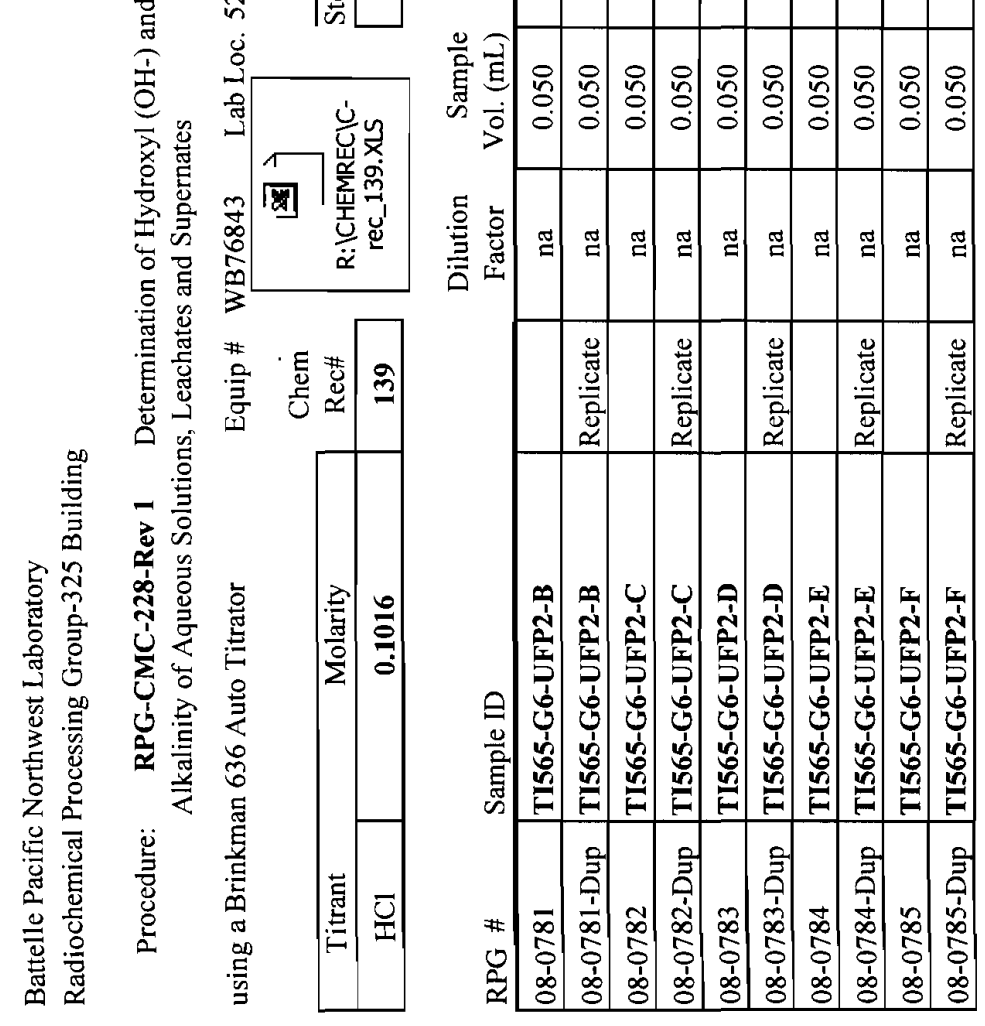

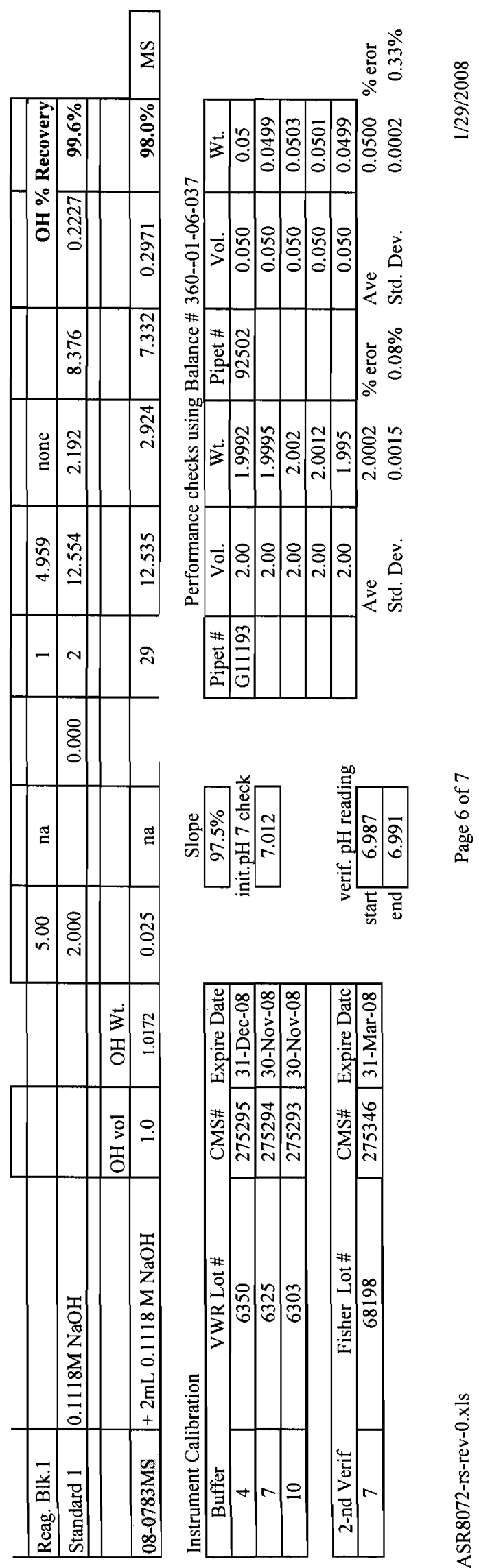



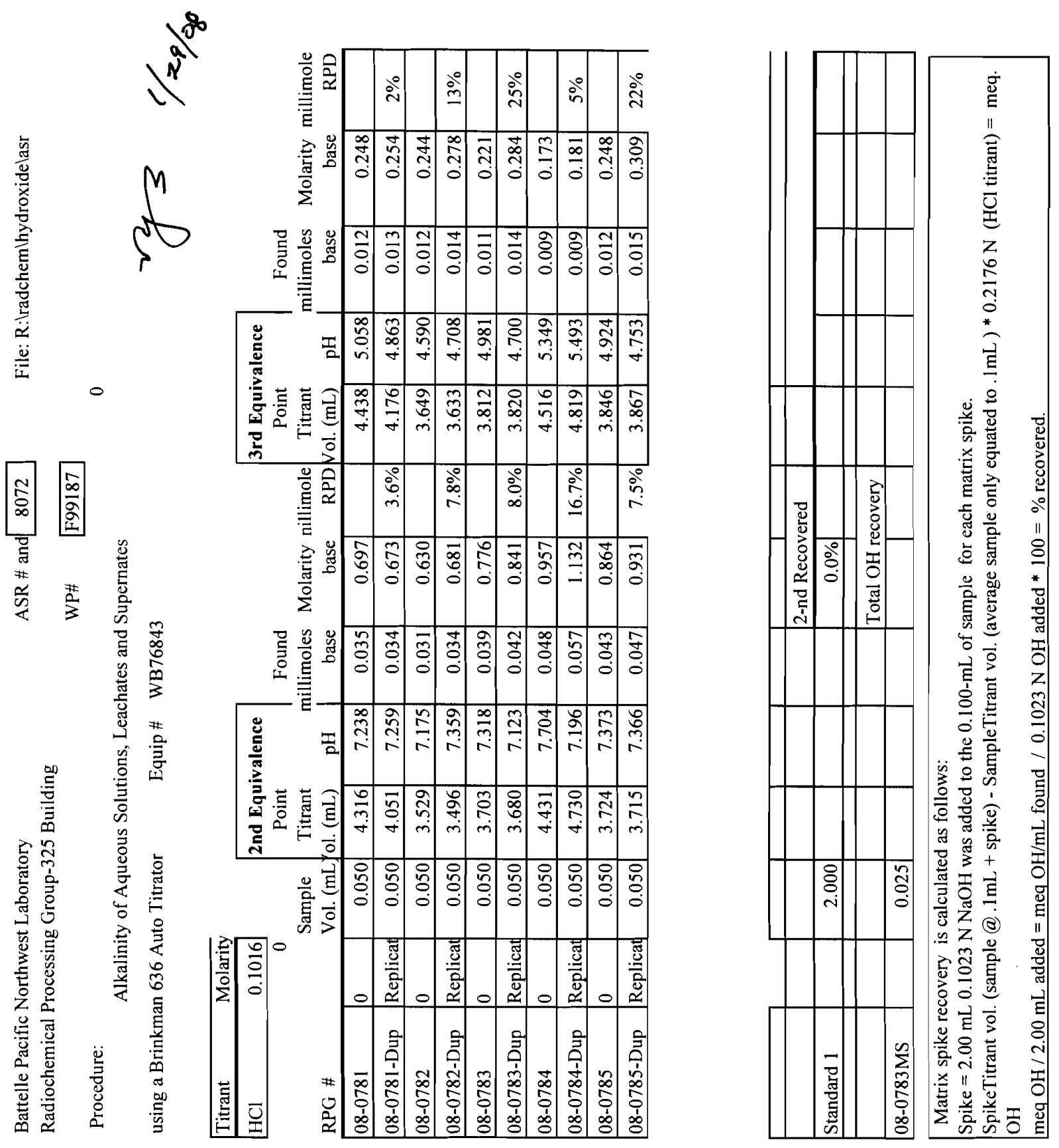
PNNL-17965

WTP-RPT-172, Rev. 0

\section{Distribution}

No. of

Copies

\section{ONSITE}

4 Bechtel National, Inc.

WTP R\&T Docs (2) H4-02

P. S. Sundar H4-02

S. Barnes H4-02

14 Pacific Northwest National Laboratory

J. M. Billing P7-25

E. C. Buck P7-27

M. K. Edwards P7-25

J. G. H.Geeting P7-28

R. T. Hallen P8-60

D. E. Kurath K3-52

G. J. Lumetta P7-25

R. A. Peterson P7-22

R. L. Russell K6-24

R. W. Shimskey (2) P7-27

L. A. Snow P7-25

Information Release P8-55

Project File K3-52 